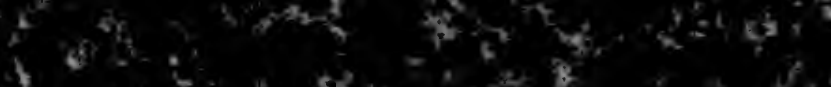

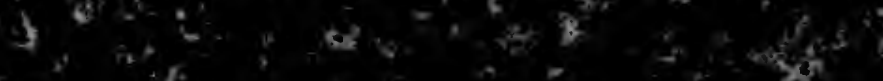

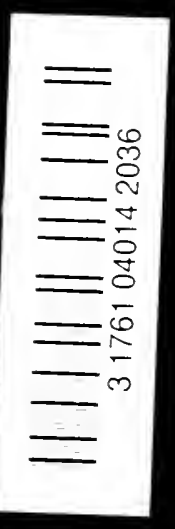

bi. C.

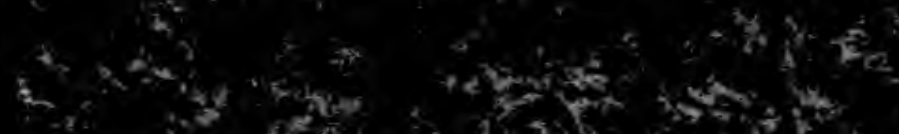

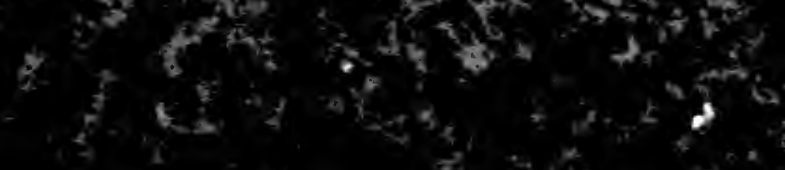

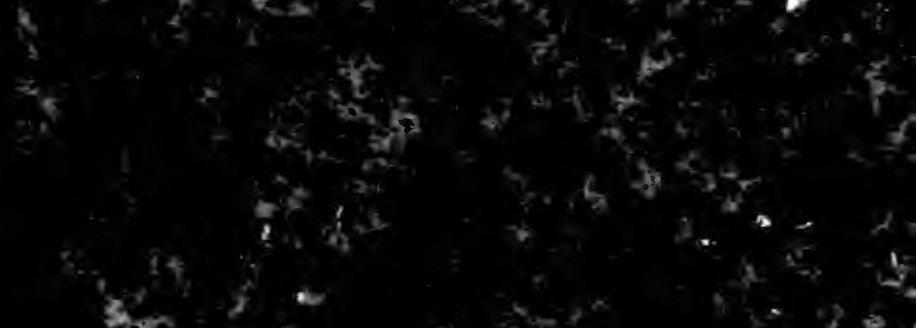
$3 x^{2}+i^{2}$

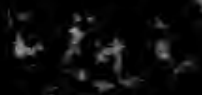

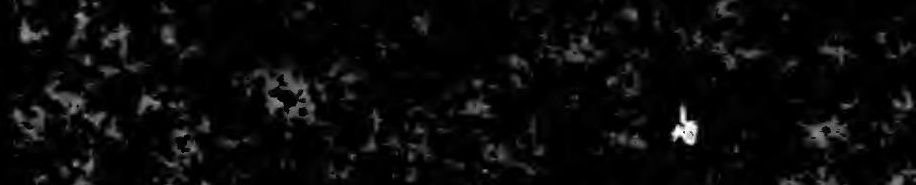

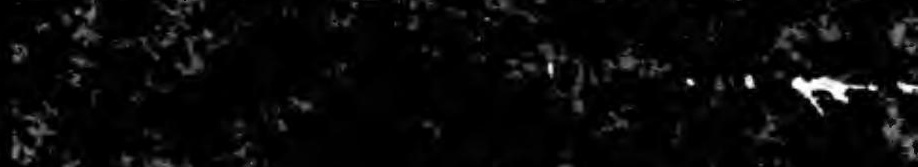

(1) 


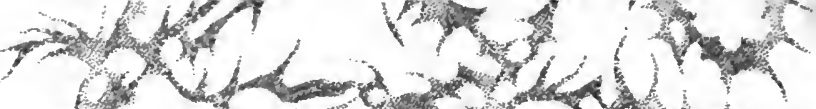
a

(2)

$\checkmark$ ong

(3)

की

v

wa $-2,32$
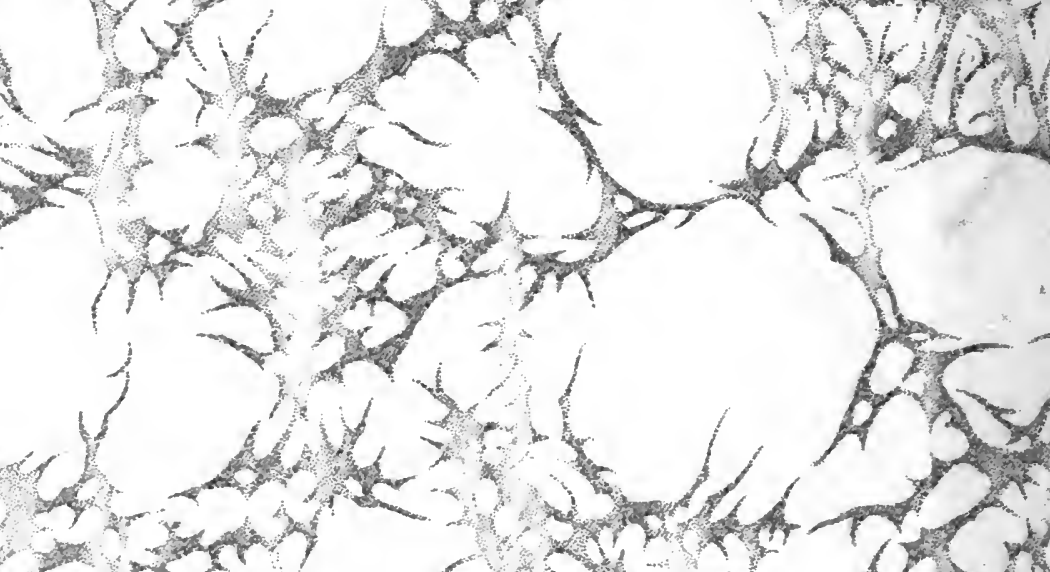

M

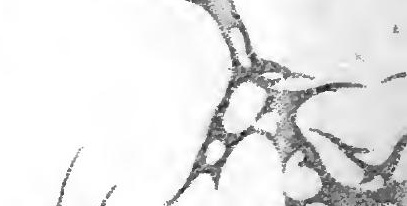




-) 


\title{
BIBLIOGRAPHIE GENERALE
}

\author{
DES
}

\section{GARTULAIRES FRANÇAIS}

Ot RELATIFS A L'HISTOIRE ID FRANCE. 

MANUELS DE BIBLIOGRAPHIE HISTORIQUE - IV

\section{BIBLIOGRAPHIE GÉNÉRALE}

INES

\section{CARTLLAIRES FRANCQALS}

OU RELATIFS A L'HISTOIRE DE FRANCE

\section{Henri STEIN}

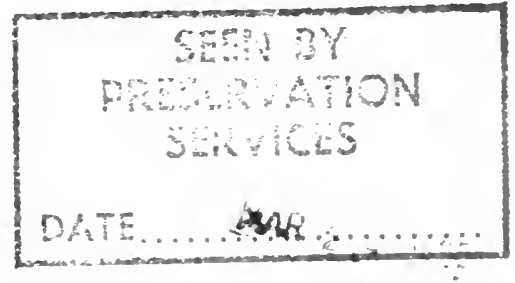

PAR IS

LIBRAIRIE ALPHONSE PICARD ET FILS

Libraires des Archires Vationnles et le la société de l"École des Chartes

S?, RUE BONAPARTE
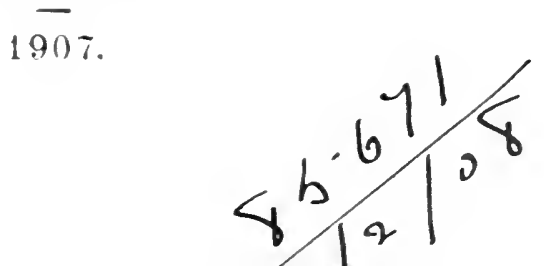


\section{A Maurice ProU,}

Professeur a L'ÉCOLE DES ChARTES,

Très affectureusement rlediè. 


\section{INTRODUCTION.}

« On appelle cuitulai es les papiers terriers des églises où se 》trouvent les contrats d'achat, de vente, d'échange, les privi» lèges, immunités, exemptions et autres chartes. Il est bon » d'observer que les cartulaires sont ordinairement postérieurs à » la plupart des actes qui y sont contenus, et qu ils nont été faits » que pour conserver ces actes dans leur entier. Les compilatemrs » des cartulaires nont donc pas toujours été filèles; on trouve 》 dans la plupart des pièces manifestement fausses ou corrompres, 》 ce qui est aisé de justifier par la comparaison des originaux » avec les copies qui ont été enregistrées dans les cartulaires, $\gg$ ou en comparant l'anciens cartulaires avw d'autres plus » nouveanx ou les mèmes actes se trourent ».

Ainsi s'exprim. Durand de Maillane dans son Dictimemelie de d.oit comovique (1). La léfinition donnée par ( $:$. I. le Ferrière en son Dictimmaire de droit et lle pratique (2) nst formulée "xactement dans los mèmes termes. On préfërera anjourd'hui, puur aroir une idér exacte de ce que la science moderne considère réritablement comme les cartulaires, sr rélërr aux notions précises qu’a données A. Giry dans sum Marmel de diplanutique (3).

Trop souvent, on a grompé improprement sous le nom de cartulaires des recueils qui ne répondent pas à * litre: principa-

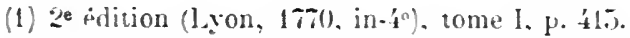

(2) Nourelle édition (Yaris, 161 , in-1\%). tome I. p. Z31.

(3) Paris, 184. $111-8^{\circ}$ (1). 28-34). 
lement des censiers, des inventaires de titres, des livres de fiefs, des repertoires d'aveux on d'hommages, des collertions de statuts de métiers, des livres d'enregistrement, des actres constitutils de fondations do messess ou d'anniversaires, mêne (comme à Périgueux) des mémoriaux ou des annales, ou (comme en Provence) des chartes originales reliées en volumes et des registres de notaires.

Dans le présent travail, tous ces divers recueils ont été laissés de côti ; on n’y tronvera que les véritables cartulaires ou recueils d'actes relatifs à un mêmo établissement, à une mêmo institulion, à une même loralité, quelle qu'en soit l'origine, quelle qu'en soit la date. Dautre part on y rencontrera les cartulaires civils (tes communes, des fimilles, des rhàtellenies, des provinces, des unirersités), an même titre que les cartulaires ecclésiastiques (évê‘hris, chapitres, abhayes, prienrés, commanderies, hòpitaux, roglises, comrents). Si l'intérêt en est diffirent, le mobilr ųui a présilfi à lom formation st identique.

Il estl'entièr ‘vilencr, an effet, que toute communautés'est vue contrainte, a un moment donni, dopuis la royantí elle-même jusqu’an plus modeste des prieurés, de transcrine en volumes les titres qui lui permettaient te justifier de ses droits publics ou privés, domanianx un financiors. On a des exemples, peu nombrenx sans donto, que re mode de consirvation fut apprécié et mis rn vigurur dis l'ajmque anolingienne; mais c'est surtont a la période de dervolopmenent inouï qui presida à la création dr nombreux étahlissiments rcclisiastiques ot des communes (XII ef XIII ${ }^{\mathrm{e}}$ siecles) que correspond la multiplicite des cartulaires. Aucune abbaye riche, aucun conrent un peu considérahlo, aucun Chapitre important, ancune ville (notamment dans l'extrême nortl et dans l'extrême sud de la France) no pul virre sans aroir codifié ses privilèges, ses chartes d'immunité at do propriéti. Les titres miginaux étant axposés a être détruits, perdus ou trop souvent communqués an dehors, en cas d'incrndie, de niggligence ou de procés, ↔n romprit aisément l"intérèt qüil y eut á posséder, dans les chartriers, à coté de ces originaux, des transcriptions plus ou moins fitèles il est vaid, plus ou moins sérieusement collationneses, mais formant un tout d'une conservation plus certaine et plus facile, qui prit fréquemment, en raison de la 
conleur de la reliure, le nom de «live roug"», « livre vert », «live jaune», «livrn noir»(1). Et au XVII" sièle "ncorr, on houve une disposition spéciale des Constitutiuns de la Congrobgation de Saint-Maur qui prescrit de laire laire dans chaque couvent une copie anthentique des originaux sur registres (2).

Tonteluis, si beaucoup dr cartulaires ont été réligés à des époques très liverses, un grand nombre ont disparu, nême de trés bonne heure. En comparaison deceux qui ont visté, bien peu en vérité ont subsistí. Ces rolumes ayant éti conservés longtemps ilans les établissements qüils concernaient ou dans des collections particulières, ils ý itaient exposés à plus de dangers de destruction qu'aujourd'hui ui la plupart ont trouré un refuge dans les dépôts publics (3).

Au XVII siècle dijji, des érudits tels que Du Cange, Mabillon, André Du Chesne, Baluze, des historiens twls que Camusat, Dupuy, Guichenon, Chorirr, ont ru, rompulsé, utilisé d" très nombreux cartulaires 1) ou ils ont retronvé drs milliers de doruments dont les originaux étaient dẹjà létruits. Tous les historiens pustérieurs ont snivi le mourement de curiosité qui portait à łépouiller ces recueils pour arriver à une phıs fidèle comnaissancr lu passé. On a beancuup copié. durant les cont cinquante dernièrs annés de

(1) Quelunes recueils sont en lorme de rouleaux ou ròles the parchemin, d'autres sont appelis " pancartes" mais (riry a tort de croire que ce nom

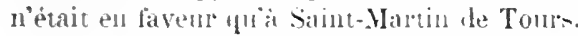

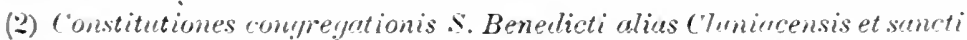

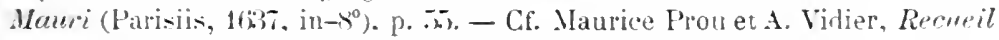
des chartes de l'abbaye de Srrint-Benoit-sur-Loire, tome I, p. Lrrr.

(3) Fendant la périoule rérolutionnaire, on a pris çit et lid des pridautions utiles pour empecher la destruction de ees registres; voir par pxemple in avis de Dom Poirier (juillet 176\%), demandant la conservation de tous les

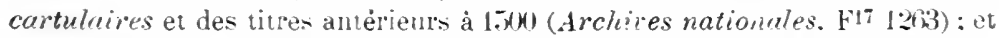
un rapport sur la conservation des cartulaires. rédige en lan Vll, par A. Barbier et Chardon de La Rochette (Cabinet histcrique, VI, Ire parie. pp. 171 . 17't).

(4) On trouve dins Dn Cange et iilleurs des citations empruntées à its «tabularia », mot qui peut s’appliquer aussi bien à des cartulaires qu'á des chartriers. Je n'ai alopté le premier sens que lorsquil y avait certitud. absolue. 
l'ancien régim», dans les cartulaires ancions; on an a transcrit quelques-uns intégralement; on en a imprimí de très nombreux extraits à titres de pièces justificatives sur un sujet déterminé 1 ; on les a dépouillés avec soin pour le «Cabinet des Chartes» et portr les numbreuses entreprises des Bénédictins en vue d'écrire ces grandes histoires provinciales dont quelques-mnes srulement ont vu le jour. « La mine était si riche que drux sièrles d'un trarail assidu n’en avaient paś même épuise les premiers filuns» (2). Il était réservé au XIXe siecle de se lincer clans la publication intégrale des cartulaires: un ensemble présentr toujours un plus grand intèrèt que des extraits. Et aujourd'hui nul no peut étudier les institutions, l’histoire du droit, la diplomatique, la propriété, la vic l'ural', l'agriculture, l'économie politique, la condition des personnes, les usiges, les monnaies de l'ancien régime, s'il n’a recturs à ces recucils qui complètent lo plus souvent des fonds d'arrhives trop insuffisants.

Faire de dínombrement des cartulaires conserves a paru également, de bonne henre, ère un travail ntile. Viritable précurseur, M. Léopold Melisle, a la suite de son Catrologre des actes de Ihilipje . Luguste (3), - il y a exactement cinquante ans, - a tenti un premier essai de reconstitution des cartulaires perdus, et ch donne le signalement en mòme temps que de cenx auxquels il avait reouru ponr son travail. Mais, à cette époque, les dépôts d’archives étaicut i peine constitués, à peine classés ;

(1) On concevrat qu'il a ét impossible dindiquer tontes les anciennes publications, lant generales que particulrères a l'hisloire les provinces, ou des documents empruntés a les cartulaires ont ét imprimés: il a fallu se restreindre à la nention des jublications l'onsemble, th mime laisser de côte, à rogret, des recueils comme coux de Ch. Duvivier: Recherches sur le Hoinut uncirn (in- $8^{\circ}$. Bruxelles, 1865), et Actes th tocuments anciens intéressant la Belgique (2 vol. in- $8^{\circ} ; 1$ s. 18 et 1943$)$, ponrtant exclusivement empruntés à des carulatires français.

(2) Voir le Raphort de M. Liopold Delisle dans la Revue des vociétés

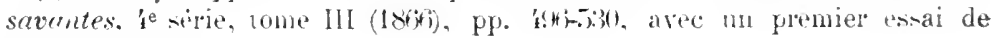
billiograplite.

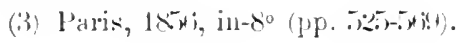


les bibliothiopues publiques étaient dépourvues d"inventaires, of, en dehors de la Bibliothiogue nationale, les recherehes ifaient prespue imposibles a ponrsinive.

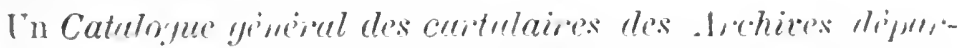
tementales (1) arait bien été publié dés 1847. Par là, l'Aministration avait reconnu tunte l'utiliti de ers rexistres et la népsité de leur boun conservation. Ce rolume, cenvere imprécisc et trop hâtive, a rendu de réels services: mais il contient nombro dinelications erronées, signale des rolunes qui nont anronn dreil au titre de cartulaires, of fut rédigé a une époque uil les

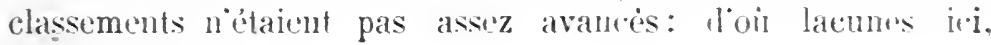
superfluités là.

Pour combler la lacune rolontairement accusér par "et ouvrage pour les cullections parisiennes, U. Robert insila au Cabinet historigne (2), puis publia a part (3). aree un supplé-

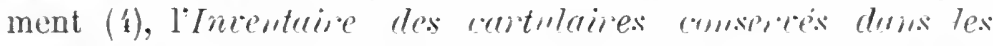

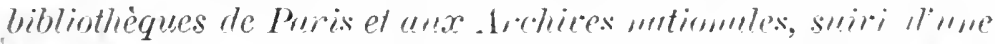

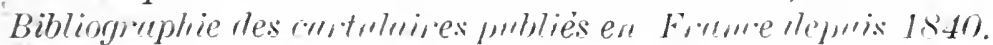
qui reprenait le travail publié en 1866 par M. L. Delisle dans la Rerne des Socicts surntes. Ciest une simple liste, un essai d'ailleurs incomplet ef dépourru de tonte rritique, qui fut cependant bien accueilli an moment deson apparition.

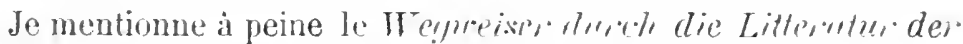

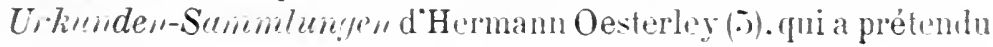
indiquer tous les cartulaires existants, manncerits of imprimés ; l'autenr. insutfisamment préparc à es travail pour lequel il s'est dispensé do toute rucherche persumull", s'ust malheureusement fonroyé trop sonvent pour ponroir ètr utilement. consulté.

(1) I'aris, Impr. rovale, lisit ; in-40 de mu-2is p.

(*) Tome XXIll, catalogue, pu. $1: 4 ;-2)$.

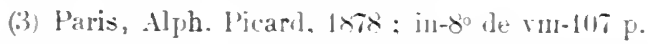

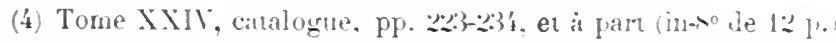

(j) Berlin. Reinter. Indj; 2 vol. intso. - La France ent comprise dians le tome II, a lexception de la flandne. de l'Artois. de lat lorraine. du la Franche-Conte, clansic (avec l'Allemagne) dans le tumes 1 . 
Bien au contraire. A. Giry se livra a une étude comparative, qu’il poursuivit pendant de longues années, des différents cartulaires que nous ont laissés les grandes et vieilles ahbayes fondés sur territoire français : il les étutia de prés et rédigea à leur sujet d'utiles observations. La mort vint le surprendre en laissant ces recherches. cumme tant d"autres, inacheries, et une main pieuse a imprimé le dussier de ses notes sous le titre de : Notices biblingruphiques sur les archives des églises et rles monasteres de l'éponque carolimgiemme' 1 .

Malheureusement son travail n'était la plupart du temps qu'ébauché, la publication so ressent grandoment de l'insuffisance de la préparation, et présente de fächouses laemes quion eût peut-ètre mieux fait d'ssayer do combler arant de liver d l’impression. Ilailleurs, il taut dire que Giry. se plaçant à un point de vue tris spécial. - la période carolingienne, éliminait par là mème me quantilé d'établissements dont la fondation niest point ansi recule.

Entin, la ('ommission ingule dristome de Belypque, il y a peu de temps, a fait rechercher, tant à l"intérieur des frontières de l’État qu'au-delá, tous les recueils susceptibles d’ètre considérés comme des cartulaires, et les missions confiées à cet effet à diverses personnes ont abuuti a trois publications successives

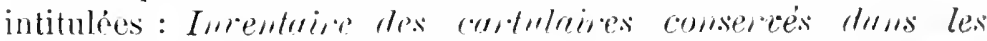

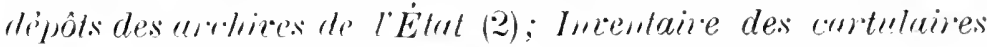

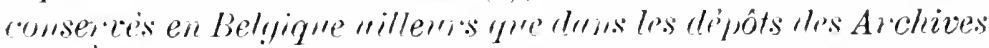
le l'Etut (3) : Incentuire des cortmlates belyes conseress à l'etrunger (4). Mais ces publications, anonymes et liâtives, sont tres imparfaites, do laveu mème des membres de la Commission qui les ordunna. On y relise moins derreurs que d'omissions, ef la Belgique est un les pays où les cartulaires, - comme les

(1) Paris, Bonillon, 1901 : in-8' de van-102 p. [Biblioth. de l'Ecole des Hautes-Études, CXXXII.]

(2) Bruxelles. Hayez, 1xis; in-s' de vr-1:3 p.

(3) Bruxelles, Hayez, $189 \%$ : in-so de vitio p.

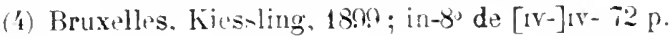


archives elles-mèmes, — se sont conservées jusqu’à nos jours arec le plus ile soin.

Apres avoir passé en revue les publications qui ont précédé la Bibliographic aujourd hui présentée au public, jai le devoir d'ajouter quelques mots sur la manière dont jai conçu mon propre travail, en m’inspirant des considérations qui ont dir té mes prédécesseurs sur le mème terrain, en essayant en outre de faire une œuvre aussi générale que possible duns le temps et dani l'espace.

Dans le temps: j’ai considéré comme cartulaires des recueils très modernes au mème titr que des manuscrits compilés au moyen-âge, parce que l'idée qui préside à la confection d'un cartulaire est toujours la mème, quelle que soit l'ẻpoque oì cette idée ait pris corps.

Dans l'espace: jai considéré comme territoire français celui oú s'est exercée à un degré quelconque l"influence de la France, soit au point de vue de la politique, soit au point de rue du langage, et c'esil ce qui m'a amené à accepter pour limites celles de la Gaule romaine, celles des circonscriptions ecclésiastiques qui ont été adoptées par les auteur's de la Gallia christiana; toutefois, à l'Est, ont été exclus la suisse allemande et les pays situés au-delà du Rhin, et au Nord, toutes les provinces formant actuellement le royaume des Pays-Bas (à l'exception des parties incorporées autrefois dans le diocèse de Liège).

Je ne me suis pas contenté de dresser une nomenclature, aussi complète que possible, les tartulaires qui existent aujourd'hui dans les dépôts publics ou dans des collections particulières, ainsi que des cartulaires on recueils factices de composition analogue, qui ont été imprimés jusqu'à ce jour. Je me suis efforcé, pour les établissements qui ont été dotés de plusieurs cartulaires, de distinguer les originaux des copies et parfois aussi entre eur les originaux appartenant à des familles différentes; et, dans cette voie, j’ai amplement profité des travaux antẻrieurs : c’est ainsi que pour Corbie, je me suis empressé de recourir au travail de M. Levillain; ponr Saint-Benuit-sur-Loire, à l’introduction mise en tête de l'édition donnée par MM. Prou et Vidier: pour Stavelot, aux conclusions de M. Halkin. Là où de tels guides me 
faisalent défaut, j n’ai pu me permettre que des conclusions provisoires on approximatives, car un travail semblable a celui de ces érudits pour chaque localité meât bien vite outrainé a des recherches trop étendues pour une modeste liblingraphie.

Jon ambition a été autrerncore. 11 m'a paru qu’il y aurait plus. qu'un intérèt de curiosité à compléter la liste des cartulaires existants par la rerherche des cartulaires disparus. De très nombreux dépouillements de londs d'archives. de manuscrits at de livres imprimés, mont permis de retrouver la trace de quantité de cartulaires dont on s'itait plus ou moins abondamment servi au XVII et au XVIII ${ }^{e}$ siècles, et dont il est mème parvenu jusqu’a nous des extraits de dimensions variables. Cette partie de ma tàche a été la plus délicate, et je n’ai pas la naîreté de croire qu'elle est détinitive; j’espère níanmoins qu'elle sera favorablement accueillie, et je souhaite qu'elle facilite le recourrement de cortains manuscrits que j’ai signalés comme "perdus » et qui sont peut-être seulement «égarés». En tout état de cause, jo n'aurais pu parvenir à ce résultat sans laide bienveillante et efficac que j’ai trourée, à la Bibliothèquo nationale, auprès d'anis déroués tels que MII. Auvray ot Poupardin, pour lo dipartement des manuscrits; MM. Vidier et Ledos, pour le départrment des imprines. Sans en concours, dont je suis heureux dr les remercier, cette tâche eût été en partie irréalisable. Fréquemment aussi j’ai demandé renseignements et verrifications a mes collègues de province et dr l’étranger ; archivistes et bibliothécaires mont fourni répnnses à mes queslions avec une obligraner qui ne s'est jamais démentir. Enfin. si j’ai pu mener à bien la partie de ce travail qui concerne la Bolgique, ja le dois particulièrement à mes anis H. Pirenne et J. Cureliere, ansi qu’i MM. (.. Callewaert et J. Laenen, dont la courtoisie m’a valu la primeur de quelques détails inédits sur des tartulaires conservés à Bruges th à Malines.

In supplémrnt a été nécessalles il comprend un cortain nombre de cartulaires retrouvés pendant l'impression, et quelques recueils imprimes anciens que leur nature permet de classer dans cette biblingraphie, en appendice tout an moins. I)ans les tables finales (cartulaires cirils classés par provinces et par pajs; cartulaires ecclesiastiques classés par dioceses, les noms précrides 
d'un astérisque sont crux qui figurent dans le supplément seul : et les noms précédés d'un double astérisque sont cenx qui figurent a la fois dans le corps du livre et dans le supplément.

Lorsque, sous un numéro unique, sont indiquées plusieurs rubriques, il s'agit d'un seul et même manuscrit conservé par des copies sans variantes appréciables, ou bien l'édition qui rn a été donnée est la simple reproduction du manuscrit précédemment mentionné; dans tous les autres cats, les numéros successifs servent à différenıier manusırits et éditions.

Plusieurs cartulaires sont catalogués ici pour la première fois. Létat des classements dans certains grands dépòts d'archives n'est pas assez arancé pour que l'on ne puisse espérer d'y retrouver encore quelques petits recueils de thartes dissimulés au milieu de liasses rarement consultées. Mais ce seront assurément des exceptions. D'autre part on a dù renoncer à comprendre dans cette Bibliographie des recueils qui, mème dans des inventaires officiels et récents, ont été indùment classés comme tels, et ne sont en réalité que des inventaires de titres.

Ion ami Maurice Prou a donné à ce livre unc marque d'intérèt "bien précieuse en en relisant régulièrement les épreures et en $y$ apportant d'utiles améliorations. Jamais on ne tait en rain appel a son érudition. 



\section{BIBLIOGRAPHIE}

I)ES

\section{CARTULAIRES}

Abbeville. - Chartreuse (dinc. d'Amiens).

1. - Cartulaire ds la Chartreuse d'Abbeville: orig- pertu.

A été ru " cité par Don Villerieille.

2. - Monuments de la Chartrense de Saint-Honoré d'Abbeville : ms. du XIXe siècle, sur papier, contenant des titres des années 1301 à 1637 , in-folio de 125 ff. (Biblioth. do ln ville d'Abbeville. ms. 148).

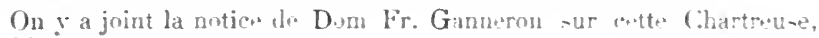
qu il a comprosin ten liti2.

Abbeville. - Eglise collégiale Saint-Tulfran.

3. - Cartulaire noir de Saint-Vulfran d'Abbeville; ms. des XIIIe-XIVe siècleś, sur parchemin. composé de plusieurs parties et contenant des actes de 1190 à $133 \pi$, in- $4^{\circ}$ de 150 li. (Bibliolh. untimale. ms. nouv, acq. latines $168 \mathrm{I}$ ).

4. - Cartulaire rouge de la mème église: ms. des $\mathrm{XV}^{\mathrm{e}}-\mathrm{XVI}$ siècles, avec additions postérieures. sur papier. et contenant des ducuments des années 1209 a 1710. in-ț" de "382 lf. (Biblioth. nationule, ms. nour. acq. latines 1682 .

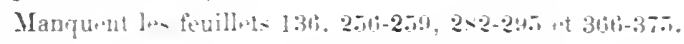

Abbeville. - Ville.

5. - Cartulaire municipal ou * Livre blane » d'Abbeville: ms. de la fin du XII siècle. continué jusqua ${ }^{\circ} \mathrm{XVI}^{\text {}}$. sur parchemin, in- ${ }^{\circ}$ de 362 II. Archices municipules d Ablecille. At 130.

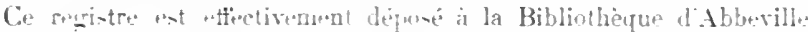

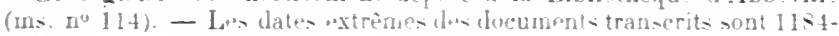
1519.

6. - Cartulaire ou "Livre rouge » de l'écherinage d'Abheville; ms. des XIII $-\mathrm{XVI}^{e}$ siecles, sur parchemin. in $4^{0}$ de 484 pages 'Biblisth. de ln rille d'Alberille. ms. 115.

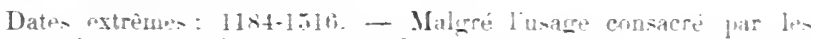
auteur locax, ce gent pas réalite un cartulair. municipal. mai

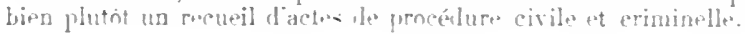


7. - Recueil des privilèges de la ville d'Abberille; ms. du XIVe siècle, avec adclitions postérieures. sur parchenin, contenant des titres de 1312 is 1779, in-folio de 85 ff. (Archires murcipales d'Abberille, AA (31).

Abenon. - Prieuré (dioc. de Lisieux).

8. - Cartulaire du prieuré de St-Barthélemy d'Abenon; ms. du XVe siècle, avec additions postérieures, sur papier, in-8* de 89 17. (Biblioth. rationale, ms. latin 11054).

Accorre (Renier), florentin, bourgeois de Provins.

9. - Cartulaire de Renier Accorre; ms. du XIII siècle. sur parchemin, in-folio de $189 \mathrm{tI}$. (Biblioth. nationale, ms. français 8593).

Dates ixtremes: 12in-1280.

Cit. Renier Accorre, fintneiter et arand proprietaire au XIII siècle, l'ar F. Bourqualot (Bibliotheque do l'École des Cihartes, de série, III, 1867 , 1. $(2 \cdot 4-81)$.

Acey. - Abbaye (dive. de Besançon).

10. - Cartulaire de l'ablaye d'Acey ; ms. du XIVe siècle, sur parchenin, incomplet du début, in-4" de 30 Il. (Biblisth. nationale. ms. latin 5683$)$.

Copie norlerne du mème. par L. Lex, sur papier (Archices dép. de lil Ilaute-Saone, $\mathrm{H}$ supplément).

Extraits faits an XYIII siecle (Biblioth. de la rille de Besancon, coll. Baverel, ms. 37, 11. 240-243).

(if. un" lettre de Inom Toustain à I)om Plancher, en date du 11

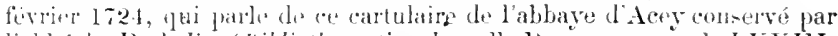
lablec de. Retherin (Biblioth. mationale, coll. lourogone, vol. IAXIII, fo 1,il). ("̈ent un antre volume sans doute qui fot simale par le

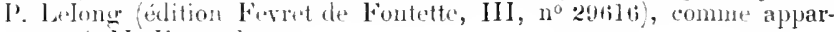
trinant a II. Fourciult.

Acy. - Privuré de Saint-Nicolas (dioc. de Scnlis).

11. - Cirtulaire du prieure de St-Nicolas d'Acy ; orieg. perdu.

Iixtraits faitsdepuisle XVII siecle (Biblioth. nationale, coll. Baluze, vol. LV. If. 225-255; ms. latin 17048, pp. 61-64; coll. Duchesne, vol. LXXT1I, ti. 27-29; coll. Clairambanlt, vol. 562, p. 351-364; et cull. Duchesne, rol. LI, qui est l' " histoire de la Naison des Bouteillers de Senlis .. par Du Chesne, pasim ; - Bibliath. de la cille de Senlis, coll. Allorty, vol. III, et Titres d'Altorty, vol. I).

Publ. : Cartulaire du priemré de Saint-Nicolas d'Acy (I 106-1244), par Am. Vattier (Comptes rendus 't Mémoires du Comité archénlogique de S'mlis. 3e série, I, 1886, pp. 50-80).

Aerschot. - Chapitre Notre-Dame (dioc. de Malines).

12. - Cartulaire dı Chapitre d'Aerschot; ms. des XVe-XVI siècles, sur papier, contenant des actes de 1460 a 1590 , in- $4^{0}$ de $58 \mathrm{tl}$. (Archices dn royantime de Belgique, à Bruxelles). 


\section{Aerschot. - Couvent de Saint-Nicolas.}

13. - Cartulaire du couvent de St-Xicolas d'Aersclot: ms. du XVII siècle [1654], sur papier, en 2 vol. in-folio de 198 et 183 ff. (Archices de l'urcheceché de Malines).

Aerschot. - Duchi.

14. - Recueil de titres relatifs au duché d'Aerschot:ms. du XVIe siecle, sur papier, contenant des titres à partir de 1284 , in $-t^{\circ}$ de $4(60 \mathrm{ff}$. (Archices du royumine de Belgique. a Bruxelles).

Afflighem. - Abbaye (dioc. de Cimbrai).

15. - Cartulaire de l'abbaye d'Afflighem; ms. du XVe siècle [1+32], sur papier, contenant des documents ile 1086 is 1432 . in- $0^{0}$ de 293 pages (Archices du royaume de Belgique, a Bruxelies).

16. - Autre cartulaire; ms. du XVe siècle, sur papier. contenant les mèmes documents avec additions jusqu'i 1454 . in-folio de 166 If. (Archives du royaume de Belgique, à Bruxelles).

17. - Antre cartulaire; ms. du XVe siècle, sur papier, contenant des

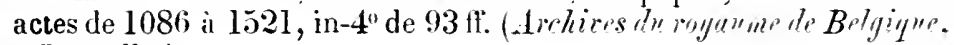
à Bruxelles).

18. - Recueil de documents relatifs à labbaye d'Afflighem; ms. du XVII ${ }^{\mathrm{e}}$ siècle, sur papier, contenant des titres de 1135 a 1549 , er 3 vol. in-folio de 465 , 505 et 489 pages (Aichices tur ruyarme de Belgique, à Bruxelles).

19. - Autre recueil ; ms. des XVII -XVIII siècles, sur papier, contenant des titres à partir de l'an 1086. en 3 rol. in-folio de 867.675 et 709 tf. (Archices du royume de Belgique, a Bruxelles).

20. - Publ. : Cartulaire de labbaye d Aflighem, par Edgr. le Mar-

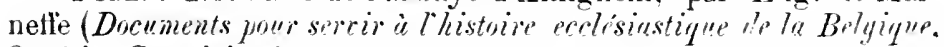
$2 \mathrm{e}$ série, Cartulaires:

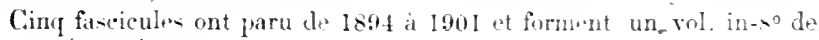
638 p. à continuer.

Agaune. - Abbaye de Saint-Yaurice (dioc. de Sion).

21. - Cartulaire de l'ablaye d'A raune; orig. perdu.

$21^{\text {bis. }}$ - Fragment d'un cartulaire d'Agaune: ms. du XIVe siecle. sur papier, avec index du XVIII ${ }^{\text {, }}$, contenant 72 actes des années 909 à

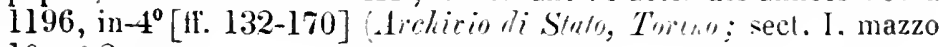
$10, \mathrm{n}^{0} 2$ ter.

Publ. : Monumenta historiae patriae. Chartarum tomus II 1853). Quelyues chartes sont aussi pul,lies dans la "Billiotheca sibusiana »)

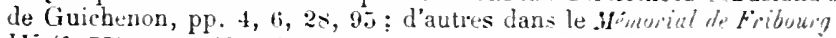
IV $(1857)$, pp. 348-359. 
22. - Recueil de privilèges relatifs ì la mème abbaye; ms. du XVII ${ }^{e}$ siècle, sur papier, in-folio (Biblioth. du Vuticun, ns. Ottoboni 3172, II. 306 et ss.).

23. - P'vbl. Origines et documents de labbaye de Saint-Maurice d'A ranne, par l'abbé .J. Gremaud. Fribouror, 1838, in-8.

Datus extrênus: .ir-101\%.

Agde. - Chapitre cathédral.

24. - Vieux cartulaire du Chapitre d'Agrde; ms. sur parchemin, contenant des titres de 1130 à 1267 ; orig. perdu.

Copie clu précédent; ms. du XVIII siècle, sur papier, par l'abbé M. G. de Gohin, infolio de 334 pages (Biblioth. de la rille de Monitpellier, ms. 33).

Agde. - Évêché.

25. - Cartulaire de l'évêché d'A grde; nus. du XIII siècle [vers 1235], sur parchemin, de $56 \mathrm{fl}$; ; orig. perdn.

Copie faite sur le précédent par l'archiviste Ant.-Gabriel Jourdan en 1764 , sur papier, incomplet an débnt, avec table en tête, in- $4^{0}$ de xx1-141 II. (Biblioth. natimule. ms. latin 9999).

Arec additions dinjès les originaux. - Les documents transerits appartiennent aux IX-Xill siectes.

Extraits du mème. faits au XVII siècle (Biblisth. nationale, ms. latin 12770 , pp. 152-159, et latin 12760 , pp. 454-457.

Agde. - Ville.

26 . - Cartulaire municipal l'Augde; ms. rédigé en 1332, sur parchemin. contenant les documents it partir de 1260, in-lolio de $43 \mathrm{fl}$. (Archires municipales d".1gde, AA 1).

27. - Autre. contenant la traduction française des privilèges et franchise- de la ville; ms. rédigé en 1602. sur parchemin, et contenant des docnments a partir de 1218, in-4" de $103 \mathrm{fl}$. (Archioes immicipules $\pi^{\circ}$ Agde, AA 2).

28. - Autre cartulair" lu XVII" siècle, sur parchemin. contenant des actes de 1076 à 15:34, in-t" de $89 \mathrm{fl}$. (Arrhires muniripales d Agde, AA:3).

29. - Autre cartulaire du XVe siècle, sur parchemin, contenant des documents de 1267 is 1458 , in-4 $4^{\circ}$ de $132 \mathrm{fl}$. (Archires muniripales (i) Aydr, AA 4).

Cé volume est spécialement consacré aux relations de la conmunauté d'Aude avec les localités roisines (Bessan, Florensac, Marceilhan, Vias).

Axal. : Inventaire sommaire des cartulaires municipaux d’Agde, par Jos. Berthelé. Montpellier, Rirard frères, 1901 ; in- $4^{0}$ de 67 p. 
Agen. - Évèchè.

30. - Cartulaire de l'évèché d'Agen : orig. perdu.

Extrait fait au XVIIIe siècle. contenant un acte de l'annér 1:266 (Biblioth. nationale. coll. Lespine, vol. XXXIII, fo 4.56).

Agen. - Ville.

31. - Cartulaire municipal d'Agen: ms. rédicé en 1.504-1506 et continué jusqu'en 1658, sur parchemin, contenant des actes de 1221 à 1658 , in-folio de 131 If. (Archices muniripales "Agen, Ad 4l).

$31^{\text {bis. }}$ - Publ. : Archives municipales d'Agen; Chartes. $1^{\text {re }}$ série (11891328), par Ad. Magren et G. Tholin. Villeneuve-sur-Lot. Duteis. 1876 ; in $-4^{0}$ de $x \mathrm{x}-3.55 \mathrm{p}$.

Aiglun. - Seigneurie en Provence.

32. - Cartulaire de la seigneurie d'Aighnn : ins. du XIY'e siecle [1:333],

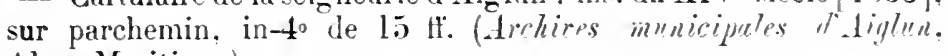
Alpes-Maritimes).

Aigues-Mortes. - Ville.

33. - Cartulaire municipal d'Aigues-Mortes : ms. daté de 17iz, sur papier, contenant 242 pièces depuis 1248, in-folio de 398 tf. (Archices dép. du Gurd, E non coté).

On peut signaler aussi un rouleau en parchemin, rélige en lots pal"

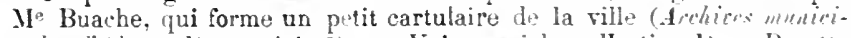
pales ditigues-Wortes, AA 2). - Voir aussi la coll cetion Won Pacotte anx Archicess dip). de l'Herenult (série $\mathrm{A}$ ).

Aillon en Bauges. - Chartreuse (dime. de Chambiry).

34. - Cartulaire de la Chartreuse d'Aillon: ms. du XVe (?) sièrle. sur parchemin, ayant contenu 156 chartes uriginairement. aujourd'hui incomplet, in-t" (a appartenu à M. le marquis Albert Co-ta de Beauregard) (1).

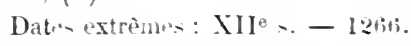

Copie du mène, par de Jussieu. sur papier, inffulio de 130 It. (Avechiess dép. de la Sarmie, C it6).

Voir aussi au mot: Sirule.

Publ. : Les Banares, par L. Murand. II Chambéry, 1890. in-s", p. $388-5+1$.

Dates extrène: : $1151-1433$.

Ainay. - Abbaye (dioc. de Lyon).

35. - Cartulaire de l'abbaye de Saint-Martin Minay: ens. Wu XIe siècle, sur' parchemin, in-t') de 101 If. (Bib'inth. mitimals. m. lattin $1102 \pi)$.

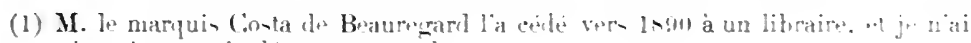
pu satuir qui en ent let detemlexur actural. 
36. - Grand cartulaire de l'abbaye d'Ainay; ms. dlu XIVe siècle [1341], avec additions postérieures, sur parchemin, in-folio de vin-315 It. (Biblioth. de lie rille de Lymon, fonds Coste, ms. 248).

Le précedent volume (nss. 247) du même fonds contient un live des fomlations (in-1" de 3I tr., SIV siècle) qui pout it la rigueur figurer au nombre des cartulaires.

37. - Petit cartulaire de l'abbaye d'Ainar; ins. dn XIIIe siècle [1:286], sur parchemin, in-folio de 40 If. (Archizes dép. du. Rhône, $\mathrm{H}$ non colé).

Ptbl. : Grand cartulaire de l'abbaye d'Ainay. snivi d'un autre cartulaire rédigé en 1286 et de documents inédits. par le Comte de Charpin-Feugerolles et II.-C. Guigne. Lyon. Pitrat ainé, I\&8.5; 2 vol. in- 4 " le xi- 684 et xxiri-368 p.

Cif. aumi Aurr. Bernarl. ro siricix.

Aire-sur-l'Adour. - Évêchè.

38. - Cartulaire de l'évèché d'Aire. ou « Livre rouge »; ms. daté de 13:35, orio. perdu.

L'xistone de cerenintre at attestén par un extrait d'acte de lannée 10 s.1 (Biblioth. nationule, eoll. Baluze, vol. VII, fo bit), et par diautres (Hem, me. latin 12774, [. 416: ms. latin 12773, p. 264 ot 275: coll.

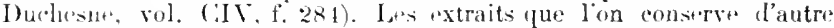
part (Aorthires dep. des Lourles, (i 67 quator, et Biblioth. de la ville de

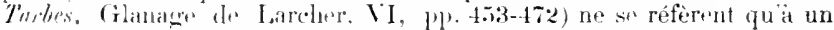
pouille du diocen exalement transcrit dans le "live rouge ".

Aire-sur-la-Lys. - Église collégiale Saint-Pierre.

39. - Cartulatire de Saint-Pierre d"Aire on " Collectanea plurimorum titulorum capituli Ariensis »; ms, des XVIe-XVII siècles, sur papier, contenant tes titres i partir de 1075 , in-10 de $245 \mathrm{li}$. (Archices dép. dn P'ss-de-Caluis, G non coté).

40. - Autre recueil des titres de la collégriale d'Aire; ms. des XVIeXVII" sièrles. sur papier. commencant également en 1075, in-4 ${ }^{0}$ de 126 ti. (Airhices dipr. d" Pas-dr-Calais, G non colè).

41. - Ancien carlulaire de Saint-Pierre d'Aire; ms. contenant entre antres une charte de l'année 1026 ; orig. perdí.

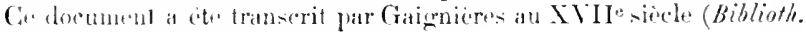

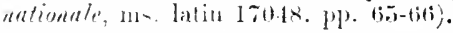

42. - Publ. : Recueil de chartes en langue vulgaire provenant des archives de la collériale de Saint-Pierre d'Aire, par N. de Wailly (Biblinthèye de l'Ecole des Chartes, XXXI. I870. pp. 261-302).

Date's "xtrêne's : 1241-1295.

Aix-en-Provence. - Archerèrhè.

43. - Cartulaire de l'archevèché d'Aix, dil «Thesaurus $»$; ms. du XIII ${ }^{c}$ siècle. avec additions postérieures. sur parchemin, contenant 170 actes des années 1146 à 1464 , in-folio de $125 \mathrm{fr}$. (Archires dép). de's Bonrless-dh-Rhinue, (i non coté). 


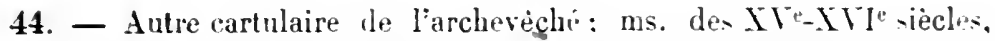
sur papier, contenant des titres des années 1218 a 1.540 . in-folio de 220 tf. (Archiress dép. des Bourless-dn-Rhoue. G non coté.

Aix-en-Provence. - Chapitre Saint-Saureur.

45. - Carlulaire dı Chapitre Saint-Sauveur d'Aix : mi. des XVIJ XVIII siècles. sur papier, cuntenant des actes il partir de 1462 ,

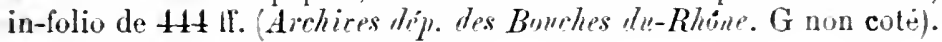

Aix-en-Provence. - Ville.

46. - Cartulaire municipal d'Aix on "Livre rourge "; ms. des XT"e XVIIe siècles. sur parchemin, avec reliure de bois, contenant des

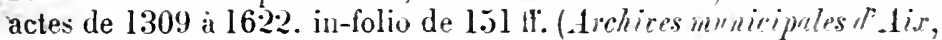
At 2).

47. - Autre "Livre rouge » : ms. des $\mathrm{XV}_{-}-\mathrm{XVI}^{\mathrm{e}}$ siècles. sur parchemin, contenant des actes de 1293 à 1560 , in-folio de $1 \mathrm{l} 3 \mathrm{ff}$. Archires dep. des Bourhes-dn-Rhine, B 1403.

48. - Recueil des privileges de la ville d'tix on « Liber Corneli »: ms. du XV siècle. sur parchemin, contenant des actes de 1300 is 1400 , in-folio de $183 \mathrm{ff}$. (Archires inunicimules d"Air. Ad 3).

49. - Cartulaire enchainé ou « Liber catene $» ;$ ms. des XIVe-IVII siècles, sur parchemin, contenant des actes de 1185 a 1674 . in-fulio de $331 \mathrm{ti}$. (Archires municipales d'tir, At 1 ).

50. - Autre « Liber catene »; ms. des XIV"-XVe siècles, sur parchemin. contenant des actes de 1293 is 1470 . in-folio de $164 \mathrm{ll}$. (Archires dép. des Bouches-th-Rhine. B 1402).

51.- - Cartulaire d'Aix; ms. du XVI siecle [1547], contenant des actes de 1292 à 1481 , in-folio de 18 ff.'Archices municipmles it Air. At 4 .

Scelle du scerat de la Chambre des Compes de Provence qui en avait eté ordonné la confecétion.

52. - Autre cartulaire ou Lirre noir: ms. des XVIe-XVII siècles, sur papier, contenant des actes de 148 a 1616 , in-folio de $60 \mathrm{lf}$. (Archices muicipales it tix. At 7 ).

53. - Publ. : Privilèges, franchises et immunités concédées par les rois et comtes de Provence en fareur de la ville didix. Aix. 1620. in- $8^{\circ}$.

- Recueil des privilèges. statuts ef franchises de la ville d'dix. Aix. 174l. in-4".

Voir ausi $r^{\circ}$ Botrges.

Aix-la-Chapelle [Aachen].

כ4. - Pcbr. : Codex diplomaticus Aquensis. edit. a Chr. Quix. 1. Aquisirrani, 1839-1840. in-4" de II-88 et 272 p.

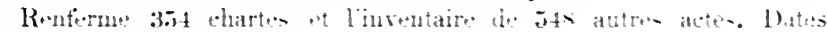
extrense- : :7!-1350. 
Aizenay. - Prieuré. - Voy. Marmoutur.

Alais. - Seigneurie en Länguedoc.

55. - Cartulaire de la seigneurie l'Alais : ms. des XIII ${ }^{e}$ XIVe siècles, sur parchemin, in-4 ${ }^{0}$ (Biblisth. de feu 1. le baron de Giverrlot).

Nous ignorons entre quellen mains est paste a rolune depuis 1883.

Alaman. - Voy. Laltrec.

Albert. - Ville.

56. - Cartulaire municifal d:Albert; ms. du XVII siècle [1673],

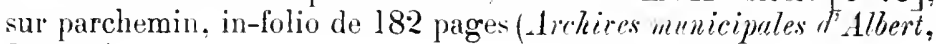
Solnme).

Albi. - Chapitre Saint-Salyi.

57. - Recueil de litres relatifs au chapitre Saint-Salvi d'Albi; ms. de 1667. sur papier, contenant des actes des années 1075-1591, in-folio (Biblinth. metionule, coll. Doat, vol. 113. I1. I-226).

Albi. - Archerèche et Chapitre cathèdral Sainte-Cécile.

58. - Cartulaire de l'archevèché d'All,i ; orig. perdu.

Extraits faits par Dom Estiennot an XVIle siecle (Bibliols. antiounle. ms. latin 127\%1. p. 275, et latin 127\%2, p. 207).

59. - Recueil de titres relatifs i l'archevèché et au Cihapitre cathédral d'Albi; ms. de $1667-166$ !), sur papier, contenant des documents des amnées !2 24 a 1608 , en 8 vol. in-folio de 387,406 , 392, 384, 374. 38. 392 et 487 il. (Biblinth. uatimnle, coll. Doat, vol. 10.-112).

Albi. - Ville.

60. - Cartulaire municipal d'Albi ; ms. des XIII - X Ve siècles, sur parchemin, contenant des acles de 1220 a 1472 , in $4^{0}$ de $74 \mathrm{ll}$. (Arelires municipules d'.llbi, At 1).

Anal. : Les cartulaires d'Albi, par Ang. Vilal (Rerue Hes langues romanes, XLV, 1902. pp. 447-469).

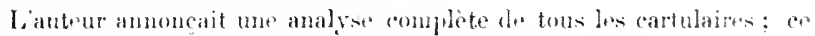
qu'il a pullic jusqu ice ne concerne que le moristre A. 1.

61. - Autre cartulaire du $X V^{\mathrm{e}}$ siècle, avec additions postérieures. sur parchemin, contenant les actes de 1220 a 1694 . in-folio de I40 $\mathrm{fr}$.

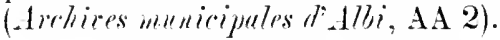

Cé volume as la copie partielle da précédent.

62. - Autre cartulaire du XVII" siècle, sur parchemin, contenant des actes de 1220 i 1600 , in-folio le $96 \mathrm{ff}$. (Archires municipules d'Albi. AA :3).

63. - Autre cartulaire ou " livre ronge »; ms. du XVIF" siecle, sur 
papier, avec additions, contenant des actes de 12232 is 1720. in-folio de 397 fl. (Archixes muicipules d'Albi, AA 9).

64. - Autre cartulaire ou "lisre blanc 》; ms. dı XVII e siècle, sur papier. contenant des actes de $1.53 \pi$ it $162 \tau$, in-folio de $469 \mathrm{tt}$. (Archives menicipales il Albi, tA 10).

65. - Autre cartulaire ou «livre vert»; ms. dı XVIle siecle. sur papier, contenant des actes de 1535 i 1679 . in-folio de $438 \mathrm{~m}$. (Archives municipales d"Albi, AA 1I).

66. - Autre cartulaire ou «livre noir »: ms. des XVIle-IVIIIe siècles, sur papier, contenant des actes de 156.) i 1703. ill-folio de $373 \mathrm{ff}$. (Archices municipales $P$ Albi. AA l-2).

67. - Autre cartulaire. com, lément du « livre noir» : ms. du XVIII ${ }^{\mathrm{e}}$ siècle, sur papier, contenant des actes de 1542 a 1742 , in-folio de $44 \mathrm{ff}$. (Archices municipales d Albi. A. 13).

Un autre registre, contenant 150 actes des années 1331 -1606, a été réintègré aux Archices muniripules drd/bi en 1899 ; il n'est pas inventorié.

68. - Recueil de titres relatifs ì la ville d'Albi : ms. daté de 1668, sur papier, contenant des actes de 1220 a 1615 . en 2 rol. in-folio de 359 et 38.5 If. (Biblioth. natimale, coll. Doat, vol. 103-104'.

Albigeois. - Croisade.

69. - Cartulaire de Langruedoc relatif à la croisade des Albigeois: ms. du XIII ${ }^{e}$ siècle. sur parchemin, de plusieurs mains, contenant des actes de 1211 a 1220 . in- $4^{0}$ de 6.5 fr. a 2 col. (Archices mutinuales, JJ 13).

Alençon. - Comté.

70. - Cartulaire du comte d'Alençon : orig. perdu.

A été utiliné par Dom Moriew.

Extraits faits au XVII' siècle 'Biblioth. natingule, ms français 22330 , p. 1 à 102 .

71. - Autre cartulaire on « iivre de Marie l'Espagne » ; orił. perdu.

A ét utilisé par Odolant-1)-nos. hivtorien du Perehr. lont les papiers sont actuellement entre les mains do If Hilaire, à Alencon

Extraits faits au XVII siecle par Nic. Ch. de Sainte-Jlarthe (Biblinth. nutionale, ms. français 20692. p. 6).

Allemagne (Bailliage d'). - Voir Boclar.

Allemagne (Empire d'). - Voir Eypike.

Alne. - Abbaye (dioc. de Liège).

72. - Cartulaire de l'abbaye d'Alne ; ms. du XIVe siècle, arec 
reliure de bois ornée de fermoirs de cuivre, sur parchemin, contenant 78:3 actes de Ilt4 à 1399 , in-folio de 332 fi. à 2 col. (1rehires de l'État ù Mons).

Axul. : par L. Devillers, Description de cartulaires et de chartriers du Hainaut, I (1865), p. 23-296.

73. - Autre cartulaire; ms. du $\mathrm{XVI}^{\mathrm{e}}$ siècle, sur papier, contenant des actes de 1224 a 1529, in-4" de 306 1l. (Arrhives de l' fitat à I/(I) $(s)$.

74. - Autre cartulaire; ms. dı XVIII ${ }^{\mathrm{e}}$ siècle, sur papier, contenant des actes de 11 ó à 1340 , in- $4^{0}$ de 143 pages et I8 fl. de lable (Arekires de l'Etut à . Wons).

75. - Autre cartulaire; ms. dı XVIII ${ }^{\mathrm{e}}$ siècle, sur papier, contenant des actes de 1182 a 13966 , in- $8^{\prime \prime}$ de 115 pages et 21 ff. de table (Arekives de l"Élut à Hons .

Ces deux derniers recueils sont des ropies partielles des précédents.

Alost. - Comrent des Carmélites (dioc. de Malines).

76. -..- Cartulaire des Carmélites d'Alost; ms. du XVIIIe siècle, sur papier, contenant des documents de 1474 i 1756 , in-folio de $438 \mathrm{ff}$. (Archices dur voyume de Belgiquer, à Bruxelles).

Alost. - Ville.

77. - Cartulaire dles privilèges d'Alost et de Grammont; ms. du XIV' siècle, sur papier, contenant des documents de 1174 à 1333 , in-4" de $1: 3$ il. (Archires du volyatume de Belgique, à Bruxelles, fonds de la Chambre des Comptes).

Cf. l"inventaire inpriné de ce fonds, t. 1, p. $21 \tilde{5}$.

78. _ «Peysboek» ou cartulaire municipal d'Alost; ms. des XVe_ XVle siecles, sur papier, contenant des documents de 1242 à 1288 , in-4" de 136 tr. (1.elires rommuntes d'Alost).

79. — «Bok met den hair »; ins. commencé en 149l, par Henric van Inxhem. clerc de la ville, et continué ultérieurement, sur papier, in-folio, II. 1-90 (Archiers communales d'Alost).

Alspach. - Abbaye (dioc. de Strasbourg).

80. - Cartulaire de l'abbaye d'Alspach; ms. du XVIII siècle, sur papier. contenant des actes de 1282 à 1732 , in-4 $4^{0}$ de 145 li. (Lichic tes Ober-Elsass, in Colmar).

Altavaux. - Prieuré (dioc. de Limoges).

81. - Publ. : Documents concernant le prieuré d'Altavaux, 11781695, par (i. Babinet de Rencogne (Bulletin de la Société archéologique d" Limousin, XXVII, 1880, p. 241-283). 
Altorff. - Abbaye (dioc. de Strasbeurg).

82. - «Protocollum abbatier Altorfensis »: ms. du XVI siècle. sur papier, in-folio de $400 \mathrm{ff}$. (Archir des Unter-Elsass. in Strasshurg).

Documents do 1248 it $15 \%$.

Amboise. - Ville.

83. - Recueil de titres relatifs à la ville d'Amboise; ms. composé au XIX'e siècle par André Salmon, sur papier, in- $4^{\circ}$ (Biblivth. do la rille de Tours, ms. 1320, fi. 141-373).

84. - PCBL. : Titres el privilèges des habitants ditmboise. Amboise. 1740 , in- $8^{\circ}$.

Ambournay. - Abbaye (dive. de Lron).

85. - Recueil de titres relatifs à l'allase dAmbournay; copies du XVII siècle, sur papier. in-folio (Biblisth. nationale. coll. Bourgogne, vol. Lxilr. tf. 36-78).

Amiens. - Abbaye de Saint-Fuscien.

86. - Cartulaire de l'abbaye de Saint-Fuscien d'Amiens; orig. perdu. Exlraits faits au XVIIe siècle (Biblioth. de l'Arsenal. ms. 52.59. ff. 17 ro-2 7 ; - Biblisth. nationale. ms. Irançais 9497, pp. 1531 : coll. Duchesne. vol. LX, f" 185); - au XViII siècle (Biblisth. de la rille de Roye, ms. 17).

Amiens. - Abbare de Saint-Jean des Premontres.

87. - Cartulaire de l'abbaye de Saint-Jean d'Amiens : ms. du YIII siècle. sur parchemin, contenant des documents a partir de $113 \%$. in $4^{\circ}$ de $116 \mathrm{ti}$. (Biblintl. te la rille t'timiens, ms. 781).

\section{Ce registre presente quelques lacunte.}

Copie du mème; ms. de 1638. sur papier, in-folio de 611 tf. (Archices dép. de la Smime, H non coté).

Extraits faits au XVII siècle (Biblioth. de PArspnal. à Paris, ms. 5260, ff. 98-114: Biblisthe nationale. ms. français 9498. pp. 187221); - au XViII siècle Biblisth. de lu rilie de Royr, ms. 1i).

88. - Fragment d'un autre cartulaire de Saint-Jean d'Amiens; us.

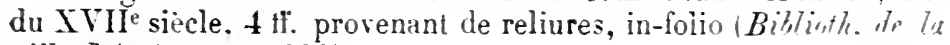
rille di imiens, ms. 991).

Contient des aetro de lannee livul

Amiens. - Ahbaye de Saint-Ylartin-aux-Jumeaux.

89. - Cartulaire de l'abbaye de Saint-Martin-aux-Jumeaux : m.. du Xill ${ }^{e}$ siècle, incomplet du début, sur parchemin. aree reliure ancienne. contenant 193 pièces des années $1131-12.54$, in- $4^{\circ}$ de 116

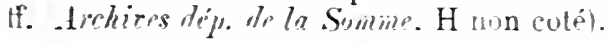


Extraits faits au XVIII siècle par J. A. F. Carlier de Corselles (Biblioth. de la rille de Roye, ms. 17).

Amiens. - Abbaye du Paraclet.

90. - Cartulaire de l'abbaye du Paraclet; mis. du XIVe siècle [1397] avec quelques additions du $\mathrm{XVe}$, sur papier, conlenant des actes à partir de 1219, in-4 $4^{\circ}$ le 148 11. (Aichices dép. de la Somme, H non (coté).

Extraits faits au XVIII siècle par J. A. F. Carlier de Corselles (Bibliath. de la ville de Roype, ms. 17).

Amiens. - Chapilie cathedral Notre-l)ame.

91. - Cartulaire I du Chapitre d'Amiens; ms. de Ia fin du XIII e siècle, sur parchemin, contenant 334 pièces des années 850-1265, in-4 de vir-188 ff. (1rchices dép. de la Somme, G non coté).

92. - Cartulaire II ; ms. des XIII -XIVe siècles, sur parchemin, contenant 395 pièces des années 850-1388, in-4 de $x-362 \mathrm{ff}$. (Aichives dép. de la Somme. (i non coté).

93. - Cartulaire III; ms. de la fin du XIII siècle, avec additions dn XIV". relié en bois, sur parchemin, contenant 305 pièces des années 8.)0-1324, in-4" de $213 \mathrm{fr}$. (Archives dép. de la Simme, G non cotè).

94. - Cartulaire IV; uns. du XIV e siècle. sur parchemin, contenant 386 pièces des années 850 ì 1294. copiées par plusieurs mains, in-4" de 161 Il. (Hectives dép. de la Somme, G non coté).

95. - Cartulaire V: ms du XIV'e siècle, sur parchemin, contenant 127 pièces dles années 1190-1242, in-4" de 94 fi. (Aichives dép. de la Somme. (r non coté).

96. - Cartulaire VI : ms. des XIII ${ }^{e} X V^{\mathrm{e}}$ siècles, de plusieurs mains, sur parchemin, avec inclex général des six cartulaires rédigé au XIV siècle ff. 16I-I82, contenant en outre 84 pièces des années 1267-14l6. in-f" de 182 fl. (Arrlives dip. de la Somme, G non coté).

97. - Cartulaire VII, dit «Compositiones»; ms. du XVI ${ }^{\mathrm{e}}$ siècle, sur parchemin. contenant 69 chartes de 1231 a 1578 , in- $4^{\circ}$ de 94 ff. (1reliers dép. de la Somime, Gr non coté).

Pebl. Cartulaire du Chapitre de la cathédrale d'Amiens, par lahlue Rose, J. Roux et A. Sorez (Mrmoires de la Société des antiquaires de Picardir. Doc umenti inédits concernant la province, XIV. 1897-1905, in-4" de 506 p.).

Premier volume seul paru. La préface donne la description complète de tous les registres dont on vient de donner la désignation (le dernier excepté). 
Extraits faits au XVIJe siècle (Biblioth. de l'Arenal, ms. 465:, tif. 169-196; ms. 5259, ff. 39-45).

Autres extraits (Biblisth. nationale, coll. Duchesne, vol. XXII. fo 464, et LX. fo 185; coll. Dom Grenier, vol. CX. f" 129 ; et Biblioth. de la cille de Roye, ms. 17).

98. - Cartulaire de l'université des chapelains de l'ëglise d'Amiens : ms. du XVe siècle, sur parchemin, in $f^{\prime \prime}$ de $7 \mathrm{ff}$. (Biblioth. de la rille d"Amiens, ms. 519 .

Amiens. - Courent des Célestins.

99. - Cartulaire du couvent des Célestins d'Amiens; orig. perdu.

Extraits faits au XVIII siècle (Biblioth. nationale, coll. Dom Grenier, vol. XCI, ff. 126-12i; - Bibliotle de la cille de Rriye, ins. 17).

Amiens. - Église collégriale Saint-Firmin.

100. - Cartulaire de l'église Saint-Firmin d'Amiens: ms. du X X'e siècle, avec additions du XVIe, sur parchemin, in-folio de $96 \mathrm{tl}$. (Biblioth. de la ville d'Amiens, ins. 520,

Extraits faits au XVII siècle (Biblioth. de l'Arsenal, à Paris, ms. 5259, ff. $10 \mathrm{v}^{-0}-11$ : Biblinth. nationule. ms. français 9497 . pp. $1-3$.

Amiens. - Évèché.

101. - Cartulaire de l'èvèché d'Amiens; ms. des XII ${ }^{\mathrm{e}} \mathrm{XIII}{ }^{\mathrm{e}}$ siècles, sur parchemin, in $\mathbf{4}^{0}$ de (?) if. à 2 col. 'Biblinth. de .M. de Cromy, au chàteau de La Guerche, Indre-et-Loire).

Peut-être est-ce loriginal de $3 \times 8 \mathrm{ff}$. couverts diune ruliure en boin garnie do cuir blane (ef. Bibliath. Io In rille d'Amiens, m. 5ti3, if. 311 $322)$.

Extraits divers faits au XVIIe siècle (Archices dép. de la Strame. G 405-406, 588, 731 et 785).

102. - Autre cartulaire de l'évẻché d'Amiens. "plus ancien ». orig. perdu.

Extraits faits au XVIII siècle (Biblisth. nationale, coll. Dom Grenier, vol. XCVII, pages 1-147, et vol. CX. f" 146.

Extraits faits au XVIII ${ }^{e}$ siècle, par J. A. F. Carlier de Corselles (Biblioth. de la cille de Roye, ms. 17.

Amiens. - Hòtel-Dieu.

103. - Cartulaire de l'Hòtel-Dieu ou hòpital Saint-Jean d’Amiens : 
ms. du XIII siècle, sur parchemin, contenant des actes de $118 t$ à 1295, in-4" de 134 If. (Archices hospitalieres d'Ainiens, A 3).

Extraits du précédent, faits au XVII siècle (Biblioth. de l'Aisenal, nus. 4652, 11. 197-220).

104. - Autre du commencement du XIVe siècle, sur parchemin, contenant des actes de 1184 à 1:300, in- $4^{\circ}$ de 56 tf. (Archives hospitalières r. Amiens, i 4).

Amiens. - Ville.

105. - Cartulaire A de la ville d'Amiens; ms. du XIV siècle, avec additions postérieures, sur parchemin, contenant des actes de 1154 à 1503 , in-folio de $276 \mathrm{tl}$. (Archives municipales d'Amiens, AA 1).

106. - Cartulaire B de la ville d'Amiens; ms. de la fin du XIV viècle, avec additions postérieures, sur parchemin, contenant des actes de 1228 à 1472, in-folio de $92 \mathrm{H}$. (Archives municipales d'Amiens, $A \mathcal{A})$.

107. - Cartulaire C; orig. perdu [cf. eoll. I)om Grenier, vol. CXX, If. 15l-154].

108. - Cartulaire D; orig. perdu.

109. - Cartulaire L; $\mathrm{ms}$. du XVe siècle ivec additions postérieures, sur parchemin, contenant des actes de 1115 a 1571 , in-1" de 366 II. (Archioes mnicipules d'Amiens, AA 5).

Une coplit des 210 premier's ff. de ce registre, exécutée au XVo siècle,

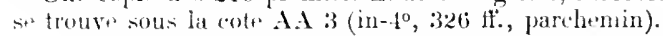

Axil. : Inventaire-sommaire des archives municipales d'Aniens, I (189L), par G. Durand, pp. 1-27 et 31-58.

111). - Publ. : Recueil des Monuments inédits du Tiers-État, par Aur. Thierry. I-II. Paris, Impr. Impériale, I850-1853. 2 vol. in-f". [Collection des Documents inédits.]

Voir aussi r" Borrgis.

Ancerville. - Prévôti.

1I l. - Recueil de titres relatifs à la précôté d'Ancerville et Éclaron ; ms. de la tin du $\mathrm{XVI}^{\mathrm{e}}$ siècle, formé par Thierry Álix, sur papier, contenant des actes de 1260 a 1320 , in-folio de 45 tr. (Archices drip). de Irinthe-et-1/s,selle, B:33i).

Ancre. - Marquisat.

112. - Cartulaire du marquisat d'Ancre; ms. perdn.

Extraits faits par Du Cange au XVII siècle (Bibleoth. de l'Airsenal, ms. 5258, ti. 4-10: Biblioth. mulioule, ms. français 9496, pp. 1-10).

Andecy. - Abbaye (dioc. de Chàlons-sur-Mlarne).

113. - Cartulaire de l'abbaye de Notre-Dame d'Andecy; frament 
d'un ms. du XIII ${ }^{e}$ siècle sur parchemin, in- $4^{0}$ de 8 If. à 2 col. (Archices dép. de la Marne, $\mathrm{H}$ non coté).

Dates extrêntes: : 1109-1145.

Punc.: Chartes d'Andecy, par l'abbé Ch. Lalore, dans Cóllection des principaux curtulaires du diocese de Troyes, IV $(1878$, , p. 259271 .

Dix-huit pièces ou analyses de pièce's, de's années 1131-125-1, d'après le cartulaire précité et les originaux conservés aux Archives dip. de la Marne. - A la fin de son Histoire de l'albaye d'Andecy (Chìlons, 1890 , in $\left.-8^{\circ}\right)$, l'abbé Ylillard annonce la publication d'un cartulaire reconstitué, qui n'a pas encore vu le jour.

114. - Autre cartulaire d'Andecy; orig. perdu [avait 45 ff.].

Extrait du cartulaire d'Andecy, fait au XVII siècłe (Biblioth. nationale, coll. Duchesne, vol. LXXIV, fo 9 ).

Andenne. - Chapitre (dioc. de Namur).

115. - Cartulaire du Chapitre d'Andenne ; ms. du XVIII siècle, sur papier, contenant des titres de 1101 à 1780 , in-folio de $320 \mathrm{lf}$. (Archives de l'État à Namur).

Publ. : Documents extraits du cartulaire du Chapitre noble d'Andenne, par Jos. Barbier (Analectes pour servir à l'histoire ecclésiastique de la Belgique, XV, 1878, p. 317-346).

Documents à partir de 1127 .

Andèrlecht. - Église collégiale Saint-Pierre (dioc. de Malines).

116. - Cartulaire de l'église collégiale d'Anderlecht; ms. des $\mathrm{XVI}^{\mathrm{e}}$ XVII ${ }^{e}$ siècles, sur papier, contenant des actes de 1078 a 1652 , in-4" de 115 et 16 ff. (Archives de l'église Saint-Pierre d'Anderlecht.

117. - Autre cartulaire; ms. des $\mathrm{XVe}^{\mathrm{e}} \mathrm{XVI} \mathrm{I}^{\mathrm{e}}$ siècles, sur papier, contenant des actes de 1292 à 1569 , in-folio de $95 \mathrm{fr}$. (Arclices du royaume de Belgique, à Bruxelles).

Andlau. - Abbaye de Sainte-Richarde (dioc. de Strasbottrg). 118. - Cartulaire de l'ablaye d'Andlau ; ms. du XIVe siècle, sur parchemin, orig. perdu.

A été amplement utilisé par Schoepflin (Alsatia diplonatica) et par Grandidier (Histoire de l'église de Sitrasbourg).

Copie du précédent, faite au XVIII siècle (Grossherzogl. Landesarchio in Karlsruhe, Nachlass Grandidier's).

Andorre. - Toy. Urael.

Angers. - Abbaye de N.-D. du Ronceray.

119. - Cartulaire de l'abbaye de N. D. du Ronceray ; ms. du XII 
siècle en six rouleaux opisthographes de parchemin, le premier de $5^{\mathrm{m}} 45$ sur $0^{\mathrm{m}} 30$, le second de $5^{\mathrm{m}} 66$, le troisième de $5^{\mathrm{m}} 75$, le cqualrième de $4^{\mathrm{m}} 48$, le cinquième de $5^{\mathrm{m}} 10$, le sixième de $5^{\mathrm{m}} 40$. et contenant en

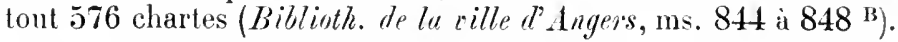

Ptibl. : Archives d'Anjou : recueil de documents et mémoires inédits sur cette province, par Iaul Marcheray ; III. Angers, Cosnier et Lachèse, 1854 ; in- $8^{\circ}$ de 382 p. - Cartulaire de l'abbaye du Ronceray d'Angers: 'Talle alphabétique des noms, par Eug. Vallée. Angers, Lachèse, 1900 : in-80 de $\mathrm{xv}$ p. et p. 385 à 495 avec $\mathrm{pl}$.

120. - Recueil de titres relatifs à l'abbaye du Ronceray, copiés au XVIII siècle (Biblioth. nutionale, coll. Dom Housseau, XII et passim).

Angers. - Abbaye de Saint-Aubin.

121. - Cartulaire de l'ahbaye de Saint-Aubin d'Anger's; ms. du XII ${ }^{\mathrm{e}}$ siècle, sur parchemin, avec additions postérieures, in-folio de $129 \mathrm{ff}$. à 2 col. Biblioth. de la rille d'Angers, ins. 829).

Contient 389 piòces des années 769 à 1174 . Queldurs chartes du début ont disparu.

lixtraits du mème, avec annotations de l'ahbé J. Rangeard; ms. du X XII ${ }^{\mathrm{e}}$ siècle, sur papier, in-4" de 142 pagres (Biblioth. de la ville thingers, ns. 830).

Extraits faits at XVIFe siècle (Biblinth. nationale, coll. Duchesne, vol. XXll, ff. 44-47; ms. français 16188, ff. 2:30-266; ms. latin 12658. Il. 1:36-1633; ms. latin 13816, tr. 18-25 et 30-33: coll. Baluze, vol. XXXIX, ff. 256-261).

Le même volume de la collection l'aluze renferme (ff. $26: 3 \mathrm{v}^{\circ}$ et suiv.) divers documents empruntés à un "autre cartulaire " de Saint-Aubin.

P'sc.: Cartulaire de l'abbaye de Saint-Aubiu d'A ngers, publié par le $\mathrm{C}^{\mathrm{te}}$ Bertrand de Broussillon, avec une table des noms de personnes et de lieux par Eurène Lelong. Angers, Germain et Grassin, 1896$1903 ; 3$ vol. in- $8^{\circ}$ de xxiI- 454 , IV-428 et iv-237 pages avec pl. [Documents historiques sur l'Anjou, publiés par la Société d'agriculture, sciences et arts d'Angers, I-IIl.]

Le tone I contient le texte du cartulaire original: le tome II un recueil factice complémentaire; le tome III les tables. Il y a un carton pour les pages 293 ì 300 du tome II. Cf. un compte-rendu de cette publieation, par Louis Halphen (Rerue de l'dnjon, XLVIII, 1904, p. $51-60)$.

122. - Cartulaire de la secrétainerie de Saint-Aubin d'Angers; ms. rédigé au $\mathrm{XVI}^{\mathrm{e}}$ siècle $[1552]$ par le frère Jean Buignon, avec additions postérieures jusqu'en 1644, in-4 de vin-132 If. (Biblioth. de la ville d'Angers, ms. 832). 
Angers. - Abbaye de Saint-Julien.

123. - Cartulaire de Saint-Julien [jadis St-Lèzin] d'Angrers: orig. perdu.

Extraits faits at XVII siècle Biblisth. nutionitale, coll. Duchesne, vol. $\mathrm{LXXV}$, If. 29-32.

Angers. - Abbaye de Saint-Yicolas.

124. - Premier cartulaire de St-Yicolas dlingers [213 ff.] : orig. des XIIe-XIII siècles, perdu.

Extraits faits au XVII siècle (Biblisth. nationale, ms. latin

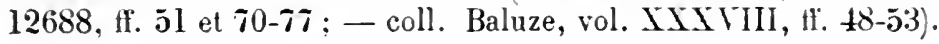

Publ. : en partie par Dom Laurent Le Peletier. "Breviculum fundationis S. Xicolai 》 Angers, 1616, in- $8^{0}$, et " De Rerum scitu dignissimarum a prima fundatione monasterii S. Nicolai Andegavensis.... epitome 》 Angers, I635. in $-4^{\prime \prime}$.

125. - Second cartulaire de St-Xicolas d'Angers: ms. du XVII siècle [1619], rédigé par le prieur Laurent Le Peletier, sur parchernin. in-folio de $1 \% 0 \mathrm{tit}$ avec table a la fin Biblisth. de lu cille d"Angers. ms. 840).

Ne contient que des acter du XVI et du Xrile siècle.

Extraits des cartulaires de Saint-Xicolas : copies du XVIIIe siècle, sur papier (Biblinth. nutionale. coll. Dom Housseau, rol. XIII: ms. français 22450, pp. 157-183; - Biblioth. de la cille d'Angers. mss. 679 et 706 , passim.

126. - Cartulaire de la secrétainerie de Saint-Nicolas d'Angers: ms. des XVIe-XVII siècles, sur papier, in-t" de $80 \mathrm{fl}$. (Biblisth. de la ville d'Angers, ms. 839.

Angers. - Abbaye de Saint-Serge.

12\%. - Premier cartulaire de Saint-Serge d'Angers : ms. sur parchemin, du Xle siecle, avec reliure de bois recouverte de cuir, de 185 fi., orig. perdu.

Copie partielle. faite pour Gaignières au $\mathrm{XVII}^{\mathrm{e}}$ siècle, sur papier, in-folio (Biblith. nutisnale, ms. latin 5446, pp. 237-299.

Extraits du mème Biblinth. uationale. coll. Brienne, vol. 27?. fo 93 ; coll. Baluze. vol. XXXIX. fo 70 ; ms. latin 13819. ff 2ii282 ; ms. latin 17030, et coll. Dom Housseau. vol. XIII;

Axal. : de l'original entier (Biblirth. nationale, cull. Dom Housseau, vol. XIII.

Marchegay a lente une reconstitution de ce recristre : - on travail es conserve en ms, aux Archices dip. dr Ifrinr-e/-Lomp.

128. - Second cartulair de Saint-Serga d'Angers : ms. du XIIe siècle 
avec additions jusqu'à 1402 , sur parchemin, incomplet, avec reliure de bois recouverte de peau blanche, contenant 376 chartes a partir du XI siècle, in-folio de 176 Il. (1) usée Dobrée, à Nantes, ms. 3).

On l'appelait aussi "liber concatenatus \#. (queliques cahiers ont été intervertio par le relieur. Le's titres prinordianx nanquent, mais on $y$ trouve ceux des prienrés.

Axal.: Le cartulaire de Saint-Serge d'Angers, par l'abbé G. Durville. Tantes, Joubin et Beuchet, 1903 ; in- $8^{*}$ de rv-220 p. extr. avec additions du Catalogue de la bibliothèque du Musée Thomas Dubrée, I, pp. 58-200,

Extraits du précédent faits au $\mathrm{XVII}{ }^{\mathrm{e}}$ siècle (Biblioth. watimale, coll. Duchesne, vol. XX, ff. 286-292, et ms. latin 13819 , fl. 268273 et $276-280$; et an $\mathrm{XVIII}^{\mathrm{c}}$ s. Idem. ms. nouv. acquisitions francaises 7430 .

Angers. - lbbaye de Toussaints.

129. - Cartulaire de l'abbaye de Toussaints d:Angers [d'au moins 66 II.] : orig. perdu.

Extraits faits au XVIII siecle (Biblioth. nationale, coll. Dom Housseau, vol. XIII).

Contient 9 chartes des anneips 1108 i 1213 .

Angers. - Chapitre Saint-Laud.

130. - Cartulaire de Saint-Laud d'Angers : ms. du commencement du XIII' siècle, incomplet et mutilé, de $99 \mathrm{HI}$. sur parchemin. in $4^{\circ}$ (Biblioth. de .1. Le maryuis de Villoutreys. an chatean de Chandron, Naine-et-I,oire).

C. notice par M. Léopold Delisle (Bibliothique de l'École des Giharles, L1X, 18:8, p. 5333 et 538$)$.

Pcbl. : Cartulaire lu Chapitre de Saint-Laud d'Angers (actes du $\mathrm{XI}^{\mathrm{e}}$ et du XII ${ }^{e}$ siècle) publié par Adrien Planchenault. Angers, Germain et Grassin, 1903; in-8 de xxiv-201 p. [Documents historiques sur l'Anjou pu\}liés par la Société d'agriculture, sciences el arts t'Angers, IV.]

\section{Angers. - Chapitre cathẻdral de Saint-Maurice.}

131. - Grand Cartulaire du Chapitre cathédral d'Angers ou «livre

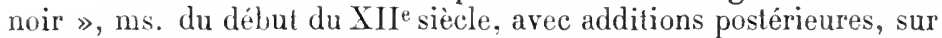
parchemin, de $139 \mathrm{ff}$., contenant 238 dlocuments des années 7711387, perdu [a été brûlé le 30 nov. 1793].

Cif. Recherches sur les cartulaires d'Anjou, par P. Marchegay (Arehices dinjou, I, 1843. p. 189).

On a une analyse des documents qui se trouvaient dans ce cartulaire ; voir l'Inventaire des titres de Saint-Maurice (Archives dép. de Maine-et-Loire, G 277, p. 777-825); — et des extraits dans la 
collection Moreau, dans la collection Baluze Biblioth. nationale, vol. XXXIX, fi. $30-34$; - dans la collection Dom Housseau, vol. 1, .et dans la collection Duchesne, rol. XXII, ff. 104-109: et à la Biblioth. de la rille d.Angers, ms. $7 \$ 3$, passim).

132. - Cartulaire de l'église d'Angers : ms. en papier. orig. perdu.

Extraits faits au XVIIe siècle Biblioth. nationale. coll. Baluze, vol. XXXIX, pp. 57-69.

I33. - Autre cartulaire du Chapitre cathédral d'Angers ou « livre violet »; orig. perdu.

On a, à la Bibliothigue de la ville d'Angers, une table dem cartulaires noir et violet, faite sur papier au XVIII siècle, par C. G. Puequet d. Livonnière (ms. 721 , ff. $1-34$ ).

134. - Recueil de titres relatifs au Chapitre de Saint-Maurice d'Angers; ms. du XVIII siècle, sur papier, in-folio Billioth. nationale, ms. français 22450 , pages 21 a 149 .

Publ. : Prochainement, par M. le Chanoine Urseau.

Angers. - Confrérie de Saint-Nicolas.

135. - Cartulaire de la Confrérie de Saint-Nicolas d'Angers; ms. du $\mathrm{XVI}$ siecle, sur papier, contenant des titres de 1520 à 1560 , in $4^{n}$ de $67 \mathrm{ff}$. (Biblinth. de la cille ditugers, ms. 761 .

Angers. - Hópital Saint-Jean.

136. - Cartulaire de l"hòpital St-Jean d'Angers ; ms. du $\mathrm{XV} \mathrm{V}^{\mathrm{e}}$ siècle, sur papier, contenant des titres du XII e siecle a 1463 , in-folio de $245 \mathrm{ff}$. (Archices dép. de Iraine-et-Loire, fonds de l'Hótel-Dieu. A4).

137. - Antre cartulaire du $\mathrm{XV}^{\mathrm{e}}$ siècle. sur papier, contenant des

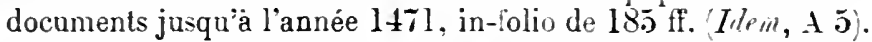

138. - Publ. : Inventaire des archives anciennes de l'hòpital SaintJean d'Angrers. précédé d'une notice historique et suivi d'un cartnlaire de cet Hòtel-Dieu, par Célestin Port. Angers, Lachèse [Paris Dumoulin], 1870 : in - 4 " de $\mathrm{xxx}-166 \mathrm{p}$.

Ce recueil factice comprend des documenti à partir de lannée 1166 . Tous les textes en irançais antérieurs à 1300 sont imprimés en entier. Il y a aussi un tirage in- $x^{\circ}$ de $1 r-96$-chxxmin p., sous ce titre different: Cartulaire de lhôpital śaint-Jean l'Angers.

Angers. - Université.

139. - Recueil des privilèges et statuts de l'Lniversité d'Angers: ms. du $\mathrm{XVII}^{\mathrm{e}}$ siècle. sur papier. in-folio de III-165 ff. (Billioth. de la ville dingers, ms. 1240 .

140. - Cartulaire de l'Université d'Angers; $m s$. du XVe siècle, contenant des titres de 1262 à 1494 . sur parchemin, in-folio de 127 ff. (Archices dép. de Main-et-Loire. D 6 , 
Ixxtraits et copies du précédent, avec additions, contenant des titres de 1350 à 1750 (Archives dép. de Maine-et-Loire, D 7).

Angers. - Ville.

141. - Cartulaire de la ville d'Angers; ms. du XVIIe siècle [1614], rélligé par plusieurs mains, sur parchemin, in- $4^{0}$ de 46 fl. (Biblioth. de la rille d'Angers, ms. $1145^{\text {bis }}$.

142. - Publ. : Recueil des privilèges de la ville et mairie d'Angers, par Robert. Anger's, 1748, in- $4^{\circ}$.

Anglure-Bourlémont. - Baronnie.

I43. - Cartulaire de la maison d'Anglure-Bourlémont; ms. de 1565, in-folio, sur papier (Bibliotl. de M. le prince d'Hénin, au château de Bourlémont.

Cif. Ducuments remes on inerlits concernant lhistoire des rosges, IV (187\%), p. 106 et ss.

Angoulême. - Abbaye de Saint-Cybard.

144. - Cartulaire de St-Cybard d'Angoulême, coté AAA: ms. des $\mathrm{XII}-\mathrm{XIVe}$ siècles, sur parchemin, contenant $25 \mathrm{l}$ pièces des années 852-I384, in-4 ${ }^{0}$ de 148 ff'. (Archires dép. de la Charente, $\mathrm{H}$ non coté .

Une copie du XVIII" sitele, in-folio sur papier, existait autrefois dans la bibliotlèeque d'Eusèbe Castaigne à Angoulême.

145. - Cartulaire coté BBB; ms. du XVe siècle, sur papier, rendu en partie illisible par l'action de l'ean. in- $4^{\circ}$ de 352 fl. (Archives dép. de la Charente, $\mathrm{H}$ non coté .

146. - Cartulaire coté CCC ; ms. des XVe-XVIe siècles, sur papier, in-t" de $217 \mathrm{fr}$. (Archices díp). de la Charente, $\mathrm{H}$ non coté).

II $y$ a dans ltr même fonds dix registres appelés aussi eommunément cartulaires de St-Ciybarl, mais te sont en partie des eollections d'hommatres, rente's ef recomaissances : on signalera seulement ici eeux cotés $\mathrm{E}, \mathrm{F}, \mathrm{G}$, qui coneernent réspectivement les prieurés de Gourville, (Champilon et Nersac, "t sont tous du XVe siècl", sur papier $(181,62$ et $68 \mathrm{ff}$.). In autre registre coté JJ (XVIe siècle, papier, $499 \mathrm{ff}$.) est particulièrement relatif à Sant-Yrieix.

147. - Copies de titres relatifs a l'abbaye de Saint-Cybard; ms. du feurliste Berthé, écrit au XVIII siècle, sur papier, en 4 vol. in-folio de 385 , 665,975 et 600 pages (Archires dép. de la Charente, $\mathrm{H}$ non coté.

Extraits diver's fails aux XVII ${ }^{\mathrm{e}}$ et $\mathrm{XVIII}^{\mathrm{e}}$ siècles $($ Biblioth. nationule, coll. Lespine, vol. XXXIY, tl. 356-369; ms. latin 17048 , pages 315-328: coll. Baluze, vol. LXXIII, ff. 87-88).

Voir en outre aux prieurés qui en dépendaient, Champalos, CoorVILLE PO NFRSAR: 


\section{Angoulême. - Comté.}

148. - Cartulaire des comtes de la Marche et d'Angoulème tin XIII' s.); orig. perdu (1).

Copie du XVIII siècle, exécutée pour Bouhier. in-folio sur papier Biblioth. nationale, ms. latin 17089, if. 477-573.

Autre copie, également du XVIII siècle 'Biblivth. nutimule, ms. latin 1719l, ff. 133-183.

Angoulême. - Confrèrie des Trinitaires.

149. - Registre de la Confrérie de l'ordre de la Sainte Trinité de la rédemption des captifs à Angoulème: ms. rédigé en 1630. sur papier, in- $\delta^{\circ}$ de 93 ff. Biblinth. nationalp. ms. français 14592.

Angoulême. - Église cathèdrale St-Pierre.

150. - Cartulaire de l'église d’Angoulème : ms. de la fin du XiI siècle. sur parchemin, in-4 $4^{\circ}$ de $105 \mathrm{ff}$. Archices du Chupitve de la cuthedrale d. Angouleine).

Copie du précédent : ms. du XIXe siècle, par A. Lièvre, -ur papier (Biblioth. de la rille de Poitiers, ms. 561).

Publ. : Cartulaire de l'ég]ise d'Angoulème. par l'abbé J. Nangard (Bulletin de la Société archéologique et historique de la Ciharente, 1899 , p. l-320), et à part : Angoulême, 1900 : in-8" de IV-33- $\mathrm{x}-296$ p. et pl.

Cif. Notes sur le cartulatir" de l'église I'Angoulème, par Idhémar Esmein (Heimoires de la Socirté arrhéologique et historique do in Charente, 7e série, II. 1902. p. 105-137).

Extraits du précédent cartulaire, faits au XVII siècle Biblinth. nationale. coll. Baluze, vol. LXXIII, fi. 92-97.

Cf. les ff. 20-2s du rolume XXXIX de la même collection Baluze.

Angoulême. - Évèché.

151. - Cartulaire de lérèché d’Angoulème : ms. du XIII siècle, sur parchemin, de plusieurs mains, in-t" de $63 \mathrm{pp}$. Biblinth. nutimule, ms. latin 13913 .

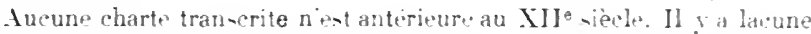
avant et après les pages 15-11. - Sur le pla dr. la reliur." armoirim

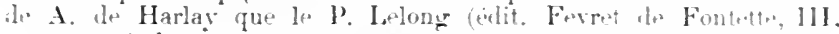
$\left.n^{0} 29145\right)$ indique comme possenserur.
}

Copie du précédent. faite au XVIII sierle. sur papier. in-folio Aichices dép. de la Charente. G non coté .

Autre copie moderne, sur papier Biblioll. do lu cillo d, Poitines. ms. 5อั3.

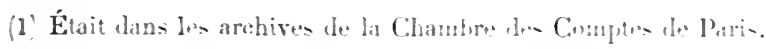


152. - Fragments de deux cartulaires de l'évèché d'Angoulême; ms. du XII siècle, in-t" sur parchenin (Biblioth. du Vatican, ms. Ottoloni 687 , if. 8-12.

Cif. Lucien Auvray dans les Mélunges Julien Hncel (189-1), p. 389-394.

Angoulême. - Prieuré de X.-D. de Beaulieu. - Voy. Beau. LIEU.

Angoulême. - Ville.

153. - Publ. : Les privilèges, franchises, libertés, immunités et statuts de la ville, faubourgs et banlieue d'Angoulème. Angoulème, $162 \gamma$, in-4".

Aniane. - Abbaye de Saint-Sauveur (dioc. de Montpellier).

154. - Cartulaire de l'abbaye d'Aniane: ms. du XIVe siècle, sur parchemin, in-folio de l:36 lf.' (Archives dép. de l Hérault, $\mathrm{H}$ non coté).

Extraits du précédent. faits au XVII ${ }^{\mathrm{e}}$ siècle (Billioth. notionale, coll. Baluze, vol. XIX, ff. 143-209).

Publ. : Cartulaires des abbayes d'Aniane et de Gellone : II. Cartulaire d'Aniane, par l'abbé Cassan et li. Meynial. Montpellier, Martel. 1900. in-4" de $1 v-450$ p. [Société archéologique de Montpellier.

Texte stul, comprenant dés pièces depuis l. VIIle sière jusquà 1214. La table vient de paraître (Iontpellier, 1905 ; in-40 de 94 p.), mais lintroduction manque encore.

155. - Recueil de titres relatifs il l'abbaye de Sinint-Siluveur d'Aniane, en partie transcrits en 1694 par D. Fitienne Dulaura. et comprenant des documents à partir dı IS" siècle jusqu en 1683, in-folio sur papier (Biblinth. nutionule, ms. latin 12660, H. 55-9I et 98-195).

156. - Autre recueil fait en 1679 par Dom Estiennot (Biblioth. nutionale, ms. latin 12760, pp. 317-331); - intre (Idem. ms. latin 13816, ff. $47-86)$.

Anjou. - Comté.

15\%. - Cartulaire du comté d'Anjou ; orig. perdu.

Extraits faits aux XVIJ et XVII' ${ }^{\mathrm{e}}$ siecles (Biblioth. nutionale, ms. français 4427, If. 97-20.); ms. français 14538 , ff. $1 \mathrm{ll}-\mathrm{ll} 5$; coll. Dom Housseau, vol. XX, ff. I15-117).

158. - Cartulaire d'Anjou et de Provence; ms. de la fin du XVI siecle, formé par Thierry Alix, sur papier, contenant des titres de 1380 is 1499 , in-folio de $193 \mathrm{fl}$. Archices dép. de Menrthe-et-Moselle, B 412 .

Annay. - Voy. La Brayelali-LEz-ANAdY. 
Antoing. - Église collégiale Notre-Dame (dioc de Trumai). 159. - Cartulaire de la collégiale d Antoing ; ms. de lia fin du XVI" siecle. sur parchemin, contenant des acles de 122.) a 1679, in-folio de lot pages (Arrhixes de létut ì Mons.

Axal. : Description de cartulaires et de chartrier du Hainant. par L. Devillers, Y 1870 . p. 43- $\mathbf{\imath 9}$

Antony. - Village près de Paris.

160. - Cartulaire d'Antony. dépendant de l'ahbaye de Saint-Germaindes-Prés: ms. du XVI siècle, sur papier, contenant des documents de 1248 a 1541 . in-40 de 98 11. Archices nationules. LL 1040.

Sous 10 titre dto "Cartulaire d'Antony et de Verrières ", Ph. Durounsin a prepare en $17 t$ un inventaire trés delaille on 2 vol. in-folio de 353 et $140 \mathrm{ff}$. (Aprhices mationales, L.L 1047-11148).

Anvers. - Abbaye de Saint-Ylichel.

161. - Cartulaire de labbaye de Saint-Michel dinvers; ms. du XIYe siecle arec additions postérieures, sur parchemin, contenant des titres à partir de 1148. in-folio de 276 pages Archices de l'Etat it Aners,

162. - Recueil des titres de l'abbaye de Saint-Michel d'Anvers; ms. du XVIII siècle, sur parchemin, contenant des titres de 1124 it 1755, en 10 vol. in-folio, dont 2 de tables Archices de TEtat in Ancers.

Anvers. - Chartreuse.

163. - Cartulaire de la chartreuse d'Anvers: ms. des X Xe-XVIJ siecles. sur parchemin et papier, contenant 778 titres de $1: 246$ à 1619 , in-4" de $372 \mathrm{ff}$. avec table grographique Arrires de l'Ftut it Anreis.

Voy. aussi Likrre.

Anvers. - Église Xutre-Dame.

164. - Cartulaire de l'église Sotre-Dame d'Anvers: ms. des XIIJ. XIT siecles, sur parchemin, contenant des documents de 1119 i

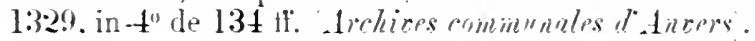

Anvers. - Ville.

165. - Cartulaire de la ville d'Anvers, ou « Roodt tluweel privilegieboeck»: ms. des XIVe-XYII siecles, sur parchemin. contenant des tocuments de 1249 i l661, in-t" de 14:3 1f. "Archires crimulumales theres.

166. - Premier regi-tre des privilèges d'Anvers: ms. du XVI siècle. sur papier. cuntenant des documents de 1299 i 16.58. avec talle.

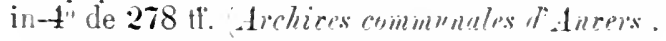


167. - Second registre des privilèges d'Anvers : ms. du XVII siècle, sur papier, contenant des documents de 1249 i 1656 , avec table, in-4" de $266 \mathrm{fr}$. (Archices communules d"Anvers).

168. - « Verschyde privilegrien der Stad van Antwerpen »; ms. du $\mathrm{XVI}$ siecle, sur papier. contenanl des documents de 1296 à 1563 , avec table. in-folio de 737 II. Archives communales d'Aneers).

169. - «Groot pampieren privilegieboeck »: ms. des XVIe-XVII siècles, sur papier, contenant les documents de $14: 36$ à 1621 , avec table. in-40 de $376 \mathrm{fr}$. (Arehives communtes aners).

170. - «Cleyn panpieren privilegieboeck»; ms. des XVe-XVI siècles, sur parchemin el papier, contenant des documents de 1463 à 1572, avec table, in-4" de 39411 . (Archires communles d'Anoers).

171. - Recueil des privilegres de la ville d'Anvers: ms. du XVIIe siècle. sur papier, contenant des aetes de 1220 à I 496, in-folio, 13 ff., British .usem it Londres. additional ms. 33953, ff. 71-85).

Aoste. - I)uché.

172. - «Liber francisiarum civilatis ef dueatus Anguslæ»; ms. du XVIlle siecle, snr papier, conlenant les documents à partir de [252, in-folio (Avelivio cupitolure di Sant Orso d'Aosta).

Aoste. - Église collégiale Sant'Ot'su.

173. - « Carlularium sincti Ursi » ms. du XVe siecle, sur papier,

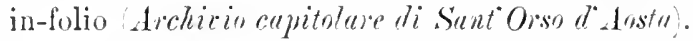

17t. - «Liber honorum ecclesize sancti Ursi »: ms. du XIVe siècle, sur parchemin. de plusiems mains, in-folio frechivio capitoluse di Sant'Orso d'Aostu).

Aoste. - Évèché.

175. - Cartulaire de l'érèché d'toste: ms, du XIlle siècle, sur parchemin, avec talıle en têle (plus récente. sur papier), conlenant I34 chartes des années $1147-1256$. in-4" de 3.) 11 . Arclivio vescorale isista .

Publ. Cartulaire de l"évèché d'Aosle, par Mgr. J. A. Duc Miscellane di Starin italiune. 2" série. VIII, pl) 183-340); el is part : Torino, I88t. in-8" de I58 p. et pl.

176. - «Collectanea ad historiam chronologican episcoporum Aunustensium ex charlis collecta » : ms. du XVIII siecle, sur papier, in-

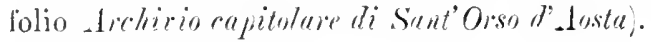

Aoste. - Ville.

17\%. - Cartolario della citlà đl'Aostil; ms. du XIIIe siècle, sur parche-

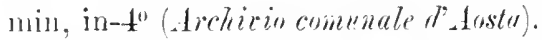

Publ. (partiellement): Monumenla historiæ palriæ, II (I8:38), pp. $29-38$.

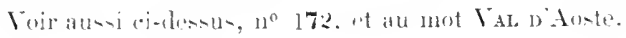


Apremont. - Chàtellenie et seigneurie en Lorraine.

178. - Recueil de titres relatifs à la chàtellenie d'Apremont: ms. du XVII esècle, formé par Thierry Alix. sur papier, contenant des titres de 796 à 1605 , in-folio de $4.53 \mathrm{ff}$. Archices dép. If Yeurtheet-1.Moselle, B 338.

Copie du précédent, faite au XVIIe siecle, sur papier Arohires dép. de la Meuse. B 250 ,

179. - Autre recueil moins complet; ms. duXVII siècle. sur papier, contenant des titres de 1287 à 1602 . in-folio de $416 \mathrm{ff}$. Lichizes dep. de Meurthe-et-1/oselle. B. 33:3).

180. - Cartulaire de la seigneurie d'Apremont: ms. du AIV siècle [vers 1355], arec table du Xinle. sur papier, de 113 et 30 p. (Biblioth. nationale. ms. français Il835.

181. - Autre cartulaire; ms. des XIII --XIV ${ }^{\mathbf{e}}$ siècles, sur parchemin, in $-4^{\circ}$ de 76 tl. contenant des actes des années 1249-1306 Archices dép. de . Veurthe-et-Moselle, B 508.

Lanalyze détaillée de ce regristre se trouv dans Du Fouruy (Atichices untionales, $\mathrm{kh} 1116$, tf. $751-779$ ).

Table de deux cartulaires de la seigneurie d Apremont. le premier comprenant 235 chartes et le second 305 : ms. du $\mathrm{X} V$ siècle. sur parchemin, in-4' de 33 ff. 'Biblinth. nationule, ms. français 11836 ;.

Apt. - Église.

182. - Cartulaire de l'étrlise d'Apt ; ms. de 139 ff., sur parchemin, orig. perdu.

Copie du XVII siècle exécutée par le P. Columbi d'après une transcription du précédent [perlue] faite pour Chorier par Grossy vers $16 \% \pi$, in-4" de 122 ff. Biblisth. He la cille de Lyon. ms. 193!.

Autre copie du précédent : ms. du XVIII siècle [170:3]. copié par Lancelot, in-4" de 57 if. Biblioth. intionale, ms. latin 17078,

Axal. : par le Vle 0 . de Poli Rerue histarique de Procence. leannée, pp. 118-126, 156-160. 189-192 el 204-205. et à part: Paris. Conseil héraldique de France. $1900:$ in $-8^{\circ}$ de 29 p.

Extraits du cartulaire de l'eglise d'Apt, faits au XVIII iècle, par M. de Remerville. sur papier, in-folio 'Biblioth. It lin cille de Carpentras. ms. 5.53 .

Un autre volume de mêne nature, prownant du P. Bicaí- le lo(Tra-

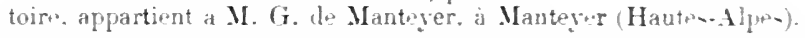

Extraits du même, faits au XVII siècle. par Grony dans ses 
«Mémoires historiques». 1. I (Biblioth. de lu rille de Carpentras, ms. 4488); t. II (Biblioth. de .1T. G. de Wanteypr).

las transcriptions. malheureusement incomplètes, de Grossy, sont préférables à celles de Lancelot.

183. - « Collectanea variorum diplomatum ecclesiæ Aptensis nobis illustrata *; m.. du XVIII siècle, sur papier, in-folio de $563 \mathrm{ff}$. (Archices de la fubrique de l'église d'Ath).

Apt. - Ėvèché.

184. - Cartulaire de l'évêché d'Apt ; orig. perdu.

On ne connait qu'une analyse sommaire des pieces faite au XVII siècle (Biblinth. de ln rille de Carpentres. ms. I654, It. 4-15).

Aquitaine. - Voy. Gascogne.

Arbois. - Ville.

18.5. - Cirtulaire municipal d'Arbois: ms. du XIVe siècle [1384], sur parchemin, de plusieurs mains, avec additions jusqu'au $\mathrm{XVI}^{\mathrm{e}}$ siècle et débutant par une charte de 1257, avec reliure aneienne de

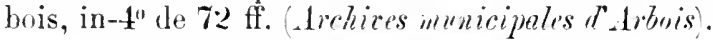

Lacunes des feuillets 12,13 of 62 .

Extraits faits au XVIIJe siècle Biblioth. nutionale, coll. Moreau, vol. 888 : - Biblioth. de ln ville de Besaneon, coll. Droz, vol. 26 et $2 \bar{i}$.

Fxtraits lu même, faits en I8.57 par E. Bousson de Mairet. Sur papier, in-4" de 152 parres (Biblisth. Ae la rille d'Arbois, ms. 24).

Pcbl. : Les comtes de Bourgogne et leurs villes domaniales; étude sur le régrime communal, forme de l'exploitation seigneuriale, d'apres le cartulaire de la ville d'Arhois, suivi du texte de ce cartulaire. XIII-XIVe siècles, par L. Stouff (Rerue brunguignome de l'enseigurment supérieur. VIII, 2, et à part : Paris, Larose, 1899 , in-8" de $226 \mathrm{p}$.

Ardenne. - Abbaye de Notre-Lame (dioc. de Bayeux).

186. - Fragment d'un cartulaire de l'abbaye d'Ardenne; ms. du XVI" siecle. sur parchemin, in-40 de 16 II. (1wrikes dép. de l'Orne, H 6 .

187. - Cartulaire des Prémontrés d'Ardenne; ms. dn XIVe siècle. avec additions postérieures. contenant 588 pièces du XII ${ }^{\text {e }}$ siècle à I640, sur parchemin, in-folio de $1 \mathrm{-}-40 \mathrm{III}$. Archires dép. d" Calrados, $\mathrm{H} \mathrm{II7.}$

Une lable rédigrée au XHI siècle (20 $\mathbb{H}^{\mathrm{e}}$. pap.) est jointe (Idem, H 11).

188. - Recueil de titres de la mème abbaye, fait en 1636 par le R. P. Rob. Duhamel: ms. du XVII' siècle. sur parchemin, en 3 vol. 
in-folio de 5:88. 576 et 490 pages Biblioth. de la rille de Cuen. ms. 303 .

189. - Autre recueil. fait au XVIII siecle, sur papier Biblisth. the In rille de Caen, coll. Mancel, ms. I60.

Ardevon. - Baronnif en Normandie.

190. - Cartulaire de la baronnie d'Ardevon. dépendant de l'abaye du Mont-Saint-Michel : ms. dia XIVe siècle, sur parchemin, in-folio de 139 ff. (Archices dip. de la Manche, $\mathrm{H}$ non coté).

Les 30 premiers feuillets sont occupés par un citat des renens do la baronnie en 1373.

Argelès. - Voy. L'cz.

Argentan. - Hôpital Saint-Jacques.

191. - Carlulaire de l'hòpital Saint-Jacques d'Argentan: ms. du XIII siècle, perdu.

Ce manuscrit, qui contenait les actes do fondation privileges, fut rédigé par orlre du fondateur (cf. Archices dip. de lOrne, H 5244).

Argoules. - Seigneurie en Picardie.

192. - Cartulaire de la seigneurie d'Argoules: ms. rédigé en 1713 par Jacques Godart de Beaulieu, seigneur d'Argoules, sur papier, in-folio (Bibliothrque de M. Jourdain de L'Etoille, au chàteau d'Atgoules. Somme).

Cf. Roger Rodièr. Voyage héraldique dans quelques églises du Ponthieu, p. 52 (Abbeville. 1905. in-8: extr. des Mémoires de la Sigc. démulation dAbberille. XXI). - Ce manuserit contient copie de pieces

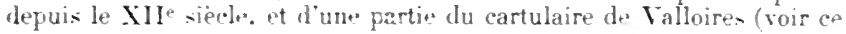
mot).

Arivour. - Vuy. LaRIYoLr.

Arlay. - Seigneurie. - Voy. Chalox.

Arles. - Abbaye de Satinte-Xlarie (dioc. d'Ehne).

193. - Livre des privilères de I'abbaye de Sainte-Marie d'Arles : orig. perdu.

Copie du précédent, faite en 1600, sur papier 'Archires dép. des Pyrénées-Orientales, H 52 .

Extraits faits au X'rile siècle pour Baluze (Biblioth. nationale, coll. Baluze, vol. CVIII. ff. 272-296.

Des extraits et copies de titr". (d"apres les origrinaux), relatifs à la

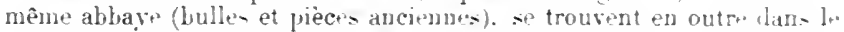
vol. CXVII de la coll. Baluz . ff. $26 \pi-319$ et $338-344$.

Arles. - Abbaye de Sitint-Císaire (dioc. d'Arles).

194. - Copies de bulles et de charles formant cartulaire de l'abbaye 
de Saint-Césaire d’Arles, par L. Bonnemant ; ms. du XVIII ${ }^{e}$ siècle, contenant des documents de 997 à 1756 , sur papier (Biblioth. de la cille d'-1rles, ms. 168. pp. 1-52 et 198-368).

Arles. - Archovêché.

195. - Cartulaire de l'archevèché d'Arles ou « Livre noir »; ms. des XII $-X I I I$ siècles. sur parchemin, contenant des titres du Ve siècle à 1279, in-t" de $170 \mathrm{ff}$. (Archices dép. des Bouches-du-Rhône, G non coté .

196. - Cartulaire « antographe » on coté B de l'archevêché d'Arles; mi. dı XIII ${ }^{\mathrm{e}}$ siècle, sur parchemin, in-folio de $145 \mathrm{ff}$. (Archices dép. lles Bouches-Alr-Rlüre, G non coté).

197. - Autre coté F ou « livre vert »; ms. du XIII ${ }^{e}$ siècle, sur parchemin, in-folio de $387 \mathrm{ff}$. (trchives dép. des Burches-du-Rhóne, G non coté .

198. - Autre coté $G$ ou «livre rouge »; ms. des XIIe-XIII siècles, in-folio. sur parchemin. de $470 \mathrm{Ir}$. (Archices dé. des Bouches-duRhine, G non colei).

Extraits du précédent, faits au XVIII siecle (Biblioth. nationale, ms. latin 9173. ff. 23 et suiv.).

(In trouve ausi des extraits des liven noir, rouge et rert dans le n11s. nouv. alcig. Jatines 1369 de la Biblinth. nationete.

199. - Autre, dit «livre jaune »: ms. des XVIe-XVIII siècles, contenant der documents du XIII" siècle à 1753, sur papier, in-folio de 839 ff. Arrhiress dép. des Bourhes-du-Rhöne. G non coté).

Extrait par Dom Chantelon, fait au XVIle siècle (Biblioth. intimale. ms. latin 12674 , fo 362$)$.

200. - Recueil de chartes relatives à l'égrlise l'Arles; ms. du XVII siècle composé d'après les archives de l'archevêché, sur papier, in $-4^{0}$ (Biblivthe nutimalis, coll. Baluze, vol. LXXXVIII.

Dites extrèmes: : 11.53-1.516.

Arles. - Chapitre métropolitain Saint-Trophime.

201. - Cartulaire dit " authentique » du Chapitre métropolitain d'Arles: ms. des $\mathrm{XI}^{\mathrm{e}}$-XIII ${ }^{\mathrm{p}}$ siècles, contenant des actes depuis le VI" siècle jusqu'à 1279, sur parchemin, in-to de 152 ff. (Archires

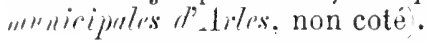

Acheté en len:3 par P. Veran. Les docunents anterieurs au NI siècle y sont 'n trand nombre. Des extraits en ont eté faits au XVIIo siècle par Dom Estiennot (Biblioth. antionale, ms. latin 12772, pp. 271-275; ef latin 12762, p. 331).

Copie du précédent, faite au XVIIJ siècle, sur papier, in-folio de 195 ff. (Bibliotle. de le rille d'Arignon: ms. 3908). 
202. - Cartulaire du sacristain du Chapitre d'Arles; ms. écril en 1775 , contenant 43 chartes depuis 1:210 (Archires do lo cutherdinle d'Arles).

C.f. Bulletin historique et philulogique du Comitr, 1xas, p. 12:.

Arles. - Commanderie de Saint-Gilles. - Voy. SAlsiGiLleEs.

Arles. - Couvent des Trinitaires.

203. - Bullaire des Trinitaires d'Arles, rédigé par François Porchier au XVIII ${ }^{e}$ siècle, sur papier, in $4^{0}$ de $545 \mathrm{ff}^{\mathrm{T}}$, contenant des actes de 1198 à 1752 (Archices dép. des Bouches-dm-Rhöne, H non coté).

Arles. - Ville.

204. - Cartulaire municipal d'Arles, dit «Rubei Arelatis et Tharasconis »; ms. du XIII ${ }^{e}$ siècle. sur parchemin, contenant des actes de 1116 à 1270, in-folio de $236 \mathrm{ff}$. (Archires dép. des Bouches-du-Rhöne. B 1069).

205. - Cartulaire municipal de la ville d'Arles; ms. du XVe siècle, sur parchemin, in-folio de $148 \mathrm{ff}$. (Biblinth. de la rille de Romen. ms. 2284).

Voir aussi ro Burrges.

Arnicourt. - Prieuré (dioc. de Reims).

206. - Recueil de titres relatifs au prieuré d'Arnicourt, dépendant de Saint-Benoit-sur-Loire; ms. du XVII ${ }^{e}$ siècle, sur papier, contenant 13 chartes de 1119 à 1330 , in $4^{\circ}$ de 22 pages (Aichires nationales, L 1002a , $\mathrm{n}^{0} 27$ ).

Plbz. : Notes sur le prieuré d'Arnicourt, par l'ablé J. B. E. Carré. Sceaux, impr. Charaire, 1887 ; in- $8^{\circ}$ de 71 p.

Arques. - Confrérie de l'Assomption de Notre-I)ame (dior. de Rouen).

207. - Cartulaire de la Confrérie de l'Assomption de X. D. d'Arques: ms. du XVe siècle avec additions postérieures, sur parchemin. contenant des actes de 1433 à 1503 , in- $4^{0}$ (Biblinth. mationule. ms. nouv. acquisitions françaises 329 , ff. 1-2l).

Le reste du registre est rempli par le's noms des membres de la Confrérie. - Au fo 2, signature de Hyacinthe Flamand, sculpteur a Dieppe (1786), qui fut un des posse'sseurs du regristre.

Arras. - Abbaye de Saint- Taast.

208. - Cartulaire de St-Vaast d'Arras, dit de Guiman; cupie du XVIe siècle, sur papier, in-folio de $391 \mathrm{ff}$. (Archices dép. du Posde-Calais, $\mathrm{H}$ l).

L’original disparu datait de 1170 environ. 
208 bis. - Antre cartulaire; ms. de la fin du XVI siècle, sur parchemin, contenant pour partie la transcription du précédent, et en outre une série de documents importants à partir dı XII siècle, in-4" sur 2 col. (Archices de l'iveché d'Arras).

Publ. : Cartulaire de l'abbaye de Saint-Vaast d'Arras rédigé au $\mathrm{XII}^{\mathrm{e}}$ siècle par Guimann et publié pour la première fois au nom de l'Académie d'Arras, par le chanoine Van Drival. Arras, Courtin. 1875 ; in- $8^{\circ}$ de xxx 448 p.

Cette publication très incomplète, défectuense et dépourve do toute "ritique, a ćté faite d'aprèn la copie de l'évêché d'Arras, et sans tenir compte des pieces annexes qu'elle contient. M. Van Drival signale dans la bibliothèque de sir Th. Phillippes une copie du carlulaire de St-Vast, laquelle n a jamais existé.

209. - Antre cartulare, ms. de la fin du XII siècle, snr parchemin, conlenant 133 chartes des années 1098-1191. in-4" de 58 ff. (Archives de l'éréché d'Arras).

Axal. : Un cartulaire de l'abbaye de Saint-Vaast d'Arras, codex du $\mathrm{XII}^{\mathrm{c}}$ siècle, par A. Gutesnon (Bulletin historique et philologique, 1896, pp. 240-305), et à part : Purris, 1896 ; in- $8^{\circ}$ de 66 p.

Dom le lez a consulté au XVIII siècle plusieurs aulres cartulaires qui ont disparu.

210. - Extraits d'un grand cartulatire de Saint-Vaast d'Arras, « couvert de cuir, reposant en la Chambre de la prévôté », communiqué en 1661 (Biblinhll. mutionale, coll. Balıze, vol. XXXIX, fo 305).

(if. les ff. ri-92 du mềne pergistra.

$210^{\text {bis }}$. - Cartulaire dı droil le Gaule; ms. du XIVe siècle, sur papier. contenant des actes de 1155 a 133.53 , in-40 de $21 \mathrm{fr}$. (Archices dip. du Prs-de-Culuis, $\mathrm{H}$ 8.22).

Arras. - Chapilre mélropolitain.

211. - «Magnum cartulare capituli sine cathena », ms. de plus de 338 ff., origr. perdu.

Il est mentionme (Biblioth. nationale, mis. latin 17\%37, fo $121 \mathrm{r}^{\circ}$ ).

212. - Cartulaire rouge, ou « Liber capituli vocatus Rouget »; orig. perdu.

213. - «Antiquum cartulare 》; orig. perdu.

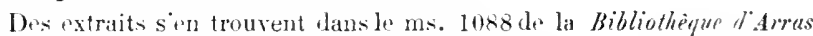
ainsi guede deux atutres petits volumes dont nous ne connaissons pas mène la nom.

214. - Livre blanc dı Chapitre d'Arras; ms. du XIII ${ }^{\mathrm{e}}$ siècle, sur parchemin. avec reliure de bois ancienne, écrit de plusieurs mains, in $4^{0}$ de xxir-87 fr. ì 2 col.. incomplet à la fin (Biblioth. nutiomule. ms. latin 9930$)$.

Dates pxtrèmes: $117.121 \%$. 
Pubr.: Le cartnlaire du Chapitre d'Arras, publié ou analysé avec extraits texluels, par A. de Loisne. Arras, impr. Rohart-Courtin, 1896 ; in $-4^{\circ}$ de $r-137 \mathrm{p}$.

215. - Autre cartulaire du Chapitre d'Arras; ms. du XVe siècle, provenant des collections Le Ver et Bordier, sur parchemin, écrit de plusieurs mains. contenant des documents de 1276 a 1467 , in $4^{0}$ de v-115 ff. (Biblinth. nationale. ms. nourelles acq. françaises 6270).

Portait It no 130 dans le catalocrue de la vente Le Ver (18Bit).

216. - Cartulaire du Chapitre d'Arras; ms. de 1282, avec additions des $\mathrm{XIVe}_{-} \mathrm{XVe}^{\mathrm{e}}$ siècles, dit « Registrum kartarum et munimentorum capellaniarum », provenant de la collection Le Ver, sur parchemin. de $145 \mathrm{ff}$. in $-4^{0}$ (Biblioth. nationnle, ms. latin 17737).

Portait les no 131 dans le même catalogue.

Arras. - Confrérie Notre-bame des Ardents.

217. - Pcbl. : Cartulaire de Notre-Dame des Ardents à trras 11151869), par Louis Cavrois. Arras, Bradier, 1876 ; in $-8^{\circ}$ de 260 p.

Recueil factice contenant des documents dont quelques-uns sont d'une authenticité douteuser.

Arras. - Église cathẻdrale.

218. - Cartulaire de la cathédrale d'Arras ; ms. des XIII -XYe siècles. sur parchemin, contenant des actes de 1213 à 1387 , in- $t^{0}$ de $110 \mathrm{fr}$. (Biblioth. royale de La Hiye. ms. $70 \mathrm{H} 54$ !.

219. - Cartulaire des chapelains de la cathédrale d'Arras ou «livre clanté »; ms. du XIVe siècle, sur parchemin, arec additions postérieures, in-folio (Archices de l'évéché d'Arras.

Arras. - Évèché.

220. - Cartulaire de l'évèché d'Arras, ou « Registrum kartarum et privilegiorum ad episcopatum Attrebatensem pertinentium $\gg ; \mathrm{m}$. des $\mathrm{XIII} \mathrm{C}^{-} \mathrm{XVl}^{\mathrm{e}}$ siècles, sur parchemin, contenant 465 pièces à partir de l'année 920, de $445 \mathrm{ff}$. in-folio (Archires de l'éréché d'Arras).

Anal. : Le cartulaire de l'évêché d'Arras, analysé chronologiquement par A. Guesnon (Mémoires de l'Aradémie des sciences, lettres et arts d'Amas, $2^{\mathrm{e}}$ série, XXXIII (1902). p. 165-323.

Quelques pièces publiées en appendice.

221. - Autre cartulaire, dit « Registrum papsraceum majus», sur papier, perdu.

Arras. - Hôpital Saint-Jean en l'Estrẻe.

222. - Cartulaire de l'hòpital Saint-Jean-en-l'listrée d'Arras; ms. commencé en 1393 et continué postérieurement, sur parchemin, in-10 (Archices de l'hopital St-Jean t'-Aross). 
Perb. : Cartulaire de l'hòpital St-Jean-en-l'Estrée d'Arras, publ. avec d'autres documents et une étude sur le régime intérieur de cette maison, par Jules-Marie Richard (. Mémoires de l'Acudémie d'Arras, $2^{e}$ série, XVI, pp. $331-425$, et à part: Paris, Champion, 1880 ; in $-8^{\circ}$ de x $-154 \mathrm{p}$.

Date's extrênes : $1183-1438$.

Quelques pièeess sont seulement analysées. Lorigrinal en contient de plus récentes.

Arras. - Ville.

223. - Pelit cartnlaire nunicipal d'Arras; ms. du XIVe siècle, sur papier, incomplet de la fin, contenant 5̆ actes des années 12951347 , in- $4^{0}$ de $37 \mathrm{fr}$. (Archives municipales d'Amrs).

II. A. Guesnon possède une copie intégrale de ce registre.

224. - Cartulaire PP; ms. dı XIVe siècle, sur papier, contenant des actes dle 1265 à 1439 . in- $4^{\circ}$ (Archices municipales d'Arras).

225. - Cartulaire A; nss. de la fin du XVe siècle, sur parchemin, contenant des actes de 1362 à 1489 , in-folio (Archives municipales d'Aras .

Copie du mène. faite en 1722. in-folio de 434 ff. (Archives municipules d'Arras).

226. - Cartutaire B; nis. de la fin du XVe siècle, avec additions du XVI ${ }^{e}$, sur parchemin; orig. perdu.

227. - Cartulaire C; ms. de la fin du XVe siècle, sur parchemin, contenant des actes de 1190 a 1496 , in-folio de 206 pages (Archives municipales d'Arras).

2:28. - Publ. : Carlulaire de la commune d'Arras (1170-1789), [par Adolphe Guesnon]. Arras, Brissy. [1862]; in-4 $4^{\circ}$ de 520 p.

Ourrage non mis dans le commerce, dépourvu de tables et d'introduction, qui contient un recuril factice de 430 actes puisés anx archives municipales, et en partie dans les cartulaires qui précèdent (cf. la note nise par A. Guesiton en tête de: Les origines d'Arras et ses institutions: Arras, 1896 , in- $\left.8^{\circ}\right)$.

Arrouaise. - Abbaye (dioc. d'Arras).

229. - Cartulaire de l'abbaye d'Arrouaise; ms. du XIII' siècle, sur parchemin, contenant des titres de 1107 à 1261 , in-4 $4^{0}$ de 278 pages (Biblioth. de la cille d'Amiens, ms. non coté).

A été ligrué à cette bibliothèque par le Cie A. de Marsy.

Artois. - Comté.

230. - Premier cartulaire d'Artois; ms. du XIIIe siècle, sur parchemin. de plusienrs mains. incomplet le lit fin, contenant 287 actes 
des années 1092 à 1293 , in $4^{\circ}$ de $110 \mathrm{tr}$. (Avelices dép. du lim, B 1593 .

A la fin, table eluronologifute, sur papior, de 79 pp. - Plusinurs marges de parchemin ont été comprés dans loriginal.

231. - Second cartulaire d'Artois; ms. des XIVe-XV' siecles. sur parchemin et papier, contenant 27 actes de 1268 is 1403 , in-folio de $15 \mathrm{ff}$. (Archices dép). Ir Nwrl. B non coté.

232. - Fragment d'un cartulaire des comtes d'Artois: ms. du

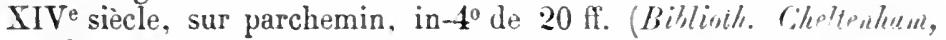
$\mathrm{n}^{0} 2895$ ).

Comprend les charles numérotes au XVIII siècle 63-102, 151-169 et $297-336$.

233. - Cartulaire dit «Premier cartulaire d'Artois»: ms. du XIII siècle, sur parchemin, contenant 187 actes de 1282 à 1299, in-folio de $32 \mathrm{ff}$. (Archices dép. du Pas-de-Calais, A 2).

La plupart des actes transcrits sont en langue francaises.

234. - Autre dit « Nouveau cartulaire d’Artois»; ms. du SIIIe siècle. sur parchemin, contenant $5 \mathrm{l}$ actes de 1236 is 1283 , in $-4^{\circ}$ de $\mathrm{l} 2 \mathrm{ft}$. (Archives dép. du Pas-de-Calais, A 1 .

Un certain nombre dacles sont également en francais.

235. - Fragment d'un autre cartulaire des comtes d'Artois; ms. du XIV' siècle, sur parchemin. contenant des actes de 1334 ì 1346. in-folio de $4 \mathrm{ff}$. (Archires dép. du Pas-de-Calais. 13 ).

Pour ces trois demiers registres, voir I Inventaire-sommaine des archives dép. du Pas-le-Calais, sério A, tome I (187s). 11) 1-10.

236. - Cartulaire d'Artois; ms. du XYIII siècle [1765]. par Godefroy, sur papier, arec table au début, in $4^{0}$ de $6\lceil 2 \mathrm{ff}$. (Biblinth. Ite la rille de Lille. fonds Godefroy, ms. 38).

Artois. - Grands baillis.

237. - Pebl. : Recueil de chartes et titres concernant les grands baillis d'Artois (1278-17it). Arras. Nicolas. 17it; in-4 de xxis$222 \mathrm{p}$.

Arvière. - Chartreuse (dioc. de Belley).

238. - Cartulaire de la Chartreuse l’Arrière: ms. Uu XVilI siecle, sur papier, in- $S^{n}$. contenant des copies de documents depuis le XIte siecle (Archires dn chatrun de Lirun, Ariège.

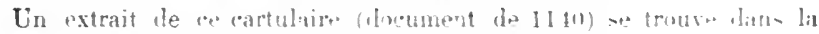
liase $\mathrm{H} 400$ des Arehive départemrnt le- de litin.

Asnières[-Bellay]. - Abbtye do Votre-bitme flioe. (l'Anger's). 
239. - Cartulaire de Notre-Dame d'Asnières; orig. perdu.

Extraits faits an XVII siècle (Biblinlti. nulionule. ms. latin 13816, 1T. 102-108); cf. Biblioth. d" Prytunée milituire de La Flèche, vol. E XII $86 / 1, n^{0} 30$ (copies - ur parchemin de cinq chartes des années 1133 à 1211 ).

Asnières. - Chapelle Saint-Euslache (dioc. de Lisieux).

240. - Cartulaire de la chapelle St-Euslache d'Asnières, dépendant de l'abbaye de Belle-filoile; ms. du XIVe siècle, sur papier', contenant des actes de 1211 à 1310, in-40 (Archices dép. de l'Orne, $\mathrm{H}$ 186).

Assé-le-RibouI. - Pricuré (dioc. lu Mans).

241. - Recueil de titres concernant le prieuré d'Assé-le-Riboul, dép ${ }^{t}$ de l'abbaye de St-Nicolas d'Angers; ms. du XVIII ${ }^{e}$ siècle, sur papier, in-40 (Lrchives dép. de la Mayenne, $\mathrm{H} 6^{\text {ter }}$ ).

Pers... : Cartulaire d'Assé-le-Riboul. par le Cie Bertrand de Broussillon, dans Archices tistoriques du Maine, III (1903), in-8 , p. 1-48.

Asti. - Seigneurie.

242. - Cartulaire de la seigneurie d'Asti; ms. du XVe siècle, incomplet à la fin, sur parchemin, in-folio de $185 \mathrm{ff}$. (Archives nationales, KK 1416).

Concerne les droits de luouis due dOrléans, frère de Charles V'I, et de Valentine de Milan, sa femme.

Ath. - Ville.

243. - Livres aux priviléges de la ville d Ath ; ms. des XVIIe-XVIII siècles, sur papier, en 2 vol. in-tolio de 156 et $169 \mathrm{ff}$. (Archives communules $t^{\prime} d t h$.

Dates "xtrêmes: : 1343-1727.

244. - Publ. : Chirrtes, staluts et ordonnances de la ville d'Ath. Ath. 1612, in-12.

Aubagne. - Seigneurie en Provence.

245. - Cartulaire te la terre d'Aubagne, appartenant à l'évêché de Narseille; ms. rédigé en 1754 et contenant des actes à partir du XIII ${ }^{e}$ siecle, en 8 vol. in- $4^{0}$ sur papier (Archires dép. des Bouchesdu-Rhône, G, fonds de l'évêché de Marseille).

Aubenas. - Courent des Cordoliers (dioc. de Viviers).

246. - Cardulaire des Cordeliers d'Aubenas, contenant 152 actes de 1294 à 1671 ; ms. du XVIIl ${ }^{\mathrm{e}}$ siècle, sur papier, de $660 \mathrm{fr}$. in $4^{\circ}$ Archires dép. de l'dideche, $\mathrm{H}$ non coté).

Aubenas. - Courent des I)ominicains.

247. - Cartulaire des Jominicains d'Aubenas, contenant 149 actes de 
1264 i 1781 ; ms. des XVIle [1643] et $\mathrm{XVIII}^{\mathrm{e}}$ siècles, sur papier, de 167 ff. in-folio (Archires dép. de l'Ardeche, H 17 prov.).

Le's transcriptions sont assez défecturuses.

Aubepierre. - Abbaye de Notre-Dame (dioc. de Limoges).

248. - Cartulaire de l'abhaye d'Aubepierre ; ms. daté de 1767, contenant 99 pièces des années $1127-1 \% 67$, sur papier. in- $4^{\circ}$ de 115 ff. (Archices dép. de la Creuse. H 147).

Les lectures $y$ sont souvent mauvaises.

Axal.: Inventaire des archives départementales de la Creuse, $\mathrm{H}$ [sous presse], p. 63-74.

Auberive. - Abbaye (dioc. de Langres).

249. - Cartulaire de l'abbaye d'Auberive; ms. du XIII siècle. avec additions du XIVe, sur parchemin. in- $t^{0}$ de $243 \mathrm{ff}$. (Archices dép. de-la Haute-Yarke, H non cotè).

Extraits du précédent. faits au $\mathrm{XV}^{\mathrm{II}}{ }^{\mathrm{e}}$ siecle (Biblioth. de l'Arspal. ms. 5261, ff. 93 et ss. : Bibliwh. mationale. ms. français 9499. pp. 177-185; ms. français 16188, tf. 296-313; coll. Duchesne, vol. XXII, fi. 65-68).

250. - Autre du XVIII siècle [1745], sur papier. en 2 vol. in-folio de 406 et $424 \mathrm{ff}$. (Archices dép. de la Haute-1Marine, $\mathrm{H}$ non coté).

M. Ernest Petit a publié quelques chartes l'après ce dernier recueil. Le vol. XXII de la coll. Duchesne (Biblioth. mationale) contient aussi une série de chartes des années $1173-1270$ sur Auberive (ff. sto-100).

Aubignac. - Abbaye de Notre-Dame (dioc. de Bourges.

251. - Cartulaire de l'abbaye d'Anbignac ; ms du XVIIe siècle, sur papier, contenant 300 documents des années 1165 à 1768 , in-folio de $447 \mathrm{fr}$. (Archires dép. de la Creuse, H 233).

Nimbreuses sont les erreurs de lectur dans ce registre.

Cf. Inventaire-sommaire des Archives défrartementales de la Creuse, série H, par F. Autorde (Guéret. [cous prese], in- $t^{\circ}$ ), pp. 113-132.

Aubigny-en-Artois. - Prieuré (dioc. d'Arras).

252. - Cartulaire du prieuré d'Aubigny. dépendant de l'abbaye du Mont-Saint-Éloi : ms. du XITe siècle, sur parchemin, contenant 153 actes de 1137-1309, in-folio de $84 \mathrm{fr}$. Archices dép. du Pas-deCalais, $\mathrm{H}$ non coté?.

Une copie de ce rupi-tre, faite en lsion, a tité rendue en nor. lcur, à Paris, avec la bibliothinge du marquis Le Ver ( $n^{\circ} 96$ du catalogu+).

Aubrac. - 1)omerienồital (dioc. de Rodez).

253. - Cartulaire de l'hòpital d'Aubrac; ms. du XIVe siècle, -ur parchemin. contenant 48 actes des années 1203-1320, in-4 $4^{\circ}$ de $111 \mathrm{ff}$. (Archires dép. de Theypron. H non coté. 
254. - Recueil de tilres relatifs à l'hôpital d'Aubrac; ms. de 1667, en 3 vol. in-folio de 274,286 et $260 \mathrm{ff}$. (Biblinth. nationale, coll. Doat, vol. 134-136).

Auch. - Archevèché.

255. - Cartulaire de l'archevêché d'Auch; orìn. perłu.

Extraits du précédent, faits au XVII ${ }^{\mathrm{E}}$ siècle (Biblisth. nationale, coll. Baluze, rol. LXXI, fl. 92-I03.

A ux ff. 112-116 du mên larium ecclesia Ausciensis vocatum liber honorum m, qui paraît être un regristre difflirent de ceux qui unt été déerits ci-dessous.

Auch. - Chapitr' tathédral.

256. - Cartulaires noir de Sainte-Narrie d'Auch : ms. des XIIre-XIVe siècles, sur parchemin [lacunes], le $196 \mathrm{ff}$. in- $4^{0}$ (trchices dép. du Ger. G I6).

Date's wtrêmes: $817-1378$. - Aux $1 f .11-26$ sont intercalées direrses

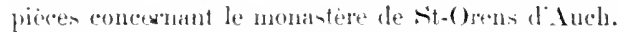

2.57. - Premier cartulaire hane de Sainte-Marie d'Auch; ms. denviron 1320, copié sur le précédent, mais incomplet [85 fi. subsistent sur 1217, sur parchemin. intolio (1m/rims tep. du Gers. (i 17.

En 17xl. il subsistait meore 113 fruillets. On l'a Jonertemps considéré commin peritu.

258. - Setond cartulaire blanc de Sainte-Xarie d'Auch; ms. du XIV'e siècle. sur parchemin. de 49 ff. in-40 (Archires dép. du Ciers, G 18).

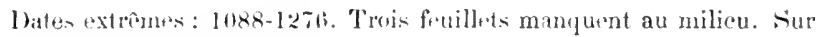
8.2 acters, 17 sont on 2 rascons.

Pebl. : Cartulaires dı chapilre le lérglise métropolitaine SainteMarie d Anch. par C. Lacave La Plagne-Barris. Auch, Cocharaux [Paris, Champion]. I899; in-8 de [r-] x1-36:3 p. [Archives historiques de la Giascogne, 2" série, fasc. III.]

Devouverts en 18603 whe\% le narquis d'Areanont, ces volumes ont fait

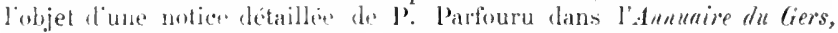
1879, 1). 3013-3328.

259. - Aulre cirtulirir" on « vieux liver vert » dı chapitre d'Auch: ms. originatrement de 217 pages. aujourd hui composé seulement de 55 pilcres très eflacées et en mauvais état. in-folio sur papier,

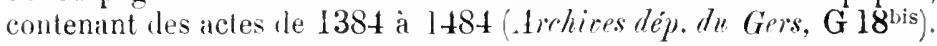

Provient auns du chanoine d Aleamont: il itait complet lor'squ'il a été utilisé par Cherin 'qui, dans sa Généalogie de la maison de Montruquiou-Fezensac, parue an 1784 , en dome deux textraiti.

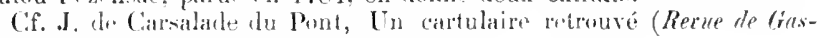
rogue, $1891,1 ., \pi 1)$.

260. - Autre cartulaire ou « livre rouge »; orig. perdu.

It existait encore en 1750 : cf. Biblioth. de ln rille de Turbes, Glanage 


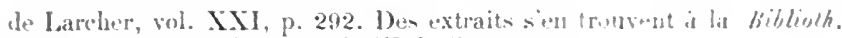
nationale, coll. Duchesne, vol. (II $\mathrm{L}^{\circ}, \mathrm{tt} .237-254$.

261. - Autre cartnlaire on « livre janne » : orier. perdu.

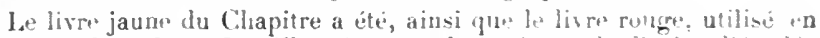
17to par Dom Brugeles (Chroniques ecelésia-tique-du diveeso d' I uch).

lixtraits du «Cartularius minor" de léglise d'Anch Billioth. nationale, coll. Baluze, vol. I.XXI. If. 108-110:-coll. 1)ucliesile, vol. CIV, ff. 1.52-219.

Auch. - Ville.

262. - Cartulaire municipal d tuch ou «livr» vert»: ins. du XVe siècle, avec additions postérieures. sur parchemin. contenant des actes de 1301 a 1634 , in- $4^{\circ}$ de $121 \mathrm{ff}$. (Avchices municipules d" Auch, At 1).

Auchy-les-Moines. - Abbaye (dioc. de Boulogne).

263. - Cartulaire de l'abbaye d'Auchy-les-Woines: ms. des XIIIeXIVe siècles, sur parchemin. contenant 172 actes de 1079 il 1388 , in-folio de $180 \mathrm{fl}$. (Avchices dép. tu Pus-de-Culais. H non coté).

264. - Autre daté de 1680, sur parchemin. in-folio de L-268 p. (Biblioth. de la rille d dbbecille. ms. 189).

265. - Publ. : Cartulaire de l'abbare de St-Silvin d'Auchy en Artois, par Dom Bétencourt; tome I. S. l. n. d. (XVIII siecle). in-4 ${ }^{\circ}$ le $416 \mathrm{p}$.

Recupil rarimime on incomple de 252 piects dos années 1000-1300, sans titre ni index.

Cif. Étude sur lo eartulair d'Auchy-les-. Joines, par l'abbe F. J.

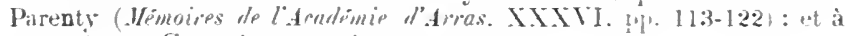
part: Arris, Courtois, 18ti: in- $8^{\circ}$.

Audenarde. - Seigneurie.

266. - Cartulaire rouge d'Audenarde; ms. du XIII siècle, sur parchemin, contenant des actes de 1187 i $128 \%$. in-folio de $132 \mathrm{ff}^{\circ}$ (Arrhices dép. du Ward. B 15\%0).

Copie du mème, collationnée par Godelroy els 1773. sur papier. avee index chronologique a la fin, in-4" le wr-200 ff. 'Bislioth. If la rille de Lille. fonds (rodefroy. ms. 4).

Aulne-sur-Sambre. - Abbaye. - Viy. Ilse.

Aumale. - Abbaye de Saint-Martin (dioc. do Rouen).

267. - Cartulaire de Saint-Martin d'Aumale; orig. perdu.

Chartes extraites dudit cartulaire el intéressant aussi le prieuré de Notre-Dame d'Onville; ms. du XVe siècle. sur papier. in- $\gamma^{\circ}$ de $58 \mathrm{ff}$. (Biblisth. mutionale. ms. français 14553 .

Autres extraits du cartulaire, faits au VVIII $^{\mathrm{e}}$ sitcle (Biblinth. nationule, ns. Clairambault 1059. ff. 235-248;. 
Aumont (d'). - Famille.

268. - Recueil de titres relatifs aux lamilles d'Aumont et de Rochechonart; ms. du XVIe siecle, sur papier, contenant des actes de 1391 a 1510 , in-folio de 52 ff. (Biblinth. nationale, ms. français $5477)$.

Plusirul's favillets sont mutilé.

Aunay (1). - Toy. Maubusson.

Aups. - Ville.

269. - Cartulaire municipal d'Aups. contenant des pièces i partir de 1245; ms. du XVIII siècle [1764]. sur papier, in-folio de 201 pages (Archices muninipales t'd lups. Tar).

Aureil. - Priemrí dive. de Limoges).

270. - Cartulaire du prieuré d'Aureil : ms, dles XII ${ }^{\mathrm{e}} \mathrm{XIII}{ }^{\mathrm{e}}$ siècles, sur parchemin, de $82 \mathrm{ff}$. in- $8^{\circ}$. contenant des transcriptions et analyses d'actes des années 1091 i 1189 (Archives dép. de la Haute-Tipnne, 1) 656 ).

Une copie en a été exécutér au XVII siecle (D 657): de plus une traduction francaise, aujourd'hui perdue, en avait été faite en 1542.

Cf. Quelques note- extraites du cartulaire d'Aureil, par Louis Guilert (Bullotin de la Sncióté des lettres, scimces et arts de la Correze, V, p. 20.5-23I), el is part: Tulle. 1883. in-8 de 31 p.

Publ. : Cartulaire d'Aureil. par II. le Cle (i. de Senneville (Bulletin de la Suci to archiologique ot historique du Limousin, XLYIII, 1900. pp. 1-X1 el 1-289.

271. - Autre cartulaire des XVII-XVIII siecles [1678-1724], sur papier, contenant des titres transcrits et analysés de 1075 à 1724 [et une tahle l'un cartulaire perdu de l'année [307], en 3 vol. infolio de 276, 287 et $195 \mathrm{fr}$. (Arrhires dép. de la Hante-Tienne, L) $6.51-653)$.

Auriol. - Ville.

272. - Cartulaire municipal d'Auriol; ms. du XVIII siècle, sur papier. contenant des titres de 1360 a l65l. in-folio de 78 ff. (Arrlires municipales d'.turiol. AA 1).

273. - Antre cartulaire; ms. du XVIII siècle, sur papier, contenant des titres de 1601 is 1717 . in-folio de 12 ff. (Archices municipales diniol, AA 2).

274. - Autre cartulaire on «Livre blanc»; ms. du XVII ${ }^{e}$ siècle

(1) Lieu-dit de la comunume de siant-Ouen-l'Aunônt". 
[1664], sar papier, avec alditions postérieures jusqu'en 1845 . contenant des titres à partir de 1:360. in-folio te 134 If. (Aichires municipales o' Auriol, AA 3).

Autun. - Abbaye de Saint-Martin.

2\%5. - Cartulaire de St-Martin d'Autun; ms. cumposé en 1 1602 par ordre de Jean Rolin, sur parchemin, areclettres ornées, in-folio de $60 \mathrm{ff}$. (Biblioth. nationale, $\mathrm{ms}$. Latin 5422 ).

La plus ancienne piece transerite est de 1170 . - le volume a appartenu à De la Mare".

Publ. : Essai historique sur l'abbaye de Saint-Martin d'Autun, par Gabriel Bulliot. Autun, 1849; 2 vol. in-8 ${ }^{\circ}$. [Société Édurnne.] Autun. - Égliso cathédrale Saint-Lazare.

276. - Cartulaire de l'église d'Autun ; orig. perdu.

Copie fragmentaire faite au XVII siecle (Biblinth. untionule, coll. Baluze. vol. LXXI. ff. $t^{6}-91$.

Publ. : Cartulaire de l'église d'Autun 67\%-1299, par A. de Charmasse. Autun, Dejussieu, 1865; in $4^{0}$ de Lxxrri-420 p. et pl. [Publication de la Société Éduenne.]

27\%. - Autre cartulaire de l'église d'Autun; ms. écrit en 1448. orig. perdu.

Copie du précédent: ms. du XVII ${ }^{\mathrm{e}}$ siècle. sur papier, in-foliu de viII-316 et $61 \mathrm{ff}$. Biblinth. de la rille de Dijon, ms. 342).

Autre copie d'un cartulaire de l'é clise d'Autun: ms. du XVIII siècle. sur papier. in-folio de $\mathbf{t} \mathrm{tf}$. (Biblinth. de la cill, to Dijon, ms. 1328).

278. - Cartulaire de l'éclise d'Autun; ms. du XVII siecle, sur papier,

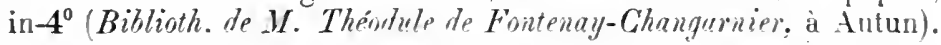

Publ. : Cartulaire de l'église d'Autun: $3^{\text {e }}$ partie (897-1399, par A. de Charmasse. Autun, Dejussien. 1900; in $4^{0}$ de [rr-]cxxvin469 p. [Publication de la Société Éduenne.]

L'intruduction indique les diffërences existantes entre le ms. de Baluze. et celui de M. de Fontenay-Changarnier. - Pour la $2^{\mathrm{e}}$ partie, roir Aetrx (évêché d').

Autun. - Église Saint-Nazaire.

279. - Cartulaire de l'èglise Saint-Nazaire d'Autun; vrig. perdu.

Extraits du précédent, faits en 1650 pour Gaignières, - sur papier (Biblioth. nationale, ms. latin 17048, pages 7i-8\%.

Autun. - Érêché.

280. - Cartulaire rouge de l’érỉsché d'Autun; ms. du XIII -iécle, 
sur parchemin, contenant 216 chartes de 1120 a 1295 , in $-4^{0}$ de 154 if. (Arehives dép. de Saône-et-Loire, G 44:3).

I'rbl. : Cartulaire de l'évèché d'Autun, par A. de Charmasse. Autun, Dejussieu, $1880 ;$ in $4^{0}$ de Lxxvn-474 p. [Publication de la Société Éduenne.]

281. - Cartulaire vert de l'évèchẻ d'Autun; ms. du XVe siècle rédigé par ordre de Jean Rolin, sur parchenin, en 2 vol. in-folio de 267-vm et $261 \mathrm{fl}$. (Archires dép. de Suône-et-Loive, G 445-146).

Le tome II est incomplet des feuillets 9 ì 16 .

Extraits des précélents, faits par Dom Plancher au XVIII siècle (Biblinth. nationale, coll. Bomrgogne, vol. I-II).

Autun. - Hôpital du Saint-Esprit.

282. - Cartulaire de l'hòpital du Saint-Esprit d'Autun, contenant 56 pièces des annèes 1269 i 14333 ; ms. du XVe siècle, sur parchemin, in-folio (Archires hospitalières d'Autun).

Copie du mème, faite an XVI" siècle (Archires hospitulières rdutun).

Autun. - Prieure de Saint-Symphorien.

283. - Cartulaire de St-Symphorien d'Autun ; orig. perdu.

Copie du XVIII ${ }^{\circ}$ siecle [1721], pour Bouhier, sur papier, in $-4^{\circ} \mathrm{de}$ 4:3 I1. Biblinth. nationale. ms. latin 18354).

La plupart des actes transcrits sont carolingiens.

Antre copie du XVII ${ }^{\mathrm{e}}$ siècle, par I). Aubrée (Biblinth. nationale, ms. litin 1:28:4. ff. 1-68).

\section{Auvergne.}

284. - PLBL. : Monmmenta pontificia Aiverniae decurrentibus IX, X, XI, XII saculis ; Correspondance diplomalique des papes concernant l'Auvergne depuis le pontificat de Nicolas I ${ }^{\mathrm{er}}$ jusqu'à celui d'Innocent IIl, par A. C. Chaix de Lavarène. Clermont-Ferrand, Bellet, $1880^{\circ} ;$ in $11-4^{0}$ de $\left.x x_{-}-50\right)$ p.

Dates extrèmes : $8602-1196$.

(.f. anssi Burrinows.

Auvers-le-Hamon. - Prieuré (dioce du Mans).

285. - Cartulaire du prieuré d'Auvers, dépendant de l'abbaye de Solesmes; ms. écrit en 1538, in-4 $4^{\circ}$, sur. papier (Biblioth. de l'abbaye de Solesmes. auj. it Appeldurcombe House, ile de Wight, Angleterre'.

L.s chartes qu il contient ont été en jartie imprimées dans le : Cartulaire des abbayes de sit-Pierre de la Couture et de St-Pierre de Solesmes. 
Auxerre. - Abbaye de Saint-Germain.

286. - Grand cartulaire de l'abbaye de Saint-Gelmain l'Auxerre, composé en 1266: ms. du XIII siècle, avec addition de trois autres petits cartulaires du XIVe et du XVe siècle fir. 102-111. 115-15t et 155-173), sur parchemin, in-folio de $212 \mathrm{ff}$. (Biblinth. de la rille d'Auxerre, ms. 161).

Axil. : Abrégé du précédent, fait par D. Gérard Ternat en 1678 (Biblinth. de la rille d'Aux'rre, ms. 163, ff. 1-67).

Inventaire chroaologique des chartes contenues dans le Grand cartulaire, dressé en 1681, sur papier, in-4 $4^{\circ}$ de 20 tf. (Arrhices dép. de l' Tonne. H $100 \mathrm{i}^{\text {bis }}$.

Talle du cartulaire de St-Germain d'Auxerre Biblinth. de la rille "Auxere, coll. de Bastard, nis. 22).

Lixtraits faits en 1670. contenant 23 chartes di 835-1211. sur papier. in-tolio de $28 \mathrm{ff}$. (Archies dép. de l' Iomne. H 1010).

Autres extraits Biblinth. nntionale, coll. Bourgogne. vol. III, ff. $18-43)$.

287. - Fragment d'un cartulaire de St-Germain d'Auxerre; ms. du XVe siècle, sur parchemin, contenant des pièces depuis le XII (Biblinth. nationale, ms. français 18693. pp. 453-458.

288. - Cartulaire de li pitancerie de Saint-Germain d'Auxerre: ms. des XIII $-\mathrm{XIV}^{\mathrm{e}}$ siècles, sur parchemin, in-folio de $\mathrm{N}$-137 ff. Biblioth. de la ville th Arerre. ms. 162.

Axil.. : Abrégé du précédent. fait par D. Gerard Ternat en 1678 Biblinth. de lu rille d" Alurerre, ms. 163, 1i. 73-93:

Auxerre. - Abbaye de Saint-Julien.

289. - Cartulaire de l'abbaye de Saint-Julien d'Auxerre; fragment du XIII siècle, sur parchemin, in-folio de $9 \mathrm{ff}$. Archires rép. de lionne, H 166\%).

Les dates extrêmps des pir̀ces sont 1934 et 1291 .

Auxerre. - Abbaye de Saint-Marien.

290. - Recneil de titres de l'abbaye de Saint-Marien d'Auxerre; ms. du XIVe siecle. sur parchemin. contrnant des actes de 1163 à 1317 , in-to de $12 \mathrm{ff}$. (trchices dép. de l'Ionn'. H 1200.

291. - Autre cartulaire du XVII e siècle, sur papier. contenant des actes de 1160 à 1635 . in-folio de $331 \mathrm{ff}$. Archices dép. de l Yonne, H 1201.

Extraits du précédent, faits an $\mathrm{XVIII}^{\mathrm{e}}$ siècle, sul papier. in- $4^{0} \mathrm{de}$ 20 $\mathrm{ff}$. (Biblinth. nutionale. ms. latin 17724'.

292. - Autre du XVIII cirecle, sur ! apipr. rédiré par un bénédictin 
nommé Painteindre, contenant des actes de 1160 a 1370 , in-4 $4^{\circ}$ de $22 \mathrm{ff}$. Archires dép. de l'Tonne, H 1202 .

Auxerre. - Abbaye de Saint-Pire.

293. - Cartulaire de Saint-Père d'Auxerre ; ms. du XVII ${ }^{\mathrm{e}}$ siècle [1660], sur papier, contenant des documents à partir de 1170. in-folio de 274 if. (Archicess dép. die l" Tonne, H 1299.

Auxerre. - Chapitre cathedral Saint-Etienne.

294. - Fragment du carılaire du Chapitre cathédral d'Auxerre: ms. du XIII siècle. sur parchemin, in-40 de 31 II. (Archires dép. de l'Yonne, G 179\%.

Extraits faits en 1680 pour Gaignières. sur papier (Biblioth. natirnale. ms. latin 17048. pages $117-150$ ).

Auxerre. -- Érichr.

295. - Cartulair de l'évèché d'Auxerre [XIII s.] : orig. perdu.

Extraits faits en 1680 pour Gainnières (Biblioth. nationule. ms. latin 17048, pages 93-100 et 109-115; - par Baluze (Idem, coll. Baluze, vol. LXX1. tr. 118-124); - par d'autres (Biblioth. nationale, coll. Bourgonne, vol. III, If. 1-17 : et Archires tép. de l'Yonne, (i 1708 .

Auxerre. - Prieuro de Saint-(ierrais.

296. - Cartulaire du prieuré de St-Gervais d'Auserre; ms. du XVIo siècle, contenant 15 chartes des années $1146-1508$, sur papier, in- $4^{0}$ de 38 fr. (Archires dép. de l' Fonne. H 1375).

Auxerre. - Ville.

297. - Cartulaire municipal d"Auxerre; ms. du XVe (?) siècle: orig. perdu.

L'abbé Lebeuf (Mémoires concernant l'histoire d'Auxerre, II) en a extrait de nombreunes charles des annéts 1188 ì 1380.

298. - Publ. : Chartres, immunitez, libertés, previleges et franchises donnees et octroyers par les comtes d'Ancere, et depuis confermees et approuvees par plusieur's roys de Fince, des preveleges des francsbourgois, minans et habitans en la ville, cité et banlieue d'Aucerre. S. l. n. d. [Paris, v. 1485]: in $-8^{\circ}$ de $16 \mathrm{ff}$.

Auxonne. - Échlist Notre-Dame dioc. de Besançon!

299. - Cartulaire de l'église Notre-Dame d'Auxonne; ms. du XVIII siècle, sur parchemin, in-40 de $56 \mathrm{tl}$. (Archiers dép. de la Cóte-d'Or, G $36 \% 0$.

Dates extrines : $1406-1716$.

Intéresse le clèréré du comté d'Auxonne et l'officialité transférée à Seurre. 
Avallon. - Courent des Capucins dioc. d'dutun .

300. - Cartulaire des Capucins d'Avallon: ms. de 1661, sur papier, in-folio de 22 II. Archires municipales d Acallon, GG 100 .

Avallon. - Église Notre-Dame.

301. - Recueil de pièces relatives à l'écrlise Notre-Dame d'Arallon: ms. du XVIII e siècle. sur papier, in-1" de $121 \mathrm{tr}$. Biblisth. Io la ville de Dijon, ms. 1055).

Avarville. - Baronnie en Normandie.

302. - Cartulaire de la baronnie d'Avarville. dépendant de l'abbaye de Lessay; ms. du XVe siècle, contenant 150 titres des années $1194-$ 1491, sur papier. in-folio de 246 It. (Archires dép. de la Wanche. $\mathrm{H}$ non coté).

Avenay. - Abbaye de Saint-Pierre dioc. de Reims:

303. - Cartulaire de labbave St-Pierre d'Avenay: ms. des XIIIXIVe siècles, contenant 11 כ̆ pièces de 1050 ì 1301. sur parchemin, de $62 \mathrm{ff}$. in-4 $4^{\circ}$ (Archives dép. de la .Mume. H non coté).

Copie moderne par A. Duchénoy. in-folio de 185 ff. sur papier (Biblioth. de la rille de Reims, ms. 1̄581.

Publ. : Histoire de l'abbaye d'Avenay. par Louis Paris. II Paris. 1879, in-80), pp. 70-161. [Truraux de P.dcadímie de Reinls, LXIII.]

Averbode. - Abbaye dioc de Malines.

304. - Cartulaire de l'abbaye d Averbode : ms. des XIIIe-XIVe siècles, sur parchemin, contenant des actes de 1135 à 1315 , in- $4^{\circ}$ de $84 \mathrm{ff}$. Archives de Tabbaye it Arerbodr.

305. - Autre cartulaire; nis. des XIVe-XVI siècles, sur parchemin, en deux parties. contenant des actes de 1143 is 1497 , in-folio de $479 \mathrm{ff}$. (Archires de l'abbaye "Acerbudr'.

Avesnes. - Ville.

306: - Cartulaire municipal d'Avesnes ou "livre rouge », contenant des documents de 1542 à 1706 ; ms. des $\mathrm{XVT}^{\mathrm{e}} \mathrm{X}$ Vîl papier, in-folio de $23 \mathrm{I}$ if. (Archires municipules d Aresnes. Nord. BB I,

Avignon. - Chapitre métropolitain.

307. - Cartulaipe du Chapitre d'Avignon : ms. du XIIe siècle, sur parchemin, de plusieurs mains, contenant 104 documents de 939 it 1174, in- $4^{\circ}$ de $49 \mathrm{fr}$. Archices dép. dé [unchuse. G non coté.

Publ. : sous presse, par M. G. de Hanteyer, dans les Hémoires

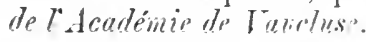


Avignon. - Commanderie.

308. - Cartulaire de la Commanderie d'Avimnon, dite « du Port de Rognonas »; ms. de la fin du XIII $I^{e}$ siècle, sur parchemin, contenant des titres de 1189 à 1245 , in-4 ${ }^{\circ}$ de $117 \mathrm{ff}$. (Archives dép. des Bouchesdu-Rhone. H non coté. fonds du Grand-Prienré de Saint-Gilles).

Avignon. - Évèchè.

309. - Cartulaire de l'évèché d'Avignon, dit «Aureum Vidimus »; ms. commencé par ordre de l'évêque Gilles Bellemère en juin 1396, avec additions postérieures, contenant des pièces de 898 à 1597, sur parchemin, in-folio de 159 17. (Archices dép. d' Vaucluse, G 8).

310. - Autre, dit «Gonterius »; ms. du XVIIIe siècle, contenant des pieces de 1538 ì 1708, sur papier, in-folio de 708 ff. (Archives dép. do Taurluse, G 20 .

Avignon. - Noviciat des Jésuites.

311. - Fragments d'un cartulaire du Noviciat des Jésuites: ms. dú XVII siecle, sur papier, in-folio (Biblinth. de la ville t'Avignon, ms. 3247 , 1f. $69-114$.

Avignon. - Iniversilé.

312. - Liber privilegiorum Universitatis Avenionensis»; ms. du XVII ${ }^{e}$ siècle, transcrit par le notaire greffier Pierre Rigand, sur papier, contenant des textes de 1303 il 1648, in-folio de $75 \mathrm{ff}$. (Archives dép. de Tancluse. D 4).

P'erb. : Cartulaire de l'T niversité l'A I. $D^{\mathrm{r}}$ Victorin Laval. Avignon, Seguin frères, 1884 ; in- $8^{\circ}$ de [vicxi-476 p.

Avignon. - Ville.

313. - Prвt. : Bullarium civitatis Avenionensis seu bullae ac constitutiones apostolica summorum pon ificum et diplomata regum, continentia libertates, immunitates et jura inclytæ civitatis et civium Avenionensimm. I. Lngeluni, 16.77, in-folio de $178 \mathrm{p}$.

314. - Cirrtulaire de la ville d'Avignon; ms. des XIIIe-XVe siècles, commencé en 1232 par Parceval Doria, podestal d'Avignon, sur parchemin et papier, contenant des copies d'actes et des analyses, in $-4^{0}$ de 132 fr. (Biblinth. de la ville do Leignon, ms. 2833).

Des copies du XVIII siecle existent dans les mss. 2467 et 2835 de la mine bibliotheque.

315. - Recneil des statuts et privileges de la ville d'Avignon; ms. des XIII $-X^{e}$ siècles, sur parchemin, in-folio de $97 \mathrm{fl}$. (Biblioth. de la ville drigum, ms. 2834).

Ces textes sunt publiés en granle partie par René de Maulde: 
Coutumes et règlements de la République d'Avignon au XIII siécle

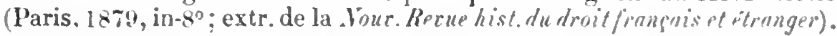

316. - Bullaire de la cité diAvignon; ms. des $\mathrm{XV}^{\mathrm{e}}-\mathrm{XVI}^{\mathrm{e}}$ sibules, sur parchemin, in-folio de $256 \mathrm{ff}$. Biblioth. de la ville tr. Arigion, ms. 2836).

Avoine. - Village.

317. - Recueil de titres concernant la commune didvoine: ms. du XVIII ${ }^{\mathrm{e}}$ siècle, sur papier, contenant des titres de 1474 i 1781 , in- $4^{0}$ de 119 ff. (Archires communales d Aruine, Indre-et-Loire, DD 1).

Avrainville. - Seigneurie.

318. - Cartulaire d'An'ainville, dép ${ }^{t}$ de l'abbaye de St-Germain-desPrés; ms. du XVIII ${ }^{e}$ siècle $[1754]$, sur papier, contenant des actes de 1070 a 1740 , en 2 rol. in-folio de 200 -xrs et 276 -xx tr. drchires nationales, LL 1044-1045).

Avranches. - Chapitre cathédral.

319. - Cartulaire du Chapitre d'Avranches, ou «livre vert »; ms. des XIII - $X V^{\mathrm{e}}$ siècles. incomplet du début, sur parchemin, in-folio de 165 ti. (Bibliath. de la ville d Avrunches; ins. 206.

320. - Autre cartulaire ou \& livre blanc »; orig. perdur.

Extrait fait an XVII siècle (Biblioth. nationale, ms. français 4911 , p. 383).

Ax. - Ville.

321. - Cartulaire de la ville $\mathrm{d}^{\circ} \mathrm{Ax}$ : ms. du XVI siècle. contenant des titres à partir de 133:3, in $4^{0}$ de 82 pagres : parait perdu.

En 1839, un certain M. Cros signala lexistence de ce registre à Angustin Thierry, mais il crut préferable, au lieu de copier les textes qui pouvaient intéresser l'histoire du Tiers-État, d'envoyer à Paris le cartulaire lui-même. Depuis, on nt l'a pas tevu, et "l'enquête à laquelle se livra M. F. Pasquier, archiviste de l'Arière (1885), pour opérer sa réintégration aux archives communales d'Ax, n'a pas abouti.

Aymeries. - Prieuré (dioc. de Tounai).

322. - Cartulaire du prieuré d'Aymeries, dépendant de l'abbaye d'Anchin; ms. "lu XIII" siècle. orig. perdu.

Copies, faites aux $X V I^{e}-X V I I I^{e}$ siècles, d'actes relatifs au mème prieuré, non rangés chronologiquement. sur papier, in-folio (Archices dép. du Nord, $\mathrm{H}$ non coté. Hi. 34-121).

Dates extrêmes : $1115-1516$.

Aywières. - Abbaye dion. In Namur).

323: - Cartulaire de labbaye d'Aywières: ms. dn XVIe siecle, sur papier, contenant des tilies de 1198 il I.008, in-40 de 15.5 H.

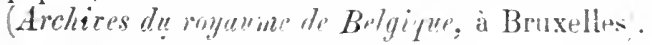


Azé. - Voy. Le Génetell.

Azun (Vallée d'). - Voy. Luz.

Baccarat. - Ville.

324. - Recueil des titres, lettres, chartes et papiers des franchises de Baccarat; ms. dn XVII siècle, sur papier, in-4 $4^{0}$ de 41 ff. (Archives municipales de Baccarat, AA 2).

Dates extremes : 1344-1630.

Bagneaux (Yonne). - Village.

325. - Cartulaire de Bagneaux, dépt de l"abbaye de St-Germain-desPrés; ms. du $\mathrm{XVI}^{\mathrm{e}}$ siècle, sur papier, contenant des actes de 1192 à 1498 , in-4 ${ }^{0}$ de $42 \mathrm{f1}$. (Archives nationules, LL 1057).

Bagnères-de-Bigorre. - Voy. Luz.

Baigne. - Abbaye de Saint-Étienne (dioc. de Saintes). 326. - Cartulaire de l'abbaye de Baigne; ms. des XIIe-XIIIe siècles (Appartenait en 1865 ì M. Morear, à Saintes).

Publ. : Cintulaire de l'abbaye de Saint-Étienne de Baigne en Saintonge, par l'abbé Cholet. Niort, Clouzot, 1868; in- $4^{0}$ de XxxıII:382 p.

Bailleul. - Ville.

327. - PubL. : Documents inédits relatifs à la ville de Bailleul en Flandre, par Ignace de Coussemaker. Paris, Picard, 1877-1878; 3 vol. in- $8^{0}$ de xi-5̆ 6,546 et 148 pages.

C'est un recueil factice de 108 documents du XIIe au XVIII siècle.

Bajoles. - Commanderie. - Voir MAS-DeU.

Balaruc. - Ville.

328. - Pubz. : Privilègres et franchises de Balaruc, d’après les textes inédits du cartulaire de Maguelone, par A. Germain (Mémoires de la Suciété archéologique de IFontpellici, IV, pp. 199-226), et à part: Montpellier. Martel ainé, 1863 ; in $-4^{\circ}$ de $30 \mathrm{p}$.

Bâle. - Évèché.

329. - Publ. : Monuments de l'histoire de l'ancien évêché de Bâle, par J. 'T'rouillat. P'orientruy, 1852-1867, 5 vol. in- $4^{0}$.

Balerne. - Abbaye (dioc. de Besançon).

330. - Cartulaire de l'abbaye de Balerne; orig. perdu (?).

Copie du précédent, copiée par Baverel au début dn XIX ${ }^{e}$ siècle, sur papier, in-10 de 114 ff. (Biblinth. de lo ville de Besancon, coll. Baverel, n1s. 38,. 
Bandouille. - Prieuré près do Bressuire dioc. de La Rochelle, - Voy. Grasmont.

Bar. - Comté.

331. - Cartulaire du comté de Bar; ı1s. du XIVe siecle, contenant 1687 chartes, sur papier, in-folio de 212 et $208 \mathrm{ff}$. (Biblisth. mutionule, coll on de Lorraine, vol. 718 et 719 ).

Dates extrêmes : 1133-1363.

332. - Aulre du XIIIe siècle, avec additions du XIVe. et table inachevée du XVIII ${ }^{2}$, sur parchemin, in- $4^{0}$ de 317 ff. (Biblioth. nationale, ms. français 118.33 ).

$332^{\text {bis. }}$ - Autre du XVIe siècle, in-folio (Biblisth. de .M. le comte Bertrand d' Inécourt, au chau d'Inor, Meuse).

Cf. aussi $\mathrm{r}^{\circ}$ LoRRALIs.

333. - Recueil de titres relatifs a la ville et chàtellenie de Bar, formé à la fin du XVIe siècle par Thierry Alix. sur papier. contenant des actes de $114 \overline{3}$ à 1586 , en 3 vol. in-folio de $45 \bar{i}, 469$ et $460 \mathrm{ff}$. (Archives dép. de Meurthe-et-10selle. B 340-342).

Copie du précédent, faite au XVII siècle. sur papier, en 2 vol. in-folio (Arckives dép. de la Meuse, B 228-229;.

334. - Cartulaire des droits de souveraineté du roi de France au Comté de Bar: ms. du XVII e siècle. sur papier, contenant des documents à partir de 1206, en 3 vol. in-folio de 454,345 et 449 ff. (Archires nationules. KK 1178-1180).

Barbeau. - Abbaye (dioc. de Sens).

335. - Premier cartulaire de l'abbaye de Barbeau ; orig. perdu.

C'est celui qui est dépouillé dans la coll. Moreau (Biblisth. nationale).

336. - Autre cartulaire du XIII ${ }^{\mathrm{e}}$ siècle : orig. perdu.

Copie du précédent, faite au $\mathrm{XVII}^{\mathrm{e}}$ siècle pour la bibliothèque de Colbert, sur papier, in $\mathbf{4}^{0}$ de 917 pages (Biblioth. nationale, ms. latin 5466).

\section{1)ates extrêmes: 1251-14t8.}

337. - Troisième cartulaire de Barbeau : ms, de la fin du XIIIe siècle, sur parchemin, in-8 $8^{0}$ de 344 ff. (Biblivth. nutionule, ins. latin 10943).

Extraits des précédents, faits au $\mathrm{XVII}^{e}$ siècle (Biblioth. nationale. coll. Balnze, vol. LXXI, ff. 128-183: ms. français 15504. ff. 3740; coll. Duchesne, vol. LXXVII, ff. 46-65; - et Biblisth. te la ville de Rouen, ms. 2087, ff. Ti-91'.

Barbezieux. - Prieuré (dioc, de Saintes'.

338. - Cartulaire du prieuré de Barbezieux : ms. du XIIIe siècle. sur parchemin, in-4 $4^{0}$ de 8 I ff. (Archices nationules, LL 1419). 
Barcelone. - Chapitre cathédral.

339. - Cartulaire du Chapitre cathédral de Barcelone, ou «Liber antiquitatum ecclesiæe cathedralis »; ms. du XIII ${ }^{\mathrm{e}}$ siècle, sur parchemin, en 4 vol. in-folio de 400, 230, 153 et $244 \mathrm{ff}$. (Archivo del Cabildo catcdral de Barcelona).

Le tome ler contient les privilèges des rois de France, le tome 111 les bulles de papes. La pièce la plus ancienne est de 878 .

Extraits faits au XVII ${ }^{\mathrm{e}}$ siècle pour Baluze (Biblioth. nationale, coll. Baluze, vol. CVII, ff. 109-135).

Barcelone. - Comtè.

340. - « Primus cartularins feudorum Barchinone »; ms. du XIVe siècle, sur parchemin, in-folio (Archivo general de la Cormana de Aragon).

Extraits faits au $\mathrm{XVII}^{\mathrm{e}}$ siècle (Biblioth. nationale, coll. Baluze, rol. CVIII. ff. 1-24).

341. - «Secundus cartularius fendorum Barchinone »; ms. du XIVe siècle, sur parchemin, in-folio (Archizo general de la Corona de Aragon).

Extraits faits au XVII ${ }^{\mathrm{\theta}}$ siècle (Biblinth. nationale, coll. Baluze, vol. (VIII, ff. 25-67).

Barcelone. - Eglise Saint-Pierre.

342. - Cartulaire de l'église St-Pierre de Barcelone; orig. sans doute perdu.

Extrait fait au XVII siècle pour Baluze, contenant la transcription d'un acte de l'année 986 (Biblioth. nationale, coll. Baluze, vol. CVII, p. I36).

Barjols. - Église collégiale (dioc. de Fréjus).

343. - Cartulaire de l'église de Barjols; ms. du XIX'e siècle, sur

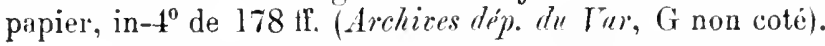

Documents à partir de 1062. - Ce registre est la transcription des originaux convervés à la Bibliothèque nationale, ms. latin 1237

Barjols. - Ville.

344. - Cartulaire de la ville de Barjols : ms. de la fin du XIVe siecle, sur papier, contenant des textes à partir de 1367 , in-4" de $174 \mathrm{ff}$. (Archives dép. du $\mathrm{Var}, \mathrm{C}$ non coté).

Cie registre ne contient en réalité que des transeriptions de délibérations des ctats de. Provence.

Bar-le-Duc. - Commanderie (dioc. de Toul).

345. - Mémorial des plus anciens titres concernant l'hópital de Bar; 


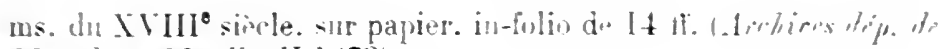

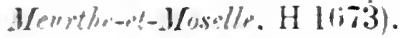

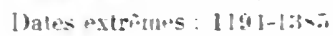

Bar-Ie-Duc. - I'rimir.

346. - Fragment dun cartulaire du prienre de BAr-le-Dnc: 11 . In

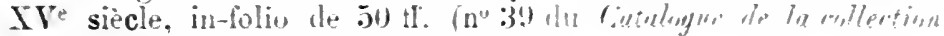

Harhom, vendue en 18509 ).

Jignore où il se trouse actuellerment.

Bar-le-Régulier. - Prirmir dion. d'Autun.

347. - Cartulaire du prieuré de Bar-le-Répnlier. uni au chapitr. de

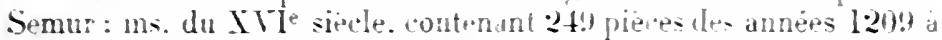

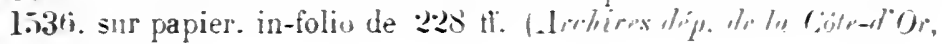
G nun coté).

Baron. - Seinumbirin Vabis.

348. - Cartulaire de la seigneurie le Garon. app' is l'abbaye de Chelle: : orig. perdu.

Extrait du précident. fuit "n ltilo. sur papier. in-t" (. 1, rkirps

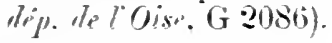

Barrois. - Piegall..

349. - Recueil de titres relatifs anx rétralm du Barrois el aus druits de la France: ms. du $\mathrm{XTIl}^{\mathrm{e}}$-ipele. Torme par Thierrs Alix. sur papier. contenant dos actes de 1166 a l604, in-folin de 42:3 ti.

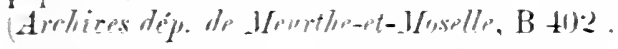

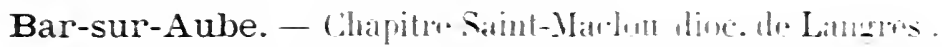
300. - Cartulaire du Chapitre Sl-Machou de Bar-sur-Anlye: ms. du XIII' siencle.

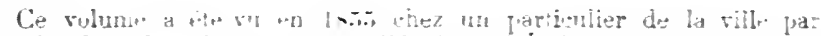

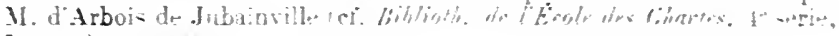

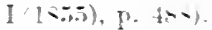

Bar-sur-Aube. - Ilülol-Liml.

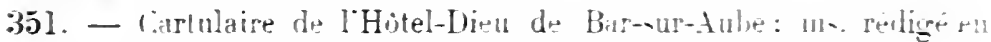

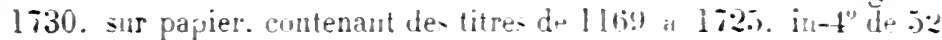

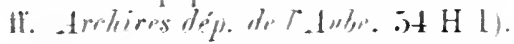

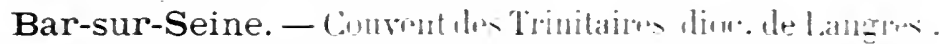
352. - Cartulaire de. Trinitaire: le Bar-sur-Srin : m-. Iu ITH

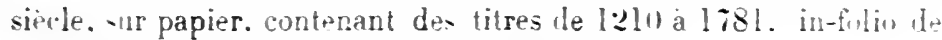

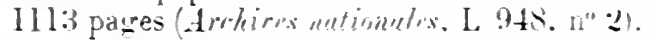

35:3. - Antre cartulaire : ms du XVIIL siecte. - sur papier, en ? rol.

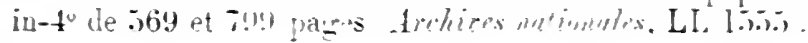


Bassac. - Allay dioc. dr Saintes.

354. - Carlulaire de labbaye de Bassac en Saintonge: orig. perlu.

Acle de l'an 1002 extrait du précédent par Dom Col an XVIIIte siecle Bithintll. "utionule, ms. latin 9196, p. 729.

Bassefontaine. - Abbaye dioc. de Troyes.

35.5. - Cartulaire de l'abbaye de Bassefontaine: ms. du XV' siecle, sur papier, contenant des actes de 1144 a $1: 281$. in-folio de $86 \mathrm{ff}$.

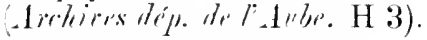

356. - Antre cartulaire de labbaye de Bassefontaine (Biblisth. du rhatem de Brirnue. Aube).

PrbL. : Cartulaire de labbaye de Bassefontaine, pas l'abbé Ch. Lalore. dans Conllaction tess principuns centulnives de diocess de Troypes, III 1878. p. 1-17:3.

I... dowumbnt- vont de 11.14 à 1298.

Basseville. - (hartrense dioc. d'Auxerre)

3.7. - Prbl. : Cartulaire de la Chartreuse de Basseville Nievre), publ. par Victor Guenara. Issoudun, Fug. Motte. 1893; in-10 de rill-1:2 p.

Basse-Wawre. - Prieuri dioc. de Malines).

358. - Cartulaire ln prieuré de Basse-Wavre: ms. du XVIIe siècle, sur papier, contenant des titres le 1086 a 1670 , intolio de ti52

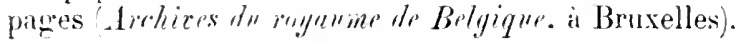

3..!. - Autre du XVIIe siècle, sur papier. contenant des titres de Il 48 à 1658 . in-foliu de 85 ti. (Archices dr roygume de Belgique, à Bruxelles!.

$$
\text { Vuy atum Frasies. }
$$

Bastia. - Hònital.

360. - Cartulaire de l'hòpital de Bastia: ms. des XVIIe-XVIII siècles, en $\tau$ rol. in-folio, contenant des actrs de 1610 à 1712 (Archirs hospituliers do Bastia).

Bastia. - Ville.

361. - Cartulaire municipal on livre des privileges de la ville, contenant des actes de 1489 à $1768:$ ms. du XVIIJ siècle, in-folio Arrhix's miniripales de Bustic).

Bauffremont (le). - Famille.

362. - Recueil de litres de la maison de Baullremont: ms. du XIX sierdr. in-folio (Biblioth. du prince de Fauffemont. duc d'Atriseo, à Paris). 
Baugerais. - Abbayo dinc. de Tours.

363. - Recueil de chartes concernint l'ahlate de Bangerain: ma nu XVII" siécle. composé par l'abbé de Mirolles. sur papier. in-4" de 475 tl'. Biblioth. mutionulis. ms. latin 10044 .

Baume-les-Moines. - Ablaye iline. to Resançon .

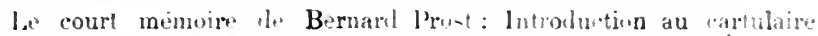

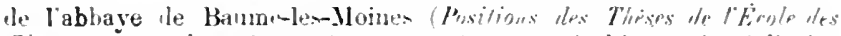
Churtes, pronotion 1868-1869, p. 21-26), punrrail faire aroire is l'xis-

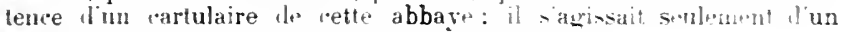

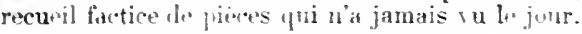

Bayeux. - Confrerir des bourhers.

364. - Cartulaire de la confrerie des francs-houchers en l'érlie StMartin de Bayenx: ms. du XYe siècle [1480]. sur parrhemin. in- $4^{0}$ de 69) ff. (Biblioth. de lu cille de Baypen., m., 4.

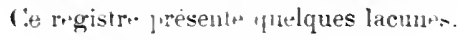

Bayeux. - Eglise rathédrale.

365. - «Antiquns 'artularins ecclesiz Baiocen-is 》, on Livre noir : ms. du XIVe siecle. sur parchemin. in-folio de $142 \mathrm{tr}$. aver quelques

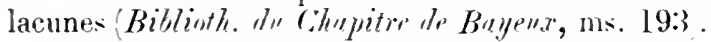

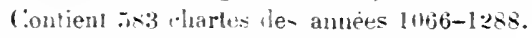

Pubr: : Antiqum cartularius ecclesiæ Baiocensis (livre noir par l'abbé V. Bourrienur. Rouen. Lestrilurant. 1902-190:3: 2 vol. in-8 de cxis-336i et rs-4+6 p. [Suciété de l'histoir de Normandie.]

Extraits (Biblinth. artiminale, ms. [5530. Ho. 98-105).

366. - " Antiquus cartularius capellæ B. Mariæ Virginis in ecclesia Bajocensi »: ms. du XIII" siècle, sur parchemin, en 2 vol. in-10 (Bibliolh. Cheltentlim m, $\mathrm{n}^{\mathrm{n}}$ 10337).

367. - Cartulaire tle la chapellenie de Langevin en l'église de Bayeux ; ms. du XVe siècle, sur parchemin, in t $^{*}$ (Biblinth. de la rille de Caen. coll. Mancel. ms. 211).

('f. Biblioth. du Chapitre de Bnyour, uss. 122. - Cf. Léchaule d'Anisy

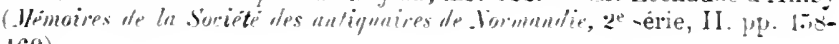
$16 ! 1)$.

Bayeux. - Ėrêché.

368. - Cartulaire de l'érèché do Bayeux ou "livre rouge »: ms. du $\mathrm{XVe}$ siècle, avec reliure de cuir rouge ornee tle coins et fermoirs [brises] de cuivre, sur parchemin. contenant 586 chartes des années 1058 à 1455 , in-folio de xxin-265 ff. (Biblinth. mutirnule. ms. nonv. acq. latines 1828).

Ie volume, fortenent endommagé prar le feu, apparienait in .11. Georges Villers, à Bayeux, qui l'avait acquis en 1844 et à la mort de qui ( $1: 101)$ i] ist entré dans les collections de la Bibliothique nationale. Il ast 
incouplet den fi:. :-12 at !3-108. la tahle qui occup* les premiers

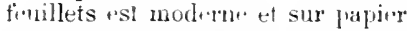

(if. (i. Hermant, Histoire du diocèse de Bayeux 170. ); - et: Le livr: rouge de l'érèque de Bayeux, par Eug. Anquetil (Bulletin de

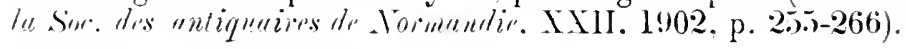

Bayeux. - Hilm-I)iru.

369. - Framment le cartulaire de l*Hòlel-Dieu de Bayenx: ms. du

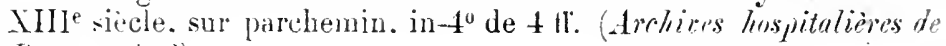
Bin!ly, $(: 3)$.

Bayeux. - Ticmmti.

$: 370$. - « Livre pelu vde Bayeux : ms. du XIVe siecle, sur parchemin, in-fulio de 97 il. Billioth. He la rille dr Buyeux, ms. 3).

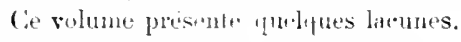

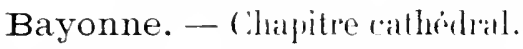

:37. _ Cartulaire dı Chapitre de Ste-Marie de Bayonne ou « Livre $\mathrm{d}^{\circ} \mathrm{O}^{\circ} \%$ : ms. des XIII"-AIV" sireles, contenant 142 documents du Ie siecle à 1:310, sur parchemin. in-to de $101 \mathrm{fl}$. (declires dép. des linswex-Pyrentex. G ist.

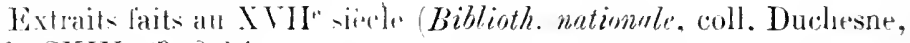
ง. CIIV, ff. 2-14).

Copie modern" par Dnlaurens. in-4" de 118 tf. (Biblinth. de la cille de Buymitir. nis. 2:3).

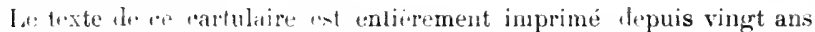
au moin, parr les suins de M. l'abbé l. Bidatehe (in- $8^{0}$ ). ll doit teujour. itre livré an public avec une introduction de Yl. labbe Dubarat, mais on iunor à yuclte diste. Lablvi lidache a jublié antérieurentent : Le livre d'or de baygune, smminire des pièces (Pau, 1894, in-16i).

Bayonne. - Abbaye dr Siliul-liernand de besbedet.

372. - Lartulaire de labbaye de Saint-Bernard de Bayonne; ms. du

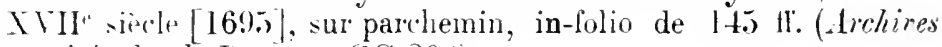

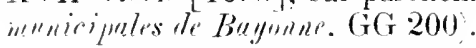

Halese extrènes : 1261-16901.

Bayonne. - Compril des Cammes.

373. - Bullarre des Carmes de Bayonne; ms. du X Ve siecle, contenant des act de $1288-1477$, sur parchemin, in-40 de :32 11. ! lrohioes drp. dis Busses-Pyrifes. $\mathrm{H} 25$.

Bayonne. - Ville.

374. - Livre des établissements de la ville de Bayonne ; ms. daté de 1:3:36, avec additions jusqu'au XVIlle siccle, sur parchemin, in-folio de 384 p. (Archires municipales de Bayonne, AA 1).

Publ. : Archises de la ville de Bayonne; Livre des établissements. Bayonne. Lamaignire, I $89^{\circ} 2$; in $-4^{\circ}$ de [IV-]LII-J 46 p. et pl. 


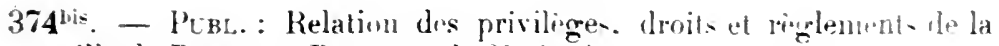
ville de Bayome. Bayoune, lasl, in- 8 ".

Beaubec. - . Mbbalre diec. de Rourn.

37.). - Cartulaire el censier de Vabhaye do Beaubec an diocise le

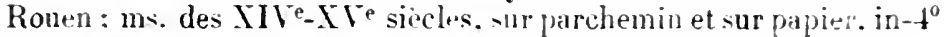

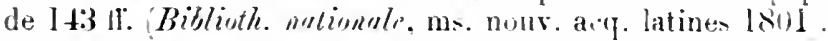

Beaucaire. - Ville.

376. - Recneil de titres relatifs i la ville de Beaucaire. frin au XVIIle siecle (Archices dép. He l'Héruull. Ponds Dom Pacotte. sirie A).

Beauchamp-en-Argonne. - Prieuré line. do Virdun.

377. - Cartulaire du prienré de Beanchamp en Argonne: ms. redigé en 1468. contenant des documents à partir de 12.2. in $4^{\prime}$ sur parchemin de 32 $\mathrm{nl}$. Archices du chatemu de Chantilly, n" I10\%" .

Beaugency. - Lbbaye de Vutro-Dame dinc. d'orlians.

378. - Cartulaire de l'ahliave de Beaugency : ms. du XIV -irele. sur

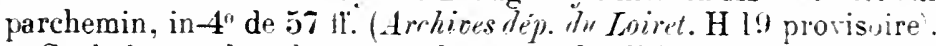

Copie incomplète du mème. dans un urdre diflérent. fait. enl lig81). sur papier. in-folio (.lirhiers dép. d" Lınir\%. $\mathrm{H}$ non coté).

Publ. : Cartulaire et histoire de liabbaye de Cotre-Iname de

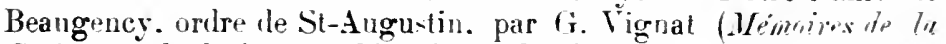

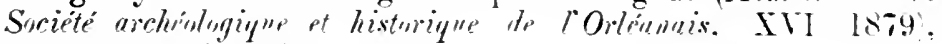
p. VII-LXVII of 1-204).

Contient 173 actors ith antees 1126 it 1316 .

Beaujeu. - Église collégiale dioc. dr Màcon .

379. - Cartulaire de l'église X.-D. de Beanjeu : ms. [incomplet] du

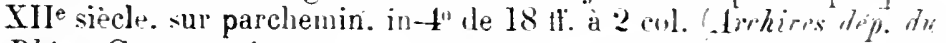
Rhine. G nou coté.

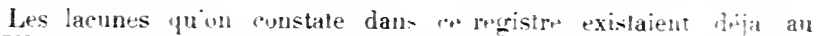

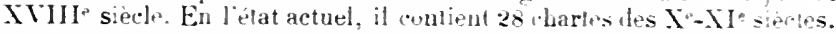

Pcrl. : Cartnlaire de l'église collégiale de X.-D. de Beaujeu, par II.-C. Guigue. Lyon, Brun, 1864 : in-40 de $64 p$.

Beaujeu. - Hôpital.

$379^{\text {bis }}$ - Recueil de copies des titres de l’hòpital de Beaujell : us. du XliII siecle. sur papier. contenant des actes de 1578 a 1737 . in- $4^{\prime \prime}$

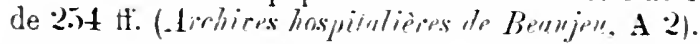

Beaulieu. - Ablaye dior. dr Boulogme-sur-Mer. - Vir. Botlonsals.

Beaulieu. - Abbayo de Saint-Pierre dioc. dr Limnger. 380. - Cartulaire de hablaye le Beanlien: mi du XIII" -ircle

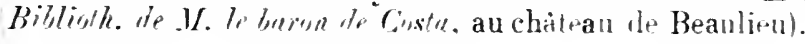




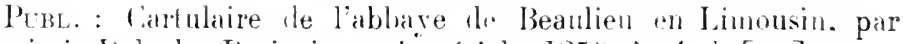
Maximin De]oche. Pari- inpre intpériale, 185!) : in-4" (le [r-] cacix-

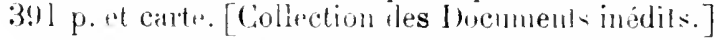

Cf. Observalion -ur la géographie thisture de (0uerey ef du Limousin is propos de la p lilication du cartulaire de Beanlieu, par

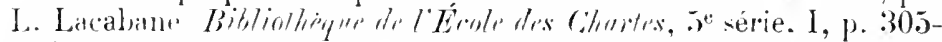
333. et 11. 1.97-122) : el : Des divisions territorialt's du Quercy anx IX". Xen XIe sircles, par Naximin Daloche: P'aris, Bertrand,

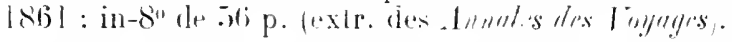

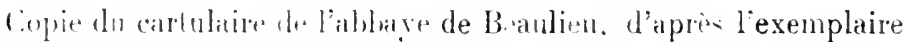

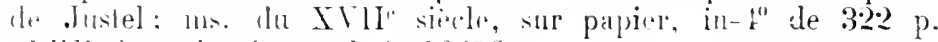

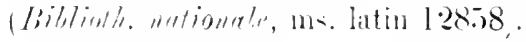

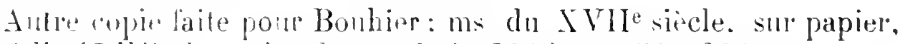

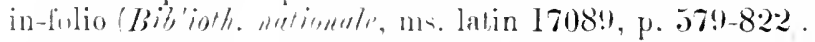

Extrats litils an XVlI" jèclo "x exemplari recenti at vitiosis-

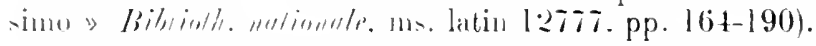

Exlraite hait aux XVIle et XVIHe siecles (Biblinth. de la rille de

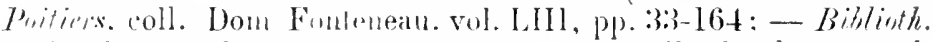

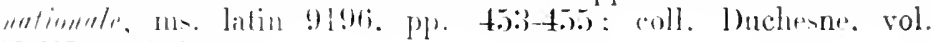
XXII. 11. $3: 1-3 ; 2(0)$.

Beaulieu. - Abray dr Nolm-1)ame, an Mams dise du Hans.

381 . - Rencueil de pieces relatives a labbave de Yotre-Dame de Brialulien-lez-Je Mans: nus. formé au XVIIe siècle par Gaigniores

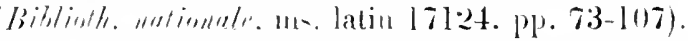

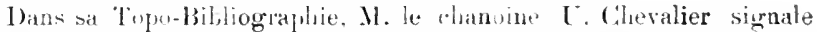
loxistence t'un cartulaire origrinal de celte ablaye dans une collection

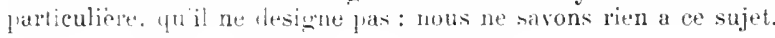

Beaulieu. - Mhary dime. dr Twoms.

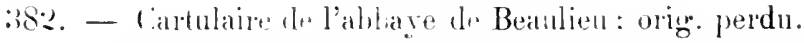

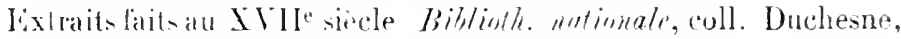

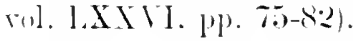

l'tro. : Charles de Beanlieu Aube), par l'abbe Ch. Lalore, dans

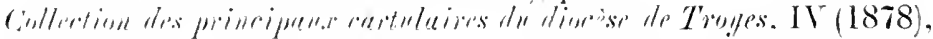
p. $272-2 !) 7$.

38 pine- on andly sur corrsplondant aux années 11 1:-1297.

Beaulieu. - Hospilalières de saint-Jean-rle-Jérusalen dioc. d. Cahors.

383. - Recueil de litres relalifs anx Hospitalières de Saint-Antuine de. Brauliru ; mi. du XVII siecle. contenant des documents de 1250 a L601 (Bijliwh. matimele, coll. Doat, vol. 123, ff. 190-3988). 
Beaulieu. - Priruré do Notro-Danre, à Angumlime.

384. - Recueil de titres relatifs au prieure de X.-D. Ir Beanliea : copies du XVIII siecte [1769)], par I) yn (Col, intlilin (Bihlintl. untiosule. ms. latin 9193, pages 450 a 50.3$)$.

Documents it partir le tos?.

Beaulieu. - Prieuré à Prianx (dioc. de linnen.

38.). - Cartulaire du prieuré de Beaulieu; rrig. perdu.

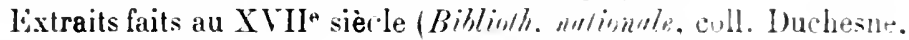
vol. XXIl, ff. :3:21-:3:(i; - ms. français 9.910). p. 84).

Beaulieu-en-Argonne. - Abhaye dime dr Trombur .

386. - Cartulaire du chambrier de l'abhaye le B ralieu-en-Argonne: ms du $X V^{e}$ siècle [1411], perdu.

Extrails faits en $17+1$ par Jean Mathieu. lieutenant particulier au bailliage de Sainte-Menehonld, pour les Binediclin (Biblinth.

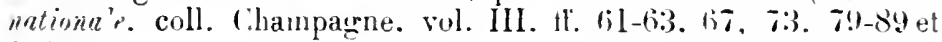
I02.

Charles du XIII sierle.

Beaumont-de-Lomagne. - Villı.

387. - Cartulaire municipal de Beaunont-de-Lomarne: m. du XIVe siecle, avec addition postérieures, sur parhemin, couvert d'une reliure en ais de bois. in $-8^{0}$ te $5 \mathrm{tt}$. en 8 cahiers 1 whires

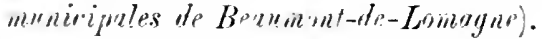

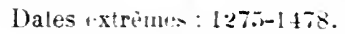

Publ. : Le livre juratoire de Beaumont-de-Lomagn : cartulaire d'une Bastide de Gascogne. par C. Balinet le Rencogne et Fr.

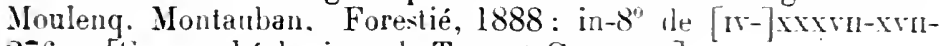
276 p. [Soc. archéologiqur de Tarn-el-Garonne.]

Beaumont-le-Roger. - Prieuré dinc. d'Érrax.

388. - Cartulaire de la Trinité de Beaumont-le-Rogrer: ms. du XIV

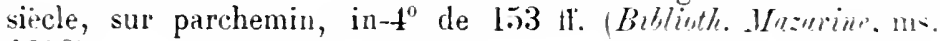
$1212)$.

Copie moderne [1874] du précédent: nus. de $1333 \mathrm{tr}$. Biblimth. nutivinule, ms. nour. acq. latines I25i.

Copie du mème, faite au XVIII siecle. sur papier. in-t" de 361$\}$

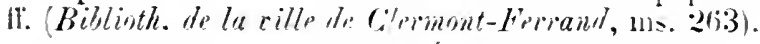

P'cbl. : Sous presse, par MI. Étienne Deville.

Beaumont-lez-Tours. Ibbaye ilime de Timm.

389. - Ptro. : tartulaire des Bénédictines de Braunont-lir-Tour 
(10!0-12!4), publ. par A. Fl[eurat]. Mennil. impr. Firmin-Didot, 1898 : in-8 de 44 p.

Recuril lactice.

390. - Cirtulaire de l'abbaye de Beinmont-lez-Tours : orig. perdu.

Extraits du précedent (Biblinth. nationtels. coll. Dom Honssean, vol. XiI, : intres 'mem, ms. latin I:3817, 1f. 291-292).

Beaumont-lez-Valence. - Primure.

391. - Curtulaire du prienré de Beammont-le\%-Valence : ms, du XVI siecte [1556]. conteniant des documents des annces 1166 it 1538 ,

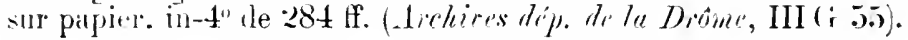

Beaumont-sur-Oise. - Mrieurid de Saint-Limor dioc. de linamvais.

392. - Cartulaire du prieuré de Beamont-sur-Oise, liependant de

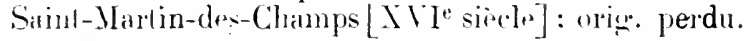

Copie collationnie du précédent: ms. du XVIII siecle, sur papier, in-4" de 25) 11. Biblintle. nationale, m: latin 9974.

Dat's exlrềm:s : $11111-12 ! 13$.

Extraits faits au XVII" siecle Bibliotle, wetionnle, coll. Duchesne, vol. LX, II. l-I(1).

Beaune. - Chappitar do Nolre-binns dior. d'Anlun.

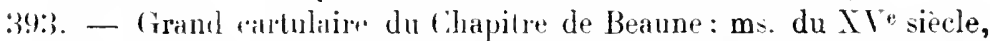
ivec addiliens jurquan $\left.\mathrm{XVII}^{\circ} 1187-16+1\right)$ sur parchemin, in- $4^{\circ} \mathrm{de}$

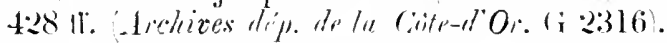

Beaune. - Commintmlonir.

394. - Cintulaire de la Commanderie de Braune: ms. date de 1490, avec additions junquau XVII" siecte, contentant des pirces des années 1:342-161:3, sur pipier. in-4" de 19 1\%. (Archices trip. de la Crilrad Or, H non cuté,

Beaune. - Courent dis Chirtroux de Fontenar.

395. - Cartulair des Chartreux de Beamn: ms. des Are-XVIJe iecles. contrnant 15.00 acles des années $1: 320$ à 1630 . en 5 vol. in-

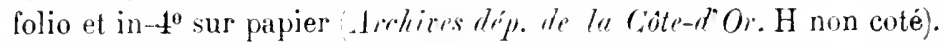
396 . - Antre cartulaire du XVII" siecle. contenant les actes des annces 1650-1713, sur papier, in-folio de $177 \mathrm{ll}$. (1)chiress dép. de la Cirte-d"Oi. H non coté.

Beaune. - Hòtel-bien.

:397. - Punc. : Prtit cartulair d. l'Hotel-Dien de Beanne, publ. par l'alıbé.J.-B. Boudrot. Beaune, Balault-Mırot. 1880 : in-4t" de vi(ii p. 
398. - Recueil de pièces relatives a lhopital de Beame: ms. du XVII" siecle. sur papier, in-folio Biblivth. natimalo. His. latin 13822 , pp. $385-4: 37$ ).

399. - Cartulaire de l'Hôtel-Dieu do Beanne: ms. du Xlil" sircle. sur papier, contenant des documents à partir de la fondation en

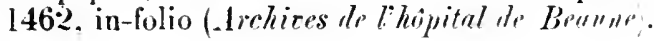

Beaune. - Ville.

400. - Cartulaire de la ville de Beaune: ms. de la fin du $8 \mathrm{~J}^{\circ}$-jecle,

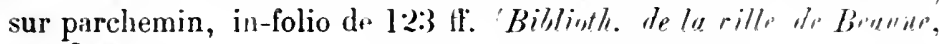
ms. 24 .

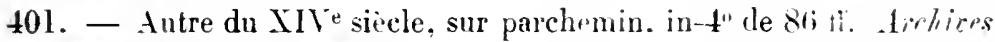
municipales de Beanne).

402. - Autre cartulaire, exécuté en 1457. sur parchemin. in-folio de 50 il. (Archices municipules de Brunile;.

40:3. - Autres fragments de cartulaires municipaux. sur parchemin, du XIVe siècle. in $4^{\circ}$ de 11 ff. [13 chartes] et de l:2 ti." [8 chartes], Ie dernier en fort mauvais état Arhives un ucipales de Benne.

404. - Recueil des privilèges de lit ville de Beaune: m.. du XVII siècle, sur papier, in-folio Biblioth. de lo rille de Tirings. ms. 204).

Beauport. - Lbbayr dioc. de Saint-Brienc.

405. - Publ. Anciens évèchés de Bretagne: diocèse le Siuint-

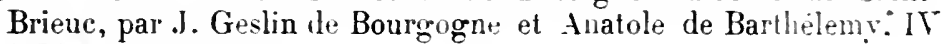
(1864), p. 45-2:21.

Recueil factice de $3: 15$ chartm, is plupart du XlIJ" sinele.

Beaupré. - Abbaye dioc. de Beaurais.

406. - Cartulaire de l'abbaye de Beaupré: ms. du XIII siè are. arec additions jusqu'au XIIII', incomplet. in-folio de 142 ti. Bithlioth. nationule. ms. latin 9973).

Axal. : Notices et extraits des documents manuscrits relatifs à lhistoire tle la Picardie, par J. Cocheris, I. n" lót.

407. - Autre cartulaire de l'abbaye de Beaupré : orig. perdu.

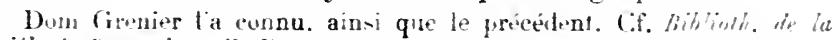

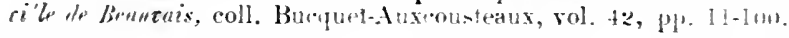

Beaupré, prís de Grammont. - Abbare dioc. de Valinis.

408. - Cartulaire de l'abbaye de Bialupé : ms. du XVI sitcle. sur papier. contenant des titres de 1214 à 1504 , in-t". If. :36-187 (Archiors de l"État is Gumd).

Beaupré. - Abbaye dioc. lo Tıul. 409. - Cartulaire de l'ahbaye de Beanpré; $m$. de la tin lu SIIe 
siecte. incomplet des 19. 1-9 et 19-7\%, sur parchemin, in- 4 "de 332 แ1. Bithlinth. metivinale, ms. lalin 11024 .

Beaupré. - Prieurar. - Voy. Le Thlobs-lihodx.

Beaurain. - Prieuré dioc. de Thromanne.

410. - Pubr. : lissai sur les prieurés de Beaurain et de Maintenay et

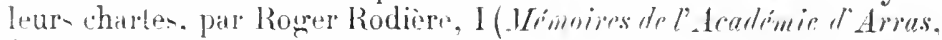
2" série. XXXl1. p. 235-390), et ì parl: Arras. 190:3: in-80 de 158

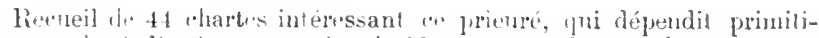
vement is st-13ertin, et ensuite de Marmoutier, d'apres des originaux

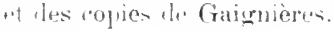

Beaurain. - Villates.

411. - Cartulaire de Beaturain, dep' de l'abbare de Saint-Denis; ms.

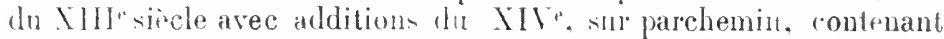
de- actes de 769 à 1:303, in-t" de 71 pares (Amhires natimales, L.L. 1168 .

Beaurieux. - Villane près de Solre-le-Chaitoau.

412. - Prit. : Documents concernant Solre-le-Chàtean et Beaurieux,

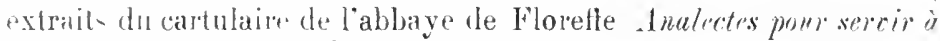

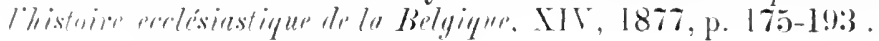

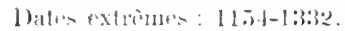

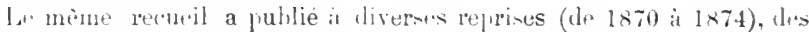

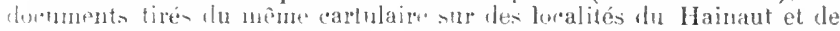

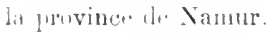

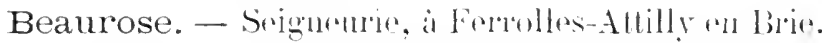

413. - Camblaire du fiel do Bararone. dép' de lahlaye de SaintVictor de Paris: m. du XII" siecle, sur parchemin, in-4" de It If. (.1\%lires matimales. S 2142. 11"4.

A.ten de 11 in is letil.

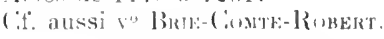

Beauvais. - . Mbarr do Saint-Lucirn.

414. - Camblaire de Saint-Lucien de Beauvais; orig. perdu.

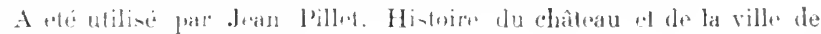

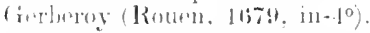

415. - Rerueil de chartes relatives is l'ahbaye de St-hucien de Beanvais: ms. du XVI sircle, sur papier. in-12 (Biblinth. de l'Iustitut. it Paris, ms. 437.

Beauvais. - Abbaye do Saint-Quentin.

416. - Cartulaire de St-Quentin de Beaurais: ms. des XII-XIVe sircles, sur parchemin. in-folio de $2: 31$ tr. (Biblioth. Ciheltenhum, $n^{\prime \prime} 74(0)$. 
Extraits faits par Rohert de livries Biblinth. nutimule, roll.

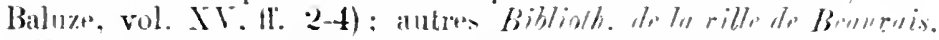

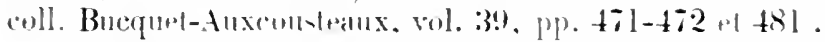

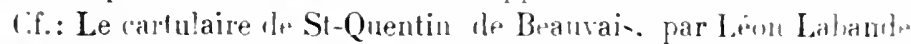

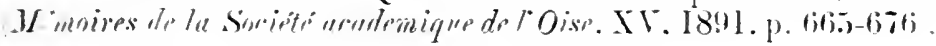

Beauvais. - Chapiter cathedral saint-Pierrer.

4li. - Premier cartulaire du Chapitre do Benurais Eomrètait à l'année 1227] : orig. perdu.

418. - Denxième cartulaire du Chapitre, on « Livre des privilinges.. écrit vers 1230: orign. perilu.

Prbl. : Lihertates, immunilates el privituria insinni, ecrolesiæe "athedralis Belloracensis. Parisiis, 16ilt. in-4".

419. - Troisieme cartulaire du Chapitr. sur papier : origr. perila (1 .

420. - Quatrième cartulaire [- arrètait rers 141:3] on « rar:ulaire le: accords s, comptant 147 tl.: oripr. pertu.

Des copies et extraits de ces ditlérents artulaires exi-tent rnore:

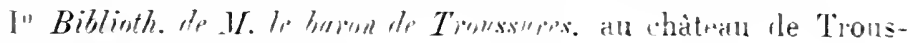
sures (Oise). reg. $V^{-2} 2^{16}$ :

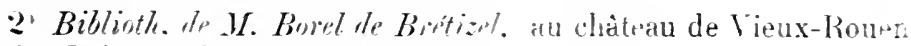
(Seine-Inlérieure), carton XIII :

:3" Biblinth. He la rille te Brencais. coll. Burquet-tuxcouteanx, vol. :31 :

$4^{0}$ Biblintl. untionnle. coll. Morean. rol. 206t. jo 32, etu. :

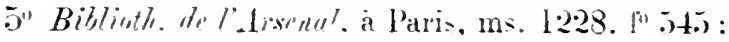

$6^{\circ}$ Biblintle. mutiomult. coll. Hom Grenier. vol. CXI :

I" Biblinth. mitumle. voll. Duchesne, vol. XXII, II. :249-250.

421. - Fragment d'un cartulaire de la catheilrale de Beanvais: m. érrit vers 1160-11\%, sur parchemin. in-1" de $14 \mathrm{tl}$. Billinth. untionule, ms. nouv. alcquis. latines 16.0(i).

Prorient des rentes Le Ver bertier.

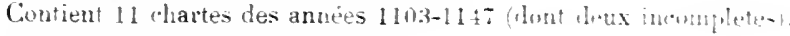

Beauvais. - Everhi.

422. - Cartulaire du trésor de l'évéché de Beaurais: ms. de XVIXrmle siecles, sur papier. in-folio de $178 \mathrm{tl}$. Biblinth. An tribuml ciril lo Beauruis).

Dates atrènes : 1590-1:1:3

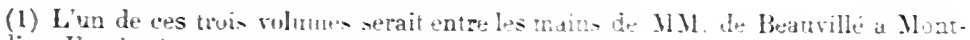

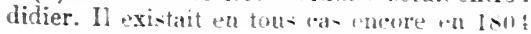


Beauvais. - Hölel-Ilinu.

42:3. - Fratrment d'un cartuliare do l'Hotel-1)ieu de Beanvar: ms.

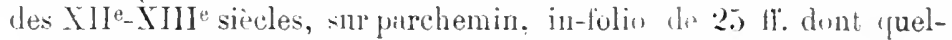

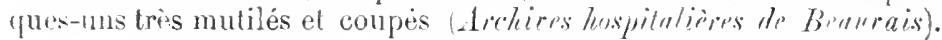

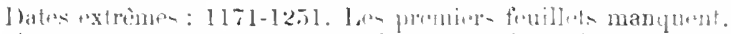

(at registre precienx, volé autrefoin aux arehives hospitalier malgré

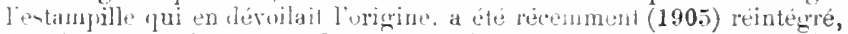

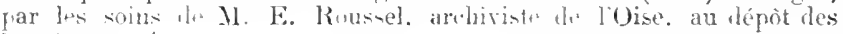
hospleess.

424. - Antre camblaire: ms. du XYI siele[1677], sur parchemin. contenint des avfer depuis le $\mathrm{XII}^{\mathrm{e}}$ siecle. in-folio de $338 \mathrm{tl}$.

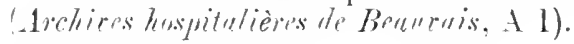

Beauvais. - Ville.

425. - Cartulaire municipal de Bennvais, dit «Lirre in cinq clons». ms. du XIVe siecle, sur parchemin, avec reliure de hois. in-folic à

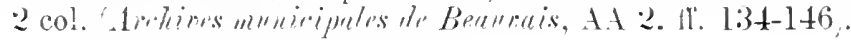

1)ate's extrines: $11: 2: 2-130: 3$.

426. - - Autre cartulair du XVI siècle. sur parchemin, contenant des

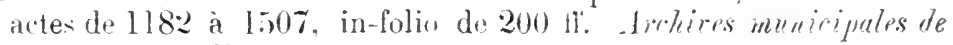
Brmerais, A 1 ).

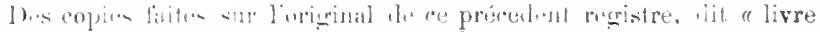

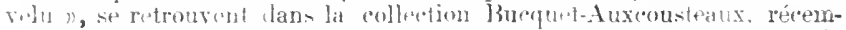

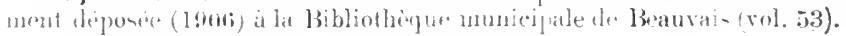

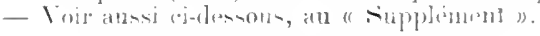

Beauval. - Seigmurir Picartir.

427. - Carlulaire de la terre de Beamal, priss de boullens: orig. perdin.

lixtraits linits an XVI" siecle (Biblioth. untionule, coll. Baluze, vol. LI. p. $: 345$.

Beauvoir. - Mbaly dion. le Bompes.

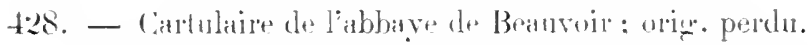

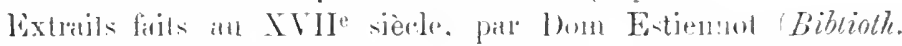
malionale. ma. latin 1:27+2, pp. 510-51!9.

Beauvoir. - Commanterir de l'Omlre Teutniture dioc. de Trovis.

429. - I'tru. : Chartes de Beauvoir, chef-lieu de lordre Teutunique en France. par l'abbé Ch. Lalore, dans Collertion des mincimun cartulaives dir dincèse de Troyges, III (1878), p. 177-328.

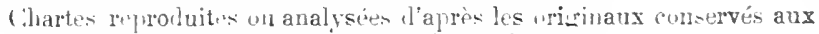

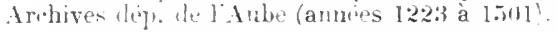

Bécheron. - Voy. La Mera-1)mis. 
Belchamp. - Hbatr dinc. dr Toul.

430. - Fragment dun cartulaire de labbaye des danoines réguliers de Belchamp: ins. du $\mathrm{XVI}^{\mathrm{e}}$ siècle. sur papier, in-folio de $27 \mathrm{HT}$.

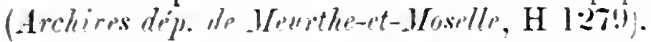

4:31. - Recueil de titres relatifs in l'ahlare do Belchamp: ms. du

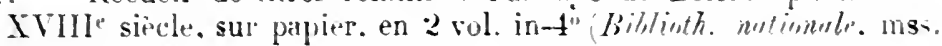
latins 10013-10014.

Belhomer. - Voy. Buors (abbate saint-Lanmer.

Bellème. - Eglise collegiale siant-Lemard (dioc. de síes). 432. - Recueil de titres relalifs is St-Lfonart de Bellème, fait par Dallier au XIX" sircle. sur papier (Biblinll. de lor rille de Vogent(e-Rotiml. ms. 9).

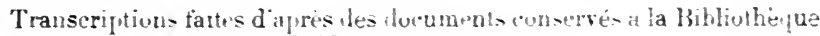
nationale (coll. Duruy) (if. Vifis-Betriuk.

Belleperche. - Abbayo dinc. de Montauban .

4:33. - Recueil de titres relatifs a liabaye de Belleperche: ms. de 1668-1669. contenant des acter des annés's $1164-1557$, en 2 vol. infolio de 307 et $447 \mathrm{ll}$. (Billinth. nutimuln, coll. Doat. vol. 91-92).

Bellevaux. - Abbaye dioc. dr besançon .

4:34. - Grand cartulaire de l'abbaye de Bellevaux: ms. du. MIII siècle avec additions postérieures. sur parchemin. in-folio de l.jult..

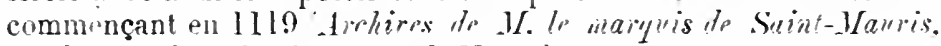
an chàteau de Colombier près. de Vesoul .

Copie faite au XVII' siecle (Billinth. antimat", coll. Morean. vol. 870 , ff. 8!!-684, el rol. 871).

Antre copie faite an XVIII siecte. sur papier. en 2 wol. in- $4^{\prime \prime}$ de 448 et $358 \mathrm{HI}$. (Billirith. de la rille dr Besuncine. coll Droz. mas. 44 et 45 ).

435. - Petit carlulaire de l'abbaye de Bellevaux : ms. du XII" siecle,

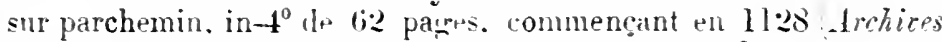

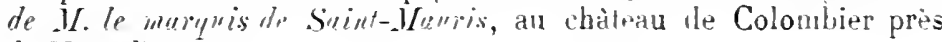
de Vinoul).

Le pertit cartulairm est miendx concervé que le grant.

Belley. - Catlimlral. Saint-Jain.

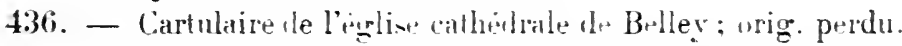

Extraits du précérlent. fats par Dom Estiensot an XVII siecle (Biblioth. matirnde. ms. latin 12768. p. 116-126).

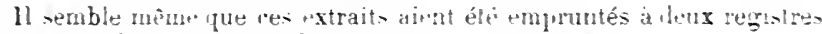
ditférents, dont lun esl indiguce cmmen "retustus".

Belley. - Cunrmit des Comleliers.

437. - Cartulare des tordelier de Belley: ms. date de lithi. sur 
papier, contenant des artes le 1448 i 1716 . in-folio de 4: 17 .

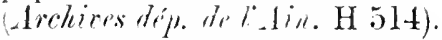

Belval. - Ibhay diuc. de Reins).

438. - Cartulaile de liabbave de Belval: ms. Iu XVIII siecle [vers $1735]$. sn papier, contenant $22: 3$ pieces de $11: 3: 3$ a 1731 , in-folio de 2(17 pages plus la tahle 'Biblioth. de M. le Dr Octare Guelliot, à Reims).

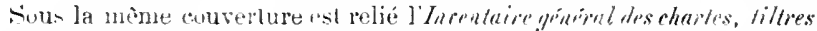

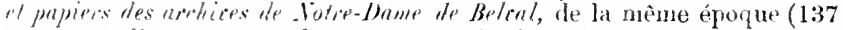
lages), indiquatit 1855 chartes et aussi (dans la $3^{e}$ layelte) "deux rartulaires "n jarchemin qui paraissent très anciens et un autre en papier" qui rst aunsi ancien n: "es registr"s ne doivent plun "xister.

Belval. - Priouré dioc. do Reims).

439. - Cinlulaire du prienré de Belval, dep' de l'ahlaye de la SauviNajenre: ms. du Ife sicele. sur parcliemin, contenant des actes de 116 !) a 1473. in-4" de l!) 11. Archines dip. de la Gironde, fonds de labbaye de la Sauva-Majelule. H is provisoire).

ProL. : dans les Arehiers historiques de la Gimonte, VIII 1866), pl. $11-26$.

Belval. - Prieurédine. de Toul).

440. - Cartulair An prieur de Belval, dep' de labbaye de Moyenmoulier: ms. du $\mathrm{X} \mathrm{V}^{\circ}$ siécle. sur papier. contenant des titres de 1240 in lótiti. in-4" de 60 tl. (Biblioth. nutionale, ms. français $5: 38: 3$.

441. - Autre cartulaire: ms. du XVII siecle, sur papier, contenant les pieces des années $11: 3$ t-1619. in-folio de 97 11. (Archives dép). de. Iruthert-Iosentr. H :31).

44:- - Autr du XVIIl" siecle. sur papier. contenant des titres des années 1175-1583, in-folio de $74 \mathrm{~m}$. (Archires dejp. de Mevrthe-etWoselle, $\mathrm{H}: 32$ ).

Belvédère. - Ville.

443. - Lirre des statuts ou cartulinire des privilizges de la commune de Belvédère, contenant des titres des années 1289 à 1715 : ms. du XVIII" siòcle, sur papier, in-4" (Archites muicipales de Beltédèr, Alpes-Naritimes.

444. - Recueil de titres relatifs à la mème commune; ms. du XVle siecle, sur papier, in-f" de vl-1l+ II. (Biblioth. de la rille de Nicr, mis. 108).

Belvoir. - Seigruenrie en Franche-Comté. 445. - Cartulaire de la -eigneurie de Belvoir ; orign. perdu. 


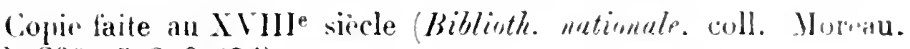
rol. 899, if. 300-374).

Autre copie de la mime époque (Biblinth. le lu cille do Besmem, coll. Droz, ins. 47. 1f. 112-159).

Benac. - Vuy. Lavedan.

Bénévent. - Abbaỵe (lioc. de limoges.

446. - Cartulaire de lahbaye de Saint-Barthéleny de Bénévent : origr. perilu.

lixhraits recupillis an XVIIe siècle par Bandel et le P'. l'nadillon, pour Gaignieres, sur papier, in-folio Biblish. netionule. mo. latin 17116, pp. 69-I30).

Copie des précédents: ms. du XIXe sièclr. par A. Bosvirux, sur

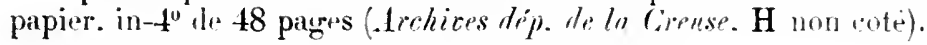

bates extrêmes: 10603 environ-.XIII sirolte.

Autres extraits du XVIII" siecle. sur papier Biblioth. nutimule. ms. nour. acqus francaises 5219, 11. 2-25).

Benoitevaux. - Abbare lioc. dr Langres.

447. - Cartulaire de l'abbaye de Benoitevallx : mi. du XVII siècle,

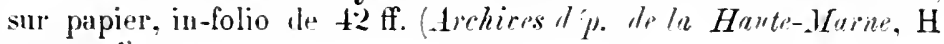
non coté).

Dates trxlrimes: 1198-16.in.

Berdoues. - Abbaye dioc. d'Auch'.

448. - Cartulaire de labibare de Berdoues: ms. dn XIIJ sjecle, sur parchemin, recouvert de hois, in-folio the $26: 3 \mathrm{tt}$, it 2 col. : arig. perdis.

\section{Dates extrêmes: 11:34-12:ix.}

Copie du précédent. litile par l'ablée de Vergès a Versailles en octobre 1779 et recollationnée en maj 1786 , in-folio sur papier (Biblioth. In Grand-S'mintive d'Auch, n" 33396"iis).

Le nième dépòt en possède une autre copie, par le mème. incomplete:

l'abbé Daignan clu s.nndat en a fait anni quelques exirits pour la "Glanage " de Larcher.

Publ.; Cartulaire de labbaye de Berdones près Mirande. parr l'abbé Cazauran. La Haye, Nijholf. 1905 : in-80 de xII-270 et 875 p. avec pl.

Bergheim. - Église (dioc. de Strasbourg).

449. - Publ. : Urkundenbuch der Pfarrei Bergheim (Ober-likass . herausg. von Eug. Hans. Strassburg. F. X. Le Roux, 18!4: in- ${ }^{\circ}$ de xII-356 p. [Archivalische Beilage des Strassburcrer Diöcesanblattes für 1893.] 
Bersheim. - Villo.

4.50. - Cirtulaire municipal de Beruhein ; ms. du XVI siècle, sur pirjir. contenant 68 chartes des années 1.257-1583, in-folio de 135

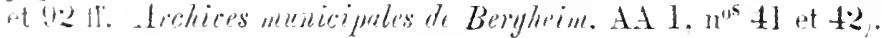

Bergues. - Ville.

451. - Registre des privilegen de la ville et rhàtellenie de Bergunes

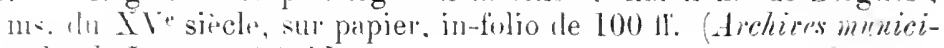
pales te Birgues, At $1 \mathrm{I}$.

45:. - Antre reneil. redigé an 1781 par Nicolas Vernimmen, sur papier. in-felio he 36.5 II. (Arheres muniripales de Bergues, Ad 8).

Bergues-Saint-Winoc. - Ablaye dioce d'Ypres.

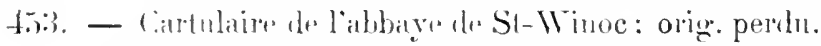

Copje du précédent: ms. du XVII" sièchr. sur papier, in-folio

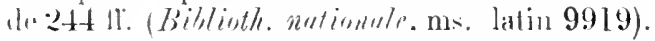

l'LBL. : Chronique et cartulaire de l'abbaye de Berones-SaintWinne, par Alex. Pruxust. S. J. Brumes. impr. de Zutlere, 18551878: : rol. in-40 dexxw-4.)6 et 88:3 p.

Bernac. - Vur. linsiconbe.

Bernardfagne. - Primuré disc le Liège).

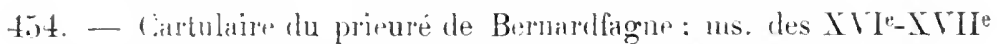

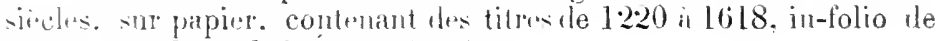

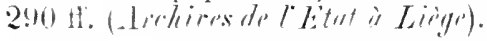

Bernes. - Commanderie dioc de Rouen).

4.5. - Cardulare des commanderies de Bernes ef de Messelan: ms. du $\mathrm{XVl}^{\circ}$ siecle. sur papier recouvert de parchemin, contenant des

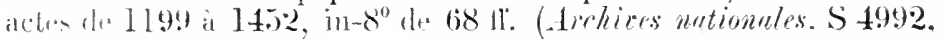
1141 .

Let's derniers feuillets sont romger par l'lumidilé.

Bertaucourt. - Mblare dior. d'Amiens.

4.ot. - Cartulaire de labbay de Notre-l)ame de Bertancourt, -

Copin presque intégrale dn précédent, faite an XrIII siècle (Biblinth. wationale, coll. D. (irenter, vol. 93, pp. 97-4l4).

Extraits (Biblinth. dr la rille d'Abberille, ms. 120, t1. 2.)-33; Biblintll. nationale, coll. Morean, vol. 99, ff. 47-48 et passim).

Il semble "[u'il y ait eu simultanénent plusieurs cartulaires de l'abbaye de liertanevurt (Biblioth. antionale, ms. latin 1266:, to 3332 ). 
Bertaud. - Abbaye de Notre-batme dioc. de (rap.

457. - PuBL. : Chartes de N. D. de Bertaul. mondstere de frmme, de l'ordre des Charlreux, par l'abbé Paul Guillaum". (Gap. Jonglard [Paris, licard], 1888: int-8 de Lvi-368 p. [Suciété il'Études dws Hantes-Alpes: Archives historiques des Hautes-Alpes. I.]

Recueil factice de chartes datée- de 1188 à $141 \%$.

Besalu. - Abbaye de Saint-Pierre dioc. de (inronat,.

458. - « Liber privilergiorum et aliorum titulorum monasterii satucti Petri ville Bisuldini " : orig. perdu.

Extraits faits an XVIIe siècle par J. Gostar. nutaire à Collioure (Archices dép. des Pyrénées-Orientales. sérir $\mathrm{H}$ ).

Besalu. - Comté.

459. - Pébl. : Colección diplonática del condato de Besalú. por Fr. Monsalvatje y Fossas. Olot. J. Bonet. 1901-1902, '2 vol. in-40 de 353 et 266 p. arec pl.

Contient 116:3 documents publiés tn entir.r un par extraits; on I

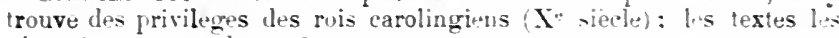
plus réénts sunt de 1180 .

Besançon. - Abbaye de Saint-Paul.

460. - Cartulaire de St-Paul de Besançon : urigr. perilu.

Extraits du précédent. faits an XVIII siècle (Billinth. nationale, coll. Moreau, vol. 868. ff. 1-18 et 59-6.5,

Copie du XVIII siècle, sur papier. contenant des titres des

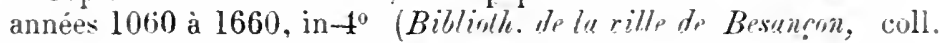
Droz, ms. 38, pp. 375 à 778 .

On trouvera (Biblinth. de la rille de kisangron, cull. Barerel. ms. 37, ff. 2-60) un table des matières. persunnes et liwux du cartulaire de labbaye de Saint-Paul. drisée au XVIIJe siercle.

Besançon. - Abbare de Saint-Tincent.

461. - Cartulaire de St-Vincent de Besançon; ms. du XVIe siecle [1535], sur papier, contenant des titres it partir de 1179 , in-folio de IV-406 ff. Archices dép. du Drubs, H 2 .

Besançon. - Archerèché.

462. - Cartulaire de l'archevèché de Besanıçon: ms. du XilI siecle, incomplet au commencement. sur parchemir. in- $t^{\prime \prime}$ de $11 t^{\prime}$ pages (Biblinglh. de lu rille de Bessuncon. ms. ilti).

Dates extrêmes: $11116-1266$.

Cupie du précédent. faite an $\mathrm{XVIII}^{\mathrm{e}}$ siecle. in-fol. de $666 \mathrm{ft}$. (Biblioth. national', coll. Moreau, rol. 86? . 
Copie moderne. faite par J. Gauthier [1897]. sur papier, in-4 ${ }^{0}$ de $141 \mathrm{Hi}$. (Archives dép. the Doubs, G 69).

Axal.: Inventaire sommaire des archives départementales du Doulus, série (r tome I (1900), pp. 25-32.

46:3. - Fxtraits d'un cartulaire de l'archevêché de Besançon, faits d'après un manuscrit appartenant à l'abbé Trouillet; ms. du XVII siecle, sur papier, in-4to de $58 \mathrm{ft}$. (Biblioth. de la ville de Salins, ms. 173 .

Besançon. - Chapitre mètropolitain.

464. - Cartulaire du Chapitre de Saint-Jean de Besançon : orig. perdu.

Copie du précédent, faite au $\mathrm{XVIII}^{\mathrm{e}}$ siècle, sur papier (Biblioth. - de la rille de Besaneran, coll. Droz, vol. XXXII).

Autre copie faite également au XVIIIe siècle, sur papier (Biblioth. nationale, coll. Moreau, vol. 866).

Extraits faits au XVIIJ siècle Biblinth. de la rille de Besancon, coll. Droz, ms. 74, fr. 1-110).

Autre recueil factice; ins. du XVIII e siècle, dû au chanoine Denizot. contenant 135 actes des années 1085-1775, sur papier, in-folio (Archices dép. du Douls, ( 175 ).

Publ. : Documenis inédits pub]. par l'Académie de Besançon, IX [sous presse].

465. - Recueil des privilèges de l'église de Besançon; ms. du XVII siècle, sur papier, in-40 de 244 tf. (Biblioth. nationale, ms. nour. acr. latines 201 j.

Besançon. - Confririe Saint-Antoine et Saint-Éloi.

466. - Cartulaire de la confrérie St-Antoine et St-Éloi de Besançon; ms. du XIVe siècle. sur parchemin, contenant 214 actes de 1243 à 1:361, in-40 (Bibliolh. de la ville de Besancon, ms. 718, il. 41-191).

Copie du précedent; uns. du XVIII siècle, sur papier, in-folio (Biblinth. nationale. coll. Moreau, vol. 864, ff. 535-801).

Besançon. - Église collégiale de La Madeleine.

467. - Fragment d'un cartulaire de la Madeleine de Besançon ; ms. du XIII siècle. sur parchemin, in-folio de 64 pages (Biblioth. Cheltenhum, $\mathrm{n}^{0}$ 7405).

Extraits faits au XVIII siècle, par. Dom Berthod, "ex antiquo cartulario canonicorum B. M. Magdalene» (Biblioth. de la ville de Besancon, ms. 1107. If. 30-32).

468. --. Autre cartulaire de la Nadeleine de Besançon; ms. du XIVe siecle, sur parchemin, avec reliure en bois du XVe, contenant des 
actes de 1073 à 1:288, incomplet, in-4" de $113 \mathrm{HF}$ a a 2 col. (Biblioth. de la rille de Bes neon. mis. 7:26).

Les eopies qui suivent on ete exécutér alon que loripinal itait danson inlegralité.

Copie du précédent, faite au XVII siècle (Biblioth. nutionale. coll. Morean, vol. 876 , ff. $2-419$.

Copie du mème, faite au $\mathrm{XVIII}{ }^{\mathrm{e}}$ siècle, in-40 de $4: 27 \mathrm{ff}$. (Biblinth. de la rille de Besanron, coll. Droz, vol. 40).

Copie moderne, sur papier, in-folio de $141 \mathrm{fr}$. (Archices dép. dn Doubs, (i 69).

Besançon.-Ėglise Saint-Étienne. Voy. Chap. métropolitain.

Besançon. - Hòpital du Saint-Esirrit.

469. - Cartulaire de l'hòpital du Saint-Esprit de Besanৎon : ms. du XVIII ${ }^{e}$ siècle, sur papier, rédigé à Rome, contenant des titres de 1208 i 1682 , in $4^{0}$ de $216 \mathrm{fr}$. Arckices hospitalières do Besaupron. C 2).

470. - Autre recueil sur papier. contenant des titres de 1483 a 1707. en 3 vol. in-folio de 278,50 et $486 \mathrm{ff}$. (Archices hospitalipirs de Besanron, D 1).

Besançon. - Hôpital saint-Jacụues.

471. - Recueil d’actes concernant l'hòpital Saint-Jacques de Besancon : ins. du $\mathrm{XVII}^{\mathrm{e}}$ siècle. sur papier, contenant des titres de 1604 à 1690 . in-folio de $79 \mathrm{fr}$. (Archices hospitulières de Besanron, At 10.

Bessancourt. - Voy. Maubuissos.

Béthune. - Confrérie des charitables de Saint-Éloi 'linc. d'Arras).

472. - Cartulaire de la confrérie des Charitables de Bétliune : m.. des $\mathrm{XV}^{\mathrm{e}}-\mathrm{XVIII}$ e siècles, sur parchemin, in-4 de v-163-rv fi. (Archives dép. du Pas-de-Calais, E non coté).

Dates extrêmes: 1289-1749.

Béthune. - Église collégiale de Saint-Barthélemy.

473. - Cartulaire ou Livre rouge de Saint-Barthélemy de Béthune : ms. des XIIIe et XVII' ${ }^{e}$ siecles, sur parchemin et papier, contenant 146 titres de 1152 a 1454 . in-folio de $132 \mathrm{Hf}$. (Archices dép. thr Pusde-Calais, $\mathrm{G}$ non coté).

Publ. : Le cartulaire de Saint-Barthélemy de Béthune, publié ou analysé avec extraits textuels, par le $\mathrm{C}^{\text {te }} \mathrm{A}$. de Loisne. Saint-Omer. impr. d'Homont, 1895; in- $4^{\circ}$ de [N]-xxr-108 p. [Socićté des Antiquaires de la Morinie.] 
Béthune. - Ville.

474. - Recueil des privilèges de la ville de Béthune; ins. du XVI siecle. sur parchemin, in-4" de $34 \mathrm{ll}$. (Archices municipales de Bétlenis, At 4 .

Dates extrêmes: l:10-151ti.

475. - Autre recueil; ıns. du XVII siècle, sur papier, in-folio de 45:211. Archires muniripules de Bethune, At 5.

Betz-en-Valois. - Srigneurir.

476. - Recueil de titres concernant la seigneurie de Betz; ms. du XVe siecle, sur papier. contenant des actes de 1296 a 1479, in-folio Biblinth. uationule, ms. français 5493, II. l-5̆l).

Bèze. - Abbay ye de Saint-Pierre (dioc. do Langres).

47\%. - " Liber memorabilinn rerum seu etiam cartarum abluatiae Besensis : : ms. du XIJe siècle. dû au moine Jean, sur parchemin, in- $t^{\circ}$ de $170 \mathrm{ll}$. (Biblinth. nutionale, ms. latin 4997).

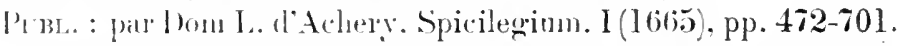

478. - Cartulaire-chronique de l'abbaye de Saint-Pierre de Bèze; us. du XVIII siècle, contenant $\$ 78$ actes á partir du XIIe siècle, sup papier, en 3 rol. in-folio (1ichires dép. de la Cóte-d'Or, $\mathrm{H}^{3} \mathrm{l}: 30$ ).

479. - Antre cartulaire dı XVIII e siecle, contenant 30 documents de 1217 i 1700, sur papier. in-to de $104 \mathrm{tr}$. (1rchices dép. de la Côte$\pi^{\circ} \mathrm{O}, \mathrm{H}^{3} \mathrm{I}: 3 \mathrm{l}$.

480. - Antre cartulaire des XVII ${ }^{\mathrm{e}} \mathrm{XVIII}{ }^{\mathrm{e}}$ siecles, contenant 180 documents des années I:350-17:27, sur papier, in-40 ${ }^{\circ}$ le $280 \mathrm{fl}$. (Archives

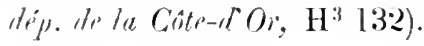

Bèze. - Villı.

481. - Cartulaire municipal de Bèze; ms. écrit en 1481, sur papier, contenant des documents it partir de 12:21, in-4 $4^{\circ}$ (Archices dép. de lic Citte-r Or. L: 29975.

Béziers. - Chapitre cathédral.

482. - Livre noir ou cartulaire du Chapitre cathédral de Béziers; copie laite en I7il, sur papier, in-40 de $344 \mathrm{ll}$. (Archires dép. de Fllivell, G non coti).

l'orignal, sans donte disparu anjourd'hui, se trouvait ì Haguenau lursipue la présente copie fut faite.

Béziers. - Eglise Saint-Nazaire.

48:3. - Cartulaire de Saint-Nazaire de Béziers; ms. du XIVe siècle, un peu mutilé et incomplet du début, contenant 150 actes des années 
I148-1318, sur parchemin, in- $4^{0}$ te 180 II. (Archires thip. the thérunlt. G non coté).

484. - Recueil de titres relatifs ì lévèché et an ( hapitre St-Nazaire de Béziers; ms. de I667-1669, contenant des locuments des aunéps 878 a 1616 . en 3 rol. in-folio de 350, 382 et $401 \mathrm{ll}$. (Biblinth. untionulp. coll. Doat, vol. 61-63).

Béziers. - Tille et courents.

485. - Recueil de documents relatis à la ville et aux courents de Béziers; ms. du XVII siècle, sur papier, in-folio de $460 \mathrm{ll}$. (Billinth. nationale, coll. Doat, vol. 60?.

Axal. : Cabinet historique, XVI (1870). pp. 1:3-31.

Biella. - Ville.

486. - "Privilegia civitatis Bugellae»: ms. du XliIJ" siecle. sur papier. contenant des documents de 1379-1420, in-folio 'Biblioth. de l' Unicersité de Twrin.

Nous ne saurions dire si ce rolume a dispraru lans linc\%n lie la ia bibliothèque.

Bielle. - Toy. Ossad (Vallér d';

Bierbeek. - Egtise.

487. - Fragment d'un cartulaire de l'église de Bierbek en Bralsant;

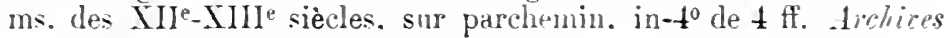
du royurime de Belgique, à Bruxelles.

Bigorre. - Comte.

488. - Cartulaire du comté de Bigorre. particulièrement relatif aux prètentions de Jacques de Vendo̊me, vidame de Chartres; ms. du XIVe siecle. sur papier, contenant des documents des année- 12281347 , in-folio de 145 17. (Archices dép. d Eure-et-Loir. E 163).

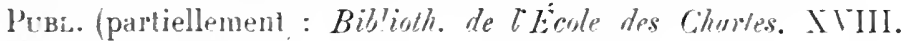
185\%. pp. $314-324$.

En autre Cartulaire de Birorre, ms. de la fin du XIII -iècle (Bibliolh. de la cille de Bordemin, ms. T4i) tol dont il exi-te deux copies

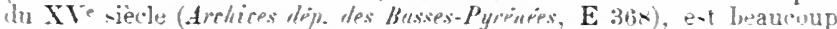
plutòt un censier el nous ne lindiquons que pour mémvire. M. (i. Balencie en prepare Ia publication pour la ciociélé des Arclives histaripues de Gascogne.

489. - Recueil de titres extraits d'un Cartulaire de Bigorre «estant en la Chambre des Comptes de Paris », en I642 (Biblivth. unlionuls. coll. Duchesne, vol. CIII. ff. 187-196.

Billettes. - Voy. Paris ' Carmes de et Boucheralinoxt.

Binche. - (hapitre de Saint-Lrimer (dioc. de Cambrai).

490. - Cartulair du Chapitre de Si-Crsmer de Binche : ms. du XVille siècle [17.99], sur papier. contenant des actes de 97.2 à 17.54 . in-fulio de 180 paces (Archices de l'Etut ì lonis's. 
Binche. - Hôpital saint-Jacques.

491. - Cartulaire de l'hòpital Saint-Jacques de Binche; ms. du XVI iècle, sur parchemin, contenant des actes de 1450 à 1596 . in $-4^{0}$ de 119 tr. et table (Archiers communales te Binche).

Bithaine. - Abbaye (dioce de Besançon.

492. - Cartulaire le labbaye de Bithaine; orig. perdu.

Copie faite an XYII ${ }^{\mathrm{e}}$ siecle (Biblioth. nationsle, coll. Moreau, vol. 872 , If. 143-304).

Blamont. - Chitellenie on Lorraine.

493. - Recueil de titres relatifs à la ville et châtellenie de Blamont; ms. lu XVII siècle, formé par Thierry Alix, sur papier, in-folio de $270 \mathrm{HF}$. (Archires dép. He Meurthr-pt-Moselle, B 346).

Dates "xtremt's: 1268-1605.

Blanchelande. - Abbaye de Promontrós dioe. de Coutancess.

494. - Grand cartnlaire de l'abbaye de Blanchelande; orig. perdu.

Extraits faits an XVIII e siecle. contenant 12 chartes des années 1154-1690 Biblioth. natimale, ms. latin 10065, It' 89-101:.

495. - Autre cartulaire le l'abbaye te Blanchelande: ms. écrit en l:27l. orig. perclu.

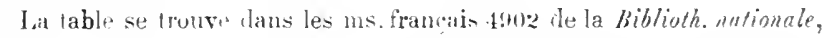
fo 2 .

Extrails faits an XVII siècle (Bibliotll. mationule, coll. Baluze, vol. LVIII, tr. 207-209?

496. - Recueil de titres relatifs a l'abbaye de Blanchelande : ms. du XVII sircle, sur papier, contenant les actes de 1154 à 1692, in-folio de $14 \mathrm{tr}$. (Arrhires dép. do ln Munche. H 830).

Cif. anssi lo $n^{\circ} \mathrm{H} 180$.

Blaye. - Dhbay de Saint-Romain dioce sle Bordeanx.

497. - Cartulaire de l'ablaye de Saint-Romain de Blaye ; orig. perlu. Extrait du précédent, fait par Dom Estiennot au XVIIe siẻcle Bislinth. nutimule. ms. latin 12733, p. 65'.

Blaye. - Ibbaye de Saint-Sanvems.

498. - Cartulaire de l'ahbaye de St-Sauveur de Blaye : orig. perdu.

lixtraits du précédent, faits par Iom Estiennot au XVII siècle Biblinth. nutimule, ms. Jatin 127733. p. 83).

Blessac. - Prieuris (dioc. de Limoges). 499. - Cartnlaire du prieuré de Blessac, de l'ordre de Fontevrauld; $\mathrm{ms}$. laté de 1586 , contenant 9 pièces iles années $1479-1561$, in-folio sur papier, le 11 II. (Arrhires dép. de lu Creuse, H non coté). 
500. - Autre cartulaire du prieure de Blessac : origr. perdu.

Copie du précélent; ms. de la fin du XVII siede. sur papier, contenant 114 actes depuis le XIIe siecle, en grande partie sous forme d'analyses, in-folio de $24 \mathrm{tf}$. (Archires dép. de lin rivense, H non coté).

L'original qui a servi à ceptto copie étrit plus con-iléable.

Blois. - Ablaye de X.-I). do Benrgenoyen.

501. - Cartulaire de N.-D. de Bourgmeyen de Blois: orig. perilu.

502. - Fragments de plusieurs autres cartulaires de X.-D. He Boururmoven de Blois; ms. du XIIJe siecle. de plusieurs mains. sur par-

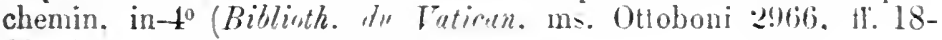
$\left.62 \mathrm{r}^{0}\right)$.

Dates extrèmes: $11: 3-1248$.

Cf. Notice sur le manuscrit Ottubunien 2966, par Lucien Anvray (. Kélunges puldiés pur l' École francaise de Rome. VI. p. 429-4.)4; et à part: Rome, 1886, in- $8^{\circ}$ le 25 p.

Donne l'analys as acts prontificaux.

Copie incomplète du précédent, faite au XVIIE siècle (Biblinth. natimale. coll. Dom Housseau. vol. XII, t1. 50-7!).

Autre copie partielle des mèmes, futite au XIX siècle par Amlré Salmon. contenant des titres de 1191 à 12:32. sur papier, in-8" (Biblioth. de la cille de Tours, m: 1213, ti. 202-25.5).

Cf. une lettre du 15 juin 166 i relative à diverses pieces du cartulaire

de Burgangen (Bibligthènu Ste-(ienpriere, à Paris, ms. 25iz, fo 60):

Extraits faits an XVII" siecle, par Duchesne (Biblinth. nutionale, coll. Duchesne, vol. XXII, ff. $163-166)$; - au XVIII siècle (Inem, coll. Moreau, vol. l:268, tr. 170-178).

Blois. - Abharr de Saint-Laumer.

503. - Cartnlaire de St-Laumer de Blois: ms. du XVIII siecle, sur papier. en $6 \mathrm{vol}$. in-folio, contenant ensemble plus de 51)0 (locument. des années 90:-17il et une table Archires dép. de Loir-et-Ciher, $\mathrm{H}$ non coté).

$503^{\text {bis. }}$ - Recueil de quelques titres relatifs à Saint-Laumer, formé par I. Ans. Le Michel au IVIJe siècle (Biblioth. anliumule, ms. latin 13818. If. 9()-100): - autre sur le prieuré de Belhomer. par Latisne. prienr de Mondonville Intem. ms. françir 24l:33. pp. :30l-31t.

Blois. - Comtí.

504. - Vienx cartulaire dı comté de Blois: ms. du XIII siècle [1272]. sur parchemin, arec table au lébut, in $4^{\circ}$ de 38 ff. (Biblisth. nationule. ms. latin 10108).

Contient 80 chartes de anners 1219-1266. - Le to 38 est llun. ecriture postérieur.

lixtraits faits au XVIP siecle Biblisth. mationale, coll. Baluze," vol. LXIII tr. $343-347)$. 
505. - Cartulạire des comtes de Blois; ms. du commencement du XIVe siècle. sur parchemin, contenant des documents à partir de 1163 , in-4" de 66 it. (Archives untionules, KK 895).

506. - Cartulaire des comtes de Blois ; ms. lu XIV ${ }^{\text {e }}$ sì̀cle, commencé en I3L9 par frire Jean de Villesaroir, sur parchemin, et contenant des actes de 107:3 à 1338, in-folio de n-114 ff́. (Archives nationales, KK 894.

Lu's actes y sont classés par chitollunies: Bluis, Romurantin, Chàteaudun, Mardyomer.

507. - Autre cartulaire du XV'e siècle, sur parchemin, contenant des actes de 1246 à 15:39, in-folio de 11-467 lf. (Archires nutionales, KK 896).

Voir aumi ro 'limes.

$507^{b}:$ - Autre cartulaire: ms. du XVIe siecle, sur papier, in-folio de $321 \mathrm{nt}$. (Amhiers nationales, KK 897 ).

Blois. - Iriprosire saint-Lazare.

508. - Cartulaire de la léproserie de St-Lazare de Blois : orirg. perdu. Extraits du précérlent. faits an $\mathrm{XV}^{\mathrm{e}}$ siècle, sur papier, in-folio (Bibliall. nutionele, coll. Duchesne, vol. XXII. If. 160-162).

(if. Nutice sur Lr cartulaire de la léprostrie saint-Lazare de Blois, par J. de (Croy (Recue do Loir-el-Cher, 18!99, pp. 169-187 et 279284). Contiont lanalyo des documents transcrits. - Voir ausi les copies

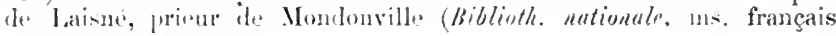
$2413: 3$, He. $369-3799$.

Blois. - Ville.

509. - Cartulaire de la ville de Blois; ms. du XVI $\mathrm{XI}^{\mathrm{e}}$ siècle, in-folio de $37: 3$ ir. (Biblinth. nutionale, coll. Clicirambault, vol. 968).

limininal purdn itail "au tricor" n le labbaye de Bourgmoyen.

Analyse et extraits du précédent, par A. Dupré; ms. du XIXe siècle. in-to de lol pages (Biblioth. de la ville de Blois, ms. 33).

Prbl. : Sous presse, par G. Tronillard et J. Soyer Mémoires de In Saciétédes letioss. sciences et arts de Loir-et-Cher).

Bocé. - Pricuré dion. d'Angrers).

510. - Cartulaire du prieuré de Bocé, dépentlant de Marmoutier; ms. du XVI" siecle. sur papier, contenant 30 dlocuments des années $1085-14 ! 17$, in- $4^{0}$ de 28 p. (.relices dej. de Maine-et-Loire, H non coté).

Bois de Vincennes. - Cumvent des Minimes. - Voy. Tincesses.

Bois-Grolland. - Abbaye dior. de Luçon).

511. - Cartulaire de labbaye de N.-D. de Bois-Grolland; ms. du 
Xllle siecle. sur parchemin, avac lacunes au milieu a dis tir. in-folio de 70 II. (Archices dép. de la Tédér, H non coti).

Pcb1.. : Cartulaire de l'abbaye du Bois-Grollaml. jar l'anl Marcheray. dans Cartulaives du Bres-Puiton Les Roches-Baritand, 1877: in $-8^{\circ}$, p. $22 !-299$ )

Extraits du cartulaire. faits au XVIJe siecle (Biblinth. matimale,

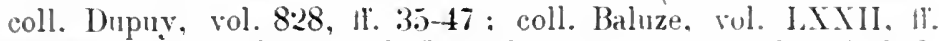
84-96 : coll. Duchesne, vol. LXXV, t1. 47-.)2 ; et ms. latin I 7048. pp. 195̆-198).

Bois-Seigneur-Isaac. - Primuré diuc. de Cambrai:

.12. - Cartulaire du prieuré de Bois-Seigneur-lsaac: आn. Hu X Ve siècle, sur papier, contenant des locuments le $13: 35$ is 1474 , in- $4^{0}$ de 23:3 ff. (Archices du myume de Brlginur, à Bruxelle-).

Boissy. - Toy. C.ergy.

Bolleville. - Léproselie et prieuré de la Marleloinm falior. de Coutances.

513. - Cartulaire de la Marleleine de Bolleville; ms. du IV'e siècle [1436], avec adlitions, sur parchemin. in $-4^{0}$ de 5.511 . 'British Wuserem, ms. additional 17:30\%.

Dates extrèmes : $\mathrm{NI}^{\mathrm{e}}$ siècle à $14 \% 1$.

Copie moderne [1878] du précédent, par miss Poulmin Sinith, sur papier, in-folio de $\mathbf{5 . 5} \mathrm{Hl}$. (Biblioth. mutionale. ms. nons. acq. Irançaises 4162 ).

Bomy. - Érlise llioc. d'Amas,

514. - Cartulaire de l’église de Bomy; ms. des XVIE-XIS" siècles. sur papier. incomplet des 8 premiers feuillets. cortenant des actes depnis 1606, in-folio de 306 If. Archires paroissinles de Brimy, Pas(le-Calais).

Ln recueil antérieur, renfremant les actrs jus ancirns, parait arvir disparu.

Bonfays. - Abbays (dioc. de Tioul:

¡).). - Cartulaire de l'abbaye le Bunfays; ms. du XVIlle sirole $[175 \%]$. sur papier, in-folio de $756 \mathrm{tr}$. (Archires dép. des listges. $\mathrm{H} 10$;

Est incomplet do 3 feuillets.

Bonifacio. - Ville.

516. - « Liher franchisiarum hominum Bonifacii. per Hieronsumm le Rocha, rectorem parrochialis ecclesie sancte Margarite le Casanova, Januensis diocesis » (août lōtl): ms. du XYle siecle. sur parchemin, de 65 ff. Biblisth. natimale. ms. nour. acq. latines 499. 
Bonlieu. - Abbaye (dioc de Limoges).

517. - Cartulaire de l'ablaye de Bonlieu-en-Marche; ms. de $223 \mathrm{ff}$, orig. perdu.

Copie intégrale du précédent, par Dom Col : ms. dı XVIIIe siècle, smr papier (Biblioth. nationule, ms. latin 9196, pages 1-401).

Autre copie, faite par Bosvienx vers 1860, sur papier (Archives dép. de la Creuse, $\mathrm{H}$ 284).

Dates extrêmes: 1141-1:3\% .

Axal.: Inventaire sommaire des archives départementales de la Creuse, série H [sons presse], p. I66-192.

Extraits faits aux XVII et $\mathrm{XVII}^{\mathrm{e}}$ siècles, sur papier (Biblinth. nutionule, ms. nouv. acq. françaises 5219, if. 27-32 ; coll. Duchesne, rol. XXII, tr. 240-242, et Aichires dép. de la Creuse, H 441 et 47I).

Bonnaigue. - Abbaye dioc. de Limoges).

5l8. - Cartulaire de l'abbaye de Bonnaigne ; orig. perdu.

Extraits faits au XVíle siècle, par Dom Estiennot (Biblinth. nutionule, ms. latin 1:2663, fo 93, et us. latin 12765, p. 235).

Bonnecombe. - Abbaye (lioc. de Rodez).

5l!). - Cartulaire de l'abbaye de Bonnecombe: ms. de la fin du XIII sierle, sur parchemin, en 4 vol. in-8 de $81.10 \mathrm{l}, 54$ el $100 \mathrm{fl}$., contenant des titres de 1167 a 1300 (Archives dép. de l'Aveyron, $\mathrm{H}$ non coté [l vol.] et Biblioth. de la Srciétr des Lettres. Sciences et Arts de l'Ateyron [3 vol.]).

Des "xtraits en sont publiés par Hipp. de Barrau (Mimoires de la

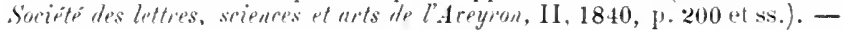
Le volume consirve aux Archives intéresep plus particulièrement Bernac 'Il Alliginois.

520. - Recuel le titres de l'abhaye de Bonnecombe ; ms. de 1667, contenant des actes des années 1 i 68 -153 31 , in-folio de 279 et 310 fr. (Biblistly. mutimule, coll. Doat, vol. 138-I3!).

Bonne-Espérance, à Tolleroille-lr-Brayoux (Hainaut). Abbare (dioce de Cambrai).

521 . - Recueil des chartes de l'abbaye de Bonne-Espérance; ms. des XVI $-\mathrm{XVIII}^{\mathrm{e}}$ siecles, sur papier, contenant des chartes de $11: 31$ à 1798 , in-folio de 317 11. Biblinth. mationule, ms. latin 10167.

522. - Extraits d'un ancien cartulaire, en vélin, de Bonne-Espérance; ms. du XVII siecle [1681], sur parchemin. contenant des actes de 1163 it 1680 , in $4^{\circ}$ de $130 \mathrm{tr}$. (Aichires nationales, $\mathrm{S}^{*} 974^{2}$ ).

Bonnefont. - Abbaye (dioc. de Comminges).

523. - Cirtulaire de l'abbaye de Bonnefont; orig. perdu.

lixtraits dans les papiers d'Ö̈henart (Bilhioth. de Mgr. de Carsalade di. Pont, évêque de Perpignan). 
Bonnefontaine. - Abbay iline. dre Reims.

524. - Cartulaire de l'abbaye le Bomnefontaine Appartenait avant 1867 à M. de La I'ons-Mélirocq. à Raismes. Nord,

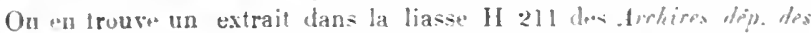

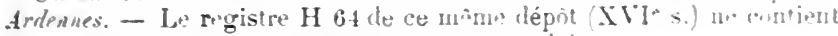
Inte des baux et ne? peut passer pour un cartulaire.

Bonnesaigne. - Abbaye a Brive illoc. dr Limenes.

52.5. - Recueil de titres formé par Dom Col au XVIII siècle 'Biblisth. nationale, ms. latin 9194. parres: 300 à 3933 .

526. - Autres copies faites par René Du Cher (Bibristh. intimulate. ms. latin 12746, p. $719-730$.

Bonneval, - Abbaye de Saint-Florentin dine de Chartres'.

527. - Petit cartulaire de l’abbaye de Bonneval : ms. du XITe siècle. sur parchemin. contenant 21 actes des amnées 1109 a 1348 , in $4^{\circ}$ de 27 fr. Archices dep. d'Eure-et-Loir. H 61)6).

528. - Cartulaire de l'abbave de Bonneval : orig. perdu.

Extraits faits an XYII siècle (Biblinth. intimule. cull. Baluze. vol. XXXVII, ti. 5-1\%.

529. - Extraits et copies relatif́s à l'alhbaye de Bunneval. feits pour Gaiqniëres an XVII' siècle d'après les originanx, in-folio de 119 pages (Biblisth. nationule. ms. latin 1ili39).

530. - Recueil des titres de l'olfice de secrétain de labbaye de Bonneval : ms. du XVI siècle, sur papier. contenant des bulles et

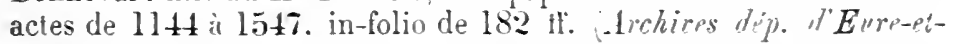
Loir. H 607 ).

531. - Recueil de titres relatifs à l'abbaye de Bonneval : ms. du XIX"e siècle formé par Lejeune, sur papier. in- $4^{\circ}$ de 224 et 26 11. Biblinth. de la rille de Cluntres, mis. 1112 ).

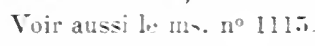

Bonneval. - Abbaye de Notre-Lame ílioe. de Rodez).

532. - Recueil de titres de l'abbaye de Bonneval: ms. de 1667, contenant des actes des amnées 1161-16:30. en :3 vol, in-folio de 322. 318 et 312 ff. (Biblinth. intismelp. coll. Doat, rul. 141)-142).

Bonnevaux. - Abbaye do Yotre-Dame ilion. die Tienne. 533. - Cartulaires de N.-D. de Bonneranx : mss. dn XIVe siẹcle, oripg. perdus.

Copie incomplète faite au XVIII sèele par d'Hozier de Sérigny. sur papier, in $4^{0}$ de $30 \mathrm{ff}$. (Archices nationales. L $1010, \mathrm{n}^{0} \mathbf{7 9}$.

Pebl. : Cartulaire de l'abbaye de Totre-Dame de Bonneraux, ordre de Citeaux, par le chanoine Ul. Chevalier. Grenoble. Allier. 
1889 ; in- $8^{0}$ de $n-198$ p. [Docmunents historiques inédits sur le Dauphiné, VII.]

1)ates extrêmes: : $1117-1279$.

Bonnevoie. - Abbaye (dioc. de Trèves).

534. - Puвs.. : Urkuntenbuch der Abtei Bonnewer bei Luxemburgr, von $\mathrm{X}$. van Werveke. Luxemburg, 1880 ; in $-4^{\circ}$ de vil-46 p.

Bonport. - Abbayr diuc. d'Evrux).

5:35. - Cartulaire de l'abbaye de Bonport; ms. du XIVe siècle, sur

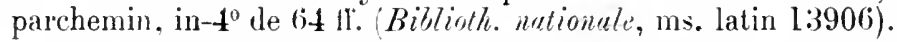

Pubr. : Cartulaire de l'ablaye royale de Notre-Dame de Bonport (1190-1467), de l'ordre de Citeaux, au cliocèse d'Évreux, par J. Andrienx. Érreux, Hérisvey. 1862: in- $4^{0}$ de xh-434 p. et atlas. 536. - Cartulaire des pauvres de l'hospice de l'abbaye de Bonport; ms. de la lin du XIVe siecle, sur parchemin et papier, contenant 24 chartes des années 12.04-1388, in- $4^{0}$ de 3 et $8 \mathrm{ll}$. (Archives dép. de l'Eure. H 181).

Bonvaux. - Prieuri de Notre-Dame (dioc. de Langres).

537. - Cartulaire du prieuré de Fotre-Dame de Bonvaux : ms. du XVe siècle, sur prrchemin, contenant 109 pièces des années 1211

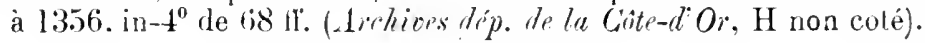

Boquen. - Abbaye do Saintr-Ilarie (dioc. de Saint-Brienc). 5:38. - Jubl. : Anciens évèches de Bretagne, diocèse de Saint-Brieuc, par J. Geslin de Bourgogne et Anatole de Barthélemy, III (1864), p. $222-311$.

Recueil fartice de 228 piècer les annérs 1148-1682.

Boran. - Prirué de Saint-Martin (diene do Beaurais). 5:39. - Cartulaire de St-Martin de Boran; orig. perdu.

Exlraits faits an $\mathrm{XVII}^{\mathrm{e}}$ siècle par Nabillon. sur papier (Biblioth. nationale, ms. latin 12682, 11. 206-211).

Bordeaux. - Abbaye de Sainte-Crois.

540. - Cartulaire de Ste-liroix de Bordeaux; ms. du XIIIe siècle, sur parchemin. contenanl 177 acles des années 1233-1283, in-folio de $66 \mathrm{dr}$. (Lirhives dép. de la Girmde. G non coté).

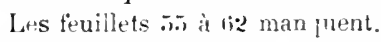

Extrail fait an XVII siècle (Biblioll. nutiontule, ms. latin 12771 , p. 182 et $21(6-224)$.

541. - Autre cartulaire; orig. perdu [depuis 175.5].

Recueil de titres concernant Sainte-Croix de Bordeaux, « extrait des cartulaires »: ms. du XVII siècle, sur papier. contenant 141 
dociments du Xe jusqu'au XIII" sirele, in-4" de 100 Ir. (Arrhires dép). de la (rivorudé, G non colé).

PUbL. : dans les Archires historiques de la Givmute, XXVII (189.2), pp. 1-292.

542. - Autre recueil de titres, fait en 1697 par Dom Dulaura, et au XVIII siècle par d'autres bénédiclins (Biblioth. nutionale, ms. latin 12666 , ff. 86-1:29 et 1:36-228).

Extraits faits au $\mathrm{XVII}^{\mathrm{e}}$ siècle [16.53], par Dom A. Liabeuf, sur papier (Bibliotle. nationale, ms. latin 12667, ti. 55.63.66 et 8:3).

543. - Fragment d'un cartulaire de Sainte-Croix de Bordeaux : ms. du XIVe siècle, sur parchemin, contenant des documents de 1214 í 1303, in-folio de $27 \mathrm{If}$. (Biblioth. nationale, ms. latin 91:36).

A appartenu à ILnteil. - I te début et la fin manquent; il y a en outre dís lacunes. ef l'humidilé a atlayué le laul des frenillets.

Quelques fiẻces sont en langm." lor.

Bordeaux. - Abbaye de saint-Pierre.

544. - Cartulaire de St-Pierre de Bordeaux : orig. perdu.

Extraits faits au XYIIe siècle Biblinth. nutionuln, coll. Baluze. vol. XXXVIII, ff. 156-184).

Bordeaux. - Archerèché.

545. - Cartulaire-obituaire de l'archevèché de Bordeaux: ms. du XIII siècle, sur parchemin, in-40 de 119 ff. (Archires dip. do ln Givonde, fonds de l'archevèché, supplément).

Provient de la hibliothèque de Thonas Phillipps, à Chellenham, uì il a porté le no $10 \times 6$.

Bordeaux. - Chapitre Saint-Antré.

546. - Cartulaire. [censier et obituaire] du Chapitre de Saint-André de Bordeaux: ms. du Xllle siècle. incomplet, sur parchemin. infolio de $122 \mathrm{fr}$. (Biblinth. Cheltpnlain, ${ }^{\circ} 1^{\circ} 82$ et 16902 .

Bordeaux. - Chapitre Saint-Sarrin.

547. - Cartulaire de St-Seurin de Bordeanx, « ou zrrand Sancius ». perdu (132 fi.) : il existait encore en 17.58.

548. - Autre, ou « petit Sancius », des XIII-XIV" siècles, contenant 380 chartes et $179 \mathrm{Hf}^{\circ}$. in- $4^{\prime \prime}$. sur parchemin, ayant appartenu successivement à Monteil, et à Th. Phillipps. no îl (. Lirkices dép. de lo Gironde, G 10:30).

Publ. : Cartulaire de l’église collegiale Saint-Seurin de Bordeanx. avec une introduction par J. A. Brutails. Bordeaux, Gounouilhou. 1897 : in- $8^{\circ}$ de cxr -444 p. [Académie les lettres. sciences et arts de Bordeaux.]

Quelques textes sont en langue romante. - Cit. du même contre 
Blade : Note sur une charte de Siant-Seurin de liordeaux (Actes de

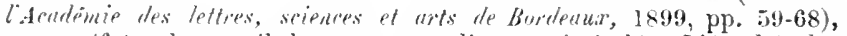
pour réfuter le travial de son contradicteur, intitulé: L'évêché des Giascons.

Bordeaux. - Couvent des I)ominicains.

549. - Cartulaire du couvent de St-Dominique de Bordeaux; ms. des XVlI ${ }^{e}-X_{1 I I}$ siècles. sur papier, contenant des actes de 1654 a 1747, in-4 de 449 II. (Archices dép. de la Gironde, H non coté).

Bordeaux. - Ville.

550. - P'url. : Privileges des bourgeois de la ville et cité de Bourdeaux (Bourdeaux. 1774, in- $8^{\circ}$ ): $-\mathrm{n}^{\text {elle }}$ éd on (Bourdeaux, 1667. in $-4^{0} \%$.

- Youveau Recueil de diverses Lettres patentes concernant les principaux privilèges des bourgeois de la ville et cité de Bordeaux (Bordeaux, Bondé-Boé. 1717. in-4 $4^{0}$; neller édons (Bordeaux, Lacoruée. 1729 ; et Racle, 1779, in- $4^{\circ}$.

551. - Cartulaire municipal de Bordeaux, ou « Livre des Bouillons »; ms. du XVe siècle, avec additions postérieures, sur parchemin, convert d'unt reliure (refaite) en bois avec ornements en cuivre et chaine d'attache en fer, in-folio de $156 \mathrm{II}$. (Archives municipales de Burdeun. AA 1).

Publ. : Archives municipales de Bordeanx: tome I : Livre des Bonillons. Bordeaux, Gomonilhou, 1867 ; in- $4^{0}$ de [IV-]Lxir-620 p. et pl.

552. - Autre cirtulaire on « Livre des privilègres»; ms. du XVle siècle, commencé en 1564 et continué jusqu’à Henri IV, sur parchemin, couvert d'une reliure en hois et cuir à coins de cuivre ajouré, in-folio de $214 \mathrm{ir}$. (Archires municipules de Borteaux, AA 2).

3s feuillets sont blancs.

Publ. : Archives municipales de Bordeaux : tome II : Livre des Privilèges. Bordeaux, Gomouilhou, 1878: in- $4^{0}$ de [Iv-]xuvin$774 \mathrm{p}$.

Contient le's textes du manuscrit ci-dessus indiqué et des textes complémentaires en appendice.

553. - Recueil des privileges de la ville de Bordeanx; ms. du XVe siecle [vers 1500], sur parehemin. avec reliure en maroquin aux armes de France, in-folio de $61 \mathrm{fr}$. (Biblioth. nationale, ms. Prançais $2690)$.

$\therefore$ compose uniøuenent d'actes les règnes de Charles VII et de I.ouis XI

Boscodon. - Abbatye (dioc. d'Embrun).

554. - Cartulaire de l'abibaye de Boscodon ou «Livre vert»; orig. perdis. 
Extraits faits an XVIlle siècle, sur papier, contenant des acter it partir de 1132 (Biblioth. nationale, ms. litin 12663, 11. 104-115).

Bosserville. - Chartreuse (dioc. de Nancy).

550.. - Cartulaire de la Chartreuse de Bosserville: ms. In XVIIe siècle, sur papier, in-folio de 154 II. (Archices dép. de . Meurthe-rtHoselle, H 667).

Intéresse spécialement lè biens de la (hartreus sis à Laxuu.

Bouafle. - Prieuré (dioc. de Rouen,

556. - Cartulaire du prieuré de Bouafle et de la seigneurie de Vanx près Meulan: ms. du $\mathrm{XVl}^{\mathrm{e}}$ siècle. sur papier, in $4^{0}$ de $37 \mathrm{tI}$. (Archives nationales. Q' 1475 ).

Ce volume contient des notices et extraits à còté de copies intégrale: : le plus ancien ducument remonte au règne du roi Robert. Il s'y trouve aussi des actes intéressant Ivry, Vitry et Villejuif près de Paris.

Vuir aussi Sirresses.

Boucheraumont-lez-Joinville. - Voy. PARIs (Carmes de). Bouconville. - Chàtellenie.

557. - Recueil de titres relatifs à la chàtellenie de Bouconville ; ms. de la fin du XVIe siècle, formé par Thierry Alix, sur papier, contenant des actes de 12.4 à 1587, in-folio de $252 \mathrm{ff}$. (Archices dép. de Weurthe-et-Moselle. B 347).

Copie du précédent. faite à la fin du XVI siècle, sur papier, in-folio (Archives dép. de la . Yeuse, B 251).

Autre copie, faite au $\mathrm{XVII}^{\mathrm{e}}$ siècle, sur papier, in-folio de $294 \mathrm{ff}$. (Archices dép. de leurthe-et-1Koselle, B 332).

Bouillon. - Courent des Augustins (lioc. de Liège).

558. - Cartulaire des Augustins de Bouillon; ms. des XVIIe-IVIII siècles, sur papier, contenant des actes de 1590 à 1744. in-folio de 722 pages (Archices de C État à Arlon).

Bouillon. - Couvent des Dames du Saint-Sépulere.

559. - Cartulaire des Danes du Saint-Sépulcre de Bonillon : ms du XV1Ile siècle, sur papier, contenant des titres de 1626 a $17+7$. in $4^{0}$ de 657 pages (Archices de l'Etat à Arlon).

Boulancourt. - Abbaye de Notre-Dame (dioc. de Troyes. 560. - Cartulaires de l'abbaye de Boulancourt ; orig. perdus.

Compilation du XVIIJ siècle. d'après les précédents, contenant 994 chartes des années 1120-1779, in-folio (Biblioth. des Capucins de Clermont-Ferrand,

Axal. (incomplète): Cartulaire de l'abbaye de Boulancourt, de 
l'ancienn diocèse de'Troyes, par l'abbé Ch. Lalore (Mémoires de la Société ncudímique de l'Aube, XXXIII, p. 101-192), et à part: Troyes, 1869 ; in-8" de $100 \mathrm{p}$.

lixtraits de cartulaires, faits an XVII e siècle par Duchesne (Biblisth. nationale, coll. Duchesne, vol. XX. 11.326-3330, et LXXVI, payes $7 I-74 ;-I d e m$, coll. Baluze, vol. XXXVIII, fI. 58-65;Biblintle. de la ville de Corpentras, ms. 1814, 10 122).

Boulaur. - Couvent de Dames de Fontevrauld (dioc. d'Auch). 561 . - Cartulaire de Boulaur ; orig. perdu.

A été cité et ulilisé par 1)om Brugèles én $17+6$.

Boulay et Sarreguemines. - Chàtellenie.

562. - Recueil de titres relatils à la chàtellenie de Bonlay et Sarregruemines [on bailliage d'Allemagne]; ms. du XVIIe siècle, formé par' Thierry Alix, sur papier, contenant des titres de 122.) à 160:3, in-folio de 4:32 et $53 \mathrm{Hr}$. (1rehires dép. de Weurthe-et-Moselle, B 38:$383)$.

Boulbonne. - Abbaye (dige. de Mitepoix).

56:3. - "Cartulaire des archives du château de Fuix pour l’ablaye de Boulbonne »: ms. du XVII siècle, sur papier, in-4" de 521 pages (Biblioth. He la ville de. Toulonste, ms. 638).

564. - Cartulaire ancien de Boulbonne; orig. perdu.

Extraits faits par Dom listipnot (Bibliotlenationule, ms. latin 12774 . pp. 3:37-345).

565. - Recueil de titres relatifs à l'abbaye de Bonlbonne; ms. daté de 1669 , contenant des acles des années $962-1605$, en 4 vol. in-folio de 379, 381,345 et $375 \mathrm{H}$. (Biblinth. nutionale, coll. Doat, rol. $8: 3-86$.

Boulogne-sur-Mer. - Abbaye de Note-Lame. - Toy. liolLuNAAIS.

Boulogne-sur-Mer. - Abbave de saint-Wulmer.

566. - Pebl. : Chartes de l'abbaye de Saint-Wuhner de Buologne, publ. par l'abbé Haigneré (Bulletin de la Société académique de Bonloyne. I, 1873, pp. 372-381).

Contte publication de trois chartes stulement ne mériterait pas d'être relevée ici si nous napprenions par les copies utilisées (Archives untimules, J 792) qu'un cartulatire en parchemin de saint-Wulner existait en $1.17 \%$.

Boulogne-sur-Mer. - Ville.

567. - PubL. : Factum contenant en abrégé les privilèges et franchises de la ville de Bonlogne-sur-Mer. S. 1., 1661, in-4 
568. - Cartulaire de l'hòtel-de-villr de Boulogne-sur-Mrer, par l'abbé D. Haigneré (Mémoires de la Suciéte acatiminue de Boulogutrsur-.Me'r, XIII, p. 5-88 et 479-489), et à part: Bonlogne-sur-Mer. 1884 ; in $-8^{\circ}$ de 100 p.

Recueil factice de pièces tirées an grande parlie dos Archives dél. du Pas-de-Calais, et remontant ì 1203. Le tirage à part, à 30 ex. seul. ment, porte eomme tilie: Cartulaire des élablissentents civils du Boulonnais: I. Hôlel-de-ville de Boulugne-sur--Her.

Boulonnais. - Ėtablissements religienx.

569. - Sols le titre générique de « Cartulatre des Établissenents REligieux du Bouloxiass ", l'abbé D. Haigneré a publié diverses brochures numérotées dont voici la liste :

I. Deux chartes inédites dı Chapitre de Thérouanne en 1119 ot 1157 (Boulogne, 1886 ; in-8 $8^{\circ}$ de $47 \mathrm{p}$ ).

II. Quelques chartes de l'abbaye de Samer. 1107-1299 Bonlogne, $1880^{\circ}$; in-8 de 164 p.) ; Supplément au recueil [1884] in- $8^{\prime \prime}$

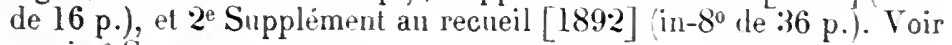
aussi vo SANER.

III. Église abbatiale de Yotre-Dame de Boulogne, l067-1567 (Bonlogne, 1884 ; in-8 de 276 p.).

IV. Abbaye de Beaulieu, ordre de St-Augustin, de la Congrégration d'Arrouaise. 11:37-15it (Boulogne, 1886; in-Su de II-36 p.).

V. Quelques chartes inédites concernant les abbayes, les prieurés ou les paroisses de l'ancien Boulonnais (Boulogne, 1886; in-8 $\mathrm{d}^{\circ}$ II $-66 \mathrm{p}$.

Ces diverses publications unt paru dabord dans las tomes XII ef XIII des Mémories de la Sirciele acralemique do Boulogue-sur-.Mer.

A titre de complement, ef.: Chartes diverses du Boulonnais, par

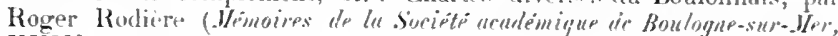
XIIV, 1946, [p. 1-241): publites en partic llapres le cartulaire de saint-Jositesur-】leur.

Bouras. - Abbaye dioc. l'Auxerre:

570. - Cartulaire de l'abluaye de Bonras: ms. du XVII siecle, sur papier. in-folio de 19 tr. 'Archires dép. del'Limne, H 1661 bis).

Bourbon-Lancy. - Église collégiale Notre-Dame dion. d'Antun).

5i1. - Cartulaire de la collégiale de Boupbon-Lancy : ms. du XVIIe siècle, sur papier, contenant 37 pièces des années $15.58-1603$, in $4^{\circ}$ de $14 \mathrm{ft}$. (Archicesdef. de Sróne-rt-Lrive. (i non coté).

Bourbon-lès-Gaillon. - Chartreuse dlix. d'Évreux.

572. - Cartulaire de la Charlreuse de Bourbon-lès-Gaillon; ms. des XVI-XVIlle siemples, sur papier, se composant de $3.5 \%$ Hi. lédigés en 
$1705-1718$, et de 26 ff. [1l. 365-390] appartenant à une rédaction bien antérieure $[15767$, in-folio de $390 \mathrm{HI}$. Archices dép. de l'Eure, H 1144).

\section{Bourbonnais. - Seigneurie.}

573. - Cartulaire ou livre des fiefs de Bourbon ; orig. perdu.

Ce volume a éte ru et cite par Brussel et La Thaumassière.

Extraits faits par Du Cange an XVII e siècle (Biblioth. nationule, m.. français 9.500, p. 31 ; - ms. français 16789 , ff. 210-2Ll).

Bourbonne-les-Bains. - Prieuré (dioc. de Langres).

57t. - Cartulaire du prieuré de Bourbonne ou «livre blanc»; orig. perilu.

Extraits d'après les archives du Doubs, copiés en 1873 par U. Robert, sur papier, in-4 ${ }^{\circ}$ (Biblioth. nationale, ms. nouv. acq. latines 1241. pp. 1-10).

Bourbourg. - Abbaye dioc. do Thérouanne, puis de Saint(Oner).

575. - Cartulaire de l'albaye de N.-D. de.Bourbourg; ms. du XIII siècle [vers 1260], sur parchemin. avec quelques additions un pen pontérieures et de plusieur's mains, in-4" de $64 \mathrm{ff}$. (Biblioth. autionale, ms. latin 9920).

Dates extrèmes : 1104-1275.

Axil. : par E. de Coussemaker (Anuales du Comité fhumid de France, IV 1859 , p. 257 et ss.).

วテ6. - Cartulaire de Bourbourg; ms. composé vers 1526, dit le " Grand livree », de plusienrs mains avec table au début, sur papier, jn-folio de 231 f1. (Biblioth. nationale, ms. latin 9126).

Documents à partir de 1106 , collationnés par P. de Rosa et J. Vasseur.

577. - Autre cartulaire; ins. du XVIIe siècle, sur papier, en quatre livres précédés chacun d'un index, contenant des chartes depuis le $X I I^{e}$ siecle, in-folio de vi-87, II- 12 , II-43 et II-48 fl. (Biblioth. nationale, ms. latin 9921).

PunL. : Un cartulaire de l'abbaye de N.-D. de Bourbourg [11041313], par I. de Conssemaker. Lille, Ducoulombier, 1882-1891, 3 vol. in-8 de [II-] xiI- 664 et 108 p.

Travail postlume publ. par A. Bonvarlet, qui cite à plusieurs reprises dans cette publication un "Cartulaire du Vicomte de Bourbourg ", faisant partie de sa propre collection et dont nous ne sarons rien.

578. - Bullaire de l'ablaye de Bourbourg ; ms. du XVe siècle, sur papier. in $-^{\circ}$ (Biblioth. nationale, ms. latin 9922, ff. 16-37). 
579. - Cartulaire de liabbaye de Bourbourr: ms. lu XVIe siecle, sur papier, in-t" de $29 \mathrm{ff}$. (Biblioth. nationale. ms. Latin 992:3).

580 . - Autre cartulaire; ms. du XVIe siecte. sur papier, in-t" de $89 \mathrm{ff}$. (Biblioth. mutionule, ms. latin 9924).

Bourbourg. - Ville.

581. - Cartulaire de la ville de Bourbourg; ms. lu XVIII ${ }^{e}$ siècle, sur papier, contenant des titres de 1360 ì 1733. in-folio de $288 \mathrm{ll}$. (Archices municiunles de Bourboung, AA 1).

Bourg-Achard. - Prieuré (dioc. le Rouen).

582. - Cartulaire du prieuré de Bourg-Achard; orig. perdu [était avant la Révolution la propriété clu marquis de Radepont].

Toussaints Duplessis l'a utilisé.

Copie partielle du cartulaire, par Dom Probst : ms. daté de 1788, sur papier, in $4^{\prime \prime}$ de $17 \mathrm{fl}$. (Biblioth. natisnale, ms. latin 9212).

Cf. Notice sur le cartulaire du prieuré de Bour-Achard, par Louis Passy (Biblinth. de l'École des Chartes, 5 série, II, p. 342367 , et III, p. 513-536). et à part : Paris. 1862 ; in- $8^{\circ}$ de $48 \mathrm{p}$.

\section{Bourg-en-Bresse. - Ville.}

583. - Cartulaire municipal de Bourg-en-Bresse; ms. du XIVe siècle, sur parchemin, contenint des actes de 1251 a 1397 , in $t^{\circ}$, le $52 \mathrm{lf}$. (Archices municipules de Bouig. At 15).

Les mêmes documents sont transcrits en un ruleau de parchemin, établi en 1404 et long de $14^{\text {m08 }}$ (Arhices municipules de Bourg, A.A 16).

584. - Cartulaire général de lin ville de Bourg-en-Bresse: ins. rédigé en 1480 , sur papier, en $2 \mathrm{vol}$. in-folio de $49 \mathrm{l}$ et $330 \mathrm{fl}$. (Archices municipales de Bourg, AA 20-21).

585. - Publ. : Cartulaire de Bourg-en-Bresse, par Joseph Brossarl. Bourg, imp. Chambaud, 1882; in- $t^{\circ}$ de [N-]chxxvi $+61 t+9$ p. et $\mathrm{pl}$.

Dates extrêmes: : 1251-1583.

Bourges. - Abbaye de Saint-Sulpice.

586. - Cartulaire de l'abbaye de St-Sulpice-lez-Bourges; nis. de la fin du Xllle siècle, sur parchemin, in- $8^{\circ}$ de !l 11 .

De ce cartulaire, très éprouvé par lincendle des archives du Cher en 18.59 , it ne subsistr qu" 39 ff. très enfommagés, mangés par les bords, et quil sera tres difficile de reconstituer (trih. dép. du Cher, $H$ non coté:

lixtraits du cartulaire de St-Sulpice de Bourges, faits au XVII siècle (Biblioth. nationale, ms. latin 13819, tr. 319-323 et 344-359).

Ce dernier extrait a ele fait avee fort peu de: soin. 
Copie du cartulaire A "jusqu'à la feuille 24 inclusivement » (Archives dét. du Cher, H nou coté).

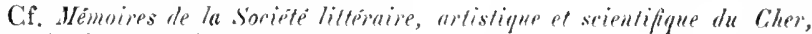
$4^{e}$ série, XI (1896), p. 32.4.

587. - Autre cartulaire de l'abbaye de Saint-Sulpice; ms. du XIVe siecle, orig. perlu.

On trouve encore à la bibliath. nationale, coll. Baluze, vol. XXXVIII, ff. $38-39$, un extrait de la pancarte de l'abhaye de Saint-sulpice, qui remonte au $\mathrm{XI}^{\mathrm{e}}$ siècle.

Bourges. - Archerèché.

588. - Cartulaire de l'archevèché de Bourges; ms. des XIII'-XIVe siècles, sur parchemin, in- $4^{0}$ de $225 \mathrm{ft}$, contenant des dlocuments à partir de 1119 . à 2 colonnes.

Ce registre a été endommagré par 1 incendie des archives du Cher en 1859 ; cependant il en reste $148 \mathrm{ff}$. en asse'z bon état, non mangés sur les bords, "t qui pourront être reconstitués (Arehires dip. du Cher, Gr non cotéj. - On en a dailleurs une copie du XVIII siècle, in-folio sur papier. de $88: 3 \mathrm{fr}$., dans le mème dépòt (Gi non coté).

Extraits par Baluze, faits an XVII siècle (Biblioth. nationale, coll. Batuze, vol. LXXIX et LXXXI, II. 1-126).

589. - Recueil de titres relalifs à l'archerêché de Bourges; ms. du XVe siecle. sur parchemin, in-4" Biblioth. de la rille de Tours, ms. 1172:

Bourges. - Chapitre de X.-D. de Montermoyen.

590. - Cartulaire du Chapitre de Montermoyen à Bourges; ms. du XIII" siècle, sur parchemin, in-8" de 2:26 11 .

Ins débris le ce cartulaire, détruit t’n partie par l'incendie des archives du Cher en 1859. pertent être reconstitués, car il en subsiste actuellement $112 \mathrm{ff}$. asisez lisibles (Archicess dép. du Cher, Gi non coté).

Bourges. - Chitpitre de Notre-Dame de Salles.

¡91. - Cartulaire dn Chapitre de Notre-Dame de Salles à Bourges: ms. llu XV" siecle, sur parchemin, eontenant des documents de 1012 a 1489 , in- 80 de $101 \mathrm{Hl}$. dont le copiste était un certain Landry.

11 n'exist, phus rien le ce manuscrit disparu dans l'incendie des arrhives du Cher en 185:\%.

Bourges. - Chapitre de la Sainte-Chapelle.

592. - Cartulaire de la Sainte-Chapelle de Bourges; ms. du XVe siecle, sur parchemin. in-folio de $70 \mathrm{tt}$., contenant des actes de 1392 aे 1417 .

C.r volume "st en grande jartie conservé : nous en avons retrouvé $62 \mathrm{tf}$. un lifu endommagrés jrar lo feu et en médiocre état, mais encore

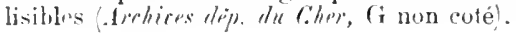


Bourges. - Chapitre de Sainte-Oustrille alt chàteau.

593. - Cartulaire du Chapitre du Chàteau de Bourges: ms. des XIII"$\mathrm{XIVe}$ siècles, sur parchemin, in-4 de $112 \mathrm{ti}$. ì 2 colonnes.

Ce cartulaire a été detruit "n partie dans l'incentic des arohives du Cher en 1859 : il en subsiste cependant $93 \mathrm{Hf}$. pn mavais etat et sunsu-

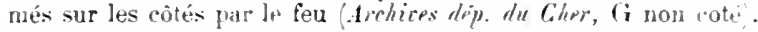

Bourges. - Chapitre de Saint-Pierre-le-Pnellier.

594. - Cartulaire ou « Pancarte » de Saint-Pierre-le-Puellier à Bourges: $m s$. des XIII $-\mathrm{XV}^{\mathrm{e}}$ siectes, in $-8^{\circ}$ de $1.30 \mathrm{ff}$.

Ce manuscrit a èté cunsumé dans lineendie des archives du (har en 1859 ; il n'en reste pour ainsi dire plus rien.

Bourges. - Chapitre de Saint-Lrsin.

595. - Cartulaire du Chapitre de St-Ursin à Bourges: ms. du XIII ${ }^{2}$ siècle, sur parchemin, in- $8^{\circ}$ de $86 \mathrm{ff}$.

De ce manuscrit, fort endommage par lincendie des archires du Cher en 1859 , il ne subsiste plus que $20 \mathrm{tt}$. en très malsatis état (Archices dép. du Cher, fi non coté'.

Bourges. - Collège Sainte-Marie.

596. - Cartulaire du college $\mathrm{S}^{\mathrm{re}}-\mathrm{M}$ arie de Bourges; ms. du XVIJ siècle, contenant des documents des années 1241-1642. sur papier in $4^{0}$ de 123 ff. Archices dep. du Cher, $D: 32$,

Bourges. - $\dot{E}$ glise cathédrale.

597. - Cartulaire de l'église cathédrale St-Étienne de Borrges: ms. du XIII ${ }^{e}$ siècle, de plusieurs mains, avec additions diverses, sur parchemin, in- $4^{0}$ de 380 ff. (Biblivith. nationule. ms. nour. acq. latines 1274).

Dates extrèmes : $\$ 03$ - fin XIII siècle. - Cf.: l.e cartulaire de

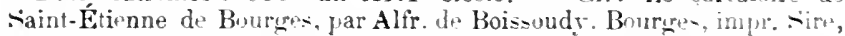

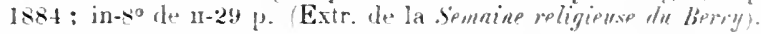

598. - Autre des XIII -XVIII e siècles. contenant 300 actes des imnees 1215-1778, sur parchemin, 2 rol. in-folio rle 479 et $2: 38 \mathrm{~m}$. L 1rhice. dép. du Cher, G non coté).

Lne reproduction héliographiqu de ce manuscrit a éfe faite en $1 S \times$

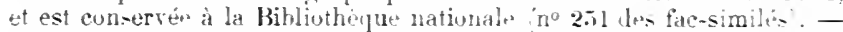
Sauf queliques lacunes, i] est intact ot pourra ètro ai-em+nt reenstitué

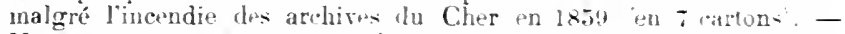

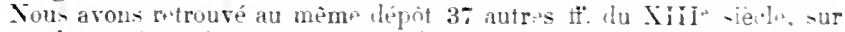
parehemin is 2 col., ten état très médivere et fracmentair. "jui parais-ent provenir diun autre cartulair" $n$ in dexit de St-Étienne de Bour... vu blutot de la conmunante dos ricaires de saint-Etienne. Cha pitr" particuliør qui s'était forme dans le Chapitre cannial "t qui arait de- bienn propres.

599. - Publ. : Libertez, immunilez et exrmptions de l'égliee patriar- 
chale, primatiale el métropolitaine de Bourges. Bourges, 1618, in $-8^{0}$.

Bourges. - Ville.

600. - Pubr.: Recueil dés antiquités et privilèges de lis ville de Bourges, par J. Chenu. Puris, 1621, in- $80^{\circ}$.

On y liouve aussi des lextes de privilèges pour les villes d'Aix, Amitus, Arles, La Rochelle, Orléans et 'Tours.

$600^{\text {bis }}$. - Recueil des privilèges de la ville de Bourges, par J. Tonbean. Paris, 164:3, - et Bourges, 165\%, in- $8^{0}$.

Bourg-lez-Valence. - Chapitre de Saint-Pierre (dioc. de Talence).

601. - Publ. : Chartularium ecclesia Sancti Petri de Burgo Valentiae, ordinis Sancti Augustini, ex monumentis ineditis descripsit, illıstravit et indicibus anxit C. U. J. Chevalier. Paris, Champion [Vienne, Sévigné], 1875 ; in-8 de 200 p. [Collection des Cartulaires danphinois, II, I; publié par la Société cl'archéologie de la Drôme.]

Dates extrêmes: fin Xie siecle it 1699 .

Bourgmoyen. - Voy. Biols.

Bourgogne. - Comte. - Voy. Franche-Compli.

Bourgogne. - Royatume.

602. - Diplomatique de Bourgogne; recueil formé par P. A de Rivaz au XVIII siècle, en 2 vol. in-folio (Biblioth. de M. Panl de Rivaz, à. Sion).

Cf. : Table chronologique des chartes contenues dans les deux volumes de Riva\% (542-1276) el pièces annexes (814-1144), par l'abbé Ul. Chevalier. S. l. n. \%. [inachevé] ; in-8 de 96 p.

Bourgueil. - Abbare ilioc. d'Angers).

603. - Cartulaire de l'ablaye de St-Pierre de Bourgueil; ms. d'au moins $406 \mathrm{fl}$., orig. perdiu.

Copie du précédent; ms. écrit en 1481, perdu.

Copie faite sur celle de 1481 , sur papier, au XVIII siècle, par Dom louquet, in-folio (Biblinth. de M. Goupil de Bouillé, à Bourgueil).

Extraits du précélent, faits pour Gaignières vers 1715, in-folio, sur papier (Biblinth. untionale. ms. latin 17127, pp. 231-250).

Luts pages 103-200 du mêne registre forment un recueil de pieces sur la neêne abbays: et les pages 25:3-272 contiennent des "excerpta ex cartulario "n qui semblent avoir une? autre origine.

lixtraits du mènte, fails an XVIIe of an XVIIIe siècle (Biblioth. 
nationule, coll. Baluze, vol. XXXVIII. ff. 18.5-196: coll. Inm Housseau, vol. XII : coll. Dupuy, vol. 816. ff. 8:3-87: latin 126663, tf. 301-30:3: latin 127\%7. pp. 258-264: latin 13816. ff. $2: 24-228$ et 2:36-237, et latin 13898 . if. 166-170).

604. - Recueil de titres relatifs a l'abbaye de Bourgueil ou essai de reconstitution d'un ancien cartulaire [du $X V^{\mathrm{e}}$ siècle]; $\mathrm{ms}$. rédigé par André Salmon vers 1860 , sur papier, in- $8^{\circ}$ (Biblioth. do la rille de Tours, mss. 1338-1339).

Dates extrêmes : $\times 95-1678$

605. - Autre recueil de titres anciens sur Bourgneil. fait par Laisné. priem de Mondonville, an XVIII siecle (Biblioth. nutionale. m. français 241333 . pp. 533-574).

\section{Bourmont. - Châtellenie.}

606. - Recueil de titres relatifs à la chàtellenie de Bourmont: ms. de la fin du $\mathrm{XVI}^{\mathrm{e}}$ siècle, sur papier, contenant des titres de $124: 3$ à 158.5 . in-folio de $48: 3 \mathrm{ff}$. (Archires dép. de Meurthe-et-1Koselle. B 348).

Intéresse également Gondrecourt, Lamarche-sur-saone et Conflanen-Bassigny.

Copie incomplète du précédent. faite au $\mathrm{XVIl}^{\mathrm{e}}$ siècle, sur papier. in-folio de $283 \mathrm{Hf}$. (Archires dép. de Mrinthe-et-Moselle, B :3:30,

Boussac de, - Famille.

60\%. - Cartulaire de la famille de Boussac: ms. du XTe siècle [rers $1430]$, contenant des actes des $\mathrm{XIII} \mathrm{e}^{\mathrm{e}}-\mathrm{X}^{\mathrm{e}}$ siecles. sur papier. in $-4^{0}$ de 134 tt. (Archices de .I. G. Clément-Simon, au chàteau de Bach. Corrèze).

Cf. les Recherches de lhistoire civile et municipale de Tulle avant l'érection du consulat, par G. Clément-simon. - Textes en dialecte limousin, très précieux pour l'état des terres et la cundition des persunnes

Boussagues. - Seigneurie en Languedoc.

608. - PlBI. : Recueil des chartes de Boussagues. par F. Pasquier (Bulletin de la Srciété scientifique et archologique de Bésiers. $3^{\text {e }}$ série. III, 1900, pp, 243-412).

Bouvignes. - Ville.

609. - Cartulaire municipal de Bouvignes: ms. du XVIle siècle. sur papier. contenant des actes de 1213 a 1607 . in-folio de $91 \mathrm{ff}$. Archires communules de Bourigurs, Belgique.

Publ.: Cartulaire de la commune de Bouvignes. par Jules Borgnet. Namur. Wesmael, 1862; in- $8^{\circ}$ de Lxxi-3:36 et :394 p. [Documents inédits concernant l'histoire de la province de Xamur.] 
Bouxières-aux-Dames. - Abbaly dioc. de Toul. (il0. - Pubi. : L'abbaye le Bonxières, par Henri Lepare (16rumires de

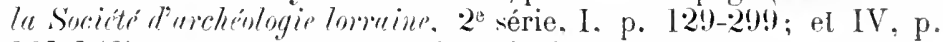
121-148); et à part: Nancy, 18.59 , in-80 le 144 p., et Nancy, s. d. $\left[18(i 2]\right.$, in- $8^{\circ}$ de $28 \mathrm{p}$.

611. - Cartulatre de l'ahhaye de Bonxières-aux-1)anes: ins. du XVIII" siècle, sur pipier, in-4" de 2:3 ff. (Biblinth. de la rille de Nenry, ms, .595, 11. 228-251).

Bouzonville. - Abbay dioce de Melz.

(il2. - Cartulazire de liabbaye de Bouzonville [fragment]; ms. du XVIII siecle, sur papier. in-to de $22 \mathrm{li}$. Archires de Lormine, à Nelz, $\mathrm{H}$ :35)!).

Brabant. - Dwhe.

61:3. - Diplomala Brihantiae; ms, du XVHIE siècle, sur papier, contenant des textes de 978 à l.5.3.) in-folio le 282 pages (1rchices royglis de Lul Ilayp. Papiers Créritrd. $\left.11^{0}: 34\right)$.

614. - Autre recueil de titres relitifs an duché de Brabaut: ms. du XIXe siecle, sur papier, contenant 102 a ates le 1078 à 1631 , in- $8^{\circ}$

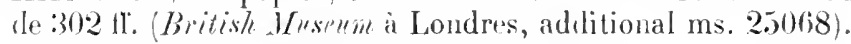

(i15). - Aulre cartulaire: ms. du XVIIL siècle. sur papier, contenant des actes de 1:3:3: a la fin dn XVIII siecle, in-folio de 10.5 li.

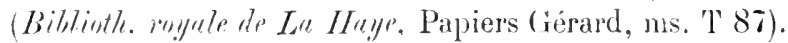

Bracancourt. - Courent des Minimes dioc. de Langres). (ilti. -- Cartulaire dés Vlinimos de Bracincourt : ms, daté de 1.527,

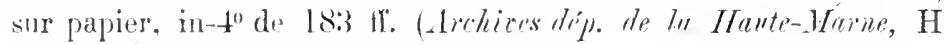
non coté).

Le courent fiut fonde en 1466 .

Braisne. - Abbaye de Saint-Yvol illoce de Soiscons.

617. - Cartulaire de l'abbaye de Saint-Tverl de Brajsne: nis. du XIII" siecle, aver quelques additions dı XVI", sur parehenin, in-t" (le ?l:s p. (Archires nutionules. LL 1.88:3).

Dates extrinn: $11: 35-1226$.

Cf. Note sur le cartulaire de Brine. par St. Prioux (Bulletin de lu

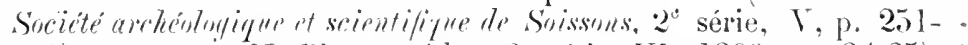
269): - el par II. Platean (iflem. 3e série, VI, 1899, p. 84-85).

lixtraits fails pour Gainnières (Biblinth. nutionale, ms. latin 549. pp. 57-110; et coll. Clanrambault 561. p. 40.7-416).

Bran. - Prisuri dior. de Poiliers.

6I8. - Carbulaire du pripuré de Bran, dép’ do l'abbaye de Marmou- 
tier: ms. en forme de pancarte sur parchemin. du XII" sièrle (Archices dép. de la T'eudér. H non coté).

Voy. aussi Marmottion.

Bray. - Prieuré do Saint-Victor, prés de Montrpilloy diuc. di. Senlis.

619. - Cartulaire du prieuré de St-Victor de Bray : ms. lu Xl1" siècle. sur papier, avec table en tète, contenant des actes de 1248 a 1488 .

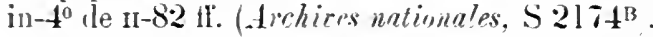

La reliure en rau, du temps, est foubles dre frapnents din incunable.

Bray-sur-Somme. - Ville.

620. - Fragment d'un cartulaire municipal de Bray-sur-Somme: ms. du $\mathrm{XVII}^{\mathrm{e}}$ siècle, sur papier, contenant des titres depuis 1210. in- $t^{\circ}$ de 20 If. (Archices inmicipales de Bray-sur-Somme, At 3).

Brem. - Voy. Brax.

Bretagne. - Duché.

621. - Cartulaire des privilegres judiciaires de la Bretagne: ms. du $\mathrm{X} \mathrm{V}^{\mathrm{e}}$ siècle. sur papier, in- $4^{\circ}$ de $96 \mathrm{ll}$.. contenant 86 pièces des années 1220-1451 Archices tép. de la Lisire-Inférieurr. Ii 113.

622. - Cartulaire de Bretagne; ms. du $X \mathrm{~V}^{\mathrm{e}}$ siècle. sur parchemin. in- $4^{\circ}$ de 114 fi., contenant 190 chartes ales années 12:20-1417\% (Archices dép. de la Luire-Inférieure, E 2:36)

623. - Cartulaire des fiefs des ducs de Bretagne en Angleterr : ms. du XIV'e sièrle, sur parchemin, contenant des actes des années 10616 à 1398, in-folio de $40 \mathrm{ff}$. (Archices trip. te le Lrive-Infrientre, E. 116 .

Contiont le texte der 4 chartes en langrue rulgaire.

624. -- Bullaire de Bretarne: ms. lu XVe siècle. contenanl la Iranscription de 85 pièces des années 12:39-1456. in-folio d 140 tf. (Archices dip. de la Loire-Inferivere. E .5.5.

Breteuil. - Abbare (dioc. de Beanrais.

625. - Cartulaire de labbaye de Bretenil : oriy. perdu.

Extrait fait an $\mathrm{IVll}^{\mathrm{e}}$ siècle (Biblinth. nutionule. m. français 9499 , p. 354).

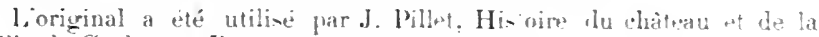
rille de Gerberoy (Rouen. lisas. in-t" .

Bretteville-le-Rabet. - Commambrie dinc. do Bareux .

626. - Rerueil de chartes rulatives a la commanderie de Brotterille-lpRabet: ms. réligé en 1497 d'après les originaux par un notaire 
apostolique, sur papier. in-t $t^{0}$ de $10 \mathrm{fr}$. (Archives nationales, $\mathrm{S}$ $\left.5048^{13}\right)$.

Dates extrèmes: $1204-12 \approx 0$.

627. - Autre recneil du $\mathrm{XVII}^{\mathrm{e}}$ siècle, sur papier, in-to de $8 \mathrm{ll}$. (Archives nationales, $\mathrm{S} .5048^{\mathrm{B}}$ ).

Breuil-le-Vert. - Seigneurir en Beauvaisis.

628. - Carlulaire de Brenil-le-Vert; ms. dressé en 1548, contenant des documents du $\mathrm{XVI}^{\mathrm{e}}$ siècle. in- $4^{0}$ sur parchemin de $18 \mathrm{ff}$. (Archices de chatrau de Chantilly, $\mathrm{n}^{0} 10 \mathrm{~s}^{\text {") }}$ ).

Briançon. - Villı.

629. - Cartulaire municipal de Briancon ou «Livre du roi », ms. de la seconde moitié du XVI siècle, transerit par Louis Olivet, procureur du roi, in-folio (Arehives municipules de Brianson).

Pebl. : par Finché-Prmelle, diuns le Bulletin de l Académie delphinule, I (1846). p. 409-422, 478-49:3, 546-562, 65:3-667, 675-682, 686-709 ; II (18.50). p. 1336-156, 305-315 et 318-326.

\section{Briançonnais.}

630. - Cartulaire du Briançonnais; ms. dı XVIe siècle, sur papier, contenint des tilres de 13222 à 1.547, in-folio de $61 \mathrm{ll}$. (Biblioth. de la rille de Grenoble, ms. 1651).

6:30 bis. - Publ. : Les transactions d'Imbert dauphin de Viennois, prince du Briançonnais et marquis de Sezanne, par Claude Desponts et Jean-Étienne Rossignol. Grenoble, 1ti4t, in-folio.

Réimprimé en 1645,1781 et 1788.

Bricquebec. - Seignemrie en Normandie.

631. - Cartulatre de la baronnie de Bricquebec; ms. exéculé en 140.) par Nicolas Demonts, contenant 11:3 pièces depnis 1189, in- $4^{0}$ de 76 I1. (Biblinth. de la rille de Caen, coll. Mancel, $\mathrm{n}^{0}$ :38.5).

632. - Autre cartulaire du XIVe siècle, sur parchemin, contenant des actes de 1194 à 1:349, in-40 (le IV-4t II. (Biblinth. de la ville de Rour!. ms. supplt 1399$)$.

provient de la eollection Julien Félix.

Ci. Les cartulaires de la baronnie de Bricquebec, par Léopold Delisle (Annuaire de la Vanche. 1899, $71^{\mathrm{e}}$ année, p. 11-34), et à part : St-Lô, 1899, in-80 de $26 \mathrm{p}$.

633. - Fragment d'un cartulaire de la seigneurie de Bricquebec: ms. du XIV" siècle, sur parchemin, in-4" de l.) ff. un peu endommagés et cotés 68 à 82 (Biblinthèque de l'auteur).

Brie-Comte-Robert. - Ville.

634. - Cartulaire des biens posséclés par l'abbaye de Saint-Y̌ictor à Brie- 
Comte-Rohert et environs (Beaurose. Grégy, Combs-li-Yille, Yëre., Grosbois, Chanteloup et Villenenve-Saint-Georges); ms. des XIT"e$\mathrm{XVI}^{\mathrm{e}}$ siècles, sur papier. contenant des actes de 1170 environ à 1513 , in $4^{\circ}$ de $95 \mathrm{fl}^{\circ}$. (Archices nationales, S $\left.2174^{1}\right)$.

Briey. - Ville et chàtellenic.

635. - Recueil de titres relatifs à la ville et chàtellenie de Briey : ins. de la fin du $\mathrm{XVI}^{\mathrm{e}}$ siècle, par Thierry Alix, sur papier, contenant des actes de 1189 à 1591 , in-folio de $42: 3 \mathrm{ff}$. (Archices dép. de .Meurtheet-1Yoselle, B 349).

Copie du précédent, rlu XVIe siècle, sur papier, in-folio de $3506 \mathrm{ft}$. (Archices dép. de la Mewse. B 239).

636. - Autre recueil de mème nature, contenant des actes de 1213 a 1453. in-folio de 12!) tf. (Archices dép. de Menthe-et-Woselle. B 3:34).

\section{Brignoles. - Ville.}

637. - Cartulaire ou « livre rouge » de la ville de Brignoles; ms. de la fin du XIVe siècle, sur parchemin. contenant des actes à partir de 12:37, in-4 de $177 \mathrm{ff}$. (Archices municipales de Brignoles, AA 1).

638. - Autre cartulaire contenant la traduction en français dı «livre rougre »; ms. de 1597 . sur papier, in- $4^{0}$ de $161 \mathrm{ff}$. Archices muncipa'ps de Brignsles. At 2,

639. - Cartulaire on « livre vert » de la ville de Brignoles; ms. de 1625, contenant également la traduction française des actes trans(rits dans le livre ronure. sur papier, in- $4^{\circ}$ de $258 \mathrm{ff}$. Archires municipales de Brignoles, A. 3 .

Brion. - Prieuré de St-Gervais et St-Protais dioc. d'Angers'.

640. - Cartulaire du prieuré de Brion, dépendant de l'abbaye de StAubin d'Angrers: ms. du XVII ${ }^{\mathrm{e}}$ siècle. contenant 40 actes dev années 1050-14ti6. sur papier, in-folio de $27 \mathrm{ff}$. (Archires dép. de Iraine-et-Loire, $\mathrm{H}$ non coté .

Briostel. - Abbaye. - Voy. Laxixor (au supplément.

Brioude. - Église Saint-Julien 'dioc. de Saint-Flour'.

641. - Cartulaire de St-Julien de Brioude ou « Liber de honoribus sancto Juilano collatis » : orig. perdı.

Copie incomplète du précédent : ms. du XVII siecle [167i], sur papier, in $-4^{0}$ de $254 \mathrm{fi}$. Biblioth. untionale, ms. latin 9086 .

On n'y trouve plus que la tran-cription de 341 actes, les plus ancienremontant an VII e siecle. Cöst l'ancien no 2641 du Catalugu Joursanvault. 
Extruils des précélent, faits an XVII siècle (Bihlioth. nationale, ms. lalin 17078, fl. 1-80: - ms. latin 12704. ff. 25-27; - coll. Baluze, vol.XIY et LXXII ; - coll. Duchesne, vol. XXII, ff. 8-27).

Pébl. : Cartulaire de Brioude, par H. Doniol. Clermont-Ferrand, Thibaud, 186:3: in-4" de:384 p. [Académie des Sciences, BellesLeltres el Arts de Clermonl-Ferrintl.]

("ist la lepurabction exacte nt non critique du ms. latin 9086 .

(Cf. : Essai sur la chronolugie du cartulair' de Brioude, précédé de quelqu's uhservations sur If texte de ce cantulaire l'après de nouveaux manuscrits, jar A. Bruel (Bibliotheque do l'École des Chantes, $6^{\mathrm{e}}$ série, 1I. $1 \times 66,1$, 445-508). Dans co travail, ou l'on trourera le texte de

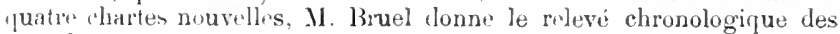
$2 \times 9$ chartes (756-10915) yu il a lu dater, avoc l'indication du no de la (-Harte dans la publication Doniul et du no qu elle portait dans l'original jerrilu.

642. - Antre recueil de copies, in-folio de 1:37 ff. sur papier, de plusieur's mains, fait au XVII siècle (drhives nationales, $\mathrm{R}^{2} 69$ ).

Sioun ce dernin' nuntéro, on 'onserve les 6 faneux feuillets détachés l'un ancien cartulaires du Xlp sivele ef publiés par l3aluze en 1695 ; on sait quer a's fiuillets, favorables aux pretentions de la maison de l3onillon dont Baluze était l'histurien. on tété à juste titre suspectés de fausseté, of ont donne lieu au retentiswant procès do lierre De Bar et consorts, dont pourtant Doniol ne parte point (cf. Arithes wationnles, L 104310.17 of 1738 . at Bibliothigne Ste-(ieneriere, ms. 824), et dont M. A. de Buislisle a projeté d'écrire l'histoire létaillée. Des pirces fausses et des

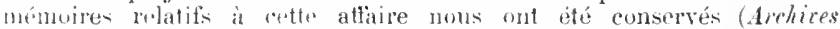

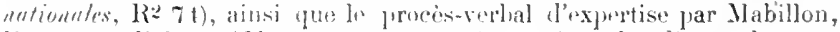
Ruinart ot Baluze (Idem, musere $n^{\circ}$ 9(01). - Aver les divers ciléments (que .11. Bruel a signalés dins son travail, on pourrait augmenter la jublication du cirtulate de Brioule du texte do 80 chartes authentiques 'fui tres probablenent figuratent dams l'original perdu.

643. - « Manus chartularius erclesie Brivatensis 》 : orig. perdu.

lixtrails faits an XVI" siede par Baluze Biblioth. nutionule. ('oll. Baluze. vol. LXXII. 1l. 14-45.

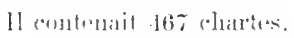

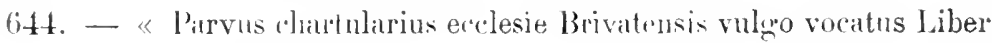
virilis $\gg:$ oriı. periln.

Extraits farits an XVII" siècle pall Baluze Billinth. mutomale, coll. Baluze, vol. LXXII, (T. 5:3-81).

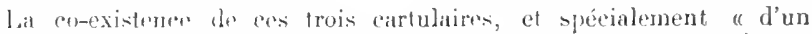
troisinne atusi crantol, aussi ancicu et plus complest que celui cechappé i) l'imencie n, est aftirnée par le proces-verhasl. fuit le 29 avril 1697 . dre qurlyues titres trouvés dans la tresor du Chapitre de Brioude après

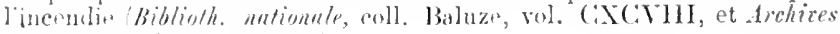
nutionetes, $R^{2}$ (it). to $\left.1334 \mathrm{r}^{\circ}\right)$.

Brioude. - Ville. - Toy. BrivadoIs. 
Brissarthe. - Prieuré de Votre-1)ame (lion. d'Angers.

645. - Recueil de chartes concernant le prieuré de X.-I). de Brissarthe, dép' de l'abbaye de Saint-Serce: ms. du XVI' siècte. contenant la copie de 35 documents depuis le XII siècle jusqu'en 148:3. sur papier, in-4" (Archices dép. de Waiue-pt-Loive. H non coté).

Brivadois. - Pays.

646. - Publ. : Spicilegrium Brivatense: Recueil de documents historiques relatifs au Brivadois et à l'Auvergne, par Aur. Chassaing. Paris, Impr. nat., 1886 : in $-4^{\circ}$ de $\left[\mathrm{IV}^{2}\right]-\mathrm{xvII}_{-15} 2$ pares.

Dates extrêmes : 874-1709.

Brive. - Ville.

647. - Recueil d'actes relatifs à la ville de Brive : ms. du XVIII siècle. sur papier. contenant des actes de 1355 à 1588 Biblioth. nationale, coll. Bréquigny, rol. XLIV. ff. 147-175).

Brix. - Forèt. - Voy. Chenbolra abbayr de Y.-D. du Vou de'.

Broechem. - Seigneurie. - Voy. Oelegles.

Brogne. - Abbave de Saint-Gérard (dioc. de Namur.

648. - Cartulaire de l'abhaye de Brogne: ms. du XVe sièle, sur parchemin, contenant des actes de 986 à 142 , in-folio Archices de l'Etat à Timur .

649. - Autre manuscrit du XVIII siècle, sur papier, contenant deactes de 932 a 1765 , in-folio Archires de l'Etat à Vamur'.

Bruges. - Abbaye d'Eeckhoutte. - Voy. Eecrioctтe.

Bruges. - Abbaye de Saint-André.

650. - Cartulaire de l'abbaye de St-André de Bruges: ms. du $\mathrm{XVI}$ siècle. sur papier, contenant des actes de 1:32:2 à 1466 , in-folio de $252 \mathrm{fi}$. (Archices de l'Etat ù Bruges.

651. - Autre recueil du XVII siècle. sur papier, contenint des actes de 1100 à 1624, in-folio de 142 lif. Archices de l" Etut à Bruges.

652. - Autre recueil dn $\mathrm{XVII}^{\mathrm{e}}$ siècle. sur papier, contenant des actes de 1177 à 1627 , in-folio de 5̆.jl tr. (Archices de l'Étut à Bruges'.

653. - Autre recueil du XVII siècle, sur papier, contenant des acter de 1203 à 15030. in-folio de $222 \mathrm{ff}$. Aichices de l"Étnt à Bruges.

Bruges. - Chapellenie de Jérusalem.

654. - Cartulaire de la chapellenie de Jérısalem à Brưres: ms. du $\mathrm{XVI}^{e}$ siècle. sur parchemin, contenant des titres de 1428 à 1519 , in-folio de 87 If. (Archices do l'etat à Bruges'. 
Bruges. - Chapellenie de Saint-Liévin an Béguinage.

655. - Cartulaire de la chapellenie Saint-Liévin à Bruges; ms. du XTIle siècle, sur papier, contenant des actes de 1185 à 1624 , in- $4^{0}$ de 3 今̆ $\mathrm{fl}$. (Archives de l'État à Bruges).

Bruges. - Collège des Jésuites.

656. - Cartulaire du collège des Jésuiles de Brugres; ms. dı XVII siècle, sur papier, contenant des actes de 1220 a 1510 , in-folio de 6339 fit. (Archives de l'Etat à Bruges).

65\%. - Autre recueil du XVII siècle, sur papier, contenant des actes le 1281 à 1615 , in-folio de 5.35 If. (Archives de l'Etat à Bruges;.

658. - Autre recueil du XVII siècle, sur papier, contenant des actes de 1332 à 1614, in-folio de $120 \mathrm{fr}$. (1rehices de l"Étut à Bruges).

659. - Autre recueil du XVII ${ }^{\mathrm{e}}$ siècle, sur papier, contenant des actes de 1569 à 1596, in-4" de 165 f\%̈. (Archives de l'État ì Bruges).

Bruges. - Commanderic. - Voy. Strates.

Bruges. - Consulat d'Espagne.

660. - Publ. : Cartulaire de l'ancien consulat d'Espagne à Brugres; Recueil de clocuments concernant le commerce maritime et intérieur, le droit des gen: public et privé, et l'histoire économique de la Flandre, par L. (rilliodts-Tan Severen. I-II (1280-1777). Bruges, impr. de Plancke, 1901-1902; in-4" de vn-642 p.

Bruges. - Couvent de Notre-l)ame-du-Mont-Carmel.

661. - Cartulaire de Notre-Dame du Mont-Carmel à Bruges: ms. du $\mathrm{XVI}^{\mathrm{e}}$ siecle, sur parchemin, in-4" de 10:3 $\mathrm{tl}$. (Archices de l'btat is Bringes.

Bruges. - Convent des Carmélites de Sion.

662. - Cartulaire des Carmélites de Sion à Bruges: ms. des XVII"XVIII sièrles, sur papier, contenant des titres de 1544 à 1713, in-folio de $827 \mathrm{ll}$. Archices de l" Etut à Bruges).

Bruges. - Couvent des Chartreux ou du Val-de-Gràce.

663. - Cartulaire des Chartreux de Bruges : ms. des XVe-XVIe siecles, sur papier, contenanl des titres de 126:3 à 1513, in-folio de 468 If. Archices de l'Etat à Brorges).

Bruges. - Couvent des l)ominicains.

664. - Cartulaire des Dominicains de Bruges: ms. dn XVIIe siècle, sur papier, contenant des titres de 12222 a 16.58 , in-folio de $4 \mathrm{I}_{2} \mathrm{ft}$. (Aichices de l'Étut ì Bruges). 
Bruges. - Église collégiale Saint-Donatien.

665. - Recueil des chartes de la collégiale Saint-Donatien de Bruges: ms. de la fin dn $\mathrm{XV}^{-e}$ siècle. sur parchemin. contenant des actes de 961 à 1240, in-folio de $196 \mathrm{ff}$. (Archices du Grand-Séminare de. Bruges, ms. n" 1+/12).

Bruges. - Estaple.

666. - Publ. : Cartulaire de lancienne estaple de Bruges: recueil de documents concernant le commerce intérieur et maritime, les relations internationales et l'histoire économique de cette ville, par L. Gilliodts-Yan Severen. Bruges, impr. De Plancke, 1903-1906 ; 4 vol. in $-4^{0}$ de Iv-747, viII- 744 , viII-737 et viI-680 p.

Recueil de chartes analystés ou publiées à partir de l'année 1168. Il sera suivi de deux autres volumes sous le titre de "Cartulaire du Grand Tonlieu v.

Bruges. - Hospice Saint-Aubert.

667. - Cartulaire de l'hospice Saint-Aubert de Bruges: ins. du XV"e siècle, sur papier, contenant des documents de 1277 a 1416 , in-4 de 112 if. (Archices de l'Etat à Bruges).

Bruges. - Hòpitaux. - Voir ci-dessous au « Supplément ». Bruges. - Prévôtẻ de Saint-Donatien.

668. - «Privilegiebouc van den prooschen ende canonixschen van Brugge »; ms. du XVIe siècle, sur parchemin, contenant des actes de 1089 à 1569, in-folio de $87 \mathrm{ff}$. (Archices cominunales de Bruges).

669. - Autre recueil relatif aux privilèges de St-Donatien; ms. du XIVe siècle, sur parchemin, contenant des actes de 1089 a 133 ‘. in-4o $(K . K$. Hofbibliothek zu Wien, ms. Jur. civ. 239. If. 37-46).

Bruges. - Ville.

670. - «Rudenbouc, ou cartulaire de la ville de Bruges; ms. des $\mathrm{XIV}$ - $\mathrm{X} \mathrm{V}^{\mathrm{e}}$ siècles, sur parchemin, contenant des actes de 1271 à 1484, in-folio de $119 \mathrm{ff}$. (Archices comimunales de Bruges).

671. - «Gheluwenbouc »; ms. du XVI siècle, sur parchemin, contenant des actes de 1279 a 1567 , in-folio de $234 \mathrm{ff}$. (Archires cominunales de Bruges).

672. - "Groenenboeck C »; ms. du XVIe siècle, sur parchemin, contenant des actes de 1281 a 1248 , in-folio de $418 \mathrm{ff}$. (Archices communales de Bruges).

673. - «Groenenboeck B»; ms. du XVIe siècle, sur parchemin, contenant des actes de 1236 à 1593 , in-folio de $418 \mathrm{ff}$. Archires communales de Bruges).

Le a Groenenbouc A ", existe aussi, mais comme il comprend spécia- 
lement des décisions et sentences du magristrat do Bruges, il n’a pas droit it prendre plaes parmi les cartulaires.

674. — « Wittenbouc B 》: ms. du XVIe siècle, sur parchemin, contenant des actes de 1514 à 1582 , in-folio de 114 fl. (Archives couiminules de Bruges).

Voir aussi vo Fraxc de Bricies.

Bruxelles. - Abbaye de Saint-Jacques-sur-Catudenberg.

675. - Cartulaire de labbaye de Saint-Jacques sur Caudenberg à Bruxelles : ms. du $\mathrm{X} \mathrm{T}^{\mathrm{e}}$ siècle, sur papier, contenant des documents de $11: 31$ a 1514 . in-40 de 71 ti. (Archives du royume de Belgique, à Bruxelles).

676. - Antre cartulaire; ms. du XVe siècle, sur parchemin, contenant des documents de 1225 a 1429, in-4 ${ }^{0}$ de 120 ll. (Archives du royanme de Belgique, à Bruxelles).

67\%. - Autre cartulaire; ms. du XVI ${ }^{\mathrm{e}}$ siecle, sur parchemin, contenant des documents de 1325 à 1404, in-folio de 83 fi. (Archives du roymerme de Belgique, à Bruxelles).

Bruxelles. - Abbaye du Saint-Sépulcre.

678. - Recueil des titres le labbaye du Saint-Sépulcre de Bruxelles: ms. du XVIII" siècle, sur papier. in-folio de $196 \mathrm{II}$. (Biblioth. royale de le Haye. Papiers Gérard, 'T 96).

Dates "xtrênes : $1078-1605$.

Bruxelles. - Béguinage du Wyngaert.

679. - Cirrtulaire lu béguinage de Wyngaert a Bruxelles; ms. du XYe siecle, snr parchemin. in-4" de $381 \mathrm{H}$. (Archices du royaume de Belgiqu", à Bruxelles).

battw extrêmes: 1250-1415.

Bruxelles. - Courent de Jéricho.

680. - Cartulaire du couvent de Jéricho à Bruxelles: ms. du XVI siecle, sur papier, contenant des actes de 1355 à 1537 , in- $4^{0}$ de 29 pages (Archires due royaume de Belyique, à Bruxelles).

681. - Antre recueil du XVII ${ }^{e}$ sieccle, sur papier, contenant des actes de 1131 i 1441 . in-4" (Archices du royaume de Belgique, à Bruxelles).

68:. - Autre recueil des $\mathrm{XV}^{\mathrm{e}}-\mathrm{XVII}^{\mathrm{e}}$ siècles, sur papier, contenant des actes de 1399 à 1548 . in-40 de 400 fl. (Archives du royaume do Belgiqur'. à Bruxelles).

Bruxelles. - Couvent des Clarisses.

68:3. - Cartulaire du convent de Sainte-Claire de Bruxelles: ms. du 
XIVe siecle, sur parchemin, contenant des actes de l:370 a $1: 375$.

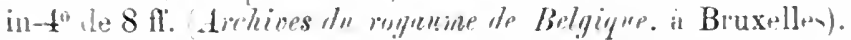

684. - Fragment d'un cartulaire alu coment des Clari-ses de Bruxplles:

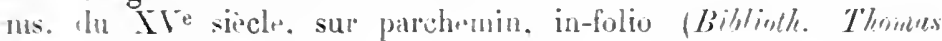
Thillipss. it Cheltonlatm).

Bruxelles. - Convent de Sainte-Eilisabell.

685. - Cartulaire du convent de Sainte-Filisabeth it. Bruxelles; 1n. les XVIe-XV111 siecles, contenant des actes de 1419 it 1779. an 7 vol. in-folio dont 5 sur parchemin et 2 sur papier (.1\%hires d, royaum, de Belyique. à Bruxplles).

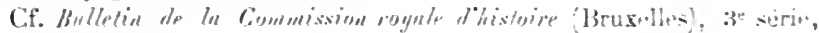
III, p. 1:1-1:4.

Bruxelles. - Eglise cathédrale Sainte-Gudule. - Voir cidessuus au «supplément».

686. - Recueil de chartes relatives à léglise Saintr-Gulule de Bruxelles, dans la « Brabantiae historia diplomatica 》 de P. a Thymo: ms. du XVe siecle. sur parchemin. lomes Il et IIl, in-folio (. Lirhires cominumales de Brirelles).

Bruxelles. - Église Notre-Dame de la Chapmlle.

68\%. - Cartulaire de l'église X.-D. de la Chapelle à Bruxellos: ms. du XVIII siècle, sur papier. in-folio (Billkish. roynte de Balyigue. à Brixelles. ms. 1658:3).

Exirait du précédent. fait au XIX"e siècle, sur papier, contenant

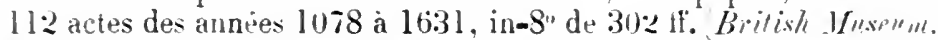
à Londres, ms. additional 25068\%.

Bruxelles. - Église siaint-Jean-au-Marais.

688. - Cartulaire tle l'eglise Saint-Jean-au-Marais de Bruxellts; m. du XVIIJ siècle, sur papier, contenant des actes de 120:3 à 1702,

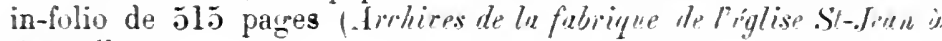
Brisolles.

Bruxelles. - Hospire de Saint-Saurar.

689. - Cartuline de l'hospice de Saint-Sauveır à Bruxelles: ms. du $\mathrm{XVl}^{\mathrm{e}}$ siècle, sur parchemin, contenant des actes de 139.5 a 1.0403 .

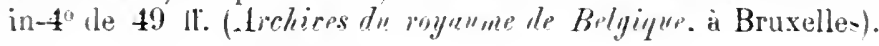

\section{Bruxelles. - Ville.}

690. -- « Groodt hoeck mette knoopen»: ms. des XIVe-XVe siecles, sur papier et parchemin, arec reliure en bois recouverte de cuir gaufré, à fermoirs et clous de cuivre. cuntenant des actes de $119^{\circ}$ à

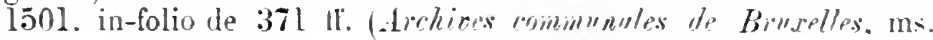
$36)$. 
691. - « Boeck met de ketinck» ou « livre ì la chaine »; ms. du $\mathrm{XV}$ siecle. sur parchemin. avec une reliure de bois recouverte de cuir. it clous de cuivre, contenant des actes le 12:25 a 1392 , in-folio de 113 1l. à 2 col. (.1rchiés communules de Broxelles, ms. 35).

692. - « Copye van de origineele privilegrien der Stadt Brussel »; ns. dn XVIII" siecle. sur papier, contenant des actes de 1226 à 1:378, in-folio de $15 \mathrm{l} 111$. i '2 col. (Arehires rommunales de Bruxelles, ms. 37 ).

69:3. - « Het borck metten hare » on « Liler crinium»: ms. dés XIV"-XVle siecles, sur parchemin, aver une reliure de bois recouverte decuir blanc a fermoirs de cuivre, contenant des actes de 1229 a 1.007, in-lolio de :50 ll. (Arehires rommunales de Bruxelles, ms.31).

Ciopie du précédent. laite au XVII" siccle, sur papier. in-folio de 6riti li. (Hichices communtes de Bruxell's, ms. 32).

694. - « Het Swerdt-hock» ou «ivre noir»; ms. du XVIe siecle, sur parchemin el papier, reconvert d'une reliure bois et cuir noir, a clous thrmoirsde cuivre, contenant des acles du XVe siècle juspa à 10̄40, in-lolio de 409 il. et lables (Archiors communales de Brmxelles, ins. $4(0)$.

Copie du précédent, taite au $\mathrm{XVI}^{\circ}$ siecle, sur papier, in-folio de

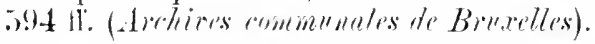

695. - « Hot Roodt Privilegieboek »; ms. du XVle siecle, sur parchemin, avec reliure en 'uir waulé, à fermoirs de cuivre, contenint des atctes de 1476 a 1497 , in-folio de :3:34 1l. (Archives commumules de Bindelles, ms. :39).

Copie du précédent (Biblioth. royale de Bruxelles, ms. $17157-$ 161).

ANA. : Inventaire des cartulaires elantres registres faisant partie des archives de la ville de Bruxelles, par Alph. Wauters. Bruxelles, Baertsoen, 1894; in-8" de xi-591 p.

696. - Ciatulaire le la ville de Bruxelles; ms. du XIV siccle, sur parchemin, incomplet, contenant des acles de 12:29 à $1347, \circ$ in-4 $4^{\circ}$ le 34 II. a 2 col. (Startbibliothek Bern. fonds Bongars, ms. 186).

Axal. : Note sur un cartulare de Bruxelles conservé à la bibliotheque de Berne, par Henri Pirenne (Bulletin de la Commission royale dristoire, 5e série, $1 \mathrm{~T}$, pp. 43-67); et à part: Bruxelles, Hayez, 1894: in-8" "le 27 p.

697. - Antre cartulaire; ms. du XIVe siècle, sur papier, contenant des chartes du IX siècle i. 1337 classées chronologiquement, sur papier, in-4" (le 116 11. (Biblinth. nationale, ms. l'onds néerlandais n" 4 ).

C.f. Crachard, I a Bibliothèque nationale à Waris, 1875, p. 293. 
698. - Autre cartnlaire : ms. th XVl" siecle, de plusienr main.

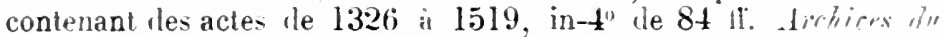
royamue de Belgigue, à Bruxelles'.

699. - «Privilegien der hoofustarlt Brussel »: 111\%. ln XVT" siecle. sur papier. contenant des actes de 1305 a 1595 . en 3 vol. in-4' de 62. 53 et 6.5 ff. Arehires tu mynn ine de Belgique. a Bruxelle-

700. - Autre cartnlaire: ins. du XIVe siecle. sur parchenin, conte-

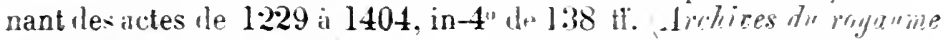
de Belginue, à Bruxelles;.

701. - Antre cartulaire: ms. du XVe sièrle sur papier. conlenant les

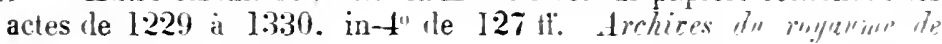
Belgique, is Bruxelles;.

702. - Autre cartulaire : ms. du XY siecle. sur parchemin. contenant

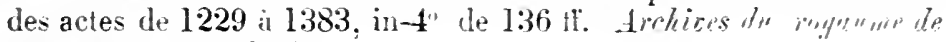
Belginge. it Bruxelles?

703. - Autre cartnlaire : ms. du $\mathrm{XV}^{-e}$ siècle, sur papior. contenant its

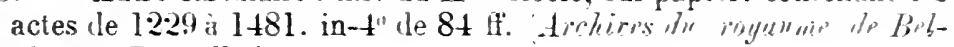
gique, à Bruxelles'.

$$
\text { Voir aumi vo Brabast. }
$$

Bucilly. - Abbare dioc. de Laonj.

704. - "Chartularim ablatiæ Buciliensis ע: ni. des XIII"-Xl Y"e siecles. sur parchemin. in-t" de $111 \mathrm{tf}$, Bibliwth. motimule. ms. latin 10121 .

Dates exlrènes: 1113-138y.

Axul. : Notices et extraits des documents manuscrits relatifs is l'histoire de la Picardie. par H. Cocheris. I. no 242.

- Cartulaire le l'abbare de Bucilly. par Élouard de Barthélemy Annales de la Surcite historique et archenlogique de Chatrun-Thiomy. 1881 [1882], p. 109-I67.

Buillon. - Abbare de Nitre-Damé diuc. de Besanȩon .

705. - Petit cartulaire de l'abbaye de Buillon : oric perdu.

Copie du précélent; ms. du XVIII siècle. sur papier Biblinth. natirimle, coll. Moreau, vol. 332. H1. 189-198.

Il ent à croiro qu'il existait aumi un "crand a cartulaire. Junt nous n'arons trouré aucune trace ni m.ntion.

Extraits faits au XVIII siècle Biblinth. de la rille de Brsturn, coll. Droz. ms. 74, if. 160-28:3 : - au XVII siècle. par René Du Cher (Biblisth. national, ms. latin 12746, p. 205).

Bulle. - Ville.

706. - PuBL. : Archices de la Sacirte ifhistuive du cunton de Fribung. $111(1871)$. p. 15+228.

Dates esirimos: 1253-1648. 
Cachan. - Village dioc. do Paris).

$70 \%$ - Cartulaire de Cachan, dép de l'abbaye de Saint-Germain-desPrés: ms. du XVIII siecle [150)]. par Pil. Duronssin, religieux, sur papier. contenant des actes de 1200 is 1742 . in-folio de $149 \mathrm{ft}$. Airlicess nationales, LL 1046 .

Gadouin. - Abbayn dioce de Sarlal.

708. - Cartulaire de l'ahliaye de Cadunin: mis. du XIII siècle, sue parchemin, de 77 [on 70 t11. : oridr.perdu.

Une copire en arait été faite par un X. Baudera, qui tut communiquées

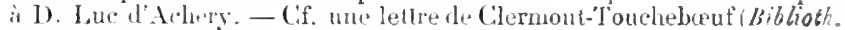

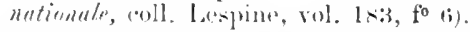

Extraits Biblioth. mationale. coll. Périgord, vol. XXXIII, $1^{0} 453$; vol. XXXIV. ${ }^{0} 106$, el vol. XXXYII, II. 161. 211-216 et 220-2:38), el par Dom Col (Idrim. ms. latiu 9196, paras 477-4!)3.

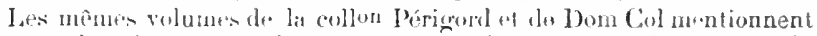
un eranul roulean "n pardirmin contenant des donations a l'ablatye de

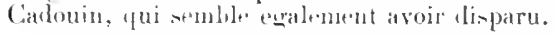

Caen. - Abbarre de la Trinité dioc. de Bayentx.

709. - Cartulaire de la 'Trinité de C'aen: ms. du XIII' siècle, de plusieurs mains, sur parchemin, incomplet de la fin, et contenant des actes a partir de 1080. in-8" de 11-95 $\mathrm{Il}$. (Biblinth. nationale, ms. latin .0660 .

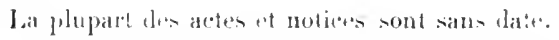

710. - Antre cartnlaire de la l'rinité de Cien; ms. du XIII e siècle, incomplet du début, avec additions du XIV", sur parchenin. contemant des documents jusqu "a 1:306, in-8" de !6 II. (Arehires dép. du Calradtax, $\mathrm{H}$ non coté.

Caen. - Abbaye dr. Saint-Étieme (dioe de Bayeux).

71l. - Carmlaire de l'abbaye de Saint-Étienne de Chan: ms. du XVIe siecle. sur papier. contenant des actes depuis le $\mathrm{XI}^{\mathrm{r}}$, in $-t^{0}$ de $100 \mathrm{ff}$. (.rehires dép. d" Cialsados. H non coté).

712. - Autre cartulitire de Saint-litienne de Caen ; orig. perdu.

Il bait probablenent lu XIle sièele et avait $81 \mathrm{fr}$. - Il en existe une analyn": "Index cartularii perretusti abbatiae saucti Stephani promartyric (adomensis ), ms. du XVIJe siecle, sur papier, in-4o de 102

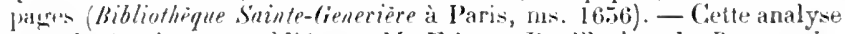
a che intégralenent publiée par .I. Etienne Deville dans la Rezue catholique de .'Formentip, t. XIV-XV', et à part: Analyse d'un ancien 'artulaire de l'abbay" dt saint-Élitenne de Caen (Évreux, impr. de l'Eure, 1905; in-8 1. 58 p.). (Cetle brochure forme le no 15 de ses " Notices sur quelguts manuserits normands conservets à la bibliothèque sainteGenevieve $).$

71:3. - Recueil de copies de chartes de Saint-Étienne de Caen, fait par M. Flays, garde du chartrier; ms. du XYIII siècle, sur papier, 
contenant des documents du Xle sieclo is 1732. in-folio en 10 cathiers

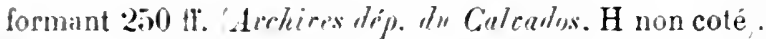

714. - tutre recueil lu XVIlle siecle, sur papier. contenant les docu-

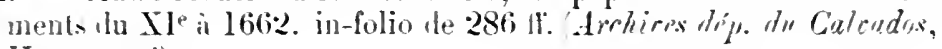
$\mathrm{H}$ non roté .

Caen. - College du Clutier.

715. - Cartulaire dn college du Cloutier i Caten: ns. ridligé en 1462 par le notaire Jean Le Briant. sur parchemin. in-4" de 26 ff. (Archices dép. du! Cialrados. I) 50.).

Caen. - Confrérie lo charite de Sint-Martin.

716. - Recueil des statuls des confrúries de charilé de la ville de Caen; ms. du XYlII" siecle, sur papier. in-folio de $261 \mathrm{fl}$. Arehires dip. du Ciulcurlus, (i non cote .

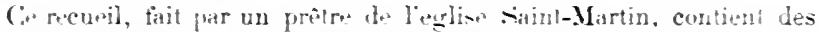

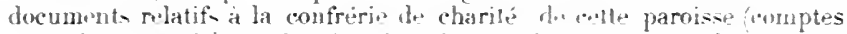

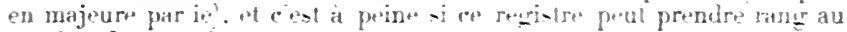
nombre des cartulaire.

Caen. - Viglise Saint-Pierre.

717. - Cartulaire de l'étrlise St-Pierre de Caen: ms du XVIe siecle. sur parchemin, [incomplet]. in-folio de $282 \mathrm{~m}$. Bibliath. natirnale, m. latin 17136 .

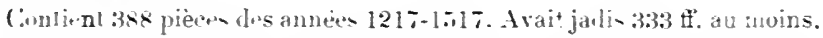

C.: : Note sur un cartulaire de Saint-Pierre de Caen donné à la Bibliolhèque nationale par M. de Caumont. par Léopold Delisle (Bulletin intoumentul. XXXIII, 186i. p. 31-38.

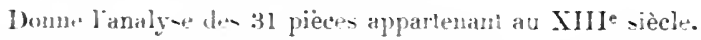

718. - Autre cartulaire de St-Pierre de Caen: ms. du XVIe siècle, [1515]. avec additions juqqu'au XVIII siècle. relié en bois couvert de pean, et contenant des actes depuis l'annee 1261. sur parchemin, in-1" de 383 ti. (Archires de Peglise Saint-Pieme de Cart).

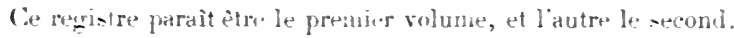

Caen. - Église Saint-Siluverr.

719. - Carlulaire de St-Sauveur de Caen : m. des AVe-XVI siecles. sur parchemin, in-folio de 67 If. Archires dép. de Calcadss. G non $\cot \dot{\mathbf{e}})$.

Caen. - Hòtel-Dien.

720. - Publ. : Recueil des chartres. statuts et regglements concernant l'Hùtel-Dieu et les paures renfermés de la ville de Carn. extraits 


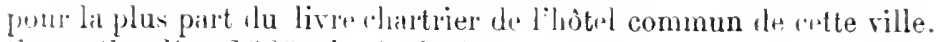
Ciren. Ciavelitr, 1686 ; in-t" de 40 p.

Gaen. - Uniwritie.

$7: 1$. - Matrolounium Lniversiatis Callommrsis » ms. contenant en partie les mallen artes royaux de priviliones. dh $\mathrm{X} \mathrm{Vl}^{\mathrm{e}}$ siècle, sur

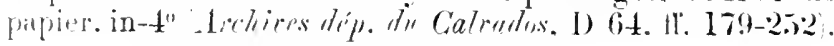

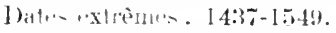

Axus. Inventaire sommaire les arclises départementales du (ialvalos série D. lome 1 1892 . pp. 171-180.

722. - tutre matrologe: ms. du XVI" siecle, in-4" Biblinth. It la rille dre Ciun, coll. Minnel, ms. 101:

Caen. - Vill..

723. - Prenrier matroluge on « le livre des orlenances, franchises et

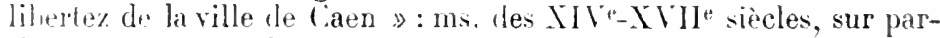
chrnin. convert d'me reliure en reau avec ilous et fermoirs en aront aux armes de lis cité, contenant les doruments de l:364 à

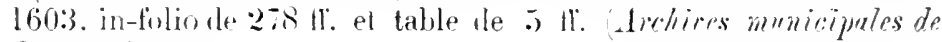
Curn. AA l .

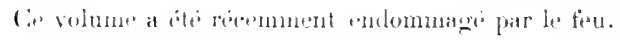

Axal. : Fitule sur la commune de Ciaen, suivie le la liste des écherins. anilyse du matrologe de la ville, par Pierre Carel. Caen, Nas-if, 1888, in-8" w. 111-31:3 p.

724. - Simond matrologe: ms. des XVI"-XVII" siocles, sur parchemin. antenint des documents de 1.586 i 1724 . in-folio de 95 ff. et

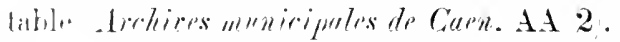

72.) - Rermeil de titres relatifs is la ville de liaen: ms. des XVIII XIX"siecles. par liabbe de La line. sur papier. in-to de 284 lf.

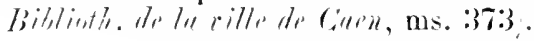

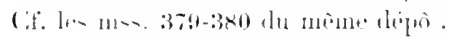

Cagnotte. - Mbliye (dioc. le Dax).

7.2ti. - Purs. : Fragment du cartulaire de Cagnutte, par l'abbé A.

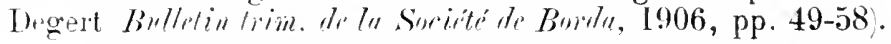

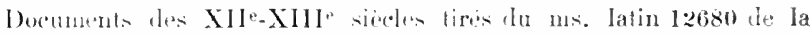

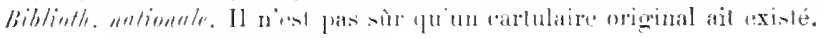

Gahors. - Collinge du Qurecy.

727. - Cirrulaite du collène de Cahors; m. du XVII' siècle. sur parchemin. contenant des actes de 1604 is 1653 , in-folio de $72 \mathrm{ff}$. Arlieres dip. dir Lot. D 8 .

725. - Recueil de tilres relatifs au collège de Cahors; ms. du XVII siecle, surpapier, in-folio (Biblioth. utationale, coll. Doal, vol. 121). 
Cahors. - Ériehr.

7:2!. - Recueil des privilioges de l'evèche de Cahors: nus. du XIt"

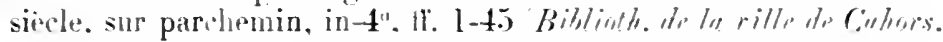
ms. 41 .

730. - Recueil de titres relatifs à l'évèché et in la cathélrale de lahors: $\mathrm{ms}$. le 1669 . contenant des artes les annè $1166^{\circ}$ à 1621 , in-folio de 2!18 ti. Biblinth. mitimele. coll. Doat. vol. 120 .

Cahors. - Lniversiti.

731. - Recueil de titres relatifs is l'Cniversité de Cahors: ms. de 1669. contenant tes acte des annees 13:31 is 1.538. in-folio de 194 fi. Biblinth. nutimull". coll. Doat, rol. 1:22.

Cahors. - Vills.

732. - Cartulaire municipal de Cahors: ms. du XY" siecle. - ar papier, contenant des artes le 1482 is I 498 , in-4" de 8.5 11 . Lrelines dip. ll" Lit. E 8.

733. - Cartulaire municipal on registre «Te initur »: ms. des XIIIXVle vieles, sur parchemin. aver reliure ancienne de hois. contrnant des documents de 1229 i 1590 . in-4" de $25.3 \mathrm{ll}$. Lirhires unnicipules de Caluras, At 1 .

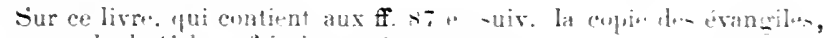

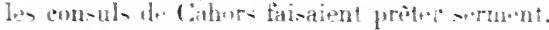

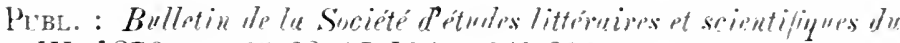
Lnt. III, 1876, pp. 6.5-68, 95-I04 et $241-270$.

734. - Antre cartulaire ou «registre tanné » : ms. des XIV"-AVIJ sierles. sur parchemin, aver me reliure ancienne de bois. conte-

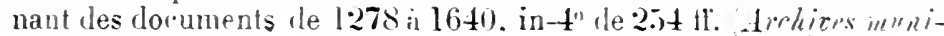
cipulos de Cinhoris. At 2 .

735. - Autre cartulaire un «live noir »: ms. des XIV"XVII" sierles, sur parrhemin. aver reliure ancienne de lioi-. contenaut iles documents de 1250 à 1650. in-folio de 182 t1. Arehires innicipules de Cahirs. AA 3 .

736. - Autre cartulaire on "live nunveau ": m. des XVI"-AVIII" sircles, sur parchemin. contenant des actes de 121 ! i 1659 . en 3 vol. in-folio de 276 . 312 et 204 t1. Archires mulemipales do Ciahors.

737. - Recueil de titres relatils à la ville de Calrors: ms. du XVII sièrle [1669]. sur papier, contenant de- doruments de $120: 3$ is $1.509 \%$ en 2 vol. in-folio de 30:3 et $291 \mathrm{ll}$. Biblinth. nutimunle. coll. Duat. rol. $118-119$. 
Calabre. - Abbaye (dim. de Sirlial).

738. - Cartulaire du monastire de Calalore: orir. perdu.

lixtraits faits an $\mathrm{XVHI}$ " siecle (Bibliolle. metimule, coll. Périgord, vol. XXX111, t1. 420-424).

Galmoutier. - Chapitre de Notre-Dame (dioc. de Besancon).

739. - Recneil de titres relatils au prieuré de N.-1). de Calmontier, copiés d'après les originaux conserves aux archives de la HauteSaône, par L. Rolert. en I873. sur paipier. in-4", Biblintlièque nutionule, ms. nouv. acq. litines 1241. pp. 11-21.

Calvi. - Ville.

740. - Livre des privilienes municipaux ou «lihro rosso " m.. des

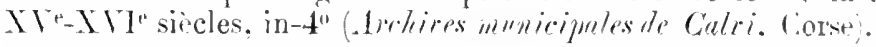

Cambrai. - Abbayede Saint-Auberl.

741. - Carmlaire de Situnt-Aubert de Cambrai: ms. du CV siècle aver adlitions du $\mathrm{XVI}^{\prime}$. sur parchemin, en 2 vol. in $4^{\circ}$ de $12: 3$ et 117 II. Briblinth. Ae la rills de Cumthrei, ms. 1144-1145'.

Cambrai. - Abhite du Saint-sépulere.

742. - Cartulaire de labbaye du Saint-S Supulıre de Cambrai; ms. du

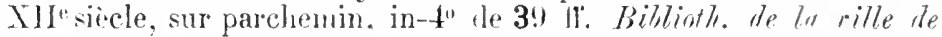
Ciembrai. ms. 122:2.

743. - Cirrtulaire de l'abbaye du Sainl-Sépulcre de Cambrai ; ms. du X Y" sièle, avec alditions jusqu'au XVIle ef me table, sur parchemin et papier, in-4" cle it el $480 \mathrm{lt}$. (Biblinth. de In rille de Cambrui, ms. $10+1$.

744. - Autredes XVIIe-XVII" siecles, contenaut des pieces de 1585 à 1711, sur paiplere, in-folio ale 2:30 et 14 II. (Billioth. de la rille de Camblai, ms. 1148.

745. - Camblaire de l'ahbilye du Saint-Sépulcre de Cambrai ; ms. du XVI" siècle. sur papier. "ontenant 173 pieres des années 1141 à

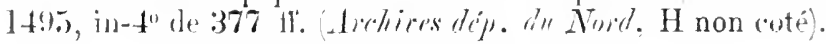

Cambrai. - Chapitre cathedral Notre-I)amr.

746 . - Cartulaire A de l'église rle Cambrai; nus. de la fin du XIIe siencle. sur parchemin, avec alditions postérienres, table en tête, et reliure ancienne en bois, contrmant 140 actes des années 817 à

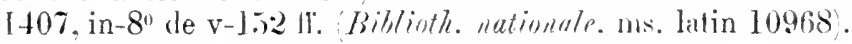

747. - Cartulaire B : perdu.

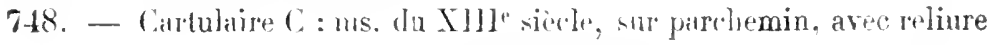




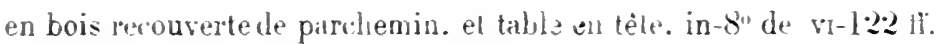
(Biblinth. matimule. ms. latin 10!96!)!

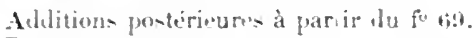

Datrs "xtrênes: $1111-1466$.

749. - Premirr cartulaire de Henri de Bermhes: as. du $\mathrm{X}$ ' siècle $[1+87]$, sur parchemin et papier, contenant 33 pieces de $11: 4$ is

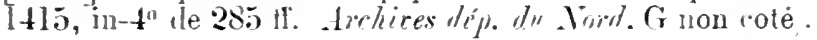

750. - Deuxième rartulaire de Henri de Berrles; ms. du Xle sierle, arec adlitions postérienres. sur papier et par.hemin, contenant 87

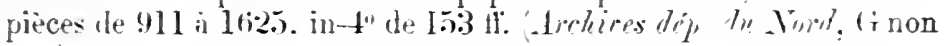
coté).

751. - Troisième cartulaire de Henri de Berules: ms lu X Ve siède. sur parchemin et papier. contenant ig pièces des années 1194 à 1500, in-4" de 289 ti. Archices dip. de Porr. G non coté.

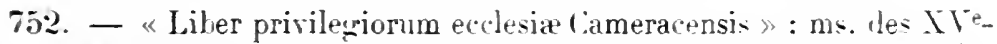
IVI ${ }^{e}$ siecles, sur parchemin et papier. contenant $t \bar{\tau}$ pièces des années 942-1507. in-4" de $190 \mathrm{d1}$. "Arclices dép. dl" Nird. G non cotée.

753. - «Liber primus titulorum ecclesiæ 'Cameracensis»: ins. du XVI siècle, sur papier, contenant 84 piece. des annees 12.5! a 158.5 , in-t" de $173 \mathrm{tr}$. Archires dép. du . Vird. G non roté.

754. - «Liber secundus titulorum ecrlesia Cameracensis »: ms. des XVIe-XVII sierdes. sur papier. contenant 84 pieces des années 1189 a 1608 , in-t" de 464 pages (Amhices dép. d" Nord, Gr non coté).

75. - "Novus lifer titulorum ecresia Camerarensis" ; recueil factice de 152 ropies te pièces des années 894 à 1780. sur papier,

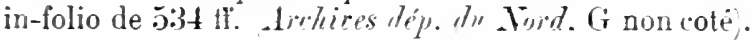

756. - Cartulaire du chapitre intitule «Arthesium »: ms. du XY"e siècle. sur papier" recourert d"une ancienne reliure de boi.. in $4^{\prime \prime}$ de rv-343 HI. Billioth. nationale, ms. latin 17736).

757. - Antre carmlaire: ms. les XVI'-XVIle siècles, sur papier, contenant 88 pieces des années 1545 à 1609 . in-folio de $176 \mathrm{tf}$.

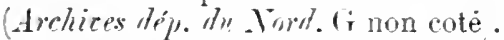

758. - Fragment d'un aulre cartulaire: ms. dn Xle siècle. sur parchemin, contenant 20 pièces des années 1182 à 1403 , in-fulio de 16 fi. Archices dip. J" Win. G non coté.

759. - Autre cartulaire : ms. du XVH ${ }^{\circ}$ siecle. sur papier. contenant 132 pièces des années 817 à $159 \%$. in-fulio de $326 \mathrm{HI}$. (4 trhices tép. du Mry. (i non coté).

Dans: L,* foml- Jo la cathedrale de fambrai aux archive departemen-

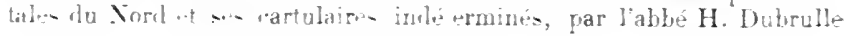




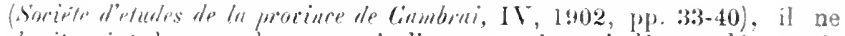
s'agit point de cen rolumes, mais d'autres registres indûnent dénommés cartulatiris.

760. - Recueil de litres relatifs au Chapitre métropolitain de Cambrai; ins. des X VIe-XVII" siècles, sur papier, in-10 de $184 \mathrm{ff}$. Biblinth. A, la rille trims, fonds Advielle, ms. 43.

761. - Cartulaire de l'échlise cathédrale de Cumbrai ; ms. Lu XIII -ifole. arec additions du XIVe, sur parchemin, in-4 ${ }^{0}$ Biblioth. dela cille the Cumbrai. ms. 1152. fi. 1-64 et 89-120.

$76: 2$. - Autre du XVIJ siecle. sur papier. in-4" (Biblinth. de la ville di Cinmthin. ms. 12:27. 11. 1-245.

Voir aturi ltw ms. 1028-1024)

763. - l'ens. : [Mutte]. Mémoire pour M. l'archerèque de Cambrai. Cinturai. 1772, in-t".

(antionl $1: 36$ andes de 81 is it 1 25:).

Cambrai. - Egliso collegiale Sainto-Croix.

7it. - Cartnlaire de l'église Sainte-Croix de Cambrai : ins. du SYo siecle, sur papier. avec table des documents. in- 4 " de xxy-490 ff. Biblenthe do lue rille de Ciemtrai, no. 1042.

Gambrai. - Élise collegiale saint-Gery.

76.5. - Liber prinus privilegiorm Sancti Gaugerici»; ms. des X I"-XVIII" siècles. sur papier. contenant 166 pièces des années

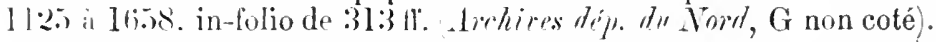
760. - " liber secmudus privilegiorum Sancli Gaugerici »: ms. des $\mathrm{XVI}-\mathrm{XVIl"} \mathrm{siecles.} \mathrm{sur} \mathrm{parchemin} \mathrm{et} \mathrm{papier,} \mathrm{cuntenant} 24 i$ pièces des annèe 1162 a 1434 . in-folio de $148 \mathrm{fl}$. Archioes dép. Al Nord, ir mon coté.

7ij. - Cartulaire de la collériale Saint-Géry de Cambrai ; ms. du $\mathrm{XV}$ sickle arec additions dn $\mathrm{XVI}^{\mathrm{e}}$, contenint (i3 actes depuis 1293 ,

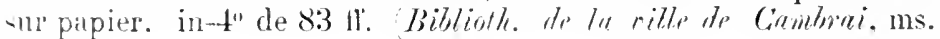
$1: 34^{2}$.

768. - Aulre des $\mathrm{XVI"}^{\circ} \mathrm{XVI} \mathrm{IJ}^{\circ}$ siecles, sur papier. contenant des actes

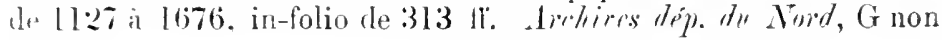
cute .

Gambrai. - Ioppilal Saint-Julien.

769. - Cartulaire de l'hòpital St-Julien de Cambrai; ms. du XIII sircle. arec additions du $\mathrm{XIV}$. écrit de quatre mains et à quatre reprises dilférentes, et contenant des artes de 1122 a 1377 , in-4" de 1.2.2 ti. Archires hospitulières de Cumbrai. I A 11).

Cupie partielle, par l'abbé Tranchant, du XVIlle siècle, sur papier, in-t" Biblisth. de le cille de Cambrei, ms. 1140 , fl. 118-231). 
770. - Autre cartulaire lu mème hópital: ms. du Ml' siecle. sur parchemin : orig. perdu.

lispie partielle dı précélent. par l'abbe Tranchanl: ms. du

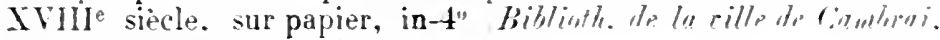
ms. 1007. Hi. 5i et sturi,

$$
\text { Dales :xtrên. : 111\%-1430. }
$$

Cambrai. - Hospice grineral.

771. - Cartulaire de l'office des chartrien de Cambrai : mo du $\mathrm{MVI}^{\circ}$ siecle, sur parchemin, contenanl de antes 1 to 1269 à 1561 , in- $4^{\prime \prime}$ de

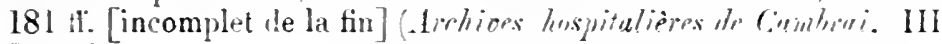
B 114).

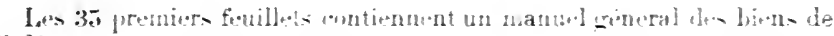
l'oftice.

772. - Cartulaire de loftice les paurres orphelins de Canbrai : ms. du XVIe siècle [1567-15\%4], avec denx ardelitions de 1610, sur papier,

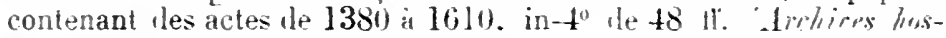
pitalimpes de Combioni, IX A 3 .

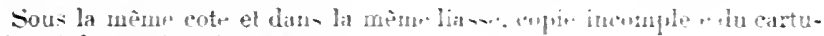
laire cirde-cus (3u ff. in $\left.-4^{0}\right)$.

Cambrai. - Leproserir de Saint-Lazan'.

773. - Cartulaire de la leproserie de St-Lazare de Cambrai; ms. dn XIII siècle, sur parchemin, contenant 45 titres les annét's 1117 a

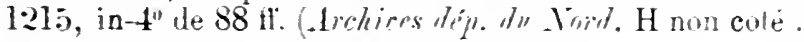

L.es deux premiers feuill. ts sont coupés.

Copie partielle, par l'ablé Tranchant. dı cartulaire précélent: ms. du XVIII sipcle, sur papier, in $4^{0}$ Biblinth. de lu rille de Combroi, ms. 1007, 17. 17-.66!

Cambrai. - Ville.

774. - Cartnlaire municipal de Cambrai on sivre is la chaine $:$ ms. du XVe siècle. sur parchemin, contenant des ducuments is partir de

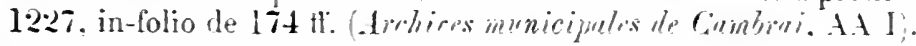

7\%. - - tutre cartulaire des privilises de la ville; copie ilu précétent, continué jusqu'en lizg et rédigree par l'échevin L. de Baralle, sur

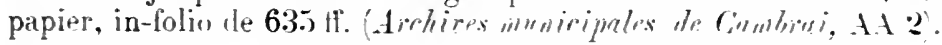

Cambron. - Abbare de Votle-Dame dior. te Cambrail.

776. - "Vetus cartularium Camberonense \$ ms. du Nil siecle. avec additions les XIII" et XIV siecles. sur parchemin. avec reliure de bois et pean, incomplet de la fin, et contenant des actes a partir

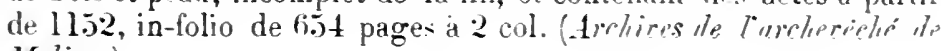
Malines).

Plbl. : Cartulaire dr l’ablaye de Cambrun, par J. J. D. Smedt. 
Bruxplles. Hayez, 1869 : in-4" de xn-1019 p. [Collection de Chroniques belges; Monuments pour servir à l'histoire les provinces de Namur, de Hainant el de Luxemlonrg. 11. ]

777. - Cartulaire de l'ablaye le Cambron; ms. de la lin da XiIIe siècle avec additions jusqu'au $\mathrm{XVI}^{\mathrm{e}}$, sur papier, in-f" de $410 \mathrm{ft}$.

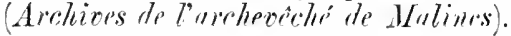

778. - Autre colé I, collationné en 1660 sur les uriginaux, contenant des actes des XIVe-XVII siècles, sur papier, in-40 de $187 \mathrm{ff}$. (Archires de l'urchereche' de Mulines.

779. - Antre coté F, de la mème époque et d'un cuntenu assez identique. sur papier, in-4" de $241 \mathrm{tl}$. Archices dr lurchereché de Mnlines).

780. - Autre coté A, de la mème époque, sur papier. in-4" le 421 pages

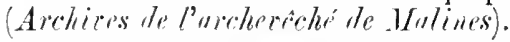

781. - Cartulaire on « Mémorial de diverses lettres appartenant il l'abbaye de Camlirou »: ms. collationné en $166 \mathrm{l}$ sur les originaux is partir du XIVe siècle, sur papier, in-t" de 520 pages (11rchiors de l'urchewrolle de lfulines).

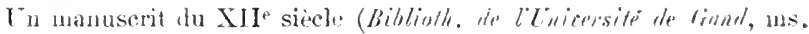
4), provenant de Cambron, a pour denire feuille de grarde un

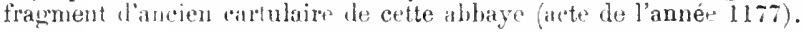

Camprodon. - Abbaye de Saint-Piere (dioc. de Barrelone). 782. - Cartulaire de lathaye de Campsodon : origo perdu.

Extraits lails au XVIJe siecle pour Baluze (Biblioth. nntinale, coll. Baluze, vol. CV11. 11. 177-178.

lif sont deux acte's de 11188 et de 116 is

Candeil. - Abbaye dioc. d'Albi).

78:3. - Fragment d'un cartulaire de l'ablatye de Candeil; un feuillet

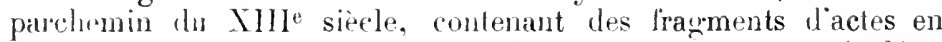

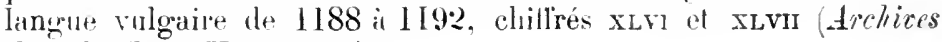
drip. dn Tarn, $\mathrm{H}$ non colé).

Domé aux arrhiven par M. Élie Rossignol.

784. - Reruril de tilses de l'ablaye de Candeil; ms. claté de 1669. contruant des artes des amnées 1153-1586, en 2 vol. in-folio de 290 et 287 II. Biblioth. mutionule, coll. Doat, vol. 114-115).

Gapestang. - Ville.

785. - Cartulaire municipal de Capestang; ms. du XVIIIe siècle, sns papier. in-folio (Arrhioes municipales de Cuprestung).

Capucins. - Ordreroligieux.

786. - Cartulaire des Cirpucins, réligé par le P. Balthazand de 1)ra- 


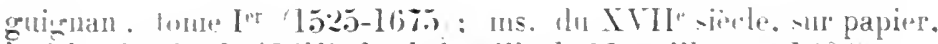
in-folio de $756 \mathrm{fl}$. (Biblintle. de le rille de Murspille. ms. 1:20:2).

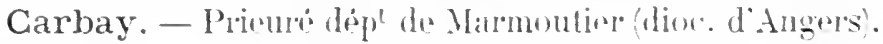

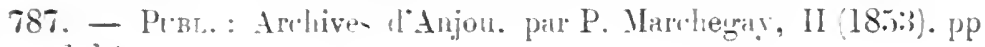
$1-14$.

Carcassonne. - Ancien dimès.

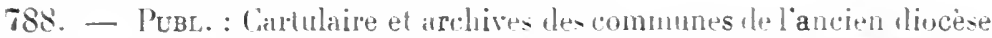
et de l'arrondissement anlninistratil de Carca-sonne. par M. Mahul. Paris. Didron, 1857-1872: 6 sol. in $t^{\prime \prime}$ (le x-42:3. 672. 4!5. 621. 774 et $514 \mathrm{p}$.

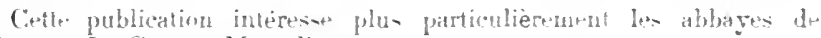
Cianes, La Grawn. Moniolieu.

Carcassonne. - Éţi hé ef chapitre cathédral.

789. - Recueil de titres relatils à l'èvêché et au chapitr cathédral de Carcassonne : ms. le 1668-1669. contenant les acte- des années 926 it 1607. in-folio de 307 if. (Biblioth. mutionule. coll. Doat. vol. 65).

Carennac. - Abbaye dioc. de Cahors.

790. - Recueil de titres relatifs is lohbase le Caremac: ms. du ITIIe siecle [1667]. contenant des documents le 11 ij à 1442. in-folio (Biblisth. nutionule: coll. Doat, rol. 123, 11. 1-59, .

Carladez. - Pars.

791. - Publ.: Documents histuriques relatils à la ricomte de Carlat. recreilli- et pullifi- par Gustare Saige et le comte de Dienne. Inprimerie de Monaco. 1900, 2 rol, in- $4^{0}$ de rin-79l et [ [15-]ccaxcit36.) pages arec pl. [Collection de documents histuriçues publiés par orlre de S. A. S. le prince Albert Ier, prince souverain de Monaco.] Dates strènes : $9.40-1: 93$.

Carmaing. - Seignemrie en Languedoc.

79\%. - Cartulate de la seigneurie de Carmaing : ms. du XVI siecle. sur papier. contenant le documents des années 1398-1516. in- $4^{0}$ de 191 ti. (Archices untimules, III $745^{13}$,

Carmes. - Ordre religirux.

793. - Recueil des privilèges de l'ordre des Carmes; ms. du XT" siercle, sur parclenin. in-40 de 23 Il. Archires dir roynnine de Belgique. à Bruxelles;.

794. - Bullaire des Grands Carmes: ms. dn XVIe siecle. sur parchemin, in-folio de $44 \mathrm{tt}$. Archices dép. dlle-et-Iiluine. H non coté).

En réalité. ce regintre ent simplement la transcription par C. Lezonardi

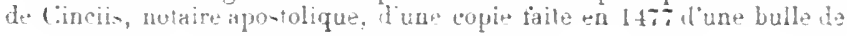


Sixtr. IV (1476) indiquant un certain nomlir" diactes pontificaux anté-

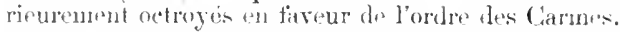

745. - Publ. : Bullarimm Carmelitanum, elibit El. Monsignanus, Ronae, 1715. 4 vol. ill-folio.

Carpentras. - Evèché.

796. - Cartulaire de l'évèché de Ciarpentras; orig. perdu.

Inventaire du cartulaire de l'éveché de Carpentras, par Marchant: 111s. du XVIII" siècle, in-t" de 199 II. (Biblioth. de la ville de Carpuntros, ns. 1306).

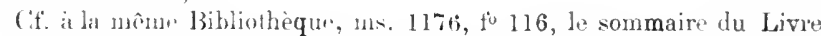

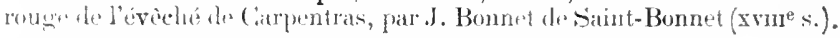

Carrières-sous-Poissy. - Seigneurir pres de Paris.

797. - Cartulaire de la seignenrie de Carrières-sous-Poissy ; ms. rédigé en $176 \%$, sur papier. in-folio de xxxi-464 paces (Archives dép. de Srint-rt-Oise, serie H. foncts le l'alinaye de St-Louis de Poisy).

1)ites extrintes: 1:305-1760.

Gasaure. - Abbare de la Sainte-Trinité, at Pescara ancion royatume de Naples.

798. - Cartulaire de l'ahlaye de Cilsilure; n1s. du XIII siecle, sur

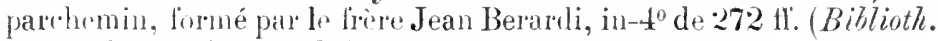
nationule, ms. latin 5411).

Copie dn mime, de la main de Baluze, in-to (Biblioth. nutionale, roll. Ballaze, vol. CALCXIII, pp. 3-340)); et extraits (Idem, muv. acq. liançaises 7405 el 98:0, passim; - ms. français 18083 , I1. :244-31:2: - coll. [Mulesie, vol. LXXY11, fo 107-111).

Publ. : pin Dom l.. d'Achery. Spicilegium, T (1661), pp. 361-531.

Gassel. - Signourie. - Voy. Jraxie de Bretagne et YOLANHE HE FLANHE.

Castanet. - Hòl-Dien slioc. de Toulousa).

799. - Cartulatre hospitulier do Cistanet; ms. du XV1I siecle, sur parpirre, contenant des documents à partir du XVe siècle, in-folio (Archires rommunales de Citustunet).

Castela (I)u). - Famille.

S00. - Ciutulaire de la finnille arentise du Caatelat (1562-1598); ms. du XVI" siècle, de 160 II. in-folio (Aichives dép. de Lot-et-Guronne, lis non coli).

Casteljaloux. - Tille.

801. - Cirtulaire municipal de Cinsteljaloux; ms. du XVe siècle, en

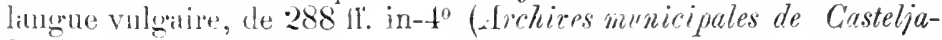
$(011, x)$. 
Castellane. - Villo.

802. - Publ. : Privilèges, franclises et immunités concédé. par les rois et comtes de Provence en favenr de la ville de latelellan.. Yarseille, $165 \%$, in- $4^{0}$.

Castelnau. - Seigneurie en Anvergne.

803. - « Cartularins Armandi de Castronwo »: 111s, du XIV" sircles. sur

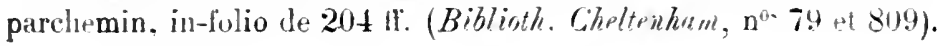

Castelnaudary. - Ville.

804. - "Lirre noir 》 on cartulaire de la ville de Castelnatulary ; orig. perdu au XIX̄e siècle.

Documents extraits du Live noir. ancien cartulaire municipal do Castelnandary 'I355-1374) ; nls. daté de 1851. copie de Bonneton. sur papier (Biblinth. de la cillo de Carcressmone. ms. 2:36).

Castres. - Abbaye.

805. - Recueil de titres rolatifs à linduare de Cintres; m. du XVI siècle [1530], oris. perdu.

Extraits dans un registre dn XVI siecle. $=11$ papier (Archices communules de Custres, At 6).

Castres. - Comté. - Vog. Lacalate.

Caudiès. - Couvent des Augustins dive. diet.

806. - Recueil des titres des Augustins de Candies: ms. lu IVIII siècle. sur papier. contenant des documents de 1398 it 1782 . in-4 $4^{0}$ de 11:2 17. (Archices dép. des Pyrénées-Orientules. H t8).

Transcription partielle du précédent [13:\$S-I676], in-folio is

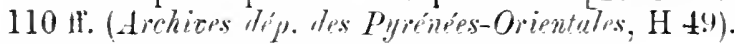

Caumont. - Prieurs dioc. de Noynu.

807. - Cartulaire du prieuré de Caumont. dépendant de labliate de Saint-Bertin; ms. du XIX siècle. sur papier, in-folio de $62^{2}$ et 87 ff. (Biblioth. de la cille de Noyon, coll. Peigné-Delacourt. vul. 16-1i).

Te contient en grado partion que des analyes.

Caunes. - Abbaye dioc. de Carcassonne,

808. - Recueil de titres relatifs à l'alubaye de Caunes: m. du STH siècle, sur papier. contenant des doruments de 787 a 1468 . in-folio (Biblisth. nationale, coll. Doat, rol. 58).

809. - Autre recueil formé par I. Estiennot en 167!' 'Bithlinth. nationale, ms. latin 12760, pp. 477-486).

Voir ausos vo Carcassusate. 
Célestins. - Orilı roligirnx.

810. - Cartulatre de l'Ordre des Célestins: ms. In XVe siècle. sur parchemin. contenant tes actes de 1294 i 1473 . intlolio de 36 ft. (Arrlires défi de lu Srine-Infiriente, G 9193).

Celle-Frouin. - Abbaye dion. d'. Ingouliome.

811. - Cartulaire de lahhay de Celle-Fronin; ms. des XIIe-XIII siectes. incomplet dn cléhut, sur parchennin. in-folio (Biblioth. mutionule. ms. lilin 9235, (II. 1-10).

Contient 20 chart's contemporaines pour lat plupart de Philippe Iar.

Copie du précedent, exéculée au XVII siècle (Biblioth. untionnle, coll. Clairambault, vol. 306, 11. 127-149).

Cercamp. - Abbaye le Notre-Dame dioc. d'Amiens.

81:. - Cartulaire de l'abbaye de Cercamp : ms. du XIII ${ }^{\mathrm{e}}$ siècle, sur parchemin. conlenant des actes de 1137 is 1285 . in- $8^{\circ}$ ale $82 \mathrm{fft}$. (1relieses dip. dn Pus-de-Cialuis, H non cote).

81:3. - Autre framment d'un carlulaire de Cercamp, concernint spécialement Saint-Hilaire-le-Frévent: ms. du XIII siècle, sur parchemin. in-80 de 8 II. (Archiress dép. d" Pıs-de-Culuis, H non coté).

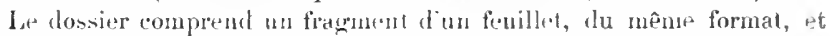

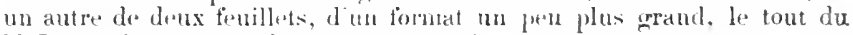
XIIIe sielele : ce sont des ipatres insignitiantes.

Cerdagne. - Comté.

814. - Cartulaire des fiefs de Cerdarne: ms. du XIII siècle, sur parchenin, orné de miniatures. contenant 276 dlocuments des années 1064-1241, in-folio de 65 If. it 2 col. (Achion te lin Corona de Aregŕn, Barcelona).

On trouvera le: linc-similé d'une page de ce registre au tone Ier, p. 28, hu livre de Ch. Baudon de Mony: Relations politiques des Comtes de Foix avec la Catalugne (Paris, $1 \times ! m, 2$ rol. in $\left.-\kappa^{n}\right)$.

Cergy. - Tillage.

815. - Cirtulaire de Cerry, Boissy et Cormeilles, dép' de l'abluaye de Saint-Denis: 11ns. lu XIIIJ siècle, sur parchemin, contenant des actes du $\mathrm{II}^{\circ}$ siècle à 1396 , in-8" de 60 lí. (Arrhires notionales, LL. $1170)$.

Cerisy. - Abbaye de Saint-Yigor (dioc. do Bayeux).

816. - Citrtulaire de St-Viror de Cerisy ou «Livre noir »; orig. perilu. Copie dn précédent ; ms. du XVII siècle, sur papier, in-folio de 834 ti. (Biblioth. de la ville d'Aleuron, ms. 114).

Autre cartulaire, contenant la traduction française des mêmes charles, de lit fin du XVIIe siècle. sur papier. in-folio de 892 pages (Archires dép. de la Munche, H 1404).

Contient 872 chartes des années 1032-1383. 
Ceyzeriat. - Ville.

817. - Cirtulaire municipal de Cevzeriat; ms. du XVle siecle, sur parchemin, couvert d'une reliure ancienne en bois et cuir tratufré. contenint des actes de 1319 à 1416 . in-folio de $17 \mathrm{ff}$. (Airhiress dép). de lin, E 432).

Cf.: Les cartulaires municipanx de Ceyzériat et de Miribel. par Max. Bourr-en-Bresse, impr. P. Barbier, 1878; in-8 de 30 p.

Chaalis. - Abbaye (dioc. de Senlis).

818. - Fragment d'un cartulaire de l'abbaye de Chaalis ; ms. du XIII siècle. sur parchemin, 2 feuillets in- $4^{0}$ (Biblinth. nationale, ms. latin 10400 , tf. 40-41).

819. - «Chartularium monasterii Caroli Loci »; ms. écrit en 1399. sur parchemin, in-8 de 392 If. (Biblisth. nationale, ms. latin 11003).

Axal. : Notices et extraits de documents manuscrits relatifs a l'histoire de la Picardie, par H. Cocheris. I, n ${ }^{0} 275$ (pp. 466-524).

Extraits du précédent. faits au XVII siècle, par Du Chenne (Biblisth. nationale, coll. Duchesne. vol. LXXVII. If. 20-25); par Gaignières (Idem, ms. latin 17113, pp. 361-386).

Ce dernier manuscrit pp. 395-40., contient des extraits "dun registre contenant plusieurs copies collationnées" qui était alors entre les mains de Du Fourny, et qui ne paraît pas être le mème que le recueil ci-dessous.

820. - Recueil des titres de l'abbaye de Chaalis, fait et collationné en 1532. sur papier, en plusieurs cahiers cartonnés, in $-4^{0}$ de $97 \mathrm{ff}$. (Biblioth. nationale, ms. latin 9984).

Dates extrêmes : 1161-1280.

Chabannes (de, - Famille.

821. - Publ. : Preures pour servir à l'histoire de la maison de Chabannes. par le $\mathrm{C}^{\text {te }} \mathrm{H}$. de Chabannes. Dijon, inpr. Jobard, 18921897. 4 rol. in $4^{0}$.

Ourrage tiré à 70 exemplaires.

Chablis. - Préròté de Saint-Martin (dioc. d'Auxerre).

822. - Cartulaire de Chablis, dép' de l'abbaye de Saint-Martin de Tours: ms. du XVIe siècle. sur papier, in-folio de 23 ff. (Hichires dép. de l' Yomne. G 2296).

Dates extrêrues : $1128-1552$.

Chalais. - Abbaye (lioc. de Grenoble).

823. - Publ. Cartulaire de l'abbaye bénédictine de Notre-Dame et Saint-Jean-Baptiste de Chalais au diocèse de Grenoble, par Em. 
Pilot de Thorey (Bulletin de la Société de statistique de l'Isère, $3^{\text {e }}$ série, VIII, p. 160-284); et à part: Grenoble, 1879 ; in- $8^{\circ}$ de $128 \mathrm{p}$.

Comprend 55 chartes dess années 1110 à 1303.

Chalivoy. - Abbaye (dioc. de Bourges).

824. - Cartulaire de l'abbaye de Chalivoy ; ms. des XIVe-X $V^{e}$ siècles, sur parchemin, in-8 de $213 \mathrm{lt}$.

De ce cartulaire, l'incendie des archives du Ciher en 1859 n'a laissé subsister que des débris insignifiants, $20 \mathrm{ff}$. en fort mauvais état ( $A)^{\prime}$ chices dep. du Cher, $\mathrm{H}$ non coté).

Challans. - Eglise Notre-Dame (dioc. de Maillezais).

825. - Publ. : Le Cartulaire de Notre-Dame de Challans (Vendée), 1396-1789, par l'albé Teillet. Vannes, Lafolye, 1895, in-8 d; 163 p. (Extr. de la Revue historique de l'Ouest).

Recueil de 135 pièces publiées d'après une transcription du XV11Ie siècle dont le posiessieur n'est pas indiqué.

Ghalon. - Famille.

826. -- Cartulaire de Chalon ou Cartulaire bleu; ms. du XIV ${ }^{*}$ siècle, sur parchemin, in $-4^{0}$ de $206^{\circ} \mathrm{tl}$., écrit par trois mains dillérentes (British Museum, à Londres, additional mss. 17305).

A ce volume, acheté en 1848 , il manque les feuillets $165,16 \%, 169$, $180-181,187$ et 202 .

Copies du'XVIII siècle, sur papier (Biblioth.nationale, coll.-Morean, vol. 889-890; - Biblioth. de Besancon, in-4 de 524 et $377 \mathrm{ff}^{0}$, coll. Droz, vol. 2l-2*; - Biblinth. de M. All. Courlet de Vregille, au château de Vregille, Haute-Saòne).

Publ. : Cartulaire de Hurues de Chalon (1220-1319), publ. d'après le ms, original dn British Museum par Bernard Prost et S. Bougrenot, avec introrluction historique et table par Jules Gauthier. Lons-leSaulnier, impr. Declume, 1904 ; in- $8^{0}$ de $x x x u-622$ p. [Publ. de la Société d'émulation du Jura.]

Contient 650 documents de's années 1220 à 1319 .

- Voir aussi Franche-Conté (salines de).

Chalonnes-sur-Loire. - Toir ST-Questre-ex-Mavge.

Châlons-sur-Marne. - Abbaye de Saint-Memmie.

827. - Cartulaire de St-Memmie de Châlons ; orig. perdu.

Copie du même, collationnée en 1483, sur papier, contenant des actes à partir de 1160, in-folio de 160 pages (Archives dép. de la Marne, $\mathrm{H} 2$ ). 
Ghâlons-sur-Marne. - Abbaye de Toussaints-en-l'lle.

828. - Cartulaire de l'abbaye de Tonssaints-en-llle: ms. des XIIIe$\mathrm{XV}^{\mathrm{r}}$ siècles, relié en bois au $\mathrm{XV}$ sur parchemin, contenant des documents de 1062 is 1304 , in- $4^{0}$ de $64 \mathrm{fr}$. (Archices díp. de la Marke, H 206).

Copie moderne du précédent [1875], in-4 $4^{\circ}$ de 32 If. (Biblioth. nationale, ms. nouvelles acquisilions latines 1278).

829. - Cartulaire-nécrologe de l'ablaye de Toussaints; ms. rédicé en 1730 d'après le précédent, avec additions, sur papier, in-40 de 62 pares (Archives dép. de la Marne, H 210).

Publ. : Chartes de l'abbaye de Toussaint-en-l'Ile, par l'abbé Ch. Lalore. dans Collection des principanx cartulaires du tiocèse de Troyes, IV (1878), p. 242-258.

Cif. Le diocèse ancien de Châlons-sur-Marne, jar Ed. de Barthélemy, II (1861). p. 397-420.

Châlons-sur-Marne. - Chapitre cathédral Saint-Étienne.

830. - Grand cartulaire de St-F́tienne de Chàlons--ur-Marne. ms. écrit au $\mathrm{XII}^{\mathrm{e}}$ siècle par le chantre Warin [ou Guérin]. contenant 34 actes de 56 à à 1111 , sur parchemin, in-40 de 48 11. (trohives dép. de la .Marne, G 462).

L'écriture de ce regristre change au fo $43 \mathrm{r}^{\circ}$. Sur la composition de ce cartulaire, voir les observations de A. Giry dans ses lotices billiographiques des églines et des monastères de l'époque carolingienne, pP. $7-8$.

Extraits du XVIII ${ }^{e}$ siècle (Biblioth. nationale. coll. Champarne, vol. IX. If. 159 et suiv. : et Biblioth. de la ville de Chitons-sn'-.Wurne, ms. 121, par Dom François).

Ptbl. : Cartulaire du Chapitre de l'église cathédrale de Chàlonssur-Marne par le chantre Warin. publ. par P. Peliciel (Kémoires de la Sociétéd'agric., sciences et arts de la Marne. 1895, p. 141-196, et à part : Paris, $189 \%$, in- $8^{\circ}$ de vill-74 p.

Cette publication rend inutiles les extraits ef analyses anterieurenent imprimés par El. de Barthélemy, d'une manière notoirement insuffisante. (Voir ci-clessous $11^{\circ} 838$ ).

831. - Petit cartulaire de St-Étienne. ms. du XIVe siecle. sur parchemin. avec une reliure en bois du $X \mathrm{~V}^{\mathrm{e}}$. contenan 4 documents de 1297-1300, in-40 de $28 \mathrm{ff}$. (Archices defo. de la Marme, G 710).

On trouve à la Biblioth. nntionale, coll. Chanpagne, XII, fi. 300 318 , le brouillon d'un index de cartulaire du Chapitre de Chàbons-surMarne.

Châlons-sur-Marne. - Église collégiale de la Trinitė.

832. - Cartulaire de la Trinité de Châlons: ms. des XIII $-\mathrm{X}$ Ve siècles sur parchemin, contenant 158 pièces des années 1022 à 1400 , infolio de $91 \mathrm{tl}$. (Archices dép. de la Larne, G I130. 
Châlons-sur-Marne. - Église collégiale Votre-Dame-enTaus.

833. - Cartulaire de la collégiale N.-D. de Chàlons: [nıs, ayant an moins 304 11.]. orig. perdu.

Extraits faits au XVII" siècle pour les Bénérlictins (Biblioth. mationale, coll. Champagne, vol. V1, tl. 74-84).

Chartes des XII -XIIJ siècles à partir de 1114.

Châlons-sur-Marne. - Courent des Augustins.

8:34. - Curtulaire des Augustins de Chàlons: ms. du XVIIIe siècle, sur papier. contenant 8.5 actes des années $1564-1746$, in-folio de 24I ii. (Areliers dip. de la Murke, H non coté).

Châlons-sur-Marne. - Courent des Cortleliers.

835. - Cirtulaire des Corleliers de Châlons: ms. du XVIle siècle, sur papier. in-folio de $25 \mathrm{tr}$. (Areleices dép. de la Marne, $\mathrm{H}$ non cotè).

Châlons-sur-Marne. - Église Saint-Nicolas.

836. - Cartulair te l'église St-Nicolas de Châlons-sur-Marne: orig. perdu.

On "u trouse de's extraits dans des adlitions au cartulaire de Toussaintsen-l'Her de Chàlons, dateres de 1730 Arch. dep. de la Murne, H 210).

Ghâlons-sur-Marne. - Évèché.

837. - Cartulaire de l'évèché de Châlons-sur-Marne, colé Il : ms. des XIIIP-XVI siecles, sur parchemin, contenint 5t actes de I260 à 1:326, in-4" de 66 il. Lichixes díp. de lat Marke, (; 10 ).

838. - Antre cirtulaire [probablement coté 1], dit « Peitu-de-veitu», infolio. de parchemin : orig. perdu.

Copie partielle du précélent perdu, commencée en 150:3, par Lonis Beschefer. sur papier, in-4" de 519 Il. (Arrhires municipales te Châlons-s"s"-Wune, Ad 1.

Extraits (Biblinth. nutionale, ms, latin 521 I", pp. 61-72).

Axal. : Cirrtulaires de l’évêché et du Chapitre de Saint-Étienne de Châlons-sur--Marne, par Ed. de Barthélemy, Chàlons, 1853, in-12.

Cif. ‘u nè̀n: Le divcèse ancien de Châlons-sur-Marne, Paris, 1861, $2 \mathrm{rol}$. in $-\mathrm{s}^{\circ}$.

Chalon-sur-Saône. - Abbayo de Saint-Marcel.

839. - Cartulaire de Saint-Marcel-lez-Chalon-sur-Saone; ms. du XIte siècle, sur' parchemin, in-folio (Biblioth. de fe't M. le $D^{\mathrm{r}}$ Abel, . Ferndet, à Verdun-sur-le-Doubs .

Noun igmano bi se troure actuellement ce regi-lre. 
Copie du XVII siècle [1721], pour .J. Bouhier. snr papier. infoliu de $61 \mathrm{tl}$. (Biblinth. Mntiongle, ms. latin 17091 .

Ditto strèms : 8 i: à 10113 inviron.

Copie du XVII siècle. par D. Camnset Biblinth. notionals. m: latin 126\%9. 11. 351-393.

Copie du XVIII siècle, par D. Aubrée Biblinth. Antionthls. ms. latin 128:4. Hi. 69-3094.

Extraits contenant 11 pièces des années 1073-1096: ms. du XVile siècle. sur papier. in-t" de $8 \mathrm{lt}$. Arehires top. de la Critod'Or, $\mathrm{H}$ non cotë.

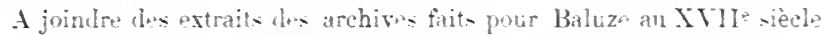

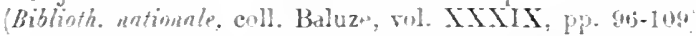

Pubc. : Cartulaire ulu prienré de Saint-Marcel-làs-Chàlon-surSaòne, par Paul Canat de Chizy. Chàlon-sur-Saòne. Marcean. 1894: in-8, de vil-152 p.

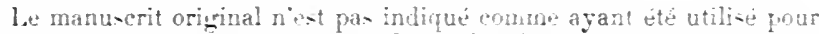

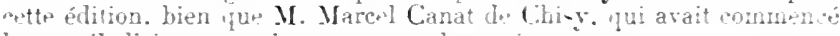
Ir travail, lait eu certainement entre lowain-

Chalon-sur-Saône. - Abbarr le Saint-Pierre.

840. - Cartulaire de l'albave de St-Pierre cle Chalon: ms du XVII siècle. sur papier. contenan 20 pièces des anness 124:3-1.58\%. in-4" de 87 pages Arrkires dép. to Subine-et-Lijire. H non cote.

Chalon-sur-Saône. - Cathèdrale saint-Tincent.

841. - Cartulaire de St-Yincent de Chalon: ms. lu XIII siecle. sur parchemin. in-4" de 273 ti. [manquent les tl. 3-11] 'Biblisth. de

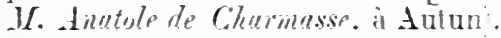

Cartulaire de St-Tincent de Chalon : copie du IVII sircle faite sur le precerlent pour Bouhier. sur papier. in-folio de 32:2 p. Birlinth. nationale, ms. latin 17090 .

Copie du cartulatire the St-Tiscent de Chalon. par dirars: Bénédictins: ms. du XVIII siècle. sur papier. de 333 ti. in-t" Biblioth. nutionale. coll. Bourgogne, tome VII

842. - Autre cartulaire de St-Vincent de Chalon: ms du X siecle, sur papier. contenant des titres de 12221 it 14.99. in-4" de $89 \mathrm{ft}$.

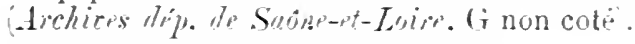

Chalon-sur-Saône. - Commanderrio du Tample.

843. - Cartulaire de la commandere de Chalon-nr-Sàne : ms. de 1481, sur papier, contenant 4l) documents des annérs 19.96-1478.

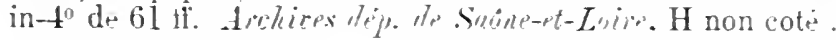

Chalon-sur-Saône. - $\dot{E}$ glise collingiale St-Grarters.

844. - Cartulaire de l'église collégiale St-C reorges de Clialon : ms. du 
XVe siècle, sur papier, contenant 366 actes des années 1441-1491, in-t" de 24!) II. (Archives dép. de Sabue-et-Loire, G non coté).

Chalon-sur-Saône. - Évêché.

845. - Cartulatire de l'évèché de Chalon, composé au XIVe siècle; orig. perdu.

Copie du cartulaire de l'évêché de Chalon, par divers Bénédictins ; ms. dn XVIII" siècle, sur papier, de $307 \mathrm{ll}$. in-4º (Biblioth. nationale, coll. Bourgogne, tome VI).

Autre copie du XVIIe siècle (Biblioth. nationale, ms. latin 17089, if. $1-476)$.

Autres copies moins complètes, du XVII siecle (Biblioth. nationale. ms. latin 13872, If. 547-696; et ms. français 4899, pp. 297$391)$.

Fxtraits (Biblinth. nationale, coll. Bonrogone, vol. LVIII, f" 367

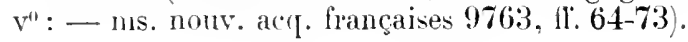

\section{Chalon-sur-Saône. - Ville.}

846. - Petit eartulaire municipal de Chalon-sur-Saône ; ms. du XIII siècle, sur parchemin, relié en hois, contenant des actes de 1227 a 1256. in-8" de $19 \mathrm{fr}$. (Avchives municipales de Chalow-Sur-Saone, AA 1).

847. - Publ. : Privilèges octroyés anx maires, échevins, hourgeois et habitans de la ville et cité de Chalon-sur-Saòne par les anciens rois de France et les dues de Bunrgonne, par B. Durand. Clialon, 1604. in-4".

\section{Chamalières. - Abbaye (dioc. du Puy).}

848. - Cartulaire de l'abhaye de Chamalières; ms. du XIII e siècle, sur parchemin, in-4" de $200 \mathrm{fr}$. [dont quelques-mus sont intervertis] (Biblioth. de l'rếche' du Puy-en-leluy).

- Publ. : Cartulaire de Chanalieres-sur-J oire en Velay, par Anrustin Chassaing. avec introduction el tables par Antoine Jacotin. Paris, Picard, 1895 ; in- $8^{\circ}$ de xiv-208 p.

II arait été antripenrement public par labbe lrayste au tome II des

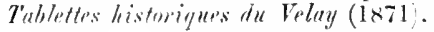

Ghambéry. - Ville.

849. - Cartulaire de la ville de Chambéry, un « Livre vert »; ms. des $\mathrm{XV}^{\mathrm{e}} \mathrm{XVI}$ "siecles, sur parchemin, contenant des documents des années 12:32-15.52, in-folio de $161 \mathrm{HI}$. (Arrhices mnnicipales de Chembersy).

850. - Autre ou « Livre noir »; ms. dı XVIe siècle, sur parchemin, contenant les ménes pières que le précétlent plus quelques autres 
jusqu'en 1566, in-folio de $204 \mathrm{HP}$. (1)chices municipules te Chambéry).

85̆l. - Autre on "Livre blanc»; ms. des XVIe-XVIIJ siecles. sur papier, continuant le précédent de 1566 à 176.5$)$, in-folio (Archices municipales de (ihambiry).

Chambley. - Seigneurie lorraine.

852. - Cartulaire de la seigneurie de Chambley ; ms. dn X'V' siècle, in-folio Archices de $V^{\mathrm{e}}$ Rollet, notaire ì Thinucourt).

Cetle indication, qui remonte à vingt ans environ, doit encore être "xacte, en modifianl le nom du propriélaire aujourd hui remplacé.

Chambon. - Abbaye de Notre-Dame (dioc. de Poitiers.

853. - Recueil de titres relatifs à l'abbaye de Chambon; ms. du $\mathrm{XVII}^{\mathrm{e}}$ siècle. sur papier. formé par Gaignières. contenant des actes de 1220 i 1476 . in-folio de 55 pages (Biblinth. nationale, ms. latin 17149 .

Une nole explique que ce sont des titres trouvés dans une armoire du chartrier de l'abhaye de saint-Laon de Thouars.

854. - Publ. : Cartulaire le l'abbaye de Chambon. par Hugues Imbert (Wémoties de la Socirté de stutistique des Deux-Sècres, 2e série. XIII. p. 191-306, et á part: Niort, 1876, in-8 de 111 p.

Recueil factice de 108 chartes des années 1212-17\%2.

Chambrefontaine. - Abbaye (dioc. de Meaux).

85j. - Cartulaire de l'abbaye de Chambrefontaine: ms. du XV siècle (?). sur papier, in-t" (Biblioth. de W. Parent, maire de Cuisy, Seine-et-Marne).

Divers extraits en ont été publiés par D. Toussaints du Plessi- dans -on Hisluire de I'Église de Meaux, tome II. Cf. Archices nationales, LI $1584, n^{\circ} 27$.

Chamonix. - Prieuré (dioc. de Genève'.

856. - Pcвl. : Le prieuré de Chamonix : documents relatifs al prieuré et à la vallée de Chamonix. par J. A. Bonnefov et A. Perrin. Chambéry, Perrin, I879-188:3; 2 rol. in- 8 " de xxxi-386 et xxxil-472 p. [Documents publiés par l'Académie des sciences. belleslettres et arts de Savoie, V.

Champagne. -- Comté.

857. - Cartulaire des contes de Champarne, ou de la comtesse Blanche: ms. du XIII siècle [vers 1220]. sur parchemin. in-4" de I8I ff. (Biblioth. nationale, ms. latin 599:3).

Fxtraits faits an XVII sièrle (Biblisth. nutimal, coll. Baluze, vol. LXXX, fl. 330-413). 
858. - Autre cartulare, formé de plusieur's parties reliées ensemble an XVe siècle: ms. du XIIJ siècle [1225-1230], sur parchemin, in-folio de 39:3 fl. (Archires nationales, KK 1064).

859. - Aulre cartulaire; ms. du XIII e siècle [rers 12:30], de plusieur's mains, sur parchemin, incomplet du commencement et de la fin, in-folio de:356 fl. (Biblioth. nationale, ms. latin 5992).

A appartenu à de Thou et est appelé it tort quel fuefois "Liber principum 1$)$.

Extraits du XVIle siècle, par A. Galland et autres (Biblioth. untionule, ms. français 16188, fl. 112-147; ms. français 16177 , If. 184 ei suiv.; ms. flançais 16650 , Ir. $4566-569)$; ms. latin 17048 , parces 219-23: : - coll. Baluze, vol. LXXX, Il. 270-368).

Copies délectuenses faites an XYII siècle. sur papier. Biblioth. de lu ville de Troyes, ms. 22, in-folio de $130 \mathrm{~m}$. ayant appartenu a Bonhier; - Biblinth. nationale. Cinq-Cents Colbert, vol. 62-63).

Table incomplite de ce recristre (Biblioth. nationale, coll. Dupuy, vol. $229,11.95-126$.

860. - Autre cartulaire: ms. llu XY' siecle, sur papier, in-folio de 1333 fl. (Biblinth. du Vatican, ms. Ottohoni 2951).

Copie incomplète llu mème, faite au XVII" siècle, sur papier, in-4" (Biblioth. natimale, n1s. Iatin 13079. tl. 134-169).

861. - Autre cartulaire; ms. ch XIII" siècle [ver's 1270], sur parchemin, rontenant spécialement des actes émanés d'autorités ecclésiasliques. et appelé par suite quelquefois « Liber pontificum », in-lolio 1] 5.52 11. (Biblioth. nutionale, ms. latin 5993.1).

Talle dre ce manuscrit (Idem, coll. Dupuy, vol. 229, (f. 3-45).

Copie léfectuense du nême, exécutée an XVIE siècle, sur papier (Item, Cinq-Cients Collert. vol. 59-62).

Extraits du même, faits en 1688 (Item, coll. Baluze, vol. LXXX, il. $1-87$ ).

86:2. - Antre cartulaire ou « Liber principum »; ms. du XIll" siecle [vers 1270], sur parchemin, contenant spécialentent des actes imanés des autorités laïques, in-folio de 484 il. ; origr. perdu.

Tathle de cro volume (Biblinth. nationale, coll. Dupuy. vol. 229, (II. $47-94$ ).

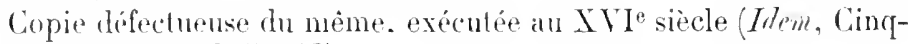
Cants (Colleert, vol. 56-58).

Extrats du mème, faits par Baluze Biblisth. nationale, coll. Baluze, vol. LXXX, II. 89-210); - par Duchesne (Item, coll. Baluze. vol. XIV, fl. 274-278); - par Nic-(Ch. de Sainte-Marthe 
(Inrm. ms. francais 20ri91. pp. 2:3:3-300): - par Du Cance Inem. uns. français 9497, pp. $285-321$, et ausi ms. franc. 4427. 11. 11-97.

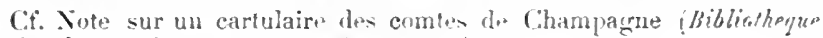
nationle, mis francais 15.199 , ti. $325-3330$ \%.

Ghampagne. - Forèts.

863. - Cartulaire des droits d'usane dans les forèts du domaine des comtes de Champarne: ms. du commencenent du XIV'e siècle. sur parchemin, in-folio à 2 col. Biblinth. national'. ms. français 4660 . ii. 9-14).

Ghampeaux. - Chapitre dioc. de Paris'.

864. - Cartulaire du Chapitre de St-Martin de Champeaux; ms. du XIII siècle. de plusirurs mains. sur parchemin. avec additions postérieures, in-8" de 6l ff. Biblinth. nulionale. ms. latin 10942.

Dates extrêmes: Xle -..-1604.

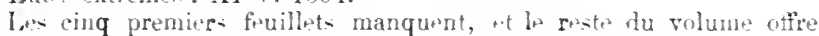
queliques lacunes, car il comptait primitivement il feuillets.

Champilon. - Pripure. - Toy. Argoclène abbaye de StCrbard de.

Champtoceaux. - Prieurè dépl de Marmoutier dioc. d'Anger's'.

865. - Pcbl. : Arehives d'Anjou, par P. Marchegray: II 1853 , pp. $68-7 \cdot 2$.

Chancelade. - Abbaye de Notre-Lame dive de Périgueux). 866. - Cartulaire de lablave de Chancelade; $n$. écrit en 1129. parchemin, in-4" ; orige perdu.

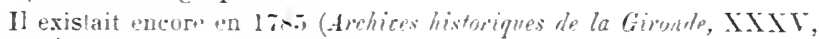
p. 344 '.

867. - Extraits d'un autre cartulaire [éralement perdu]. collationnés par Brugière. notaire royal: ms. du XV111 siècle [1729]. sur parchemin, in-4) de 6 tl. (Biblioth. untionule. ms. latin 99:3i).

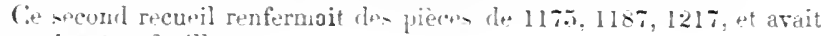
au moins 1 $1 \times$ ! fruillerts.

Autres extraits faits an XVIII siècle Biblinth. mutionule. coll. Lespine. vol. XXXIII, fi. 15. 197. 200. 328, 3:30-359. 361-364, 380.386 et $399 !)$.

Chantilly. - Seigneurie.

868. - Cartulaire de Chantills : ms. de la fin Iu XIVe siècle, contenant des documents des années 1347-1397, in-4" sur papier de 81 ff. (1rchices du chätrun de Chuntilly. n" $107^{b}$.

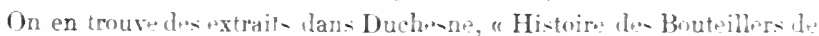

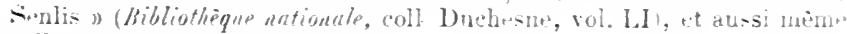
collertion, vol. AXV, ti. :301-3i. 
Chantraine en Brabant. - Commanderie.

869. - Cartulaire de la Commanderie de Chantraine : ms. du XVIIIe siècle, sur papier, contenant des titres de 1220 à 1686 , in- $4^{\circ}$ (Archives du royaume de Belgique, à Bruxelles).

870. - Autre recueil ; ms. du XVIII ${ }^{\mathrm{e}}$ siècle, sur papier, contenant des titres de 1109 à 17.21, in-folio de 6:3 fi. (Archires de l'État à Numur.

Voy a ausi Vallaaroxt.

Gharenton. - Hòpital de la Charité.

871. - Cartulaire de l'hòpital de la Charité de Charenton, près de Paris; orig. perdu.

Table du précédent, faite an XVIII ${ }^{e}$ siècle, sur papier, in- $4^{0}$ de $15 \mathrm{ff}$. (Archives nationales, F F 15).

Charleroi. - Ville.

872. - Publ. : Collection des actes de franchises, de privilèges, octrois, ordonnances, règlements, donnés spécialement à la ville de Charlervi par ses souverains, par D. A. Van Bastelaer. Mons, Manceaux, 1868-1878, 6 vol. in-8" de 101, 106, 100, 177, 178 et 167 p. (Extr. des Documents et rupports de lu Saciété paléontologique et archéologique de Charleroi, vol. II à V, VII, IX et XIII).

Charlieu. - Abbaye (dioc. de Màcon).

873. - Cartulaire de l'abhaye de Charlieı ; orig. perdu.

Appartenait an XVIIe siècle à M. de Chaponav, "seigneur de l'IsleAtan "), qui l'a communiqué à Guichenon (cf. 'Biblioteca Sebusiana, 1. 115$)$.

Charon. - Abbaye. - Voy. LA Grâce-Notre-I)Ame.

Gharroux. - Abbaye (dioc. de Poitiers'.

874. - Cartulaire de l'abbaye de Charroux ou «Liber de constitutione » : orig. perdu.

Copie du précédent; ms. du XV'e siècle, sur parchemin, in-4 (Biblioth. de la Sacieté Éduenne, a Autun).

Autre cupie du mème: ms. du XVe siècle. sur parchemin $(B i-$ blinkh. antionele, ms. latin 5448, fr. 45-166.

C"est le " gros cartulaire " dont parle I)om Fonteneau (Bibliothèque nutionale. coll. . Ioreau, vol. II, fo 102).

Extrails (Biblioth. de lu rille de Pritier's, coll. Dom Fonteneau, vol. LV. pp. 161 et suiv. : Biblioth. nationale, ms. latin 12753, ff. 2.54-25.); ms. latin 12754, f" 480 ; ms. latin 12777, pp. 322-324).

875. - Petit cartulaire de Charroux; ms. du XII siècle, sur parchemin : orig. perlu.

Dom Funtentau l'a vu et compulisé dans 1. trésor de l'abbaye (Biblioth. nationale, coll. Moreau, vol. I, p. 74). 
Extraits du précédent, faits au XYII siècle pour Baluze (Bibliotll. nationale, coll. Baluze, vol. LXXII, II. 35.5-368;.

876. - Recueil de titres relatifs à l'abbaye de Charronx: ms. du XVII ${ }^{\mathrm{e}}$ siècle, sur papier, contenant $16 \mathrm{l}$ documents de 817 à 1626. in-folio de 598 pages (Biblioth. de la ville de Pritiers, coll. Dom Fonteneau, vol. IV).

Il y a en outre (Biblioth. nntionale, ms. latin 12604, ff. b3-96i) des extraits du a Liber de privilegiis Carrofensis cenobii ", qui parait devoir ètre identifé arec l"un des registres précédents (" liber de constitutione 1$)$.

Chartres. - Abbaye de Saint-Jean-en-Tallée. - Voy. SAINT-JEAN-1:N-VALL $\dot{E}$.

Chartres. - Abbaye de Saint-Père.

877. - Cartulaire d'Aganon, ou « Aganon vetus ». ms. compilé par le moine Paul au commencement du $\mathrm{XII}^{e}$ siècle, sur parchemin, in-4" de v-138 ff. (Biblioth. de la rille de Chartres, ins. 1060 .

Copie abrégée du précédent avec variantes: ms. du XII siècle. sur parchemin, in- $4^{\prime \prime}$ de $109 \mathrm{ff}$. (Biblioth. de la ville de Chartves, ms. 1061).

Cf. Notice sur l'A granon vetus, par Herisson (Chartres, 1856, in-8) : et Wémoires de In Societé des antiquaires de France, IX (1832), p. 140-17\%, et XIII (1837), p. $438-459$.

878. - Cartulaire ou livre d'argent: ms. du commt du XII ${ }^{e}$ siècle. sur parchemin, contenant $5 \% 1$ chartes des années 928 à 1] 71 . in- $4^{\prime \prime}$ de in-92 ff. à 2 col. (Biblinth. nationale, ms. latin 10101).

Ce rolume était jadis " coopertum argento, figuris encausto pictis, urnatum plurimis lapidibus pretiosis $»$.

Copie du précédent. exécutée au $\mathrm{XVII}^{\mathrm{e}}$ siècle. sur papier. in-folio le 36 et 5.58 p. (Biblioth. de l'Arsenal, ms. 993.

La table des deux cartulaires anciens de st-Père est aux Archres d'Eure-et-Loir, $\mathrm{H} \cdot 2-3$.

879. - «Carlularium S. Petri Carnotensis» : extraits lu XVIII esiècle faits par Gaignières. in-folio rle $\mathbf{5 9 0}$ pages (Biblinth. nutionu'e. ms. lalin 5417).

880. - Recueil de titres relatifs à St-Père de Chartres : ms. dressé de 1772 a 1775 par Dom Muley. comprenant les transcriptions des trois précédents, en 5 vol. in-folio, sur papier (Biblioth. de la rille de Chartres, ms. 1136.

Extraits des cartulaires, par Dom Le Michel Biblioth. nationale. ms. latin 13819. ff. 86-124; par Duchesne Inem, coll. Duchesne, vol. XXII. If. 172 et 181, : par Laisné, prieur de Mondonville (Idem, ms. français 24133, pp. 187-223 .

Prrz. : Cartulire de l'abbaye de St-Père de Chartres. par Benj. 
Guérarl. Paris, imp. royale. 1840: 2 vol. in 4 " de caclaxi ot 848 pages [Collection des Documents inédils.]

881. - Petit cartulaire de St-Père de Chartres; ms. du XIle siècle, incomplet au débul, sur parchemin, in-4", avec table dressée au IVIII" siècle (Biblinth. It la rille de Churtres, ms. 1038. It. 92116 .

Chartres. - Chapitre cathédral ot évèché.

882. - 《Cartularium ecclesix Carnotensis ». ou " petit livre blanc »; ms. du XIIle siècle. sur parchemin. de 70 11. in-t" (Biblinth. nationnale, ms. latin 11062 .

883. - «Privilegria ecclesie Carnotensis 》: ms. du XIII siècle, avec adtlitions jusqu'au XVe. sur parchemin, in-4" de $252 \mathrm{p}$. (Biblioth. natimule, ms. latin 10094).

Antre analogne an précédent: in-t" de vin-159 If. (Biblinth. nutionule, nis. lalin 1009.).

884. - Cartulaire de l'érèchí de Chartses, on «livre noir »: ms. du XIIJe siecle arec adrlitions jusquan XVII". sur parchemin, in-folio levin-158 Il. (Biblinth. nationale. ms. latin 10096).

885. - Cartulaire des privilemes du Chapitre de Chartres on « livre rougre »: ms. du XVII" siècle. dlaprès l'origninal récligé par Mallurin Bellois en 148:3. sur papier, in-4" de 530 ff. (Billlinth. de lu rille de Cilurtirs, ms. 1162 ).

886. - Autre cartulaire: ms des $\mathrm{XV}^{2} \mathrm{XVI}$ siecles. sur papier, in-to de 210 11. (Biblinth. de le rille de Troulouse. ms. 590).

Paraît itre l'original du recueil préecident. Dates extrêmes: IX゙"s.-1 163.

Extrails divers de la "pancarte de l'évèché de Charlress », des livers noir el rouge Biblioth. matimule. ms. latin 5185\% pp. 119$300)$.

Autres extraits en copies du XVI" siecle d'apròs le " primus » et le «secundus cartularius" (Biblioth. untimele, coll. Baluze, vol. LXXII. II. 249-35:3) : - el antres (Biblivth. de la ville de Lyon, ms. 198. 11. 76-12:3: Biblinth. mtionle. ms. français 24133, pp. 1-28).

Pubs. : Cartulaire de Jotre-I)ame de (harrles d'après les cartulaires a les litres originanx, par li. de Lépinois et Lucien Merlet.

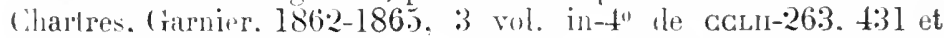
$443 \mathrm{p}$.

Contient les desuments antérieur au $\mathrm{XV}^{*}$ siecle et à partir de 573 Lat nis. «t' Toulount" n'a pas été utilisé.

Ghartres. - Ėglise Saint-Saturnin.

887. - Cartulaire de l'eglise Saint-Saturnin de Chartres; ms. du XTe 
siecle. sur papirar. contenant des documents de $12\left(j_{0}\right)$ à 1450 , in-folio

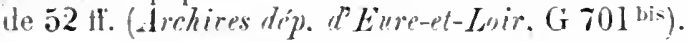

Chartres. - Ville.

888. - Recueil des privileres de la ville de Chartres: ms. du XIVe siecle. sur parchemin. contenant des documents des anuées 12051:307. in $4^{\circ}$ (Bibligth. wationale. ms. français 5:382, ti. 1-10 et 1441).

Chartreux. - Orilre religieux.

889. - Fragments diun cartulaire des privileres de lordre des Chartreux: ms. du XIVe sieccle, sur parchemin. contenant 19 bulles. in-folio de $8 \mathrm{tf}$. (Bibliotle. de la cille de Béthune: ms. 2).

890. - Publ. : Reperlorium privilegiorum Ordinis Cartusiensis. Basileae, 1510, in-folio.

Chastellux (de). - Famille.

891. - Vieux livre noir des Chastellux : ms. commencé au XVIJ siècle, par Guillaume-dntoine de Chastellux, sur papier. in-folio de

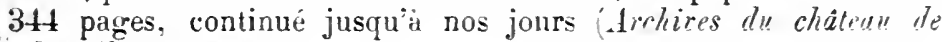
Chastellux-sur-Cure).

Contient partie des titres (dep. le XIV'es.) du château brûlés en 1793: M. le Comte de Chastellux les a publiés dans son live : Histoire généalogique de la maison de Chastellux (Auxerre, impr. Perriquet, $18699^{\circ}$ in- $\left.4^{\circ}\right)$. Il est fait allusion dans cet ouvrage a un " nour au lire nuir " qui depuis a été détruit.

\section{Châteaudouble. - Ville.}

892. - Cartulaire municipal de Chàteaudouble : ms. des XVIIe-XVIII siècles. sur papier: contenant des actes a partir de 14:39. in-folio de $88 \mathrm{tf}$. (Archices muicipules de Chateaudouble. At 1.

Château-du-Loir. - Seigneurie.

893. - Cartulaire de la seigneurie de Chàteau-du-Loir : orig-perdu.

Ixtraits en copien défectueuses du précédent, faits au XVIII siecle. sur papier. in-folio Biblioth. nationale. ms. latin 9067, ti. 250-38:3 .

894. - Prbl. : Cartulaire de Château-du-Loir. par Eugène Vallée. Le Mans. 1906. in-8 de [1v-] xr-336 p. TSociété des archives historiques du Maine. VI.]

Les documents $y$ contenus vont de l'au 1000 à l'an 1400. - Cf. R. Roulleau, La forêt de Bercé et le cartulaire de Chàteau-du-Luir (Lat Procince die Wuine, XIV, 1906, pp. 145-151).

Châteaudun. - Abbaye de la Madeleine (dioc. de Chartres. 895. - Cartulaire de la Madeleine de Chàteaudun : orig. perdu.

Extraits faits au $\mathrm{XVII}^{\mathrm{e}}$ siècle par Dom Estiennot Biblioth. de l'Arsenal, ms. 1008. pp. 458-491. 
Châteaudun. - Abbaye de Saint-Avit.

896. - Cartulaire deSaint-Avit de Chàteaudun ; orig. perdu.

Extraits faits au XVII siècle (Biblioth. de l'Arsenal, à Paris, ms. 1008, pp. 17-20 et 157-160); - an XVIII siècle (Biblioth. de la cille dOrléans, ms. $435^{\text {bis, }}$, copie de Polluche; et ms. $394^{\mathrm{B}}$ ).

C.f. Sommaire des chartes de Saint-Avit de Châteaudun, par Ch. Cuissard (Bulletin de la Sueiplé dunoise, IX, 1898, pp. 169-200).

Châteaudun. - Châtellenie. - Toy. Brors (comté de).

Châteaudun. - Hòtel-Dieu.

897. - Publ. : Archives de la Maison-Dieu de Châteaudun, transcrites et placées par ordre clironologique (1101-1296). par Aug. de Belfort, avec introduction par L. Merlet. Paris, Société française de numismatique et d'archéologie, 1881 ; in-8" de xur-293 p.

Château-Gontier. - Prieuré de Saint-Jean-Baptiste (dioc. l'Angers).

898. - Cartulaire du prieuré de Château-Gontier; ms. du XVII siècle, contenant 73 actes des années 1229-1674, sur papier, in-40 de $90 \mathrm{fr}$. (Archires dép. de la . Kayenne, $\mathrm{H}$ non coté).

Château-l'Abbaye ou Ghâteau-lez-Mortagne. - Abbaye dioc. de Cambrai .

899. - Cartulaire de Châtean-l'Abbaye ; ms. sur parchemin, de 38 ff., orig. perdu.

Cf. Biblioth. nationale, coll. Morcau, vol. 97, fo 123 ; vol. $100, f^{\circ} 45$, ste. (copies de Dom Queinsert en 17\%z).

900. - « Codex titulorum Castelli Abbatialis »; ms. du XVIII ${ }^{\mathrm{e}}$ siècle [175l], contenant des transcriptions d'actes des années 1155 à 1681 , reliées en cartulaire factice, sur' papier, in-folio (Archives dép. du Nord, H non coté).

I.e recueil a élé formé par l'archiviste I.e Glay.

Château-l'Hermitage. - Prieurẻ (lioc. dır Mans).

901. - Recueil de chartes du prieuré de Châtean-l'Hermitage, près de La Fliche ; ms. du XVIII siècle [1728]. sur papier, contenant des titres lepuis le XII", in-4" (Biblioth. Sainte-Geneviève, à Paris, ms. 675, parces 272-298).

\section{Château-Queyras ou Château-Ville-Vieille. - Ville.}

902. - Cartulaire municipal de Château-Queyras ou « Livre vert »; ms. de la fin du XVII" siècle, in-4" (Archives municipales de ChâteauQueyras;. 
Châteauroux. - Seigneurie.

903. - Cartulaire des seigneurs de Chàteauroux, de la famille de Chauvigny : ms. transcrit en 1510 , sur parchemin. contenant des actes depuis 1220. in $\mathbf{t}^{\circ} \mathrm{de} 107 \mathrm{fl}$. (Archires nationales, $\mathrm{Q}^{\mathrm{t}} 33 \mathrm{3}$ ).

La majorité des documents transerits est composée d'hommages, tt c'est à peine un eartulaire.

904. - Cartulaire du duché de Chàteanroux : ms. du XVII siècle. sur papier, contenant des actes de I222 à $16 i 4$, in-folio de $18 \mathrm{I} \mathrm{ff}$. (Archices dép. de l'Iulre, A $\mathbf{7}$ ).

Ghâtellerault. - Vicomté.

905. - Pancarte de la vicomté de Châtellerault. ou " Livre noir »; ms. du XTe siècle, sur parchemin, in-folio de lSt ff.' 'Biblioth. nationale, ms. français 8817 ).

Châtel-sur-Moselle. - Châtellenie.

906. - Recueil de titres relatifs à la chàtellenie de Châtel-sur-Moselle: ms. du XVII siècle, formé par Thierry Alix, sur papier, contenant des titres de 1227 à 1608 , in-folio de 392 ff. (Archires dép. de Meurthe-et-Moselle, B 351 ,

Châtenois. - Prieurẻ de Saint-Pierre 'dioc. de Toul).

907. - Cartulaire du prienré de Châtenois, dépt de l'abbave de Mrolème; orig. perdı.

Copie du précédent, faite en $1 \mathbf{7} 46$, sur papier, in-folio de $107 \mathrm{ft}$. (Biblioth. de l'Arsenal, à Paris, ms. 1066;.

Documents à partir de 1079.

Autre copie du XrIIIe siècle [1731], par Dom Claude Granddidier, sur papier, in-folio de 123 ff. Archices dép. des Iosges, H ว́อ̆).

Châtillon-en-Woëvre. - Abbare (dioc. de Verdun;.

908. - Cartulaire de l'abbaye de Chàtillon, du Xile siècle; origr. perdu.

Extraits faits au XVIIIe siècle (Biblioth. nationale, coll. Lorraine, vol. 282, ff. 15+15i).

909. - Cartulaire du XVIIle siècle, sur papier, contenant des documents des années 1190-I264, in-folio de $87 \mathrm{ff}$. Archires dép. de la Meuse, $\mathrm{H}$ non coté).

Les mêmes archives possèdent encore un cartulaire destitres pour les biens de l'abbaye situés en Bourgogne (16i1), deux pour les biens de l'abhaye situés en France et deux pour les biens de l'abbave situés en Lorraine ( $\mathrm{XVIII}^{\mathrm{e}}$ siècle); les actes transcrits à partir du X゙II e siècle.

Extraits du cartulaire de l'abbaye de Chàtillon-en-Woëwre; ms. 
du XIX" siècle, par Bellot-Herment, sur papier, in-4" (Biblioth. de la ville de Ber-lr-Dur. ms. 152, pp. 169-186).

Châtillon-sous-Bagneux. - Voỵ. VAllextox

Châtillon-sur-Saône. - Châtellenie.

910. - Recueil cle tilres relatifs à la ville et chàtellenie de Châtillonsur-Saône: ms. de la fin dı XVIe siècle, sur papier, contenant des actes de 1261 à $1.57 \%$, in-folio de 379 II. (Archices dép. de Meurtheet-1Hoselle, B 35:2.

Châtillon-sur-Seine. - Abbaye de Notre-Dane (dioc. de Langres).

911. - Cartulaire des XIVe-XVIIt siecles. sur parchemin, contenant 209) actes des années 1137-170t, in-t" de 209 11. (Archives dép. de la Cóte-d' Or, $\mathrm{H}$ non coté).

Copie du précédent; ms. daté de 172:3, sur papier, in-folio (Biblioth. de la ville de Chatillont-su's-Seine, ms. 5, pp. 129-320).

Châtillon-sur-Seine. - Église.

912. - Recueil de titres de l'église de Chàtillon-sur-Seine; ms. du XVII" siecle, contenant 25 documents des anuées 1195-1523, sur papier, in-folio de $24 \mathrm{tl}$. (Archices dép. de la Cóte-d'Or, G non coté).

Châtillon-sur-Seine. - Ville.

91:3. - Recueil de titres relatifs à Châtillon-sur-Seine; ms. du XV'e siècle, sur papier, in-folio (Biblioth. nationule, ms. français 5491, li. $103-111$.

Ghâtillon-sur-Sèvre. - Toy. Mauléox.

Chaudefontaine. - Prieuré de saint-Lament (dioc. de Reims).

914. - Ciartulaire du prieuré de Chandefontaine; ms. du XVIe siècle, sur papier, in-t" de 240 ir. (Aichices municipales de Reims, D non coté, fonds du Collegge des Bons-Enlants).

La table de ce registre a été publiée par Éd. de Barthélemy dans sa nolice: Le prieuré de Sit-Laurent de Chaudefontaine (Paris, $1 \times 78$, in- $8^{\circ}$; exlr. de l'Annutire de la I/arne), pp. 16-20.

Chaumes. - Abbaye (dioc. de Sens).

915. - Cartulaire de l'abbaye de Ghaumes; orig. perdu dès le XVII siècle.

(if. Biblioth. nationale, ms. latin 12664, fo 1 .

Chaumont-en-Vexin. - Prieuré de Saint-Pierre (dioc. de Rouen!. 
916. - Cartulaire du prieuré de Chammont-en-Vexin, dép de l'abbaye de Saint-Denis; ms. du X $\mathrm{V}^{\mathrm{e}}$ siècle. sur papier, incomplet de la tin, in- $4^{0}$ de $45 \mathrm{lf}$. (Aichies mutionales. S $22: 37$ ).

Dates extrêmes : $1146-1397$.

Chaumouzey. - Abbaye (dioc. de Saint-Dir.

917. - Cartulaire de l'abbaye de Chaumouzey : ms. du XV" siecle [14:27]. écrit par Alb. Nicolay, curé de Dompierre, avec additions jusqu'en 1545 , sur parchemin, in-folio de $110 \mathrm{ll}$. (Arehies dép. des Vosges, $\mathrm{H} \mathrm{l} \mathbf{2})$.

Autrefois ms. 1xĩ de la Bibliothèque d'Épinal.

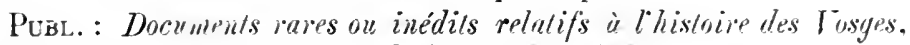
X (1891), pp. 1-306, et XI (1896), pp. 307-442.

Dates extrêmes : 1102-1406.

918. - Recueil de titres relatifs a l'abbaye de Chaumonzey: ms. des XVII $-X V^{2}{ }^{2}$ siècles, sur papier, contenant des actes de 1102 a 1725, en 5 cahiers de 252 pages (Aichices dép. des Visgges, $\mathrm{H} 13$.

Autrefois ms. 202 de la Bibliothèque d'Épinal.

Chauny. - Tille.

919. - Cartulaire municipal de Chauny : ms. du XIVe siècle, contenant 208 acies, sur parchemin, in-folio ; orig. égaré dans une bibliothèque particulière $(\mathbf{l})$.

Copie moderne du mème, sur papier, in-folio (Biblisth. de lu ville de Noyon, coll. Peigné-Delacourt, ms. 12,

Autre copie moderne du mème, sur papier Biblinth. de ll. Poissonniei. curé-doyen de Crécy-sur-Serre.

Chelles. - Abbaye dioc. de Paris:

920. - Cartulaire de l'abbaye de Chelles: ms. du XVIe siècle. sur parchemin, en 2 vol. in-folio de 277 et $237 \mathrm{ff}$. Biblinth. de la rille de Meaur, mss. ว9-60.

921. - Autre cartulaire perdu. "Chartularium vetus Kalense ». dont il existe des extraits et inventaire dressé au $\mathrm{XVII}^{\mathrm{e}}$ siècle (Biblioth. nationule. ms. français 16188 , If. 2-74.

Il en existait encore au moins un autre, puisque Dom Martène vit en lils "les quatre beaux cartulaires de (helles".

Chemillé. - Prieuré de Saint-Pierre dioc. d'Angers's.

922. - Cartulaire du prieuré de Chemillé, dépendant de Marmoutier : ms. du XIII siècle [1246], arec additions postérieures. sur parchemin, contenant 216 pièces à partir de l'année 849 , in-folio de viI-it; et 4 il. (Archives dép. de Mainte-et-Livire. $\mathrm{H}$ non coté).

Lacune apres le feuillet 38.

(1) Etail encore il y a vingt-cinq ans aux Arehives munipipales. 
923. - Antre dn XVe siècle [vers 1480] avec additions postérieures, contenant 110 tilres des années 1040-1501, sur papier, in-folio de $8 \mathrm{I}$ II. (Archires dép. de Maine-et-Loire, $\mathrm{H}$ non coté).

Ces deux cartulaires se complètent l'un par l'artre.

(it. P. Marchegay dans ses Archives d'Anjou, I, p. 223.

Extraits faits au XVIII siècle (Biblioth. nationale, coll. Dom Housseau, vol. XII).

Cheminon. - Abbaye (dioc. de Châlons).

924. - Cartulaire de l'abbaye de Notre-Dame de Cheminon; ms. du XIII siècle, contenant to actes de 1103 à 1212, sur parchemin, in-t" de 18 tr. (Archives dép. ré la Marne, $\mathrm{H}$ non coté).

925. - Autre cartulaire de la fin du XVI siècle, sur papier, contenant des actes de 1110 à 1517 , in-4" de 94 11. (Archives dép. de la Marne, H non coté).

Extraits des cartulaires de Cheminon; ms. du XVIIIe siècle, sur papier (Biblioth. nationale, coll. Champagne, vol. XIV, I1. :31-533).

I'ubr. : Recueil des chartes de l'abbaye de Notre-Dame de Cheminon, publiées pour la première fois et annotées d'après les originaux conservés aux archives de la Marne, par le comte Ed. de Barthélemy. Paris. Champion, 1883 ; in -80 de 16.5 p. et pl.

la plupart des pièces sont analysées; celles dont le texte est donné en entier sont la minorilé.

Gherbourg. - Abbaye de Notre-Dame-du-Vœu (dioc. de,

Coutances).

926. - Cartulaire de l'abbaye de Notre-Dame-du-Vœu; ms. du X Y I ${ }^{*}$ siècle, sur parchemin, contenant 341 titres depuis le XIII siècle [1258], in-folio de 345 p. (Bibliath. de la ville de Cherbourg, ms. 115 .

Des tables de cri volume, par matiere's, noms de personne ef noms de lieu (XVIII s.), sont conservées aux Archices dép. de la Hanche, H 2262, 2263 et 2265$)$.

9:27. - Recueil des titres de l'abbaye de Notre-Dame-du-T'œu pour les forèts de Brix; ms. du XVII" siecle, sur papier, in-folio de $38 \mathrm{ff}$. (Archives dép. de la Hanche, $\mathrm{H} 2087$ ).

Dates patrênes: $1456-1575$.

Cherbourg. - Hòlel-Dieu.

928. - Cartulaire de l'Hôtel-Dieu de Cherbourg; ms. du XVe siècle, sur parchemin, contenant des documents de 1268 à 1470 , in- $4^{0}$ de $109 \mathrm{fi}$. (Archives hospitalières de Cherbourg, A 3).

L's ff. 2 ì 7 ont disparu.

Copie du mème; ms. du XIXe siècle, sur papier, in-4" de $57 \mathrm{ff}$ (Biblioth. de la ville de Cherbourg, ms. 118). 
Chercq-lez-Tournai. - chartrense de saint-Antré.

929. - Cartulaire de la Chartreuse de Chercq-lez-Tournai: ms. du XVIII siècle, sur papier, contenant des actes de 1369 à 1727 , en 2 vol. in-folio (Arrhires de l'Etut à .Mons).

930. - Autre cartulaire, contenant des bulles pontificales et des privilèges rovaux : ms. du XVIII siècle, sur parchemin, in $-4^{0}$ de $3: 3 \mathrm{ff}$. (Archites de l'Etat à .1Yons).

Cherlieu. - Abbaye dioc. de Besançon!.

931. - Cartulaire de l'abbaye de Cherlieu: ms. du XIII sièele, sur parchemin, in-to de $73 \mathrm{ff}$. Biblinth. watisiule, ms. latin 10973) 51).

Axal. : Notice du précédent Cabinet histsrique. XX, 1874. p. 32-

Copie du mème. faite au XVIII siècle Biblioth. nutionole, coll. Moreau, vol. 874, ff. 6-90, et idem. vol. 873, tf. $446-488$.

932. - Autre du XVII e sjècle, sur papier, contenant 92 actes de 11.27 à 1209, en cahiers in-folio Archires díp. de la Hurte-Suriur. H 246,

Cherré. - Prieurè (lioc. du Mans.

933. - Cartulaire du prieuré de Cherré, dépt de l'abbaye de la Conture du Mans; ms. du XVII siècle, contenant 13 chartes, sur papier. in $4^{\prime \prime}$ (Archires dép. de la Sarthe. H supplém".

Ghevreuse. - Hòtel-Dieu (dioc. de Paris.

934. - Cartulaire de l'Hòtel-Dien de Cherreuse : ms. du XVIe siecle, sur papier, contenant des documents le 1496 a 1596 . in- $t^{\circ}$ de 80 II. (Archires haspitalières de Ciheripuse. A 3 .

Chevreuse. - Ville.

935. - Cartulaire de Chevreuse, Dampierre et Trappes. dépendant de l'abbare de Saint-Ienis : ms. du XIII e sierle. incomplet an commencement et à la fin, sur parchemin. contenant des actes des années 1227-1232. in $4^{\circ}$ de $23 \mathrm{fr}$. (Archires natisnales. LI. 1169.

Chezal-Benoit. - Abbaye 'ilioc. de Bourges'.

936. - Fragment d'un cartulaire de Chezal-Benoit : ms. du XII siècle, in- $8^{\prime \prime}$ à 2 col. [11. 28 et 29 ]. comprenant 8 documents dont un acte inachevé (Biblioth. natisnale, ms. latin 9862.

cas deux feuillets faisaient parlie dun critulnium efustum, quont connu les bénédietin - du XVII sièce : "ex veteri cartulario in membrana solum continentes quatuor quaterniones $n$.

Copies partielles de ce cartulaire, faites en 1643 par Rene Iru Cher 
et en I676 par Dom listiennot, sur papier (Biblioth. nutionale, ms. latin 13816, 11. 296-309, et ms. latin 12744, pp. 179-2.66).

Dans le volunte lzitl sont comprisis to pièces des annétes 1099 à 1321, tran-crites d'après les originaux.

9:37. - Autre cartulaire de Chezal-Benoit; ms. du XIII ${ }^{\mathrm{e}}$ siècle, orig. perdu.

Extrails faits au XVII siecle (Biblioth. netionale, ms. Iatin 12664 , fi. $120-121$.

938. - Bullaire de la mème abbaye; ms. sur parchemin, de $92 \mathrm{ff}$., orig. perdı.

Extraits faits au XVII' siècle (Biblioth. nationule, ms. latin 1:3816, ff. $31: 3-3(3)$.

Chézery. - Abbaye de Notre-Dame (dioc. le Genève).

93!). - Cartulaire de l'abbaye de Chézery ; orig. perdu.

Copie du X YIII siècle, sur papier, par Perrenot, in-folio de 38 11. (Biblioth. de la ville de Dole, ms. 13i).

lixtraits faits au XVIII siècle (Biblioth. de la ville de Besanson, coll. Droz, ms. 74, ff. 286-332).

Les chartes de l'abbay' de Chézery (XII s.) publiées par J. Vuy

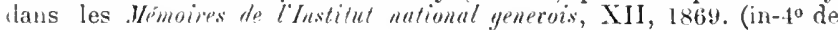
is p.) sont au nombre de cinq seulement, et enpruntées à un ins. du XIII siècle de la Biblioth. de la cille de Bourg (ms. 53, ff. 101-103), où elles se trouvent transerites par hasart.

Chézy. - Mblaye de Saint-Pierre (dioc. de Soissons).

940. - Recueil ıles titres de l'abbaye de St-Pierre de Chézy ; ms. du X YHI" siecle. rédigé par Dom Vİuley, sur papier, in-folio (Biblioth. nationale, coll. Dom Grenier, vol. XXII.

Axal.: Analyse du cartulatre de Saint-Pierre de Chézy, par Édouard de Barthélemy (Mémoires de la Sociétéacudémique de SaintQuentin, 4térie, I, p. 241-308).

Contient (is chartes des années 1063-1412.

Chièvres. - Couvent des Oratoriens.

941. - Cartulaire de l'Oratoire de Chièvres; ms. des XVIIe-XVIIIe siècles, sur parchemin, contenant des actes les années 1626-1726, in-folio de $5: 3 \mathrm{fr}$. (Archives du royaune de Belyique, à Bruxelles).

Chinon. - Ville.

942. - Recueil de titres relatifs à la ville de Chinon; ms. composé par André Salmon au XIXe siècle, sur papier, in-4" (Biblioth. de la ville de Tour's, ms. 1343, ff. 141-240). 
Chiny. - Comti.

94:3. - Recueil de tutres relatifs atix comtis de Luxembonror et de Chiny: ms. de la fin da XYI siecle, formé par Thierry flix, sur papire. contenant des titres de l204 à 1478. in-folio de $264 \mathrm{tl}$. (Archices dép. de Meurthe-pt-1Kselle. B 407 .

Copie du précédent, faile au XVII siècle. in-folio. sur papier (Stuals-Avchic z" Durizig.

Choiseul. - Chàtellenie.

944. - Recueil de titres relatifs à la chàtellenie de Choiseul et Colombey : ms. de la fin du XVI siècle. formé par Thierry Alix, sur papier. contenant des actes de 1406 à 1587 , in-folio de .) 11 . (Archices dép. de Meurthe-et-Woselle. B 355 J.

945. - Recueil de titres relatifs à la châtellenie de Choiseul et (irami : ms. de la fin du XVIe siècle, formé par Thierry Alix. sur papier. contenant des acles de 1335 a 1582 , in-folio de $220 \mathrm{tI}$.' Archices dep. de Meurthe-et-_Woselle, B 356 ,

Choisy-au-Bac. - Prieuré dioc. de Sorssons.

946. - Cartulaire du prieure de Choisy-au-Bac, dép' de Saint-Médard de Soissons: ms. du XVe siècle. sur parchemin. in-to de 84 lit. (Archices nationules, LL 1023).

Table d'un ancien cartulaire perdu. de (ii) ti. Biblioth. Mationale, ms. latin 1266.5, 11. 26-28.

Choisy-le-Temple. - Commanderie dioc. de Meaux.

94\%. - Cartulaire de la commanderie de Choisv-le-Temple: ms. du XYe siècle. sur papier. contenant des actes de 1185 i 1489 . in-4" de 49 ti. Archices nutionales, \$ 5 186 .

Chypre. -- Voy. Lesigrix.

Ciney. - Courent des Carmélites dior. de Namur' .

948. - Cartulaire des Carmélites de Ciney; ms. des XVIJ -XVIII siècles, sur papier. contenant des titres de 1629 à 1792. in-t" "le 56 t1. Archices de l'Étut à Tuinur.

Giney. - Ville.

949. - Publ. : Cartulaire de la commune de Ciney (1321-1758, par Jules Borgnet. Namur. Wesmael, 1869 ; in-8" de cxrrm1-32:3 p.

Cisterciens. - Ordire religieux.

950. - Bullaire de lorlre de Citeaux; ms. llu XVIe siecle. -ur parchemin. in-4" de $40 \mathrm{HI}$. Biblinth. inational?. ms. latin !750.

951. - Autre bullaire: ms. du XIT"e siècle. sur parthemin. in-t" de

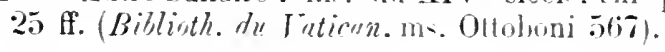


952. - Autre recueil dn $\mathrm{XVI}^{\mathrm{e}}$ siècle, fait par le frère Gabr. Gabriecy d'après les archives de l'Ordre, sur parchemin, in-4" de $10 \mathrm{fl}$. (Biblioth. nationale, ms, latin 975l).

953. - «Privilegia ordinis Cisterciensis 》; ms. du XrVe siècle, sur parchemin, in-4" de $156 \mathrm{fr}$. (Biblioth. de la ville de Colmar, ms. 292).

provient de l'abhaye de Bebenhausen.

954. - Bullaire de l'ordre de Citeaux; ms. du XIVe siècle, sur parchemin, en mituvais état et incomplet lu débuat, in-8" de 45 lf. (Biblioth. de. la ville d'Épinal, ms. 90.

95̄5. - Publ. Menologium Cisterciense notationibus illustratum; accedunt seorsim Regula. constitutiones et privilenia ordinis Cisterciensis. a R. P. Chr. Henriquez. Antverpiae, apud Moretum, 1630; 2 vol. in-folio.

956. - Liber privilegiorum sacro ordini Cisterciersi per summos ponlifices concessorum, el per christianisimos nostros Francize el Navarrae rexes parisiis. 1666, in-4".

957. - Privilènes de lordre de Citeaux. recoleillis el compilés [par Louis Méchel]. Paris. 1713, in-4*.

Citeaux. - Mbaye (dioce de Chalon-sur-Saòne).

958. - Cartulaire le l'abbaye de Citeilux : ms. du XIII ${ }^{\mathrm{e}}$ siècle, avec additions du $\mathrm{XIV}^{\circ}$. contenant 1178 actes des années 1044-1302, sur parchemin, en 3 vol. in-4" Archices dép. de la Cóte-d'Or, $\mathrm{H}$ non coté.

959. - Fragments d'un cartulinire de Citeaux; actes du XIII ${ }^{\mathrm{e}}$ siècle, copiés an X Ve et se trouvint sur des fenillets de garde (Biblioth. de la rille de Dijon, ms. 184).

960. - Bullaire de l'abbave de Citeanx; ms. du XV'e siècle, sur parchemin. contenant 1:38 bulles et xxir-24!) pages (Biblioth. de la ville de Dijon, ms. 5!8.

961. - Ancien cartulaire des XII"-XII" siècles, sur parehemin, contenant des actes de 1098 à 12!90. in-folio de 98 fr. (Archires dép. de la Câte-d" Or, $\mathrm{H}$ non coté.

962. - Cartulaire crénéral de Citeiux : ms. des XYe-XYII siẻcles, sur parchemin. contenant près tle 3000 actes de 1098 à 1609 , en 10 vol. in-folio Archires dép. de la Cinte-d'Or. H non coté).

963. - Autre du XV" siecle. sur parchemin, contenant 90 actes des années 1209-1394, in-4" de 115 tf. (Arrhices dép. de la Côte-d Or, H non coté .

964. - Autre du XT'e siecle, lormé de trois pelits recueils, sur papier, contenant 215 pièces des années 1180-148\%. in-folio de $2: 38$ fl. (Arhices dep. de la Catr-d: Or. H non cotée. 
Clairefontaine. - Abbaye (dioc. de Besançon).

A lire larticle intitulé : Étude dhistoire sur le cartulaire dro l'ancienne abbaye de Clairefontaine-les-Platincourt, de l'ordre de Citeaux, par

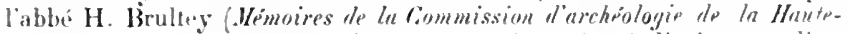
Sione, IV, 1865. p. $373 \mathrm{et} s$.$) , on pourrait croire à l'existence d'un$ cartulaire de cette abbaye : ee serait une erreur, et on compremal mal le titre de l'article que riran ne justitite.

Clairefontaine. - Abbaye (dioc. de Tréves).

965. - Cartulaire de labbaye de Clairefontaine; ms. dn X $\mathrm{V}^{\mathrm{e}}$ siecle. avec additions postérieures. sur papier, contenant des actes de 1163 à 1531. in-4" de 232 pages (A'chices de l'stat ù Allon.

966. - Autre carlulaire; ms. du XVIII siècle. sur papier, contenant des actes de $158: 3$ à 1627 , in-folio de 280 pages Archiress de l" Etrt ì Airin).

967. - Publ. : Cartulaire de Clairefontaine, ou recueil de documents presque tous inédits concernant cette ancienne abbaye, par le R. P. Goffinet. Arlon, Brick, 1877 ; in- $8^{\circ}$ de xxiri-28t p. el pl.

Clairefontaine. - Abbaye (dioc. de Soissons.

968. - Cartulaire de l'ablaye de Clairefontaine; orig. perdu.

Ex!raits du cartulaire, faits au XVII ${ }^{\mathrm{e}}$ siëcle par Duchesne $B$ Bhlioth. nationale, coll. Paluze, vol. LI, tf. 144-1522 ; par Du Cange, Idein, ms. (rançais 9500. pp. 90-9l).

Clairlieu. - Abbaye (dioc. de Toul.

969. - Cartulaire de l'abhaye de Clairlieu: ms. du XVe siècle. sur papier. in-folio de $18 \mathrm{tf}$. Archires dép. de Werthe-et-Moselle. $\mathrm{H}$ 461 .

P'CBL. : Labbaye de Clairlieu, de l'ordre de Citeaux, par Henri Lepange Bulletins de la Société derchéologie lorruine. V, I85.5. p. 98$21 \div$

Cinquante chart's des annets $1150-1792$ sont publiées ou analysétes en pièces justiticativess.

Clairmarais. - Abbaye dioc. de Saint-(Omer).

970. - Cartulaire de l'ablaye X.-I), de (lairmarais. réunie à Clairvaux : ms. du $\mathrm{X} \mathrm{V}^{\mathrm{e}}$ siècle. contenant des actes des années 1222-I475. sur papier. in-4" de $118 \mathrm{fr}$. Archices dép. de l'Aube. H non coté,.

Extraits faits au XVII siècle Biblinth. nutionule. coll. Duchesne. rol. XXII, ti. $471-476$,

Clairvaux. - Abbaye (dior. de Langres.

971. - Cartulaire le l'abbaye de Cilairvaux : ms. du XIIle siecle, avec 
quelques additions postérieures, sur parchemin, in-4" de vi-342 fr. (Biblioth. nutionale. ms. latin 10947).

Datess extrèness: : 1121-1410.

Le $\rightarrow$ feuillets $16-19,76-80, \times 2-83.1177,199-200,212-219,273-278$ et 321 manquent. Ce volum, aclieté en l'an XI a la vente Truelle-Chambouzon, a été rendu a la libliothèque en aril 1816 par to chevalier Armynot.

972. - Cartulaire de l'abbaye de Clairvaux; ms. du XIII' siècle, en 2 vol. sur parchemin, contenant des actes de 1121 à 1260. in-4" de 205 et $147 \mathrm{tr}$. Biblintl. dr la ville de Troyes, ms. 703, et [tome II]

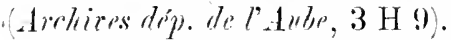

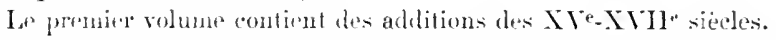

Copie du précédent [tome II], moderne [187:3], in-folio de $376 \mathrm{p}$. (Biblinth. nutiritale, ms. nouv. acq. latines 1208;.

973. - Autre cartulaire du XVII sjèle, sur papier, in-folio de 75 ft. Areliers dip. de la Cótr-dr Or. H non cote.

974 . - Autre artulaire du $\mathrm{XV}^{\circ}$ siecle, sur papier, contenant des documents de 1185 environ à 1485 . in $-4^{0}$ de 51 il. (Archices dép. del'.l'l,', $3 \mathrm{H} 10$.

975. - Autre cartulaire du XVII" siecle, sur papier, contenant des locmments de 1200 environ à 1692 , in-folio de $208 \mathrm{tr}$. Archixes dép. de l. Aube, $3 \mathrm{H} 12$.

Glam $\_$cy. - Ville.

976. - Cartulaire de la ville lte Clamery ms. du XIX siècle, sur papier, in-folio de 395 p. Billinth. Je lin rille de Clamecy, ms. 1).

Clermont-en-Argonne. - Seigneurie.

97\%. - Cartılaire de la chàtellenie de Clermont-en-Argonne: ms. du IVIIe siècle, sur papier, contenant des locuments depuis le XIII", en 2 vol. de 436 et 215 tl. (Arrhires dre chatean de Cilrentilly, $\left.n^{0} 107^{\circ}\right)$.

978. - Autre du $\mathrm{XVII}^{\mathrm{e}}$ sipcle. sur papier, contenant des actes des années 1373-1570, in- $4^{0}$ de 487 11. Archices de chatean do Clanntilly, $\left.n^{\circ} 104^{\prime \prime}\right)$.

Voy. aussi vo Chernustus.

\section{Glermont-en-Beauvaisis. - Comti.}

979. - P'CBL : Recherches historiques et criliques sur l'ancien comté et les comtes de Clermonl en Beauvoisis du XIe au XIII' siècle, par 1.. de Lépinois. Beauvais. impr. Pìre. 1877 ; in- $8^{\circ}$ de 525 p.

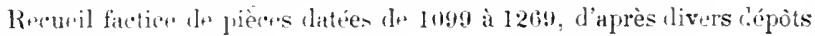
d'archives.

980. - Cartulaire du comlé de Clermont; m: du XIVe siècle, avec 
quelques additions postérienres. sur paroliemin. contenant des acles de 1197 i 1388 . in $4^{\circ}$ (Biblinth. nationale. ms. francais 4663 , (f. 9-95).

Axal. : Notices et extraits des documents manuscrits relatifs a l'histoire de la Picardie, par H. Cocheris, I, no 303 .

Clermont-Ferrand. - Abbaye de Saint-André.

981. - Cartulaire de St-André de Clermont, dit «sous la Croix simple »; ms. du $\mathrm{XVH}^{\mathrm{e}}$ siècle. sur papier. en 7 vol. in-folio Archices dép. du Puy-de-Dime. $\mathrm{H}$ non coté).

Complet, il comprendrait 10 rolumes; $1+1$ er, le $3^{\text {e et }} 1 \cdot$ derniter funt défaut. Les rlates extrêmes des actes transcrits soni 1212 ot 1 tizo.

982 - Autre dit « sous la Croix double»; ms. des XVIe-XVI ${ }^{e}$ siècles, sur papier. en 1:3rol. in-folio (Archires dép. du Puy-de-Drime, $\mathrm{H}$ non coté).

Le dernier volume seul manque ici. Les transeriplions, de differentes main-, comprennent des actes de 1150 à $16 \% 5$. - Il 5 a en outre une table genérale, incomplète de la fin 'in-foliu de $354 \mathrm{ff.}$, réclicrée en 1681 .

\section{Glermont-Ferrand. - Évèché.}

983. - Cartulaire de l'évèché de Clermont ; orig. perdu.

Extrait du précédent. fait au XVile siècle (Biblioth. nationale, coll. Baluze, vol. LXXII. fus 1 et 118 ).

\section{Clermontois. - Pars.}

984. - Publ. : Les chartes du Clermontois convervées an musée Condé à Chantilly (1069-1352), par A.ddré Lesort (Mémoires de la Société des lettres. sciences et urts de Bar-le-Dur. ${ }^{e}$ série. II. pp. 1-2i3), et a part : Paris. Champion. 1904; in- $8^{\circ}$ de $15-273 \mathrm{p}$.

\section{Cluni. - Abbaye dioc. de Màcon).}

985. - Cartulaire A de l'abbaye de Cluni : ms. de la fin du XI siècle. sur parchemin. in-folio de 308 tf. (Biblistl. nutimale, ms. nour. acq. latines 1497 ).

(.f. A. Bru.l 'ouvrage mentionue plus loin zous le $n^{0}$ Imu1). I. p. xar.

986. - Cartulaire $B: \mathrm{ms}$. de la fin du $\mathrm{XI}^{\mathrm{e}}$ siècle. avec idditions jusquau XIII e siècle. sur parchemin. in-folio de $30 \mathrm{lff}$. (Biblinth. mationale. ms. nour. acq. latines 1498 ).

C.f. 1. Bruel, ibidem. p. xxir.

987. - Cartulaire C: ms. du commencement du Xil siècle, sur parchemin, in-folio de $68 \mathrm{fr}$. (Biblisth. untionale. ms. nour. acq. latines $226:$ ).

988. - Cartulaire D : ms. du XIII siècle, sur parchemin. in- $4^{0}$ de 156 If. (Biblinth. nutionule, ms. nour. acq. latines i66).

Cif. A. Bruel, ilidem, P. xxxi. et tomt VI fpreface, b. I-vin, wì l'un trouvera la deseription thistoire de ce manuscrit. 
Copie du cartulaire précédent; ms. du XVIIIe siècle, exécuté pour Bonhier, sur papier, et relié aux armes du cardinal de Bouillon, in-folio de 1133 pages (Biblioth. nationale, ms. latin 17087).

Autre copie du même; ms. exécuté en 1701, de la main de Baluze, sur papier, in-40 de 321 pages (Biblishl natimale, ms. latin 5459).

Cf. lattestation du carlinal de Bouillon (Biblioth. mutionale, coll. Batuze, rol. CiCiTIII)

989. - Cartulaire E; ms. de la fin du XIII siècle, sur parchemin, in-4 $4^{0}$ de 285 1l. (Biblioth. nutionale. ms. latin 5458).

(if. A. Bruet, ihidem, p. xxxr-xxxr.

Copie du cartulaire précédent, depuis longtemps incomplète; ms. de la fin du XIV $V^{\mathrm{e}}$ siecle. sur parchemin, in-40 de $94 \mathrm{ff}$. (Biblioth. nationale, ms. nouv. acq. latines $14 ! 99)\left({ }^{(}\right)$.

(C'est le regintre apyenle I par Lambert de Barive.

Extritit du précédent. fait en 1680 ponr Gaignières (Biblioth. mationale, ms. latin 17048. parges 373-391).

990. - Fragment l'un cartulaire de l'abbaye de Cluni; ms. du XHIe siècle, sur parchemin. composé de $4 \mathrm{ff}$. in- $4^{\prime \prime}$ contenant 12 actes (Biblinth. mationale, ms. nour. acq. latines 7.56).

Cif. A. Bruel. Fragment diun cartulaire de Cibuy renfermant un diplome inédit de Philippe Auguste (Biblioth. de l'Éeole des Chartes, LXIH1, 1902, 1. 67x-681).

991. - Grand cartulaire des moines de Chuni : orig. perdu.

992. - Cartulaire du petit Trésor de Chıni ; oriy. perdu.

Ces deux registres sont sirnalés par Baluze (Biblioth. nationale, coll. Baluz*, rol. IXXXVI, ft. 291-294.

(if. L. Delisle, Catalogue des actes de Philippe-Auguste, p. 536.

993. - Autre cartulaire, sur parchemin, de 225 fl. [du XVe siècle]; orig. perdu.

Est nu+ntionne par Lambert dre Barive comne existant de son temps dans les arhives du monastère (Biblioth. nationale, ms. latin 9091, fo $(28)$.

994. - Autre cartulaire, sur parchemin. de 238 tl. ; orig. perdu.

Nignale par Lambert de Barive dans tr mêne recueil (fo 129). Le même savant inonce d'ailleurs, d̀ la suite. encore 8 uu 9 cartulaires sur

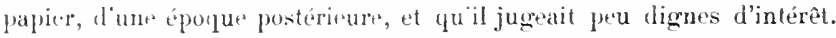

995. - Cartulaire de la pitancerie de l'abbaye de Cluni ; ms. des XIVeXVe siècles, sur papier. in-folio de 94 If. (Biblinth. nationale, ms. Latin 9878).

(1) Sur les cartulaires A-E de l'ablares de Cluni, voir L. Delisle, Inventaire des manuserits de la Bibliothequ+ nationale, fonds de Ciluni (Paris, Champion, 188.1, in-80), 11. 22:1-236. 
996. - Cartulatre on rearistre de l'administration des abbés Raimond de Cadoëne ef Robert d'Echaudessolle: ms. du $\mathrm{XV}^{\mathrm{e}}$ siecle. sur papier, in-folio de 213 tl. (Biblioth. nutionule. ms. latin 9879).

997. - Fraırment d'un cartulaire; ms. du XVI ${ }^{\mathrm{e}}$ siècle, sur parchemin. contenant la transcription dactes passés au profit de l'abbaye de 1592 à 1600. in-folio de 33 if. (Biblioth. natimale, ms. nouv. acq. françaises I269).

998. - Recueil de titres relatifs a labbaye de Cluni; ms. le la fin du IVII siècle, sur papier, en majeure partie copié de la main de Baluze daprès les cartulaires et les originanx (Biblioth. natiostale. coll. Baluze, vol. LXXXVI).

Extraits du «grand» cartulaire (Biblinth. natimals. coll. Clairambanlt, vol. 1067, tf. 3506-375).

Cf. encore Catalingue du fonds Joursanvault (1830), no 2159 : - et $\mathrm{ms}$. la in 13816 , ff. $313-318$ ( $\mathrm{x}$ bullario membranto habente fulia 92 veteri manu scripta).

999. - Publ. : Bibliotheca Cluniacensis. anct. M. Marrier et A. Du Chesne (Parisiis, 1614 , in-folio de 1832 et $178 \mathrm{col}$. ).

1000. - Recueil des chartes de labbaye de Cluny, formé par tur. Bernard, complété, revisé et publiè par Alexandre Bruel. Paris, impr. nationale. 1876-1903,6 vol. in-40 [Coll. des Doc. inédits.]

Contient 5506 pièces classées chronologiquement de l'annét she a 1300. Le tome VIl introduction et table) ist en preparation.

1001. - Charters and Records among the Archives of the ancient Alther of Cluni (107i-1534), by $\operatorname{sir}$ G. F. Duckett. London, 1888 : 2 vol. in-8 de [n- $]$ n-262 et $10-323$ p.

Cognac. - Abbaye dr Sitint-Légerer dioc. d'Angoulême .

1002. - Cartulaire de Saint-Létrer de Cognac; orig. perdu.

Sommaires de quatre chartes du XII siècle, tirées de ce cartulaire (Biblioth. de la ville de Poitiers, coll. Dom Fonteneau. vol. LVI. pp. 19-24).

Extraits faits au XVII siècle par Dom Estiennot (Biblioth. metiounle. ms. latin 12754. pp. 219, 414.417, 421. 456).

Cognac. - Ville.

1003. - Cartulaire municipal de Cognac ou « livre rouge ». contenant des actes des années 1262 à 1718: ms. du XVIII siècle. sur papier. in- $4^{0}$ (Archices municipules de Congnac).

1004. - Publ. : Privilegres de la ville de Cugnac en Anıroumois. S. I. n. d.. in $-4^{0}$.

Coincy. - Prieurd de Saint-Pierre dioc. de Soissons'. 1005. - Cartulaire du prieuré de Coincy, dépt de lahhaye de Cinni : 
ms. du XVII siecle. sur papier, in- $t^{0}$ de 819 pages (Biblioth. antionale. ms. français 12021).

Dates extremes : 1072-1683.

Axal. : Totices et extraits des documents manuscrits relatifs à l'histoire de lia Picardie. par H. Cocheris, I, nº 307.

Collioure. - Ville.

1006. - Cartulaire municipal de Collioure; ms. commencé en 1380 et continué jusquáan X VIJ siècle, sur parchemin, contenant des actes du XII siecle à 1691, in-folio de 125) II. (Archixrs municipales de Collinere. At 1).

1007. - Autre cartulaire: ms. commencé vers 1360 et continué jusqu'au XYIII siècle, sur parchemin. contenant des actes catalans tu XII siecle it 1721, in-folio de 74 II. (Archires municipules de Colliome. AA 2).

Colmar. - Couvent de Sainte-Catherine dioc. de Bàle).

1008. - Petit livre ronge du convent des relinienses de Sainte-Catherine à Colmar: ms. des $\mathrm{XV}^{p}-\mathrm{XVI}$ siecles. sur papier, contenant 10 documents des années 1265 à 1.331 , in-8" de $50 \mathrm{fl}$. (Archiv des Olop-Elsass, in Colmar).

1009. - Autre cartulaire des XVIe-XVIII siecles. sur papier. in-folio de .515 tr. (Arrhir des Ober-Elsass, in Colmar).

Le plus ancien document lianserit est de $131 \%$

Colmar. - Comvent des Augustius.

1010. - Cirtulaire dles Augrustins de Colmar: ms. rérlizé en 1600, contenant des titres à partir tle l'année 1337. sur papier. in-4 ${ }^{0}$ de 240 tr. (. Lecleir des Oher-Elsess, in Colmar).

Colmar. - Couvent des « Interlinden».

1011. - Cartulaire du couvent des religieuses aux Unterlinclen à Colnar: ms. la té rle 1500, sur papier. contenant 82 actes des années 1274-1442. in-t" de 30 it. (Arrhir des Obr-Elsuss, in Colmar).

Colombey-sur-Saône. - Châtellenie. - Toir (Horszld.

Combourg. - Prienri dioc. de bol.

1012. - Cartulaire du prieuré de Combourø., dépendant de Marmontier ; orign. perdu.

Extraits (Biblinth. untimule, coll. Baluze, vol, LXXVII, 1, 137).

Combs-la-Ville. - Village. - Voy. Brie-Covte-Robert.

Comines. - llôpital dioc. de Toumaii).

101:3. - Cartulaire de l'hôpital de Comines : ms. des XVIe-XVIIe siè- 
cles. sur papier, contenant des actes de 1246 a 1616 , in- $t^{\prime}$ de $1101 \mathrm{ll}$. (Archices hospitulières de Comines, A 1).

1014. - Autre du $\mathrm{XVI}^{\mathrm{e}}$ siècle, sur papier, contenant des actes de 1194 à 1579 , in-folio de $211 \mathrm{ff}$. (Archires herspitulieres de Cominines, A 2).

Le remistre a 3 contient (in-folio de $23 \times$ p.) la traduction den pience en latin at en tlamant dis deux prérétents.

Comines. - Seigneurir.

1015. - Cartulaire de la seigneurie de Comines; ms. rédigé en 1470 , sur papier. contenant des actes a partir de 1250. in-folio de $1: 37 \mathrm{fl}$. (Biblioth. de.M.A. de Ghellinck. an chàteau d'Elserhem, Flandre Orientale.

Comines. - Villè.

1016. - Recueil des privilèges de la ville de Comines; m. du XVI siècle, sur papier, contenant des titres de 1276 à 15\%2. in-folio de 245 ti. (Archices municipales de Comines, At 2 .

Commequiers. - Prieuré de saint-Pierre. - Voy. Marmottier.

Commercy. - Chàtellenie.

1017. - Recueil de titres relalifs à la chàtellenie de Commercy et Pierrepont; ms. de la fin du $\mathrm{XVI}^{\mathrm{e}}$ siècle, formé par Thierry Alix. sur papier. contenant des titres de 1238 à 1.361 , in-folio de $229 \mathrm{li}$. (Archires dép. de Meurthe-et-Moselle. B 35i,

1018. - Carlulaire de la seigneurie de Commercy, rédigé en 1506, sur papier, contenant des pièces des années 1243-150.3, in- $4^{\circ}$ de IV109 tf. (Biblioth. nationale, ms. français 11837.

1019. - Autre du XVII ${ }^{e}$ siècle, contenant des pièces des années $1344-$ 1602. in-folio de $19 \mathrm{l}$ tl. Biblisth. nationule, coll. Lorraine, vol. $617^{\text {bis }}$.

1020. - Antre du $X V^{\mathrm{e}}$ siècle. sur papier. in- $t^{0}$ Biblisth. mationale. ms. français 19832 , tf. $69 \mathrm{v}^{0}-119$.

Pièces franẹises des XIVe-

Comminges. - Comté-érèché.

1021. - Cartulaire-mémorial du comté-évèché de Comenge ou Comminges: ms. écrit par Larcher en 1769. sur papier. contenant detitres de 1208 a 1768 , in $-4^{0}$ de 510 pages Archices dép. des HuntesPyrénées, fonds Larcher, rol. IX!.

Contient entre autres ehoses un certain nombre dte copies faites sur les originaux les archives du chapitre cathédral de Saiml-Bertrand; lensemble forme un rolume du "Dictionnaire historiquet généalogiqut v de Larcher 
Compiègne. - Abbaye de Saint-Corneille (dioc. de Soissons). 1022. - Cartulaire blanc de St-Corneille de Compiègne [incomplet]; ms. du XIII siècle, contenant 520 documents du Xe siècle a $12 \% 2$, sur parchemin, in-1" de 143 ff. Archices nationales, LL 1622.

Axal. : H. Cocheris, Notices et extraits des documents manuscrits relatifs à l'histoire de la Picardie, I, $\mathrm{II}^{0} 319$.

1023. - Cartulaire rouge de St-Corneille de Compiègne ; ms. de la fin du XIII siècle, sur parchemin, in- $4^{0}$ de $76 \mathrm{ff}$. (Bibliolh. de 1Y. Pouillet, à Clermont).

A été utilisé par Dom Grenier.

II. Pouillet est récemment décédé, le registre est conservé par ses heritiers.

1024. - Fragment d'un cartulaire roure ; ms. de la fin du XIII siecle, sur parchemin, in-folio de $63 \mathrm{ff}$. Biblioth. de la rille de Compiègne, ms. 6).

La table de ce dernier recueil a été clonnée par A. de Marsy (Rerue des Sociétés sacantes, is serie, IV, 1876, p. 458-179).

Copie moderne du précédent (Biblioth. nationule, ms. nouv. ac(. latines 2197).

Cif. Biblioth. nutionte, coll. Dom Gireniter, vol. LXIII, tf. :317-326.

Copie du précédent, exécutée au XVII siècle, alors que l'original était complet (Biblioth. nutionule, ms. latin 9l7l); — autre datée de 1672 , in $4^{\circ}$ de $750 \mathrm{P}$. et tables (Archives nationales, LL 1623), analyse far $\mathrm{H}$. Cocheris, $\mathrm{n}^{0} 320$; - et extraits divers Biblioth. nutionale. ms. latin 13816. fl. $413-424$ [d'apres les cartulaires rouge petit et Hanc 1]. par Dom I.e Michel: - coll. Duchesne. vol. LXYI, ff. 28-39 ; - ms. latin 13891. fr. 42-4:3; - ms. français 16188, tr. 149-173; - ms. français 17048, tr. 419-429; - ms. français $18762-18764,19841-19842$ et $24063-24067$, passim ; nonv. acq. françaises 7433, IT. 198-199) ; - Archives nutionales, LL 16:3-1624 et $S 4565$.

1025. - Publ. : Cartulaire de l'abbaye Saint-Corneille de Compiènne, par l'abbé E. Morel. 'Tome I. Compiègne, Lefehvre, 1894-1904; in- $4^{0}$ de xi- 488 p. [Société historique de Compiègne.]

Comprend liss ammens 877 a 1216.

Compiègne. - Courent des Tisitandines.

1026. - Cartulaire des Visitandines de Compiègne: ms. des XVII _ XVIII siècles, sur papier. contenant des titres de 1648 à 1768 , in-folio de 138 t1. 'Archives dép. de l'Oise. $\mathrm{H}$ non coté).

(1) "L" plus ancien des d*ux qui restent." 
Compiègne. - Hótel-Dieu.

1027. - Fragment d'un cartulaire de l'Hótel-Dieu de Compiengne: ms. du $\mathrm{XV}^{\circ}$ siècle sur parchemin. in- $8^{\circ}$ de $19 \mathrm{If}$. Archires hospitalieres de Compiène?.

Contient quelques pièns du Xille siècle.

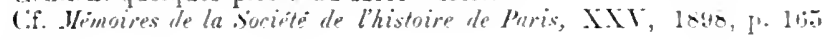
note.

Compiègne. - Yille.

1028. - Cartulaire de la ville de Compiègne : orig. perdu.

Copie partielle par Dom Grenier au XriII e siècle Biblisth. nationale, coll. Moreau. vol. CXX, ff. 22-23.

1029. - Autre cartulaire en papier : orig. perdu.

On en troure mention au XVIne siecle 'Biblisth. nutionale, coll. Mureau. vol. Cicil, fo 129 ;

Conches. - Abbare de Saint-Pierre (dioc. d'Érreux).

1030. - Cartulaire de l'abbaye de Conches : ms. [avant plus de 260 if.] perdu.

Fragment d'une copie exécutée au XTII siècle mais endommagrée par l'humiclité. sur papier. in-to de 185 tr. Aichires dép. de l'Elìe. H 262 ).

1031. - Autre cartulaire ou « livre blanc »: orig. [140 paginarum] perdu.

Extrails du précédent, faits au XVII siècle 'Biblisth. nationale, ms. latin 13816. fi. $458-461$ ?.

1032. - Recueil de pièces relatives à l'abbaye de Conches, envorées à D. Luc d'Acherr par Dom Pl. Simonnet, prieur. en 1648. sur papier, in-folio Biblisth. nutionule. ms latin 12777. pp. 715-737,

Condé-en-Barrois. - Seigneurie.

1033. - Cartulaire de la terre de Condé-en-Barrois : ms. du XIVe siècle, par D. Claude de Custine, in-40 de 122 tf. (Catalogue de la collection Marchand. $\mathrm{n}^{0} 3$.

On ignore ce quest devenu ce manuscrit.

Cif. Archices dép. de .Wourthe-et-V'selle, B 359 i et ci-dessous, vo sintMHitel.

Condé-sur-Escaut. - Église Totre-Dame (dioce de Cambrai).

1034. - Cartulaire-censier de l'église Yotre-Dame de Condé : ms.

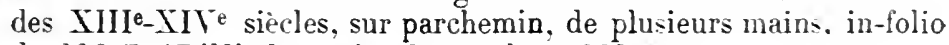
de 112 ff. (Biblioth. nationale, ms. latin 9917 .

En réalité ce volum est formé de deux fragrments, l'un d'eux occupant les ff. 94-101 et étant d'un format plu- petit. - Le's dates extrêmes des documents transerits sunt 11113-1338. En tète un compte de 1504 relatif à la construction du clocher. 
Condom. - Abbaye de Saint-Pierre, puis Chapitre cathédral.

10:35. - Cartulaire de l'abbaye de Saint-Pierre de Condom ou « livre blanc»; orig. perdu.

Copie du précédent : ms. du $\mathrm{X}^{\mathrm{e}}$ siècle. sur parchemin, in- $4^{0}$ de 62 ff. (Biblinth. mulionale, ms. latin 565:).

Copie du même, faite au XVIJe siècle (Biblioth. de feu M. 1. Plieux, à Lectoure,

Autre copie datée de 1784, sur papier, in-folio de 113 ff. (Archices dép. du Ciers, G 6l).

Autre copie, par le chanoine Lagutère (Biblioth. de $y^{\text {me }}$ la Comlesse de (iensıc, à Condom).

Publ. (partiellement) : par Dom L. d'Achery dans son «Spicilegium », XIII (éd de l67\%), pp. 432-511, et II (édon de 1723), pp. $580-602$.

10:36. - Recueil de titres relatifs an Chapitre de Condom: ms. du XVHI siecle [177t], rédigé par Larcher, sur papier, in-40 de 626 pages (Aichires municipales de Condom, Mémoires sur le diocèse. .

Condom. - Évèché.

1037. - Cartulaire de l'évêché de Condom ; orig. perdu.

lixtraits laits au XVIIe siècle (Biblioth. nationalr, coll. Duchesne, vol. CIN. ti. 255-283.

Condom. - Hijpital de lit Charité.

1038. - Cartulaire de l'hòpital de la Charité de Condon; ms. du XVIII" siècle, sur papier, contenant des titres de 1610 à 1718, infolio de 2:27 fl. (Archices hospitalières de Condom, B l.

Condom. - Ville.

1039. - Cartulaire municipal de Condom on «Livre eadenat»; ms. du XIVe siècle, sur parchemin. continué à partir du $1^{\circ} 94$ par des additions jusqu'au $\mathrm{XVIJ}^{e}\left({ }^{1}\right.$, et muni d'une reliure du $\mathrm{XVI}^{\mathrm{e}}$ en bois recouvert de veau brun, avec coins de cuivre, et contenant des documents à parlir de 1244 . in-folio de vin-164 et $18 \mathrm{ff}$. à 2 col. Archives municipales de Condom, AA l.

(Quelques fiouillets manquent; mais la numérotation du XVII siècle que nous avons indiquée est postérieure aux lacunes et n'en tient pas conpte.

(1) Les additions du XVII siècle sont relatives au college de Condom (Oratoriens). 
1040. - Autre recueil de titres relatifs à la ville de Condom; ms. du XIVé siècle, sur papier, contenant des actes de 1286 à 1314 , in $4^{0}$ de 90 tf. (Archires dép. du Gers, E 243).

Extraits faits au $\mathrm{XVII}^{\mathrm{e}}$ siècle (Biblioth. nationale, coll. Baluze, vol. XXIV, ff. 1-2l).

\section{Conflans-en-Bassigny. - Châtellenie.}

1041. - Recueil de titres relatifs à la ville et à la prévôté de Conflansen-Bassigny ; ms. de la fin du XVIe siècle, formé par Thierry Alix, sur papier, contenant des actes de 1249 a 1583 , in-folio de $217 \mathrm{ff}$. (Archives dép. de Meurthe-et-Moselle, B 358).

Conflans-en-Jarnisy. - Chàtellenie.

1042. - Recueil de titres relatifs à la chàtellenie de Conflans-enJarnisy; ms. de la fin du $\mathrm{XVl}^{\mathrm{e}}$ siècle, formé par Thierry Alix, sur papier, contenant des titres de $125 \mathrm{l}$ à $158 \%$, in-folio de $312 \mathrm{lf}$. (Archives dép. de Mewrthe-et-1Yoselle, B 359).

Copie du précédent, faite au XYII siècle, sur papier Archives dép. de la Meuse, B 248).

Conques. - Abbaye de Sainte-Foi (dioc. de Rodez).

1043. - Cartulaire de l'abbaye de Conques ; ms. du XII ${ }^{e}$ siècle, sur parchemin, avec quelques additions, en 3 parties, contenant $\mathbf{5} 68$ chartes des années 801 à 1180 , in-8 de $267 \mathrm{fl}$. (Biblioth. de la Société des lettres, sciences et arts de l'Aveyron.

La reliure est du XVIe siècle.

Publ.: Cartulaire de l'abbaye de Conques en Rouergue, par Gustave Desjardins. Paris, Picard, 1879; in- $8^{\circ}$ de cxx-518 p. [Documents historiques publ. par la Société de l'École des Chartes.]

Comprend 581 chartes des années 801 à 1225.: Cf. Notes rectificatives sur quelques actes du cartulaire de l'abbare de Conques qui font mention des localités situées dans le Carladez, par L. Juhle (.Yémoires de la Société des lettres, sciences et arts de liAceyron, XiVI, 1905, pp. 44-58).

Extraits faits au XVII siècle (Biblinth. nationale, coll. Baluze, vol. LXXIII, ff. 24l-27l ; ms. latin 17048, pp. 403-409).

1044. - Recueil de titres relatifs à l'abbaye de Conques; ms. de 1666, contenant des actes des années 772 à 1571 , en 2 vol. in-folio de 293 et 336 tf. (Biblioth. nationale, coll. Doat, vol. 143-144).

Cons-la-Grandville. - Ville.

1045. - Recueil des privilèges et franchises de la communauté de Cons; ms. du IVIIIe siècle, rédigé par le greftier François Harau- 
champs, sur papier, in- $4^{0}$ de $110 \mathrm{ff}$. (Archives municipales de Consla-Grandville, AA 2).

Dates extrêmes : 1248-1697.

Constance. - Évêché.

1046. - Publ. : Codex diplomaticus Alemanniae et Burgundiae TransJuranae infra fines diocesis Constantiensis, edit. T. Neugart. SanktBlasien, 1791-1795; 2 vol. in- $4^{0}$ de 687 et 718 p.

Voyez aussi ro Burrgogse (royaume de).

Corbeil. - Abbaye de Notre-Dame (dioc. de Paris).

1047. - Cartulaire de l'abbaye de N.-D. de Corbeil ; orig. perdu.

Jean de La Barre, auteur d'une Histoire de la ville et châtellenie de Corbeil, l'a utilisé au XVII ${ }^{\mathrm{e}}$ siècle.

Corbeil. - Église Saint-Spire.

1048. - Cartulaire de Saint-Spire de Corbeil; ms. du XIIIe siècle, sur parchemin, avec additions postérieures [XIVe s.], in-4 $4^{0}$ de $138 \mathrm{ff}$. (Archives de la falrique de l'église de Saint-Spire, à Corbeil).

Les feuillets originaus 87 à 101 ont disparu.

Publ. : Cartulaire de Saint-Spire de Corbeil au diocèse de Paris, par E. Couard-Luys (Mémoires et documents publiés par la Société archéologique de Rambouillet, VI), et à part: Rambouillet, 1882; in- $8^{0}$ de Li-24l p.

Extraits du précédent, faits au XVII ${ }^{\mathrm{e}}$ siècle, sur papier (Biblioth. nationale, ms. français 16182 , ff. 220-232).

Corbie. - Abbaye (dioc. d'Amiens).

1049. - Cartulaire de l'abbaye de Corbie; ms. de la fin du $\mathrm{X}^{\ominus}$ siècle, sur parchemin, relié au XVII , et contenant 8 actes et diplômes depuis le VII ${ }^{e}$ siècle, in- $4^{0}$ (Kgl. Bibliothek in Berlin, fonds Th. Phillipps, $\mathrm{n}^{0}$ 79, ff. 93-128).

On trouve ce manuscrit conservé successivement à Verdun, au collège de Clermont, chez Meermann et à Cheltenham ( $\left.\mathrm{n}^{\circ} 1776\right)$.

1050. - Fragments de cartulaires de l'abbaye de Corbie; ms. des $\mathrm{XI}^{{ }^{-}}$XIIIe siècles, sur parchemin, en trois parties comprenant au total 19 actes dont quelques-uns incomplets, in- $4^{0}$ de $52 \mathrm{ff}$. (Biblioth. nationale, ms. latin 17764).

On n'y rencontre que des documents mérovingiens et carolingiens, avec un diplôme de Hugues Capet. Ce recueil a été dénommé parfois au XVIII siècle llercator.

1051. - Fragments de cartulaires de Corbie; ms. du XII ${ }^{e}$ siècle, sur parchemin, en quatre parties comprenant au total 11 actes dont quelques-uns incomplets, et tous antérieurs à l'an mil, in- $4^{\circ}$ de $39 \mathrm{ff}$. (Biblioth. nationale, ms. latin 17762).

A été désigné parfois sous le nom de Casimirus. 
1052. - Cartulaire de Corbie: ms. du XIIe siècle. sur parchemin, incomplet et endommagé par l'humidité, contenant les anciens privilèges de l'abbaye, in-40 $4^{0}$ de 72 fr. (Biblioth. nationale, ms. latin 17763).

1053. - Cartulaire noir de Corbie ou « Magnus cartularius 》; ms. rédigé au $\mathrm{XIII}^{\mathrm{e}}$ siècle [1295] par le moine Jean de Candas, sur parchemin, avec additions postérieures, et quelques interversions de feuillets dans la reliure, in-folio de Ix-25l ff.'(Biblioth. nationale, ms. latin 17558).

C'était le véritable cartulaire officiel de l'abbaye; le ms. français 25250, du XVIJe siècle, en donne la table alphabétique.

1054. - Cartulaire blinc de Corbie; ms. du XIII ${ }^{\mathrm{e}}$ siècle, sur parchemin, contenant des actes de 856 à 1239 , in $-4^{\circ}$ de xrr-183fl. (Biblioth . nationale, ms. latin 17759).

Les transcriptions y sont défectueuses. - Voir la table dans le vol. XCIX de la coll. Dom Grenier (Biblioth. nationale).

1055. - Autre cartulaire dit « Nehemias »; ms. du XVe siècle, sur papier, contenant des actes depuis le XIIe, in $-4^{0}$ de $364 \mathrm{ff}$. (Biblioth. nationale, ms. latin 17761).

1056. - Autre cartulaire dit «Esdras»; ms. du XVIe siècle, un peu détérioré au début, sur papier, contenant des actes de 662 à 1550 , in $-4^{0}$ de $209 \mathrm{ff}$. (Biblioth. nationale, ms. latin 17760).

1057. - Autre cartulaire dit «Habacus»; ms. du XVIe siècle, sur papier, contenant des actes de 1509 à 1517, par Pierre de Riencourt, in $-4^{0}$ de $307 \mathrm{ff}$. (Biblioth. nationale, ms. français 24145 ).

C'est à peine si l'on peut donner le nom de cartulaire au registre dú $\mathrm{XVe}$ siècle (ms. latin 17765) qui, dans ses 21 feuillets, renferme seulement la traduction française de deux bulles relatives à Corbie.

1058. - Autre cartulaire ; ms. de la fin du $X I^{e}$ siècle, sur parchemin, couvert de damas rouge, perdu.

Sur la valeur relative et le classement de chacun de ces cartulaires, voir pour plus de détails : Examen critique des chartes mérovingiennes et carolingiennes de l'abbaye de Corbie, par Léon Levillain (Paris, Picard et fils, 1902, in-8), pp. 10-24, que nous avons simplement résumé

Extraits des cartulaires précédents, faits aux XVII et XVII ${ }^{\mathrm{e}}$ siècles (Biblioth. nalionale, coll. Baluze, vol. XLII, ff. 194-226, ex veteri codice : ms. français 9499 , pp. 296-328 et 348-351, d'après le cartulaire noir ; coll. Dom Grenier, vol. LIII ; mss. เatins 12777 , pp. 743 ss., et 12665 , pp. 121 ss.)

Corbigny. - Abbaye de Saint-Léonard (dioc. d'Autun).

1059. - Recueil de titres relatifs à l'abluaye de Corbigny, du $\mathrm{X}^{\mathrm{e}}$ an $\mathrm{XV}^{\mathrm{e}}$ siècle, fait au $\mathrm{XVII}^{\mathrm{e}}$ (Billioth. nationale, ms. latin 12665 , ff. 224-234). 
1060. - Autre recueil dressé par Dom Aubrée au XVIII ${ }^{\text {e }}$ siècle, contenant des actes de 1060 à 1643, in- $4^{\circ}$, sur papier (Biblioth. nationale, coll. Bourgogne, vol. CriII, ff. 13-555).

Publ. : Chartes de Corbigny, par A. de Charmasse (Mémoires de la Société éduenne, nouv. série, XVII, pp. 1-40); et à part: Autun, Dejussieu, 1889, in- $8^{\circ}$ de $41 \mathrm{p}$.

Corcieux. - Ville.

1061. - Recueil cles privilèges accordés à la commune de Corcieux par les ducs de Lorraine; ms. du $\mathrm{XVI}^{\mathrm{e}}$ siècle, sur papier, in-4 ${ }^{0}$ de $26 \mathrm{ff}$. (Archives communales de Corcieux, AA 2).

Cordes. - Ville.

1062. - Cartulaire municipal ou « livre ferrat» de Cordes; ms. sur parchemin, in- $4^{0}$ de 65 11.' (Archives municipales de Cordes, déposées aux Archives dép. du Tarn, AA 1).

Dates extrêmes : 1273-1625.

Cordillon. - Abbaye (dioc, de Bayeux).

1063. - Cartulaire de l'abbaye de Cordillon; ms. du XIII ${ }^{\mathrm{e}}$ siècle, sur parchemin, in $4^{0}$ de $48 \mathrm{ft}$. (Biblioth. du Chapitre de Bayeux, ms. 162 .

Contient 238 chartes antérieures à 1279. - Sera publié dans le tome II (sous presse) de l'Histoire de l'abbaye de Cordillon, par Cadet de Gassicourt.

Cormeilles. - Voy. Cergy.

Cormery. - Abbaye de Saint-Paul (dioc. de Tours).

1064. - Cartulaire de l'abbaye de Cormery ; ms. du XVI' siècle, par J. Périon, bénédictin, sur papier, in-folio de $163 \mathrm{ff}$, comprenant 150 documents des années 791-1505, et avec table au début rédigée en 1740 (Biblioth. de la ville de Tours, ms. 1349).

Extrait par J. Perion (Biblioth. nutionale, ms. latin 12665, ff. 248251).

Publ. : Cartulaire de Cormery, précédé de l'histoire de l'abbaye de Cormery d'après les chartes, par l'abbé J. Bourassé (Mémoires de la Société archéslogique de Touraine, XII), et à part: Tours et Paris, 1861 ; in- $8^{\circ}$ de cxLIV-355 p. et $\mathrm{pl}$.

1065. - Autre cartulaire plus ancien ; orig. perdu.

Extraits faits au XYII siècle (Biblioth. nationale, ms. latin 13817, ff. 15-18).

1066. - Recueil de titres relatifs à l'abbaye de Cormery; ms. du XIX' siècle, par Anllé Salmon, sur papier (Biblioth. de la ville de Tours, ms. 1348, fr. 141 à 405).

106\%. - Autre recueil fait au XVII ${ }^{\mathrm{e}}$ siècle (Biblioth. nationale, coll. Baluze, vol. XLYII, ff. 147-158 et 185-193). 
Corneux. - Abbaye (dioc. de liesançon).

1068. - Cartulaire de l'abbaye de Corneux: ms. du XVIIIe siècle, sur papier, contenant 171 documents des années 1133 -1746, in-folio de 149 II. (Archives dép. de la Haute-Saine, H 747.

lixtraits du cartulaire de l'abbaye de Corneux; ms. du XVIII ${ }^{\mathrm{e}}$ siècle, sur papier, in $4^{0}$ (Biblioth. de la rille de Besancon. coll. Droz, ms. 46 , 1f. 13 i $35 \%$ ).

Corneville-sur-Rille. - Abbaye (dioc. de Rouen).

1069. - Vieux cartulaire de l'abbaye de Corneville; orig. perdu.

Extrait du XVIIe siècle [1670], sur parchemin, in $-4^{0}$ de 24 pages (Biblioth. nationale, ms. latin 10060).

Contient un acte de l'année 1290.

Cornillon. - Seigneurie en Forez.

1070. - Cartulaire de la baronnie et seigneurie de Cornillon en Forez; orig. perdu.

Copie faite au XVIII siècle (?).

Cop e de la précédente, faite vers 1840 , par II. de La Tour-Varan, sur papier, in-folio de 250 pages (Biblioth. de la rille de SuintÉtiense, ms. 273).

Autre copie sur papier, moderne, in- $4^{0}$ de 255 pages (Biblioth. de la ville de Saint-Étienne, ms. 171).

Corny. - Seigneurie en Vexin.

1071. - Cartulaire de la seigneurie de Corny ; ms. du XVIII siècle [1767], sur papier, in-40 de xxxin-396 pages (Archices dép. de Seine-et-Oise, série H, funds de l'abbaye de St-Louis de Poissy,

Dates extrêmes : $12 \pi \%-1 \%$ ibo.

Corps et Goncelin. - Villes.

1072. - Recueil des privilèges des villes de Corps et Goncelin; ms. du XI $\mathrm{Y}^{\mathrm{e}}$ siècle, sur papier, contenant des titres de 1309 à 1336 , in $-4^{0}$ de $104 \mathrm{ff}$. (Avchives dép. de l"Isère, B 3322 .

Correns. - Prieuré (dioc. de Frẻjus).

1073. - Cartulaire du prieuré de Correns, dépendant de l'abbaye de Montmajour; ms. des XIe-XII e siècles, sur parchemin, in-so de 169 pages Archices dép. des Bouches-du-Rhine, série H, fonds de Montmajour).

Le rolume, qui ne contient que des acles du $\mathrm{XI}^{e}$ siècle (à partir de 1024), est incomplet d'un feuillet au début et se termine par une table additionnelle de 3 ff. écrits au XVIII siècle. 
Cortenberg. - Abbaye (dioc. de Malines).

1074. - Cartulaire de l'abbaye de Cortenberg; ms. du XVII siècle, sur papier, collationné par le notaire J. van der Duncq en partie [16:8], avec additions du XVIII ${ }^{\mathrm{e}}$ siècle, in-folio de 406 pages Archives de l'archevéché de Malines).

Contient des documents depuis le XIo siècle.

Cotignac. - Ville.

1075. - Cartulaire ou « livie rouge » de la ville de Cotignac: ms. des XVI ${ }^{\mathrm{e}}-\mathrm{XVII} \mathrm{e}^{\mathrm{e}}$ siècles, sur papier, contenant des actes à partir de 1493, in- $4^{0}$ de 387 ff. (Archives muncipales de Cotignac, AA 1).

Coudrie. - Commanderie à Challans (dioc. de Luçon).

1076. - Publ. : Cartulaire de Coudrie, par Louis de La Boutetière (Archives historiques du Poitou, II, 1873, p. 149-215).

Coulombs. - Abbaye (dioc. de Chartres).

1077-1078. - Grand et petit cartulaire de l'abbaye de Coulombs; tous deux perdus.

Extraits faits au XVII ${ }^{\mathrm{e}}$ siècle (Biblioth. nationale, coll. Baluze, vol. XXXVIII, If. 25-33; ms. latin 17048, pages 431-446; ms. latin 1277\%, pp. 657-660; coll. Clairambault, vol. 561, pp. 45-47; coll. Duchesne, vol. LIV, fr. 44-50), ce dernier d'après les origrinaux.

Analyses d'un grand nombre de chartes utilisées dans les Mémoires historiques sur l'abbaye de Coulombs [vers 1775], par l'abbé d'Espagnac (Biblioth. de la ville de Chartres, ms. 1106).

Les "Mémoires " de l'abbé d'Espagnac ont servi de base aux travaux de Marre : Les seigneurs de Nogent-le-Roi et les abbés de Coulombs (Dreux, 1861, in-12), et de L. Merlet : Histoire de l'abbaye de N.-D). de Coulombs (Hémoires de la Soc. arch. d'Eure-et-Loir, III, $1865)$.

Extraits du «vieil cartulaire» de Coulombs, par Laisné, prieur de Mondonville (Biblioth. nationale, ms. français 24133, pages 107144 .

Coulommiers. - Prieuré de Sainte-Foi (dioc. de Meaux).

1079. - Recueil de pièces relatives au prieuré de Coulommiers en Brie; ms. du XVII ${ }^{\mathrm{e}}$ siècle, sur papier, in-folio Biblioth. nationale, coll. Doat, vol. 144, ff. 305-336).

Coulommiers. - Ville.

1080. - Recueil de titres relatifs à la ville de Coulommiers; ms. du $\mathrm{XVIII}^{\mathrm{e}}$ siècle, composé par N. Hébert, en 9 vol. in-folio sur papier (Biblioth. de. I. Gaston Ogier de Baulny, à Coulommiers). 
Courtrai. - Albbaye de Groeninghe (dioc. de Tournai.

1081. - Publ. : Speculum Beatæ Mariæ Viruinis el Chronique et cartulaire de l'abbaye de Groeninghe à Courtrai. par F. Van de Putte. Bruges, Vandecasteele-Verbrouck. 1822: in-1" de xxxvinLxxxvir-176 p. [Publication de la Société d'émulation de Bruges.]

Dates extr3̀mes: $1237-1797$.

Courtrai. - Collégiale Notre-Dame.

1082. - Publ. : Cartulaire de l'ancienne église collégiale de NotreDame de Courtrai, par C. Mussely et E. Molitor. Gand. impr. Annoot-Braeckman, 1880 ; in- $4^{\circ}$ de vi-434 p. et pl.

Contient 846 chartes. Dates extrêmes : 1190 enr. à 175\%: mais à partir de 1287 ce ne sont plus que des analyses. Les auteurs se sont servi d'un manuscrit conservé à Courtrai, dont on trouvera la désignation au "Siupplément".

Courtrai. - Ville.

1083. - Recueil des privilèges de la ville de Courtrai ; ms. des $\mathrm{XVI}^{\mathrm{e}}$ XVII siècles, sur parchemin, contenant des actes de 1190 à 1544 , in-folio de $458 \mathrm{ff}$. (Archires communales de Courtrai).

Goutances. - Chapitre cathédral.

1084. - Cartulaire du Chapitre cathédral de Coutances ou "livre blanc »; ms. de la fin du XIV siècle, avec additions du XVe et du $\mathrm{XVI}{ }^{e}$, sur parcheinin, contenant des actes de 1060 à $15 \mathrm{l} l$, in-folio de 450 ó pages (Archives de l'évéché, à Coutances).

Copie moderne, in-10 sur papier (Biblinth. nationale, ms. nouv. acq. latines 1364).

I1 y avait autrefois trois cartulaires au lieu d'un (rus par Toustain de Billy); les deux registres perdus avaient respectivement 444 et $553 \mathrm{ff}$. au moins. Cf. une table de ces trois cartulaires, sur papier, du XVIe siècle (Biblioth. nationale, ms. latin 5200, ff. 60-89).

Coutances. - Église Saint-Pierre.

1085. - Cartulaire ou «livre noir » de Saint-Pierre de Coutances ; ms. du XVe siècle [1490], sur parchemin, dù à Jean Baril, trésorier de l'église, et contenant des documents à partir de 1316 , en 2 parties in-folio de 107 et $115 \mathrm{ff}$., séparées par quelques actes transcrits postérieurement (Archives de la fabrique de l'église Saint-Pierre, à Coutances).

Cif. Recueil des Hist. des Gaules et de la France, XXIII, pp. 493-5.42.

Coutances. - Hôtel-Iieu.

1086. - Publ. : Essai historique sur l'Hôtel-Dieu de Contances, l'hôpital général et les Augustines hospitalières depuis l'origine jusqu’à la Révolution, avec cartulaire général, par Paul Le Cacheux. 
II (Cartulaire). Paris, Picard et fils, 1899 ; in- $8^{\circ}$ de [vI- $\mid x x ı v-$ $490 \mathrm{p}$.

Recueil factice de pièces, la plupart publiées d'après les originaux, de 1209 à 1712 .

1087. - C'artulaire de l'Hôtel-Dieu de Coutances ; ms. du XVe siècle, sur parchemin, in $-4^{0}$ de 27 ff. (Biblioth. Cheltenham, $\mathrm{n}^{0} 9411$ ).

1088. - Autre; ms. du XVe siècle, sur parchemin, incomplet, avec une reliure de bois recouvert de cuir, in-40 122 pages (Biblioth. du Chapitre de Bayeux, ms. 124).

1089. - Fragment d'un autre cartulaire; ms. du XVIII siècle, sur parchemin, contenant des actes de 1209 à 1261 , in $4^{\circ}$ de 20 ff. (Archives hospitalières de Coutances).

Couvin. - Couvent des Récollets (dioc. de Liège).

1090. - Cartulaire des Récollets de Couvin; ms. du XVIII siècle, rédigé par le $\mathrm{P}$. Le Soin et contenant des documents à partir de 1464. in-folio de 379 pagres sur papier (Avchives de la fabrique de Couvin).

Cf. : Le cartulaire des Récollets de Couvin, par le P. Ubald d'Alençon (Revuc historique ardennaise. XI, 1904, p. 297-332).

Couvin. - Ville.

1091. - Publ. : Cartulaire de la commune de Couvin (Belgique), 1096-1791, par S. Bormans. Namur, Wesmael-Charlier. 1875; in- $8^{\circ}$ de cxxviI- $322 \mathrm{p}$. et pl. [Documents inédits relatifs à l'histoire de la province de Namur, V.]

Coye. - Village.

1092. - Recueil des titres relatifs aux fiefs de Malépargne et de la Barre à Coye; ms. fait pour Claude de La Barre en 1599 , sur parchemin, in-4" de 62 fr. (Archires du chateau de Chantilly, ms. 104 $)$.

Dates extrême's : 1363-1598.

Craon. - Église collégiale Saint-Nicolas (dioc. d'Angers).

1093. - Cartulaire de Saint-Nicolas de Craon; ms. des XVI ${ }^{e}-\mathrm{XVII}^{\mathrm{e}}$ siècles, contenant 201 pièces des années 1540-1666, sur papier et parchemin, in $4^{0}$ de $692 \mathrm{ff}$. (Archives dép. de la Mayenne, $\mathrm{G}$ non coté).

Craon. - Famille.

1094. - PUbL. : La maison de Craon (1050-1480), étude historique accompagnée du cartulaire de Craon, par A. Bertrand de Broussillon. Paris, Picard. $1893 ; 2$ vol. in- $8^{\circ}$ de [Iv-]xiv-388 et Iv-402 p.

A chargue chapitre, une série danalyses tet de transcriptions de documents constitue le " cartulaire " indiqué sur le titre. 
Craon. - Prieuré de Saint-Clément (dioc. d'Angers).

1095. - Cartulaire du prieuré de Craon, dépendant de l'abbaye de la Trinité de Vendôme: ms. du XVIe siècle avec additions postêrieures, contenant 223 actes des années 1040-165\%, sur papier, in-4" de 685 ff. (Archizes dép. de la . Mayenne, $\mathrm{H}$ non coté).

II $y$ a quelques lacunes dans ce registre.

Créant. - Prieuré près de La Fléche dioc. l'Angers,

1096. - Recueil de titres relatifs au prieuré de Créant, dépt de l'abbaye du Mont-Saint-Michel ; ms. du XVII siècle, formé par Gaignières, sur papier, in-folio (Biblioth. nationale, ms. latin $5430^{a}$, pp. 100-109,

Crécy-en-Brie. - Hôtel-Dieu 'dioc. de Meaux).

1097. - Cartulaire de l'Hòtel-Dieu de Crécy-en-Brie : ms. du XITe siècle, sur parchemin. contenant des actes de l209 à 1330, in-12 de 8 ff. Archices nationales. S 4853).

Publ. : Cartulaire de l'Hôtel-Dieu de Crécy-en-Brie, par H. Stein 'Bulletin de la Conférenco d'histoire et d'archeólogie du diacèse de Meaus, II, 1899. pp. 136-145).

Crécy-en-Brie. - Tille.

1098. - Cartulaire de Crécr-en-Brie: ms. du XVI siècle, sur papier, contenant des documents de 1137 à 1487. in-4" de 18 ff. 'Archices nationales, K $1153, n^{0} 49$.

Creil. - Église Saint-Érremond (dioc. de senlis).

1099. - Cartulaire de Saint-Érremond à Creil; ms. du XVIII siècle, contenant des titres de 1330 a $14 \%$. in $-4^{\circ}$. sur papier, de $68 \mathrm{ff}$. Archices du chateau! de Chantilly, $\mathrm{n}^{\prime} 119^{\mathrm{d}}$.

Aral. : Une mauraise analyse en a élé donnéa par le $D^{r}$ Boursier, Histoire de la ville et chàtellenie de Creil (Paris. 1883, in-8 ${ }^{\circ}$ ). Grémarest. - Église Notre-Lame dioc. d'Arras.

1100. - Cartulaire de l'église de Crémarest: ms. rédigé au XVe siècle [1+36]. avec quelques additions postérieures. sur parchemin, in-40 de $27 \mathrm{ti}$. Archires tép. du Pas-de-Calais. G non cotë.

A été donné à c" dépôt par l'ałhé Haigneré, ancinn archivis'e de Boulogne-sur-Mer. Les actes transcrits ront de 1332 à 1499 .

Copie du mème. faite en 177l. sur papier, in-40 de 35 If. (Archices de la fubrique de Cremurest.

Crépy-en-Valois. - Église collègiale Saint-Aubin. 1101. - Cartulaire de la collégiale Saint-Aubin de Crépy : orig. perdu.

Existait encore au XYlle siocle: Carlier. dans son "Histnir" du duché dos Yalois n, III, pr., p. xril et Lrr, en a tiré deux chartes. 
Grépy-en-Valois. - Église collégiale Saint-Thomas (dioc. de Senlis).

1102. - Cartulaire de la collégiale Saint-Thomas de Crépy, ms. en parchemin à 2 colonnes; orig. perdu.

dété connu de Dom Grenier (cf. Bibliotí. untionale, coll. Moreau, rol. 99, fo 87 ).

Crépy-en-Valois. - Prieuré de Saint-Arnoult.

1103. - Cartulaire du prieurí de St-Arnoult de Crépy ; orig. perdu.

Dom Grenier a connu un "registre premier aux archives du prieuré » (ef. Biblioth. nationale, coll. D. Grenier, vol. CXI, fo 215).

Grespières. - Village (dioc. de Chartres). -- Voy. Suresnes. Grespin. - Abbaye (dioc. de Cambrai).

1104. - Cartulaire de l'abbaye de Crespin ; orig. perdu [sur parchemin, de 155 ff., XIII ${ }^{\mathrm{e}}$ siècle].

A été vu vers 1772 par Dom Queinsert, qui lui a emprunté divers actes en copie aujourd'hui dans la coll. Grenier et dans la coll. Moreau (IV, fo 82). Cf. : Recherches sur le Hainaut ancien, par Ch. Duvivier (1865), p. 303.

Voy. aussi Pummerti.

Crisenon. - Abbaye (dioc. d'Aluxerre).

1105. - Cartulaire de l'abbaye de Crisenon; ms. du XIII e siècle [1291], sur parchemin, in $-4^{\prime \prime}$ de III-122 ff. à 2 col. (Biblioth. nationale, ms. latin 9885).

Une seule addition postérieure au dernier feuillet. Les 261 chartes qui y sont transcrites sont des années 1134-1298. Le volume est incomplet à la fin.

Groixmare (Guillaume de), chevalier normand.

1106. - Cartulaire de Guillaume de Croixmare; ms. de la fin du XIV ${ }^{0}$ siècle [vers 1389], in-folio de xxxvi-293 ff. (Biblioth. de la duchesse douaivière de Polignac, an chau de Saint-Jean-de-Cardonnay).

Cf. Le cartulaire de Guillaume de Croixmare, notice par Léopold Delisle (Bulletin de la Sociéte de lhistoire de Normandie, VII, p. 122151), et à part: Rouen, 1894 ; in $-8^{\circ}$ de $32 \mathrm{p}$.

Gubas. - Prieuré (dioc. de Périgueux).

1107. - Livre jaune du prieuré de Cubas, dépt de l'abbaye de Fontevrauld; ms. dı XVII ${ }^{2}$ siècle [1629], sur papier, in-folio de 155 (1) fl. (Archives tép. de Maine-et-Loire, $\mathrm{H}$ non coté).

Le plus ancien document transcrit est de 1271 .

(1) 32 dans un sens et 123 dans l'autre. 
Cuers. - Ville.

1108. - Cartulaire municipal de Cuers, ou «Livre jaune » : ms. du XVII siècle, sur papier. contenant des documents à partir de 1318 , en 2 vol. in-folio de 264 et $96 \mathrm{fr}$. (Archires municipales de Cuers, Ad 1-2).

Cuxa. - Abbaye de Saint-Mrichel (dioc. d'Elne).

1109. - Cartulaire majeur de l'abbaye de Saint-Michel de Cuxa [sur parchemin, de $136 \mathrm{ff}$.]; orig. perdu.

Voir une mention précise (Archices des Pyreñées-Orientales, $\mathrm{H}$ 66).

Extraits faits en 1660 du cartulaire majeur de Saint-Michel de Cuxa, depuis le $\mathrm{IX}^{\mathrm{e}}$ siècle jusqu'au $\mathrm{XI}^{\mathrm{e}}$ Biblioth. nationale, coll. Baluze, vol. CXVII, ff. 84-143. 172, 232-234 et 247-255).

La copie intégrale a été faite jusqu'au fo 41 ; à la suite ce sont surtout des analyses.

Copies de Fossa, faites au XriII siècle (Biblioth. nationale, coll. Moreau, vol. XXX, ff. 1-8 et 4l-45).

1110. - Autre cartulaire de St-Michel de Cuxa [sur parchemin de 243 ff.]; orig. perdu.

Extraits faits en 1660 de bulles et de diplômes contenus dans le vol. précédent (Biblioth. nationale, coll. Baluze, vol. CXVII, ff. 176-208).

1111. - Autre cartulaire dit «antiquissimus », [sur parchemin, infolio de $130 \mathrm{ff}$.] ; orig. perdu.

Extraits faits en 1660 (Biblioth. nationale, coll. Baluze, vol. CVII, ff. 366-372, et vol. CXVII, tf. 209-218;.

Le même tome CrII, ff. 375-411, contient des extraits des archives de la même abbaye.

1112. - Recueil de titres relatifs à l'abbaye de Saint-Yichel de Cuxa ; ms. de 1668-1669, in-folio sur papier, contenant des actes des XeXIII siècles (Biblioth. nationale, coll. Doat, vol. 82, ff. 310-383).

Cuxac-d'Aude. - Ville.

1113. - Recueil des privilèges de Cuxac-d’Aude; ms. du XVIe siècle, sur papier, contenant des titres de 1329 à 1555 , in-4' de $10 \mathrm{ff}$. (Archives communales de Cuxac-d'Aude, At 1).

Cysoing. - Abbaye de Saint-Caliste (dioc. de Cambrai).

1114. - Cartulaire de l'abbaye de Cysoing; ms. du Xrie siècle [15̆17], sur parchemin, contenant 329 documents à partir de 867 , et terminé par une table des matières, in-folio de 261 tf. (Archives de l'État à Mons). 
1115. - Pubr. : Cartulaire de l'abbaye de Cysoing et de ses dépendances, par I. de Conssemaker. Lille, Desclée et de Brouwer, 188[6]; in-8 de xil-1024 p.

Recueil factice de documents empruntés tant à ce cartulaire qu'aux Archives dép. du Nord et aux archives de Tournai.

1116. - Recueil de titres relatifs à l'abbaye de Cysoing; ms. du XVII ${ }^{\circ}$ siècle, contenant des actes des années 858 à 1458, in-folio de 514 tr. (Biblioth. nationale, coll. Flandre, vol. 73).

Dalon. - Abbaye (dioc. de Limoges).

1117. - Cartulaire de l'ahbaye de Dalon ; orig. perdu.

Copie et extraits par Baluze. in-4" de 71 p. avec table (Bibliall. nationale, coll. Baluze, vol. 375).

Extraits faits au XVIII siècle (Biblıth. nationale, coll. Périgord, vol. XXXIII, ff. 392-395; vol. XXXIV, fo 7, et vol. XXXVII, II. $395-400$ ).

Autres par 1). Jacques Boyer, au XVII siècle (Biblioth. nationale, ms. latin 12697 , fi. 151 et 156 ).

1118. - Extraits par Gaignières d'un cartulaire in-folio en parchemin le 133 ff., communiqué par M. Vion d'Hérouval (Biblioth. nutionale, ms. latin 17120, pp. 1-208).

Cf. : Poésies complètes de Bertran de Born, publiées avec des extraits du cartulaire de Dalon par Antoine Thomas. Toulouse, Privat, 1888 ; in-16 de LII-210 p. [Bibliothèque méridionale, Ire série, I.]

Dampierre. - Voy. Cherreuse.

Darney. - Chapitre Saint-Nicolas (dioc. de Besançon).

1119. - Cartulaire du Chapitre de Darney ; ms. du XVIIIe siècle [1742]. sur papier, contenant des dlocuments des années 1308-1742, in-folio de 37 fl. (Archives dép. des Tosges, G 19).

\section{Dauphiné.}

1120. - Cirtulaires du Dauphiné; ms.. des X $\mathrm{Y}^{\mathrm{e}} \mathrm{XVI} \mathrm{XI}^{\mathrm{e}}$ siècles, sur papier, contenant des ducaments à partir de 1023 , en 11 vol. in $4^{0}$ de $120,66,52,658,699,418,280,341,325,290$ et 59 ff. (Archices dép. de l'Isère, B 3245 à 3255).

Intéressent aussi le Gapençais, le Valentinois, et le Diois.

Dauphiné. - Hospitaliers et Templiers. - Voy. Roass et SAINT-PAUL-LES-ROMANS.

Dauphins de Viennois. - Voy. Viensols. 
Davayé. - Châtellenie en Bourgogne.

1121. - Recueil de titres relatifs à la châtellenie de Davayé : ms. du XVIII siècle [17it], par Henrion de Saint-Amand, sur papier, in- $8^{\circ}$ de 83 ff. (Biblioth. nationale, ms. latin 17218).

Ce sont surtout des extraits des cartulaires de Cluni, pour les années 900 à 1749 ; le réritable recueil n'occupe que les ff. 1-30.

Davron. - Prieuré de la Madeleine, à Feucherolles dioc. de Chartres).

1122. - Fragment du cartulaire du prieuré de Davron, dépt de l'abbaye de Josaphat : ms. du $\mathrm{XI}^{e}$ siècle. sur parchemin. contenant 34 chartes-notices non datées, in- $8^{\circ}$ (Biblisth. nationale, ms. latin 5288, if. 77 vo à 85 ,

Dax. - Érêché.

1123. - Cartulaire de l'évêché de Das, ou « liber memorialis qui liber privilegium vulgariter appellatur »; ms. du XIIe siècle avec additions postérieures, sur parchemin, de 83 ff. ; orig. perdu.

Extraits faits par Oỉhenart au XVII siècle (Biblioth. nationole, coll. Duchesne, vol. CXYIII, ff. 58-69).

Extraits fails au XVIII siecle, sur papier, in-folio de 23 pages (Archices nationales, $\mathrm{G}^{9} \mathrm{I} 31$.

Extraits des XI-XVI siècles. - Cf. Marea, Histoire de Béarn, et Recueil des Historions des Gaules et de la France, XII', p. 183 et ss.

Dax. - Prieuré du Saint-Esprit.

1124. - Cartulaire du prieuré du St-Esprit de Dax; ms. du XIVe siècle, sur parchemin, in-8 de 12 tf. (Archices dép. des Landes, $\mathrm{H}$ $243^{1}$ ).

Dates extrínes : 1224-125\%.

Dax. - Ville.

1125. - Cartulaire municipal de Dax ou « livre rouge »; ms. de la fin du XIVe siècle, sur parchemin, avec reliure de hois recouvert en cuir estampé, contenant i3 chartes, dont plusieurs en langue romane, de 1170 à 1400 , in $4^{\circ}$ de $70 \mathrm{ff}$. (Archires municipales de Dax, At 3).

1126. - Autre cartulaire ou «livre noir »; ms. du $\mathrm{Xl}$ "e siècle, sur papier, in- $4^{\circ}$ de $126 \mathrm{ff}$. (Archires municipales de Dax, At 4).

Ce second registre est en grande partie la iranscription du promier. Voir aussi une série de testes transcrits au XIII siècle (Biblioth. nationale, coll. Baluze, vol. XXV, ff. 1-51).

PcBd. : Le livre noir et les établissements de Dax, par Fr. Abbadie. Bordeaux-Paris, 1902 ; in-10 de cLxxxri-595 p. et pl. [Archives historiques du dépt de la Gironde, XXXVII.] 
1127. - Recueil des privilèges des hahitants de Dax; ms. du XVIe siècle, sur parchemin, contenant des actes de 1295 à 1553 , in- $4^{0}$ de $18 \mathrm{fr}$. (Archives dep. des Landes, E 40).

1128. - Publ. : Recueil des chartes, lettres patentes, déclarations des rois, arrêts, sentences, ordonnances, franchises et exemptions de la, ville et cité de Dax. Dax, 1750, in-40.

Decize. - Prieuré de Saint-Pierre (dioc. de Nevers).

1129. - Fragment d'un cartulaire du prieuré de Saint-Pierre de Decize, dépt de l'abbaye de Saint-Germain d'Auxerre; ms. du XVII siècle, de 3 ff. de papier in-folio, contenant uniquement des bulles de papes à partir de 1194 'Archives dép. de la Nièore, H 317).

Delle. - Ville.

1130. - Cartulaire municipal de Delle; ms. du XVII e siècle, sur papier, contenant des documents de 1530 à 1664, in-4 $4^{0}$ de $157 \mathrm{ff}$. (Archives municipales de Delle, AA 1).

Déols. - Abbaye (dioc. de Bourges).

1131. - Cartulaire de l'abbaye de Déols ; ms. du XVe siècle [1445], sur papier, collationné par Jean de La Mote, procureur di seigneur de Châteauroux, contenant des actes depuis la fondation jusqu'en 1443 , in- $4^{0}$ de 64 pages (Biblioth. nationale, ms. latin 12820).

$1131^{\text {bis }}$ - - Bullaire de l'abbaye de Déols ; ms. du XVIIIe siècle, rédigé par un chanoine de St-Martin de Châteauroux, sur papier, in-folio (Biblioth. de M. de Fougères, à Châteauroux).

Voy. aussi vo Tours (église $\mathbf{S}^{t}$-Martin).

Deuil, près de.Montmorency.

1132. - Cartulaire de Deuil, dép ${ }^{t}$ de l'abbaye de St-Denis; orig. perdu.

Extrait du précédent, fait au $\mathrm{XVII}^{\mathrm{e}}$ siècle (Biblioth. nationale ms. latin 17048, fo 515 ).

Deux-Ponts. - Duché. - Voy. Gueldre.

Deux-Ponts. - Ville. - Voy. Zwerbrücken.

Deynze. - Couvent de Sainte-Marguerite ou de Bethléem.

1133. - Cartulaire du couvent de Sainte-Marguerite de Deynze; ms. du XVI ${ }^{\mathrm{e}}$ siècle, sur papier, contenant des titres de 1272 à 1543 , in-4 $4^{0}$ de 393 ff. (Archives de l' État ̀̀ Gand).

1134. - Autre recueil ; ms. du XVI ${ }^{\mathrm{e}}$ siècle, sur papier, contenant des titres de 1480 à 1520, in-folio de $534 \mathrm{ff}$. (Archives de l'tetat à Gas d, . 
Dhuisy. - Prieuré (dioc. de Ieaux).

1135. - Cartulaire du prieuré de Dhuisy ; ms. du XVI e siècle [1573], sur papier, contenant des actes de 1170 à 1487 , in- $4^{0}$ de $97 \mathrm{ff}$. (Biblioth. nationale, ms. français 11568).

Die. - Église Notre-Dame.

1136. - Cartulaire de l'église de Die; ms. du XIII e siècle [1231], sur parchemin, comprenant 33 chartes des années $1178-1224$, in-4 ${ }^{0}$ de $48 \mathrm{ff}$. (Biblioth. nationale, ms. latin 18356).

Publ.: Cartulaire de l'église de Die, par l'abbé Ul. Chevalier (Documents inédits relatifs au Dauphiné, II, Grenoble, 1868, in- $8^{\circ}$, p. 1-74).

Die. - Évêché.

1137. - « Cartularium episcopatus Diensis »; orig. perdu.

Extraits des années 1158-1229 (Biblioth. nationale, ms. nouv. acq. françaises 7387, ff. 193-195).

Die. - Ville.

1138. - Recueil des privilèges de la ville de Die, transcrits d'après les originaux par le $\mathrm{D}^{\mathrm{r}}$ Denis Long ; ms. du XIX ${ }^{\mathrm{e}}$ siècle, sur papier, in- $8^{\circ}$ de $149 \mathrm{ff}$. (Appartenait autrefois à M. de La Morte-Félines).

Copie du précédent par Jules Ollivier (Biblioth. de la ville de Grenoble, ms. 1444, pp. 473-580, et ms. 1458, pp. 107-183).

1139. - Pubr. : Cartulaire de la ville de Die, par l'abbé Ul. Chevalier (Documents inédits relatefs au Dauphiné, II, Grenoble, 1868, in- $8^{\circ}$, p. 75-193).

Recueil factice comprenant des pièces des années 1218-1441.

Diepenbeke. - Seigneurie en Flandre.

1140. - Cartulaire de la seigneurie de Diepenbeke, dépt de l'abbaye de Villers; ms. du XVIo siècle, sur parchemin, in- $8^{\circ}$ de $30 \mathrm{ff}$. (Archives du royaume de Belgique, à Bruxelles).

Dieppe. - Ville.

1141. - Publ. : Recueil général des édits, déclarations, lettres patentes et arrêts du Conseil d'État donnés en faveur des habitants de la ville de Dieppe, concernant les privilèges, franchises et exemptions de ladite ville. Dieppe, Pillon, 1700-1720, in-folio.

Diest. - Ville.

1142. - «Registrum copiarum cartarum 》 ou cartulaire de la ville de Diest; ms. du XIV' siècle, sur parchemin, contenant des actes de 1228 à 1399, in-40 de 59 ff. (Archices communales de Diest).

1143. - Autre cartulaire ou "Oude Rootboeck »; ms. des XIVe_ 
$\mathrm{XVe}^{\mathrm{e}}$ siècles, sur papier, contenant des actes de 1228 à 1449 , in- $4^{0}$ de $87 \mathrm{ff}$. (Archives communales de Diest).

1144. - Autre cartulaire; ms. des $\mathrm{XV}^{\mathrm{e}}-\mathrm{XVI} \mathrm{I}^{\mathrm{e}}$ siècles, sur papier, contenant des documents de 1447 à 1522 , in- $4^{\circ}$ de 383 pages (Archives municipales de Diest).

1145. - Autre cartulaire; ms. du XIVe siècle, sur parchemin, contenant des actes de 1228 à 1346, in- $4^{0}$ de 39 fí. (Archives du royaume de Belgique, à Bruxelles).

1146. - Recueil de titres relatifs à la ville de Diest; ms. du XVIII siècle. sur papier, in-folio de 14 pages (Archives royales de La Haye, Papiers Gérard, $n^{0} 52$ ).

Dieu-en-Souvienne. - Prieuré (dioc. de Toul).

1147. - Cartulaire de l'abbaye de Dieu-en-Souvienne; ms. du $\mathrm{XIII}^{\mathrm{e}}$ siècle, sur parchemin, in-4 ${ }^{0}$ (Archives dép. de la Meuse, série G, fonds de St-Maxe de Bar).

Extraits faits au XVIII' ${ }^{\theta}$ siècle (Biblioth. nationale, coll. Lorraine, vol. 282 , ff. 194-223).

Documents à partir de 1201 .

Digne. - Église cathédrale.

1148. - Recueil des titres de l'église de Digne; ms. de la fin du $\mathrm{XV}$ e siècle avec additions jusqu'en 1631 , sur parchemin, contenant des actes depuis 1269, in- $4^{0}$ de 61 ff. (Archives dép. des BassesAlpes, G non coté).

Digne. - Ville.

1149. - Cartulaire municipal de Digne ou « livre doré »; ms. de la fin du XIVe siècle, sur papier, contenant des documents de 1191 à 1346, in-40 de 85 fr. (Archives municipales de Digne, dit 1).

Dijon. - Abbaye de Saint-Bénigne (dioc. de Langres).

1150. - Cartulaire-chronique de Saint-Bénigne; ms. des $\mathrm{XI}^{\mathrm{e}}-\mathrm{XII}^{\mathrm{e}}$ siècles, débutant par un diplôme de Charles le Chauve, sur parchemin, in-folio, tf. 59-121 (Biblioth. de la ville de Dijon, ms. 591 ).

Analyse des pièces du grand cartulaire de Saint-Bénigne, et table des matières du même (Biblioth. natioilale, coll. Bourgogne, vol. XIV, ff. 2t-112).

Des 114 pièces contenues dans ce cartulaire, 81 sont publiées par Pérard, les 33 autres par Joseph Garnier dans les Mémoires présentés par divers sacants ì l'Académie des Inscriptions et Belles-Lettres, $2^{\ominus}$ série, II (1849), p. 1-168.

1151. - Autre cartulaire de St-Bénigne; ms. de la fin du XIII ${ }^{\mathrm{e}}$ siècle, 


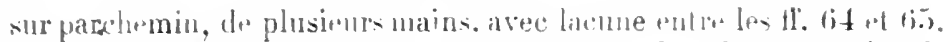
contenanl des actes de llit à l:301). in-t" de 11711. "Billiollh. nalivnale. ms. nutr. acquis. latines . 1 ti2.

Copie-faites an XVI" siecle de litres lelatils a lablaye do Sl-

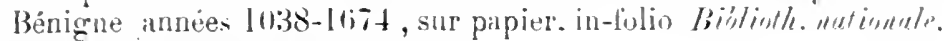
ms. Iatin 1:387:2. payer $145-3+11$.

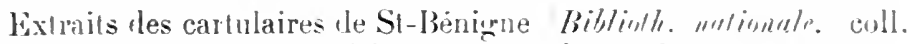
Bourrogne, vol. XI. 11. 14.7-160: 111:. latin 17048. pages 479484 et $4 ! 13-494:$ :oll. Wuchesne. vol. LAlII, 11. 73-82.

On trouve encure un recueil dacles relatifo it sainl-Bénirne, reuni-

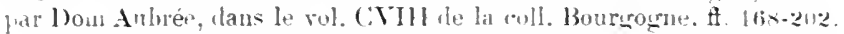

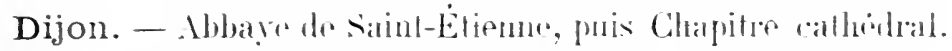
1152. - I'remier cartulaire de St-Fitienne de bijon : orig. perdn.

Copie de ce cartulairr: ms. du XII" sircle. avec quelques adulitions. sur parchemin, contenant des actes de 801 i $11 \%$. in-folio de il ti. (Archices díp. de la Cite-r Or. (i 125).

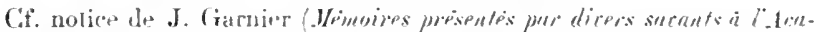

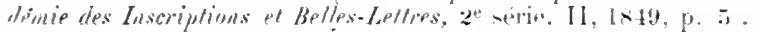

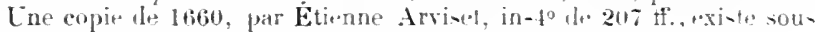
la cote G 129: deux autres plus recentes sous la cotefi li22 et à la Biblioth. antiounle. ms. lalin Biose.

Extraits faits au XVIIe par A. Duehesne (Bihlirull, mutinimale. coll. Baluze, vol. XXXIX, II. 116-128,

11ว̆:3. - Second cartulaire : ms. du XV" siècle. sur parchemin. contenant des actes de 1113 it 1483 , in-folio de 110 11 . Arrhirss drip. de la Ciste-ror. G 126 .

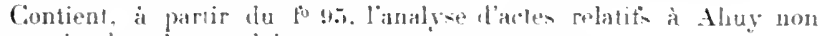
transcrits dans ir carlulairo.

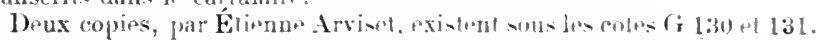

1154. - Troisième cartulaire: ms. du XVI Ie siecle. sur parchemin, contenant des actes de 1233 a 1.312 , in-folio de 310 ff. Lreliress dép. de la Citte-t'Oi: (; 127 .

1155. - Quatrième cartulaire: ms. du XIIP siècle. formé de quatre caliers incomplets, et contenant des actes de 122:3-1291. sur par-

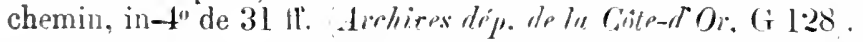

1156. - Cinquième cartulaire; m. de 1664, par Richard Arviset, sur papier. contenant des actes de 10:32 a 1299. in-4" de 2.58 $\mathrm{tr}$.

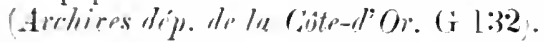

1157. - Sixième cartulaire: mi. de 1662. par le mème. sur papier.

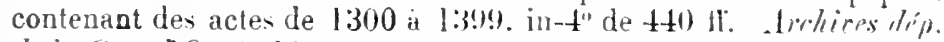

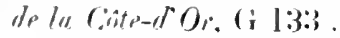

1158. - Septième vintulaire: ms. de 1661-i6ti.j, par le mème sur 
papier, contenant les actes de 1401 a 1499 . in-to de $966 \mathrm{fr}$. Arehices dep. de la Cinter Or. G 134 .

1159. - Huitième cartulaire; ms. de 1661-1667. par le mème, sur papier, contenant des actes de 1500 à 1593 , in-f" de $549 \mathrm{HF}$.

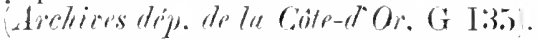

1160. - Neuvieme cartulaire: ms. de 1661-1684, par le mème, contenant des actes de 1600 à I678, in-40 de 74. If. Archires dép. de la Citte-1'Or. ( \& I 336 ).

Cn inyentaire des litres anciens transcrits cians les cartulaires susdits, fait en 1735, in-folio de $149 \mathrm{fr}$., ast sonservé sous la cote G 35 . - Voir "'ll outre l'analyse de tous les volumes dans l'Inemtaire des Archires dép., rérie $\mathrm{G}$, tome $11, \mathrm{p} .81-16 \mathrm{~s}$

1161. - Autre "artulaire lu XIV" siècle, sil papier. contenanl des

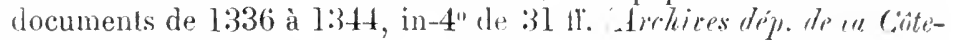
d"Or. (' $1: 37$.

1162. - Autre du XVII", sur papier, conlenant des docunents de

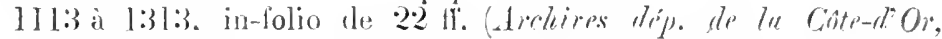
(i) $1: 38$.

1'r31.. : Historre de l'église abbutiale et collégriale de Saintlitinne de l)ijon, par l'abbé (i. Fyot. 1)ijon, l696, in-folio.

On a entrejuis it l'Lniversite d. Dijon la publication romplete liun cantulain meneril de labbaye de Sitint-Étienne; il en o déja paru des fragrnents dans les fuatre theses suivantes:

Les foires et nnarches a Dijon et chartes de l'allbave de saint-Étienne de Dijon de 1200 it 12:30, par En. Colethr (Dijon, Jobard, 1905; $\left(n-\lambda^{\circ}\right):$

- L'enchute rivile en Bourgurne et chartes de l'abluay de SaintÉtiemue de Dijon de 1300 a 1309 , jrar .11. Guill rmard (Dijon, Jobard, $1 !\left(06\right.$ : : in $\left.-8^{\circ}\right)$;

- Essai sur les procureurs au larlement de Bourgogme ct chartes de l'abbaye de Saint-Étienne de Dijon, de 1309 ì 1320 , pair P. Parisot (1)ijon, Jobard, 190(i, in-8 $)$;

- Escai sur le lail a cens en Bourrome et chartes de labbaye de Saint-Etirnne de l)ijon, de 13!\% à 1400 , par L. Gally (1)ijon, Jobard,

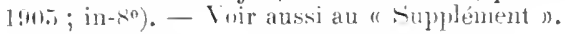

Dijon. - Chamtreuse.

1163. - Recuril de pieces relatives à la Chartrense de Dijon; ms. du XVII" siècle composé par P. L. Baudol et contenant des documents depuis le XIV" siècle, sur papier, in-4" de 58 "ll. (Biblioth. de la rille de Dijom, ms. 1015 .

11fit. - Cartulaire de la Chartrense; ms. du XV'e siècle. contenant plus de 1000 actes des années 1384 à 1489 , sur parchemin, en 5

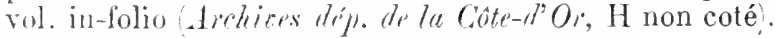

Dijon. - Commatmlerio de la Madeleine.

1165. - Cartulaire de la cummanderie de la Madeleine de Lijon; ms. 
du XVIII siecle. sur papier. contenant 208 pièces de année- $116: 1$ -

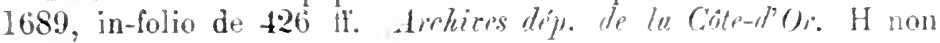
coté .

Dijon. - Couvent des Cirmen.

1166. - Cartulaire des Carmes de bijon: ms. du XV'e siecle [1480], sur parchemin, contenant des titres a partir de 1288, in- $4^{\prime \prime}$ de $38^{\prime}$ lif. Archices dép. de le Câte-rl'Or. $\mathrm{H}$ non coté).

Dijon. - Couvent des lominicains.

1167. - Cartulaire des Dominicains de I)ijon: ms. laté de l2sij, contenant 157 dlocuments des année-12:2i-t28.5. sur parchemin,

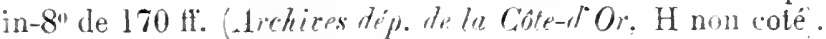

Dijon. - Couront des Minimes.

1168. - Cartulaire des Vinimes de Jijon; ms. du XVIII sircle. contenant 209 documents des années 1597-17-11. sur papier. infulio de $200 \mathrm{tr}$. Archires dép. de la Côte-d"Or; $\mathrm{H}$ no:1 coté .

Dijon. - Ilopital du siant-Esprit.

1169. - Cartulaire de la maison rectorale de I'hòpital du SaintEsprit de Inijon: 1ms. du XVIII siècle [I769], exécute par le recteur $\mathrm{Fr}$. Calmelet. sur papier. in-folio de 515 pagres tichires hospitalières de Dijon. A 6 .

Dijon. - Hòpital general.

1170. - Cartulaire de l'hipital général de Ilijon: ms. comntenö́s en 1695 et continué jusqu'en 1\%01, sur papier, in-folio 1te $90 \mathrm{Hl}$. Archices hospitalinips do Dijom. II A 12 .

1171. - Antre cartulaire : ms. du XVII siecle, sur papirs', contenant des titres depuris 1396, in-folio de 268 If. et table Archeres hospitalières de Dijon. II A 1:3.

1172. - Cartulaire géneral : ms du XVIII" sièrle [depuis 1711]. sur papier, en 9 vol. in-folio de 694. I 426 . 862 . 1618. 612. 922 et 2288 paues (Archices huspitalières do Dijon. II + l à 9 .

Dates extrèm-: 1356-1734.

Dijon. - Sainte-Chaprlle.

1173. - Cartulaire de la Ste-Chapelle de Dijon: ms. du X $\mathrm{Y}^{\mathrm{e}}$ siencle [1415], sur papier. in-4" Biblislh. nationale. ms. latin 9868, ii. $22-54$.

1)ates extreme: : III siede-1409.

1174. - Cartulaire de la Sainte-Chapelle de Inijon: ms. du XVIIe 
sipcle. in-folio sur papier (Bibliotl. nationule, ms. latin 17083, 1i. $\mid-3: 3)$.

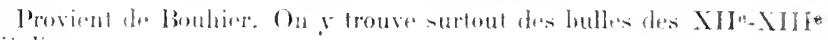
sierlin.

117.) - Recueil de titres de la Sainte-Chapelle de Dijon; ms. du IVIII" siècle. par ( raudelet. contrnant plus le 5000 actes des années 1171-17333. en 18 vol. in-folio sur papier lwhires dep. de la Cateत) (i) (i 1217-12:34.

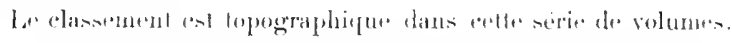

1176. - Cartulaire des titeres de la Sainte-Chapelle de Dijon, concernant les chapelles: ms. du XVII" siecle contenant des actes des

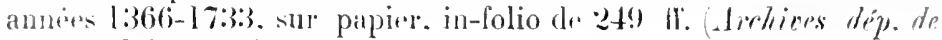
lu Ciate-d Or. (i 1210 .

1175. - Cartulaire de ha rhapelle de Ieanme d'Are-sur-Tille dame de Vantonx. fonter m la Ste-Chapelle de llijon : ms. du XVIr siècle, sur papier. contenant des documents de 13\%.) a 15l8. in-4" de 720 ff.

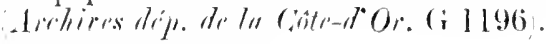

\section{Dijon. - Villr.}

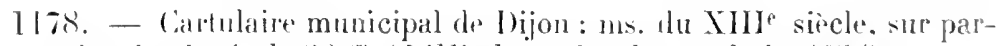
chemin. in-4" de $333 \mathrm{tr}$. Biblieth. nutionule. ne. latin 4654).

1179. - Antre cartulaire: ms. du XIV" siecle, sur partumin, in-8"

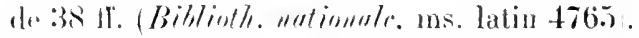

1180. - Antre cartulinire: ms. du XIVe sircele. sur parchemin, in-8

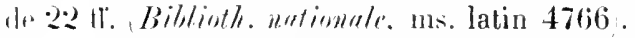

1181. - Autre carmlaire: ms. du XIVe sierle. sur parehemin. in-4" dr. $5: 2$ li. Bitlinth. de le rille de Dijon, ms. 7:39).

1182. - Antre "artulaire; ms. du XIV" siecle, sur parchemin, conte-

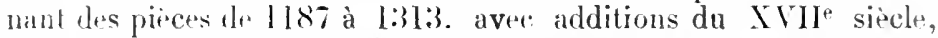
sur papiet. in-4" de 63 It. Biblinth. de lie pille dre Dijom, ms. 741).

$11 \mathrm{~K}: 3$. - Autre cartulaire; ms. des SIV' - XVe siècles. sur par-

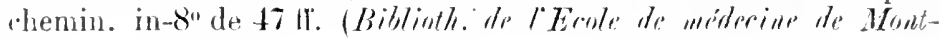
prllipr. ms. :38:3).

Volume provenant do Boubier.

1184. - Autre cartulaire: ms. du XV'e siecle. sur parchenin, contenamt des pièces de 1187 a $14.5 \mathrm{I}$, in-folio de $11-62 \mathrm{ff}$. Arrlbines natiomins. KK 1109 .

118. - Antre cartulaire: ms. du XVe sicele [vers 1407], sur par"hemin. in-4" de xu-110 $\mathrm{Ir}$. Billinth. de la rille de Dijon, ms. 741).

1186. - Antre rartulaire: Ins. du XVe siècle, snl parchemin, conte- 


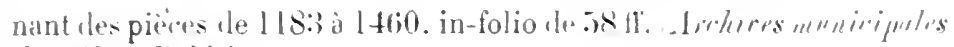
di I lijoil. B ||$(i)$.

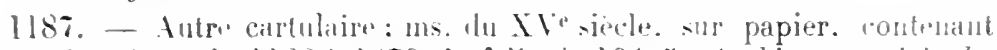
des pieres de 1183 i 1479 . in-folio de 104 11. Lirhires immiripulex de Dijur. B $(18)$.

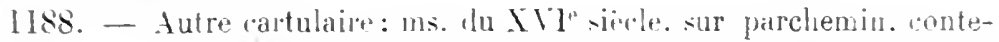

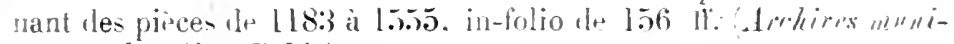
ripules di Dijoul. B 114 .

Copie du pricrident. faite an $\mathrm{XVN}^{\mathrm{e}}$ - iecle. sur parchemin. in-tolio

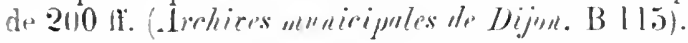

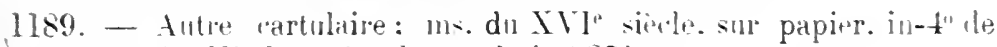

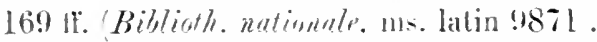

1190. - Autre "artulaire: uns. du XVI" siecle, sur papier. in-t" de 153 ti. Biblioth. untionale. ms. latin $98 \% 2$.

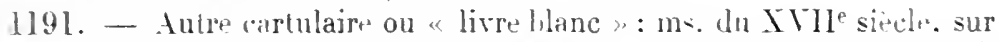
papier. contenant des pièces de 1483 à 1610 . infolio de 163 tf. Arelieres manicipules de Dijun. B 117.

1192. - Aulre cartulaire : m“ clu XVIle sipcles sur papier. contenant des pières de $11 ! 6$ à 1650 . in-folio de tioff. Arckices muniripules de Dijur. B $11 !$.

1193. - Fxtrails d un cartulaire de la ville de lijon. fait par Indiesne an XVII siele Biblinth. metimule. coll. Baluze. vol. XXIIS, pages $1: 30-1: 3: 3$.

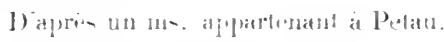

1194. - Cartulaire le IVijon: ms. du XIVe siècle [1330]. sur parchemiu. in-8" Biblintly. untivenle. coll. Horeau, vol. 9:3. ti. $57-86$. précéli l'une traduction francaise des mèmes actes faite an IVe siècle sur papier.

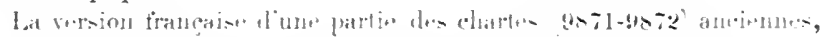

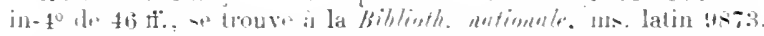

1195. - Autre cartulaire; ms. du XV siètr. contenant des transcriptions françases d'actes latins, avec tahle en tẻte. sur parclımin,

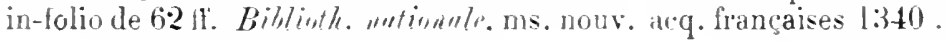

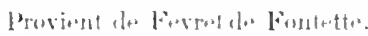

Dilo. - Abbaye (dioc. de rens).

1196. - Cartulaire de labbare de l)ilo : orige perdu.

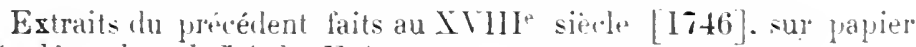

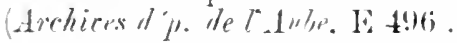

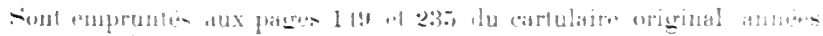
11 ti2 et $11 \div 11$. 
11!1\%. - Fragment de cartulaire de labbaye de loilo: nus du XVe

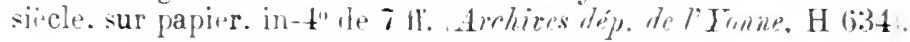

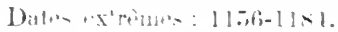

lixtraits fait, au SII" sicele du cartulaire original complet,

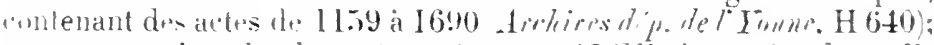
antres extraits de la mème rpoque Biblin!ls. mtimmle, coll. Baluze. vol. XXXVII. Il. 2!ri-2!S : - lu IVIII" siècle Ihm.

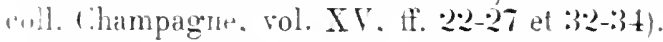

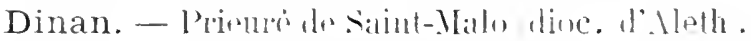

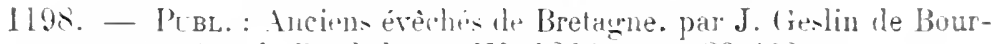
cogne tet An. de Barthelems. IV 1864. pp.:389-12:3.

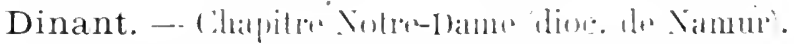

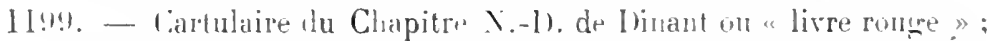

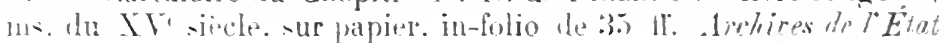
is $111,1 \%$.

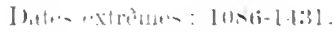

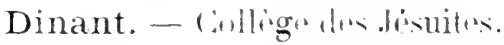

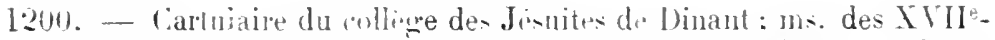

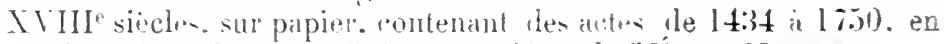

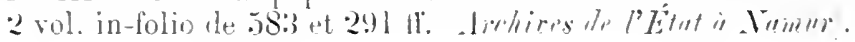

Dinant. - Villי.

1211. - PenL. : 'artulair de la commune de linant. par S. Borman. then Lahaye. Namur. We-mael-1harlier. 1880-1906: 6 rol.

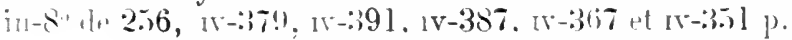

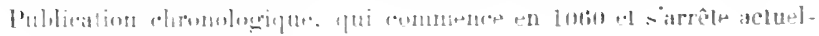

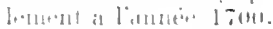

Dol. - Chapitre athrimllal.

1:002. - Cartnlaire tu Chapitre de Wul. Liher qui dicitur Alanus s; rrig. perdu.

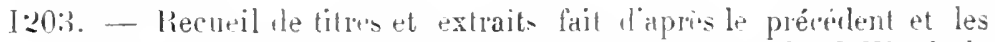

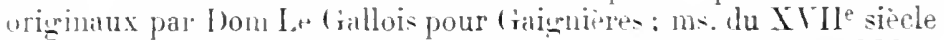
[164.]. sur pipier. "ontenant des locuments les années $1: 223$ a

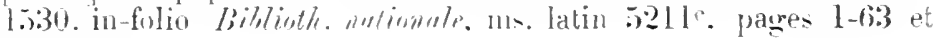
7t-11:2.

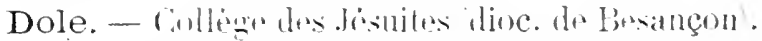

1204. - "Liber contractum collegrii Dolani ": ms. du XVII siecle. -ur papier, contenant des antes Appuis 1244, in-Folio de 76.5 te.

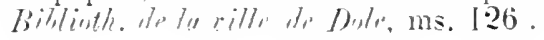




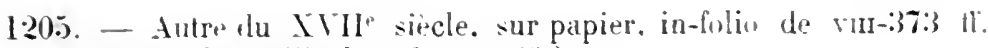
(Biblinth. di lu cille de Dulp. ms. 398 .

Dole. - Eglist collingiall.

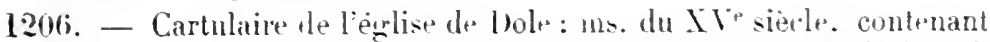
100 actes des annóns $1275-1466$. sur parchenin. in-4" de $185 \mathrm{tf}$. (Archires dijp. dn. Juin. ( i non coté.

Dole. - Vills.

1207. - Recueil de titres relatifs à la ville de Hole. par Cournut: ms. du XlAe siecle. sur papier. in-t" de 255 p. Biblinth. de la rille de Dol.e. ms. 143 .

1208. - Autre par Fransquin ; ms. du XIX" ierte [1819]. sur papier, in-foliu de 134 p. B Biblinthe de le rille do Dule. ms. 319 .

Domart-en-Ponthieu. - Villı.

1209. - Rewistre-matrologe le la ville et conmunatú de Domart; ms. du Xile sierle [commencé en 151:3]. sur parchemin. contenant des chartes depuis le Xile siecle. in-t" de 27 ti. (Avelices huspitulières do Drumitren-Punthien.

Dombes. - Principaute.

1210. - Recueil de litres relatils à la principanté de Dumbes: ms. du XVII siecle, sur papier, contenant des actes de 1594 a 1699 , in-folio Biblisth. metimulr. coll. Clairambault. rol. 997. ff. 229-349.

1211. - Prb1.. : Bibliotheca Dumbensis un Recueil de chartes et documents pour servir à l'histoire de Dombes, par Valentin Smith et M.-C. Guigue. Trévous. Jeannin. 185t-1885: 2 rol. in $t^{\prime \prime}$ de $[\mathrm{rv}-] \mathrm{xI}-760$ et $\mathrm{w}-2 \% 2+203 \mathrm{p}$.

Acles de !) an Xint" viècle.

Domène. - Pripuré dioc. de (irenoble.

1212. - Cartulair du prienré de homène; ms. du XIII siecle. de $140 \mathrm{ft}$.. orig. perdu.

Ste trouvait en 167 :! entre le- mains de Du Buurhel, et, à la fin du XVIIJ siècle, dans lis arehives du prieuré de st-D nis de la Chartre à Paris.

Copie du précédent, sur papier, in-f" de $141 \mathrm{ll}$. British J/userm. ms. Harleian 3712 .

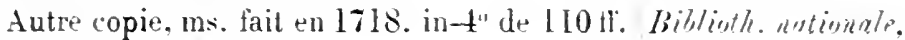
ms. latin 17102 .

Autre copie ligurée. datant lu XVIII sierle. sur papier. in-t" de $150 \mathrm{ff}$. (Biblioth. mutimule. ms. latin 17\%29.

Copie faite en 1743 « ex antiquo coul. ms. perameneo in polertate 
nob. 1). Cl. J. (irmsin le Mailly »: 11s. sur papier. in-t" de 2 (il p. (Biblioth. de la rille de larerein, ms. 14:3.

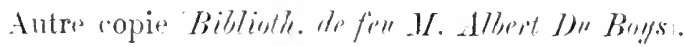

Prbi.. : Cimlulare monasterii beatormm I'alri et Panli de Iomina, Ciluniacensis ordinis. Gratianopolitanat llocesis. Lugduni. l'errin, $18.5 ! 9$ : in-8" de Lil-47.) p. et. pl.

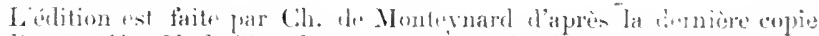

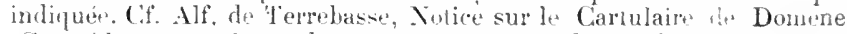
(Grenoble. 1860, in-so de 11 p.), et Anu. Rernad dans Rerue des

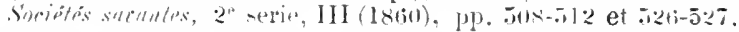

lixtraits laits an XVII" sitcle Biblinth. untiounle, ms. latin 12668. 11. 30.)-306: pour (inignieres "n li80 Int'm. ms. latin 170-48, payes

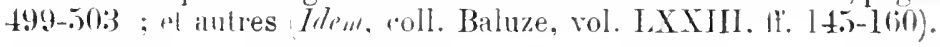

Domèvre. - Mbbira ilioc. ar Tuml.

121:3. - Cartulaire de l'abliave te llomerne; ms. Ilu XVII siecle.

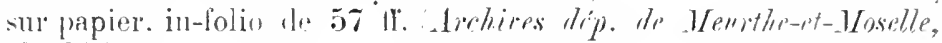
H 1374 .

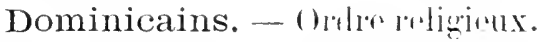

1:214. - Bullare de lordere des Iominicains : ms. flu $\mathrm{XV}^{\circ}$ siecle, snr

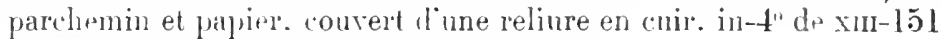
fi. Bibliwh. de la rille de Lille, แ1s. 670 .

1215. - Prol. : Cantulaire un Histoine diplomalique de ant Dominique. pull. el conmente. Tomes I-II par le R. P. Francois Balme pt le R. I'. Lelaidier: lome III par les RR. I'I'. Balme et. A.-1.

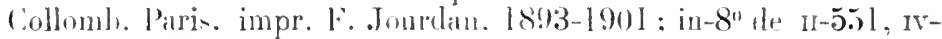
4 (1) el xiI-4!6 p.

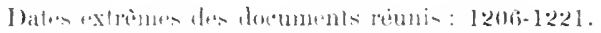

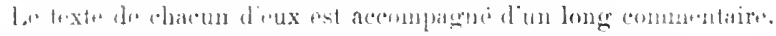

1216. - Bullariun Ordinis Praerlicalorum, opera Th. Ripoll, recognitum ah Ant. Brenond. Romae. 17:29-1740, 8 vol. in-folio.

Dommartin. - Mbbirr. - Vuir SANT-Josite-AL-Jins.

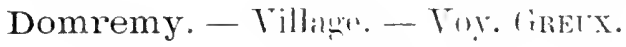

Donchery. - Prieuri (dioc. de Reims).

1217. - Cartulaire lu prieuré de Donchery: arig. perdu.

lixtrait lail an XVII" siocle Biblinth. "utionml", coll. Durhesne, vol. IXIl, 10 $21: 3$

Donjeux. - Fróresile lil (harité Notre-l)ame dioc. de Cihàlons-sur-Jlarne.

1218. - P131..: Recuril des tilres el privileyes des freres de la Charité

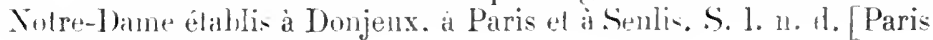
v. 1485$] ;$ in-8u de $84 \mathrm{tt}$. 


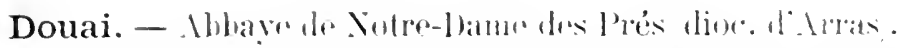

121!. - Cartulaire de l'ahhaye cistercienne de Totre-1)ame les l'ris: ins. Ilu XIV siecle, sur parchemin. infolio de 65 Il.. contentant dus

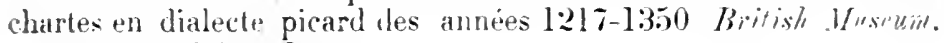
ms. allitional $239: 32$.

1:2020 - Autre ms. du XIVe siecle. sur parchenin. in-4" d. 993 ti.

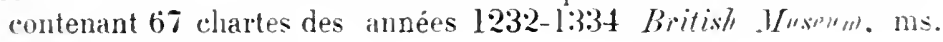
additional 23933 .

Axal. : Cartulaires da l'abbaye de Sotre-l)ame le- l'rís de Donai; notice de denx manuscrits du Muse hritannigue. par $Y$. Valois Le Cubiuet histminge, XXVII. 1881. p. 40-82.

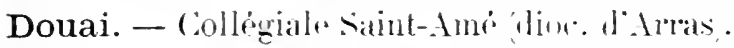

12:21. - Cartulaire de St-Amé de Donai; ms. du XIIle siecle, sur parchemin, avec table du $\mathrm{XV}^{-e}$, contenant 1 ì actes à partir du $\mathrm{XI}$,

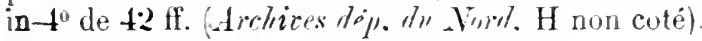

Douai. - Villı.

1222. - Cartulaire de la ville de Donai, lit Cartulaire T on Premier registre aux privilèges; ms. du XIVe siècle avec adılitions pustérieures et table dressée en 1488. sur parchemin, aver reliur't ${ }^{\prime}$ h hois recouvert de rean gaufré. in-fulio de $101 \mathrm{tt}$. Archires immiripules te Dimai, At 84 .

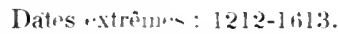

1223. - Autre, dit Cartulaire $\mathrm{H}$ ou second regri-tre anx privileges: ms. des XVe-XVlle sièdes. sur parchemin avec reliure en reau

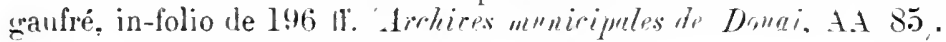

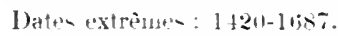

AN.r. : Inventaire analytique des archives communales de houai antérieures i 1790. par F. Brassart. 1 1876 . pp. 10-21.

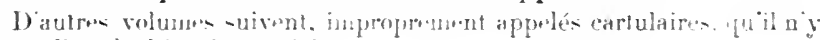

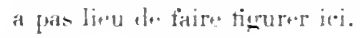

Doullens. - Ville.

12:24. - Cartulaire municipal ou "livr" roure " le Doullen. : ms. du $\mathrm{XVe}$ iecle, sur parchemin. contenant iles artes de 1:202 a 1456 , in-folio de 117 it. Archires immiriputes do Dimullens, AA 1 .

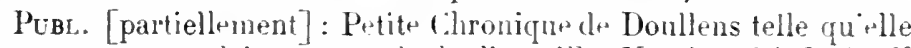
se trouve au cartulaire rouge do la dite ville. Vervins. 18.52: in- $8^{\circ}$ ile $16 \mathrm{p}$.

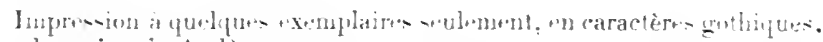
par les soin in .1. lemarsy.

1225. - Antre cutotulaire de Doullens: ms. du XV1I siècle, sur papier. 
contenant des actes de $1: 373$ a 16333 , in- fl) de $62 \mathrm{fl}$. (Archives municipales de Domllens. AA 2 .

Douy. - Prieuri. - Voy. OrLéaxs (X. D. de Bonne-Nouvelle). Douzens. - Commanderie.

12:26. - Cartulaire des Templiers de Duuzens; ms. du XIIe siecle [incomplet], contenant 14:3 actes des années 1102-1182, sur parche-

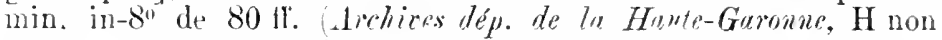
cote.

1:27. - Autre du XII siecle, contenant 80 documents des années 113.j-1182. sur parchemin. in-12 de 92 ti. Archizes dép. de la Haute-Guromur, $\mathrm{H}$ non coté.

Draguignan. - Villı.

1225. - Cartulaire nunicipal de Dragnimnan; ms. des XVI $\mathrm{XVVIIJ}^{\mathrm{e}}$ sièrles. sur papier. contenaut des actes à partir d. 12:36, in-folio de 27 tr. Archires municipules de Dreguiguten, AA 1 ).

1:2!). - Autre cartulaire on "livre violet "; ms. de 162\%, sur papier, contenant la traduction en frinçais de quelques-uns des actes contenus clans le précédent cartulaire à partir de 1320, in-folio de $2: 1 \mathrm{ff}$. Archives municipules de Draguignan, AA 2 .

Dreux. - Comti.

1:30. - Recueil de titres relatifs an comté de Irenx; ms. du XVII -ircle. in-folio, contenant des actes des années 1180-1515 Biblioth. metivinale. coll. Doat, rol. 248. ff. 2:30-384.

Dreux. - Église saint-Etienn (dioe. de (Alartres).

1231. - Cartulaire de Saint-Étienne de Dreux: ms. du XVe siècle, sur parchemin. avec table au lébut. in-1" de vi-o) $0 \mathrm{tr}$. (Biblioth. metionnle, ms. latiu 10106 .

Dates extrênes: $1110-1270$.

Ce volume paraît ditre la copir d'un recuril plus aneinn.

lixtrats faits au XVI" siech Biblinth. mutionale, coll. Baluze, vol. LXXIII. p. 118-14:3: ms. latin 17048, pares 507-514).

Droiteval. - Abbayr puis prieure (dire. de Toul).

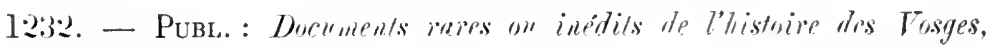
IV 1877 , pp. 11-28.

Actes de 1140 à 1709 .

Dunes. - Abbaye (dioce de Bruges).

1:2:33. - «Transcripta privilegriorum ecclesice Dunensis»; ms. des XIII ${ }^{e}-X_{V}$ siecles, sur parchemin, contenant des actes de 1129 à 
1309. in-1:2 de 1!5) ff. a 2 col. (Biblinth. An Groml-simimine de Breggrs. ms. n" 169 \%34.

1234. - Cartulaire drabbaye dr Dunes: ms. du Xre sircle. sur parcliemin. contenant des acte de 1 16.5 a 1434. in-4" te $206 \mathrm{tl}$. (Archires de l'Etut is Bringis).

12:35. - Autre cartulaire du $\mathrm{XV}^{\mathrm{V}} \mathrm{e}$ siecle. sur parchemin. contenant des

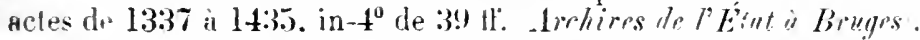

Publ. : Chronica ot cartularium monasterii dt. Dunis [par F. Van de Putte]. Brugis. Vandecasteele-Werbronck. 186t: in-4" dexix$10.5 \mathrm{p}$. [Publicatiun de la Socif́té d'émulation de Brug ${ }^{*} \mathrm{~s}$ ]

Dunois. - Cimuli. - Vir. Thos.

Durbon. - (hantrouse dine. de (iaj).

12:36. - Cartulaire vert de la Chartreuse it. Durbon: ms. du XIII siecle. sur parchemin. contenint 319 actes des années $1116-1216$, in $4^{0}$ de $11 \%$ tr. Biblinth. de fen. IK. Climent dimut, conseiller général des Hautes-Alpes. anj. le M. J. Roman. au chàtean de Picomtal, Hautes-Alpes .

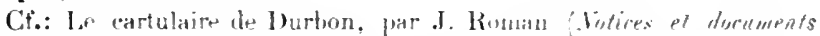
publ. jar la société de l'histoire de liance. Inst. p. 101-120).

Copie molerno (185:3 . par liharronnet Airhires dep. Hes HantesAlpes, Н 209 .

Copie morlerne isi3 par Laudy Lrohires dép. des Bumches-dyRhione?

Pebl. : Chartes de Durbon, quatrime monastere de l'ordre des Chartreux. diocèse de Galp. par l'abbé Paul (iuillaume. Montrenilsur-Mer. impr. Notre-Dirme-des-Prés, 1893 ; in- $8^{\circ}$ de xxx-904 p. [Société d'Étudrs des Hautes-tlpes.]

1237. - Autre cartulaire. formant la suite du livere vert : orig. perdu.

Conpie du préredent laite en 1722 a Bonpas par D. Ant. Tournus.

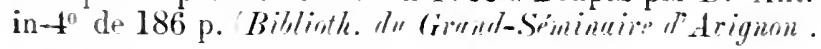

Eaunes. - Abbarr lior. de Tindouse .

12:38. - Fragment d'un cartulaire de l'abbayr d'Eaunes; ms. du XII siecle, sur parthmin, in-to de 1t il. monlés sur onglet (Biblinth. nationule. nos. latin 11012.

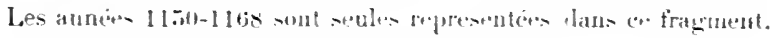

Ébreuil. - Abbayr dioc. de Clermont.

1239. - Cartulaire de l'abbaye d'Él,reuil : orig. perhu.

Hxtrait fait au XVII siecle par Dom Estiennot (Biblinth. nationale, ms. latin 1274.) p. .2:2: et m. latin 12754. 10 4:21. 
Echternach. - Mblity dion. dre lrevers.

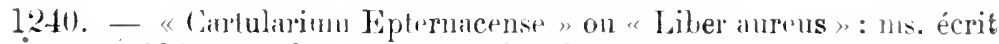
rntre 11933 ret 1220, contenant des documents depuis le VIJ siècle, sur parchemin, in-folio Mrrogl. Bithlioth. (inthe, ms. 67t.

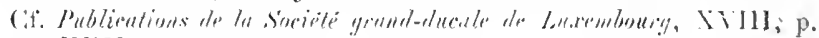
!r, el XXY, p. 303.

1241. - "Copia authentica quormulam diplontatun jura et posiessiones monasterii Epternacensis concernentimm : ms. daté de 1470,

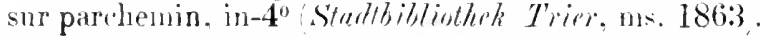

1242. - Recuteil de titres relatifs it lahlaye d'Echternach: ms. du XVI" siecle, sur parpire, in-t" dr 16 II. Königl. Biblinthek in Berline, ms. latin 37!9.

Éclaron. - Voy. Axcerville.

Écoquenéauville. - Sirigneurio en Normandie.

1243. - Cartulirire de la terre d'kcoquenéauville, dép de l’ablaye de Nonteboure: ms. du XVe sierle, sur pareln'min, contemant des

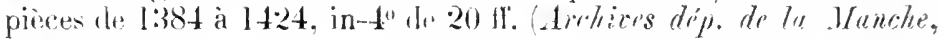
$\mathrm{H} 83 \% 8$.

Écurey. - 1bbaye dince de Jimples.

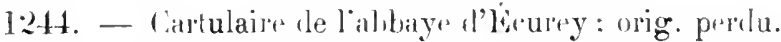

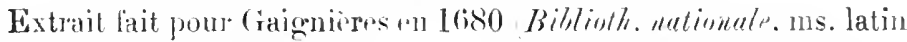
$17(48$, pilines $519-526$.

Eeckhoutte. -- Mbharr de chanoines reguliers les saintAugustin (dior. de linges).

1245. - Cartnlaire de l'iblaye d'keckloutte: ms. écrit en 1:395-1402 par le diacre Jean Vulre, sur parchemin, contenint des lextes depuis 1130 , avec adılitions jusqu'au XVIII' sieccle, in-folio de 197 et $111 \mathrm{ff}$. (Biblintll. dn (rond-Séminnire de Brugrs. fonds d'Eeckhoutte).

Eenaeme. - Nhbaye dioc. de Malines).

1:46. - Cartnlaire de l'abhaye d'Ennteme: ms. du XlY siede, sur parchemin. rontentunt des actes dre 1064 i 1279 . in-8" de $375 \mathrm{ll}$.

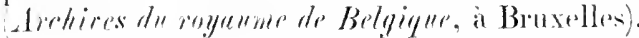

1247. - Autre ms du XVe siccle. sur pipier, contenant de artes de

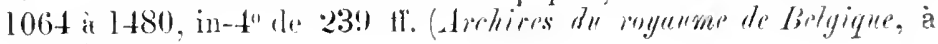
Bruxelles:

1246. - Autre rartulaire du XVI" siecle. sur papier, contenant des

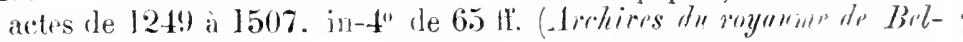
gique. is Bruxelles,

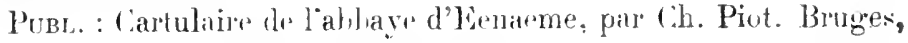


We \%uttere-Yan Kersichaver. 1881 : in-4" de vin-432 1. [l'ublicalion de la Socifte d'emulation de la Flandre.]

Date's extremmes: 1063-15\%or.

Élan. - Abberre dioce do Rerims .

124!). - Cartulaire de lahbaye d'Élan : orig. perdu.

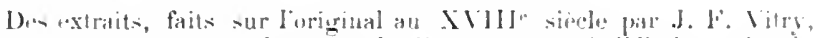

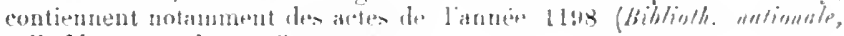

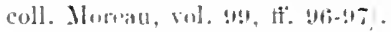

Elne. - Egliso cathelralo.

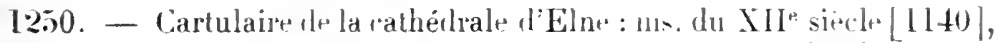
sur parchemin, ave reliure le bois et cuir. contenant des documents

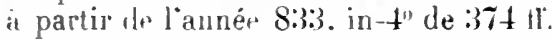

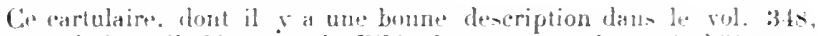

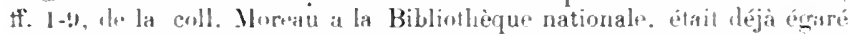

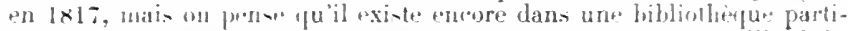

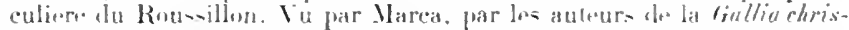

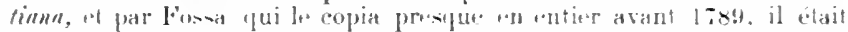

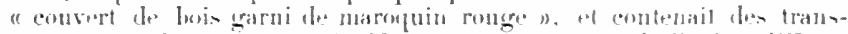

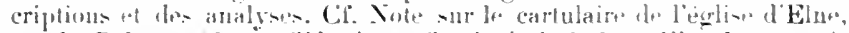

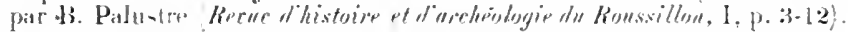

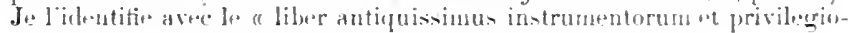

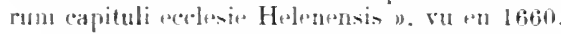

Extraits par Fossit. laits an XVII ${ }^{\mathrm{e}}$ siecle Biblinth. nutimule, coll. Moreau. rol. XXI, XXII, XXY. XXX, XXXVII. XLII, passin1 : autres du XVI" siecle dans les papiers sle Marea Biblinth.

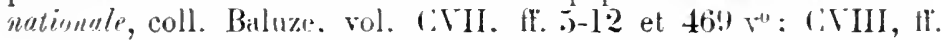
101-119, 1:31-135. I41-143. 147-149. et CXVII. If. I $7-20$ et 80 . où il est question 16(io), de "liversis cartulariis ecclesiæ Helenensis».

1251. - Autre «grand livre " In Chapitre. sur papier : orig. perdu. Extrait fait en 1660 par tntoine Mir Biblintls. nationrle. coll. Baluze. vol. C:TII, f" 32 .

Elne. - Ville.

1252. - Livre vert on "artulaire muniapal d'Elne" urier. perdu.

Embrun. - Cathidratr.

1253. - Cartulaire de léglise archiépisopale d'Eubrum ou «livre rert $"$ : origr. perilu.

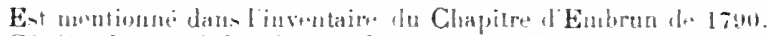

Cf. (iuichenon. Bibliotheca Sebusiana, p. 14,47, il et $x \tau$. L.'historien dauphinoi de Valbonnais l'a ausoi utilisé.

1.554. - Fragment du live des fondetions de X.-L. d'Embrun: nus.

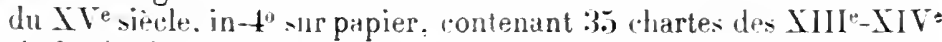
siècles (Biblisth. dr M. J. Romun. au chiteau de Picomtal, Hantro Alpes. 
Embrun. - Ville.

125.). - Cartulaire munieipal d'Embrun ou « Livre vert » ou « Livre carré »: ms. de la fin du XVesièle, avec additions postérieures, sur papier. in-lolio de 2!l0 IT. Arrhines muniripales d'Embrnn).

baten extrênes: 1241-1sith.

\section{Empire.}

1256. - Recueil de titr's relatifs anx droits de l'Empire en Lorraine; ms. rlu XVII siecle, lormé par Thierry Alix, sur papier, contenant des titres de 1398 à 1609 , in-folio de 271 11. Lrehires dép. de Menrthe-et-.Moselle, B 40.).

Enghien (Belgitpur). - Couvent des Carmes.

125\%. - Cartulaire des Carmes d'Enchien : ms. des XVe-XVI siècles, sur par'hemin. ('ontenant des actes de 1407 it 1440 , in-4" de $113 \mathrm{fr}$. (Arrhires de l' Étut à . Wouss).

Enghien (belgigur). - Ville.

1258. - Cartulaime de la ville d'Enghien ; ms. des XVe-XVIe siècles, sur papier. contenant des documents de 125i3 à 1679. in-folio de 2.33 If. Arhives cominuales of Enghien.

Envermeu. - Priruré de Saint-Laurent (dioc. de Rourn).

12.59. - Cartulaire du prieuré de Saint-Lanrent d'Envermen ; ms. du IV" sierle. sur papier, de 434 pateres in-lolio ; orig. perdu.

Copir du précédent, "xécutée au XVIII" sircle [1770], sur papier, in- 4 " le va $-4+4$ pages (Biblioth. nutionule, ms. latin 10058.

Lioriginal fut alors trouvé chez de prisur commendataire. temeurant

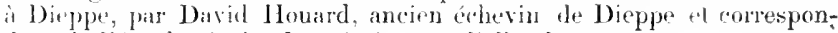

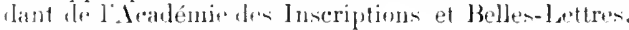

Dates extrimes: loists-1480.

Épernay. - Ab)ayr de Sidint-Martin dioc. de Reims.

1:260. - Cartulaire le l'ahbay de Sitint-Martin l'Épernay; orig. perclu.

Extraits laits au XVIII siecle par (i. Montgérard (Biblioth. de la ville t'Eprinay, ms. 88 .

J'après d'autres extraits recueillis (Biblioth. mationale, coll. Champagne, vol. $\mathrm{XV}$, ff. $101-10(i)$, il semble bien qu il y ait eu deux registres de chartes à l'abbaye de Si-Nartin d'Épernar, J'un s'arıêtant à 1481 , lautre à l'année lliz夕. Cif. aumi Coll. Champagne, vol. XIX, fo 145.

l'ubl. : Épernay et l'abbaye St-Martin. par tug. Nicaise. Châlonssur-Marne, impr. Le Roy, i869) : tome II. p. 109-186.

Épernon. - Prieure de Sinint-Thomas dioc. de Chartres). 1261. - Pris. : Cartulaires de Saint-Thomas d'Épernon et de Notre- 
Dime de Maintenon,prieurés dépendlant de l'abbaye de Mitrmoutier. par Aug. Moutié et Ad. de Dion (.Vrimeives it documents publiés par la Suriéte archénlogique de Rambrumillet, IV, 1878. p. 1-188.

Épinal. - Chapilre Saint-Gö̈ry (dioc. de Toul).

1262. - Framment dun cartulaire de Saint-Goëry dÉpinal : nss. du XVI" siècle, sur parchemin, contenant des actes depuis 1119 . in- $4^{\circ}$ de $6 \mathrm{tI}$. (Archives rlép. des Vosges. G 109).

1263. - Cartulaire-inventaire de Saint-Goëry d'Épinal ; m* d• 1779. rédigé par Dom Maugerard, sur papier, contenant des documents de 1003 à 1518 . in-folio de $373 \mathrm{ff}$. Amhiess tróp. des Vosges. G 106.

Autre copie du mème. sur papier', in-4" de $32+7+12+33+$ 57 il. en cahiers Biblinth. de la rille de llets, ms. 1153: anc. Salis 7).

Épinal. - Chàtellenie.

1264. - Recueil de titres relatils à la châtellenie d'Épinal: ms. du $\mathrm{XVII}^{\mathrm{e}}$ siècle, formé par Thierry Alix. sur papier, contenant des actes de 1272 à 1601. in-folio de 307 II. Archices dép. de MrnothpotMoselle, B 360 .

Cif. aussi le rogistre $B$ o\% du mène dépōt, partiellement publié dans les brocuments ruress on incidits de lhistoire dess Vosges, III (107:3)

\section{Épinal. - Ville.}

1265. - Recueil des pièces relatives à la ville d'Épinal; ms. dn $\mathrm{XVII}^{\mathrm{e}}$ siècle, sur papier, contenant des titres de 962 à 1599 , in- $4^{\circ}$ de 216 et 206 ff. (Biblioth. nationale, mss. français 18881-18882.

Copie partielle du précédent, fait en 183\%, in-folio sur papier (Biblioth. de la ville d'Épinal, ms. 191,

Épinlieu. - Lbbaye, à Mons (dioc. de Cambrai).

1266. - Cartulaire de l'abbaye d'Épinlieı; ms. lu XIII ${ }^{\mathrm{e}}$ siecle. sur parchemin, incomplet de la fin, in $4^{\prime \prime}$ de 57 If. Apparlenait en 1867 à M. Lescarts, arocat à Mons).

ANal. : par L. Devillers. Descliption de cartulaires et de chartriers du Hainaut, III 1867 ) - pp. :3-84.

Époisses. - Prieuré de Totre-Dame frioc. de Chalon-surSaône).

1267. - Cartulidire du prieuré d'Époisses, dép' de l'ordre de Cirandmont: ms. du XVIL iècle. sur papier, contenant 67 pièces de 118 ? a 1659 , in-folio de 16 If. Archices dép. de la Cóte-d Oir, $\mathrm{H}$ non coté. 
Éringhem. - Conval los (intllelmitos (dioc. d'Y pres). $126 x^{2}$. - Cartulaire des Guillelmites d'Firinghem [translérées à Noordperne : ms. du X Ve siecle, sur pirchemin, orig. perdu.

Apparlenail aulrefois a un collectionneur de Bergues (I. Herwon) et a eté utilisé par Louis de Backer dans un travail sur Noordpeenene

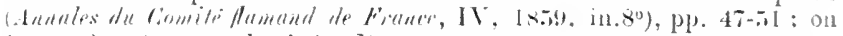
ignore à présent su destinee. Datus extrinus : 12til-14ti.

Escaut. - Flınir.

120139. - Recueil de titres relatil's a la navigation de l'Escaut, ou «Stroomprivilegrienbueck » : ms. «lı $\mathrm{XVI}^{\mathrm{e}}$ siècle, sur parchemin, in-t" de 1:3:3 II. Archices communules do Frund.

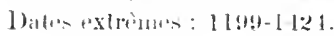

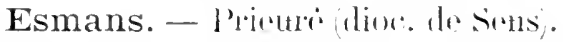

1270. - Cantulair Il'Esmans el de Saint-( iermain-Laval, dép' de l'abbaye de Saint-Germain-tles-l'sés: m. du XIV" siicle, sur papier, contenant des artes te 11 !) i 1:390. in-80 we $36 \mathrm{ft}$. (Arehires natiomales. LL. 1064.

Esne. - Villago.

1271. - l’cbl. : Nolice sur le villaze d'bine en Cambrésis. suivie des charles on lois ortrovees is rette commune el in celle de. Walincourt, par 1. L" Glay. Cambrai, 1835, in-8.

Espagnac. - Ablaye diox. de Rudez.

1272. - Recueil de titres relatils a l'abbaye d Lispannac ; ms. du XVIJ iecle. contenant des documents te 1213 i 1.531 Biblisth. nationale, coll. Loat. rol. 124, tt. 1-153.

Espierre. - Signemie en Flandre.

1:273. - Cartulaire les seignenrs d'Espierre; ms. du XV'v siècle, sur parchemin, contenant des documents de 136.3 à 141.5 , in- $4^{0}$ de

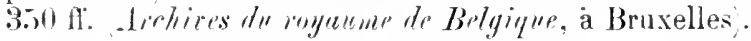

Espira-de-l'Agly. - Prientri dr Xotre-1)antur (dioc. d'Elne). 1274. - Cartulaire dı prieuri de N.-I. d'Lispira, «de Aspirano»; orim. perdu.

Fixtraits et analyses du précédent, faits au $\mathrm{XVH}^{\mathrm{e}}$ siècle (Biblioth. untimule. coll. Baluze. vol. CXVII, II. $74-82$.

Ibates extrentus : 1119-1151.

les extraits sont faits diapres les 31 premitere ferullets de l'original.

Étain. - Ville ol rhatellenir.

12\%. - Kecueil de titres relatif's à la ville et châtellenie d'lítain : ms. le la lin du XVI' siècle. formé par Thierry Alix. sur papier, conte- 
nant des titres de 1250 a 1587 . in-folio de $347 \mathrm{n}$. Amires dép. de Weuthe-et-.Woselle, B 361.

Copie lu précétlent. faite an $\mathrm{XVII}^{\mathrm{e}}$ siècle. sur papier dichires de lo Mruse, B 236 .

Étampes. - Église collégiale Notre-Inatne (dior. de sens.

1276. - Cartulaire de N.-D. d'Élampes: ms. du $\mathrm{XT}^{-\bullet}$ siècle. sur papier, avec additions du $\mathrm{XVI}^{\mathrm{e}}$. contenant 114 pièces des années 1045 à 1572. in-4" de 13I parres Archires de la fubrique de NitreDame d' Etampes'.

Plbl. : Cartulaire de Notre-Dame d'Étampes. par l'abbé J. II. Alliot. Paris. I'icard, 1888 ; in-80 de xxvi- 163 p. [Société historique et archéologrique du Gàtinais.]

Éterpigny. - Commanderie dioc d'Amiens.

127\%. - Cartulaire de la commanderie d'Éterpigny ; ms. écrit en 128.). sur parchemin. in- $4^{0}$ de xum-137 ff. Biblisth. Cheltenham. n"2972.

Étival. - Hbaye dioc. de Motz.

1278. - Recueil des titres de l'abbaye d'Étival: ms. de la fin du XVII ${ }^{\mathrm{e}}$ siècle. sur papier. contenant des actes des années 880-1491. in-folio de 734 p. (Biblisth. du Grand-Séminatre de Nency, ms. 168 .

$1278^{\text {bi.. }}$ - Copie du cartulaire oririnal perdu; ms. du XVIII siècle. par Dom Ligier, sur papier, in-folio de $629 \mathrm{p}$. (Biblioth. de la rille de Saint-Dié, ms. non colé, fonds Édouard Ferry?.

Extraits faits an XVII siècle Bitlinth. nationale, coll. Baluze, vol. XXXVIII, II. 281-284.

Eu. - Comté.

1279. - Cartulaire du comté d'En: ms. du XIII siècle. sur parchemin. incomplet à la fin. in- $4^{0}$ de $83 \mathrm{lf}$. à 2 col. Biblinth. nat imule. ms. latin 13!04.

Dates extrèmes: 1119-1255: beaucoup de pièces ne sont pas datées : aux ff. 33-69 sont réunies les chartes relatives à l'abbaye de NotreDame d'Eu. Le premier feuillet est coupé. Au XVI $\mathrm{XV}^{\mathrm{e}}$ siècle, le volume appartenail à Philippe de Croy, comte de Poreien, dent la signature se roit à la tìn.

Eu. - Ville.

1280. - Cartulaire municipal d'Eu ou «Livre rougre »: ms. des XIII ${ }_{-1 V l I l}$ siècles, sur parchemin, contenant des documents des années 1272-1717, en 2 vol. in-t" de 255 et 216 If. Biblioth. de lie ville de $E "$, ms. 6-ī,

C.f.: Lo ice sur le livre rouge conservé aux archives de la nairie d'Eu, par Le Roux de Lincy Rerue frangaise et étrangere, IV, 1837, 
pp. 94-115). - Cif ausi : Archives anciennes de la ville de saintGuentin. l (1888), introduction par A. Giry, pp. ix-xru.

Copie moderne du mème, sur papier, in-4 Billioth. de .1. P. de Krimiaingunt, à Paris .

Eure-et-Loir. - Templier's.

1281. - Pcbi.. : Les Templiers en Eure-et-Loir: locuments publiés par l'abbé Métais Archires du diocèse de Charties, 2 année, 1896 ; in- 8 " de 208 p.).

Contient 204 documents publiés surtout d'après les originaux des Archives nationales répie si. Dates extrèmes : $1136-1600$.

Évaux. - Abbaye dioc. de Toul).

1282. - Cartulaire de l'ahhare l'Éraux; ms. lu XVIII siècle, sur papier. in-folio de 216 tr. Lichices dép. de la Meıse, H non coté).

Évergnicourt. - Prieuré (dioc. de Reims).

128:3. - Cartulaire-terrier du prieuré d'Évergnicourt, dépendant de liallaye de Saint-Hubert: ms. du XVIle siècle [1636]. sur parchemin, in-4". ne contenant pas de documents anciens (1rchices de listot ì 1 irlouil.

Eversham. - Abbare dioc. l'Y Pres).

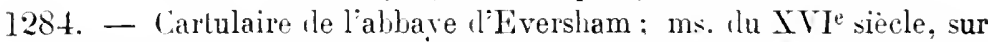
papier. contenant des actés de 1091 à 1284 , in-40 (Archives de l. Etat is Birges'.

Évian. - Ville.

1285. - Recueil des franchises accordées à la ville d'Évian par la maisun de Saroie : ms. du XVIII siecle. sur papier, contenant des titres de 126.5 à 1714, in-folio de $179 \mathrm{ff}$. (Biblinteca di $S$. M. il Rè, Torino).

1:286. - Autre recueil ; ms. du XVIJe siècle [16:3], fait par Fr. Privost, chàtelain d'Évian, sur papier, avec index, in-4 $4^{0}$ de xvil372 pages Biblioth. cont. et unirersitnire de Lausunne, Hist., C 27a).

Evreux. - Abbaye de siaint-Taurin.

1287. - Petit cartulaire de Saint-Taurin d'Évreux; ms. du XIII siecle [ff. 43-112]. arec arlditions faites en 1767 , sur parchemin, contenant 1.56 titres depuis le $\mathrm{X}^{\mathrm{e}}$ siècle copiés par des mains différentes. in-folio de 122 lf. Archices dép. de l'Eure. H 793).

1288. - Granıl cirtulaire de Saint-Taurin d'Érreux; ms. du XIV̈e siècle. contenant 552 titres depuis la fin dı $\mathrm{X}^{\mathrm{e}}$ siècle à 1532 , sur parchemin, in-folio de $367 \mathrm{ff}$. (Aichires dép. de l'Eure, $\mathrm{H}$ 794).

Ces deux cartulaires se complètent, très peu d'actes se trouvant faire douhle emploi. Cif. Inventaire sommaire des archives dép. de l'Eure, serie $H$, pl. 144-156. 
Évreux. - Chapitre cathédral.

1289. - Cartulaire I du Chapitre de Notre-Dame dÉvreux; ms. des XIII-XII'e siècles, sur parchemin. contenant des documents de 11.53 à 1391 . in-folio de $173 \mathrm{fr}$. (Archices dép. de l'Eure. G 122.

1290. - Cartulaire II du Chapitre; ms. du XV' siècle arec additions postérieures, qui est en partie la copie du précédent. in $4^{\circ}$ de 200 ff. (Archires dép. de l'Eure, G 123).

1291. - Cartulaire III du Chapitre: ms. du X $\mathrm{Y}^{\mathrm{r}}$ siècle. contenant 507 actes des années 1228-145.5. sur papier. in- $\mathbf{t}^{\prime}$ 'le $42.5 \mathrm{ff}$. Aichices dép. de l'Eure, G 124).

1292. - Cartulaire IV du Chapitre: ms. du XVe siècle. incomplet à la fin, contenant 466 actes dès années 1:200-1432. sur papier. in- $t^{\prime \prime}$ de $340 \mathrm{ff}$. Archices dép. de l'Eure, G 125.

Axal. : Inventaire sommaire des archives dép. de l'Eure. série G. pp. $56-96$.

1293. - Cartulaire V du Chapitre, spécial aux fonılations des chapelles de Notre-Dame d'Évreux; ms. du XVe siècle. contenant 26. actes des années 1181-1436. sur papier. in-folio de $340 \mathrm{ff}$. Archires dóp. de l'Eure, G69.

AxaL. : Idein. pp. 42-44.

1294. - Autre cartulaire du Chapitre cathédral d'Évreux: ms. du XVe siècle. commencé en 1436 par les chanoines Pierre Le François, Geoffroy Lamy et Jean Lesage. sur papier. arec reliure de lois.

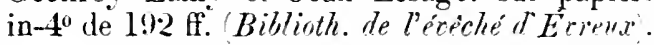

Cif. Mélanges publiés par la siociete ite l'Hintuire d. Normandie, $2^{e}$ série (Rouen, 1893, in-8 ${ }^{0}$, P. 272.

1295. - Fragment d'un autre cartulaire du Chapitre d'Évreux; un feuillet in-folio du XVe siècle. sur papier Archices dép. de lEvipe, G 126 .

1296. - Fragment d'un autre cartulaire: ms. du XVI siècle. sur papier. contenant des textes idep. 1142 déja presque entièrement contenus dans le registre G 122 'Archires drip. de $T$ Eure. G 126 .

1297. - Fragment l'un autre cartulaire: ms. du XVIII sieccle. sur papier. contenant des actes incomplets des années 1265 à 1431 (Archives dép. de l'Eure. G I26.

Évreux. - Ėvèché.

1298. - Cartulaire de l'évèché d'Étreux; ms. du XIV'e siècle. contenant 335 actes des années 1113 à 1350, sur papier, in-folio de 170 fl. (Archices dép. de l'Eure, G 6 .

Lacunes après los feuillets 38,123 et 135 . 
Axal. : Inventaire sommaire des archives départementales de l'Eure. série G, pp. 3-26.

Évreux. - Iéproserio Saint-Nicolas.

12:99. - Cartulaire de la léproserie Si-Nicolas d'Évreux ; ms. du XIII siecle [vers 1240], avec additions presque contemporaines, sur par-

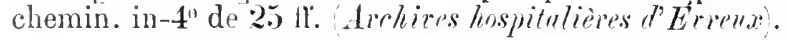

It contient 96 actes depuis 1150 environ jusquat 1252.

Évron. - Abbaye (dioc. (lu Mans).

1300. - Cartulaire-thronique de l'abbaye d'Évron; ms. du XVIIe siècle [1668], par Don Iog. Chevalier, sur papier, in-40 de 864 pagres plus les tables, contenant des documents. des années 1144 à 1668 Archices dép. delu Muypune. H 204 provisoire.

la cartulate proprement dit, "Variat seripturat" ex originalibus transumpta" 1), oceupe 400 parges.

Le volume se trouvait autrefois aux archives de la fabrique paroissiale d'Evron dont il porte eneore le timbre.

1301. - Autre cartulaire [liher pergamenus]; ms. in-folio, de 1 I6 ff., orig. perdu.

Extraits du précédent, faits au XVII ${ }^{\mathrm{e}}$ siècle (Biblioth. nationale, ms. Jatin 13817, 11. 138-15.); ms. latin 17124, pp. 127-186).

Autres extraits du mème faits en 1627 par Dom Briant Biblioth. nutionule, ms. latin 100:38, fr. 82 et 90).

Faremoutiers. - Mblyye (dioc. de Meaux).

1302. - Cartulaire de l'ablaye de Faremoutiers; ms. du XIII siècle, sur parchemin, de 1.22 tl. in-4" (Biblioth. C'heltenham, $\left.\mathrm{n}^{0} 9535\right)$.

Dates extrênes: 1139-12:39.

Extraits (Biblinth. mutimule, ms. francais 1550), ff. 1-4; coll. Baluze, vol. l.I. p. $: 202$.

1303. - Autre cartulaire de Faremoutiers; ms. des $\mathrm{XVI}^{\mathrm{e}}-\mathrm{XVII}$ siècles, contenant des documents de 677 à 1526 , in- $4^{\prime \prime}$ de $125 \mathrm{ff}$. (Biblinth. Stp-Genevière, ì Paris, ms. 358).

Faucigny. - bomaine.

1304. - Cartulaire des Genevois-Yemours, ducs le Savoie, pour leur domaine du Faucigny ; ms. exécuté en 1577 el années suivantes par Fr. Flamen, sur papier, contenant des actes des années 1290-1597, in-4" de 244 tl. (Hichices dép. de la Hante-Savoie, A 11).

1305. - Cartulaire du Faucigny ; ms, de la fin du XIVe siècle, sur parchemin, contenant des documents de 1208 a 1360 , in-folio de 113 tr. (Archivin Comerale, is Turin). 
Fauverney. - Pricure (dioc. dr Langres).

1306. - Cartulaire du prienré-cure de Fauverney; ns. du SVII siècle. contenant 26 documents les annèes $1128-1+39$. sur papier, in-4" de 16 "f. Archires dép. de la Ciste-d O ${ }^{\circ}$, G non caté,

Faverney. - Abbaye (dioc. de Bresançon'.

1307. - Cartulaire de l'abbave de Faveruey. en 5 portefeuilles transcrits aux XVII et XVIII" siècles, sur papier. in-4" we 372, 541. 270, 304 et $282 \mathrm{ff}$. Archires dép. de lu Hunte-Suvite, H $435-439$.

Contient des actes du VIII - viècle à Ireb.

Copie partielle du cartulaire le Faverney; m: du XVIII siecle. sur papier, in-folio Biblinth. natimale, coll. Noreau. vol. 87l, if. 613-678;.

Faverney. - Ville.

1308. - PtBL. : Les franchises municipales du bourg de Faverney, par Jules Finot Bulletin de lu Société ingriculture. sciences et urits de la Haule-Satue, $3^{e}$ série, $\mathrm{X}, 1880$. pp. 491-573,

Dates pxtrêmp: : 1260-165.

Fayt. - Toy. Ginani-Fayt et Maronles.

Fécamp. - Abbaye de la Trinité dioc. de Rouen).

1309. - Cartulaire de l'abbaye le Fécamp: ms. llu SIII siècle. sur parchemin. in $\mathbf{t}^{\prime}$ de 146 "ff. Biblioth. de la rille de Ronen. ms. 1207.

Extraits faits en 1680 pour Ciaignières Billinth. ututionde. ms. latin 17048. pages 561-574: - par Baluze Ihem. coll. Baluze. vol. LXXIII. 11. 33-52 .

1310. - Copie du précédent avec alditions. ms. du XIX siècle. contenant des documents des années 1006-1518. sur papier. in-folio de $207 \mathrm{tt}$. 'Biblinth. de lie rille de Remen. ms. 1210 .

Contient surtout ilm bulle.

1311. - Autre des XIII -XIVe siècles. sur parchemin. contenant des titres des années 1114 it 1324 . in-t" de $30: 3 \mathrm{tr}$. Archices dep. de la Seine-Infésieure, H non coté.

Copie du précérlent: ms. du XVIe siecle. sur papier. in-folio de 430 pages Biblioth. Cikeltruluin. n" 21189 ).

Fépin. - Vọ. Revix.

Féricy-en-Brie. - Villagé.

1312. - Recueil de tocuments relatifs à Féricy. dép' de la Sainte- 
Cliapelle de l'aris: ms. du XV'e siècle. de plusieurs mains, sur papier. contenant des titres de $13: 26$ a 1496 , in-4" de $5 \mathrm{l} \mathrm{fl}$. (Archires nationules, S $986^{\mathrm{B}}$ ).

On y a joint un document de l'année 1516.

1313. - Autre recueil du XYle siècle [15.50], sur prapier, in-40 de $100 \mathrm{tr}$. Archires nutionules, S $986^{\circ}$ ).

Ferrières-en-Gâtinais. - Abbaye (dioc. de sens).

1314. - Cartulaire de l'abbaye de St-l'ierre le Ferrières; orig. perdu.

Extraits faits par Dom G. Morin en I6I6 Biblinth. nationale, 11ns. nour. ac(unisitions françaises 7433. fr. 2I6-224; - par Iu Chesne Inem, ms. latin 17048. 11. 55:3-560).

Fervaques. - Abbaye (dioc. de Noyon).

1315. - Cartulaire de l'abbaye de Fervaques; ms. du XITe siècle, sur parchemin. incomplet du début, in-4" de 94 tî. (Biblioth. natiomale, ms. latin 1 lozl'.

Manquent les 60 premièren thartes.

ANaL. Nolices et extraits des documents manuscrits relatifs à l'histoire de la Picardie, par H. Cocheris. II, n" 5.53.

Copie moderne du précédent. sur papier, in-folio de $217 \mathrm{fl}$. Biblinth. de la rille de Yoyon, coll. Peigné-l)elacourt, ms. 13).

1316. - Antre cartulitire: ms. des XVII'-XVIII siècles, contenant 160 pièces des années $1148-1768$, sur papier, in-folio de $312 \mathrm{fl}$.

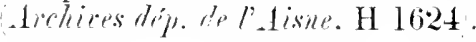

Fesmy. - Abbaye de Sint-Etionne (dioc. de (ambrai).

1317. - Cartulaire de lahhave de Fesmy ou «Live rouge»; ms. du Ir"siecle; orig. perdu.

Copie du précédent; ms. du XVIII siècle. exécuté par ordre de l'abbé commendataire Coignet. sur parpier. contenant des documents des années $1108-1494$. avec en têle un index chronologique. in-folio

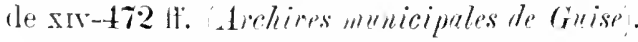

Ax.s. : Lénglise et le cartulaire de Fesmy 'Aisne, près du Cateau Nord par R. Minon Mémives de lu S'wiété mehéologique de l'ary. "1essus. V. I901. 2 partie. p. 1-9.5, et i part: 1902, in-8" de $99 \mathrm{p}$.

Lixtrait Bibliotle, matimale, coll. Baluze. vol. XL. fo 95).

1318. - Recueil de titres relatifs it l'abbaye de Fesmy ; ms. du XVIII siècle. rédicué par Dom Caffiaux Bibliuth. nutirinale. coll. Dom Grenier. vol. CI. tl. l et ss.'. 
Fieffes. - Commanderie dlioc d'.lmirns.

1319. - Cartulaire de la haillie de Fiefles: ms. rélligé en l40!3. sur parchemin, in-folio de 38 If. Bilstinth. Chelterhthin. n" 4:37.2.

1320. - Premier cartulaire de Fieffes : ms. du Xll ${ }^{e}$ siècle. in-4" d+ 7 fi. sur parchemin Archires nationules, S 5059. n" 10 .

1321. - Deuxième cartulaire de Fieffes : ms. du XIII" siecle. in-4" de $8 \mathrm{ti}$. sur parchemin tichices nationules. S 5059. n" 11 .

1322. - Troisième cartulaire de Fielfes [incomplet du délıut]; ms. du

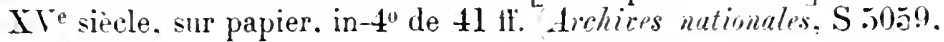
$\mathbf{n}^{0} 8$.

1323. - Quatrième cartulaire de Fietles; ms. du XVe siècle. sur papier, incomplet du début. in-f" de 21 tf. Awhires nutionules. S $5059, n^{n} 7$.

Lianalyse de cos quatre recueils se troure lans H. Cocheris : Vitices el extraits des documents manuscrits relatifs it lhistoire de lat Pieardie, II, $n^{\circ 5} 560-563$.

1324. - Cartulaire de la commanderie de Fieffes: ms. du XVIe siecle. sur papier, avec reliure ancienne, contenant des documents des années 1174-15̆l4. in-40 de $378 \mathrm{lf}$. Archires nutionules. S5j333.

Figeac. - Abbaye dioc. de Cahors.

1325. - Recueil de titres relatifs à l'abbaye de Figeac et au prieuré de Fons en dépendant: ms. du XVII" siecele. sur papier. contenant des documents des années 75.5-15.56 [pour Figeac] et 959-1493 [pour Fons]. in-folio de 285 if. Biblinth. mintimals. coll. Doat. vol. 126 .

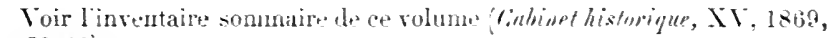
p. $37-46)$.

Figeac. - Ville et courents.

1326. - Recueil de titres relatifs aux courents et i la ville de Figeac: ms. du XVIJ siècle. in-folio de $208 \mathrm{HI}$. Biblinth. nutionule. coll. Doat. rol. 125 .

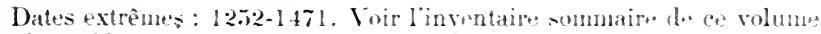
Conbinet histminge, XV, 1869. P. 16-23.

Flandre. - Comté.

1327. - Cartulaire de Flandre dit de Guy de Dampierre; ms. du MITe siècle. sur parchemin. contenant des actes de $128^{\circ}$ a $13, \%$. in- $4^{\circ}$ de $205 \mathrm{tr}$. Archics dn myanme de Belgique, is Bruxellos.

1328. - Cartulaire de Flantre. dit de P'inilippe le Bel : ms. du XIV"e siècle, sur parchemin. rontenant des actes des années 1:309-1310,

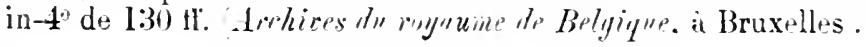


I329. - Cartulaire de Flantre. dit de Louis de Male; ms. du XIVe siècle. contenant les actes émanés de ce comte, sur papier, in-folio de $259 \mathrm{tr}$. (Archices de l'Etut ̀̀ (rund).

Dates extrêmes: : 1:348-1358.

Publ. : Carlulaire de Louis de Male, comte de Flandre. publ. par le $\mathrm{C}^{\text {te }}$ Th. de Limburg-Stirum. Bruges, De Plancke, 1898-1901, 2 vol. in- $4^{\circ}$ de $[1 v-]$ Xx-663 et vi-684 p.

13:30. - Cartulaire de Flandre : ms. des XIII'-XIV'e siècles. sur parchemin et papier. en 9 vol. in-folio de 171, 420, 58. 84. 234. 176, Ill, 160 et 94 fr. (Archives dép. dn Tord, B $1561-1569$.

1)ates extrêmes : 819-1384. Le classement n'est poin! chronologique.

1331. - Antre cartulaire de Flandre; ms. des XIVe-X VIIe siècles, sur papier et parchemin, en 80 rol. in-folio Lrchires dép. dn Kord, B $1.996-167.4$.

Dates extrimes: 1086-1786. Le classenuent n'est pas darantage chronologique.

1332. - Cartulaire de Flandre; ms. du $\mathrm{X} 1 \mathrm{~J}^{\mathrm{e}}$ siècle, sur parchemin, contenant des actes de 1274 a 1340 , in-folio de 86 If. (1)hires depp. dn. Vord, B 1595 .

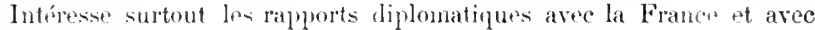
l'Angleler'rt'.

1333. - Cartulaire de Flandre: ms. du XVe siecle, sur parchemin, contenant des actes de 1190 i 1328, in $4^{0}$ de $96 \mathrm{fr}$. (Archives du royumme de Belyique, at Bruxelles).

13:34. - Autre cartulaire; ms. du XVI $\mathrm{X}^{\mathrm{e}}$ siecle, sur papier, contenant des actes de 1294 a $15 \% 5$. in-folio de $35 \%$ fr. (Lehives de l'Etat à Gilut.

1:335. - Autre cartulaire ; ms. du XVIe siècle, sur papier, contenant desactes de 1414 i 1522 , in- 4 " de 34 If. (Archices du roynume de Belgique. i Bruxelles).

13336. - Autre cartulaire: ms, rlu XVIII siècle, sur papier. en 3 vol.

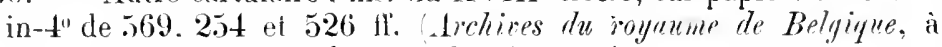
Brnxelles. fonds de la Chambre des Comptes).

Cif. l'Inventanre imprimé di ce fonds, t. 1, p. 21.1. Dates exlrèmes: $1165-1335$.

1337. - Autre cartulaire, dlit "Diplomalarium Flandrix "; ms. du X YIII" siècle, sur papier. avec tables. en 4 vol. in-folio de 339-xxI, 272-xхт. 329-xxi et 266-xxiv pares (1)chives du royame de Hollande, a La Haye, Papiers Gérard, n"s 61-64).

Dates extrêmes: $1056-1456$.

1338. - Autre cartulaire; ms. du XVIII siècle, sur papier, contenant des actes de 1056 a 1168 , in-folio de 66 pages (Archives du royuzume de Hollunde, a La Haye. Papiers Gérard, no 67 . 
1339. - Autre cartulaire: ms. du XVIII siècle. sur papier. contenant des actes de 1163 i 1190 . in-folio de 142 pages Archices du royaume de Hollande. à La Haye, Papiers Gérard. $\mathrm{n}^{0} 68$.

Peu de diplomes proprement dits.

1340. - Antre cartulaire; ms. du XVIII ${ }^{e}$ siècle. sur papier, en 6 vol. in-folio de 130. 257. 44. 558. 470 et 375 pages Alechires du royaume de Itollande, à La Haye. L'apiers Gerard. n's 69-it.

Dates extrèmes: $1100-1420$.

1341. - Recueil de pièces copiées dans les archives de Flandre; ms. du IrIII $^{e}$ siècle, sur papier. en 2 vol. in-folio contenant 622 chartes des années 1195-1594 (Biblioth. nutionule, mss. Iatins 91249125).

Cif. Comptes rendus de le Commission roynle dhistoire de Belyinue, te serie, II, pp. 110-116. - Il y a également beaucoup de copies dans Ie fouds Moreau à la Bibliothèque nationale.

1342. - Autre recueil; ms. du XVII ${ }^{\mathrm{e}}$ siècle. sur papier. contenant des acles de 1099-1634. in-folio de $327 \mathrm{ff}$. British Ihseum. alditional ms. 30716 , ff. $1-32 \boldsymbol{\gamma})$.

1343. - Autre recueil ; ms. du SVII siècle, sur papier, contenant desactes de 1372 a 1634 . in-folio de $97 \mathrm{tf}$. British Musem.m. additional ms. 30719. $\mathrm{tr}$. 1-97).

1344. - Cartulaire dit "Wittenbouc A»; ms. du XVIe siècle. sur parchemin. contenant des actes de 1549 it 1583 , in-folio de $123 \mathrm{fr}$. Archives communules de Bruges.

Concernéspécialement les quate menbre de Flandre.

1345. - Cartulaire dit « Wettelyke recorden $»$ ms. du XVI siècle, sur papier, contenant desactes des années $1294-1575$ relatifs spécialement aux gildes. in-folio de $35 \tau \mathrm{fl}$. 'Archices de l'Etut ù Cirud.

1346. - Cartulaire de Lorraine pour la Flandre ; ms. de la fin du XVIe siècle. formé par Thierry Alix. sur papier. contenant destitres de 1256 à 15.56 , in-folio de 258 II. Archires dép. de Werrthr-etMoselle, B 413 .

Flaran. - Abbaye (dioc. d'Auch.

Cartulaire de l'abbaye de Flaran : orig. perilu ?.

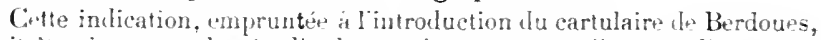
doit ètre inexacte : les érulit- locaux ignorent complètement l'existence de ce rolumin.

Flavigny. - Abbaye de Saint-Pierre lioc. d'Autun).

1347. - Cartulaire de l'abbaye de Flavigny : orig. perdu.

Copie du précédent : ms. du XVII siècle. sur papier. in-folio de 109 p. Biblisth. metionele, ms. latin 17220. 
Lixtraits du précèdent faits pâr Du Chesne au XVIIe siècle (Biblioth. nationule, coll. Baluze, vol. XL, ff. I4-17, 36 et 43-49).

Lioriginal a été commu et amplement utilisé par Du ('hesne (Preuves de Thistoire de la maison de Veroy).

Copie du cartulaire de Flavigny; ms. dı XVIII siècle, sur papier, in- $4^{0}$ (Biblisth. Io lu ville de Chatillon-sur-Seine, ms. 6).

Cif. une analyse de 96 chartes du VIIJe au XII siecle, par M. Collenot (Bulletin de la Sarieté des sciences historiques et naturelles de Semur, $2^{e}$ série, III. 1886, p. 33-109). - L'analyse a été faite sur une transcription moderne de la précédente eopie, qui appartient à la société de S.emur.

1348. - Autre cartulaire; ms. du XVII siècle. contenant 198 actes des années 1227-1664, sur papier, in-folio de $177 \mathrm{ll}$. (Archices dép. de ln Cinte-d"Or. H non coté

1349. - Autre cartulaire: ms. dn XVIe siècle, sur papier, in-folio (Biblioth. myale de bruxelles, ms. 7856).

Flavigny-sur-Moselle. - Prieuré (dioc. de Toul).

135̆0. - Cartulaire-censier du prieuré de Flavigny, dép de l’abbaye de Silint-Yianne de Verdun : ms. du XYIIe siècle [1681], sur papier, in-folio de 53 pares (Catulogue de la libruirie Ermest Dumont, novembre 1905. n" 968 .

On y trous ha transcription d'un certain noubre de chartes des XIII et XIV́e siecles.

1351. - Framment d'un cartulaire du prienté de Flavignny en Lorraine; ms. lu XVII siecle. sur papier, in-folio (Archires dép. de Mrurthert-J/wsille, H 104.

Fleury-en-Bière. - Prieuré (dioc. le Sens).

1352. - Cartulaire du prieuré de lileury-en-Bière, dépt de St-Victor

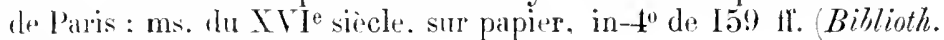
mutimule, ms. nouv. acq. latines 1865 .

Fleury-sur-Loire. - Toy. SAINT-BExoIT-SLR-L OIRE.

Flines. - Abbayc (dioc. de (ambrai).

135:3. - Cartulaire de l'abbaye de N. 1). de Flines: ms. de 1540, sur parchemin. réligé par messire Gérard Bétremieu, en 2 vol. in-folio de 644 fl.. contenant des actes i partir de l'année 1234 (Archives dip. dly Word, $\mathrm{H}$ non cote $)$.

1354. - Antre cartulaire B; ms. du XIV siècle avec additions du XVe, sur parchemin, contenant des documents jusqu'ì I:310, in- $4^{0}$ te 410 II. (Arehires díp. du Nord. H non coté).

135.). - Autre cartulaire $\left(. ;\right.$; ms. du $\mathrm{XIY}^{\mathrm{e}}$ siècle. incomplet à la fin et 
renfermant surlout des tilres de rentes (1280-1362), in-4' de tit il. (Archices dép. du Nord. H non coté,

1356. - Autre cartulaire I) : ms. du $X V^{\top e}$ siècle avec additions poitérieures, sur papier. assez incorrect, in- $4^{n}$ de 1222 ti. (1relires dép. de. . Tord, H non colé.

135\%. - Antre cartulaire $\mathrm{E}$; ms. du $\mathrm{XVI}^{\mathrm{e}}$ siècle, sur parchemin. infolio de $4 \mathrm{llf}$. Archices tép. du Nort. H non coté,

1358. - Autre cartulaire $\mathrm{H}$; ms. dressé en 1730 par A. F. Deroulaaix. receveur de l'abbaye. sur parchemin. el contenant 29 pièces des années 1609-1727, in-folio de $80 \mathrm{ff}$. plus 5 pages de table Arhires dép. de Nord, H non coté).

1359. - Punt. : Cartulaire de l'alıbare de Flines. par l'abbé E. Hantcœur. Lille, Quarré, I873: 2 vol. in- $8^{\circ}$ de xv-1029 p. et pl.

Recueil factice de $10 \% 0$ chartes des annéps 1200-1630, analyeérs ou publiées.

Flixecourt. - Prieurẻ (dioc. d'Amiens).

1360. - Cartulaire du prieuré de Flixecont : ms. du XVII ${ }^{\text {- siècle. }}$ sur papier. contenant des titres it partir de 11.57 . in-folio de $138 \mathrm{tl}$. (Archices dép. de la Somme, D 63 .

Flobecq. - Chàtellenie en Hainaut.

1361. - Cartulaire des châtellenies de Flolecq et Lessines: ms. du SVIe siècle [15ll]. sur papier. contenant 26 actes des années 1276 1428. in-folio de $64 \mathrm{tr}$. Archires de l"Etut à lrojis'.

L'original de ce registre appelé primitirement " cartulaire des terres de débat n, et aujourdhui perdu, avait eté rédigé par un secretare de Philipus le Bon, duc de Bourgogne.

Axal. : par Léop. Devillers dans les Comptes-remlus de l" Cominission myale thistrime Bruxelles. $4^{\mathrm{e}}$ série, III. 1876, p. 467-5l:2.

Flône. - Mbarye dioc. de Liège,

1362. - Cartulaire de labbave de Flòne: ms. des XIV-Xre siècles [1386-1408]. sur papier. contenant des actes les années $109 \mathrm{~L}$ à 1403. in-4" de 88 ti. Archices de la fumille Donckier te Disnced. à Liège.

Publ. : par II. l'abbé Evrard. dans les Analectes pron serreir ì lhistsire ecclísiustique de la Belqique. XXIII 1892 - p. 273-454. et XXIV 1893 , p. 395-492.

1362 bis. - Autre cartulaire de la mème abbare: ms. du XriIe siecle arec additions du XVIII , sur papier. en 3 vol. in-folio de 344 .

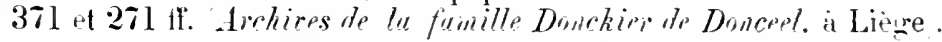

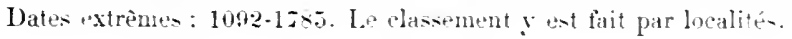


1363. - Autre cartulaire on «Liber secundus privilegriorum »; ms. chu X VIII siècle, sur papier. rédligé par l'abbé J. I. de Schroots, contenant des documents de 1730 ì 1782, in-folio de $111 \mathrm{ff}$. (Archires de la famille Donckier de Donced, is Liège).

La" "liber prinus \# (16;0-1730) est perdu.

Floreffe. - Abbare dioc. de Namut).

1364. - Cartulaire de l'abbaye de Floreffe: ms. du XIII ${ }^{e}$ siècle [1292]. sur parchemin. contenant des documents de 1121 a 1292 , in-folio de vin-237 ff. Archices de l'État à Yamur.

1365. - Antre cartulaire llu XVII siècle, sur papier, contenant des documents de 1191 a 16.58 , en 2 vol. in-folio de 420 et 45.5 paces Archices de l'Etat is Vimur.

Publ. : Cartulaire de labbaye de Floreffe, par Jos. et Victor Barbier Anclectes ynur servir à lhistnire pcclésiastique de la Belgique, XVII. 1881, p. 7-67.

Recuril fartiee de documents dess années 1121-1255, l'après les cartulairso et les originaux.

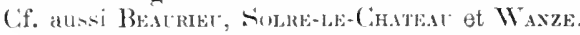

Florennes. - Chitpitre collegial saint-Gengoux (dioc. de Liège).

1366. - Recueil des titres dn chapitre collécial de Florennes: ms. du XVIII siècle. sur papier, in-1" de 273 tt. (Archices de la fabrique de lerglise de Florenues.

1367. - PubL. : Documents concernant le chapitre de la collégiale de Saint-(iengoux de Florennes. par V. Barbier Analectes pour servir à Thistnive eeclésiastique de la Belgique, XXI, 1889, p. 38.5-485.).

Dates pxtrênes: : 102!-1636.

Foicy. - Prieuré (diox. de Troyes'.

1368. - Calulaire du pripuré de Foicy : ms. daté de 1599, contenant 12.5 actes des années $1134-1542$, sur papier, in-folio de 35 ff. drehires dion. de li lube. H non coté.

Foigny. - Mblaye de Notre-lane dioe. de Laon).

1369. - Cartulaire de labbhaye de Foimny [incomplet à la fin], ms. du XIIe siecte avec talle en tête et reliure le bois et de cuir, sur parchemin. in-4" de $88 \mathrm{dr}$. Biblioth. natimale, ms. latin 18373).

1370. - Autre cartulaire de Foigny : ms. dn XIIIe siècle avec additions, sur parchemin. mutilé par endroits, et relic en bois reconvert de veau brun. in-4" de $231 \mathrm{fr}$. (Bitlioth. de la ville de Reims, ms. 1563).

Dates extrèmes: 1121-11\%5.

Provient do Peigné-1) lacourt. - In feuillet (entre 87 et 88 ) a été coupé, et les douze premiers manquent. Les rubriques en rougte ont été couperes par un relieur malatroit. 
Axal. : Analyse du cartulaire de labbaye de Foigny. par lidunard de Barthélemy. "Vervins. impr. du .Journäl de Vervins, 1879: in-4" de 162 p. [Société archéologrique de Vervins.]

1371. - "Cartularium Fusniacense »: ms. du XIIIe siècle. avec additions et table en tète. sur parchemin, in-8" de 308 If. 'Biblinth. mationale, ms. latin 18:374.

Analyé par H. Cocheris dans ses Colices et extraits des documents manuscrits relatifs at lhistoire de la Picardie, II, no 580.

La pièce lat plus récente est de 1394. - Le volume provient dits la bibliothèrue de la cathédrale de Paris.

Extraits du précédent Biblioth. nationale. ms. français 9501), pp. 7-24; ms. nour. acq. françaises 7425. ff. 280-305 : ms. nouv. acq. françaises 7433. If. 162-182 .

1372. - Cartulaire de labbaye de Foigny : ms. du XVIJ siecle. sur papier. in-folio de 222 tr. "Archices de'p. de l'disne. H 623.

Foix. - Château.

1373. - Cartulaire dn châtean de Fuix : ms. du XIII siecle. contenant 615 pièces les $\mathrm{XI}^{\mathrm{e}} \mathrm{-} \mathrm{XII} \mathrm{I}^{\mathrm{e}}$ siècles, sur parchemin, in-4 $4^{0}$ de 247 If. 'Biblioth. de lu Sisciéte' archérlogique de Hontpellier, ms. n" 10 .

Cie volume. qui provient des anciennes archives du chàtrau de Foix et a été acquis n 1858 par la soe. archéol. de Montpellier. se réfer. surtout aux Trencavels, conles de Careassonne et ricomtes de Bézier. Il a été connu le Iom Vairète et utilisé par lui jef. nouv. eut. VI. 1. 792$\}$.

Foix. - Ville.

1374. - Cartulaire municipal de Foix: ms. rédigé en 1387. avec quelques additions postérieures. sur parchemin, contenant 27 pièces des années 1244-1430. in-4" de 129 ff. Archires municipales de Foix, .

Ce' registre contient en outre la copie des évangiles, sur lesquelon prêtait serutent. - Quelques actes sont en langue romane: il y a dws notes anciennes sur les narges.

1375. - Recueil de titres relatifs à la ville de Foix; ms. du XVII siècle, contenant des actes des années 1244 à 1594 . in-folio sur papier Biblioth. nationale, coll. Doat, vol. 96. ff. 1-26t.

Les: ff. $265-381$ du mêne volume intéressent labbaye de St-Volusien de Foix.

Fons. - Prieuré. - Toy. Figfac (abbaye de).

Fontaine-Daniel. - Abbaye (dioc. du Mans.

1376. - Recueil de titres et extraits concernant l'abluaye de Fontaine-

Daniel, formé par Gaignières au $\mathrm{XVII}^{e}$ siècle, sur papier. in-folio (Biblinth. nationule. ms. latin 5475 . ff. $7-90$ ). 
Copie moderne, par l'ablié H. Angot; ms. de 132 pages in-4 ${ }^{0}$ (Archires dép. de la Maycune, H 211 provisoire).

Dates extrêmes: 1191-1328.

Publ. : Cartulaire de l'ablaye cistercienne de Fontaine-Daniel, pullié et traduit par A. Grosse-Dupéron et L. Gouvrion. Mayenne, Poirier-Béalu, 1896 ; in-80 de $4: 37$ p. et pl.

Fontainejean. - Abbaye (dioc. de Sens).

137\%. - Cartulaire de l'abbaye de Fontainejean ; orig. perdu.

Fxtrait fait an XVII" siècle (Biblioth. nationale, coll. Baluze, vol. XXXVIII, ff. 3I2-3I3).

Fontaine-Mesland (pricurẻ de). - Toy. Messand.

Fontaines. - Prieuré de Saint-Jean. - Toy. Maruoutier.

Fontaines-les-Blanches. - Abbaye (dioc. de Tours).

1378. - Fragment d'un cartulaire de l'abbave de Fontaines-lesBlanches [f" 16]. ms. du XIIJ siècle, à 2 col. Biblioth. de la ville de Bloisi.

Xon indiyué dans le catalogue des manuscrits de Blois publié par Ein. Coyecque.

Cf. : Notice sur un feuillet détaché du cartulaire de l'abbaye de Fontaines-les-Blanches, par A. Dupré Revue des Sociétés stavantes, 5 série, VIII, 1874. p. (5ă-73:

lixtraits du manuscrit complet, faits an XVIII siècle (Bitlinth. natimale, coll. Dom Houssean. vol. XII et passim).

Fontaines-les-Nonnes. - Prieuré (dioc. le Meaux).

1379. - Cartulaire lu prieuré de Fontaines-les-Nonnes; orig. perdu.

Copie d'un framment de ce cartulaire, faite par A. Dı Chesne au XVII" siecle (Biblinth. nutionale, coll. Baluze, vol. XL, f" 143).

1380. - Cartulaire daté de 1788. sur papier, contenant 229 titres des années 1115 i 1706 , in-folio de 343 il. (Archives dép. de Seine-etWarm, $\mathrm{H} 492)$.

1381. - Cartulaire de lésclise ct prienré de Fontaines, de l'ordre de Fonlerrauld; ms. dressé en 1789 par Louis-Ph. Cherrier, administrateur de l'Hòtel-Dien de Neaux. sur papier, in-folio de $194 \mathrm{lf}$. Biblinth. de la rille de Meaux. ms. 68 . 
Fontblanche. - Prieuré dépi le l'abbayc de la Couronne, à Exoudun (dioc. de Poitiers).

1382. - Pcrl.: Documents relatifs du prieuré de Nolre-I)ame de Fontblanche (1220-I66is) par G. Babinet de Renconne Mémoires de lu Société de stulistique des Deur-Sèrres, 2 érie. XII. pp. 1-40); et à part ; Niort, Clouzot. 1874: in- $\zeta^{\circ}$ de $40 \mathrm{p}$.

Fontcaude. - Abbaye (dioc. de Saint-Pons.

1383. - Cartulaire de lahbaye tle Fontcaude: ms. du XIVe siècle [1344], sur parchemin, in-4" de 44 p. Archices de .Ve Baither, notaire à Cruzy).

Fontdouce. - Abbaye (dioc. de Saintes).

1384. - Recueil de titres relatifs à l'abbaye de Fontdonce et an prieuré de Lien-Dieu : ms. du XYI siècle, sur parchemin, incomplet à la fin, in-4" de $71 \mathrm{fl}$. (Biblisth. nutionale. coll. Baluze, vol. 286).

Fontenay. - Abbaye de Saint-Etienne (dioc. (le Bayeux). 1385. - Cartulaire de l'abbaye de Saint-Étienne de Fontenay: ms. du XIII siecle, sur parchemin, in-8" Archices dép. du Calrados. $\mathrm{H}$ non coté, lf. 32 à 111 .

Le reste du volume comprend des documents joints, plus modernes.

1386. - Autre recueil de titres relatifs à l'abbaye de Fontenar. formé par Lamare ; ms. du XVIlle siecle, sur papier. in- $8^{\circ}(B i)^{\circ}$ irth. de la rille de Caen, coll. Mancel, $\mathrm{n}^{\circ} 2295$.

Fontenay. - Abbaye de Notre-Dame (dioc. d'Autun).

1387. - Cartulaire de l'abbaye de Fontenay ; ms. du XrIHI siècle, contenant 280 actes des années $1141-15 \% 6$, sur papier, en 2 vol. in-4 de $221+106$ et $135 \mathrm{ff}$. Archices dép. de lu Cóte-d Or. H non coté).

Fontenay-aux-Roses. - Voy. Valeston.

Fontenay-le-Marmion. - Seigneurie en Normandie.

1388. - Cartulaire de la seigneurie de Fontenay-le-Marmion : ms. du XIVe siècle, contenant I29 chartes des années 1165-1333, sur parchemin, in-4to de $57 \mathrm{fl}$. (Archives du Pulais de Monaco).

Publ. : Cartulaire de la seigneurie de Fontenay-Ie-Marmion provenant des archives de Matignon. par Gustave Saige. Imprimerie de Monaco, 1895 : in-4 ${ }^{\circ}$ de xu-231 p. [Collection de documents historiques publiés par ordre de S. A. S. le prince Albert Ier prince souverain de Monaco.]

Fontevrauld. - Abbaye (dioc. de Poitiers). 1389. - Cartulaire ancien de Fonterrauld ; orig. perdu. 
1390. - Cartulaire de l'abhaye de Fontevrauh, incomplel [les pares 257 à 350 seules sulsistent ]; 11 s, des XII'-XIVe siècles, sur parchemin, in-folio de l:37 if. Biblioth. Cheltmham, n" 67 ).

Copie du précédent, moderne, pir P. Narchesay (trchives dép. de Muine-et-Loinor).

Voir ci-dessus ro 1,rbach).

Recueil de pièces d’après le précédent et les suivants, fait par André Salmon ver's 1860 , sur papier. in-4" de $162 \mathrm{ff}$. (Biblioth. de la ville de Truers, ms. 1169 .

Extraits du P. Lardier, faits au XVII siècle (Biblioth. nutionale, coll. Dom Housceau, vol. XII. pp. 144-160. et XVIII).

Autres extraits faits par I) Em Listiennoten 1675 (Biblioth. nationale, ms. latin I2755. ff. 370. 662 et 668: - par Du Chesue (Idem, coll. Duchesne. vol. XXII, fl, 401-418.

1301. - Recueil de titres et privilèges relitifi à l'alliaye de Fontevaulel; ms. du XVIII siècle $[1744]$, sur papier, contenant des actes de 1146 is 1465 , in-4" de $170 \mathrm{If}$. (Archires nutionales, LL 1599A).

Fontgombaud. - Abbaye (dioc de Bourges).

1392. - Cartulaire-Histoire de l'abhaye de liontgombaud; nss. écrit an $\mathrm{CVIII}^{\mathrm{e}}$ siècle par Nicolas Andrieu, religieux, contenant des transcriptions d'actes des années $1089-1670$, in-4 $4^{\circ}$ de 141 ff. Archires mationales. LL 10II.

Fontjoncouse. - Seigneurie en Languedoc.

139:3. - Publ. : Cartulaire de la seigneurie de Fontjoncouse, par G. Mouynes Bulletin de la Commission urchiologique et littéraire de

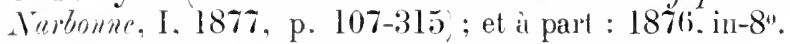

Texte dre 44 chartes des annéts $7933-1624$.

Fontmorigny. - Abbaye (dioc. te Bourges).

I394. - Cautulaire de l'abbaye de Fontmorigny ; ms. du XIII siècle, sur parchemin, in $4^{\prime \prime}$ de $167 \mathrm{fl}$. (Biblioth. de la rille de Bourges, ms. 218.

Cere regristre est inconplet du début ; des leuillets ont été arrachés, et la foliotation ent foute molerne et postérieure à cet acte de vandalisme.

[395. - Autre cartulaire; ms. du XIII' siecle, sur parchemin, in-24 de $264 \mathrm{fr}$.

Do ce volume écrit en très petite minuscule, l'incentle des archives du Chè en 18.19 n'a laissé subsister que 174 fr. qui pourront être en partie reconstitués, n'ayant pas trop souffert des atteintes du feu (Archires dep. du Cher, $\mathrm{H}$ non coté).

1396. - Publ. : Les acles des sonverains antérieurs au XVe siècle 
conservés lans les archives départententales du Cher, transcrits in-extrnso arec des analves. par Jacques Suver; II. Alubar de

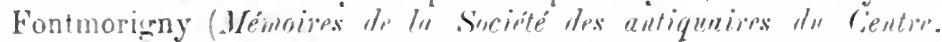

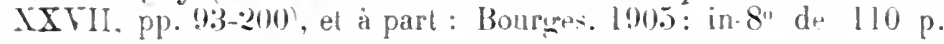

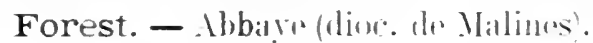

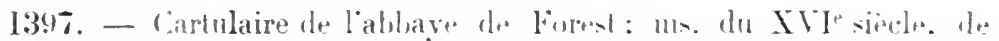
dilferenter mains. sur papier. contenant des docmuents de 1100 a

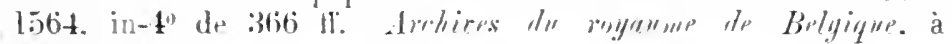
Broxelle:

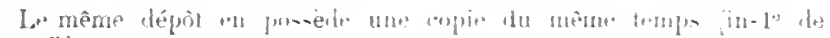
$\$ 319 \mathrm{ti}$.$) .$

Forest. - Église.

1:398. - Cartulaire le léglise de Forest : ms. du XVI siécle. sur papier. contenant des actes de 1273 à 15\%8. in-4" de 1411 11.

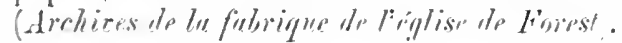

Forez. - Comté.

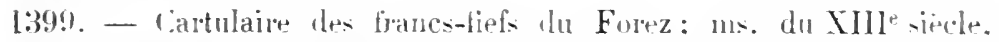
sur parchemin. en lome de roulean découpé en 14 ti. a 2 col.. inPolio Arrices natinnoles. P $140 \mathrm{I}^{*}$, rote 1076 .

Purt. : Cartulaire des franc-liefs du Forez lo90-1:29:2 . par le Cle de Charpin-Fengerolles. Lyun. Perrin. 1882: in-t" do xw$29 \%$.

1400). - Cartulaire un "live de compesitions du comte as" For"z:

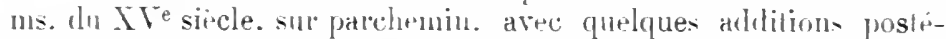
rieures. contenant des chate's de 1158 i 1490 . in-folio le lib4 li.

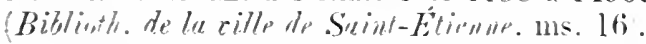

Copie du même, faite an IVIIJ siectr. sur papier, in-lolin de 341 t1. Archires mutiounlis. EK 1113.

Antre copie très défecturnar. quoingu cullationnée anx uriginanx par Ch. Faucon, intemlant dr. I, vomnais ot Forez. avec corrections en interlienes, sur papier. in-linlio de n-otion 11. Biblinth. nutimale. m. latin 12870 ;

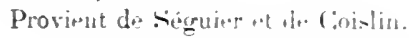

Axaz. : Inventaire des litrov dh comté de Forez. de Jacques Lhullier. pull. par A. Charerondier Roanne, I860. in-8\%. appendice. pp. 60\%-65\%.

Formigny. - Chapelle (dioc. dle Bayeus).

140I. - Cartulaire de la chapelle de Forminny ; ms. du XV $\mathrm{I}^{\mathrm{e}}$ siecle, sur parchemin, in-folio (Biblinth. de la cille de Cuen. coll. Mancel. m.. is. 
Fossard. - Prieuri (dior. de Cihartres).

1402. - Cartulaire du prieuré St.-Rohert de Fossard. dépendant de lahliaye de Josaphat: ms. dı XVII siecle, sur papirs, contenant des actes de 1150 a I6 LI). in-folio de $8 \mathrm{ll}$. (Archives déy. de Eure-etLoir. H 2195 .

Fosses. - (hapitre dr Saint-Feuillen flioc. de Namur).

1403. - Cartnlaire dn Chapitre collécrial de liosses: ms. dn XVIIIe [1734], sur papier. contenant des tocuments de 1092 is 1:374, infolio de 1 I3 II. Archires de l"Etat is Namu*).

Publ. : Docments extraits du cartulaire du Chapitre de losses

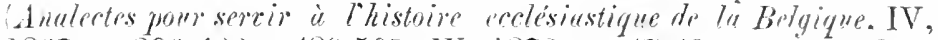
1867 . p. 396-42.2 et 489-50.) : IX. 1872. p. 47-49; el Xill, 1876, p. $361-384$ el $492-493$.

Dutus extrêmes: 1222-162E.

Fosses. - Ville.

1404. - Recneil des priviligha de la ville de Fosses; mas. réligri ver's

1710. contenant des documents a partir de 1444. in-4" de lol li. Arekires de liktut ù Virmm.

Publ. : Cartulaire de la communte de Fusses. par Jules Borunet. Nanur. W"smael. 1867 : in-8" de Lxiv-364 p. [Hocunents inédits relatifs à l'histuire de la province de Namur.]

Foucarmont. - Mbbarr (dive. do Rumen).

1405. - Cartulaire de lahbaye de Notre-Dame et Saint-Jean-Baptiste de Foncarmont: ms. du XIIJ siècle, sur parchemin. in-folio de 170 II. Biblicth. de la rille de Rouren. ms. 12:24.

Copie moderne dn même Biblinth. nutionale, ms. nons. acq. latines 248 .

1406. - Antre cartulaire le Funcarmont : orige perdu.

Lexistrnce de "derux anciqns cartulaips tres beaux n ent atteslée par

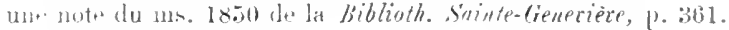

Foug. - châtellinnie.

1407. - Recueil de titres relatifs is la chatellenie de Fougr ms. de la lin du XYI" siecle. formé par Thierry Alix, sur papier, contenant des litres de 1239 i 1584 , in-folio de 36 tl. (Archives depo de Wenthe-rt-Wuselle. B 362.

1408. - Autre recueil du XVIe siecle, sur papier, in-folio de $313 \mathrm{th}$ Arhires dejo de la Meuse. B 245 .

Fougères. - Abbare de saint-Pinre de Rillé dioce de Rennes'.

1409. - Cartnlaire de l’ablaye St-Pierre de Rillé à Fongères: nus. du 
XVII siecle. sur papier, contenant 62 actes de 1204 is 1:353. in $4^{0}$ de $91 \mathrm{t1}$. (Biblinth. de la rille de Renurs. nis. 2it.

Puns. : en partie dans Dum Morice. Histoire de Bretagne. III (preuves; .

Fougères. - Pricuri.

1410. - Punc. : Chartes du prieure de la Sainte-Trinite le Fougeres, par A. de La Borderie Bulletin archéologique de l. Assoriation bretonne, III. 1851 , p. 178-20) et 2:36-250,

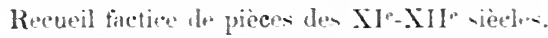

Fougères. - seigneurie en Bretanne.

1411. - Cartulaire de lia seigneurie de Fongìres: orig. perdu.

Fouilloy. - Collégiale le saint-Mathieu (dioce d'Animss). 1412. - Cartulaire dn Chapitre de Fouilloy: ms. dn XIVe siècle, avec alditions posterieures. sur parchemin. contenant des pièces de 1:204 it 1520. in-folio de 1:30 tr. Archices dép. do la Somme. (i non coté).

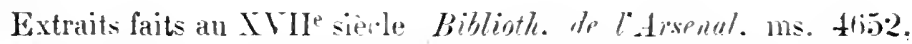
11. $415-462$.

Franc de Bruges. - Chàtellenie.

1413. - Cartulaire du Franc de Bruges on «Roedenboech »: ms. Ues $\mathrm{XV}^{\mathrm{e}} \mathrm{XVle}$ siècles, sur parchemin, contenant dts documents de 1232 a 1581 . p 4 vol. in-folio de $100,208,272$ et 184 li. Archires de l'Etat à Birliges .

14l4. - Aulre cartulaire ou "Wittenhoeck»; ms. des XVe-XVI" siècles, sur parchemin. contenant des documents de 1230 a 1501 . in-folio de 105 tr. Archices de l'Etat is Bruges.

1415. - Autre cartulaile ou « Zwartenhoeck sur papier, contenant les document- de 1232 à $15 \% 5$. in-folio de $18+11$. (Archices de l'Etut a Bruyes.

1416. - Antre cartulaire; ms. du $\mathrm{XVT}^{*}$.iècle. snr papier. contenant des documents de 1279 a 1488. in 4 "de 284 t1. Hichices de l'Étut à Bruges,

1417. - Autre cartulaire: ms. du XV1e siecle. sur papier, contenant des documents de 1460 à 1547 . in-folio de $343 \mathrm{H}$. Archices de l'État à Bruges,

1418. - Autre cartulaire: ms. du $\mathrm{XVI}^{\mathrm{e}}$ siècle. sur papier. contenant des docnments de 1538 à 15.53 . in-folio de $116 \mathrm{Hi}$. Archires de l'etat is Bruges'.

1419. - Antre cartulaire: ms. du XVIII siecle, sur papier, 
contenant des docmments de 13:2:3 a 1702, in-tolio dr:35 11. Arrluives de le Etat is Bringes:

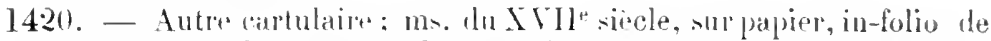
!I Il. Biblioth. nationale de Ptris. fonds noerlandais. ms. T2.

Voir atunis ro bremias.

\section{France.}

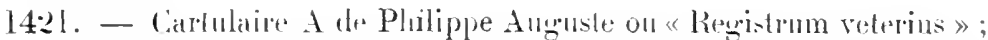
ns. In XIII siocle [1201]. arec additions postérienres jusqu'en

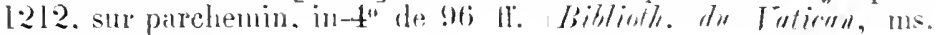
Oltoboni 2796 .

Pubs. : Reprorluction héliugpique du cartulaire de Plilippe Anumste conservé an Valican, par Léopold l)elisle. Paris et Rome, 188:3. in-4" [tiré it 100 exempl.].

Carlulaire B de Philippe Auruste: ms. du IIV siocle. smo parchemin, contenant la copie du précédent moins les pièces cancellées, iu-4" de 99 11. (Amblires "nliminles, J.J 8).

142:2. - Cantulare Cide Philippe tugnste : mo. du X111" siocle [1211], copie du précédent avec addilions postérienres jusqu’en l:200, sur' parehemin. in-4" de 14.) $\mathrm{Al}$. drathes natiomales. .JJ T).

14:3. - Cartulaire E de Philippe Aurnsle on « Remale regristrum

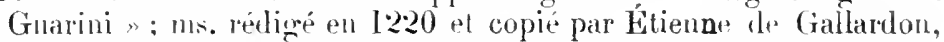
avec addilions postériemes, contenant les actes des années 1080 à 1276 . in-folin dr $388 \mathrm{H}$. a 2 col. (Aichires mationales, J.J 26 .

Elail autrefois conserve a la Bibliothègut nationale w provenait de

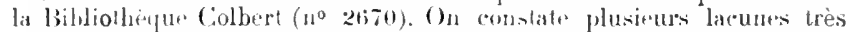
ancirenter ot plusieurs interversions de feuillets.

(it. : A propos d'unt ralum dans un register de Philippe Auguste,

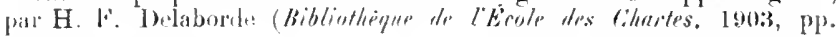
:21013-31:3).

Copie du mème exéculée en l69.5). sur papier, in-folio de tofith. (Biblioth. del' lasent. à Paris. ms. 1004).

1424. - Cartulaire I te Philippe Aurusle: ms. dn XIII" siècte, reprouluisanl en mantr parlie le volume précédent, avec additions de la chancellerie de Lomis IX pour les annés 1248-1255, sur parchemin. in-folio de 28:3 11 . i 2 col., incomplet au commencement el a la lin Biblinth. nationulp. ms. fançais 9778.

Pour toun les regislre's de Philippe Auguste. on ne peut que se

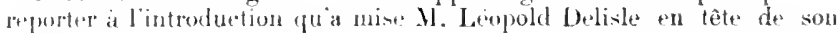

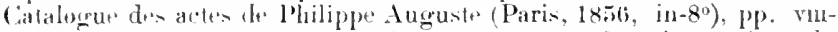
xxr: trn complétant ers renseignemento par: Les inventaires du Tresor des Charten drensis par Gérarel it. Iontaigu, notice par H. Fancois 1) daborte (Paris, Inpr. Hationale, 1900: in-40 de $15-54$

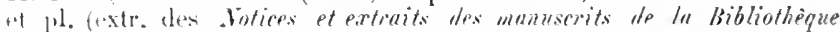
mutionnte. XXXVI, pP, 5.45-598), ou l'on trouvera de très utiles concordances citablies pour la premiere tois. 
1425. - Cartulaire le saint Lunis un "rogistrum velutmu : ms. du Xll ${ }^{\circ}$ sircle. sur parche-mill. ave table en téts. contenant teractes de 1192 à 12606 . in-follio do 140 fi. à ? col. Lrhires nationales. JJ 31 .

14:06. - Autre cartulaire le, saint Lunis on "reri-trum grosum velutum >: ms. iln XII ${ }^{\mathrm{e}}$ sicele. sur parchemin. avec lable en tète.

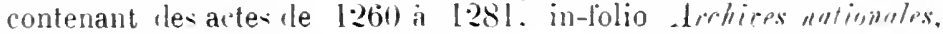
.J.J $30^{4}$. If. 100 i 217 .

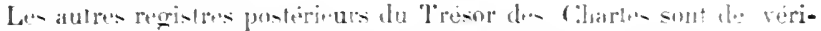

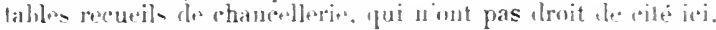

1427. - Antre rartulaire ou "Rerivtrum tenue : ms. du SIII"siecle, avec arlditions poslérieures. sur parchenin. termine par un table.

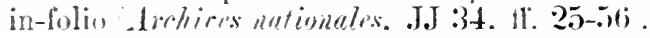

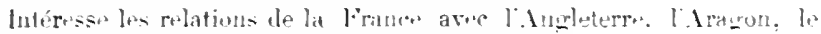

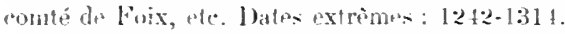

1428. - Premier artulaire ou "Transcripta " tle lancien Trésor des Chartes: ms. clu $\mathrm{XV}^{\mathrm{e}}$ sircle. sur parchemin. conlenant des actes de

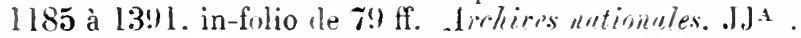

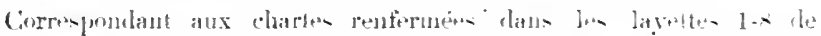

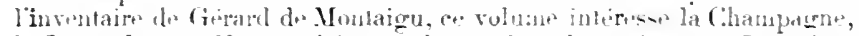

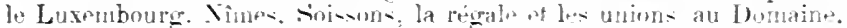

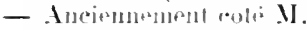

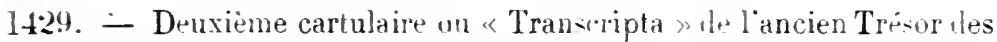
Chartes: ms. lu X siècle. sur parchemin. contenanl les acte- de

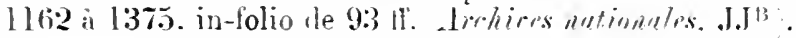

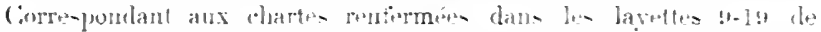

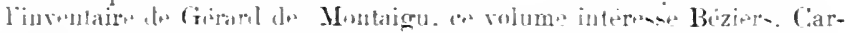

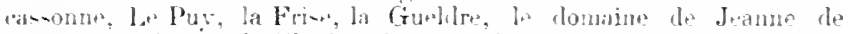

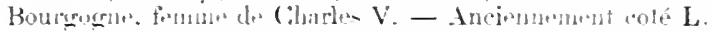

1430. - Troisième cartulaire ou «Tan-cripta du Tré-or des Chartes; ms. du Xl" siecle. sur parclemin. contenant de actes le l:22) à 1:3!2. in-folio de $81 \mathrm{t1}$. Airhires antionales. JJC.

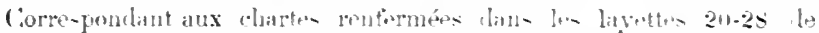

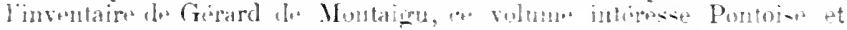
sinlis. - Ancienmenent cutri 1 .

1431. - Quatrième cartulaire on "Tunsipta" du Tré-or "les Chartes: ms. du IV sipcle, sur parchemin. contenant des arles de 11 i゙:) à

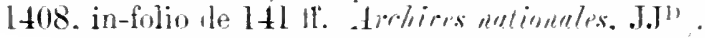

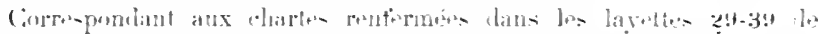

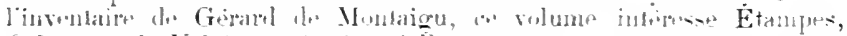

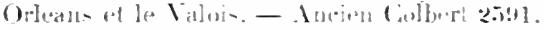

14:32. - Cinquieme rartulair on "Transcripta » de l'ancien Trésor des Chartes: ms. du Xl"sim.l. sur parchemin. contenant der actes

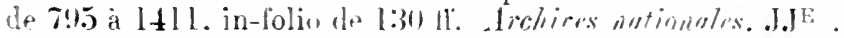

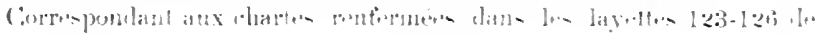




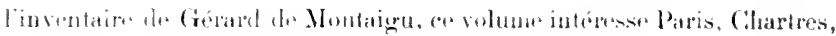

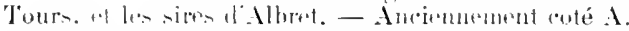

143:3. - Sixième cartnlaire on "Transcripta» de l'ancien Trésor des Chartes: m. llu XVe sircle. sur parchemin, contenant les actes de

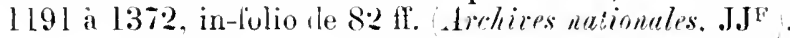

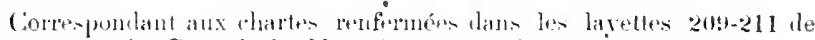

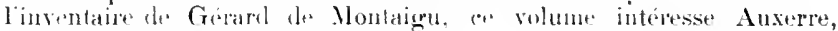

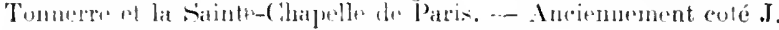

14:34. - Septiime cartulaire on «Transcripla " de l'ancien Trésor des Chartes: ms. du X $\mathrm{Y}^{\prime}$ sifele. sur parchemin, contenanl des actes de

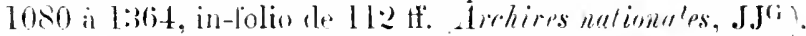

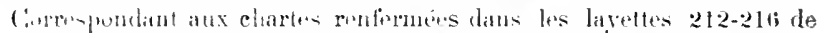

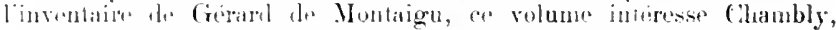

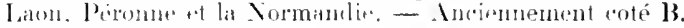

143.). - Huilième cartulaire ou « Transcripta » de l'ancien Trésor des Chartes: ms. du $\mathrm{XV}$ " siicle. sur parchemin. contenant des actes de

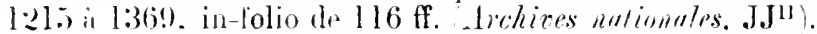

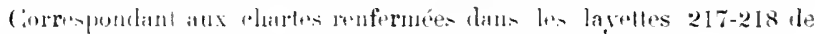

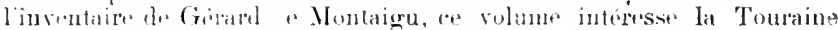

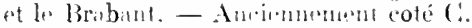

14:34. - Nenviemm cartulitire nu «rancripla » de l'ancien 'Tresor des Chartes: ms. du XVI" siche. sur parchemin. rontenant rles actes de

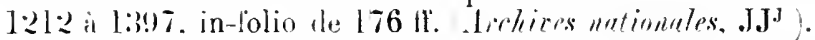

corresumlant and chartes renfermén dans les layeites $219-222$ de

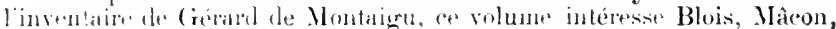

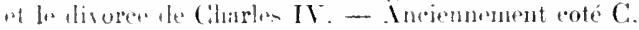

14:37. - Dixième cartulaire ou « 'l'anscripta » le l'ancien Trésor des Chantes: ms. du $\mathrm{XV}^{-p}$ siocle. sur parhemin. contenant des actes de $13: 33$ a 1:3:16, el incomplet is la lin. in-folio de $48 \mathrm{fl}$. (Arrliocs

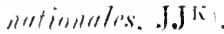

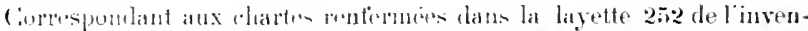

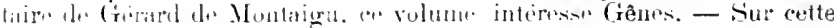

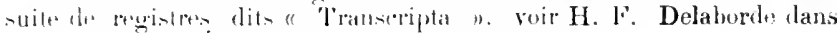

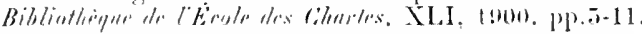

143丸. - Carlulaire cliplomalique de Philippe le Bel : ms. du XIV sierle. sur parchemiu, aver tahle en tète. in-t" le 14 Ir. (Arrhines malimules. J.J 16 .

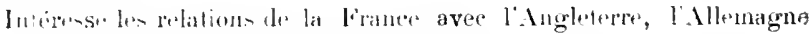

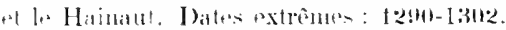

14:39. - Aulre cartulaire diplomatique de Philippe le Bel; ms. du $\mathrm{X} \mathrm{V}^{\mathrm{e}}$ siecle. sur parchemin, avec lettres ornées, in-4" de $125 \mathrm{ft}$. lirlieres antioneles. JJ I.

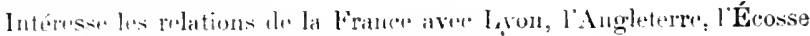

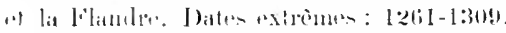

1440. - Recueil de titres relatifs anx relations de la lirance avec la 
Lorraine: ms. de la tin du XVIe siecle. forme par Thierry Alix. sur papier. contenant des textes de 1311 à 1584 . in-fülio de 211 et

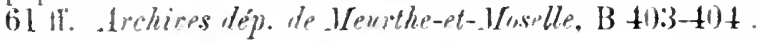

France.-Grande an nonerio.

141. - Pebs. : Bulle- et documents concernant la gramle aumỏnerie de France et le chapitre de Saint-Denis. publ. par A. Tardif l:241853. Pari-. Impr. impériale. [85.) : ? vol. in-4" de [15-] xri-313] et ri-:240 p.

Franche-Comté. - Comté.

1442. - Cartulaire de la comté de Bourgoune: ms. des XIII'-AIVe siecles. sur parchemin. in-4" de $296 \mathrm{ft}^{\circ}$. Biblinth. He la rille de Dijon. ms. 7901 .

1443. - Cartulaire des comtes de Bourzogne, ms. rédigé en 13181:321. sur papier. contenant 513 actes de 1166 à 13221 transcritssans ordre. in-folio de v-102 ti. Arhires d'p. d! $D, \ldots, s, \mathrm{~B} \mathrm{I}$.

Copie dn précédent: ms. sur papier. in-folio de vin-127 ti. Arehiess dep. dn Dmils, B 2 .

Cupie lu précédent : ms. du XVIII siècle. sur papier. intlolio de 5.j) tf. Biblinth. nutionule. coll. Morean. vol. 87i).

Antre copie du XVIII" sierle sur papier. in-4" le itt th. Biblinth. de la rille de Besumroul. coll. Droz. ms. 9.

Axic. : Inventaire sommair des archives départemenlales du Douk : : Chambre des Comptes. I 1883 . pp. 1-i.

Prbi. : Cartulaire des comtes de Bourogone [Dmoinents inédits velatifs is llistrive de lit Frauch-Comte, publ. parl'Academie de Besanron. VIIl. sous prese?.

1444. - Cartulair des fief- de la comté de Bourgogne: no du Xre sipcle [ 144$]$. sur papier. contenant des actes de 1169 a 1417 . in-4 de 88 if. Lrelices dép. de la rite-d Or. B 10440).

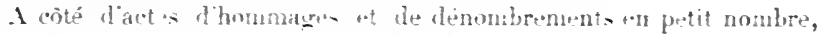

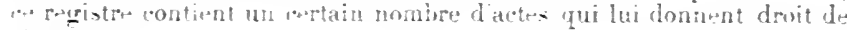
ait. in. i.

Franche-Comté. - Salines.

144.). - Cartulaire des salines ou du comte Jean de Ciralon: ms, du XIII siècle. avec alditions postérieures du XIT"e el suivi d'une table morlerne. sur parchemin. in-4" de vnr-112 1t. 'Biblioth. Ho In rille

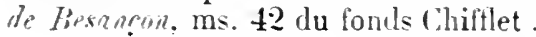

Contient 110 charte- dos année 1184 a 1203.

Copie Ilu précédent: ms. dı XVIII siècle. sur papier, in-1" de 310 if. Biblioth. Ie In rille de Besunenn. fonds de l'ancienne Académie. nus. 47 . 
Autre copie morlerne du mène: ms. in-t" de 242 19. Arrhines dép. dir Domls. $13205: 3^{\text {hin }}$.

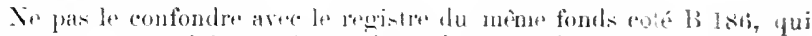

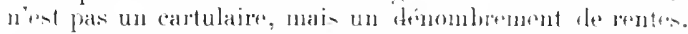

Anat. : Inventaire sonmaire des archives departementales du Doubs, série 13, t. I11, pp. :37.)-377.

Franciscains. - Vuy. FRikes misiurs.

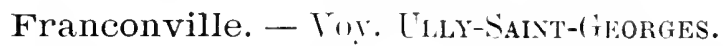

Frasnes-lès-Gosselies. - J'riemr (dior. de Namur).

146. - Cartulaire des prieurés cle lirusnes et Basse-Wawre: ms. du XVI" siecle, sur papier, contenant les artes de 1140 a $\left.14^{\circ}\right)^{\circ}$, in- $4^{\prime \prime}$

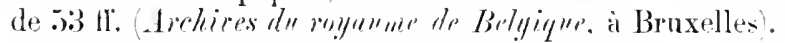

Fraulautern. - Abbayr (lloc. do Treves).

147. - Prbi.. : Die Anfinire des Klosters Fraulautem hei Sarlouis,

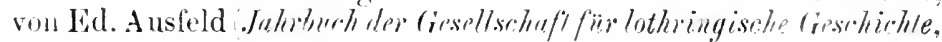
III. 1900, pp. I-60).

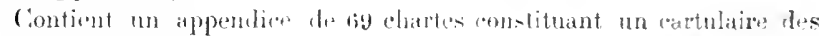
années 11:1-12919.

Freistrof. - Ibbaye lioc. dr Net\%).

148. - Cartulaire des dames dr Frejolorf. écrit en 13:38. avec amlitions jusqu'en $1: 397$; ms. sur parchemin. in-folio de $137 \mathrm{ll}$. Biblinth. Cheltemhan, n" 1:320).

Frères de la Gharité Notre-Dame. - Voy. ButsuladiMONT of hONJEUX.

Frères Mineurs. - Order roligrixux.

1449. - Recuril des privileges des Frires Mineurs d. l'Ob-ervance ; ms. llu XVle siecle. sur papier, contenant des titres de 1439 à 1555 ,

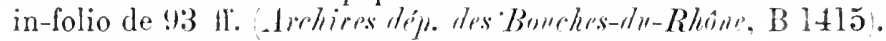

1450. - Autre recueil; ms. du XVle siecle [1.504]. sur parchemin,

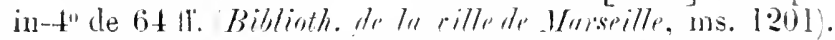

14h̆1. - Bullaire des Frères Mineurs : ms. du XVe siècle. sur parche-

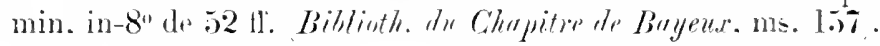

1452. - Autre bullaire: ms. du XV'siecle. str parchemin. in-4" de xI-145 11. (Biblieth. de le rille de Suint-Bripue. ms. 9.

1453. - P’ubl. : Bullarimu Franciscanum. Romanorum pontificum constitutiones, episiolas ac diplomata conlinens, rrilus ordinibus Minorum. Clarissarum et Poenitentium a seraphico patriarcha sancto Franciseo inslitutis concessa, a .J. Hyac. Sliaralea. Romar, 17591780 , in vol. in-lolio. 
Fresnoy-la-Montagne. - Seigneurif ten Lorratir.

1454. - Cartulaire de la signenrie de Franoy-lir-Uontagne: ms. dressé en 17.5-1746 par Fr. W. de Te-ch. seigneur du lieu, sur

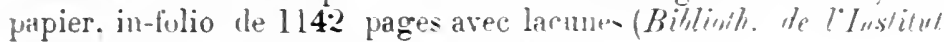
arehroblogique d" Lerrulburmy. à Arlon.

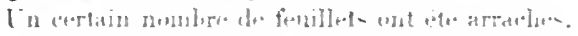

Axul. : Le cartulaire Troch de Frenoy-lis-Nontagne 14la-1746', par Jules Vanméu Arlon. Brüch. 1905: in-s" de 57 p. Extrait

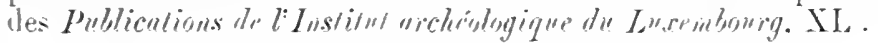

Friardel. - Preure de saint-Cyr dioc. de Lisieux).

1455. - Cartulaire du prieuré de Friardel: ms. dn XIVe siècle. sur parchemin. incomplet de la fin avec table anx ff. $47-49$. arec une

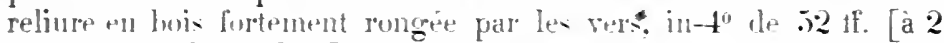

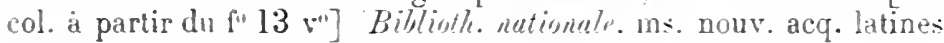
lit..

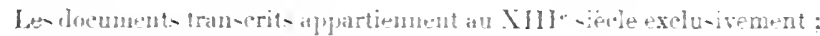

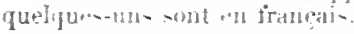

Froimont. - Abbres dive lle liaturais).

1456. - Grand cartulaire de l'abbay de Froimont : orig. perdu.

Extrait du precident [qui comptait $306 \mathrm{f1}$. environ] : ms. des

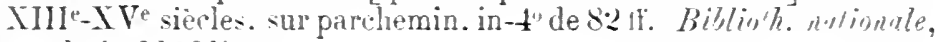
ms. latin llnoll.

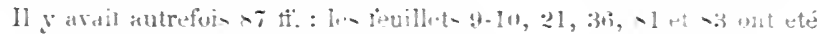

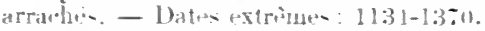

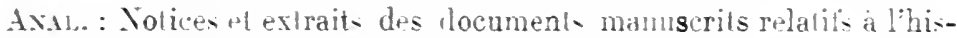
toire de Picardie. par H. Cocheri.. Il. pp. 304-337.

Extraits par Dom (irenier Biblinth. mfinule. coll. Yurean. vol. 48. f" 119, - par Duchesne 'Itom, coll. Duchesne. vol. IT. pp. $277-289$

Extrait du meme. pour (iaignieres: ms. du XVIJe siècle. contenant les documents a partir le 1136, in-folio sur papier Biblinth. nutionil'p. ms. latin 5471, pateses 191-371.

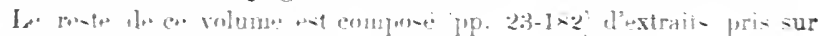
les ariginaux oux-hisinus.

1457. - Cartulaire du XVIII siecle [1733]. sur papier. contenant des titres a partir le 1134. en 3 vol. in-4" de 455.576 et $420 \mathrm{ff}$.

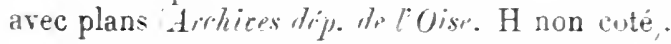

Fronsac. - Printre dive. de Bordeatux,

1458. - Cartulaire du prieuré de Sainte-fenevieve de Fronsac: ms.

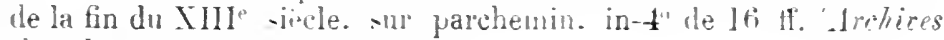

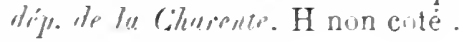


Publ. : Cartulaire dı pripuré de Sainte-(ienevieve de Fronsac, par Tallet et J. de La Martiniere Arrhives historiques de la Gironde. XXXYIII, 19103, p. 1-35.

Fructuare. - Abare de Saint-Bẻnigne (dioc. de Turin).

14.3!). - Carluline de l'ablaye de Fructuare : orig. perdu.

Existail an XVII" siecle: Guilenon, dans son Histoire gringlogigu

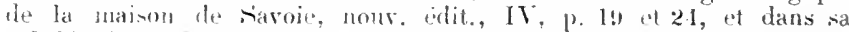

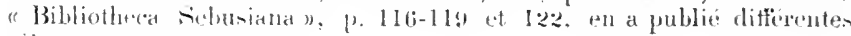
pièces.

Fumay. - Voy. Risix.

Furnes. - Abbay dr Saint-Ninolits (dioc. d'Ypres).

14601. - Cartulaire de labbaye de Saint-Nicolas de Finrnes: ms. du $\mathrm{Xl}$ "siecle, sur parchemin. contenant des titres dr 1124 à 1408 , in-folio de $241 \mathrm{tl}$. Archires de la Flundre scridentale, a Bruges).

Pund, : Chronicon et ratulurium ahbatia sancti Nicolai Furnensis, pdid. F. Y Yan de Pulle] et C. C[arton]. Bruges. VindlecasteeleWerhronck. 184!): in-t" de xrm-268-12 p. [Publication de la Swriété d'émnlation de Bruges.]

Furnes. - lillr.

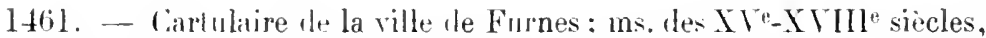
sur pipier. contenint des actes des anmées 1240-10̆83, in-4" de 528

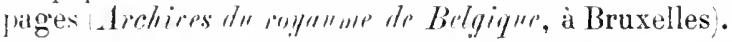

14(i2. - Cartulaire dit "Privilegieboek A » : ms. des XVI"-XVII siècles. sur papier. contenant des acter de 11 z6 a 1617 , in-lolio de

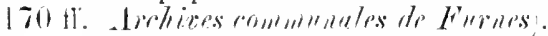

1463. - Autre dit "l’rivilegiehonck B »: ms. du X VII" siècle [1694], sur papier. contenant des actes de 1269 it $\$ 5 \%$. in-folio de 188 If.

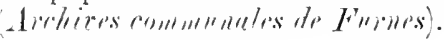

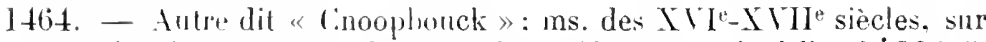
parchemin, contenant des actes de 1240 i 160:3. in-folio de $176 \mathrm{lt}$. Arriegs communales de Furues.

146.). - Attre dit "Roorlenhouck»; ms. des XVIe-XVIIe siècles, sur parchemin. contenant des actes te 1176 a 161 . in-folio de 236 11. Arthices rommumeles do Furuss.

1466. - Autre dit "Wiltebonck»: ms. des XVI"-XVIII siècles, sur papier. contenant des actes de 1586 it 1781. in-folio de 378 tif. Aichices communules de Furues).

Gaesbeek. - Seigneurie en lirabant.

14tiz. - Cartulaire te lit seignenrie de Gaesbetk: ms. dn XV'e siècle, 
de différentes mains, sur papier, in-4". de 20.5 ff. $11 \mathrm{chires}$ grumples dn Rrummume. is Bruxelles.

Dates textrèmen: : 1281-139s.

Gaillac. - Abbaye de Saint-Michel (dive. d'Albi)

1468. - Recueil de titres relatils is l'abbaye de Saint-Michel de Gaillac: $m s$ de 1669 , contenant des pieces des anuées $97 \cdot 2$ i 1537 . in-fulio Bibliofl, untionule. coll. Doal, rol. Ilti, ff. 266-406.

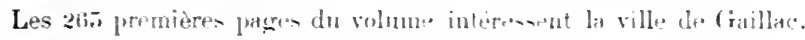

Gamaches. - Église collég. Notre-Dane (dioc. d'Aniens). 1469. - Cartulaire de la cullégiale de (ramaches [-ur parchemin]; orig. perdu.

Copie du précédent : ms..lu XVIII siecle [17:28]. smu papier, conte-

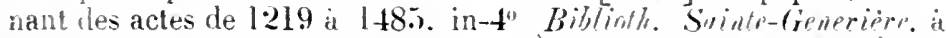
Paris. ms. 18.00. pp. I55-:345 .

Axus: Notices et extraits des documents nanuscrits relatifs a l'histoire de la l'icardie. par H. Cocheri.. II, n' 16.5.

Copie dı mème cartulaire: ms. du XIX siècle. par R. de Belle-

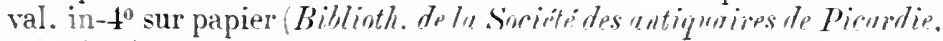
it tmiens).

Gand. - Abbaye de Baudeloo.

1470. - Cartulaire de labbave de Baurlejoo is liand: ns. du XVI

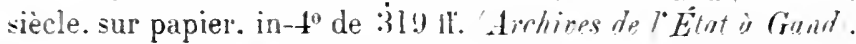

1471. - Autre du XVI siècle [1544]. sur papier, in-40 de $368 \mathrm{ft}$. Arrbices de l'Etat ì Gand.

1472. - tutre du $\mathrm{NVI}^{\mathrm{e}}$ siècle. sur papier, in-folio de $2 \cdot 27 \mathrm{tr}$. dochives de l'Étut à fruml.

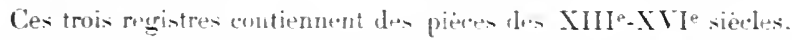

1473. - Autre du XVIIe siècle, sur papier. in-folio de 136 tr. Arrhires de Fitut ì Frudt.

Dater extrimes : $1394-16011)$.

Gand. - Abbare le saint-Baron.

1474. - Cartulaire de l'abbaye de Saint-Barun le (iand: ms. des XII $-\mathrm{XIV}^{\mathrm{e}}$ siecles. sur parcliemin, cuntenant des actes de 819 í

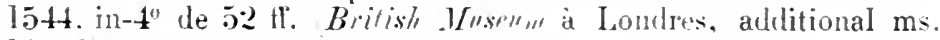
$169 \div 2$.

Axar : Comples-rendus de la Commission ioyalo d'hisoire Bruxelles', 2 serie. XII, I859, p. 26i-31.

La partie la plus ancienne du voinne compremi les fí. 8 a 36 , la partie qui précède el la partie qui suit sont lus chacune à un autre main. 
1475. - Grant cartulaire rle Saint-Baron; mis des XIVe-XYe siècles,

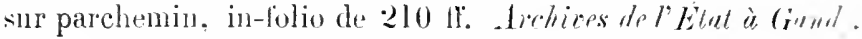

1476. - Autre cartulaire: ms. de la tin tu $\mathrm{XV}^{\mathrm{e}}$ siècle avec: adhlitions postérieures. sur papier. in-folio le $: 38: 3$ p. Arekires is l' Etat ì

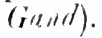

1477. - Autre cartulaire: ms. du XVe siècle, sur parchemin, in-lolio

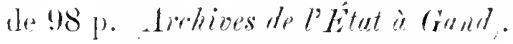

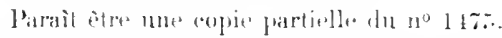

1478. - Autre eartulaire [framents] : ms. les $\mathrm{XIV}-\mathrm{X}$ Ve sireles. sur

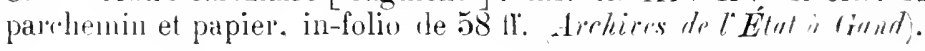

1479. - Antre cartulaire [frament]: ms. du XV"iecle. sur papier,

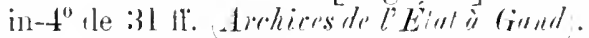

1480. - Antre cartulaire: ms. du XVI" sitele. sur papies, int-lolio de

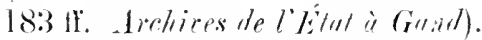

Ax.n. : Histoire de l'albaye de Saint-Bavon. par A. Van Lokeren. (iand. Hebluelyck. 185.): in-4" de xr-25i-174 p. el pl.

1481. - P'ls1.. : Cartulaire de Saint-Bavon. par C. Ih. Serrure. Gand. Annoot-Brapckman. [1830i]. in-4" de 280 p.

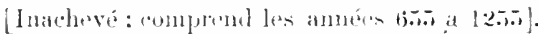

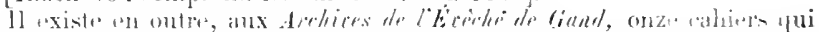

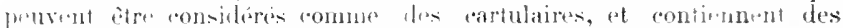

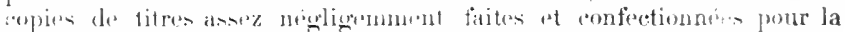

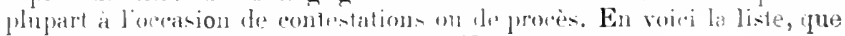

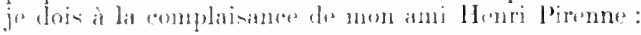

148:. - Recuril in- $4^{0}$. sur papirr ilates "xlrèmes: 1130-1500):

1483. - Recueil in- $t^{0}$. sur parchemin 1(16.5-(3:3!) :

1484. - Recueil in-folio. sur papier el parchemin '1190-133:34;

148.5. - Recuril in-folio. sur papier el parchemin (12227-145; :

1486. - Recueil in-to s str papier ol parchenin (1319-1396:

1487. - Recueil in-folio de 16 lï.. sur papier 1:3:8-152:3) :

1488. - Recueil in- $4^{0}$. sur papier l:36il-146t;

1489. - Recueil in-4". : $1 u^{\circ}$ papier 1389-1456; ;

1490. - Recueil in-4", sur parchemin 1:38!9-1611);

149]. - Recueil in- $t^{\prime \prime}$, sur papier 14J0-14333;

14!2. - Recueil in-40. sur papier 1:370-1545.

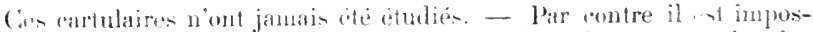

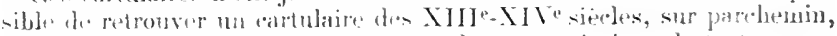

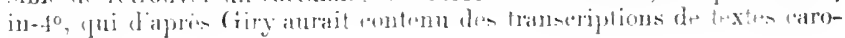
linguints. 
Gand. - Abbaye do Saint-Benoit.

1493. - Cartulaire de labbare de Saint-Benoil de Gand: ms. du

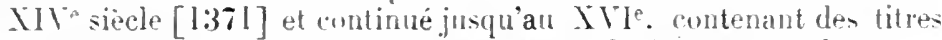

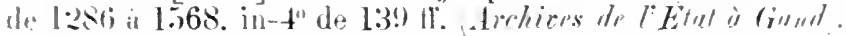

Gand. - Abbaye do caint-Pierre.

14!1. - Cartulaire de lahbare de Saint-Plerre de Gand: ms. du

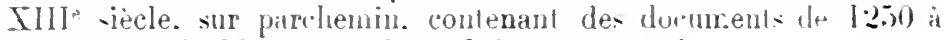

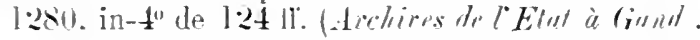

14\%5. - Aulre du Xill sierle. sur papier. contenant des locment:

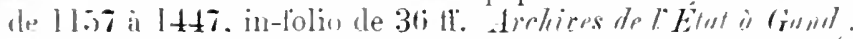

1496. - Antre des XlIJ -X VI" siécles. sur parchenin et papier. cunte-

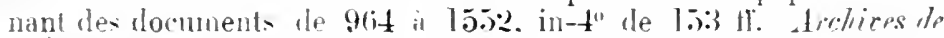
lo lint is Goul.

1497. - Autre des XIII"XIV siècles. sur papier. in-4" de I'20 II.

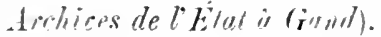

1498. - Autre des $\mathrm{XI}^{\mathrm{e}}-\mathrm{XIII}^{\mathrm{e}}$ siècles. avec addition du $\mathrm{XVI}^{\mathrm{e}}$, et comprenant des notices et des transcriptions, sur parchenin el papier,

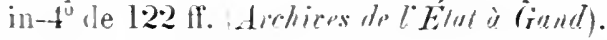

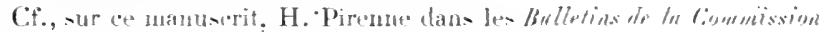

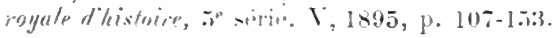

P'BL. : Liber traditionnm sancti Petri Blandiniensis: Lirre des donalions faites à l'abhave de St-Pierre de Gand depuis ses origines jusquau XI siècle. avec des additions jusqu en 1273 , par Arnold Faren. Gand, impr. Mever-Yan Loo, 1906: in- $8^{\circ}$ de xw-311 p. et 2 pl. [Cartulaire de la ville de Gand : 2e série. Chartes et rlocuments. t. I.]

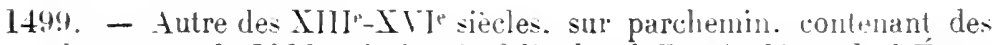
documents de $11 \mathrm{IS}$ is 1484 . in-folio de $9 \mathrm{Lff}$. Arhires do létut is (indid).

1500. - Autre du XVe sièle sur parchenin. contenant des documents

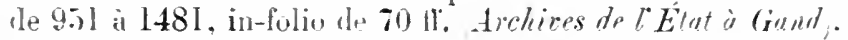

1.701. - tutre du XV siecle [1 479]. sur papier. contenant des documents de 116.3 a l47.). infolio de $18 \mathrm{ff}$. Archices de P Étnt is (iunt).

$150 \%$. - tutre du $\mathrm{XV}^{-}$siectr. stu parchenin. contenant des docments

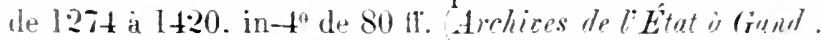

150:3. - Autre du $\mathrm{SVI}^{\mathrm{e}}$ siècle, sur papier. contenant des dor uments de 1046 a 1450 . en 2 vol. in-t" de $1: 38$ et $251 \mathrm{fr}$. Archices de TEtut is (ixall.

1504. - tutre du XI $\mathrm{IJ}^{\mathrm{e}}$-iecle. sur parchemin, contenant des docu-

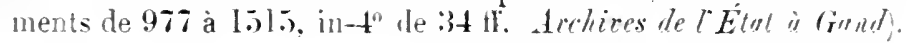


1505. - Autre du XVle sièche. sur parchemin. contenant de documents de 1104 it 15:36, in-8" de 193 ff. (Archices de l'Etal à (rand).

1506. - Autre du XVe siècle. sur parchemin, contenant des documents de 1389 à 1414 , écrits de diflérentes inains, in- $t^{0}$ de $183 \mathrm{fl}$. (Archives de l'Etat is Gund.

1507. - Autre du XVI ${ }^{\mathrm{e}}$ siècle, sur papier, contenant des documents de 858 a 1416 , écrits de lifférentes mains, in-folio de 144 fi". (Archives de l'Etut à fioud.

1508. - Antre dn XVle siècle. sur parchemin. contenant des documents de 1190 à 1544, in-folio de $133 \mathrm{fr}$. (Archives de l'Etat ì (iand).

1509. - Autre des XVIe-XVII siècles, sur parchemin, contenant des docments de $1176 \mathrm{j}$ i 1622.2 . in $-4^{\circ}$ de $36^{\circ} \mathrm{ff}$. Archives de l'litut is Gand.

1510. - Autre des $\mathrm{XVI}^{\mathrm{e}}-\mathrm{XVII}^{\mathrm{e}}$ siècles, sur papier. contenant des documents de $1: 396$ is $167 \%$. in-4" de 410 il. Archives de listut ì (inul).

1511. - Autre du XVIJ siècle, sur papier, contenant des documents de 800 it 14ti5. infolio de 176 1r. Archices de litut is Gumbl.

1512. - Antre du XVIII siècle. sur papier, contenant des docunents de 1118 i 1576. in-folio de $134 \mathrm{fr}$. (Archices de l'Etat à Gund).

Copie partielle du précédent, sur papier, in-folio de $60 \mathrm{ti}$. Archices de l' litut is (itud.

Axal : Notice sur le dépòt des archives de la Flandre orientale, par $J$. de Saint-Genois, p. 32-33 et 50-53.

1513. - Pebl. : Chartes et documents de labbaye de Saint-l'ierre au Mont-Blandin is Giand. par A. Vin Lokeren. Gaul, Hoste. I869: $\because 2$ vol. in $4^{\circ}$.

Le troiniène volume qu devait terminer la publication na jamais paru.

1514. - Recueil des titres relatils aux possessions de labbaye de SaintPierre de Gand en Angleterre: nis. des XIVe-XVe siècles, sur papier et parchemin. de plusieur's mains, contenant des textes à partir de l'année 918. in-40 le 346 pages Bibliotlièque de l' Unicersité de Gand. ms. 536 .

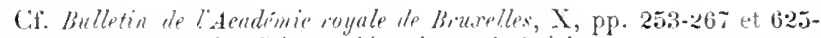

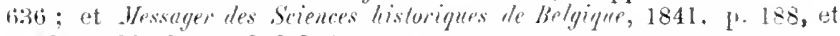
$1 \times 12$, p. $238-261$ et $309-326$.

Gand. - Béguinage de Sainte-Élisabeth.

1515. - Pubs. : Ciurtulaire clu léguinage de Sainte-Élisabeth de Gand. par le baron J. Béthune. Bruges, De Zuttere, 1883 : in-4 $4^{0}$ de $334 \mathrm{p}$. 
[Société d'émulation ponr l'ende de lhivioire et des antiquités de la Flandre.]

Documents des XIIIP+XVIII" sièdes.

Gand. - Collégiale de Sainte-Pharaïlde.

1516. - Cartulaire de la collégiale de Sainte-Pharaïle à Gand: ms.

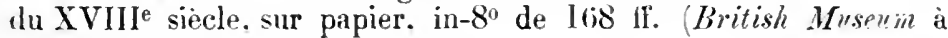
Londres, additional ms. 16954 .

Dates extrêmes: 1073-1709. - Le cartulaire proprenent lit s'arrête au fo 131 .

15I7. - Recueil de titres relatifs au chapitre de Sainte-Pharälde de Gand; ms. du XVIII ${ }^{e}$ siècle. de la main de J. B. de Castillon, prévòt de cette église. sur papier. contenant 16 chartes de II90 à 1412 , in- $4^{\circ}$ (Biblioth. del Unirersité de Gund, ms. ăfit. pages 9l à 133).

15l8. - Autre cartulatire-inventaire; ms. du XVIlI siècle, sur papier, contenant la transeription a lactes du XIIe au $\mathrm{XVIl}^{\mathrm{e}}$ siècle. in- $8^{\circ}$ de 330 pages (Biblioth. de l Unicersité de Gurd, ms. 572).

1519. - Autre cartulaire moderne, sur papier. contenant des transcriptions d'actes à partir de 1235. in-folio de:264 pages (Biblioth. de l'Université de Gund, ms. 573).

Gand. - Couvent de la Byloke.

1520. - Cartulaire du couvent de lis Brloke ì Gand: ms. du XVII siècle [1637]. sur papier, contenant des actes de 1228 à 1595 . in-4 ${ }^{\circ}$ (Archices des lespiers de (iund).

Tous les lextes français ou latins y sont trarluits en flamand.

Gand. - Courent des Augustins.

1521. - Cartulaire de Angustins de Ganıl ; ms. du XVIIIe siècle. sur papier, contenant des actes de 1374 i 1663 . in-folio de 263 tit. (Archices de TEtat is (reud).

Gand. - Couvent des Riches-Claires ou Lrbanistes.

1522. - Cartulaire du couvent des Riches-l laires de Gand: ms. du $\mathrm{XVI}^{\mathrm{e}}$ siècle, sur parchemin. contenant des actes de 1232 à 1 706, in$4^{\circ}$ de $377 \mathrm{ff}$. (Archices de l État à Gind).

Gand. - Couvent du Nouveau-Bois.

1523. - Cartulaire du couvent du Nonveau-Bois de Gand: ms. du $\mathrm{XVI}{ }^{\mathrm{e}}$ siècle, sur papier, contenant des titres de 1219 à 1430 . in-4 $4^{\circ}$ de $27 \mathrm{ff}$. (Archives de l'Etut ù frond.

1524. - Autre cartulaire du $\mathrm{XVI}^{\mathrm{e}}$ siècle. sur papier. contentant des titres de 1279 à 1507 . in- $4^{0}$ de 72 If. Archices de l' Étut à (Ǵtud.

Gand. - Évéché. - Voy. (Gàn (Abbaye de Saint-Bavun de). 
Gand. - Hospice Wenemarr.

1525. - Cintulaire de 1\%rospice Wenemier it Gand; ms. du XIV sièch. aver adlitions pustérieures, sur parchemin. in-4" de 5 ill.

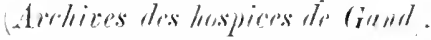

Dates extrênem: 1:3:3-15:1.

Copie du précédent. récutée en 15\%, sur papier Arrliress des

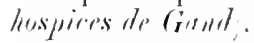

Gand. - Ville.

15:26. - Recueil des privilemes de la ville de Grant; ms. du XIII siecle. sur pardemin, contenant des documents de 1173 it 12:37, in-

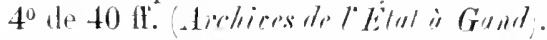

15:27. - Fragment d’un cartulaire de la ville de Gand: ms. du XIVe

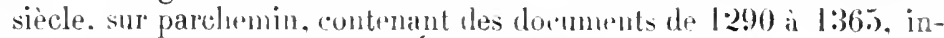

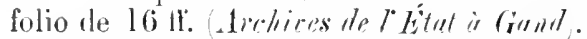

1528. - Cartuliure intitulé "Cores pour lis ville de Gand》: ms. Ilu XIV siècle, érrit par diflérentes nains. sur parchemin. lontenant

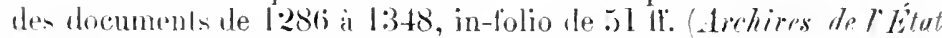
à (imind.

15:9. - Recupil des privilegetes the la ville de (rand; ms. du XV'e siècle, sur parchenin, conlenint des ducuments de 1173 a 1293 , in-40 de 46 til. (Arehiress de Fitul is (iond).

1.330. - Antre recueil du X $\mathrm{T}^{\circ}$ sièche, sur parchemin, contenant des

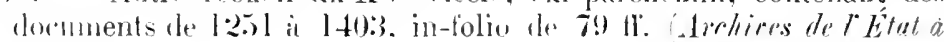
(rand).

1.531. - Recueil des privilèges octroyés ou contimés à la ville de Gand par (Gui de l)ampierre: mis. du XV'e siècle, sur parchemin. in-folio de $46 \mathrm{ff}$. (British M/"s'm. Harleian ms. 32999, if. 1-46).

1532. - Recueil tes privilènes de la ville le Gand: mis. du $\mathrm{XV}^{\mathrm{e}}$ siècle, sur parchemin, contenant des docmments de 1296 is 1429 ,

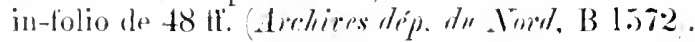

1533. - Cartulaire de la ville de Gaml : ms. du XIVe siècle, sur parchemin. contenant des documents de 1173 is 1294, in-4" de $91 \mathrm{ft}$. (Archires rommumestes di (imud).

15:34. - Autre cimtulaire ou « Wilteboek»: ms. du XVe siècle, sur parchenin, contenant des documents de 1173 a a 1440 , in $-4^{0}$ de $2 \cdot 29 \mathrm{ft}^{\circ}$. (Archives crimmunules de (iond).

Cartulaire semblable an précédent (à 7 chartes près) ; ms. du XV" siècle, sur parchemin, appelé "Cartulaire Van Hulthem ", in-4" de 214 II. (Biblioth. royale de Bruxelles, ms. 16700).

Aval. : Bibliotheca Hulthemiana. VI, $n^{0} 567$. 
1535. - Autre cirtulaire ou "Gentsch Charterboeck»: ms. du $\mathrm{AV}^{\mathrm{e}}$ siecte, sur parchemin. contenant des locuments de ll!19 it l:3:92. in-4" de $48 \mathrm{tl}$. (Arehices communules de Giunt.

1536. - Autre cartulaire, dit «Ghehwen boeck» ou « Rooden boeck»; mis, des $\mathrm{XIV}^{\circ}-\mathrm{NVI}^{\mathrm{e}}$ siècles. sur parchemin. contenant des document de 1191 a 15:39. in-lolio de 265 tf. (Aichices crmmunales de Gund).

1.337. - Autre cartulaire ou «Groene boeck»: ms. des XIVe-XV sièrles, sur parchemin. contenant des documents tle 12.5l a 1470 , in-4" de 27 tf. Archices communales de liend.

1538. - Autre cartnlaire dit «Pememan »: ms. du $\mathrm{XVl}^{\mathrm{e}}$ siècle, sur papier. contenant des documents de 1168 a 1546 , in- $4^{0}$ de vu- 356 tf. Archices communales de Gund.

1539. - Autre cartulaire ou « Eersten witten boeck»: ms. du XVI siècle. sur parchemin. in-folio de 25.5 ff. Archires commumules de Guid $)$.

1540. - Autre cartulaire on «Ouden gheluwen boeck»: nus. du SVIe siecle. sur parchemin. contenant des documents de 1251 a 1541 . in-folio de $315 \mathrm{ff}$. (Archices commumales de Guid,

1.541. - Autre cartulaire on «Ouden rooden boeck": ms. du XVI siècle. sur parchemin, contenant des docmments de 1456 a 1550 in-folio de $423 \mathrm{HI}$. Archires comimunales de Gand,

1542. - Autre cartularre ou " Nieuwen gheluwen boeck»; ms. du XVIe siècle, sur parchemin. contenant des documents de 12 il à 1550. in-folio de 4.53 If. Archixes cominnales de Gand,

1543. - Autre cartulaire on «Tancten hoeck»: ms. du $\mathrm{XVI}^{\mathrm{e}}$ siècle. sur parchemin. contenant des documents de 1168 a 1505 , in-folio de 498 11. Archices crimmunales de Gand).

1544. - Autre cartulaire ou «Vijften zwarten boeck»: ms. du XVI siècle, sur parchemin. contenant des documents de 1353 à 1564 , in-folio de 420 fi. (Arcaices crmmunules de Gand).

1545. - Autre cartnlaire ou "Nieuwen rooden boeck»; ms. du XYle siècle. sur parchennin. contenant les documents de 1183 a 15.56 , in-folio de 4:35 1f. Archices commmanles de Gand.

1546. - Autre cartulaire. dit « Register van octroien, brieven. statuten ende ordonnantien $»:$ ms. lu $X \mathrm{VI}^{\mathrm{e}}$ siècle, sur parchemin. contenant des clocuments de 967 à 1568 , in-lolio de $408 \mathrm{ff}$. Archices communules de cindl.

154\%. - Autre cartulaire ou «Eersten swarten boeck», alias Vranw Marie »: ms. des $\mathrm{XV}^{\mathrm{e}}-\mathrm{XVI}^{\mathrm{e}}$ siecles. sur parchemin. contenant de: documents de 1129 à 1539 , in-folio de vi-296 ff. Archices comm!nnales de Gend,. 
1548. - Antre cartulaire, dit «Diversche privilegiën 》, ms. des XV $V_{-}$ XVIe siècles, sur parchemin, contenant des ducuments de 1255 i

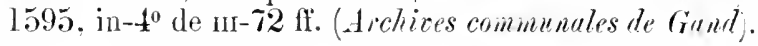

1549. - Antre cartulaire. dit "Verzaemelinghe van oude wetten. cueren ende privilegiën »: ms. des $\mathrm{XVI}^{\mathrm{e}}-\mathrm{XVIIJ}{ }^{\mathrm{e}}$ siècles, contenant des documents de ligl a 1549 , in- $4^{0}$ de 320 fl. (Archives communales de (itud).

Las mènes archives possèdeut encore 7 registres intitulés: Ondonuntien politique, qui renfernent des chartes de privilèges des XIIle. XIVe siecles. - Sur toute cette série de cartulaires, voir : Inventaire des archives de la ville de Gand, Catalogue méthodique général, par Victor Van der Haeghen (Gand, 1896, in- $8^{\circ}$ ). pp. 15 et ss., où ils sont d'ailleurs classés dans un ordre différent. - l.e même volume (pp. 115 et ss.) indique des cartulaires pour les corporations de certains métiers bouchers, charrons, merciers, bateliers, charpentiers, menuisiers, tanneurs), où sont transcrits leurs privilègres.

1550. - Cartulaire de la ville de Gand; $\mathrm{ms}$. des $\mathrm{XV}^{\mathrm{e}}-\mathrm{XVI} \mathrm{e}^{\mathrm{e}}$ siècles, sur papier, in-t" de $96 \mathrm{tl}$. (Biblioth. nalionule de Puris, ms. néerlandais 5).

Cf. Gachard, ha Bibliohlièue nationale ì Paris (1875), p. 468.

1501. - Publ. : Petit cartulaire de Gand, par Fr. De Potter. Gand, Lelidert et Sillert, 1886 ; in-8 de $411 \mathrm{p}$.

1552. - Prbl. : Second cartulaire de Gand, par Fr. De Potter. Gand, Leliaert et Siffert. 1887 ; in-8 $8^{\circ}$ le 418 p.

Gap. - Évèché.

155:3. - Recueil de titres relatifs à l'évèché de Gup; ms. du XIVe siècle. sur parchemin, contenant des titres de 1247 à 1309 , in-folio de $42 \mathrm{fr}$. Archives dép. des Bouches-du-Rhöne, B 1:373).

Gap. - Ville.

1554. - Cartulaire municipal on « livre rouge»; ms. du X̌Te siècle [1407]. sur parchemin, avec additions jusqu" au XVIII ${ }^{\mathrm{e}}$, avec reliure en ais de bois reconverts de cuir, contenant des actes de 1178 a 1774 , in-4" de vill-l $66 \mathrm{ff}$. (Archices muncipales de Gup, At 1).

Axal. : Inventaire sommaire des archives municipales de la ville de Gap [sous presse], pp. 1-19.

1555. - 《Copie tangentes civitatem Vapinci »; ms. du XVe siècle, sur papier, contenant des titres de 1184 à 1432 , in-4 $4^{0}$ de $72 \mathrm{ff}$. (Archives dép. de l'Isère, B 375:3).

\section{Gascogne.}

1556. - « Litterae, chartae et tractatus Vasconiae et Aquitaniae tempore Henrici I, Edwardi I et II, Henrici III »; ms. du XIVe siècle, sur parchemin, avec alditions de papier, contenant 299 pièces des 
année 1027 a 1325. in-40 British Museum, ms. Cotton, Julim le l. ff. $1-72$.

Une copie assez ineorreete de ces docunents so trouve it la Biblioth. uationule, coll. Bréquirrny. - Cf. Bibliotheque de l'École des Cilinites, XVI (18.55), p. 111, et LII (1890), p. 299.

Geaune. - Abbaye (dioc. d'Aire).

1557. - Cartulaire ou « livre ronge » de Geaune : origr. perdu.

Ine mention de ce volume se trouve dans le "Glanage " de larcher (Biblioth. de la rille de Turbes, vol. XXII, p. I16): mais déjat le eartulaire nexistait plus, car l'extrait fait á cette ipoque (17.il) avait été emprunté à une copie.

Gellone. - Abbaye (dioc. de Lodève).

1558. - Cartulaire de Gellone ; ms. des XIIe-XIlI siècles. sur parchemin, in-folio de $215 \mathrm{ff}$. Archires dép. de l'Hérault. H non coté).

Pubc. : Carlulaires des abbayes d'Aniane et de Gellone: I. Cartulaire de Gellone, par Paul Àlaus, l'abbé Cossan et E. Mernial. Montpellier, Martel. 1898 : in- $4^{0}$ de $\mathrm{rv}-\check{l l}$ p. [Société archéologique de Montpellier.]

Texte seul, comprenant des pièces depuis le IXe siècle jun fü à 1236 . Lintroduction manque, mais la table vient de paraitre (Montpellier, 1905 : in $-4^{\circ}$ de $11+$ p.)

"Les documents 'jui composent la première partie du cartulaire de Gellone ue doivent être acceptés quavec les jilus grandes réserves: les 59 charles yui la romposeul nont pas été copiés sur le- titres origrinaux, brùlés dans un incendie, mais ont été roconstituéc d'apres les souvenirs des moines. ;) (Em. Bonnet, Bibliographie du diocèse do. Montpellier, 190 1 , page 109, note 7 ).

Sur les noms de lieu dans le cartulaire de Gellone. voir un article te Y. H. d'Arbois de Jubainvilie (Rerue cellique, XX. I 94: p. 35\%362 ; et Comptes-rendus de l'Acadénie des Inscriptions et Belles-Lettres, 1899, p. 229-236). - Sur les rapports de Gillone et du Rouergue, voir l"abbé Hermet dans les Jémoires de la siocioté... de l'Arrymn, XVI (1906), pp. 4ny-478.

1559. - Recueil de titres sur l'abbaye de Gellone: ms. fait par Dom Estiennot en 1679 (Biblioth. natiouale, ms. latin 12761. pp. 31\%345 ; ms. laiin 12770, pp. 160-169, 191-192 et 240-248).

Gembloux. - Abbaye dioc. de Liège).

1560. - Recueil de titres sur l'abbaye de Gembloux: ms. du XVIIIe siècle, sur papier. contenant des actes de 961 à 1610. in-folio de 80 pages (Archires rrayales de La Haye, Papiers Gérard. no l1)8”.

1566l. - Autre recueil : ms. du XVIIJ siècle. sur papier. contenant

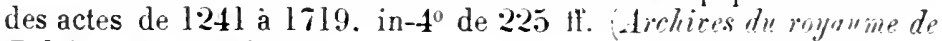
Belgique. à Bruxelles'.

Genève. - Comté.

1562. - Recueil de titres relatifs au comté de Genève : $\mathrm{ms}$. du XVe 
siècle, sur papier, contenant des actes de $126: 3$ à $1: 319$, in $4^{\prime \prime}$ de

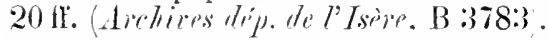

Genève. - Église.

1.563. - Cartulaire de l'égrlise de Genève: orig. perdu.

Copie du précédent, faite au XVII siècle pour (ruichenon avec corrections de sa main. et tahle des chartes à la fin, sur papier, contenant des actes de 1124 au $\mathrm{XVI}^{\mathrm{e}}$ siècle, in- $t^{0}$ (Biblioth. nutionale, ms. latin 1018:2. 1r. 1-148).

Au fo 1, on lit cette note" : Loriginal du mantscrit, qui est propre-

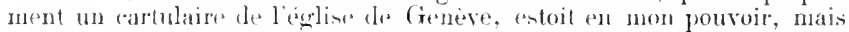
je lay dome a Messiens du Chapitre de Crenève à Annecy, at en ay

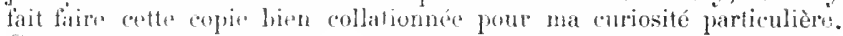
Gigarisex m.

Peri.. : (par fragments) dans Guichenon, Bibliotheca Sebusiana.

Genève. - Ville et diocèse.

1564. - I'ıв.. : Chartes inédites relatives a l'histoire de la ville et du diocèse de Genève et antérieures à l'année 1312. par Ed. Mallet

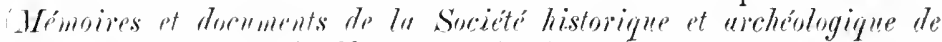
Geneep, XIV, 1862. in- $8^{0}$ de $\mathrm{xx}-.000$ p.).

Dates axtrèmes: : $12216-1311$.

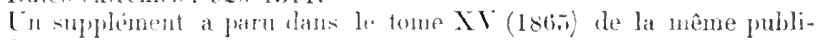
ration.

1565. - P'rz.: Recueil des franchises et lois municipales des principales villes de l'ancien diocèse de (ienève (1:234-1546), par Paul Lullin et Ch. Le Fort (Idtm, XIII, 186:3, in-8" de xxrur-248 pp.).

Genevois-Nemours. - Fanille.

1566. - Cartulaire des lues de Generois-Nemours; ms. du XVII siècle. contenant les transcriptions des privilèrres accordés à celte famille par les dues de Savoie et les rois de France de 1434 a 1615 , sur papier. in-folio Biblioteca del Rr. à l'urin. ms. Patria 155.

Le nus. Patria 167 de la même collection contient une autre transaription clis mênes titres dams un autre ordre.

Foir atumi: Falcinisy.

Gerberoi. - (hapilre (dioc. de Beaurais).

1567. - Cartulaire du Chapitre de Cierberoi : ms. du XIII siècle [ver's 1290]. sur pirchemin, contenant 193 pièces des années 1172 1290 , in-folio de 212 pages; orig. perlu.

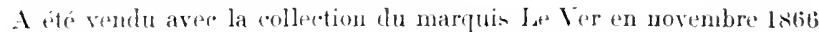
(n ${ }^{0}$ bi du catalogrue oi on trouvera le? detail du contenu du registre, 1'p. 1-1-16). On nien a pu suive la trace depuis cette époque.

Gerbéviller. - Coturent des Carmes (dioc. de Toul). 1568. - Cartulaire des Carmes de Gertériller; ms. du XVII siècle, 


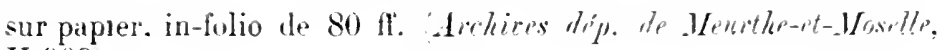
H 909 .

Gerona. - Chapitre cathèlral.

1569. - «Cartularium ecclesie Gerundensis 》. ou Libro de Cislo Magno : ms. du XIII siècle. avec additions postérieures. sur parchemin. in-folio Areflicen del Crebildo de Gerone .

Extraits faits en 16\%) par Dom Estiennot (Bibliwth. mutionsle. ms. latin 1275.5. fo 380$)$.

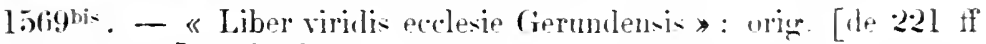
an moins] perilu ? .

Extraits du livre vert du Chapitre de Gérone Biblinth. intimule, coll. Baluze, vol. CV1II. pp. 17.5-204.

Dans lo vol. CXVI de la mème collection Balnze, on trouvera. fï. 12-

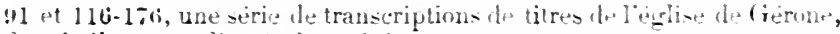
depuis l'an s5o, dapre- les originaux.

PLbL. (fragments) : España sagrada.XIIII.p. :36i-4it: et XIIV, p. 259-322.

Géronsart. - Abbaye de Notre-Dame (lioc. de Namur).

1570. - Cartulaire de $\mathrm{X}$ h. de Géronsart: ms. dır XIIIe siècle. siu parchemin. contenant des actes de 1134 a 128.5 . in-fol. de $68 \mathrm{lt}$. Archures de l'Etut is Nitulr).

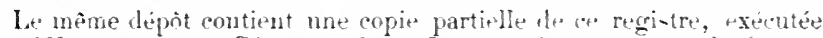
au XVI siècle. - Ct. V. Barbier, Histome In thonasterte de Gréronsart Namur, 1siti, in-1?.

\section{Gévaudan.}

15il. - l'tru. : Cartulaire Gevaudanais: Recueil de chartes et documents intéressant l'ancien Gévaudan. Mende. 1904. in-8" [à suivre].

Publimation sans codre elorunolopique faite ennme annex au

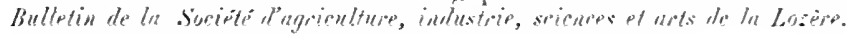

Ghislenghien. - Abbaye (diocèse de Cambrai).

15\%2. - Cartulaire de l'abhave de Ghislen whien : ms. lu XI $\mathrm{V}^{\mathrm{e}}$ siecle. sur parchemin. contenant des documents de 1195 a 1310 . in- $8^{\circ}$ de $12 \mathrm{ff}$. Archices de l'Etat is Mous.

1573. - Autre cartulaire du XVI $\mathrm{XI}^{\mathrm{e}}$ siecle, sur papier. contenant $246^{\circ}$ acles des années $11: 3: 2-1526$. in-folio de 234 17. Amhires do litut th lyous.

Axar. : parr l'abbé L. Baudelet. dans le Bullutin de lo Surirte hishorique et littermive de Tommai. XIV. 1870. pu. l19-181.

Gif. - Village. - Voy. Mora.igis.

Gignac. - Comrent des Piécollets (dioc. de Lodère). 15\%4. - Livre archivial du couvent des Récollets de Gïnnac: ms. 
dressé ver's l670 par le l'. Cambin, in-40 sur papier (Archives municipules de Gignuer).

Cé livre ent un mérnorial où ont été insérées quelques chartes.

Gimont. - Abbaye (dioc. d'Auch).

1575. - Cartulaire de l'abhaye de Gimont ; ms. du XIII siècle, sur parchemin, en 2 vol. in- $4^{\circ}$ de 158 et $135 \mathrm{ff}$., commençant à l'année 1142 Archires dn Grond Sominuire d'Auch, $\left.\mathrm{n}^{\text {ss }} 44-45\right)$.

Extraits faits au XVIIe siècle (Bibloth. nutionale, coll. Duchesne, vol. XX. tol. 282'.

Pcbl. : Cartulaire de l'abbaye de Gimont, par M. l'abbé Clergeac (Archices historiques de la Cruscogne, 2 érie, IX, Paris-Auch, 1905; in-8" de xrin-50 03 p.).

Glandières. - Mblaye de Saint-Martin (dioc. de Metz).

I576. - Cartulaire de labbaye de Glandières; ms. du XIVe siècle, sur parchemin. avectable dés chartes à la fin et additions postérieures, contenant des actes de 819 a 1528 . in- $\mathbf{4}^{\circ}$ de 119 fr. à 2 col. (Bibliath. untirumle, ms. latin 10030.

Quelques chartes du Xili se siècle sont en français.

Glandiers. - Chartreuse (dioc. de Limoges).

157\%. - Cartuline de la (hartreuse de Glandiers (XIII -XVe siècles); orice. periln.

Lxtraits faits au XVII siècle, en partie par le P. Pradillon en 1687. sur papies (Biblioth. nationule, ms. latin 17118, pp. 267-270 et $291-301$ ).

Aux pages 259-26ti du mêne volume, ou tronve des extraits d'un "perit livere des donations ") in $-8^{\circ}$, qui se tronvait dans les archives de la mên Cihartreuse, et probablement different du cartulaire.

Glanfeuil. - Voy. Saint-Maur-sur-Loire.

Goailles. - Abbaye (dioc. de Besançon).

1.578. - Cartnlaire de l'ahlaye de Goailles: ms. du XIVe siècle, arec addilions postérieures jusqriau XVI. sur parchemin, contenant des actes a partir de 1212. in-40 de 68 II. Biblioth. de .1\%. Léon Gunthier, à Marnay.

Appartenait précédemment à feu M. l'abbe Morèt.

Gohory. - Prieuré (dioc. de Chartres).

157!) - Recueil de titres relatifs an prieuré de Gohory, dépt. de l'alhare du Iont-Saint-Michel; ms. du XVII siècle. fait pour Gaignières, sur papier, in-folio (Biblinth. nutionsle. ms. latin $5430^{\circ}$, pages $83-999$.

Documento à partir de l'année $10 \times 1$. 
Gomerfontaine. - Abbare dioc. de Rouen).

1580. - Cartulaire de l'albaye de Gomerfonlaine; vrig. perdu.

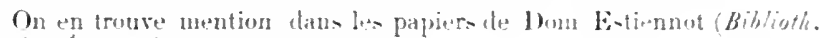
uationalf, usis. latin 127\$1, p. 315).

Goncelin. - Toy Conps.

Gondrecourt. - Préròté.

1581. - Recueil de titres relatifs a la prévòté de Gondrecourt : ms. de la fin du XYle siècle. formé par Thierry Alix. sur papier. contenant des textes de 12299 a I584. in-folio de 380 fí. (Archires dép. de Meurthe-et-Moselle. B 364 .

Voir aussi ro Butruost.

Gonesse. - Hòtel-Dien (dioc. de Paris).

1582. - Ptbi.. : Frarments de l'histoire de Gonesse. principalement tirés des archives hospitalières de cetle commune. par Léopold Delisle (Bibliothique de l'Ecole des Churtes, 4e série. V. p. 11:3-170 et 24i277. et à part : Paris, 1859 : in- $8^{\circ}$ de $15-7 l$ p.

Recueil factice, dailleurs peu important, de docunents des XIII XIVe siecles, analysés on publies.

Gonesse. - Vor. Macblisos.

Gorze. - Alhave (dioc. de Metz).

1583. - Cartulaire de l'abbaye de Gorze: ms. de la fin du XII siècle. sur parchemin. arec reliure de bois. contenant des acies de 7201 a 1173. arec additions du XIII siècle, in- $4^{\circ}$ de I35 ff. à 2 col. $\langle B$ ibligth. It la rille de Metz. ms. 76 :

Ln facsimilé se trouve dan lid publication lld. d'Herbomez men. tionnée ci-dessous.

Copie du precédent : ms. du XVIII siècle, sur papier, in-folio de $97 \mathrm{fr}$. Bithioth. nutionule, ms. latin 5436).

Tabie des chartes contenues dans le mème manuscrit (Biblioth. de lu rille de. Mete. ms. 923. et Bitlioth. nationule. mis. nour. acquas françises 4879 ;.

Pebl. : Cartulaire de l'abbaye de Gurze par trm. d'Herlomez. Paris. Klincksieck, I898-1901. in- $8^{\circ}$ le [ri-] xur-67:3 p. et pl. [Yémoires et Document: publ. par la Société nationale des antiquaire- de France: Mettensia II.]

C. Remarques chronologiques et toporraphiques sur le cartulaire de Gorze. par Paul Marichal. I'aris. Ḱlincksieck. 1902: : in-8" de vi-105 p. et tableaul. [Mémoires et Ilocuments publ. par la Suciété nationale des antiquaires de France: Mettensia III.]

1584. - Cartulaire de l'abbaye de Gorke: ms. llu XVe siècle, sur 
papier, in-folio de 149 11. Biblioth. In Grust-Srminaire do Nancy, mis. 163 .

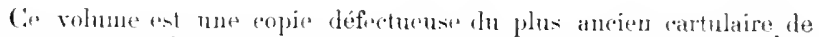

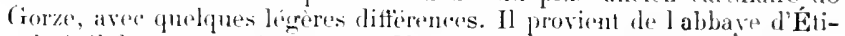

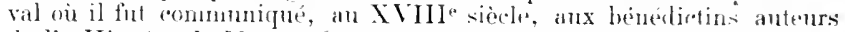

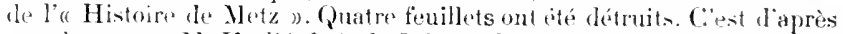
"e volume que .I. H. d'Arbois de Jubainville a édité sés notes intitulées:

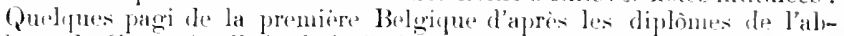

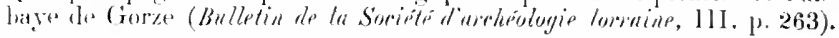

Copie du mème cartulaire de Gorze, avec artditions jusqu'à l'année 14:35; ms. du XVIII" siècle, sur papier, in-to Biblinhth. de lit rille de .1Yeta, ms. 77.

Copie ligurée du précédent. faite an XVIIre siècle. sur papier Biblinth. He l' lustitut. à Paris'.

Gosnay. - Charlreuse du Val Saitt-Esprit (dinc. d’.Mras). 1585. - Cartulaire de la Chrirtreuse de Gosnay : ms. de la fin dlu XVe siecle, arec quelques additions du XVIII", conlenant plusieurs frargments reliés ensemble d'anciens cartulaires. sur parchemin. in-folio de 47. 87 et $116 \mathrm{ft}$. Biblioth. de la rillo de Bothune, mss. 3-5.

Dates extrêneses: : 1319-161\%

1586. - Autre cartulaire: ms. des XIT"-XVII siècles, sur parchemin et papier. contenant des titres de 13328 a 1548. en '2 vol. in-folio de

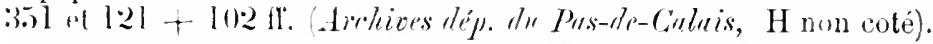

Copie inconplète. collationnés à l'original en 1616, sur parche-

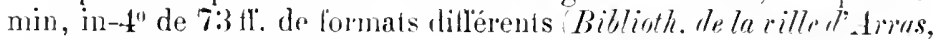
fond Adrielle. ms. 42 .

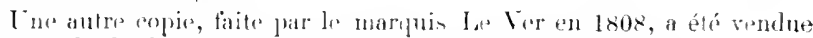

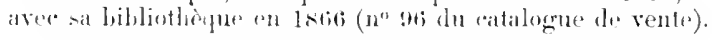

Gouis. - Prieuro de Nolre-Dame (dioc. d'Angers).

1587. - Cartulaire du prienré de Gonis. dépendant de St-tulin Angers: ms. lu XVI" siècle [1.542]. exécuté d'après les oritginaux par frère Jean Buignon. cliantre, sur papier avec lettres initiales dessinées, et arec tahle contemporaine an déluut, contenant des acles en partie non dittés du XI" siècle à l.709. in-folio de 76 if. 'Biblinth. "mtionale, ms. latin .747).

Sir tromvait autrefois dams la coll. Balu\%e.

Gourdon. - Ville.

1588. - Cartulaire de la ville de Gourdon: ms. du XVe siècle. sur parchemin, contenant des documents de 1288 a 1488 , in-4" Lrchives unuicipulss de Gourdon. BB l8).

Gournay-en-Bray. - Errlise collégiale Saint-Hilderert. 1589. - Cartulaire de la colléwriale de Gomrnai : ms. du XIVe siècle 
ovec adclitions pustérieures jusqu'au $\mathrm{XVIl}^{\mathrm{e}}$. sur parchemin. (ontenant des actes depuis 1186 . in-4" 'roprietaire inconnu.

Copie faite sur le précélent, "n 1864. par II. C.h. de Beaurepaire, sur papier, in-folio de $100 \mathrm{ff}$. Awhirestep. do lo Spine-Inféripme. G $942 \%)$.

Gournay-sur-Marne. - Prieuré (dioc. le Paris).

1590. - Cartulaire du prienré X. D. de fournay-sur-Marne : ms. In XII siècle, sur parchemin. in $4^{0}$ le 40 II. Arrlices antionales. LI. 1:397).

Dates extrinte: : 1122-12*3.

Extraits faits par l)uchesne (Biblinth. matimule. coll. Balıze. vol. LV, Hi. 19:3-I 95 et 224-225 ; par D. Anselure Le Michel'Idrm. ms. latin 13817 , If. $401-403$.

1591. - Autre cartulaire de Gournay : ms. du XVIe siècle. sur papier. in- $4^{0}$ de $226 \mathrm{ft}$. Archires mutionales. I.L 1:398.

Dates extrèmes: $1109-1570$.

Gourville. - Prieurẻ. - Voy. Axgoclèse (abbaye de StCybard de).

Graçay. - Baronnie en Berri.

1592. - Cartulaire de la baronnie de Graçay : ms. du XIII siècle. sur parchemin à 2 col.. in-12 de ?) tf.

De ce cartulaire non cite, et détruit en tre-spande partite par lincendie des arehive du Cher en lsio, non- aron retronve 18 ff. tris endom-

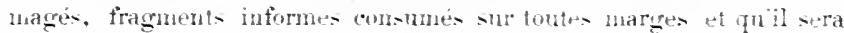
bien difficile de reeon-tituer (Arhicess drp. Iu tiher, E non cotes.

Graindor. - Seigneurie dans la vicomté de Caudubec en Caux.

1593. - Cartulaire lu fief le Graindor: $m$. In XVI siècle. sur papier. in-4" de 38 i p.. contenant des acte- le l:380 i 1533 (Biblinth. de l' listitut, it Paris, ms. 44t).

Grammont. - Abbare de Saint-Adrien (dioc. de Malines).

1594. - Cartulaire de St-Adrien de Granmont : ms. dn XIV sièrle. sur parchemin, contenant des documents de 1181 a 1394 . in-80 de $50 \mathrm{Hif}$. (Archices de l Etul is (Fuml).

Grammont. - Ville.

1595. - Cartulaire de la ville de Granmont: m: du XVII" siècle. sur papier. contenant des titres de 1396 it 1626 . in-fulio de $201 \mathrm{ft}$.

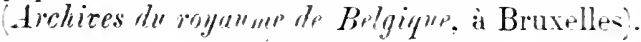

Grand. - Chàtellenio. - Voit Chosect. 
Grand-Bigard. - Abbaye (dioc. de Malines).

1596. - Cartulaire de l'abbaye de Grand-Bigard: ms. des $\mathrm{XVe}$ el XVIII ${ }^{\mathrm{e}}$ siècles, sur papier, contenant des actes de 1133 ì I704, in-4" de 3:2 et $40 \mathrm{Hr}$. (Archires du royaume de Belgique. à Bruxelles).

1597. - Autre cartulaire du XVIII siècle, sur papier, contenant des acles de 11333 à 1487 , in-folio de 206 $\mathrm{fl}$. Arclices turoyaume de Belgique, à Bruxelles).

Granchamp. - Abbaye de Notre-Lame (dioc. de Chartres) 1598. - Curtulaire de l"abbaye de Grandehamp, près sle Houdan; orig. perdu.

Un acte de 1211 a été transerit d'après ce cartulaire en 1686 (Archices nationales, si 4349 ).

Grand-Fayt près de Maroilles.

15.99. - Recueil de titres relatifs is Grand-Fayt: ms. du XVIII siecle, sur papier, contenant des actes de 1169 à 1718 Archices dép. du Norit, G non colé.

Grandmont. - Ordre religieux et abbaye (dioc. de Limoges).

1600. - Cartulaire de l'ablaye de Grandmont; ms. de la fin du XVe siècle, contenant 42 chartes des années 1180-1487. sur parchemin, avec jolie reliure de hois, in-folio de $184 \mathrm{ll}$. avec gnloses marginales (Arrhires dép. de Maine-pt-Laire, $\mathrm{H}$ non roté).

Intéresse non seulement les propriétés de I'ordre en Anjou (Bandouille, La Primandière, atc.), nais encore les prieurés situés dans les riocèses de Cahors, Evreux, L، Mans, Paris, Poitiers, Rouen et Saintes.

1601. - Bullaire de l'ordre de Gramlmont ; ms. du XVIJe siècle, sur papier. in-4" de 239 1f. (Biblioth. An. Gront-Séminaire de Limoges, m.. 8:3).

Recueil de titress allant de 11 in à 1400 , rusté inachevé.

1602. - Recueil des privilèıres dı mème Ordre: ms. dı XVIle siècle [1617]. sur papier, in-8" de $220 \mathrm{fr}$. Biblioth. de le rille d'Angers, ms. 410 .

Grandpré. - Abbaye (dioc. de Liège'.

l603. - Cartulaire de l'abbaye de Grandpré : ms. des XVIIe-XVIII siècles. sur papier. contenant des titres de 1210 a 1764 . en 3 vol. in-folio de l:201 tl. formant, un tolal (.1'chires de l'Etut à Wamur).

Grandpré. - Prieuré de Saint-Médard dioc. de Reims.

1604. - Cartulaire clu prieuré de St-Médard ıle Grandpré, dép' de l'ablaye de Saint-Remi de Reims: ms. des XIIe-XVle siècles, sur parchemin, contenant des titres de 115.) a 1529 . in- $4^{0}$ de $31 \mathrm{ff}$. Archicesden. des Adennes, $\mathrm{H} 5$ ). 
1605. - Extrits de titres relatifs au même prieuré. faits en 1729, sur papier, in-4" de is pages (Biblinth. mationule. mis. nouv. ary $]^{\text {ons }}$ latines 400 ).

Grandselve. - Abbaye (dioc de Toulouse;

1606. - Cartulaire de l'abbaye de Grandselve : ms. dn XII siècle. sur parchemin, in-4" de $226 \mathrm{ff}$. (Biblioth. nationule, ms, latin 11008 .

1607. - Autre du XIle siècle, sur parchemin, in-40 de $26 \mathrm{ff}$. Biblioth. nutionale, ms. latin 11009.

1608. - Autre du XIlle siècle, sur parchemin. in-4 $4^{0}$ de 172 tf. Biblioth. nationale, ms. latin 11010 .

1609. - Autre du XlII siècle, sur parchemin, in-4o de $196 \mathrm{ff}$. Biłligth. nationule, ms. latin 11011).

1610. - Autre dn XIII siècle, sur parchemin, in-4" de 25:3 ff. (Biblioth. nationale. ms. latin 9994).

1611. - Antre du Xlile siècle, en rouleau sur parchemin de 2 mètres 2.5 de long sur 0 mètre 14 de large. contenant des actes de 1139 à 1182 (Archices dép. de la Huute-Garonue. $\mathrm{H}$ non coté).

1612. - Recueil de titres relatifs à l'abbaye de Grandselve: ms. de 1669. contenant des actes des années 1113 -1514. en 5 vol. in-folio de $398,41 \%, 424.430$ et $420 \mathrm{ff}$. (Biblioth. intignale, coll. Doat. vol. 76-80).

Granville. - Ville.

1613. - Recueil des titres et privilèges de Granville: ms. du XVi siècle, sur papier. contenant des actes de 1446 a 1598 . in- $4^{\circ}$ de 30 ff. Biblisth. nutionale. uns. français 5356 .

Le premier feuillel manque.

Grasse. - Église.

1614. - Cartulaire de l'église de Grasie: ms. du XV siècle [142.5]. sur parchemin. contenant des titres de 1166 a 1425 . in-lolio de I0 it. (Archires dép. des Bouches-du-Rhiou. B 1407).

Grasse. - Ville.

1615. - Cartulaire de la ville de Granse: ms. du XVIe siècle. sur parchemin. contenant des titres de 1235 a 15l:3, in-folio de $47 \mathrm{fr}$. (Archices dép. des Bouches-du-Rhine. B I+11).

Graville. - Prieure (dior. 1+2 Rouen).

1616. - Cartulaire du prienré de Graville: ms. des XIVe-Y Ve siècles. sur parchenin. contenant 2:35 actes des années 1200 à 1499 . in-4 de $86 \mathrm{ff}$. Archices dep. de la Seine-Inférieure, $\mathrm{H}$ non coté. 
Gray. - Hópital du Saint-Esprit (dior. do Besançon).

1617. - Cartulaire de l'hòpital du Saint-Fsprit de Gray; ms. commencé en 1+28 par ordre de frère Lambelet Vernier ; ns. sur papier, contenant des actes de $12: 38$ a 141 , in- $4^{\circ}$ de vin-74 lí.. terminé par une table dressée en l66i3 par le notaire Claude Anidey dichiors lisspitalimess de Besaneon. C $1^{3}$ ).

\section{Grégy. - Village. - Toy. Brie-Conte-Robert.}

Grenoble. - Coment des 1)ominimains.

L618. - Cantulaire des Dominicains de (irenohle; ms. du XVII" siècle, contenant des titres des années 1:288-1674, sur papier, in-4" de 94 ff. Archiers dép. Ae l'lseren $\mathrm{H}$.t24.

Pros.. : Vécrologe et castulaire des Dominicains de Grenoble, par lablue [1. Chevalier. Romans. Rosier, 1870: in-80 de 82 p. [Documents historiques inéelits sur le louphiné. je livr.]

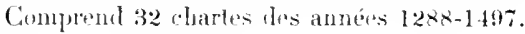

Grenoble. - Évidié.

1619. - Cartulaire A le leèvèdsé de Grenohle: ms. du XIIe siècle, (onlenant 34 ehatpre des annces 739-1109. in-40 de 89 ff. Bibtioth. nutionule, ms. latin l:3879.

1620. - Cartulare B ue l'évèché de Grenoble; nus. du XII" siècle, avec aulditions des $\mathrm{X} 11 \mathrm{l}^{\mathrm{e}} \mathrm{- \textrm {X }} \mathrm{V}^{\mathrm{e}}$ siocles, contenant 129 chartes des années 10.5-1111. in-t" de 104 If. Aichivess dép. de l'Isère li 208).

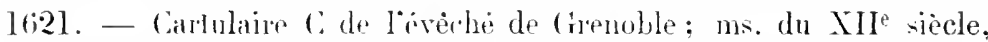
aver: alditions des XIII"-XIVe siectes, conteniant 137 chartes des années 879-1147. in-4" de 74 ff. Arehiess dép. de l'Isère, (i. :209).

Lxtrait ale "arlulaires de l'énlise de Gremoble ; ms. du X VIII" siècle,

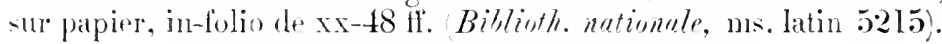

Autrefoir dians las collection bon (irenier paq. $x, n^{0} 3$.

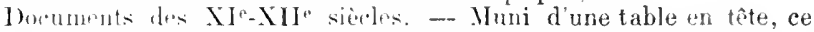
registre parail incomplet de la fin, el les douze premiers feuillets ont été enlevés ou détruits par le temps.

tutre extrait; ms. du XVIle siècle, sme papier, in $4^{0}$ le $46 \mathrm{ll}$. Biblin/lh. nationule. ms. latin 9909).

Pros.. : Cartulaires le l’église cathédrale de Grenoble dits artulaires de saint Hurnes. par Jules Marion. Paris. impr. impériale, 1stig: in-4" de xar-5ot; p. el pl. [Collection des Documents inérlits.]

(.f. Recue critique. V. 1870. p. 38-48.

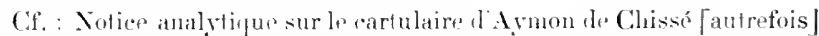
anx areliven de l'éviclué de Grenoble, par l'albé L'l. Chevalier. Colmar,

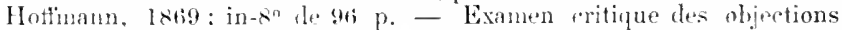

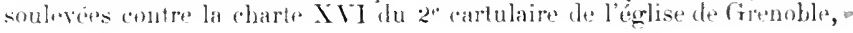




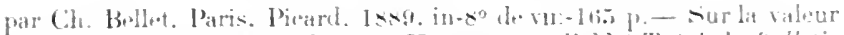

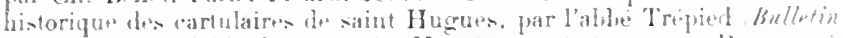

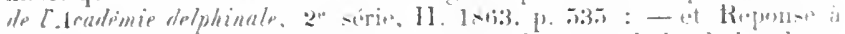

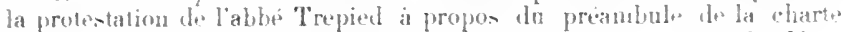

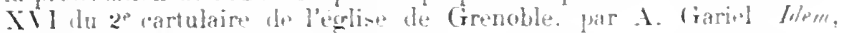

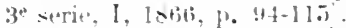

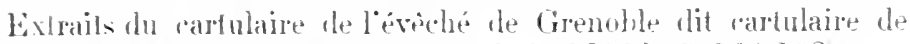
saint Hugues Biblinth. nutimule. ms. latin 12768. 11. l6:3-168.

\section{Grenoble. - Ville.}

162:2. - Cartulaire de la ville de Grenohle ou "Livre de l"kvangilp" : ms. de la fin du $\mathrm{XY}^{-\mathrm{e}}$ siécle. orné de miniatures et couvert d'une reliure contemporine. sur parchemin. rontenant des documents de

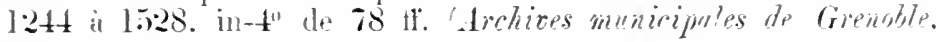
A. 4 .

1623. - Cartulaire municipal: ms. du $\mathrm{XY}^{\mathrm{e}}$ siècle. sur papier. contenant les actes de 1244 is 1427 . in- $t^{\circ}$ de 130 ff. Archires muncipales de Gringle. At 5 .

1624. - Autre cartulaire on "Livre de la Chaine »: ms. du XVI siècle. sur papier. contenant des actes de 1244 a 1556 . in-folio de 476 tr. Archices municipales de Greatoble. At 6 ?.

sur ces differents registres, roir l'Ynventaire-sommaire des arehives

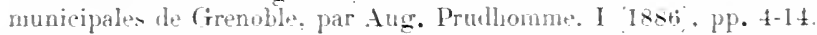

1625. - Cartulaire de la ville de Grenothe: ms. laté de 1404. sur parchemin. in-4" de 158 if. Bibligth. nutionale. ms. latin $10966^{\circ}$.

Cl. Notice sur un cartulaire inédit de la ville de Grenoble. par

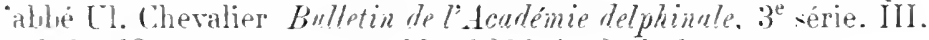
p. 341-358, et it part: (inenolle. 1868. in-8" te 19 p.

Greux. - Village.

1626. - Cartulaire des privileges octrovés anx villes de Greux et Dimremy par les rois de France: ms. du XVI ${ }^{\mathrm{e}}$ siècle [1596]. rédigé par Monzeot. greftier de l’élection de Chamont. sur papier. in-folio

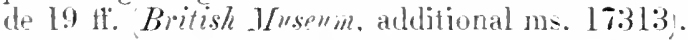

dequis en France, en 1848. Dates extrèmes : 1429-1495.

Copie moderne du mènts: 59 If. in- $\mathbf{4}^{0}$ Biblioth. nutionule, ms. noux, acer françaines 20007 .

Grimberghen. - Abbar de Prémontrés (dioc. le Malines). 1627. - Cartulaire de lahhave de (irmberghen : ms. du InI siecle.

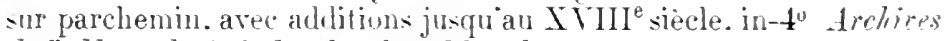

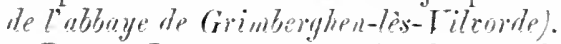

Publ.: Documenls extraits du cartulaire de Grimberchen Anulectes prou sercir à lisistrive ecclésinstique de la Belgique. IX. 187.2. pp. 41-45. et XI. pp. 9-38

Dates estremes : $115: 3-123 \%$. 
Groenendael. - Prieurc (dioc. de Malines).

I628. - Cartulaire du prieuré de Groenendael; ms. des $\mathrm{XV}^{\mathrm{e}}-\mathrm{XVI} \mathrm{I}^{\mathrm{e}}$ siècles, sur papier, contenant des actes de 1457 a 1674 , in-4 $4^{0}$ de 150 pages (Archives du royaume de Belgique, it Bruxelles).

1629. - Antre cartulaire du $\mathrm{XVI}^{\mathrm{e}}$ siècle, sur papier. contenant des actes de 1566 i 157l. in- $t^{\prime \prime}$ de 98 ff. (Archices du royaume de Belgique, à Bruxelles).

Grosbois. - Village. - Voy. Brie-Conte-Robert.

Gruyère. - Comté.

1630. - Pubi. : Monuments de lisistoire dı comté de Gruyère et d'autres liefs de la maison sonveraine de ce nom, par J.-J. Hisely et l'abhé J. Gremaud (Mémoires et Documents publ. par. la Société d'histoire de la Suisse mmande. XXII ei XXIII. 1867-1869, 2 vol. in $\left.-8^{\prime \prime \prime}\right)$.

Recueil factice de documents des années 900-157\%.

Guebwiller. - Couvent des Dominicains (dioc. de Strasbourg).

163L. - Cartulaire des Donimicains de Guebwiller: ms. du XVIII siècle. sur papier, contenant des actes des années 1:311-1758, in-10 de $39.5 \mathrm{fl}$. (Archiv des Ober-Elsass, in Colmar).

Gueldre. - Iuché.

1632. - Recueil de titres relatifs aux rapports de la Lorraine avec les duchés de Ginelelre, de Denx-Ponts et de Nassau; ms. de la fin du $\mathrm{XVI}^{\mathrm{e}}$ siècle, formé par Thierry tlix. sur papier. contenant des textes de 1290 à 1581. in-folio de 379 tr. (rohives dép. de Meurthe-etWrselle. B 409 .

Guérande. - Courent des Dominicaius (dioc. de Nantes).

1633. - Cartulaire des Dominicains de Guérande; ms. du XVIIe siècle, sur papier. contenant des actes de 1509 à 1619 , in- $4^{0}$, de $58 \mathrm{ff}$. (1rchires dép. de la Loire-Inférierre, $\mathrm{H}$ non coté).

A élé domné à ce dépról il y a qquelques années et n'est pas inventorié.

Guéret. - Église (dior. de Limoges).

16:34. - Cartulaire de la communanté des prètres de léglise de Guéret; ms. incomplet du XVllI ${ }^{e}$ siècle, sur papier, in- $t^{\circ}$. ff. 134 à 501 (Avclices dép. de lu Creuse, Gr non coté).

Guillaume. - Tille.

1635. - Recueil des privilèges accordés à la ville de Guillaume par les comtes de Provence et les rois de France, de 1399 à 1548 ; ms. 
du XVII siècle, incomplet, sur papier, in $4^{0}$ de $42 \mathrm{tr}$. Aichires communales de (ruillume, Alpes-Maritimes).

Guines. - Abbaye de Saint-Léonard (dioc. de Boulogne).

1636. - Copies de titres relatifs a l'abbaye de Saint-Léonard de Guines; ms. du XVlle siècle, sur papier intlolio. contenant des

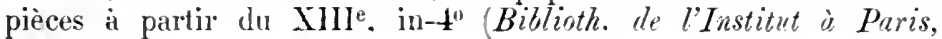
ms. 442

Guise. - Seigneurie en Vermandois.

1637. - Cartulaire de la terre de Guise; ms. de l'amnée 1327. arec additions postérieures $\mathrm{XV}$-XVIe siècles), sur parchemin, in-folio de $372 \mathrm{ff}$. (Biblioth. nationale, ms. latin $17 \%$ i ).

Axal. : Notices et extraits des documents manuscrits relatifs à l'histoire de la Picardie, par H. Cocheris, II, n $766^{\circ}$ pages 499617 .

Extraits du mème. faits au $\mathrm{XVII}^{\mathrm{e}}$ siècle par Du Cange Biblivth. de l'Arsenal, ms. 5259, ff. $92 \mathrm{r}^{\circ}-98$.

1638. - Autre cartulaire de la terre de Guise ; ms. du XVe siècle, sur parchemin, in-folio de $138 \mathrm{ff}$. Biblioth. du Vatican, ms. Ottoboni $2791)$.

Provienl de Petau (M. 45).

Guise. - Seigneurie. - Voy. Jorville.

Haerlebecke. - Chapitre Saint-Laurent (dioc. de Malines). 1639. - Cartulaire du Chapitre Saint-Laurent d'Haerlebeke; ms. du $\mathrm{XII}$ siècle, en un rouleau de parchemin de 2 mètres de long sur $0^{\mathrm{m}} 46$ de large (Archices de l'État à Bruges).

1640. - Antre cartulaire du chapitre de Haerlebeke [appartenait en 1869 à M. le Dr Wittouck, à Hulste].

Publ. : Extraits du cartulaire du Chapitre de Harlebeke. par E. Reusens (Analectes pour servir à l'histoire ecclésiastique de lu Belgique, VI, 1869, p. 179-181).

Dates extrèmes : $11 \%-1202$.

Haerlebecke. - Chapitre Saint-Saureur.

1641. - Cartulaire du Chapitre Saint-Saureur d'Haerlebeke; ms. du XVIII ${ }^{e}$ siècle. sur papier, contenant des titres des années 1063-1 759 . in-4" (Avchices de l'Etat ù. Bruges).

Haguenau. - Couvent des Augustins (dioc. de Strasbourg). 1642. - Cartulaire des Augustins de Haguenau; ms. du XVIIIe siècle. sur papier, contenant des actes de 1237 à 1663. en 2 vol. in-folio de 274 et $262 \mathrm{ff}$. (Archio des Unter-Elsass, in Strassburcr). 
Haguenau. - Compent des Primontres.

1643. - Cartulare des P'rémont rés de Hagneman: ms. du XVIII sièche, sur papier, contenanl des actes des années 1189 a i 15:35, in-lolio de 232 ff. (Archir des Litro-Elsuss, in Strasshurin.

Haguenau. -- Eglise Silnt-(ienges:

1644. - P'ubl. : Cartulaile de l’égrlise Saint-Georres de Hagnenan, publ. par l'ahlé C.-A. Hananer. Sirashourç. Mündel, 1898: in-8 de xrr-60t p. [Archivalische Beilange des Sirassburger Diöcesanblalles für $189 \%$ ].

Contient des documents à partir de 968 , extraits en majeure partie de deux carculaires de l'église de Haguenatu qui ne sont pas décrits.

Haguenau. - Ville.

1645. - Cartulaire municipal de Handuenau; orion. perdu.

A cote grandement utiline prar sichereptlin dans son "Alsatiat diplomatical $)$.

Hainaut. - Comte.

1646. - Cartulaire du conté de Hainaut; ms. des XIII-XIYe siècles, sur parchemin. contenant des actes de 1176 a 1310 , in-40 de $25 \%$ ff. (Biblinth. de la rille de Valenciennes, ms. 784).

Voir une table sommaire de ce manuserit dans lo. Catalogue des manuscrits de la bibliotheque de Valneiennes, par E. Mangeart (1861), 1. $706-712$.

1647. - Antre du XI" siectr. sur parchemin. contenant des actes de 1298 a 1328, in-t" de 105 tr. (Biblinth. nutionale. ms. français 5608 .

1648. - Cartulaire dn conte Gruillamme Ier $:$ ms. du XIVe siècle, sur parchenin, contenanl 17.2 actes des années 1.28 a 1312 , in-8" de 168 if. (Archives du roy. une de Belgique, à Bruxelles).

Aval. : par Gachet dans les Bulletins de la Commission royale dhistrire (Bruxelles, 2e série, IT, 18.2, p. 9-118.

1649. - Autre cartulaire du comte Guillatume Irr : mss. du XIVe siècle, sur parchemin. conlenart des actes tle 13316 a 13337 . in-folio de $15 \mathrm{ff}$. (Archires royales de Hollande, a La Haye, AL 38. C nº 22).

Anal. : par L. Deviller's daus les Bulletins de la Commission royale dilistoire, 3e série. VII, 1865, pp. 351-382: réimprimé dans: Description des cartulaires et chartriers du Hainaut, II (1866), pp. $3-34$.

1650. - Cartulaire de Hainaul: ms. des XIIJ-XIVe siècles, sur parchemin, contenant des documents de 852 a 1:384. en 5 vol. in-folio 


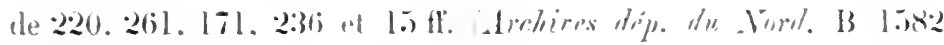
1585 ef 1587 .

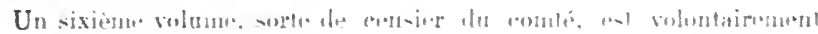

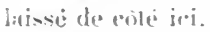

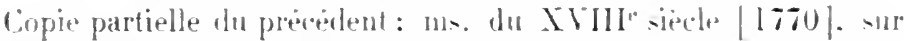

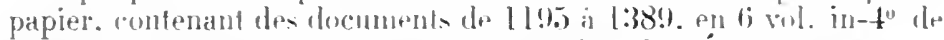

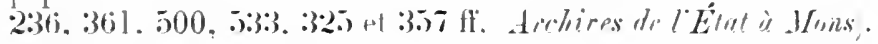

P'erbe: Monument pour servir il l'hishaire des provinces de Namur. de Hainant et de Luxembonrur. I et 111 1844 et 1874. par A. de Reillenberg et Leip. Devillers.

Traduction française du premier cartulaire de Hainaut. arec additions : ms. dn $\mathrm{NVl}^{\circ}$ siecle, sur papier, in-folio de $96 \mathrm{ff}$. Bibliwh. delu cille de Lille, niss. 591' .

l6..5l. - Antre recueil l'acter des $\mathrm{MII}^{\mathrm{e}}-\mathrm{XVI}^{\mathrm{e}}$ siècles relatifs an Hainaut : ms. dn $\mathrm{XVI}^{\prime}$ siècle. sur papier. in-lolio Biblistl. d" l" rille de Lille, ms. 592. 17. 11-2:21) .

1652. - Cartulaire de la trésorerie des contes de Hainaut: ms. du

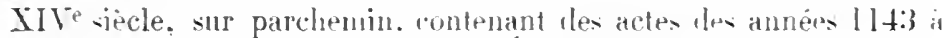
1314. in-4" de 120 ff. Archiress de I'Élat is Woms.

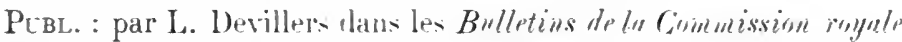
thistoire. 3e serie. XII. 1871. p. 333!-t6i8: reimprime dans: Description des cartulaires et chartriers dı Hainaut. VI 187:2, pp. :3-1:32.

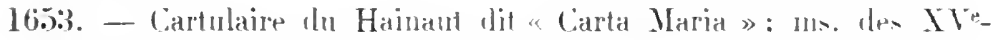

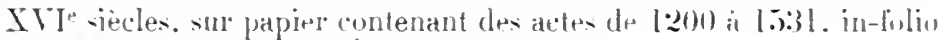

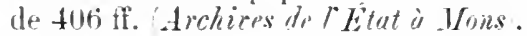

1654. - Recueil de chartes du Hainaut: ms. du XVIJe vierle. all patpier. contenant des actes de 1200 a 1483. arec lable. intolin its xin-lgh ff. Archieps de l'Etat ì Mons.

16.5.5. - Antre recueil commencé en 15017. el continue jusqui an milien

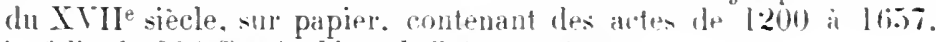
in-folio de $334 \mathrm{fl}$. Archices do l'Etut is Mroses.

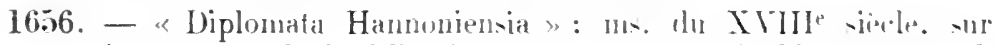
papier. en 2 vol. infolio de $4 ! 90$ et $3(00)$ tl. Archires royntes de Hollunde. à La Haye. l'apiers (iérard. n" 80-81.

Dates extrêmen: 11501)-1433.

1657. - «Diplomata Hannonix »; ms. du XVIIJ sièche, sur papier.

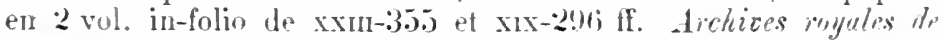
Hollande, à La Haye. l'apiers Gererdrd.

Dates exlrêsues: : 111;1-111:.

1658. - Recueil de chartes relatives au Hainant ms. du XVIII siède. 
sur papier. contenant des actes de 1200 a 16960 . in-folio de $25 \%$ ff. Biblinth. de la rille de Valenciennes, ms. 888.

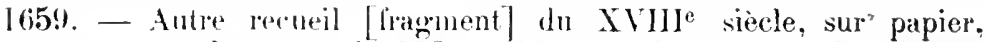
coutenant des arles de l286 a 1407 , in-folio de $66 \mathrm{ff}$. (British Muspum. adclitional um. 30715. ff. 1-666.

l660. - Autre aroulaire du comté de Hainant; ms. des X111eXIV'e sièles. orig. perdu.

Copir du préécilent. collationnée en latiz pour la duchesse de Parme; perdue.

Copie faite sur la precidente au XVIII siecle, sur papier, in-lolio de 242 fI. Arrkires nationules, KK I:244.

1)itu' extrênes: : 1:01-13:12.

1661. - Probl. : Cartulaire des contes de Hainaut de l'avènement de (inillaune II à la mort de Jacqueline de Bavière (1337-1436), par Léopold Devillers. Bruxelles. Hayez, 1881-1896; 6 vol. in-40 de

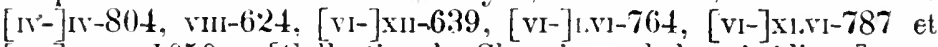
[v1-]Xxxu-1050 p. [Collection des Chroniques helges inédites.]

Hainaut. - Forits.

I662. - Rerofeil de titres relatifs anx hois of forèts dn Hainaut: ms. dn $\mathrm{XVI}$ sièrle. sur papier, contenant des doemments dle $150 \%$ à 1500 , in-folio de $115 \mathrm{fr}$. Arelives de l'Etat ì Mons).

Hainaut. - Narigalion.

l66i3. - Recoueil de lifres relatifs à la navigation des rivières en Hainaut; ms. du $\mathrm{XVl}^{\mathrm{e}}$ sièrle, sur papier, contenant des documents

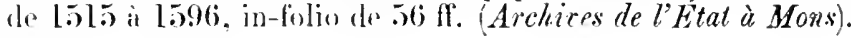

Hal. - Ville.

1664. - Cartnlaire de la ville de Hal: ms. du XVo siècle, sur parchemin. contenant des actes de 1263 à 1565 . in $-4^{\circ}$ de $12 \mathrm{ff}$. Archices du royanme de Belgique, is Bruxelles.

Hallate. - Forit.

I6(i.). - Cartulaire de la forèt de Hallate; ms. du XIII siècle, sur parchemin. in-folio de 87 ff. (Archives nationales, KK 945).

lixtraits pen importants (Biblioth. rationale, coll. Duchesne, vol. XXII. If. 124-125).

Ham. - Abbayr de St-Laureur (dioc. de Thérouanne). .

1666. - Cartulaire de l'ahhaye de Ham, fait en 1487, sur papier; oriz. perdu.

II exi-tail encore au tenys de Dom Grenier. 
Fxtraits fails pour Gaignières Biblinlh. nutionule, m1.. Jatin 1767.). ff. 56-61 : ms. françai: 22366. pp. (il-6.5).

Hambye. - Abbaye de Notre-Lame (dioc. de Contanc.si).

1667. - Carlulaire de l'abhaye de Hanlyye : orig. perdu.

Extraits relatifs à la fanille latrnel. faits an $\mathrm{XVll}^{\mathrm{e}}$-iècle. sur papier contenant des actes depuis 1145 . in-folio le in ff. dicliires dép. de la Manclie, H 4:309).

Cif. dans les mème dépôt la liass H 1310 (cople menlernio du prócédent. en $70 \mathrm{fr}$. papier) et la liasso H $4: 311$ (mentions lu cartulaire original).

\section{Hanse teutonique.}

1668. - Prbl. : Hansisches Crkundenbuch. von Konstantm Höhll ranm und [später von] Karl Kunze. Leipzig. Duncher nnd Hmmblut. $1876-1905 ; 6$ rol. in-8".

Recuril commençant à 97\% el sorrètant actuellement at lanne 1433 .

Harlebeke. - Toy. Haerlebrcie.

Hanswijck. - Courent des Augustins, près de Malines (dioc. de Malines).

1669. - Cartulaire du couvent de Hanswijch. rédiré en l:381) : orig. perdu.

Copie faile an XVIII siècle, avec additions, sur papier. in- $8^{\circ}$ de

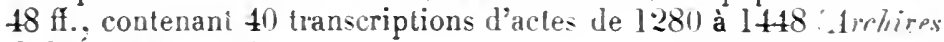
de l'Étut ù Átucerss).

Hasnon. - Abbaye de Saint-Pierre (diocese d'Arras).

1670. - Cartulaire de labbaye d'Hasnon: ins. du XIlle siecle. जur parchemin, contenant des documénts de 1077 a 1261 , in- $\delta^{0}$ de $129 \mathrm{ff}$. Archires de l'État à Mons).

1671. - Autre cartulaire d'Hasnon; ms. de la tin dn XVe siècle. sur parchemin, in- $4^{0}$ de $\mathrm{xx}-164 \mathrm{ff}$. Biblioth. de la cille de Domai, ms. $1342)$.

Provient du legrs Tailliar.

Hasselt. - Béguinage (dioc. de Liège).

1672. - Cartulaire du Béguinage de Hasselt : ms. des XVII ${ }^{e} \mathrm{IVIII}^{\mathrm{e}}$ siècles, sur papier. in-folio de 133 pages (Archices de l'Étatò Hasselt).

Hasselt. - Couvent des Augustins.

1673. - Fragment d'un cartulaire des Augustins de Hasselt; m. des XVII $-X V I I{ }^{e}$ siècles, sur papier, contenant des titres depuis le XIVe, in-folio de $104 \mathrm{ff}$. (Archives de l's: tat à Hasselt). 
167it. - Aulte du XVI" siecle sur papier, in-folio de $488 \mathrm{ff}$. Arohioes de litat ì Hasselt.

Hastière. - Voy. Wallsor't.

Hastingues. - Vill .

16is. - Recueil de docments relatifs it Haslingrues, forme an XVIle viecle et contenant des dormuents de 145.) a 1584 . sur papier Bithlith. natimale. coll. Duchesne, vol. X(XI. ff. (88-87).

Cif. une auter sirite dactes du XVI" sirele frem, coll. Baluze, vol. $X X Y$, ff: $5(1)-45)$.

Hattonchâtel. - Privòte.

16izi. - Recueils de litres relatifs a la prevòté d'Hattonchàtel; nos. لlı XVIJ siècle, lormé par Thierry Alix, sur papier, contenant des textex de 122.) a 1603, in-folio de 162 fl. Archives dep. de Meurthe-

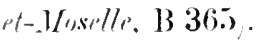

Hautcrêt. - Abhaye (dione de Lausanme).

167\%. - Carlubare de labhaye de Hauterèt: ms. du Xlle siecte, sir parchemin. in-8" de 5l il. [incomplet] (Archioes cantonales de Fribining .

Pr zl... Cartulaire de labbaye de Haulerêt, par J.-J. Hisely Vimeries et Dricuments publ. par la Suciété dihistoire de lu Suisse

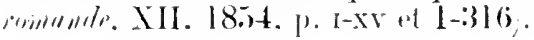

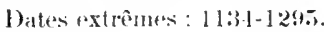

Haute-Avesnes. - Commanderie (dioc d'Arras).

lizs. - P'BL. : Titres de la commanderie de Hante-Avesnes antérienrs ¿1312. publ. par Charles l'Héricourt Mémeives de l'Académie H.1r\%s. IXIX. p. 7-77. el it part: Arrats, Courlin, 1878; in-12 de $73 \mathrm{p}$.

Ja plus antien dee unent est de 1158 .

Hautecombe. - Mbaye (dioc. de (ienere).

1679. - Carmbire de labbaye de Hautecombe; origr. perdu.

A éle connu de Guichenon, qui en a extrait deux charles dans son

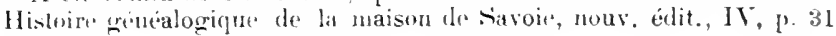
of 41 .

Hauterive. - Mbaye (dime de Latuanne).

16811. - Carmaire de lablalye l'Hanterive; ms. du XIII siecle, sur parchemin, in-4", cont'nant 320 résmmés d'actes (Archives cantonales dir Fillowig.

Y'BL. : Archives de la Suciete dhistoive du cunton de Friboury, VI, I896, pp. 1-Y1 et 1-I68. 
Copir alu précelent faite en 1488 par J. Carementrant. motaire.

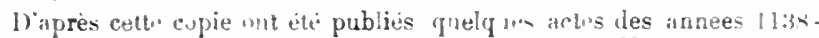

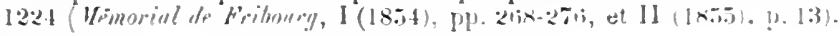

Haute-Seille. - Mbare (dioc. wo Tunl).

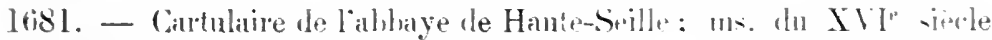

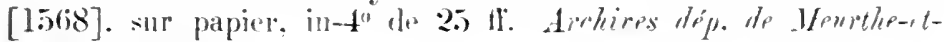
llowelle. H 54.3 .

Hautmont. - Abbaye (dioc. le Cambrai).

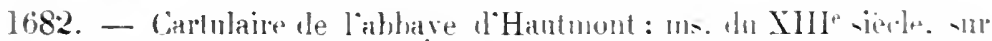

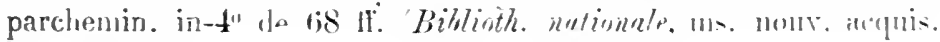
latines l38ti?.

Dales axtrimes l losi-12ix. Le volume prisente des lacunes.

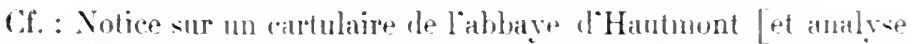
des actes, XIle-XIII s. ]. par Leopold Devillers Mrimoires de lo Sucinté urchéologique de l'urr. Ir.Aresnes. II. I867. p. 20: et Descriptiondes cartulaires et chartriers du Hainaut, III. 186i. pp. 113-23: .

Appartenail on lxis a M. Michaux dritrene.

Hautrage. - Hópital (dioc. de Cambrai).

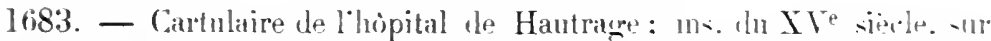
parchemin, comtenant des actes de 14.28 is 1441 . in-t" de til ti. Archioes de l'Étrat à Moins.

Hautvillers. - Abbaye de saint-Piere (dime de Reims).

1684. - Cartulaioe le lahluaye d'Hautvillers : orige perdı.

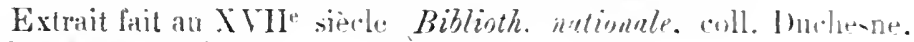
vol. LXXIV. fo $84_{i}$.

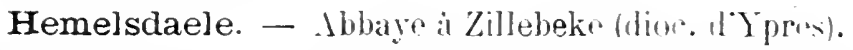

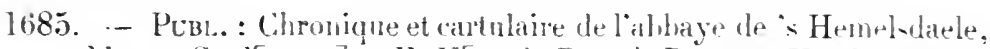
puli. par C. C.jarton $\rceil$ et F. VFan de Putle\}. Brupes. VauderateeleWerbrouck. 1858 ; in-4" de 164 p. [Publication de la Sociele d"ennlatinn de Bruges.l

Hénin-Liétard. - Ville.

1686. - Cartulaire de la ville d'Hénin-Liptarl nu "Livre lulan :

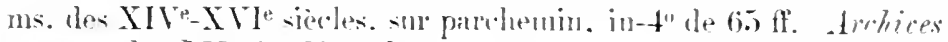
communales đT Hénin-Liéturd.

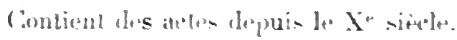

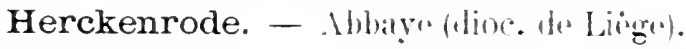

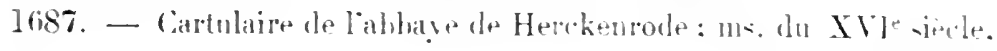


snr parchenin, contenant des actes de 1209 a 1547 , en 2 vol. in-folio de :37:3 et 226 ff. (Biblinth. dn' S'minatre de Liège).

Aval.. : Bulletin de l'Institul archéologique lirgeois, X, p. 470506, et Xi. p. 19-106.

Itis8. - Autre cartulaire: ms. du XVI* siècle [15I0], sur parchenin, intefilio de $208 \mathrm{fr}$. (Bibliolle. dl" Séminaire de Liège).

H'rn.. Histoire des pirroisses de lancien diocèse de Lièrge, par 11. Maris. $11^{\prime}(1883$ - p. . -138; - locuments relatifs a l'abbaye de Herckenrode. par lí. Reusens. dans Inalectes pour servir à lhistoire cerlesiestique de ln Belgique. XVI (1879 - p. 22L-317.

Hérinnes |flam. Hsks], pres d'Enghien (Hainanl). - Chartraser dr X.-D. de lit Chapelle (dioc. de Cambrai).

168\%. - Cimlulare le la Chartreuse d'Hérimes: ms. des XIVe-XVe siecles. sur prirehenin. contenant 304 actes de 13331 a 1439 , in-folio

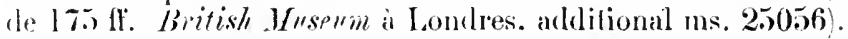

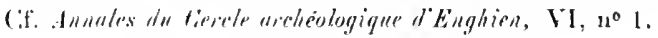

Hérival. - Abbayro (dioc. Ir Toul).

1690. - Cinlulaire de l'ahlaye d'Hérival: ins. du XVIlle siècle, sur pripier. in-folio Archives dip. Hes Iosqes, G 870).

If ast inséri dans le artulaire du Chapitre de Remiremont.

Hérivaux. - Abhatye (dioc. do Paris).

1691. - Fragment d'un cartulaire de l'abbaye d'Hérivaux; nıs. du IVe siède. sur parchemin, in-Eo Biblinth. nationale, ms. latin 11411 , fi. $74-81$.

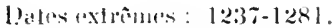

169:2. - Recreil de titres relatils à l'abbaye d'Hérivaux, fait au Xl11l" siècle pour ( raignieres (Biblioth. nalionale, ms. latin 17048, p. (1883-1593,

Héronval. - Prirurc (dioc. de Noyon).

169:3. - P’rnı. : Cartulaire d'Héronval (114L-1326). Noyon, Andrieux, 188:3: in-4" de xt-110 p. [Comité archéologique de Noyon.]

la preface est signér: E. Tassus. - Les documents contenus dans refle publication sont extrails du eartulaire de Longpont [voir ce nom] conservé che\% .I. (i. de Cihauvenel, au château de Lesdins (Aisne).

Hertsberg. - Prérôté en Flandre.

lir94. - Cartulaire de la prévòté d'Hertsberg: ms. du X V'iI siècle, sur papier, contenant des titres de 876 à 1516 , in- $8^{\circ}$ de $38 \mathrm{ff}$. Archives de l'Etut ì Bruges. 


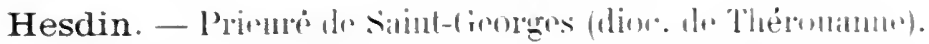

1695. - Cartulaire du prienré des Saint-(ienorges l’Hesdiu: Ins. du $\mathrm{XII}^{\mathrm{e}}$ siède, sur pardhemin. contenant des actes de 108.5 is 1187.

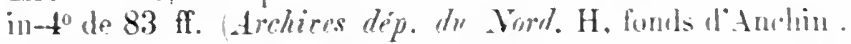

Copie moderne [1873] du précédent : in-folio de lis p. Bibliollh. nationale, ms. nouv, ately, latines 1:22:1:.

Hesdin. - Vill.

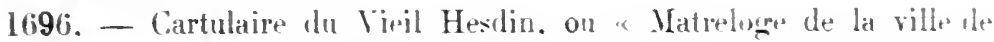
Hesding ": ms. compuse pn l:345. sur parchenin, atec illusirations. in-folio de $108 \mathrm{ff}$. [et $\boldsymbol{i} \mathrm{ff}$. sur papier ajoutes] Arohires muniriportes i.Hestin.

Héverlé. - Couront des Cẻlestins dioc. de Malinos).

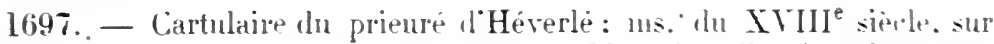

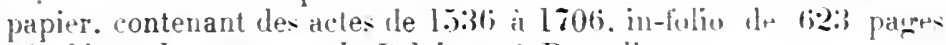
Archizes du royaume do Belginue. in Bruselles.

Héville. - Voy. Mordare.

Heylissem. - Abbaye (dioc. de Liege).

1698. - Cartulaire de lalihaye de Heylisen : ms. du XIV siecle. sur

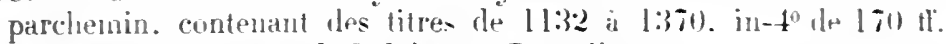
Arehires du royume do Belgique. à Bruxeller.

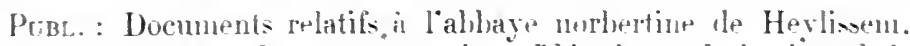

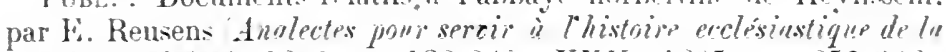
Belgique, XXIV. 1893. p. 182-240: XXV. 189. p. 2.97-338: et Xíril. 18!9. p. 114-196;

Homblières. - Abbạe (dior. le turon).

1699. - Cartulaire de l’abbare de Homblieres : ms. du XVIIe siècle. sur papier contenant 87 acles de 946 à 13.31 . in-4" de $40 \mathrm{tr}$. Archires lép. de l'Aisne, H 588 '.

Copie du précédent. faite au XVIII sièlte. sur papier, in-t" de 99 ff. Biblinth. rulionule. us. latin 1:39ll'.

Hornbach. - Mbbage (diox. de Met\%).

1700. - "Renovatio privilegrorum monasterii in Hornlach» on

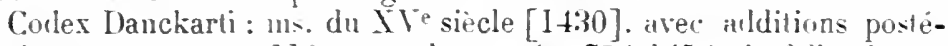

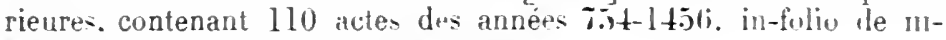
48 II. Allg. Reichsurchir in Uünelien.

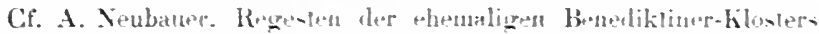
Hornbach (Millhilungen des histuriselien bereins der Hals. XXVII. 1904).

Hospitaliers de Saint-Jean-de-Jérusalem.

1701. - Cartulaire des Hospitaliers de Saint-Jean de Jérunalen ; nus. de 
lat fin dn $\mathrm{XVI}^{\circ}$ siecle. sur papier. conlenant des transcriptions de diplomes et actes des rois de France de 1219) a 1598, in-t" le 5.3 ff. (Archices natimnles. S .5010. 11"3).

1702. - Bullaire des Hospitaliers de Saint-Jean-de-Jérunaltrm, dit Bullaire XP: 1us. du XV11e siècle, par ordre de G. Bosio, sur papier,

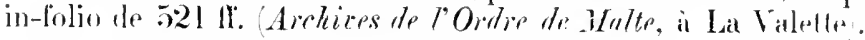

Las feuillets 127-277 mituquent.

170:3. - 《Bullarimu rubeum 》: ms. du XVle siècle. sur papier.

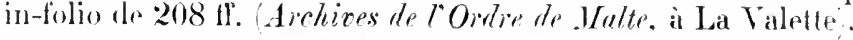

1704. - Bullaire rote A [perdu depuis le XV1IJe siecle].

1705. - Bullaire cote B : ms. du XVII" sièce. sur papier, contenant des actes de 1200 a 1500. in-folio (Arkices de l'Ordre to Walte, i) Lat Valette.

1706. - Bullaire C (Idem).

Est plutot un inventaire, dommant des colies de bulle- den années Ils it $15 \% 1$.

1707. - Bullaire 1) (Idem).

Copir pare ot simple da préécilent.

1708. - Bullaire li: perdu.

1709. - Bullaire F; periln.

1710. - Bullaire G; ms. du XVII siècle. sur papier, contenant des

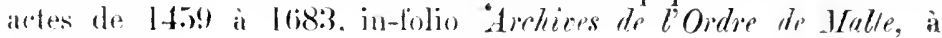
Lil Valeite:

Siur tous ces derniers regristres, woir: J. Delaville la Roulx : less arrhives, la bibliothègu ef le tresor de londre de saint-Jean-deJérusalem it Malte (1'aris, 1883, in-80), pp. 45-48.

1711. - Cartuliare des Hospilaliers de Sinnt-Jean-de-J férusalem ; ms. du XV7e siècle. sur parchenin. contenant des actes des annies 13339-

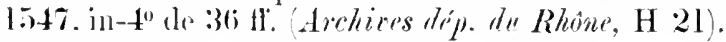

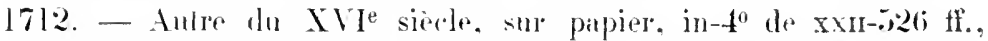
contenant des artes de 1113 a 1526 Archives dep. du Rhone, $\mathrm{H} 22$ ).

1713. - Antre du $\mathrm{Xle}$ siecle. sur parchemin ot papier, contenant 146 acles de 1181 i 1495 , in-t" de 91 fr. Arrlive des Untri-Elsuss, in Strasimrge.

1714. - Livre des privilìges de Sinint-Jean de Jérusalem: nus. du $\mathrm{XVI}^{\mathrm{e}}$ siècle. snr papier, contenant des tilres de 1172 à 1586 , in-folio de 8.5 ff. (Archires dip. des Pypénirs-Orientales. H, fonds de Malte).

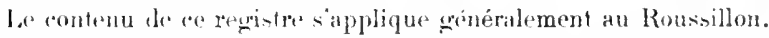

1715. - Recueil des privilegres du mème Ordre: ms. In XVIIe siècle, par frère Ame dr Naberal. sme papier. an 2 vol. in-lolie (Biblinth. untionale, ms. latin $900 \mid-9002 ?$. 


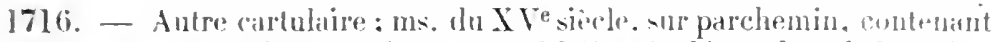

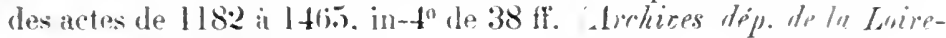
Inférieure. $\mathrm{H}+59$ ).

1717. - PubL. : Codice diplomatico del Silcro Militalo Ordines (rasoro-

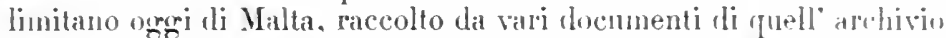
per servire alla storia dello stesso Ordine in Soria Lucar. 1733:3. in-folio : - Codice diplomatico........... per servire alla -turia dello stesso Ordine in Rodi ed in Malta Lncea. 1737. in-folio.

1718. - Privilèges des papes. empereurs. rois et princes de la Chrétiente arcordez a lordre Saint-Jean de Hiérusalem. par 11'livilızeaux. Paris. Le Mercier. 1700: in-folio de vu-1:307 p.

1719. - Cartulaire général de loordre des Hospitaliers de Saint-Juan de .Jérusalem, par Joseph Delaville-le-Roulx. Paris, Leroux. I8? 1 $1901,4 \mathrm{vol}$. in-folio.

Dales extrêmes : 11110-1311.

Houffalize. - Prieuré de Sainte-Catherine (dioc. dr I irige). 1720. - Cartulaire du prieuré d'Hontfalize : ms des IVe-XVI -iècles, sur papier. contenant des titres de 1235 it 1652 . in-4 de 304 paupes Archices de l'Etut à Arlon.

Huiron. - Abbaye (dioc. do Chàlons-sur-Marne).

1721. - Cartulaire de l'abbaye de St-Martin d'Huiron: ms. du XVIII siècle [176i]. sur papier. intfolio de 624 pares "Archires dép. de la Marne, $\mathrm{H}$ non cote.

Les locuments qui y son transcrits remonlent à la premier novité du XII siecle. - Cif. quelques documents reproduils dans: Chronique de l'abbaye de Saint-Martin de Huiron. par Dom P. Baillet, publie prar le $\mathrm{D}^{\mathrm{r}}$ Mougin (Chàlons, $1 \times 7 \%$, in-8 (le $228 \mathrm{p}$.)

Huy. - Couvent des Carmélites (dior. de Liège).

1722. - Cartulaire des Carmélites de Hıy : ms. du XVe siècle, avec additions postérienres, sur papier, contenant des titres des années 1339 à 1625. en 4 rol. in-folio de 403. 195. Th et $340 \mathrm{ff}$. Archires de l'Etat à Liègè.

Huy. - Courent des Flères- Vlinemrs.

1723. - Cartulaire des Frères Mineurs de Huy : ms. du XVIII sircle. sur papier, contenant des actes de 1356 i 1452 . in-folio de $217 \mathrm{ff}$. (Archices de l'État à Lìge.

Huy. - Église collégiale Notre-Dame.

1724. - Cartulaire de la collégiale de Huy : uns. du XIII siècle. sur parchemin, contenant des titres des année 1066 - 1284 , in- $4^{\circ} \mathrm{de} 14 \mathrm{ff}$. (Archiress de l'Etat à Liège'. 
Pıвı. : Notice d'un cartulaire de l'ancienne église colléyriale Solrm-l)ane it Huy, par Em. Schoolmeesters et S. Bormans (Compteierdus de ln Commissinn royule d'histoire, $4^{\mathrm{e}}$ série, I, p. 83-L:20), of it part: Bruxelles, Hayez, 1873 ; in-80 de $70 \mathrm{p}$.

Igny. - Abbaye (diox. de Reims).

1725. - Cintulaire de l'abbaye d'Igny: ms. du XIIle siècle, avec additions des $\mathrm{XlVe}-\mathrm{XV}^{\mathrm{e}}$ sièrles, écrit de plusieurs mains, sur parchemin. imcomplet du commencement et de la fin, et contenant des documents des années 1126-1366, in-40 de 270 ff. à 2 col. Billioth. nutionale. ins. latin 9904.

Indre. - Département.

I726. - Prвı.. : Recueil historique des chartes intéressant le département de l'Indre (VIe-XI siecles), par Fun. Huhert (Reoue du Brity, 1899. pp. $81-272)$.

Innimont. - Pricuré (dioc. de Lyon).

1727. - Cartulaire du prieuré d'Innimont; orig. perdu.

Exislait au XVII siecle: ; of. Guichenon, Histoire de Bresse (1650),

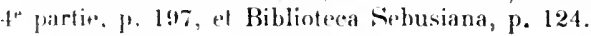

Is-en-Bassigny. - Église.

1728. - - Cartulaire de l’église d’Is-en-Bassigny ; ms. dı XVII siècle, sur papier. in-t" Archives municipales d'Is-en-Bassigny. HauteMarne?

\section{Israélites.}

1729. - P'вг. : Recueil des lovis, décrets, ordonnances, avis dı Conseil d'Étrit. arrìtés el rèrlements concernant les Israélites depuis la Revolution de 1789, par Achille Halphen. Paris, aux Bureaux des Arrhives Israélitiques. 1851, in-8 ${ }^{\circ}$.

Issenheim. - Commanderie de l'ordre de Malte (dioc. de Stratsherirg).

1730. - Cartulaire de la connanderie d'lssenheim; ms. du XVIIIo sirele. sur papier. in-4 de $286 \mathrm{fl}$. (Archio des Ober-Elsass, in Colmatr,

1.2 plus ancien document transerit est de 1296.

Issy. - Village (dioc. de Paris).

1731. - Cartulaire d'Issy, dépendant de l'ablaye de Saint-Germaincle-Press : ms. dlu XVIe siècle, sur papier, contenant des documents it partir le 127:3. in-4 $4^{0}$ de 154 pages (Archives nationales, LL I074). 1732. - Cartulaire d'lssy et de Vaugirard; ms. du XVIII ${ }^{\theta}$ siècle [1753]. sur papier, rérligé par Ph. Duroussin, religieux, contenant 


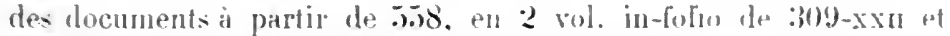
38:-xxis ti. "Archires nationulex, I.I. 1049-10.50.

Issy-l'Évêque. - Église (dior. d'.lutıu).

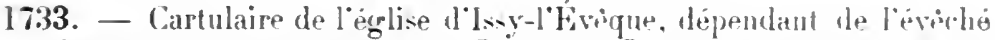

d'Autun; ms. du $\mathrm{XV}^{\mathrm{e}}$ siècle [incomplet]. contenant 202 actes des années 1439-1454. sur parchenin. in-folio de itf. Arohires dip. do lin Coute-d"Or. (i i.).

Ivry-le-Temple. - Commanderie (dioc. 16 loanuais).

1734. - Cartulaire de la commanlerin d'Irro-le-T'muple: ms. du XVle sieccle. sur papier relié en parchenin. rédięe d'après les oritrinanx par Nicole Sinson. prostre. et contenant des actp- 1t. 1168 a

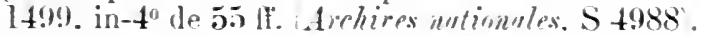

Ivry-sur-Seine. - Voy. Boyalle.

Ixelles. - Hospico Sininto-(roix (dion de Malines).

1735. - Cartulaire 1to l'huspin Sainte-linix d'Ixelles-les-Bruxelles; ms. dles XVe-XVII siècles. sur papier. contenant des titres de 1:340)

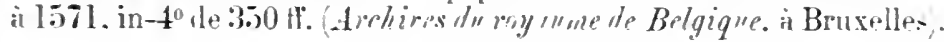

Janville-en-Beauce. - Fid de la rilange-le-Pui.

1736. - Cartulaire de la (irange-le-Roi in Janville. dépendant des Célestins de Sens: ms. du XVIe sieccle. sur parchemin. contenant des actes des anmés 1284-147\%. m-folio de :37 If. Arrhires dip. do l'Yimne, $\mathrm{H}$ öfi.j).

Jand'heures. - Ablaye (mim. 1, Twul).

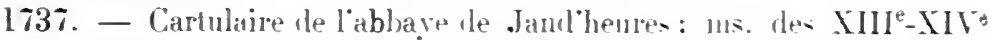
siècles. sur parchemin. in-t" de io tl. "dirhices dép. de Weurthe-etWriselle, B 47!).

Extraits faits an XVII" sièrle 'Biblighll. untionmle. mns nonv. acq. françaises 742.5. f1. 154-189.

1738. - Autre du XV111 siècle [1780]. sur papier. en 2 wal. infolio de:390 et 251 II. (Archires dép. de lu Yeuse. H non coté

Dates extrènes: 11 ini-1;i:.

Jaucel. - Abbaye (disc. le Biziers).

1739. - Cartulaire de labhave do Jancel : oritr. perdu.

Extrait fait par Dom Estiennot en 1679 Biblioth. nutionule. ms. latin 12761. p. 473 .

Jeanne de Bretagne, damo de Cassel.

1740. - Cartulaire de la lame de Cassel: ms. du XIV siecle. sır 


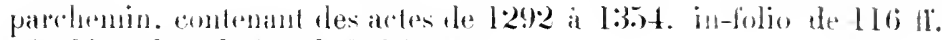
Archives dép. de Vort. B l.573.

Jérusalem. - Église du Saint-Sépulıe.

1741. - Cartnlaire du Si-Sépulere de Jérnsiltem : ms. dn XIVe siècle, sur parchemin, in-4" de $1.8 \mathrm{fl}$. (Biblinth. dr Valiran, ms. 7241).

Extraits faits an XVII" siècle Bibliolh. molionule, coll. Duchesne, vol. LVI).

Antre cartulaire, un peu moins complet, et contenant senlement (Iuatre documents de plus (gue le précédent; ms. clu XIVte siecle, sur parchemin, in-folio de 12!) 19.' Bibliolh. d" Valican. ms. 4947).

Copie moderue du mème (Bihliolh. du Vulican. ms. Ottuboni 985).

Publ. : Cartnlaire de l’église du Saint-Sépuldre de Jérusalem, publie daprès les mannscrils du Valican par bingène de Revière.

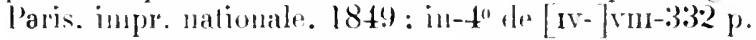

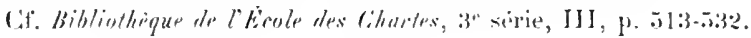

Joigny. - Hôtrl-l)iru (dioc. lo soms).

1742. - Cartulaire de l'Hotel-Dien de Joimny : ms. du X Ye sierle, sur

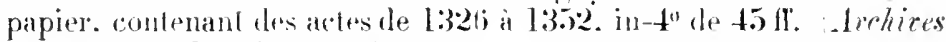
lisspitulieres de Joigny. A 4 .

Joinville. - Érliso anllogiale Silnt-Lamment (dime de (Châlons-sur-ylarne).

1743. - Cartulate du Chapitre de Saint-Lanren do Joinville : ms. des $\mathrm{X} I \mathrm{I}^{\mathrm{e}} \mathrm{-X} \mathrm{V}^{\mathrm{e}}$ siecles. sur parchemin. contenant des titres de 1178 it

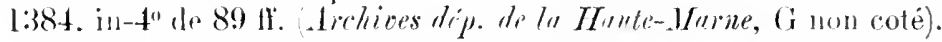

Lixtraits du mense. laits en li8!' Billioth. natimnle, ms. Prancais 115.39, fi. $6-26 \mathrm{i}$.

1744. - Aulre carbulaire des XIVe-XVIe siecles 1:364-1.57t. contenant !) If. : origg. perdu.

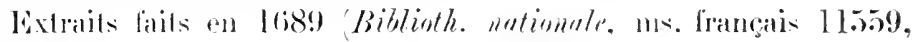
II. $28-51$.

Joinville. - Plinipaluli.

1745. - Cartulaire alrégé de la principante de Joinville: ms. perdu [se trouve peut-itre dats les anchives de la lamille d'Orléans it Drenx].

Copie faile par Virabel de Voisin. allache is 11 . le lue d'Orléans, en lévrier 17tl : in-t" de 27 lf., sur papier, contonant des artes de 1:270 is 1:328 Biblioth. untimale, ms. francois 11570).

174t. - Rerueil de litres pelatifs anx seignemries de Cinise et de Joinville: nus. de la lin da XVIe sierde. forme pate Thierre Alix. sur 


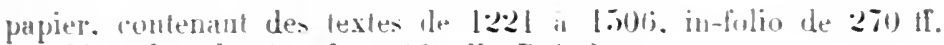
Archices dip. do, Merrthe-et-Misplle. B Hos.

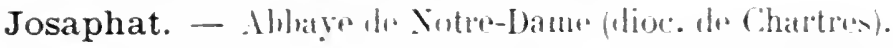

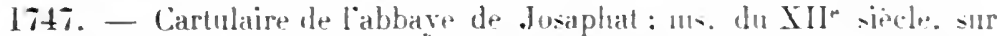

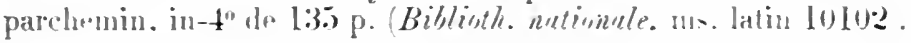

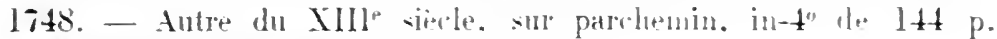
Biblinth. nutionulı. m. Latin 1010:3.

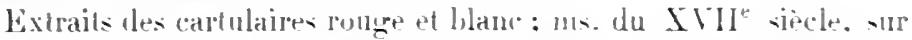
papier. in-folio de li ll. Archices rep. ot Eure-et-Loir. H 198:3,

Exirait. de carlulaires. par Durhesne Biblinth. nationule. roll. buchesne. vol. IV. pp. 249-255. et par Dum La Mirhel Jlpm. 1ns. latin 1:3818. 11. il-7t.

Ce dernitr provient din regintre "peratanton-integer t el d"un autre regristre a linolutus 1.

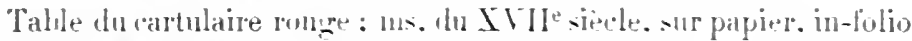
de $24 \mathrm{tl}$. Archires dip. d'Emve-pt-Lnir. H 1 !st.

1749. - Recuril de titres forme d"apres le rartulare et les urierinaux

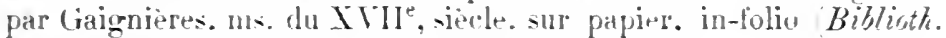
neationnle, mis. latin $5+18$. tl. $333-157$.

Dates extrêmes: : 1117-11:016.

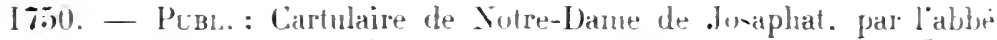

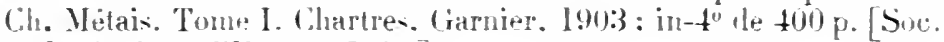

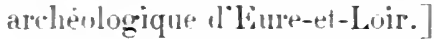

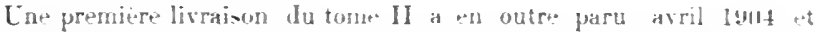

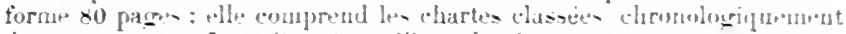
de 1213 a 1230 . Jus fu ä present lintroduction mangur.

Josaphat. - Eqrlise Notre-Dame (Terre-sainte).

1751. - Ptrb. : Chartes de Terre-Sainte pruvenant de l'abbase de X. D. de Jusaphal. par H. F. Delaburle. Paris, Thorin. 1880;

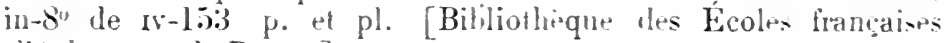
I'Athènes et de Rome.]

Diales extrême: : 1112-128:4.

Jouarre. - Abbare (dioce de Jraux).

1652. - Cartulaire de liabbaye de Junare : orig. perdu.

A éte connu de Dom Toussaints du llessis quand il a eerit sun Histoire de l'église de . Mleaux (17:31.

175:3. - Cartulaire-censier de la mène abbave: ns. du XIIle viecle. sur parchemin. in-1" Biblisth. nutimale. Ins. français 115\%l.

Queldues chartes seulement, iranscrites aux fif. 73-76 et $85-91$.

Jouhe. - Primure (dian. de Besancon).

1754. - Cartulaire de prienter, de Junhe ef de Yontruland : ms. dn 
XVe sierde |14!8], sur papier. in-4" de 37 fr. Biblioth. de la ville de Dole, ms. 1:38).

Contient le texte de: 33 rhartes des années 1318-1418.

1755. - Recueil des titres du prieuré de Jouhe; ms. du XVIIIe siècle, sur papier, contenant des documents des années 1289-1744, in-4 ${ }^{\circ}$ xiI-584 ff. (Biblioth. de la ville de Dole, ms. 144).

Joussineau (de). - Famille.

1756i. - Recueil de litres relatif's il la famille de Joussineau; ms. formé par 1)om Col, en 1769. d'après les archives du chàteau de Tourdonnet en Limousin, et contenant des actes de 1301 à 1693 , sur papier, in-folio (Biblioth. nationale, ms. latin 9197, ff. 74-341). Jouy. - Abbaye de Notre-Dame (dioc. de Sens).

1757. - Cartulaire de l'ahbaye de Notre-Dame de Jouy; ms. in-4", sur parchemin, de 289 parges : orig. perdn.

D'après le P Lelong, nouvelle édition, III, $n^{\circ} 29659$, il faisait fartie de la billiothèque th M. Bouthillier te Chavigny, évêque de Troyes.

Extraits laits pour Gaimulieres an XVIJe siècle [1692], sur papier (Biblioth. nutionole, ms. latin 54ti7, pag. 159-219).

l. nuentur volume contient des extraits ef copies de pieces des années 11.43-1579, aux pages 71-356, avec table onomastique en tête.

Wxtraits laits an XVII" siècle par A. Du Chesrie (Biblioth. nution., ms, nouv. acc. lrangaises 7433. fl. 2:38-239), et au XVIII siecle (Biblioll. nutionale, coll. Champagne, vol. XV1I, ff. 206 et 211-214).

D'après ce dernier extrait, l'original était ècrit par D. Nicolas Proffit, et il y a lieu de ponser 'ju'il s'arit d'un seul et mème registre.

Joyenval. - Abbaye (dioc. de Chartres).

1758. - P'rnL. : Recueil des principales chartes de l'abbaye de Joyenval. pit A. Dutilleux (Mémoires de la Société historique et arrhéologique de Pontoise et du Vexin, XIII, 1890, pp. 74-114).

Dates extremes: 1196-1147. Recucil fort incomplet.

Jugon. - Prieuré dr Notre-I)ame (dioc. de Saint-Brieuc).

1759. - Pri.. Anciens évêchés de Bretagne, par J. Geslin de Bourgrogne el An. de Barthélemy. IV (1864), pp. 331-339.

Juigné-la-Prée. - Prieuré (dioc. d'Angers).

1760. -- Cartnlaire du prieuré de Juigné-la-Prée, dépendant de St-Serge d'Angrer's: ms. des $\mathrm{XV}^{\mathrm{e}}$-XIX $\mathrm{X}^{\mathrm{e}}$ siècles, contenant 46 pièces à parlir de 1060. sur papier, in-folio de $55 \mathrm{ff}$. (Archives dép. de Inine-et-Loire, $\mathrm{H} 108: 2$.

Ne contient que des extraits du cartulaire de St-Serge d'Angers, laits en $1 \$ 87$ par Jean Dupré, greffier de l'Université (pour la $1^{\text {re }}$ partie) et en 1840 par P. Aarchegay (pour la $2^{\circ}$ ). 
Jully-les-Nonnains. - Prieuré (dior. dr lamgres).

1761. - P'vbr. : Cartulaire du prieuré de Jully-les-Nonnaius. par Ernest Petit Bulletin de la Saciété des sciences historiques of unt!relles de l'Yune. XXXIV. 1880. p. 24!9-301). el a part: Auxrre. 1881: in-8 $8^{\circ}$ de $11-54 \mathrm{p}$.

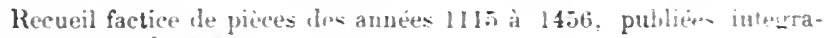
lement ou analyscées.

Jumièges. - Abbare (dioc. de Rumn).

1762. - Recueil do titres et extraits relatils à labbave de Junimpe: ms. du XVII siècle formé pour Gaignières. sur papies. intfulio Biblioth. nationale. ms. latin 5424. pages 35 is 187 .

Dites extrêmes: VIIIte sieclé-1591.

1763. - Grand cartulaire de Junièzes: ms. du XIIle siente. - parchennin. avec additions du $\mathrm{XVe}$. contenant 311 actes des annes 1218-1442. in-folio de $152 \mathrm{ff}$. 'Archires dép. de la Seine-Inférieur. H non cote'.

1764. - Petil eartulaire; ms. des XIII -XIte siocles, sur parchemin. contenant 178 pièces des années 1211 a 1385 , in- 8 " le $140 \mathrm{fl}$. (Archices dep. de la Seine-Infírieure, H non cote).

1765. - Autre des XIVe-XVe siècles. sur papier. contenant 4!) pieces des années 1027-1409. in-8" de $75 \mathrm{ff}$. Archives dép. de lo SeineInférieure, $\mathrm{H}$ non cuté,

Extraits du grand cartulaire. faits par A. Wn Clasne 'Biblioth. nationale, coll. Balnze. vol. XL. ff. 105-405; n1s. latin 1:381;, ff. 349-355.

L'Abbaye-au-Bois. - Abbaye (llioc. do Paris).

1766. - Cartulaire de l'Ahlave-aux-Bois : ms. In XIXe siecle. runtellant des titres des années ${ }^{2} 200-1768$, sur papier. in-folio de $4114 \mathrm{tt}$. (Biblioth. de la cille de Iryon. coll. Peigné-I elacunrt, ms. 14.

L'Abbayette. - Prieuri de Saint-Ilichel (divc. Hu Mans).

1767. - Perc. : Cartulaire de St-Wichel de l'Abayette prieure de l'abbaye du Mont-St-Wichel 997-1421 par A. Bertrand ite Broussillon Bulletin de ln Commission listorique de l" Mayentse. IX. appendice). et a part: I'aris. 1894 ; in-8 $8^{0}$ de 6.3 p. et pl.

Recueil de chartes empruntées aux dichices dëp. de ta Manche et it des copies de Gaignières (Biblioth. nationale, ms. latin it:3ya , pp. $147-172)$.

La Bénisson-Dieu ou Nizors. - Abbaye (dior. dr SaintBertrand de Comminges).

1768. - Cartulaire de La Bénisson-I)ieu : orig perilı. 
Fxtraits haits pal (Silrenart an XVIJ siecle (Biblioth, nationale, coll. Iuchesne, vol. CXVIII. If. 5:3-57.

\section{La Bloutière. - Prirurri (dioc. de Contances).}

1769. - Fragment d'un cartulaire du prienré de Saint-T'homas de La Blontière; ms. du XIVe siecle, sur parchemin, in-folio de $12 \mathrm{ft}$. Lrehices díp. de la Wanche, H non roté.

Copie du mêne dans le mis. français 4900 de la Biblioth. nationale.

La Bonne-Maison. - Couvent des Minimes, à Choisy-aubac (dioc. de solsions).

1770. - Cartulaire des Minines de la Bome-Maison: ms. du XVIIe siercle [ [640]. sur parchemin, contenant des titres de 1664 a 1640 , in-4" de 62ti palges Archices dép. de Seine-et-Oise, H non toté).

La Bourdinière. - Pricuré (dioc. de Chartres).

1731. - Cartulaire du prienre de la Bourdinière. dép' de l'abbaye de lat Gitline: urige. perdul.

A tété connu de Lainné, prieur te Mondonville, qui le cite (Biblioth. untiumle, ms. français 24133 , fo 971 ).

La Brayelle d'Annai. - Abbaye (dioce d'Arras).

178.2. - Cardulate de liablaye de X. 1). de La Brayelle; orig. perdu.

Cupie dn précrent. par Etienne Le P'ez. religienx de Saint-Vaast, faile au X TII" siecle, sur papier. in-40 Biblioth. de la ville d'Arras, min. 606 .

Copie noderne du mène. sur papier. in-4" de $118 \mathrm{ff}$. (Idem, ms. 11 tit.

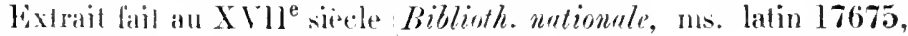
Ili. $44-45$.

Pl'ms. : Cartulaire el ablesses de La Brayelle d'Annai, par Albert Inenarquelle. Ire partie. Iille. Duroulombier, $188^{\circ}-86^{\circ}$; in- 8 " de [1] $]-x \times 1-4: 32 \mathrm{p}$.

Le's documents puhliés aux pages 2.ri-3015 de ce volume onl pour Valros cxtrênes 11906-13ìti.

La Brosse. - Prieuré de Siant-Blaise (dioc. de Chartres).

I733. - Cartulaire du prienré de La Brosse on Saint-Blaise, dépendant de laibhaye de Josaplat; ms. du XVII siècle, sur papier, in-lolio de 38 Ii. Archives tép. d'Eurp-et-Lair, H 2:205.

Dates extrênes: 11:3-15.18.

L'Absie. - Mbbaye (dione. de Poitiers).

1774. - Cartulaire de labbaye de VAbsie; ms. du XIle siècle, in-40

de 1:34 ff. an moins. contenant 5.5 actes; orig. détruit par l"incendie qui irclata is la prélecture des lenx-Sivres en 1805. 


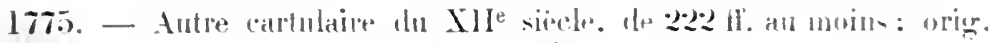
détruit en mène temps qun le précedent.

Extraits par Busly Biblistle. nutionale, coll. Hupuy. vol. 70:2. 815.). 8:2. 8:8 el 841, pasim : - par Tiagnipre en 1680 Biblinth. nationale, ns. datin 17048. pp. 1-.59.

Publ. : Cartulaire of chartes de liabhave de L; Absie. par B. Ledain (Archices historiques Il! Poiton. XIV, 185.5. p. vil-xv +t I-234).

Extraits faits an IVIE sievle par André Du Cilnesn* Biblinth. nutionale, ms. nowv. acq. francaises 7433. I1. :3-19: - ot d'apres Besly Idem. ms. Latin l:3816. If. $11-1: 3$.

La Bussière. - Ibbaye (dioc. ll' Autun).

1776. - Cartulaire de labhave de La Bısiese: ms. du XIIJ siecte [1280]. sur parchemin. in-8" de 119 ff. Biblinfl. mulionule, ms. lalin $) 4(3: 3$.

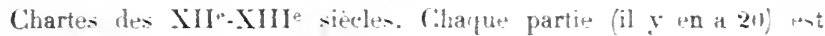
précédée d'un index.

Copie du précédent. filte an X VII sierle pour Bunhier. sur papier. avec table en tẻte. in-folio de xxv-25l pares Biblinth. nutiomale, ms. latin 17722 .

Fxlraits faits an XVIP siecle Biblinth. natimule. coll. Balnze. vol. L.XXII, ff. 100-I I6.

La Cambre, pres do Bruxelles.- - bbaye (rloc. dr Malinws).

1777. - Cartulaire de labliaye de La Cambre: ms. du XV sienele. sur papier. contenant des actes de 1201 is 1484 . in- $t^{\prime \prime}$ le $78 \mathrm{fl}$. (Archices du roymume de Belgique, a Bruxelles.

1778. - Autre des XV-XVII siecles. sur papier. contenant des actes

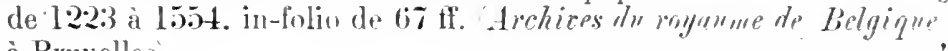
à Brixelles'.

La Canourgue. - Prieure de Saint-Martin (dive. lte Yende). 1779. - Recueil de titres relatils an prienre de St-Mintin de lit

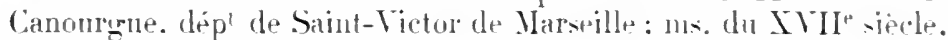
forme par Dom C.hantelun Biblinlh. nutionule. ms. Latin 1:3845, ff. $34-39$.

\section{Lacapelle-Livron. - Vill..}

1780. - Cartulaire municipal de Lacapelle-Livion. contenant les actes depuis 1268: ms. écrit en 15.51. sm" papier. in-t" lichires muniripnles de Lucupelle-Lirvon. 'Tamrn-et-Garonne.

La Case-Dieu. - Abbay (dioc. d'Aurh).

1781. - Cartularir de labbate de La Carse-Dieu : orige perdu. 
Simblrenx extraits finits an XVII" siècle [1747] dims les

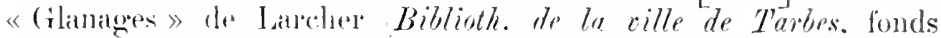

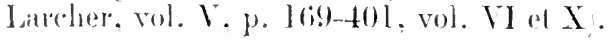

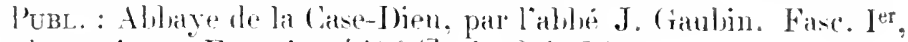

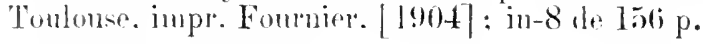

\section{Lacaune. - Ville.}

1782. - Cartulaire municipal de Lanature on live vert; ms. du

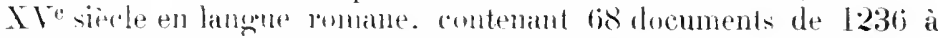
14:38, sur parchenin. in-t" de lon) fr. Arhires municipules de Cinstelnumini?!

C.f. Cartulinire de Latcanue. dil livre verl. par F. Nartin (Proces-

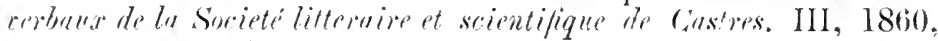
p. 121-127. $140-144+192-200$.

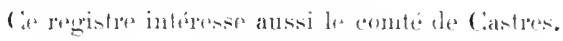

\section{La Chaise-Dieu. - Abaye (dioc. du Puy).}

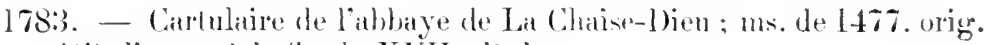

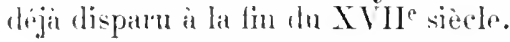

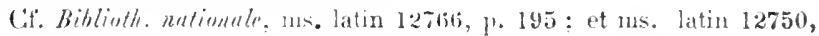
p. 204 .

1784. - Recomeil de litres relatils a l'abbaye de La Chaje-Dien. copiés

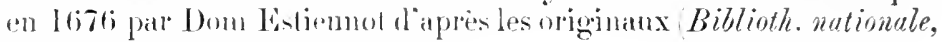
ms. litin I:27.5, pp. 35.7-414.

1785. - Recueil de bulles, diplomes et antres actes relatils a l'abbaye [intricalees en mignal on en Iraduction dans l" " Histoire du munastère de La Chais--I)ien. par II. (rardon. religienx. 1643》]. (Biblinth. nationule, ms. lalin 12757, pp. 3633-565).

A la prage 385 de ce recueil, on trouve nuentionnée une " Pancarta monaterii Catsulei at notario transeriptat anno $1381 \mathrm{n}$.

La Chaise-Dieu. - Priemé (dioc. l'Evreux).

1786. - Cartulaire dn prienré de La Chaise-Dien. dépendant de Fouterrank, orig. perdu.

Copies faites an XVII siècle. d'après ce cartulaire, str papier, in-4" de 4:3 11. Arehiers dip. de l" Eure, H 14:37.

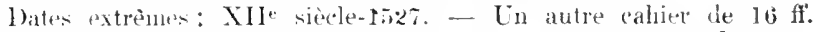
XVIle sincle rontient éralentent des analyses des extraits de même

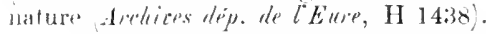

La Chaise-le-Vicomte. - Prieuró de Saint-Nirolas (dioc.

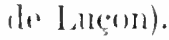

1787. - Punt. : Cammbire du prienré de La Chatise-le-Vicontr, dépt de Marmontier, par Panl Iarcheyary, dims: Cartulaires du Bas- 


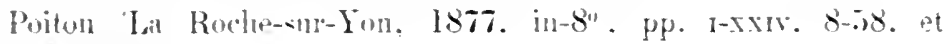
$3: 39-349$.

La Chalade. - Abbave (dioc. de Virmun).

1788. - Recueil de titre relatils a lablaye de la chalade MII"

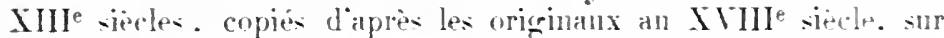
papier. in-folio Piblioth. nutionnle. coll. Champarene. vol. $\mathrm{V}$. ff. $90-111$,

La Chapelle-Aude. - Prieuré (dioc. 16 Bourges).

1789. - Cartulaire de La Chapelle-tude on de Saint-Deni- de la Chapelotte: origr. perdu.

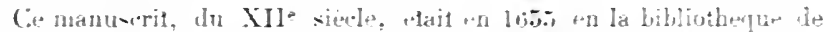

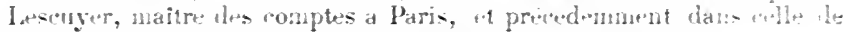
M. Galland: il a ete vu par 1)n Cange, habbe th Mabillon.

Fixtraits faits an XVII siecle Biblioth. de Thesenul. m. 5260. ff. 7i-80:-Biblinth. mutionule, cull. Balnze. vol. LXXIll. pp. 16:216: ms. français 9498. pp. 147-154: ms français $18083.1^{\circ} 20$ : coll. Duchene. vol. XX. ff. 271-295; - Biblinth. de les rille de Dijor. mi. 916 . ff. .i2-5)

1790. - Prbu. : Frazments du carlulaire de La Chapelle-Aulte. par M.-A. Chazaud. Moulins. Desrozier. $1860:$ in- $\delta^{\prime \prime}$ de [ $\mathrm{r}$ ]-xcrv-198 p. [Publication de la Société d'Émulation du Bourtonnais.] — Pièces curieuses on inédites relatives à l'histoire Iu Bontbonnaiv: additions au cartulaire de Lal Chapelle-Aude. par le mème: . d. . in-8" de 11 p.

La Chapelle-aux-Planches. - Abbaye (dioc. dr Truyes).

1791. - Cartulaire de labhaye des Prémontrés de La Chapelle-anxPlanches: ns. du XIII siëcle. avec additions du XIVe, contenant de chartes de 1147 à 1312 . in $-4^{\prime \prime}$ de 39 ff. Archioes dép. de lo. Hure-lerme. H non cote.

Extraits faits an XVII iècle Biblioth. nutionale, coll. Duchesne. vol. XX. ff. 378 et 388 .

Pcbl. : Cartulaire de labbare de La Chapelle-aux-Planches. par labbe Ch. Lalore. dans: Collection des principun curtuluires du diocèse de Troyes. IV 1878; p. 1-87.

La Charité-sur-Loire. - Prieuré (atior. d'Auxerre).

179.2. - Cartulaire dn prienre de La Charite-sur-Loire: orig perdu.

1793. - Autre cartulaire: ms. du XVIle siecle. sur papier. in-folio de 700 ff. Biblisth. de .H. C. Giverd. à Orleans,

Cf. Biblisthique de TEcole des Chartes, III, p. 563.

Prbc.: Cartulaire du prieuré de La Charité-sur-Loire (Nière), ordre de Cluni. par Rene de Lespinase. Nevers. Morin-Bontillier 
[Paris. (Chanpion]. 1887 : in-8" de [r-]xir-479 p. cl pl. [Société nivernaise dess lelleses, sciences ef arts.]

La Charmoye. - Ablap̣e de Notre-Dame (dioce de Châlonsvilr-Marno).

1794. - Axul. Recueil des chartes de lahbaye de La Charmoye Marme par Lal. de Barthélemy. Paris. Champion. 1886. in-l2 de

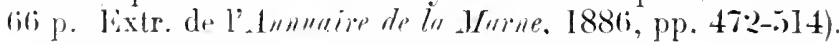

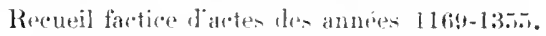

La Chassagne. - Abaye (dior. dr Lyon).

1795. - Carmbine de l'abbatye de La Chalswagne en Bresse; orig. perrlus.

Existail entor" all XVl]" sièle; dinn sil Bihlothecal Sebusiana, Guichenon en a publié trois chartes (p. 22, 129 ef 1:31).

La Chatille, à Bithines. - Commanderie (dioc. de Poitiers).

1796. - Prbl. : Cambulaise le Lai Chatille, par Allred Richard drehires historiques d" Poitun, VII. I878, pp. 1-72).

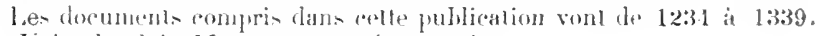

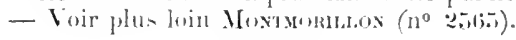

La Chaussée. - Préròté.

1797. - Rerneil de tibres relalifis à la prévòté de La Chanssée; mo. de lil fin du XVI" siecte. formé par Thierry Alix. sur papier, contenant des texters de 1244 ì 1586 . in-folio de 230 ff. Lrelices dép. de

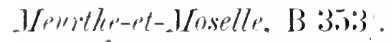

Cople du precédent. finte an $\mathrm{XV}^{\mathrm{e}}$ siecle, sur papier, in-folio Archices depr. de le Mense. $13: 24: 3$.

La Clarté-Dieu. - Abbayco (dioc. dr Toms).

1798. - Recueil de chartes relatives a labbaye de La Charté-Dieu; nis. du XIXe siècle. sur papier, contenanl des copies d'actes de I219 i 1544, par Andri Salmon (Biblinth. de lin ville de Tours, ms. 1347, ff. 1-11:).

La Cochère. - Prieurr do saint-Sanveur (dioc. de Sées).

1799. - Cartulaire du prieuré de Saint-Sauveur de La Cochère, dép du prieuri de Sle-Barbe-en-Ange; ms. du XVIe siecle; orig. perdu.

Copie d'un extrail de ce cartulaire; nus. du XVIe siècle, contenant destitres de 1201 i 1594, sur papier, in-folio de $14 \mathrm{ff}$. (Archives dép. del'one, $\mathrm{H} 334$ ?'.

La Cornouillère. - Prieuré de saint-Blatiso (dior. de Rouon). 1800. - Cartulaire du prienré de La Cornouillère, dépendant de 
Josiphat: ms. dn XVIle -ieme [162!)], sur papier. in-folin re 2!) ff. Archices dép. de Eure-el-Lrir. H :2:27.

Daltés extrênes: : 11701-1019.

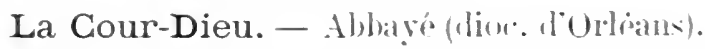

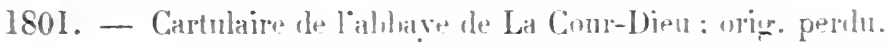

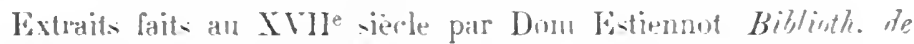

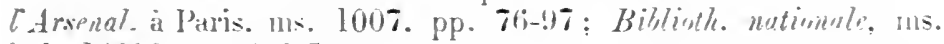
latin 1:2739. pp. 497--0):3.

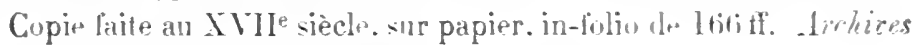
dep. d" Lripet, $\mathrm{H}$ i2 previsuire.

Publ. partiellement: Histuire de labbaye de La Cour-1)ien.

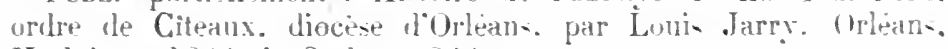
Herluison. 1864: in-8o de sin-2:34 p.

La Cour-Notre-Dame on Michery. - Abbaye dim. de sins).

1802. - Cartulate de l'albure de La Cour-Jotre-Dame: m. du

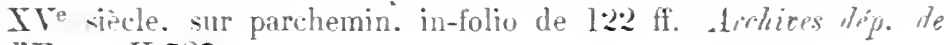
lYomin. H 78\%.

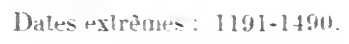

La Couronne. - Ablaye (dioc. d'Angouleme).

1803. - Cartulaire le l'ahbave de La Conronne: m. late de l:275. -111 parchemin. contenant des actes des annes II $18-129.5$. in-18 de 40 ff. Arahices dep. de la Churente, $\mathrm{H}$ non coté.

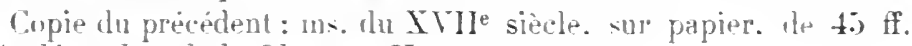
Archies dép. de lu. Churente. H non coté.

Pebl. : Chartes aintomeatise de l'ablare de La Couronme par G. Babinet de Rencoune of Paul de Flenry Archires histroriques de la Saintonge et do l"1unis. VII. 1881). pp. 17-284.

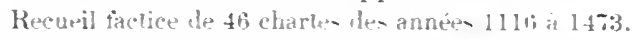

La Croix-en-Brie. - Commanderie (dim. de Sens).

1804. - Cartulaire de la commanderie de La Croix-en-Brie: orig. perdn [il avait an moin- $11: 2 \mathrm{ff}$.$] .$

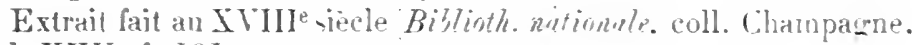
rol. XXY. f" 191 .

La Croix-Saint-Leufroy. - . bbaye (dive. l'Érreux).

1805. - Cartnlaire de lablinge de La Croix-Saint-Leufruy : min. perdn.

Extraits faits an XVIII sirele Biblioth. mationnte. mi. nomvelles acr. françaises $7: 384$. fin $3: 1-47$. 
La Ferté-Avrain. - Colligialr St-Barthélmuy (dior. de Blois).

1806. - Cartulaire de la collégriale Saint-Barthétemy de La FerléArain; ms. dn XVIe siecle. sur papier', contenant des documents

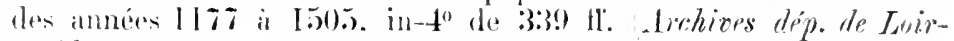
et-Cher. ( $\mathrm{r}: 3: 37$.

1807. - Recoueil de litres relatifis a la mème explise : ms. du Xlve siècle. sur papier, in-4" de 181 puges (Billioth. mutimale, ins. Clairambiult 970 .

La Ferté-sur-Grosne. - Mbbaye (dior. lle Cihalon-sursilono.

1808. - Cartulaire de l'abbarye de La Ferti-sur-(irosne; ms. du XIl" viecle, en forme de pancartes. sur parchemin lichives dep. de

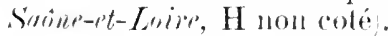

Copir du cartulaire de lahbaye de Lat Ferté-sur-(irosne; mo. du

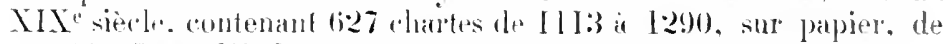

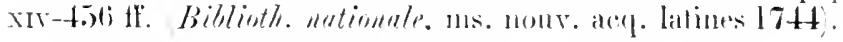

La Forêt-sur-Sèvre. - seignemrie en Poitou.

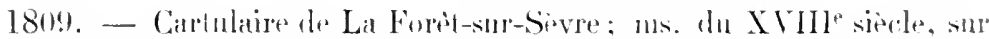
papier. contenant des actes de 1406 a 1723 . in-folio de $4.54 \mathrm{ff}$. British Muserin. ms. ald litional 17:316.

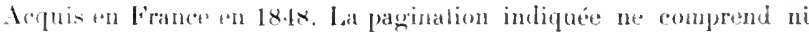
la lable analytique du début, ni la table alphabélique des matieres qui

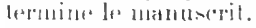

La Garde-Châtel. -- Comrent des Carmes (lior. d'Évreux).

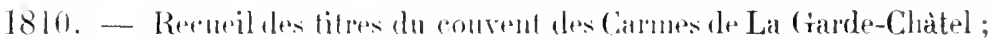

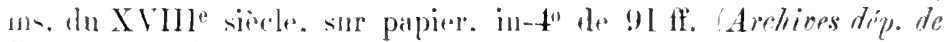
l'Enir. H l0.s!) .

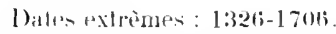

1811. - Autre recheil ; ms. du XVIr vivele, sur parpier, in-40 de $118 \mathrm{ff}$. - lirkiress dip. de l'Etere. H I060).

Dater uxtrènes: : 1 th!t-16xti.

La Garde-en-Arvert. - Primuri de Totre-bame. - Toy.

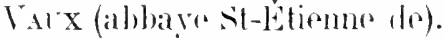

Lagny-sur-Marne. - Ablaye (dion. dr Paris).

1812. - Cartulaire de l'abbaye de Lagny ; ms. rédiuré en 1.5l:3 par Nicolas Vincelol, notaire royal andit lien; ms. dn XVIe siècle, aver additions a la lin el lacune de 4 fenillets. sur parchemin avec lettros ornées el reliure originale en bois. contenaul des actes de 1178 it 15:21, intfolio de vin-2!) [f. (Biblioth. nationale, ms. latin 9902). 


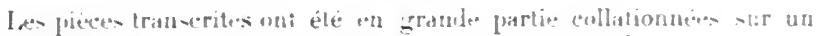

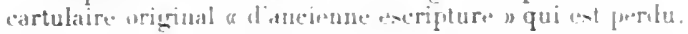

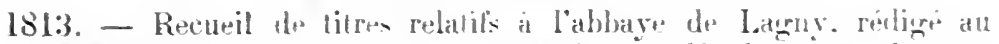

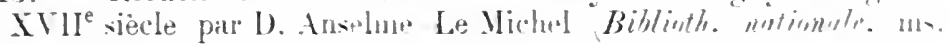
latin 1:3818. if. i6-St.

La Gràce-Dieu. - Abbay! (dioc. Mr Maillezars).

1814. - Pebl. : Recueil de document- relabilio a liablave de La Gràce Dieu. par G. Muswet Arrlices historiques do lu Saintronge ot do PAlnis. IXVII. 18:18. p. 1:34-527.

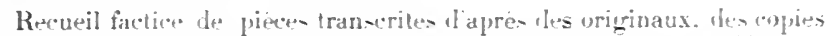

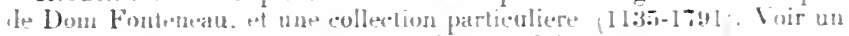

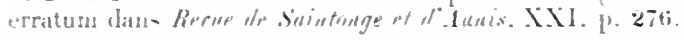

La Gràce-Notre-Dame. - Abbạe, à Claton flion. Ite Lat Rochelle).

1815. - Recueil de titre- relatif a l'albaye de La Greice-Lutre-Dante:

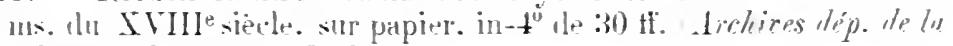
Chupente-Inférienre. $\mathrm{H}: 2 \mathrm{I}$.

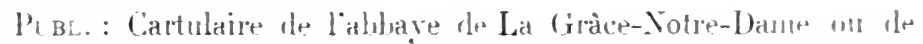

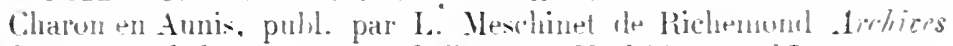

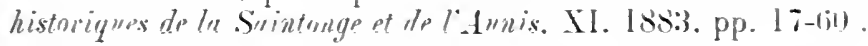

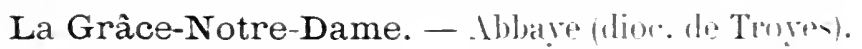

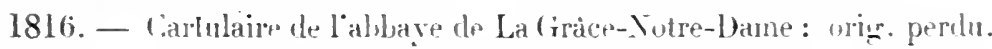

Extraits faits an XVI" -iecte, par le notaire perturwot. dactes des

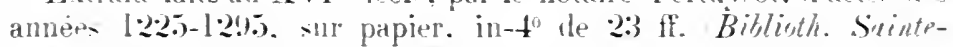

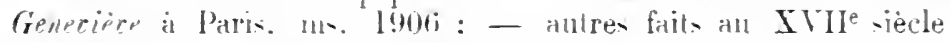

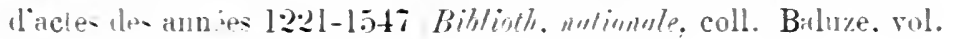
LI, pp. $2: 34-2: 36$.

La Grande-Chartreuse. - Chatrens (dien de (monoble).

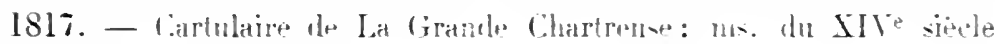
[131:3]: wrig. perdu.

Extrats faits par Dom E-tiennol an XVIr siacle Biblinth. nutionals, ms. Latin 127tis. Pin 81 et $24 !$.

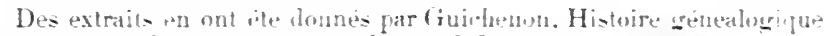

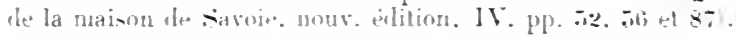

1818. - Recueil de documents sur les possesiuns de La ciramle Chartrense en lalip: mi. du X ve siècle, provenant de San Martino da Yapoli, in-4" Biblioter" Bimmecinnu, is Saples. corl. 2 F 10 .

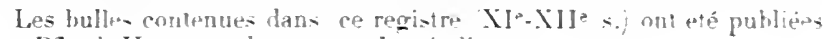
par Pfugh-Hamelung dians son "Iter italicuu s. 


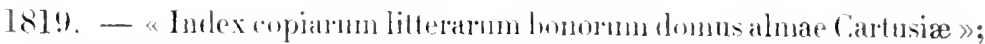

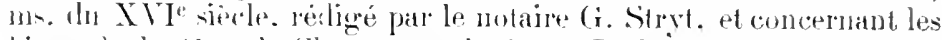

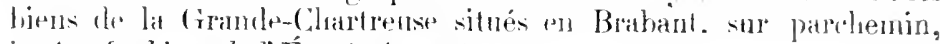
in-t" Arohires do l'Etut is Aurees.

1)aten extrentus: 1:392-1530.

La Grasse. - Mhaye de Saint-Hilaire dioce de Carcassilltie),

1820. - Lives verts de labbaye de La Grasse. contenant des dociments de 806 i I603. termintes loim en l408. l'anlre vers 1610 : mss. sur papier. de 275 et II8 ff. in-40 Archices dep. de l'dude. H 8-9).

1821. - Livre noir de liablate de La Grase. contenant 16.5 documents de 959 i 1769 : ms. éril an $\mathrm{XVH}$ e siecles snr papier. de $459 \mathrm{ff}$. in-folio Archires dip. de l:Aule, $\mathrm{H} 10$.

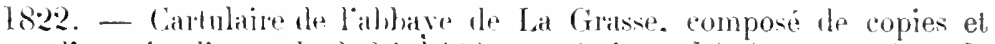
thextrails d'atetes de 806 i i 4 !):3: ms. écrit en 14!4. strl papier, de 112 fI. in-f" Item'.

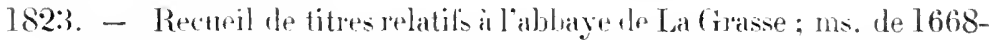
166i9. rontenitut des docmuents de 806 is 164ti, en 3 vol. in-lolio de 44. 4.88 et 390 tf. Biblisth. nutinnale, coll. Doat, vol. bit-68).

1824. - Antre recueil de titres relatils a l'alhaye de La Grasse; ms.

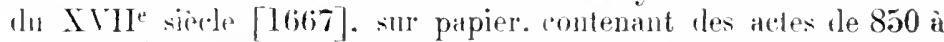
1509. in-folio Bithioth. motimmle. coll. 1) bat. vol. 7l. ff. 1-503).

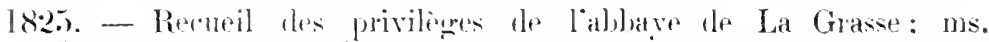
[incomplet de la lin]. Wh XIVe siede. sur papier. contenant des

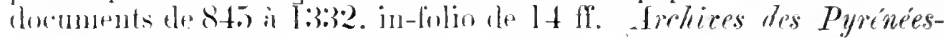
Orientales. B:2.

1826. - Bullatre lle lablate de Iat Grasse: ms. du XVlle siecle, sur papier. contentult des dormments le 1119 i 1507 . in-40 de $21 \mathrm{ff}$. Lelices dép. de linde. H 16 .

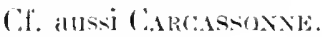

La Grenetière. - . Whayro (dione. do Poiliess).

1827. - Recneil de tites de labbare de La Girenetiere: ms. du XV1II sierle. sur papier. contenant 10:3 pières des années $1106-$ 1625. in-4" Biblioth. de la rille de Puitiers, coll. Dom Fontenean, vol. IX. pp. 85 is 3366 .

Laguépie (Talln-1-( raronme). - Ville.

1828. - Cartulatire munipipal le Languepir: ms. du XVe siècle [1435] avec aulditions du XVI" sisele. contemant aussi des fragments

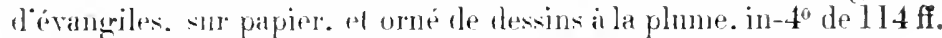
Awhires de rhitemn de Combret. pres de Mamillate dieyron!. 
La Haye-aux-Bonshommes. - Prinur (dior. d'Angers).

1829. - Cartulaire du prienrí de Ia Haye-itux-Bonshommes: me. de

la fin du XVe sièrle. sur parchémin. orne darmurites coluripas. in-folio de 2:39 ff. Biblioth. de lin cille dingers. ms. 85,

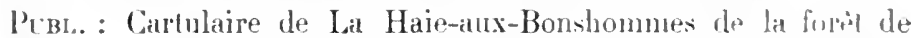
Craon, publ. par M. Paul de Farey Bulletin de la Commissirul histo-

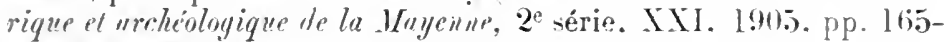
199 et $295-324$.

lixtraits dn mène. faits ponr Gaignières, sur papier Biblinth. nutionale, 111 . françis $224.50, \mathrm{pp} .221-2322$.

La Haye-Pesnel. - Hôtel-Di̊ru (dior. d'Arranchess).

1830. - Cartulaire de l'Hòtel-Dieu do la Haye-Pesnel: m. lróligé en 1687 par frère Gilles Lescolace d’après le cartulare du prieuré de La Bloutière, et contenant des locuments a partir dn XIJe -iecle, in-folio sur papier (Biblioth. de la cille "Arrunches. mo. 21!.

C'pst sans doute le mème volume yui a été signalé commo appartenant a la rure de Folliguy Manche ; cf. Champollion-Figeac, Documents historitgues, I. p. 349.

La Howarderie. - Famille.

1831. - Un Cartulaire de la Howarderie. publ. par le C'e de La Howarderie-Nenrireuil. Tournai, Vasseur-Delmée. 1889; in-folio de II-234 p. et fig.

Laitre-sous-Amance. - Prieuri (dioc. lle Toul).

1832. - Cartulaire du prieuré de Laitre-sons-Anance: mıs. daté de 1534 . in- $t^{\circ}$, le 24 el I? ffr.

$\mathrm{C}^{2}$ volune figurait sous le $n^{0} 31$ dans le catalogue de la vente Marehame in 1859): on ignore (or qüil est devenu depuis lor..

La Joye-lez-Nemours. - Abbaye (dioc. de Sens).

1833. - Cartulaire de l’abuave de La Jove : origr. perdu.

Copie faite en 1717. contenant des documents depuis 1230. sur papier. in-folio de 14 if.

Indiqué ains dans le catalogrue de $184 \pi$, ce resueil ne se retroure plus aujourd hui aux Archices tip. de l'Fune.

Voir allsi: Villiers-la-Joye.

La Joye-Sainte-Claire. - Prieure (dioc. de Sioissons).

1834. - Cartulaire du prienré de La Jove. dit Sainte-Claire: ms. du XVille siècle, contenant des titres de 1240 à 1692, sur papier, in $-4^{\circ}$ de $124 \mathrm{fr}$. Biblioth. nutionule, ms. latim 9172.

Copie moderne du mème, sur papier. in-folio de 520 p. 'Bitrinth. de la wille de Voym, collection Peimné-Delacourt. ms. 19 . 
La Lance. - Chartreuse (dioc. de Lausanne).

1835. - Cartulaire de la (hartrense de La Lance, dit Cartulaire A; uns. du $\mathrm{XIV}^{-r}$ siècle. incomplet. copié par J. de Eschallens, prètre, in-4o de $1.21 \mathrm{tr}$. Arehives contimules de Lansunue).

1836. - Autre dit Cartulaire B : ms. du XIV siècle, écralement incomplet et contenant seulement quelques acles manquant au prérédrnt. in-4 de !) 11 . Arrhives cantonales de Lausannej.

1837. - Pr. BL. : Documents relatifs à la Chartreuse de La Lance, par labblé .I. Grénamil Mémoires et docunents publ. par la Saciéte d'histoire de la Suisse romende. XXXIV, 1879. pp. 539)-588).

(Quelyues documents den années 1:318-15:39 tirés des cartulaires et des originaux.

Lalinde. - Ville.

1838. - Cartulaire on livre consulaire de Lalinde; nus. commencé en $15 l^{\circ 2}$ el continué jusqu'en 1737 . sur parpier. in-4" de $619 \mathrm{tl}$. Lplus $t$ suppl.]. reconvert d'unte relinse en vean roux du XVIII siècle Archires dip. de lin Dordogne. li non coré).

La Luthumière. - Prinure (dioce de Contances).

I8:39. - Cartulaire du prienré de La Lathumiere, dép' de St-Sanveurle-Vicomle: ms. daté de 14.52 . contenant to actes des années 114t-1446. sur parchemin. in-t" de 3.5 tr. dirhives dép. de la Mrrnlie. H non colé.

La Luzerne. - Mbbare (dior. d'Avranclues).

1841). - Publ. : Casulairesa de la Manche: Ablaye de La Lazerne, par M. Muluse. Siant-Ló. Jacqueline, 1878 ; in-t" de v-2.5.3 p.

Recueil fatches de documents allant de 1140 at XVle siècle. Le manuscrit qui a servi ì limpression, daté de 18.4. est. constrvé aux arelives drip. de lat Manche (in-40 sur papiel de $200 \mathrm{ff}$ ).

La Madeleine de Bolleville. - Léprosirie el prieuré (dion. dr. Coutances). - Voy. Bolleviluk.

La Magdeleine-lez-Orléans. - Prieuri(dioc. d'Orlians).

1841. - Cintulaire du convent de La Matuleleine-lez-Orléans, dép te

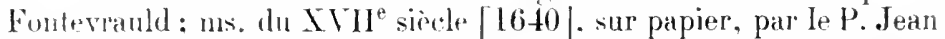
Iardier". religieux, en lo vol. in- $4^{\prime \prime}$ [le lome IV manque] (Biblioth. nationule. ms. lrançais 1197\%-1198\%).

La Maison-Dieu. - Priruré près de Saint-Jean de Losne (dioc. do Besançon).

1842. - Cartulaire du prienré de la Maicon-Dieu, dépl de lablbaye de Citeaux; ms. du XVII" siecle, sur papier, contenant 52 chartes 


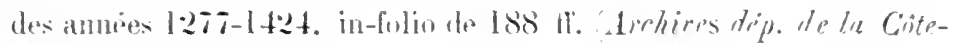
तOr. H nou culii.

Lamarche. - Prevote.

184:3. - Recuril de lím relalifs a la prónte de Lamarche: me. de la fin du XVIe siecle. forme par Thierry Alix, sur papier. contenant des

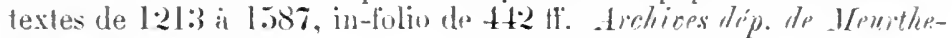
et-1Ynselle. B:36i;.

Voir ansi yo Butryost.

Lamarche. - Trinitaims (dime. le Totil).

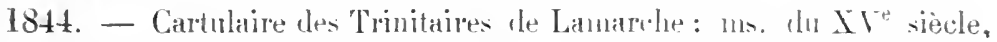
smr papier. in-lolio de :3I ti. Lwhires dip. de Monrth-et-Moselle. B 712 .

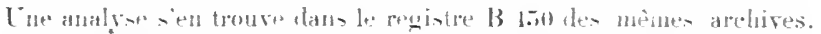

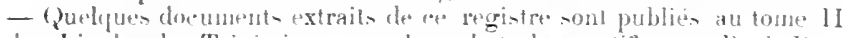

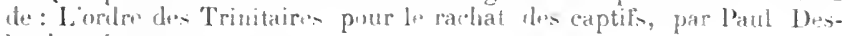
landres (190:3.

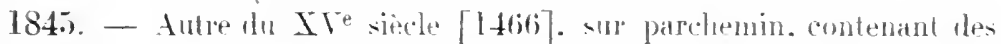

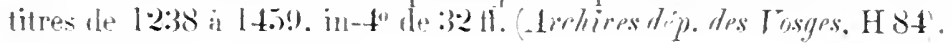

Lamarche. - Tille.

1846. - Cartulaire mumipal in Latnarehe-sur-Sàne, écrit en 1788,

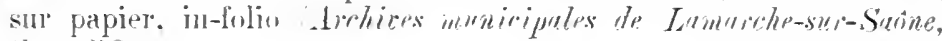
Còte-li"Or*

La Marche. - Cilapelle Notre-Lame (dioc. de Cambrai).

1847. - Retueil le litres rehtif a la chapelle Tutre-Dane du chàtean de La Marche: ms. du Xle sierle. sur pipier. contenant des titres de

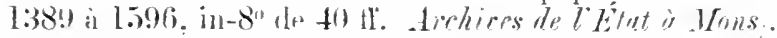

Lamballe. - Prienré ur saint-Iartin (dioc. de Saint-Brieuc). 1848. - Prbi. : Anciens érèchés de Bretanne. part .J. Geslin de Bourugogne el An. de Bartléleny. IV'1864. pp. 300)-3328.

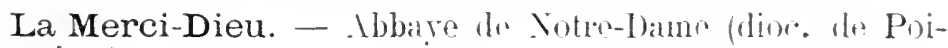
timis).

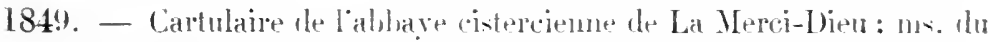

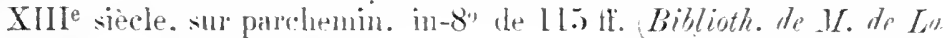
Fourlundière, à Poitiers.

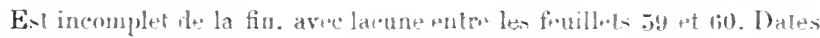
"xirême: : $11.31-12 ! 1$.

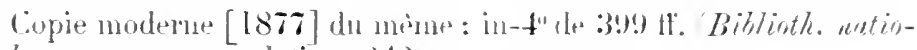
nule, ms. noux. acq. latines :24:2.

La copprest médiocre et presente der lacunes.

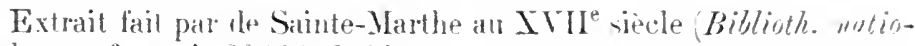

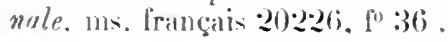


Antres extraits laits en I75l. sur papier. in-folio Biblioth. natiounle, collection Clairamlanlt. vol. (99!). If. I-(i2 .

P'sr..: Archives historiques the Poiton. XXXIV 1905), par Henri Clonzol, Poitiers, Oudin. 1905: in-80 de xxry-45o p.

Extruits fails an XVIII siecle Biblioth. nutionule. collection Dom Honssealu. passim).

18.90. - Recureil de copies lle pieces relatives a l'ablave de La Nercibiru: n1s. du XIX siècle. sur papier. contenant des actes dn Xlle siecle i I 474. par Andre Salmon Biblinth. dr lu ville de Tours, 111. 1:347, If. 12(i-2:20).

\section{La Mothe-en-Bassigny. - Previte.}

1851. - Recueil de titres relatils à la prévòté de La Mothe; mo. de la lin du XVI siècle. formé par Thierry Alix. sur papier. contenant des textes de 1217 a 1527 . in-folio de $430 \mathrm{ll}$. Archioes dep. de Meurtheet-1/osille, B :36it.

\section{L'Amour-Dieu. -- Abbarr (dioc. de Chàlons-sur-Jarne).}

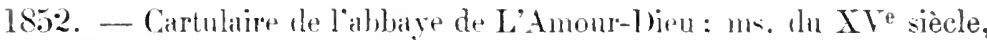
sur pipier. contenant des actes les années 12:31i-1 111 , in-4" le 53 ff. drelices drip. de ln Marne, H non coté).

Lancé. - Priente. - Voy. Marmutier.

Landévennec. - Abayr (dioc. No Quimper).

185:3. - Cartulatre de l'ahlatve de Latndivennec: ms. du XIe siècle.

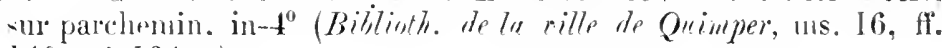
$140 \mathrm{v}^{0}$ à $\mathrm{I} 64 \mathrm{v}^{\text {r1)}}$.

Copie faite au XVIe siècle, sur papier, lle 80 ll. Biblinth. nutionale, 111. latin 9746).

La lacune de 2 ti. existait quand cette copie fut executée.

Pubr.: Cartulaire de Landivennec. par F. Le Men el Émile Eimanlt. avec une préface de H. d'Arboí de Jubainville (Mélanges historiques. publ. dans la Collection des Durmments inédits. V, 1886, pp. 5333-(600).

- Cartularire le liablate de Landévemec, texte du cartulaire, avec nutes variantes. par Arth. de La Borderie. Rennes, Plihon et Herve. ]888: in-8" de xn-2l8 p. [Société archéolggique du Finistire.]

Deja l'attention avait été nttirée sur "e texte très important pour l'hisforre de Bretagne par H. d'Arbois de Jubainville (A,chives des Whissions srientifiques, $3^{\circ}$ série, 1, 1873, pp. 52-5-734), par Alf. Ramé (Bulletiu d" Cumits ins tracaux historiques, 1882, pp. 419-448: 1883, pp. 55-57;

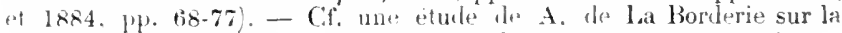

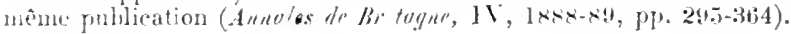




\section{Landrecies. - Vis. Marollits.}

La Neuville-lez-Châlons. - cimmandritr. dim. 11. Chàlons-sur-.larmo.

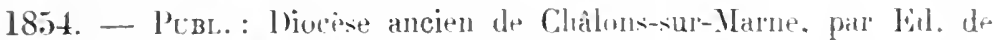
Barthélemy, I 1861 . p. 394-4:36.

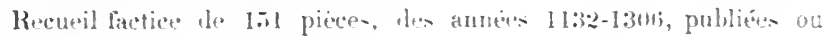
analyation.

Langres. - (:hapitre cathèlral saint-Mammés.

185̄5. - Cartulaire du Chapitre de Langres: m- du XIIle siècle. écrit de plusieurs mains sur parchemin. et contenant 320 actes des années 889 a 1282. in-folio de $112 \mathrm{ff}$. Archices dep. de ln Hente-Vurne, G non coté,.

1851\%. - Répertoire du cartulaire du Chapitre de Lannress: ms. du Xille siècle. sur parchemin. infolio de $113 \mathrm{ff}$. Biblioth. Cheltenhum. $\mathrm{n}^{0} 2983$.

185\%. - Antre cartulaire: ms. du XIT"e siecle, sur parchemin, contenant 79 actes des innées 1306-1394. in-1" de 172 $\mathrm{tt}$. Archices dép. de la Haute-Warine. G non coté.

Extraits des cartulaires du Chapitre de Langres Biblioth. natiomule. coll. Baluze, vol. XL. tf. 2l6-221, ef LXXIT, ff. 31-55; - m. français 4901 , ff. 196-2:34.

1858. - Autre cartulaire dn Chapitre de Lamgres : orig. perdu.

Copie du précéclent : ms. llu XIV siècle, sur parchemin et papier, in-4" Biblisth. nationale, ms. latin $5993^{13}$. ff. $169-254$,

Dates extrines: 1168-1276. Ce volume a appartenu it pithou, id de Thou et a Collert.

Copie du mème. linte an $\mathrm{XVI}^{\mathrm{e}}$ siècle. sur papier", in-t" de $20 \mathrm{I} f \mathrm{f}$. (Biblioth. notionule, ms. latin 5189.

Autre copie du $\mathrm{XVII}^{\mathrm{e}}$ siècle. sur papier Biblisth. mutionule, ms. latin $138 \% 2 . \mathrm{pp} .17-144$.

Autre copie pour J. Buthier: ms. du XVII" siècle, sur papier, in-folio de xxix-liz p. arec talle en tète Biblioth. nationale, ms. latin 17100 .

Autres copies Biblinth. mutimule. cull. Bumromene. vol. VIII, f1. 1-169; et ms. lrançais 4901. pp. 196-234.

Langres. - Érèché.

1859. - Cartulaire de l'évêthé de Lanures ou « Liber feudurum pcctenie Lingonensis » : ms. du XIII siècle. sur parchemin, avec reliure du XVIe, in-4" de $180 \mathrm{ff}$. Biblioth. de le ville de Langress. ms. 37.

Les $\mathbb{4}$. 151-152 manquent. 
Copir moderne dis pricrelent, sur papien. in-folio le $216 \mathrm{tf}$. Biblioth. de M. 1. de Lu Boullaye, a Troyes.

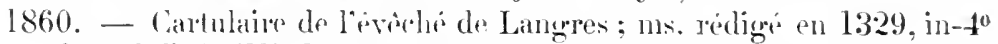
de $291 \mathrm{ff}$. (Biblioth. nationale, 1ns. latin 5188).

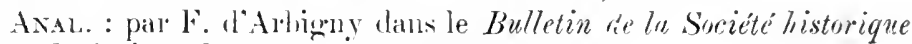
et archéngagique de Langies, $11^{0} 70$ déc. I904).

Copie du précedent laite an XVII siecle. sur papier. in-lolio de

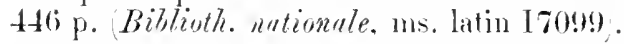

Autre copie du XVII" siecle. sur papier. in-lolio de 640 p. (Biblinth. nationule, coll. Clairambanlt, vol. 974).

Antre copie lu XVIII siecle Biblioth. nutionale, coll. Bourgogne, vol. VIII. ff. $170-437$.

Jximits doun cortulaire de l"rvèch de Langres. contenant des actes de 1272 a 1297. el laits an XVII siecle. sul papier Biblioth. nutionule, roll. Inuchne. vol. XXII, fï. 102-10:3): - autres extraits (Idem. coll. Baluze, vil. XLV).

\section{Languedoc.}

186I. - Cartulaire de Langrnedoc on «Registrum Ciuriae», avec priface ef table des rubriques an débat; ms. du XIlle siècle, sur parchemin. avere leliuge en maroquin anx armes de France. in-folio 1te $119 \mathrm{ff}$. Biblisth. nutimnle, ms. Iatin 9988).

Transcription du rogistre précrdent; ms. dı XIIJ siècle, sur parchenin. in-folio de $7: 3 \mathrm{fI}$. Lrchices nationules, JJ $30^{\mathrm{B}}$ ).

Copie da próédent. laite an XII" siecle. sur parchemin et papier, in-folio Biblinth. du Taticon, 1ms. Ottohoni 25:37, tf. 42-124).

Ancien lostau $x$ t:3.

Aubre copie ancienue Arehiers nutionules, .J.J $30^{-1}$, ff. 1-89).

Copje inachere par Baluze Biblinth. notionule, ms. latin $4168^{\mathrm{a}}$, (1. $127-218$.

(if. Aug. Molinier dans la Biblinthèque de lécole des Chartes. XXXIV, $1873, \mathrm{p} .163 \mathrm{ss}$, et lucien Aurray dan les Melanges Julien Havet $(1894), 3.3 \times 3-388$.

186:2. - Cartulaire de Ianmeduc; ms. du XVI siecle, sur papier, contenant des actes de 14.5 ( a 1523 , in-folio de m-2:23 ff. (Bibliath. de la ville de Reims, ns. 1.22!).

Voir, sur ce volune, le (iatalogue wenéral des manurcrits des billioth. publiques de l'rance (Departements), XXXIX, pp. 737-743.

Lannoy ou Briostel. - Abbaye (dioc. de Beauvais).

1863. - Cartulaire rle labbaye de Launoy; orig. perdu.

lu par Ihom Villeviulle dans les archives de l'úvêché de Bearais.

Ixxtraits faits an XVIII siècle (Biblioth. de le ville de Beauvais, coll. Bucquet-Anxconstemux. vol. XLII. pp. 466-470). 
La Noé. - Abbận (dioc. d'Érreus).

1864. - Framents d'un cartulaire de liabhave de Lat Noé : uns. [2 If. complets et 2 antres mutilés] de la fin du Xille siècle. sur parchemine contenant lir copie intégrale on partielle de 16 chartes cotéas anc. xxvm à A Arehiess tép. de l'Eup, H 705 .

Lantenac. - Abbayede Notre-Lame (dive dr Saint-Brieuc). 1865. - Pubs. Anciens évèchés de Bretagrne ; diocèse de Saint-Brieuc, par J. Geslin de Bourgogne et An. de Barthelemy. IT 1864. pp. $247-250$.

Laon. - Abbar de saint-Jean.

1866. - Cartnlaire de l'ahbaye de Saint-Jean de Laon: ns. du

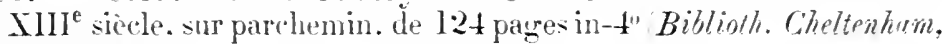
$n^{n} 13: 35$.

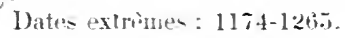

Analyse diactes Biblioth. nutionale. coll. 1). Grenier. rol. 236. ff. $220 v^{-0}-2 \cdot 24$, et vol. 268 . ff. $19 \mathrm{v}^{-11}-25$.

1867. - Autre "urtulaire dispurn. mentionné dans linventaire des titres dressé par Geruzet en 1790 'Archices dép. de l'Aisne. H I'. et où les actes remontaient au noins à 1143 Idem. H 2 .

Extraits faits an XVIII siècle (Biblintl. nutionule. coll. Dom Grenier, vol. 268 , ff. $25 \mathrm{v}^{-n}-27$.

Laon. - Abbave de Saint-Martin.

1868. - Cartulaire de labhave de St-Martin de Laon. contenant 1683 pièces de 11:22 a 1731 ; ms. en 3 roluntes sur papier in-folio. ferits en 1733 Archices dip. de l'Aisne, $\mathrm{H}$ S7l-873,.

1869. - Autre des XIII -XITe siècles. sur parchemin, in-4" de $173 \mathrm{ff}$. à 2 col. (Biblioth. He lu rille de Laon, ms. 582.

Laon. - Abbaye de Saint-Tincent.

1870. - Grand cartulaire de St-Tincent de Laun : ms. des XITe-IV"e siècles, écrit par ordre de Jean de La Forèt, sur parchenum [incomplet des ff. 89 à 390 ]. in-folio 'Biblioth. Cheltenhum, n" 68 .

Quelques-uns des feuillets manquants $[89,90$ et 92$]$ sont a la $\mathrm{Bibl}$. nationale, nouv acquisit. latines 231, ff. 12-14.

1871. - Moven cartulaire de St-Vincent de Laon: ms. de la fin du $\mathrm{XIII}^{\mathrm{e}}$ siècle. sur parchemin, provenant de Petau Archires du Vatican, Misc. Arm. X 145, ff. 1-134.

Publ. : Cartulaire de Saint-Vincent de Laon, analyse et pieces inédites. par René Poupardin Mémoires de la Sociélé dél'histoire de Puris, XXIX. p. 173-267, et à part : Paris. 1902 : in-80 de $99 \mathrm{p}$. 
1872. - Pedil cartulaire de St-Vincent de Laron; ms. de la fin du XII siacle. clont il ur sulsiste plus que deux feuillels (Bibliath. natimiale. ms. nouv. atcq. latine $2: 31$ ).

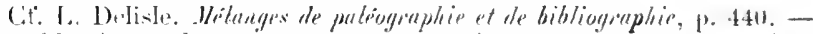
Lne lable de ce dernite" cartulaire a été drescée par boum le Michel,

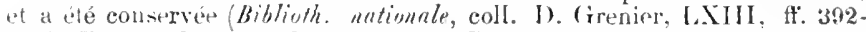
3:mi. Extrait dams 1). Cirmier, rol. CX, t1. I et 12: et CCXXXI1, fi. $219-2501$.

Copie of extraits dn XVII" ot du XVIII" siecle Biblioth. nutionale,

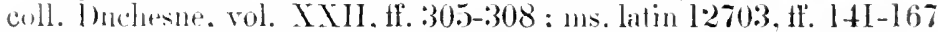
[ce dernier d'après le registre actuellement au Vatican], et :3-86; 11.. latin 1:2704, 11. 278-282.

\section{Laon. - Chapilere calhedral Notre-Dame.}

1873. - Cartulatere de la catherbale de Laion; ms. des XIII siecles, aver alditions justu'an XVIII", sur parchemin, de $182 \mathrm{ft}$. in-folio Biblinth. Cheltenlenin, n" it.

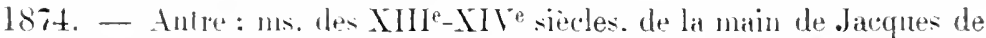
Troyes [Lrhain IV]. sur parchemin, in-folio de 35.8 ff. Biblinth. du Chenpitive die Lanin).

Axir. : Cn cartulaire du Chapitre de la cathédrale de Laon. par

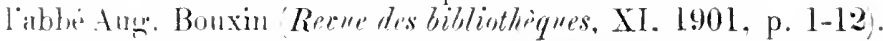

Extrait dn XVII" siecle Biblinth. nutionale, coll. Dom Grenier, vol. (X.X. Hi. :39. 58, 99\%. 21il et $\cdots .$.

1875. - Antre cartulaire de la catheilrale de Laon : origo perda 1 .

Est eité frar Dom (irenieter (Itrm, vol. CCLAXIX, fo 1 ).

Extraits d'mu « cartulaire ronge » de l'église de Laon, faits au XVIJ siècle (Biblimth. muliounle, coll. Duchesue, vol. XXII, tf. 3(1)9-310).

Laon. - Érichir.

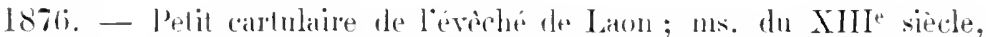

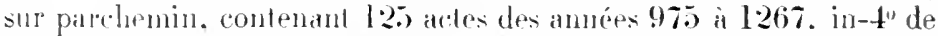

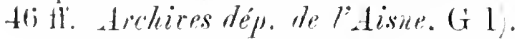

Mannacrit incomplet: In reste st trouve is la Biblioth. Cikeltenham, 114. 1322 (14 fi.).

Analyne dn mêtur. fitle au XVIII siècle. sur papier. in-folio drelires dip. de l'disne. G.).

(1) Le regristre des déliberations du Chapitre de laon (vers 1240). que Dom Grenier a connu et decrit, of qui est actuellenent entre les mains de M. Lobjois, à laon. contitnt un grand nombre de clartes copiées in-extenso. 
1877. - Grand cartulaire de lévèché de Lanon: ins. du XIV̈ siècle. sir parchemin, contenant 276 actes des années $1125-1: 320$. in-folio de 111 ir. à 2 col. Archives dép. de l'Aisine, G 2 .

C. : Deux cartulaires de l'évèché de Laon, par Thillois Buliotin do la Societe acudemique de Lnon, II, 1853. p. 207-228). - CP. ausi Varin : Archives administratives de la ville de Reims. I, p. cLx.

Analye du précedent, faite au XVII ${ }^{e}$ siecle [1768], mais defectuense. sul papier (Archices dép. de l'Aisup, G :3.

Extraits faits an XrIIL sièle Biblioth. untimule, coll. Dom Grenier, vol. CX. ff. 26, 43. 45, 50. 77, 96 et 164 .

\section{Laon. - Hôtel-Dieu.}

1878. - Cartulaire de l'Hòtel-I)ieu de Laon: ms. sur parchemin. du XII ${ }^{e}$ siècle, à l'exception des dernieres pare transcrites an XIV"e. contenant 522 documents. in-folio de $214 \mathrm{ff}$. Archires hospitulières de Larin, A 2).

En tète on trouve une table des rubriques (17 ff.). incomplete tet ne correspondant pas à ce registre.

1879. - Fragment d'un antre cartulaire du XIII siècle. sur parchemin, écril le la mème main que le précédent, contenant 170 charles, in-folio de $69 \mathrm{ff}$. (Archices hospitulières de Laon, A :3 .

\section{Laon. - Ville.}

1880. - Cartulaire municipal de Laon ; ms. du XVe siècle [vers I 40.2], sur parchemin, avec additions jusquan XVIII', in-folio de $12.5 \mathrm{Ht}$. (Archices muncipules de Luon. At 1 .

Dates extrêmes: $1128-1725$. Ce volume test léposé indùment a la bibliothèque de laon.

1881. - Cirrtulaire de la ville ou de la préròté de Laon; ms. du XVe siecle [vers 1480], sur papier. in-f" de $78 \mathrm{ff}$. Biblinth. He ln rille de Reims, ms. 15.99 .

C'est le rolume indi đué par le P. Lelong. nour. élon, tume IHI, no 2911561 .

1882. - Recueil de titres relatifs ḋ la ville de Laon. forme au XVII siecle et comprenant $4 \mathrm{l}$ actes des annét $11 \cdot 2 !$ ! 1481 . in-folio sur papier 'Biblioth. natimale. coll. Bréquigny. rol. XLIV. Hi. 12121 .

La Paix-Notre-Dame. - Iblaye (dioc. de Lithil).

1883. - Cartulaire de labbaye de La Paix-Notre-Dame: n1s. du XIIle siecle, sur parchemin, contenant des acter de 1:245 a 1263 , in- $4^{\circ}$ le $11 \mathrm{ff}$. Archices nationules, S $4960^{\circ}$.

La Pelice. - Abbaye (dioc. du Mans).

1884. - Recueil de lilres relatifs à l'abbaye de Ia Pelice: mi. du 
XIXe siècle, rédigé par Dallier. sur papier. in-folio (Bithloth. de la rille de Vogrut-le-Rotron, ms. ?'.

1) apmes des transcriptims recueillies par Gajegnieren cot conservées à la Bibliothe untionule.

La Penche. - Ville.

1885. - Cantulaire nunicipal de Lapenledes: ns. du XVII siècle, sur parchemin. in-80 de of $\mathrm{fl}$. Archives municipales de Lin Penche, Tarn-et-Garome).

La Perrine. - Prienri (dioce de Coulanes).

1886. - Nebl. : Ciarulaires de la Nanche ; prienré de la I'errine, par'

M. Dubosc. Saint-Lo. Jacqueline, 1878 ; in-t" de xi-107 p.

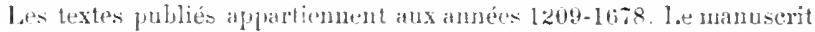

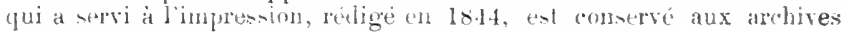
dep. de la Manche, in-lo sur prifier de tio ti:

La Piscine. - Abbaye (dioc. de Rrims).

1887. - Cartularie de labbaye de Lal Piscine; mo. de la lin du

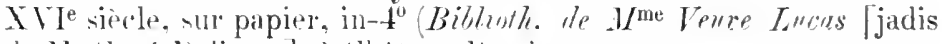
de .l. Sené-1) ligny ]. à Chàtratu-Porcien!.

Lexistence de" ce manuserit int signalee par M. Marlin, Essaj sur

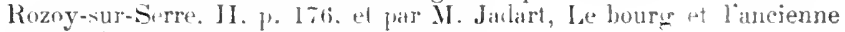
athbaye de Chàteau-Porcitan, 1!n-1, P. 9.

La Presle. - Irieure Notre-Dame et Sintr-Marguerite (dioc. de Reims).

1888. - Cartulaire du prienri de La l'resle: ms. du XVIIe siècle

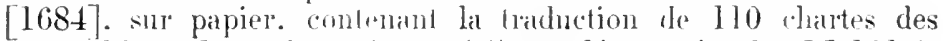
années l209 à 1477. in-4" (le IV-öb ff. Archires nutionales. LL 1019).

Publ. : Histoire el cartulaire du prienré de La Presle, pres d'Asfeld, par l'alué J.-B.-Li. Carré Rerne de Chumpagne ot de Brie, 2e série, IV, 1892. p. 5-27. 190-197. 41:3-427. el V, 1893. pp. 20-54, 348$368,432-44$ ) ef $508-514$.

L'elitrur a pris soin, lompuil a ju retrouver les chartes originales dans le fonds de Molêsme (Archicess dep. de In Cöle-d Or), I'en domer le texle à colé le li traduction. Il aurait pu en mênze lengs corriger les erreurs accumulesen par le tralueteur a propos des noms propres.

La Primaudière. - Priemé (dioc. d'Angers). - Voy. Grandmont.

La Réale. - Abbaye (dioc. d'Elne). - Voy. Esliba-DEL'AGLY.

La Règle. - Abbaye (dioc. de Limoges).

1889. - Cartulaire de l'abbaye de La Règle; ms. du XVIII e siècle, 
sur papier. contenant des documents depuis 1406. en 2 vol. in-folio (Arrhices dép. de la Hunte-Tienne. H non colie.

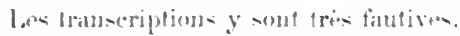

1890. - Recueil de titres lorme par Dom Col en 1769 Biblioth nationale. $11 \%$. latin 9194. pp. 177-298.

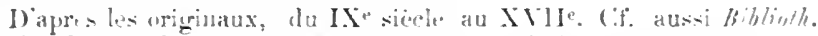

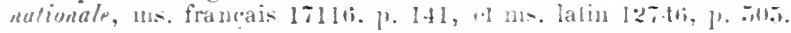

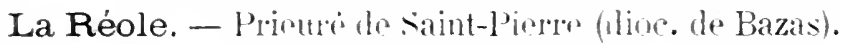

1891. - Cartulare du prieure de La Riole. depa de lahbaye de SaintBenoil-sir-Loire: origr. perdu.

Copie du précédent ; ms. du XVIII -iècle. sur papier. in-folio do 57 ff. Archices mulicipales te Lu Rénle. II it .

Extrais cln méne par Balnze Bibliuth. nutionale. coll. Balnze, vol. XXVI, p. 453-460. et vol. XLVI. p. 217-222: - par Dom Fstiennol Biblisth. nutimule. ms. latin 12701. pp. 398-409; - par d'antres an XVII siecle Biblioth. mutionule. coll. Dupuy. rol. 821 et 822; - roll. Duche-ne. vol. CXIV. ff. 60-67: - ms. français 20349. el ms. latins 1:2690 et 12759 : - el par Dom Chazal, Historia monasterii S. Benedicti Floriacensis 17.5. à la Biblioth. de la ville d'Orléuns, mss. $490-491$ ).

Publ. partielle dáprès le texte de La Kéole : Cartnlaire du prieure conventuel de Saint-Pierre de La Réole en Bazalais du IX an XII -iècle. par Ch. Grellet-Balgnerie Archices historiques du dép. de la Gironde. V. 1864. pp. 99-186, et à part in-4ºp. 99-186).

Cir. Rerueil de- Chartes de l'abbaye de saint-Benoit-sur-Loire, par II. Prou el A. Vielier, t. I Intrenluction' at pp. 159-1 h5 Examen des charles de restauration el de dotation de La Rénle'.

Larivour. - Abbaye de Notre-Dam+ (dioc. dr Troyes).

1892. - «Chartulariun lieate Marie de Ripatorio »: ms. du XIII siècle. sur parchemin. in-4 de $98 \mathrm{ff}$. Archices dép. de l'Aube. H non coté).

Copie moderne [1873] du précédent, in-folio de $129 \mathrm{ff}$. Bibliath. nationale. ms. nowv. acq. latines 1228;.

Extraits faits au XVII siècle Biblioth. nutionale. coll. Baluze, vol. XLVI. pp. 309-313. et coll. Duchesne, vol. LXXVI. pp. 62-69).

La Roche. - Abbaye de Notre-Dame (dioc. de Paris).

1893. - Cartulaire de l'abbaye de La Roche: ms. du XIIle siècle, contenant 98 chartes des années 1190-1:265. sur parchemin, in-4 $4^{\circ}$ de 115 p. (Bibliath. nationale. ms. latin 10996).

Publ. : Cartulaire de l'ablaye de Notre-Dame de La Roche. de lordre de Saint-Augustin. au diocèse de Paris, d'après le manuscrit 
original de la Bihliohthène impériale. par Auguste Moutié. Paris, Plon. 1862 : in-80 de xxxi-476 p. el allas in-folio de $40 \mathrm{pl}$. [Société archoologrique de Rambonillet.]

La Rochebeaucourt. - Chapitre collégial (dioc. de Perigueux).

1894. - Recueil tle tilres relatifs an Chajitre de La Rochebeancourt; ns. du XVIII siècle, sur papier (Bibliolh. milionale, coll. Lespine, vol. XXXIT, ff. 15:3-170).

La Rochefoucauld. - Prieure dr Saint-Florent (dioc. d'Angonlème).

1895. - Cartulaire du prieure de Saint-Florent de La Rochefoucauld, dep' de l'alibaye de St-Florent de Sammur orig. perdu.

Fitrait fait par Dom Col d'un fragment du précédent, conservé au XVIII siècle dans les archives du chàlean de La Rochefoucaud, rontenant un acte de 1060 et d'autres pièces non datées (Biblioth. untionule, ms. latiu! 9)!97. ff. (60-62.

La Rochelle. - Commanderie du Temple.

1896. - P'vbl. : Chartes de la commanderie magistrale du Temple de La Rochelle, par L. Meschinet de Richemond Archives historiques de Suintonge et d'Aunis. I, 1874, p. 2l-50).

Dates extrênes: : 11:39-1268.

La Rochelle. - Ériche ct "athédrale.

1857. - Recueil rles litres de l'évìché et de la cathédrale de La Rochelle; ms. du XV111e siècle. sur papier, contenant 85 pièces des années 10.5.5-1596. in-4" Biblinth. de lo ville de Poitiers, coll. bom Fontenear. vol. XXY, pp. 11 a 268 .

La Rochelle. - Ville.

1898. - «Live de la Poterne» I) de La Rochelle; orig. perdu. Copie du précédent: ms. du XVIIle siècle. sur papier (Biblioth. de la ville de La Rochelle, ms. 40.

Wxtraits du mème (Biblioth. uationale, ms. Prançais 16906, ff. 4278: el Biblisth. de lu rille de La Rochelle, ms. 153, passim).

1899. - Recueil de litres relatifs à la ville de La Rochelle; ms. du XV111 siècle, sur papier, in-f" le 376 pares (Biblioth. de la ville to Lu' Rorleelle, ms. 84).

Les "live rougen et "livre vert" de La Rochelle, aujourd'hui

(1) Improprement dit de la "Paterne". 


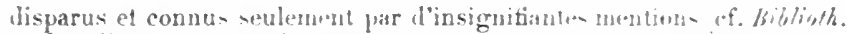

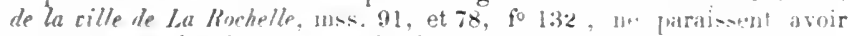
contenu que des doruments reliblifs aux métiers, ol to* sauraitont intro considérés connute cle véritables cartulaires.

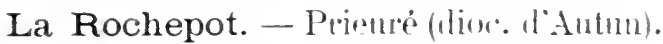

1900. - Recupil de titres relatifis al prieure de la Rochepol: ms. du XVIII siecle. sur papier. contenant de actes de lise? il lobl.

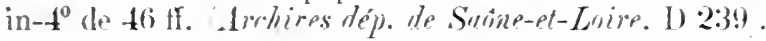

La Roche-sur-Buis. - Vill'.

1901. - Cartulaire municipal de lá Roche-su-Buis: ma. du XVII siècle. sur papier. contenant de- actes le I 226 ia 1618 . in-folio de $224 \mathrm{ff}$. Archires dép. Ho lo Dirime. Le 2920.

La Roche-sur-Yon. - Prieuré do saint-Liesue dink. de Luţ̧on).

1902. - Pancarte du prienré de La Roche-ur-Ton. dépendant de Marmontier : roulean de parchemin du XII ${ }^{e}$ iècle, 3 tf. incomplets. mesurant $\mathrm{I}^{\mathrm{m}} .82$ de long sur $0^{\mathrm{m}} .22$ de larre dichices dép. He la Vendée, $\mathrm{H}$ non coté.

Pebi.. : Cartularium prioratu: Roche super Oiunem dependentic a Majori Monavlerio Turonensi. a Paul Marchegray. dans: Cartulaires du Bas-Poiton La Roche-vur-Yon. 187\%. in-80. pp. 149-180 et $221-225$.

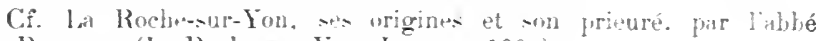
1.. Rou-smau (La Ruchesur-Ion, Ironnet, 189s).

La Roë. - Abbaye le Notre-Lame (dive. d'Aneres).

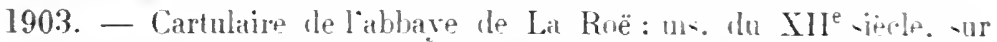
parchemin. combert dine reliure ancienn à aiv de boik. in-t" de

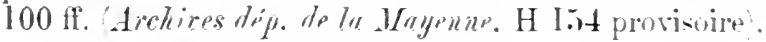

Date- extrèmes: $11196-11$ su.

Copie moderne [1848] du priceident. par I'. Narcheyar. in-folio de $510 \mathrm{fr}$. 'Biblinth. nutionale. ms. nour. acr. latines 1:22:

Extraits faris an $\mathrm{IVII}^{\mathrm{e}}$ iecle Biblisth. intionale. collection Baluze. vol. XXXVIII. If. 76-91; us. Prançais 16188. II. 290-295).

1904. - Pcor. : Cartulaire de lablaye rovale de chanoine- de SaintAngustin de X.-D. de La Roë. arec introduction. notev of lables, par Jnles Planté. Hamers. Fleury et Dangin. 1888. in-8".

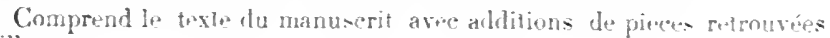
ailleurs.

Larreube. - Abbay de Saint-Orens (dior. dr Tarbess).

1905. - Cartukair de l'ahbaye de Larrenke: orig. perlu. 
Extrait lait au XVII" siacle Bibtioth. nutionale. collection Baluze, vol. LXXt, II, $77-81$.

En courl "xlmail de cee cartulaire se lrouve ausai dans le " (imanage n de lareher liblioth. de la rille de T'arbes). vol. I, no las. 1,e volume existail tonte enterre en $17.4 \%$.

Larrey. - Pripuré (diox, dr langres).

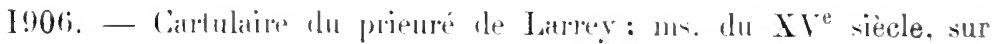

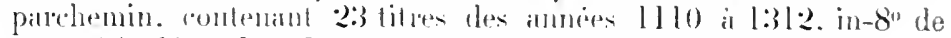

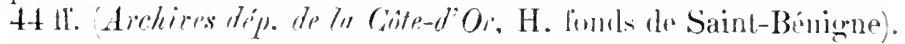

Larroumieu. - Prienéde Notr-Ibame (dion. do (andom).

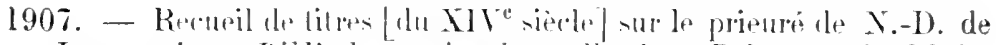

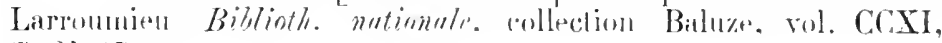
11. $81-9 \%$

L'Artige. - Primé丶 (dion. Ho Limugas).

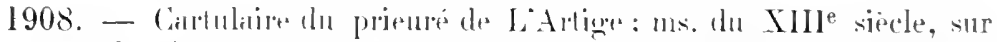

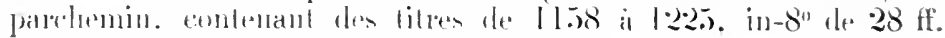

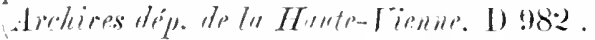

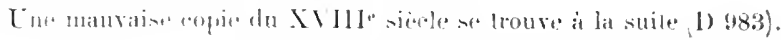

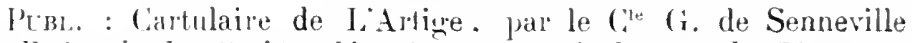

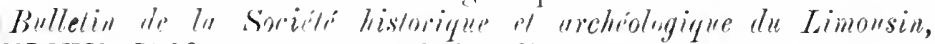
XIVIII, I!900. pp). xu-xun et $291-500)$.

La Saussaye. - Prinué, à Tillejuil (dior. dr Paris).

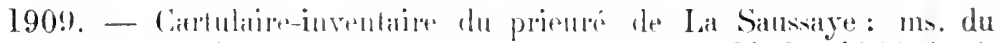

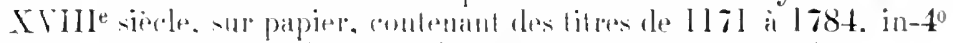

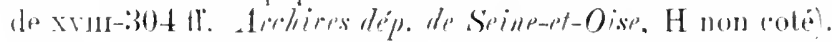

La Sauve-Majeure. - Ablayo (dime do Bmolnaux).

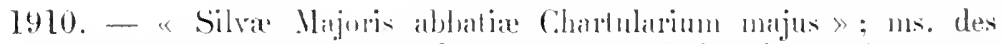

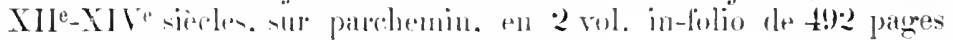

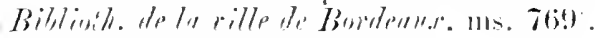

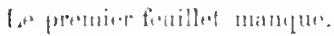

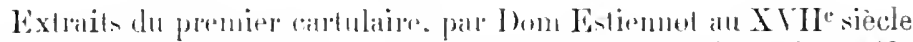

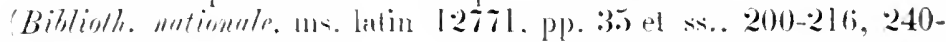

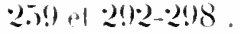

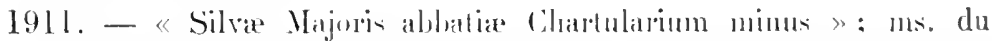
XIVe sircle. sur pardentun. angmente de lenillets supplémentaires

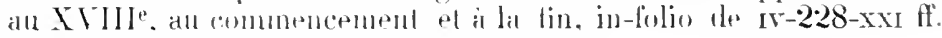
(Biblinthe de la rille de Burderax, als. 870 ).

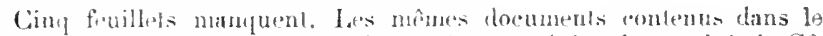
préceident registre sont en grande parlie reprobuils dans celui-ci. Ct.

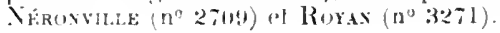


1912. - Autre cartulaire de l'abbaye de Lal Saluve-Majare. incomplet

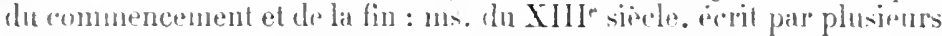

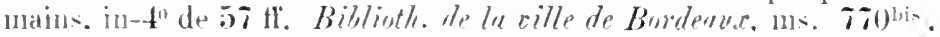

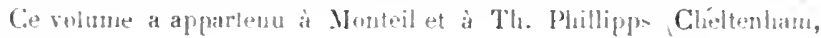
$n 1^{0}(6 ! 1)$.

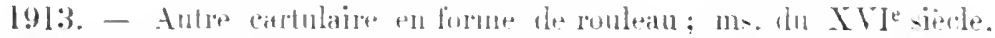

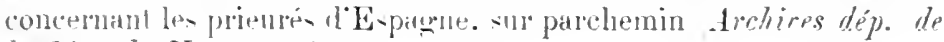
In Gironde. H non cote.

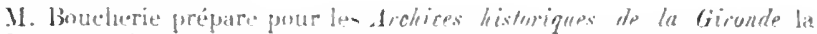
fublication de cartulares de la saure-Mageure. - CP. Dncuruents extraits du cartulate le I a sisure sur le prieuré d'Exeat en Aragon. par

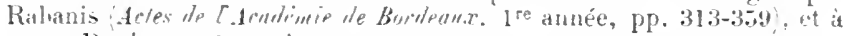

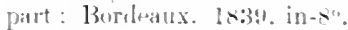

Vos aus-i : Vote sur un cartulatre en forme le rouleau provenant de

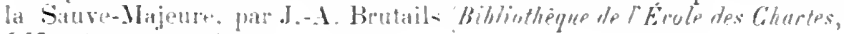
I.II, $1 \times 91,1 \%, 418$.

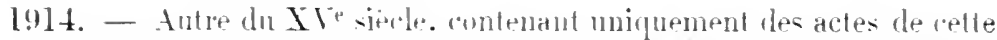

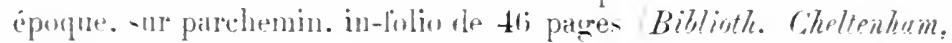
I1" $4: 3(i 4$.

La Selve. - (ommandrirt. (dior. do Toulouste).

1915. - Cartulaire des Templiers de La Selve: ms. de XIJe-XIVe siectes. contenant 170 acter des annés $1180-1346$. sur parchemin,

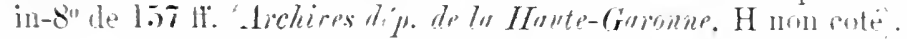

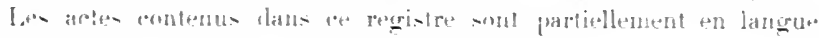
ro: wane.

Lastours (1.0). - Falmillr.

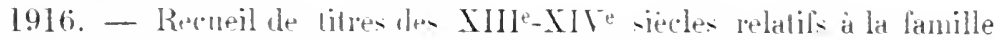
der Lal-lunrs: ms. formé par hem Col en litig d'après les arehives du

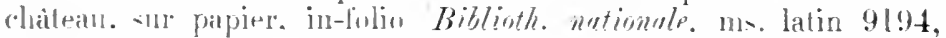
pitae- 1 ili $7-19.5 \%$

La Trappe. - Abbaỵ de Notre-Lamo (dion. lle sées).

1917. - Cartulaire de X.-1). Je La Trappe: ms. du Xlle siecle sur

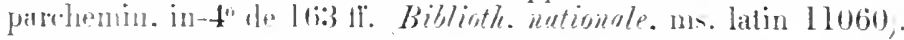

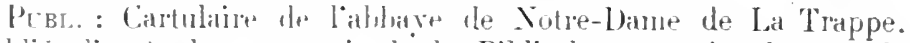
publip diapre la manuscril de lal Bibliothèque nationale. par le Cle de Chineneery. Alpruon. Renanl De Broise. 1889) in-8" de

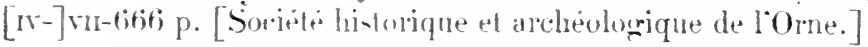

Cf. Faussete d'une charte de saint Lonis pour l'abbaye de la Trappe,

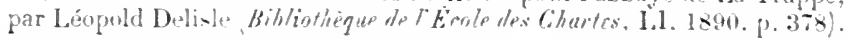

\section{L'Aumône on Le Petit-Cìteaux. - Abbaye flim. de Hiluis).}

1918. - Cartulaire de lablinge de Litumòne ; oriz. perdu.

A été connu d. Laisne prirur de Mondonville, qui le cite Biblioth. nationale, ma. francais $2+1333$, fo 971 ). 
Lausanne. - Chapitre :athèdıal.

1919. - « Cartularium Lausannense »; ms. du XIII siècle [de mains diflerentes], commence par ordre du imand prévòl Conon d" Estavayer en 1:228, sur parchemin. in-folio de $1336 \mathrm{it}$. (Biblioth. de la rille de Brom. mintin B 219.

Pi вь. : Cartulaire du Chapitre de Notre-Dame de Lanisanne 1228124: - par A. Jahn. Fr. Forel el F. de Gingins (Mémoires et Documents jubl. pue la Socintri d'histoire de la Suisse romende. VI. 1851, 1 vol. in-8" de txxy-zo7 p. aree pl.).

Cif. Analyser teponymique du passage do cartulaire de latusanne relatif à lit nuort destint Prothais, pas E.-I. Burnet Reru hisforique culderise, XIII, I905, $1^{\circ} 3^{\text {'. }}$

Lausanne. - Eviché.

1920. - Pris.. : Recuril de chartes. slatuts el documents concernant lancien iviché de lansanne. parr Fr. de Cingins-la-Sarra et Fr. Forel

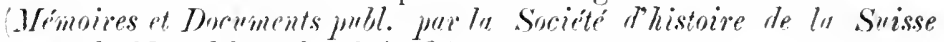
romande. VII. 1846. I vol. in-8".

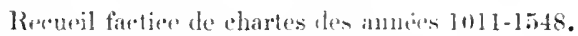

19:20 bis. - Cartulaire de lévèché de Lansanne, copie du SYIII" siècle, sur pilpier. in-folio (Biblioth. nationale, coll. Moreau, vol. 905).

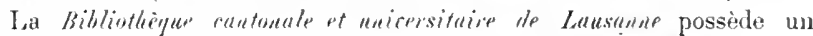
manuscrit de Ruchat (in-folio, XIX" s.) intitulé: " Monumenta Lausannensia in dita; Bullarium Lausanense o (815-1536).

Lautenbach. - Église collégiale (dioc. de Bàle). 1921. - Cartulinire de lis collégriale de Lautenhach; orig. perdu. Co manuserit a dinparu lors de l'invasion suédoise en Alsace.

Lautrec. - Finnille.

1922. - Prbi.. : Un carlulaire et divers actes des Alaman, des de Lautrec et des de Livis. seiments des XIl Ie et XIVe siècles, par E. Cabie et l. Vazens. Paric. Picard. $188: 3$; in-8 $8^{0}$ de Lxxwm-235 p. et pl.

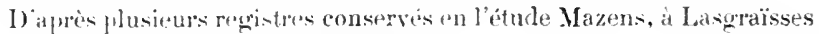
(Tarn). Dilles cxtrênen: 12:35-1:343.

Lautrec. - Viromlé.

1923. - Recneil de titres de la vicomté de Lautrec; ms. du XVIIe sierle. contentant des actes des années $1181-1557$, sur papier, in-folio (Biblintl. natimale. collection Doat, vol. 248, (f. 1-227).

1924. - Recueil d'actes relalifs anx vicomtés de Lantrec et de Villemur; mis. du XIVe siecle. sur parchemin, contenant des actes de 1128 à 1308, in-folio de 25) If. (Archives dép. des Basses-Pyiénées, E 489).

Laval (do). - Finmillo.

1925. - Publ. : La maison de Laval $1020-1605)$, étude historique 
accompangée du cartulaire de I anval et des Vitré. par A. Bertrand de Broussillon. Paris, Picard et fils. $189.5-1900 ; 3$ vol. in- 8 " de IN-320, 404 et $11-392$ p. avec fig.

La Val-Dieu. - Abbaye de Prẻmontrés (dion. der Rrimi).

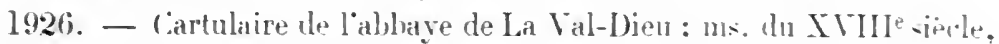
sur papier. contendant des pièces de 1176 à 1734 . in- $4^{0}$ drolires dip. des Ardennes, $\mathrm{H} 493$.

Ce recueil contient uniquement des piense relative anx droits de

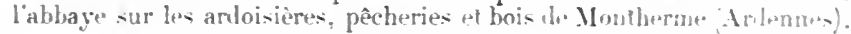

La Val-Roi. - Abbaye (dioc. de Reims).

1927. - Cartulaire de labbaye de La Val-Roi ; mo. de la tin du XIIe siècle. incomplet lu début. sur parchenin. in-8" de $2 \cdot 2$ ff. Biblinth. nutionale, ms. latin 10945).

Le plus ancien acto transcrit est de 11 t.

1928. - Autre cartulaire de labuave de La Val-Roi : m. du XV1e siècle, sur papier, contenant 120 chartes des années $1148-1231$. in $4^{\circ}$ Archices dep. des Ardennes, H $26 \mathrm{I}$.

Copie du mène: ms. du XVIJ siècle. wr papier. infolio de $125 \mathrm{ff}$. 'Biblisth. wutisnale, ms. nouv. acq. latine- 1289 .

Axal. : Analyse diun cartulaire de labbaye de la Valruy. par l'abbé I. Desilvé Bulletin de la S'sciété aradémique de Luril, XIII, p. $111-250)$. et a part : Laon. 1877 : in-8 de 144 p.

Less clocuments analyés appartiennent aux annés. 1020101211.

Lavardin. - PrieurP. - Voy. Marunttier.

Lavaur. - Èvèıhé.

1929. - Recueil de tilres relatifs a léplice de Lavanr. formé an XVile siecle. sur papier Biblioth. Mutionule. coll. Baluze. rol. LXXXV11. ff. 239-305.

Lavaur. - Ville ot Chapitre.

1930. - Recueil cle tilres relatifs à la ville et an Chapitre de Lavaur: ms. de 1667-1668, contenant des actes des années 12.54 at 1526 . in-folio sur papier (Biblioch. mutionule. coll. Doat. vol. 81, ff. 12791.

Lavedan. - Vicomtio.

1931. - Cartulaire des vicomtes de Lavedan, ou Livre vert de Benac : ms. du XVII siècle. sur papier. in-4" 'Biblioth. de .K. Gostrin Diryt, à Tarhes:.

Extrait fait au XVIII siecle Biblinth. do la cille de Turbes. Glanaze de Larcher, vol. VIII, p. 179-186,. 
l’ubl. : Livre vert de Bénac. par ( riston Balencie (Bulletin de la Société académique des IInntes-Pyréneses, "serie docunentaire, 1901 $1902,1^{6 s} 36$ a 42 .

Voy. aussi r+1) Litz.

La Valette. - Abbays (linc. do Tullr).

1932. - Cartulaire de l'abbaye cistercienne de La Valette; orig. perdu.

()in en trouve mention dans la "Gallia Christiana ", II, p. 217.

La Victoire. - Abbayr (dioc. de Senlis).

1933. - Cartulaire de l'abbaye de N.-D. de La Victoire ; origr. perdu.

Extraits faits an XVII" sièle (Biblioth. nutionule, coll. Duchesne, vol. LXXVII, l" 25; ms. latin 17049, pp. ..5.)-.567); - Bibliolh. de lu ville de Senlis, titres d'Afforty, passim).

19:34. - Cartulare de l'abbaye de La Victoile: ms. du XVIII" siocle, redien par le P'. 'Trxier, sur papien', contenant des actes de l2222 à 1690. in-folio de $376 \mathrm{ff}$. Archires depe. de lo Ose, H 742 ).

Copie molerne [18.52] du meme. in-4" de 609) p. Clrelives mationales, L.I. 1 Hi! .

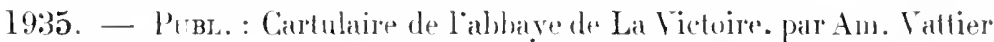
(Comptes-mentus of Bemoives d" Comitr archiologique de Senlis, 3" sirie, II, 1887, pp. 333-60, w IV-V. 1889-90, pp. 129-1:3:3).

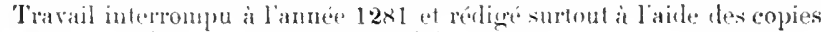
d'Attionty (Biblichth. de la ville de Serdis).

La Vieuville. - Abbare (dioc. de Dol).

I936. - Camblaire de l'abbaye de La Viemville; orig. perdu.

Extraits faits an $\mathrm{XVII}^{\mathrm{e}}$ iècle (Bibliolh. nationale, coll. Baluze, vol. XLVII, it. $208-217$.

l'origrint apprartenait alors au marquis de Molace.

La Voute en Auvergne. - Priemeri (diox. du P’uy).

1937. - Cartulaire du prience de La Voule : origr. perdu.

Extraits faits en 1460). sur papiel, contenant lo actes du XIe siècle

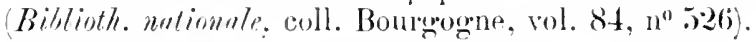

Laxou. - Seignenrie en Larraine.

1938. - Cartulaile de la seigneurir de Laxou, dépendant de la Chartreuse de Bosserville; ms. du XVIle siècle, sur papier, in-folio de $54 \mathrm{ft}$. (Avehires dép. de Menthe-et-1Yoselle, $\mathrm{H} 6667$ ).

Lay-Saint-Ghristophe. - Prieurí ( lioc. de T'oul).

1939. - Cartulaire dı prieuré de Lay-Saint-Christophe, à la suile du 
Cartulaire dt. la maison des Misions rovales de Sancy Biblioth. du

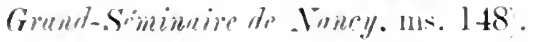

1940. - Autre. de la lin du XVIIJ sièl. sur papier. in-40 de $210 \mathrm{ff}$. Arrices drip. de Mrurthe-et-Moselle, H 18.5.

1941. - Autre de la lin lu XVIII siècle. sur papier, in-folio de 150 p. (Aichices dip. de Wewthe-et-1Moselle. H 180 .

LEau. - Abbave (diox. do Chartres).

1942. - Cartulare de l'abbave de L'Eau : ms. du XVIJ siecle [1672], copie par le notaire Pierre Fraslon, contenant des acte depuis 122\%, sur papier. in-folio de I $2: 3 \mathrm{H}$. Arehiess dép. d'Eure-el-Lriv. H non cotis.

lixtrait- daits au XIX" siecle Biblinth. de lu cille de Chorties. ms. $15: 37$.

Probl. : Sera publiz par lahbe Melais. arece adulition dantres pieces el rollation sur los uriginan encore existants.

Léau. - lisplise et béminase (alioc. no Malines).

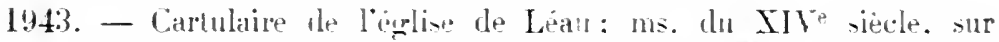

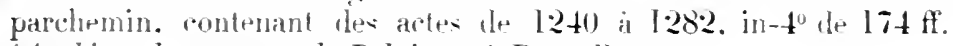

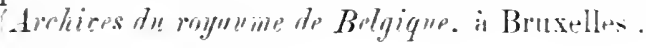

Léau. - Ville.

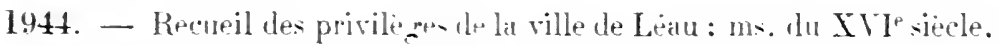
sur papier. contenant des artes de $\mathrm{I} 2 \mathrm{l}: 3$ a $\mathrm{I} 30 \%$. in-folio de $11 \mathrm{ff}$.

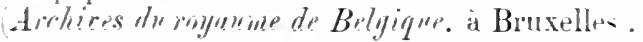

1945. - Autre du XV11" sierle. sir parchemin. contenant des actes de

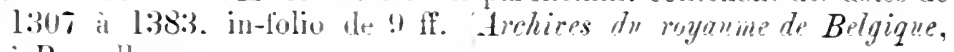
ì Brinelles.

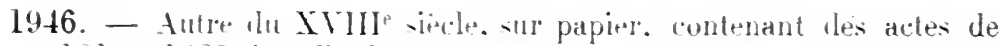

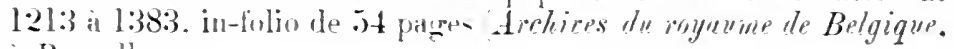
it Brisilles.

Le Bec-Hellouin. - Abayr (dior. dr Rouen).

1947. - Fragment diun carbulaire de l'abbare du Bec: ms. du

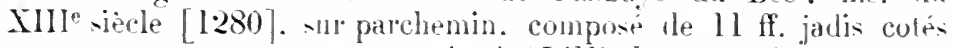

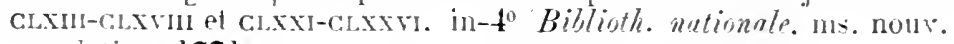
acy. latines 1771 .

1948. - Fragment diun autre cartulaire dn Bec: ms. de la fin du Xille siecle, sur parchemin, in-t" he $90 \mathrm{ff}$. a 2 col. Arrhices dép. de l'Eure, H 91).

Contient les transcriptions intéuralto ou partielles de 549 charter des XIIe-XIII siècles. 
1949. - Fragment d'un antre cartulaire dn Bec; ms. ln XIIIe siecle, sur parchemin, contenant 1 feuillet jadtis coli $\mathrm{Lxxx}$, in $-4^{0}$ à $2 \mathrm{col}$. Archires dép. de l'Eupe, $\mathrm{H} 89$ ).

1950. - Fragment diun autre cartulaire du Bec: ms. du XIII siècle, sur parchemin, composi de l feuillet jadis coté cocxuI, contenant der: transcriptions de chartes de l'année 1261, in-4" (Archices de l'En, H 90 .

1951. - Fragment d'un antre cartulaire du Bec; ms. du XVe siècle, sur parchemin, composé de 3 ff. contenant des artes des années $1242-$ 1:392, in-4" (Archioes dep. de l'Eure, $\mathrm{H} 93$ ).

lixtraits faits an XVIJ viècle (Biblioth. nationale, ms. latin 1:2884, "Chronicon Beccense». passim; ms. latin 13905, par Dom J. Jonvelin. passim); - (Arclioes nationules, $\left.\mathrm{T} 153^{12}\right)$.

1952. - Recneil dle titres fait d'après un ancien cartulaire de labliaye dı Bec, et concernant spécialement les prieurés en dépendant; ms. du XVIIJ siècle. sur papier, in-folio de $10 \mathrm{ff}$. Archives dép. de l'Eure, $H 7(i)$.

1)ates extrèness: $107 \pi$ environ - 1276.

Le Beuil. - Ablaye (dioc. de Limoges).

195:3. - Cartulaire de l'ahbaye du Benil ; origr. perdn.

Extraits dn précédent par Dom Lstiennot et René I) Cher (Biblioth. nutionale, ms. latin 12746. p. 205 et 571).

Le Breuil-Benoit. - . Ibbaye (dioc. l'Évreux).

1954. - Cartnlaire de labbaye du Brenil-Benoit ; orig. perdu.

I été commu de laisné, prieur de Montonville, qui le cite (Riblioth. nutimale, 111s. français 24133, fo 971$)$.

Le Bugue. - Abbaye de Saint-Sauveur (dioc. de Périgueux). 145็5. - Cartulaire de labbaye du Bugne [sur parchemin, in-4" de $32 \mathrm{ff}$.] ; orig. perdu.

Lixtraits faits an XVIIIe siecle (Biblioth. natimnale, coll. Lespine, vol. XXXIII, ff. 268 et 278-282).

Le Cannet. - Villr.

1956. - Cartulaire nunicipal du Cannet: ms. du XVII siècle, sur papier. contenant des actes à partir de 1262, in-40 de $144 \mathrm{ff}$. (Archives immicipules du Cannet, AA 1).

Le Cateau-Cambrésis. - Abbaye de Saint-André flioe. de Cambrail.

1957. - Cartulaire de l'abbaye de Saint-André du Cateau : orig. détruit. 
Extrait fait an XVIIo siècle (Biblinth. natinnale, coll. Baluze, vol. XL, fin 92 .

Copie du précédent; ms. du XVIII siècle [incomplet de la fin], contenant 43 documents des années $\mathrm{I046}$ à 13366 . sul parchemin, in-folio de 50 ff. Archices dip. d" Wrod. H nom coto.

Le Charme, pres de Neuilly-Saint-Front. - Prieuro (dioc. de Soissons).

1958. - Cartulaire du prieuré Notre-Dante et Saint-Laurent du Charme; orise. perdu.

Lxiraits faits an XVII siècle Bibligth. nutionule. coll. Baluze, rol. XL. fo 144; ms. latin 17048, pp. 233-2:39.

Le Fay, prés d'Ivry-le-Temple. - Commul des Trinitaires.

1959. - Cartulaire des Trinitaires du Fay-aux-Anes: ms. de 1529, écrit par frère Charles Le Gendre. ministre du convent. sur papier,

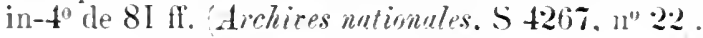

Chartes des .III - Iresièdes.

Le Fournet. - Seignemrie du pays d'Auge.

1960. - Cartulaire de la seipneurie dn Funrmet; ms. du début du XVI siècle, sur papier. in-4 Archices déf. du Calcados, E non coté..

A élé clonné a ce dépoit par M. Le Court Rapport de l'archiviste pour 1901 .

Le Gard. - Abloye de Notre-Lime (dioc. d'Amiens).

1961. - Cartulaire de labbaye du Gard: ms. du XVIIle siecle [vers 1709], sul papier, contenant des pièces des années l174-1615, en 2 vol. in-folio de 557 et 559 p. Archices depo. de la Somme. $\mathrm{H}$ non coté,.

Extraits laits an XYIIJ siècle par J. A. F. Carlier de Corselles (Biblioth. de la ville de Roye. m. 17.

Conpie du précédent. avec quelques additions. par le marquis Le Ver. en 1811 . sur papier. in-folio de $914 \mathrm{p}$.

Formait le $1^{\circ} 129$ du catinlogue de la rinte du cabinet lee Ver en 1866.

Le Géneteil. - Prienré, à Chàtrau-Gontier (dioc. d'Angers).

1962. - Recueil de chartes d'Azé et du Géneteil. dépendant de SaintNicolas d'Angers: ms. du Xrille siecle. sm papier. in-4" de

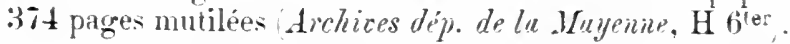

I'ubl. : Cartulaire d'Azé el du Géneteil. publ. par' II. Du Brossay (Archives historiques du .Vuire. III, 1903, p. 49 à 168. 
Le Grais. - Prieuré, à Azay-sur (Cher (dioc. de Toms). 1963. - Cartulaire du prieuré du Grais; ms. du XVllI siècle [v. 1780]. contenant des topies et extraits à partir de 1127, sur papier, in-folio de $198 \mathrm{fl}$. (Archices dép. d'Indre-et-Loirp. H 659).

Le Grand-Beaulieu-lès-Chartres. - Léproserie.

1964. - Cartulaire de la léproserie du Grand Beaulieu, près de Chartres; ms. du XIII siecle (1259), sur parchemin, rédigé par le frère Vincent, dit «livre roure », avec table et répertoire du XVIlle siècle, in-to de $44 \mathrm{ff}$. et 206 p. (Biblioth. nutionule, nis. nouv. acq. lat. 608).

1965. - Cartulaire ou "livre noir »; ms. du XIVe siecle. sur parchemin. contenant des documents de 1109 a a $127 \%$. avec analyses faites au XVIII siècle. sur papier, in-80 de $272 \mathrm{ff}$. Biblinth. te la ville de Chartres. ms. 1509 .

siept feuillets de cre manuscrif se trouvent égarés aillenr' Biblioth.

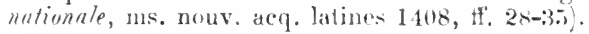

Copie clu précédent, faite an XYIIle siècle. sur papier. in- $4^{0}$ de 295 fi. Biblioth. de la ville de Chartirs. ms. 1079).

Autre copie. laite sur le prócedent en 1854 par Ed. Leferre, sur papier, in-4" de $365 \mathrm{ff}$. Biblioth. nutionale, ms. nouv. acq. latines 1408).

Extraits faits pour Gaignières an XVI1 siecle (Biblioth. nationale, ms. latin 17048, pp. 179-183.

Une table de ces deux cartulaires, copiée par Lejeune sur le manuscrit de V. Cherard, existe en $96 \mathrm{p}$. sur papier (Biblinth. de la rille de Chartres, ms. 15i2.

Pl'Bl. : Cartulatire du Grand-Beaulien-lès-Chartres, par René Merlet. Chartres, impr. Garnier, 1907; in-40 LArchives d'Eure-etLoir ; collection de Cartulaires Chartrains, II].

Le Gué de l'Orme. - Voy. OrLicass (abbaye de SaintEuverte).

Le Hamel-lès-Bréval. - Prieuré de la Trinité (dioc. d'Evreux).

1966. - Cartulaire du prieuré du Hanel-lès-Bréval, dépendant de l'abbave du Bec-Hellouin; ms. dn XVle siècle, sur papier, de 94 ff. in- $4^{0}$ (Biblioth. nationale, ms. nouv. acq. francaises 6354 .

Dates exlrêmes: 1176-1494.

Léhon. - Priemé (dioc. de Saint-Malo).

1967. - Publ. : Anciens évêchés de Bretagne; diocèse de SaintBrieuc, par Geslin de Bourgogne et Anatole de Barthélemy, IV (1864), p. 358-385. 
Le Jard. - Abbaye (dioc. le Sens).

1968. - Cartulaire de labbaye de St-Jean du Jard : orig. perdu.

Cf. : Index chronologique du cartulaire de siant-Jestn du Jard, par le P. Vallée, grénovéfain: ms. du XVille siècle, sur papier, in-4º (Bibliolh. Sante-fipnecièce, à Paris, ms. 1980, tf. 2:3-31). Les dates extrêmes sont: 1152-1:11.

1969. - Autre cartulaire de laibbaye du Jard : ms. du XIVe siècle, sur papier, in-folio de $86^{\circ} \mathrm{ff}$. (Biblioth. nationale. ms. français 2697).

A appartenu à de Thou et à Colbert, et ne contient guère que des titres du Xile siècle.

Extrails des précedents faits au XVII siècle, par Baluze (Biblioth. nationale, coll. Baluze. vol. LI. pilges 183-195 :- pour Gaignières (Idem, ms. latin 5482, pages 249-256 ; - par Du Chesne 1dem, coll. Inchesne. vol. LXYVII. ff. 46-47: - par un bénédictin (Idem, ms. français 1808:3. H1. 215 vo a 220 .

Le ms. latin 5482 contient diautres copies et extraits d'après les originax (dates extremes: $1137-1601$ ).

Le Jardin-lez-Pleurs. - Ab)aye de Notre-1)ame (diou. de Troyes).

1970. - Martyrolone et chartes de l'abbaye de Notre-Dame du Jardinlez-Pleurs (Marne), recueillis et mis en ordre par Léonce Lex Mémoires de la Société acudémique de l'A tube. 3 érie. XXI, pp. 365398 , et à part : Troyes, Dufour-Bouquol. 1885 ; in- $8^{\circ}$ de 36 p.

Publie 25 chartes des années 1235-1316, daprès les copies de la eoll. de Chaupagne (Biblioth. nutionnle).

Le Lieu-Notre-Dame. - Abbaye (dioc. d'Orlẻans).

1971. - Cartulaire de liabbave du Lien-Notre-Dame; ms. du XIII siècle, sur parchemin, in-4" de $52 \mathrm{ff}$. Archices dép. de Loiret-Cher, $\mathrm{H}$ non coté,

Publ. : Cartuliire de l’abbaye royale du Lien-Xotre-Dame-lèsRomorantin, de l'ordre de Cîleaux. publ. d'après l'original avec introduction, notes et appendice, par l'ablué Plat. Romorantin, Sandachar, 1892 ; in- $4^{0}$ de ['III-]xi-200 p. et firg.

Le Liget. - Chartreuse (dioc. de Tours).

1972. - Cartulaire de la Chartrense dn Ligret; ms. du XIVe siècle. sur parchemin, avec reliure ancienne en cuir noir, contenant 370 chartes des années 1178-1344. in-t de $169 \mathrm{ff}$. (Archices dép. dIndre-et-Laire, H 167.

1973. - Fragment d’un cartulaire du Ligret: ms. du XIII siècle. sur parchemin, in-80 de $26 \mathrm{ff}$. (Biblioth. de la ville de Tours, ms. 1356).

Le dernier cahier [ff. 15-36] contient des actes des années 12791282 , cotés 56-74. I.e reste renferme des bulles générales pour l'ordre des Chartreux. 
1974. - Autre frignment du XIII siècle, de dimensions un peu plus vrandes que le precédent, sur parchemin, contenant les If. 4:3-68, in-s" Biblioth. de la cille de Tours, ms. 13350).

Contient 81 prieces des annér's 1274-1287, cotées 40-121.

Fxlraits laits an XVIII" siècle diaprès les «Antiqua cartusise Lineti Monumenla 》 (Biblinth. nutionale, coll. Dom Housseau, vol. XIl, 11. 22:3-2:32).

Le Louroux. - Abbaye (dioc. d'Angers).

1975. - Recueil de tilues relatifs à l'albatye du Louronx. copiés au AlIII siecle (Bibliollh. nutionale. coll. Dom Honssean, vol. XII).

Le Luc. - Villr.

1976. - Cartulaire municipal du Lac: 11s. da XVIre siècle, sur papier, contenanl destitres depuis 1247. in-folio de $411 \mathrm{ff}$. (Archives muniripales d" Lur. A.A 1 .

Le Lys. - Ab)aye (dioc. de sens).

1977. - Cartulaire de l'abbaye du Lys ; ms. des XIIIe-XIV'a siècles, sur parchenin, in-to de 69 If. (Biblioth. nationale, ms. latin 13892).

Copir moderne du même, sur papier, in-80 Bibliolh. de l' Société listorique st archéologiqu" d" (ratinais, à Fontainebleau).

1978. - Aulre daté de 1607, sur papier, contenant 149 pieces des ammée. 12.52 a 1549, in-folio de $280 \mathrm{Ir}$. (Archives tép. de Seine-etMriue. H 565$)$.

Le Mans. - Abbaye do La Conture.

1979. - Carlulaire de l'abbaye de La Conture; ms. du XIII" siècle avec alditions postórieures, sur parchemin, in- $t^{0}$ de II-67 7 ff. (Bibliath. de la rille du Mans, ms. 1!)8.

Copie du précédent, pour Gainnières; ms. du X VII siècle, in-folio, sur papier (Biblioth. nationale, ms. latin 17123, pp. 209 a 484).

l.es Il) 1 à 196 du nême volume, relatives au mème objet, sont transerites d'après less originaux.

P'erzi.. : Cartulatre des albbayes de St-l'ierre de La Couture et de St-Pirrere de Solesmes, par les Bénédiclins de Solesmes. Le Mans, Nomover, 1881 ; in-4" de $\mathrm{xv}-\mathbf{5 3 6} \mathrm{p}$. et $\mathrm{pl}$.

Lixtrats du mème, faits au XVII ${ }^{\mathrm{e}}$ siècle, par Dom Nichel Layneau, prévòt de l'abluaye (Biblioth. nutionule, ms. latin 13817, (1: 5)-59).

Le Mans. - Abbaye de Saint- Yincent.

1980. - Fragment d'un cartulaire de Saint-Vincent du Mans; ms. du XIV siècle, sur parchemin, 2 feuillets in-8" (Biblioth. nutionale, ms. lalin 11411 , ff. $72-7: 3$. 
1981. - [Premier] cartulaire de Saint-Vincent dı Mans ; origr. perdu. Extraits du précédent. laits an XVIJ siècle par Dom Anselme Le Michel Biblioth. nutionale, ms. latin 13820, if. 204-217 ${ }^{-19} ;$;

1982. - [Second] cartulaire de Saint-Yincent du Mans: nis. du Xille siecle. sur parchenin. in-4" de $115 \mathrm{ft}$. Biblioth. de la ville du Muns. ms. 95.

Copie du précédent. faite an XVII sièce [1696] ponr Gaiznières, sur papier, in-folio de 648 parges Biblioth. mutionale. nis. latin 544 .

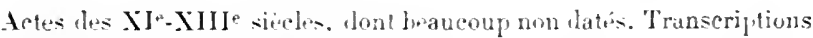
d'après des rouleaux eoter par lettrons.

Copie moderne par Bilard. ms. du XISe siècle. -nr papirr. in-folio le 2:35 ff. (Biblioth. de la cille d" Maits. nus. 473.

1983. — « Cartularius recenter sed elecranter scriptus »; oriı. perdu.

Le fragment dont il subiste $2 \mathrm{ff}$. (no 1981i) provient paut-être lto cot registre.

1984. - « Cartularius recentior »; origr. perdu.

Extraits on notes informes. tirés des deux volumes précédents par Dom Anselme Le Michel Biblioth. untionule, ms. lalin 1:38:0. ff. $218-220$

Le nrène bénédictin cite meore Item, f 234, un .

1985. - «Vieux registre de Saint-Vincent dı Mans. de papier. couvert de bois $»$ : orig. perdu.

Il $n$ en a extrait que des actes du $\mathrm{XV}^{\circ}$ siectr.

Extrait d'un cartulaire de Saint-lincent. fait at XVII siecle (Biblioth. ationule. coll. Inchene. vol. XXIl. 11. 272-275.

1986. - Prbt.. : Cartulaire de Saint-Vincent du Mans. ordre de SaintBenoit. 1. I (52-1184), par Rohert Charles et S. Menjot d'Elbenne. Mamers, Fleury et Dantrin, 188i ; in- $4^{\prime \prime}$ de 239 p.

Le Mans. - Chapitre cathédral Saint-Julien.

1987. - Cartulaire de l"érlise du Mans on «Live blanc »: ms. du XIII siècle en llenx parties [ $\mathrm{r} .12: 36$ et $\mathrm{v}$. I289] sur parchemin. arec additions et tables, in-foliv in 2070 fi. Biblinth. de lu ville du Mans. m:. 259 .

Les fruillets $21-223$ som oripinaux. - Cif. Notice sur le livrt blane de légrlise du Mans, par Leoplohl Dedisle Bibliothèque de rÉcole des

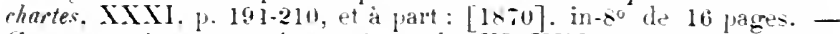
Ce unanuserit romprend -22 pieces des Xe-XIJ" siedes. - L.e ns. latin 17at eontiont de-feuillets. XIII siècle en partie delruit par lhumidite, qui proviennent du Live blanc.

1988. - Extrait diun cartuliure du Chapitre du Mans. écrit vers I320; copie faite ponr Gidinnières all XV1I" siecle par Dom Aulren 
Biblioth. nationsle. ms. latin 5211"3, pp. 1-68: et ms. latin 9206, ff. 13-36.

Publ. : Chartularium insignis ecclesie Cenomanensis quod dicitur Liber albus capituli. par A. Ciavin. Le Mans, Nonnoyer, 1869; in- $4^{0}$ de $44: 3$ et 88 parges.

1989. - Recueil des privilèges du Chapitre du Mans: ms. du XVe siècle. sur parchemin. in-folio de 61 if. (Biblioth. de lu ville du lians, ms. 25l!.

1990. - Antre recueil [incomplet an début]; ns. dı XVIe siècle, sur papies. in-4" de .2.2 $\mathrm{fr}$. (Biblioth. de la ville du Mans. ms. 275).

1991. - Extraits d'un cartulaire de l’église St-Julien du Mans. faits an XVII siecle Biblisth. nationale. coll. Duchesne, vol. LAXT, (f. 2()$-34$.

Le Mans. - Chapilno de Saint-Pierre-de-la-Com.

1992. - Prbu. : Cartulaire dn Chapitre royal de Saint-Pierre-rle-laConr an Mans, par le Vte Menjot d'Elbenne. Mamers, Flenry et Dangin. I904; in-8" te 291 p. et firr. [Archires historiques du Naine, IV. ler fare.].

L'isstroduction et lat lable n'ont pas encore paru.

1993. - Cartulaire de Saint-l'ierre-de-la-Cour an Nans: ms. du XIII siecle, orig. ditruil.

Copie du précédent. faile an $\mathrm{XVII}$ siècle, sur papier, in-40.

C"est cefle coppe qui a en grancte partie servi à la pullication ci-dessus indicquer.

Le Mans. - Courvent des Cordeliers.

1994. - Cartulaire des Corleliers du Mans; n1s. du XVII siècle, sur papier. contenant des titres de l28t a 1623 . in-folio de $411 \mathrm{lf}$. (dichires dép. de la Sarthe. H l284).

Le Mans. - Evirhic.

1995. - Livre hane on Cartulaire de lévèché du Yans; ms. des XVe-XVIe siècles. sur parchenin. intolio de $107 \mathrm{tr}$. Biblioth. de lu ville der M(nus. mis. 25.5.

C'est une continuation du Livre blanc du Chayitre: les documents qui y sont tramerits ne remontent pas au-deda du Xil' siècle.

1996. - Livré rolıre de l'évèché du Mans ; orig. perdu.

Il ext mentionné dans un acte de 1662 comme étant entre les mains de Jacques fournier, greffior de la baronnie de Tourvoie $\mathrm{ef}$. Em. Chambois, Le Vieux Mans. 1904, p. 25).

1997. - Livre vert de l'évèché du Mans ; orig. perdu.

Extraits des cartulaires blanc, ronge el vert de l'évêché du Mans, 
faits an XVIe sionde patr Dom Briant Biblisth. nationmle. ms. Latin $100: 38$. 11. $: 3: 3-41$. 42-.50 et $51-62$.

On ne saurait dire quel est colni de (ons rolumes ynia ve bom Estiennol " in bibliother"a eminentisini 1). Cardinalis Bonsii arehie-

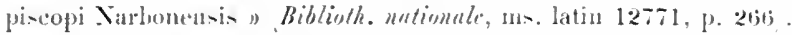

P'bi. : Cartulaire de lévèné du Mans 9:36-1790. pulıl. par le

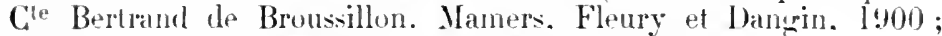
in-So de xv-360 p. [Archires historiques dn Wrine. I.]

Celte publication peut en quelque sorto tite consideries conne un complement du Cartulare publé par Cauvin (ri-tessus no $198 x)$.

Le Mans. - Prieuré de Saint-Victeur.

1998. - Publ. : Cartulaire de Saint-Victeur an Mans. prieuré de l'abbaye du Mont-Saint-Michel, par A. Bertrand de Broussillon (9941400). Paris, Picard et fils, 1895: in- $8^{0}$ de xir- 356 p. et pl. [Société d'acriculture, sciences et arts de la Sarthe.]

Recueil factice d'après les originanx des Arehices de la . Innche et le ms. latin 5430 a de lit Biblintlipque nationale.

Le Mans. - Ville.

1999. - Recueil des privilèges de la ville du Mans; ms. du XVII siècle. sur papier. in-4" de $60 \mathrm{fr}$. Biblioth. de la ville d" Mans. ms. 199.

Publ. De l'arlministration municipale dans le Maine. par A Canvin Le Mans, 1842. in-12.

Le Marteroy près de Vesoul. - Prieuré (dioc. do Besançon). 2000. - Recueil de titres relatils au prieuré du Marteroy, copiés d'apres les originanx conservés aux archives de la Haute-Saòne par C. Rohert. en 1873, sur papier. in-4" Biblioth. nutionule, ms. nour. acr. latines 1241 , pp. 25-36;.

\section{Le Mas d'Agenais. - Ville.}

2001. - Cartulaire municipal du Nas d'Agenais; ms. du XVIIIe siecle, sur papier. contenant des actes de 1267 a 1736 . in- 4 " de $79 \mathrm{H}$. (Archices muicipales dn IKas-d'Agennis. At l .

Le Mas d'Azil. - Abbaye (dioc. de Rieux).

2002. - Cartulaire de liablbaye du Mas d'Azil ; orig. perdu.

Copie du XIVe siècle, lormant ronlean de parchemin de $4^{\text {m }} .15$ de long Archices dép. des Basses-Pyrénées. E 475.

Autre copie du $\mathrm{XVII}^{\mathrm{e}}$ siecle, en 2 cahiers de 18 et $9 \mathrm{fr}$. Arehices dep. de latiège, $\mathrm{H}$ non coté).

Extraits du précédent, faits par Oïhenart au XVIJ siècle Biblioth. nationale. coll. Duchesne, vol. CXIIII, fi. 98-123.

Cf. le rol. 97 du fonds Doat, à la Bibliothèque nalionale. 
Publ. : Ahlave du Mas-d Azil ; monomraphie et cartulaire (8171774), par l'ablice 1). Can-Durlan. Foix, Pomiès, 1897 [1896]; in-80 de 210 p. el pl. 'Extr. du Bulletin de la Saciété ariégeoise des sciences, lettres et arts, $\mathrm{V}, 1896, \mathrm{p} .297$ et passim).

Le Mesnil-Amey. - Prieuré de saint-Blaise (dioe. de Coutances).

2003. - Cartulaire du prieuré du Nesnil-Amey, dépendant de St-Tigor de Cerisy ; ms. des $\mathrm{XV}^{\mathrm{e}}-\mathrm{XVI}^{\mathrm{e}}$ siècles, sur parchemin, in-4 ${ }^{0}$ de t5 It. Biblioth. d" Cikupitse de Bayeux. ms. 161).

Le Miroir. - Ablaye de Notre-Dame (dior. de Lyon). 2004. - Cartulaire de labbare dn Miroir; ms. du XVe siècle. sur papier, contenant 62 actes des années $1182-1459$, in- $4^{0}$ de 72 fr. Lichires drip. de Saúle-et-Lnire, H non coté).

Le Monastier-lès-Chirac. - Priemé (dioc. de Mende). 2005. - Cartnlaire du prienre de St-Sinveur du Monastier en Gévaudan: ms. thes XVII-XVIII siètes, sur papier, en 4 vol. in-folio de 375. 336, 286 el 232 ff. Archives dép. de l'Aveyron, D 2 ¿े.

Dates extrêmes: 1062-1701.

Le Mont-Dieu. - Voy. Moxt-1)IEt.

Le Mont-Notre-Dame. - Abhaye (dioc. de Sens).

2006. - Cartulaire de labhaye du Mont-Notre-Dame; orig. perdu [avait an moins $88 \mathrm{fr}$. .]

Extruts du précedenl, contenant des actes de 12:36 a 1435, sur papier, in-folio (Biblinth. nationale, coll. Champagne, vol. XXII, fil. $21-30$.

Le Mont-Sainte-Catherine pris de Provins. - Abbaye (dioc. de Sens).

2007. - Cartulaire de l'abbaye du Mont-Sainte-Catherine; orig. perdu.

Extrail fail an XVII" siècle (Biblioth. nationale, coll. Champagne, vol. XVII, fo 206 .

Le Mont-Sainte-Marie. - Abluaye (dioc. de Besançon).

2008. - Cartulaire de l'abhaye du Mont-Sainte-Narie; ms. du XVIII siècle, sur papier (Biblioth. nutionale, coll. Morean, vol. 872, ff. $35.5-451)$.

Le Mont-Saint-Martin. - Abluaye (dioc. de Cambrai). 2009. - Cartulaire de labbaye du Mont-Saint-Martin; ms. de la fin du XIII siècle, sur parchenin, avec table en tête et additions posté- 


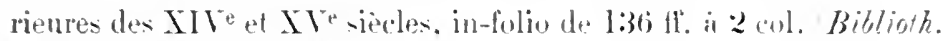
nationale, ms. latin 5478 .

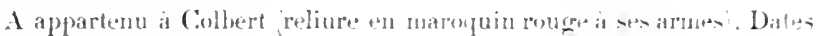
extrèmts:s: $1119-117$ ij.

Copie du precerlent, faile en I740. sur papier, in-lolio de 547 p. (Biblioth. nationale. ms. latin 9128.

Autre copie du XVIIle siecle. sur papier. in-folio de $406 \mathrm{ff}$. (Archices dép. de l: lisile. H 1116 .

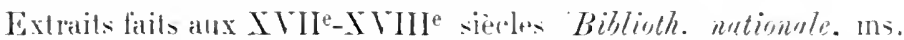
nouv. acq. lrançaises 7385. 11. 28it-285 : coll. Baluze. vol. LXXIV, ff. 232-26I ; ms. français 9500, pp. 108-129).

Le Mont-Saint-Martin. - Chapelle Sutro-Dame-te-Confurt (dioc. de Cilialon-sun-Siono).

2010. - Cartulaire le la chapelle Solre-l)ane de Confort: ma. des IV"e-IVI siecles. sur papier. in-4" de 223 tf. dont lieanoup sont blancs Biblioth. nationale. ms. numr. acq. françaises ito?.

Le Mont-Saint-Michel. - Abbayo (dioc. d'Arranches).

2011. - Cartulaire de l'ahbave du Mont-Saint-Wichel ou « livere vert»: ms. des XIIe-XIII siècles. sur parchemin. in-folio de l:38 $\mathrm{tl}$. (Biblioth. de la cille d'Acrunches. 11s. 210.

Le texte proprement dit ne commenes quau fo 13. - Lne tahl de ce regiatre so trouve aux tf. 243-24! tu mo. francais 4902 de la Biblioth. intiounle.

2012. - Antre cartulaire de l'abbaye du Mont-Saint-Michel; ms. du IVe vièle, uring perdu.

2013. - Recueil de titres et extraits fails pour Gainieses d'apres les deux manuscrits précédents: ms. du Xlle siecle. sur papier. conte-

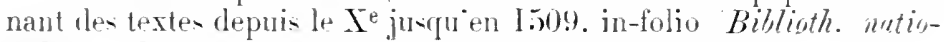
nole. ms. latin 54:30" pages 1-19. 3:3-6; et 29.5-:305. .

On y a réni ausi quelyue textes nlatifo nux prieures dependant do labbaye du Mont-Fant-Miched. et notament a ceux de saint-Germain. sur-di pp. 73-4!4, Pontorson pp. 75-s2, Gohory x3-99. Créan

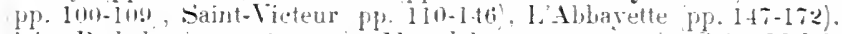

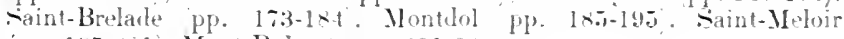
PP. 195-221, Mront-Rohitut Pp. 221-240. ete.

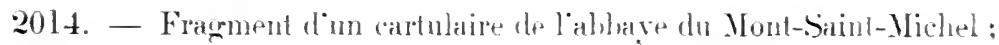

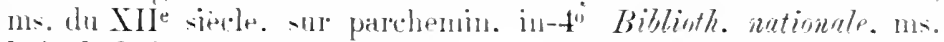
latin $148: 32$. 11. $177-184$.

Contient des chartes tres anciennes. - lo rolume a unt reliure en

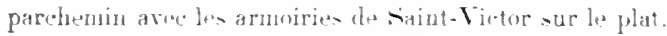

Le Mont-Saint-Quentin. - Abbaye (dinc. d'Amirns).

2015. - Cartulaire-chronique du MonI-Saint-Quentin : ms. dn X VII 
siente. sur papier. contenant la transcriplion de 76 tilles des années 1095-1240, in-folio (Arhices dép. de la Somme. H non coté).

Copie du mime, faite en 1671-I674 par 1). Jean (ielle (Biblioth. mationule, ms. latin $120 ; 92$. 11. 172-2(j.).

Copir moderne du mime. sur papier. in-lolio de 2622 pages Biblioth. de lo rille de Joyon, colleclion Peigné-l lelacourt, ms. Ió).

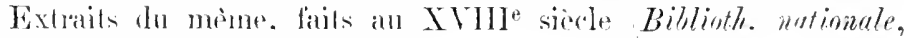
roll. Dom Girenier. vol. CVIII.

Lens [Hainaul]. - Compent des Trinibures (dioc. de Cambrai). 2016. - Carlulare des 'Triniaires de Lens; ms. du XVIJe siècle [I685] ] rédiwri par Anloine lachier. sna papier. conlenant des dilres

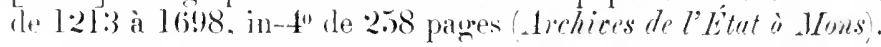

cif. loredre des Trinilaires pour le rachat des captifs. par paul Deslandis's, II (19):3:

Léoneel. - Mbbare de Nolre-Dame (dioce de Dio).

2017. - Prib.: Cartulaire de l'abbaye de X.-I). de Léoncel. an

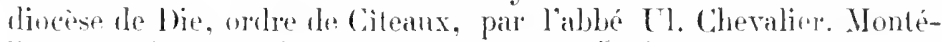
limar. $\therefore$ inpr.. 1869); in-8" 4e :320 p. Collertion de cartulaires diuphinois, IV.]

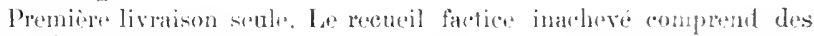
areter de: 1142 it 1303 .

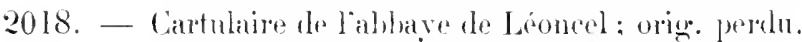

Cif. Guichemen, Biblintera Sebusiana, pp. 13 el 18.

Le Palais. - Abbaye (dioc. de Limoges).

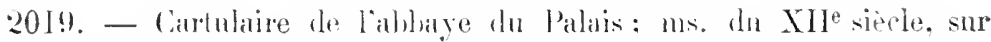

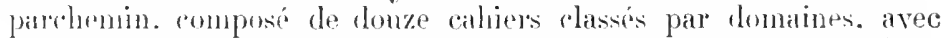

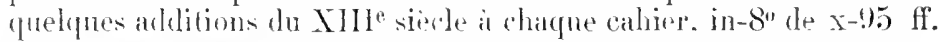
British 1Mustum. mis. atditional 19887.

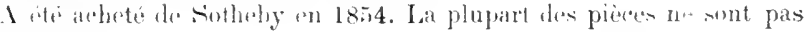
dittion.

Copie du preceident. quasi lan-simile. faite an XIX" sipele, sur palpier. aver notice en tete de Panl Meger. in-8' de 98 li. Biblioth.

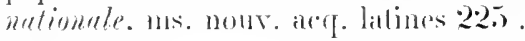

Le Paraclet. - Ablaye (dioc. d'Imiens). - Toy Amens.

Le Paraclet. - Abilye (diac. de Troyes).

2020. - Cartulaire du Paraclet : ms. du XI se sieke. sur parchenin, te 2:is ti. in-4" Biblinth. de le ville de Troyes, nus. 2284,

Autre du XYI" siècle. sur papier. in-t" le to fr. Arehires dép. de latubr. H non colè,

l'ubs, : Cimlulare du Paraclet. par l'allbé Ch. Lallore, dans 


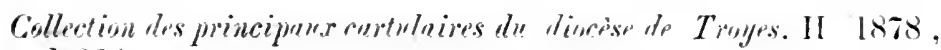
p. 1-364.

Extraits faits an $\mathrm{XVII}^{\mathrm{e}}$ iicele Biblinth. notionule. coll. Baluze, vol. XIXI. p. 11:2-132,

Le Parc-en-Charnie. - Chartreuse.

2021. - Cartulaire de la Chartrense du Pare-en-Charnis: 1ns. in-4", sur parchemin. orige perdu.

Extraits faits pour Gaignières an XVIle siecter Biblivth. antionule, ms. latin 17048. pp. $295-299$.

Le Parc-les-Dames. - Abbaye à Wesemarl (dice. de Malines).

2022. - Cartulaire de l'abhave du Parc-les-Dames: ms. dn XVesiecle. sur papier. contenant des titres de 1263 à 1459 : in-4" de $279 \mathrm{ff}$. (Archices du royume de Belgiqup. a Bruxelles.

Le Parc-lès-Louvain. - Abbare (dioc. de Malines).

2023. - Recneil de titres [bulles] relatifs a lahbaye du Parc-lèsLouvain: ms. les $\mathrm{XVI}^{\mathrm{e}} \mathrm{XVI} \mathrm{I}^{\mathrm{e}}$ siècles. S1r papier, contenant 31 documents de 1142 à 1520 . in-t" de $60 \mathrm{ff}$. British 1/usenin à Londres. additional ms. 1695:3.

2024. - Cartulaire de l'ablare sn Pare: ms. du XVIII siècle. sur papier, contenant des actes de 1134 à 1264 . in-4" de $24 \mathrm{tr}$. Archices du molume de Belquque. à Bruxelles.

Le Perray-aux-Nonnains. - Abbare (lior. d'Angers).

2025. - Cartulaire de l'ablaye du Perray : orig. perdn.

Recueil de titres relatifs à la mème abbave. copiés an $\mathrm{XVII}^{\mathrm{e}}$ siècle Biblivth. nutisnale. coll. Wom Houseari. vol. XII et XVIII.

Le Petit-Citeaux. - Voy. L'Almone.

Le Piéton. - Commanterir de St-Jan de Jerusaltru (dion. le Tournai).

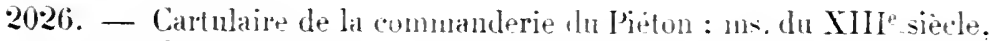
sur parchemin. contenant des actes de $114 t$ is 1.2333 . in-t" de $58 \mathrm{ll}$. Archires de liktut is Mors.

Axul. : Description de "artulaires et de chartriers du Hainaul. par L. Devillers II 186ti - pp. :3i-115.

202i. - Rerneil des bulles et diplomes de la comnanderie du Piaton: ms. du XVIII siècle [litis]. sur papier. in-folio Archices de l'Elat ì Mrins. 
Le Pigny (Thomas), bourgeois de Saint-Lô.

2028. - Cartulaire de Thomas le Pigny, "seigneur des francs-fiefs de Lat Meatufe ef d'Airel en la paroisse de Rampan 》 (Manche); ms. date de 140:3. sur parchemin, in-folio de $31 \mathrm{fr}$. (Avchives dép. du Culcudos. Fonds Anquetil, F non coté).

On peut rapurocher de ceregistre un recueil analogue relatif aux possestions de l'homas Ie ligrny à Saint-Lo, Lison, Milly, etc., et autres garoisses des vicomlés de bayeux, Coutanes of Saint-Lo, pour la fin lu XIVe sic̀ele ef le début du XV" sièrle, ef contenant des

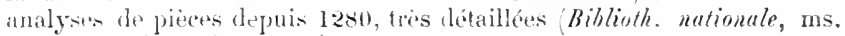
notr. ace]. française's 1122$\}$.

Le Plessis-Grimoult. - Priente de saint-Etienne (dioc. de Bilyenx).

2029). - Cartulaire du prieuré du l'lesisis-(irimonlt : ms. daté de 1493. contenant des actes a partir de [2.)]. en 3 vol. in-folio sur parchemin, (Arrkicess dép. the Cintrudtos. H non coté.

Le Plessis-Iès-Tours. - Cournit des Minimes flioc. de T'ours).

20:30. - Cartulate des Ninines dn plessis-les-Tours [in-folio, sur parchemin. de $406 \mathrm{ft}$.$] ; orig. perdu.$

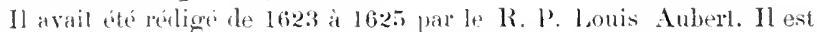
mentionne dans un inventaire des titres du XVII I' siecle (Archires dip.

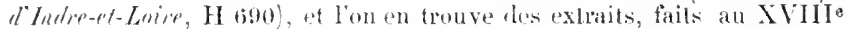

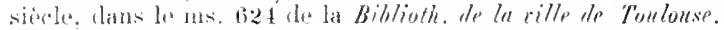

Le Pont-aux-Dames. - Abbaye (dioe de Meaux).

2031. - « Camtularinm Pontis bominarmm »: ms. du XVIJe siècle,

sur parchemin, de 1.5.) ff. in-8" Biblinth. netionule, ms. latin 10944.

20:32. - Andre cartulaire perdu. dont s'est servi bom Tonsaints du Plessi- Hist, de l'Tirlise de Meanx'

Pobs. par extraits on analyses : Lablaye lu Pont-aux-I)ames, orde de Citsanx, assise en lia paroisse de Conilly. par Berthanlt. Neanx. Le Blondel, 1877 ; in-8". p. 1-87 de l'appentice.

20:33. - Copies de titres relatifs a l'abluaye un Pont-aux-Danes; ms. collationué +n 1673 par Bazin. anditeur des Comptes à Paris, d'après nur original datant de 1547 . sur papier, in-4" Biblinth. nationale, ms. français thici), df. 3.5 $\mathrm{v}^{0}-61$ ).

Le Puiset. - Prienré de Saint-Mlatin (dioc. d'Orléans). 2034. - Pubr. : Charles du prienré du Puiset, dipandant de Marmou-

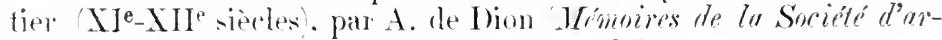

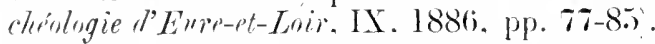

Le Puybéliard. - Prieure de Saint-Pierre (dioc. de Luçon). 2035. - Publ. : Carmalaire des prieurés de Darmoutier en Bas-Poitou, 


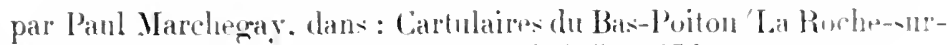

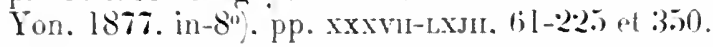

Le Puy-en-Velay. - Hospitaliers.

2036. - P'br. : Cartulatre des Hospitaliers 'ordre de St-Jean de, Jérusalem) du Vélay (1153-14.59. par Augustin Chamaing. Parir, Picard, 1888 ; in-8" de Lxwir-278 p.

Le Puy-en-Velay. - Templiers.

2037. - Pubc. Cartulaire des Templiers du Puy-en-Telay, par Augustin Chassaing Annules de ln Socirté d'agriculture, sciences, arts et commerce d" Pny. XXXIII. p. 139-2633. et a part: latris. 188: in- $\mathcal{S}^{\circ}$ de $\mathrm{xxxy}-93 \mathrm{p}$.

Dates extrêmes: 1170-1291. Publication faite d'après un rouleau du parchemin (XII s.) conservé aux Archics depp. tu Rhône (série H.

Le Quesnoy. - Abbaye de Sainte-Elisabeth (dior. de Cambrai).

2038. - Cartulaire de labluaye de Ste-Élisabeth du Quesnor : m- du XVIe siècle sur papier. contenant 228 artes de 1261 a 1516 . aree une table in-4" de $237 \mathrm{ff}$. Archires dép. d" Tord. ms. 38:3.

Le feuillet 59 manque.

Le Reclus. - Abbaye. - Voy. Reclus.

Lerinnes. - Couvent des Trinitaires (dioc. de Liège).

2039. - Cartulaire des Trinitaires de Lerinnes : ms. du XVII siècle. papier, contenant destitres de 1220 à 14.58. in-to le 4 ff. Archires de l'Etut is Wons'.

Cif. Lordre des Trinitaires pour le rachat des caplif. par I'au? Deslandres. II (15013).

Lérins. - Abbaye de Saint-Honorat (dioc. de Grasse).

2040. - Cartulaire de St-Hunorat de Lênin: ms, date de 1508. arec adlitions contenant des documents de 954 is 15:32. sur papier. in-4" de $8.5 \mathrm{ff}$. Archires dép. des Bonches-du-Rhine. B 1+14).

2041. - Cartulaire de St-Honorat de Lérins: ms. du XilP siècle. areec additions postérieures jusqu en $14: 30$. in- $4^{\prime \prime}$ de $162 \mathrm{fr}$. Lichires dép. des Alpes-Luritimes. H non coté.

Copie morlerne $[1868]$ du précédent par lablé Tisserand : in-follo de $36.3 \mathrm{ff}$.'Biblinth. nationule. mo nour. aeq. latines 115.5 .

2042. - Prbs. : Cartulaire de labluave de Lerins, par Henri Moris [et Ed. Blanc]. Yaris. Champion. 1883-1905: in- $4^{\prime \prime}$ le Ln- 143 ei [rui-]cx-296 p. arec pl. [Société des lettres, science, et arts des Alpes-Maritimes.]

Le premier volume contient lo trexte du cartulaire no 2041 chartes 
depuis le $1 \mathrm{X}^{\mathrm{e}}$ siecle) ; le second, par H. Moris srul, est un supplément formé ave des chartes indépendantes des XIIIe-XVHIe siècles. - Sur le premier volume, consulter les comptes-rendus de '). Meyer, Romania, XIII, pp. 133-134, et de A. Bruel, Bibliotheque dr l'École des Cihartes, XLI, pp. 203-209. Cette édition appellerat encore d'antres observations an point le viue de la chronologie dos chartes.

- Cartnlaire de labbaye de Lérins, par H. de Flamare. Nice, Canvin-Jimpereur, 1885); in-8" de 42.) p. [Société niçoise des sciences naturelles et historiqnes.]

Publication restée inacherée.

Le Ronceray. - Abbaye (dioc. d'Angers). - Voy. Axeers. Les Aix d'Angillon. - Toy. Siluy.

Les Alloix. - Abbaye (dioc. de Limoges).

2043. - Cartulaire de l'abbaye des Alloix ; vrier. perdu.

Recueil de litres formé an XVHe siècle par Dom Esliennot, en parlie d'après le cartulaire Biblioth. nutionale, ms. latin $\mathrm{I} 2 \mathbf{7 4 6}$, pp. $609-624)$.

Le Saulce-sur-Yonne, pris d'Arallon. - Commanderie (dioc. d'Auserre).

2044. - Cartulinire de la commanderie du Saulce; ms. du XIIIe siècle, sur parchemin, avec une arlition postérienre, contenant des actes de 11922 i 1317 , in- $4^{\prime \prime}$ de $70 \mathrm{ft}$. (Arehices nutionales, S 5235, $\mathrm{n}^{* 1} \mathrm{l}$ ).

Lescar. - Ibbaye.

2045. - Cartulaire de l'abbaye de Lesear ; onig. détruil en 1787.

A éte utilise par l'hintorien Marca.

Lixlmils faits an XVII siècle th précédent (Bibliolh. nationale, ms. Lilin 127.51. p. 744); - par Ö̈henart (Idem. coll. I)uchesne, vol. CXIV.ff. 21-26; - - an XVIII siècle par Larcher (Biblinlh. de la rille de Tarbes, (ilanime, VI, pp. 98-114).

Les Châtelliers. - Abbayo (dioc. de Poitiers).

2046. - Cintulaire de lahbaye des Chàtelliers; orig. perdu.

Exlrats faits par lom Estiennol, au XVIJe siècle Biblioth. metimente, ms. latin 12666, th, 1-14).

2047. - Pron. : Cartulaire de labhaye royale de Notre-Dame des Chatelliers, par Lonis Duval. Niorl. Clouzol. 1872; in-80 de crim-3:38 p.

Recuetl factice de 358 pièces des années $1145-1725$.

Les Écharlis. - Abbitye (dioc. de Sens).

2048. - Ciartulaire de l'abbaye des Écharlis ; orig. perdu.

Il est mentionné dans le recueil de Graignières cité ci-apress. 
2049. - Recneil de titres relatifs a labbave des Geharlis (11:31-1180. fait au XVIIe siecle Bihlin/l. natimmli. coll. Champacrne. vol. XV.

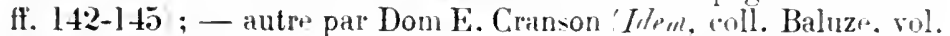
XXXYII, II. 304-311 ; - antre ponr Gaignières ' Kons. ms. latin 17097, pp. 1-35).

Les Écouges. - Chartrense (dive. de (irenoble).

2050. - Prac. : Cartulaire de lancienne chartrense des Econges. diocèse de Gremolle. par le chanoine Auverone Dorminents inédits

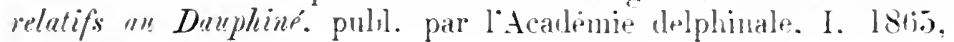
p. $81-26 i 7$.

Recueil factice de: il chartes des anné-1104-1 14it.

Les Fontenelles. - Abbare de Notre-Lame (dior. de Lucon). 205I. - Cartnlaire de l'abbare de X.-D. des Fontenelles : orin. perdu. Lixtrait fait par Besly an Xrile siecle Biblinth. untionule. coll. Dupny. rol. 8:8. fi. $500-7 i$.

Les Fouteaux. - Prieuré (dion. do Blois).

2052. - Cartulaire du prienré des Fouteanx. dipendant de linhare de Tiron : ms. du $\mathrm{XVI}^{\mathrm{e}}$ siècle. sur papier. in-t" le liff. 'Aichires dép. (t) Eure-et-Loir. H 1893.

Le conlenu dre ce registro, is lesception de qualre pieen du

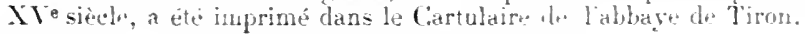

L'Espinasse. - Prieuré (dioc. de Toulouseo).

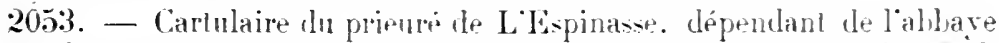
de Fontevranlıl: mi. "Ln XVI" siecle. sur papier. in-4" de atj if. (Archices dép. de Iruilu-et-Lsive. H non coté.

Le plus ancien doeument transerit est de $11 \% 3$.

Les Riceys. - Prieuri. - Toy. Picer.

Les Saintes-Maries. - Ville.

2054. - Carmlate mmicipal des Saintes-Maries un « Lirre noir »;

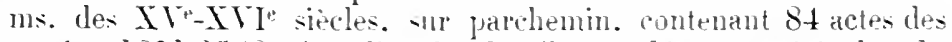
années 127l-1548. in-folio de 8:3 tf. dorkires municipales des Saines-Mories. At 1 .

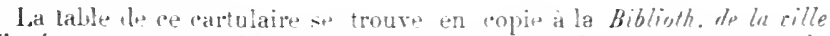

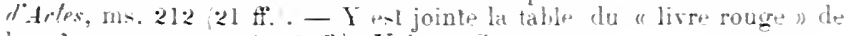
la mènze communaule 12 ff:. Voir au SCPPLËMarr.

Lessay. - Ablare de la Sainto-Trinité (dioce de Comtanes). 2055. - Frament diun cartulaire de labbare de Lesary : m-. du X $V^{\circ}$ iècle [ff. 1:36-13:1]. collationné en 1462. contenant lo actes depuis l'année 1233. sur parchemin. in-folio de $4 \mathrm{tr}$. Archices dip. de lu . Wancle, $\mathrm{H}+6668$. 
2056. - Autre cartulaire de l’abbaye de Lessay on « Livre noir » [ms. de 1221]; orign perdu.

Jixtraits faits en I634-I6:37. in-folio sur papier (1rchives dép. de la

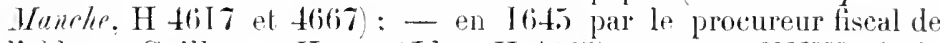
l'abbave. Guillanme Henry Id?'m. H 46(6.5); - el au XVIIJe siècle (Idem.H 4666$)^{\circ}$.

Les documents transcrits dans ces extraits sont des Xle-XIIIe siècles.

Lessines. - Voy. Flobecr.

Lessines. - Hòpilal de Notre-Dame à la Rose (dioc. de Cambrai).

2057. - Cartulaire de l’hòpital X.-1). de Iessines; nıs. du XIXe siècle, sur papier, avec table, contenant des transcriptions d'acles des annéea 124:3 à 1738. in-folio (Arrhives de l' litut à Hons).

Lesterps. - Ablaye (dior. de Limoges).

2058. - Fragnent d'un cartulaire de l'abbaye de Lesterps; ms. du X11I" siècle, contenant qualre chartes des années 975-1140, 2 ff. de parchemin in-4" a 2 col. [appartenait en $186+$ a $\mathrm{XI}$. Borean-Lajanadie, president du tribmal civil de Confolens].

Cl.: Xotire ef dissertation sur un fragment du cartulaire de l'abbaye de Lesterps. par G. Balinet de Rencogne Bullelin de la Société "archédogiqu" de la Churente, 3" série, 1. 1V, 1864, p. 47-63), et is part : l'aris, 1862 ; in-80 de 19 p.

L'Estrée. - Abbaye de Nulre-D)ame (diox d'Évreux).

$205 \%$. - Carlulaire de l'abbaye de Llistrée ; ms. de la fin du X Ve siècle, conlenanl 197 atedes des années $11+4-1483$, sur parchemin, in-40 de 111 if. Arehives dip. de l'Eure, H :319.

Copie du précredent, faite an XVII" siecle (Bibliothe nationale, coll. Claimambanll. vol. 995.

Les Trois-Épis. - Prieuré (dioc, le strasbourg).

2060. - Carlulaire du prieuré les Trois- Śpis, réuni à la commanderie l'Isenheim ; ms. du XVII" siecle. sur papier. in-folio de $33 \mathrm{ff}$. (Arhic des Ober-Elsass. in Colmar.

les documents sont des amnées 1500 à 1704.

Les Vaux-de-Cernay. - Mbaye (dioce de Paris).

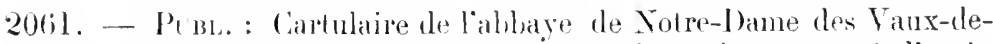
Cernay, de lorelre de Citeaux, au diocèse de Paris, composé d'après les chartes originales conservés anx archives do Seine-et-Oise (1 I 18179) . par Lucien Merlet el Aun. Nontié. Paris. Plon, 1857-1858; 2 vol. in-4" de xxru-783 el 412 p. el atlas in-folio [Société archéologrique de Rambouillet.] 
Les Vieux-Jones. - Commanderie do lindre Tetnonique, près de Bilsen (dioc. de L iège).

2062. - Cartulaire des Vienx-Junes; ms. du XIV siecle, sur parchemin, in-4" Stuntsarchic zu Diusseldorf".

Contient des bulles et des diplònes impériaux des XII -XIV sièces.

2063. - Autre du XrII sièle. sur papier. contenant des actes de 1434 à 1661 , in-folio de $93 \mathrm{ll}$.' 'Idein.

2064. - Autre du XVIII siècle, sur papier. contenant des actes de 1467 a 1746 , in-folio (Idem) .

Il semble que ce depôt contienne dautres recurils de piès relatits à la mème commanderie (cf. J. Cuvelier. Les archives th la grande commanderie de lordre Teutonique des Vieux-Jonrs ronserves à Düsseldorf (Comptrs-readus de la Commission royale thistoire de Belgique, I.XXl, 1913, no 4$)$.

L’Étanche. - Abbaye de Bénédictines (dion. de Saint-Dié). 2065. - Cartulaire de l'ablave de L'Étanche: ms. du XVI siècle [1548], sur papier. contenant des actes de 1148 a $132: 3$, in-4" de $29 \mathrm{ff}$. Archives dép. des Trasges. $\mathrm{H}$ non cotè,

L'Étoile. - Abbaye (dive. de Poitiers).

2066. - Cartulaire de l'abhaye de L'Étoile s orig. perdu.

Extrait fait an XVII siècle 'Biblioth. nutionale. mis. français 20226, fo 36 .

Le Tréport. - Abbaye dr Saint-Michel (dion. de Romen).

2067. - Cartulaire de labbave du Tréport; ms. du XVIII sèclo [1728]. sur papier. contenant des actes de 1036 à 1500. in 4 " de II-340 pages Biblioth. Sainte-Generière, à Paris, ms. 165l).

Copie moderne (Biblioth. nationale, ms. nour. acq. latines 249.

Publ. : Cartulaire de l'abbaye de Saint-Michel du Tréport. ordre de Saint-Benoît. par P. Laffleur de Kermaingant. Paris. FirminDidot, 1880 ; in- $4^{0}$ de claxy-427 p. et atlas in-folio de $8 \mathrm{pl}$.

2068. - Autre cartulaire; ms. du XVIlle siecle. sur papier. contenant des documents de 1036 à 1389 . in-folio de $91 \mathrm{ff}$. Arehires dép. de la Seine-Inférieure, $\mathrm{H}$ non coté;.

Le Trésor. - Abbaye (dioc. de Ronen).

2069. - Cartulaire-censier de labbaye du Trésor; ms. du XrII ${ }^{\circ}$ siècle, contenant 171 titres à partir de 1233 , sur papier, in-folio de 319 ff. (Archires dép. de ll Eure. $\mathrm{H} 1410$.

Le Valasse. - Abbaye, dite aussi du Tou (dioc. de Rouen). 2070. - Cartulaire de l'abbaye du Valasse ; ms. du XVI* siècle [rers 
1500]. sur papier, en 6 vol. in-folio (Arrhives dép. de la Seine-Infévieure. H non cotè

Le tome IV manque à la collection. - Cif. Bibliollièque do l'Érole des Charles, XXIX (1868), p. 203 .

Le Val-Benoît. - Abbaye (dioc. de Lienge).

2071. - Cartulaire de lablbaye ilu Val-Benoil; ms. du XVIIe siècle, sur papier, contenant des titres de l206 a 1410 , in-folio de 298 II. (Archices de litut à Liège .

2072. - Autre cartulaire du XVII siecle, sur papier, contenant des titres de 12:39) à 1396, in-folio de 298 I1. (Archives de l'Étrt à Liège). 2073. - Publ. : Cartulaire de l’abbaye du Val-Benô̂t, par Joseph Cuvelier. Bruxelles. Kiessling, 1906; in-4" de [1v-]L-9:33 p. [Académie royale de Belgique; Conmision royale d"histoire.]

Le Val-de-Bugny. - Léprosirio (dioe. d'Aniens).

2074. - Frament d'un cartulaire de la léproserie du Val de Bugny ; ms. du XIIle siècle, sur parchemin, in-t" de 17 II. (Biblioth. nationule. coll. I nom Grenier, vol. CCXXXVIII, If. 66-82.

Dates extrênes : 1164-1215.

Le Val-de-Sainte-Aldegonde. - Chartreuse fdioc. de Saint-Onin' $)$.

2075. - Cartulaire du Val de Sainte-Aldegronde; ms. du XVe siècle [1463]. avec additions, contenant des actes de 1184 à 1539 , sur parchemin, in-folio de 335) 11. (Biblioth. de la ville de Saint-Omer, 111s. 901 .

Pebl. : Cantulaire de la Chartrense du Val de Sainte-Aldegonde près Saint-Omer. par J. [Deschamps] de Pas. Saint-Oner, 1905; in-4" de [11-]xxrn-2617 p. et pl. [Société des Antiquaires de la Morinie.]

Le Val-des-Choux. - (irand priemé de Trappistes (dioe. de Lingres).

2076. - Cartulaire du grand prienré du Val-des-Chonx ou Val de Saint-Lieu en Bourgogne, ef des prieurés de Beaupré. Remonvaux et Vauclair, contenant des documents de 1205 à 1780 ; ms. du XVIII siecle, en 7 parties formant 5 vol. in-folio de xxin-542, $\mathrm{xx}-543, \mathrm{xv1}-783, \mathrm{x}-474$ et $\mathrm{xxiv-668}$ pages, sur papier (Archives dép. de l'Allirr, $\mathrm{H}$, fonds de Septfonds).

2077. - Autre cartulaire; ms. du XVIIJ siècle, sur papier, in-40 de 707 pares (Archives dép. de la Coterl' Or, $\mathrm{H}$ non coté).

Le Val-des-Écoliers. - Abbaye (dioc, de Langres). 2078. - Cartulaire de l'abbaye du Val-des-Écolier's; ms. des XVII 
[1674] et XVIII siècles. contenant 350 pieces des annes 1:21:2.

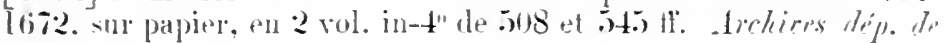
la Hante-.Harne. H num coté.

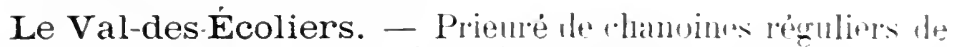
Saint-Augustin, ì Lian (diore dr Malines).

2079. - Cartulare du prieurédu Val-des-Ecoliers: un du XV" siécle.

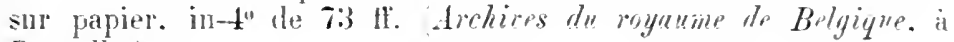
Bruxwlles.

Lets documents trancerits appartiennent au XIV el au XV siecles.

Le Val-des-Vignes. - Abbiyp (dioc. dr Langres).

2080. - Cartulaire de labluaye du Val-des-Vinnes. mie à Clairvan: ms. du XVIe siecle. contenant des pièces a partir de l:2:20. sur papier. in $\mathbf{t}^{\prime \prime}$ de $16 \mathrm{llt}$. Archires dép. de l: Aube. H non cute.

Le Val-Dieu. - Chartrouso (dioc. de Sées).

2081. - Cartulaire de la Chartrense du Val-Dien : ms. des Ille-Ire siècles. sur parclemin. contenant 530 actes des annees 1:26-1480. in-folio de $145 \mathrm{lf}$. (Biblinth. de la rille d"Alenerne ms. 108.

Le Val-d'Osne. - Abluave (dioc. dó Chàlons).

2082. - Cartulaire de liablave du Val-d'One : orig. perdu.

Copie partielle du précédent, faite an XVIII siecle. sur papier (Biblioth. mationule. coll. Champagne. vol. CIX. If. 40-51)

Le Val-Notre-Dame. - Abbaye dioc. de Liègre). - Voy. Val-Notre-Danie.

Le Val-Notre-Dame. - Abbare (dinc. Le Paris).

2083. - Cartulaire de labbave de Notre-Dame du Val: ms. du XIII sieccle sur parchemin. contenant des actes de 1127 i 1217 . in- 80 de 69 If. Archices nutisinules. LL 1541.

Table du mème : ms. dn XV1le siècle [1669-16733]. sur papier. in-folio, avec additions jusqu'en 1531 trehices mution?es. LL 1542.

2084. - Autre cartulaire de Jotre-l lame du Val : origr. perdu.

Copie faite an $\mathrm{XVII}^{\mathrm{P}}$ siecle. sur papier. in $\mathbf{t}^{\circ}$ de 214 payes (Biblioth. nutimale. coll. Jouranvault. vol. 936.

2085. - Autre cartulaire : origr. perdu.

Table des trois cartulaires de labbave de Notre-Dame-du-Tal. faite en 1669-1675. sur papier. in-16 de in-250 fi. Biblinth. rustinmale, ms. nour. acr. frangaises $\mathbf{4 6 6 .}$

Voir au fo log pour le seconel regristre, au fo 161 pour le troisiem. 
Extrails faits an XVII" siècle. par A. Du Chesne (Biblioth. nationale, coll. Baluze, vol. LT, ff. 50.5-5l2); - pour Gaimières (Idem, ms. latin 5462; - par un inconnu (Idem, ms. latin 10999).

Le Val-Notre-Dame. - Hòpital de l'abbaye.

2086. - Cartulaire de l'hôpital de l'abbaye dı Val-Notre-Dame; ms. du XIIle siècle, arec additions du XIV'e siècle, sur parchennin, in-8" de $46 \mathrm{ft}$. Biblioth. mationale. ms. nonv, acquisitions latines 8:6).

1)ates extrêness : 1214-1205.

P'cre. : Carlulaire de l'hòpital de l'abbaye du Val-Notre-Iame au diocese de Paris, par Henry Onont Mémoires de la Société de l'histoire de Paris et de l'Jle de Frrane, XXX, p. 127-175), el is part: Paris. 1904 ; in-8" de II-50 p.

Le Val-Saint-Bernard. - Abbaye a lliest (dioc. de Malines).

2087. - Cartulaire de labbaye dn Val-Saint-Bernard; ms. dn XVle siecles sur papier. contenant des titres de 1255 à 1525 , in- $4^{0}$ de $128 \mathrm{ti}$. Arrhires du roymume de Belgique, it Bruxelles,.

Le Val-Sainte-Marie. - Chartreuse, a Bomvantus flioc. de Talencer).

M. l'abbé [1. Clytralier a cilé dans un de ses travaux le cartulaire du Val-sainte-Marie, recueil faction qüil se disposat à publer, mais qui n'a jamais ru ke jour.

\section{Le Val-Saint-Georges. - Voy. S.lziñe.}

Le Val-Saint-Lambert. - Ablaye (dioc. de Liège). 2088. - Cartulaire de l'ahlave du Val-Saint-Lambert: ns. du XIVe sècle, sur parchemin arec lithle en tête sur papier, in-ț" de rm-6:3ff. is 2 col.. incomplet de lit fin Biblinth. nationale, ms. latin 10176). 2089. - Aulre dn XVI siecle, sur papier, in-4" de vi-74 If. (Bitblioth. untimale, ms. latin 10157 .

Le Val-Saint-Pierre. - Chartreuse (dioc. de Iaon). 2090. - Cintulaire de la Chartreuse du Val-Saint-Pierre; orig. perdu.

A ité "onnu ut ntilisé par Don Villevieille.

Le Verger. - Abbaye (dioc. de Cambrai). 2091. - Cartulaire de l'ahbaye du Verger ; orim. perdu.

Extraits laits pour Gaignieress an XVII siecle (Biblioth. nutionale, ms. latin 17049 , pp. 539-5.53, 
L'Évière. - Prieuré (dioc. d'Angers).

2092. - Cartulaire du prienré de l'ḱvière, dipt de lahbaye de la

Trinité de Vendòme : orig. perdu.

A été utilisú au XVII" siècle par Launot dans son "Inquisitio in privilegiis monasterii Vindocinensis $"$.

Levroux. - Église collégiale (dive. de Bourges).

2093. - Cartulaire dn Clapitre de Saint-Srlvain de Levroux: m. des XIII-XIY̌e siècles. contenant des actes der années 101:2-1:316. sur parchemin. in-4" de 10.5 If. 'Archires dép. de l'Intre. (: 110 .

Leyme. - Abbaye (dine. de Cahors).

2094. - Recueil de titres relatifs a labluaye de Leyme: mo. du XVII siècle, contenant des documents de 121:3 is l.435 Biblinth. nationale. coll. Doat. vol. 124. ff. 154-227.

Lezat. - Abbaye de Saint-Pierre (dioc. de Rieux).

2095. - Cartulaire de lahbaye de Lenzat. du XIIe siècle ; orig. perdu.

Extraits faits par Oihenart des fir. 192-210. sur papier Biblinth. de.M. de Cursalude du Pont. érèque de Perpignan.

2096. - Cartnlaire de lablhaye de Lezat : ms. du Xille siècle [1:248]. sur parchemin. in-folio de $3226 \mathrm{ff}$. it 2 col. (Biblioth. wutimute. m. latir 9189 .

I es chartes trmserites sont du XIIe et th XIII sionte. - las

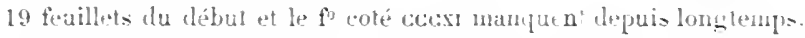

2097. - Recueil de titres relatils à liablare de Lárat; ms. dat. de

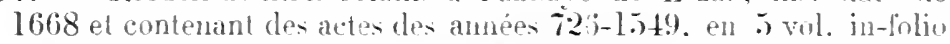

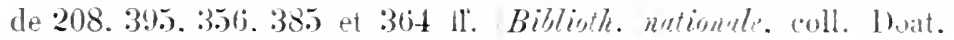
vol. 98-102.

Libaud, à La Réorthe. - Prieuré (dioc. de Lutecon).

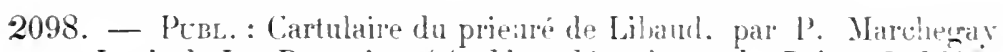
et Louis de La Bonletière Archices histuriques du Priton. I. 18 i:. p. ริ3- 78 .

Recueil de pieces lirées du cartulaire de lout rauld in 13.10,

Libourne. - Ville.

2099. - Cartulaire manicipal te Libourne on "livre velu»: ms. commencé ea l-79). avec additions port irientes. sar parchemin.

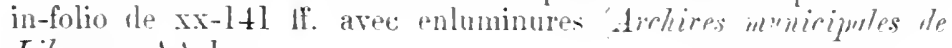
Libourne. Ad I.

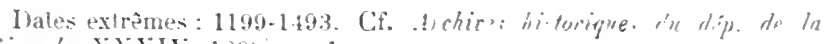
Gircnde, XXXIS l896, , 1. 
Licques. - Abbaye de Notre-Dame (dioc. de Boulogne). 2100. - Pubr. : Chartes de l'abbaye de Notre-Dame de Licques, publ. par l'abbé Haigneré (Mémoires de la Société académique de Boulogne, XV, 1890, pp. 34-175).

Liège. - Abbaye de Beaurepart.

2101. - Cartulaire de l'abbaye des Prémontrés de Beaurepart à Liège; ıns. du XVIe siècle, continué jusqu’an XIXe, sur papier, contenant des chartes à partir de 1203, in-folio de 192 fl. (Archives de l'État à Maastricht).

2102. - Autre du XVII siècle, sur papier, contenant des chartes de 1101 à 1658, in-folio de 132 ff. (Archives du Séminaire de Liège).

Publ.: par le chanoine J. Daris dans le Bulletin de l'Instilul archéologique liégeois, IX, pp. 331-372.

Liège. - Abbaye de Saint-Jacques.

2103. - Recueil des titres de l'abbaye de Saint-Jacques de Liège ; ms. du XVIle siècle, contenant des chartes de 1459 à 1545 , sur papier, in-folio de 398 pages (Bibliothèque du Chapitre de Trèves, ms. 78).

Liège. - Abbaye de Saint-Laurent.

2104. - Cartulaire de l'abbaye de Saint-Laurent de Liège; ms. des: $\mathrm{XII}{ }^{\mathrm{e}}-\mathrm{XIII} \mathrm{I}^{\mathrm{e}}$ siècles, sur parchemin, contenant 48 actes des années 1142-1214, in-8 de 38 fr. (British Museun, à Londres, additional ms. 17396).

Registre incomplet qui commence au fo xxvı.

Axar.: Comples-rendus de la Commission royale dhistoire(Bruxelles), $2^{\mathrm{e}}$ série, XII, p. 19-26.

2105. - Autre cartulaire; ms. des $\mathrm{XVI}^{\mathrm{e}}-\mathrm{XVIII}{ }^{\mathrm{e}}$ siècles, sur papier, contenant des chartes de 1034 à 1759 , in-folio de $314,336,323$, 336, 267, 298, 350 el 4l4 ff. (Archives du Séminaire de Liège).

Anal. : par le chanoine J. Daris (Bulletin de la Société deart et d'histoive du diocèse de Liège, 11, 1882, pp. 144-286).

Liège. - Aumône des paurres en Ile.

2106. - Cartulaire de l'aumône des pauvres en lle ; ms. du XVIe siècle, sur papier, contenant des documents à partir du XIII ${ }^{\mathrm{e}}$, in-folio de 303 ff. (Archives de l' État à Liège).

2107. - Autre cartulaire des XVII $-X V 11 l^{\mathrm{e}}$ siècles, sur papier, in-folio de $150 \mathrm{ff}$. (Archives de l'État à Liège).

2108. - Autre cartulaire du XVlJIe siècle, sur papier, en 6 vol. in-folio dont un de tables (Archives de l'État à Liège). 
Liège. - Collège des chanoines de Saint-Materne.

2109. - Cartulaire de Saint-Materne de Liège ; ms. des XVIeXVIII siècles, sur papier, contenant des titres de 1200 à li22, in-folio de $209 \mathrm{fr}$. (Archices de l'État io Liège).

Liège. - Courent des Carmes.

2110. - Cartulaire des Carmes de Liège ; ms. des XVe-XVI siècles, sur papier, contenant des titres de 1400 à 1531 , in-folio de $35 \mathrm{ff}$. (Archires de l' État ì Liège).

Liège. - Courent des Jésuites.

2111. - Cartulaire des Jésuites de Liège ; ms. dn XVIIe siècle, sur papier, contenant des titres de 1155 à 1632 , in-folio de 435 pages (Archires de l'État ì Liège).

Liège. - Église cathédrale Saint-Lambert.

2112. - «Liber chartarum ecclesiae Leodiensis »; ms. des XIII"XIVe siècles, sur parchemin, in-folio de $428 \mathrm{ff}$. (Archices de l'Éta! à Liège).

Publ.: Cartulaire de l'église Saint-Lambert de Liège, par S. Bormans et E. Schoolmeesters; I-IV. Bruxelles, impr. Hayez, $1893-1900 ; 4$ vol. in- $\mathbf{4}^{0}$ de LiI-699, rv-671, $15-721$ et vi-784 p.

Le tome V est sous presse. - Cf. Examen critique du Cartulaire de l'église Saint-Lambert de Liège, par Edm. Reusens (Analectes pour l'histoire ecclésiastique de la Belgique, 2e série, IX, pp. 93-210), et à part : Louvain, 1894 ; in- $8^{\circ}$ de $115 \mathrm{p}$.

2113. - Cartulaire rouge de St-Lambert; ms. du XVe siècle, sur parchemin, contenant des actes de 1243 à 1488 , in-folio de $184 \mathrm{ff}$. (Archives de l'État à Liège).

2114. - Autre cartulaire dit « Stock A »: ms. des XVe_XVIII siècles, sur papier, contenant des documents de 1410 à 1728 , in-folio de $277 \mathrm{ff}$. (Archives de l'État à Liège).

2115. - Cartulaire de la grande prévôté de Saint-Lambert; ms. du $\mathrm{XVe}$ siècle, sur parchemin, contenant des titres de 1250 à 1447 , in-folio de $69 \mathrm{ff}$. (Archices de l'État à Liège).

2116. - Autre cartulaire de la grande prévôté ; ms. du XVIIe siècle, sur papier, contenant des titres de 1200 à $16 \%$, in-folio de 15 á ff. (Archices de l'État à Liège).

2117. - Cartulaire de l'aumônerie de Saint-Lambert; ms. du X VIe siècle, sur papier, contenant des titres de 1328 à 1560 , in-folio de $510 \mathrm{ffr}$. (Archives de l' Litat à Liège).

2118. - Cartulaire de St-Lambert de Liège ; m.. du XVIe siècle, sur 
papier, contenant 104 actes des années 1204 à 1480 , in- $4^{\text {n}}$ de $124 \mathrm{ff}$. (British Museum à Londres, Egerton ms. 992).

Commence an fo 184 et est incomplet. Il parait être transcrit d'après le $n^{\circ} 2112$ ai-dessus.

Liège. - Église collégiale Saint-Barthélemy.

2119. - Cartulaire de l'église collégrale Saint-Barthélemy de Liège; ms. du XIVe siècle avec additions du X Ve, sur papier (actes de 1031 a 1459), in-folio de $290 \mathrm{ff}$. (Biblioth. du Grand Séminuive de Liège).

Anal. : par le chanoine J. 1)aris, dans : Nolices historiques sur les coglises du diocèse de Liègre, VI, pp. 177-22:3.

Liège. - Église collégiale Saint-1)enis.

2120. - Cartulaire de la collégiale Saint-Denis de Liège; ms. du $\mathrm{XVIII}^{\mathrm{e}}$ siècle, sur papier, en 3 rol. in-folio de 325,308 el $324 \mathrm{fr}$., contenant des actes de 1220 a 1701 (Archires de l' Etat ì Liège).

2121. - Anlre cartulaire de Saint-Ienis de Liège; ms. des XVIeXVII ${ }^{e}$ siècles, sur papier. contenant des actes de 1220 is 1654 , in-folio de $452 \mathrm{tr}$. (Archixes de l' État à Liège).

Fait en partie double rmploi avec le précédent et avec le suirant.

2122. - Antre cartulaire des XVe-XVIII ${ }^{\mathrm{e}}$ siècles, sur papier, contenant des actes de 1221 i 174I, in-folio de 225 II. (Archives de l' État à Liège).

Axat.. : par St. Bormansdans les Comptes-Rendus de la Commission royale dhistripe (Bruxelles), 3 série, XIV, p. 23-190; et à part: Bruxelles, Hayez, 1872 ; in- $8^{\circ}$ de $170 \mathrm{p}$.

Liège. - Église collegiale Sainte-Croix.

2123 - Cartulaire de Sainte-Croix de Lierge ; ms. du XIVe siecle, sur parchemin, arec additions postririenres, contenanl des actes de 1005 à 1508, in-folio de 407 fr. (Archiees de l'Elat à Liège).

Cif. Comptes-ipudus de la Commission royale dhistoire (Bruxelles), $3^{0}$ serie, $V, 1863$, p. 419-122

2124. - Aulre dn XVI siecle, sur papier, in-folio de $278 \mathrm{fr}$. (Archives de l'État à Liègr .

2125. - Autre du XVI siecle, sur papier, in-folio de 245) ff. (Ar.lives de le État à Liège).

2 Liz6. - Autre du XVI" siède, sur papier, in-folio de $340 \mathrm{ff}$. Archives de l'Elat ì Liegè.

2127. - Autre dn XVIe siecle, sur papier, in-folis de 3338 fl. (Archives de l'Etat is Licige).

2128. - Autre du XVI" sièrle, sur papier, in-folio de $441 \mathrm{ff}$. Archives de l'Etat à Liège). 
2129. - Autre du XVI siècle. sur papier, in-fulio de 400 fi. Archices de li litat à Liège.

21:30. - Autre du XVI siècle. sur papier. in-folio de jotio ff. Archires de l'Etat is Liège.

Ces différents recueils contiennent "n partie les mèmes docunents, et, sauf le dernier, ont été continués jusqua aux XV'II et XVIII' siècles.

Liège. -- Église collègiale Saint-Jean l'Évangéliste.

2131. - Cartulaire de la collégriale Saint-Jean de Liège: ms. du XIVe siècle, sur parchemin, in-folio de $66 \mathrm{ft}$. Archires de l'Etat ì Liège).

2132. - Autre des $\mathrm{XV}^{-}-\mathrm{XVI}^{\mathrm{e}}$ siècles. sur papier. contenant des titres de 1391 à 1520, in-folio de $182 \mathrm{ff}$. Archices de l'Etat ì Liège).

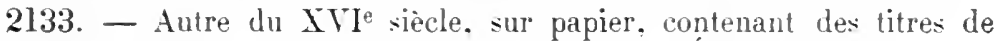
$98: 3$ à 1597 , in-folio de $155 \mathrm{ff}$. (Archices de LEtat à Liège).

2134. - Autre du $\mathrm{XVI}^{\mathrm{e}}$ siècle. sur papier. contenant des titres de 1147 à 1435 , in-folio de $91 \mathrm{ff}$. (Archives de l" Étut à Lirge.

2135. - Autre des XVIe-XVII siècles, sur papier. contenant des titres de 983 à 1660 , in-folio de $166 \mathrm{ff}$. (Archices de l'Étut à Liège).

2136. - Autre des $\mathrm{XVII}$ - $\mathrm{XVIII}$ siècles, sur papier, contenant des titres de 1107 à 1719 , in-folio de $335 \mathrm{ff}$. (Archives del Etat à Liège).

Liège. - Église collégiale Saint-Paul.

2137. - Publ. : Cartulaire ou recueil de chartes et documents inédits de l'église collégiale de Saint-Paul, actuellement cathédrale de Liège. par l'abbe 0 . Thimister. Liège. Grandmont-1)onders. 1878; in-80 de vir-701 p. et pl. - Supplément Bulletin de lu Saciété do art et dhistoire de Liège. VIII, 1894, pp. 355-366.

Liège. - Église collégiale Saint-Pierre.

2138. - Cartulaire de la collégiale Saint-Pierre de Liège : ms. des XIV-XVe siècles. sur papier. contenant des artes de 1345 à 1460 , in-folio de $81 \mathrm{ff}$. Archices de l'Étut ù Liège,.

Un autre (artulaire du XIVe siècle, sur parchemin, de 90 ff., existait encore à la fin lu XVIIIe siècle: on en trouvera la table dans Ed. Poncelet, Inventaire analylique des chartes de la collégiale sil-Pierre à liège (Bruxelles, 1906, in-8\%), p. 409-417.

Liège. - Pays. - Voy. Looz.

Lierde-Saint-Martin. - Chartreuse dioc. de Malines).

2139. - Cartulaire des Chartreux de Bois-Saint-lfartin : ms. du XVIo siècle, sur parchemin. contenant des actes de 13228 à 15:31, in-folio de $30 \mathrm{lff}$. Archices de T Etut ù Gand.

Lierre. - Béguinage (dioc. d'Anvers).

2140. - Cartulaire du hégninage de Lierre; ms. du XVe siècle, sur 
papier, in-4" de 37 it., contenant 28 documents de 1258 i 1496 (Archives de l' litut à Anoers).

\section{Lierre. - Chartretse.}

2141. - Cartulaire des Chartrenx de Lierre; ms. du XVI" siècle, de plusieurs mains, sur parchemin, avec additions du XVIIe siècle, sur papier et index en tête, in-4" de 325 ff. (Archives de l'État à Anvers).

Dates extrèmes: 1299-1645. Le fonds même du eartulaire intéresse presque exelusivement la Chartreuse d'Anvers, transférée à lierre en 1543 (ef. J. Vannérus, dans la Revue des Bibliothèques et Airchices de la Belgique, 1905, p. 494)

\section{Lierre. - Ville.}

2142. - Cartulaire de la ville de Lierre; ms. des $X V^{\mathrm{r}}-X V I I^{\mathrm{e}}$ siècles, sur papier, contenant des documents a partir de 1275, in-4" (Archives communales de Lierre).

Liessies. - Abbaye (dioc. de Cambrai).

2143. - Cartulaire de l'abbaye de Liessies; ms. du XIII siècle, sur

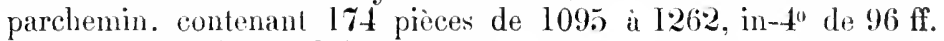
(Archices d'p. du Nind, $\mathrm{H}$ non coté).

2144. - Aulre du XVo siècle. sur papier, contenant 149 pièces de 1210 à 14.$) 1$, in-8 de (ir ff. (trchives dép. du Nord. H non coté).

2145. - Autre dn XVII siecle, sur papier, contenant 38 pièces de 1294 à 16:37, in-t" le 54 ff. (Archives dép. du Nord. H non coté).

2146. - Aulre du XVII siècle, sur papier, contenant I24 pièces de I26.5 a 16.5l, in-folio de 521 ff. (Archiess dép. du Nord, H non colé).

2147. - Autre des $\mathrm{XVe}^{\mathrm{N}} \mathrm{XVIII}$ siècles, sur papier, contenant 98 pièces de 1106 a 1754, in-folio de $180 \mathrm{ff}$. Archives dép. du Nord, $\mathrm{H}$ non $\cot \hat{)}$.

2148. - Autre du XIII siècle, sur parchemin, contenant 272 chartes, in-folio de 222 ff. (Avchires tu royaume de Belgique, i Bruxelles).

Était précédemment conservé à Choltenham $\left(n^{\circ} 8839\right)$. C'est celui qu'on trouve signalé à la Biblioth. nationale, eoll. Moreau, rol. 9\&, fo 166.

Lieu-Groissant. - Abbaye (dioc. de Besançon).

2149. - Cartulaire de l'abbaye de Lien-Croissant on des Trois-Rois; ms. du $\mathrm{XVI}^{\mathrm{e}}$ siècle. sur papier. avec table finale rédigée au siècle suivant, in-4" de 52 ff. (Billioth. de le ville de Besencon, ms. 774).

Des extraits lu mêmr, faits au XVIII sièce, se trouvent dans le nus. 39 (fonds laverel) de la mème bibliotbèque.

Copie du mème; ms. du XVIII' siècle, sur papier, in-folio Biblinth. nationale, coll. Morean, vol. 874, ti. 211-294).

Antrecopie moderne. sur papier (Archires dép. du Douls, Hnon coté). 
Lieu-Dieu. - Voy. Fostmolce.

Lieu-Restauré. - Ablaye (dioc. de Sioissons).

2150. - Cartulaire de labbaye de Lien-Restauré; ms. dn Xíre siècle, sur papier. contenant des titres de 11 t.) à 15.36 , in-t" de $67 \mathrm{ffr}$. (Archives dép. de lOise. H non cotè).

Voir ci-dessous ro Moriental.

Ligny-en-Barrois. - Chàtellenie.

2151. - Recueil de titres relatifs ì la chåtellenie de Ligny-en-Barrois; ms. de la fin du XVIe siècle. formé par Thierry Alix; sur papier, contenant des textes de 1:212 à $158 \%$. in-fulio de $419 \mathrm{ff}$. 'Archires dép. de Weurthe-et-1Coselle. B 344 .

2152. - Autre recueil ; ms. dn XVII siècle. formé par Thierry Alix, sur papier. cuntenant des textes de 1194 à 1602 , in-folio de $205 \mathrm{ff}$. (Archices dép. de Weurthe-et-3oselle, B 269 .

Copie partielle du précédent, faite au XVII siècle, in-folio de $215 \mathrm{ff}$. (1rchices dép. de Weurthe-et-1roselle, B 331).

Ligny-en-Barrois. - Collégiale Notre-Dame (dioc. de
Toul).

2153. - Cartulaire de la collégiale Notre-Dame de Ligny-en-Barrois ; ms. du XVIe siècle, sur parchemin, in- $t^{0}$ de $45 \mathrm{ff}$. Biblisth. de la ville de Bur-le-Duc. ms. 86 .

Une copte molerne se troure dans le ms. 8 i de la mème bibliothèque.

Ligueux. - Abbaye (dioc. de Périgueux).

2154. - Cartulaires de l'abbaye de Ligueux; orig. perdus.

Extraits faits au XVIIIe siècle de deux volumes différents. incomplets (Biblisth, nutionale, coll. Lespine, vol. XXXIV, ff. 43-633) •

Dom Estiennot en a eu égralement un entre les mairs en 1676 (Biblioth. nationale, m. latin $1270 \%$, p. $179 \%$.

Lihons. - Prieuré do Saint-Pierre (dioc. d'Amiens).

2155. - Cartulaire du prieuré de Lihons-en-Santerre: ms. du XilI siècle. arec additions postérienres, sur parchemin, in- $\mathbf{t}^{0}$ de $5 \tau$ ff. (Biblioth. wationnle. ms. latin 5460).

Copie du mème, faite an XVIII siècle [1750], sur papier. in-folio de $104 \mathrm{ff}$. Biblinth. de la rille d"Aniens. ms. 530 .

Extraits faits an XVII siecle Biblioth. de l'Arsenul, ms. 4652. fo 256; ms. 5262. f" 37: - Biblioth. nationate. coll. Balluze, rol. LXXIV, p. 3-14: m* latin 17049. pp. 73-8:3.

Copie moderne. sur papier. in-folio de I20 ff. (Biblioth. de la rille de Nóyon. coll. Peigné-Delarourt, ms. 18;. 
L'Ile-Barbe. - Abbaye de Saint-Martin (dioc. de Lyon). 2156. - Cintulicire de l'abbaye de St-Martin de l'Ile-Barbe; pancarte composée de 43 peatux des $\mathrm{XIII}^{\mathrm{e}} \mathrm{XIVe}$ siècles, sur parchemin (Archires lép. du Rhône, $\mathrm{H}$ non coté).

2157. - Recueil de pièces sur l'aumônerie de l'abbaye de l'lle-Barbe, Iranscrites ou analysées; ms. composé en 1489, de plusieurs mains,

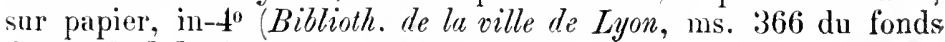
Coste, il. 1-106).

Lille. - Couvent des Augustins (dioc. de Tournai).

2158. - Cartulaire des Augustins de Lille; ms. des XVIIe-XVIII ${ }^{e}$ siècles, sur papier, contenant des pièces de 1614 à 1734 , in-folio de 515 pages (Archives dép. du Nord, H non coté).

Lille. - Courent des Dominicaines de l'Abbiette.

2159. - Cartulaire de l'Abbiette de Lille; ms. du XVIe siècle, sur papier, contenant 98 actes des années 1250-1576, in-folio de $184 \mathrm{ff}$. (Archices dép. du Nord, $\mathrm{H}$ non coté).

2160. - Antre on Livre rouge; ms. de 1516, sur papier, contenant des titres ì partir de 1279, in-folio de 216 fr. (Archives dép. du Nord, $\mathrm{H}$ non coté).

Voir aussi au "Supplément ».

Lille. - Couvent des Dominicains.

2161. - Citrulaire des Dominicains de Lille ; ms. du XIII ${ }^{\mathrm{e}}$ siècle, sur parchemin [les 14 premiers ff.], avec additions jusqu'à 1601 sur papier, in-40 de $386 \mathrm{ff}$. (Biblioth. de la ville de Lille, ms. 676).

\section{Lille. - Courent des Minimes.}

2162. - Cartılaire des Minimes de Lille ; ms. des XVIIe-XVIIIe siècles, sur papier, contenant 157 pièces des années 1553 à 1736 , in-folio de $109 \mathrm{ff}$. (Arclives dép. du Vord, H non coté).

Lille. - Église collégiale Saint-Pierre.

2163. - Cartulaire de la collégiale Saint-Pierre de Lille ou « Liber catenatus »; ms. du XIII ${ }^{e}$ siècle, avec additions postérieures jusqu'au $\mathrm{XVe}$ siècle, sur parchemin, in- $4^{\circ}$ de 35 et $427 \mathrm{fr}$. (Biblioth. de la ville de. Lille. ms. 657).

2164. - Autre cartulaire dit « Decanus »; ms. du XIII ${ }^{\mathrm{e}}$ siècle, avec additions postérieures jusqu'au XVe, sur parchemin, recouvert d'une relinre en cuir ganfré, in-40 de ni-218 ff. (Biblioth. de la ville de Lille, ms. 658).

N'est pas un véritalule cartulaire.

2165. - Punt. ; Cartulaire de l'église collégiale de Saint-Pierre de 
Lille, par li. Hintcenn. Lille. Quarré [I'aris. I'icard], 1894: 2 vol. in-8 $8^{\circ}$ de $\mathrm{xx}$ is $1210 \mathrm{p}$.

L'éditrur a utilisé, outre les cartulaires ci-dessus, dautres recueils dont il donne l'énumération dans son introduction.

2166. - Cartulaire du Chapitre Saint-Pierre de Lille : ms. du XV111e siècle. sur papier. conlenant des actes du XIYe siècle à 1769 , transcrits sans ordre, en 3 vol. in-4" (Archices municipules de Lille).

Lille. - Hôpital Comtesse ou Notre-Dame.

2167. - Cartnlaire de l'hòpital Comtesse à Lille : ms. des XVe-Xille sieccles. sur papier et couvert d'une reliure en cuir, in- $t^{\circ}$ de xru-o27 ff. Biblioth. de ln ville de Lille. ms. 688).

Une traluction française des litres latins in-folio de $208 \mathrm{ff}$.) se trouve aux Archives hospitalières de Lille, $n^{\circ} 4343$.

2168. - Cartulaire de l'hòpital Comtesse; ms. rédigré en 1676. sur papier, contenant des actes de 1236 a 1586 . in-folio de $33 \mathrm{ff}$. (Archires hospitulières de Lille. $n^{0} 4329$ ).

Lne copie molerne et défectueuse de ce registre (in-folio de $65 \mathrm{ff}$.) est classée sous le $n^{\circ} 4330$ du mème dépòt.

Lille. - Hòpital Notre-Dame ou des Grimarets.

2169. - Cartulaire de l'hòpital Yotre-Dame de Lille; ms. rédigé en 1681. par les dominicains Alb. Lecomte. sur papier, in-folio de $111 \mathrm{ff}$. Archires haspitalières de Lille. XIX A 2).

Lille. - Hôpital Saint-Sauveur ou Saint-Jean l'Évingéliste.

21\%0. - Cartulaire [incomplel] de l'hòpital Saint-Saureur de Lille; ms. dı XVI ${ }^{e}$ sièrle. sur papier. contenant des titres de 1219 à 1457 , in-to de $50 \mathrm{ff}$. (Archices hospitalieres de Lille, VI \& 6).

Lille. - Hospice Cantois.

2171. - Cartulaire de l'hospice Gantois à Lille; ms. de la fin du $\mathrm{XV}^{\mathrm{e}}$ siècle. sur parchenin. convert d"nne reliure de bois. et contenant des actes du $\mathrm{X}^{\circ}$ siècle. in- $4^{0}$ de $76 \mathrm{ff}$. Archires hospitalières de Lille. VIII \& 3 .

Lille. - Ville.

2172. - Livre " roisin » ou cartulaire de la ville de Lille. coté AAA; ms. dur $\mathrm{XIT}^{-e}$ siècle, sur parchemin, in-folio Archices municipales de Lille).

Copie du précédent. faite au $\mathrm{XV}$ siècle. in-folio Archires municipales de Lille, suppl. $\left.n^{0} 129\right)$.

Autre copie du mème, faite au $\mathrm{XVI}^{\mathrm{e}}$ siècle, in-folio (Biłlioth. de la ville de Lille, fonds Godefroy, ms. 140). 
Autre copie du mème faite par Pierre Lemonnier en 1617, in-folio (Biblioth. de la ville 'e Lille, ms. 212).

Autre copie dı mème cotée CCC, faite par Pierre Lemonnier officiellement en 1618, par ordre du magistrat de la ville, sur parchemin, in-folio (Avchives municipules de Lille).

Publ. : Roisin ; Franchises, lois et coutumes de la ville de Lille, par E. Brun-Lavainne. Lille, Vanackère, 1842 ; in- $4^{0}$ de 496 p.

2173. - «Registres anx titres » ou cartulaires municipaux de Lille; mss. du XVIe siècle, contenant des actes depuis le XIIIe siècle sans ordre chronologique ni ordre de matières, sur papier, en 14 vol. in-folio (Arelives municipales de Lille, AA 2 à 15 ).

Il existe des tables mal eonçues et inutiles.

2174. - Autres «Registres anx titres »; mss. du XVI $-\mathrm{XVIII}^{\mathrm{e}}$ siècles, contenant des actes de 1578 à 1786 , en 15 vol. in-4 avec une table (Arclives municipules de Lille, AA 21 à 35 ).

2175. - Recueil de titres relatifs à la ville de Lille; ms. du XVIH siècle, sur papier, contenanf principalement des actes des comtes de Flandre des années 1066 à 1565 , in-folio de 718 pages (Biblioth. de la ville de Lille, $\mathrm{ms} .2 \mathrm{I0}$.

Limay. - Convent des Célestins (dioc. de Rouen).

2176. - Cirrtulaire des Célestins de Limay ; ms. du XVé siècle, sur parchemin. contenant des acles des années 1261 à 1488 , in- $4^{\circ}$ de $90 \mathrm{fr}$. Archivess dép. de Seine-et-Oise, $\mathrm{H}$ non coté).

Limbourg. - Duché.

2177. - «Codex diplomaticns Limburuensis»; ms. du XIXe siècle, par Ch. Quix, sur papier, contenant des actes de 887 a 1294 , in- $4^{0}$ de $72 \mathrm{ff}$. (Königl. Bibliotheh in Berlin. cod. latin 244.

Publ. : Dans : Histoire du Limbourgr, par S. P'. Finst, VI (Liège, 184\%. in-8"), pp. $7.5-4(i l$ et $474-494$.

Limoges. - Abbaye de Saint-Martial.

2178. - Cantulaire de l'ahbaye de St-Martial de Limogres ; orig. perdu.

bixtrats fiits all XVII siecle par I)om Fstiennot (Biblioth. uationule, ms. latin 12740 , paces $397-398$, et ms. latin 12759 , pp. 2:31-239 ; coll. Lespine, vol. XXXIV, ff. 96 et 101).

Jointre une série de pièes dans le ms. latin 17118, p. 221-240.

Limoges. - Couvent des Oratoriens.

2179. - Curtulaire de la maison de l’Oratoire de Limoges; ms. de 1729 , sur pilpier. contenant 97 documents depuis 1624 , in-folio de 13.5 f1. (Avehizes dép. de la Haute-Tienne, H 965t). 
Limoges. - Église cathédhale Saint-Étienn'.

2180. - Cartulaire de Saint-Étienne de Limogres; origr. perdu.

Extraits fails an XVII siècle par André Du Chesne (Biblioth. nationale. ms. nouv. acq. françaises 7433, ff. 633-81'; coll. Duchesne, vol. XX. ff. 234, 248 el 259:- - pour Balnze Idem. coll. Ballue, vol. XL, ff. 194-198, et LXXIV. ff. 168-183: - par Besly (Idem, coll. Dupuy, vol. 828, ff. 23-33.

Quelques pièces publiées par Besly. - Cif. ms. latin 17118, p. 89-108.

2181. - Recueil de titres relatifs à Saint-Étienne de Limoges. formé en 1769 par Iom Col, en partie d'après le cartulaire, en partie d'après un registre dit "Anniversariorum » coté G, sur parchemin, de la fin du IIII siècle Biblioth. nutionale. ms. latin 9193, pp. 1285).

Limoges. - Érêché.

2182. - Cartulaire de léêeché de Limoges dit «0 Domina »; ms. rédigé vers 1310 par Bernard Filhol, prieur de Bonnac, sur parchemin et papier. in-folio de rr-99-52 fr. Archives dép. de la Haute-Tienne, G 9 .

Ce registre contient un mélange de chartes et d'actes de foi et hommage. La plupart du temps d'ailleurs, les documents sont analysés et dépourvus de dates: c'est donc à peine à considérer comme un cartulaire. - Même observation pour le registre "Tuæ hodie ",

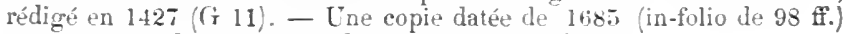
est conservée dans le même dépót sous la cote Gi 10.

Limogès. - Hòpital de Saint-Martial.

2183. - Cartulaire de l'aumònerie de St-Martial de Limoges: rouleau de $3^{\mathrm{m}}, 80$ de long sur $0^{\mathrm{m}}, 12$ de large. sur parchenin, du $\mathrm{XI}^{\mathrm{e}}$ siècle (Arckires haspitulières de Limoges. À 2 .

2184. - Autre rouleau de $0^{\mathrm{m}} .81$ de long sur $0^{\text {mit. }} .98$ de larre, sur parchemin. des $\mathrm{XI}^{\mathrm{e}} \mathrm{XII}$ siècles Archives hospitalioves te Limoges, A 3).

Pebl. : Premier el second cartulaires de l'Aumònerie de SaintMartial. par Alfred Leroux Drounents historiques bus-lutins. mocencaux et fruncrais concernant principalement la Harche et le Limousin. publ, sous les auspices de la Société arch, et hist. du Limousin. II, 1885, p. 1-25.

Limoges. - Ville.

2185. - Publ.: Némorial du Consulat de Limoges, publ. par C. Chabaneau (Revue des lungues rommes, XXXVIII. 189.5, 2e partie, pp. 1-J04).

Contient ell outre une série le notices nou placées chronolocriquement et en partie non datées. Le texte est du Xille siecle $(1208-12 \% 0)$. 
Limours. - Villige. - Voy. Morangis.

Limoux. - Ville.

2186. - Recueil des privilèges de la ville de Limonx; ms. du $\mathrm{XVI}^{\mathrm{e}}$ siècle [1576], sur parchemin, in-4" de $34 \mathrm{fr}$. (Biblioth. de la ville de Carcassonne, ms. 89).

2187. - Pubr. : Lihertés et contunes de Limoux, par L.-A. Buzairies.

Limonx, Boute, 1851 ; in- $8^{\circ}$ de $144 \mathrm{p}$.

Extraits des archives municipales.

Linas. - Église collégiale (dioc. de Paris).

2188. - Cartulaire de la collégriale St-1lerry de Linas; ms. du $\mathrm{X} l 1 I^{\mathrm{e}}$ siècle, sur parchemin, avec additions postérienres, contenant 341 documents de 1205 ì 1602 (Archives dép. de Seine-et-Oise, G $2(64)$.

Axar..: Inventaire sommaire des archives départementales de Seine-et-Oise, par Li. Conard, série G, tome I (1895), pp. 15̌l-173.

lixtraits faits an XVIle siècle, par André Du Chesne (Biblioth. nationale. ms. nouvelles acq. françaises 7433, ff. 234-237).

Liré. - Prieuré (dioc. d'Angers).

2189. - Cartulaire du prieuré de Liré, dépendant de Marmoutier ; ms. du XVle siècle, contenant 54 documents de 1090 environ à 1478 , sur papier, in-t" de 202 ff. (Archives dép. de Ifaine-et-Loire, $\mathrm{H}$ non $\cot \hat{)}$.

Appartenait il y a cinquante ans aux Arehives dép. du Loiret qui l'ont restitue it son véritable possesseur. Giry indique à tort un cartulaire du prieuré de Liré comme existant aux archives de la Loire-Inférieure: je me suis assuré qu'il ne s'y trouvait pas.

PUbl. : Archives d'Anjon, par P'. Marchergay, II (1853), pp. 15-27.

Lisieux. - Couvent des Jacobins.

2190. - Cartulaire des Jacohins de Lisieux; ms. du XVIIIe siècle, sur papier, contenant 360 actes des annćes 1307 à 1715 , in-folio de 338 ff. (Archives dép. du Calbados, $\mathrm{H}$ non coté).

Lisieux. - Eglise cathėdrale Saint-Pierre.

2191. - Framment d'un cartulaire de l'érlise de Lisieux; ms. du

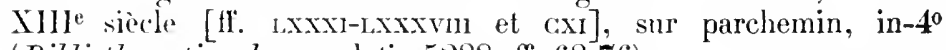
(Biblistl. nationale, ms. latin 5288, ff. 68-76).

Contenant des chartes de $11: 47$ ì 1268 . Voir aussi au « Supplément 》. Lisieux. - Évèrhé.

2192. - Cartulaire de l'évêché de Lisienx; ms. rédigé vers 1470, sur parchemin, in-folio de $269 \mathrm{ff}$. (Biblioth. de la ville de Lisieux, ms. 5).

Voir un table de ce cartulaire dans: Histoire de l'ancien évêchécomté de Iisieux, par M. de Formeville, II (1854). 
Lisieux. - Hôtel-Dieu des Mathurins.

2193. - Cartulaire de l'Hòtel-Dieu des Mathurins de Lisieux; ms. du XVII siècle. sur papier. contenant des actes dn XII siècle à 1648. in-40 de 33 fl. (Archices hospitulieves de Lisieur. II A 8 .

Axal.: Inventaire sommaire des archives départementales du Calvados; série H supplt , t. I. par Arm. Bénet 1891 . p. 128-132.

Cf. Quelques extraits et copies sous la cote II $\mathrm{A}$ $\mathrm{T}$.

L'Isle-en-Barrois. - Abbaye (dioc. do Toul).

2194. - Fragments du cartulaire de l'abbaye de l'Isle-en-Barrois: ms. du XIVe siècle. sur parchemin, compósé de 4 ff, non consécutifs (Archices dép. de lo Merse. H non coté).

Ont été donnés à ce dépôt par M. Marchal, ancien archiviste.

Extraits du précédent. faits an XVI siècle Biblioth. nutionale, coll. Duchesne, rol. XXII. If. 79-86,

2195. - Cartulaire de l'Isle-en-Barrois ; ms. du XVille siècle. sur papier, en 2 vol. in-folio de 572 et $445 \mathrm{fr}$. Archices dép. de lu .Meuse, $\mathrm{H} 27^{6}$ provisoire).

Dales extrèmes : $11+3-1755$.

L'Isle-en-Jourdain. - Comté.

2196. - Cartulaire ou «saume » de l'Isle-en-Jourdain : ms. du XVII siècle. sur papier. contenant des titres de 1061 à 1608. in-folio de 1623 ff. Archires dep. de Tarn-et-Garonne. A 297 .

Extrait du précédent. contenant des actes de 1240 à 1292. sur papier. infolio Biblioth. nutionale collection Languedoc, vol. XCVIII. tf. 10ł-126.

\section{L'Isle-en-Jourdain. - Ville.}

2197. - Cartulaire des coutumes et privilènes de la ville. ou « libre de las Poustetos » : ms. dn XVe siecle. sur parchemin. contenant des actes des années 1214-1368. in-folio Lrchires municipales de T Isleen-Jourdain.

Lissac. - Prieuré (dioc. de Cahors).

2198. - Recueil de titres relatifs au prienré de Lissac, dépt de l'abbaye de Leyme: ms. du XVIJ siecle. contenant des documents de 1241 aे $159 \% 3$ Biblinth. nationale. coll.1)uat. vol. 124. 1f. 228-272.

Livry. - Abaye (dioc. de Paris).

2199. - Cartnlaire de l'ablaye de Livry; orieg. perdn.

Ent souvent cité jar l'ablé Lebeuẗ qui I"a connu. 
Lobbes. - Abbaye de Saint-Pierre (dioc. de Cambrai). 2200. - Cartulaire de l'abbaye de Lobbes; ms. du XVe siècle, sur papier, avec lacunes, contenant des actes depuis l'année 972 , in-4 ${ }^{\circ}$ de 303 ff. (Archives de l'État à Mons).

$2200^{\text {bis }}$. - Cartulaire-chronique de l'abbaye de Lobbes ; ms. du XVIIIe siècle, sur parchemin, contenant des actes de 697 à 1754 , in-folio de 180 ff. (Biblioth. de feu M. le chanoine Vos, à Tournai).

Aval. : par L. Devillers (Annales du Cercle archéologique de Mons, $2^{\mathrm{e}}$ série, VIII, p. 22-32), reproduit dans: Description de cartulaires et de chartriers, III (1867), pp. 87-98.

Loc-Dieu. - Abbaye (dioc. de Rodez).

2201. - Publ. : Documents sur l'ancienne abbaye de Loc-Dieu. Villefranche de Rouergue, Soc. anonyme d'imprimerie, 1892 ; in $-8^{\circ}$ de n-220 p.

Recueil factice de documents dont les dates extrêmes sont 1124-1792.

2202. - Cartulaire de l'abbaye de Loc-Dieu; orig. perdu.

Extraits du précédent, faits au $\mathrm{XVII}^{\mathrm{e}}$ siècle, sur papier, in-4 $\mathbf{4}^{0}$ (Biblioth. nationale, ms. latin 10975, ff. 2-5).

Loches. - Collégiale Notre-Dame (dioc. de Tours).

2203. - Cartulaire de la collégiale N.-D. de Loches ; orig. perdu.

Nombreux extraits faits au XVIII ${ }^{\mathrm{e}}$ siècle (Biblioth. nationale, coll. Dom Housseau, pp. 233-236 du vol. XII).

Loches. - Couvent et collège des Barnabites.

2204. - Cartulaire des Barnabites de Loches; ms. du XVII ${ }^{\mathrm{e}}$ siècle [1680], sur papier, in-folio de $535 \mathrm{ff}$. (Archives dép. d'Indre-et-Loire, H 627 ).

Lodève. - Couvent des Récollets.

2205. - Livre archivial du convent des Récollets de Lodève; ms. dressé en 1671 par le P. Cambin, in-4 $4^{0}$ de $207 \mathrm{ff}$. (Archives dép. de l'Hérault, $\mathrm{H}$ non coté).

Ce registre est à peine un cartulaire, mais plutôt une chronique dans laquelle sont transcrits un certain nombre d'actes relatifs au couvent.

Lodève. - Évêché.

2206. - Ancien cartulaire de l'évêché de Lodève; ms. du XIII siècle, orig. perdu.

A été utilisé pour rédiger le suivant.

2207. - Cartulaire de l'église de Lodève [XIVe siècle]; orig. perdu.

Cet ouvrage, que fit faire Bernard Gui pendant qu'il occupait le siège 
épiscopal de lodłère, se composait de $\neq$ vol. in-folio de a Recognitiones „ (avec additions jusqu'en 1370).

2208. - « Liber privilegriorum et concessionum ecclesie Lodovensis »; ms. du XIV'e siecle. sur parchemin, in- $4^{0}$ de 249 ff., orig. perdu.

Le cartulaire proprement dit s'arrêtait au fo 103 et comprenait 153 pièces. Il est aussi l'œurre de Bernard Gui.

Axal. : Dans l'Inventaire des chartes et registres de l'évêché de Lodève, dressé en 1498 par ordre de Guillanme Briçonnet, évèque ; ms. sur papier, in $4^{0}$ de $158 \mathrm{ff}$. et $44 \mathrm{ff}$. de table (Archices dép. de CHérault $\mathrm{G}$ non coté, ff. $65 \mathrm{r}^{0}$ à $\left.158 \mathrm{r}^{0}\right)$.

C'est aussi bien l'inventaire du "Liber privilegiorum o que des "Recognitiones ».

2209. - "Livre vert 》 de l’évêché de Lodève; orig. perdu.

Axal.: Dans l'Inventaire de Guillaume Briçonnet, ff. 37-65.

A consulter, pour tout ceci : Les ouvrages loderois de Bernard Gui reconstitués, par L. Guiraud (Paris, Picard et fils, 1900 ; in $-8^{\circ}$ de 32 p. ; extr. de l'Histoire de la Ville de Lodère, par Ernest Martin, t. II, pp. 398-425).

Lodève. - Ville.

2210. - Pubi. : Cartulaire de la ville de Lodève, dressé d'après des documents inédits pour servir de preuves à l'Histoire de la ville de Lodève, par Ernest Martin [publ. par L. Guiraud]. Montpellier, impr. Serre et Roumégous, 1900 ; in- $8^{\circ}$ de 498 p.

Lodres. - Prieuré (dioc. de Coutances).

2211. - Cartulaire du prieuré de Lodres, dépendant de l'abbaye de Montebourg; ms. du début du XIV'e siècle, sur parchemin, in $-t^{0}$ de $71 \mathrm{ff}$. (Archires dép. de la Manche, $\mathrm{H}$ non coté).

Longchamp. - Abbaye (dioc. de Paris).

2212. - Cartulaire de l'abbaye de Longchamp; ms. du XVe siècle, sur parchemin, avec table au début, contenant 63 pièces des années 1250-1270, in-4 ${ }^{0}$ (Archires nationales. $Q^{1} 1072$, ff. $\left.1-45\right)$.

2213. - Fragment d'un cartulaire de l'abbaye de Longchamp: ms. du XIV ${ }^{e}$ siècle, sur parchemin. de $4 \mathrm{ff}$. in-8 (Archives nationales. L 1021).

Longeville. - Voy. SalNT-MARTIN-DE-LA-GlaidiÉre.

Longpont. - Abbaye (dioc. de Soissons).

2214. - Cartulaire de l'abbare de Longpont; ms. du XiII siècle, sur parchemin, contenant des actes des années 1140-1221 transcrits par 
deux mains différentes, in- $8^{\circ}$ de $40 \mathrm{fr}$. (Biblioth. nationale, ms. latin 11005 .

N'existe plus intérralement et doit être complété par les copies suivantes.

Copie du cartulaire de Longpont : ms. écrit en 1735 par Collielle, contenant 115 pieces des années 1132-1618. sur papier, in-folio de 116 fl. (Archices dép. de l'Aisne, H 692).

Copie du précédent, exécutée en 1764 par Dom Grenier, sur papier, in- $\mathbf{4}^{0}$ de 247 pages (Biblioth. nationale, collection Dom Grenier, vol. XXIV).

2215. - Antre cartulaire des XIII ${ }^{\mathrm{e}}$-XITe siècles, avec quelques additions du $\mathrm{XVII}^{\mathrm{e}}$, sur parchemin, avec reliure en bois, in-40 de $17 \mathrm{lfl}$. Biblioth. de M. Guston de Chanvenet, au chau de Lesdins, Aisne).

Dom (pueinsert l'a comnu et dépouillé "n $17 \sigma 4$ lorsqu'il était en l'étude de Me Fouguet de Lanehy, notaire à Saint-Q puentin. Ce volume coneerne d'aillrurs spécialement le prieuré de Héronval et le fief du Tronquoy près de Lesedins $(1138-1347)$; la partie relative à Héronval a été publiée (voir ce mot).

2216. - Recueil de titres et extraits relatifs à labbaye de Longpont, fait pour Gaignières an XVII siecle. sur papier, in-folio (Biblioth. nationale, ms. lalin 5470, pages $69-161$ et $165-221)$.

Dates extrèmes : 1156-1306. Ia première partie d'après les originaux, la seeonde d'après le cartulaire.

Longpont. - Prieuró (dioc. de Paris).

2217. - Cartulaire du prieuré de Longrpont; ms. du XII ${ }^{e}$ siècle, sur parchemin, in-4" de 56 ff. (Biblioth. nationale, ms. latin 9968).

Copie du précédent, fait pour Gaignières an XYII siècle, sur papier, in-folio (Biblioth. nutionale, ms. latin 5470, pages 233-282).

Publ. : Cirrulaire du prieuré de N.-I). de Lougpont, de l’ordre de Cluny, an diocise de P'aris, [par A. Marion]. Lyon, P'errin, 1880; in-8 ${ }^{\circ}$ de $37 \mathrm{l}$ p. et pl.

L'éliteur anonymr de ce volume y publie, pp. 2iz-290, la tahle d'un autre cartulaire qui parait bien ctre le suivant, d'après un inventaire

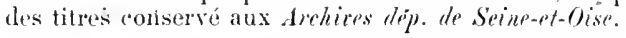

2218. - Antre cartulaire; ms. du XIII ${ }^{e}$ siècle. sur parchemin, in-4 ${ }^{0}$ de 36 If. (Biblioth. Cheltrahum, no 9331).

Longpré-les-Corps-Saints. - Église Notre-I)ame (dioc. d'Amiens).

2219. - Cartulaire de Notre-I)ame de Longpré ; orig. perdu (1).

(1) Daprès M. Ph. Fugrere des leris, La Picurdie listorique et monumentale, III, $n^{\circ} 2(1905), p \cdot 155$, ce registre élait cncore en place il y a une quinzaine d'années. Cif. cependant Mémonies's de le Sociélé des Anliquaices de France. 1875, p. 153. 
Extraits faits an $\mathrm{XVII}^{\mathrm{e}}$ siècle Biblinh. Io l'Arsenal, ms. 5262, fo $162 \mathrm{v}^{-0}$; - Biblioth. nutionale, coll. Baluze, vol. IXXVIII, ff. $213-229$.

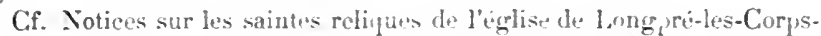
Saints, par labbé 1. Thierry (Compiègue, 1885, in-16,.

Longuay. - Abbaye (dioc. de Langres).

2220. - Fragment diun cartulaire de l'abluave de Longray : ms. du XIII siècle. sur parchemin. de différentes mains. arec additions postérieures. incomplet du début el de la fin. contenanl des chartes

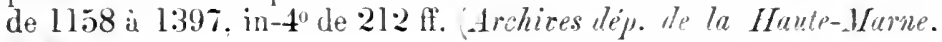
$\mathrm{H}$ non coté).

L'ordres des cahiers a été intervarti dans la reliure, et les feuillets blanes ont été utilisés après coup.

2221. - Fracment d'un antre cartulaire: ms. du XIII siecle. sur parchemin. avec addition. de la fin du mème sicle. incomplet du début et de la fin, contenant des chartes de 112; environ à 1290 . in- $4^{0}$. ff. 87 a 212 a 2 col. presque partont Archices dip. de la Haute-Marne, $\mathrm{H}$ non coté).

A été relié arec le précédent: quelques feuillets ont été coupés.

Extrait d'un cartulaire de Longuay, fait an XVIIe siècle (Biblioth. nationale, coll. Duchesne. vol. XXI, ff. 10-12. el vol. XXIl. ff. 69-72,

Longueau. - Prieuré (dioc. de Reims).

2222. - Cartulaire du prieuré de Longueau. de l'vrdre de Fonterrauld, près de Châtillon-sur-Marne: ms. du XVIlle siècle. sur papier, contenant 110 chartes des années 1140 à 1248 . in-folio de 47 ff. (Archires dép. de lu Marne, H non coté,

Axal. : Le cartulaire du prienré de Longuean. par Paul Pellot (Recue di Champagie et de Brie. 2" série. VII. 1895. pp. 19-39, 161-180. 279-288. 337-350 . et à part: Areis-sur-Aulie, Frémont, 1895 ; in- $8^{\circ}$ de 66 p.

Voir aussi au "supplemnnt".

Longues. - Abbaye (dioc. de Bayeux).

222:3. - Cartulaire de l'abhaye de Lontrues: ms. du XIII e siècle, contenant 190 chartes antérieures à 1.27 .5 . sur parchemin, in-4" de $59 \mathrm{ft}$. (Biblioth. du Cihapitre de Bayeux, ms. 163.

Longuesse. - Village (dioc. de Ro $k^{\prime n}$ ). - Voy. Suresses. Longueville. - Prieuré (!lioc. de Rouen).

2224. - Recueil des titres du prieuré de Lonurueville: ms. du IVIII siècle. sur papier. contenant des slocments de 1419 at 1694. in-folio de 316 parges Biblioth. de lis rille de Dieppe. ms. 46. 
2225. - Autre recueil; ms. du XVI ${ }^{\mathrm{e}}$ siècle, sur parchemin, in-4 ${ }^{\circ}$ de 14 If. (Biblinth. nationale, ms. latin 10059).

\section{Longwy. - Prérôté.}

2226. - Cartulaire de la prévòté de Longwy; ms. dn XVII siècle, sur pilpier, contenant 87 pièces des innées 1242-1587, in-folio de 213 If. (Biblioth. nationale, ms. français 11839).

Lonlay. - Abbaye (dioc. de Sées).

2227. - Cartulaire de labbaye de Lonlay ; orig. perdu.

Un extrait, trouvé dans les papiers de Caillebotte (auteur d'une Histoire de Donfront) a paru dans le Bulletin de la Société hist. et arch. de liorne, II (1883), 1. 23.

Loo. - Abbaye de Saint-Pierre (dioc. de Cambrai).

2228. - Publ. : Cartulaire de l'abbaye de St-Pierre de Loo, de l'ordre de Saint-Aurustin (1093-1794), par I. Van Hollebeke. Bruxelles, Weissenbruch, 1870 ; in-40 de Lxvin-193 p. et pl. [Publication de la Société d'émulation de Bruges.]

Loonbeek. - Chapelle Saint-Antoine (dioc. de Malines).

2229. - Cartulaire de la chapelle du châtean de Loonbeek en Brabant; ms. du XVIe siècle, sur papier. in-folio de $460 \mathrm{fr}$. (Archives générales du royaume de Belgique, it Bruxelles'.

Loos. - Abbaye de Notre-Dame (dioc. de Tournai).

22:30. - Cartulaire de liabhaye de Loos; ms. du XVIII siècle, sur papier, en 5 vol. in-folio de $115,143,213,195$ et 219 ff. (Archives dep. du Nond, H non coté).

Il $y$ a une forte lacune dans le premier volume; les transcriptions comprennent des actes depuis le XII ${ }^{\mathrm{e}}$ siècle.

Looz. - Collégiale Saint-Odulphe (dioc. de Liège).

2:2:31. - Recueil de titres concernant l'église collégiale Saint-Odulphe

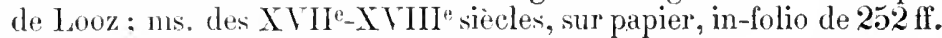
(Archives de l'Etut è Itusselt).

Dates extrêmes: 1358-1793. C'est le tome V' d'un recueil général.

\section{Looz. - Comte.}

22:32. - 1'ubl. : Codex diplomaticus Lossensis, on recueil et analyse le chartes servant de preuves à l'histoire de l'ancien comté de Looz, par II. J. Wolters. (iand, Gyselinck, 1849 ; in- $8^{\circ}$ de Iv-452 p. et $2 \mathrm{pl}$.

22:3:3. - Recueil des édits, rèrlemens, privilèges, concordats et traitez du païs de Lière et comté de Looz, par G. de Lourrex. Liège, 17141735,3 vol. in-folio de $x-489-26$, xir-601 el $385 \mathrm{p}$. 


\section{Lorraine.}

2234. - Cartulaire du duché de Lorraine, extrait dn Trésor des Chartes par' Jean Lud en 1485 ; ms. sur papier. in-folio de X-364tf.. avec table du $\mathrm{XVI}^{\mathrm{e}}$ siècle au début et analyses par Th. Alix (Bibliath. nationale, ms. français 11823 ).

Cf. Catalogue des manuscrits.... de la collection de Lorraine, par Paul Marichal, p. 372-3\%4.

2235. - Recueil de titres relatifs à l'histoire de Lorraine; $\mathrm{ms}$. de la fin du $\mathrm{IV}$ siècle, formé par Thierry Alix, sur papier. contenant des texter de 1107 à 1595 , en 5 vol. in-folio de 42:3. 100. 369. 438 et $426 \mathrm{fr}$. Archices dép. de Meurthe-et-Moselle. B $415-420$.

2236. - Cartulaire de Lorraine; ms. du XIVe siècle. sur parchemin, contenant environ mille actes des années 1202-1304, de $439 \mathrm{ff}$. in-10 (Archices dép. de la .Meuse, B 256).

Cf. Notice de Em. Duvernoy: sur ce registre (Bulletin de la Société tarchéologie lorraine, mai 1903, p. 107-111).

2237. - Cartulaire de Lorraine; ms. du XVII siècle [1656]. sur papier. contenant 212 actes. en 4 vol. in-folio de vir-44l, 439.379 et 518 p. (Biblioth. de la ville de Wuncy, ms. 709-712.

Publ. : en partie dans le Recueil de documents sur. lhistoire de Lorruine, publ. par la Société d"archéologie lorraine.

Voir en outre aux muts": Axcerville, Apreyuxt, Bar, Blayost, Botcostille, Botruost, Beiey, Chatel-scr-Moselle. Chatillon-scrfiose. Cholsect, Commercy, Conflans, Eypree, Épisal, Étais, Flasdre, Forg, Frasce, Goxdrecolrt, Getedre, Geise, Hattoschatel, la Chacssée, Layarche, Ligny, Lolppy, Lexemburrg, Mavdres, Merceerr. Metz, Morley, Nasct, Norroy, Pierrefitte, Post-aMotssox, Protexce, Rembercolrt, Saist-Mihrel, Sixgy, Siche, Sochlly, Toll, Treites, Trogson, Valdémost, Verdex, Vosge.

Lorraine. - Mines.

2238. - Recueil de titres relatifs aux mines de Lorraine; ms. du XVII siècle, sur papier, contenant des titres de 1483 a 1572 . in-folio de 130 If. (Archices dép. de Meurthe-et-Moselle, B +2l).

Lorraine. - Salines.

2239. - Recueil de titres relatifs aux salines de Lorraine: ms. du XVII siècle. sur papier. contenant des titres de 1296 à 1666 , in-folio de $46 \mathrm{I}$ et $31 \mathrm{l}$ if. Archires dép. de Meurthe-et-1Yoselle, B $422-423)$.

\section{Louppy-le-Château. - Préròtè.}

2240. - Recueil de titres relatifs ả lis prévòté de Louppy : ms. de la fin du $\mathrm{XVI}$ siècle. formé par Thierry Alix, sur papier. contenant des textes de 12399 a 1479. in-folio de 97 fr. Arkixes dép. do Weutheet-Woselle, B $3 \pi 1$. 
Copie du précédent, faite an XVII ${ }^{\mathrm{e}}$ siècle, in-folio, sur papier (Archives dép. de la Meuse, B 232).

Louvain. - Abbaye de Sainte-Gertrude (dioc. de Malines).

2241. - Cartulaire de l'ahlaye de Ste-Gertrude de Louvain; ms. du XVII siècle [1672], sur pirchemiu, contenant des actes de 1200 à 1268. in $4^{\circ}$ de $42 \mathrm{ll}$. (Archives du royaume de Belgique, ì Bruxelles).

Louvain. - Couvent des Lrsulines.

2242. - Cartulaire du couvent des Onze mille vierges de Louvain ; ms. de 1616, sur papier, in-folio de $158 \mathrm{fr}$. (Archices de l'arehevéché de Malines. Documents depuis le XIII siècle.

Louvain. - Église collégiale Saint-Jacques.

2243. - Cartulatire de léglise St-Jacques de Louvain; ms. du XVIo siècle, sur parchemin, contenant des actes de 1252 à 1482 , in- $4^{0}$ de 189 fi. (Archives de l'égtise St-Jacques de Louvain).

Louvain. - Église collégiale Saint-Pierre.

2244. - Cartulaire de l’église St-Pierre de Louvain: ms. du XVIe siècle, sul papier, contenant des actes de 1466 à 1522 , in-4 (Archires de l'iglise Stint-Pierre de Louruin).

Louvain. - Prieuré du Val-Saint-Martin.

2245. - Cartulatire du prienré rlu Val-Siant-Martin à Louvain: ms. des $\mathrm{XV}^{\mathrm{e}} \mathrm{X} \mathrm{Vl}^{\mathrm{e}}$ siecles. sur papier, contenant 115 acles du XVe siècle, in-8", fl. 1 i $10 \mathrm{l}$ (Archives du royaume de Belgique, à Bruxelles).

Comprend en outre des documents relatifs aux chanoines de Win. desheim et aux droits de risite qu'ils possédaienl sur les couvents affiliés it la célèbre congrégation.

Louvain. - Université.

2246. - Fragment de cartulaire de l'Université cle Lonvain; ms. des XVIe-XVIle siecles, sur papier, contenant des documents de 1426 à 1477, in-folio de 2:2 ff. (British Museum, à Londres, Harleian ms. 4521

Incomplet de la fin. Provient de Séguier.

2247. - Cartulaire de l'Lniversité de Louvain; ms. des X $V^{\mathrm{e}}-\mathrm{XVI} \mathrm{I}^{\mathrm{C}}$ siècles, sur papier. de plusieurs mains, in-4to de $333 \mathrm{fl}$. (Biblioth. du Vatican, ì Rome, ms. latin 3881).

2248. - Cartulaire de l'I'niversité de Louvain ; ms. des XVI" siècles, sur papier, in-folio de $58 \mathrm{tr}$. (Biblioth. de l'Université de Gand, ms. 124).

Publ. : Valerius Andreas, Fasti academi i studii generalis Lovaniensis. 2a edit. Lovanii, 1650, in-4". 
2249. - Publ.: Documents relatifs is l'histoire de l'Lniversité de Louvain (1425-1797), par Edm. Rensens. I (Université en général et corps enseignant). Lonvilu, 1893-1902; 2 vol. in-8" de $15-7.58$ et 284 p. - II-IV Collèges et pédagouries). Louvain, 1881-1892; 3 vol. in-80 de IV-504. IV-5056 et IV-6I2 p.

Louvain. - Ville.

2250. - Cartulaire de la ville de Louvain ou "Groot Charterboeck »; ms. des XIII -XIVe siècles, avec additions, sur parchemin. contenant des actes de 1249 i 1566 . in-to de 311 fr. (Archires communales de Louvain.

2251. - Autre cartulaire ou «Cleyn Charterboeck»; ms. commencé par Gérard Raese en 1366 et terminé an XV viècle. sur parchemin, contenant des actes de 1216 à 1431. in-4" de 8.5 tf. Archives communules de Lourain.

Il existe également une cupie de chacun de ces deux regristres.

2252. - Autre dit «Het boeck metter $\mathrm{A}$ »; ms. des $\mathrm{XVl}^{\mathrm{e}}-\mathrm{XVIl}$ siècles, sur papier, contenant des actes de 1332 a 1600 , in-folio de $217 \mathrm{ff}$. (Archives communales de Lourain).

2253. - Autre dit «Het boeck metter G»; ms. des XVe-XVII siècles, sur papier. contenant des actes de I2l6 à 1609, in- Archires communales de Lnuvain).

2254. - Autre dit «Groot Gemeynboeck B»: ms. des XVe-XYI siècles, sur papier, contenant des actes de 1225 à 1536. in-4" de $450 \mathrm{ff}$. Archires communales de Louvain.

2255. - Autre dit «Het Gemeynboeck C »: ms. du XVIe siècle. sur papier, contenant des actes de I 415 à 1522. in-folio de 26 ff. Archives communales de Lourain.

2256. - Recneil de chartes: ms. des $\mathrm{XV}$ - $\mathrm{XVI}^{\mathrm{e}}$ siècles. sur papier, conternant des actes de 1269 à 1564. in-folio de 168 fr. 'Archices communules de Louvain).

225\%. - Recueil de privilèges : ms. des XVIe-XVIre siècles. sur papier, contenant des actes de 1249 a 1566 , in-t" de 661 Hi. 'Archices communales de Lourain.

2258. - "Charters ende andere munimenten der stad Loven»; ms. écrit par A. Cuypers en 1696-1698, sur papier, contenant des actes des années 1216-1670, en $11 \mathrm{rol}$. in-folio de 229. 327. 278. 306, $277,318,404.378,324.401$ et 385 ff. Archixes communales de Louruin.

I de documents y sont classés par orlre alphabétique de matières.

Louvemont. - Seigneurie en Champagne.

2259. - Cartulaire de la seigneurie de Louvemont ; ms. de la fin du 
XIVe siecle, sur parchemin, contenant des actes de 1214 à 1395 , in-80 de 61 pages (Archives municipules de Reims, H non colé, fonds de St-Remi).

\section{Louviers. - Ville.}

2260. - Publ.: Cartulaire de Lonviers's documents historiques originaux du $X^{\ominus}$ au XVIII ${ }^{e}$ siècle, par Th. Bonnin. Évreux, Hérissey, $1870-1883 ; 5$ vol. in-4" de Iv-347, rv-19), Iv-265,1v-171 et Iv-215 p. S'arrète it l'annće 1600 . - Le tome $\mathrm{V}$ contient les tables.

Lubersac (de). - Famille.

$226 \mathrm{l}$. - Recueil de titres relatifs à la famille de Lubersac; ms. formé par Dom Col en I 769, d'après les archives du château, et commençant par un acte de 1275, sur papier, in-folio (Biblioth. nutionale, ms. latin 9193, pagres 633-689).

Lucelle [Lülzel]. - Abbaye (dioc. de Bàle).

2262. - Recueil de titres relatifs à l'abbaye de Lucelle; ms. du XVII sièce, sur papier, in-folio (Biblioth. de la ville de Porrentruy).

2263. - Cartulaire de lahblaye de Lucelle; ms. da XVIII siècle, sur papier, contenint des actes des années 1182 a 1747, in-folio de $1333 \mathrm{ff}$. (Archic des Ober-Elsass, in Colmar).

Luçon. - Cathèllale et évêché.

2264. - Recueil de pièces relitives à la cathédrale el à l'évêché de Lucon; ms. du XVIIL siecle, sur papier, contenant I58 titres des années $\mathrm{I} 080$ à 1642 , in- $4^{\circ}$ de 991 p. (Biblioth. de la ville de Poitiers, coll. Dom Fonteneau, vol. XIV).

Lucq-en-Béarn. - Abbaye de Saint-Vincent (dioc. de Lescar). 2265. - Cartulaire de l'abbaye de Lucq en Béarn ; orig. perdu [a été utilisé par Oïhenart et Marca].

Copie du XVIIe siècle, par M[ J. de Candoinec, chanoine de Lescar, sur papier Biblioth. nationale, coll. Baluze, vol. LXXIV, ff. $59-66)$.

Extraits faits par Oïhenart au XVII siècle (Idem, coll. 1)uchesme, vol. CXIY, IT. 80-83).

Publ. : Cartulaire de St-Vincent de Lucq, par L. Barrau-1)ihigo et R, Poupardin (Revue du Bíarn el du pays basque, Ire année, 1904, p. $451-460$ et 547-557), et a part: Pau, impr. Garet, 1905; in-8 de IV-32 p.

Lugny. - Chartreuse (dioc. de Langres).

2266. - Cartulaire de la Chartreuse de Lugny ; ms. du XIIIe siècle, sur parchemin. in-4" de $70 \mathrm{fr}$. (Biblioth. nutionale, ms. latin I0948). 
2267. - Autre cartulaire; ms. du XIIIe siècle. contenant 946 acles des années 1164 a 1.568. sur papier, in-folio de 3996 tl. (Archices dép. de la Cote-d Or, $\mathrm{H}$ non colé).

Lunéville. - Courent des Minimes (dioc. de Toul).

2268. - Bullaire du couvent des Minimes de St-François de Paule à Lunéville; ms. du $\mathrm{XVII}^{e}$ siècle, contenant des actes des années 1508-1583. sur papier, in-folio de $42 \mathrm{fl}$. (Archives dép. de Meurtheet-1Yoselle, H 1029 .

Lure. - Abbaye (dioc. de Besançon).

2269. - Recueil des privilèges de l'abbave de Lure: ms. du XVII siècle, sur papier. in-folio de $154 \mathrm{ff}$. Biblioth. nationale. ms. latin 亏138).

Voy. aussi dírrach.

Lusignan. - Famille.

2270. - Publ. : Histoire de lîle de Chypre sous le règne des princes de la maison des Lusignan. par L. de Was-Latrie. Pari.. Didot. 1852$1861 ; 3$ vol. in $-t^{\circ}$.

Chartes des années 1191-1670 dans les tomes II-III. - A compléter par un supplément (Bibliothèque de TÉcole des Churtes, XXXII, pp. 341-378, XXXIV, pp. 47-87, XXXY, pp. 99-158); et it part: Paris, 1874, in- $8^{\circ}$.

2271. - Documents pour servir à l'histoire des Lusignans de la petite Arménie, par V. Langlois (Reoue archénlogique, XYi, 1859. pp. 109$116,142-166$ et 216-234); et à part : Paris. 1860 , in-8 de 54 p.

Dates extrêmes: : 1342-1394.

Luxembourg. - Abbaye Notre-Dame ou du línster (dioc. de Trèves).

2272. - Cartulaire de l'abbaye du Nunster a Luxemboury; in. dı XVII ${ }^{e}$ siècle. sur papier, incomplet du début, conterant des documents de 1464 à 1696 , in- $4^{0}$ de $148 \mathrm{ff}$. (British .ruseum. additional ms. 2.5057).

2273. - Cartulaire de l'abbaye du Munster à Luxembourg: ms. du XIVe siècle. sur parchemin. contenant des documents a parlir de la fondation en 1083, écrits par deux mains différentes. in-1" (Archices de IÉtut ì Luxembourg'.

Copie du précédent, faite au XIX siècle. sur papier (Biblioth. de l'Institut, à Paris. ms. non coté).

Luxembourg. - Ville.

2274. - Publ. : Cartulaire ou recueil de documents politiques et administratifs de la ville de Luxembourg $(1244-1795)$, par Fr. X. 
Würth-Paquet el Nic. van Werveke. Luxembourg, Bück, 188I ; in- $8^{\circ}$ de xil-426-x pares. [Mémoires de l'Instilut R. Grand-ducal luxemburegenis, XXXY.]

Recueil factice de 225 doeuments dopuis le XIII' siècle jusqu'à 1794.

Luxeuil. - Abbaye (dioc. de Besançon).

2275. - Recueil des titres de l'abbaye de Luxeuil; ms. du' XVIIIe siècle, sur papier, avec table au rlébut. contenant des titres du VII siècle a 1766 , in-40 de 483 1f. (Biblinth. de la ville de Besancon, coll. Droz, ms. 4l).

Dans l'introluction à l'inventaire de la série $\mathrm{H}$ des Archices dep. de Lt Hnte-Suthe, il est question d'un eartulaire de Luxeuil qui existerait à la libliothèque nationale: cette indieation est controuvée, à moins qu'il ne s'agisse de la copie suivante.

Copie partielle dı même. faite au XVIII siècle, sur papier (Biblioth. nutionule, coll. Moreau, vol. 869, tr. 313-456).

Luz. - Vallée des Pyrénées.

2276. -- Cartulaire des vallées de Luz et d’Argelès, dit « Cartulaire Noalis" » ms. du XVIII siècle, sur papier, in-folio (Archives de . Ve Lumpt, notaire ù Marsoms, Hautes-Pyrénées).

Intéresse aussi la vallée d'Azun, le Lavedan et Bagnères-deBigorre.

Lyon. - Archerêché.

227\%. - Recueil de titres concernant l'église de Iyon; ms. du XVe siecle, sur papier. in $4^{0}$ de $64 \mathrm{tr}$. (Biblioth. de la ville de Lyon, fonds Coste, ms. 102).

2278. - « I'rivilegia imperialia et papalia ecclesie Lugdunensis »; frament d'un cartulaire du XIV siècle. sur papier, in-40 de $14 \mathrm{ff}$. (Aichices díp. de lisire, B 378t).

Ces sont les ff. 61-74 de l'original, eontenant des pièces des années 88.5-118.1. - Sous la cote B 3786 du mème dépòt, on trouvera les If. 1-ix du mène registre origrinal, avec des documents des années 12:28-143\%. - Le "major " cartulaire de l'église de Lyon, que cite Guichenon, "Bibliotheca Sebusiana ", 1. 26, doit être perdu.

Lyon. - Ville.

2279. - Cartulaire municipal de Lyon, dil d'Étienne de Villeneuve; ms. des $X T^{\mathrm{e}}-\mathrm{X} \mathrm{V}^{\mathrm{e}}$ siècles. sur parchemin, contenant des actes de 1245 à 1444 , in-folio de 222 et $48 \mathrm{Hl}$. Archives municipales de Lyon, A. 1-2).

Répertoire analytique du même, avec atditions. ms. du XIVe siècle. sur papier, in-folio de $55 \mathrm{fl}$. Archives municipales de Lyon, AA 3 . 
Publ. : Cartulaire municipal de la ville de Lyon. privilèges, franchises, libertís et antres titres de la commune. recueil formé au XIVe-siècle par Etienne de Villenenve. publif d"apress le ms. original

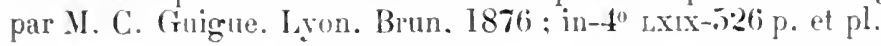

2280. - « Cartularinm Lugrhnense » on recueil de bulles el diplomes relatifs a lohistoire de lyon: ms. du XIVe siecle. sur parchemin, avec sa relinse originale, contenant 20 documents de 1116 is 1307 , écrit par plusieurs mains. in-40 de II-86 tf. Biblinth. de la rille de Lyon, ms. 1388 .

Publ. : Histoire civile et consulaire de la ville de Lyon, par le P. Menestrier, (preuves). Lyon, 1696, in-folio.

2281. - Recueil des titres relatifs aux droits du roi dans la ville de Lyon; mss. des $\mathrm{XT}^{-\theta}$ et $\mathrm{XVI}$ siecles. le premier sur parchemin, avec reliure en maroquin anx armes de France. le second de plusieurs mains. avec demi-reliure. in- $4^{\circ}$ de 137 et $129 \mathrm{fr}$.' Biblioth. nationale, mss. latins 10032-10033).

2282. - Publ. : Recueil des priviléges. authoritez, pouvoirs, franchises et exemptions des prévost des marchans, echevins et habitans de la ville de Lyon. Lyon, 1649, in- $4^{0}$.

2283. - Recueil des chartes, lettres patentes, etc., donués par nos rois depuis 1271 anx bourgeois et habitans de Lyon...., notamment en ce qui concerne l'exemption des tailles. Lyon, li71, in-folio.

\section{Lyonnais.}

2284. - PubL. : Cartulaire lyonnais: Documents inédits pour servir à l'histoire des ancienres provinces dı Lyonnais. Forez. Beaujolais, Dombes. Bresse et Bugrey comprises jalis dans le Pagns major Lugdnnensis, par M. C. Ginigue. Lyon. Association typocraphique, 1885-1893: '2 vol. in- $4^{\circ}$ de $1 x-686$ et $\mathrm{w}^{\circ}-756$ p. [Académie des Sciences. Belles-Lettres et Arts de Lyon.]

Dates extrêmes: : 65j-1311.

2285. - Publ. : Recneil des titres et autres pièces authentiques concernant les privilèges et franchises du Franc Lyonnais, par Hubert de Saint-Didier. Lyon, 17l6, in- $4^{0}$.

Cif. aussi Charléty, Bibliographie de lhistoire de Isyon, $\mathrm{n}^{05} 1114$ et $125 \pi$.

Lyre. -- Abbaye de Notre-Dame (dioc. d'Érreux).

2286. - Fragment du cartulaire de l'abbaye de Lyre: ms. du XIII siècle, sur parchemin, contenant le lexte de 8 chartes des années 1279-1280. in-4" de $4 \mathrm{fr}$. Biblioth. uatiosule, ms. latin 11053 , ff. 10-13.

Aux fi. 6-9 se trouve une table du XiII e siècle, incomplète de la fin, comprenant 1 I 1 numéros. te se rapportant à un autre cartulaire perdu de la même abbaye. 
Copies collationnées en 1704, d’après ce ms., alors plus complet, d'actes du XIII siècle (Archives dép. de l'Eure, H 561 ).

Extraits faits en 1640 par Dom Anselme Le Michel (Biblioth. nationale, ms. latin 13818, if. 133-135).

Le volume était alors entre les nains de Petau, et Dom Le Michel en eut connaissance par André Du Chesne.

228\%. - Petit cartulaire de l'abbaye de Lyre; orig. perdu.

Mention dans les notes du mêne búrédictin (Ídem, fo 129).

Maastricht. - Église collégiale Saint-Servais.

2288. - Cartulaire de St-Servais de Maastricht; ms. du XII siècle, orig. perdu.

2289. - « Codex diplomatum Trajectensium »; ms. dı XVIII siècle, sur papier, in-folio de $268 \mathrm{lf}$. (Archives de l' État à Muastricht).

2290. - «Cartularium ecclesiæ collegrialis sancti Servatii ad Mosam »; III (Documenta varia) : ms. du XVIII siècle, sur papier, in-folio de $190 \mathrm{fr}$. (Archives de l'État à Maastricht).

2291. - Curtularium sancti Servatii on «Liber privilegiorum »; ms. du XIII ${ }^{e}$ siècle, sur parchemin, avec additions sur papier jusqu'au $\mathrm{XVII}$ siècle et table préliminaire rédigée au $\mathrm{XVI}^{e}$, et avec lacunes des feuillets xxv-xxix, couvert d'une reliure en bois à fermoirs de cuivre, in-folio de $136 \mathrm{p}$. (Archives de l' Ĺtat à Hasselt).

Anar. : par C.. de Borman, Comptes-rendus de la Commission royale dhistoire de Belgique, 3 érie, IX, 1867, pp. 7-1 I8, avec quelques textes publiés intégralement.

2292. - Cartulaire de l'église de St-Servais de Maastrichit; uns. du $\mathrm{XVII}{ }^{\mathrm{e}}$ siècle, en 3 vol. in-folio de 218,365 et $462 \mathrm{ff}$. (Biblioth. nationale, mss. latins 10178 à 10180).

Dates extrêmes: 1051-1603.

Machemont. - Prieuré (dioc. de Noyon). - Voy. SaintAmand.

Mâcon. - Éğlise saint-Vincent.

2293. - Livre rougre de St-Vincent de Mâcon ; orìn. détruit.

2294. - Cartulaire de St-Tincent de Mâcon; origg. détruit en 1567 (Livre à la chaíne).

Copie du cartulaire enchậné de la cathédrale Saint-Vincent de Vàcon ; nıs. dlu XTII siècle. sur papier, in-folio de 203 p. (Biblioth. nationule, ms. latin 17086).

Autre copie de 1\%50, in-lolio. sur papier de 308-cxi ff. (Archives dep. de Suáne-et-Lrivi', (i non coté). 
Purl. : Cartulaire de Saint-Yincent de Màcon, connu sous le nom de Livre enchinne, par C. Ragut. Màcon, l'rotat, 1864; in-40 de cccxvin-588 p. [Ácadémie de Màcon.]

Extraits faits au XVIII' siècle par Dom Aubrée (Biblioth. nationale, coll. Bonrgrogne, vol. CVIII. fí. 111-161 .

Madiran. - Prieuré (dioc. de Tarbes).

2295. - Recueil de titres relatifs au prieuré de Madiran. dépt de l'abbaye de Narcillac près de Calor's ; ms. du XVII siècle, contenant des documents à partir de 1088, in-folio sur papier (Biblioth. nationale, coll. Doat, vol. 152, ff. 146-225).

2296. - Cartulaire du prieuré de Madiran; orig. perdu.

Il y en a des extraits dans les papiers de Larcher (XVIIIe s.) aux Archives des Hautes-Pyrénées, et dans les papiers d'Oihenarl (resr. app ${ }^{t}$ a Mgr. de Carsalade du Pont, évêque de Perpignan).

Axal. : par Larcher. dans son Glanage (Biblioth. de la ville de Tarbes, t. VIII, pp. 211-240).

Cf. J. de Jaurgain, La Yasconie (Pau, 1902, in-80), II, p. 590.

Maeseyck. - Église Notre-Dame (dioc. de Liège).

2297. - Cartulaire de N.-D. de Naeseyck; ms. des $\mathrm{XVI}^{\mathrm{e}}-\mathrm{XVII}^{\mathrm{e}}$ siècles, sur papier. contenant des actes de 1426 a $167 \%$, in-folio de $18: 3 \mathrm{ff}$. (Archives de l'État ¿̀ Hasselt).

2298. - Autre des XVII -XVIII siècles. sur papier, contenant des actes de 1629 à 1732. in-folio de $284 \mathrm{fr}$. (Archices de l' État à H(sselt).

Maguelone. - Chapit:'e cathédral.

2299. - Cartulaire du Chapitre cathédral de Maguelone pour ses propriétés de Rouet et des vallées de l'Hérault, du Brestalon. du Terrieu. du Liron et du Lez; ms. du XVe siècle. sur papier, in-folio de 155 ff. (Minutes de Me Calvet. notuire is Saint-Martin-de-Londres, Hérauli).

Maguelone. - Érêché.

2300. - Fragment d'un cartulaire de l'évêché de Maguelone: ms. du XIII ${ }^{e}$ siècle, sur pirchemin, contenant 5 chartes des années 120812\%, in-4 $4^{0}$ de 9 ir. (British 1ruseum, additional ms. 17308. ff. 5-13).

230l. - Autre composé en 1368. avec quelques additions des XVe$\mathrm{XVI}$ siècles, en 6 vol. in-folio sur parchemin, contenant des documents des années I05.)-1368. et cotés A-F (Avchives depo. de T'Hérault, Gi non coté).

Un $\tau^{e}$ volume à joindre (in- $\left.t^{0}\right)$ contient la table méthodiqute dees six volumes. 
Fxtraits partiels dı précédent; ins. composé en 1:368, contenant 15:2 chartes, sur parchemin, in- $\mathbf{t}^{\circ}$ de $100 \mathrm{ff}$. (Avchives dép. de l'Héraull, G non coté).

lixtraits du mème [bullaire]; ms. composé en 1368, et contenant des acles depuis 1081, sur parchemin, in $4^{0}$ de $72 \mathrm{ff}$. (Archives dép. de l' Hérault, G non coté).

Extrait dn mème [fiefs nobles]; ms. composé en 1368, sur parchemin, in-4' de $188 \mathrm{ff}$. (Archives dép. de l'Hérault, G non coté).

«Bullae el privilegia episcopatus Nagalonae»; ms. du XIVe siècle, sur parchemin, in-40 de 85 ff. (Biblioth. nationale, ms. latin $14688)$.

C'est une copie du bullaire précédemment cité.

2302. - P'BL. : en préparation par A. Fabrège et J. Berthelé.

Maillé (de). - Famille.

2303. - Publ. : La maison de Maillé, par l'ablué Ambroise Ledru et l'abbé L. J. Denis. Paris, Lemerre, $1905 ; 3$ vol. in-80 de viI-464, 523 et 471 payres.

Les deux derniers volumes contenant les preuves forment un véritable cartulaire de la famille.

Maillezais. - Abbaye, puis Ėvêché.

2304. - Publ. : Histoire de l'abhaye de Maillezais depuis sa fondation jusqu'a nos jours, par l'abbé Lacurie. Fontenay-le-Comte, Fillon, $185^{\circ}$; in- $8^{\circ}$ de 593 p.

Contient un recueil factice des chartes de l'abbaye d'après les copies 4. D. Fonteneau.

Maintenay. - Prieuré de Yotre-Dame (dioc. d'Amiens).

2305. - Prob. : lissai sur les prienrés de Beaurain et de Maintenay, par Rogrer Rodière. Arras, impr. Gnyot, 1904 ; in-8 $8^{0}$ p. 293 à 425 Wxirait des Mímoires de l'Académie d'Aros, 2" série, XXXV, pp. $311-443)$.

Recuesil factice de documents depuis l'an 1100 jusqu'à la fin du XVIII siecle, qui forme une suite a Bracrax (voy. ce mot).

Maintenon. - Prieuré de Notre-Dame (dioc. de Chartres). - Toy. Epernon.

Maison-Dieu en Brie. - Prieuré (dioc. de Meaux).

2306. - Cartulaire du prieuré de Maison-Dieu en Brie ; ms. des XIIIXIVe siècles. contenant 70 actes des années 1112-1301, sur parchemin, in-8" de $66 \mathrm{fl}^{\circ}$. (Avchives dep. de la Côte-d $\mathrm{Or}$; $\mathrm{H}$ non coté, fonds de Molème). 
Maizieres. - Abbaye de Totre-Dame (dioc. de Châlon-surSâone).

2307. - Cartulaje de lablare de Maizieres: mss. du $\mathrm{CVIII}^{\mathrm{e}}$-iecle. sur papier, in-folio de 146 if., 346. $585,369,338$. 302. $3926,484$. 268 et 531 pages Biblioth. nutionale, ms. nour. acq. françaises $8672-8681$ ).

l'rovient de l'ancienne collection Joursanvault.

Majorque. - Royaume.

2308. - Cartnlaire des rois de Majorque: ms. du XIVe siècle. sur papier. in- $4^{\circ}$ de $131 \mathrm{ff}$. Archices nationales. $\mathrm{KK} 1413$ ).

$\mathrm{L}^{* 2}$ véritable recueil de chartes commence au fo 49 ot contipnt des actrs de 1228 à 1350. - Quelyues pieces ont été imprimées dans le volume d'A. Lecoy de la Marche, Le royaume de Majorque Paris, Leroux, 1892, 2 vol. in $\left.-8^{\circ}\right)$.

[Voir ausil : Mostpeller (Ville de ].

Malines. - Commanderie de Pitzenbourg, de l'ordre Teutonique.

2309. - Cartulaire de la commanderie de Pitzenbourg : ms, rédigé en 1420, contenant des actes des XIVe-XVTe siecles. in-folio de 506 II. sur papier 'Archices de lordire Teutonique, à Vienne. Autriche.

Malines. - Couvent des Augustins.

2310. - Cartulaire des Anurustins de Malines; ms. du XVII siècle, écrit par J. Bruyn van Harlingen, sur papier, contenant des titres de 1254 à 1692, in-folio de $186 \mathrm{fr}$. (Archices de l Etut ì Ancers,

Malines. - Courent des Carmes.

2311. - Cartulaire du couvent des Carmes de Malines: ns. du XVe siècle. sur parchemin. in $4^{\circ}$ de $180 \mathrm{fi}$. Archices du royaume de Belgique, a Bruxelles.

Malines. - Église Saint-Rombaut.

2312. - Cartulaire de l'écolise cathédrale St-Rombant de Malines: ms. du XVIe siècle. sur papier. contenant des actes de l:2:30 à 1445 . in-4" de $18 \mathrm{ff}$. Archires du royaume de Belgique. à Bruxelles.

Malines. - Ville.

2313. - Cartulaire municipal de Malines on « Oudste privilegieboeck»: ms. lu XVe siecle. sur papier. contenant des docment. de l252 it 1445 , in-4" de $67 \mathrm{tr}$. Archires communales de valines .

2314. - Recueil de tilres relatifs à la ville de Malines. dit « Privilemia et monumenta »: ms. lu XVIII siècle. sur parchemin. contenant des documents de 981 à 1706 . en 6 vol. in-4" de 267 + $63.3 .287+$ 
$35,232+30,372+46,400+83$ et $254+64$ pages, chaque volume terminé par une table (Archives municipales de Malines).

l'ordre chronologique des pièces est presque régulièrement respecté.

2315. - Recueil de titres relatifs à la ville de Malines; ms. du XVIII ${ }^{\circ}$ siècle. sur papier, contenant des acles de 1157 à 1520 , in-folio de 217 pages (Archives royales de La Haye, Papiers Gérard, $\left.n^{*} 56\right)$.

Mallemort. - Seigneurie en Provence.

2316. - Cartulaire de la terre de Mallemort près d'Arles, appartenant ì l'évêché de Mar'seille; ms. daté de 1752, contenant des documents depuis le XIII siècle. en 3 vol. in-4" sur papier (Archives dép. des Bouches-du-Rhône, G non eoté).

Malmédy. - Voy. Stavelot.

Malonne. - Abbaye (dioc. do Namur).

2317. - Cartulaire de l'abbaye de Malonne; ms. da XVII siècle, sur papier, contenant des actes de 1147 à 1665 , in-folio de $383 \mathrm{ff}$. (Archives de litat à Namur).

2318. - Autre du XVII siècle [1660], continué jusqu'au milieu du XVIII ${ }^{e}$, sur papier, contenant des actes de 1284 à 1756 , in- $4^{0}$ de 707 panges (Archives de l'État ì Namur).

Publ. Cartulaire de l'abbaye de Malonne, par l'abbé V. Barbier (Anulectes pour servir ì l'histoire ecclésiastique de la Belgique, XX, 1886, p. $5-48$ et $129-192$. - Cf. dn méme auteur: Histoire de l'abbaye de Malonne (Namur, 1894, in-8 ${ }^{\circ}$.

Dates extrêmes : 1212-1756.

Malte (Ordre de). - Toy. Hosprtaliers de Saint-Jean de Jírusalei et Tettonique (Ordre).

Mamers. - Couvent des Visitandines (dioc. du Mans).

2319. - Cartulaire du couvent de la Visitation de Mamers; ms. du XVIII siècle, sur papier, in-folio de $291 \mathrm{ff}$. (Archives dép. de la Surthe, H 1749).

Mandres-en-Barrois. - Prévôté.

2320. - Recueil de tilres relatifs ì lil prévôté de Mandres; ms. de la fin du XVI $\mathrm{XIècle}^{\mathrm{e}}$ formé par Thierry Alix, sur papier, contenant des textes de 1:274 a 1587, in-folio de $350 \mathrm{fr}$. (Archives dép. de Meurthe-et-1Yoselle, B 372).

Copie du précédent, faite au XIIIe siècle, sur papier, in-folio (Archives dip. de la .Meuse, B 249). 
Manosque. - Ville.

2321. - Cartulaire municipal de Manosque; ms. du XIVe siècle. sur parchemin, relié en bois. in-40 de $182^{\circ} \mathrm{ff}^{\circ}$. (Avchires municipales de Manosque, AA 8).

1)ates extremes : 1169-1315.

Les ff. 70-72 ont été arrachés. La traduction du latin en provençal a été faite par le notaire Audebert Gauzis en 1293.

Publ. : Livre des privilèges de Manosque, cartulaire municipal latin-provençal, par M. Z. Isnard, suivi de remarques philoloçiques sur le texte provençal. par C. Chabaneau. Digne-Paris, 1894 ; in- $4^{\circ}$ de xcII-243 p.

Cf. : Les habitants de Manosque au moven-àge d"après le cartulaire municipal, par M. Barret Bulletin de la Société scientifique et littévaire des Basses-Alpes, VHI, 1898, p. 197-228).

2322. - Autre cartulaire de Manosque: ms. du XVI siècle, contenant 18 actes des années 1206-1293. sur papier, in-8 $8^{\circ}$ de $94 \mathrm{ff}$. (A)chives dép. des Bouches-du-Rhóne, $\mathrm{H}$ non coté, fonds de St-Yictor).

Mantes. - Courent des Cẻlestins (dioc. de Rouen).

2323. - Cartulaire des Celestins de Mantes; ms. du XVe siècle, sur parchemin, in-4 $4^{0}$ de iI-154 ff. (Archives nationales, $\mathrm{R}^{2} 281$ ).

Un autre cartulaire du même temps est connu par un fragment d'un feuillet $\left(\mathrm{f}^{\circ} 187\right)$ à la Biblioth. nationale, ms. latin $17 \mathrm{li \pi}, \mathrm{f}^{\circ} \mathrm{i8}$.

Maraye-en-Othe. - Ville.

2324. - Recueil de titres relatifs à Maraye-en-Othe; ms. du XVIII siècle, sur papier, in $4^{0}$ (Archices communales de Maraye-en-Othe).

Marbaix. - Toy. Marollles.

Marcenay. - Prieuré (dioc. de Langres).

2325. - Cartulaire du prieuré de Marcenay, dépendant de l’abbaye de Molême: ms. dn $\mathrm{XV}^{\mathrm{e}}$ siècle, contenant 58 pièces des années 1270-1420. sur parchemin et papier. in $4^{0}$ de $43 \mathrm{ff}$. (Archires dép. de la Côte-d Or, $\mathrm{H}$ non coté, fonds de Molême).

Marche. - Comté. - Voy. Axgoulêse.

Marchenoir. - Chàtellenie. - Voy. Buors (comté de).

Marchiennes. - Abbaye de Sainte-Rictrude (dioc. d'Arras). 2326. - Cartulaire de labbaye de Marchiennes; ms. du XVIe siècle [1540], sur parchemin, in-folio de $556 \mathrm{ff}$. (Biblioth. du chateau de Gommecourt, Pas-de-Calais).

Cf.: Les miniatures et la reliure artistique du cartulaire de Marchiennes, par L. Quarré-Reybourbon (Réunion des Sociétés des Beaux-Arts des départements, XIV. 1890. pp. 476-489. 
2327. - Cartulaire de labbaye de Marchiennes; ms. du XIII siècle avec additions jusqu au $\mathrm{XV}^{\prime} \mathrm{II}^{\mathrm{e}}$, contenant 328 documents des années 887-1448, sur parchemin, in-folio de xvil-189 fi. (Archices dép. du Nord, H non cotí.

Cf. : Ies miniatures du cartulair" de Marchiemes, par le Cte A. de Loisne (Bulletin arehéologique du Comite, 1903, p. 476-489 et pl.).

Copie figurée du mème [1872], par U. Rolert (Biblioth. nutionale, ms. nouv. acq. latines 1204).

2328. - «Codex secundus chartarum »; ms. du XVIII ${ }^{e}$ siècle, sur papier. contenant 47 pièces de 1038 i 1594 , in-folio de 112 ff. (Archices dép. du Tord, H non coté).

Extraits du précédent, faits en 1608 (Archives nationales, K 1160 , $\left.n^{0} 19\right\rangle$.

Autres extraits Biblioth. nationale, coll. Duchesne, vol. XXII, ff. 363-364; nouv. acq. françaises 7:385. fr. 286-289. .

2329. - «Codex tertius chartarum »: ms, du XIX siècle, recueil factice de copies de 77 pièces des années 975 à 1318, in-folio de $180 \mathrm{tr}$. (Avchices dép. du Nord, $\mathrm{H}$ non coté:

2330. - «Codex quartus chartarum 》: ms. du XIX siècle, analogne au précédent, contenant 44 actes des années 81:3-1394, in-40 de $82 \mathrm{fl}$. (Archives dép. du Nord, H non coté).

2331. - « Liber privilegiorum ecclesiae sanctae Rictrudis Marchianensis »; ms. du XIVe siècle, sur parchemin. contenant des titres des XII ${ }^{e}-\mathrm{XIII}^{\mathrm{e}}$ siècles, arec index en tête, in- 12 de $188 \mathrm{fr}$. (British Museum. ms. additional 16611 .

Marcigny. - Abbaye (dioc. d'Autun).

2332. - Cartulaire de labbaye de Marcigny : orig. perdu.

Voir au mot PARAY-LE-MIONLLL.

Marcillac. - Abbaye (dioc. de Cahors).

2333. - Recueil de titres relatifs à l'abbaye de Narcillac; ms. du $\mathrm{XVIJ}$ siècle, contenant des documents de 1100 is 1594 (Biblioth. nutionule, coll. Doat, vol. I2:3, fI. 60-189, .

Marcoussis. - Prieuré (dio. de Paris).

2334. - "Registre de chartes el escriptures du prieuré de Marcoussis ». lait par Dom (i. La Vieille en 1505; ms. dn XVI siècle, sur papier. in-to de 172 If. Biblioth. de lu ville de Rouen, ns. 1228).

Cest sans doule celui que D. Anselme Le Michel eite à plusieurs reprises dans ses copies relatives it si-Wandrille (roir ce mot).

Maréchaussée.

2335. - Pubr. : La Connestablie et maréchaussée de France, ou 
recueil de tous les édils, déclarations et arrèts, etc., par J. Pinson de la Martiniére. Paris, Rocolet, 1661, in-folio.

- La Maréchaussée de France ou recueil des ordonnances. édits, déclarations et privilèges de tous les officiers et archers des maréchaussées, par G. Saugrain. Paris, 1697 , in-4 ${ }^{0}$.

Marienthal. - Abbaye de Notre-Dame (dioc. de Trères). 2336. - Cartulaire de l'abbaye de Marienthal; ms. du IIII siècle, orig. perdu.

\section{signalé dans un document de $131 \%$.}

2336 ${ }^{\text {bis. }}$ - Cartulaire de labbaye de Marienthal; ms. daté de 1511 , écrit par le frère Conrard Richard de Rothweil. sur papier. contenant 307 titres des année: 12:32 à 1317. in-folio de $245 \mathrm{ft}$. Archices du Grand-Duché de Luxeinbourg,'

2337. - Publ. : Cartulaire de Marienthal, par Nic. van Werreke (Publications de la Section historique de l Institut $R$. Grand-Ducal de Luxembourg, XXXVIII-XXXIX. 1885-1891, 2 vol. in-8 de xxx372 et vi-346-Lv p.).

Publication de 331 pièces, révisées quand il a été possible sur les originaux, arec additions des pièces absentes du cartulaire original (1232-1783).

Marigny (Enguerrand de), comte de Longuerille, ministre de Philippe-le-Bel.

2338. - Cartulaire d'Enguerrand de Marigny ; ms. du XIVe siècle. sur parchemin, in-folio de $225 \mathrm{tf}$. Biblioth. nationale, ms. latin 9785 ).

Copie du précédent, faite an XVe siècle, in-folio de $176 \mathrm{tf}$. (Biblioth. nationale, mi. latin 9786;.

Marly. - Voy. Morargis.

Marmagne-en-Auxois. - Prieuré (dioc. d'Autun).

2339. - Cartulaire de Marmagne. dépendant de l'abbaye de N.-D. de Fontenay; ms. du XVIII siècle. sur papier. contenant 142 actes des années 1206-171l. in- $t^{0}$ de $241 \mathrm{ff}$. (Aichices de la Cote-tor, $\mathrm{H}$ non coté. fonds de Fontenay).

Marmande. - Ville.

2340. - Recueil de titres relatifs à la ville de Marmande, contenant des actes des XIVe-IVIJ siècles, sur papier, in-folio (Biblisth. nationale, coll. Baluze vol. XXV, ff, 100-209).

Marmoutier. - Abbare (dioc, de Tours).

2341. - «Cartularium Turonense »: $\mathrm{ms}$. déjà en partie détruit au XVII siècle; auj. perdu. 
Copies extraites du précédent, faites au XVII ${ }^{\mathrm{e}}$ siècle (Biblioth. nationale, coll. Baluze, vol. LXXVIl, ff. 135-136; coll. Dom Housseall, II², ff. 35-61).

De mauvaises analyses sont réunies par P. Nobilleau dans le volume intitulé: Dom CI. Chantelou, Cartulaire Tourangeau (Tours, 1879, in- $\left.8^{\circ}\right)$.

2342. - «Cartularium Andegavense ».

Ne parait pas avoir existé, mais P. Marehegay a publié: Les prieurés de Marmoutier en Anjou, inventaire des titres et supplément aux ehartes des Xle ot. Xile siècles (Archires d'Anjou, II, 1853, pp. Ixuvin et $1-90)$, et ì part: Angers, 1846 , in- $8^{\circ}$. Ce recueil eontient 73 cliartes des pricurés angevins de Marmoutier pour les années 989-1200.

2343. - « Cartularium Blesense »; orig. perdu.

Reeonstitué d'après originaux et copies, il a été publié par l'abbé Ch. Métais : Marmoutier, Cartulaire blésois (Chartres et Blois, 1891, inl- $8^{\circ}$ ). On $y$ trouve 800 documents depuis l'an 832 jusqu'au XVIII siècle.

2344. - « Cartularium Britannicum »; orig. perdu.

Extraits du précédent, fails en 1730 Biblioth. nationale, coll. Baluze, vol. LXXYII, pages 12:3-134).

On consultera, pour rémédier à la perte de ce eartulaire, le's réeueils suivants: Anciens évêehés de la Bretagne, par Geslin de Bourgogne et An. de Barthélemy, IV (1864), passim : - Les titres de Marmoutier aux archives de la Vendée et le la Loire-Inférieure, par Ch. de sourderal (Bulletin de la Société archéologique de Touraine, I, pp. 218228) : - Inventaire des titres des prieurés de Marmoutier situés dans l'évêché de. Nantes (Bulletin de la Socièté archéologique de Hantes, V'I, 1866. pp. I01 et ss., et VII, 1867, pp. 35 et ss.). - Chaeune de ees publications fournit to texte d'un certain nombre de ehartes depuis le. XIe sic̀cle.

2345. - «Carlularium Carnotense »; orig. perdu.

2346. — «Cartularium Cenomanense »; orig. perdu.

Extruils du précédent. faits an XVIlle siècle (Biblioth. nutionale, coll. Baluze, vol. LXXVII, p. I-40; - et coll. Dom Housseau, vol. XlI:

Le Bulletin de la Commatssion archéologique de la . Wayenue en annonce la prochaine publieation.

2347. - « Cartularium l)unense »; ms. du XII siècle, sur parchemin, in-4" de 49 1l. Biblinth. nationale. ms. latin 12874).

l'ubl. : Cartulaire de Marmonl ier pour le Dunois, par Em. Mabille. Chàteaudun, impr. Lecesne, 1874, in-8 de [v-]Lxiv-308 p. [Société dunoise.]

Contient les 95 documents du manuscrit et 188 autres pièces d'après d'autres sources (originaux et copies) ; dates extrêmes : 995-1300.

2348. - «Cartnlarium Normannicum »; orig. perdn. 
Extraits du précédent, laits an XVIII siècle Bıblisth. notionale. coll. Baluze, vol. LXXVII. pp. 4l-il.

2349. - «Cartularium Pictaviense».

Ne parait pas aroir existé.

Publ. : Cartularium rerum Majoris Monasterii 'lurunensis in inferiori l'ictavia, dans: Carlulaires du Bas-Poiton, par P. Marchegay. Les Roches-Barilaud (Vendée). 187\%, in- 8 " (pp. xxrm-Lxm. $59-225$ et 350 .

Contient 73 chartes des XIe-XIV"e siècles. - Intéress les priearés suivants: Aizenay, Brem, Commequiers, Fontaines, Le l'ụbéliará, La Roche-sur-Yon, Saint-Benoit de Quincay, Salertaine. Sigournay et Treize-Vents.

2350. - "Cartularium Perticum ». Cif. Vietx-Beli.k̂ne.

2351. - "Cartularium Vindocinense»; ms. dn XIJ siècle. sur parchemin, incomplet a la fin et présentant des lacunes, in- $t^{\prime \prime}$ de 40 ff. à 2 col. (Biblioth. nationule, ms. latin 5442 .

Extraits du précédent, faits en'171:3 Biblioth. nutionale, coll. Baluze, vol. LXXYII. ff. 276-321.

Publ. : Cartulaire de Marmoutier pour le Vendomois. par A. de Trémault. Vendòme, Lemerrier. 189:3; in-S" de [15-] xxxm-5lo p. [Société archéol. du Vendònois.]

La publication comprend, outr l l 166 pieces du cartulaire original, $8 b^{\circ}$ aulrés pièces puisées à des sources différentes: dates extrêmes: 8a3-1523. Intéresse l'église de Naveil, les prisurés do Lancé, lavarlin, Prìy, Troô et Véndòme.

235̃2. - "Liber de servis "; ms. du XII e siècle. sur parchemin. in- $t^{\prime \prime}$ de $4 \mathrm{fl}$. Biblioth. de lu rille de Torirs, ms. 1376.

Extraits faits au XVIII siecle (Biblioth. nationale, coll. Baluze, vol. LXXYII, ff. 140-148,

Publ. : Liber de servis Majoris Monaslerii Le livre des serfs de Marmoulier, publ. par fell André Salmon, suivi de chartes sur le même sujet el précédé d’un essai sur le servage en Touraine, par Ch.-L. de Grandmaison. Tuurs. Ladevèze, 1864 ; in-8 de Xr.rY-245 p. [Société archéologique de Touraine: Mémoires, t. XVI.]

Arec lappendice ajoulé par l'élitour, la publication compren:t 193 pièces des années 986 it 1269 .

2353. - Recueil de lilres relatiss a labbaye de Marmoutier; ms. compilé ron dibut du XVIIJe siècle par Hom Inalène, en 3 val. in-folio Bibliwth. nutionale. ms. latins 12878-12880).

Cerecuril consilérable contenait les preuves de l'histoire de l'abbare, écrite ausi par Dom Martène pulliéte seule jar l'abbé C. Chevalié

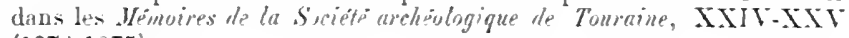
$(1874-1875)$. 
2354. - Extraits de cartulaires et de pièces originales, faits au XVIJe siècle par Dom A. Le Michel, sur papier, in-10 de $294 \mathrm{ff}$. (Biblioth. de lin ville de Tours, ms. I38I).

Cf. le ms. latin 12875 de la Biblioth. nutionale.

235̄. - Autre recueil de titres relatifs à Marmoutier et à ses prieurés, firl pour Gaignières au XVII siècle, par Noël Mars, d'après les cartulaires et les originaux, sur papier, en 4 vol. in-folio (Biblioth. nationale, mss. latins $5411-5+44$ ).

Voir le détail de ces volumes au Supphéakext.

Extraits divers (Biblioth. nutionale, coll. Dom Housseau, et fonds Morean, passim).

Marœuil-lez-Arras. - Abbaye (dioc. d'Arras).

2356. - « Privileoria et cirte monasterï beatorum Amandi et Bertillie de Mareolo»; ms. dı XVe siècle, sur parchemin, contenant 219 documents des anuées 977-1422, in-folio de 138 ff. (Archives dép. du Pas-de-Calais, $\mathrm{H}$ non coté).

Copie du précélent recueil, par Dom Le Pez; ms. du XVII siècle (Biblioth. de la ville d'Arras, ms. 672).

lixtraits faits an XVII siècle (Biblioth. nationale, ms. latin 17675, ff. 46-53).

Maroilles. - Abbaye (dioc. de Cambrai).

235̆7. - Carhulaire de l'abhaye de Maroilles; ms. du XVIIe siècle, 2 vol. in-folio, sur papier, de 395 et $322 \mathrm{ff}$., contenant $20 \mathrm{I}$ documents des années 1I5̆l-1620 (Archives dép. du Nord, H non coté).

23558. --- Autre cartulaire; ms. du XVIII ${ }^{\mathrm{e}}$ siècle, sur papier, contenant 42 documents des années 1151-178:3, in-folio de 453 p. (Archives dép das Nord, H non coté).

l.es mêmes archives conservent des registres concernant les possessions de l'abbaye de Maroilles à Marbaix (253 ff.), à Fayt (252 ff.), à Landrecies (303 ff.), à Prisches (529 ff.) et à Saunières-Mézières (269 ff.). Tous ess récueils ont été formésau X YIII ${ }^{\circ}$ siècle.-Cf. quelques pices des XIVe-XVI siècles transcrites par Du Cange (Biblioth. nationale, ms. français $9500, \mathrm{p}$. 188-215).

Marolles-en-Brie. - Priemé (dioc. de Paris).

2359. - Cartulaire du prieuré de Marolles-en-Brie; ms. du XVIe siècle, sur papier, in-40 de 82 ff. (Archives dép. de Seine-et-Oise, A 1110).

Dates extrêmes : $1117 \cdot 1584$.

Extraits firils par Du Chesne an XVII' siècle (Biblioth. nationale, coll. Baluze, vol. LV, ff. 194-195).

Marquette. - Abbaye (dioc. de Tournai).

2360. - Cimtulaire de l'ablaye de. Marquette; ms. dı XIII e siècle, sur parchemin, de plusieur's mains, avec quelques additions postérieures, et talles irès sommaires (en tête, anx fr. I34-141 et 144-145), 
contenant 336 chartes des années 1:201-142:2. in-8' de 192 ff. 'Biblisth. nationule. ms. Iatin $1096 \%$.

2361. - Autre cartnlaire de labbaye de Marquette; ms. du XViIr siecle [1767-1769]. sur papièr, en 10 vol. in-folio contenant des documents de 1232 à 1768 . Archices dép. Ju Jarr. H non coté).

Marsannay-la-Côte. - Prieuré (dioc de Langres).

2362. - Cartulaire du prieuré de Marsannay-la-Cóte. drept du Chapitre cathédral de Dijon: ms. du ITe siècle. sur parchenin et papier.

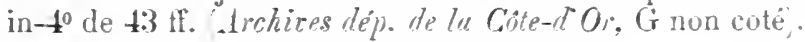

Marseille. - Abbaye le saint-Tictor.

2363. - Grand cartulaire de St-Yictor de Marveille; ms. des XI' XIle siècles. contenant 350 pièces des années $790-112 \%$. sur parchemin. in-folio de $187 \mathrm{ti}$. Archices dep. des Bouches-tu-Rhöne, H non cote".

2364. - Petit cartulaire Le Si-Victor de Marseille; ms. du XIII srecle. contenant 245 pieces des années 780-1318. sur parchemin. in-4" de 190 ff. (Archices dép. des Bruches-du-Rhine, H non coté).

Publ.: Cartulaire de labbaye de St-Yictor de Marseille. par B. Guérard. avec la collaboration de A. Marion et I. Delisle. Paris. Lahure. 18.5 7 : in-4 de CLvi-6.5 et $945 \mathrm{p}$.

1132 pièces entre les années b83 et 1336 .

2365. - Livre noir de St-Yictor de Yareille: ms. des XVI-SVIII siècles, contenant des documents des années 1079-1790. sur papier. in-folio de $107 \mathrm{ff}$. (Archices dép. Hes Bouches-du-Rhine, H non coté).

2366. - Recueil de quelques titres relatifs à ladite abbare: ms. formé par Dom Anselme Le Iichel au XVIle siecle Biblioth. wutionnle. ms. latin 13820. lif. 167-181 : autres extraits par Dom Estiennut au XVII siècle Idem, ms. latin 1.2702. fi. $14+148$,

Voir l'indication de deux autre: recueils au Scpplément

Marseille. - Chapitre cathédral.

2367. - " Livre jaune " ou cartulaire du Chapitre cathédral de Marseille; ms. du XIII siècle avec additions postérieures. sur parchemin. contenant des actes des années $1119-1535$, in- $4^{\circ}$ de $50 \mathrm{ff}$. Archives dép. des Bouches-dy-Rhine. G non coté.

Le a livre rougge " (NIIIe s.), consarvé dans le même dépñt, nest pas un véritable cartulaire.

Marseille. - Couvent les Capucins.

2368. - Cartulaire des Capucin- de Saint-Louis; m- du XVII siècle. sur papier. in-folio 'Biblioth. de la cille de . Wurgeille. ms. 1204.

Marseille. - Évèché.

2369. - Livre vert de l'évèché de Narseille: ms, du XIIIe siècle avec 
additions postérieures, contenant des actes des années 1141-1541, in-folio sur papier de 168 ff. (Archives dép. des Bouches-du-Rhone, G non coté).

\section{Marseille. - Ville.}

2370. - Livre des statuts; ms. des XIII ${ }^{e}-\mathrm{XVI}^{\mathrm{e}}$ siècles, sur parchemin, couvert d'une reliure ancienne de bois, in-folio de vin-249 ff. (Archires municipales de Marseille, AA 1).

Les documents (la plupart en langue vulgaire) y contenus vont de 1219 à 1558 . - Lne traduction en rrancais de la plupart des mêmes documents, à partir de 1257 , se trouve dans le registre AA 4.

Le mème, incomplet, écrit en 1257 ; ms. sur parchemin, in-folio de IX-lăl ff. (Idem, AA 2).

2371. - Livre noir ou Cartnlaire mumicipal de Narseille; ms. des XIIIe-X VII e siècles, sur parchemin, in-folio de vir-335 ff. (Archives muincipales de Warseille, AA 5).

Dates extrèmes des pièces : 1216-1621.

2372. - Livie rouge: ms. des XIII ${ }^{\mathrm{e}} \mathrm{XVII} \mathrm{X}^{\mathrm{e}}$ siècles, contenant des documents de 1216 i 1665 . sur papier. in-folio de 287 pages et une table (Archires municipales de Marseille, AA 6).

Marvejols. - Hôpital (dioc. de Mende).

2373. - Publ. : Cartulaire de l'hôpital de Marvejols, publ. par l'abbé

R. Pourcher. Saint-Martin-de-Boubaux, impr. Pourcher, 1889; in-8*.

Marville. - Châtellenie en Lorraine.

2374. - Cartulaire de la chàtellenie de Marville ; orig. perdu.

L'existence di ce volume est certifíe par la mention qui est portée dans un inventaire du XVIIle siècle (Archices nutionales, T 1612, $\mathrm{n}^{\circ} 28$ ).

Mas-Deu. - Commanderie (dioc. d'Elne).

2375. - Cartulaire des commanderies de Mas-Deu, Orle et Bajoles, dit le «Llibre de la Creu»; ms. du XIII e siècle [vers 1280], avec

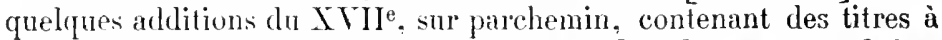
partir de 1132 , in-folio de $779 \mathrm{fr}$. (Archices dép. des Pyrénées-Orientales, H non coté, fonds du Temple).

Massay. - Abbaye (dioc. de Bourges).

2376. - Fragment d'un cartulaire de l'abbaye de Massay; ms. du XIII siècle, contenant des actes des années 1253-1265, sur 2 ff. in-8" it 2 col. Biblioth. nutionale, ms. latin 9864.

Extraits faits au XVII ${ }^{\mathrm{e}}$ siècle Biblioth. nationule, coll. Duchesne, vol. XXII, fo 137; - par Dom Estiennot en 1682 (Biblioth. 
nutionale, ms. latin 12742 , pp. 378-379, 386 et 39.2 ; par le même en 1674 (Idem, ms. latin 12743. pp. 341 et 348 .

Mateigne (1). - Voy. Máblissos.

Maubeuge. - Chapitre de Sainte-Aldegonde (dioc. de (ambrai).

2377. - Cartulaire de l'éolise et Chapitre de Ste-Aldegronde de Maubeure: ms. du XVIII siècle, sul papier. in-4" de 175 ff. (Biblioth. de la ville de Douni, ms. 1104):

Extrait fait par P. d'Hozier an XVII e siècle (Bibliolh. nationule, ms. français 32423 .

2378. - Antre cartulaire-inventaire de Ste-Aldegronde de Maubeuge; ms. du XVIII siècle. sur papier, en 6 vol, in-folio Biblioth. de M. A. Jennepin, chef d'institutiol: à Cousolre, Nord,

Publ. : Charte: concernant le Chapitre noble de Sainte-Aldegonde de Maubenge, par Ern. Matthieu (Analectes pour sercir ì Thistoire ecrlésiastique de la Belgique, XVII, 1881, p. 129-14i).

Maubuisson. - Mbaye (dioc. de Rouen).

2379. - Cirtulaire de l'abbaye de Manbuisson ; orig. perdu.

Extrait fait au XYII siècle par Dom Estiennot 'Biblioth. nationale, ms. latin 12741. p. 309).

2380. - Cartulaire de l'abbaye de Maubuisson; ms. écrit en L668, sur papier, contenant destitres à partir de $123 \%$ «fidèlement traduits en françois de l'ordre de Madame Louise Marie. princesse Palatine », en 4 vol. in- $t^{0}$ de xw-37\%, xn-489. xir-421 et xu-433 pages (Archives dép. de Seine-et-Oise, $\mathrm{H}$ ron coté).

Pcbl. : Cartulaire de l'abbaye de Maubuisson Notre-Dame la Royale), par A. Dutilleux et J. Depoin. Irs partie (Chartes concernant la fondation de l'abbaye et des chapelles. Pontoise, impr. Paris, I890; in-4" de rv-188 p. [Documents inédits publ. par la Société historique du Vexin.]

Recueil factice de 86 pièces d̀ partir de 1241. L'introduction n'est pas encore publiée.

2381. - «Recueil des titres et pièces étant dans le trésor de l"abluaye de Maubuisson 》; ms. du XVIII ${ }^{e}$ siècle, sur papier, contenant les titres de 1243 à 1669 , in- $4^{\circ}$ de xry-472 et xxrI-701 pages (Archices dép. de Seine-et-Oise, $\mathrm{H}$ non coté .

2382. - Recueil de titres concernant les droits de l'abbaye à Mateigne,

(1) Lieu dit de la conmune de Saint-Ouen-I'Aumòne. 
Aunay, Bessancourt, Gonesse et sur le minage de Pontoise; ms. du XVIII siècle, sur papier, contenint des titres de 1204 à 1668 , in-folio de vi-727-xxiv parges (Archives dép. de Seine-et-Oise, $\mathrm{H}$ non coté).

2383. - Autre recneil de même nature; ms. dı XVIII siècle, sur papier, contenant des titres de 1237 i 1742, in-folio de $256 \mathrm{ff}$. (Archives dép. de Seine-et-Oise, $\mathrm{H}$ non coté).

2384. - Recueil de titres relatifs à Gonesse et à Pontoise; ms. du $\mathrm{XVIII}^{\mathrm{e}}$ siècle, sur papier, contenant des titres de 1 I88 à 1740 , in- $4^{\circ}$ de 424 ff. (Archives dép. de Seine-et-Oise, $\mathrm{H}$ non coté).

Mauléon ou Châtillon-sur-Sèvre. - Abbaye de la Trinité (dioc. de Maillezais).

2385. - Cartulaires de l'ahbaye de la Trinité de Mauléon [utilisés dans une compilation faite en 1673 par Jacques Thieulin, conservée à la Biblioth. Sainte-Geneviève, ms. 1876]; orig. perdus.

2386. - Publ. : Documents pour servir à l'histoire de l'abbaye de la Trinité de Mauléon, pull. par B. Ledain (Archives historiques $d u$ Poitom, XX, I889, p. 1-9I).

Reeueil factice d'actes des années 1090-1623, d'après les copies de la collection Dom Fonteneau, vol. XVII et LXVI.

Mauléon-de-Soule. - Ville.

2387. - Cartulaire de la ville de Mauléon ; orig. perdu.

L'existence d'un eartulaire ou livre des privilèges de Mauléon est eonstatée par une lettre de Louis XII au roi de Navarre qui en réelame la restitution à la vill de Mauléon (eatalogue Dumont, libr. à Paris, novermbre $1902, n^{0} 2823$ ).

Maupas. - Prieuré, à Capelles-les-Grands (dioc. de Lisieux). 2388. - Fragment d'un cartulaire du prienré de Maupas; ms. du XIII ${ }^{e}$ siècle, sur parchemin, mn fenillet in-40 (Biblioth. nationale, ms. nouv. acq. latines 2388).

Contient trois aetes des années 1272-1274.

Mauriac. - Abbaye (dioc. de Cilermont-Ferrand).

2389. - Cartulaire de l'abbaye de Mauriac; orig. perdu.

Extraits faits au XVIII siècle (Biblioth. nationale, collection Moreau, vol. 347, ff. 232-25I).

2390. - Publ. : La chronique de Manriac par Montfort, suivie de documents inédits sur la ville et le monastère, par le $\mathrm{D}^{\mathrm{r}}$ de Ribier.

Paris, Champion, 1905 ; in-8" de $260 \mathrm{p}$.

Maurienne. - Diocèse.

239I. - Publ. : Chartes du diocèse de Maurienne, publ. par Mgr. 
Alexis Billiet et lahbé Alhrienx. Chambéry, Puthod fils. 1861 ; in- $8^{\circ}$ de $r$ - $\mathbf{4 6}$ p. [Académie impériale de Saroie: Decuments II.]

Recueil factice d'actes des années 887 à 1042 daprès les archives de l'érêché en très grande partie.

Mauzac. - Voy. Mozac.

Mazan. - Abbaye (dioc. de Tiviers).

2392. - Cartulaire de l'ahbaye de IIazan [incomplet des feuillets 157 et 168], contenant 69 pièces des années $1217-1615$ : ms. des XIVe_ XVIII siècles, sur parchemin et papier. de 209 ff. in-folio Archices dép. de T Ardèche, H 3 provisoire).

Traduction moderne. par F. Borel d'Hauterive, sur papier. infolio de 753 p. (Biblioth. de lu ville de Saint-Étienne, ms. 103..

Mazères. - Ville.

2393. - Cartulaire municipal de Iazères (Ariège, : orig. [de 15.58] perdu.

Copie ou «Vidimat » du précédent: ms. de 1786. collationnésur l'original par un bénédictin de l'albaye de Boulbonne. sur papier, contenant 52 documents de 1252 à 1504 , in-40 de 292 ff. Archires municipules de Wazères\}.

Meaux. - Abbaye de Chage.

2394. - Cartulaire de l'abbaye de Chage à Meaux; orig. perdu.

Dom Toussaints Du Plessis l'a connu et utilisé ; roir préface de son a Histoire de l'église de Meaus 》) (1731).

Extraits faits au XVIIe siècle 'Biblioth. nationale, coll. Baluze, vol. LI. pp. 203-208.

Meaux. - Abbare de Saint-Faron. - Toir SAINT-FARON.

Meaux. - Chapitre cathédral.

2395. - Cartulaire du Chapitre cathédral de Meaux: ms. du SIII siècle [vers 1285]. avec additions postérieures. contenant des titres des années 1004-1699. et une tałle chronologique par Thomé dressée en 1765. sur parchemin et papier. in-folio de 385 et $59 \mathrm{p}$. (Biblioth. de la ville de Mearx. ms. 63 .

2396. - Autre cartulaire ou fragments de divers cartulaires du XIII siècle, sur parchemin. in-folio. pp. 3-106. 149-186. 189-196 et 203-224, avec tatle sur papier par Thomé dressé au XVIII siècle (Biblioth. de la cille de Weaux, ms. 64 .

2397. - Autre cartulaire C on fragments de cartulaires des XIII ${ }^{\theta}$ et XIVe siècles, sur parchemin. in-folio. pp. 1-2:39 el 239-270. arec table sur papier par Thomé dressée au XYIII siècle. 52 p. Biblioth. de la ville de lleaux, ms. 65.

Les dates extrèmes des actes sont 1004 et 1283 . 
2398. - Autre cartulaire D ; ms. des XIVe-XVe siècles, avec additions postérieures, contenant des actes de 1289 à 1597 , sur parchemin, in-folio de $1+4 \mathrm{p}$. et table de $18 \mathrm{p}$. (Biblioth. de la ville de Meaux, ms. 66).

Meaux. - Église cathédrale Saint-Étienne.

2399. - Cartulaire de l'église cathédrale de Neaux ; ms. du XIII' siècle [1260]. de plusieurs mains, avec additions postérieures (1289-1390), sur parchemin, in- $4^{\circ}$ de 105 ff. a 2 col. suivis d'une table de $6 \mathrm{ff}$. sur papier (Biblioth. nationale, ms. latin 5528).

Dates extrêmes: 1139-1255. Provient de Lancelot et parait être la copie d'un manuscrit plus ancien, perdu.

2400. - Antre du XIVe siècle, sur parchemin, avec table au début, contenant des actes des années $115+1353$, in-4" de n11-9l ff. (Biblioth. nationale, ms. latin 18355 ).

Textes parfois meilleurs que dans le précélent. Provient de l'église cathédrate de Paris.

Copie du précédent, faite au $\mathrm{XVII}^{\mathrm{e}}$ siècle, de xxxvir-204 p. (Biblioth. nationale, ms. latin $5185^{\mathrm{F}}$ ).

Autre copie du XVHI siècle, in-folio de 318 p. (Biblioth. de M. Gatellier, curé-doyen de Crécy-en-Brie).

Cf. sur ce dernier, le Bulletin de la Confervence historique et archéologique de Heanx, III, p. 116). Des 216 chartes des XII-XIVe siècles conterues clans ce volume, la plus grande partie est inprimée parmi les pièces justificatives de "l'Histoire de l'église de Meaux ", par Dom Toussaints Du Plessis.

Extraits Biblioth. nationale, coll. Champaone, vol. XIX, ff. 169171 : - nowv. acq. françaises 7398, fi. 153-157 ; - coll. Baluze, vol. XL, fi. 161-170, et LXXIV, ff. 208-229;.

Meaux. - Église collégiale Saint-Saintin.

2401. - Cartulaire de l'égrlise Saint-Saintin de Meaux; orig. perdu.

Existait encore au commencement lu XVIIJe siècle quand Dom T. Du Plessis l'a utilisé.

Meaux. - Hôtel-Dieu.

2402. - Cartulaire de l'Hòtel-Dieu de Meaux ; ms. du XVIII siècle, sur papier. contenant des actes de 1172 à 1780 , en 3 vol. in-folio de 248. 2:38 et 317 If. (Archives hospitalières de Meaux, A 4 à 6).

Meaux. - Maladrerie de Saint-Lazare.

2403. - Cartulaire de St-Lazare de Meanx; ms. du XIVe siècle, sur parchemin, contenant des actes de 1187 à 1309 , in- $4^{0}$ de $32 \mathrm{ff}$. (Archives hospitalières de Meaux, II A 3). 
Meaux. - Ville.

2404. - Puru. : Recueil danciens titres et pièces concemant la communauté des habitants de la ville de Meaux. Meaux, Fr. Alart, 1739 ; in-4u de 69 parres.

$$
\text { Dates extrêne's: } 1447-1739 .
$$

Melinais. - Abbaye (dioc. d'Angers).

2405. - Recueil de chartes de l'albaye de St-Jean de Melinais: ms. du XVIII e siècle [1728], sur papier. contenant des actes des XII ${ }^{\text {- }}$ XVIII siècles. arec table. in-folio Biblioth. Sainte-Generière, à Paris. ms. 67\%. pages $1-270$ et 299-308;.

Mellemont. - Prieuré (dio . le Namur).

2406. - Cartulaire du prieuré de Mellemont: ms. du XVIe siècle, sur parchemin. contenant des actes de 1153 a 1560 . in-folio de $400 \mathrm{ff}$. Archires du ioyaume de Belgique, à Bruxelles;.

Melleray. - Abbaye (dioc. de Nantes).

2407. - Cartulaire de l'abbaye de Nelleray : orig. perdu depuis 1792. Wxtraits du précédent faits an XVIIle siècle Biblioth. nationale, ms. latin 22319. pp. 197-214).

Copie de ces extraits. par Arth. de la Borderie, sur papier, in- $4^{0}$ (Archices dép. de la Loire-Inférieure, H 75 ,

Melun. - Éclise Notre-Dame (dioc. de Sens).

2408. - Cartulaire de Yotre-Dame de Melun : orig. perdu.

Extraits faits au $\mathrm{XVIII}^{\mathrm{e}}$ siecle Archices municipales de Melun, Notes Gauthier. 1er cahier: - Archires dip. de Seine-et-Marne, 1: 218 .

Mende. - Chapitre cathédral.

2409. - Cartulaire ou «Liber compositionum capituli Yimatensis» ; ms. sur parchemin, de $420 \mathrm{ff}$, orig. perdu.

Mention en est faite dans un inventaire du $\mathrm{XVI}^{\mathrm{e}}$ siècle (Archires depp. de la Losère, G 1448).

Mercœur. - Duché.

2410. - Recueil de titres relatifs au duché de Vercour; ms. du XVII siècle, formé par Thierry Alix. sur papier. contenant des textes de 1460 à 1608. in-folio dè $374 \mathrm{ff}$. (Archices dép. de Wew theet-Moselle, $\mathrm{B} 410)$.

Mérindol. - Seiqneurie en Provence.

24l1. - Cartulaire de la terre de Jérindol. appartenant à l’érêché de 
Marseille; ms. des années 1752-1758, contenant des documents à partir du XIIle siècle, en 2 vol. in- $t^{0}$ sur papier (Archives dép. des Bouches-du-Rhône, G non colé).

Mesland. - Prieuré (dioc. de Blois).

2412. - Cartulaire-censier du prieuré de Mesland, dépendant de l'abbaye de Marmontier; ms. dn XVe siècle, sur parchemin, in-4 ${ }^{0}$ de 59 fr. (Archives dép. de Loir-et-Cher, $\mathrm{H}$ non coté).

Ne contient la transcrip;ion intécrale que de quelques chartes seulement.

Messelan. - Commanderie, à Frouville (dioc. de Beauvais). - Voir Bernes.

Mésy. - Commanderie, à Créteil (dioc. de Paris).

2413. - Fragment d'un cartulaire de la commanderie de Mésy ; ms. de la fin du XIII ${ }^{\mathrm{a}}$ siècle, sur parchemin, contenant des actes de 1:2931294, in-40 de 12 $1 \mathrm{fr}$. (Archives nationales, S $5095^{\mathrm{a}}$ ).

Mettlach. - Abbaye (dioc. de Trèves).

2414. - Cartulaire de l'abbaye de Mettlach; ms. du XVe siècle [1488], sur papier, in-4 ${ }^{\circ}$ de $325 \mathrm{ff}$. (Stadtbibliothek Trier, ms. 1670).

Metz. - Abbaye de Notre-Dame.

2415. - Fragment d'un cartulaire de Notre-Dame de Metz, contenant 90 chartes en français des années 1348-I355 [incomplet]; ms. du XIVe siècle, sur parchemin, in-4to, folioté xcvir ì cxulu (Bizlioth. Cheltenham, n" 7(6).

2416. - Autre fra'ment du XIVe siècle, sur parchemin, in-40 (Biblioth. nationale, ms. latin 1002\%, ff. 45-50).

Metz. - Abbaye de Saint-Arnould.

2417. - Petit cartulaire de l'abbaye de Saint-Arnould de Metz; ms. de la fin du XIII ${ }^{e}$ siècle, sur parchemin, in- $4^{0}$ de $57 \mathrm{ff}$, et $2 \mathrm{ff}$. papier pour la table des matières jointe (Biblinth. de la ville de Metz, ms. 1099).

Provient de la coll. Char ener.

Copie du précédent; ms. de la fin du XIVe siècle, sur parchemin, in-4" de 135 pages (Biblioth. de la ville de lletz, ms. 6t [anc. 814]).

Autre copie faite ver's 1480 , sur parchemin et papier, avec additions postérieures, in-t $\mathbf{t}^{0}$ de $116 \mathrm{ff}$., incomplet de la fin (Biblioth. de la ville de Metz, ms. 1225 [anc. Salis 76]).

Autre copie; traduction du XVe siècle, sur papier, in-4 $4^{\circ}$ (Biblioth. nationale, ns. nouv. acq. françaises 6700 , fr. 1-45).

Provient de Aug. Prost ef contient la traduetion française des actes eontenus dans les eartulaires précédents. Dates extrêmes: IXe siècle1471 . 
Extraits faits au XVII siècle « ex cartulario Sancli Arnulfi » (Biblioth. nationale, coll. Baluze, vol. XLVII, II. 120-128;.

2418. - Grand cartulaire de Saint-Arnould de Metz; ms. du XVe siècle. sur parchemin, orig. perdu.

Copie du précédent, exécutée en 1561 par le curé O. Grave. sur papier, in-40 de 247 pages (Biblioth. de la rille de Metz, ms. 815).

Une traduction française des cartulaires de Saint-Arnould, faite au $\mathrm{XVI}$ e siècle, existe aussi en un vol. in- $4^{\circ}$ de 1.18 pages (Biblioth. de la ville de .Hetz, ms. 816).

2419. - Recueil des titres de Saint-Arnould de Metz; ms. copié en I761 par Dom Roliert. sur papier, et contenant des documents de 682 a 1761 , in-folio de vi-381 pages Biblisth. de la rille de Metz, ms. I088).

Provient de la coll. Chartener.

Metz. - Abbaye de Sainte-Glossinde.

2420. - Cartulaire de Ste-Glossinde de Metz; ms. du XVe siècle, sur papier, 2 vol. in $4^{\prime}$ de 525 et $432 \mathrm{ff}$.. plus les tables (Bibl. Cheltenhum, nus 2246 et 13639 ).

2421. - Autre cartulaire; ms, daté de 1292, avec addilions du XIVe siècle, de plusieurs mains et avec table à la fin, sur parchemin, in $-4^{0}$ de 73 Ir. (Biblinth. nationale, ms. latin 10024).

Dates extrèmes : 1138-1346. Beaucoup de chartes en langue française.

Metz. - Abbaye de Saint-Pierre aux Nonnains.

2422. - Cartulaire de Saint-Pierre aux Nonnains de Yetz; ms. du XVe siècle, sur parchemin, in-folio de 84 p. Archires de Lorraine, à Metz, H non coté).

2423. - Fragments de cartulaires de St-Pierre de Metz ; ms. du XIVe siècle, sur parchemin, in-4 $4^{\circ}$ Biblisth. nationale, ms. latin 10027, ff. $1-42$.

Metz. - Abbaye de Saint-Symphorien.

2424-25. - Cartulaire de l'abbaye de Saint-Symphorien de Metz; ms. des XIII'-XIVe siècles. sur parchemin. in-1" de 161 p. (Bibl. Cheltenhair, $\mathrm{n}^{\text {os }} 10456$ et 13619 ,

Metz. - Abbaye de Saint-Vincent.

2426. - Cartulaire de Saint-Vincent de Metz; ms. des XIIIe-XIVo siècles. de plusieurs mains, avec table au début. sur parchemin, in-folio de $155 \mathrm{lf}$. Biblioth. nationale, ms. latin 10023 .

Dates extrêmes : 1221-1323. Mais lés actes de l'année 1323 paraissent être des additions un peu postérieures. 
Metz. - Chapitre cathédral Saint-Étienne.

2427. - Cartulaire du Chapitre de Metz; ms. du XIIIe siècle, avec additions des XIVe et XVe, sur parchemin, in- $4^{\circ}$ (Biblioth. nationale, ms. français 11846, ff. 1-217).

Dates extrèmes: 1282-1348.

2428. - Fragment dı cartulaire du Chapitre cathédral de Metz; ms. du XIV siècle, sur parchemin, incomplet du commencement et de la fin, in- $4^{0}$ (Biblioth. nationale, ms. latin 10027, ff. 53-87).

Metz. - Couvent des Grands Carmes.

2429. - Cartulaire des Grands Carmes de Metz; ins. du XVII siècle, sur papier, contenant des documents de 1614 à 1669 , in-folio de 186 ff. (Archives de Lorraine, à Metz, H 2765).

Metz. - Église collégiale de Saint-Thiébaut.

2430. - Cartulaire de la collégriale de Saint-Thiébaut de Metz; ms. du XIVe siècle, sur parchemin, contenant des titres de 1163 à 1353, in-folio de $n \mathrm{II} 3 \mathrm{fr}$. (Archives du Chapitre de la cathédrale de Metz).

On $y$ a ajouté, en détruisant la renliure primitive, quelques cahiers de papier donnant la traduction en français des mêmes actes, puis 'quinze parchemins originaux, de formats très clifférents.

Metz. - Église Notre-Dame-la-Ronde.

2431. - Cartulaire de l'église Notre-Dame-la-Ronde à Metz; ms. du XIVe siècle, sur parchemin, in-4 $4^{0}$ Biblioth. nutionale, ms. latin 10026 , pages $1-100)$.

Dates extrèmes : 1244-1344. Nombreuses chartes en langue française.

Metz. - Église Saint-Sauveur.

2432. - Cartulaire de Saint-Saureur de Metz; ms. du XIIIe siècle, de plusieurs mains, avec additions postérieures ( $\mathrm{XVI}^{\mathrm{e}}-\mathrm{XVII}$ ), sur parchemin, avec tahle sommaire en tète, in- $4^{0}$ de rv-103 ff. (Biblioth. nationale, ms. latin 10029).

Dates extrêmes : 1096-1684.

Metz. - Érèché.

2433. - Cartulaire on «vieil registre des fiefs » de l'évêché de Metz; orig. perdu.

2434. - « Second registra des fiefs » de l'évêché de Metz; orig. perdu.

Un essai de reconstitution de ces deux recristres vient d'ètre fait, d'apris les vol. 717 (ff. $450-181$ ) et 721 (ff. $469-509$ ) de la collection de Lorraine ì la Bibliotheque nationale [Mettensia, V, 190\%], par M. Paul, Marichal à la suite de la publication ci-dessous.

2435. - «Troisième registre des fiefs » de l'évèché de Metz; ms. 
écrit en 1462 par ordre de l'évèque Georges de Baden, sur papier, contenant 266 pièces écrites le plusieurs mains $999-1441$. in- $4^{0}$ de $309 \mathrm{ff}$. (Biblioth. nationale, m. latin 10021).

Publ. : Cartulaire de l'évêché de Metz, publ. par Paul Marichal.

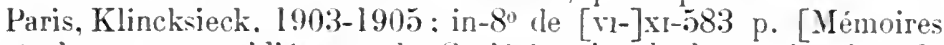
et documents publiés par la Société nationale des Antiquaires de France; Mettensia. IV.]

2436. - Autre cartulaire: ms. des $\mathrm{XV}^{\mathrm{e}} \mathrm{XVI}$ e siècles, sur papier, en 8 vol. in $4^{0}$ de $258,140.250,206.238 .184$. 192, et $107 \mathrm{ff}$. (Archives de Lorraine, à .Metz, G à à 13 .

2437. - Extraits des cartulaires de l'évèché de Metz faits, au IrII siècle par Dom Robert. sur papier, en 9 vol. in-folio (Biblioth. de lu rille de Metz, mss. 799 is 807 .

Metz. - Hòpital Saint-Nicolas.

2438. - Cartulaire de l'hòpital Saint-Nicolas de Metz: ms. de la fin du $\mathrm{XYI}$ siècle, sur papier. in-folio de 448 pages (Biblioth. de lu ville de Metz, ms. 936:

Metz. - Ville et érèques.

2439. - Recueil de titres relatifs aux rapports des ducs de Lorraine arec la ville ct les évèques de Metz; ms. du XVIIe siècle, formé par Thierry Alix, sur papier, contentnt des textes de $13+2$ a 1605. in-folio de $131 \mathrm{ft}$. Archires dép. de Weurthe-et-Moselle. B 373).

Metz. - Ville.

2440. - Cartulaire de la cité de Metz; ms. des XIVe-XVIe siècles. sur parchemin, in-4' de $104 \mathrm{ff}$. (Biblioth. de la ville de Wetz, ms, 75l).

Analyse et extraits du précédent, par Dom Jean François: ms. du XV̌lle siecle [1793]. sur papier, in-4" de 24 et 117 pages (Biblinth. de lu rille de Metz. ms. To2.

2441. - Extraits des « atours » du urand Cartulaire de la cité de Metz (1215-I529; ms. du XVIII siêcle, sur papier. in-folio de $180 \mathrm{ti}$. (Biblig'h. nutionale, ms. nonv. acq. françaises 6686 .

Provient d'Aug. Prost.

2442. - Recueil de mémoires et ducuments concernant la ville de Metz; ms. du XVII siècle. sur papier, contenant des actes de 1252 à 1604 , in-folio de $395 \mathrm{ff}$. (Biblioth. nationale, ms. français 2743).

Meulan. - Prieuré de Saint-Nicaise (dioc. de Chartres).

2443. - Cartulaire du prieuré de St-Nicaise de Meulan; ms. du XIII siècle, sur parchemin, arec additions postérieures. in $4^{\circ}$ de $76 \mathrm{ff}$. (Biblioth. nationale, ms. latin 13888'.

Dates extrềmes. 1150-1320. 
Cupie du XVII ${ }^{\mathrm{e}}$ siècle [1678], sur papier, in-40 de xri-169 pages (Archives dép. de Seine-et-Oise, $\mathrm{H}$ non coté).

Copie partielle dn XVe siècle, avec additions et censier (Biblioth. nationale, coll. Vexin, vol. LXXIX, iu-8 ${ }^{0}$ de 243 ff.).

Meung-sur-Loire. - Église collégiale Saint-Liphard (dioc. d'Orléans).

2444. - Cartulaire de l'église collégiale de Meung-sur-Loire; orig. perdn.

Extrait fait par Dom Estiennot an XVII' siècle (Biblioth. de l'Arsenal, ms. 1008, p. 283).

Copie du XVIII siècle, «Cartularium Magdunense », sur papier, in- $8^{\circ}$ de $74 \mathrm{ff}$. (Archives dép. du Loiret, G non coté).

Documents du XYI siècle à 1530 .

Extraits faits en 1713 (Biblioth. nationule, coll. Baluze, vol. LXXVIII, p. 152-291; - ms. latin 12739, p. 255-257).

\section{Mévouillon. - Ville.}

2445. - Cartulaire mmicipal de Mérouillon; ms. du XVIe siècle, sur papier, contenant des titres de 1305 à 1546 , in- $4^{\circ}$ de $184 \mathrm{ff}$. (Archives dép. de la Drôme, E 3189).

Meymac. - Abbaye (dioc. de Limoges).

2446. - Cartulaire de l'abbaye de Meymac ; orig. perdu.

Extraits du précédent par Dom Col, faits en 1769, et copies de tilres (Biblioth. nationale, ms. latin 9194, pages 61 à 174).

Documents du XIIe siècle à 1641 .

Meyriat. - Chartreuse (dioc. de Lyon).

2447. - Cartulaire de la Chartreuse de Meyriat ; orig. perdu.

Existait au $\mathrm{XVII}^{\mathrm{e}}$ siècle: Guichenon, dans son Histoire de Bresse, $4^{\mathrm{e}}$ partie, p. 199, et dans sa 13iblioteca Sebusiana, p. 129 (ex antiquo cartul. carthusiac Majorevi), en a publie quelques chartes.

Meyrueis. - Ville.

2448. - Cartulaire municipal on Thalamus de la ville et communauté de Neyrueis; ms. dn XYII ${ }^{e}$ siècle $[1620]$, rédigé par $\mathrm{J}^{\mathrm{e}} \mathrm{Jean}$ de Geli, lientenant du viguier en la baronnie dudit lien, sur papier, in-folio (Avchices municipales de Meyrueis).

(if. Notice sur un manuserit du XVIII e siècle concernant la ville de Irrruess, par Frédéric Cazalis Bullotin de la Société d'agriculture, industite, sciences et arts de li Liseiere, X, 1859, p. 5.42-547; XIII, 1862, p. $262-2 \tau 1$ ot $439-47 \tau)$. - L prenier extrait contient une table d'aill urs insuffisante du registre. 
Mézières. - Église collégiale Saint-Pierre (dioc. de Reims). 2449. - Cartulaire de l'éğlise St-Pierre de Mézières; ms. des XIII XIVe siecles, sur parchemin. contenant des actes de 1176 à 1542 , in- $t^{0}$ (Archives dép. des Ardennes, G 42 ).

Ancien m. $n^{\circ} 48$ de la Biblioth. de lu cille de Charlerille.

Mézières. - Ville.

2450. - Cartulaire municipal de llézières: ms. du $\mathrm{XV}^{e}$ siècle. sur papier, avec table en tète, in-1 $\mathbf{t}^{\circ}$ de 111 tf. Biblisth. natisnale, ms. français 5401 ).

Michery. - Abbaye. - Voy. La Cocr-Yotre-Dane.

Micy-Saint-Mesmin. - Abbaye (dioc. d'Orléans).

2451. - Cartulaire de l'albave de Xicy ; ms. du Xilie siècle [125j], composé par ordre de l'abbé Adan ; orig. perdu.

C.f. Hemoires de lidcadémie de Suinte-Crvix, IX, p. 517. Un chanoine de Sainte-Croix d'Orléans s'était, dans un long mémoire daté de 1659 , élevé eontre l'authenticité de ce cartulaire, qu il déclarait avoir été fabriqué de toutes pièces au $\mathrm{XY}$ siècle inem, p. 390): il a existé jusqu'à la Révolution française. Cf. "Alverlissentent servant à l'examen des titres et ehartulaires de l'alhaye de St-M les faussetez ) (Biblioth. mationale, Recueil Thoisy, no 384, fo 69). D'après ce meme recueil, fo 65 , il y eut certainement plusieurs cartulaire's distincts.

Extraits faits au XVII et au XVIII siècle, pour Gaignières (Bihlioth. nationale, ms. latin 5420. pages 5l-tios et 91-103: :par Dom Estiennot Biblioth. del'Arsend, ms. 1008. pp. 631 et 63i: et Biblioth, nationale, ms. latin 12739. pp. 289-336. 449-468 et 481-484; ms. latin 12776. pp. 336 et 352; ms. latin 17609. passim; - par A. Duchesne Idem, coll. Baluze, vol. XLI, tf. 178-208, et vol. Lxxrill, tr. 91-150; - par Pulluche Biblisth. de lin cille

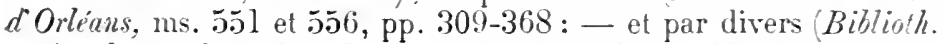
nationale, ms. latin 10091. sur papier. in- $t^{0}$ de vint-380 ff. contenant des actes de 1237 à 1678 avec table en tète: mis. latin 10090. sur

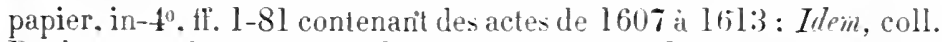
Duchesne, rol. LVI. fit. 418-41.9 ; ms. français 1808:3, tf. 313-315: coll. Fontette, vol. XXXII. ff. 96-103: nour. aeq. françaises 7433 . ff. 82-89, et 9654 . passim .

Miglos. - Seigneurie.

2452. - Cartulaire de la seigneurie de Miglos : ms. incomplet du début et de la fin, en rouleau de parchemin du XIV'e siècle (Archizes dép. de l'sliège, É non coté.

Copie du précédent. d'après l'original complet, faite en 1693 par Jean Lauriol. sur papier Archices dép. de l'Ariège, E non cotè). 
Publ. : La baronnie de Miglos. étude historique sur une seignenrie du haut comté de Foix, par.J. Barrière-Flavy. Toulonse, Chauvin, 1894 ; in-8 $8^{\circ}$ le $x-240 \mathrm{p}$.

Millau. - Maladrerie de Saint-Thomas.

2453. - Cartulaire de la maladrerie St-Thomas de Millau; ms. du XIVe siècle, sur parchemin, in-80 (Archives hospitalières de Millau). Textes depuis 1153, en latin et en roman.

\section{Millau. - Ville.}

2454. - Cartulaire municipal de Nillau; ms. du XIVe siècle, perdu. Copie médiocre dı précédent, faite en 1668, sur papier, in- $4^{0}$ de 134 ff. (Archives municipales de Millau, AA 11).

1'ubl.: Le livre de l'Épervier, cartulaire de la commune de Milhau (Aveyron). par L. Constans. IIontpellier, impr. Grollier fils, 188:2 ; in-80 de xvi-316 p. [Publication de la Société pour l'étude des langues romanes.]

2455. - Recueil de litres relatifs à la ville de Millau; ms. de 1667, sur papier, contenant des pièces de 1070 à 1587 , in-folio de $311 \mathrm{ff}$. (Biblioth. nationale, coll. Doat, vol. 145).

Yoir l'inventaire dans le Cubinet historique, XI, 1865, p. 173-185.

2456. - Publ. : Notice historique sur les libertés, privilèges, coutumes et franchises de la ville de Millau, suivi de documents inédits jusqu'en 1789, par J. F.Artières (Mémoires de la Société des lettres, sciences et arts de l'Aveyion, XVI, 1906, pp. 171-274).

2457. - Recristre de Millan; ms. du XVe siècle, sur papier, in-8 $8^{\circ}$ (Biblioth. nationale, ms. nouv. acq. latines 185, ff. 1-115).

Contient des vilimus de lettres royales (1315-1339) relatives aux péages.

Milly-sous-Glermont.-Commanderie.-Voy.Sommereux. Minimes. - Ordre religieux.

2458. - Privilèges concédés et octroyés tant à saint François de Paule, fondateur et instituteur de l'ordre des Vinines, qu'aux couvents et religieux de son ordre par les rois de France... (1+88-I643).S.l.n.d., in- $4^{0}$.

Mirande. - Ville.

2459. - Cartulaire de la ville de Mirande; ms. du XVe siècle, avec additions postérieures à partir du fo 104 , sur parchemin, contenant des actes des années 1281 à 1400 , in-folio de $128 \mathrm{ff}$. (Archives municipales de Mirande). 
Mirebeau. - Prieuré (dioc. de Langres).

2460. - Cartulaire du prieuré-cure de Mirebeau: ms. du XVe siècle, contenant 27 documents des années 1:200-139:3. sur parchemin, in-folio de $10 \mathrm{fl}$. (Archices dép). de la Cote- (l) Or, G non coté.

Mirecourt. - Ville.

2461. - Cartulaire municipal de Mirecourt; ms. du XVIe siècle. sur papier. contenant des actes de 1455 a $157 \%$, in-folio de $64 \mathrm{ff}$. Archires municipales de . Virecourt, A.t 4).

Mirepoix. - Évèché et ville.

2462. - Recueil de titres relatifs à l'évèché et à la ville de Jirepoix, fait an XVIII siècle 'Biblioth, nationale. coll. Doat. vol. XXXII. ff. $290-425)$.

Axal.: Cabinet historique. XII (1866), pp. 115̆-121.

Mirepoix. - Ville.

2463. - Cartulaire municipal et féodal de Mirepoix : ms. des Xille$\mathrm{XVe}$ siècles. sur parchemin, in-40 Archires du châtenu de Lérun, Ariège).

Publ. : Sous presse; paraîtra prochainement par les soins de M. Félix Pasquier.

\section{Miribel. - Ville.}

2464. - Cartulaire municipal de Niribel; ms. du XVI siècle, sur parchemin. contenant des actes de 1253 à 1527 , in- $4^{\circ}$ de $39 \mathrm{ff}$. (Archives dép. de l'din, E 463).

Cf. Les cartulaires municipaux de Ceyzériat et de Miribel, par Max. Bourg-en-Bresse, impr. Barbier, 1878 ; in- $8^{0}$ de $30 \mathrm{p}$.

Miséré. - Prieuré de Saint-Martin (dioc. de Grenoble). 2465. - Recueil des privilèges du prieuré de Saint-Martin de Miséré; ms. des XV-IVII ${ }^{e}$ siècles, sur papier. contenant des titres de 1222 à 1412 , in- $4^{\circ}$ de 88 ff. Archires dép. te l' Tsère, $\mathrm{H}$ non coté).

Moiremont. - tbbaye (dioc. de Châlons-sur-Marne). 2466. - Cartulaire de l'ablaye de Moiremont; ms. du XVIII siècle, sur papier, contenant 340 actes des années $1074-1570$, in-folio de $114 \mathrm{ff}$. (Archices dép. de ln . Warne. $\mathrm{H}$ non coté).

Axal. : dans l'Annuaire de lu Marne. 1865. pp. 471-484. par Ed. de Barthélemy (jưqu'à l'année l:398 seulement).

Table d'actes contenus dans le dit cartulaire 'Biblioth. nationale, coll. Champagne, rol. XX. ff. 181-199, 
Moissac. - Abbaye de Saint-Pierre (dioc. de Cahors).

2467. - Fragment d'un cartulaire de l'ablaye de Noissac; ms. du XII siècle, contenant 39 actes des années 1097-1176, sur parchemin, in-40 de 15 ff. (Archives dép. de la Haute-Garonne, H non coté).

Extraits du précédent, faits au XVII siècle (Biblioth. nationale, ms. latin 12771, pp. $115-118$; - coll. Baluze, vol. XLI, pp. 55-70).

2468. - Recueil de titres relatifs à l'abhaye de Noissac; ms. de 1669, contenant des acles des années 672 à 1618 , en 4 vol. in-folio de $35 \mathrm{l}$. 389. 379 et $362 \mathrm{fr}$. (Biblioth. nutionule, coll. Doat, vol. 128131).

2469. - Cartulaire de la justice de la ville et de l'abbaye de Moissac; ms. du XVII siècle, sur papier, contenant des documents depuis 1220, in-4" de $86 \mathrm{tr}$. Archives dép. de Thrn-pt-Garonne, G 551 ).

Aux archives municipales de Ifoissac on conserve un inventaire des archives de l'abbaye, dresse par Er. Andurandy on 1728-1730 (in-folio de $771 \mathrm{fẗ}$.) où quelques titres ont été transcrits intégralement.

Moissac. - Hôtel-Diøu.

2470. - Cartulaire de l'Hôtel-Dien de Moissac; ms. du XIVe siècle (Archives hospitalières de Moissuc, B 32).

Moissac. - Ville.

2471. - «Livre de la Charte»; ms. commencé à la fin du XIlI siècle, avec additions postérieures, sur parchemin, in-40 de 183 ff. (Archives municipales de Woissac, AA l).

Ce nest pas à proprenent parler un cartulaire municipal, mais il rontient quelques actes intéressant less privileges de la comnunauté. On en trouvera la description dans les Etudes historiques sur Moissac, de Lagrrèze-Fossat, I, p. xi (1870).

2472. - Recueil de titres relatifs à la ville de Moissatc; ms. de 1669 , contenant des actes des années 1197 i 1519 , in-folio de $286 \mathrm{ff}$. (Biblioth. nationale, coll. Doat, vol. 127. $21 \pi$.

Cf. l'inventaire de ce volnme (Ciabinet historique, V'II, 1861, p. 206-

Molême. - Abbaye (dioc. de Langres).

2473. - Premier cartulaire de l'abbaye de Molème ; ms. du XII ${ }^{\mathrm{e}}$ siècle, contenant 289 actes des années 1076 is 1170 , sur parchemin, in-folio de $63 \mathrm{fl}$. (Arehives dép. de la Côte-d'Or, $\mathrm{H}^{3} 6$ ).

2474. - Denxième cartulaire; ms. du XIII siècle, contenant 752 actes des années 1101-1250, sur parchemin, in-folio de $153 \mathrm{fl}$. (Archives dep. de la Cóte-r $\mathrm{Or}, \mathrm{H}^{3} \mathrm{~T}$.

Il y a en outre une copie (1638) de ce dernier.

Publ. : Chartes inédites extraites des cartulaires de Molême 
intéressant un grand nombre de localités du département de l'Aube, par Émile Socard Mémaires do la Snciété acurtémiqup de TAube, XXIV, p. 16:3-264. et à part: Troyes, 1864 ; in-8 de $204 \mathrm{p}$.

Comprend 227 chartes des années 1080-1250. - c.f. H. d.Irbois de Jubainville, dans la Bibliotheque de I'Ecole des Chartss, XXVII, 1860, p. 393.

Extraits des deux cartulaires Biblioth. nationale, ms. nouv. acq. françaises 7401. ff. $431-432$ : coll. Baluze, vol. XLV).

II. Jaciques Laurent prépare pour la Commission des antiquités de la Cinte-dOr la publication intégrale des cartulaires de Moleme. Voir aussi $\mathrm{v}^{\circ}$ Dutchr.

Moncassin. - Ibbaye (dioc. d'Auch).

2475. - Cartulaire de l'abbaye de Moncassin ; orig. perdu.

II en est fait mention dans les Glanages de Larcher (Biblioth. ie la rille de Turbes').

Monceaux. - Prieurẻ de Notre-I)ame (dioc. de Sées).

2476. - Cartulaire du prieuré de Monceaux. dépendant de l’abbaye de St-Jean-en-Tallée: ms. du $\mathrm{XY}^{\top}$ e siècle, sur papier, in-folio de $12 \mathrm{ff}$. (Archices dép. ¿̂ Etre-et-Lnir, H 3440).

Dates extrèmes: 1282-1421.

Mondaye. - Abbaye (dioc. de Bayeux).

247\%. - Cartulaire de labbaye de Mondaye; ms. du XIII siecle. sur parchemin. avec additions du XIV $\mathrm{V}^{-\mathrm{e}}$ in- $\mathrm{t}^{\circ}$ de $331 \mathrm{ff}$. Biblinth. du Chapitre de Buyeux, ms. 164.

2478. - Cartulaire-cenier de Mondaye; ms. des XIVe-IVIe siècles, sur parchemin. in-folio de $104 \mathrm{fl}$. Biblinth. du Chapitre de Bayeux, ms. 165 ).

2479. - Autre cartulaire du X $\mathrm{X}$ e siècle [14:31]. sur parchemin, incomplet du début, in-1" de $66 \mathrm{ft}$. 'Biblioth. du Chupitrè de Buyeux, ms. 166 .

2480. - "Premier chartrier » de l'abbave de Mondaye: ms. du

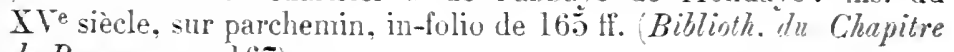
de Bayeux. ms. 167 .

2481. - "Second chartrier" " de l"ahbaye de Yondaye: ms. du XVe siècle [l489]. sur parchemin. in-folio de 153 ff. Biblisth. du Chapitre de Buyeux, ins. 168).

2482. - «Tiers chartrier 》 de l'abbaye de Mondave: ms. du $\mathrm{XVe}$ siècle, sur parchemin, incomplet de la fin, in-folio de $122 \mathrm{ff}$. (Biblioth. du Chapitre de Buypur, ms. 169.

2483. - Cartulaire du moulin de Héville. appart. it labhaye de 
Mondaye; ms. du XVe siècle, sur parchemin, in-14 de $79 \mathrm{ff}$. (Biblioth. du Chapitre de Bayeur, ms. 170).

Monmouth. - Prieuré (dioc. (le Hertford).

2484. - Publ. : Chartes anciennes du prieuré de Monmouth en Angle- . terre, au dioc. de Hereford, membre de l'abbaye bénédictine de Saint-Florent près Saumur, par Paul Marchegay. Les Roches-Baritaud, 1879 ; in-8 de $35 \mathrm{p}$.

Monnais. - Prieuré de Notre-I)ame des Bonshommes (dioc. d'Angers).

2485. - Cartulaire des Bonshommes de Monnais, dépendant de l'ablaye de Grandmont: ms. daté de 1493. et copié par le prieur frère Vincent, contenant 155 actes de 1155 à 1491 , mais incomplet de la fin, sur papier, in- $4^{0}$ de 460 pages (Archives dép. de Maine-etLoire, $\mathrm{H}$ non coté).

Les pages 113-120, 415 et 435 sont endommagées.

Mons. - Béguinage le Cantimpret (dioc. de Tournai).

2486. - Cintulaire du héguinagre de Mons; ms. du XIVe siècle, sur parchemin. contenant des chartes de 1245 à 1308 , in-40 de 28 ff. (Archives de l' Litat ì Mons).

Publ. : par L. Devillers, Description de cartulaires et de chartriers du Hainaut. II (1866, p. 119-164 [avec additions de pièces originales jusqu'en 1767].

Mons. - Chapitre Saint-Germain.

2487. - Cartulaire dı Chapitre Saint-Germain de Mons; ms. des XIV-XViesiecles. sur parchemin, contenant des actes de 1182 à 15:31. in-4" de 162 parges (Archives de l' État a Mons).

2488. - Autre dı $\mathrm{XVIl}^{\mathrm{e}}$ siècle, sur papier, contenant des actes de 1182 a 1545, in-folio de $99 \mathrm{fi}$. (Archives de l'Ftat is Mons).

Mons. - Église collégiale Siainte-IVaudru.

2489. - Cartulaire de Sainte-Waudru de Mons; ms. du XVe siècle, sur papier, contenant des titres de 1137 ì $145 \mathrm{l}$, in-folio de $284 \mathrm{ff}$. (Archives du grend S'minaire de Tournai).

Axal. : Ammles du Cercle arehéologique de Mons, XXVII (1897), pp. 311-328, par Dom Berlière.

2490. - Petit cartulaire du Chapitre de Sainte-Vaudru ; ms. du XIVe sièclt. sur parchemin. in- $t^{0}$ de $20 \mathrm{ff}$. (Archires cominunales de Mons).

Axal. par L. Devillers, dans: Description de cartulaires et de chartriers du Hainaut. VII (1875, pp. 165-213.

2491. - Recueil des privilègres de Sainte-Waudru; ms. du XVe siècle, 
sur papier. contenant des acles de 1327 à 13:31. in-folio de $47 \mathrm{pp}$. (Archices de lítul à Mons.

2492. - Autre recueil de privilèges de Sainte-WVaudru: ms. du XVe siècle, sur papier. contenant 68 actes de 1164 à 14.59 . in-folio de $224 \mathrm{ff}$. (Biblioth. de lu ville de Wons).

Anal. : par L. Devillers, dans - Description de cartulaires et de chartriers du Hainaut, IV (1869), pp. 37-149.

Mons. - Établissements de charité.

2493. - Publ. : Cartulaire des hospices et établissements de charité de la ville de Mons, par Léop. Deviller's dans: Description de cartulaires et de chartriers du Hainaut, VIII 1878. pp. 113-348 ; et dans: Annales du Cercle archéologique de Mons, XXXI, 1902, pp. 241-348, el XXXII, 1903, pp. 305-329.

Dates extrêmes : 1201-1548.

Mons. - Grande aumóne des paurres.

2494: - Cartulaire-censier de la Grande aumône des pauvres de MIons; ms. du XVe siècle [1405]. sur papier. contenant 85 actes de 1278 à 1427, in-folio de $384 \mathrm{ll}$. Archices des hospices de . Mons).

Mons. - Hòpital de l'Enfant-Jésus.

2495. - Cartulaire de l'hòpital de l'Enfant-Jésus à Mons ; ms. du XVIII siècle, sur papier, contenant des actes à partir de 1672 , in- $4^{0}$ de 316 pages (Archives des hospices de . Yons).

Mons. - Ville.

2496. - Cartulaire de la ville de Mons ou «Livre jaune » el « Livre rouge »; ms. des XIVe-IVIII siècles. en 5 vol., les deux premiers sur parchemin, les trois autres sur papier, in-folio de $140,170,307,62$ et 33 if. (Archires communales de IYons).

Dates extrêmes: 1246-1738. Le $3^{e}$ volume est la transcription, faite en 1664 , arec additions, du premier.

Axal. : Inventaire analytique des archives de la ville de Mons, par L. Devillers (3 vol. in-8 ${ }^{\circ}$, passim).

Monségur. - Ville.

2497. - Cartulaire municipal de Monségur Gironde), dit l'Esclapot; ms. du XVe siècle, in- $4^{0}$ de 84 ff. Archives municipales de Monségur, AA 1).

Dates extrêmes : $1205-1432$.

Publ. : L'Esclapot ou cartulaire de Monségur, par Francisque Michel (Archives historiques de lo Giroule, V, p. 1-98, et à part: Bordeaux, 1863 ; in $4^{0}$ ile $98 \mathrm{p}$.

- Privilèges de Monségur, par J.-B. Archu. Salweterre, Chollet, 1886 ; in- $8^{\circ}$ de xnt1-66 $\mathrm{p}$. 
- Le Calendrier de l'Esclapot (cartulaire de Monségur), par l'abbé S. Léglise, avec une introduction sur l'histoire de ce manuscrit par le $\mathrm{D}^{\mathrm{r}}$ Ern. Berchon (Société archéologique de Bordeaux, XII, 1887, pp. 1-64).

\section{Montaigu-Vendée. - Seigneurie.}

2498. - Cartulaire ou « papier rouge » de la seigneurie de Montaigu; orig. perdu.

Existait autrefois dans les archives du château de Landreau (Vendée). Il doit en exister quelques extraits et copies du XVIII siècle (cf. Annuare de la Société d'émulation de la Vendée, L, 1903, p. 50).

Montargis. - Ville.

2499. - Pubr. : Les privilèges. franchises et libertez des bourgeois et habitans de la ville et fauxbourgs de Montargis-le-Franc. Paris, Chevalier, 1662, in-8*.

Montauban. - Abbaye de Saint-Théodard, unie au Chạpitre rathédral.

2500. - Recueil de titres relatifs à l'abluaye de Saint-Théodard de Montauban; ms. date de 1669, contenant des documents des années 1121-1600, en 2 vol. in-folio de 382 et $234 \mathrm{ff}$. (Bibliolh. nationale, collection Doat, vol. 89-90.

La suite du volume 80 (ff. 235-37-1) contient une série de documents des années $12.1 \times-1523$ sur le Chapitre de St-Étienne de Tescou à Montauban.

Montauban. - Chapitre cathédral.

2501. - Cartulaire du Chapitre cathédral de Montauban; ms. du $\mathrm{XVI}^{\mathrm{e}}$ siëcle, sur papier, contenant des actes depuis 1320, collationnés par le notaire R. Deporta, in-folio de 25:3 ff. (Avchives dép. de Tarnet-Garonne, G 211).

2502. - Cartulaire du Chapitre cathédral, jadis coté II; ms. du $\mathrm{XVI}^{\mathrm{e}}$ siècle, sur papier, contenant des actes des $\mathrm{XII}^{\mathrm{e}}-\mathrm{XIV}^{\mathrm{e}}$ siècles arec tahle initiale, in-t" de 7.21 ff. (1rchives dép. de Tarn-et-Garonne, G 239 .

2503. - Autre cartulaire jadis coté $\mathrm{P}$; ms. du $\mathrm{XVI}^{\mathrm{e}}$ siècle, sur papier, contenant des actes des XIII $-\mathrm{XV}^{\mathrm{e}}$ siècles avec table initiale, in $-4^{0}$ de $692 \mathrm{ff}$. (Hrchives dép. de Tarn-et-Guronne, G 240).

Le volune avait $715 \mathrm{ff}$, environ quand il était complet. - Les autres cartulaires du Chapitre ont été perdus dès le XVIe siècle.

Cif. aussi Bulletin de la Sociptés areléologique de Tarn-et-Ciaronne, 1902, pp. $172-176$.

Montauban. - Chapitre de Saint-Étienne de Tescou.

voir le $n^{0} 2500$. 
Montauban. - Couvent des Augustins.

2504. - Cartulaire des Augustins de Montauban: ms. écrit en 161l, sur papier, de t20 ff. Archices dép. de Turn-et-Graronne, H 103.

\section{Montauban. - Ville.}

2505. - Cartulaire municipal de Montauban ou « Livre jaune »: ms. commencé en 1608 et terminé en 1658. sur parchemin, in-folio de $188 \mathrm{ff}$. (Archires imunicipales de . Kontunban, AA 1 .

2506. - Autre cartulaire ou "Livre rougre »: ms. des XIIe-XVI siècles, sur parchèmin, avec addition d'une table sur papier en 1710 , contenant des titres de 1194 à 1316 , in-4" de 1l8-xrr ff. "Archices municipules de Montuuban, AA 2.

2507. - Autre carlulaire ou "Livre armé »: ms. des XiII $-\mathrm{XVI}^{\mathrm{e}}$ siècles, sur parchemin, avec additions d'une table des 170 premiers feuillets faite en 1456 , in-40 de $228 \mathrm{ff}$. (Archices municipales de Montauban, AA 3.

2508. - Autre cartulaire ou «Livre des serments»; ms. des Xille_ XVII siècles, sur parchemin, contenant des titres de 1168 à 1618 , in- $t^{\circ}$ de $178 \mathrm{ff}$. 'Arehires municipales de Montumban, AA 4).

2509. - Recueil de titres relatifs à la ville de Montauban; ms. daté de 1669. contenant des actes cles années I l 44 à 161 l, en 2 vol. in-folio de 382 et $234 \mathrm{ff}$. Biblioth. nutionale, coll. Doat, vol. 87-88, 303).

Voir I'inrentaire du rol. 87 (Cabinet historiqne, XIX, 1873, p. 286-

Montaut. - Prieurẻ (dioc. d'Avignon).

2510. - Cartulaire du prieuré de Montaut, fondé en 1340 par le cardinal Pierre Bertrand : ms. du XITre siècle. sur parchemin, relié en bois, in-10 de 90 ff. Biblioth. He la cille d'Arignon, ms. 4035).

Cf. Bulletin historique et archéologique de Vuucluse, II (1860), p. 3; notice de A. sagnier.

Montazé. -- Prieuré, à Sarignẻ (dioc. de Poitiers).

2511. - Cartulaire du prieuré de Montazé, dépendant de l'abbaye de Fontevrauld; ms. du XTe siècle, sur parchemin, in-t" de $23 \mathrm{ff}$. (Archives dép. de Muine-et-Lórie, $\mathrm{H}$ non coté).

Dates extrêmes: $112 \bar{j}-1200$. - L même dépòt contient 2 ff. de parchemin, écrits au début du XIIe sjèrle, et contenant 215 notices relatives au même prieuré (cf. Hémoires de la S'ociëté des antiquaries de l"Onest, $1853, \mathrm{pp} .89$ et ss.)

Montbard. - Prieuré (dioc. de Langres).

2512. - Cartulaire de Montbard, dépendant de l'abbaye de N.-D. de Fontenay; ms. du XVIII siècle, sur papier, contenant 212 actes des 
années 121l-1660, in-4 $4^{0}$ de 222 ff. (Archives dep. de la Côte-d'Or, Hnon coté, fonds de Fontenay).

Montbard. - Ville.

2513. - Cartulaire de la ville de Montbard; ms. du XVII ${ }^{\mathrm{e}}$ siècle [vers 1690], composé par Jean Nadault, en 2 vol. in-folio (Biblioth. de la ville de Montburd).

Montbéliard. - Comté.

2514. - Recueil de chartes et documents relatifs à l'histoire de l'ancien comté de Montbéliard; ms. du XIX siècle, rédigé par A. Tuefferd, en 2 vol. in-folio (Biblioth. de la ville de Montbéliard, mss. 158-159).

Dates extrêmes: 747-1786. - Cf. aussi le ms. 198 de la même bibliothèque.

2515. - Purl. : Monuments de l'histoire des comtes de Montbéliard, par Alex. 'Tuetey. Montbéliard, [vers 1866]; in-80 de 160 p.

Ce recueil, publié par la Société d'émulation de Montbéliard, est resté inachevé et non distribué.

Montbéliard. - Ville.

2516. - Publ. : Franchises et libertés des bourgeois de la ville de Montbéliard. Montbéliard, 1732, in- $\mathbf{t}^{0}$.

Montbenoit. - Abbaye (dioc. de Besançon).

2517. - Cartulaire de l'abbaye de Montbenoit; ms. rédigé vers 1670 , et contenant des titres depuis 1145 , sur papier, in-40 de $98 \mathrm{ff}$. (Archives dép. du Doubs, H non coté).

Montbrison. - Église collégiale Notre-Dame (dioc. de Lyon).

2518. - Cartulaire de la collégiale N.-D. de Montbrison, ou « Speculum »; orig. perdu [arait an moins 188 fl.].

A été utilisé par La Mure dans son Histoire des ducs de Bourbon et des comtes de Forez (roir nouv. édit., III, 1868, passim).

Montbrun. - Seigneurie en Attvergne.

2519. - Recueil de pieces relatives à la seigneurie de Montbrun; ms. du XVII siècle, sur papier, contenant des actes de 1324 à 1626 , in-4 ${ }^{0}$ de 78 1i. (Biblioth. de la ville de Clermont-F'errand, ms. 727).

Mont-Caret. - Prieuré (dioc. de Périgueux).

25:0. - Cartulaire de Saint-Pierre de Nont-Caret; ms. de la fin du XI $I^{\mathrm{e}}$ siècle, en rouleau de parchemin de $2^{\mathrm{m}} 69$ sur long. sur $0^{\mathrm{m}} 22 \mathrm{de}$ large, contenant 45 pièces non datées (Archives dép. 'de Maine-etLoire, $\mathrm{H}$ non coté).

Extraits faits an XVIII ${ }^{\mathrm{e}}$ siècle (Biblioth. nationale, coll. Lespine, vol. XXXIT, Il. 84-85).

Publ. : par P. Marchegay dans ses Chartes de Saint-Florent près Saumur pour le Périgord. (Voir ci-dessous n ${ }^{0} 3410$ ). 
Montdidier. - Ville.

2521. - Cartulaire de Montdidier ou «Livre rouge »; orig. perdu.

Lixtraits du livre rouge (Biblioth. nutionale. coll. Dom Grenier, vol. CIX, p. 2(6-38).

Mont-Dieu. - Chartreuse (dioc. de Reims).

2522. - Cartulaire de la chartreuse de Mont-Dieu; ms. dn XVII siècle. sur papier, contenant des actes des années 1136 à 1614 , in-folio (Archices dép. des Ardennes, H 276-277).

Montdol. - Prieuré. - Voy. Le Movt-Saint-Mirghel.

Montebourg. - Abbaye (dioc. de Coutances).

2523. - Cartulaire de labbaye de MIontebourg; ms. du Xille siècle. avec additions a la fin, sur parchemin, in- $4^{\circ}$ de 351 pages Biblioth. nationale, ms. latin 10087 .

2524. - Autre cartulaire: ms. du XVe siècle [1453]. écrit par le frère Simon Naubert. arec quelques additions postérieures de la mème main, et mutilé par endroits. sur parchemin. in-folio de $30 \mathrm{ff}$. (British Museum, additional ms. 15605).

Dates extrêmes: 1080-1460. C.f. P. Marchegay, dans la Bibliothèque de [École des Chartes, $4^{\mathrm{e}}$ série, I (1855), pp. 114-115.

2525. - Fragment d'un autre cartnlaire; ms. du XIVe siècle, sur parchemin (British . Fuseum, additional Charters, latin 15288).

2526. - Cartulaire de l'obiterie et de la pitancerie de Montebourg; ins. dn X Ye siècle. sur parchemin, contenant des actes depuis la fin du XIre [non datés]. et collationné en 1460 par Le Lesaut. tabellion à Monteboury. in-folio de l67 ff. (Archices dép. de la Manche, H 8370$)$.

2527. - Livre de l'aumònerie; ms. du XVe siècle [1450]. avec quelques additions postérieures, sur parchemin. contenant des actes de 1.259 à 1466. in-4" de 126 If. Archives dép. de lu Manche, H 83il).

Montélimar. - Ville.

2528. - Publ. : Cartulaire municipal de la ville de Montélimar; Monuments inédits de l'histoire du tiers-état. par l'abbé Ul. Chevalier. Montélimar, Bourron, 1871 : in- $8^{\circ}$ de $1 v^{-352}$ p. [Collection de Cartulaires dauphinois, $\mathrm{Y}$.]

Montfaucon-en-Argonne. - Abbare de Saint-Germain (dioc. de Reims).

2529. - Cartulaire de l'ablarye de Montfaucon-en-Argonne; orig. [48ff. parchemin] perdu. 
Copie exéculée an XVI siècle [1562], sur papier, in- $\mathbf{4}^{0}$ de $113 \mathrm{fr}$. (Archives nationales, J $\left.760, \mathrm{n}^{0} 44\right)$.

Dates extrèmes: $1247-1307$.

Montfaucon. - Seigneurie en Franche-Comté.

2530. - Cartulaire de la seigneurie de Montfaucon; ms. du XIVe siècle [1315-1320], sur parchemin, contenant 234 pièces de 1204 à 131 o, in- $4^{0}$ (Archives de M. le duc de La Rochefoucauld, au chàteau de Bonnétable).

Copie clı précédent, faite an XVIIJ siècle, in-folio de $482 \mathrm{ff}$. (Biblioth. nationale, coll. Morean, vol. 891).

Autre copie du XVIIIe siècle, sur papier, in-f" de $473 \mathrm{ff}$. (Biblioth. de la ville de Besancon, coll. Dro\%, vol. 23).

Montfleury. - Couvent des Dominicains (dioc de Grenoble). 2531. - Cartuliaire de la communauté dominicaine de Montfleury ; ms. dı XIVe siècle, contenant des titres de 1301-1396, sur papier, in-4 ${ }^{\circ}$ de $106 \mathrm{fl}$. (Archices dép. de l'Isère, $\mathrm{H}$ 844).

Montfort[-l'Amaury]. - Comté.

25:32. - Cartulaire hinc de Montfort; ms. du XIVe siècle, contenant des actes de 1207 à 1311 ; orig. perdı en 1737 dans l̈incendie des arehives de la Chambre des Comples de Paris.

A été connu et utilisé par Brussel et par Dom Morice (Preuves de l'llistoire de Bretagne).

Extraits faits an XVIJe siecle par D) Cange (Bib!ioth. de l'Arsenal, à Paris, ms. 52(6l, fl. 13-15) et par N. de Sainte-Marthe (Biblioth. nationule, ms. français 20691. pp. 569-577).

Cif. Note stur le eartulaire do Béatrix de Montfort, par A. de Dion. Rambouillet, imm. Raynal, s. d. ; in $-8^{\circ}$ de $16 \mathrm{p}$.

Monthermé. - Voy. La Val-IJeu.

Montheron. - Abbaye (dioc. de Lausanne).

2533. - Pubi.. : Cartulaire de l'ablaye de Montheron, par Fr. de Gingins (Mémoires et Docuñents publ. par la Société d'histoire de la Suisse romunte, XII, 1854. p. I-Xvin et 1-154).

Recueil factice de documents des années 1142-1539.

Montiéramey. - Abbaye (dioc. de Troyes).

2534. - «Cartularium Arremarensis monasterii 》 [ou monasterii Arremari] ; orig. perdu dès le XVI siècle.

lixtraits dı précédent, contenant des actes à partir de l'année 837, par Audré Dı Chesne (Biblioth. nationale, coll. Balıze, vol. XXXIX, fi. 147 et 154-239, - et coll. Champagne, vol. XXII, fr. 85-92). 
2535. - Cartulaire de l'abbaye de Montiéramey : ms. du III e viècle [incomplet], sur parchemin, in- $4^{\circ}$ de $20 \mathrm{ff}$. Archices dép. de liube, H non coté).

2536. — «hartularium monasterii Arremarensis»; ms. du XIVe siècle. sur parchemin, in-4" de $126 \mathrm{ft}$. Biblioth. nationale, ms. latin $54: 3 \cdot$ ?

Copie du précédent; ms. du XVIJ siècle, in-folio de $672 \mathrm{p}$. (Biblioth. nationale, ms. latin 54:33.

Extraits faits au XVII siècle (Biblioth. nationale, coll. Baluze, vol. LXXI, 1 . $27-45$.

Publ.: Cartulaile de l'abbaye de Montiéramey, par l'abbé Ch. Lalore et Léon Pireotte. dans Collection des principanx cartulaires ru dincèse de Troyes, VII 1890, in-80 de xvil-489 p.

\section{Montier-en-Argonne. - Abbare (dioc. de Châlons-sur- Marne).}

2537. - Cartulaire de l'abbaye de Montier-en-Argonne: ms. du XIIe siècle. sur parchemin. in $4^{0}$ de $42 \mathrm{tr}$. (Biblioth. nationale. ms. latin 10946 .

2ว38. - Fragment d"un cartulaire-inventaire de la mème abbaye : ms. du XVe siècle, sur papier, contenant des actes de 1163 à 1398 (Biblioth. nationale, coll. Champagne, vol. XXIII, ff. 1う̄-61).

Au XVIII siècle, secousse possédait dans ses papiers quelques cahiers d'un " cartulaire ancien" de cette abbaye: je suppose qu'on peut les identifier avec celui-ci.

2539. - Autre cartulaire du XVe siècle. sur parchemin. in-folio de $20 \mathrm{ff}$. Archices dép. de Weurthe-et-Woselle, B 482 .

2540. - Autre cartulaire: ms. rédigé en 1533. sur parchemin, contenant des actes de 1138 a 1322 , in-folio de 40 1f. Archices dép. de la Waine, $\mathrm{H}$ non coté).

Ax.r. : Labbaye de Y.-1), de Montiers-en-Argonne: analvse du cartulaire. par Charles Remy (Congrès archéologique de France, $42^{e}$ session il Chàlons-sur-Marne. 187\%, pp, 267-33 l

2541. - Autre cartulaire; ms. du XTI siècle. sur papier, de plusieurs mains, contenant des actes de 1134 a 1589 , in-folio de xLI550 ff. (Bibliath. nationale. ms. latin 9905).

Ce rolume a appartenu à Levesque de La Ravalière, qui l'acquit en 1719 , et fut vendu apres sa mort $(1762)$ ì Capperonnier pour la bibliothèque du roi.

2542. - Extrait « diun petit cartulaire en parchemin » de la mème abbaye. fait pour Gaimnières an $\mathrm{XVII}^{\mathrm{e}}$ siecle'Biblioth. nationule, ms. latin 17049 . pp. 133-154). 
Publ. : Quelques pièces dans: Diocèse ancien de Châlons-surMarne, par Ed. de Barthélemy, II (1861), pp. 421-439.

Montier-en-Der. - Abbaye (dioc. de Châlons-sur-Marne).

2543. - Premier cartulaire de l'abbaye de Montier-en-Der; ms. du $\mathrm{XII}^{\mathrm{e}}$ siècle, sur parchemin, contenant des actes des années 662 à II96, in-4 de $166 \mathrm{fl}$. (Archives dép. de la Haute-Marne, $\mathrm{H}$ non coté).

2544. - Deuxième cartulaire de Montier-en-Der ; ms. dn XIIIe siècle, avec additions du XIVe, sur parchemin, contenant des actes des années $11 \mathrm{I} 4$ à 1362 , in-4 $4^{\circ}$ de IV-90 ff. [avec lacune des ff. 47-60 pour laquelle on se référera à la table] (Archives dép. de la HauteMarne, $\mathrm{H}$ non coté).

Copie moderne à la Biblioth. nationale (nouv. acc. latines 1251-1252) en 2 vol. de 139 et $92 \mathrm{ff}$.

2545. - Troisième cartulaire de Montier-en-Der ; ms. exécuté en 1524, sur parchemin, contenant des documents des années 1110 à 1493 , in-4 $4^{\circ}$ de $14 \mathrm{ff}$. (Archives dép. de la Haute-Marne, $\mathrm{H}$ non coté).

Concerne spécialement le prieuré de Perthes (Haute-Xarne) qui en dépendait.

2546. - Quatrième cartulaire; ms. exécuté en 1536, sur parchemin, contenant des actes des années 1230 à 1510 , in- $4^{\circ}$ de $40 \mathrm{ff}^{\circ}$. (Archives dép. de la Haute-Marne, $\mathrm{H}$ non coté).

2547. - Cinquième cartulaire; ms. du XVII siècle, sur papier, contenamt des actes de 1539 a 1619 , in-folio de 470 p. avec préface de Dom l)umay, dernier archiviste de l'abbaye (Archives dép. de la Haute-Marne, $\mathrm{H}$ non coté).

Une lettre jointe du généalogiste Chérin fils (1786) indique que ce volume a été restitué par lui, sur les indications laissées par son père.

2548. - Sixième cartulaire; $\mathrm{ms}$. du XVIJ ${ }^{\mathrm{e}}$ siècle, sur papier, in-folio de 275 ff. (Archives dép. de la Haute-IMarne, H non coté).

Transcriptions de pièces accompagnées de commentạires historiques.

Extraits du premier cartulaire « ex antiquiori chartario », faits au XVIIe siècle (Biblioth. nationale, ms. latin 12668, fr. 7-20 et 26-35; coll. Champagne, vol. XXII, fr. 125-228).

Extraits du second cartulaire, faits au XVII siècle (Biblioth. nationale, ms. latin I2668, ff. 2L et 36-37; coll. Duchesne, vol. XXII, ff. 73-78).

I'unc. Chartes de l'abbaye de Montier-en-Der, par l'abbé Ch. Lalore, dans Collection des mincipunx carlulaires du diocèse de Troyes, IV (1878), pp. 90-240.

Cet auteur n’a publié que des chartes intéressant les paroisses situées dans le département actuel de l'A ube. 
2549. - Recueil de pièces relatives à la mène abbaye, formé au XVII siècle (Biblioth. nationale, coll. Baluze. vol. XXXIX, ff. 2-15 et $248-253)$.

Montier-en-l'Ile. - Prieuré (dioc. de Langres).

2550. - Cartulaire du prieuré de Montier-en-l'Ile, dépendant de l'abbaye de Montiéramey ; ms. du XVe siècle, contenant 33 actes des années 1185-1466, sur papier, in- $4^{\circ}$ de $56 \mathrm{fr}$. (Archires dép. de l'Aube, $\mathrm{H}$ non coté).

Montier-la-Celle. - Abbaye (dioc. de Troyes).

255̆. - Ancien cartulaire de Montier-la-Celle; perdu.

2552. - Grand cartulaire de Montier-la-Celle ; perdu.

Copies d'après ces deux recueils dans l'Inventaire des titres de l'abbaye de IIontier-la-Celle; ms. du XVIII siècle en 2 vol. in-folio de 289 et $414 \mathrm{ff}$. (Archives dép. de l'Aube).

Publ. : Cartulaire de Montier-la-Celle, par l'abbé Ch. Lalore, dans Collection des principaux cartulaires du diocèse de Troyes, VI (1882), in-8 de LxII-415 p.

Recueil factice de 288 actes des VIe-XIIIe siècles.

Montierneuf. - Abbaye de Saint-Jean (dioc. de Poitiers).

2553. - Recueil de pièces relatives à l'abbaye de Montierneuf ; ms. du XVIII e siècle, sur papier, contenant 170 pièces des années 1076 à 1621, in-10 (Biblioth. de la ville de Poitiers, coll. Dom Fonteneau, vol. XIX, pp. 11 à 680 ).

2554. - Cartulaire de labbaye de Montierneuf ; orig. perdu.

Extrait fait par Dom Anselme Le Michel an XVIIe siècle (Biblioth. nationale. ms. latin $\left.13820, \mathrm{f}^{0} 4 \mathrm{v}^{0}\right)$.

2555. - Recueil de titres relatifs à la même abhaye: ms. formé en 1653 d'après le cartnlaire et les originaux, sur papier (Biblioth. nationale, ms. latin 12685, ff. 151-186).

Montivilliers. - Abbaye (dioc, de Rouen).

2556. - Cartulaire de l'abbaye de Montivilliers; ms. perdu.

On en trouve mention dans les remarques du marquis Le Ver sur la Chronique de Centule (éd. Prarond, 1899, p. L).

Montivilliers. - Hôpital.

2557. - Cartulaire de l'hòpital de Montivilliers; ms. du XVIe siècle, sur papier, contenant des actes depuis 1241, in-folio (Archires hospitalières de Nontivilliers,. 
Montluel. - Ville.

2558. - Cartulaire municipal de Montluel; ms. du XVe siècle, sur parchemin, in-folio (Archives municipales de Iontlucl, Ain).

Montmajour. - Abbaye (dioc. d'Arles).

2559. - Cartulaire de Montmajour, dit de Saint-Antoine; ms. des XIVe-XYe siècles, contenant les documents relatifs aux rapports avec l'ablaye de Saint-Antoine de Viennois, sur parchemin, in-folio de 250 II. (Archives dép. des Bonches-du-Rhone, H non coté).

2560. - Recueil de titres relatifs à l'abbaye de Montmajour, fait par Dom Estiennot en 1680, d'uprès les originaux (Biblioth. nationale, ms. latin 12762, pp. 295-315).

On trouve aussi une série de pièces transerites dans l'Histoire de l'abbaye de Montmajour, rédigée par. Dom Chantelou, et dont il existe cing exemplaires (Biblioth. nationale; Archires des Bonches-du-Rhône; Biblioth. Mrjanes it Aix; Biblioth. de la ville d'Arles fonds, Téran et Bonnemant).

Montmartre. - Abbaye (dioc. de Paris).

2561. - Cartulaire de labbaye des Dames de Montmartre; ms. du $\mathrm{XVI} \mathrm{I}^{\mathrm{e}}$ siecle, sur papier, contenant des acles de 11333 à 1516 , in $-4^{0}$ de $64 \mathrm{fP}$. (Archives nationales, LL 1605).

2562. - Autro du X111" siècle, sur parchemin, in-4 ${ }^{0}$ de $24 \mathrm{fr}$. (Archioes nationales, LL 1613).

Dates extrênes : 1133-1245.

Pubc.. : Recueil des clartes de l'alibaye royale de Montmartre, par Édouard de Barthélemy. Paris, Champion, 1883 ; in-8" de rv-347 p.

Publication faite avec peu de soin.

Montmerle. - Chartreuse (dioc. de Lyon).

2563. - Cartulaire de la charlreuse de Montmerle en Bresse ; orig. perdu.

Existait au XVII" siècle; ef. Guichenon, Histoire de Bresse (1650), 4 partie, p. 8, 12, 120-121, et Histoire généalogique de la maison de Savoie, nour. éd., IV, p. 160.

Montmorel. - Abbaye (dioc. d'Avranches).

2564. - Pebs.. : Cartulaires de la Manche; Abbaye de Montmorel, par M. Dubosc. St-Lò, Jacqueline, 1878 ; in-4" de III-320 p.

Les chartes publiées appartienuent aux XII et XII ${ }^{e}$ siècles. Le manuscrit qui a servi à l'impression, et daté de 1848 , appartient aux Archives dép. de la Manche. - Le cartulaire original de Montmorel existait an XVI Ie siècle (Biblioth, nationule, coll. Baluze, vol. Xl.I, p. 43).

Montmorency. - Voy. Clli-S'T-Georges. 
Montmorillon. - Hôtel-l)ieu (dioc. de Poilirr's).

2565. - Cartulaire de l'Hotel-I)ien de . Iontmorillon: oriź. perdu après $168: 3$ [in-folio de 288 pages. parchemin].

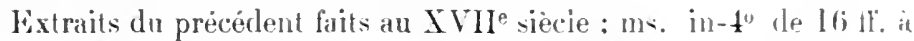
2 col. (Archixes dép. de la Tienne. $\mathrm{H}$ non coté.

Autres extraits faits an XVe siècle par le notaire Reveron. in-folio de $\mathrm{I}$ âf. (Archives dép. de la lienne, $\mathrm{H}$ non coté.

Ce dernier cahier concerne la commanderie de La Chàtille froir ce mint).

2566. - Fxtraits d'un cartulaire de X. I. et Saint-Vincent de l'aumonerie de Montmorillon, fails an XVIIe siècle pour Gaimnières (Biblivth. nationale, ms. latin 17049, pp. 597-601): - autres par A. Galland (Idem, ms. français 16188, f" 216 .

Montolieu. - Abbaye (dioc. de Carrassonn"

2567. - Cartulaire de lablaye de Montolieu : origr. perdu.

Extrait du cartulaire. contenant des actes des $\mathrm{X}^{\mathrm{e}} \mathrm{XIII}$ siecles (Biblioth. nationale, coll. Languedoc, vol. XIV. II. 185-187.

2568. - Recueil de titres relatifs a lablarye de Montolien: m. de 1666-I668, contenant des actes des amnées 815 à 1565 . in-folio de $437 \mathrm{fl}$. (Biblioth. nationale, coll. Hoat, vol. 69.

Voy. aussi Ciarcassosin.

2569. - Recueil de quelques titres relatifs à la dite abliaye. forme par Dom Estiennot en 1679 Biblinth. untionale, ms. Iatin 1:2760, pp. $409-428$;

Montpellier. - Collège des Douze-Ylẻdecins.

2570. - Cartulaire du Collège des Douze-Médecins à Montpellier : ms. du XVe siècle. sur papier, in-4o de $124 \mathrm{ff}^{\circ}$. 'Archices dép. de l' Hermult, fonds de l'érêché de Maguelone, G IV 62.

Montpellier. - Courent les Récollets.

25\% I. - Livre archivial des Récollets de Yontpellier; ms. du XVIII siècle. contenant des titres des années 1662-1778. sur papier. in-folio de 279 ff. (Archives dép. de l'Hérıult, $\mathrm{H}$ non coté).

Montpellier. - Couvent des Trinitaires.

2572. - Cartulaire des Trinitaires de Yontpellier; ms. du IVIII siècle, sur papier. contenant des actes de $16 \mathrm{I} 6$ à 1725. in-4 de $259 \mathrm{ff}$. (Archives dép. de l'Hérault, $\mathrm{H}$ non coté).

Montpellier. - Ordre hospitalier du Saint-Esprit.

2573. - P'cBL. : Diplomata pontificia et regia ordini regulari Sancto 
Spinilu Monspeliensi concesial [anct. J.-A. 'Tousart]. Paris,

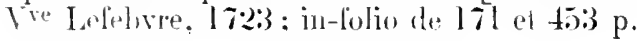

\section{Montpellier. - Seigneurie.}

2574. - Carmbire de la seigneurie des Guillems de Montpellier dit « Io Mémorial des nobles : ms. du XII" siècle. sur parchemin, in-folio de 2l6 If. Archies mmiripules de Wontpellier, AA 1).

Summaire dn mème, par le $x^{r}$.Ioflie. clressé en 1676 , in-folio de 4(i ti. et:3:27 p. Iflome. A. 2 .

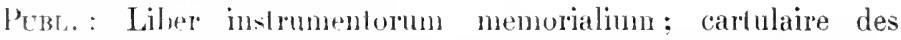
Grillens de Monlpellier. publ. par la Sociélé archéologique de Montpellier [par A. Germain. arec introduction de C. Cihabanean]. Montpellier. IIartel. 1884-1886: in-t" de [xn-]Ixx-vin-850-rin p. el pl.

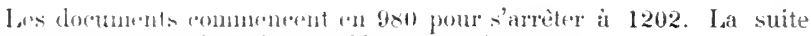
du rerueil a fail lobjet de lat publiention suivante:

2575. - Púbr. : Le cartulaire momlpellièrain des rois d'Aragron et des rois de Majorque seinnens de Munlpellier, d'Ammelas, etc., par J. Berthelé. Montpellier. impr. Serre el Rommégrous, 1904; in-4*, de p. 3:29 a $(i l: 2$ avec $p l$. [Arehives de la ville de MLontpellier ; Inven-

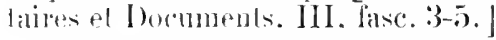

Lat publication th Ifemerial des Xoblen, entrepriste par A. Montel

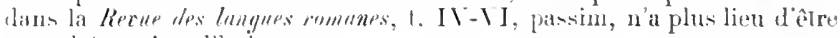
ronsultere anjomel'luai.

\section{Montpellier. - Iniversiti.}

257t. - Privilenda Lniversitatis medica Monspeliensis; ms. du XVI siecle, sm parehemin et papier, in-folio de xiv-178-v fl.

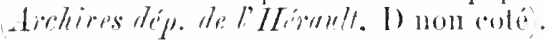

2577. - Privilenere slaluls de la Faculte de Nédecine de Montpellier;

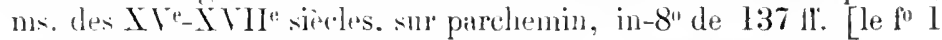
manque] Archices de la Fuculté de médecine de Montpellier).

2578. - Cartulaire de la Faculté de medecine: ms. du XIX siècle. composé par A. (iermain $1180-1815)$. en 3 rol. in- $4^{\circ}$ de $929 \mathrm{ff}$ à parrinalion conlinue. avec lable cilnonologique an délun (Biblioth. de lu rille de lontprellier, nss. 10:3-105.

257!). - Cimtulaire de la Faculté de droit de Montpellier, on Liber reclormm: ms. dn XVe siècle avec additions postériemres, sur parchemin. in 4" de l:39 1r. (Biblinth. de l'Université de Montpellier).

Copie du prérédent. ms. lu XVII siécle, sur papier, in-folio de 370 H'. (Arohices dipn. de l'Héruult, I) non colé.

(if. J. Castelnau, Notice sur le "Liber rectorum " (Mémoires de la Socisté arehínloyique de .lontpellier, II, 1850, p. 55-88). 
Autre transcription du mème augmentée. par A. Germain (1:3391723 : ms. du XIX" siècle, de 35t ti. Biblinth. de l" ville de Montpellier, ms. 11\%.

2580. - 1'ubl. Cartulaire de l'Cniversite de Montpellier: I (L1811400). [par A. Germain]. Montpellier. Ricard frères. 1890: in-4" de $[\mathrm{VI}-] \operatorname{xxxix}-760 \mathrm{p}$. et pl.

Montpellier. - Ville.

2581. - Grand Thalamus ou cartulaire municipal de Montpellier ; ms. des XIII ${ }^{e} \mathrm{XVII}^{\mathrm{e}}$ siècles, sur papier, contenant des actes de la fin du XII siècle à $16 \% 5$, en 2 vol. in-folio Archives municipules de Monipellier, tit 5 .

Sommaire du Grand Thalamns. par le s Jothre. dressé en 1676. in-folio de 33 ff., 527 et 140 pages Archices imulacipales de Montpellier, At 6).

Le petit Thalamus, contenant les coutunits et les reglements de l'administration municipale, ne saurait ètre comsideré comme un véri. table cartulaire.

2582. - Livre noir on cartulaire municipal de Montpellier: ms. du XIII siècle. sur parchemin, contenant des actes lle 1204 a 1:247,

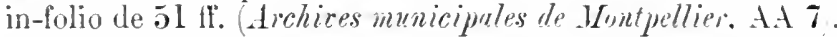

Sommaire du Livre noir. dressé an XVIle siecle. sur papier. in-foliu de $10 \mathrm{tt}$. et 57 pares (Archices municipules de Montpellier Ad 8 .

2583. - Cartulaire dit « Liher consnetudinum Miontispessulani » : orì perdu.

Fragment d'une copie du précédent, faite au XIII siècle, sur parchemin. in-folio de $19 \mathrm{ff}$. a 2 col. (Archires antirianles. J 339. n" ${ }^{\prime \prime}: 3$.

Cf. Teulet, Treisor des Chartes, II, p. 2:2, 3111, 648, ete.

2584. - Sommaires. tahles el extrails des principaux cartulaires des archives municipales de llontpellier: recueil compusé par J.-J. Desmazes, sur papier. en 2 vol. in-4" de 37 3 et $307 \mathrm{fl}$. Billioth. de la Sraciété archéndrigique de .Montpellier, m.. 17,.

2585. - Recueil de titres relatifs à la ville de Muntpellier. cupiés au XVII siècle Biblinth. mationale. coll. Batuze. vol. XXVII.

Montréal. - Église collégiale saint-Tincent (dior. do Carl(assonnic).

2586. - Recueil de titres relatifs à la cullériale de IIontréal : ms. du XVII siècle. contenant des documents de l:264 a 1542 . in-fulio sur papier Biblioth. nutionole, coll. Woat. vol. il. 11. 537-59:2. 
Montréal. - Ville.

2587. - Pubu. : Les contumes, lihertés et franchises de Montréal

(Aude) d'après un manuscrit inédit de 1321, par l'abbé Sabarthès

(Mémuires de la Suciétr des sciences et arts de Carcassonne, VIII, I896. pp. :3-75).

1)'apress un cahier (en mauvais état) de $45 \mathrm{ff}$. in $-1^{1}$.

Montreuil-Bellay. - Église collègiale (dioc. de Poitiers). 2588. - Cartulaire du Chapitre de Montreuil-Bellay ; ms. du XVIII siècle, sur papier, contenant des actes depuis le milieu du $\mathrm{XI}^{e}$ siècle jusqu en 170:3, in-folio de 76 pages (Archives dép. de Maine-et-Loire, (inoll coté).

Montreuil-sous-Bois. - Village pris de Paris.

2589. - Cartulaire de Montreuil-sous-Bois, dép' de l'abbaye de Saint-

Victor; ms. du XIVe siècle. sur papier, contenint des actes de II32

i 1396, in-to de $16 \mathrm{ti}$. (Archioes nationales, S 2139).

Montreuil-sur-Mer. - Abbaye de Saint-Sanve (dioc. ('Amiens).

2590. - Cartulaire de labbaye de Simt-Sanve de Montreuil, en 2 vol. in-folio, sur parchemin ; orig. perdu.

Extraits et analyses du précédent, laits au XVIIIe siècle [vers $1770]$ par un religienx : recopiés à leur tour par le marquis Le Ver (Biblioth. de .M. de Calonne. au (hàtean de Romont, Pas-de-Calais).

348 chartes des années 1040-1535. - M. de Belleval en avait fait lactuisition à laniable avimf la vente Le Ver ( $n^{\circ} 125$ du (atalogue). Extraits laits par l)om Estienuot an $\mathrm{XVII}^{\mathrm{e}}$ siècle (Biblioth. de CArsenal a Paris. ms. 465:2, fl. 63-69).

2591. - Recueil de tilres relatifs à l'abbaye de Saint-Sauve de Wontrenil, fait an XVIJ siècle (Biblioth. nutionale, ms. latin 12695, 17. $: 24:-2066$.

lar ce même volune, fo 236 , on voit que 1)om Estiennot a connu le cartulaire original dont il a extrait un diplome du roi Henri Ier.

Montreuil-sur-Mer. - Hôtel-Dien.

592. - Cartulaire-censier de l'Hôtel-Dien de Montreuil, fait par Guillaume Poullain, administrateur, en 1477, sur parchemin, in-folio, de 18.5 IT. et fig. Archives hospitalières de Montreuil-sur-Mer.

Extrait fail an XVII siècle (Biblioth. de l'Arsenal ì Paris, ms. 465.2. (11. $59-(60)$.

Copie du précédent, faite par le marquis Le Ver en 1806, in-folio.

Porfinit l $n^{0}$ 121 dans le catalogue de lat bibliothèque dn marquis I.e Ver 1866$)$ - Cif. Wémsires de la Commission dep. des momuments der Ptis-de-Cinlais, II, p. 425-150. 
Montreuil-sur-Mer. - Maladrerir.

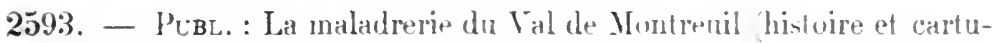
laire). par le Ce $A$. de Loisne. Abbeville. Lafusis. 19003: in-8" de $137 \mathrm{p}$.

Montreuil-sur-Mer. - Ville.

2594. - Cartnlaire de lécherinare de Montrenil-nur-IIer": nus, de la fin du $\mathrm{XVI}^{\mathrm{e}}$ siècle. contenant ime traluclion parfois incorrecte des

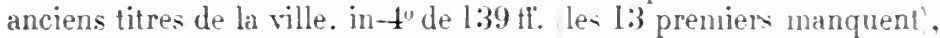
orig. égaré [appartenant autrefois à M. Henneyruer. lihliophile de Montreuil-sur-Mer. décéclé en 187:2].

Copie partielle, moderne Biblioth. de . H. Buron de Culonne, an

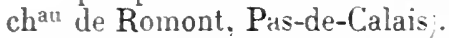

PLBL. d'après la copiè : Le cartulaire de la ville de Montreuilsur-Mer. par Georires de Lhomel. Alberille. Lalfosse, 1904: in-4 de III $-408 \mathrm{p}$.

Exlraits faits an XVIle siècle drchices dop. de la Stimine, G 621).

2595. - Fragment d'un cartulaire municipal de Iontreuil-sur-Mer; ms. du XIVe siècle. sur parchemin. contenant 14 chartes des années 1209 a 137t. 3 tf. in-folio cotés anciennement xxxur. $x L$ et XLI (Biblioth. nationule, ms. latin 1il46:.

Montrieux. - Chartreuse (dioc. de Marseille).

2596. - Cartulaire de la chartrense de Muntrienx: ms. dn XIII sieccle. sur parchemin, arec additions postérieures. contenant 250 actes de 1123 a 1565 . in-4" de $94 \mathrm{fl}$. (Archices dép. du Int. H non coté).

Analyse moderne. par $Y$. Teisier Biblinth. nutionale. ms. nouv. acq. latines 1156 .

2597. - Autre. incomplet du début et de la fin. sur papier. contenant 45 actes de 1248 i 13220 . in-4" de $146 \mathrm{tf}$. Archires dép. du I'ar. H non coté.

Mont-Rohaut. - Prieuré. - Voy. Le Mowl-AINT-MiCheL.

Montroland. - Prieur'. - Voy. Joche.

Montsaujeon (Léger de), écuyer.

2598. - Cartulaire de Léger de Montsarjeon. seimnenr de Lon rpré; ms. du XVIe siècle. sur papier. in-4" de 45 fi. (Arehices líp. de l Aube, E 873 .

Montsaunès. - Commanderie de Templiers (dior: de Com minges).

2599. - Cartulaire des Templiers de Iontsaunèn: ms. du XIII siècle, sur parchemin. incomplet de la fin. in $4^{0}$ de $\cdot 2 \cdot 2$ tf.. contenant des actes de 1156 à 1190 Archices dep. de lu Hunte-Garmine. H non cote, 
Morangis. - Village près de Paris.

2600. - Cartulaire de Morangis. de Marly. de Gif et de Limonrs, dép. de labbaye de St-Viclor de Paris: ms. du XIVe siècle, sur papier, contenant des acles de $11 \%$ environ à 1310 , $1 n-4^{\circ}$ de $27 \mathrm{fr}$. (Archives nutionules, S $2145, n^{0} 5$ ).

Morbihan. - Département.

2601. - Punc. Cartulaire général du Morlihlau: Recueil de documents anthentiques pour servir a l'listoire des pays qui forment ce déparlement : cunve posthmme de Louis Rosenzweig. Tome $\mathrm{l}^{\mathrm{er}}$. Tannes, Lafolye, 1895 : in-8" [10-] $\mathrm{x}-444$ p. Extr. de la Revue historique de louest.)

Ce vohume comprend les docunents des années 814 à 1331 . On y trouve les pièces relative's aux abbayes et prienrés compris dans letentue du départentent.

Mores. - Abbaye (dioc, de Langres).

2602. - Publ. Chartes de l'abbaye de Mores, par l'ahbé Ch. Lalore (Memoires de la Société académique de l'Aube, XXXVII, p. :-112), et il part: Troyes. 1873; in-8" de 109 p.

Recolpil factices de 139 chartus des XII"-XIVe siècles, d'après une ropie faite au XVII par le P. Vignier (Biblioth. nutionale, ms. français 5995). Sur le cartulaire original perdu, voir aussi coll. Baluze, vol. LI, pp. $227-2: 30$.

Morienval. - Abbayo (dioc. de Sinlis).

260:3. - Cartulaire de lablubaye de Norienval: ms. laté de 1:323, de 2!) $\mathrm{fl}$., sur parrelsemin ; wrion. perdu.

Copie chu précrident; ns. de 1764. snr papier, contenant des docunents des $\mathrm{X}^{\mathrm{c}}-\mathrm{XII1} \mathrm{l}^{\mathrm{e}}$ siècles, in-40 de xir-91 II. (Biblioth. nationale, mis. latin 9987 .

Publ. : Cartnlaire de Morienval, par J. Peigne-1)elaconrt. [Senlis, Payen], 1879; in-fo de xc-76 p., sans litre ni préface. [Comité archéologrique de Senlis.]

J appendim (1). 71-76) contiont 22 chartes relatives à labbaye de l.iru-Restauré (1138-1298), dapris le cartulaire cité plus haut sous le $1^{\circ} 21510$. - On trouve dautres ropies dans le vol. LXXIY de la coll. lialuze, pp. 184-206. Iom (irenier a du consulter un autre cartulaire de. Moritenvil.

Morigny. - Abbaye (dioc. de Sens).

2604. - Cartulaire de l'ablaye de Morigny; ms. du XIII siècle, sur parchenin, in-4" de 144 II. (Biblioth. nationale, ms. latin 5648).

Copie dı mène. faite au XVII sièele pour Colbert, in-40 de 280 il". (Biblioth. nationale, ms. latin 5439 ).

Extraits Biblioth. nationale. ms. latin 17049, pp. 95-114; ms. français 15504. II. 158-162: nouv. acq. frangaises 7433, If. 206$207 ;$ - coll. Baluze, vol. LXXIV, If. 184-206). 


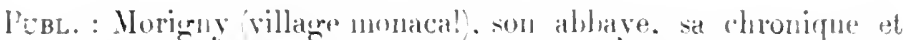
son cartulatre. par li. Meniull. Paris. Anhry. 1867 : in-8" de xxrT$212-209 \mathrm{p}$.

116 pieres des années $11146-1.42$.

2605. - Recueil de quelques titres relalifs a lablatye de Worigny, formé par le prienr de Iondonville, sur papier Biblinth. nutionnile, ms. français 241333 . pp. 49.5-503).

Morimont. - Abbaye (dioc. de Langres).

2606. - Cartulaire de l'ahbaye de Morimont.

On mossure qüil existe un martulairt ancirn de Jorinont dan- une bihliothène particuliere, à Burbonne-He-Bains (Hantw-Marns). IDe Who amples renseignements mantyont.

Morlaas. - Pricuré de Sainte-Foi (dior. d'Oloron).

2607. - Cartulaire de Ste-Foi de Morlass: ms. du XII siecle sauf une charte', sur parchenin, in-4" de $11 \mathrm{Hr}$. 'Biblighth. nationalp. ms. latin 10936).

Publ. Carmaire de Sannte-Foi de Morlans. par Léon Cadier (Bulletin de la Saciété des sciences, lettres at uits de Pun. 2uérie. XIll. p. 289-365, et à part : l'an. 1884: in-8" de xxxril-81 p.

Morley-en-Barrois. - Prérôtẻ.

2608. - Recneil de titres relatifs à la prévité de Morley : ms. de la fin du XVI siècle. formé par Thierry Alix. sur papier. contenant des lexter de 1188 a 1586 . infollio de 80 it. Archires dép. de .Yevithr-et-..Yoselle. B :3it.

Mormant. - Commanderio, à Lellonds (lioc. dra Lingres). 2609. - Cartulaire de la commanderie de Mormant en Champanne: ms. daté de 1506. sur parchemin. in-4" de $99 \mathrm{tr}$. Arehires dép. de la Cốr-r Or, H non cotée.

Mortagne. - Ville et :'àtollonie.

2610. - Cartulaire de Mortagne: ms. du XVI siècle. m pipier, contenant des actes de 1546 a 1562 collationnes par le wreffier Van Trap. in-4" de 45 patres Archices dre mynume de Belgiqup. à Bruxelles. $n^{0} 392$ dn fonds des cartulaires.

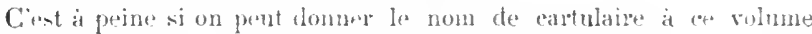
yui contient surtout des extraito d'un respistre de justice.

Morteau. - Ville et priemri.

2611. - Cartulaire du Val de Morteau on «livre noir ». contenant des titres de 1188 i l.514: m\%. de la fin du $\mathrm{XVe}$ siècle. avec quelques additions postérieures. sur papier relié avec des ais de hois reconverts 
de cuir noir saufré, in-folio de 191 if. (Archives municipales de Inortern, Iloubs).

En tête du fo 192 on lit: "T. surplus du préseut livre a été perdu par linvasion des suédois (1639), ayant du depuis demeuré plusieurs anders en suissen"

Mortemer. - Lbbaye (dioc. de Rouen).

2612. - Cartuline de l'abbaye de Nortemer; ms. de la fin du $\mathrm{XII}^{\mathrm{e}}$ siècle. sur parchemin. in-4" de $113 \mathrm{fr}$. (Biblioth. nationale, ms. latin 18:369.

Axal. : Folice sur le carlulaire de Mortemer, par Ch. T. Langlois (Bulletin de la Socirté des Antiquaires de Normandie, XIII, 1885, pp. 94-1I8).

Mostuéjouls. - seigneurio an Rouergue.

2613. - Cartulaire de la seigneurie de Vostuéjouls; ms. du Xr'esiècle, contenant des artes des années 1264-1416, in-80 de $149 \mathrm{ff}$. dont les 3 premints manquent et les derniers sont en fort manvais état (Avchives nutionules. $Z^{2}=25.52^{\mathrm{bis}}$.

Moulins. - Abbaye (dioc. dr. Nimur).

2614. - Cartulaire de lablibaye de Ioulins: ms. du XVe siècle, sur papien el parchemin, conlenant des titres de 1224 i 1494 , in-folio

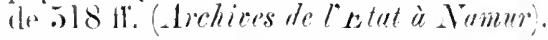

2615 . - Antre du X V'e siecle, de diverses mains; ms. sur papier, contenant des lilres de 1252: a 149:3, in-folio de 86 fr. (Archives de l' État is $Y$ (rimer).

Moustier. - Chapitre (dlioe. Ir Namur).

2616. - Carlulaire du Chapitre de Noustier ; ms. du XVII siècle, sur papier. contenant des titres de 1478 a 1646 , in-folio de 11 ó fr. Lrchices de lÉtut is Vemur).

Moutier-Saint-Jean. - Abbaye (dioc, de Langres).

261\%. - Cartuliare de lahluage de Réome ou Moutier-Sainl-Jean ; ms. des XVIIe-XVIII siècles, sur papier, contenant 100 acles des ammes 11.00 a 17.54, in-4" de 134 li." (Archives dép. de la Cóte-d"Or, H non coté).

Mouzon. - Abbaye (dioc. de Reims).

2618. - Cimbulaire de l'abhaye de Mouzon ; orig. perdu.

On le voit cité au Xirinte sièrle (Biblioth. nationale, mis. nour. acq. françaises 3407 , fo $312 \%$.

Mouzon. - Ville.

2619. - Cartulaire municipal dle Mouzon; ms. commencé en 1555 
par Ponce Habert, prochrear grénéral du roi. el contibura par son fils Jean et son petit-fils. Jacques. sll papier. in-f" de 17:3 11. [manquent

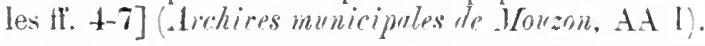

Axic. : Notice sur le cartulaire municipal de Monzon. par l'anl

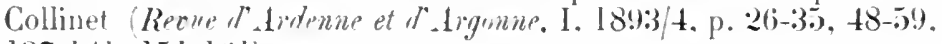
$137-1+1,151-161)$.

Dates axtrèmes: ar:3 acte faux it 16:32. - 1, manuserit est en assez mankais eitat.

Moyenmoutier. - Abbaye (dioc. de Tonl).

2620. - Cartulaire de l'abbaye de Muyenmoutier: ms. du XV $\mathrm{I}^{*}$ siècle. sur papier, contenant des actes des années 126il-lob66. in-folio de $173 \mathrm{ft}$. (Archiers dip. des Tisgyes. H 1!).

2621. - Autre du $\mathrm{XrIl}^{\mathrm{e}}$ siecte. sur papier. contenant des actes des années 1601-1616. in-folio de 1:24 p. drchices dép. des Trogges, $\mathrm{H} \mathrm{I} 9^{\text {his }}$.

\section{Moyvillers. - Tillage. - Vuy. Ll.LY-SALTtieorges.}

Mozac. - Abbayr (dio: llo (ilermont).

2622. - Cartulaire (?, ou "ancien live en parchemin de labbaye de Mozac, couvert de limes diarzent el d"ivoire»; origr. perdu.

Extrait fait de ce livre au XVII siècle, et contenant un acte de 1197 Bibliolle nutionale, ms. nux. acquisitions françaises 7455 , ff. $319-32 \cdot 2$.

2623. - Recueil de titres relalifs à l’abbaye de Mozac. formé au XVII

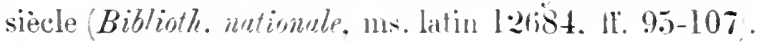

Mulhouse. - Ville.

2624. - Publ. : Carlulaire de Mulhouse, par X. Mussmann. Sirasbonror,

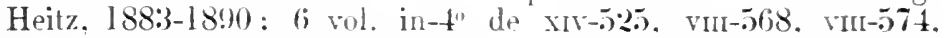
vIII-592. vili-596 et riII-75!) p.

Dates extremmes des dommenls publiés: 12:31-1707.

Muno. - Prienré (aliux. do Lieger).

2625. - Recueil de copies de titres du prieuré de Muno: ms. du XVII siècle. contenant des actes des années 1317-1676. sur papier, in-folio Biblioth. nutionale, coll. Lorraine, vol. 724. If. 89-96;.

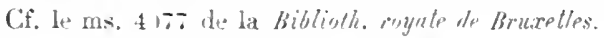

Münster. - Abbay dioc. de Bâle,

26:6. - Cartulaire de l'abbaye de Münster ou de Saint-Grémoire: ms. du XVII siecle, sur papier. contenant des actes de 1269 à 1602, in-4 $4^{0}$ le 32.5 ti. Lrohic des Oher-Elssss, in Colmar).

Münster. - Abbaye (dlioc. d. Trères). - Voy. Luxenbourg. 
Murat. - Ville.

2627. - Recueil des privilegres de la ville de Mural; ms. du XVI॰ siècle. sur papier. contenant des actes de $13660^{\circ}$ a 1469 , in-folio (Biblioth. nutionule, ms. nouv. acq. françaises 745. fi. 197-22:2).

Murbach. - Abbaye (lioc. de Bàle). 2628. - « Cartnlarium vetus Mnrbacense »; orig. perdu.

Wist cité et utilisé par schœpflin dans son "Asatia diplomatica".

2629. - Cirtulaire de labbaye de Murbach: ms. du XVe siecle, sur papier. contenant des titres des années $727-1382$. in- $4^{0}$ de 62 tf. Archio des Ober-Elsass. in Colmar).

2630. - Antre dit «Vidimis Murhachischer Privileurien», du XVe siècle $[1476]$. sur parchemin. in- $4^{\prime \prime}$ de 21 ff. Archir des OberElsuss, in Colmar.

Denx autres volumes in-to contiennent la traduction en langue allemander des textes latins contemus dans le prédent cartulaire, avec l'adhlition d'un diplome imperial de 1480.

2631. - Autre du XVI siècle. sur papier. contenant des document's des années 727 à 1523 , in-folio de 244 ff. Archio des Ober-Elsuss, in Colmar .

2632. - Bullaire de lahilaye de Murbach: ms. du XVIJe siècle, sur papier. contenint des textes de 1139 i 1570 . in-folio de $152 \mathrm{ff}$. Arehio des Ober-Elsuss, in Colmar".

26:33. - Autre cartulaire du XVII e siècle, sur papier, contenant des actes de 959 i 171:3. in-folio de 200 ff. Lrelic des Ober-Elsass, in Colnirir.

Contint les textes relatifs's a la réunion des abbayes de Murbach et d.: Istre?

Mureau. - Abbaye (dioce de Toul).

2634. - Cartulaire de liablaye de Murean: ms. du XVII siècle, sur papier, en 2 vol. in-folio de $877 \mathrm{fr}$. (Archices dip. des Vosges, H 3I).

l’ubl. : Quelques extrails imprimés dans les Documents rares ou inédits concemunt lihistrive des Vosy's, II (1869) et ss.. passin.

Najac. - Ville.

2635. - Recueil de tilres relatifs a la ville de Najac; ms. du XVII siècle. contenimt des documents de 125.5 à 1500 Biblioth. nutionale, coll. Woal. vol. 146, fi. 1-112,

Cif. lanalys qui en a éte clonnée dans le Ciubrnet historique, $\mathrm{X} \mathrm{V}$, 1×69. p. 1515-15.2.

Namur. - Chapitre Notre-Dame.

26:36. - Cirtulatre dn Chapitre Notre-I)ame de Namur ou «Grand 
Papier »: ms. de la fin du XIVe siècle. arec atditions putérieures. contenant des documents de 12:31 i 1426. in-folio de 6:3 If. 1\%chires de Tlitut à Tumur".

Publ. partiellement : Monmments pour servir à l'histoire des provinces de Namur, de Hainat et de Luxemboure. par le laron de Reiflenherg: I Bruxelles. 1844. in- $4^{\prime \prime}$. pp. 3-81.

Namur. - Chapitre Saint-Aubain.

2637. - Cartulaire du Chapitre de Saint-Auhain de Sanur: 11-. du $\mathrm{XV}^{\mathrm{e}}$ siècle. sur papier. contenant des documents de 1:202 is $1: 394$. in-folio de $80 \mathrm{ff}$. 'Archices de l"Étut à Numur".

Pcbl.: Iocuments extraits du cartulaire du Chapitre de SaintAubain de Namur, par Jos. Barljer Anulectes pour servir is listoire ecclésiustique de lu Belgique. V. 1868. p. 198-204 et 480-491: VI, 1869. p. 182-203: VIII. 1870, p. 465-466: IX. 1872. p. 44.7-50l ; et II. 1874. p. 99-128,

2638. - Antre des XVe-XVIe siècles. sur papier. cuntenant des documents de 1159 i 1306. in-4" de 41 ff. Archices de TEtut is Tamur!

Namur. - Comté.

2639. - Cartulaire du comté de Namur: ms. du Mive siècle. sur parchemin. in-t" Archires du roynume de Belgique. it Bruxelle-.

S.e trouve joint au cartulaire de Flandro (Gui de Danpirre.' que nous arons inscrit plus haut sous le n० 1:32 documents transcrits sont $1262-1284$.

2640. - Cartnlaire du comté de Tamur : ms. de 1770. contenant des copies faites par Godefror d'actes des années 1234-1299, sur papier. in-4" de $219 \mathrm{ff}$. (Archices du imyume de Belgique, à Bruxelles).

2641. - Publ. : Monuments pour servir à lhistoire des provinces de Namur. de Hainant te de Luxembourg. par le baron de Reilfenterg. I (Bruxelles, 1844, in-4\%). pp. 83-308.

D'aprè: les deux recueils cité:.

2642. - Cartulaire du conte de Namur: ms. du XIVe diecle. sur parchemin. contenant des actes de 1:209 à 1:321. in-4" de :i: If. Archires dép. de Wist. B 1591,

Copie du précédent. par Godefroy. en 1773, arec table tinale. sur papier. in-4" de 238 If. Biblioth. de lu cille de Lille. fond- Goulefror, no5.

2643. - Recueil des titres relatifs au comté de Namur: ms. du XrIHe siècle. contenant des titres de 1185 a 147 . sur papier. 2 vol. in-folio (Archices royales de lu Hrye, Papier Gérard. n"s 82 et 8:3 . 
Namur. - Convent des Annonciades.

2641. - Cartulaire des Annonciades de Namur; ms. du XVII ${ }^{\theta}$ siècle, sur parchemin, contenant des titres de 1517 à 1609 , in- $4^{0}$ de $18 \mathrm{ff}$. (Arhives de l'stut à Nanur).

Namur. - Courent des Bénédictines do la Paix-Notre-Dame. 2645. - Carmlaire des Bénédictines de Namur; ms. de 1647 avec additions postérieures, sur papier, in-t" de 116 lf. (Archives de l'État à lemm.

Publ. Documents relatifs à la fondation du monastère des Bénéslictines de la l'aix-Notre-Dame à Namur, par Jos. Barbier Analectes pour serrir à lhistoire ecclisinstique de la Belgique, XIV, 187\%. p. $105-160$ ).

Dates extrêmes: 1613-1742.

Namur. - Courent des Carmes.

2646. - Cimlulaire des Carmes de Sammu ms. du XVIIJ siècle [1780]. sur papier, contenant des actes de 1212 a 1741, in-folio de 3:2 ti. Arelives de l' litut is . Tamur).

Namur. - Evềlhé.

2647. - Cirrtulaire de l'évèché de Namur" ms. du XVII siècle, sur papier, contenant des documents de 1304 à 1634 , in- $4^{\prime \prime}$ de 81 pages Arhires de listat is Nimur).

Namur. - Grant hôpital.

2648. - Ciarulaire on " mémorial » du grrand hòpital de Tamur; ms. du $\mathrm{XVI}^{\mathrm{e}}$ siècle, sur papier. contenant des acles des années 15:2815̈ti. in-folio de $106 \mathrm{II}$. Archioes de l' Ėtat ì Namur).

Namur. - Ville.

2649. - l'ris., : Cartulaire de la ville de Namur, par Jules Borgnet et S. Bormans. Nimur, Wesmael, 187l-1878; 3 vol. in-8" de GGXvili-220, IV-4033 ef $\mathrm{N}-3799 \mathrm{p}$.

Nancy. - Châtellenis.

2650. - Recueil de titres relatifs à là chàtellenie de Nancy; ms. de la fin du XVI siècle, formé par Thierry Alix, sur papier, contenant les textes de [2:24 a 1591 , infolio de $4 \mathrm{I} 1 \mathrm{ff}$. (Archives dép. de Meurthe-et-1Yoselle, B :375).

2650 $0^{\text {bi. }}$. Mème recueil un pen plus complet (1189-1605), fait au XVIIesiècle, sur papier, in-folio de $424 \mathrm{ff}$. (Archives dép. de Meurtheet-.Moselle, B 376).

Nancy. - Commandrrie de Saint-Jean du Vieil-Aitre. 2651. - Cartulaire de Saint-Jean du Vieil-Aitre à Nancy; ms. du 
XVII siècle, sur papier, contenant des pièces des années I1.58-16.59, in-folio de I30 fi. (.Lrchives dép. de Meur'he-et-Moselle, H 304:3,

2652. - Antre [incomplet] du XVIJ siècle, sur papier. contenant des pièces des années 1244-1635, in-folio de 2:3 1f. (Archires dip. de Meurthe-et-Moselle. H 3044 .

Extraits faits en Iti81 Biblinth. nutionale, collection Lurraine, vol. 715, ti. $8-11$ ).

Nancy. - Couvent des Dominicains.

2653. - Cartulaire des Dominicains de Nancy ; ms. du XVIII siecle, contenant des actes des années I647-1759. sur papier. in-fulio de $3 \mathrm{I}$ if. (Archices dép. de Meurthe-et-.Moselle, H 816;.

Nancy. - Église Saint-Georges.

2654. - Cartulaire de l’église Saint-Georges de Nancy: ms. du XIVe siècle [I35i] avec additions du XVe, sur parchemin. in $-4^{\circ}$ de $73 \mathrm{fl}$. [avec quelques lacunes] (Biblioth. do la ville de . Vancy. m- 605).

Nancy. - Hôpital Saint-Charles.

2655. - Cartulaire de lihôpital Saint-Charles de Nancy : ms. du XVIII siècle. sur papier, contenant des titres de $160^{2} 6$ is 1702 , in-folio de $193 \mathrm{tf}$. Archires hospitalieres de Nancy. II A I,

2656. - Autre cartulaire contenant des titres de 1736 à 1786. in-folio de I0I ff., sur papier (Atrehices hospitulières de Vancy, II A 3.

Nancy. - Hôpital Saint-Jean-de-Dieu.

2657. - Cartulaire de l'hòpital Saint-Jean-de-Dieu de Nancy ; ms. du XVIII siècle, sur papier, contenant des titres de I750 à I 766 , in-folio de 96 t1. (Archices hospitalières de Nuncy. III A 1).

Nancy. - Hospice de Saint-Joseph ou des Prẻmontrẻs.

2658. - Cartulaire de la maison de Saint-Joseph de Nancy : ms. daté de 1787, sur papier, in-folio de $146 \mathrm{fl}$. Lichices dép. Ap . Yeurthe-etMoselle, H l:6:3.

Nancy. - Hospice des Enlants trouvés.

2659. - Cartulaire de l'hospice des Enfants trouvés de Nancy : ms. du XVIII siecle. sur papier, contenant des titres de I77t à 1791, in-folio de $96 \mathrm{ff}$. (Archices hospitalières de Noncy, VA I).

Nancy. - Missions royales ou Maison des Jésuites.

2660. - Cartulaire de la maison des Missions royales de Nancy : ms. du XVIII siècle. sur papier, in-folio de I:200 p. (Bibliuth. di Gival Séminuire de Vuncy, ms. I48. 
Nancy. - Prieuré de Notre-l)ane.

2661. - P'́bl.: Documents sur le prieuré Notre-Dame de Nancy recueillis aux Archives départementales de la Côte-d'Or, par Chr. Pfister (Anuales de l'Est. XI, pp. 77-122), et a part: Nancy, BergerLevraulı. 1897 ; in-8" de $49 \mathrm{p}$.

Dates extrènés: 1120 env. à 1543.

Nancy. - Ville.

266:2. - Castulaire municipal de Nancy ; ms. des XVIe-XVII siècles, sur papier, contenant des actes des années I497-1623, in-folio de $313 \mathrm{fl}$. Archives municipales de Vancy, AA 3 .

Cf. Les archives de Xancy, par H. Lepage, I (1865), p. 232-236.

Nant. - Abbaye (dioc. de Rodez).

2663. - Recueil de litres relatifs à l'abbaye de Nant; ms. du XVIIo sierle. contenint des documents de II3ö à I 427 (Biblioth. nutionale, coll. Doil. vol. I49, fir. $2(4)+2: 36$.

Nanterre. - Courent des Génovélains (dioc. de Paris). 2664. - Carlulaire des Génovéfains de Nanterre; ms. du XrII ${ }^{\mathrm{a}}$ siècle, sur papier. in- $4^{0}$ de $180 \mathrm{fl}$. (Archires nutionales, LL 148).

Nantes. - Couvent des Minimes.

2665. - Cartulaire dn convent des Minimes de Nantes; ms. du XVII siecle, sur parchemin, contenant des titres des années 1491160:3. in-folio de 4.2 II". (Lrchives dép. de ln Loire-Inférienre, H 320).

Nantes. - Évèrhé.

26666. - Cartulinire de l'évêché de Nantes: nus. du XVe siècle, sur parchemin ; orige. perclu.

On ton trour des mentions dans certains documents eonservés aux dichires dip. de le Lotire-Inferiente.

2667. - Recueil des droits et privilèges de l'èvêché de Siantes; ms. du XVIII" siecle, sur parchemin et papier. contenant des actes de I247 ¿̀ I764. in-folio de 110 et 500 If. (Archices dép. de In Loire-Inférieure, G I).

Nantes. - Prieure de Notre-Lame.

266i8. - Recueil de titres relatifs au prieuré de Notre-Dane de Nantes; nns. dn XVIJ siècle, sur papier, contenant des pièces des années I074 i 1161 , in-40 (Archices dép. de la Loire-Inférieure, H 154).

Ce sont de simplus extraits du cartulaire de Sainte-Croix de ( )uimperlé (roir ce nom).

Nantes. - Ville.

2669. - P'cbl. : Privilèges accordés par les rois anx maires, échevins et haliblants de la ville de Nantes. Nantes, 1734, in-8". 
2670. - Cartulaire des privilines de la ville de Nantes: nis, sur parchemin de 125 if., du $\mathrm{MVI}^{\mathrm{e}}$ siecte ; perdn.

2671. - Autre dit « papier rouge », anssi perdu.

2672. - Cartulaire des privilèges et franchists de la ville de Nantes; ms. du X'V" siècle. sur panchemin. de $97 \mathrm{tr}$. in-4" (tichices dép. do la Loire-Inférieure, E I.38.

2673. - Pubr. : Privilènes de la ville de Nantes, par S. de la Nicollière-Teijeiro. Nantes. Société des Billiophiles bretons. 1883, in-t' de [II-] xxir-2ll p. [Archices de Bretague, I.]

Nanteuil-en-Vallée. - Abbaye (dioc de Poitiers).

2674. - Cartulaire de l'abbaye de Kanteuil-en-Vallée orił. perdu.

Extraits faits au XVIle siècle par André I)u Chesne (Biblioth. nutionale, ms. nuw. acq. françaises 7433. H1. 20-25) : autres par Galland (Id $m$, ms. Irançais l6188, fo 196).

Nanteuil-le-Haudouin. - Prieuré (lioc. le Meaux).

2675. - Cartulaire du prieure de Santenil-le-Haudonin; ms. des XIVe-XVe siècles, sur papier. contenant des actes de 1097 a 1405. in-40 de $36 \mathrm{tl}$. (Archives dép. He lOise. H non cutë).

Nantua. - Abbaye (dioc. de Lyon).

2676. - Cartulaire de St-Pierre de Nantua : ms. de l604. sur papier, contenant des documents depuis le VII e siècle, in- $\mathrm{S}^{\prime \prime}$ de $66^{\circ} \mathrm{tt}$. (Archives dép. de l'Ain, H 50 .

Perb. : La légende de Saint-Amand. l'abbaye de Santua el la ville d'Orindinse; petit cartulaire de Nantua. par J. Brossard. Bourgr, Authier. 1889 ; in-8" de 104 p. Extr. des Annules de l" Soriété d'érulation de l'Ain. XXI. p. 319. et XXII, p. 161).

Nantua. - Eggliso.

2677. - Cartulaire de l'église de Nantua : origr. perdu.

A été utilisé par fruichenon, Histuire de Bresse (1650), $4^{\circ}$ partic, pp. $212-215$.

Naples. - Maison d'Anjou.

2678. - Pubr. : Sagrorio di Codice diplomatico furmato sulle antiche scritture dell Archivio di Stato di Napoli. par C. Minieri Riccio. Napoli, Furchheim. 1878-1883; 4 rol. in- 8 ".

Recueil factice de documents des annés soo à 1434 .

Naples. - Royaume.

2679. - Cartulaire des titres par "lesquels apert le bon droict que tres chrestien roy de France Charles VIII de ce nom a au rovaulme 
de Sicile »; ms. dn $\mathrm{XV}^{\text {r }}$ siecle [1494], éril et collationné par Ginillaume de Sailly. clerc en la Chambre des Comples, sur papier, in-folio de 26 11. (British .Yusrum, ms. Harleian 902, t1. 108$13: 3$.

Voy, anssi : Sulles.

Narbonne. - Arelıerèché.

2680. - Livre rouge de l'archevèché de Narbonne; orig. perdu.

Extraits dn livre rouge, faits an XVIJ siècle (Biblioth. nationale, coll. Duchesne, vol. LXXII, fi. 94-95; coll. Balıze, vol. CCCLXXIV, pp. 445-45. ; ms. latin 12778, [0 242 ).

Le mème volume do la coll. Baluze renferme, de la page 1 à la page 4.41, la transcription le beaucoup da bulles et pièces très anciennes (carolingienne's en partien) relative's à larchevêché de Narbonne, d'après les originaux constrves dans les archives an XVIIe siècle.

2681. - Fragment de cirtulaire de l'archevèché de Narbonne; ms. du XIle siècle, sur parchemin, in-4" (Biblioth. nationale, ms. latin $11015,11.5-19)$.

Co eartulaire, fait par ordre de l'ardurégue Pirre d'Anduze en $11 \mathrm{int}$, comptait $157 \mathrm{ff}$. quand il était complet.

Fxtrats du prééédent, faits an XVIJe siècle (Biblioth. nationale, coll. Balıze. vol. LXXX11, 11. 52, 169, 172, 175, 181 et 188).

11 ne peut convenir didentifier l* present volume avec le "livre rompre" (Quant an "livre vert " conservé aux Arclsives de l'Aude (G 2) ot public par l'aul laturent en 1886 , c'est un livere des fiefs et nullement un eartulair".

Narbonne. - Église cathèdrale Saint-Just.

268:3. - Cartulaire de l'église St-.Just de Narbonne; orig. perdu.

Extraits faits au XVII siècle par Itom Estiennot (Biblioth. untionulp. ms. latin 122780, p. 111-116 et 120-122).

2684. - Recneil de pièces sur l'écolise de Narbonne, fait au XVIJe siècle (Biblinth. nutionule, coll. Baluze, vol. CCLXXVI, fr. 24-36).

Documents depuis l'an 1030 .

Narbonne. - Église collégiale Saint-Paul.

2685. - Ciurtulaire de St-Panl de Narbonne; orig. perdu.

Extraits faits an XVII" siècle (Biblioth. nationale, coll. Baluze, vol. LXXXII, p. 124; 111. latin 12760, p. 469 ; ms. latin 12761, p. 334).

Narbonne. - Vicomtes.

2686. - Cintulaire des vicomtes de Xarhonne: ms. du XVe siècle, sur papier, in-fl" de 24 tr. (Biblioth. nationale, ms. latin 9998). 
Narbonne. - Ville.

2687. - Cartulaire municipal de Yarbonne ou Premier Thalamus; ms. sur parchemin, contenant des actes de 1148 à $156 \%$, in-folio de 387 ff. (Archices municipules de Verbonne, AA 99).

Une copie moderne est conservée sous la cote A 100.

2688. - Deuxième Thalamus ; ms. sur parchemin. contenant des actes de 1148 à 1503 , in-folio de $182 \mathrm{ff}$. (Archires municipales de Tarbonne, AA 101 ).

Une copit moderne est conservée sous la cote AA 102.

2689. - Troisieme Thalamms ; ms, sur parchemin. contenant des actes de 1153 an $\mathrm{XVI}^{\mathrm{e}}$ siècle. in-folio de $13 \mathrm{ff}$. Archixes municipales de Narbonne, At 103.

2690. - Quatrième Thalamus; ms. sur parchemin. contenant des actes de 1126 au $\mathrm{XVI}^{\mathrm{e}}$ siècle. in-folio de $203 \mathrm{fr}$. Archires municipales de Narbonice, At 104).

2691. - Cinquième Thalamus ; ms. sur parchemin. contenant des actes de 1146 au XVI ${ }^{e}$ siècle, in-folio de 11 ŏ $\mathrm{fr}$. Archives muniripales de Narbonne, At 105).

2692. - Sixième Thalamus ; ms. sur parchemin, contenant des documents de 1148 au $\mathrm{XVI}^{\mathrm{e}}$ siècle. in-folio de $115 \mathrm{ff}$. Archives municipales de Tarbonne, At 106).

2693. - Septième Thalamus; ms. sur parchemin, contenant des documents de 1210 à 1484 . in-folio de $104 \mathrm{ff}$. (Archires municipales de Narbonne, At 107).

2694. - Huitième Thalamus; ms. sur parchemin. contenant des documents de 1221 au $\mathrm{XVI}^{\mathrm{e}}$ siècle, in- $\mathrm{t}^{0}$ de $44 \mathrm{ff}$. (Archixes municipales de Virbonne, tt 108).

2695. - Veuvième Thalamus; ms. sur parchemin. contenant des actes de 1221 à 1613 , in- $\mathbf{4}^{\prime \prime}$ de $76 \mathrm{ff}$. Archives municipales de Varbonne, At 109).

2696. - Dixième Thalamus: ms. sur parchemin, contenant des actes de 1221 au XVI siècle. in-folio de 143 19. Archices municipales de Narbonine, At 110).

2697. - Onzième Thalamus : ms. sur parchemin, contenant des actes de 1246 à 1488. in-folio de $105 \mathrm{ff}$. (Archices municipales de Varbanue. AA 111).

Dis feuillets manquent au début de ce registre.

2698. - Douzième Thalamus: ms. sur parchemin. contenant des actes de 1483 a 1555 . in-folio de 1:36 ti. Archires municipales de Narbonne, At 112 .

2699. - Cartılaire A; ms. sur parchemin, contenant des actes de 
1559 à $15 \% 2$, in-folio de 42 fr. (Archives municipales de Narbonne, AA 113 .

2700. - Cartulare B ; ms. sur papier, contenant des acles de 1313 à 1707. in-folio de $236 \mathrm{fl}$. (Archices municipales de Narbonne, AA 114.

2701. - Cartulaire C ; ms. sur parchemin, contenant des actes de 1583 à 1587 , in-folio de $6 \mathrm{fr}$. Archices muicipales de Varbonne, AA 115 .

2702. - Cartulaire D; ms. sur papier. contenant des actes de 1613 à 1645, in-folio de $241 \mathrm{fl}$. (Archices municipales de Varbmue, AA 116 .

2703. - Cartulaire E; ms. sur papier. contenant des actes de 1619 à 1799, in-folio de 25t tf. (Archices municipales de Narbonne, AA 117 .

Nassandres. - Prieuré de Saint-Lambert (dioc, de Lisieux). 2704. - Curtulaire du prieuré de St-Lambert de Nassandres, dép ${ }^{1}$ de l'abbaye du Bec; ms. du XYe siècle [145\%], rédigé par le prieur Jacques Grente, avec additions du $\mathrm{X} \mathrm{Tl}^{\mathrm{e}}$ siècle, sur papier, contenant des chartes de 1126 à 1495 , in-4" de 1332 pages 'Biblinth. de la rille de Cuen, coll. Mancel. ms. I15).

Nassau. - Duchi. - Voy. Gueldre.

Navarre. - Royaume.

2705. - Cartulaile navarrais de Philippe III. « Cartulario del Rey don Felipe »: nns. du $\mathrm{XIII}^{*}$ sìcle, en deux parties (l'une d'une main espaunole. lautre d'une main francitise), sur parchemin, in-folio de 2:3 II. à 2 col. (Archuro de la Camerce de Contos de Nararra, à l'ampelune).

Contient 150 mandements de Philippe III (1277-1279), un de la reine Jeanne, et deux de se's ofticiers. - Ce cartwaire contenait prinitivenent 34 ff. : non ami Henni Courteault croit aroir retrouvé unc partie des manenants dans le "Cartulaire Il te la chancellerie de Nuvarre "n aux menues arehives (ef. Brutails, Documents des Arelizes de la Chambre des comptes de Vacarre, introd., page rn); ce sont les pagres 167-18I de ct volume, contenant 45 nonveaux mandements ou actes des années 1279-1282.

Publ. : M. Henri Courteault prépare la publication intégrale de cet important cartulaire.

2706. - Cartnlaire de Navarre : ms. du XIV'e siècle, stur papier, in-4 ${ }^{0}$ de 102 [jadis 107] If., contenant des documents de 1297 à 1372 (Archives dip. des Busses-Pyjénées, E 5l3).

Contient surtout des actes des rois Philippe VI, Jean II et Charles V' ceux qui intéressent Charles le Maurais ont été publiés 
dans les Preures de Secousse. - Il existe encore aux Archives do Pampelune quatre registres de la chancellerie uavariaise (dont un spécial à Thibaut Ier comte de Cliampagne, et un autre spécial à Charles le Maurais), (Iui appartiennent aux XIII ${ }^{\circ}$ et XIV ${ }^{\circ}$ siecles, et dont on trouvera une suffisante deseription dans Brutails, op. cit., Paris, 1890, in- $8^{\circ}$ [Bibliothèque de l'École des Hautes-Études, vol. $84]$.

Naveil. - Église. - Voy. Marmoutier.

Nemours. - Duché.

270\%. - Recueil de titres relatifs an duché de Nemours: ms. du XVII ${ }^{\mathrm{e}}$ siècle, sur papier, contenant des actes de 1507 à 1638 , in-folio (Biblioth. nationale, ms. français 16681, ff. 126-192).

Néronville. - Prieuré (dioc. de Sens).

2708. - Cartulaire du prieuré de St-Pierre de Néronville, dép ${ }^{t}$ de l'abbaye de la Sauve-Majeure; ms. de 56 tr., perdu depuis le XVII siècle.

Extraits du précédent, faits au XVII ${ }^{e}$ siècle (Biblioth. nutionale, coll. Baluze, vol. LXXIY, pp. 264-269 ; ms. latin l7049, pp. 195210 ).

2709. - Puru. : Recueil des chartes du prienré de Néronville près de Château-Landon, par Henri Stein Annales de la Société historique et archéologique du Gâtinais, XIII, 1895, pp. 298-373.

Dates extrêmes : 1080 environ à 1222. - L'éditeur a utilivé également les textes contenus dans le.s carlulaires de la Tauve-Majeure.

Cf. : Nons celtiques dans les chartes du prieuré de Néronville, par H. d'Arbois de Jubainville Recue coltique, XVIII, 1897, pp. 24.5 247).

Nersac. - Prieuré. - Voy. Axgoulème (abb. de St-Cybard (de).

Nesle. - Seigneurie, près de Chàtillon-sur-Seine en Bourgogne.

2710. - Cartulaire de la seigneurie de Yesle; ms. rédigé en 1271, contenant des documents depuis 12:39, in-t" sur parchemin de $117 \mathrm{fr}$. (Archives du chateun de Chuntilly, $\mathrm{n}^{0}$ xivi'),

Nesle-la-Reposte. - Abbaye, à Villentuxe (dioc. de Troyes).

2711. - Cartulaire de l'abbaye de Seste-la-Ruposte: ms. du X $T^{-e}$ siecle, sur papier. contenant des actes de 1126 a 1407 , in-4 $4^{\circ}$ de $37 \mathrm{ff}$. (Archices dóp. de l 1 ubp, $8 \mathrm{H} \mathrm{l}$ ).

Neubourg. - Abbaye de Notre-Dame (dioc. de Strasbourg), 2712. - Cartulaire de l'abbaye de Yeubourg; ms. du Xille siècle, sur parchemin. orimp perdu?

A été utilisé par sic'noepflin Alsatia dip.omalica. 
Quelques extraits dı précédent, faits au XVIII e siècle (Grossherzogl. Landesarchio in Kurlsruhe, Nachlass Grandidier's).

Neuchâtel. - Comté.

2713. - Pcbl. : Honuments de l'histoire de Nenchâtel, publ. par G. A. Matile. Nenchâtel, J. Attinger, 184t; in-folio de vir-1224 p. et pl.

Contient 817 chartes des années 998 à 1396.

Neufchâtel. - Seigneurie au comtẻ de Bourgogne.

2714. - Cartulaire de la maicon de Neufchâtel; ms. du XVe siècle, sur parchemin. in-folio (Archives de .1. le comte de Durort-Civrac, au chàteau d'Huppeneau, Loir-et-Cher).

Copie du XVII" siecle. in-folio de $720 \mathrm{fr}$. (Biblioth. nationale, coll. Moreau, vol. 898).

Autre du XVIII s., in-4" sur papier. de 420 et 518 fr. (Biblioth. de lu ville de Besancon. coll. Droz. vol. 24 et 25 ).

Autre copie du XVIHe siecle, de 235 ff. (Lichives nationales, $\mathrm{K}$ $1798)$.

Copie moderne du mène. faite en 1878, in-10 de 55ว ff. (Biblioth. nationale, ms. nouv. act. Prançaises 3535).

Extraits faits an XIX ${ }^{e}$ siècle (Biblioth. de la ville de Montbéliard, ms. 169, pp. 228-257).

Prbl.: Vingt-six chartes extraites du cartulaire de Neufchâtel (12:32-128\%, par Jules Gimthier (Ménoires et documents inédits pour servir à l'histoire de la Frrunche-Comté, VII (1876, p. 519-548).

Neuviller. - Abbaye, puis collégiale de St-Étienne (dioc. de Strasbourg).

2715. - Cartulaire du Chapitre collégial de Nenviller; ms. dn XIVe siècle, en 2 vol. in- $4^{\circ}$ sur papier, de 53 et 26 II. (Archio des UnterElsass, in Strassburgry.

Les documents les plus anciens sont de 1192 .

Nevers. - Comte.

2716. - Quitre cartulaires ont existé d'après les archives de la Chambre des Comptes de Nevers; ils ont tous disparu.

Extraits faits par Baluze en 1710 d'après ces diflérents registres (Biblioth. nutionale, coll. Baluze, vol. LXXIT, fi. 382-427).

En outre un fragment d'inventaire de ces cartulaires, rédigé par l'abbé de Marolles, existe à la Biblioth. nationale, Cinq-Cents Colbert, vol. 284, ff. 129-192 ( $\mathrm{xrrl}^{\mathrm{e}}$ siècle).

Nevers. - Église cathédrale Saint-Cyr.

2717. - Cartulaire de l'église St-Cyr de Nevers (XIIe s.); orig. perdu. Extraits faits en 1710 par Baluze, contenant des actes depuis 
le'VIIIe siècle jusqu'en 1360. d'iprès un manuscril comptant au moins 66 feuillets Biblialh. nutionale. coll. Baluze, vol. LXXIV. ff. $320-375$.

L'un des deux cartulaires a été utilisé par Dom Géron: Gaignières en arait fait prendre égalenent des extraits (Biblioth. nutionale, mis. latin $920 \%$, in-folio de 23 tf. sur papier), ainsi que Du Chesne (Itlem, coll. Dachesne, rol. LXIII, ff. 22-42), et P. Dupug (Illem, coll. Dupuy, vol. $702, f^{\circ} 2\left(0^{3}\right)$.

Nevers. - Évèché.

2718. - Cartulaire de lévêché de Yevers [Cartularium episcopi]; orig. perdu.

Extraits faits par Baluze d'un cartulaire contenant $115 \mathrm{ff} .$. avec en-tête une table sommaire (Biblioth. nationale, coll. Baluze, vol. LXXIV, ff. 274-315).

Nevers. - Prieuré de Saint-Étienne.

2719. - Cartulaire du prieuré de St-Étienne de Nevers : orig. perdu. Extraits du précédent, faits au XVII siècle Biblioth. nationale, coll. Baluze, vol. XLI, fr. $71-76$,

Il est cité aussi par A. Du Cihesne (Histoire de la maison de Vergy, p. 435 , etc.).

2720. - Fragments d'un autre cartulaire de Saint-Étienne de Nevers; ms. dn X Xie siècle, in $t^{0}$ de $6 \mathrm{ff}$. de parchemin. contenant des documents des années $1185-1450$ (Archices dép. de la Vierre, $\mathrm{H}$ $\left.58^{\mathrm{B}}\right)$.

2721. - Recueil des titres du prieuré de St-Étienne de Yevers. rédiçó en 1674 par Jean Simonin. procureur; ms. sur papier, in-4 $4^{0}$ de 190 pages (Archires lép. de la Vière, $\mathrm{H} 58^{\mathrm{A}}$ ).

Ce registre, vendu une première fois à Paris le ler avril 185b, a été acquis à la rente Grangier de la Marinière. - II. René de Lespinasse se propose de Ie publier.

Néville. - Prieuré (dioc. de Coutances).

2722. - Cartulaire du prieuré de Néville. dépendant de l'abbaye de Montebourg; ms. du $\mathrm{XV}^{\mathrm{e}}$ siecle, incomplet, contenant 59 actes des années $1163-1454$, sur parchemin. in- $t^{0}$ de $27 \mathrm{ff}$. Archices dép. de la. Manche, H 8:37\%).

Nice. - Église cathédrale Sainte-Réparate.

2723. - «Liber nimer ecclesie cathedralis Niciensis »: ms. du XIVo siècle, sur parchemin. contenant des docaments de 1002 à 1200 , in-folio de $64 \mathrm{ff}$. Archires du Chapitie cuthédrul de . Vice.

Deus autres fr. ont été retrourés à l'Archirio di stato, à Turin ffonds Monaco e Turbia). 
Publ. : Cartulaire de I'ancienne cathédrale de Nice, par le Cle Eug. Cais de Pierlas. Turin, 1888 ; in $4^{0}$ de' xxxur-173 p. et pl.

Cf. Paul Meyer dans la Reoue critique, 1889, XXVIII, p. 233-235.

Nice. - Ville.

2724. - Recueil des privilèges et statuts de li ville de Nice; ms. du XVII siècle. sur papier, contenant des documents à partir du XIVe, in- $4^{\prime \prime}$ (le $\mathrm{x}-368 \mathrm{ff}$. (Biblioth. de la ville de Nice, ms. 97).

Nicosie. - Église (Chypre).

2725. - Cartulaire de l'église de Nicosie; ms. du XVIe siècle [1524], sur parchenin, transcrit « ex veteri codice ». in- $4^{0}$ (Biblioteca Marciana, ì Venise. cod. LVI classis rv).

Dates extrèmes: 1196-1510. Quelques actes sont en français.

Copie du précédent. faite en 1855 à la demande de Mas-Latrie par le coadjuteur de la Marciana Lorenzi : ms. sur papier, avec table en tête, in-4 (le 484 pages (Biblioth. nationale, ms. latin 10189).

Nieppe. - Prieuré (dioc. d'Ypres).

2726. - Cartulaire du prieuré de Nieppe, dép ${ }^{t}$ de l'abbaye de Marmoutier (Appartenait en 1880 ì M. Ignace de Coussemaker, à Bailleul.

\section{Nieuport. - Ville.}

2727. - Cartuliaire de la ville de Nieuport : ms. des XVe-XVIle siècles, sur parchemin, contenant des actes des années 1168 à 162l, in-folio, de I:36 If. (Archives communales de Nieupmt).

2728. - Autre recueil ; ms. des XVIII -XIXe siècles, sur parchemin, contenant des actes de 1163 i 1753 , in-folio de $261 \mathrm{ff}$. (Archives communales de Nienport).

Nîmes. - Chapitre cathédral.

2729. - Cartulaire In Chapitre épiscopal de Nìmes, on « Liber de honore canonicorum $\nu$; ms. dı XII siècle, sur parchemin, in-folio de $118 \mathrm{ff}$. (Archices dép. du Gard, (: 1333).

Lxtraits du précédent faits au XVIII ${ }^{e}$ siecle (Biblinth. de la ville de Nimes, ms. 175).

P’ubl. : Cartulaire du Chapilre le l'église N. 1). de Nìmes (8761156 ), publ. par Eur. (Germer-Durand (Mémoires de l'Académie du Gard, XXXVI, 1872, p. 1-144. et XXXVII. 1873, p. 145-398); el à part: Nimes, 1874 ; in-80 de CLxir-402 p.

Cf. Aug. Molinier dans la Recue critigur, 1874, p. 337-340.

Ninove. - Abbaye (dioc. de Cambrai).

2730. - Cartulaire de liabaye de Ninove; ms. dı XIVe siècle, sur 
parchemin, contenant des actes de $117 \tau$ i $13 \% \pi$, in-4 de 1206 pages (Archices de listal it Gand).

2731. - Autre cartulaire du XVIII siècle, sur papier. contenant des actes de 11322 à 1703. in-folio de $196 \mathrm{ff}$. Archires de l' Eitut ì Gand).

Publ.: Codex diplomaticus abhatiae Ninoviensis 1092-1317), dans: Collection des chroniques de Flandre, par .J.J. De Sulet. II (1841). pp. 749-983. [Chroniques belges inédites.]

2732. - Cartulaire de l'ahbaye de Ninove; ms. du XIVesiècle. sur parchemin, avec additions postérienres, reconvert l'une reliure en bois ornee de fermoirs, in- $t^{0}$ de $139 \mathrm{ff}$. a 2 col. Archices de larcheréché de Lulines).

2733. - Autre cartulaire: ms. dlu XVIe siècle. sur papier. avec reliure également ancienne à fermoirs, in- $\mathbf{4}^{\text {" de }} 239 \mathrm{ff}$. Lochices de lurchevêclé de Mulines'.

Nioiseau. - Abbaye (dioc. d'Angers).

2734. - Cartulaire de l'abbaye de Nioiseau ; origr. détruit.

Copies et extraits de pièces d’après ce cartulaire Biblioth. nationale, coll. I)om Honssean, vol. XII 2 et XVIII).

Niort. - Prieuré de Saint-Martin, dépt de l'abbaye de La Couronne (dioc. de Poitiers).

2735. - Publ. : Documents relatifs au prieuré de Saint-Martiu de Niort (1200-1662), par G. Babinet de Rencogne (Mémoires de la Société de stutistique des Deux-Sèrres, $2^{e}$ série, V, pp. 235-25I); et à part : Niort, Clouzot, 1866 ; in- $8^{\circ}$ de 20 p.

Nivelles. - Chapitre Sainte-Gertrude (dioc. de Namur).

2736. - Cartulaire du Chapitre Sainte-Gertrude de Nivelles: ms. du XVI siècle. sur papier, contenant des titres de 1214 à 1404 . in- $4^{0}$ de 20 pares Archives générales du royaume de Belgique, à Bruxelles).

2737. - Autre cartulaire des $\mathrm{XV}^{\mathrm{e}}-\mathrm{XVI}^{\mathrm{e}}$ siècles. sur papier. contenant destitres de $87 \%$ à 1556 . in- $4^{0}$ de $623 \mathrm{ff}$. Archices générales du royaume de Belgique, à Bruxelles.

2738. - Autre cartulaire; ms. du $I V^{\mathrm{e}}$ siècle, sur papier. contenant des actes de 1181 à 1354 , in- $t^{\circ}$ de $8 \mathrm{ff}$. (Archices générales du royaume, à Bruxelles).

2739. - Cartnlaire de la communanté des chapelains de la méme échlise; ms. du $\mathrm{XVI}^{\mathrm{e}}$ siècle $[1541]$. arec un index, sur papier, contenant des actes de 1.213 a 1461 , in- $4^{0}$ de $180 \mathrm{ff}$. (Archives générales du royaume, à Bruxelles). 
Nivelles. - Couvent des Carmes.

2740. - Publ. : Cartulaire de l'ancien convent des Carmes de Nivelles, par T. Le Bon (Lnules de la Société archéologique de Nivelles, II, 1881 , pp. 140-365).

Nivelles. - Ville.

2741. - Cartulaire municipal de Nivelles; ms. du XVe siècle, sur parchemin, contenant des titres de 1:304 a 1455 , in-4" de 46 ff. (Archices communales de Nivelles, Belgique).

Pcbl. : Cartulaire de Nivelles, extrait des archives communales de Nivelles, transcrit et annoté par J. Buisserel et Edg. Prelle de la Nieppe (Annales de la Société archéologique de Nicelles, IT, 1892, pp. $141-259$ ).

Nivernais. - Inuché.

2742. - Recueil de titres relatifs à la maison de Nevers; ms. du XVI siècle, sur papier, contenant des titres de 1539 a 1582 , in-4"de III-131 ff. (Archives nationales. KK 1111).

Ites trois premiers feuillets, contenant la table, sont mutilés.

Nizors. - Vuy. La Bénisson-Dieu.

Noëfort. - Prieuré de Saint-Nicolas (dioc. de Meaux):

2743. - Cartulaire de St-Nicolas de Noëfort; ns. dı XV'e siècle, sur parchemin. contenant des actes de 1183 à 1433 (textes d'après les originaux et traductions), in- $8^{0}$ de $125 \mathrm{ff}$. (Biblioth. nationale, nIs. français 19835).

Copie du précédent; ms. rédigé en 1780, sur papier, in-40 de 74 tf. (Archives dép. de Scine-et-ILarue, H 610).

Nogent-l'Artaud. - Prieuré (dioc. de Soissons).

2744. - Cartulaire de Yorrent-l'Artaud, prieuré dépendant de SaintGermain-des-Prés; mis. dn XVIe siècle, sur papier, in-40 de $241 \mathrm{ff}$. (Arrhives nationales, LL 1083).

Nogent-le-Rotrou. - Hôtel-l)ien (dioc. de Chartres).

2745. - Recueil de titres relatifs à l'Hòtel-Dien de Nogent-le-Rotrou, extraits des archives hospilalières, par Dallier, au $\mathrm{XIX}^{\mathrm{c}}$ siècle (Biblioth. de la ville de Nogent-le-Rotrou, ms. 9).

Nogent-le-Rotrou. - Prieure de Saint-Denis.

2746. - Cartulaire de St-Denis de Nogrent-le-Rotron; ms. dn XVe siècle. sur papier, in-4 ${ }^{0}$ de 64 ff. (Archives dép. d'Eure-et-Loir, $\mathrm{H}: 2601$.

Dates extrimes : 1031-1240. 
Copie moderne du précédent (Biblioth. de la ville de Nogent-leRotrou, ms. 16).

Extraits Biblioth. nalionale, coll. Duchesne, vol. XX. ff. 217219 ; et vol. XXII, ff. 172-174 et 276-298.

Publ. : Saint-Denis de Nogent-le-Rotrou (1031-1789, par l'abbé Ch. Métais. Vannes, Lafolye, 1895 ; in-80 de cxxiv-34 7 p. et pl. [Archives historiques du diocèse de Chartres.]

- Archives du diocèse de Chartres; I. Saint-Denis de Nogent-leRotrou (1031-1789); histoire et cartulaire, publ. par le V'le de Souancé et l'abbé Ch. Nétais. Édit. rerue et augmentée. Vannes, Lafolye, 1899 ; in- $8^{\circ}$ de CLX -353 p. et fig.

Un supplément à la fin du volume contient des pièces étrangères au registre original.

Nogent-sous-Coucy. - Abbaye de Notre-Dame (dioc. de Laon).

2747. - Cirtulaire-chronique de l'abbaye de Nogent-sous-Coucy ; ms. exécuté par Dom V. Cottron en 1665, contenant des documents de 1059 à 1413 , sur papier, in-folio de $239 \mathrm{ff}$. Archires dép. de l'Aisne, $\mathrm{H}: 325)$.

Cf. une note de labbé Daras sur ce volume (Bulletin de la Société historique et urcheologique de Soissons, III, p. 123-125).

Copie moderne du mème [1865], sur papier, in-folio de $336 \mathrm{p}$. (Biblioth. de la ville de Woyon, coll. Peicné-Delacourt, ms. 21).

2748. - Cartulaire de l'abbaye de Nogent-sous-Concy : orig. perdu.

Extraits du précédent. faits au XVII siècle. sur papier (Biblioth. nationale, ms. latin 12683. ff. 98-99 et 104-107).

A partir du fo 83, ce même volume renterme d'autres pièces, depuis le $\mathrm{XI}$ siècle, intéressant cette abbaye.

Autres extraits faits au $\mathrm{XVIII}^{\mathrm{e}}$ siècle (Biblinth. nutionule, coll. Dom Grenier, vol. 268, ff. 11-15).

Nonancourt. - Ville.

2749. - Cartulaire municipal de Nonancourt, contenant des titres de 1204 à 1783; ms. du XVII siècle. avec additions postérieures, sur parchemin, in-4" de 1:30 ft. Archices municipales de Tonancount, AA 4).

Copie du précédent. moderne, sur papier (Archives dép. de l'Eure. non coté).

Nonenque. - Abbayn de Notre-Lame (dioc. de Vabres).

2750. - Cartulaire de l'abbaye de Nonenque : orig. perdu.

A été connu de loom Estiennot qui l'a ru en 1680 ief. Bibliotheque nationale, ms. latin $12761, \mathrm{p} .30 \mathrm{~J})$. 
275l. - Recueil de titres relatifs a l'abbaye de Nonenque; ms. du XVH ${ }^{\mathrm{e}}$ siècle, contenant des documents de 1139 à 1440 (Biblioth. nutionale, coll. Noal, vol. 149, ff. 146-208).

Nonnenboosche. - Abbaye (dioc. d'Ypres).

2752. - l'ubl.: L'abbaye de Nonnenbossche, de l'ordre de SaintBenoit, près d'Ypres (110l-1796), suivi du cartulaire de cette maison, par L. Van Hollebeke. Briges, Vandecasteele-Werbrouck, 1865; in-4" de xir-l68 p. et pl. [Publication de la Société d'émulation de Bruges.]

Noordpeene.-Couvent des Guillelmites.- Voy. Eringhem. Normandie.

2753. - Cartulaire normand; ms. du XVe siècle, sur parchemin, fait par un religrieux célestin de Ronen, et contenant des actes de 1433 ì 1449 , in-folio de $63 \mathrm{ff}$. (Archires dép. de la Seine-Inférieure, G 9195).

Ce registre, dont on trouvera l'analyse dans l'Inventaire sommaire des archives dép. de la Seine-Inférieure, VII, $2^{e}$ partie (1905), p. 91-93, intéressé spécialenent l'occupation anglaise en Normandie.

2754. - Cartulaire normant, particulièrement relatif au bailliage de Caen ; ms. du XIIJe siècle, sur parclienin, in-t" de $90 \mathrm{fr}$. (Biblioth. de la ville de Rouen, mis. 1235).

Cf. Le cartulaire normand, par Léopold Delisle (Mémoives de la Société des untiquares de Narmandie, '2érie, V1, 1852 , p. vin-x).

2755. - Publ. : Cartulaire normand de Plilippe Anguste, Louis VIII, Sinint-Louis et Philippe le Hardi, par Léopold Delisle (Mímoires de lu Société des entiquaires de Vormantie. 2e série, VI, Pp. I-XL et 1-390, el à part: Caen, 1852 ; in-4" de xi-591 p.

Normandie. - Parlement.

2756. - Publ. : Recueil des édits, déclarations, etc., concernant la Chambre des Requêtes du Parlement de Normandie. Rouen, 1708, in-12.

Norroy-le-Sec. - Prévôté.

2757. - Recueil de titres relatifs à Sorroy, Trommon et Sampigny; ms. de li fin du XVle siècle, formé par Thierry Alix, sur papier, contenant dac textes de 1235 ì 1587 , in-folio de 216 ff. (Archives dip. de Wewthe-et-1Foselle, B 392).

Voir aussi vo Trognon.

Notaires-secrétaires du roi (Collège des).

2758. - Curtulaire du collège des notaires ou secrétaires royaux (13201497 ; ms. du XVe siècle, sur parchemin, in-40 de 94 fif. (Biblioth. du Vatican, ms. Ottoboni latin 3086). 
2759. - Autre du $\mathrm{XVI}^{\mathrm{e}}$ siècle. ms. sur parchemin. in-80 de $133 \mathrm{ff}$. (Biblioth. de l'Ecole des Bentu-Arts, à Paris, n² 21013).

Notre-Dame-de-Bonheur. - Prieuré (dioc. lle Mende).

2760. - Pubr.. Contribution ì l'histuire de Meyrueis: cartulaire du prieuré de N.-1). de Bonheur. [par Germer-Duranl]. clans: Mémoire concernant la haromie de Meyrueis Mémoires de la Saciétéd'agriculture, sciences et arts de ln Lazève, 1902, p. 17-254 et table de $\operatorname{\operatorname {xxIx}}$ p.).

Recueil d" doeuments des XIIe-XVIII e siècles, l'après la liasse Gi 97 des Arehives départementales du Gard.

Notre-Dame-de-la-Blanche. - Abbaye en l’ile de Noirmoutier (dioc. de Iuçon).

2761. - Cartulaire de lahbave de X.-I). de la Blanche, écrit en I632; mis. sur parchemin. de Il 23 pages in-folio Biblinth. Cheltenham, $n^{0} 740(i)$.

Notre-Dame-de-la-Presle. - Prieuré (dioc. de Langres).

2762. - Cartulaire du prieuré de Notre-Dame de la Presle; ms. du XVIII siècle, sur papier. in $4^{0}$ de $110 \mathrm{p}$. (Archices nutionales, LL $1019)$.

Notre-Dame-des-Clairets. - Abbaye (dioc. de Sées).

2763. - Cartulaire de l'abbaye de X.-D. des Clairets: ms. rédigé en 1720 , contenant des actes du XII siècle à 1719 , sur papier, in- $t^{0}$ de 752 p. (Biblioth. nationale, ms. latin 17140).

Copie moderne, in-40 de $151 \mathrm{ff}$. (1rchires dép. de l'Oine, H 3919).

Prbi. : Lihistoire et le cartulaire de l'abhaye de Notre-Dame-desClairets (Orne), de l'ordre de Citeaux (1202-1790). par le Y'te de Souancé. Nogent-le-Rotrou. Hamard. 1894 ; in-8" de 350 p.

Notre-Dame de Sery. - Voy. Serr.

Notre-Dame-des-Moulineaux. - Prieuré (dioc. de (Chartres).

2764. - Publ. : Recueil de chartes et pièces relatives an prieuré de Notre-l)ame-des-Mfoulineanx. de l'or'dre de Grandmont, et à la chàtellenie de Puinny arrt de Rambouillet). par Ang. Moutié. Paris, Firmin-Didot, 1846 : in- $4^{\circ}$ de cxrrm-107 p. et pl. [Soc'été archéologique de Rambouillet.]

Notre-Dame-des-Prés. - Abbaye (dioc. de Troyes).

2765. - Cartulaire de Intre-Dame-des-Prés; ms. du XVIe siècle. sur papier. contenant 170 actes à partir de 1206, in-10 de $86 \mathrm{lf}$.' Archires dép. de l'Aube, $\mathrm{H}$ non coté . 
Notre-Dame-des-Prés. - Chartreuse (dioc. de Boulogne). 2766. - Publ. La Chartreuse de N.-D.-des-Prés à Neuville sous Montreuil-sur-Mer ; Documents, par l'abbé F.-A. Lefebvre. Neuville sous-Montrenil, 1890 ; in- $8^{\circ}$ de xiI-610 p. et pl.

Notre-Dame-des-Ternes. - Couvent des Célestins (dioc. de Limoges).

2767. - Cartulaire de Notre-Dane-des-Ternes ; ms. daté de 1761, sur papier, contenant 400 actes des années 1299 à 1520, en 4 vol. in-folio (Archives dép. de la Creuse, $\mathrm{H}$ non coté).

Notre-Dame-du-Désert. - Prieuré (dioc. d’Évreux).

2768. - Cartulaire dı prieuré de Notre-Dame-du-Désert; orig. perdu [il était jadis dans les archives de l'ahbaye de Lyre].

Copie du précédent, faite en 1612 , sur papier, contenant des actes de 1135 à 1495 . in-folio de $72 \mathrm{ff}$. (Arch. dép. de l'Eure, $\mathrm{H}$ non coté).

Notre-Dame-du-Pont, à Leynhac (Cantal). - Abbaye.

2769. - Fragment de cartulaire de l'ablaye de Notre-Dame-du-Pont ; ms. du XIV ${ }^{\theta}$ siècle, en langue vulgaire (Biblioth. du Vatican, fonds de la Reine, vol. 168, fl. 21-30).

A appartenu ì Petau.

Copie partielle du précédent par Du Chesne (Biblioth. nationale, coll. Duchesne, vol. XXX ViII, ff. 91-92).

Notre-Dame-du-Val. - Toy. Le Val-Notre-I)ame.

Notre-Dame-du-Val sous Apremont. - Prieuré (dioc. de Metz).

2770. - Cartulaire du prieuré de Notre-Dame-du-Val sous Apremont, dépt de l'abbaye de Gorze; ms. du $\mathrm{XV}^{\mathrm{e}}$ siècle, sur papier, in-40 de $30 \mathrm{ff}$. (Biblioth. natio ale, ms. latin 17752).

Notre-Dame-du-Vœu. - Abbaye. - Voy. Le Valasse.

Notre-Dame-la-Royale. - Abbaye. - Voy. Maubursson.

Nouaillé. - Abbayr (dioc. de Poitiers).

2771. - Recueil des titres de l'abbaye de Nouaillé; ms. du XVIII siècle, sur papier, contenant 418 titres des années 696-1624, in-4 ${ }^{0}$ de 751 et 704 pacres (Biblioth. de la ville de Poitiers, collection Dom Fontenean, vol. XXI-XXII).

Voir aussi au Sepplémext.

Novy. - Prieuré (dioc. de Reims).

27\%2. - Cartulaire dı prieuré de Novy ; ms. du XIIIe siècle, contenant 
des pièces des années 1097-1264, in-4t de 89 10. (Archives dép. des Ardenines, H ll).

Publ.: Cartulaire du prienré de X̃.-I). de Nory [analyse des pièces], par Ed. de Barthélemy (Reove historique des Ardennes, 1867, livr. 4, p. 41-64), et à part: Paris, 1867: in-8 de $26 \mathrm{p}$.

Noyers. - Abbaye (divc. de Tours).

2773. - Cartulaire de l'abbaye de Noyers; orig. perdu.

2774. - Cartulaire de l'abbaye de Noyers; ms. dn XVIII ${ }^{e}$ siècle, sur papier, in-4 $4^{\circ}$ de 657 et 912 pages (Biblioth. de la rille de Poitiers, coll. D. Fonteneau, vol. LXXI-LXXII).

Extraits faits au XVIII siècle (Biblioth. nationale, coll. D.Housseau, vol. XII. 2 partie).

2775. - Publ. : Cartulaire de l'abbaye de Noyers, par l'abbé C. Chevalier (Mémoires de la Société urcheologique de Touraine, XXII, p. 1-815), et à part : Tours, 1872 ; in-8 $8^{\circ}$ de riII-816 p.

Noyers-en-Vexin. - Seigneurie.

2776. - Cartulaire de la seigneurie de Noyers-en-Texin; ms. du $\mathrm{XV}^{\prime} \mathrm{III}^{\mathrm{e}}$ siècle [1767], sur papier, in $4^{0}$ de XIv-250 pages (Archices dép. de Seine-et-Orse, $\mathrm{H}$ non coté, fonds de l'abbaye de St-Louis de Poissy).

Dates extrêmes : 1322-1764.

Noyon. - Abbaye de Saint-Barthélemy.

2777. - Cartulaire de l'abbaye de St-Barthélemy de Noyon; ms. [avait au moins $239 \mathrm{ff}$.] perdu.

Cité souvent par Dom Grenier dans son Introduction à l'histoire de Picardie : cf. Comite archeologique et historique de . Voyon: Comptes-rendus et mémoires, XIX (1904), p. 2.

Noyon. - Abbaye de Saint-Éloi.

2778. - Recueil de pièces relatives à l'abbaye de Saint-Éloi de Noyon. fait au XVII siècle. et contenant des actes du $\mathrm{X}^{\mathrm{e}}$ au XVe, sur papier (Biblioth. nationale, ms. latin 12669. ff. 105-12l).

Noyon. - Chapitre cathèdral.

2779. - Fragments d'un cartulaire du Chapitre de Noyon, foliotés 358363 ou $383-388$; ms. du XIY'e siècle. sur parchemin, in- $4^{\circ}$ (Biblioth. Cheltenhan, $\mathrm{n}^{0}$ 17838).

2780. - Autres fragments d'un autre cartulaire, cahier coté IIII ; ms. du XIVe siècle, sur parchemin. $8 \mathrm{ff}$. à 2 col. in $4^{\circ}$ (Biblioth. Cheltenham, $\mathrm{n}^{0} 22882$ ).

2781. - Cartulaire du Chapitre de Noyon; ms. des XIIIe-XIVe siècles, 
sur parchemin, contenant 594 pièces depuis l'année 841 , in-folio de $355 \mathrm{fl}$. (Archives dép. de l'Oise, G 1984).

Cif. Inventaire analytique du eartulaire du Chapitre eathédral de Noyon, par A. Rendu. Beauvais, 1875 , in $44^{\circ}$ de $15-72$ p. (extr. du tome I de l'Inventaire sommaire des archives départementales de l'Oise).

Dom Grenier et Le Vasseur (Annales de l'église cathédrale de Noyon) ont cormu et utilisé d'autres cartulaires tous perdus. - F. Sézille, dans son Histoire de Noyon (Biblioth. nationale, nus. français 12030-12031), signale également, outre un eartulaire en papier, un eertain nombre d'autres cartulaires sur parchemin cotés par les lettres de l'alphabet (A, B, D, E, N, R, S, Y).

Noyon. - Evêché.

2782. - Livre ronge de l'évèché de Noyon; ms. du XIVe siècle, in-folio à 2 col. ; orig. perdu.

Extraits faits au XVIII siècle (Biblioth. nationale, coll. Dom Grenier, vol. CX, ff. 190 et ss.).

2783. - Autre petit cartulaire : orig. perdu.

Noyon. - Tille.

2784. - "Lirre rouge » óu cartulaire municipal de Noyon, commencé par Colars Burry, nommé clerc de la ville en 1389, el continué par ses successenrs (XIVe-XVe siècles). sur papier, in-4. ${ }^{\circ}$ te $52 \mathrm{ff}$. (Archives municipales de Noyon, AA l).

Dates extrèmes : 1140-1410. Lancienne reliure rouge a fait place en $177 \%$ à une autre en veau plus moderne et de couleur différente.

Publ. : Le livere rougre de la ville de Noyon, par J. Poissonnier (Comptes rendus et Mémoires du Comité archéologique et historique de Noyon, X, 1893, pp. 3-121.

Noyon-sur-Andelle [aujourd'hui Charleral]. - Prieuré (dioc. de Rouen).

2785. - Cartulaire du prieuré de Noyon-sur-Andlelle; ms. exécuté en

1536, sur parchemin, contenanl des actes de $12: 38$ a 1491 , in $4^{0}$ de $8 \mathrm{ff}$. Arehices de lione, $\mathrm{H} 733$ ).

2786. - Autre du XIII siecle; orig. perdu.

Un double feuillet de ce registre, sur parchemin, in $-4^{\circ}$, subsiste seul aux Archices dry. de l'Eure, H 835 ; il contient quelques chartes du XIII" siècle.

Nuits. - Voy. VERGY.

Nyon. - Ville.

2787. - Publ. : Chartes inédites relatives au fief de l'archevêque de Besançon sur la ville de Nyon, par le $\mathrm{C}^{\text {te }}$ de Foras (Mémoires et Documents publ. par la Société d'histoire de la-Suisse romande, $\mathrm{XX}, 1865$, pp. 197-209).

Actes tirés des arehives de Turin (1272-1368). 
Obazine. - Abbaye (dioc. de Limoges).

2788. - Cartulaire de l'ablarye d'Obazine: mis. du XIIe siècle, sur parchemin, avec quelques rures additions du XIII' dans les hlancs, contenant beancoup de pièces non datées et lia plus récente de $123 \%$. ayant 6 feuillets mutilés, in- $4^{\circ}$ le $35.3 \mathrm{ff}$. (Biblioth. nationale, ms. nonv. acq. latines 1560 .

Cif. Notice sur le cartulair de l'abbaye cistercienne d'Obazine, par Louis Guibert (Bulletin de la Société des lettress, sciencess et arts de la Corrése, XI, 1890 , p. 435-459). - Ce manuserit fort beau arait été prêté en 1886 à l'Exposition rétrospective de Limoges par M. Joseph Brunet.

Extraits du nême. par D. Jacques Boyer (Biblioth, nationule, ms. latin 12697. ff. 152-15:3 et 157-158).

Oeleghem. - Seigneurie en Flandre.

2789. - Cart nlaire des seigneuries de Broeckem et d'Oeleghem; ms. du XVII siècle, sur papier. in-4 $4^{0}$ de 332 ff. de différentes mains, contenant des actes de 1158 à 1666 (Archices de l État à Anrers).

Oelenberg. - Couvent des Augustins (dioc. de Bâle).

2790. - Cartulaire du convent des Angustins d'Oehlenberg; ms. du XVe siècle, sur parchemin, in-4" de $13 \mathrm{ff}$. (Archir des Obpr-Elsass, in Colmar;:

CEuf. - Prieuré dépt de Marmoutier (dioc. de Boulogne).

2791. - Publ. : Le prieuré d'CEuf, par l'abbé D. Haigneré (.Kémoires de la Société des anliquaires de la .Morinie, XXII, pp. 65-86); et à part : Saint-Omer. 1891, in- $8^{\circ}$ de $20 \mathrm{p}$.

Documents des années 1213 à 1325 .

Oignies. - Prieuré (lioc. de Namur).

2792. - Cartulaire dn prieuré d'Oignies: ms. des XVI-XVIIIe siècles, sur papier, contenant des titres de 1187 à 1539 . in-folio de $125 \mathrm{ff}$. (Archires de l'État ì. Wouss.

Oigny. - Abbaye de Notre-Dame (dioc. d'Autun).

2793. - Cartulaire de l'abbaye de Notre-Dame dogny ; ms. des XVeXVIe siècles. sur papier. contenant 60 titres des amnées 1190 à 1472 , in-folio de $24 \mathrm{ff}$. (Archices dép. de la Cóte-r Or, $\mathrm{H}$ non coté).

Oleron (île d').

2794. - Cartulaire des fiefs de l'abbaye de Fonterrauld dans l'île d'Oleron : ms. du Xre siècle, sur papier, in-4" de 12 tf. (Archires dép. de. Waine-et-Loire, $\mathrm{H}$ non cotè).

Dates extrèmes : 1197-1397. 
Ollioules. - Ville.

2795. - Cartulaire municipal d'Ollionles; ms. du XVIII' siècle, sur papier, contenant des titres à partir de 1276, in-folio de $137 \mathrm{ff}$. (Archives municipules d Ollioules, AA I).

Oloron. - Chapitre cathédral.

2796. - Cartulaire du Chapitre d'Oloron ; orig. perdu.

Extraits faits par Ö̈henart an XVII' siècle (Biblioth. nationale, coll. Wuchesne, vol. CXIV, ff. 27-31).

Oloron. - Ville.

2797. - Cartulaire municipal d'Oloron: ms. dn XVIe siècle, sur parchemin, in-folio de $111 \mathrm{ff}$. (Archives municipales d'Oloron, AA l).

Publ. : Le cartulaire d'Oloron, publ. par Maurice Marque. Pau, $V^{\text {ve }}$ Ribaut, 1900 ; in-8 de xx-91 p.

Oost-Eecloo. - Abbaye (dioc. de Gand).

2798. - Cartulaire de l'abbaye d'Oost-Eecloo; ms. des XVIe-XVII siècles, sur papier, contenant des documents de 1226 à 1630 , in-4 de 234 if. (Archives de lÉtut à Gand).

Orange. - Évèché.

2799. - Fragment d'un cartulaire de l'évêché d'Orange; ms. du $\mathrm{XII}^{\mathrm{e}}$ siecle, un feuillet de parchemin $\left\{0^{\mathrm{m}} 42\right.$ sur $\left.0^{\mathrm{m}} 32\right)$, à 2 col., contentunt la transcription de 11 pièces de l'année 862 au XI ${ }^{\circ}$ siècle (Biblioth. de la ville de Carpentras, ms. 1589).

A servi de couverture à un autre registre.

2800. - Fragment d'un autre cartulaire du XII ${ }^{e}$ siècle ; deux feuillets de parchemin $\left(0^{\mathrm{m}} 31\right.$ sur $\left.0^{\mathrm{m}} \cdot 21\right)$ (Biblioth. de la ville d'Avignon, ms. $18: 30)$.

Pvbl. : Fragrments d'anciens cartulaires de l'évèché d'Orange, par L. Duhamel (Mémoires de l'Acudémie de Vaucluse, 1896, p. 383396 ).

Orange. - Principauté.

2801 . - Recueil de titres relatifs à la principauté d'Orange, formé au XVIIe siècle, sur papier, in-folio (Biblioth. nationale, coll. Clairamhault, vol. 997 , ff. 3-2:28).

Orange. - Ville.

2802. - Publ. : Privilegres et libertez octroyées à la cité et ville d'Orange. Orange, 1607 , in- $4^{0} ;-1647$, in $-4^{0} ;-1719$, in- $4^{0}$.

Orbestier. - Abbaye de Saint-Jean (dioc. de Luçon). 2803. - Cartulaire de l'abbaye d'Orhestier ; ms. de 1454, sur papier 
et parchemin, in-4 $4^{0}$ de 324 pages (Archives dép). de la Vendée, $\mathrm{H}$ non coté).

Extrait (Biblioth. nationale, ms. latin 12688, ff. 477-482; coll. Dupuy, vol. 828, f0 78 ro).

Publ. : Cartulaire de l'abbaye d'Orbestier, par Louis de La Boutetière (Archives historiques du Poitou, VI, 187\%, p. Ix-xxm et $1-673$.

Ordios. - Prieuré et hôpital de pélerins (dioc. de Dax). 2804. - Cartulaire de l'hópital d'Ordios ; orig. perdu.

Extraits faits au XVII siècle par Oihenart (Biblioth. nationale, coll. Duchesue, vol. CXVIII, ff. 12t-133).

Orienten. - Abbaye (dioc. de Liège).

2805. - Cartulaire de l'abbaye d'Orienten ; ms. du XIVe siècle. sur parchemin, contenant des actes de 1238 à 1376 , in-4" de $165 \mathrm{ff}$. (Archices du royaume de Belgique, à Bruxelles.

Origny-Sainte-Benoite. - Abbaye (dioc. de Laon).

Il ne parait pas qu'il $y$ ait jamais t'u de rartulaire de cette abbaye ; celui que cite Ch. Gonıart, dans son Essai historique sur la ville de Ribemont (St-Quentin, 1869 , in- $8^{\circ}$ ). n'est autre que le ms. 87 de la Bibliothèque de Saint-Quentin, qu'il est impossible de classer au nombre des cartulaires.

Orle. - Commanderie. - Toy. Mas-Det.

Orléans. - Abbaye et collégiale de Saint-Aignan. 2806. - Cartulaire de Saint-Aignan d'Orléans; orig. perdu.

Est cité par Le Maire dans ses "Antiquitez de la ville et du duché d'Orleans "(Orléans, 1648, in-folio), p. 203.

Orléans. - Abbaye de Saint-Eurerte.

2807. - Cartulaire de St-Euverte dOrléans; ms. du XIVésiècle, orig. perdu.

Copie du précédent, exécutée en 1755, sur papier. in- $4^{0}$ de $11-589$ + 31 p., contenant des acles des années 1022-1367 Biblioll. mirmale, ms. latin 10089 .

Exiraits Biblinth. dOoléuns, ms. 596, fr. 233 v'-240: Biblioth. nationule, ms. latin 12682, fl. 100-117; - ms. latin 1:27:39. p. 247248 ; - Ins. latin 1275\%, par Dom Estiennot, fu 11 ; - ms. latin 17049. p. 237-251; - ms. français 8783 , in-4", de 266 17.: - et coll. Baluze, vol. LXXVIII, t1. 65-90.

Les pièces contenues dans le certulaire de Saint-Euverte qui concernent le prieuré du Gué de l'Orıne sont publiées par A. Yidier : Ermitages orléanais an XIle siècle (Le .Hoy॰n-Rige, 1906, sp. $57-96$ et 134-156), et à part : Paris, s. d., in-8 de 64 p. 
2808. - Copie du "Livre rouge » de Sinint-Enverte: ms. daté de 1538. sur papier, in-4" drehires dép. du Loivet. H non coté). C'est beaucoup plus un recueil do baux yu un cartulaire proprement dit.

Orléans. - Chapitre do Siant-Avit.

2809. - Cartulaire-olituaire de Saint-Avit d'Ordians: ms. du XIII siècle aver alditions postérienres. sur parchemin, in-40 de $117 \mathrm{ff}$. (Biblioth. autionale, ms. latin 12886.

Prbe. : Cartulaire du Chapitre de Saint-Avit d'Oriéans (1112 1418 . par (i. Timnat. Orleans. Herluison. 1886 ; in $4^{0}$ de xlvir-237 p. el pl. [Collection des Cartulirires du Loiret, II.]

Orléans. - Commanterie de Saint-Mare.

2810. - Cartulaire de lir commanderie de Saint-Marc d’Orléans; ms.

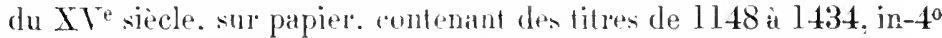
de $11-80 \mathrm{HI}$. Archites nutionales. S 5010. 11"4.

2811. - Recueil de litres sur lit mène commanderie. fait au XVII siacle (Biblioth. nutionule. ms. latin 12726. pp. 410-464).

Orléans. - Couvent des firands Cammes.

2812. - Cartulaipe des Giands Carmes d’Orléans; ms. du XVIII siecle. sur papier. en 4 vol. in-folio de 249. 25.5. 25. el $107 \mathrm{ff}$.

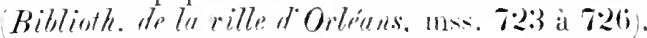

Orléans. - Courent des binidictines de Notre-bame de Iomne-Nouvelle.

2813 - Cartulatere de X.-U. de Bonne-Nonvelle dOrléans: ms. du XVII" siecle. sur papier. in-folio de $89: 3$ pages. avec table finale de $10 \mathrm{Hr}$.. et contenant des acles de 1691 is 1700 Biblioth. nationale, ms. francais 8784 .

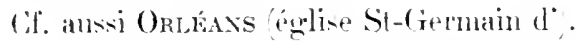

2814. - Aulre cartulaire on « Copia aliquarum cartarum heate Marie Boni Nuncii An elianensis s; ms. du XV siecle, sur papier. in-4 de:37 fl.. conteninul des actes de 10:30 a 1425 drelices dép. du Lrivet. H 116 provisoire.

2815. - Recueil des titres de X.-1). de Bonne-Nonvelle it Orléans; ns. du XVIII sièrle. avec index. sul papier, in-folio de xxi-752хи fr. Bitlinth. untionale, ms. latin 9218;.

Concerne aussi te priemé de 1)ouy qui en dopendait. Dates extrêmes: $10201-1703$.

Orléans. - Imehé.

2816. - Cartulinires des fiefs du duché d'Orléans; orig. perdus. 
Extraits des precedents. faits an $\mathrm{XVIH}^{\circ}$ siecle, in-to sur papies (Biblioth. dr la ville d Orlénes. ms. 487. 11. 2:29-270,

Orléans. - Église cathérlrale Sainte-Croix.

2817. - « Cartulariun relus ecclesia turelianensis »; orirg perdu.

Copie du précédent. faite en 1665 de la main de Baluze. sur papier. contenant 61 chartes des IX'-XIIe siècles Bithlioth. untinumle, coll. Baluze. vol. LXXili. II. 1-49.

I li fin on lit: "Hact"nus Chartularium ecclesiæ Aurelianensis retus quod integrum transeripsinus anno umiLxri mense januario frigidisimo: verun in transeribendo non sumus steuti ordinem qui extat in veteri endice........

2818. - Antre cartulaire de Sainte-Croix d'Orléans ou «livre rouge»; nıs. sur parchemin, avec reliure de bois ornée de fermoirs. et avec miniatures, orip. perdu.

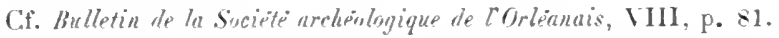

Extraits faits par Dom Estiennot an $\mathrm{XVIl}^{\mathrm{e}}$ siecle Bibliath. de l'Arsenal. ms. 1008. pp. 280-283: Biblinth. uationale, ms. latin 12739. pp. 485-487; par Baluze Biblinth. nationale. coll. Baluze. vol. CXYVIII. fo 275 : coll. Moreau. passim (copies de Dom Gérou): et par Polluche (Bibligth. de lis rille r'Orlénns. ms. 5.5.

2819. - Aulre cartulaire: orig. perdu.

2820. - Prbi. : Cartulaire de l’échlise cathedrale Sainte-Croix d'Orleans. par Joseph Thillier et Eug. Jarry Mémoires de la Société archéologique et historique de TOrléunais, XXX. 1906; in-80 de cxix-634 p.).

Dates extrêmes : 814-1300. - Cf. D. L. l'Achery, s̈picilegium, IIII (1668), pp. 13r, 148, 155 et 197 .

Orléans. - Église Saint-Germain.

2821. - Cintulaire des érlises de Saint-Germain et de Bonne-Youvelle d'Orleans; ms. des XVI ${ }^{\mathrm{e}}-\mathrm{XVII}^{\circ}$ siecles, sur parchemin, contenant des documents de 1503 à 1668 , in-folio de $890 \mathrm{p}$. Biblioth. de ln ville dOrléuns. ms. 485 .

Orléans. - Églist Saint-Pierre-en-Pont.

282:. - Fragment d'un cartulaire de l'érliwe Saint-Pierre-en-Pont d'Orléans : ins. du XIII siècle. contenant des actes de 1188-1272, sur parchemin. in-4" Biblioth. du Tuticun. ms. Regina 863. ff. 3845.

Publ. : Totice el extraits du manu-crit $86 j: 3$ du foml- de lat reine

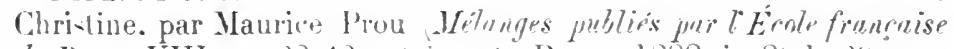
de Rome. VIII. pp.28-42, et a part : Rome, 1888, in-8" de 29 p. 
Orléans. - Érêché.

2823. - Cartulaire des fiefs de l'évêché d’Orléans; orig. perdu.

Extraits des précédents, faits au XVIIIe siècle, in-4" sur papier (Biblioth. de la ville d'Orléuns, nus. 487, If. 286-326; Biblioth. nationale, ms. nouv, acq. Irançaises 9654. r" Benuvildier, fo $\left.59 \mathrm{v}^{\prime \prime}\right)$. II. Jules Devaux a transerit ces textes ct se propose de les publier.

Orléans. - Forèt.

2824. - Cartulaire ou livre des usages de la forêt d'Orléans; ms. du XV siècle, sur parchemin, in-4" de 134 fl. (Archives nationales, $Q^{1 \star 591) . ~}$

Date's extrèmes: 1123-1402.

Orléans. - Grand cimetière.

2825. - Cartnlaile du grand cimetière d'Orléans; orig. ( $\mathrm{XVe}^{\mathrm{v}} \mathrm{s}$.) perdu. Extrait fait pour Gaignières an XVII ${ }^{\mathrm{e}}$ siècle Biblioll. nationale, ms. latin 17049, pp. 253-254.

Orléans. - Hôtel-1)ieu.

2826. - Punı..: Les chartes originales de l’ancien Hôtel-Dieu d'Orléans. par Ch. Cuissard (Mémoires de la Société archéologique et historique de Orléunis, XXVII, 1902, pp. 259-388).

Dates extrèmes de ce recueil factice : 856-17\%.t.

Orléans. - Prieuré de Saint-Samson.

2827. - Carlulaire du prieuré de Saint-Samsun d'Orléans; ms. du XVo siècle, contenant 275 pièces des annëes 1152 à 1439 , sur papier, in-4" de 259 II. (Archives dép. du Loiret, D 386 provisoire).

Extrait dn précédent fait an XVIJ siècle (Biblioth. nationale, coll. Balize, vol. IXXXYIll, l" 107 ,

\section{Orléans. - Université.}

2828. - Carlulaire de la nation d'Allemanne à l'Lniversité d'Orleans;

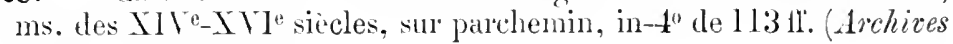
dép. du Loivet, D 4).

2829. - Cartulaire de la nation de Champayne à l'Université d'Orléans; ms. dn XVe-XV1e siècles, sur" parchemin, in-4" de 83 ff. (Archives dép. du Loirst, D 5).

2830. - Cartulaire de la nation d'Écosse à l'Université d’Orléans: ms. du XVe siècle, sur parchemin, in- $4^{\circ}$ (Bibliath. du Vatican, ms. Regina 405, ff. 14-6:3).

$$
\text { Cf. Aichives hes Missions, V, Pp. 58-63. - Ancien Petau (X-39). }
$$


2831. - Cartulaire de la nation de France à l'Tuniversité d’Orléans; ms. des $\mathrm{XIV}^{\mathrm{e}}-\mathrm{XVI}^{\mathrm{e}}$ siècles. sur parchemin. in-4" de $54 \mathrm{tl}$. (Archices dép. du Loiret, I) 6).

(C; volume, plus complet autrofois, a perctu ses fenillonts 40 it b3 ut 72-79 qui ont éte refrouves heureunement (1rehices dip. du loriret, D 7).

2832. - Autre cartulaire de l'Lniversití et de la ville d'Orleans: ms. du XVI" siècle, sur papier, in-folio de $194 \mathrm{ff}$. (Biblisth. d" Vaticar, ms. Ottoboni 3083).

Ancien Petau (E-45).

2833. - Autre cartulaire ; ms. dı XVe siècle, sur parchemin, in-4 de 69 ff. (Biblinth. nutionule, ms. latin 422:3a :.

2834. - Antre cartulaire ; ms. du XVe siècle, sur parchemin, in-4 ${ }^{0}$ (Herzigl. Biblinthek Wolfentiultel, Cod. Aug. 788).

2835. - Live dı Recteur de l'Université d'Orléars: ms. des XVe XVI ${ }^{\mathrm{e}}$ siècles. sur parchemin. in-folio de $70 \mathrm{fl}$. Archices dép. du Loiret, D 3 .

2836. - Publ. : Les statuts et privilèges des Universités françaises, par Marcel Fournier. I (1890), pp. I-259 : III (I892), pp. 445-493.

Orléans. - Ville.

2837. - Publ. : Les privilèges, franchises, libertés des hourgeois et habitants de la ville et fauxbourus d Orléans. Orléans. 1636, in-4 ${ }^{0}$.

2838. - Petit cartulaire mmicipal orléanais: ms. dı Xie siècle, sur papier, in $\mathbf{t}^{\prime \prime}$ de $102 \mathrm{fl}$. Biblioth. iutionale, ms. français 11988 .

2839. - Livre rouge de la ville d'Orléans : orig. perdu.

Voir aussi ci-dessus le $n^{0} 2832$.

Orsan. - Prieuré (lioc. de Bourges).

2840. - Cartulaire du prienré d'Orsan ; orig. perdu.

Extraits faits au XVII siecle par Dom Estiennot (Biblioth. nutionale. mss. latins 12742, pp. $536-538$; et 12743, pp. 290 et 306$)$.

Orsons. - Hospitaliers's (dior. de Saint-Papoul).

2841. - Cartulaire des Hospitaliers l'Orsons: ms. In XIVe siècle, contenant t3 documents des années 1:298-1380. sur parchemin et papier [en mauvais état], in-folio de $49 \mathrm{tl}$. Archices dip. de la Haute-Gizronne, $\mathrm{H}$ non coté).

Réunion de textes latins et mans.

Orthez. - Ville.

2842. - Cartulaire de la ville d'Orthez, dit le « Martinet »: ms. du 
XIVe siecle. avec adilitions jusqu'au X XIJ", sur papier, in-folio de $28: 311$. (Archixes mulcipales d"Orthez).

Tous les textes que contient cent cinorme registre sont en langue héanaist. Lá partie qui intéresse l'Lniversité d'Orthez au $\mathrm{XVI}^{\mathrm{e}}$ siècle

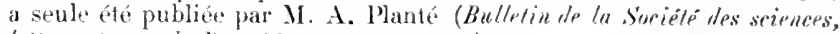
lettres of arts de lun, 188., pp. 208-31:1).

lixtraits faits par Ö̈henart au XVIJ siècle (Biblioth. mulionale, coll. Duchesne, vol. CXVI, Hf. $106-122)$.

Orval. - Abbaye (dioc. de Trives).

2843. - Cartulaire de l'abbaye d’Orval. dit « de l'ablú Henrion »; ms. du XVIII siecle, sur papier. eontenant des docmments de 1201 a 1753. en 4 vol. in-lolio de 740, 805. 754 et 660) pages (Archives de lEtut à Arlonit.

2844. - Cartulaire de l'ablare d'Orval. dit s de l'abbé Mommerts »; mis. du XVIII siecle, sinr papier. contenant des documents de 1029 is 1766, en 6 vol. in-folio de 847. 665. 612. 595. 556 et 600 parges Archives de l' litut à dron).

Dans l'un of l'autre de ces recueils, le classement des actes est chronologique par volume seukment.

Publ.: Cartulaire de l'ablaye d'Orval depuis l'origine de ce monastère jusqu’a l'année l:36\%). par le R. P. Hipp. Goftinet. Bruxelles, Hayez. 1880 ; in-4" de xxxrmi-800 p. [Collection des Chroniques belges.]

- Supplément an cartulaire de l'abłaye d'Orval (Bulletin mensuel de lo Swiétr d'merhénlogie lorwine. 1901, p. 284).

Cif. Rerherehe sur l'epoque de deax chartes du Cartulaire d'Orval, à propes de Gilke de Cons, par Léon Firmain. Nancy, Sidot, 1895; in- 8 , le $11 \mathrm{p}$.

2845. - Cartulaire de l'ahbaye d'Orval; ms. du XVII" siècle. sur papier, conlenant des actes de 1124 a 1675 , en 2 rol. in-folio de 260 ef $293 \mathrm{Hl}$. Studtbibliothek Trier, ms. 1333.

P'ubl. : Chartes inédites de l'abhaye d'Orval, par A. Delescluse. Bruxelles. Hayez. 1896 ; in-t" de xn-67 p. - Nouvelles chartes indites de l'abbaye d'Orval, par A. Delescluse et Karl Hanquet. Bruxplles, Kiessling, 1900 : in-4" de $15-36$ ]. [Collection des chroniques lielones.]

\section{Ossau (Vallée d").}

2846. - Cartulaire de la vallée d'Ossia ou «Livre rouge »; ms. du $\mathrm{XV}^{*}$ siecle. sur papier. reconvert d'une reliure contemporaine en hois et cuir unafré, contenant des documents de 1187 a $148: 3$. in-4 de $1 \mathrm{x}-406 \mathrm{il}$. (1 rehives du syudicat dr Ossan [antrefois à Bielle, AA 1], anj. deposére inx Arehices dép. des Basses-Pyrénées). 


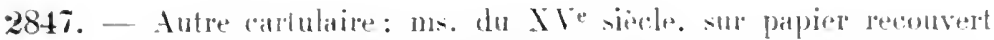
d'une vieille reliure en manvais itat. contenant des docmments de 1243 i 147t, in-t" do 111 ll. Idem. At 2.

2848. - Autre cantulaire: $11 \mathrm{~s}$. du $\mathrm{XVI}^{\mathrm{r}}$ siecle, non relic. sur papier. contenant des documents de 142:3 a 15.5. in-folio de 56 H. IIlem, A A : 3 .

Une irrande partip des actes se trouvent repétés dans los trois registres. - Cf. l'Inventaire sommaire des archives dép. des BansessPyrénés. 1. V (1873), par P. Raynond, p. 135, où d'ailleurs les analyses des trois registres sont tout à fail insuftisantes.

Oudenbourg. - Abbaye de Saint-Pierwe (dioe. de Bruges).

2849. - Cartulaire de l'ahbave d'Oudenbourg: ms. du XVe sierle, sur parchemin. contenant des titres de 1119 a 1454 . in-t" de $191 \mathrm{ff}$. Archires de l' Étut à Bruges.

Pebl. : Codex diplnmaticus monasterii Aldenburensis 1087 1797. dans F. Van de Putte. Chronique ru monastere d'Oudenbourur (Gand, 184:3. in-4".

Oudenbourg. - Vill .

2850. - Cartulaire municipal d'Oudenbourge ms. du XVe siecle [145\%]. sur parchemin. in-40 drchices muricipules dondenbramg).

Publ. : Histoire t'Oulenhour. accompannée de pièces justificatives comprenant le cartulaire de la ville et de nombreux extraits de Comptes communar. par E. Fers et D. Van de Casteele. Brures. De Zuttere. 1875. 2 vol. in $4^{0}$ de 176 et 368 p. [Publication de la Société d'Émulation de la Flandre occidentale].

Ouges. - Prieuré (dioc. de Langres).

2851. - Cartulaire dOures, clépendant de l'abbaye de Citeanx: ms. du XVe siècle. sur papier. contenant 3.57 actes des années $1202-1450$. in-folio de $2 \cdot 26 \mathrm{Hi}^{\circ}$. Sichires de la Catp-d Or. $\mathrm{H}$ non coté. fonds de Citeanx'.

2852. - Autre du XVII siecle. extrait du précédent. in-folio de $40 \mathrm{tr}$. Archires dép. de la Cóte-d'Or. H nou coté. fonds de Cî̀teax .

Oujon. - Chartreuse (dioc. de Lausanne).

2853. - Cartulaire de la Chartreuse d'Orjon : ms. du XIII" siècle, sur parchemin. in-4" de 172 p. Archires de "urcheoêché de Chambéry'.

Publ. : Cartulaire de la Chartreuse d'Oujon. par .J.-J. Hisely Cémoires of Documents publ. pur la Socipté thistoive de lu Suisse

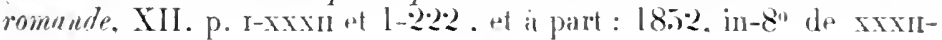
$2 \cdot 23$ p. el pl.

Oulx. - Prévòtè ét église Saint-Lament (dioc. de Salures). 2854. - Ciartulate de la prevote d'Oulx : origr. perdu. 
Copie du précédent; ms. du XIII siècle, sur parchemin (Archivio capitolare d'Oulx).

Antre copie du XVe siècle, sur papier (Archivio del vescovato da Pinerolo).

Autre copie du XVIlle siècle, sur papier, in-folio de 293 p. (Biblioth. de la ville de Grenoble, ms. 1166 ).

Publ. (incomplet): Berta e Rivautella, Ulciensis ecclesiæ charlarium animadversionilus illustratum. August Taurinorm, 1753 ; in-4 $4^{\circ}$.

Cf. Sui cartolari della prevostura d'Oulx; nota par Giov. Collino. Torino, Paravia, 1902 ; in-4 de 36 p. (estr. dei Hiscellanea di Storia italiana, ser. III, tomo IX). - Line publication intégrale est en préparation (cf. Le Itoypu-Alye, 1901, p. 481).

Ourscamp. - Abbaye (dioc. de Noyon).

2855. - Cartulaire de l'allaye de N.-I). d'Ourscamp; ms. des XIVe$\mathrm{X} \mathrm{V}^{\mathrm{e}}$ siècles, sur parchemin. incomplet de la fin, avec lettrines ornées et reliure de hois is fermoirs de cuivre, contenant 950 titres de 1124 a 1496, in-folio de 229) ff. à 2 col. (Archives dép. de l'Oise, $\mathrm{H}$ non coté).

Pubs. : Cartulaire de l'ahbaye de N.-D. d'Ourscamp, de l'ordre de Cîleaux. Condé en l129 au diocèse de Noyon, par Peigné1)elacourt. Amiens, Lemer, 1865 ; in- $4^{\prime \prime}$ de vir-620 p. [Documents. inédits de la Société des antiquaires de I'icardie, VI.]

2856. - Franments d'un cartulaire de l'alhaye d'Ourscamp, foliotés I-XxIx [concernant Lassigny]; ms. du XIVe siecle, sur parchemin, in-4" (Biblisth. Cheltenham, n⿳0 16868).

2857. - Recueil de titres relatifs ì l'abbaye d'Ourscamp, formé par Gaignières en partie d'après le premier cartulaire (Biblioth. nationale, ms. latin 5473 .

Ouville. - Prieuré de Notre-Dame. - Voy. Aumale.

Oyes. - Abbaye de Saint-Pierre (dioc. de Troyes).

2858. - Cartulaire de l'abbaye d'Oyes; ms. du XIVe siècle, contenant des actes de 1102-1305, sur parchemin, in-4" de 32 ff. (Archives dép. de l'. Lube, $\mathrm{H}$ non coté).

Copie moderne [1874] du précédent, in-40 de 25 ff. (Biblioth. nationule, ms. nouv. acq. latines I2:31).

Anal.: Cartulaire de l'ablbaye Saint-Pierre d'Oyes, canton de Sézanne, par le comte Ed. de Barthélemy. Chàlons-sur-Marne, Thouille. 1882. in-8" de $42 \mathrm{p}$. (Extr. de l'Annmaire de la Marne).

Pairis. - Abbaye (dioc. de Bàle).

2859. - Cartulaire de l'abbaye de Pairis; ms. du XVII siècle, sur 
papier. contenant 52 actes des années $1160-1651$. in- $8^{\circ}$ de 191 ff. (Archio des Ober-Elsass. in Colmar.

Pamiers. - Abbare de Saint-Antonin.

2860. - Recueil de titres relatifs i l'ablaye de Saint-Antonin de Pamiers; ms. de 1668 , contenant des actes des années 1111 à 1344 , in-folio de 28:2 Iï. Biblioth. nationale, coll. Doat. vol. 94.

2861. - Recueil d'actes relatifs à la mème abhave: ms. du XVIIe siècle, sur papier, contenant des actes de 970 i 1481. in-folio (Biblioth. nationale. ms. nouv. acq. françaises 404. If. 225-473).

Pamiers. - Courent des Dominicains.

2862. - Plbl. L Les Frères prècheurs à Pamiers aux XIII et XIV'e siècles; documents inédits pulbl. par l'al)bé C. Douais (Congrès archéologique de France, LI. 1885. pp. $254-347$ ).

Dafes extrèmes: : 1269-1333.

Pamiers. - Église cathédrale.

2863. - Extrait d'un registre des archives de Foix concernant l'église de Pamiers: ms. de lis8. sur papier. in-folio (Biblinth. nationale, ms. nouv. act. françaises 404, ff. 176-223).

Contient 34 actes des années 1241 à 1309 .

Pamiers. - Villi.

2864. - Recueil de titres relatifs ì la ville de Pamiers: ms. de 16661668. contenant des actes des années 1232 à 1546 , in-folio de $306 \mathrm{ff}$. (Biblioth. nutionule, coll. Doat, vol. 93).

Panthemont. - Abbaye (dioc. de Beaurais). 2865. - Cartulaire de l'ablaye de Panthemont ; orig. perdu.

Extrait fait a XIII siècle Biblioth. nationale, coll. Baluze, vol. LXXIII bis. fo 105 .

Papauté. - Voy. Rome.

Paray-le-Monial. - Prieuré (dioc. d'Autun).

2866. - Cartulaire du prieuré de Paray-le-Monial: orig. perdu [XIII ${ }^{e}$ siècle, in-f' de $114 \mathrm{fl}^{\prime}$.].

Se trouvait autrefois conservé ì l'abbaye de Cluni.

Copies et extraits dn précédent. faits an XVIJ siècle (Biblioth. nationale, ms. lat in 12689. If. 15-31 ter : coll. Baluze. vol. LXXV, ff. 1-16) : - par I)u Bouchet an XVlI siecle (Biblioth. de feu A. Giruud, - par I.mbert de Barive en 1782. in- $4^{0}$ de $46 \mathrm{ff}$. (Biblioth. nationale, ins. latin 9884, 
Extraits des cartulatres de Iarcigny et de Paray-le-Monial, lranscrits en 1725 sur parchemin, in-4" Archives dep. dn Rhone, $\mathrm{H}$ non ('otề.

Pebl. : Cartulaire du prieuré de Paray-le-Monial. ordre de SaintBenoit. survi d'un appendice de chartes et de visites de l'ordre de Cluny. par l'abbé Ul. Chevalier. Paris, Picard [Monthéliard, Holfnann]. 1890 ; in-8" de xx-220 p. [Collection des Cartulaires dauphinois. V111, 2.]

Paris. - Abbaye de Saint-Antoine.

2867. - Curtulaire de l'abbaye de Saint-Antoine; ms. des XIIIe-XIVe siècles, avec quelques additions, sur parchemin, précédé d'une table ancienne. et contenant des titres jusqu'à l'année 1370 , in- $4^{0}$ de $99 \mathrm{ff}$. (Archires untionalos, LL 1.595).

2868. - Cartulaire tle l'abbaye de Saint-Antoine; ms. du XVIII" siècle, sur papier, contenant des dorments de 1200 à 163\%. in-folio de $118 \mathrm{ff}$. Arrlives nationales, S 4386.

Paris. - Abbarede Sainte-Geneviere.

2869. - Cartulaire de l'ahbaye de Ste-(reneviève : ms. du XIII siècle, poursuivi au XVIe. sur parchenin, contenant des documents de 997 it 1527 avec tahle au début, in-folio de xx-392 pages (Biblioth. SainteGenevieve. il Paris. ms. 350 .

Extrails faits an XVII siècle par Du Chesne (Biblioth. nationale, coll. Baluze, vol. LV, ff. 1+0-179).

Il y avait autrufois plusieurs cartulaires de sainte-Genevirve, celui-là seul subsiste.

Paris. - Ablaye de Saint-(iermain-des-Prés.

2870. - Cartulair de l'al,baye de Saint-Germain-des-Prés ou « Cartu-

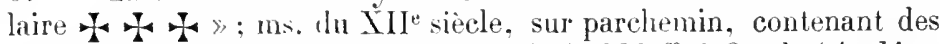

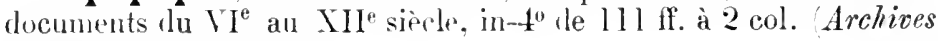
nutionules. L.L 1024.

2871. - Autre rartulaire clit « Curtulaire A B »; ms. du XIII siècle, sur parchenin, eontenant $3: 32$ dlocuments de 1077 ì $127 \mathrm{l}$, in $-4^{0}$ de $2: 37$ ff. a 2 col. Aréites nationales. LL. 1025.

2872. - Autre cartularire. dit « Curtulaire de l'abbé Guillaume »; ms. du XIII sièle, sur parchemin [avec lacunes], contenant des documents de 5.58 a 1.348 , in-t" de 29.5 tr. à 2 col. (1rchives nationales, I.I. 1026 .

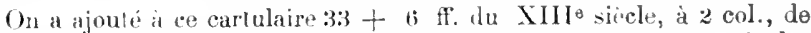
plusieurs mains, avec additions du Xl $V^{\circ}$ e, qui appartiennent à des origines diflérentes.

2873. - Livre de la pilancerie on « Cartulaire AD »; ms. du 


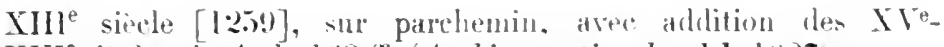

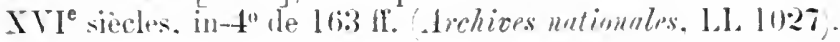

Les ft. I ì 13 (bulles) derribint être réunis au registre précédent.

2874. - Autre cartulaire de la pitancerie ; ms. du XIVe siecle, sur parchemin, in-folio (1rchices milommles. LL 1102. ff 89-157 et204-218).

287.). - Regristre des privilèges on "Cartulaire VH" " ms. du commencenent du XIV sipcle. sur parchemin, avec additions du

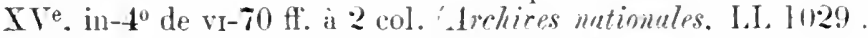

Transcriptions faites d'apris le L.L 1026.

2876. - Autre cartulaire des $\mathrm{XV}^{2}-\mathrm{XVl}^{2}$ siècles, sur papier. contenant des documents de 14.54 is 1581 . en 3 rol. in- $4^{0}$ de xxrt-93. 1x-138 et $\mathrm{r}-260 \mathrm{ff}$. Archires untionules. LL. 1031) à 1032 .

2877. - Autre rartulaire du XVe siècle. sur papier. contenant des documents presque entièrement postérieurs à 1400 . in- $4^{0}$ le $429 \mathrm{ff}$. Archives nutionules, L.L 10:34.

2878. - Frarment d'un cartulaire: ms. du XIVe siècle, sur parchemin, contenant des documents de 13336 à 1397. in-folio de 12 ff. [cotés ă-16] Archices mutionules. L 75:3, $\mathrm{n}^{0} \cdot 21$.

2879. - Autre cartulaire. concernant spécialement les propriétés de l'abbaye ì Paris; ms. du XVI siècle. sur papier. in-t" de $193 \mathrm{ff}$. (Arclieses nationales. LL I035).

On trouvera en outre, aux mots Anfoity, Aorintille, Bagueaux, Cachnn, Cihatillon, Cirespières. Esmats, Fontentay. Issy, Suresnes, Falouton. des cartilaires spéciaux is ces differentes propriétés de l'abbaye, écrits en 174t-175t far Ph. Duroussin, moine de labbaye.

2880. - « Cartulaire en latin et en françois abrégé de Paris et de l'Université»; ms. du XVI siècle. sur papier, contenant des actes transcrits ou analysés des XIIJ-XIVe siècles. in-4 de lll ff. (Archices mulionales. LL 1144).

2881. - Fragment d'un cartulaire de Saint-Cermain-les-Prés; ms. du XIII sièce. sur parchemin. comprenant ? fenillels Biblioth. nationale. nns. latin 13089 . If. 1:27-1:28.

288:. - P'LbL.: Les clartes de Saint-Germain-des-Prés des origrines an XIII siècle. par R. Pouparlin [en préparation. Société de l'histoire de Paris et de l'Ile-rle-France].

Paris. - Abbaye lr. Saint-Ylagloir

2883. - Petit cartulaire cle Saint-Yarrloire. « dis de lahhé (inillanme »; ms. du XIII siecle [1294]. sur parchenin. arec additions el table, mais incomplet de la fin. in-4" de n-1.50-II ff. Archieps untionales, 1.L. 39. 
2884. - Cartulaire de Saint-Magloire; ms. du XIII ${ }^{\mathrm{e}}$ siècle, sur parchemin, contenant des actes de 1237 à 1277 , in- $8^{\circ}$ de 182 pages (Archives nationales, LL, 40).

Les deux derniers feuillets sont mutilés.

2885. - Cartulaire de Saint-Magroire; ms. du XIVe siècle [1331], commencé par Jean de Rozoy, avec additions jusqu'en 1440, sur parchemin, in-folio de $201 \mathrm{ff}$. (Bibliotlièque nationale, $\mathrm{ms}$. latin 5413).

A appartenu à Petau.

Copies du précédent,faites au XVII siècle, 3 vol. in-folio de 171 ff., 676 et 454 p. (Archives nationales, LL 41 ì LL. 43).

Autre copie datie de 1756 , transcrite sur papier par l'abbé Sallier, avec tables, in-40 de L11-78: p. (Archives nationales, LL 44.

Autre copie du XVIII siècle, sur papier, in-folio de $312 \mathrm{ff}$. (Archives nationules, LL 45).

Dates: $\mathrm{X}^{\mathrm{e}}$ siecle à 14.10 .

2886. - Autre cartulaire dı XVII ${ }^{e}$ siècle, transcrit sur papier pour Gaignières, in-4 de xvi-412 et 57 p. (Biblioth. nationale, ms. latin 5414 .

Extraits des deux cartulaires par In Chesne (Biblioth. nationale, coll. Balıze, vol. I.T, ff. 293 et 315 ; vol. LXXXIII, p. 150-189, 277 et 293 .

Une table des denx cartulaires, grand et petit, se trouve comprise dans le ms. additional 11535 du Brilish Museum, ff. 123-167.

Autrefois le $n^{\circ} 1034$ de la rollection Joursanvault.

Paris. - Abbaye de Saint-Victor.

2887. - Cartulaire de Saint-Virtor de Paris; ms. du XIIJe siècle, avec quelques additions, sur parchemin, sous une ancienne reliure de bois, in $-4^{\circ}$ de $215 \mathrm{ff}$. (Archives nationales, LL 1450 .

Dates extrêrnes: $1113-1254$ et 1316 . Sous la cote LL $1450^{\mathrm{B}}$ on consirye une table moderne du présent cartulaire.

2888. - Antre cartulaire du $\mathrm{XVI}^{\mathrm{e}}$ siècle. sur papier, in-4 $4^{0}$ de $124 \mathrm{ff}$. Biblisth. nationule, nis. lat in 14672 .

Les 91 premiers feuillets ne contiennent que des bulles. - Dates extromes : 1113-1545.

2889. - Cantulaire des prébendes; ms. du XIII ${ }^{\mathrm{e}}$ siècle, avec additions postérieures, sur parchemin. de plusienrs mains et avec table en tête, in $-8^{0}$ de $\mathrm{v}-81 \mathrm{ff}$. Biblioth. nutionule, ms. latin 15057 ).

Dates extrêmes: 1170 environ- 1418.

2890. - Cartulaire de la Chambre dit « Cartulaire de Brie »; ms. dn $\mathrm{XVI}^{\mathrm{e}}$ siecle, sur papier, in-4" de 95 ff. (.1rchives nationales, $\left.\mathrm{S} 2174\right)$.

Dates extrènes: 1177-1512. Il concerne spéeialement les possessions en Brie. 
2891. - Cartulaire de l'aumônerie; ms. de la fin du XIII siècle, arec additions, sur parchemin, de vil-164 ff.

A été vendu a l'aris le 15 décembre 18.5 .

Extraits faits au XVII siècle du premier cartulaire. par Du Chesne (Bibliothèque nutionnle. coll. Baluze, vol. LV. ff. 257-292, :- autres (Idem. Clairambault, rol. 5(i2. p. 469-188).

Paris. - Abbaye du Val-de-Grâce.

2892. - Cartulaires du Val-de-Gràce; mss. du XVII siecle. sur papier, in-folio de 904, 486, 436. 1100 et 454 p. (Archices nationales, LL 1614 i 1618 .

Paris. - Archerèché. - Voy. PAris (Évêché).

Paris. - Chambre des Comptes.

2893. - Publ. : Ordonnances, édils. déclarations, etc., concernant l'autorité et la juridiction de la Chambre des Comptes de Paris. Puris, 1726, 2 vol. in $-4^{0}$.

Paris. - Chambre du Trésor.

2894. - Publ. : Recueil de plusieurs édicts, lettres patentes. déclarations, arrests, etc.. concernant la jurisdiction de la Chambre du Thrésor. Paris, Métayer, 1641, in-folio.

Paris. - Chapelle Saint-Yves.

2895. - Cartulaire de la chapelle Saint-Tres à Paris ; ms. de l'année 1791, rédigré d'après les originaux par Caillar de Courcelles, avocat, sur papier, contenant des titres de 1347 à 1650 , in $-t^{\circ}$ de $29 \mathrm{ff}$. (Archices nationales. L.L $963^{\mathrm{J}}$.

Paris. - Chapitre cathedral Notre-Lamı.

2896. - Livre noir du Chapitre de Totre-Dame de Paris; ms. du SII siecle. sur parchenin. arec additions posterienres. in-to de $212 \mathrm{ff}$. Archices nutionales, I.L 78 .

Actes des $\mathrm{X}$ - $\mathrm{XT}$ 'e siecles.

2897. - Grand pastoral de l'église Nolre-bame de Paris; ms. du XIII siècle. sur parchemin. avec reliure de bois. in-folio de 874 pages Archices nutionules. LI. 76.

2898. - Petit pastoral de l’étrise Notre-Dame; ms. du XIII siècle, sur parchemin. avec intercalation d’actes postérieurs. contenant des actes de 528 à 165l. relié en bois. in-folio de 377 pages Archices nationales. II Ti.

2899. - Cartulaire de l'uffice du Mandé; ms. du XITe siècle, sur parchemin, in-folio de $40 \mathrm{ff}$. Aichices untinuales. LI 83.

Dates extrèmes : 1209-130J. 
Extraits des cartulaires précédents. faits an $\mathrm{XVII^{ \textrm {e } }}$ siècle (Bibliothèque nutionale, coll. Duchesne. vol. LY. ff. 1-67; ms. latin 5l85) ; coll. Baluze, vol. LXXXIII, XCVII et CXXXIX.

2900. - Pubr. : Cartulaire de l'église Notre-bame de Paris, par Benjamin Guérard. Paris, Impr. nationale. $1850 ; 4$ vol. in-4 $4^{0}$. [Collection des Documents inédits.]

Paris. - Chapitre de la sainte-Chapelle.

2901. - Cartulaire de la Sainte-Chapelle de Paris ; ms. du XVIe siècle, sur papier. contenant des titres de 1310 a 1509 . in- $4^{0}$ de $400 \mathrm{ff}$. Arclives nationales, S 981 .

Extrait du précédent, fait au XVII siècle par A. Galland 'Biblioth. nationale. ms. francais 15504 , ff. 154-158.

Paris. - Chapitre de Sainte-Opportume.

2902. - Carlulaire du Chapitre de Sainte-Opportune; ms. dn XIII siècle. contenant des pièces des années $1150-1271$. sur parchemin. in- 4 " de $4 \mathrm{I} \mathrm{ff."} \mathrm{Archives} \mathrm{natiounles.} \mathrm{LL} \mathrm{.584.}$

2903. - Autre cartulaire de Sininte-Opportune; ms. du XIVe siècle avec additions postericures jusquau XVII ${ }^{e}$, sur parchemin, in-folio de 1:26 ff. Biblintera del Card. Rossi, it la Propagande. à Rome).

(Gité par Bethmann lans l'Arehio de leertz, XII, 112. - Il y a peu de temps, ce manuscrit a quitte Rom: pour une destination nouvelle;

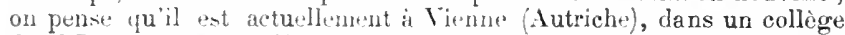
des lP. Jesuiten. - (f. unt notice plus detaillée de ce volume dans le

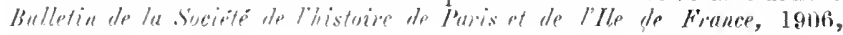
p. 212 .

Paris. - Chapitre le Saint-Étiemn-des-Grès.

2904. - Cartulaire du Chapitre de Saint-litienne-des-Grès: ms. du XIII ${ }^{e}$ jècle. sur parchemin. in-folio de $6: 3 \mathrm{ff}$. (Archives nutionales. LL $46 \%$.

Paris. - Chapitre de Saint-Grmain-l'Auxerrois.

2905. - Cartulaire du Clatpitre de Saint-(iernain-l'Auxerrois: ms. les XIII"-XIV" siècles.sur parchenin, in $t^{\prime \prime}$ de $119 \mathrm{ff}$. (Archives nutimnles. L.L : 386 .

l)ates txtrènes: $1108-1399$.

2906. - Autre de XIV"-XV"e siècles. sur parchemin, in-f" de $142 \mathrm{ff}$. (Arrlives metionales. LL 387.

La filupart des actes sont déja contenus dans le registre précédent.

2907. - Autre du $\mathrm{XVI}^{\mathrm{e}}$ siècle. sur parchemin, in-to de $14 \mathrm{ff}$. Arelives nutionules, LL :388.

Date's extrênes: 1203-1560.

2908. - Frangment d'un cartulaire de Saint-Germain-l'Auxerrois; ms. 
du XIlle siècle, sur parchemin. I feuillet in-4" Biblisth. natimnle, ms. Latin 10400 . folio 42.

Paris. - Chapitre de Saint-Honore.

2909. - Cartulaire du Chapitre de Saint-Honoré: ms. du XVIII siècle [155]. sur papier. en 3 vol. in-folio de 1106.989 et I012 pages Archices nutionales, LI 494-496.

Docunents depuis lannée 1126.

Paris. - Chapitre de Saint-Mareel.

2910. - Recueil de titres relatifs an Chapitre de Saint-Marcel; ms. de XVIII siècle. sur papier. contenant des actes de 1682 à 1738. in-folio de I24 ff. Archires iutionales, S 1639 .

Paris. - Chapitre du saint-Sépulcre.

2911. - Cartulaire du Chapitre du Saint-Sépulere: ms. du XVIe siècle, sur parchemin. in-folio de 144 ff. 'Archices nationales. LL 488 ,

Paris. - Collège d'Autun.

2912. - Recueil de titres relatifs au collège d’Autnn: ms. du XVe siècle. sur parchemin. in $t^{\circ}$ de $7 t \mathrm{ff}$. Biblisthèque de l'Université. ì Paris, ms. 966).

Paris. - Collège de chirurgie.

2913. - Statutz. priviléges et réglemens du collége de chirurgie de la ville de Paris. Paris. 1743 , in $4^{0}$.

Paris. - Collège de Cornonailles.

2914. - Cartulaire du colleze de Cornonailles is Paris: ms. du XVII siecle. contenant des copies collationnèes en 1672 par deux notaires dactes à partir de I321, sur papier. in-folio de 814 ff. (Archives nationales. MNI 393 .

Paris. - Collège de Laon.

2915. - Cartulaire du collège de Laon à Paris : ms. du X Te siècle, sur parchemin. in- 8 de $4 \mathrm{ff}$. Archices nationales, III 416 .

Acles de 1327 is 1409.

Extrait: faits an $\mathrm{XVII}^{\mathrm{e}}$ siecle par André Du Chesne 'Bibliothèque nationale. ms. nouv. acquisitions françaises i433. ff. 2l0-2II.

2916. - Autre cartulaire du collegre de Laon: ms, du $\mathrm{XV}^{\mathrm{e}}$ siècle. sur parchemin. in-40 de $285 \mathrm{fr}$. Archices matimales, MII 418 ,

Dales axlrèmes : 1297-1375.

Paris. - Collège de Maitre-Gervais un de Bạeux.

2917. - Recueil de titres relatifs an collège de Maitre-Gervais : ms. du 
$\mathrm{XVIII}^{\mathrm{e}}$ siècle, sur papier, in-folio de vin-122 pages (Biblioth. de l'Unizersité, à Paris, ms. 118.

Documents jusqu'en 1528.

Paris. - Collège des Apothicaires.

2918. - Cartulaire du collège des apothicaires parisiens ; ms. des XVIé $X \mathrm{VII}^{\mathrm{e}}$ siècles, sur parchemin, commencé en $157 \gamma$ à la requête des maîtres jurés et gardes de la corporation, et contenant dẹs documents de 1557 a 1645 , in-folio de $175 \mathrm{ff}$. (Archives de l's cole de pharmacie de Paris).

Manquent les ff. 2, 71-94, 135-137 et 166 .

Aval.: par Marius Barroux dans le Bibliograplee moderne, IX (1905), pp. 242-250.

2919. - Recueil de titres relatifs aux apothicaires de Paris; ms. du $\mathrm{XVI}$ e siècle, sur papier, in-folio (Biblioth. royale de Bruxelles, ms. 17939).

Paris. - Collège des Bernardins.

2920. - Cartulaire du collège des Bernardins : ms. du XVI siècle, sur papier, in-folio de $264 \mathrm{fl}$. (Archives nalionales. MII 366 .

Les dates extrêmes des pièces sont 1275 et 1596 .

Paris. - Collège des Cholets.

2921. - Cartulaire du collège des Cholets; ms. du XIII ${ }^{e}$ siècle, sur parchemin, in- $4^{\circ}$ de $12 \mathrm{Hr}$. (Archives nutionales, MM 374 ).

Dates extrêmes : 1279-1297.

2922. - Autre du XVIII ${ }^{\mathrm{e}}$ siècle, sur papier, contenant des titres de 1289 à 176l. in-folio de 93 fl. Archices dép. de l'Oise, G 773).

2923. - Recueil de titres concernant les biens possédés par le collège à Hallencourt, Castel et Tilloloy en Picardie : ms. du $\mathrm{XVI}^{\mathrm{e}}$ siecle, sur parchemin, contenant des actes de 1453 à 1517 , in-4" de $15 \mathrm{ff}$. (Archives nationales, MM 375).

Paris. - College du Plessis-du-Mont.

2924. - Recueil de titres relatifs au college du Plessis-du-IIont; ms. du XVII siècle [1621], sur papier, in-8' de '252 pages (Biblioth. de l'Universite, à Paris, ms. 970.

Paris. - Commanderie de Saint-Jean-de-Latran. - Voy. Hospitaliers ( $\left.n^{0} \cdot 2957\right)$.

Paris. - Coufrérie aux prêtres et bourgeois.

2925. - Cartulaire de la confrérie Notre-Dame aux prètres et bourgeois de Paris; ms. du XIII ${ }^{e}$ siècle, sur parchemin, contenant 38 chartes de $12033^{2} 1267$, in-4" de $3+$ ff. (1rchives nationales, LL 435). 
Publ. : Recherches sur la grrande confrérie Notre-Dame aux prètres et bourcreois de la ville de Paris, suivie du cartulaire et des statuts originaux de cette confrérie, par Leroux de Lincy Mémoires de la Société des antiquaires de France, XVII, 184t, p. 200-3I7); et à part: Paris, 1844 , in $-8^{0}$ de $123 \mathrm{p}$.

2926. - Autre cartulaire de la confrérie Notre-Dame; ms. du $\mathrm{XIII}{ }^{\mathrm{e}}$ siècle, sur parchemin, contenant entre autres 15 chartes des amees $127 \mathrm{I}-1292$. in- $4^{0}$ de $152 \mathrm{ff}$. (Biblioth. nationale, ms. nouv. acquisitions latines $85 . \overline{5}$.

Publ. : Documents nouveaux sur la grande confrérie Notre-Dame aux prêtres et bourgeois de Paris. par Henry Omont Mémoires de la Société de l'histoire de Poris, XXXII, p. l-88, et it part: Paris, 1905 ; in-80 de IV-88 p.

Paris. - Cour des tides.

2927. - Publ.: Recueil d'édits concernant la Cour des Aides, par J. Corbin. Paris, 1623. in $\mathbf{4}^{0}$.

Paris. - Couvent des Barnabites.

2928. - Cartulaire des Barnabites de Paris ; ms. commencé en 164l, sur papier, in-folio de $376 \mathrm{ff}$. (Arclives nationales, LL 1483).

Dates extrèmes : $1622-165 \%$.

2929. - Autre cartulaire des Barnabites; ms. du XVII siècle, sur papier, in-folio de 858 pages (Archives nationales, LL 1484).

Dates extrêmes: $1631-1675$.

Paris. - Couvent des Blancs-Manteaux.

2930. - Cartulaire des Blancs-Ianteaux; ms. du XVIe siècle. sur papier, in-folio de 182 t1.' Archives nationales, LL 1422,

Paris. - Couvent des Carmes-Billettes.

2931. - Cartulaire du convent des Carmes-Billettes de Paris et de Boucheraumont près Joinville ; ms. du XVIe siècle, sur parchemin,

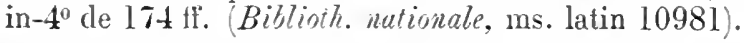

2932. - Cartulaire des Carmes-Billettes de Paris ; ms. du XVIIe siècle, sur papier, en 2 vol. in $-4^{0}$ de 515 et 341 p. (Archices nationales, LI. 1492).

2933. - Autre; ms. dn XYIIe siècle, sur papier, in- $\mathbf{t}^{0}$ de 881 p. (Archives nationales. LI. 1493.

2934. - Autre; ms. dn XVe siècle. sur parchemin, in- $8^{0}$ de 81 ff (Bibliath. de la ville "timiens, m: 74 du fonds Lescalopier).

Contient aunsi des documents sur les frères de la Charité Cotre-Dame de Rognon en Champagne ou Boucheraumont, courent fondé en 1285, qui ont fait place aus Billettes. - Cif. aussi vo Dossecx. 
Paris. - Couvent des Carmes déchaussés.

2935. - Cartulaire des Carmes déchaussés de Paris; ms. du $\mathrm{XVII}$ siècle, sur parchemin, in-folio de $53 \mathrm{fr}$. (Archives nationules, L.L 1494).

Paris. - Couvent des Célestins.

2936. - Cartulaire des Célestins de Paris ; ms. dı XVIIe siècle, écrit par plusieurs mains, sur papier, avec table finale, contenant des titres de 1367 à 1682 , in- $4^{0}$ de 631 pages (Archives nationales, LL. 1505).

Contient surtout des titres de fondations.

Paris. - Couvent des Cordeliers.

2937. - Cartulaire des Cordeliers de Puris; ms. du XVII ${ }^{\mathrm{e}}$ siècle, sur papier, contenant des titres de $15 \% 2$ à 1622 , in-folio de $127 \mathrm{fr}$. (Archives nationales, LL 1517).

Paris. - Couvent des Feuillants Saint-Honoré.

2938. - Cartulaire du monastère de Saint-Bernard ou des Feuillants Saint-Honoré ; ms. du XVII ${ }^{\mathrm{e}}$ siècle, sur papier, contenant des titres de 1585 à 1639 , in-4 ${ }^{0}$ de $89 \mathrm{fr}$. (Archives nationales, LL 1539).

Paris. - Couvent des Filles de Saint-Magloire.

2939. - Cartulaire des filles de Saint-Magloire, de l'ordre de SaintAugustin, à Paris; ms. de la fin du XVII ${ }^{e}$ siècle, sur papier, contenant des titres de 1496 à 1698, in-folio de 199 ff. (Archives nationales, LL 1683).

Paris. - Couvent des religieux de Picpus.

2940. - Cartulaire des religieux de Picpus; ms. du XVII ${ }^{e}$ siècle, sur papier, contenant des titres de 1603 à $163 \mathrm{l}$, in-folio de $49 \mathrm{ff}$. (Archives nationales, LI, 1580).

Paris. - Couvent des Trinitaires.

2941. - Cartulaire des Trinitaires ou Mathurins de Paris; ms. du XIII ${ }^{e}$ siècle, sur parchemin, in- $4^{0}$ de $88 \mathrm{ff}$. (Archives nationales, LL 1544.

Dates extrêmes: 1197-1294.

Paris. - Église Sainte-Geneviève-des-Ardents.

2942. - Cartulaire de l'église Sainte-Geneviève-des-Ardents ; ms. rédigé en 1617 , sur papier, avec reliure de cuir contemporaine, in-folio de xxvi-339 ff. (Archives nalionales, LL 726).

Paris. - Église Saint-Gervais.

2943. - Cartulaire de l'église Saint-Gervais ; ms. du XVIe siècle, de plusieurs mains, sur parchemin, contenant des titres de 1394 a 1570 , in-folio de viII-418 ti. (Archives nationales, LL 756). 


\section{Paris. - Eglise Saint-Merry.}

2944. - Cartulaire de l'église Saint-Merry de Paris : ms. du commencement du XIV"e siècle, sur parchemin, de 63 ff. in- $4^{0}$ (Biblioth. Vaticane, ms. Regina 907, ff. 37-62,

Provient de Petau.

Pub1.. : Cartulaire et censier de Saint-Merry de Paris, par Léon Cadier et Camille Couderc (Mémoires de lu Ściété de l'histoire de Paris, XVIII, 1891, p. 101-271), et à part: Yogent-le-Rotrou, in $-8^{\circ}$ de $173 \mathrm{p}$.

Paris. - Église Saint-Nicolas-des-Champs.

2945. - Cartulaire-censier de l'église Saint-Xicolas-des-Champs ; ms. du XVIe siècle, sur papier. avec une reliure en bois contemporaine, in-folio de $209 \mathrm{ff}$. (Archives nationales, LL 861).

Copie du même, du $\mathrm{XVI}^{\mathrm{e}}$ siècle. sur papier, in-folio de $224 \mathrm{ff}$. (Archices nationales, LL 862).

Paris. - Église Saint-Paul.

2946. - Cartulaire de l'église Saint-Paul; ms. du XVIe siècle, sur papier, in-folio de $222 \mathrm{ff}$. (Archives nationales, LL 884).

2947. - Autre du XVIe siècle [1548]. sur papier, in-folio de $99 \mathrm{ff}$. (Archires nationales, LL 886).

Paris. - Église Saint-Roch.

2948. - Cartulaires de l'église Saint-Roch; ms. des X $\mathrm{V}^{\circ}$ XVIIIe siècles [1495-1 $\% 66$, sur papier, en 4 vol. in-fol. de 528 p.. 999 p., 347 et $124 \mathrm{ff}$. (Archives nationales, LL 916-919).

Paris. - Évèché.

2949. - Cartulaire de l'évêché de Paris ; orig. perdu.

Extraits faits au XVII siècle Biblioth. de l'Arsenal, ms. 5260 , folio 71 ; Biblioth. nationule. coll. Duchesne. vol. XXII, ff. 140151).

2950. - Autre cartulaire; ms. du XIII e siècle. sur parchemin, in-12 de $157 \mathrm{fr}$. Biblioth. untionule, ms. latin 5.526).

A appartenu successivement à Pithou (1648), à de Thou et à Dupuy. - La table se troure dans le ms. 1095 de la coll. Noreau (Biblioth. nationule), ff. 240-255.

Copie du précédent. faite pour Gaignières : ms. du XVII siècle, in-folio de 274 p. (Biblioth. mationule, ms. latin 5185$)$.

Autres copies du mème. faites au XVIII siècle Archices nutionales, L1. 185-186: Biblisth. nationale. ms. latin 9150 .

Dat’s extrêmes: $1070-13 \times 6$.

295̆1. - Grand cartulaire de l'évèché : ms. du XIVe siècle, sur 
parchemin, avec reliure aux armes de l'archevêque de Beaumont, eontenant des actes de 1064 à 1423 , in-folio de $356 \mathrm{ff}$. (Archives nationales, LL T).

2952. - Petit cartulaire de l'évêché; ms, du XIVe siècle, sur parchemin, avec additions postérieures et relinre aux armes de l'archevèque de Beaumont, contenant des actes de 1120 à 1486 , in-folio de $281 \mathrm{ff}$. (Archires nationales, LL 8).

Extraits de divers cartulaires faits par Baluze (Biblioth. nationale, coll. Baluze, vol. LXXXIII); - (ms. latin 11836, ff. 49-144).

Tables du grand et du petit cartulaire, faites au XVIII ${ }^{\mathrm{e}}$ siècle, in-folio (British Museum, ms. additional 11535, ff. 1-55 et 55-100).

Autrefois le $n^{\circ} 1034$ de la collection Joursanvault.

Publ. : partiellement dans Guérard, Cartulaire de l'église NotreDame de Paris (voir ci-dessus $n^{0} 2900$ ).

Paris. - Hôpital des Quinze-Vingts.

2953. - Cartulaire de l'hòpital des Quinze-Vingts, ms. du XIVe siècle [v. 1335], sur parchemin, avec reliure en bois, in-4 $4^{0}$ de $388 \mathrm{ff}$. (Archives de l'höpitul des Quinze-Vingts, $\mathrm{n}^{0}$ 5848).

Cf. la notice de M. Léon Le Grand sur ce manuscrit (Hémoires de la Soc. de l'histoire de Paris et de l'lle de France, XIII, 1886, p. 108).

2954. - Bullaire de l'hòpital des Quinze-Vingts ; ms. composé en 1541, sur papier, contenant 46 pièces de 1441 à 1459 , in- $4^{\circ}$ de $49 \mathrm{ff}$. (Archives de l'hspitul des Quinze-Vingts, $n^{0} 5816$ ).

Paris. - Hòpital Saint-Jacques aux Pèlerins.

2955. - Recueil de titres relatifs ì l'hopital Saint-Jacques aux Pélerins ; ms. du XVIII" siècle, sur papier, in- $4^{0}$ de 618 p. (Biblioth. de la ville de Paris, ms. 447).

Paris. - Hôpital Siint-Lazare.

2956. - Cartulaire de l'hòpital Saint-Lazare; ms. du XIII siècle, contenant des pièces des années 1145-1210, sur parchemin, in-folio de $139 \mathrm{fl}$. (Archives nationales, MII 210).

Paris. - Hospitalier's de Saint-Jean de Jérusalem.

2957. - Cartulaire de l'Hòpital de Jérusalem à Paris ; orig.perdu.

Existait dans la bibliothèque de Pétau.

Extraits faits an XVII ${ }^{\mathrm{e}}$ siècle par André Du Chesne (Biblioth. nationale, ms. nouv. acq. françaises 743:3, ff. 212-215).

Paris. - Hôtel-Dieu.

2958. - Cartulaire A de l'Hôtel-I)ieu de Paris ; ms. du XIII' siècle, sur parchemin, écrit de deux mains dillérentes, et contenant 205 
documents des années 1140 (environ) a 1253 , in- $8^{\circ}$ de 181 ff. (Archives de l'Assistance mblique. à Paris'.

2959. - Cartulaire B de l'Hòtel-Dien de Paris: ms. du Xille siècle, sur parchemin, formé de différents petits registres indépendants et juxtaposés, écrits par trois mains différentes, et contenant 758 documents des années $1168-1260$, in $-4^{0}$ de $191 \mathrm{fir}$ a 2 col. Archices de l'Assistance publique. à Paris.

2960. - Cartulaire C de l'Hòtel-Dieu de Paris; ms. du ẌIIJ siècle [1295].sur parchemin.avec additions et lacunes de quelques feuillets, contenant 280 actes des années 1119-1324. in-40 de $146 \mathrm{fr}$. Archires de l'Assistance publique. à Paris).

2961. - Publ. Archives de l'Hôtel-Dieu de Paris (1157-1300), publié par Léon Brièle. avec notice, appendice et table par Ernest Coyecque. Paris. impr. nationale, 1894; in- $4^{0}$ de [v"II-] LxI-633 p. [Coll. des Documents inédits.]

La préface contient la notice détaillée des trois cartulaires. Joindre les documents pulliés aux pp. 28 $;-394$ du tome I de Ern. Coyecque: L'Hôtel-Dieu au moyen-âge (Paris, 1891 , in- $8^{\circ}$; Soc. de l'histoire de Paris). Cess do uments vont de $131 b^{\circ}$ à 1552 .

Paris. - Notaires au Chàtelet.

2962. - Pcbu. : Chartres, lettres. titres et arrèts de l'antiquité de la chapelle, droits, fonctions, pouroirs. exemptions, et privilèges des notaires et garde notes du roi au Chàtelet de Paris, par Me Guillaume Levesque, notaire au Chàtelet. Paris, 1663, in-4".

2963. - Traité des droits, priviléges et fonctions des conseillers du roy, notaires, gardes-notes et gardes-scel de Sa Majesté au Chàtelet de Paris, avec le recueil de leurs chartres ei titres, par S. F. Langloix. Paris. Coignard, 17:38; in- $4^{0}$ de xim-572 p.

Paris. - Prévôté des marchands.

2964. - Fragment d'un cartulaire de la ville de Paris: ms. du $\mathrm{XV}^{\mathrm{T}}$ siècle, sur parchemin. incomplet de la fin, contenant de: actes de 1165 à 1435. in-folio de $89 \mathrm{tr}$. Biblioth. nationale, ms. latin 9162 ).

Paris. - Prieuré do Notre-Dame des Champs.

2965. - Cartulaire du prieuré de Notre-Dame-des-Champs. dépt de l'abbaye de Marmontier ; orig. perdu.

A été connu de Saural qui le cite (Histoire de Paris, IIl, preures, p. 6), ainsi que de l'abbé Lebuf, qui lindique comme appartenant au Séninaire d'Orléans, où il stmble quon doive le che:cher en vain aujourd'hui.

Paris. - Prieuré de Saint-Denis-de-la-Chartre.

2966. - Cartulaire du prieuré de Saint-Denis-de-la-Chartre, dépt de 
l'abbaye de Saint-Martin-des-Champs; ms. du XVII ${ }^{\mathrm{e}}$ siècle, sur papier. contenant des actes de 1015 à 1666 , in- $4^{\circ}$ de 612 p. (Archives nutionales, LL 1:399).

La table placée en tête indique des actes qui n'ont pas été transcrits.

2967. - Autre du XVII siècle, sur papier, in-folio de $96 \mathrm{ff}$. (Archives nationales, LL, 1400).

2968. - Recueil de titres relatifs au prieuré de Saint-Denis-de-laChartre; ms. du XVI ${ }^{\mathrm{e}}$ siècle, sur papier, contenant des titres à partir de 1133 , in-4 ${ }^{\circ}$ de I29 fl. (Archives nationales, S 1056).

Paris. - Prieuré de Saint-Éloi.

2969. - Cartulaire du prieuré de Saint-Éloi, dép de l'abbaye de Saint-Maur-des-Fossés ; ms. du XIVe siècle [1392], sur parchemin, in $-4^{0}$ de $83 \mathrm{ff}$. (Archives nationales, LL 75 ).

2970. - Autre cartulaire; ms. du XVe siècle, sur papier, contenant des actes de 1140 à 1490 , in- $4^{0}$ de $270 \mathrm{ff}$. (Archives nalionales, $\mathrm{S}$ 1129).

2971. - Fragment de table d'un cartulaire du prieuré de Saint-Éloi ; ms. du XVIII siècle, sur papier, in-folio (British Museum, ms. additional $11535, f^{\circ} \cdot 230$ ).

Paris. - Prieuré de Saint-Martin-des-Champs.

2972. - Cartulaire A de Saint-Martin-des-Champs; ms. du XIIIe siècle, sur parchemin, in-4" de vni-125 ff. (Archives nationales, LL 1351).

2973. - Cartılaire B de Saint-Martin-des-Champs; ms. du XVe siècle, sur papier, in-40 de $141 \mathrm{ff}$. (Avclives nationales, LL 1352).

2974. - Cartulaire C de Saint-Martin-des-Champs; ms. du XVIe siècle, sur papier, in-folio de $209 \mathrm{ff}$. (Archives nationales, LL 1353).

2975. - Cartulaire D de Saint-Yartin-des-Champs; ms. du X VIe siècle, sur papier, in-folio de 320 ff. (1rchives nationales, LL 1354).

2976. - «Liber testamentorum »; ms. du XII ${ }^{\mathrm{e}}$ siècle sur parchemin, in-8 de $94 \mathrm{ff}$. (Biblioth. nutionale, ms. latin 10977).

Publ.: Liber Testamentorum sancti Martini; Reproduction annotée du manuscrit de la Bibliothèque nationale, [par J. Depoin]. Paris, Picard et fils, 1905 ; in- $8^{\circ}$ de $\times v-125$ p.

2977. - Cartulaire de la chambrerie; ms. des XIVe-XVe siècles, sur papier, in- $4^{0}$ de $39 \mathrm{ff}$. (Archives nutionales, LL 1374).

2978. - Cartulaire de l'hòtellerie; ms. du XVe siècle [1418], sur papier, in-t" de 94 il. (Archives nationales, LL 1358).

Extraits Biblioth. nationale, ms. français 15504, ff. 49-78; coll. Baluze, vol. LV, If. 213 et ss.)

2979. - Extraits du cartulaire « couvert de veau noir et doré sur 
tranche », par Laisné, prieur de Mondonville (Biblialh. nationule, ms. français 24133, pp. 619-640; - et dn cartulaire " couvert de bois avec des bouillons de cuivre », par le mème (Idtim. pp. 641-662).

2980. - Recueil de titres relatifs an prieuré de Saint-Martin-desChamps; ms. du XVIlle siècle, sur papier, avec table en tate, contenant des titres de 1584 i 1725 , in-folio de $107 \mathrm{fr}$. (Archices nationales, $\mathrm{S}$ 1441).

2981. - Autre recueil du $\mathrm{XVll}^{\mathrm{e}}$ siècle, sur papier, contenant des documents de 1060 à 1684, in-folio de 74 ff. (Archioes nationales, LL 1373).

2982. - Publ. : Martiniana, id est literae, tituli, cartae, privilegia et documenta tam fundationis, dotationis et confirmationis... monasterii seu prioratus conventualis S. Martini a Campis. Parisiis, N. du Fossé, 1606, in-8 .

Paris. - Université.

2983. - Publ. : Recueil des priviléges de l'Université de Paris accordez par les rois depuis sa fondation jusqu'à Louis Le Grand, par C. E. Du Boulay. Paris, 1674, in- $4^{0}$.

2984. - Chartularium Universitatis Parisiensis (1200-1452); edit. P. H. Denifle et Aem. Chatelain. Parisiis, 1889-1897; 4 rol. in-folio de xxxvi-715, xxi1 -800 , xxxvir-779 et xxxvir-837 p.

A joindre les 2 rol. des mêmes auteurs: Auctarium Chartularii Universitatis Parisiensis; Liber procuratorum nationis Anglicanae (Alemanniae) in Universitate Parisiensi (1333-1466).

2985. - Livre des privilèges de l'Université de Paris; ms. du XIVe siècle, sur parchemin, in- $4^{0}$ de $75 \mathrm{ff}$. (Biblioth. Cheltentham. ms. 876).

Mème recueil ; ms. du XIVe siècle (Biblioth. du Vatican, Reg. 406). Cf. aussi le ms. 283 du Corpus Christi College, à Oxford, et à Vienne (Autriche) le ms. latin 7219 .

2986. - Cartulaire de la Sorbonne; ms. du XIVe siècle. sur parchemin, contenant des titres de 1227 i 1279 , in- $4^{0}$ de 149 ff. à 2 col., plus une table chronologique sur papier [1f. 15l-159] (Biblinth. nationale, ms. latin 16069 ).

2987. - Autre cartulaire de la Sorbonne; ms. du XVle siècle, sur papier, contenant des titres des années 1263-1573, in-folio de $370 \mathrm{ff}$. (Archives nationales. MM 281).

2988. - « Livre du recteur » de l'Université de Paris; ms. du

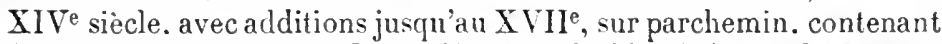
172 actes des années 1218 à 1652 , in-4t de $220 \mathrm{ff}$. (British Museum, ms. additional 17304.

2989. - Cartulaire de la nation d'Angleterre et d'Allemagne de l'Ĺni- 
versité de Paris; ms. des $\mathrm{XIV}^{\mathrm{r}} \mathrm{XVVIJ}^{\mathrm{e}}$ siècles, sur parchemin, in- $4^{0}$ de $175 \mathrm{fr}$. (Biblioth. nationale, ms. nouv. acq. latines 535).

Anal. : Le livre ou cartulaire de la nation d'Angleterre et d'Allemagne dans l'ancienne Université de Paris, par Em. Chatelain (Mémoires de la Société de l'listoire de Paris, XVIII, 1891, p. 73$100)$; et à part: Nogent-le-Rotrou, 1892 ; in-8 de $28 \mathrm{p}$.

2990. - Autre cartulaire, moins complet, de 1355 environ, sur papier (Archives de l'Université de Paris, ì la Sorbonne, reg. 94).

Contient des actes à partir de l'an 1200.

2991. - Cartulaire de la nation de Normandie à l'Université de Paris, ou « Codex Harcurianus »; ms. des XlVe-XVHI e siècles, sur parchemin, orné de miniatures et avec reliure anx armes du collège d'Harcourt, in-40 de vili-200 ff. (Biblioth. de la ville de Chartres, ms. 595) (1).

Cf. Bulletin de la sociéte de l'histuire de Paris, XII, 1889, p. 121-123.

2992. - Cartulaire de la nation de France de l'Université de Paris; ms. des $\mathrm{XIV}^{\mathrm{e}}-\mathrm{XVI}$ e siècles, sur parchemin, avec table aux ff. 123128, in-4 ${ }^{\circ}$ de 189 ff. (Biblioth. nulionale, ms. nouv. acq. latines, non coté).

Acquis en 1907.

2993. - Cartulaire de la section de Picardie de l'Université de Paris ; orig. perdu.

Est souvent cité par 1)u Boulay.

Paris. - Ville.

2994. - P’uns.. : Cartulaire général de Paris, ou recueil de documents relatils à l'hisloire et à la topographie de Paris, par Robert de Listeyrie. I (528-1180). Paris, Impr. nationale, 1888; in-4 ${ }^{0}$ de Lxv-570 p. et pl. [Histoire générale dle Paris.]

2995. - Publ. : Documents parisiens du règne de Philippe VI de Valois (1328-1350) extraits des registres de la Chancellerie de France, par Jules Viard. Paris, Champion, 1899-1900; 2 vol. in- $8^{\circ}$ de [IV-] xxiv-339 el 409 p. [Société de l'histoire de Puris.]

2996. - Cartulaire de la ville de Paris; ms. du XVII ${ }^{\mathrm{e}}$ siècle, sur papier, contenant des actes de 1515 à 1604 , en 2 vol. in-folio de 342 et 365 ff. (Archives nationales, KK 101:2-1013).

Voir aussi un autre recueil qui porte souvent le nême titre mais que nous avons classé de préfértence, vu son contenu, au mot a Prévôté des marchands ").

[Voir en outre, pour divers recueils imprimés, au Supplémext.]

(1) Ancien $n^{\circ} 662$ : ce volume a passé longtemps pour un cartulaire du collège d'Harcourt. 


\section{Pau. - Ville.}

2997. - Cartulaire municipal de l'au ou "livre rouge », contenant des documents des années 1406 à 1812 : ms. du XYle siecle, sur papier, avec additions successives, in-folio de $318 \mathrm{ff}$. (1rchices municipales de Pau, AA l).

Extraits du cartulaire de Pau, faits an XVIJ siècle par Oühenart (Biblioth. nationale, coll. Duchesne, vol. CXVI. ff. 102 et is.).

Paunat. - Abbayo (dioc. de Périgueux).

2998. - Cartulaire de l'abbaye de Paunat; orig. perdu.

Extraits faits au XVIII siècle (Biblioth. nationale, coll. Lespine, vol. XXXIY, ff. 86 et ss.).

2999. - Publ. : Fragments de cartulaire du monastère de Paunat (Dordogne). par René Poupardin et Antoine Thomas Annules du Minl, XVlll, 1906, pp. 5-43 ; et à part: Toulouse, Privat, 1906 ; in $-8^{\circ}$ de $39 \mathrm{p}$.

Publié d'apres des notices écrites dans les marges ou sur les feuillets restés blancs d'un ms. du Xe siècle provenant de St-Martial de Limoges (Biblioth. nationale, ms. latin 3851 a). La plus ancienne notice est de l'année 856 ; la plupart appartiennent au XIe siècle. - On pourrait joindre deux actes anciens copiés aux ff. $142 \mathrm{r}^{0}-143 \mathrm{du} \mathrm{ms}$. latin 1785 .

Cf.: Note sur une charte du monastère de Paunat et sur les origines - de Saint-Martial de Limoges, par Léon Levillain (Bu!lptin de la Société des Antiquaires de l'Ouest, $2^{\mathrm{e}}$ série, X, 1906, pp. 526-533).

Pébrac. - Abbaye (dioc. de Saint-Flour).

3000. - Cartulaire de l'abbaye de Pébrac: ms. du XII siècle, sur parchemin, avec additions jusqu'au XVIe. in- $f^{\prime \prime}$ de 26 ff. 'Biblioth. de l'éréché du Puy.

Copie du même faite en 17ll, sur papier, par le frère $\mathrm{X}$. Le Comte : in- $4^{p}$ de $31 \mathrm{ff}$. (Biblisth. nationale, ms. latin 9855).

Prbl. : Cartularium sive terrarium Piperacensis monasterii, ordinis canonicorum saneti Angrustini, ex menuscripto et originali codice transcriptum cura J. B. Payrard (Tablettes historiques du Velay, $\mathrm{V}, 1875$, pp. 129-214), et it part: Anicii [Le Puy], 1875; in- $8^{\circ}$ de vili- $80 \mathrm{p}$.

Perche. - Prorince.

3001. - Pcbi. : Géographie du Perche et chronologie de ses comtes, suivies de pièces justificatives formant le cartulaire de, cette province, par le v $v^{\text {te }}$ O. de Romanet. Mortagne. impr. de l'Écho de l'Orne, 1890-1902; in- $8^{\circ}$ de 176.272 et virI- 73 p. arec carte. [Documents sur la province du Perche. $2^{\mathrm{e}}$ série. I.]

Dates extrêmes : 1132-17\%. 
Périgny. - Prieuré (dioc. de Blois).

3002. - Cartulaire du prieuré de Périgny, dépendant de l'abbaye de

Saint-Laumer de Blois; orig. perdu.

Copie partielle du précédent, « Codex exiguus papyraceus qui ex alio ampliori et generali transcriptus est »; également perdu.

Extraits faits an $\mathrm{XVII}^{\mathrm{e}}$ siècle par Dom Anselme Le Michel ( $B$ iblioth. nationale, ms. latin 13818, ff. 93-99).

Périgueux. - Ville.

3003. - Publ. : Privilèges, frunchises, libertés de la ville, cité et banlieue de Périgueux. P'érigueux, 1662, in- $8^{\circ}$.

Péronne. - Église collégiale Saint-Fursy (dioc. de Noyon). 3004. - Cartulaire de la collégiale Saint-Fursy de Péronne; orig. perdu.

Jention en est faite à diverses reprises (cf Biblioth. nationale, coll. Moreau, vol. 99, fo 160 et 202 ; vol. 206, fo 201 ; coll. D. Grenier, vol. CisI, fo $135 \%$.

Péronne. - Ville.

3005. - P'UBL. : Les privilìges, franchises et libertés donnés par le roi aux bourgeois de Péronne. Paris, 15:36, in-8 ${ }^{\circ}$.

Perpignan. - Église collégiale Saint-Jean.

3006. - « Liber privilegiorum et ordinationum ecclesiæ sancti Johamnis Perpiniani »; ms. dn XVe siecle, sur papier, in-40 de $78 \mathrm{ff}$. (Biblioth. de la ville de Perpignan, ins. 78).

3007. - Fragrment d'un carbulaire de la collécriale Saint-Jean de Perpignam; ms. du XIVe siècle, sur parchemin, contenant des documents depuis 8:34, in-4" de 3 ff. Archives dép. des PyrénéesOrientales, (i 231$)$.

Extrait du précélent, fait au XVII siècle par $H$. Sunyer, notaire de la dite église (Biblioth. natiomale, coll. Baluze, vol. CVIII, ff. 137-1:38).

Wixtruts de plusienrs cartulaires de la même église; ms. du XVIIl siecle, sur papier, in- $t^{\circ}$ de $9 \mathrm{ff}$. (Archives des PyrénéesOrientules, G 2:31).

Perpignan. - Confrèrie des cordonniers.

3008. - Carlulaire de la confrérie des cordonniers de Perpignan; ms. des XVIe-XVII siècles, contenant des actes des années 1552 à 1713, sur parchemin, in-folio de 94 ff. (Biblioth. de la ville de Perpignan, ms. 92). 
Perpignan. - Confrérie des Saintes-Ëpines en l'óglise SaintMathien.

3009. - Cartulaire de la confrérie des Saintes-Épines de Perpignan; ms. du XVIII siècle. sur papier. contenant des titres de 1638 a 1764 , in-folio de I99 ff. Archices dép. des Pyréntées-Drientules, G 685,

\section{Perpignan. - Hôpital.}

3010. — «Libre major » de l'hopital de Perpignan; orig. perdu. 3011. - «Libre de la Font» de l'hôpital de Perpignan; orig. perdu. Ces deux volumes ne peurent être tout au moins qu'égarés : ils existaient encore lorsque, il y a quarante ans, Alart préparait sun recueil do Privilèges (ci-dessous no 3267 ) où ils sdnt cités p. 27.4 .

\section{Perpignan. - Ville.}

3012. - «Liber privilegiorum et ordinationum oppidi Perpiniani »; ms. du XIV"e siècle. sur parchemin, in-4 de $72 \mathrm{ff}$. (Biblioth. de la rille de Perpignan, ms. 83;.

3013. - «Livire rert majeur»; ms. commencé en 1392. et continué jusqu’à la fin du XVIIII siècle, en 2 vol.. le premier sur parchemin contenant des actes de 1162 a 1785 , le second sur papier contenant des actes de 1766 à 17688 . in-folio de xII-491 et XLII-235 ff. (Archires municipales de Perpignan, At 1-2).

3014. - 《Livre vert mineur »: ms. du Xille siècle, continué jusqu'au $\mathrm{XVIII}^{\text {e en }} 2$ vol, sur parchemin. le premier contenant des actes de 1185 à 1413. le second des actes de 1074 a 1729. in-folio de $707 \mathrm{ff}$. ensemble (Archices municipales do Perpignan, A. 3-4.

Ax.r. : Inventaire sommaire des archives communales de la ville de Perpignan [sous presse]. pp. 1-56.

3015. - Autre cartulaire municipal de Perpignan: ms. des XIVeXVI siècles. sur parchenin. in $t^{\circ}$ de $212 \mathrm{ff}$. Biblisth, nationale, ms. latin 9995).

3016. - P'BL. : Recollecta de tots los privilegis. provisions, pragmatiques e ordinacions de la firlelissina vila de Perpenya. por Rigau. Barcelona, J. Rosenbach. 1510, in-folio.

Perrecy-les-Forges. - Pricuré (dioc. d'Autun).

3017. - Cartulaire du prieuré de Perrecy, dépendant de l'abbaye de Saint-Benoit-sur-Loire; orig. perdu.

Vu encore par Mabillon en 1682.

Publ. : Recueil cle plusieurs pièces curieuses servant à l'histoire de Bourgrogne. par Pérard. Paris, C. Cramoisy. 16tit; in-folio (pp. 22-46. 
Copie faite au XVII ${ }^{\mathrm{e}}$ siècle par le P. Chifflet [incomplète]; ms. sur papier, in-folio (Biblioth. des Bollandistes, à Bruxelles).

$\mathrm{U}_{n}$ des feuillets manquants se retrouve à la Biblioth. nationale, coll. Baluze, vol. XL, fo 73 .

Autre copie, exécutée en 1721 par Bouhier; ms. sur papier, in $-4^{0}$ de 96 pagres (Biblioth. nationale, ms. latin 17721).

Autre copie partielle [incomplète]; ms. du XVIII ${ }^{\mathrm{e}}$ siècle, sur papier, in-40 de $11 \mathrm{ff}$. (Biblioth. de la ville de Dijon, ins. 1132).

Autre copie partielle; ms. du XVII ${ }^{\mathrm{e}}$ siècle, sur papier, in-folio (Biblioth. nationale, ms. latin 12689, ff. 63-88).

Ne conticnt pas les textes les plus anciens.

Cf. : Recueil des Chartes de l'abbaye de Saint-Benoit-sur-Loire, par M. Prou et A. Vidier, t. I (Introduction), et pp. 23 et ss.

Perrières. - Prieuré de Saint-Vigor (dioc. de Sées).

3018. - Cartulaire du prieuré de Saint-Vigor de Perrières, dépendant de Marmontier ; ms. contenant des pièces des $\mathrm{XI}^{\mathrm{e}}-\mathrm{XV} \mathrm{V}^{\mathrm{e}}$ siècles, in- $\mathbf{4}^{0}$ (Appartenait en 1870 à la collection Boismorand, à Poitiers).

Perseigne. - Abbaye (dioc. du Mans).

3019. - Cartulaire de l'abbaye de Perseigne; ms. du XVII siècle, sur papier, in-4" de 175 pages (Biblioth. nationale, ms. latin 5474).

Publ.: Cartulaire de l'abbaye cistercienne de Perseigne, par Gabriel Fleury. Mamers, Fleury et Dangin, 1880 ; in- $4^{0}$ de cxxvir271 p. et fig.

Perthes. - Prieuré. - Voy. Montiérender.

Pertuis. - Ville.

3020. - Cartulaire municipal de Pertuis: ms. du XVe siècle, avec additions du $\mathrm{XVI}^{\mathrm{e}}$, sur parchemin, contenant des actes de 1298à 1524 , in-folio de 62 ff. (Archives dép. des Bouches-du-Rhóne, B 1412).

En tète, l'autorisation dounée en 1428 par Charles d'Anjou, gouverneur de l'rovence, au conseil communal de Pertuis de dresser sous forme de cartulaire la copie des principaux privilèges de la commune et de la déposer aux archives royales de Provence, à l'abri de l'incendie.

$3020^{\text {bis. }}$ - Cartulaire de Pertuis et Peyrolles ; ms. du XIII ${ }^{\mathrm{e}}$ siècle, sur parchemin, in-40 de $19 \mathrm{ff}$. (Avchives dép. des Bouches-du-Rhone, B 1416).

Pessan. - Abbaye (dioc. d'Auch).

3021. - Cartulaire de l'abbaye de Pessan ; orig. perdu.

Ce cartulaire, qui contenait des actes du IX $\mathrm{X}^{\mathrm{e}}$ siècle au moins, a été connu (1746) de Dom Brugiles qui le cite it plusieurs reprises. - Des chartes du XIII sicele relatives à cette abbaye ont été publiées dans la Reiue de (iuscogue, XXXV (1894), Pp. 269-272. 
Peteghem-lez-Audenarde. - Abbaye (dioc. de Gand). 3022. - Cartulaire de l'abbaye de Peteghem; orig. perdu.

Fixtraits faits au XVIIe siècle par D. Anselme Le Michel (Biblisth. nationale, ms. latin 13820 , if. $27-31$ ).

Peyrolières. - Prieuré de Sainte-Foy (dioc. de Toulouse). 3023. - Cartulaire du prieuré de Sainte-Foy de Peyrolières: ms. du XVII siècle, contenant 84 actes des années $1154-1644$. sur papier, 2 vol. in-folio (Archices dép. de la Haute-Garanne, $\mathrm{H}$ non coté).

Peyrolles. - Voy. Pertuls.

Pézenas. - Ville.

3024. - Cartulaire $A$ de la ville de Pézenas; ms. de la fin du XVe siècle avec additions du XVIe, contenant des titres de 1280 à $15 \% 9$, sur papier. in-folio de $190 \mathrm{ff}$. (Archices municipales de Pézenas, AA 1).

3025. - Cartulaire B ; ms. des XVe-XVIIe siècles, contenant des titres de 1345 à 1670, sur papier, in-folio de 366 ff. (Archires municipales de Pézenas, AA 2).

3026. - Cartulaire C; ms. du XVIIe siècle, contenant des titres de I345 à 1596. sur parchemin, in- $4^{\circ}$ de 51 ff. (Archives inunicipales de Pézenas, Ad 3).

3027. - Recueil des privilèges de Pézenas; ms. du IVIII siècle, contenant des titres de 1345 à 1757 , sur papier, in-folio de $65 \mathrm{ff}$. (Archives municipales de Pésenas, At 4).

Picquigny. - Église collégiale Saint-Martin (dioc. d'Amiens). 3028. - Livre rouge de Saint-Martin de Picquigny ; orig. perdu.

Copie du précédent; ms. du XVIIe siècle, sur parchemin. in-folio de 280 pages (Biblioth. de lu rille de Rouen, ms. 2266).

Lne autre copie du XVIII siècle (in-folio de 544 pages) a figuré dans la vente Le Ver, en 1866 , sous le $n^{\circ} 75$. - Cf. des extraits faits au XVIII siècle (Biblioth. de la tille de Roye, ms. 17).

Picquigny. - Seigneurie.

3029. - Cartulaire ou Livre rouge des vidames de Picquigny ; ms. des XIIIe-XIVe siècles. sur parchemin. in-folio de 108 fi". (Irrchives nationales, $\mathrm{R}^{1} 35$ ).

La Société des Antiquaires de Picardie en possède une copie, faite par R. de Belleval vers 1860.

Extraits faits par Du Cange au XVII siècle (Biblioth. de l'Arsenal, à Paris, ms. 4652, ff. 258-263 : et ms.5261, ff. 78-87; et Bitlioth. nationale, ms. français 9499 , pp. 145-161). 
Pierrefitte. - Châtelleniẹ en Lorraine.

3030. - Recueil de titres relatifs à la châtellenie de Pierrefitte : ms. du

XVI ${ }^{\mathrm{e}}$ siècle, formé par Thierry Alix, sur papier, contenant des textes de 1266 à 1576 , in-folio de $100 \mathrm{ff}$. (Archives dép. de Meurthe-etMoselle, B 385).

Copie du précédent faite au XVII ${ }^{e}$ siècle, in-folio, sur papier (Archives dép. de la Meuse, B 252).

Pierrefonds. - Maladrerie (dioc. de Soissons).

3031. - Cartulaire de la maladrerie de Pierrefonds; ms. du

XVII siècle, sur papier, contenant des titres de 1301 à 1549 , in $-4^{0}$ de 43 ff. (Archives dép. de l'Oise, $\mathrm{H}$ non coté, fonds du prieuré de St-Pierre-en-Chastres).

Pignerol. - Abbaye (dioc. de Turin). 3032. - Cartulaire de l'abbaye de Pignerol ; orig. perdu.

Existait encore au XVII siecle; Guichenon en a publié des extraits dans son Histoire généalogique de la maison de savoie, nouv. éd., IV, p. $18-19$ et 27 .

Poigny. - Châtellenie près de Rambouillet. - Voy. NotreDame-Des-Moulineaux.

Poissy. - Passage sur la Seine.

3033. - "Cartulaire du bac » contenant « les titres de propriété du droit de voiture sur la Seine, appartenant aux dames du couvent de Saint-Louis de Poissy »; ms. de 1766, sur papier, in-40 de xvi-362 pages (Arcliver dép. de Seine-et-Oise, $\mathrm{H}$ non coté).

Dates extrêmes : 1311-1760.

Poitiers. - Abbaye de la Trinité.

3034. - Cartulaire de la Trinité de Poitiers; orig. perdu.

Extrait fait par Dom Estiennot en 1675 (Biblioth. nationale, ms. latin 12755 , pp. 489 et 494 ).

3035. - Recueil des titres de l'abbaye de la Trinité de Poitiers ; ms. du XVIII ${ }^{e}$ siècle, sur papier, contenant 148 pièces des années $936-1634$, in-4" Biblioth. de la ville de Poitiers, coll. Dom Fonteneau, vol. XXVII, pp. 15 à 708).

Poitiers. - Abbaye de Montierneuf. - Voy. Montrerneuf.

Poitiers. - Abbaye de Saint-Cyprien.

3036. - Cartulaire de Saint-Cyprien de Poitiers; ms. du XII siècle, sur parchemin, de plusieurs mains, in- $4^{0}$ de $127 \mathrm{ff}$. (Bibliath. nationale, ms. latin 10122). 
Copie du précédent, faite au XVII siècle, sur papier, in-folio de $211 \mathrm{ff}$. (Biblioth. nationale, ms. latin 12896).

Autre copie par Dom Fonteneau, XVIII ${ }^{\mathrm{e}}$ siècle. in- $4^{\circ}$ de 724 et 737 pages (Biblioth. de la ville de Poiliers, coll. Dom Fonteneau, rol. VI-VII).

Ces deux copies contiennent le feuillet qui manque à la fin de l'original.

Extraits faits au XVI ${ }^{\mathrm{e}}$ siècle [1675] par Dom Estiennot (Biblioth. nationale, ms. latin 12755, pp. 187-191, 225, 249, 530-531, 536$552,557-562,567-580$ et 627 ; ms. latin 12758, p. 388); - par A. Galland (Idein, ms. français 16188, fo 202); - par André Du Chesne (Ideiil, ms. nouv. acq. françaises 7433, ff. 26-47); - et par d'autres (I!lem, coll. Baluze, vol. LXV, ff. 75-76; ms. latin 138I 7 , ff. 71-93; ms. latin 1712 $;$, pp.343 etss.; ms. latin I 7148 , pp.33-148).

Le ms. latin 12755, ff. 418-4i3, contient encore diverses copies relatives à la même abbaye.

Publ. : Cartulaire de l'abbaye de Saint-Cyprien de Poitiers, par L. Rédet (Archices historiques du Poilou, III, 1Sit; in-80 de xcrv448 p.).

Dates extrêmes : 888-1155.

Poitiers. - Chapitre cathèdral Saint-Pierre.

3037. - Cartulaire du Chapitre cathédral de Poitiers; ms. du XVIII siécle, sur papier. contenant 99 acles de $1025-1578$. in- $4^{\circ}$ de 653 pages (Biblioth. de la ville de Poitiers, coll. Dom Fonteneau, vol. II).

Poitiers. - Chapitre de Sainte-Radegonde.

3038. - Recueil des titres du Chapitre de Sainte-Radegonde de Poitiers; ms. du XVille siècle. sur papier, contenant 63 pièces des années 926-15\%. in-4 Biblisth. de la rille de Poitiers, coll. Dom Fonteneau, vol. XXIT, pp. 11 à 248 .

Poitiers. - Chapitre de Saint-Hilaire le Grand.

3039. - Cartulaire de Saint-Hilaire de Poitiers ou " livre de la Chaìne »; orig. perdu.

Extraits faits au XVII siècle par André Du Chesne (Biblioth. nationale, ms. nour. acq. françaises i433, ff. 48-62) ; par Dom Estiennot en 1655 (Idem, ms. latin 1255, pp. 518-524).

3040. - Recueil des titres dı Chapitre de Saint-Hilaire-le-Grand ì Poitiers; m. du XVIII siècle, sur papier, contenant 431 pièces des années 768-1633, in-4 de 63\%. $2 \cdot 23$ et 610 pages (Biblioll. de lu ville de Poitiers, coll. Dom Fonteneau, vol. X, XI et XII). 
3041. - Publ. : par L. Rédet (Mémoires de la Société des Antiquaires de l'Ouest, XIV, 1847, pp. 1-362, et XV, 1852, pp. 1-462).

Documents à partir de l'année 768.

Poitiers. - Évêché.

3042. - Cartulaire-pouillé de l'évêché de Poitiers, dit le "GrandGauthier »; ms. du XIVe siècle [vers 1:310], avec additions du $\mathrm{XVe}$, sur parchemin, in-folio de $228 \mathrm{ff}$. (Biblioth. de la ville de Poitiers, ms. 381, ff. 17-128).

Publ. : Cartulaire de l'évêché de Poitiers, publ. par L. Rédet (Archives historiques du Poitou, X, 1881, xxxi-424 p.).

Copie du même, faite au XVIII ${ }^{\mathrm{e}}$ siècle, en 2 vol. in-folio (Biblioth. Cheltenham, ms. 10845).

Poitiers. - Prieuré de Saint-Nicolas.

3043. - Cartulaire du prieuré de Saint-Nicolas de Poitiers; ms. du $\mathrm{XVe}$ siècle, sur papier, in-4" de $14 \mathrm{ff}$. (Archives dép. de la Vienne, $\mathrm{H}$, fonds de l'abbaye de Montierneuf).

Publ. : Cartulaire du prieuré de Saint-Nicolas de Poitiers, par L. Rédet (Archives historiques du Poitou, I, 1872, p. 1-51).

Poitiers. - Ville.

3044. - Cartulaire des titres du corps de ville de Poitiers; ms. du XVII ${ }^{e}$ siècle, sur papier, contenant des documents des années 1575-1662, in-folio de $49 \mathrm{ff}$. (Biblioth. nationale, ms. français 12049).

3045. - Registre des privilèges de la ville de Poitiers; ms. du XVII siècle [1637], sur papier, in-folio (Arch. dép. de la Vienne, E non coté).

Poitou. - Province.

3046. - Recueil des documents concernant le Poiton contenus dans les registres de la Chancellerie de France, publ. par Paul Guérin (Archives historiques du Poitou, tomes XI (1881), XIII, XVII, XIX, XXI, XXIV, XXVI, XXIX, XXXII et XXXV (1906); 10 vol. in- $\left.8^{0}\right)$.

Cet important recueil comnence avec l'année 1302 et s'arrête actuellement à 1464 .

Polignac (de). - Famille.

3047. - Publ. : Prenves de l'histoire de la maison de Polignac [sous presse], par A. Jacotin, archiviste de la Hante-Loire.

Poligny. - Courent des Dominicains (dioc. de Besançon). 3048. - Cartulaire des Dominicains de Poligny ; ms. dı XVIe siècle, contenant des documents depuis 12\%2, in-folio (Archives dép. du Jura, $\mathrm{H}$ non coté). 
Pommerœul. - Chapelle saint-Nicolas (dior. de Cambrai). 3049. - Recueil de titres relatifs à la chapelle Saint-Nicolas de Pummercul, dépendant de l'abbaye de Crespin; ins. du XVIIe siècle, sur parchemin et papier, contenant des actes de 1082 is I692, in-folio de $80 \mathrm{fr}$. (Archices de l'Kitat à Hons .

PLBL. [partiellement]: par M. G. Decamps Annales d $v^{\prime}$ Cercle archéologique de Mons, XXIII. p. 233-281,.

Pons. - Hòpital (dioc. de Saintes).

3050. - Publ.: Archives de lihòpital neuf de Pons. publ. par G. Musset Archives historiques de la Shintonge et de l'Aunis, IX, I881, p. 5-357).

Recueil factice d'actes des années 121 4-1387, d'apris les archives municipales de Pons.

Pons. - Seigneurie.

3051. - Pcbl. : Chartrier de Pons, par G. Musset Archives historiques de la Saintonge et de l'Anis. XXI, I892, in-8 $8^{0}$ de 460 p.).

Dates extrêmes: $1245-1784$. Les documents sont empruutés tn majeure partie aux archives de .I. le duc des Cars.

Pont-à-Mousson. - Châtellenie.

3052. - Recueil de titres relatifs à la châtellenie de Pont-à-1Iousson; ms. de la fin du XVIe siècle, formé par Thierry Alix, sur papier, contenant des textes de l22:0 a 1587 , in-folio de 387 et $456 \mathrm{ff}$. Arrhizes dép. de Weurthe-et-Moselle, B 386.

Copie du précédent, faite au XVII siècle, sur papier. in-folio (Archives dép. de lu Meuse, B 230).

Pont-à-Mousson. - Séminaire des Chanoines réguliers (dioc. de Toul).

3053. - Cartulaire du séminaire des chanoines régutliers de la congrégation du Sauveur à Pont-à-Mousson; ms. du XVIJe siècle, sur papier, in-folio de $51 \mathrm{ff}$. Archives dép. He Meurthe-et-Moselle, H 1574 ).

Pont-à-Mousson. - Iniversité.

3054. - Cartulaire de l'Université et du collège de Pont-à-Mousson ; ms. du XVII siècle, sur papier, in-folio de $89 \mathrm{ff}$. (Archices dép. de Meurthe-et-Moselle, $\mathrm{H} 2104$ ).

Pont-à-Mousson, - Ville et marquisat.

3055. - Recueil des chartes et privilèges de la ville de Pont-àMousson; ms. du XVIe siècle. sur papier, contenant des titres de 1284 à 1519, in- $4^{0}$ de $124 \mathrm{ff}$. Archices dép. de la Meuse, B 230. 
Pont-Audemer. - Église (dioc. d'Éreux).

305̆6. - Cartulatre de L'énglise de Pont-Auclemer; orign. perdu.

Extraits par Baluze «ex cartulario P'ontis Audomari » Biblioth. nationale, coll. Baluze, vol. CXX, ff. 76-78; ms. français 2845, ff. $9.5-112$.

Pont-Audemer. - Liproserio Siant-Gilles.

3057. - Cartulaire de lit léproserie de Siint-(iilles de Pont-Andemer ; ms. du XIII ${ }^{e}$ siècle, sur parchemin, in-t" de $106 \mathrm{ff}$. (Biblioth. de lu ville de Rourn, ms. 12:32 .

Pontfraud. - Maladrerie (dior. dre Sens).

3058. - Recueil [factice] de pièces relatives à la maladrerie de Pontfraud près de Châtentu-Landlon (Seine-et-Marne), du XII e an $\mathrm{XV}^{\mathrm{e}}$ siècle; - pour paraitre prochainement dans les Annales de la Sociéte' hist. et archénl. d" Gatinnis.

Ponthieu. - Comté.

3059. - Cantulaire de Pouthieu; ms. du XIII ${ }^{e}$ siècle, sur parchemin, incomplet de la fin, en 2 cahiers de grandeur différente cousus ensemble, in-folio de $16 \mathrm{ff}$. (Archives nationales, .J 235, $\mathrm{n}^{0} 1$ ).

Dates extrêmes : 1178-1275.

3060. - Cirrtulaire du comté de Ponthieu; ms. du XIVe siècle, sur parchemin, in-folio de $419 \mathrm{ff}$. (Biblioth. nationale, ms. latin 10112).

Tiable ancienne (XIVe s.) du précédent, in-folio sur parchemin (Arrhices muicipules d'Abbeville, AA 128.

Cif. la table moderne, in-4o de $210 \mathrm{ft}$., par René de Jelleval (Biblioth. antionnte, mis. latin 10112bis). - Voir aussi le ms. 218 de la Biblioth. de lit cille dibberille (XJXe s.), in-4 de $235 \mathrm{ff}$ - Aug. Thierry . Monuments du Tiers-État, I, p. 852) croyait ce cartulaire perdu.

Publ. : Le cartulaire dn Comté de l'onthieu, publ. et annoté par Ern. Prarond. Paris, Picard, 1898 ; in-4" de iv-5049 p. (Extr. des Mémoires de la Société d'émulation d'sbbeville.)

Pontigny. - Abbayo de Notro-Dame et Saint-Edme (dioc. d'Auxerere).

3061. - Cartulaire dle l'abbaye de l'ontigny ; ms. des XII -XIII' siècles, sur parchemin, contenaul 4l9 chartes des années 1119-1270, in-fol. de $60 \mathrm{ff}$ is 2 col. (Bublioth. natıonace, ms. latin 9887).

(Changenent d'écriture à partir du folio 20.

Copie du précédent, du XVIII ${ }^{\mathrm{e}}$ siècle, sur papier, in-folio de $352 \mathrm{ff}$. (Archioss dép. de l'Yonne, H 1400). 
306:. - Antre cartulatre dn XIVe siecle, sur parchenin, in-4n de 310 pages (Biblinth. vationnle, m. latin 5465,

Une analyse sommaire est dans coll. Baluze, vol, LAXY, fr. 17-333

Copie du précédent. du XVIII siècle. sur papier, in-fol. de 70.) fr. (Archices dép. de l'Yonne. H 1401).

I)ates extrênies : 112(1)-1318.

3063. - Recueil de titres formé par Giaignières, en partie d'après les originanx. en partie l'après le regristre précédent Biblioth. mationale, ms. latin 17049 . p. $317-369$.

Extraits laits an XVII siècle (Biblinth. nationule, coll. Duchesue, vol. LXXIV, ff. 88-95; et vol. LXXVI. pp. 107-117.

Pontlevoy. - Abbare de Notre-Dame (dion. dr Blois).

3064. - Cartulaire de l'abbaye de Pontlevoy ; orig. perdu.

Extrait (acte de 1196) par Dom Gérou au XVIII ${ }^{e}$ siècle [176.5] (Biblioth. nationale. coll. Morean, vol. 97, folio 143,

3065. - Recueil de titres relatifs à l'abbaye de Puntleroy: ms. du XVII siècle, sur papier Biblioth. nationale, ms. latin 1268:3, ff. $195-213)$.

Il existe, au śminaire de Pontleroy (anc. Cullège), une Histoire de l'abbaye de Pontleroy, ms. de Dom Čhazal (XVIII siècle), accompagnée de preures qui forment un ensemble important de pieces. La Biblioth. mationale (ns. nour. acq. françaisss 6278) en possèle une copir.

Pontoise. - Abbaye de Saint-Martin (dioc. de Rouen).

3066. - Grand cartulaire de Saint-Martin de Pontoise: ms. du S1I* sièrle. sur parchemin, de it ff.. orig. perdu.

Transcrit en partie par Dom Estiennot, dans l” « Histoire de SaintMartin-sur-Viosne-lez-Pontoise 》, composée en 1671 (Biblioth. nationale, ms. latin 12741 ; Biblioth. de la ville de Pontoise, fonds Pihan de la Forest; et Bibliath. Wazarine, ms. 3:368,

3067. - Petit cartulaire de Saint-Martin de Pontoise : ms. de $242 \mathrm{ff}$., orig. perdu.

Extraits des deux cartulaires (Biblioth. nuionale. coll. Baluze. vol. LT, ff. 519-520; ms. latin I274l; coll. Vexin. passim; nouv. acq. françaises i4:3:3. ff. 208-209).

Pcbl. : Cartulaire de l'abbaye de Saint-Martin de Pontoise. par J. Depoin. Pontoise, Société historique de V'exin [Montdidier. inpr. Bellin]. 1895-1901; in-40 de IV-rmi-3:31 p.

Recueil factice de 231 docuinents des années 1032 il 1199.

Pontoise. - Courent des Cordelier's.

3068. - Cartulaire du couvent des Cordeliers de Pontoise ; ns. com- 
mencé en 154:3 et authentiqué par les notaires Gérard Ledru et Pierre Morean, sur papier, in-40 de $152 \mathrm{ff}$. (Archives dép. de Seine-et-Oise, H non coté.

Pontoise. - Couvent des Trinitaires on de Saint-Nichel. 3069. - Cartulaire des Trinilaires de Pontoise; ms. du XVI siècle, sur parchemin, in-4" de 31 ff. (Biblioth. de la ville de Pontoise, ms. 13).

Pontoise. - Église collégiale Sitnt-Mrllon.

3070. - Cartulaire de Saint-Mellon de Pontoise, dit " Liber jur"d-

torum »; origs. perdu.

A été utilisé par Dom Estiemnot (Biblioth, natiomale, nins. latin 12741, p. 35).

Pontoise. - Église Notre-Dame.

3071. - Cintulaire de Notre-Dame de Pontoise; orig. perdu.

Extraits faits an $\mathrm{XVII}^{\mathrm{e}}$ siècle (Biblioth. nationale, coll. Baluze, vol. $L V$, ff. 527-530).

Pontoise. - Hòtel-1)icu.

3072. - Cartulaire de l'Hôtel-Dieu de l'ontoise; ms. du XIVe siècle, sur parchemin. in- $4^{0}$ de $128 \mathrm{ft}$. (Biblioth. nationale, ms. latin 5657).

P'ubl.: Cartulaire de l'Hôtel-1)ieu de Pontoise, par Joseph Depoin. Pontoise, impr. P'aris, $1886^{\circ}$; in-4 $4^{\circ}$ de xur-136 p. [Société historique du Vexin.]

Pontoise. - Voy. Maubuisson.

Pontorson. - Prieuré. -- Voy. Le Mont-Saint-Mighel.

Pontron. - Abbaye (dioce d'Angers).

3073. - Franmenl de cartulaire de l'abbaye de Pontron; ms. du XVII siècle, contenant des titres depuis le $\mathrm{XII}^{\mathrm{e}}$, sur papier, $2 \mathrm{ff}$. in-4 ${ }^{0}$ (Arckives dép. de Maine-et-Loire, $\mathrm{H}$ non colé).

Le's extraits faits pour Gaignières (Biblioth. nationale, ms. français 22450 , pp. 3-14) ne semblent provenir d'aucun cartulaire.

Pont-Saint-Esprit. - Église et hôpitaux (dioc. de Nîmes). 3074. - Publ. : Cartulaire de l'œuvre des église, maison, pont et hôpitaux du Saint-Esprit (1265-1791), par L. Bruguier-Roure (Mémoires de l'Académie de Nimes, fesérie, XII, pp. 1-96, et XIII, pp. 97-240), et à part: Nîmes, 1889-1895; in-80 de GxLIv-480 p. it pl.

Pont-sur-Yonne. - Seigneurie.

3075. - Cartulaire de la terre et justice de Pont-sur-Yonne; ms. du $\mathrm{XVe}$ siècle, sur papier. contenant des documents de 1181 à 1410 , in-folio de 58 ff. (Archives dép. de l'Yonne, G 1330). 
Poperinghe. - Priruré de Saint-Birtin (dior., d' Y Press).

3076. - Perc.: Recueil des chartes du prieuré de Saint-Bertin à Poperinghe et de ses dépendances à Bas-Warnetıu et a Couckelaere, par F. II. d'Hoop. Bruges. Vandecasteele-Werbrouck, 1870; in-4" de 3:24 p. [Société d'Émulation de Bruges.]

Comprend des pieces des années 745 à 1361 , puisées aux Archives do l'État à Gand.

Portes. - Chartwuse (dtior. de Lyon).

3077. - Cartulaire de la Chartreuse de Portes; ms. clu X Tre et du XVIe siècle, contenaul les titres de fondation et autres à partir de 1115. en deux caliers de papier, in- $t^{0}$ de 10 et $14 \mathrm{ff}$. Archives dép. del Ain. $\mathrm{H} 218$.

(:f: L Apremonl du Cartulaire de lorles, jar l'abbé I. Joly (Bulletin do la Socipti des sciences naturelles et d'archéologie de C.1 in, 1903, [. 7084).

Extraits faits par Dom Estiennot an XVII siecle Biblioth. nationale, ins. latin 1:2768. fr. $21-40$.

Port-Royal. - Ablaye (dioc. de Paris).

3078. - Cartulaire de l'ahbaye de Port-Royal: mis. du XIIIe siècle, sur parchennin, in-16 (Biblisth. nationale, ms latin 10957. ff. 1-110.

Dates extrêrnes : 1204-1248. Let reste đu volume contient un censier.

3079. - Autre cartulaire du XIIle siècle, sur parchemin, in-lti de $30 \mathrm{ff}$. Biblioth. nutionnle, ms. latin 10998 .

Dates extrênes: 12.15-1269.

Plbu. : Cartulaire de l'abbaye de Porrois an diucèse de Paris, plus connue sous son nom niystique Port-Royal, par A. de Dion. I (1204-1:280 : Paris. P'icard et fils. 1903 ; in-8 de xvi-3:39 p.

Il $y$ avait dans la collection Joursanvault (Catalogue, n ${ }^{\text {os }} 1039$ et 1042 deux fragments de cartulaires du XIII siecle, contenant chacun deux pieces. On iguore où ils se trouvent aujourd'hui.

Pothières. - Ablatye de Saint-Pierre (dioc, de Langres).

3080. - Cartulaire de lahbaye de Saint-Pierre de Pothières; m. du XVIII siècle, sur papier. contenant 360 documents des années 869 ? à 1747, in-folio de $377 \mathrm{ff}$. Archires dép. de ln Cóte-d"Or, $\mathrm{H}$ non coté .

Poussan. - Seigururie "n Languedor.

3081. - Cartulaire de la seigneurie de Poussan; ms. du Xive siècle [1339], contenant 1366 pièces. sur parchemin, in-40 de $260 \mathrm{ff}$. (Biblioth. de la Saciété archéalogique de Montpellier, ms. no 11 ).

Il avait primitivement $2 \tau 1$ feuillets. Toutes les pieces transcrites sont du XIV'e siecle. 
Cf. Notice sur un cartulaire seigneurial inédit, par A. Germain (Mémoires de la Société archéologique de Montpellier, IV, p. 439-480); et à part : Montpellier, 1858 ; in-4 $4^{\circ}$ de 44 p.

Prades. - Ville.

3082. - Cartulaire municipal de Prades on « livre rouge ", contenant des documents à partir de 865 et jusqu'en 1757 ; ms. des XVII XVIII siècles, sur papier, de 869 ff. in-folio (Archives municipales de Prades).

Prats de Mollo. - Ville.

3083. - Cartulaire municipal de Prats-de-Mollo ou « livre vert »; ms. des $\mathrm{XIV}^{\mathrm{C}}-\mathrm{XV}^{\mathrm{e}}$ siècles, sur parchemin, mutilé, contenant des documents de 1241 à 1449 , in- $4^{0}$ de $60 \mathrm{ff}$. [au lieu de $8 \check{5}$ à l'origine] (Archives municipales de Prats-de-Mollo, AA 1).

Préaux. - Abbaye (dior. de Lisieux).

3084. - Cartulaire de l'abbaye de Saint-Pierre de Préaux; ms. du $X V^{\prime e}$ siècle, sur parchemin, in-folio de xiv-202 ff. (Biblioth. Cheltenhain, $\mathrm{n}^{0} 85$ ).

Copie du même, faite au XIX ${ }^{\mathrm{e}}$ siècle, sur papier, in-folio de 171 pages (Biblioth. Cheltenham, $\mathrm{n}^{0} 25090$ ).

3085. - Antre cartulaire de Saint-Pierre de Préaux; ms. rédigé en 1227 par "magister Willelmus» [ff. 1-81 et 97-147] avec additions postérieures. sur parchemin, contenant 640 chartes de 1034 à 1494 , in-4" de $238 \mathrm{ff}$. (Archioes dép. de l'Eure, 'H 711 ).

Appartinait précélemment à M. le vicomte de Blosseville qui l'a donné en 1857.

Prébenoist. - Abbaye (dioc. de Limoges).

3086. - Extraits des titres de l'abbaye de Prébenoist, faits au XVII siècle pour Gaignières (Biblioth. nationale, ms. latin 17049, pp. 371-380).

Prémontré. - Abbaye (dioc. de Lian).

3087. - Cartulaire de l'abbaye de Prémontré; ms. du XIIle siècle [vers 1275], avec additions du XIVe, sur parchemin, in-folio de 112 ff. (Biblioth. de la ville de Soissons, ms. 7).

Cf. Observations sur le cartulaire de Prémontré, par l'abbé Daras (Bulletin de la Société archéologique de Soissons, X, 1856, p. 12-14).

Extraits faits au XVII ${ }^{\mathrm{e}}$ siècle par André Du Chesne (Biblioth. nationale, coll. Baluze, vol. LI, pp. 132-153).

3088. - Fragment d'un autre cartulaire de Prémontré [pièces cotées 6 à 16$)$; ms. du XIII ${ }^{\mathrm{e}}$ siècle, sur parchemin, in-4 $4^{0} \mathrm{de} 8 \mathrm{ff}$. (Biblioth. Chelienham, $\mathrm{n}^{0}$ 1321). 
Prémontrés. - Ordie religimux.

3089. - « Nonumenta manuscripta Ordinis Praemonstratensis » ; ms. rédigé par labué Hugro d'Étival en 1718, et formant 18 vol. in-folio (Biblioth. du Gound Séminaire de Nancy, ms. 48).

L'ordre suivi est alphabétiqu pour tous les monastires. If ne manque que les titres du couvenl ile Pont-a-Mousson, arrachés du tome XI par un lecteur mathonnete.

Prémy. - Ablayc. - Voy. Cambra.

Preuilly. - Abbaye (dioc. dr Sens).

3090. - Cartulaire de l'abbaye de Preuilly : orig. perdu.

Recueil, formé pour Gaignières, de titres relatifs in celte abbaye. en partie d'après le précédent cartnlaire. in-folio (Biblioth. nationale, ms. latin 5469, pp. 3-129).

Prières. - Abl ye dioc. de Vannes).

3091. - Cartulaire de l'albaye de Prières ; orig. létrnit.

Copie du précédent, faite en 1648 par Dom G. Gautier et complétée en 1768, sur papier (Biblioth. de M Me $V^{\text {re }}$ Rosenzlaceig, à Vannes).

Cf. Anmales de Biphigup, 11, p. 515 .

Pringy. - Prieuré do Notre-1)ame (dioc. dro Sons).

3092. - Cartulaire du prienué de Pringy; ms. du XV1e siecle, in- $\mathrm{t}^{0}$ sur papier Biblinth. Nu chatern de Montgermont, Seine-el-Marme).

Prisches. - Voy. Maromlaes.

Prouille. - Pricuré (dior. do Saint-Papoul).

3093. - Histoire et cartulaire clu prienré de Pronille. ordre de SaintDominique. d'après le ms. composé en 1726 par le l'. dominicain Lahadie: ms. du XYIII ${ }^{\mathrm{e}}$ siecle [1780], sur papier. in-folio de $\mathbf{4 2}$ ff. avec table finale (Biblioth. nutionale, ms. françai 8671 ).

Documents des XIII e-XVIe siècles.

3094. - Recueil de titres relatifs an prienté de Pronille: ms. du XVII ${ }^{e}$ siècle [ 1668 ]. contenant des documents de l:269 à li388, in-fol. de 2:34 ff. Biblioth. nationule, coll. Doat. vol. 98.

3095. - Pubr. : Cartulaire de l'rouille (1206-1340), par M. Jean Guiraud. Paris. Picard fils, 1907 ; in-10 de cccrv-286 ef rv-35.5 p.

Provence. - Comti.

3096. - Carlulaire des countes de Provence. on "Recristrum pergatmenornm »: ms. des XIIJ-XIVe siecles. contenint 4.52 actes des 
années 112.5-1311, sur parchemin, in-folio de 333 ff. (Archives dép. des Bouches-du-Rhone, B 2 .

3097. - Recueil des privilèges inpérianx et comtanx octroyés à la Provence; ms. du XIVe siecle, sur papier, contenant des actes de 1112 a 135.). in-folio de $27 \mathrm{ff}$. (Archives dép. des Bouches-du-Rhône, 1313777 .

Provence. - Province.

3098. - Recneil d'actes relatifs ì la Provence; ms. fait en 1788-1789 par le président de Saint-Vincens, contenant 139 pièces du VI ${ }^{\mathrm{e}}$ au IVIII ${ }^{\mathrm{e}}$ siècle, sur papier, in-folio (Biblinth. de la ville d'Aix-enPiocence, nis. 754).

Continué par le suivanl:

3099. - Cartulaire de l'rovence: n1s. des XVIII ${ }^{\mathrm{e}} \mathrm{XIX} \mathrm{X}^{\mathrm{e}}$ siècles, sur papier, in-4" de $320 \mathrm{ff}$. (Bib!ioth. de la ville d'Aix, ms. 1280).

3100. — « Cartularium provençale »; ms. du XVIIIe siècle, préparé par P. J. le Haitze, sur papier (Biblioth. de ln ville de Murseille, ins. 1500, If. :398-802.

3101. - Recueil le tocuments livers relatifs à la Provence; ms. du XVIII ${ }^{\mathrm{e}}$ siècle, sur papier, de plusieurs mains, en 3 vol. in- $4^{0}$ de 596 , 516 et 598 p. (Bibliolh. malionale. ns. nouv. acquis. latines 13671369 .

Provins. - Mbbaye de Saint-Quiriace (dioc. dr Sens).

3102. - Cartulaire de l'abbaye de Saint-Quiriace de Provins; orig. perlu [avait au moins 55 ff.]

Extraits linits an XVII ${ }^{\mathrm{e}}$ sièle (Biblinth. nationale, coll. Champanne, vol. XXV, ff. 25 et suiv.).

Le " livre pelu " le la mème abbaye, écralement perdu, n'était pas un vrai cartulaire.

Provins. -- . bhaye du Mont-Notre-Dame.

3103. - Cartulaire du Nont-Notre-Dame-lez-Provins ; orig. perdu.

Extrail lait au XVIII siècle (Biblioth. nationule, coll. Champagne, vol. XXV, folio .158).

Provins. - Lbbaye du Mont-Sainte-Catherine.

3104. - Cartulaire du Iont-Sainte-Catherine de Provins; orig. perdu.

Avail au moins 83 feuillets.

Extraits faits an XVII e siècle (Biblioth. nationale, coll. Champagne, vol. XXV, ff. 260-272).

Provins. - Chapitre de Saint-Nicolas.

3105. - Cartulaire de Saint-Nicolas de Provins ; orig. perdu. 
Extrait fait an XVII siocle Biblioth. notionalp. coll. Cihampanne. vol. XXV, tf. 118-1:37.

Provins. - Comminderie des Trmpliers.

3106. - Cartulaire des T'empliers de Provins: ns. du Xlle siècle, de plusienrs mains. sur parchemin, in-10 de $24 \mathrm{ff}$. Lrchices nationales. S $1562^{\mathrm{B}}, \mathrm{n}^{0} \cdot 26$.

Dates extrênes: $1133-1242$.

Cf. Totice sur le cartulaire des Templiers de l'rovins. par Félix Bourquelot Biblioth. de l'École des Chartes, 4"serie. IV. p. 171190 , et is part : Paris, 1858 : in $-8^{\circ}$ de $20 \mathrm{p}$.

Une note lu XVIJI sipele (Biblioth. untionulp, coll. Champagne, vol. XXV, t" 238), disait déja : "Le cartulaire de la conmanderie de Provins a sans doute été transporte au thrésor commun des archives du Temple puisqu'il ne se trouve plus à La Croix-en-Brie n.

Provins. - Église collegiale Notre-Dame-du-Val. 3107. - Cartulaire de Notre-Dame du Val de Provins; orig. perdu.

Avait au moins 109 feuillets.

Extraits laits an XVII" siècle Biblinth. nutionals, coll. Champagne, vol. $\mathrm{XIY}$, ff. 48 et 78-98.

Provins. - Hòtel-Dieu.

3108. - Grand cartulaire de l'Hòtel-Dieu de Provins; ms. du XIII siècle, avec additions du XIV $V^{-e}$ sur parchemin. convert d'une ancienne reliure en bois. et contenant tes documents des années 1176 a 1369. in-folio de $186 \mathrm{ff}$. à 2 col. 'Archices hrspitalières de Procins, $\mathrm{B}:$.

Ce regristre est incomplet des deux premiers fenillets, mais le cartulaire ne commence véritablement 'qu'au folio sw.

3109. - Petit cartulaire de l'Hòtel-Lieu : ms. du XIII siècle avec additions postérieures, sur parchemin. couvert d'une ancienne reliure en bois. et conlentunt des documents des années 1179-1:359, in- $4^{0}$ de $118 \mathrm{ff}$. Archices hropitulières de Procins. B 2a .

Provins. - Ville.

3110. - Cartulaire de la ville de Provins : ms. des XIIle-XIVe siècles, sur parchemin. de plusieurs mains, in-folio de $206 \mathrm{ff}$. à 2 col. (Bibliath. de la cille de Procins.

Cf.: Yotice sur le manuscrit intitule Cartulaire de lat ville de Provins. par Félix Bourquelot (Biblioth. de l'Ficole des Cilintes, $4^{\text {e }}$ érie. II. pp. $193-241$ et $428-460$. et à part: l'aris. 1856 , in $-8^{\circ}$ de $82 \mathrm{p}$.

3111. - Cartulaire de I'ruvins, par Vichel Caillut : ms. du XVIle siècle, contenant des actes des années 980-1637, sur papier, in- $4^{0}$ de 
610 p. [avec tahle par $\mathrm{N}$. Billate dressée en 1729] (Biblioth. Ie la ville de Provins, ms. 9:2).

Cf. Bourquelot, Foires de Champagne et de Brie, II, pp. 276-280. On trouvera ì la Biblioth. nationa!e, coll. Champarne, vol. XXV-XXVI, divers extraits des cartulaires de l'Hòtel-Dieu et de la ville de Provins.

Prüm. - Abbaye (dioc. de Trèves).

3112. - «Liber aurens ahbatiæe Irumiensis »; ms. du XII siècle, avec additions postérienres, sur parchemin, contenant des pièces depuis l'année 720, in-40 de 114 ff. (Stadt-Bibliothek Trier, ms. 1709).

Psalmodi. - Abbaye (dioc. de Nimes).

3113. - Cartulaire de l'abbaye de Psalmodi ou Livre A; ms. rédigé en 1683 et contenant des documents de 789 a 1647 , sur papier, in-4 de $339 \mathrm{ff}$. (Archives dép. d" Gard, H non coté).

3114. - Autre ou livre B; ms. des XVIIe-XVIIIe siècles, contenant lles documents de 1209 à 1769 , sur papier, in-4 ${ }^{0}$ de $306 \mathrm{ff}$. (Archives dép. du Gard, H non coté).

Puchay-en-Vexin. - Seigneurie.

3115. - Cartulaire de la seigneurie de Puchay; ms. rédigé en 1765, sur papier, in-4o de xix-362 pages (Archives dép. de Seine-ct-Oise, H non coté, fonds de l'ahbaye de St-Louis de I'oissy).

Dates extrimes : 1311-1765.

Puigcerdá. - Ville.

3116. - Cartulaire municipal de P’uigcerdá ou «Llibre vert»; ms. icrit en 1298 par Matthieu de Oliana, sur parchemin. et orné d'une miniature au début, contenant des actes à partir de 1181 , in- $8^{\circ}$ de 28 ff. (Archino municipal de Puigcerda).

Il est suivi d'un cahier supplémentaire, de papier, contenant le texte de prestation de serment des officiers royaux (1554-1617).

Copie dn précédent ou « Trasllat »; ms. commencé aussi en 1298, sur parchemin, conlenant des actes de 1181 à 1318 , in- $8^{\circ}$ de $24 \mathrm{ff}$. à 2 col. (Archioo municipal de Puigcerda).

3117. - « Libre dels privilegris de la insigne vila de Puigcerdá »; ms. icrit en 1382, avec additions postérieures, sur parchemin, contenant des actes royaux te 1181 a 1599 , in- $4^{0}$ de $\mathbf{1 5 6} \mathrm{ff}$. (Avchivo municipal de Puigcerida).

Puiseaux. - Prieuré (dioc. de Sens).

3118. - Carlulaire du prieuré de Puiseaux, dépendant de Saint-Victor de Paris: ms. du $\mathrm{XVe}^{\mathrm{e}}$ siècle. sur papier, in- $4^{0}$ de $25 \mathrm{ff}$. (Archives nationales. S 2150. $\left.n^{0} 14\right)$. 
Puteaux. - Voy. Suresses.

Puyferrier. - Seigneurie en Poitou.

3119. - Cartulaire de la seigneurie de Puyferrier; ms. compilé en 1759 , sur papier, in-folio de $195 \mathrm{ff}$. (Biblioth. nationale. ms. français 1:2050).

\section{Quesnoy-le-Comte. - Domaine.}

31:20. - Cartulaire du domaine de Quesnoy-le-Comte en Hainaut : ms. composé en 1462 par Jean Dyévin; orig. perdu (?).

Copie du précédent, faite au $\mathrm{XVII}^{\mathrm{e}}$ siècle, sur papier, in-folio de 571 ff. (Biblioth. nationale, coll. Flandre. vol. 78 ;.

Quimper. - Église.

3121. - Cartulaire de l'église de Quimper; ms. des XIII -XIT ${ }^{-e}$ siècles, sur parchemin, in-4 $\mathbf{4}^{\circ}$ de $66 \mathrm{ff}$. (Biblioth. nationale, ms. latin 9890). 3122. - Autre du Xive siècle, sur parchemin, in-4 $4^{\circ}$ de II-66 ff. à 2 vol. (Biblioth. nationale, ms. latin 9891).

3123. - Autre du XIV siècle. sur parchemin. in-4 de 95 ff. (Biblioth. nationale, ms. latin 9892).

Cf. Notice sur le cartulaire de Quimper' ou l'église de Cornouaille du XIII au XV'Ie siècle, par Ch. Fierville (Hémoires lns ì lo Sorbonne, Histoire-philologie, 1865, p. 769-797).

Publ. : Cartulaire de l'église de Quimper. par le chanoine Peyron (Bulletin de la Cominission diocésaine d'architecture et d'archénlogie du diocèse de Léon [Quimper]. I. 1901, pp. 30-46. 73-85, 126-137, 177-186, 226-231, 276-283 : II, 1902. pp. 39-48, 99-105, 159-169, 22.5-235, 262-271, 346-355 ; III, 1903, pp. 36-46, 90-103, 148$158,229-236,348-356 ; 1 \mathrm{~T}, 1904$, pp. 24-32. 73-87, 146-167, 194201, 271. 278. 311-332; V, 1905, pp. 13-18, 57-73, 97-109, 146-1ล2, 193-202, 241-253, 281-288 [ä suivre].

La publication chronologique s'arrête en 1904 à l'année 1321.

Quimper. - Prieuré de Locmaria.

3124. - Publ.: Chartes inédites de Locmaria de Quimper (10221336), publ. par Arth. de La Borderie (Bulletin de la Saciété arehéologique du Finistère, XXIV, 1897, pp. 96-113).

Quimperlé. - Abbaye de Sainte-Croix (dioc. de Quimper). 3125. - Cartulaire de Sainte-Croix de Quimperlé; ms. du Xile siècle. avec additions du XIII . sur parchemin, in- $8^{\circ}$ de $163 \mathrm{ff}$. (British Museum, ms. Eggerton 2802).

Cf. I.e cartulaire de l'abbaye de Quinperlé, par Hardouin (Kulletin de la Soriétét archéologique du Finistere, 1889 , p. sLr-Lmil); A collation of 
the Cartulary of Quimperlé, by Wh. Stokes (Archiv für Celtische Lexicographie, 1898, p. 143-150).

Copie moderne, par Léon Maître (Archives dép. du Finistère, $\mathrm{H}$ non coté).

Autre copie moderne (Biblioth. nationale, ms. nouv. acq. latines $1427)$.

Extraits (Biblioth. nationale, ms. latin 1:3819, ff. $162^{\mathrm{b}}-169$; coll. Baluze, vol. XLI, ff. 1-22, et vol. LXXIV, ff. 15-30).

Ce cartulaire a été souvent cité par lı́s auteurs anciens (Mabillon, Isobineau, Morice, Du Cange, Dubuisson-Aubenay, etc.).

Publ. : Cartulaire de l'albaye de Sainte-Croix de Quimperlé, par Léon Maître. Paris, Leclevalier, 1896 ; in-40 de [rv- $] \mathrm{xIv}-331$ p. ; - 2 édition revue, corrigée et augrmentée, par Léon Maître et Paul de Berthou. Rennes, Plihon et Hommay [Paris, Champion], 1904: in- $8^{\circ}$ de xı 408 p. [Bibliothèque bretonne armoricaine, fasc. IV.]

C.f. Le cartulaire de Quimperlé, par léopold Delisle (Bibliotheque de IÉcole des Chartes, XLII, 1881, P. 2511-253). - Cette publication a été fort utilisée par Loth pour sa "Chrestomalhie bretonne ".

3126. - Autre cartulaire de Sainte-Croix de Quimperlé; ms. in-4́, perdı.

A été connu de Dom I'. Le Duc (édité par Le Mlen en 1881, in-8 de Iv-6tiz p., où l'on trouvera en outre, pp. 583 ss., une série de pièces justificatives relatives à la même abbaye).

Quinçay. - Prieuré de Saint-Benoit. - Voy. Marmoutier. Quincy. - Abbaye (dioc. de Langres).

3127. - Fragment de cartulaire [bullaire] de l'abbaye de Quincy; ms. des $\mathrm{X}^{7} 1^{e}-\mathrm{X} V \mathrm{II}^{\mathrm{e}}$ siècles, contenant 56 pièces depuis le XIIe siècle, sur papier, in $4^{0}$ de $3 f_{\text {ff. }}$ (Biblioth. de la ville de Tonserre, ms.39).

Le volume présente quelques lacunes.

Raamsdonck. - (hiartreuse (dioc. de Liège).

3I28. - Cartulaire de la Chartreuse de Riamsdonck; ms. du XVe siècle, de plusieurs mains, sur parchemin, contenant 599 chartes des années 1315-1454, in-4" de vi-198 ff. Archives de l'État à Anoers).

3129. - Autre carlulaire; ms. du XVIe siècle [1518], avec additions, sur papier, contenant 124:3 documents des années 1431 à 1578 , in-4 $\mathbf{4}^{0}$ de $325 \mathrm{ff}$. (Archives de l'État à Anvers.

sur ces deux regislres, voir J. Vannérus dans Rerne des Bibliotheqques et Archives de Belgique, 1905, pp. 489-491.

Rabastens. - Prieuré (dioc. d'Albi).

3130. - Cartulaire du prieuré de Rabastens; ms. du XVII siècle, conteuant 145 pièces dont la plus ancienne est de 1613 , sur papier, 
in-folio de $269 \mathrm{fr}$. (Archires dip. de la Haute-Garonne, $\mathrm{H}$ non cote. fonds du collège des Jésuites de Toulouse.

Rabastens. - Ville.

3131. - Publ.: Cartulaires de l'hôtel-rle-ville de Rahastens, par Emile Marty. Albi, Nouguiès, 1902 ; in- $8^{0}$ de xn-148 p. (Extrail de la Reoue du Turn, 1901-1902.

Ont été utilisés entre autres, pour cette publication, les rleux registres cotés AA 1 et 2 (Licre des anges), aux archives communales de Rabastens (Tarn).

Ramerupt. - Abbaye de N.-D. de la Pièté (dioc. de Troyes). 3132. - Recueil de titres relatifs à l'abbaye de la Piété-lez-Ramerupt. des années 1234-I406: ms. du XVII ${ }^{\mathrm{e}}$ siècle, sur papier (Bibliall. nationale, coll. Duchesne, vol. IV. pp. 35-4l).

Rampan. - Voy. Le Pigry.

Rancié, près de Foix. - Mines.

3133. - Publ.; Recueil des titres authentiques. chartes, privilèges, franchises, tc., concernant les mines de fer de Rancié (Arièrrej. par R. Barbe. Toulouse, Bonnal et Gibrac, 1865 ; in- $8^{\circ}$ de 227 \%.

Rangéval. - Abbaye (dioc. de Toul).

3134. - Cartulaire de l'abbaye de Rangéval; ms. des XIIIe-XIVe siècles, sur parchemin, in-4 $4^{0}$ de $49 \mathrm{ff}$. (Archives dép. de .Meurthe-et-1/oselle, B 477).

3135. - Autre; ms. du XVIII siècle, sur papier. contenant des actes du XIII au XVIe, in-folio de $141 \mathrm{ff}$. (Archioes dép. de la Meuse). H $28^{3}$ provisoire).

Rangéval. - Égrlise.

3136. - Cartulaire de l'éulise de Rangéval et de la cure de Jouy-lesCôtes; ms. daté de $146 \mathrm{I}$, sur papier. in-folio de $20 \mathrm{ff}$. (1rchives dép. de Weurthe-et-Hoselle, B 478 .

Rarécourt (de). - Famille.

31:37. - Publ. Titres de la maison de Rarécourt de la Vallée de Pimodan, vérifiés en 1766 par MI. de Beaujon, généalogiste des ordres du roi, avec continuation jusqu’à nos jours, par Alph. Roserot. Paris. l'lon-Nourrit, 1903 ; in-tu de [IV-] vin-463 p. et pl.

Ravensberghe. - Abbaye (dioc. de Thèrouanne).

3138. - Fragrment d'un cartulaire de lahbaye de Ravensberohe ; ms. du XIII siècle, sur parchemin, in $-4^{0}$ de 8 if. (Biblioth. nationale, ms. latin 10970 .

Cf. Notice sur labbaye de Ravensberg, par I. de Coussernaker 
(Annules du Comite famand de France, VI, p. 223-282), et ì part: Lille, 1862 ; in-8 de 71 p.

Rays (Sires de).

3139. - Cartulaire des sires de Rays ; ms. du XVe siècle [1447] copié par Oudry pour l'amiral Prégrent de Coëlivy, sur parchemin, avec une table en tête et quelques additions à partir dı fo 302 [incomplet de la fin], contenant 336 actes des années 1160 à 1449 , in-folio de $353 \mathrm{ff}$. (Chartrier de Thouars, à M. le duc de La 'Trémoille).

Publ. : Cartulaire des sires de Rays, publ, par René Blanchard (Archives historiques du Poitou, XXVIII, 1898, et XXXI, 1901, 2 vol. in $-8^{\circ}$ de cxci-320 et II-59l p.).

Copie moderne, sur papier, in-4 $4^{0}$ de xxxvir-980 p. (Biblioth. nationale, ms. nouv. acq. françaises 6.501 ).

Anal. : Cartulaire des sires de Rays ; notice. tables analytique et alphabétique, par Paul Marchegay (Revue des provinces de l'Ouest, III, 1857, pp. 449 el suiv.) et à part: Paris et Nantes, 1857 ; in- $8^{\circ}$ de $99 \mathrm{p}$.

Le mêne auteur avait déja fait paraître antérieurement: Observations sur quelques dates du cartulaire des sires de Rays (Bulletin de la Société archéologique de Sintes, XVI, 1877, pp. 15-52), et à part: Nantes, 1877 ; in $-8^{\circ}$ de $36 \mathrm{p}$.

Rebais. - Abbaye de Saint-Pierre (dioc. de Meaux).

3140. - Fragment d'un cartulaire de l'abbaye de Rebais; ms. du $\mathrm{XII}^{e}$ siècle, sur parchemin, in $4^{0}$ (Biblioth. nationale, ms. latin 13345 , fl. $216-221)$.

Le cartulaire de Rebais existait intégralement au commencement du XVIII sicrle: dans la préface de l' "histoire de l'Église de Meaux" (1731), D. Toussaints Du Plessis déclare l'avoir utilisé.

Reckheim. - Seigneurie en Limbourg.

3141. - Recueil des titres de la seigneurie de Reckheim; ms. du $\mathrm{XVII}^{\mathrm{e}}$ siècle, sur papier, contenant des actes de 1485 à 1632 , in-folio de 319 ff. (Archives de l'litat à Hasselt).

Reclus. - Abbaye de Notre-Iame (dioc. de Troyes).

3142. - Cartulaire de l'abbaye de Notre-Dame de Reclus; ms. du XIII ${ }^{\mathrm{e}}$ siècle, sur parchemin, in-8 ${ }^{\circ}$ de $18 \mathrm{ff}$. (Archives dép. de la Marne, $\mathrm{H}$ non coté).

Dates extrèmes : 1178-1240.

Extraits faits au $\mathrm{XVII}^{\ominus}$ siècle (Bibliolh. nationale, coll. Baluze, vol. LI, pp. 231-2:33).

Redon. - Abbaye de Saint-Sauveur (dioc. de Vannes). 3143. - Cartulaire de l'ablaye de Redon; ms. du XI' siècle, sur 
parchemin. de diflèrentes mains, avec de fortes lacunes, in-folio de $142 \mathrm{fr}$. plus les feuillets de garde /jadis $18.5 \mathrm{tr}$.] (Bibliath. do l'archereché de Renites.

Les deux premiers copistes furent Jutlicaël et Guégon.

Copie moderne, collalionnée par A. de Lat Borderie; ms. in-folio de 455 et 108 If. Biblioth. nutionale. ms. latin 17093 .

Pcal. : Cartulaire de l'abbaye de Redon en Bretagne, par Anrélien de Courson. Paris, impr. impériale. 186:3; in-4" [w-]xir-Cccxlrt76l p. et pl. [Collection des Documents inédits.]

Cf. Examen chronologique des chartes du cartulaire de Redon antérieures au XIe siecle, par Arthur de La Borderie (Bibliothéque de ¿École des Chartes, jo série, tome V, pp. 259-28: et 393-434) : tot La chronologrie du cartulaire de Redon, par le mêne (Rennes, inp. Oberthür, 1901: in $-8^{\circ}$ de 260 p. : extr. des Amnales de Bretagne, V, pp. 535-630; XII, pp. 473-522 : et XIII, pp. 11-42, 263-279, 430458 et $590-611)$.

Parni les comptes-rendus dont cette publication fist l'objet, cituns ceux de A. Gaidoz (Recue celtique, I, P. 469-477, et II, pp. 404-407): A. de Barthélemy (Recue urchénlogique, ze série, VII, 1863, pp. 397405 , et VIII, 1) $181-188$ ).

Extraits et copies du XVIre siècle (Biblioth. nationale, coll. Baluze, vol. 376 .

3144. - Fragment d'un cartulaire de l'abbave de Redon; ms. du $\mathrm{XII}$ siècle, sur parchemin à 2 col. in-folio, contenant deux feuillets où sont transcrites six chartes complètes et huit parliellement(Biblioth. nalinnle, ms. nouv. acq ${ }^{\text {ons }}$ latines 2208).

Un de ces feuillets a été acquis en 1878 dans une ventr: l'autre fut donné par Aurélien de Courson.

3145. - Autre petit cartulaire de Saint-Sauveur de Redon, in-t" ; origr. perdu.

Extrait fait au XVII siècle (Biblinth. nutionale, ms. latin I72923).

Cf.: Remarques sur quelques pièces qui se truuvent dans un fragment du cartulaire de l'abbaye de Redun [ 3 cahiers de parchemin petit in-fulio de 3 feuilles chacun et formant en tout $24 \mathrm{ff}$.$\rceil (Archices$ nationales, II 522, Rohan, $\left.n^{0} 4\right)$.

Regny. - Abbaye (lioc. d'Altxerre).

3146. - Cartulaire de l'abbaye de Regny ; ms. rédicré vers 1500. sur papier. incomplet de la fin, et contenant des actes des anuées 1100 id 1492. in-40 de $37 \mathrm{fl}$. er crrancle partie éprouves par l'humidité (Biblinth. nationale, ms. latin 17\%25).

se défier des mentions marginales, souvent inexactes.

Extraits du préedent, faits an XVIII siecle Biblioth. nationale, ms. latin 17049. pp. 38!)-400 ; Archices dép. de l'Yonue, H 1562. 
Reims. - Abbaye de Saitil-1)enis.

3147. - Cartulaire de lablaye de St-Denis de Reims; ms. du X VIII siècle [1728], sur papier, de II-710 p. in-4" Biblioth. SainteGeneviève, à Paris, ms. I650).

1)ates extrèmes: 1067-1641. Les notes et corrections en marges sont modernes.

3148. - Copie du mème, exécutée au XV'Ille siècle, sur papier, en 203 cahiers in $4^{0}$ non reliés, en $(\mathrm{i}$ cartons (Archives municipales de Reims, fouds départemental, $\mathrm{H}$ non coté).

Il y a quelques lacunes dans cette série considérable de transcriptions faites arec soin.

3149. - Autre copie du XVIII siècle [1732], sur papier, par les chanoines P. N. Pinchart et P. Hocmele, en 2 vol. in $-8^{\circ}$ de 710 pages (Biblioth. de la ville de Reims, mss. 1821-1822).

Au début du tome I seulement, les documents sont transcrits intégaralement; ensuite ils ne sont plus quanalysés. 1)ates extrêrnes : 10671552 .

Reims. - Abbayr de Saint-Nicaise.

3150. - Cartulaire de l'abbaye de Saint-Nicaise de Reims; ms. du $\mathrm{XIII}^{\mathrm{e}}$ siecle avec atditions, sur parchemin, in-folio de $113 \mathrm{ff}$. Biblioth. de lu ville de Reims, ms. 1843).

Dates extrèmes: $1061-160 \%$.

Extraits (Biblioth. nationule, ms. latin 12688, ff. 38-41; coll. Champilune, vol. CXV1, pp. 1:21-196).

Publ. : Les chartes de ce recueil concernant les dépendances de Simint-Nicaise en Flandre et en Belgique ont été publiées sous le titre de : Chartes inédites extraites du cartulaire de St-Nicaise de Reims, par le Conte $O$. de Gourjault. avec annotations d'Alph. Wauters, dans les Comples-Rendus de la Commission roy. d'histoire de Belgique, 4e série, 1. X, pp. 167-246); et à part: Bruxelles, 1882 ; in-80 de 82 p.

Du (irand cartulaire on a des extraits à la Biblioth. nationale, coll. D. Grenier, vol. LXIII bis, ff. 40-45, et latin 12779, ff. 128134: - du Petit cartulaire on a des extraits dans les mêmes registres, à la suite des autres.

3151. - Petit cartulaire de l'aumônerie de Saint-Nicaise; ins. des $\mathrm{XIIJ}-\mathrm{XIVe}$ siècles, sur parchemin, contenant des titres relatifs à Nenflize, in $4^{0}$ de $23 \mathrm{ff}$. (Archives municipales de Reims, fonds départemental, H non coté).

Reims. - Abbaye de Saint-Remi.

3152. - Cartulaire A de Saint-Remi de Reims; ms. du XIVe siècle, 
in-folio de 663 p. sur parchenin à 2 col. (Archires municipules de Reins).

3153. - Cartulaire B ; ms. du commencement du X1110 siècle, sur parchemin, de 159 p. à 2 col. Archizes municipales de Reims.

3154. - Cartulaire C; ms. de la fin du XIII ${ }^{\mathrm{e}}$ siècle, sur parchemin, de $48 \mathrm{ff}$. à 2 col. (Archices municipales de Reims.

3155. - Cartulaire D ; ms. des $\mathrm{XVe}^{\mathrm{N}} \mathrm{XVI}$ e siècles, sur papier. de $63 \mathrm{ff}$. (Archices municipales de Reims).

Extraits et copies (Biblioth. nutionale, mss. latins 12693-12694, passim ; - ms. latin 13819, ff. 224-25l; coll. Baluze, vol. XLVI, p. 237-263; - coll. Duchesne, vol. XXII, ff. 251-252 ; - et coll. Champagne, vol. XXVII, ff. 185-187, et ff. 330-343, table du cartulaire A).

Cf. Documents historiques inédits, par Champollion-Figeac, I, p. 355 (pour les deux premiers); - et Varin. Archives administratives de la ville de Reims. I. p. Caxvin-GGxix (pour le tout.

Il paraît certain qu il $y^{y}$ a eu au moins sept cartulaires de Saint-Remi, car il $y^{*}$ a, au fo 205 du ms. Iatin 12693, un a extrait du ze rolume des chartes de l'archimonastère taint-Remi dont Dom Ruinart a demandé copie $).$

Reims. - Abbaye de Saint-Thierry.

3156. - Cartulaire de l'abbave de Saint-Thierry de Reims: ms. des $\mathrm{XII}-\mathrm{XVI}^{\mathrm{e}}$ siècles. sur parchemin. in-40 de $410 \mathrm{ff}$. Biblisth. de la cille de Reims, ms. 1602 .

Dates extrêmes: 923 à fin Xille siècle, avec un acte de 1192. Ce recueil contient des fragments de trois volunes arbitrairement réunis. L.e plus récent forme les feuillets ajoutés $76-7 \%$. L Lun de ces volumes doit être le "petit cartulaire de saint-Thierry ") dont it est question dans le vol. CXI de la coll. Baluze (Biblioth. nationale), fo 130 .

Extraits informes faits an $\mathrm{XVII}^{\mathrm{e}}$ siècle Biblinth. nutionule, coll. Duchesne, vol. LXXIV, fo 7 l,

Reims. - Archevèchè.

315\%. - Cartulaire de l'archevèché de Reims: ms. du XVII siècle, sur papier. in-4" de $142 \mathrm{ff}$. Archices nutionules, KK 1067.

Dates extrèmes: 1220-1586.

3158. - Autre. dit Cartulaire $\%$ copié an XVe siècle d'après an volume plus ancien. sur papier. in-folio de $28+\mathrm{ff}$. Atrchices municipules de Reims, G 289 .

3159. - Autre, dit Cartulaire A. copie dn précédent XVIes. . sur papier. in-folio de $192 \mathrm{ff}$. Archices muniripnles de Reims. 
3160. - Autre dit Cartulaire B, transcrit vers 1580, sur papier, in-folio de $198 \mathrm{fr}$. Archives municipales de Reims).

3161. - Cartulaire C ; ms. transcrit vers 1650 , sur papier, in-folio de 494 p., ne contenant guère que des pièces du XVII ${ }^{\mathrm{e}}$ siècle relatives aux démélés de l'archevêque avec l'échevinage (Archives municipales de Reins).

Un autre cartulaire de l'archevêché de Reims a été rédigé en 2 volumes par Dom Oudard Le Bourgeois (XVIIe siecle); Duchesne (Histoire des cardinaux) le cite ainsi que Dom Marlot, mais il parait aujourd'hui perdu.

\section{Reims. - Chapitre métropolitain.}

3162. - Livre ronge du Chapitre de Reins, ou recueil A, formé de plusieurs fragments réunis au $\mathrm{X} \mathrm{VI}^{\mathrm{e}}$ siècle, sur parchemin, in-folio de $367 \mathrm{ff}$. (Archives municipales de Reims, fonds départemental).

3163. - Cartulaire A-B, copié vers 1350 d'après le précédent et le F ; ms. sur parchemin, in-folio de $15 \mathrm{lf}$.(Archives municipales de Reims).

3164. - Cartulaire B ou livre blane; ms. du XIV siècle, sur parchemin, in-folio de $685 \mathrm{ff}$. (1rchives municipales de Reims).

Actes des XIle-XIY"e siècles.

3165. - Ciartulaire $\mathrm{C}$; ms. du $\mathrm{XVI}^{\mathrm{e}}$ siècle [vers 15.50], sur papier, in-folio de $307 \mathrm{ff}$. (Archives municipales de Reims.

Actes des XIle-XIVe siecles, mal transcrits.

3166. - Cartulaire I ou livre noir; ms. dn XVIe siècle, rédigé par Jean Godart, snr papier, in-folio de $313 \mathrm{ff}$. (Archires muicipales de Reims.

Sur ces différents registres, voir Varin, Archives administratives de la ville de Reims, I, pp. chxxi-chxхr.

3167. - Cartulaire li on « Gros registre »; ms. des XIIIe-XVe siècles, sur parchemin, in-folio de $170 \mathrm{ff}$. (Archives municipules de Reims).

Assez semblable au livre rouge.

3168. - Cartulaire F: ms. du XIII ${ }^{\mathrm{e}}$ siècle, sur parehemin, in-40 de $74 \mathrm{ff}$. (Biblioth. Cikeltenham, ms. 2275.

3169. - Cartulaire G on « Livre vert »; ms. du XIII siècle, sur parchemin, in-folio de $127 \mathrm{ff}$. (Arahires municipales de Reims).

3170. - Recueil de titres relatifs an Chapitre de Reims; ms. du XVII ${ }^{e}$ siècle, sur papier, in- $4^{0}$ de 1:31 pages (Biblioth. de la ville de Reims, ms. 1780).

Reims. - Collège des Bons-Enfants.

3171. - Cartulaire dn collège des Bons-Enfants de Reims ; ms. dressé en I7\%7, orig. perdu. 


\section{Reims. - Hòtrl-lieru.}

3172. - Cartulaire de l'Hótel-Dieu de Reimn: ma. de la tin du XIVe siecle. arec quelques additions postérieuren. sur parchenin, in-folio avec table an delout (Arkires hospitulipess te Reims. D I.

Extrait fait au XrII siecle Biblioth. mutimule, coll. Iuchesile, vol. 1.XXIV. 38 .

\section{Reims. - Ville.}

3173. - Cartulaire A ou Livre rouge de l"ehevinaze: mo. des $\mathrm{SII}^{\mathrm{e}}$ XITe siecles, sur parchemin. in-folio de 224 p. Lrehires muicipules de Reins.

C'est plutòt un registre de juridiction qu'un cartulaire.

31\%4. - Cartnlaire B on Livre blanc de l'échevinage: m. du $\mathrm{XV}$ re siecle, sur parchemin, in-folio de $376 \mathrm{ff}$. Archires municipmles de Reims .

Dates extrêmes: $1182-1429$.

$31 \%$. - Cartulaire $\mathrm{C}$ : parait détruit.

3176. - Cartulaire D : ms. dn $\mathrm{YVI}^{\mathrm{e}}$ siècle. sur parchemin. in-folio de 150 p. Archices mulcipales de Reims.

Nombreux actes de juridiction.

Cf. : Archives administratives de lit ville de Reims. par P. J. Varin. I (1839), p. xuht-Xlit.

Rembercourt-aux-Pots. - Préròté lıtraine.

317\%. - Recueil de titres relatifs à la préròté de Rembercourt-auxPots: ms. de la fin du $\mathrm{XVl}^{\mathrm{e}}$ siècle. formé par Thierry Alix. sur papier. contenant des titres de 1359 à 1587. in-folio de $86 \mathrm{ff}$. Archices dép. de Weurthe-et-Woselle, B 388.

Remiremont. - Abbaye (dioc. de Saint-Lié.

3178. - Cartulaire de labhave de Saint-Pierre de Remiremont: m. rédigé en 138.). sur parchemin. in-fulio Biblioth. watioule. m. latin 12866. ff. 67-110.

Contient des pieces des annees 1110-135., en prartie en langue française.

3179. - Autre formé en 1788-1780 par le I'. minime Vuillemin. sur papier, en 4 rul. in-fulio dreliees dep. des Tosyes, G 8:34-8:37.

Remiremont. - Église collègiale saint-Piern.

3180. - Cartulaire de la colléciale Saint-Pierre de Remiremont : ms. du XVII siecle [vers 1785]. rédigé par le P. minine Vuillemin, sur papier. cuntenant des actes de 640 a 1769 . en 4 rol. in-folio de

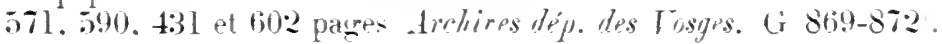


Anal. : Inventaire sommaire des archives départementales des Vosges, série G, tome II (1897), p. 6-17.

3181. - Cartulaire du Chapitre de Remiremont ; ms. du XVlIIe siècle, sur papier, contenant des documents jusqu'en 1780 , in-4 $4^{0}$ de $343 \mathrm{ff}$. (Biblioth. de la ville de Remiremont, ms. 17).

Remonvaux. - Prieuré. - Voy. LE Val-des-Choox.

Remoulins. - Ville.

3182. - Cartulaire de Remoulins, par G. Charvet. Alais, typ. Martin, 187:3-1876; in-8 de vi-64 p.

Rennes. - Abbaye do Saint-Georges.

3183. - Cartulaire de l'abbaye de St-Georges de Rennes; ms. du XIVe siècle [inachevé], sur parchemin, in-folio de $16 \mathrm{ff}$. Archives dép. d'Ille-et-Vilaine, $\mathrm{H}$ non coté).

P'bl. ; Cartulare de Saint-Georges de Rennes, par Paul de La Binne-Villeneuve (Bulletin et Mémoires de la Société archéalogique dille-pt-Viluine, IX, 1876, p. 127-312).

Contient 75 pieces des années 1030-1312.

3184. - Autre cartulaire de St-Georges de Rennes, «minor el vetuslior »; orig. perdu.

Exlraits faits par D. Anselme Le Michel (Biblioth. nationule, ms. latin 12672, ff. $290-296$ ).

Rennes. - Abbaye de Saint-Melaine.

3185. - Cartulaire de l'abbaye de Saint-Melaine de Rennes; ms. du XlVe siècle. écrit sur parchemin par plusienrs mains, débutant par une table rédigée an $\mathrm{XVIIl}^{\mathrm{e}}$ siècle, et contenant 320 chartes à partir de l'année 11:39, in-4 de xiv-226 ff. (Biblioth. de la ville de Rennes, ms. 271).

On trouve quelques copies de pièces sur cette abbaye dans un recueil bénédictin (Biblioth. nationale, ms. latin 13818, ff. $343 r^{\circ 0}-349$ ).

Rennes. - Chapitre métropolitain.

3186. - Cartulaire du Chapitre de Rennes; ms. dı XVIIIe siècle, avec addilions postérieures contenant des titres des années 1174 1764, sur papier, in-folio de 3:24 ff. (Archives dép. d'Ille-et-Vilaine, 2 ( 1 ).

Renty. - Prieuré (dioc. de Boulogne).

3187. - Publ. : Les clrarles du prieuré de Renty, par Félix de Monnecove et l'ahihé Haigneré (Bulletin de la Société des antiquaires de la Horinie, VI, pp. 664-684, et VIII, pp. 205-224), et à part: SaintOmer, d'Homont, 1881 ; in-8n de 44 p. 


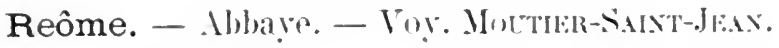

Rethel. - Comte.

3188. - Cartulaire du comté de Rethel. contenant des pieces de 111 i

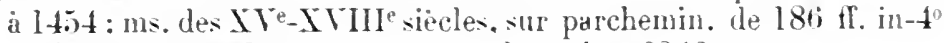
(Biblinth. nutionule. ms. nouv. acq. françatises 6366 .

A appartenu antérieurement au marquis de Clermont.

Cf. Notice sur le Cartulaire du comté de Rethel. par Léopold Delisle 'Annuive-Bulletin de la Sociélé te lhistoire de Fronce. 1867. 2 partie. p. 5-160, et à part: Paris. 1867 : in- $8^{\circ}$ de 160 p.

3189. - Pı́bl.: Trésor des Chartes du comté de Rethel. publ. par

Gnstave Saige et Henri Lacaille. Imprimerie de Yunaco. 19021904: 2 vol. int-4 de Lvi-8.59 et xxir-i2.5 p. [Collection de Documents listoriques publiés par ordre de S. A. S. le prince thlert I ${ }^{\text {er }}$ prince sourerain de Monaco.]

Cette publication, qui se terminera avec un $3^{e}$ volune. comprend actuellement les années 1081 id $141 \%$ : elle a pris pour base tant la cartulaire ci-dessus mentionné que les originaux conservés aux ar.hives du Palais de Monaco.

Reuil. - Prieuré (divc. de Meaux).

3190. - Prbl. : Recueil d'arrests et transactions concernant le prieuré de Reuil en Brie (1645-1726). Chaalons. Senleuze. s. d. ; in- $4^{0}$ de $72 \mathrm{p}$.

Revin. - Ville.

3191. - Cartulaire des villes de Fépin, Fumay et Révin. contenant

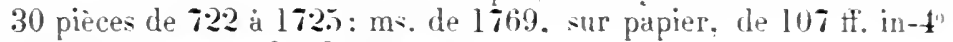
(A)rhices cominunales de Fuminy.

3192. - Pcbl.: Hémoire historique concermant les droils du roi sur les bourgs de Fumay et de Revin. S. l. n. d. [17i2] : in-folio de $267 \mathrm{p}$.

\section{Rhénans (Parss).}

3193. - Publ. : Lrkundenbuch für die Geschichte dw Niederrheins. oder des Erzstifts Cöln. der Fürslenthümer Jülich und Berı. Geldern. Neurs. Cleve und Mark. von Th. .J. Lacomblet. Düsseldorf. Schöp-

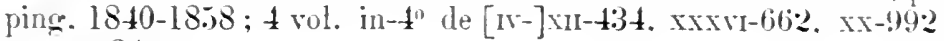
et $\operatorname{xxr}-846 \mathrm{p}$.

Dates extrêmes : 779-1609.

3194. - Codex diplomaticus Rheno-Mosellanus, von Wr. Gï̈nther. Coblenz, 18:2-1826: 6 vol, in-8" et pl.

3195. - Lrkundenbuch zur Geschichte der jelzt die prensischen Regierungabezirke Cohlenz und Trier bildenden niltelrheinischen 
Territorien, von H. Bever,L. von Eltester und Adam (iörz. Coblenz, 1860-1874; 3 vol. in-4o de vin-821, caxir-784 et x-1208 p. Dates exlrêmes : $₫ 3 t-1260$.

3196. - Crkunden und Abhandlungen zur Geschichte des Niederrheins und der Niedermais. von W. Ritz. I. Aachen, Mayer, 1824. in-8 de $176 \mathrm{p}$.

\section{Riaucourt. - Village.}

3197. - Publ.: Le cartulaire de Riancourt. recueil de documents inédits et anciens relatifs à l'histoire de ce village. par Mtor. Fèvre. Saint-1)izier, impr. Saint-Aubin et Thévenot, 1892: in-8 de vi-206 p.

Ribeaupierre. - Srignemie en Alsace.

3198. - Livre des fiefs et des privilènes de la seigneurie de Ribeaupierre: ms. dı XVII siècle. sur papier. contenant 230 documents des années 1269 i 17.06. in-folio de $401 \mathrm{ff}$. Archic des Ober-Elsuss, in Colmar).

3199. - P'вь.: Rappoltstemisches Trkutenluch 759-1500; herausy. von I ${ }^{r}$ Karl Albrecht. I-V 759-1400 . Colmar, Barth. 18901898 ; 5 vol. in- $4^{\circ}$ de xr-707. vill-695, vin- 675 , vin- 725 et vil- 720 p.

Ribemont.-Ablayede Saint-Nicolasdes Prés (dioc.de Laon). 3200. - Cartulaire de lahbave de Ribemont; ms. du XIIIe siècle. sur parchemin. de $80 \mathrm{ff}$. in- $4^{\circ}$ "Archices nutionales, LL. 1015.

Publ. : Le cartulaire de l"ablaye de Saint-Nico'as-des-Prés sous Riliemont. publié et annoté par Henri Stein Mémoires de la Société "carlémique de Sunint-Quentin, $4^{\mathrm{e}}$ série, V. p. 112-3337, el a part: Saint-Quentin. 1883 : in- $\delta^{\prime \prime}$ de $231 \mathrm{p}$.

Ricey. - Priruré (dioc. do Langres).

3:01. - Cirtulaire du priemré de Ricey. dépendant de labbaye de Saint-l'ierre-?e-Vif ; m. de la fin du X Ve siecle. contenant $2 \cdot 2$ actes des années 1173 it 1492 . sur papier, in-folio de $15 \mathrm{ff}$. Archives dép. de l'Yonne, H :24?.

Richelieu. - Ville.

3202. - Y'cbl.. : I'rivileges. exemptions ef franchises accordés par le roi aux hahitants de la ville de Richelieu. 'Tours, 16:33, in-4".

Richerenches. - Commanderie du Temple (dioc. de SaintPaul-Trois-Chàteanx).

3203. - Cartulaire des Templiers de Richerenches; ms. du XII siècle, sur parchemin, in- $4^{0}$ de iII-156 ff. (Biblioth. de la ville d'Avignon, ms. 2488).

Publ. : Cartulaire de la commanderie de Richerenches de l'ordre 
du Temple (1136-1214), publ. par le mis: de Ripert-Monclar. Avignon, Seguin [Paris, Champion]. 1907 ; in-8" de cLxiv-307 p. [Mémoires de l'Académie de Vancluse.]

Rieux. - Compent des Trinitaires (dioc. de Vanues).

3204. - Cartulaire des Trinitaires de Rienx. près de Redon; ms. du XVIII siècle [1766], sur papier. contenant des actes de 1344 à 1416 , in $4^{0}$ de $20 \mathrm{ff}$. Archires nutionules, $\mathrm{S}+269^{-1}, \mathrm{n}^{0} 17$.

Riez. - Ville.

3205. - Cartulaire municipal de Riez on « livre de Mélan »: ms. rédigé en 1600, et contenant des documents de 1293 à 1541 , in-folio de $289 \mathrm{ff}$. Archices municipales de Riez, At 1 ).

Rigny. - Abloyye (dioc. d'Autun).

3206. - Cartulaire de l'abbaye de Rigny : orig. perdu.

Extraits faits par A. Du Chesne et publiés dans son Histoire de la maison de Vergy, p. 411 et ss.

Dom Villevieille a aussi connu et utilisé le manuscrit origrinal. Courtépée (Description du duché de Bourgogne, nouv. élit., IV', p. 367) raconte que Dom Marlot, étant procureur de Rigny", "rérligea les titres et chartes de cette abbaye n en un seul rolume in-folio, que le prieur voulut bien lui communiquer en 17\%4.

Rillé. - Prieuté dép de Marmontier (dioc. de Tours).

3207. - PLBL. : Archives d'Anjou, II (1853), pp. 28-49.

Ripoll. - Abbaye (dioc. de Barcelone).

3208. - Cartulaire du monastère de Ripoll : ms. du XIII siècle, sur parchemin. in- $\mathbf{t}^{0}$ Biblioth. du duc de Medina Coeli, à Madrid,

Cette indication, due à A. Giry, n’a pu ètre vérifiee. D'autre part II. Rudolf Beer, dans un tout récent mémoire que publient les sitsungsberichte de l'Académie de Vienne, affirme quil y eut deux cartulaires de Ripoll et que tous deux ont été détruits.

Extraits faits pour Baluze au XVIe siècle Biblinth. nutionale, coll. Baluze. vol, CVII, ff. 292-304.

Le nième volume contient (ff. 180-281' une série de textes relatifs à la mène abhaye, Iranscrits d'apres les originaux.

Rivesaltes. - Ville.

3209. - Livre ronge on cartulaire municipal de Rivesaltes: mi. rédigé par le notaire Jean Bartès. commencé en 1:312 et poursuivi jusqu'i 1793. sur papier. in-folio de 350 ff. Archices municipales de Rivesaltes, At 1 .

Rixheim. - Commanderie de londre Toutonique (dioc. de Bàle).

3210. - Cartulaire de la commanderie de Rixheim; ms. du 
XVIHe siècle [1772], sur papier, contenant des actes à partir de 122I, in-4" de $55 \mathrm{ff}$. (Archio des Ober-Elsass, in Colmar).

Roaix. - Commanderie de Templiers (dioc. de Vaison).

3211. - Cartulaire de la commanderie des Templiers de Roaix; ms. du XIII siècle, in-40 de 40 ff. [nanquent les ff. 25-32] (Biblioth. nationale, ins. latin 11082 .

Publ. : Cartulaire des Hospitaliers et des Templiers en Dauphiné, par l'abbé Ul. Chevalier. Vienne, Savigné, 1875 ; in-8", p. 103187. [Collection des cartulaires dauphinois, III, l.]

Robermont. - Abluay (dioc. de Liege).

3212. - Cartulaire de l'abbaye de Robermont; ms. du XVIIe siècle, sur papier, contenant des documents de 1184 a 1592 , in-folio de $169 \mathrm{ff}$. Archives de l'itat à Liège).

3213. - Autre cartulaire du XVII siècle, sur papier, in-folio de $357 \mathrm{fr}$. (Archices de l' lítat ù Liège).

On $y$ trouve ì peu près les mêmes transcriptions que dans le précédènt.

3214. - Autre cartulaire des $\mathrm{XVI}^{\mathrm{e}}-\mathrm{XVII} \mathrm{I}^{\mathrm{e}}$ siècles, sur papier, contenant des documents des 1263) à 1619, in-folio de $179 \mathrm{ff}$. (Archives de l'stat à Liègè.

3215. - Autre cartulaire des XVIe_XVII" siècles, sur papier, contenant des documents de 1373 i 1702 , in-folio (Avchires de l'Étut à Liège).

Rocamadour. - Prieuré. - Voy. Tullf.

Cf. Notice sur le cartulaire de Rocamadour, par G. Clement-Simon, dans: Archives historiques de la Corrèze, 11 (Paris, Champion, 1905; in- $8^{\circ}$ de $645 \mathrm{p}$.).

Rochechouart (de). - Famille. - Voir Aumost.

Roches. - Abbaye cistercienne (dioc. d'Auxerre).

3216. - Cartulaire de l'albaye de Roches ; orig. perdı.

Il est mentionné dans un fragment dinventaire des archives de l'abbay", en cahiers de papier du XVIII siècle, que possèdent less Archires depo. de la kievore (série $\mathrm{H}$ ), et où se trouvent des copies partielles de chartes.

Rocroi. - Ville.

3217. - Cartulaire de la ville de Rocroi ; ms. du XVIII ${ }^{\text {siècle, sur }}$ papier, contenant des documents de 1449 à 1742 , in-folio de $136 \mathrm{ff}$. Aichives dep. des Aidennes, E 764. 
Rodez. - Chapitre catlièdral.

3218. - Cartulaire du Chapitre de Rodez; ms. du XIV siècle, sur parchemin, contenant 18 actes des $\mathrm{XII}^{\mathrm{e}}-\mathrm{XI} \mathrm{T}^{\mathrm{e}}$ siècles, in- $4^{0}$ de $40 \mathrm{ft}$. (Archices dép. de l Aceyron, G non coté .

3219. - Autre cartulaire: ms. du XIVe siècle, sur papier, contenant

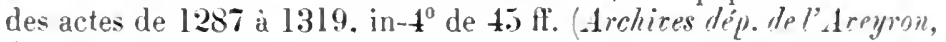
G non coté).

Rodez. - Collège.

3220. - Cartulaire du collège de Rodez; ms. dn XliJe siecle. sur papier. contenant des titres de 1560 à 1698. in-t" de 2.)t fit. Archices dép. de l'Aceyron, D 55050 .

Rodez. - Domerie-hôpital de sainte-Marthe.

3221. - Cartulaire de la domerie de Sainte-Marthe de Rodez; m. du XVIII siècle. sur papier, in-folio de $118 \mathrm{ff}$. Archires dep. de l'A ceyron, D 6 .

Dates ertrêmes : 123,-1701.

Rodez. - Érèché.

3222. - Cartulaire de lévèché de Rodez: ms. du XVe siècle. sur papier. contenant des titres des $\mathrm{XII}^{\mathrm{e}} \mathrm{XI} \mathrm{Y}^{\mathrm{e}}$ siècles. in-folio de $24 \mathrm{ff}$. Archives dép. de l'Aceyron, Gi 9 .

322:3. - Autre du XVe siècle, sur papier. contenant des titres de I192 à 1340 . in-folio de $278 \mathrm{ff}$. Archices dép. de l'Areyron, G 10 .

3224. - Recueil de titres relatifs à l’évêché et au chapitre de Rodez: ms. de 1668. contenant des actes des années $105 \mathrm{l}$ à 1567 . in-folio de 339 ff. (Biblioth. nationale, coll. Doat, vol. 133 .

Rodez. - Ville et couvents.

3225. - Recueil de titres relatifs in la ville. aux albbayes et auz couvents de Rodez: ms. de 1666-1568, contenant des actes des années 814 à 1589 , in-folio de $367 \mathrm{ff}$. Biblinth. Mutionale, coll. Doat. vol. 132 .

Rodez. - Ville.

3226. - Prbr.. : Contumes et privilères du Rouerune: I Rodez. par Em. Bailland et P. A. Verlarnet. Tonlouse, Privat. 1904; in- $8^{10}$ de xn-344 p. [Bibliothèque méridionale. 2e série. IX.]

Documents entierement emprunlés aux archives municipales de Rodez.

Rœulx. - Abbaye de Saint-Fenillen (dioc. de Cambrai).

3227. - Cartulaire de l'ablaye de Roulx; ms. de la fin du XIlle siecele 
sur parchemin, avec additions postérieures, contenant 249 actes de 1125 à 1622 . in-folio de $143 \mathrm{ff}$. (Archives de l'Etat à Mons).

32:28. - Autre cartulaire du XIVe siècle, sur parchemin, contenant des actes de 1125 à 1272 , in- $4^{\circ}$ de 262 . pages (Archives de l'Etat à Mons).

Ax.1L. : Description sommaire du cartulaire de l'abbaye de SaintFeuillen de Roulx, par Léopold Devillers (Annales du Cercle archéologique de Yons, XXI, 1888, pp. 285-316).

Romainmotier. - Priruré (dioc. de Lausanne). 3229. - Cartulaire de Romainnotier ; ms. des XIIe-XIVe siècles, sur parchemin, in-folio de $45 \mathrm{ff}$. (Archives cantonales de Fribourg).

Pebl. : Cartulaire de Romainmotier, publ. par Fr. de Gingins-laSarra Mémoires et Documents publ. par la Société d'histoire de la Suisse romande. III, 1844, p. I-X11. 417-575 et 903-915).

C.' cartulaire avait servi à l'abbé Guillaume pour son Histoire des sires de Salins (175\%), et les dix premiers feuillets avaient été imprimés seuls dans les Srhweiserische fieschirhtsforscher en 1820.

Romans. - Abbaye de Saint-Barnard (dioc. de Vienne). 32:30. - Cartulaire de l'abbaye de Saint-Barnard de Romans; ms. du XIII siècle. sur parchemin. relié en bois, in-folio de $351 \mathrm{ff}$. Arrhices dép. de la Dróme, (i non coté).

A été remis à ce dépôt par M. Giraud.

Pcbl. : Essai historique sur labbaye de Saint-Bernard et sur la ville de Romans, accompagné du cartulaire de Romans annoté, par P. E. Girand. Lyon, Perrin, 1856-1859; 3 vol. in- $8^{\circ}$ de 330,261 , 393. 393 et 281 pilges. - Complément textuel dn cartulaire, par le mème. Lyon. Perrin, 1869 : in- $8^{\circ}$ de xvi-283 p.

Cif. l'abbé U. Chevalier, dans Bulletin do la Societe d'archeologie et de stutistique de la Divime, I, pp. 240-249, et II, pp. 169-188; et l'abbé (.) Perrossier Irlem, XXVI, pp. 406-4l3).

Rome. - Pouroir temporel des Papes.

3231. - Prbl. : Codex diplomaticus dominii temporalis S. Sedis; Recueil de documents extraits des archives du Vatican, par le 1'. Aug. Theiner. Romae, 1861-1862; 3 vol. in-folio.

Romorantin. - Chàtellenie. - Voy. Blols (comté de).

Roncevaux. - Abbaye (llioc. de Pampelune).

3232. - Recueil de titres relatifs à l'abbaye de Roncevanx ; ms. formé par Oïhenart an XVlI ${ }^{\mathrm{e}}$ siècle, sur papier (Biblioth. nationale, coll. Duchesne. vol. XCIX, ff. 1:24-170).

Dates extrêmes : 1137-1525. 
Rosas. - Abbay de saint-Pierme (dion. de Grema). 32:33. - Cartulaire de labbaye de Saint-Pierre de Rosas ; orige perdu. Extraits faits au Xrile siècle pour Baluze. et contenant des documents carolingiens et du $\mathrm{XI}^{\mathrm{e}}$ siècle (Biblioth, nationale, coll. Baluze, vol. C.VII. ff. 426-446).

Rosières. - Abbaye (llioc. de Besançon).

3234. - Cartulaire de l'ahlaye de Rosières : ms. du XTIII siècle. sur papier, contenant des titres des années $1135-1193$, in- $4^{\circ}$ de $311 \mathrm{ff}$. (Biblioth. de la cille de Besancon, coll. I)roz. ms. 43.

Autre copie du XVIII siècle (Biblinth. nutionule, coll. Noreau, vol. 871, ff. 318-512.

Extraits (Biblioth. de la rille de Poligny. mis. 2, ff. 101-131 .

Roubaix. - Ville.

3235. - Recueil des privilères et franchises de la ville de Roubaix; ms. des $\mathrm{XVII}^{e}-\mathrm{XV}$ III $\mathrm{I}^{\mathrm{e}}$ siècles. sur papier. contenant des actes de 1414 à $178 \overline{7}$, in-t" de 116 ff. Archices municipales de Roubluix. At 3 .

Rouen. - Ablaye de Sainte-Catherine ou de la Sainte-Trinité du Mont.

3236. - Cartulaire de la Sainte-Trinité du Mont : ms. du XII siècle, contenant $9 \bar{i}$ chartes ou notices de cette époque, sur parchemin, in- ${ }^{0}$ de $20 \mathrm{ff}$. (Archices dép. de la Seine-Inférieure, $\mathrm{H}$ non coté.

Publ. : par M. Deville [dans le Cartulaire de labbaye de SaintBertin, par B. Guérard. p. 403-4877.

Rouen. - Abbare de saint-Amand.

3237. - Cartulaire de l'abbaye de Saint-Amand de Ronen : ms. du XIII siècle, sur parchemin, contenant 486 documents des années 1030 à 1296. in-8 de 270 ff. Archices dép. de ln Sinne-Inférieure, $\mathrm{H}$ non coté).

Rouen. - Abloave de Saint-Oum.

3238. - Grand cartulaire de Saint-Onen de Rouen. ou " Cartularium sancti Audoeni », intitulè «Rothomagum ef foresta »: ms. de la fin du $\mathrm{XV}^{\top} \mathrm{e}$ siècle, contenant 8:7 pièces des annèes 1026-1490. sur papier, in-folio de $350 \mathrm{ff}$. Archices dép. de ln Seine-Inférieure. H non coté.

3239. - « Registrum cartarum conventus sincti Audoeni 》: ms. composé par le frère Th. Lescarre en I 483. sur papier, in-folio de $187 \mathrm{ff}$. Archices de lu Seine-Inférieure, H non cotè).

3240. - Autre cartulaire. rédigé en I487, sur papier. in-folio de 207 p. (Archices dép. de la Srine-Inférieure, $\mathrm{H}$ non coté. 
3241 . - Autre cartulaire, de la fin du $X \mathrm{~V}^{\mathrm{e}}$ siècle, sur papier, in-4 $4^{0} \mathrm{de}$ $67 \mathrm{ff}$. Archives dép. de la Seine-Inférieure, $\mathrm{H}$ non coté).

3242. - « Chartularium monasterii sancti Audoeni Rotomagensis ע; ms. composé pour Gaignières an XVIIle siècle, infolio de 237 p. sur papier (Biblioth. nationale, ms. latin 5423).

Un "petit» cartulaire du XIII siècle, qu'on trouve cité dans la "Neustra pia " et utilisé par Dom lee Noir au XVIIIJ siècle, paraît perdu.

Pour mémoire on peut mentionner un recueil de chartes anciennes, mais fausses pour la plupart, sur papier, du XVe siècle (Biblioth. nationale, nus. latin 12777 , ff. $106-124)$.

Extraits divers des précédents, faits en 1615 (Biblioth. nationale, ms. latin 13816, ff. $\left.120 \mathrm{v}^{0}-124\right)$.

Rouen. - Archevêché.

324:3. - Cartulaire de l'archerêché de Rouen, dit de Philippe d'Alençon ; ms. du XIVe siècle, avec additions du XVe, sur parchemin, contenant des documents des années 1133-1470, in-folio de $1099 \mathrm{ff}$. (Archires de la Seine-Inférieure, G 7 .

Extraits du mème (Biblioth. nationale, coll. Baluze, vol. LXXV, ff. 136-181). - Les ff. 94-133 en contiennent une analyse sommaire partielle.

324t. - Fragrment d'un carlulaire de l'archevêché de Rouen; ms. du X Ve sircle, sur papier, contenant des chartes mérovingiennes, carolingriennes et jusqu'à 1177 , in-4" Biblioth. nationale, ms. latin 12777. pp. 106-125.

Rouen. - Chapitre mètropolitain.

3245. - Cartulaire du Chapitre métropolitain de Rouen; ms. du XVII siècle, sur papier. contenant des documents de 874 à 1597 , in-folio de 182 fr. (Archives dép. de la Seine-Inférieure, G 2087).

3246. - Autre de la fin du XVe siècle, sur papier, contenant des documents de I268 à 1488. in-folio de 412 ff. Arehives dép. de la Seine-Inférieure, G 2088).

3247. - Antre du XVe siècle, sur papier, contenant des documents de 1224 a 1442 , avec quelques additions postérieures, in-folio de $548 \mathrm{ff}$. (Archives dép. de la Seine-Inférieure, (i 2089).

3248. - Autre dn $\mathrm{XV}^{\mathrm{e}}$ siècle, sur papier, contenant des documents de 1240 i 1440 , avec quelques additions postérieures, in-folio de $412 \mathrm{ff}$. (Archices dép. de la Seine-Inférieure, G 2090).

3249. - Autre de la fin du XVe siècle, sur papier, contenant des documents de 12:38 à 1473, in-folio de 285 fi. (Archives dép. de la Seine-Inférieure, G 2091).

3250. - Cartulaire-lullaire dı XVI ${ }^{\mathrm{e}}$ siècle, sur parchemin, contenant 
des actes des années 1:372-15:30, in-4 de 100 ff. Archires dép. de la Seine-Inférieure, G 2092 .

Rouen. - College de Saint-Marc ou des notaires a postoliques. 3251. - Cartulaire du college de Saint-Mare de Rouen; ms. des XVe-XVII siècles, sur parchemin, contenant des documents de 1405 à 1628, in-folio de $203 \mathrm{ff}$. Archioes dép. de la Seine-Inférieure, G 9028).

\section{Rouen. - Couvent des Célestins.}

3252. - Cartulaire du couvent des Célestins de Rouen; ins. de la fin du XVe siècle, sur parchemin, contenant des titres de I4I:2 à 1482 , in- $4^{0}$ de $19 \mathrm{ff}$. (Archices dép. de la Seine-Inférieure, G 9194.

Rouen. - Courent des Cordeliers.

3253. - Bullaire des Cordeliers de Rouen ; ms. de la fin du XIII siècle, sur parchemin, contenant des actes de 1218 à 1285 , in- $4^{0}$ de $44 \mathrm{ff}$. (Archires dép. de la Seine-Inférieure, $\mathrm{H}$ non coté,

Rouen. - Courent des Dominicains ou prieuré des Emmurées. 3254. - Cartulaire du prieuré des Emmurèes de Rouen; ms. du $X Y^{\text {e }}$ siècle, sur papier, contenant 837 actes des années 1235 à 1475 , in-folio de $570 \mathrm{ff}$. (Archires dép. de la Seine-Inférieure, $\mathrm{H}$ non coté).

Rouen. - Église cathédrale Notre-Lame.

3255. - Cartulaire de léglise cathédrale de Rouen: ms. des Xille$\mathrm{XIVe}$ siècles, avec table moderne, sur parchemin, in $\mathbf{4}^{0}$ de $226 \mathrm{ff}$. (Biblioth. de la ville de Rouen, ms. 1193).

Copie moderne du mème, in- $4^{0}$ de $286 \mathrm{ff}$. (Biblioth. nationale, ms. nouv, acq. latines 1363 ,

Rouen. - Église Sainte-Croix.

3256. - Cartulaire de l'église Ste-Croix de Rouen: ms. des $\mathrm{XVI}^{\mathrm{e}}$ XVII siècles, sur parchemin, contenant 180 titres des années 1340 à I686, in-folio de $200 \mathrm{ff}$. Archices dép. de la Seine-Inférieure. G 6379).

Rouen. - Église Saint-Marlou.

3257. - Cartulaire de l'église St-Maclou de Rouen : ms. du X $\mathrm{V}^{\mathbf{e}}$ siècle, sur parchemin, contenant des actes depuis le $\mathrm{XII}$, in- $4^{\circ}$ de $95 \mathrm{ff}^{\circ}$. (Archires dép. de la Seine-Inférieure, G 6872).

32508. - Cartulaire de leéglise St-Maclou de Rouen: ms, des $\mathrm{XVI}^{\mathrm{e}}$ et $\mathrm{XVII}^{\mathrm{e}}$ siècles, sur parchemin, contenant des actes de $\mathrm{I} 40 \mathrm{~T}$ a 1632 . in-folio de $459 \mathrm{ff}$. Archices dép. de la Seine-Inférieure. G 6873. 
Rouen. - Hospice général.

3259. - Cartulaire de l'hospice grénéral on burean des paures de Rouen; m.. du $\mathrm{XVI}^{\mathrm{e}}$ siècle [1582], sur parchemin, contenant den titres depuis 1530, in-folio de $143 \mathrm{fr}$. (dichives dép). de la SeineInférieure. H non coté).

3260. - Autre cartulaire; ms. des $\mathrm{XVI}^{\mathrm{e}}-\mathrm{XVII}^{\mathrm{e}}$ siècles. faisant suite au précédent. sur parchemin, contenant des titres de 15505 à 1646 , in-folio de $466 \mathrm{ff}$. (Archices dép. de la Seine-Inférieure. H non coté).

Rouen. - Ville.

3261. - Recneil de titres relatifs à la ville de Rouen; tome I [seul], ms. du XVII e siècle, sur papier, contenant des documents depuis le $\mathrm{XlIl}^{\mathrm{e}}$ siècle, in-4 ${ }^{0}$ (Biblioth. nationale, ms. latin 10057, ff. 1-391). Rouge-Gloître. - Prieuré (dioc. de Malines).

3262. - Cartnlaire du prieuré de Ronge-Clôtre; ms. du $\mathrm{XV}^{\mathrm{e}}$ siècle, sur parchemin, in-folio de $268 \mathrm{lf}$. (Biblioth. Cheltenham).

\section{Roussillon.}

32633. - Lilher lendorum A ou Cartulaire roussillonnais; ms. du $\mathrm{XIV}^{\mathrm{e}}$ siècle, sur parchemin, contenant des actes de 1165 à 1324. in-folio de 117 ff. Archires dép. des Pyrénées-Orientules, B 15).

3264. - Liber feudorum B; ms. perdu.

3265. - Liber feudorum C : ms. du $\mathrm{X}^{\mathrm{e}}$ siècle, sur parchemin, contenant des actes de 976 a 1341 , in-folio de $170 \mathrm{ff}$. Archires dép. des Pyrénées-Orientales, B 16).

3266. - Cartulaire roussillonnais. copies et extraits de documents des $\mathrm{IX}^{\mathrm{e}}-\mathrm{XVII}^{\mathrm{e}}$ siecles, par B. Alart : ms. du $\mathrm{XIX}^{\mathrm{e}}$ siècle. sur papier, en 46 vol. in-4" 'Biblinth. de la ville de Perpignan, ms. 107).

Deux tables, permettant de se retrouver dans cette collection, forment les miss. 108-109 de la mème bibliothèque.

3:267. - Publ. : Privilèges et titres relatifs anx franchises, institutions et proprietés communales de Roussillon et de Cerdagne depuis le $\mathrm{XI}^{e}$ siècle jusqu'à l'an 1660 , par B. Alart. Ire partie. Perpignan, Latrobe, 1874 ; in- $4^{\circ}$ de $11-348 \mathrm{p}$.

3268. - Publ. : Cartulaire roussillomais, par B. Alart. Perpignan, Latrobe, 1880 ; in-8 de n-125 p.

Recueil factice de 90 chartes des années 865 à 1106.

Rouvray-en-Bray. - Prieuré (dioc. de Rouen).

3269. - Curtulaire de Saint-Vincent de Rouvray ; ms. du XVIIl ${ }^{\mathrm{e}}$ siècle, sur papier, in-folio de 1057 p. (Archives nationules, LL 1553-1554). 
Royallieu. - Abbayro (dioce de Soissons).

3270. - Cartulaire de labbaye de Royallieu. de l'ordre du Val-rlenÉcoliers, puis des Bénédictins; ms. lli XIV"e siècle [13.58]. composé par ordre du prienr frère Simon de Senlis, sur parchenin. avec table en tête, miniature el lettres ornées. contenant des documents de $111+$ a 1350 , in- $t^{0}$ de vint-172 ff. à 2 col. Biblioth. mationale, ms. latin 5434 .

Royan. - Prieuré de Saint-Nirolas (dioc. do Saintes).

3271. - Publ. : Chartes du prieuré de Saint-Nicolas de Royan. publ. par A. Inpré Archices historiques de la Saintonge et de l'Aunis, XIX, 1891 . p. 25-43).

Documents des années 1092-1121, publiés diprès le-cartulaires de la Saure-Majeure.

Royaumont. - Abbaye (dioc. de Beaurais).

3272 . - Cartulaire de l'abbaye de Royamont : ms. du $\mathrm{XV}^{\mathrm{I}} \mathrm{Il}^{\mathrm{e}}$ siècle, sur papier, contenant des titres de 1218 a 1733 . en 2 vol. in-folio de 2166 pagres plus 2 tables de 24 et 20 pages Archices dép. de Seine-et-Oise, $\mathrm{H}$ non coté.

3273. - Autre cartulaire, en grande partie double du précédent, achevé en 1703 ; ms. sur papier en 4 vol. in-folio formant 1695 payes (Biblioth. nationale. mss. latins 9166-9169;.

3274. - Antre cartulaire perdu [in- $4^{0}$ sur parchemin].

3275. - Recueil de titres formé par Gaignières an XVlle siecle, d'après le précédent et les origmaux (Biblioth. nutiourale, ms. latin 5472 ; autre Idem, coll. Clairambault, vol. 562 , pp. 38:3-429.

Extraits du mème (Biblioth. nationale, coll. Duchesue. vol. XXII, ff. 110-111 : et coll. Clicambault, vol. 562. pp. 431-4:3.).

Roye. - Église (dioc. d'tmiens).

3276. - Cartulaire de l'église de Roye : origr. perdu.

Extrait du précédent fait au $\mathrm{XVIl}^{\mathrm{e}}$ siècle (Biblinth. metionule, ms. latin 11743. ff. 15.5-162.

Rozoy ou Villechasson. - Abbaye (dioc, de Sens).

32\%\%. - Cartulaire de l’abbaye de Rozor-le-Jeune : ms. dn XV $\mathrm{Il}^{\mathrm{e}}$ siècle, sur papier, contenant $367^{\circ}$ documents à partir de 1115 . de $324 \mathrm{tit}$. in-folio (Archices dép. de l' Yonne, H 950 .

3278. - Recueil factice de documents. fait au $\mathrm{XVH}^{\mathrm{e}}$ siècle. servant de preuves à une histoire de lahbaye par le P. Jacques Vignier Biblioth. nationale. ms. français 5990. ff. 194-250.

Cf. Anumles de le Socioto hist. of archéol. du Gintinais, XXIII (1905), p. 88-98. Un recueil de pieces sur l'abbaye de Rozoi-le-Jeune. par L. Aurray. 
Rozoy. - Chapitre (dioc: de Laon).

3279. - Cartulaires dı Chapitre St-Laurent de Rozoy en Thiérache ; orig. perdus.

Cf. Histoire du chapitre de Rozoy, tirée de ses cartulaires et chartes; ms. du XVIII ${ }^{\mathrm{e}}$ siècle (Biblioth. nationale, ms. français 14589 ).

3280. - Recueil de documents relatifs au chapitre de Rozoy, fait en 1469 (Biblioth. nationale, ms. français 4787, ff. 67-83).

Rue. - Ville.

3281. - Cartulaire municipal de Rue; orig. perdu.

Extraits du livre ou ancien cartulaire de Rue en Picardie [XIVe_ $\mathrm{XVI}^{\mathrm{e}}$ siècles], faits au $\mathrm{XVIII}^{\mathrm{e}}$ siècle (Bıblioth. nationale, coll. Dom Grenier, vol. XCVII, p. 207-262).

Rueil. - Village près de Paris.

3282. - Cartulaire de Rueil, dépendant de l'abbaye de Saint-Denis ; ms. dı XIII siècle, avec addition d'un acte de l303, sur parchemin, contenant des titres à partir du $1 \mathrm{X}^{\mathrm{e}}$ siècle, écrits par plusieurs mains, in- ${ }^{0}$ de 56 fl. (Archives nutionales, LL. 1167).

Saint-Acheul. - Abbaye (dioc. d'Amiens).

3283. - Cartulaire de l'abbaye de Saint-Acheul ; ms. composé en 1308, perdu an XVIII' siècle.

Copie du précédent, faite en 1654 , et contenant 237 pièces des années 1085-1307, sur papier, in-4 ${ }^{\circ}$ de 186 fr. (Archives dép. de la Somme, H non coté).

Extraits faits au $\mathrm{XVIJ}^{\mathrm{e}}$ siècle (Biblioth. de l'Arsenal, ms. 5259 , fl. $111 \mathrm{v}^{0}-116 ;-$ Biblioth. nationale, coll. Duchesne, vol. LX, II. 188-192; ms. français 9497, pp. 228-2:39; - Biblioth. de la cille de Royje, ms. 17).

3284. - Autre des $\mathrm{XIVe}^{\mathrm{e}} \mathrm{XVII^{ \textrm {e } }}$ siècles, sur parchemin et papier, in-4 de 1922 II., contenant 189 chartes des années 1087 à 1370 British Wuseum, ms. additional 15604).

Manquent les ff. 128,136 à 146 ; il y a de plus quelques transpositions.

Cif. Étude critique sur les chartes de Thibaut, évêque d'Amiens, qui sont dans le cartulare de st-Acheul (Biblioth. de la ville d'Amiens, ms. $\left.50.1, t^{\circ} 30\right)$.

Saint-Affrique. - Ville.

3285. - Recueil de titres relatifs à la ville de Saint-Aflrique; ms. du XVII siècle, contenant des documents de 1238 à 1453 (Biblioth. mutionale, coll. Doat, vol. 149. ff. 1-145). 
Saint-Amand. - Commanterier de trimpliers (dion. de (hàloms-sur-2larme).

3286. - Cartulaire de la commanderie de Saint-dmand; ms. de la fin du XIVe siecle. sur papier. rontenant des chartes de IIJ̈ anviron i) 1:293, in-t" de $26 \mathrm{tl}$. Archices dép. de ln. Wurne, H non coté.

3287. - Antre cahier: ms. du $\mathrm{XVI}^{\mathrm{e}}$ siecle. sur papier. contenant la Iraduction plus on moins correcte des actes contenus dins le précédent regristre frchires dép. de la larire. H non coté.

Axal. : Le cartulaire de la commanderie de Saint-Amand, par Anatole de Barthélemy Cubinet historique, 1882. pp. 38-50). et à part : Paris. Champion. in-8" de $16 \mathrm{p}$.

Saint-Amand. - Prieuré (dioc. de Noyon).

3288. - Pubr.. : Le prieure de Saint-Amand, de loordre des Bénédictins, dipendant de lahbave de Saint-Martin de Tuurnay. situé sur le territoire de Machemont (Oive) snivi de son cartulaire. par L. A. Gordière. Compiemne [Paris. Lecheralier]. 1886 ; in- $\delta^{\prime \prime}$ de xxv-393 p. et pl.

Saint-Amand-de-Boixe. - Abbaye (dioc. d'Angoulème). 3289. - Cartulaire de Saint-Amand-de-Buixe; origr. perdu.

Copie dir précédent. faite au $\mathrm{XVII}^{\mathrm{e}}$ siècle. sur papier. in-4 ${ }^{v}$ de 18:3 11: Biblinth. nationale, ms. latin I'2898;. $55^{2}$.

Copie moderne. par A. Livire (Bibliath. de la ville de Poitiers. ms.

3290. - Autre cartulaire; ms. du XVIII secle. sur papier. in-folio de 185 pares [très mauvaise copir] Archices dép. de ln Charente, $\mathrm{H}$ non cotét.

Hixtraits faits an XYII sicele Biblioth. antionale, coll. Baluze, vol. XXXVIII, ff. 111-119. et vol. I.XXI, p. 1-4: ms. latin 9197, fi. :35-38 et $54 v^{0}-58$.

Saint-Amand-d'Elnone ou Saint-Amand-les-Eaux. Abbaye (dioc. de Tommai).

3291. - "Cartularius Sancti Amandi EInonensis. qui codex collectus est anno Domini MCX VII a domno Crualtero, monacho tunc temporis armarii custode » : origr. perclu.

Arait ar feuillets de parchemin.

Extraits du précédent. faits au $\mathrm{XVH}^{\mathrm{e}}$ siècle Bibliath. nutionale, ms. latin 12658, 11. 223-229: - au XV111 siecle par Dom Gupinsert (Idem. coll. Moreau, vol. 98, fo 87 et pasim).

3292. - Cartulaire de l'abhaye de Saint-Amand en Pévèle: ms. dı XII e siècle avec diverese alditions jusqu'au XVIJ'e. comprenant 
$56 ; 3$ actes des annees $634-1672 ; 2$ vol. in-folio de 148 et 295 ff. sur parchemin drehioss dep. dr. Word, H non cote).

Copie moderne (1873). par L. Rohert Biblioth. nutionale, ms. nouv. acq. latines 1219-1220).

329:3. - Antre cartulaire on « liber ruber»: mis. du XVe siècle, sur parchemin, contenant 147 ducuments des innées 1200-1445, in-folio de $14 \mathrm{fr}$. (Archires dép. du Nord, H non cote).

3294. - Un fenillet detaché d'un autré cartulaire dit « Liber bonorum » ( $\mathrm{X}^{\mathrm{e}}$ siecle? a été retrouvé en mauvais chat (Biblioth. de la ville de Vuleuriennes, ms. 375.

Cf. drechir de Pertz, XI, p. 5:1.

3295. - Antre cartulaire: ms. du XVIe siecle, sur papier, contenant des litres de 649 à 1288, in-folio de 34 II. (Archives de l'Etat à Gund).

Saint-Amarin. - Église (dior. de Bàle).

3296. - Cartulaire de l'oplise de Saint-Amarin ; orig. perdu.

A été utilisé par śchøepflin pour sun "Alsatia diplonalica ". - Un volume conservé aujourd'hui aux Archives d'Ober-Elsass (Colmar), fonds Murbach, lad 47 , et quelquefois cilé comme cartulaire, n'est qu'un inventaire sans aucun rapport avec celui-lit.

Saint-André. - Prieuré (dioc. de Gap)).

3297. - Cartulaire du prieuré de Saint-André ; origr. perdn.

lixtraits laits an XVII siècle (Biblioth. nationale, ms. latin 12659, p. 35:3-354).

Saint-André-au-Bois. - Abbaye (dioc. d'Amiens).

3298. - Cartulaire des Prémontrés de Saint-André-au-Bois ou Livre rongre; 111 s. des $\mathrm{XVI}^{\mathrm{e}}-\mathrm{XVIII^{ \textrm {e } }}$ siècles, contenant 439 actes des années $1160-1715$, sur papier, en 2 vol. in-folio de 492 et $272 \mathrm{fr}$. (Archives dép. Au Pus-de-Cialuis, $\mathrm{H}$ non rotè).

Copie du précédent, exécutée en 1808, sur papier, in-folio de 248 el 165 pages (Vemle de la bibliollh. dn im Le Ter, en 1866 , $11^{\circ} 124$ du Catalorue).

Saint-André-en-Gouffern. - Abbayr (dioc. de Sées). 3299. - Cartulaire de l'ahbaye de Saint-André-en-(ioufferm; ms. du XIV" siecle, sur parchemin, de plusieurs maius, in-4" de $143 \mathrm{ft}$. (Arehires dép. du Cialtudos, $\mathrm{H}$ non coté).

Saint-André-lès-Aire. - Couvent des chamoines réguliers de Suint-Augustin (dioc. de Suint-Omer).

3300. - Cartulaire de Saint-André-lès-Aire ; origo perdu. 
Notes extraites du précédent Biblintli. nntionalp, coll. Cilairambault, vol. 563, p. 3 ; ms. latin 17675. Al. 54-55.

Saint-Antoine-de-Viennois. - Ordlי loligieux.

3301. - Bullaire de Saint-Antoine de Viennois: ms. du XVIte siècle.

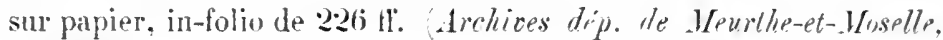
$\mathrm{H} 1626$ ).

3202. - Autre; ms. du XVI" siècle Biblisth. del'Uniressité de T'urin. ms. F IV 21 .

3303. - Publ. : Recueil extraict des bulles de nos ss. peres les papes et des lettres patentes des roys, contenant les privilégres, droicts, libertez et franchises par enx octroyees en faveur de l'ordre de Sainct Antloine de Viennois. S. l. n. d. ; in- $4^{0}$ de xrr-296 p.

C., aussi ro Mostmajotr.

\section{Saint-Antoine-lès-Paris. - Ablaye (llioc. dr Paris).}

3304. - Cartulaire de l'abbaye de Saint-Antoine: ms. dlu XIV siecle, sur parchemin. in- $t^{\prime}$ de vir-120 ff. (Archives nationales, L.L 1595 .

3305. - Cartulaire de l’abbaye de Saint-Antoine ; ms. du XVII"siècle. sur papier. contenant les titres de ses propriétés hors Paris depuis le XIII ${ }^{e}$ siècle, in-folio de 118 tf. (Archices nutionales, $S^{\star} 4: 386$ ).

Dates extrênes : 1201-163\%. Ce regristre a élé mentionné faussement comme carlulaire de Charenton.

Saint-Antonin. - Abbaye (dion. de Rodro).

3306. - Recueil de titres relatifs à l'abbaye de Saint-Antonin; ms. du XVII siècle. contenant des documents du VIII siècle à 1521 (Biblinth. nationale, coll. Doat, vol. 124, ff. 273-383).

\section{Saint-Antonin. - Ville.}

3307. - Recueil de titres relatifs à la ville de Saint-Antunin; ms. du XVII siècle, contenant des documents de 108.5 à $160 \mathrm{l}$ (Biblioth. nutionule. coll. Doat, vol. $146, \mathrm{ft} .1133-3326$.

Cif. l'analyse qui en a été donnée dans le Cubinet historique, IV, $1869, \mathrm{p} \cdot 156-161$.

Saint-Apollinaire. - Primuré (dior. de Langres).

3308. - Cartulaire dı prieuré de Saint-Apollinaire; ms. du XVIe siècle, sur papier. contenant 1.5 pièces des années 12:35 a 15:30, in-4" de 34 ff. (Archives dép. de lu Côte-r Or. H non coté. fonds de St-Bénigne).

Saint-Astier. - Abbaye dioc. de Périgueux. 3309. - Cartulaire de l'ahhaye de Saint-Astier ; orig. perdu. 
Extraits faits an XVIII siecle (Biblinth. autionale, coll. Lespine, vol. XXXIV. ff. 188-282 et 33:37-350).

(Ce dernier extrait a été fait "sur un fragrment de cartulaire du Xlle siecle trouvé dans le's arehives du Chapitre en juin 1790 \%.

Saint-Aubin-Châteauneuf. - Signeurio en Bourgogne 3310. - Cartulaire de la terre de Saint-Aubin-Châteanneul': ms. du XVIe siècle. sur papier, contenant des actes a partir de 1205. in-40 de $31 \mathrm{ft}$. Archives dép. de l' Tomne, (i 1:340).

Saint-Aubin-des-Bois. - Abhaye dioc. dr Saint-Brienc). 3311. - Publ. : Anciens évèchés de Bretañe, diocise de Saint-Brienc, par J.(ieslin de Bourogone et Anatole de Barthéleny. III (1864), pp. 34-202, 31:2-318 et 370 .

("ist un recueil factice de 353 chartes innées 115:-1667).

Saint-Aubin-des-Fresnes . - Prirur à Amfrevill- laCampagno dioc. d'Érreux/.

3312. - Cartulaire du prieuré de Saint-Aulin-des-Fresnes: ms. du $\mathrm{XV}^{\mathrm{e}}$ siècle, sur papjer, contenant 159 documents des anneses 1030148, in-4" de (is If. Archices dép. de l'Eure, H 977.

Saint-Aubin-du-Cormier. - Ville.

3313. - Cartulaire municipal de Saint-Aulin-du-Cormier : ms. de la fin du $\mathrm{XVI}^{\mathrm{e}}$ siercle, sur papier, contenant des actes à partir de 1:225, in-40 (Archives rommunales de Saint-Aubin-du-Cormier.

Saint-Augustin - lès - Thérouanne. - Ablay" dioc. de Theroulanne).

3314. - Cartulaire de l'abbaye de Saint-Augustin-lès-Théroname ; ms. du XIII siècle, sur parchemin, contenant 150 actes de 1167 i 1273, in-4" (Biblioth. royale de Bruxelles, ms. 4132, ff. 9 v"-157).

3315. - Cartulaire-terrier de l'ahlaye de Sam-Auglistin-lèsThérouanne: ms. du $X \mathrm{~V}^{\mathrm{e}}$ siècle, sur papier, in-lolio de $90 \mathrm{ff}$. Biblioth. de la ville de Saint-Omer, nus. 57:2).

Actes divers des années 1413 à 1486 .

Saint-Barthélemy-du-Buisson. - Prieuré, près de Provins (dioc. de Sens).

3:316. - Cartulaire-censier du prieuré de Saint-Barthélemy du Buisson, dép de l'abbaye de Saint-Pierre-le-Vif de Sens; $m s$. de la fin du $\mathrm{XV}^{\mathrm{e}}$ siècle, avec quelques petites additions, sur papier, recouvert d'une lasane ancienne, in- $4^{0}$ de 216 pages (Archives nutionales, S 1012).

I)ales extrèness: 1211-1502. 
Saint-Basle. - Abliaye diore dre Reims.

3317. - Cartulaire de lialdatye de Saint-Basle: oring. perdu.

A été connu des autaurs de la "Crallia christiana ".

lixtruit fait an $\mathrm{XVIl}^{\mathrm{e}}$ siècle. sur papier Biblinth. nutionate, ms. latin 13816, ft. 163-166).

Saint-Benoit-du-Sault. - Prieuré (dioe de Bourges).

3318. - Recreil de titres du prieuré de Saint-Benoit-du-Siult : Ins. du XVIII siècle. sur papier. en deux caliers in- $8^{0}$ et in- $4^{\prime \prime}$ reliés ensemble. de plusieur's mains. Ir-59 ff. Archires nutionales, S 69905 .

Contient 116 pieces des années $11-14-1581$ ), avec quelifues traductions.

Saint-Benoit-sur-Loire. - lbbaye dioc. d'Orléans .

3319. - Cartulaire A de l'abhaye bénédictine de Saint - Benoit-sur Loire: ms. dn XIII siècle. ì : col. : orig. perdu.

In seul feuillet a élé retrouvé (Bibliohth. Futirnnt, à Rone; ms. R.gina $\left.566, \mathrm{f}^{\circ} 34\right)$. Loriginal a lû être détruit a $\mathrm{XVl}$ e siecle.

3320. - Antre cartulaire B : ms. du Xve siècle, sur papier, de 210 ff.; oritr. perdu.

Non comn que par queldues extraits qui en furent faits en 1597 it

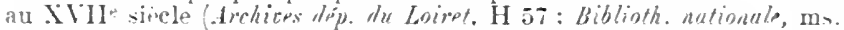
latin 13810, ff. 323-329: Alchices dép. du Ciher, $\mathrm{H}$ nou cotéj.

Copie dn précédent; ms. dn XVIII siècle. de deux mains différente. - vir papier. in-folio de 453 ff.. contenant 819) chartes des anmés 818 is 1404 Archices dép. de Liviret. H 30 .

3321. - Antre cartulaire D ; m. dn XVII siècle. sur papier, in-4 de II-546-xir tf. Archices lép. d" Cher, H non coté. fonds de l'archevèché .

3322. - Autre cartnlaire $\mathrm{F}$ : ms, du $\mathrm{XV}^{\prime} \mathrm{I}^{\circ}$ siècle [167-2]. sur papier, in-fulio de rn-4l-vi tf.. collationné par le notaire Pierre Chartier (Awhires dép. d" Loivet. H 20.

Copie d'un manuscrit de 97 tr.. se rapprochant to colui du XVe siecle, et perilu.

Copies diverses de tilres relatifs a l'abbave de Suint-Benoit-surLoire. l"après les précédents manuscrits; miv. de 1688 Biblioth. de la ville d'Orléans, miss. 492-4933: - ms. de Dom J. Jandot. daté de 1681 Biblisth. de .K. Eung. Jurry, a Orléans: - par Dom Estiennot

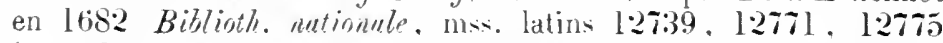
(pp. 499-51l et 127i6 Pp. 463-482, el Biblioth. de l'Arsenal, mss. 1007-1009 : - mis. de Dom Chazal, date de 1725 Biblioth. de lu cille or Orléans, ms. 490-491 ; - par Dom Gérou vers 1764 (Biblisth, mutionale, coll. Horean, pasim .

3323. - Cartnlaire de l'ablaye de Saint-Benoit-sur-Loire; ms. du Xrile siècle. contenant des chartes de 1400 a 1672 , sur papier, en 
6 vol. in-folio de 254, 472, 403, 31 1, 147 et 438 ff. Aiclives dip. du Loiret, $\mathrm{H}$ non cotí).

3324. - Publ. : Recueil des chartes de lahlarye de Sainl-Benoit-surLoire, publ. par Manrice Pron et Alex. Vidier. I. Paris, Picard et fils, $1900-1907$; in- $8^{\circ}$ de $c-400$ p. [Sociéte historique et archéologique du Gâtinais, Jocuments, V.]

Vuir spicialement l'introduction, M1. LL-L,H.

Saint-Bertin. - Ablaye, à Saint-Oner.

3325. - « Vetus Folquinus » [vers 962] ; origr. perdu.

Cf. Houss dichir, VI, 1881, p. 415-438.

Copie dı précédent; ms. du XII $\mathrm{I}^{\mathrm{e}}$ siècle, sur parchemin, in- $t^{0}$ de (i) fi. (Biblioth. de la ville de Boulogne-sur-1Mer, ms. 146 A).

Incomplet du dernier feuillet.

Autre copie incomplète, faite en 1693 par 1om R. Portebois; ms. sur papier, in-8" de 174 pages (Biblioth. nutionale, ms. nouv, acq. latines 275$)$.

Autre copie. exécutée au XVIlle sjeccle par Don Dewilte: ms. sur papier, in-folio de 368 et xir-344 p. Biblioth. de la ville de SaintOmer, ms. 815).

3326. - Cartulaire de Saint-Bertin, suite du Folquimus par le moine Simon [XII siècle]; orig. perdu.

Copie faile entre 1148 et 1163 , sur parchemin, in-4" de $33 \mathrm{ff}$. Biblioth. de la ville de Boulogine-sur--1Yer, ms. $146^{\mathrm{B}}$ ).

Copie faite an XVIe siècle par Dom Allard Tassard, sur papier, in-folio de $302 \mathrm{fr}$. (Bibliolli. de li ville de Strint-Omer, ms. 750).

3327. - Grand cartulaire de l'allaye de Saint-Berlin, par Dom Ch. Dewilte; ms. du XVIlle siècle [1776], en 13 vol. in-folio, dont 2 ale tables in-8" (Biblioth. de la ville de Saint-Omev, ms. 803).

D́ubl. : Les chartes de Saint-Bertin, d'après le grand Cartulaire de Dom Ch.-Jos. Dewitte (648-1779), publiées ou analysées par l'abbé D. Haigneré, Saint-Omer, d'Homont, 1886-1899; 4 vol. in $-4^{0}$ de Lxvi-471, 532, 600 et 543 p. [Société des Antiquaires de la Morinie.]

l'récédemment avait perdu un travail de Edn. de Coussemaker: Résumé analytique des cliartes du grand cartulaire de Saint-Bertin relatives à la Flandre maritime (Lille, 1871 ; in- $8^{\circ}$ de 129 p.: extr. du Bulletin du Comité famand de France, V.)

D'apres Dom Dewitte il a existé à Saint-13ertin 42 cartulaires ou recueils de chartes parmi lesquels on peut citer :

3328. - « Charlularium Rertinianum »; ms. des XIJe-XVe siècles, contenant des documents des années 1056-1396, sur parchemin, in-4n de $189 \mathrm{ff}$. (Biblioth. de la ville de Boulogne-sur-Mer, ms. 144). 
Copie de 8.5 chartes. sur papier Biblio'h. Ar ln cille de SuintOmes. 1111. 735.

Autre copie. faite an XIX siecle, sur papier, in- $t^{0}$ de 70 ff. (Bibliath. matioule, ms. latin 9928.

3329. - Frarments tires de plusieurs cartulaires; ms. les XIV-XV iecles, sur parchemin, in-4" de 65 ff. Biblioth. de lin cille l'dirns, mis. 1020 .

3330. - « Chartularimm monasterii $\mathrm{S}$. Petri in Silhin»: m. fait on liol. in-ful. de 280 p. Biblioth. Mafiomule, ms. latin 5439 .

3331. - Frament de cartulaire: ms. du XIVe siècle. sur parchemin. contenant des actes de 10.36 i $125 \%$. in-s" de 12 If. Biblinth. mationule ms. littin 10971 .

Autres extraits Biblinth. mutionule. Coll. Balnze. vol. IXXI. H. 267-373: - coll. lucherne. vol. XXIl. ff. 477-485; - coll. Clairambanlt. vol. 5(i3), ff. 25.5-265; - ms. latin: 12662, ff. 34t360, et franchain 2:2866. ff. 167-171: - et Biblialh. de la rille de Salint-Oner; mss. Fin3 et 819 .

Les extraits le la collection Baluze provienuent do quatre cartulaires differents ainsi designés; Majus eartularium iff. 2nit-298); parvus (30)-329; ; te-tius (332-34.5): quartu- $\left(34 b^{3}-3733\right)$.

3332. - Pcblo: Cartulaire de labhaye de Saint-Bertin. par Benj. Gnerard. Paris. impr. royale. 1841 : in-4" de c-487 p. [Collection des Docments ineslitis]:- Appentice au cartulaire de lahbaye de Saint-Bertin, par F. Morand. Paric impr. impériale, $1867:$ in-4" de $x x-115 \mathrm{p}$.

Saint-Bertrand-de-Comminges. - thbaye.

3333. - Cartulaire le lablure de Saint-Bertrand de Comminzes; orier. perdu.

Extraits faits au $\mathrm{XVHI}^{\mathrm{e}}$ sière. par Larcher drhices des Hantes-

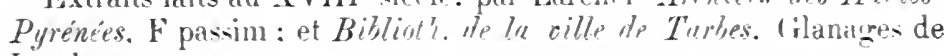
Larcher.

Saint-Bertrand-de-Comminges. - Voy. Cuмmisrs.

Saint-Blaise. - Primur. - Vur. LA Bruss.

Saint-Brelade. - Prieuré. - Voy. Le Moxt-sirt-Michel.

Saint-Calais. - Ablayn (liok. du Mans).

3334. - "Parrum chartarium Anisolen-e » Cartu'aire de l'abbaye de Saint-Calais : ms. du $\mathrm{Xl}^{\mathrm{e}}$-iecle. existant encore [a l'etat incomplet] an XYIte siècle. orig perlu.

3335. - «Carłarinm tnisolense » : autre ms. également perdu.

3336. - Aulde cartulaire de l'abbaye de Saint-Calais Cartularium 
regalis ahbatiae sancli Carileti : ms. date de 1709, sur papier, in-folio de $42 \mathrm{ff}$. Biblioth. de la famille Megret-Ducombloy, à Saint-Calais).

Plвi.. : Comblaire de labluaye de Saint-Calais, par l'abbé I.. Fromer. Nimmers, Flemry el Dangrin, 1888 ; in-80 de xxv-98 p. el pl. [Societs historique el archiolonique du Mane.]

33:37. - Copie partielle du cartulatre de Saint-Calais-dn-Désert; ms. du XVIJ" siecle. sur papier (Biblinth. de la ville de Dijon, ms. 916, II. $: 30-51$.

(if. Questions nérovingiennes, par Julien Havet: IV, appendice

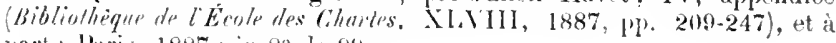
part : laris. 1887 : in-8 de $99 \mathrm{p}$.

Saint-Géré. - Villo.

3338. - Cantulaire municipal de Saint-Cere: ms. des XVo-XVI1 siecles, sur parchemin. contenant des actes de 1276 a 1642 , avec relinre en hois. in-lolio de 50 ff. Arolires communales de SaintCére:

Plobs. : l'rivilizeres franthises el liberlés de Saint-céré, par V. Fomratin Bulletin de lu Sociétr des étules littéraires, scientifiques et "ristignes du Lot. XXV11. 1902. p. 2:3-37, (55-89 et 156-175).

Saint-Césaire. - Villı.

33:39. - Cimblutare municipal de Saint-Césaire: ms. écrit au XVIIJ siècle ef contenant des actes des siecles précédents, in-folio Archices mmiripmles de Saint-Césuive, Alpes-Maritimes).

Saint-Ghaffre-du-Monastier. - Abbaye (lioc. du Puy).

3340. - « Liber de reparatione chartarun sancti Theofredi Camaliacensis » on liverouge ; origr. perdu.

Copie laite an XVIle siccle sur papier. in-lolio de 10l pages Biblinth. nationale, ass. latin 5 $5.5(0.1)$.

Copie partielle par llom Estiennot en 1676 (Biblioth. nationale, nis latin 1276.5 , t1. $18-89$.

Fxtrats faits at XVII siccle Biblioth. nationale, ms. latin 12749 , II. 3:3, 209 et passim, et coll. Baluze, vol. I.XXV, pp. 207-210).

3341. - P'us. : Carlulaile dauphinois de lablaye de Saint-Chaffre, par l'ablé $\mathrm{Cl}$. Chevalier. Grenoble, 'rullomme, 1868 ; in-80 de Ix-60 p. [Uocunents incedits relatifs au Dauphiné, II, 6].

- Cartulaire de l'alhbave de Saint-Chaffre dn Monastier, ordre de Sinint-Benoît. suivi de la chronique de Saint-P'ierre du Puy et d'un appendice de chartes (570-1370), par l'abbé Ul. Chevalier. Paris, Hicard. I884; in-8 de Lrv-244 p. [Tablettes historiques du Velay].

Lat préface est datée diarril 1888 . Le texte arail paru dans les Tablettes historiquess du beluy à la diate do 1879 . 
Saint-Chamond. - Chapitre draint-Jan-Baptiste (diox: (do Lion).

334:. - Cartulaire du Chapitre de Saint-Jean-Baptiste de SaintChamond: ms. des XVIJ-XVIIJ siecles. sur papier. in-folio de $147 \mathrm{ff}$. Biblioth. de lu ville de Suint-Chumont, ms. 11 .

Saint-Cheron. - Abluave (dion. dr Chartres).

3343. - Recueil de titres relatifs à l'abbaye de Saint-Cheron. formé an $\mathrm{XVII}^{\mathrm{e}}$ siecle pour (iainnières. sur papier, in-folio (Biblinth. mingmele, ms. latin 5418. p. 13:3-159.

Exiraits et copies d'originaux ayant pour dates extrênes 1150 et 1378.

3344. - Cartulaire de l'abbaye de Saint-Cheron ; ms. formé par E. Lefèvre au XIS e siecle, in-4" de 364 payes, sur papier Biblioth. nuliomale, nouv, acquis. latines 1409 .

Saint-Christophe-en-Halatte - Prieuré (dioc. de sinlis).

334.. - Pubi. : Cartulaire du prieuré de St-Christophe en Halatte, par labbé A. Yattier. Senlin. Payen. 1876; in-4 de xc-ióp. [Comilé archéologrique de Senlis.]

Publié d'apres des copies faites par Afforty et conservées à la bibliothique de la ville de Senlis [t. X]

Saint-Claude. - Abbaye.

3346. - Cartulaire de l'ahbaye. puis évéché de Saint-Clande: ms. daté de 174.5 . contenant des titres à partir de 1184 , sur papier, en 4 vol. in-folio de 514. 372. 399 et 401) ff. Archices dép. du Jura, $\mathrm{H}$ non coté.

3347. - Autre du $\mathrm{MIX}^{\mathrm{e}}$ sipele. sur papier. en 5 vol. in-folio et in-40 de :28:2. 764. 130 pages el $93 \mathrm{ff}$. Biblioth. de l'écéché de SaintClumile.

3348. - Recueil de titres relatifs à l'abbaye de Saint-Claude: ms. du XVIII siècle, formé par Droz et contenant des actes de 1100 à 1484. sur papier. in-4" de 398 ff. (Biblioth. de la rille de Besancon. coll. Droz. nls. 42 .

Le "livre des vassaux " de saint-Claude, publié par A. Vayssière en 1884 (Mpinvires de la Société d"émulation du Jura, $3^{e}$ série, V. pp. 171-239\}, n'est pas un cartulaire mais un dénombrement des premier années du XIV'e siècle; toutefois l'éditerur y a annexé en appendice 12 chartis dess années 1084 à 1259 .

Saint-Cloud. - Église collégialr (dioc. de Paris). 3349. - Cartulaire de la collégiale de Saint-Clond ; orig. perdı. 
Copie alı XVIII siècle [1725)], in-4" de :34 tf. Biblioth. nationale, ms. latin $5185^{\mathrm{D}}$ ).

Autre du XVIII siècle. de $32.29 \%$ Biblinth. mationale, ms. latin 9165 .

Saint-Grépin-en-Ghaye. - Abl)ayr (diox. de Soisons). 33300. - Cartulaire de l'alluaye de Saint-Crépin-en-Cliaye; ms. du XIII ${ }^{e}$ siecle, sur parchemin. in- $4^{\prime \prime}$ de 108 ff. Biblinth. nationale, ms. latin 18372 .

Cf. Le cartulaire de Saint-Crépin-en-Chaye, par M. Plateau Bulletin de le Sociéte urchosologique et scientifique de Soissons, XX, 1892 , p. I76-18I).

D. (irenier a connu un autre cartulaire sur papier, qui semble perdu.

Extraits faits an XVIJe siècle (Biblioth. nationale, coll. Baluze, vol. LXXIII, p. 22:9-2:38; - ms. nouv. acq. françaises 7433, ff. 192-194; ms. latin 17048, pp. 447-468).

Saint-Gyr. - Maison de Saint-Louis.

3351. - Recueil des titres concernant le temporel de la maison royale de Saint-Louis à Saint-tyr ; ms. des X VII e-XVII e siècles, inachevé, sur papier. in-folio de xxr-592 pages drchives dép. de Seine-etOise, D 104 .

3352. - Autre recueil des XVII $-\mathrm{XVIII}^{\mathrm{e}}$ siècles [incomplet des pp. 2(6!)-330)]. sur papier. in-folio de xxx-334 patues (drchices dép. de Serine-et-Oise, D 105).

3353. - Recneil des titres de la maison de Saint-Louis a Saint-Cyr; 111s. dalé de 1719, sır papier, contenant 48 pièces, in-folio de 178 ff. (Biblioth. He la cille it Aix-en-Provence, m. 1171).

3354. - Autre du XVIII siècle, sur papier, contenant 96 pièces, in-folio de 136 if. (Archives dép. de Seine-et-Oise, H non coté).

335.). - Autre dı XVIII ${ }^{\mathrm{e}}$ siècle, sur papier. contenant 89) pièces, in-lolio de 295 ff. (Avchives dép. de Seinp-et-Oise, H non coté).

33.56. - Autre dı XVIII siècle, sur papier, contenant 38 pièces, en 2 vol. in-folio (Archives dép. te Seine-et-Oise, $\mathrm{H}$ non coté).

Saint-Damien. - Pricuré (dioc. de Marseillo).

3357. - I'vbr.. : Historre du prieuré de Saint-I)anien, suivie du cartnliare dn prieuré rural de St-Damien, on recneil de chartes... extrait des archives de l'ancienne abbaye de Saint-Victor et des archives de La Cadière, par l'abhé 11. Girand Bulletin de ln Sociétédes sciences, belles-lettres et arts du d purt. du Var, XVII, 1849, pp. 83-117.

(è recueil comprend 26 pièces des années 966-1554. 
Saint-Denis. - Abbayo (dioc. de Paris.

3358. - Frament d'un cartulaire de l'ablaye de Saint-Denis: ms. du XI siecle, sur parchemin. contenant 2:3 documents du VII ${ }^{\mathrm{e}}$ siècle à 1068 , in- $4^{0}$ de 2.5 ff. [1-25. plus les ff. 73.75 et 77 ] Biblioth. nationale, ms. nouv. acqquisitions latines 326 .

3359. - Livre des privilèges de lahbaye de Saint-Denis: ms. du XIII ${ }^{\mathrm{e}}$ siècle, inconplet de la fin et endommané par l'humidité. - -ur parchemin, contenint des titres très anciens jusqu'en 1250 environ. in-folio de 106 ff. à 2 col. (Archices nationules, LL 1156).

3360. - Cartulaire hlane de Saint-Denis: ms. de la fin du XIII siècle. sur parchemin, dans une reliure dn XYI siècle en basane, contenant des titres de 630 à 1300, en 2 vol. in-folio de xxxvi-931 et 626 pares ì 2 col. (Archives intionales, LL 1157-1158).

Table du XVIIe siecle dans le ms. latin 17112.

Copie du Cartulaire blanc [tome II], avec table moderne; ms. du XVII ${ }^{\mathrm{e}}$ siècle, sur papier, in-folio de l100 et $7 \tau$ pages (Avchires dép. de Seine-et-Oise, D 5I8 et $518^{\mathrm{bis}}$.

3361. - Cartulaire de la pitancerie: ms. du XIII ${ }^{\mathrm{e}}$ siècle. sur parchemin, contenant des documents de 11 it à 1299 , in-folio de 137 pares a 2 col. Archices nutionules, L.L 1159 .

3362. - Autre cartulaire dit « Cartulaire de Thon » ou «Colbertin »: ms. de la fin du Xille siècle, d'une seule main. sur parchemin. in- $4^{0}$ de 513 pages à 2 col. Biblioth. nutionale, ms. latin 5415 .

A appartenu à de Thou et à Colbert Cod. 1980'. - Lne copie du XVII e siècle (in-folio de 369 pages) se troure aux Archices nationales, L.L 1160 , et une antre du meme temps mais incomplete Biblioth. nationale, ms. latin 17110 ), provient de Bouhier $\left(n^{\circ} 41\right)$. Le document le plus récent est de 1288 .

3363. - Cartulaire de la chantrerie: ms. du XIIIe siècle. sur parchemin. contenant des titres de 1183 a $127 \%$. arec une addition de 1390, in- $4^{0}$ de $47 \mathrm{ff}$. (Archices nationales. L. 1163).

Ces titres se trouvent dejà transcrits dans le "Livre blane".

3364. - Cartulaire de la chambrerie, ou « petit cartulaire de Chrourse $»$ : mıs. du XIVe siècle. sur parchemin. contenant des documents de 1 It5 i 1401. in-4" de :290 parres Archices nationul.s. L.L 1172 .

Traduction du même cartulaire: $m:$ du $\mathrm{XVI}^{\mathrm{e}}$ siècle [15ll], rédigé par Nicolas Nicart. sur papier. in-40 de 325 pagres Archices nationales, LL 1173.

3365. - Cartulaire de laumònerie: ms. du XIII siècle sur parchemin. contenant des documents de 1111 à 1306 , avec additions postérienres. et incomplet de la fin, in- $8^{0} \mathrm{de} 62 \mathrm{ff}$. Archires nationules, L.I. 1175 . 
3366. - Antre cartulaire de l'anmónerie; ms. des XIIJe-XIV'e siècles, de plusieurs mains, stu parchemin [sauf les ff. 28-29], contenant des documents de 1111 à 1369. in-8 de .51 pages it 2 col. (Arçhires nationales, I.I. 1174.

3367. - Autre cartulaire de laumònerie; ms. du XIII" siècle, avec additions postérieures, de plusieurs mains, sur parchemin, contenant des documents de 1111 à 1:369, in- $4^{\circ}$ de 298 parres Archives nationules, L.L. 1176 .

Les transcriptions sont défectueuses.

3368. - Cartulaire de l'office clanstral du grand prieur; ms. du XIII siècle, sur parchennin, contenant des acles de 1193 a 1296 , in- $8^{\circ}$ de 48 if. drchires intionules, LI. 116.5.

3369. - Autre curtulaire-inventaire du nème litre; ms. des XVe. $\mathrm{XVI}$ siècles, sur papier, contenant des documents de 1193 à 1578. in-folio de 763 et 114 pages (Archices nutionales, L.L I166).

Concerne surtout Dugny et Cionesse.

3370. - Antre cartulaire du mème titre: ms. du XVII siècle, sur papier, contenant des documents de 1258 a I685, en 2 vol. in-folio de 776 et 972 p. plus 90 pases de table (Archives nutionales, L.L I $178-1179$ ).

3371. - Livre vert de Saint-Denis [rers 1400] ; orig. pertu.

Copie fracrnenlaire dn précédent: ms. dn XVII1 siècle, sur papier, in- $4^{0}$ de 1:20 pacres Biblio'h. Cheltenhem, ms. 15361).

3372. - Cartulaire de la fondation de Charles V : ms. du XVe siècle, sur papier. contenanl des litres de 13.56 a $\mathrm{I} 4.50$, in-40 a 2.56 pages (Archices nationales, LI. $117 \%$.

Nombreuses onl ete les copies laites dans ces divers cartulaires par Du Chesne (Biblioth. antionale, coll. Baluze, vol. LV); - par Jacques Sirmond (Id., coll. Baluze, vol. CXXXIX); - pour Gaimnieres (Id., ms. latin lalll ; - par divers Bémédictins (Id., nss. latin 12668); etc.

On trouvera en outre, aux mots Beaurain, Boissy, Cergy, Ciheoreuse, Cormeilles, Lampierer, Francontilte, Maturillers, Montmorency, Rueil, Saint-Jartin, Tinpups et Ully-Saint-Georyes, des cartulaires spéciaux à ces différentes propriétés de l'abhaye, ct composés d'actes en majeure partie enpruntés aux recueils qui viennent d'etre décrits.

Saint-Denis. - Chapitre de Saint-Paul.

3373. - Cartulaire-inventaire dı Chapitre de Saint-Panl a Saint-Denis ; ms. des $\mathrm{XVII}^{\mathrm{e}}-\mathrm{XVIII}{ }^{\mathrm{e}}$ siecles, sur papier, contenant des titres de 1134 à 1706, in-4" de 131 ff. Archices nutionales, LI, 677).

Saint-Denis-de-1a-Chapelle. - Prieur (dioc. de Boturges). - Voy. Ia Chaphlise-Aldo. 
Saint-Denis-en-Broqueroie. - Ahay yo diu. do (immbai). 3374. - Cartulaire de lialbave de Saint-Denis-en-Brogneroie; ms. des XIlle-XIVe siodes, sur parchemin, de plusienrs mains, contenint

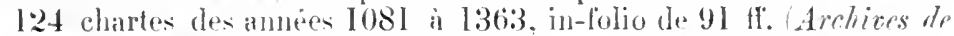
l'Étut à 1 rons.

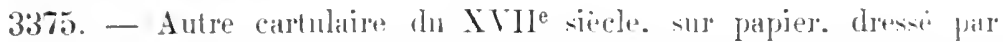
Gérald Sacre. moine de liahlaye, contenant 2:2!) chartes des annés 1081-1657. in-t" de v-5is pacres Archices de l'litnt à Wous.

Ax.u. : Iescription de eartulaires et le clartriers du Hainant. par Léopold Devillers. Y 1870), p. 10:3-2Iti lixtrait des Aumles du. Cercle urchéologique de Mons, X.

Saint-Denis-en-Vaux. - Pricuré iline. dr Poitiers).

3376. - Prbl. : Recueil de pièces sur le prieuré de Saint-Denis-en-

Vaux Archives historiques du Poitou, VII, 1878. p. 345-360.

Chartes des années 1109 à 1232 , tirées du tome II du Cartulaire hanc te l'abhaye le Saint-D+nis (p. $432-538$ ), tont ce jureuré déprutait.

Saint-Dié. - Chapitre cathedral.

3377. - Inventaire-curtulaire dı Chapitre de Sirnt-Dié; ms. des $\mathrm{XV}^{-\mathrm{e}}$ XYII siecles, en 9 caliers de papier. contenant des copies dictes depuis 1051, in-folio de $146 \mathrm{fr}$. Archires tén. des Vosges, G 2:30.

3378. - Recueil de privilèges dı Cliapitre de Saint-Dié; ns. du

XVIule siècle. sur papier, contenant des actes depais 664, in-folio de $101 \mathrm{fl}$. Archices dép. des Dosges, G $2: 34$.

Saint-Dié. - Église.

3379. - Cirtulaire de l'englise de Saint-Die on «Livre rouıre »: nns. commencé en 1461 et continué jusqu an XVII siècle. sur parchemin, contenant des documents sepuis 1090, in-folio de $261 \mathrm{ff}$. Biblioth. de le ville de Suint-Dié. m1.. 29.

Quelques titres exlrails de ce regristre ont élé publiés dans les Drocuments incilits on rares de lhistoire des losges, II (1869). - Cf. : Histoire de l'église de Suint-Diez, par Jean-Claude Fornmier (saintDiez, Bouchard, 1726 , in-12), pp. 336-479. - Les manuscrils 8, 9, 51 de la kiblioth. de Saint-Dir contiennenl aussi des copies de filres relatifs à l'église de saint-Dié. - Voir aussi une histoire (hronologique, avec pretuves (XIII sièrle), surpapier in-10 (Studt-Bibliothek Trier, ms, 139i).

Sainte-Barbe-en-Auge. - Prieuré dive. de Lisifux?

3380. - Cartuliure du prieuré de Sainte-Barlie-en-Auge: ms. In - XVII siecle, contenant 282 pieces des annèes 1395-1618. sur papier, in-folio de $442 \mathrm{ff}$. (Archices déy. du Calrados, H non coté).

Sainte-Croix-sous-Offémont. - Couvent des Cỉlestins (dioc. de Solssuns).

3381. - Cintulaire des Celestins de Sainte-Croix-sons-Offémont; ms. 
du XVIII siècle, sur papier, contenant des actes de 1414 a 1725 relatifs à Erquery, Bois d'Airion et Cuignieres, in-folio de $172 \mathrm{ff}$. Archices dép. de l'Oise, $\mathrm{H}$ non coté.

On ne saurait prendre ì la Jettre l'indication de M. l'abbé Eugr. Müller, "Courses archéologitues autour de Compiegne" (Compiègne, 1905, in-8), p. 49, d'apres lequel $\mathrm{H}$. Meyer aurait laissé à la kiblioth. nationale un moreeau du Ciartulaire de Sainte-C'roix-suns-Offímont qu'il tenait de Prigné-D lacourt. En réalité le don de H. Mezer ne contenait qu'un censier et de's pices origrinales relativement it cet établissement ecelésiastique.

Sainte-Gemme. - Priruré (dinc. do Saintes).

338:2. - Cartulaire du prieuré de Sainte-Gemme ; orig. perdu.

Extraits faits an $\mathrm{XVII}^{\mathrm{e}}$ siècle Biblioth. natimnale, coll. Baluze, vol. XL, tf. 84-87.

Sainte-Gauburge. - Abbayc (dioce dre Chartres).

3383. - Cartulaire de Sainte-Gauburre; ms. du XIX siecle, par

Dallier, sur papier, in-4" de 62 fr. [dunt quelques-mus blancs $]$ (Biblioth. de la ville de Nogent-le-Rotrou, ms. 10 .

Sainte-Hoïlde. - Abbaye (dioc. de Toul).

3384. - Cartulaire de l'abbaye de Ste-Hoïlde; ms. dn XIII siècle, sur parchemin, de 52 ff. in-40 (Biblioth. nutionale, ms. nouv. acq. françaises 4168 .

Plbl. : Cartulaire de l'abbaye de Sainte-Hoïlde (1225-1442), par All. Jacol (Mémoires de l.n Sociélé des lettres, sciences et arrs de Bur-le-Duc, 2e série, I, pp. I-113), et à part : Bar-le--Duc, ContantLaguerre, $188^{\circ}$; in-8" de xir-115 p.

3385. - Cartulaire-chronique de Sainte-Hoülde ; ms. du XVIIIe siècle, sur papier, in-40 de $66 \mathrm{fl}$. (Archives dép. de la Meuse, $\mathrm{H} 30^{7}$ provisoire.

C'est en réalité une clironique renfermant des renvois exacts au cartulaire précédent, arec la transcription de pieces complémentaires.

Saint-Éloi-Fontaine. - Abbayo (dioc de Noyon).

3386. - Cartulaire de l'abbaye de Saint-Éloi-Fontaine [incomplet à la fin ] : ms. des $\mathrm{X}^{-e}-\mathrm{XVI}^{e}$ siècles, sur papier, contenant des actes de 10:33-[.5.31, in-t" de 327 If. (Biblioth. de la ville de Noyon, ms. 27).

Copie moderne, sur papier, in-4" de 507 ff. (Biblioth. de la ville te Noyon, ms. 20,

Sainte-Marie-au-Bois. - Abbaye (dioc. de Toul). 3387. - Cartulaire de l'albbaye des P'rémontrés de Sainte-Marie-auBois : orig. perdu.

A été utiliné en 1712 par 13. Picart (Supplément à l'histoire de la maison de Lorraine.) 


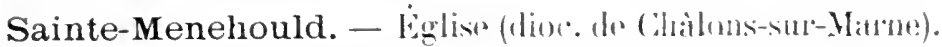
3388. - Cartulaire de léérlise de Sainte--Ylenehould: ms. daté de 1419. sur parchemin. in-t" de it If. Arelices dép. He lin Marne, (i) $18.5 \%$.

Copie faite au $\mathrm{XVIII}^{\mathrm{s}}$ siecle, sur papier. in-folio de $28 \mathrm{ff}$. Itemi.

P'ubl. : Cartulaire de l'érolise de Sainte-Mlenehould. publ. d'apres le mis. original [par Lidouard de Bartlélemy]. Paris. Champion. 1879 : in $-8^{0}$ de $2.3 \mathrm{p}$.

Malgré le titre, c'est un recueil d'analyser et d'obits, uniquement.

Saint-Émilion. - Pripuré (diec. dr Bordeattx). 3389. - Cartulaire du prieuré de Saint-Émilion ; origr. perdu.

Extraits faits an XVII siecle par Dom Estiennol (Biblioth. notionale, m.. latin 12201. p. 363.

Saintes. - Ablitye de Noter-bittme.

3390. - Cartulaire de X.-I). de Saintes; orign. perdu [ditruil dantis lincendie de la libliothèque de Sainter].

Cif. : Docunents historiques inédits, par Champollion-Figetac, I, p. 75, et II, p. 171 .

Pebl. : Cartulaire de l'ahblaye royale de Yolre-Dane de Saintes. par l'abbé Th. Grasilier, dans les Curtuluires inédits de la Suintonge, II Yiort. 1871 . in- $8^{\circ}$ de $\operatorname{xxx}-251 \mathrm{p}$.

Recueil de 276 pieces comprises entre 1010 et 1300.

Extraits du cartulaire Biblioth. de la ville d" La Rochelle, ms. 130, If. 1-26: Biblisth. mationule. coll. Lespine, vol. XXXIV, f" 110 : coll. Bahre. vol. LXXY. fo 211 . et ms, latin 12754. pp.311 et 35\%-356, et mis. latin 12759. p. 2067.

Dans ce clernier recueil, on troure aussi une série de copies et pieces relatives au meme monastere (pp. 325-354).

3391. - Recneil des titres de labbaye de Notre-Dame de Sainles: ms. du XYIIle siècle, sur papier, contenant des pièces des anníes 1010-1182. in-t" Biblisth. de la rille de Poitiers, coll. Dom Fonteneau, vol. XXY, pp. 331 it 584 , et vol. LXXX, pp. 29 it 95 .

Saintes. - Érêchè et Clhapitre.

3392. - Pubs. : Recueil de titres relatifs à l'évèché et an Chapitre de Saintes. publ. par Lonis Audiat Arclieces listoriques de lu Suintrimge et de l'teris, X, 1882, p. 21-14:.

Dates extremes : $1111-1785$.

Saintes. - Prirtté de Sainl-Eutrope.

3393. - Cartnlaire de Saint-Eutrope de Saintes; orirr. perdn. A été conuu et utilisé par Marca et Dom Estiennot. 
3394. - Pubc.: Saint-Enlrope et son prieuré, par Louis Audiat Archives historiques de la Saintonge et de l'Aunis, II, 1875, p. 249448 ; III, 1876, p. 17-296; XIX, 1891, p. 234-252).

Saint-Esprit. - Ordre hospitalier.

3395. - Bullaire de l'hòpital du Saint-Esprit; ms. du X V'e siècle, smr parchemin, ormé de 22 miniatures, in-folio de $60 \mathrm{Hr}$. Archives hospitalières de Dijon, A 2).

3396. - Bullaire; ms. du XVI siècle [1522], sur parchenin, relié en cuir noir ganfré, in-4" de $25 \mathrm{fl}$. (Archives hospitalières de Dijon, A 3 ).

3397. - Autre bullaire; ms. du XVI siècle [15+3], sur parchemin, in-40 de $74 \mathrm{fr}$. Archices hospitalières de Dijon, A 4).

Dates extrimes: 1256-1515.

3398. - Antre bullaire; ms. du XVI siècle, sm papier, in-4v de $170 \mathrm{ff}$. (Archives hospitnlières de Dijon, A 5).

Site et supplément du précédent.

Toil aussi yo Muxtremlitir.

Saint-Étienne-de-Vaux. - Abbaye (dioc. de Saintes).

3399. - Cartulaire de l'abbaye de Saint-Étienne-de-Vaux; ms. du XIII ${ }^{\mathrm{e}}$ siècle, de plusieurs mains, sur parchemin, contenant des actes de 1075 i 1237, in $4^{0}$ de $47 \mathrm{ff}$. (Biblioth. nationale, ms. latin 10124).

Copie du précédent, faite au XVIII ${ }^{e}$ siècle sur papier, in- $4^{0}$ de $64 \mathrm{ff}$. (Bibliolh. nationale, coll. Clairambault 567).

Extrait par llom Estiennot an $\mathrm{XVII}^{\mathrm{e}}$ siècle (Biblioth. nutimule, ms. latin 12754 , p. 392 .

A la suite, pp. 392-403, quelques piòces relatives à la même abbaye.

Publ. : Cartnlaire de l'abluaye de St-Étienne de Vaux, de l'ordre de St-Benoit, suivi des chartes du prienré conventuel de Notre-Dame de la Crarde en Arvert. le loordre de (irammont, par l'abbé Th. Grasilier. Niort, Clouzot, 1871 ; in-4" de Lxiv-176 p. [Cartulaires inédits de la Saintonge. 1.]

Saint-Étienne-sur-Usson. - Prieuré. - Voy. SiadxilLANGES.

Saint-Évroul. - Abbaye (diot. do Lisieux).

3400. - Cartulaire de l'alhbaye de Saint-Évroul; ms. du XIII siècle, avec additions postérienres et table des localités à la fin, sur parchemin, contenant des actes de 1050 environ à 1393 , in- $8^{\circ}$ de $226 \mathrm{ft}$. (Biblioth. nationale, ms. latin 11056).

Un tome II formant suite paraît manquer.

3401. - Petit cartulaire de Saint-Évroul; ms. des XIII -XIV'e siècles, sur parchemin, contenant des actes de 1223 à 1349 , in- $8^{\circ}$ de $53 \mathrm{ff}$. (Biblioth. nationale, ms. latin 11057).

A appartenu à Monteil. 
Extraits faits au $\mathrm{XVI} \mathrm{H}^{\mathrm{e}}$ siècle « ex majori » et « ex minori cartulario S. Ebrulfi » (Biblioth. nationale, ms. latin 1:38I7. If. 194-199).

Saint-Faron-lès-Meaux. - Abbaye (dioc. de Meaux). 3402. - «Cartularins adhue niger anni 1540. a Medardo Le Dieu thesaurario et priore Adonis, seriptus in papyro »; ms. perdu.

Extraits faits au XVII siècle Biblioth. nationale, ms. latin 13817. fo 267); - coll. Baluze, vol. XL. ff. 13+145.

Il semble bien, d'apres une charte transerite par les Bẻnédictins au XVIII siècle (Bibliolh. nationale, coll. Champagne, vol. XIX, f' 125), qu'il $y$ a eu un autre eartulaire de saint-Faron plus aneien.

Saint-Félix-lès-Valence. - Abbare, puis prieuré.

II. l'abbé L1. Cheralier a cité dans un de ses travaux le cartulaire de Saint-Félix-lez-Valenee, recueil factice quil voulait publier mais quj est jusqu’à présent demeuré en projet ou manuscrit.

Saint-Fiacre en Brie. - Prieuré (dioc. de Meaux).

3403. - Cartulaire du prieuré de Saint-Fiacre-en-Brie ; orig. perdu.

Existait encore au XVIII sièce, cité par Dom Toussaints Duplessis

Extraits faits au XVIIIe siècle Biblioth. nationule, coll. Chanpagne. vol. XlX, ff. 13t-135,

Autres extraits faits an XVII siècle Biblioth. nationule, ms. latin 13817. fus 270 et 279 ; coll. Baluze. vol. Xl. ff. 139-141.

Saint-Florent-lès-Saumur. - Abbaye (dioce d'Angers).

3404. - Cartulaire ou "livre noir" de Saint-Florent de Saumur: ms. du $\mathrm{XI}^{\mathrm{e}}$ siècle, sur parchemin. in-folio de $141 \mathrm{fr}$. à 2 col. (Biblioth. Cheltenhum, $\mathrm{n}^{0} \boldsymbol{i 0}$ ).

Ce volume a été dérobé vers 18311 aux archives de Maine-et-Loire. Ignorant son sort, P. Marchegay en arait tenté une reconstitution qui comprend la table de 167 chartes, et a paru dans les trehices d'. Lnjou, I (1843), pp. 227-292.

Copie du précédent. faite vers 18.50 par Salmon. Narchegay et Dom Pitra Archires dép. de Main’-et-Loire. H non coté).

Antre copie faile par Salmon Bibliath. de la ville te Tours, ms. 1171).

Lixtraits faits an XVII siecle Biblioth. nationale, ms, nuus, acq.

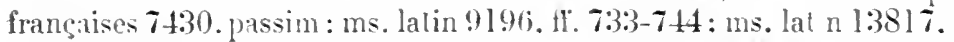
ff. 299-30:3 et 318 ro ; coll. Baluze, vol. XL, If. $70-i 1$ : au XVIII siècle Idem. coll. Iom Honssean, rol. II ${ }^{1}$.

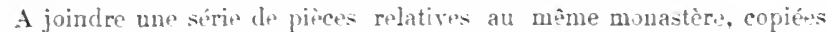
par Laisné, pritur de Mondonvill (Biblolk. nationt'e, ms. français 24133, pp. 509-5220. 
3405. - Antre cartulaire ou « livre blanc » de Saint-Florent; ms. du XII siècle. sur parchemin, contenant des actes de 717 a 1120, avec reliure de lois, in-folio de $130 \mathrm{fr}$. 'ं 2 col. (Archives dép. de Maineet-Loire, $\mathrm{H}$ non coté).

3406. - Autre cartulaire ou «livre d'argent»; ms. du XII ${ }^{\circ}$ siècle, sur parchemin, conteniunt 170 actes de 824 à 1170 , de plusieurs mains, in-folio de $86 \mathrm{fr}$. à $2 \mathrm{col}$. (Archives dép). de Maine-ct-Loire, $\mathrm{H}$ non coté.

Les feuillets 40 et 62 manjuent.

3407. - Autre cartulaire on "livre rouge »; ms. dı XIIIe siècle, sur parchemin, contenant I 80 chartes des années 824 i 1258 , in-folio à 2 col. (Archires dép. de Maine-et-Loire, $\mathrm{H}$ non coté. ff. 1-45 et 66-72).

3408. - Recueil de pièces extraites du Livre noir, dı Livre rouge et du Livre d'argent, par Antré Satmon; ms. du XIXe siècle, sur papier, in-40 de $209 \mathrm{fl}$. (Biblioth. de la rille de Tours, ms. 1171).

(if. Bibliotheque de TÉcole des Cihurtes, te série, I (1855), pp. 127-131.

Les textes contenus lans le " livre noir" se retrouvent en partie dans le " livre rouge " et le "live d'argent ». - Des extraits des mèmes cartulaires so trouvent dans le ms, latin 13817 de la Biblioth. nutionale, ff: 293-299, 30:3-310, 313, 321-324; et dans le ms. 916 de la Biblioth, de la ville de bijon, ff. 56-74.

Extraits des cartulaires de Saint-Florent et particulièrement du « livre noir », relatifs an Poiton Biblioth. de la ville de Poitiers, coll. Dom Fonteneau, vol. LVIII, pp. 4l7-466).

3409. - Fragment d'un cartulaire de Saint-Florent; ms. du XIII siècle, sur parchemin, in- $8^{\circ}$ de $5 \mathrm{ff}$. (Biblioth. nationale, coll. D. Housseau, vol. XIII' ${ }^{1}$,f. 286-290).

Voir aussi au "Śupplément".

3410. - Punc. : Chartes poitevines (833-1160) de l'abbaye Saint-Florent de Saumur. par Panl Narcheray (Avchices historiques du Poitou, II, 1873 , pp. 1-148; : et à part: Les Roches-Baritaud, 1873, in-8 ${ }^{\circ}$.

Chartes de Saint-Florent de Sammr concernant l'Angoumois, par Paul Marchegray Bulletin de la Sucióté urch. et hist. de la Charente, 1877 , pp. 341-363, el a part : in-80 de 32 p.

Chartes nantaises du monastère de Saint-Florent près Sammur de 1070 environ à 1186, par Paul Marchegay (Bulletin de la Société areléolonique de Nantes, $187 \%$, pp. 65-111), et a part: in-8 de 48 p.

Chartes saintongreatises de Srint-Florent près Saumur (1067-1200), par I'. Marchegay Archives historiques de la Saintonge et de l'Aunis, IV, 1877, p. 17-733, et i part: Tours, Bousrez, 1877 ; in-80.

Chartes mancelles de l’ablaye de Saint-Florent près Saumur 848-1200, par P. Marchenay (Revue historique et archiologique du Maine, III, 1878, pp. 347-370). 
Chartes bordelaises '1080-1185) tirées des archives du inonastère de Saint-Florent près Saumur, jar P. Marchegay. Les RochesBaritaud, 1879 : in- $8^{\circ}$ de 20 p.

Chartes anciennes de Saint-Florent près Saumur pour le Périgord (1080-1186), par P. Marchegay Bulletin de la Société historique et archéslogique du Périgord. VI. 1879, pp. 47-51, 118-14:3 et 220-242), et à part: 1879 , in- $8^{\circ}$.

Chartes et antres titres du monastère de Saint-Florent près Saumur concernant lile-de-France de 1070 à 1220 environ, par Paul Marchegay (Mémoires de lu Saciété de l'histoire de Puis. V. 1879, pp. 132-15\%) et à part: Paris, 1879 ; in-8 de $30 \mathrm{p}$.

Charles normandes de labbaye de Saint-Florent pres Samur (710-1200 par P. Marchegay Mémoives de la Société des antiquaires de Normandie. 3e série, X, 1880. pp. 663-71.1); et à part: 1879, in-80.

Les prieurés anglais de Saint-Florent près Saumur, notice et documents inédits tirés des archives de Maine-et- oire. par P. Marchegay (Bibliothèque de l'Ecole des Chartes, XL. pp. 15t-194, et à part: Togent-le-Rotrou. 1879 : in- $t^{\circ}$ de $47 \mathrm{p}$.

Voy. aussi ro, Sanst-Gundus-scr-Loire.

Saint-Florentin. - Hòtel-I)ieu (dioc. de Sens).

3411. - Cartulaire de l'Hòtel-Dien de Saint-Florentin. composé en 1794, et contenant des titres des années 1207 à 1792. in-folio. sur papier (Archires hospitalières de Saint-Florentin. Ionne,

Saint-Flour. - Prieuré de Cluni, puis Érèché.

3412. - Cartulaire du prieuré de Saint-Flour [sur parchemín, contenant $1: 30$ chartes et $124 \mathrm{ff}$.] ; orig. perdu.

Index et extraits du précédent. faits au $\mathrm{XYH}^{\mathrm{e}}$ siècle Biblioth. nationale. coll. Baluze. rol. LXXIII. pp. 53-69 et zl-86) : ms. nouv. acq. françaises 7455, ff. 329-332; ms. latin 17048, pp. 589-608).

Certain: de ces extraits sunt communi yués par X. Vron d'Hérouval en 1666 et 1678 ; dautres sont empruntés à un manuserit appartenant à la même époque à Claude Hardy, conseiller au Chàtelet de Paris.

3413. - Autre cartnlaire fait vers 1320, dit « de l'évesché de SaintFlour » et contenant des titres des années 1131-1314; orig. perdu.

Ene copie en a été retrouvée aux Archices du palais th Honnco.

Cf. Notes sur le cartulaire de Saint-Flour. par Marcellin Boudet (Bulletin historique et philologique du Comité. 1902, p. 436-437).

P'cbl.: Cartulaire du prieuré de Saint-Flour, par Marcellin Boudet. I (972-1275). Imprimerie de Monaco. 1902 : in-10 de Ir-16I p.

Saint-Fromond. - Prieuré (dioc. dr Coutances).

3414. - Cartulaire du prieuré de Saint-Fromond ; m.. redigé en 1844, 
contenant des titres de 1154 à 1348 , sur papier, in- $4^{0}$ de $100 \mathrm{ff}$. (Archives dép. de la Manche, $\mathrm{H}$ non coté).

Saint-Fuscien-au-Bois-lès-Amiens. - Abbaye (dioc. d'Amions).

3415. - Cartulaire de Saint-Fuscien-an-Bois ou « Livre rouge »; ms. antérieur à I384, sur parchemin ; orig. perdu.

Extrait fait en 1750, nn feuillet de papier Archives dép. de l'Oise, H 1534 .

Saint-Geniez-d'Olt. - Ville.

3416. - Cartulaire municipal de Saint-Geniez; ns. du XIVe siècle, sur parchemin, avec additions sur papier jusqua XV XII siècle, in-10 $4^{\circ}$ de 18 If. (Archices municipales de Saint-Genirz, Aveyron).

Saint-Georges de Boscherville. - Abbaye (dioc. de Rou(n).

3417. - Cartulaire de lahliaye de Saint-Georges de Boscherville; ms. du XIIle siecle (avec tables faites an XVIII e siècle), sur parchemin, in-4" de 226 ft. (Biblioth. de lu ville de Rouen, ms. 1227).

Saint-Geosme. - Prieuré (dioc. de Langres).

3418. - Cartulaire dn prieuré de Saint-Geosme, dépendant de l'ahlaye de N.-D. anx Nonnains à Troyes: ms. du XVe siècle, sur papier, in-40 de 41 it. (Archive's dép. te la Hauté-Wame. H non coté).

Saint-Gérard. - Abbaye. - Voy. Brogse.

Saint-Germain-en-Laye. - Hòpital.

3419. - P'́bi..: Recueil de pièces concernant l'Hôpital royal de Saint-Germain en Laye, Paris, $17: 34$ : in- $t^{0}$ de $45 \mathrm{p}$.

Saint-Germain-en-Laye. - Pricurc (dior. de Paris).

3420. - Cartulaire du prieuré de St-Ciermain-en-I alye, dépendant de liabaye de Conlombs; ms. du XVe siède. avec additions du $\mathrm{XVI}^{\mathrm{e}}$. sur parchenin, contenant des actes de 1073 à 1539 , in- $4^{\circ}$ de 117 If. sur parchemin frelices nutionales, $\mathrm{T}^{\star} 67 \mathrm{I}, \mathrm{n}^{0}(\mathrm{~b})$.

Provient dr papiers saisis à la Révolution chez un avoué nommé Leduc.

Publ. : Vingr-quatre pièces de ce cartulaire ont été publices par J. Depoin, Le prienré de St-Germain-en-Laye : Origines et cartulaire (Commission des Antiquités et des Arts de Seine-et-Oise. XV, 1895, p. $102-129)$.

Saint-Germain-lès-Gouilly. - Village.

3421. - Inventaire-cartulaire des hiens possédés par labbaye de Saint-Germain-des-Prés à Saint-Germain-lès-Couilly ; ms. du 
XVIe siècle. sur papier, cuntenant des actes depuis le XIe siècle, in- $4^{0}$ de $33 \mathrm{fr}$. Archives matiniales, L, 806 .

Un certain nombre d'actes sont intégralement tanscrits. ()山 en peut dire autant du registre des . Lorhices nitionales LI, 1092.

Saint-Germain-sur-Ay. - Primure (dioc. lliranches).

3422. - Cartulaire du prieuré de Saint-Germain-sur-Ay, dépendant de labbaye du Mont-Saint-Michel : ms. du XVIe siècle, sur papier, contenant des actes des XII et $\mathrm{XIII}^{\mathrm{e}}$ siècles, in- ${ }^{0}$ de $53 \mathrm{lf}$. Archices dép. de la .enche. E 4882?.

Voy. aussi ci-dessus, ro Le. Mustr-inist-Mrghre.

Saint-Germer-de-Flay. - Ablaye (dioc. de Brauvais).

3423. - Cartulaire de l'abbaye de Saint-Germer-de-Flay : orig. sur parchemin. perdı.

Des mentions de ce cartulaire se trouvent aux Archices dép. de toise, H 1336 et 1596: à la Bibliofh. unlionalp. ms. latin 12741, p. 310 ; ms. français 9499 , p. 353 ; et les pxtraits à la Biblioth. de la ville de Beaucais, coll. Buequet-Auxcousteaux, rol. XLII, pp. 261-269. - Dom Villevieille a connu et utilisé le " premier cartulaire de Saint-(iermer", ce jui laisse supposer qu'il en a existé plusieurs simultanénent.

3424. - Publ. : I. labbé Bornet. curé-doven de Saint-Germer, prépare la publication d"un cártulaire factice contenant les chartes relatives à l"abbaye de Saint-Germer (ms, en 2 vol. in-folio).

Saint-Gervais-lès-Fos. - Abbaye (dioc. d'Aix).

3425. - Prbr. : Les chartes de Saint-Gervais-lès-Fos, précédées d'une lecture sur Whistoire de cette abbaye. par louis Blancard Répertnire des travanx de lu Saciété de statistique de Marseille. Be série. II, pp. 201-2:30), et à part: Marseille. Cayer. 1878: in-80 de 50 p.

Saint-Ghislain. - Abbaye (dio. de Cambrai).

3426. - Cartulaire de lahlaye de St-Ghislain : ms. du XIVe siècle, sur parchemin [incomplet]. contenant des titres de $117 \%$ a 1360 , in-40 de $50 \mathrm{tr}$. Arelices de l"Etat it Wons.

3427. - Antre cartulaire du XVe siecle, sur parchemin, avee une reliure ancienne garnie de cuivre. contenant 412 chartes des années 965 a 1424 . in-folio de $348 \mathrm{ff}$. Archires de restat is Wons;.

Douze feuillets ont été arrachés. C.f. Notice sur un cartulaire de l'abbaye de Saint-(ihislain, par Léopold I) villers, dans: Description de cartulaires et de chartriers du Hainaut, l (1865), pp. 5-20 (extr. des Annales du Girele archéologique de .Wons, t. TV).

3428. - Cartulaire de lahhaye de Saint-Ghislain: ms. da X $\mathrm{V}^{\mathrm{e} e}$ siècle, sur parchemin. contenant des titres de 965 à 1456 , in-folio de $45 \mathrm{ff}$. Biblioth. de .1. II ins. à Mons.

3429. - Autre ms. un XIVe vièele; orig. perdu.

Mentionné dans un inventaire des titres dr l'abbaye, du XVIII siecle. 
3430. - Petit cartulaire de Saint-Ghislain; ms. écrit en I628, sur papier. contenant cles actes de (9) is 1.584 , in- $4^{0}$ de $30 \mathrm{ff}$. (Biblioth. royale de Bruxelles, ms. 6257.

3431. - Cartulaire-chronologie de l'abluaye de Saint-Ghislain ; ms. du X Ylle siècle, sur papier, in $-4^{0}$ de $139 \mathrm{fl}^{\circ}$. Biblinth. nationale, ms. latin 13880$)$.

3432. - Recueil de titres relatifs à Saint-Ghislain; ms. du XVIII siècle, sur papier, contenant des actes de 96.) à 1:386, in-folio de 172 pares (Archives royales de La Haye, fonds Gérard, ms. 79).

Saint-Gilles. - Abbaye (dinc. de Nimes).

3433. - Bullaire de labbaye de Saint-Gilles; ms. des XIIe-XIVe siècles, sur parchemin, mutilé au délut, avec lettres ornées et reliure maroquin, in-16 de $76 \mathrm{ff}$. (Biblioth. nationale, ms. latin 11018).

Plbs. : Bullaire de l'abbaye de Saint-Gilles, par l'ablué Goiffon. Nimes, Jouve, 1882 ; in- 80 de $1 \mathrm{v}-355 \mathrm{p}$.

l'éditeur a ulilisé en outre un recueil, formé ver's 1830, et appartenant aux archives de l'église paroissiale do Saint-Gilles. Cf. L. Delisle (Bibliotheque de TÉrole des Cihartes, XLV, 188.1, up. 209-211), et L. Robert Bulletin de la Saciets des antiquaires de France, 1883, pp. 294-297). - Dans un article du Scizadok (Budapesi, mai 1906) sur les relations de l'abbaye de Saint-Crilles avee la Hongrie, $r$. Baungarten a étudié les bulles et charles concernant la fondation de l'abbaye de Ciomogyvár ‘n I091, et corrigé sur ce point spécial les auteurs francais, notamment Baluze et Groiffon.

Saint-Gilles. - Grand prieuré de l'ordre de Malte, à Arles.

3434. - Cartulaire on « Authenticum domus Hospitalis prioratus Sancli Fugidii »: ms. dı XIIJ siècle. sur parchemin, contenant 373 actes des années 1129-1210, in-folio de 18.5 11. (Archives municipales d'Ales).

Axal. : Inventaire analytique du cartulaire de l'Hôpital de Saint(rilles, par le Baron du Roure (Revue historique de Provence, 1890 , pp. $13,5 \%, 80$ et 115 .

lixtraits laits par Peiresc an XVII siècle (Biblisth. de la ville de Cirrpentros, ms. 1816, t1. 598 et 603-607); - par Du Cange (Biblintl. de l'Arsenal, ms. 5259, l" $181 \mathrm{r}^{\mathrm{n}}$ '.

$3434^{\text {bir. }}$ - Recueil fait au $\mathrm{XVI}^{\mathrm{e}}$ siecle l'actes de 1294-1575, sur papier in- $4^{0}$ de 67 lf. Archices dép. du (rard, $\mathrm{H}$ 6:33).

3435. - Cartulaire du grand-prieuré de Saint-Gilles. formant les prenves d'une histoire par Rityband: ms. copié sur l'original Lperdu] de I766, sul papier, in-folio (Biblioth. de la ville d'dix-en-Provencs, ms. 339 .

Saint-Gilles-lès-Bruxelles. - Couvent de Sainte-Claire (dion. de Malines). 
3436. - Cartulaire du couvent de Sainte-Claire à Saint-Gilles ; ms. du XIVe siècle, sur parchemin, cuntenant des actes de l:368 à 1377, in- $4^{0}$ de $8 \mathrm{ff}$. (Archires du royame de Belgique, à Bruxelles:

Saint-Gondon-sur-Loire. - Prieure (dio a d’orléans).

3437. - Punc. : Cartulaire dı prieuré bénédictin de Saint-Gondonsur-Loire (866-1172, tiré des archives de l'abloyye de Saint-Florent près Saumur, par 1'. Marchegay. Lus Roches-Bantitaud, 1877; in- $8^{0}$ de $64 \mathrm{p}$.

Saint-Guilhem-du-Désert. - Abbaye. - Voy. Geldose.

Saint-Hilaire-près-Longchamps. - Prieuré (dioc. de Toul).

3438. - Cartulaire du prieuré de Saint-Hilaire : ms. du XVIII siècle, sur papier, contenant des titres de 1110 à 1237 , in- $8^{0}$ de 15 ff. (Archioes dép. de la Meuse. $\mathrm{H} 29^{1}$ provisoire).

A figuré sous le $n^{\circ} 3$ r dans le catalogue de la vente Marchand.

Saint-Hilaire-sur-Yerre. - Prieuré (dioc. de Chartres).

3439. - Cartulaire-inventaire du prieuré de Saint-Hilaire-sur-Yerre, dépendant de l'abbaye de Mrumoutier; ins. de 1720, contenant quelques transcriptions de tilres à partir le l'année 1038 , in- $4^{\prime \prime}$ sur papier de 234 p. (Archices dép. d'Eur-et-Loir, H 2424).

Saint-Hubert-en-Ardenne. - Abbaye (dioc. de Lièg ').

3440. - Cartulaire de l'abhaye de Saint-Hubert ; ms. du XVII siècle, sur papier, in- $0^{0}$ de 389 pages (Archires de l'Etat ù trlon).

Ne contient pas de documents antérieurs au $\mathrm{XVI}^{\ominus}$ sièele.

3441. - Autre du XTIe siècle, sur papier, relié en cuir rougre contenant des titres depuis le XIII jusqu'en 1542, dressé par Dom Henry de Chirmont, in-folio de $2: 38 \mathrm{ff}$, et 8 de table (Archives de l'Étut à Arlon).

3442. - Recueil gónéral des titres del’abbaye de Saint-Hubert ; ms. en 2 vol. du XVIII siècle, écrits le premier par Dom Th. Hauzeur en 1766, le second par Dom J. André en 17\%2. in-folio de 285 et 376 pages, plus des tables (Avchives de l'Étut à Arlon.

Le premier tome contient les documents relatifs aux biens de l'abbaye dans toutes les localités dont le nom commence par les lettres A et B : les autres volumes n'existent plus. - Le second tome, intitulé "Quatriène registre n, concerne plus spéeialement les biens de l'abbaye à Freux, à Jemelle, et en France prieurés de Pries et de Chàteau-Porcien).

3443. - Bullaire de la mème abbaye. exécuté en 1477 par l'ordre du pape Sixte IV; orig. perdu [in-folio. parehemin].

3444. - Publ.: Charles de l'albaye de Saint-Hubert-en-Ardenne, 
publ. par G. Kurth. I. Bruxelles, Kiessling, 1903 ; in $-4^{0}$ de [IV-]

LxxviI-761 p. [Documents inédits pour servir à l'histoire de Belgique.]

Dates extrêmes: $687-1317$.

Saint-Hugon. - Chartreuse (dioc. de Chambèry).

3445. - Cartulaire de la chartrense de Saint-Hugon du Val-SaintHugues; ms. du XIII siecle, sur parchemin, in- $4^{0}$ de 61 fr. (Biblioth. de la ville d'Annecy, ms. 6).

Publ.. : La Chartreuse de Saint-Hugon-en-Savoie, par Eug. Burnier (Iémoires de l'Académie impériale de Saboie, $2^{\mathrm{e}}$ série, XI, 1869, pp. 1-567), et à part: Chambéry, 1869, in-8 .

Saint-Hymer. - Prieuré (dioc. de Lisieux).

3446. - Cartulaire du prieuré de Saint-Hymer; ms. de la fin du $\mathrm{XIll}{ }^{\mathrm{e}}$ siècle, sur parchemin (Biblioth. de $\boldsymbol{M}$. Aug. Le Prérost, en 1850 ).

Extraits faits pour Gaignières à la fin du XVIle siècle (Biblioth. nationule, ms. latin 17049, pp. 637-654).

Le volume se trouvait alors entre les nains de Du Fourny.

3447. - Autre du X V1lI siècle [ 752 ], rédigé par l'abbé de Roquette, in-folio sur papier (Biblioth. nationale, ms. nouv. acquisitions latines 2097 .

C"est le même qui appartenait en 1850 à M. de Formeville. - Un autre est incliqué par Honel (col. 297) comme existant à la Bibliothèque de l'Institut, à Paris, mais il n'a pas été retrouvé.

Saint-Jacut. - Abbaye (lioc. de Dol).

3448. - Publ. : Anciens évèchés de Bretarne, diocèse de Saint-Brieuc, par J. Geslin de Bonrogogne et An. ile Barthélemy, IV 1864), pp. $276-296$.

Saint-Jean-au-Bois. - Abbaye (dioc. de Soissons).

3449. - Cartulaire de l'abbaye de Saint-Jean-au-Bois ; orig. perdu.

Extraits faits an XVII siècle, sur papier (Biblioth. nationale, ms. latin 1:3816, $\mathrm{f}^{\circ} 439$, et ms. latin 13891, p. 268).

Saint-Jean-d'Angély. - Abbaye (dioc. de Saintes).

3450. - Cirlulaire de l'allbaye de Saint-Jean-d'Angély; orig. [du $\mathrm{XII}{ }^{e}$ siècle, sur parchemin, de 143 ff.] perdu.

On le dénommait par'ois "Fidelle testamentum ", mots par lesquels débutait la première page (Biblioth. nationale, ms. latin 12778, fo 278).

Copie du précédent; ms. [sur papier, de I52 fr., collationné en 1669 ] perdı. 
Antre copie; ms. du XVII ${ }^{e}$ siècle. sur papier, in-folio de $172 \mathrm{ff}$. (Biblioth. nutionule, ms. latin 5 551 ).

L.es textes y sont sourent incorrects.

Vidimus de quelques pièces, fail en 1688 par les notaires Cherpantier et Mestadier, collationné en 17:27 Biblioth. de la rille de La Rochell', ms. 5.) \%. (0 94-101).

tutre copie partielle du XVIJ siècle, par Jaillot, sur papier (Biblioth. de la ville de L' Rochelle, ms. 128. ff. 1-111).

Autre copie dn XVIII siècle, presque intégrale, mais non suivie (Biblinth. de les ville de Pritiers, coll. Dom Fonteneau, vol. XIII, pp. 20-264, XXVII bi, pp. 259-561. LXII, pp. 389-683, LXIII, pp. $23-830)$.

3451. - Cartulaíre neuf, « Fovum Cartoplylacium ex vetustioribus cartulis »; ms. [exécuté en 1678 par le frère Jean Desprès, contenant au moins 599 pages]; perdu.

Cif. Biblioth. de ln rifle de La Rochelle, ms. 558, fo 78 .

Publ. : Cartulaire de Saint-Jean-d'Angély, publ. par Gieorges Mirsset. Paris, Picard et fils, 1901-1903; 2 vol. in- $8^{0}$ de 442 et cclvi-464 p. [Archives historiques de la Saintonge et de l'Aunis, XXI et XXYII].

Extraits faits an XVII siècle par Dom Estiennot et autres Biblinth. nntiousle. ms. Latin 12753. pp. 204-211: - ms. latin 12754. pp. 52-57. 202-20:3. 275-290. 365, 414, 452; - ms. latin 12755. p. 486 et $6 \mathrm{I} 1$; - et autres Biblioth. nitionale, coll. Balıze. vol. XXVI. ff. 352-378, et vol. LXXI. ff. 5-25; - ms. latin 9196. pp. 44-452, et ms. latin 13818, ff. 1-18).

Saint-Jean-de-Fos. - Ville.

3452. - Cartulaire municipal cle Saint-Jean-de-Fos ; ms. clu XVIII siècle. sur papier, contenant d'ume part un inventaire. de l'autre une transcription de litres, avec traduction, le tout rédigé par Caulier (d'Aniane, in-folio Archires muiripales de Saint-Jean-de-Fos.

Saint-Jean-de-Maurienne. - Érêché. - Voy. Mauriexne. Saint-Jean-en-Vallée. - Abbaye (dioc. de Chartres).

3453. - Cartulaire de l'ahllaye de Saint-Jean-en-Tallée; ms. composé an XIII siècle [12607. " ad exemplar lihri pilosi et de omnibus novis litteris », avec additions du XIV"e siècle, recouvert d'une reliure en bois et muni en tìte d'une table mal reliée, sur parchemin. in- $4^{\circ}$ de $84 \mathrm{ff}$. à 2 col. [a partir dlu fox] (Biblioth. Nationale, ms. latin $11063)$.

Extrait informe fail an XVIJ siècle. sur parchemin, in- $4^{0}$ Brblioth. nationale, ms. français 5382. ff. 11-13. 
I'vbi. : Cantulaire de Saint-Jean-en-Tallée de Chartres, par René Merlet. Chartres, impr. Garnier, 1906 ; in-4 ${ }^{\circ}$ de xxxu-272 p. [Archives d'Eure-et-L.oir ; collection de cartulaires chartrains, I.]

Publication du registre préeédent avec de nombreuses additions; dates extrêmes: 1028-1682. Toutefois un choix a été fait dans les documents a partir du XIVe siècle.

Saint-Josse-au-Bois. - Abbaye (dioc. d'.'miens).

3454. - « Cartularium Sancti Jodoci »; ms. de la fin du XIIIe siècle, sur parchemin, contenant 149 actes des années 1206-1284, in-4 de 80 tf. 'Biblioth. de la ville de Metz, ms. 1197 ; anc. Salis 50).

3455. - Copie d'un cartulaire de Saint-Josse-an-Bois, faite an XVIIo siècle, in-folio de $232 \mathrm{ff}$. Biblioth. nationale, coll. des Cing Cents Colbert, vol. 161).

3456. - Antre cartulinire de 1666, sur papier, en 2 vol. in-folio, contenant des titres de 1118 a 1662 (Archives dép. du Pas-deCalais, $\mathrm{H}$ non coté).

Ce recueil comprend la foliotation bizarre suivante: I (ff. 1-489), de 1225 à 1662 ; - II (ff. 384-418, de 1118 ì 1482 ; - Cartulaire A (92 4f.) de 1159 à 1248 ; - Copie lu petit cartulaire (86 ff.) de 1120 à 1206. 11 semble done qu'on y troure juxtaposées des transeriptions différentes de recueils disparus, et autres que le cartulaire actuellement conservé à Mletz.

Saint-Josse-sur-Mer. - Mbaye dioc. d'Amiens).

3457. - Cartulaire de l'abbaye de Saint-Josse-sur-Mer; ms. du XII ${ }^{\mathrm{e}}$ siècle, sur parchemin, in-folio de $20 \mathrm{ff}$. Archives dép. de Pas-deCalais, $\mathrm{H}$ non coté).

Dates extrêmes: 1100-125\%.

Copie dn précédent, faite en 1674 (Biblioth. nationale, ms. latin 11926. ff. 116-164).

Extraits faits an XVII ${ }^{\theta}$ siècle (Biblioth. de l'Arsenal, ms, 5262, ff. $\left.42 \mathrm{v}^{0}-47\right)$.

Publ. : Chartes de Monchy-lez-Neuville en Boulonnais (Mémoires de la Sociélé académique de l'arondissement de Boulogne-sur-.Mer, XXIV, 1906, pp. 8-28).

3458. - Autre cartulaire lu.XVIII siècle,sur papier, in-folio de 346 p. (Biblioth. de la ville d'Abbeville. ms. 190).

Extraits divers (Biblioth. nationale. coll. Baluze, vol. XI, ff. 253269 : — coll. Horean, passim (par Dom Grenier) ; ms. français 9500, pp. 97-107; ms, latin 1267\%. ff. 97-104\%

I. dirnier extrait fut fait d'après un volume in-folio velié en vélin, eopié lui-même par II. Moreau, abbé de S't-Josse, derenu évêque d'Arras, sur un ancion cartulairé écrit sur parchenin qui au XVII siecle se trouvait entre les nains de II. Bourcier, avocat au Grand Conseil. Ides transcriptions y étaient souvent fautives. 
Saint-Jouin-de-Marnes. - Mblaye (dioc. do Poitiers).

3459. - Recueil de pièces concernant labhaye de Saint-Jouin-deMarnes, formé pour (raignières au XVII siécle. sur papier, in-folio (Biblioth. notionule, mis, latin .0449, pages 2:3-122.

Bates extrèmes : $876-1653$.

P'BL. : Chartularium Sancti Jorini. par Charles Grandmaison (Mémoires de ln Société de statistique du dép. des Deux-Sèreres, XVII, 2), et à part : Niort, 18.54; in- $-8^{\circ}$ de xur-135 p.

Saint-Julien. - Ab) baye (dioce de Tiviers).

3460. - Cartulaire de l'abbaye de Saint-Julien; ms. dn XIII siècle en forme de roulean, mesirant $\mathrm{l}^{\mathrm{m}} 90$ de long sur $0^{\mathrm{m}} 15$ de large, contenant des notices d'actes non datés.

En 18,3 ce rouleau, qui provenait des arehives de la famille Agrain des ["bats, étail derenu la propriété de l'abbé J. B. Payrard. J'ignore quelle esl sa destinée.

Prbl. : Cartularium Sancti Juliani. Vivariensis diocesis, ex originali codice transcriptum et publicatum a .J. B. Payrard Tublettes historiques du Télay, Y, 1875 . p. 485 à 494. et à part: Le Puy, $18 \% 5$ : in $-8^{\circ}$ de $13 \mathrm{p}$.

Saint-Julien. - Église (dioc. de Chalon-sur-Saòne).

3461. - Cartulaire de l"ëglise de Saint-Julien : ms. du $\mathrm{XVI}^{\mathrm{e}}$ siècle, sur papier, contenant t3 titres des annees $1: 321$ is 1576 . in- $4^{0}$ de $105 \mathrm{fr}$. (Archices dépt. de Sabre-et-Loire, G non coté .

Saint-Julien-de-Douy. - Prieuré bénédictin (dive. de Chartres).

3462. - Cartulaire du prieuré de Saint-Julien de Douv, dépendant du prieuré de Bonne-Nourelle d'Orléans; ms. des XVII ế-XVinIe siècles, sur papier, in-folio de $63 \mathrm{fr}$. arec table an début Archires dép. du Loivet, H 118 provisoire?

Ce n'est pas a proprement parler un cartulair mois un recueil des actes concernant l'union de cet établissement à Bonne-Nouvelle (1631. 1706).

Saint-Just. - Abbaye de Prémontrés (dior. de Beaurais). 3463. - Cartulaire de l'ablaye de St-Just en Beauvaisir : orimg. perdu. Extraits faits au XVlle siècle 'Biblioth. matignale, coll. Duchesne, vol. LXXIY. ff. 151-152 : m. français 5483. patre $781-795$ : coll. Baluze. vol. LXXIII. pp. 1-16, - Biblioth. de lin oille de Bennouis, coll. Bucquet-Auxcousteaux. vol. XLII, pp. 525-536,

Saint-Laurent-au-Bois. - Pripuri (dioc. dimiens). 3464. - Petit cartulaire du prienré de Saint-Laturent-au-Bois uni à 
l'allayye de Corbie; origg. perdu [était au $\mathrm{XVII}^{\mathrm{e}}$ siècle entre les mains de M. de Montmignon, conseiller dn roi à Amiens].

Extruits faits au XVII ${ }^{\mathrm{e}}$ siècle (Biblioth. de l'Arsenal, ms. 46ă2, ff. 353-4l1); - an XVIII (Bibliolh. de la ville de Roye, ms. 17).

Saint-Lazare. - Ordre militaire.

3465. - P'ebl. : Fragment d'un cartulaire de l'ordre de Saint-Lazare en Terre-Sainte, par A. de Marsy (Archives de l'Orient latin, II, 1884, doc., pp. 121-157).

Renferme 40 charles des années 1130-1240 environ.

Saint-Léger. - Prieuré (dioc. de Langres).

3466. - Cartulaire du prieuré de Saint-Léger; ms. du XVII ${ }^{e}$ siècle [1647], sur papier, contenaut 70 actes des années $1258-1636$, in- $4^{\circ}$ de $232 \mathrm{ff}$. (1rchives dép. de la Cote-d'Or, $\mathrm{H}$ non coté).

Saint-Leu-d'Esserent. - Prieurè (dioc. de Beaurais).

3467. - Cartulaire dn prienré de Saint-Leu d'Esserent; orig. [sur parchemin, relié en cuir, de $30 \mathrm{ff}$. plus une table] perdu.

On en trouve mention en 1489 et 1499 ( 1 rch. depp. de COise, A 2139). Copie faite au XVIII siècle, sur papier (Biblioth. nationale, coll. Baluze, vol. XLNI, pp. 3-110).

3468. - Publ. : Cartulaire du prieuré de Saint-Len-d'Esserent (10801538. pull. par l'abhé Furg. Müller. Montdidier, impr. Bellin, 1900-1901; in-4" de 210 p. [Pul,lications de la Société historique et archéologique de Vexin.]

Saint-Lô. - Abbaye (dioc. de Coutances).

3469. - Cartulaire de l'abbaye de Saint-Lò en Cotentin; ms. daté de 1843. contenant des actes depuis le XII ${ }^{\mathrm{e}}$ siècle, sur papier, in $-4^{0}$ de $610 \mathrm{ff}$. (Avelives dép. de la .lunche, H non coté).

Les pièr's anciennes sont seules transcrites intégralement; les autres ne sont qu'analysées.

Saint-Lô. - Église Notre-Dame.

3470. - Cartulaire du trésor de Notre-Dame de Saint-Lô; ms. du XIVe siccle $[1437]$. sur parchemin, in- $4^{0}$ de $9 \check{\partial}$ ff. (Archives de la fabrique de Notre-Dume de Saint-Ló.

Cie registre avait, complet, 105 fenillets.

l'crb.: Le cartulane de l'árglise Notre-Dime de Saint-Lò, [reconstitué], par Ed. Lepingard (Notices et Mémoires de la Société Trayiculture, archóologie et histoire nuturelle du département de la Wenche, XVII, 1899, pp. 99-146; XVIII, pp. 131-146; XIX, pp. 72-90). 
Saint-Lô. - Hòtel-I)ien.

3471. - Livre ronı̀e de l'Hótel-Dien de Saint-Lò : ms. du XIII ${ }^{e}$ siècle, sur parchemin. contenant 348 pièces des années $1217-1273$, in- $4^{\prime \prime}$ de $123 \mathrm{fr}$. (Archices hospitalieres de Suint-Lî, A $\mathrm{T}$.

3472. - Antre cartulaire: m.. rédiuré au $\mathrm{XTII}^{\mathrm{e}}$ siècle par ye David Vauderire, sur papier, in-fulio de 5.59 ff. Lrchices hospitalières te Saint-Lh, A 8 .

Saint-Maixent. - Abbaye (dioc. de Poitiers).

3473. - Cartulaire de l'abbaye de Saint-Maixent: [ms. du XIIe siècle, in- $4^{0}$ parchemin de 342 pages, contenant 289 actes du $1 \mathrm{X}^{\mathrm{e}}$ siècle à 1150, arec quelques additions de 1280]: orig. perdu.

3474. - Autre cartulaire. contenant la transcription dı précédent par Dom Liabœuf vers $16 \%$, arec additions d'après les originaux; ms. perdu, détruit par lincendie qui éclatà à la Préfecture des: DeuxSèvres en 1805 .

Extraits faits an $\mathrm{XVII}^{\mathrm{e}}$ siècle par Besly 'Biblioth, nutionale. ms. latin 6007. passim. et coll. Dupuy. vol. 805 et 820:- par Dom Chazal en 1718 Biblisth. de la cille d'Orléans, ms. 314. et Biblioth. de la ville de poitiers, ms. 441). - et dans la coll. Dom Fonteneart. vol. XT, XYI. XXYII bis, XXYIII, XXXIX, et LXYI, pp. 161-334).

34\%. - PcBl. : Chartes et documents pour servir à l'histoire de l'abbaye de Saint-Maixent. pulll. par Alfred Richard Archices historiques du Poitou. XVI et XIII. 1886, 2 rol. in-8" de crxim-384 et II-627 p. avec cartes .

3476. - Recueil de titres relatifs à l'abbaye de Saint-Maixent, fait par D. Ans. Le Mlichel au XVII siècle (Biblioth. nutionale, ms. latin 13818, ff. $23 i-303$.

Les ff. $296-303$ sont des extraits du cartulaire.

Saint-Marc. - Abbaye (flioc. lle Bàle).

347i. - Cartulaire de l'abbaye de Saint-Mlare. près de Guebwiller: uı. du $\mathrm{XV}^{\mathrm{e}}$ siècle. sur papier. contenant des titres à partir de l'année 960. in-t" de $20 \mathrm{ff}$. (Archic des Ober-Elsass, in Colmar).

Saint-Marcel. - Abbave (dioc. de ChaLon-sur-Saônte). Toy. Chalos-sur-Saòe.

Saint-Martin-au-Bosc. - Prieuré (dioc. de Rouen).

3478. - Cartulaire du prieuré de Saint-Martin-au-Bosc. près d'Eu. dépendant de l'abbaye du Bec-Hellouin: ms. du $\mathrm{XT}^{\mathrm{e}}$ siècle. sur parchemin. contenant des actes de 1106 à 14is. in-folio de $69 \mathrm{ff}$. Archices dép. de la Seine-Inférieure. D 20, 
3479. - Recueil de copies relatives an mème prieuré; ms. du $\mathrm{XVII}^{\mathrm{e}}$ siècle, sur papier, faisant suite au précédent, in-folio de $48 \mathrm{ff}$. (Archires dép. de lu Seine-Inférieure, D 21 .

Saint-Martin-au-Val. - Prieure (dioc. de Chartres). 3480. - Cartulaire du prieuré de Saint-Martin-au-Val; orig. perdu. Exiraits faits au XVII siècle (Biblioth. nationale, coll. Duchesne, vol. XX, fo 24t).

3481. - Recueil de pièces relatives au même prieuré, fait au XVII siècle (Biblioth. nationale, ms. latin 12776, pp. 234-257).

3482. - Cartulaire de Saint-Ylartin-au-Yal, dépendant du couvent de Notre-Dame de Bonne-Nouvelle à Orléans; ms. du XVII ${ }^{\mathbf{e}}$ siècle, contenant 33 documents des années 1660-1685, sur papier, in-folio de $179 \mathrm{ff}$. (Archives dép. du Loivet, $\mathrm{H}$ non coté).

Ne contient que les pièees relatives à l'union de Saint-Martin-au-Yal à Bonne-Nouvelle. Ce n'est pas à proprement parler un cartulaire.

Saint-Martin-de-la-Glandière ou Longeville-lès Saint-Avold. - Abbay (dioc. le Metz).

3483. - Cirtulaire de l'alhbaye de Saint-Martin de la Glandière ; ms. du XVII siècle, sur papier, contenant des actes de 855 à 1684 , in-4 ${ }^{\circ}$ de iv-20:3 ff. Archires de Lorraine, à Met\%, H 1028.

3484. - Antre cartulaire dı XVII ${ }^{e}$ siècle, sur papier, in-folio de 24 ff. (Archices de Lorruine, à Yetz, H 1029).

Dates extrèmes : $1345-1565$.

Saint-Martin-devant-Metz. - Abbaye (dioc. de Metz).

3485. - Cartulaire de l'abhaye de Saint-Martin-devant-Metz; ms. du XVIII siccle, sur papier, in-folio de $48 \mathrm{ff}$. (Archives dép. de .Meurtheet-.Moselle, (i 55.5$)$.

Cf. Reconstitution du cartulaire de Saint-Martin-devant-Metz, par

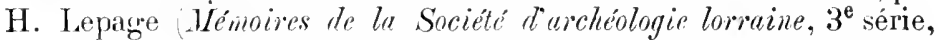
VI, 1878, pp. 109-238.

3486. - Antre cartulaire; ms. du XIV e siècle, sur parchemin, in-4 de 122 If. Biblioth. nationule, ms. français 11848;

Saint-Martin-du-Ganigou. - Abbaye (dioc. d'Elne). 3487. - Cartulaire de labbaye de Saint-Martin du Canigou en Conflent ; orig. perdn.

Extraits faits en 1658 pour Bahne (Biblioth. nutionale, coll. Baluze, vol. (VIII, ff. 333-340 et 351-360).

Saint-Martin-du-Tertre. - Toy. Llly-SaInt-Geonges. 
Saint-Martin-ès-Aires. - Abbaye (dioc. de Troyes).

loauteur d'une histoire de cette abbaye (Mémoires de la Saciété academique de l'Aube, XXXIX, 1875, pp. 231-286), affirme aroir eu l'intention dinsérer comme complément une sorte de cartulaire de l'abbaye (pièces des années 1120-1520).

Saint-Maur-des-Fossés. - Abbaye (dioc. de Paris). 3488. - Livre noir de Saint-Mlaur-des-Fossés; ms. du XIII ${ }^{e}$ siècle, sur parchemin, in-folio de $290 \mathrm{fr}$. (Archices nationales, LL 46).

Dates extrêmes : 818-1285.

Copie du précédent. faite an XVIII siècle, par Carpentier, in-folio de 805 p. (Archioes nationales, LL 47).

3489. - Livre blanc de Saint-Manr-les-Fossés; ms. du XIII e sièclo [128t], par l'ablé Guillamme. prévòt, sur parchemin, avec une reliure en peau de truie, et contenant des actes de 840 à 1332. in-fol. de 150 p. (table) et 339 il. (Archives nationules, LL 48).

Une table de ce rolume est aussi au British .Musenint, add. mss. 11535, ff. 168-229.

Copie du prẻcédent, faite an XVII siècle, de xxıv-600 p. (Biblioth. nationale, ms. latin $54 \mathrm{I} 6$ ).

3490. - Autre cartulaire. daté de 1400, sur papier, in-folio de 152 ff. (Archires nationales, LL 49).

Dates extrêmes : 643-1279.

Copie du précédent. faite au XVIII siècle [1779], par Carpentier, in-folio de $161 \mathrm{p}$. Archives nationales, LL 50).

Extraits du livre noir (Biblioth. nationale, ms. latin 12671, ff. 197-202; coll. Baluze, vol. LXXIV, ff. 67-15̆l).

Extraits divers Biblioth. nationale, coll. Baluze, vol. XLI, ff. 126-153, et nouv. acquis. françaises 7433, ff. 200-205,

Saint-Maur-sur-Loire. - Abbaye 'dioc. d'Angers).

3491. - Fragments de cartulaire de Glanfeuil ou Saint-Maur-surLoire; ms. du X゙II ${ }^{e}$ siècle, de plusieurs mains, sur parchemin, contenant des documents compris entre le VIe et le XII ${ }^{\mathrm{e}}$ siècle $(1147)$, in-folio de $29 \mathrm{ff}$. à 2 col. Lichives dép. de Maine-et-Loire, $\mathrm{H}$ non coté).

Cee cartulaire a été très éprouvé par le feu.

Extraits (Biblioth. nationale, coll. Baluze, vol. XLI. pp. 154-168. et vol. LXXIV, ff. 154-155: coll. Dom Housseau. vol. XII1 ${ }^{2}, \mathrm{n}^{0} 1446$, et passim ; ms. français 16188, f0 284; ms. latin 13818. If. 257-261).

Publ. : Le cartulaire de Saint-Maur-sur-Loire, par Paul Marchegay, dans les Archices d'Arijou, recueil de documents et mémoires inédits sur cette proxince (Anger's, 1843, in-8), I, p. 319-429. 
Saint-Maurice-en-Valais. - Voy. Agaunf.

Saint-Maximin. - Courent des Dominicains (dioc. d'Aix). 3492. - Purl. : Le courent royal de Saint-IIaximin de Provence, de l'ordre des Frères l'rêchems, ses prieurs, ses annales, ses écrivains, a vec un cartulaire, par l'abbé J.-H. Albanès (Bulletin de la Société d'études scientifiques et archóologiques de Diaguignan, XII, p. 1-167); et à part : Marseille, 1880, in-8

Saint-Maximin. - Ville.

3493. - Cartulaire municipal de Saint-Maximin en Provence; ms. des XIV-XYe siècles, sur parchemin, contenant des actes depuis 1295, in-4 $4^{0}$ de $90 \mathrm{fr}$. (1rchices municipales de Suint-Maximin, AA 1).

Publ. : Cartulaire municipal de Saint-Maximin, suivi de documents puisés dans les archives de cette ville, par' L. Rostan. Paris, Plon, 1862 ; in $-4^{\circ}$ de $x v-185 \mathrm{p}$.

Saint-Meloir. - Seignetuie en Bretagne.

3494. - Recueil de titres relatifs à la seignenrie de Saint-Meloir, dépendant de l'abbaye du Mont-Saint-Michel; ms. dn XVIIe siècle, fait pour Gaignières, sur papier, in-folio Biblioth. nationale, ms. latin $5430^{\mathrm{a}}$, pages $195-221$ ).

Documents à partir de l'année 1030 .

Saint-Mesmin. - Voy. Micy-Saint-Mesmix.

Saint-Michel-de-la-Cluse. - Ablaye (dioc. de Turin). 3495. - Cartulaire de l'abluaye de Saint-Nichel-de-la-Chise; ms. du XIII siècle, sur parchemin, in- $t^{\circ}$ (Archivio di Stato, Torino).

Cf. Gaudenzio Claretta, Storia diplonatica dell antica abbazia di san Michele della Chiusa con documenti inediti (Torino, Civelli, 1870 ; in $-8^{\circ}$ de $\left.x+1-369 \mathrm{p}.\right)$.

Copie du mème, faite au XVI siècle (Archivio arcivescovile di Torino.

3496. - Recueil abrégé des droils de l'abbaye de Saint-llichel de la Cluse. extrait du livre intitulé « Recueil des tilres, enseiunemens et instructions servans pour l'ahlaye de Sirint-Michel de la Cluze en Piedmont, par le sien Michel Bonnefont" Biblio'h. mationale, ins. latin 1:3819, ff. 1-4.

Saint-Michel-en-Thiérache. - Abloye (dio: de Laon).

3497. - Cirtulaire de St-.Yichel-en-Thiérache; ms. du XIIle siècle avec addilions jusqu au XV", sur parchemin, in-4" de 378 p. Biblioth. nationale, ms. latin 18:375).

Copie dı précédent, exécutée par Dom Annonld en 1783, sur papier, in-4" de 406 pages (Biblioth. de la ville de Soiss 31 , ms. 250). 
3498. - Autre cartulaire [ru au XVII sifels par bom Lelong]; orig. perdu.

Ax.n. : Cartulaire de Saint-Yichel-en-Thierache, par Am. Yiette. Vervins, impr. du Journal de Vervins, 188:3 [1890]: in-4" de 128 p. [Société archéologrique de Vervins.]

Cf. Observations sur le cariulaire de saint-IIichel-en-Thiérarhe

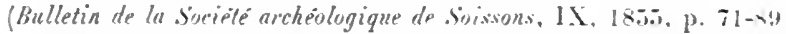

Saint-Mihiel. - Abbaye de Saint-Wichel (dioc. de Verdun). 3499. - Cartulaire de l'athaye de St-Yihiel ; ms. des XII ${ }^{t}-\mathrm{XIII}{ }^{e}$ siècles, sur parchemin, contenant 120 acles des années 705-1298, in- $t^{\circ}$ de $99 \mathrm{ti}$. Archices dép. de la .Keuse, $\mathrm{H}$ non colë.

Formait précédemment le $n^{\circ} 1$ du catalogue Marcluand ( $\left.18-53\right)$.

Copie du précédent. faite an $\mathrm{XVI}^{e}$ siècle, sur papier, in-40 de 106 p. (Biblioth. de he ville de Suint-IYhiel, ms. Z :31.

Copie moderne du mème, faite en 1876 . in- $4^{\circ}$ de 199 p. Biblioth. nationale, ms. nouv. acq. latines 1283 .

3500. - Autre cartulaire; ms. du XVII siècle, contenant 262 pièces des années 956-1463, sur papier. in-folio de $214 \mathrm{ft}$. Archices depo. do la .Mels.se, $\mathrm{H}$ non coté).

Dans son Histoire de Saint-Mihiel (Nancy, 175;, in- $4^{\circ}$, Dom Joseph de l'Isle cite et utilise un cartulaire en deux rolumes, dont l'un avait au moins tot; pages et l'autre 300, el qui ne peuvent être identifiés avec aucun des registres cinlessus décrits. - Voir aussi au \& supplément 》.

Saint-Mihiel. - Chàtellenir.

3501. - Recueil de titres relatifs à la chàtellenie de Saint-Mihiel ; ms. de la fin du XVI siècle. furmé par Thierry Alix. sur papier, conlenant des textes de 1240 à $157 \%$, in-folio de 416 et $324 \mathrm{ff}$. Arclices dép. de Meurthe-et-.Moselle, B 389-390,

Copie du précédent, faite an XVII siècle, sur papier, en ? vol. in-folio (Archives dep. do la Weuse, B 2:3:3-2:34.

Saint-Mihiel. - Église.

3502. - Cartulaire des deux chapelles fondées en l'église paroissiale de Saint-Mihiel par Jeannette, veuve de feu Henri Hausse; ms. des XVe-XVIe siècles, sur parchemin, in $-4^{0}$ de $64 \mathrm{tf}$. (Biblioth. untionale, ms. nouv, acq. françaises 10446 ).

Dates extrèmes : 1479-1519.

Saint-Mont. - Prieurẻ (dioc. d’Auch).

3503. - Cartulaire du prieuré de Saint-Mont; ms. du Xli siècle, sur parchemin, contenant des documents de 1052 a 1124 , in- $8^{\circ}$ de 26 ff. (Biblioth. de M. le comte J. de Corneillan, au chàtean de Saint-Germé. Gers. 
Copie du même. faite an $X Y^{\prime} I^{e}$ siècle, sur papier, in-40 de 43 ff. (Biblioth. nationale, ms. latin 5 $460^{\mathrm{a}}$ ).

Prbi.. : Cartulaire du prieuré de Saint-Mont (ordre de Cluny), par J. de Jaurgain, avec introduction et sommaires de J. Hanmus. Auch. Cocharanx [Paris, Champion], 1904; in-80 de xiv-152 p. [Archives historiques de Gascogne, $2^{2}$ série, fasc. 7.]

Sur l'authenticité de certains actés de ce cartulaire et les altérations qu'ils ont pu subir, voir le comple-rendu de cette publication par L.-H. Labande (Rerue critique, $n^{0}$ lu 17 octobre 1904).

3504. - Antre cartulaire de Saint-Iont; ms. du XIIe siècle, sur parchemin. en forme de roulean de $5^{\mathrm{m}}, 80$ de longr sur $0^{\mathrm{m}}, 15$ de large Biblioth. de M. Le comte J. de Corneillan).

Sur ce rouleau, qui n'a pas été utilisé dins la publication ci-dessus, voir : Mélanges historiques inédits, par Champollion-Figeac, I (1841), pp. $168-182$.

Exiraits faits an $\mathrm{XVIl}^{\mathrm{e}}$ siècle par Oïhenart (Biblioth. notionnle, coll. Duchesne, vol. CXVIII, ff. 32-50).

Saint-Nicolas-aux-Bois. - Abbaye (dioc. de Laon). 3505. - Cartulaire de Saint-Nicolas-aux-Bois ; orig. perdu,

II est cité dans le nis. relatif à l'abbaye de Nogent-sous-Coucy (Biblioth. nationale, coll. Don Grenier, vol. 268, ff. $15 v^{\circ}-16$ ).

Saint-Nicolas-de-la-Ghaise. - Prieuré. - Voy. Portuers (St-Nicolas de).

Saint-Nicolas-de-la-Chenaie. - Maladrerie (dioc. de Bayeux).

3506. - Cartulaire de la maladrerie de Saint-Nicolas près de Bayeux; ms. du XVe siècle [1445], avec table en tête, par le tabellion Jean des Maires, sur parchenin, in-folio de xxxrv-848 p. (Biblioth. de la ville de Bayeux, ms. 1).

Saint-Nicolas-des-Lochereaux - - Prieuré (dior. d'Angers).

3507. - Cartulaire du prieuré de St-Nicolas des Lochereaux, dépendant de l'abbaye de Nioisean; ms. du $\mathrm{XII}^{\mathrm{e}}$ siècle, en 2 ròles de parchemin reliés, contenant 48 chartes du même temps, in-folio (Archives dép. de Maine-et-Loire, $\mathrm{H}$ non coté).

Saint-Nicolas-du-Port. - Ville.

3508. - P'Bb.. : Ordonnances, statusts, privilèges el règlements accordés par les dnes de Lorraine à la ville de Saint-Nicolas-du-Port. Nancy, 1750, in-8".

Saint-Omer. - Abbaye de Saint-Bertin. - Voy. SalnTBertis. 
Saint-Omer. - Chapitue de Notre-I)ame.

3\%09. - Cartulaire du (Chapilre de Notre-I)ame de Saint-Oner: ms. des $\mathrm{XVe}_{-} \mathrm{XVI}^{\mathrm{e}}$ siècles, sur parchemin, in-folio de $16 \mathrm{l} \mathrm{ff}$. Archices municipales de Saint-Omer, (i jo:3,

Saint-Omer. - Église Saint-Denis.

3510. - Cartulaire de l'église Saint-Denis-de Saint-Omer; ms. lu $X V e$ siecle [1415]. sur parchemin, in-te de 30 fi. Biblintl. to lo ville de Saint-Omer, ms. 893).

Saint-Omer. - Ville.

3511. - Publ. : Recueil de chartres qui se trunvent dans les archives des mayeurs et échevins de la ville de Saint-Omer en la province d'Artois concernant la jurisdiction ordinaire .... Saint-Omer, Fertel, 1739. in $-4^{\circ}$ de $120 \mathrm{p}$.

Recueil de documents commençant en $112 \pi$ et finissant en 1680 .

3ä12. - Cartulaire de la ville de Saint-Omer; ms. du XIlle siècle. sur parchemin. in-12 de $11-56 \mathrm{ff}$. Biblioth. do lo rille de Saint-Omer, ins. $8: 29$.

Contient iz chartes de priviliges.

3513. - Publ. : par Arth. (iiry, dans : Histoire de la ville de SaintOmer et de ses irrtitutions jusqu'au XIV"e siècle (Paris. 1877. in-8", p. $330-501$.

Recueil factice de 102 pieces (annèes 1043 à 1320) intéressant l'histore civile de saint-Omer.

Saintonge. - Province.

3514. - Documents extraits des registres du Trésor des Chartes relatifs à l'histoire de la Saintonge et de l'Aunis, publ. par Paul Guérin (Archives historiques de la Saintonge el de l'Aunis, XIl, 1884, pp. 11-245).

Recueil comprenant les années 130 ż̀ 1321 .

Saint-Pair. - Prieurè (dive. d'Arranches).

35l5. - Fragment du cartulaire dn prieuré de Saint-Pair. dép. de l'abbaye du Mont-Saint-Michel : ms. du XVe siècle, sur papier. in- $4^{0}$ de $14 \mathrm{ff}$. (Archives dép. de la Manche, $\mathrm{H}$ non cotél.

Ne contient que des textes du Xive siècle.

Saint-Papoul. - Évêché.

3516. - Cartulaire de l'évèché de Saint-Papoul; ms. du X Y'e siècle avec additions jusqu'au $\mathrm{XVIII}^{\mathrm{e}}$, sur parchemin et papier, in-folio de 810 pages (Archives dép. de l'Aude, G suppl.)

Dates extrêmes: 1315-1789.

Ce manuscrit a été offert aux archives de l'Aude, en 189s, par Mae la marquise d'Hautpoul et $\mathrm{W}$. Hennet de Bernuville son gendr. 
Saint-Paul-en-Chablais. - Priemé (dioe. de Genève).

3517. - Cartulaire du prieuré de Saint-Paul-en-lihablais; ms. en forme de rouleau, du XII" siècle [vers 1280], sur parchemin, contenant 12 chartes depuis l'annee I.2.2 Archives du chatean de Thrysel, Hante-Savoie .

Prbl. : par le comle An. de Foras Mémoires ot Doruments publiés pur l:Aculémie Stlésienue. XXII. 1899. pp. I65-179.

Saint-Paul-lès-Romans. - Hospitalirus dioc. de Vienne). 35̄18. - Publ. Cartulaires des Hospitaliers el des Templiers en Daupliné, par l'abbé Cl. Chevalier. Yienne, Savigné, 1875) in-80, p. 5-101. [Collection des cirtulaires dauphinois, III, 1.]

Saint-Paul-Trois-Châteaux. - Évìłhr.

3519. - Curtulaire de l'évêché de Saint-Paul-Trois-Chàteatux; uss. du

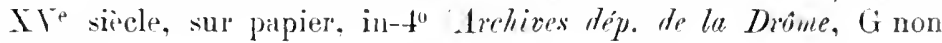
colè .

Saint-Pé-de-Générez. - . Dbatye (dior. de Tarbes).

3520. - Fragment de cartulaire de l'abbaye de Saint-Pé-de-Générez; ms. copié par Larcher en 1769. sur papier, in-4" de 20 ff. (Archives dép. dés Ifaules-Pyréuées, $\mathrm{H}$ non coté, vol. X.

Les lates extrines des pieces sunt 1032 et 1318.

lon Villevieille in connu et utilisé l'original disparu, ainsi que Marca et Oilsenart.

3521. - Extraits de l'origrinal, laits an XVIJ siècle par Oühenart Biblioth. nutionalo, coll. Dnchesue. vol. CXIV, ti. 52-59\%

Puns. : Anumire dn Pelit Séminaire de Suint-Pé, I881, 1887, etc.

Saint-Pierre-en-Chastres. - Couvent tles Célestins (dioc. 1. Soissons).

35.2.2. - Cartulaire des Célestins de Saint-Pierre-en-Chastres; ms. du

XYI e siecle [1521]. contenant des docments de $1: 309$ i $1: 398$, in- $4^{0}$ de 20 ll. Archives dép. de l'Oise, $\mathrm{H}$ non coté,

Saint-Pierre-le-Moutier. - Abbaye (dioc. de Nevers). 3523. - Cartulaire de l'ablaye de Saint-l'lerre-le--Youtier ; or'ig. perdu. Fixtrait fait an XVII" siecle (Biblioth. mutionale, coll. Bourgogne, rol. C:VIIl, $\mathrm{f}^{0} \cdot 2 \cdot 26$ ).

Saint-Pierremont. - Lbbaye (dioc. de Metz).

3524. - Cartulitire de l'abhaye de Saint-Pierremont ; ms. du XIII ${ }^{e}$ siècle, [I292], arec additions di XIVe, sur parchemin, contenant des 
chartes de 1099 a a $1: 321$, in-folio Biblinth. matimule. ms. Latin I2866, II. L-66i .

Vombreuses pirces en lanırue française.

3525. - Autre cartulaire: ms. du XVIII siecle, sur papier, in-fl de

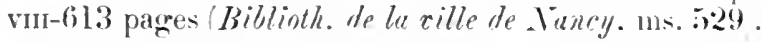

35:6. - Cartulaire de la pitancerie de Saint-lierremont: ms. du XVIe siècle. sur papier, contenant des actes de l2:3t i l 298 . in- $4^{\prime \prime}$ de $25 \mathrm{fr}$. Archices de Lorruine. à Met\%, H l:2020.

Saint-Pol-sur-Ternoise. - Ville et romté.

3527. - Recneil de titues relatifs is la ville el an conte de Saint-Pol; ms. du XVII" siècle. rédligé par le l'. Turpin, doninicrin. sur papier, in-folio Biblioth. de lll rille de Sulnt-Oriler, ms. 551 .

Saint-Pons. - Mblyye (dioc de Nice).

3528. - Cartulaire de labbaye de Saint-Pons: 111. pxécuté en 1706 par Ch. Fr. Torrini, et contenant des transcriptions de docunents a

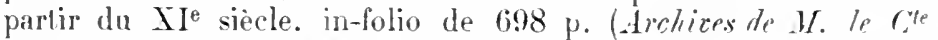
$G$. Alberti, de La Briga .

3529. - Aulre formé an XVIII siècle, par .J. B. Lanteri drchires de 11. Lanteri, de La Briga .

3530. - Publ. : Chartier de labhaye de Saint-Pons hors les mur de Nice, par le C'te E. Cais de Pierlas, continué par (i. Saige.

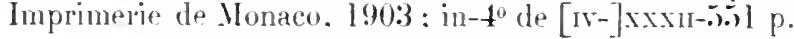

Ceelle publication comprent 42 ; charles des anmes 699 id 1749.

Saint-Pons-de-Thomières. - Évôché et albaye.

35:31. - Cartulaire de Saint-Pons-de-Thomières ; vrig. perdı.

lixtraits fails an $\mathrm{XVI}^{\mathrm{e}}$ siecle par Dom Estiennot a ex cartulario Tomeriensi asservato in archivio regio Carcasonensi » Biblioth. nationale, ms. latin 12771. pp. 158-162.

35:32. - Recueil de titres relalifs is Saint-Pon-de-Thomieres. fait en 1679 par le même Biblioth. nutionale. ms. latin 127.5. pp. 493512 .

Saint-Pons-de-Thomières. - Villi.

3533. - Publ. : Le livere des franchises el libertes des habitants de la ville de Saint-Pons-de-Thomières [1442]. par Lomis Yoguier (Bulletin de ln Sociéts urchénlogique de Beziers. 2e serie, IX. I878, pp. 5-39.

Nest qu'un extrat, 'm langue romant, "d'après un ms. perdu.

Saint-Quentin. - iblaye de Saint-Plix (dioc. de Noyon). 3534. - «Cartularium sancti Prejecti juxta Sanctum Quintinum »; ms. de 225 II. [du Xllle siècle], orig. perdu. 
Extraits faits au XVIIe siècle de documents antérieurs à l'année 1222 Biblioth. nutionale, coll. Baluze, vol. LXXV, ff. 34-72).

Cf. D. L. d'Arhery, Spicilegium, XII (1675), p. 156.

Saint-Quentin. - Église collégiale.

35:35. - Cartulaire du Chapitre de St-Quentin ; ms. du XVe siècle,

dr l:30 If. sur parchenin, contenant des actes des XII ${ }^{e}-\mathrm{X} V \mathrm{e}$ siècles (Bibliolh. mationale, ms. latin 11070 ).

Axal. : Analyse du cartulaire du Chapitre de Saint-Quentin en Vermandois. d'après un mannscrit de la Bibliothèque nationale de Paris. par (Ch. Desmaze Mémoires de la Société académique dé Srint-Quentin, 3e série. X. p. 461-478, et à part: Saint-Quentin, I874. in-8" de $22 \mathrm{p}$.

3536. - Livre ronge; ins. du XIVe siècle, sur parchemin, contenant les docmments des années 86:3-1364, in-folio de 335 ff. (Archives untionmles. LL. 1018).

lixtraits par In Chesne Biblioth. nationule, coll. Baluze, vol. XI.I, 11. $77-78$.

3537. - Carlulaire du XIII siecle ; orier. perdu.

On a des fraguenls d'une table d'un ancien cartulaire du Chapitre (Archires dej). He l'Aisur, (r 838).

35:38. - Cartulaire de la chapelle Saint-Jean-Bapliste en l'égrlise de Sitint-Quentin en Vermandois; ms. du XIVe siècle, sur parchemin, in-f" le I2 If. Biblioth. nutionale, ms. français 14590 ).

35:39. - Autre carlulaire du «doyemé » de Saint-Quentin; orig. perdu.

J'ignore s'il convient de considérer comme un volume distinct le " cartularium decanatus Sancti Quintini" dont on trouve des extraits at la Biblioll. nationa'e, coll. Duchesne, vol. LXXIV, fo 147.

Saint-Quentin. - Ville.

3540. - Cirlulaire municipal on « Livre rouge » de Saint-Quentin; mis. dn XI'e siècle. sur parchenin, avec additions des $\mathrm{XVe}_{-}$ XVIII siècles, relié avec clous de cuivre, in-folio de 369 pages Arimress muniripales de Saint-Quentin).

l'ubl. : Le livre rougre de l'hòlel de ville de Saint-Quentin (10451725 . par H. Bonchot et Emm. Lemaire. Saint-Quentin, imp. Poelle. 1881 ; in-4 de cxil-497 p. el pl. [Société académique de Siint-Quentin.]

Saint-Quentin-en-l'Ile. - Abbaye (dioc. de Noyon).

354l. - Carlulaire de l'abbaye de St-Quentin-en l'Ile; ms. r'édigé en 1386, sur parchemin, in-folio de $68 \mathrm{fH}$. (Archives nationales, LL 1016). Documents de 986 à 1401 . 
Copie du préciclent faile en 1764. par A. G. Jourdan. sur papier, in-folio de 5!) p. (Biblinth. rationale, ms. latin 10116 .

Autre copie: ins. du XVII" siècle. sur papier, de $192 \mathrm{fr}$. in-40 (Archices dép). de l'. Lisne. H $\mathbf{5} 35$.).

Autre copie, moderne, sur papiel. in-folio de 146 tf. (Biblioli. de la ville de St-Quentin. ms. 19:2

3542. - «iber cartarum et privilegiorum beati Quintini martyris de Insula »; ms. du XVI $\mathrm{XI}^{\mathrm{e}}$ siècle. sur papier. par 1). L.ıc d'Achery, in-folio de $143 \mathrm{ft}$. Biblioth. nationale, ms. latin 12895 .

Ce volume parait être la copie d'un registre "antiquius "ou "primus" perdu.

3543. - Autre cartulaire 14 XVI siecle [1588]. sur parchemin. in-folio de 1:32 17. (Archites nationales, LL 1017).

3544. - Cartulaire de l'abbaye de Saint-Quentin-en-l'Ile, contenant 97 pièces de 982 i 1242 ; ms. du XVIII siècle, sur papier, de $84 \mathrm{ff}$. in-40 'Archives dép. de l'Aisne, $\mathrm{H}$ 5:34.

Saint-Quentin-en-Mauge. - Prieuré (diuc. d'Angrers).

30̈45. - Cartulaire du prieuré de Saint-Quentin-en-Maugre et de Chalonnes-sur-Loire. dépendant de Narmoutier : ms. du XVIIe siècle. contenant des tilres de 1050 à 1539. sur papier, in-4' de $31 \mathrm{ft}$. Archires dép. de Wuine-et-Lnive, $\mathrm{H}$ non coté.

Saint-Remi-lès-Senlis. - Abbay (dioc. tle Senlis).

3546. - Cartulaire de l’abbaye de Saint-Reni-lez-Senlis: ms. du $\mathrm{XIII}^{\mathrm{e}}$-iècle. sur parchemin, in-40, précédé de 5 tf. de papier contenant une table summaire Bibliolh. nationale. ms. latin 11002. ff. $1-34$.

Dates extrintes: 1156-1241.

Saint-Remy-la-Varenne. - Prieuré (dior. d'Angers).

3547. - Cartulaire du prienré de Saint-Remy-la-Varenne, dëpt de l'abbaye de Saint-Florent; ms. du XVle siècle. sur parchemin, in-1" de 50 tit. Archices dép. de Muine-et-Loire. H non coté).

A été lé:rué rẻcemment à ce dépòt par l'abbé Allard, de Nantes.

Saint-Rion. - Albaye (dior de Saint-Brieuc).

3548. - Publ. : Anciens évèchés de Bretagne, diocèse de Saint-Brieuc, par J. Geslin de Bourgurne el An. de Barthélenny, IV 1854, pp. 8-13.

Saint-Riquier. - Abbaye (dioc. d'Amiens). 3549. - « Chronicon Centulense »; ms. commencé au XIe siècle par 
le moine Sixowal. continué par le moine Hariulf, vers 1100 ; orig. perdit.

Copie faite anx $\mathrm{XII}^{\mathrm{e}}-\mathrm{XIII}$ siècles, sur parchemin (Biblioth. nationale, ins. latin 11733, ff. 215-277).

Autre copie faite an $\mathrm{XV}^{\mathrm{C}} \mathrm{II}^{\mathrm{e}}$ siècle d'm ms. provenant de l'abbaye de Corlie et ayant appartenu à Petan [perdu] Biblioth. de la ville d'dmiens, ms. 531 .

Quelques pièces anciennes nous ont été conservées par ce volume qui d'ailleurs est bien plutot une chronique qu'un eartulaire. En les copiant avant le 28 août 11:31, date de l'incendie de l'abbaye, on les sauva de la destruction.

Plbi. : [incomplète] dans le Spicilegin de Hom Luc d'Achery, IV (1661),pp. 419 et ss. : [meilleure] par Iom Ursin Durand dans

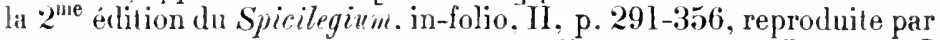
Migne, Jutrologia latinu. CLXXIV, coll. 12ll-1366;-[définitive] par Ferd. Lot dans la « Collection de textes pour servir à l'étnde et it l'enseignement de l'histoire » (Paris, 1894, in-8 ${ }^{\circ}$.

3550. - Cartulaire de l'ablaye de Saint-Riquier : orig. perdu.

Fixtraits par Du Cance an XVIJ siècle (Biblioth. de l'Arsenal, ms. 5260, If. 55-56; et Biblioth. nutionale, ms. français 9498, pp. $101-1033)$.

3551. - Répertoire-cartulaire de lablaye de Saint-Riquier; ms. dn XYIII siecle. sur paipier. contenant des documents de 1103 i 1628 , in-fotio de $228 \mathrm{ff}$. Archives dép. de la Somine, $\mathrm{H}$ non coté.

Copie de l'inventaire dresse par Eustache le Quieux, abbé de $\therefore$-Riquier, en 1489 .

Copie fiumée dn précedent, moderne Biblioth. nationale, ms. framsais 120:30 .

Saint-Robert-de-Cornillon. - Prieuré (dioc. de Grenoble). 3552. - Cartulicire du prieuré de Saint-Robert de Cornillon ; ms. du $\mathrm{XVII}^{\mathrm{e}}$ siècle, contenant des actes des années 1269-1482, in-folio de 107 fr. (Archives dép. de l'Isère. H 46).

l'ubl. : Cartulaire dı prieuré de Saint-Robert-de-Grenoble, par l'abbé Auverorne Documents znédits relatifs un Dauphiné, publ. par l'Académie delphinale; Grenoble. 1865 , in-8 $8^{\circ}$ p. 1-80).

Cite recueil factice comprend des ehartes allant de 1209 à 1356.

Saint-Ruf. - Abaye (dioc. de Valence).

3553. - Cartulaire de Saint-Ruf de Valence; orig. perdu.

Extrait fait en 1612 par le prieur de Saint-Victor (Biblioth. de la ville de Carpentras, ms. 1860, pp. 57:3-579).

3554. - Рсвь. : Tenor quorumdan privilegriorum canonicorum rega- 
larium sicrae ablatia et ordinis sancti Ruli Valentiæ per summos pontifices concessormm necnon per christianisimmm regen Henricum IV confirmatum. Parisiis, 1621 . in $-8^{\prime \prime}$.

355̌5. - Cartulaire de l'abbaye de Saint-Ruf; ms. dı XVIIe siecle. contenant des titres des années 1158-167\%, sur papier. in-4" de $145 \mathrm{ff}$. Archives dép. de la Drôme, $\mathrm{H}$ non coté.

3\%56. - Autre cartulaire moderne de lahlave de Saint-Ruf. cupié sur les oriuginaux des archives de la Dròne 1038-1171 : ms. sur papier in-folio Biblinth. de la ville de Grenoble. ms. 1458. tï. :3:3106.

3557. - Publ. : Codex diplomaticus ordinis sancti Rufi, publié d'après les chartes originales par l'abbé Ll. Chevalier Bulletin de la Soriété d'archéologie et de statistique de la Drome, XIV, pp. 1-128. it it part: Valence, 1891 ; in- $8^{\circ}$ de 128 p. [Collection des Ciartulities dauphinois, IX.]

Saint-Satur-sous-Sancerre. - Abbaye (dioc. dr Bomges!.

35̆58. - Cartulaire de l'abbaye de Saint-Satur-sous-Sancerre: us. du XVII siècle [l689], sur papier. in-folio de $900 \mathrm{ff}$. Archices dep. du Cher, $\mathrm{H}$ non coté.

Échappé à l'incendie de 1859 , ce rolume a cependant souffert, et nombre de pages tombent en poussière à mesure qu'on les tenillette.

35.59. - Publ. : Les actes des souverains antérieurs an XVe siècle conservés dans les archives départementales du Cher: I fonds de l'abbaye de Saint-Satur-sous-Sancerre). par Jacques Soyer Mémnires de la Société des antiquaires du Centre, XXVI, 19102, pp. 2i-144. et à part: Bourges. 1903 ; in- $8^{0}$ de 1

Saint-Sauveur-en-Rue. - Prieuré (dior. de Lyon).

3560. - Ciartnlaire du prieuré de Saint-Sanvenr-en-Rue : oriz. perdu.

Copie du précédent faite an XVIL siècle. sur papier, in-4" de 497 ff. (Avchices du chateau de Feugerolles, Loire).

Extrait fait par Dom listiennot en 1676 Bibliolh. motionale. ns. latin 12745 , p. $356^{\text {bis }}$.

Yubl. : Cartulaire dı prieure de Saint-Sauveur-en-Rue Furez, dépendant de l'abbaye de La Chaise-Dieu 1062-1401. par le comte de Charpin-Fengerolles et II.-C. Guigue. Lyon. impr. Perrin, 1881 ; in- $4^{0}$ de $x x 1 v-379$ p.

Saint-Sauveur-le-Vicomte. - Abbaye dioc. de Coutances).

3561. - Cartnlaire de labbaye hénédictine de Saint-Sauveur-le-Vicomte, on * Livre noir »: ms. du XIII ${ }^{e}$ siècle. avec additions pusté- 
rieures jusqu'en 1446, sur parchemiu, in-to de vir-208 pages (Archives dép. de la Manche, $\mathrm{H}$ non colí.

Copie du XVIIle siècle, sur papier. in-folio de $\mathrm{xxxv}-412 \mathrm{fl}$. Biblioth. nutionale, nss. latin 171:37.

Une table de ce manuscrit se trouve dans le ms. français 4901, fi. $61 \cdot 128$.

Saint-Savin-de-Lavedan. - Abhaye (dioc. de Tarbes).

3562. - Cartulaire de Saint-Savin-de-Lavedan; ms. dı XIre siècle, sur papier. in-4" de $30 \mathrm{fr}$. Archives dép. des Basses-Pyrénées, H 147. Dates extrèmes : $94 \overline{5}-1718$.

35̆63. - Autre [fraumenl]. écrit en I769, sur papier, in-40 de $333 \mathrm{fr}$. Arclices dip. des Huntes-Pyrénées, H non coté.

Cf. le vol. XI des Glanages de Larcher (copies de 1765), à la Biblioll. de la ville de Turbes.

Pcbi.. : Cartulaire des Bénédictins de Saint-Savin-de-Lavedan 945-1175, par Ch. Durier. Tarhes. Latrolse, 1880 ; in- $8^{\circ}$ de vin48 p. [Société des Beaux-Arts de T'arbes.]

Saint-Seine. - Abbaye (dioc. de Langres).

35̆64. - Cartulatre de lahblaye de St-Seine; ms. du XIII siècle, sur parchemin avec reliure de cuir gaulfé. contenant 86 actes des IX'Xllle siècles. in-4" de $186 \mathrm{HI}$. (Archives dép. de la Cöte-d'Or, H 165).

Copie dı XVII' siècle, par Bouhier, in-40 de 105 p. (Biblioth. matiounle. ms. batin 17085).

Autre copie du XVIII siècle, in-40 de 81 11. (Biblioth. nationale, m.. latin 9874 .

3565. - Autre cartulaire de l'abbaye de Saint-Seine ; orig. perdu.

Copie faite an X YIII" siècle, par D. Anbrée Biblioth. mationale, ms. lintin 1:28:24, ff. :310-.519.

Saint-Sever. - Abbaye (dioc. d'Aire).

3566 . - Vienx cartulaire de Saint-Sever; org. perdu.

Nous en conuaissons l'existence par une lettre transerite par Pithou d'un " vieil chartulaire du monastère de Saint-Sever " au XVII'siècle (Biblioth. de la ville de Carpentras, ms. 1782, fo 41 ). - . Cf. Biblioth. de lo ville de Tarbes, Glanages de Larcher, XXI (1750), pp. 252-261.

3567. - Fragment d'un cartulaire de l'abbaye de Saint-Sever; ms. du

$\mathrm{X} \mathrm{Yl}^{\mathrm{e}}$ siècle; sur parchenin, in-4 ${ }^{0}$ de $18 \mathrm{ff}$. (Archives dép. des Landes, $\mathrm{H} 5$.

3568. - Frament d'un antre cartulaire de Saint-Sever; ms. rédigé an $\mathrm{XVI}^{\mathrm{e}}$ siecle [1580], par Bernard Dabadie, nolaire royal, sur papier. in-12 de vin-83 If. (Archives dép. des Landes, H 14).

3569 . - Antre recueil du XVIII siècle; ms. sur papier, in-40 de $14 \mathrm{ff}$. Archices dép. des Landes, $\mathrm{H} 237$. 
3570. - Píbl. : Fixlrail du petil cartulaire de labbaye de Saint-Sever. par Paul Raymond Bibliothèque de l'Érole des Chmoves, XXXIII. 1872. p. $28: 3-28 \%$

Contient un acte de 1120 , extrait d'une histoire de labbare do saint-

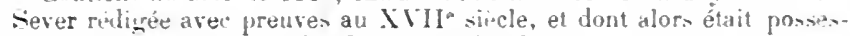
seur l'abbé Luygat, curé de Villeneure-de-Marsan.

Saint-Séverin-en-Condroz. - Prieuré dince de Liègej.

3571. - Publ. : Doruments concernant le prieuré de Saint-Séverinen Condroz. par Joseph Halkin Comptes rendus de lu Conmission royale d'histrive te Belgique, 5e série, IV. 1894, pp. 165-192.

Saints-Maurice-et-Lazare. - Orlle militaire.

35̃2. - Pubı. : Bullarium sen litteræ Romanorum puntificun pertinentes ad sacram religionem et ordinem militarem D. Mauritii el Lazari... Augnstæ Tanrinorm, s. d. [1778], in-folio.

Il $\mathrm{y}$ avait eu précédemment deux autres recurils imprimés; cf. Ant. Manno, Bib iografin storica degli Stati de la momarline di Saroia. I (1881), no 2691 .

Saint-Sulpice-en-Bugey. - Abbaye (dioc. de Belley).

3573. - Cartulaire de liallaye de Saint-Sulpice en Burey: ms. du XIII siècle. sur parchemin, in- $8^{\circ}$ de $16 \mathrm{ff}$. Arrhives dëp. de la Coled" Or, B $1165 ; 3$.

Publ.: Petit cartulaire de l'ahbaye de Saint-Sulpice en Burey, par I.-C. Guigrte. Lyon. Mougin-Rusand. 1884 ; in-8 de Ix-198 p.

Date-estrènes : 977-1429 (pp. 1-2\%). Cf. du mème auteur une notice de 23 chartes dans la Rexue des Sycipos sazailes, 1872, pp. 299-3117.

\section{Saint-Sulpice-la-Forêt. - Abbay (dioc. do Pennes).}

3574. - Cartulaire de labbaye de Saint-Sulpice-la-Forêt; ns. du XVIIe siecle. wr parchemin, contenant 40 actes des XIJe-XVI siècles, in-folio de $23 \mathrm{fr}$. Biblinth. de lis rille de Renues, ms. 27:3.

3574 bis. - Publ. : Cartulaire de labbaye de Saint-Sulpice-la-Forèt. par P. Anger 'Bulletin ot Wémoires de ln Sociétr' urchéologique d'Ille-etVilaine, XXXIV, 1905. p. 165-262, et XXXV, 1906, p. 325-388; à suivre).

Saint-Thibaut-en-Auxois. - Prieuré (Hioc. Al'Aun).

3575. - Cartulaire du prieuré de Saint-Thibaut-en-Auxois: us. du Xle siècle, sur parchemin, in- $4^{\circ}$ Bithlioth. de M. Ernest Petit, au château de Yausse, Yonnel.

Saint-Thibéry. - Abbaye (dioc. l’Agle).

3576. - Cartulaire de l'abbaye de Saint-Thiberry ; uriy. perdu.

L'existence de ce manuscrit m'est connue par un extrait d'acte $d \rightarrow$ 
1134 à propos diun ditférend avee labbaye de La Chai-e-Dieu (Biblooth. nationale, coll. Baluze, vol. VII, lo 5iz).

3577. - Recueil de titres relatifs a l'ahlatye de Saint-Thibéry, fait en

1679 par Dom Fistiemot Biblioth. dutionule, ins. latin 12760 , p.. 385-408).

Saint-Trond. - Ibbaye (dioc. do Liège).

3578. - Cartulaire de lahbaye de Saint-Trond : ms. dla XIII siècle, sur parchemin. contenant des actes à partir llu XI'. in $-4^{0}$ de $2: 34 \mathrm{HF}^{\circ}$. Biblioth. de l'Unirersité de Liègr, 111s. 268

3579. - Antre cartulaire: ms. In XIII siècle. avec additions du XIVe, sur parchemin. contenint des actes de 1161 il 1262 , in $-8^{0}$ de 24:3 fi. (Archives de l's tut à Hasselt).

3580. - Autre cartulaire; ms. dı XIVe siècle [1:372], sur papier, avec quelques additions postérieures, contenant des actes depuis le $\mathrm{XI}^{\mathrm{e}}$ siècle, in-40 de $169 \mathrm{ff}$. Biblinth. de l'Université de Liège, $\mathrm{ms}$. 266 .

3581. - Cartulaire de la pitancerie de l'ahbaye de Saint-Trond; ms. des XIVe-XVe siecles, sur parchemin, contenant 1333 actes de 1281 i) $139: 3$, in- $4^{0}$ de $116 \mathrm{fr}$. avec table finale te $7 \mathrm{ff}$. sur papier, British In'senm. adhlitional ms. 25054).

3582. - Antre cartulaire : ms. du XVIe siècle, sur parchemin contenant des atces de I107 i 1577. in-folio ale $304 \mathrm{ff}$. Archires de l'Etat ì Itrsselt:

358:3. - Antre cartulitire: ms. du XVIe siècle, sur papier, contenant

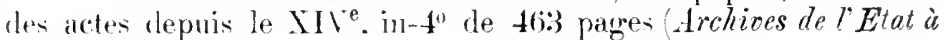
Husselt :

3584. - Autre cartulaire: ms. des $\mathrm{XVI}^{\mathrm{e}}-\mathrm{XVII}^{\mathrm{e}}$ siècles, sur papier, (s)ntenant des actes de $11: 31$ a 1:397, in- $8^{\circ}$ de 100 pages (Archives de l'Etut ù Hasselt .

3585. - Autre cartulaire; ms. des XVIe-XVIII siècles, sur papier, contenant des actes de 1141 a 177\%, en 6 vol. in-folio (Archives de l'Elut à H(ussplt).

3586. - Autre cartulaire: ms. du XVIII siècle, sur papier, contenant des artes de 1288 i 1595 , in-40 de $39 \mathrm{ff}$. Archices de l'Etat à Ilisselt.

3587. - Autre cartulaire; ms. du XVIII ${ }^{e}$ siècle, sur papier, contient des actes de 1:261 à 1615 . in-4 de 389 pages (Archizes de l'Etat à Hasselt .

3588. - Antre cartulaire: ms. du X VIIIe siècle, sur papier, contenant des actes de 1140 i 1605 , in- $4^{\circ}$ de 429 pagres Archires de l'État à Hasselt). 


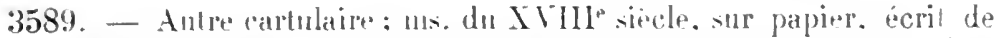
differenter mains. et contenant des arter de 1192 a 1744 , in- $4^{\circ}$ de 200 paures (Arehices de l'Etul ì Hasselt.

3590. - Autre cartulaire: ms. du XVlle siècle, sur papier. érit par differentes mains. contenint des actes de I:391 a 1780), in-4" de 245 pares Archices de l'Étut is Husselt'.

3591. - Purt. : Cartulaire de labbaye de Saint-Trond 74l-I366, par (ih. Piot. Bruxelles. Hayez. 1870-1874: 2 vol. in-4" de 68:2 et cxix-668 p. [Collection des Chroniques belires inédites.]

Saint-Trond. - Hòpital.

3592. - Cartulaire de l'hòpital de Saint-Trond; nus. dn XV'e siecle, sur parchemin. contenant des actes de 1210 a 1440 , in-fulio de $39 \mathrm{ft}$. Archives de l'Etut à Husselt.

Saint-Trond. - Ville.

3393. - Cartnlaire de la ville de Saint-Trond: ms. dn XVII siècle, de mains différenles. sur papier, contenant des actes de I:304 a I669, in- $4^{0}$ de 506 pages Archives de l'État is Hosselt.

3594. - Autre cartulaire du $\mathrm{XVI}^{\mathrm{e}}$ siècle. de mains diffërentes. sur papier, contenant des actes de $\left[280\right.$ a 15.51 . in- $4^{0}$ de 4.00 pages Archices de l'Etat is Hasselt.

3595. - Autre cartulaire tes $\mathrm{XVI}^{\mathrm{p}}-\mathrm{XVII}^{\mathrm{e}}$ siècles, sur papier. contenant des actes de 1060 it 1693. in-4" de $186^{\circ} \mathrm{fr}$. Arrices de lFint is Hasselt).

Ces deux derniers recueils contienntent spécialenent les actes relatifs aux droits respectifs de l'érêché de Liènt et de l'abbayede saint-Trond sur la villte.

Saint-Tropez. - Ville.

3596. - Cartulaire municipal de Saint-Tropez: ms. du XVIII siecle, sur papier. contenant des documents depnis 980, in-folio de 202 pages Archires muicipules de Saint-Tinper. At 1.

Saint-Valery-sur-Somme. - Abbaye (dioc. d'Amiens).

359\%. - Cartulaire de labblaye de Saint-Valery : origr. perdu [avait au moins 299 pagres].

Extraits faits an XVII siècle par D. Rupert de Bournonville (Biblioth. nationale, ms. latin 12704. ff. 156-201).

3598. - Recueil de titres concernant la mème abbaye, fait au XVI" siècle daprès les originaux Biblioth. intionale. Ins. latin 12701, If. $170-201$ et $2: 3: 2-2.53$.

35̆99. - Antre recueil du mème temps 'Idem, coll. Baluze. vol. XLVII, ff. I94-20\%). 
Saint-Vallier. - Abbaye (dioc. le Valenıe).

3600. - Publ. : Cartulaire de Saint-Vallier, on relevé des chartes et documents concernant son abbaye, ses seigneur's et ses habitants, par A. Caise. Paris, Dumoulin [Valence, Combier], 1870; in- $8^{\circ}$ de 167 p. et pl.

Saint-Victor-en-Caux. - Abbaye (dior. do Rouen).

3601. - Publ. : Recueil de chartes concernant labbaye de SaintVictor-en-Catx, par Ch. de Robillard de Beaturepaire (Mélanges publiés par la Société de l'histoire de Normundie, 5 ${ }^{\mathrm{e}}$ série, 1898, p. $333-437$.

Recueil factice de pièces des années 1137 à 1310 .

Saint-Vincent-au-Bois. - Abbaye dioc. de Chartres). 3602. - Cartulaire de Saint-Vincent-au-Bois ; orig. perdu.

Il fut communiqué à Du Cange en 1655 par M. Vyon d'Hérouval et appartenait alors à Galland. Le P. Lelong (édon Fevret de Fontette, III, $n^{\circ} 29713$ ) le cite également.

Fxtraits faits par Du Cange an XVII siècle Biblioth. del'Arsenal, ms. 5260, ff. 135-137; et Biblioth. nationale, ms. français 9498; pp. 264-268).

Saint-Vivant-sous-Vergy. - Pricuré (dioc. d'Autun).

3603. - Cartulaire du prieuré de Saint-Vivant-sous-Vergy; ms. du XIVe siècle, contenant 98 actes des années 1200 à 1330 , sur parchemin, in-4 de $39 \mathrm{ff}$. (Archives dép. de la Côte-d'Or, H non coté).

Saint-Wandrille. - Abbaye (dioc. de Rouen).

3604. - Cartulaire de l'abbaye de Saint-Wandrille; ms. des XlIIX VI siècles, sur parchemin, contenant plus de 2500 pièces des années 1204-1773, in-folio de 337 ff. (Archices dép). de la Seine-Inférieure, $\mathrm{H}$ non coté).

3605. - Cartulaire dn $\mathrm{XIV}^{\mathrm{e}}$ siècle, avec quelques additions postérieures. sur parchemin. contenant 161 actes de l'année 854 à 1500 , in-folio de $117 \mathrm{fl}$. (Bibliolh. nationale, ms. latin 17132).

Ce volume, qui provient de la vente du narquis Le Ver $\left(n^{0} 49\right.$ du catalogue), est remarquable par sa magnifique reliure originale du XVle siécle, en maroquin à coins, avec garniture en cuivré ciselé et fermoirs de cuir.

3606. - Cartulaire du $\mathrm{XVll}^{\mathrm{e}}$ siècle, en 4 vol. in-4 ${ }^{0}$ sur parchemin, contenant plus de 2500 acles (Archives dép. de la Seine-Inférieure, $\mathrm{H}$ non coté).

3607. - Cartulaire des $\mathrm{XV}^{\mathrm{e}}-\mathrm{XVI}^{\mathrm{e}}$ siècles, sur parchemin, contenant 
373 pièces des années $1 \cdot 227-1502$, in- $4^{0}$ de 333 tí. (Archires dép. de lus Seine-Inférieure, $\mathrm{H}$ non coté).

3608. - Cartulaire daté de 1649, sur parchemin [incomplet à la tin], contenant 90 pièces des années 1273-1649. in- $4^{\circ}$ de $258 \mathrm{ff}$. (Archices dép. de la Seine-Inférieure, $\mathrm{H}$ non coté).

Copies faites pour Gaignières an XVIII siècle, sur papier. in-fulio de $207 \mathrm{ff}$. (Biblioth. nationule. ms latin 5425 .

Extraits (Biblioth. nationale, coll. Baluze, vol. XL. pp. (97-10:2, et IVIII, pp. 86-101 : - ms. nouv. acq. françaises 7454. II. :34 vo69; coll. Dom Grenier. vol. CXI. ff. 206-207).

Saint-Yrieix. - Voy. Axgoulème (abb. de St-Cybarl).

Salanques. - Abbaye (dioc. de Rirux).

3609. - Recueil de chartes relatives à l'abbaye de Salanque.. lait an XVII siècle par Ö̈henart Biblioth. nationule, coll. Ducherne. vol. C.XVIII. If. 19-31).

Salertaine. - Prieuré de Saint-Martin (dioc. de Luçın).

3610. - Publ. : Cartulaire des prieurés de Marmoutier en Bas-l'uitun, par Paul Marchegay, dans: Cartulaires du Bas-Poitou La Rochesur-Yon, 1877, in-8 $\%$, p. I-xxiv et 61-2:25.

Salettes. - Chartrense (dioc. de Grenoble).

3611. - Cartulaire de la Chartreuse de Salettes : ms. du XY'II -iècle, contenant des actes des années 1299-1655, sur papier, in-folio de $55 \mathrm{ff}$. (Archives dép. de l'Isère. H 831).

Salins. - Église collfrgiale Saint-Maurice (dioc. de Besançon).

3612. - Cartulaire de Saint-. Yaurice de Salins; ms. du XVIIle siècle, collationné par $\mathrm{M}^{\mathrm{A}} \mathrm{A}$. I. L'Inglois, contenant 13 pièces des années 1198-1738, sur papier, in-folio de $42 \mathrm{ff}$. (Arclices dép. du Jura, G $1: 299$.

3613. - Autre du XVI siècle, contenant 7 pièces des années 11981430, sur papier, in-folio de $60 \mathrm{ff}$. (Archires dép. du Jura. (; 1300).

Salins. - Église Saint-Anatole.

3614. - Cartulaire de l'église Saint-Anatole de Salins; ms. du Xillo siècle arec additions du XIVe, sur parchemin, in-40 de $5 ! 1 \mathrm{ft}$. (Biblioth. de la rille de Besançon, ms. 728,.

Salins. - Ville.

3615. - « Cartularium Salinense »; ms du XVIII siècle, réuni par Jules Chifflet, sur parchemin et papier, de diverses mains. contenant 
des actes des XIII ${ }^{\mathrm{e}}$-XIVe siècles, in- $4^{0}$ de vin-112 ff. Biblioth. de la rille de Besauron, coll. Chifflet, ms. 42 .

Salival. - Abbaye (dioc. de Metz).

3616 . - Cartulaire de l'abbaye des Prémontrés de Salival; ms. du XVIIle siècle, sur papier, contenant des documents depuis 1172, sur papier, en 3 vol. in-folio de 533. 540 et 527 ff. (Avchivess dép. de

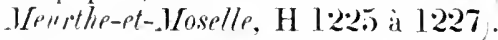

\section{Saluces. - Narquisat.}

3617. - Recueil de titres relatifs an marquisat de Saluces considéré comme dépendance du Dauphiné; ms. du XV'le siècle, sur papier, contenant des actes de 1063 à 1549 , in-4 $4^{0}$ de $18 \mathrm{fr}$. Archioes dép. de l'Isère. B 385:3.

3618 . - Recueil de pièces et d'extraits relatifs an marquisat de Salnces : ms. du XVIIe siècle, sur papier, in-4" (Biblioth. nationale, ms. français 16923 . ff. 29-3337.

Dates extrèmes : 1169-15:36. - Cf. aussi le manuserit no $\mathrm{n}^{0} 1692 \%$.

Salzinnes. - Abbayr du Val-Saint-Georges (dioc. de Namur).

3619. - Cartulaire de l'abbaye du Val-Saint-(ieorges; ms. du XIVo siècle, sur parchemin, contenant des actes de 1293 i 1302 , in-4 $4^{\circ}$ de $39 \mathrm{ff}$. (Archires de l'Etat à Namur).

36:0. - Autre cartulaire; ms. icrit en 1673, sur papier, contenant des actes de 1205 à 1562. infolio de $157 \mathrm{ff}$. (Archives de l'Etat à Vamur).

3621 . - Antre cartulaire; ms. écrit en 174l. sur papier, contenant des acles de 119.5 i 17:38, in-folio de 250 ff. (Archives de l'bitat is Pinur.

Pebl. : Documents concernant l'abbaye du Val-Saint-Georures Aunlectes pour servir à l'histoire ecclésiastique de lu Belgique, IV, 1867 , p. 75-86; VII, 1870 , p. 115-128; et XVI, 1879, p. 328$: 34: 2$.

Dates extrêmes: 1219-1358. Lets documents sont empruntés à un cartulaire conservé au château de Dhuy.

Samer. - Abbaye. - Toy. Boulonnals.

C.f. E. Rigaux, Tote sur quelques chartes de Samer et examen critique (Bulletin de la Sociéte academique de Boulogne-sur-Her, VI, 1904, pp. 361-369). - Cet examen porte sur les chartes publiées par l'abbé Haigneré.

Sampigny. - Châtellenie.-Voy. Norroy-Le-SEc et Trogron.

San Cugat del Vallés. - Abbaye (dioc. dr Barcelone). 3622. - Cartulaire de laabaye de San Cucufate ou San Cugat; 
ms. du XIlI siecle, sll parchemin, in-folio Arehico de la Cornna ¿Aragon, Barcelona!.

Extrait fail pour Baluze an $\mathrm{XVII}^{\mathrm{e}}$ siècle Biblinth. nationale, coll. Baluze, vol. CVIII. fo 236 .

Sancy. - Prévòté en Lorraine.

3623. - Recueil de titres relatifs à la prévôté de Sancy: ms. de la fin du $\mathrm{XVI}^{\mathrm{e}}$ siècle, formé par Thierry Alix. sur papier, contenant des titres de 894 à 1583 , in-folio de $392 \mathrm{ff}$. Archires drip. de Wenrthe-etMoselle, B 393).

Copie du précédent. faite an XVIJ siècle. sur papier. in-folio Archives dép. de lu Meuse, B 253.

Sarreguemines. - Voy. Bollay.

Saulieu. - Église (dioc. d'Autun).

3624. - Cartulaire de l'égrlise Saint-Andoche de Saulieu ; orig. perdu.

Le P. Lelong (édon Ferret de Fontette, III, n 29712) l'indique comme existant dans la bibliothyue de M. de La Mare, à Dijon.

Saumur. - Voy. Sant-Florext-LES-SAUMUr.

Saunières-Mézières. - Voy. Marollles.

Sauqueville. - Église collégiale (dioc. de Rouen).

3625. - Cartulaires de l'église de Sauqneville; ms. du XIII siècle, en

forme de rouleaux de parchemin. l'un mesurant $0^{\mathrm{m}} 42$ sur $0^{\mathrm{m}} 22$. l'autre $^{\circ}$ $0^{\mathrm{m}} 31$ sur $0^{\mathrm{m}} 28$ (Archives dép. de ln Seine-Inférieure, Gr non coté).

Sauvelade. - Abbaye (dioc de Lescar).

3626. - Cartulaire de l'abbaye de Sanvelade; orig. perdu.

A été utilisé par Marca et Oihenart.

Extraits faits an XVII siècle par Oïhenart (Biblioth. nationale, coll. Duchesne, vol. CXIY, ff. 36-46.

Sauxillanges. - Abbare (dioc. de Clermont).

3627. - Cartulaire de l'abbaye de Sauxillanges : orig. perdu.

Copie du $\mathrm{XVII}^{\mathrm{e}}$ siècle, sur papier. contenant 960 pièces des $\mathrm{IX}^{\mathbf{e}}$ XII ${ }^{\mathrm{e}}$ siècles, de $189 \mathrm{ff.}$ in- $4^{\circ}$ Biblioth. nationale, ms, latin 5454 .

Autre copie du XVII siècle, de $529 \mathrm{ff}$. Archices nationales, LL 1014).

Extraits faits par Dom Estiennot en 1676 (Biblioth. nationale, ms. latin 12745 , pp. $516.532-534,567,6505,612-614$ et 631 ; mis. latin 12750 , p. 174, pour Baluze (Idem, coll. Baluze, vol. LXXXVI).

Pcbl. : Cartulaire de Sauxillangres, par Henry Doniol. Clermont. 
Thibaud [Paris. Dumoulinr], 1864; in-4" de $740 \mathrm{P}$. [Académie des sciences, helles-lellres el arts de Clemont-Ferrand.]

Cif. : Rapport sur le eartalaire du hiauxillanges, par Léopold Delisle

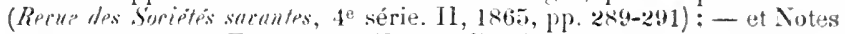
historifues, Saint-Etienm-sur-Lsson, dapress ls cartulaire de Sauxillanges, par Alb. Lasmaris (Paris, Larose, $1904:$ in-8 de 127 p).).

Saverne. - Couvent des Ricollets (dioc. de Strasbourg).

3628. - Recueil te titres relatils aux Récollets de Saverne; ms. de

177\%, formí par cirndidlier d'après leur's archives, sur papier, infolio Grossheragl. Landesurchic in Karlsmhe, Nachlass Grandidiers).

Saverne. - Eglise colligiale.

3629. - «Antiqum chartularinm ecclesiæ Tabernensis »; ms du XVI siecle, orin. perdu.

A été abondamment utilisé par (irandiclier, dans son Histoire de

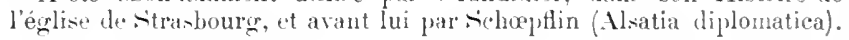

Saverne. - Villir.

3630. - « Sladthuch » un cartulaire municipal de Saverne: ms. du XVte siecle?, in 4" (Arehires mmicipales de Sureme).

Savigny. - Abbaye (dioc. d'Aranches).

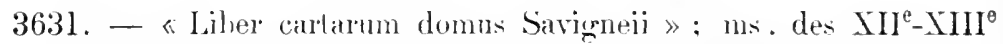
viècles, contenant 679 pièces des ambes $1082-1232$, sur parchemin, infolio de $178 \mathrm{ff}$. Archices dép. de la Manche, $\mathrm{H}$ non colé).

Copie du cartulaire re labbaye de Saviony ; ms. du XIX siecle, sur papier, de 221 pagres infolio (Biblioth. Cheltenhum, $\mathrm{n}^{0} \cdot 21188$ ).

C.f.: Un prétendu cartulaire de l'abbaye de Savigny, par Léopold Delisle Biblinthèque de l'Ecole des Clurites, XXXV. p. 323-324; et

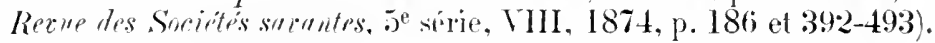

Cif. le ms. latin loozs de la Bibliotheque nationule, pp. 1-139 et $173-255$.

3632. - Cirtulaire de Savigny pour le Maine; ms. dn XVII' siècle, sur parchemin, contenant dés llocuments (groupés par possessions) de 1137 a 1517 , in-folio drchives dép. de la Munche, H non coté).

Cit. : Charten et titres concernant les possessions de l'abbaye de Savigny it Angerset dans ses environs, par P. Marehegay (Mémoires

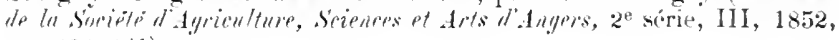
Pp. $22(1-241)$.

Savigny. - Abbayr (dioc. de Lyon).

36:33. - Cartulaire de labbaye de Savigny; ms. du XII siècle [contenant 960 chartes depuis le $\mathrm{X}^{\mathrm{e}}$ siecle] : orig. perdu.

Copie du précédent, faite à la fin du XVI siècle, sur papier, in-4 de 30 et $160 \mathrm{fr}$. Bibliath. de la ville de Lyain, fonds Coste, ms. 392). 
Autre copie du XVII secle, in-folio de libl fi. Biblinth. mationale, ms. latin 100:35).

Antre copie des $\mathrm{XVII}^{\mathrm{e}} \mathrm{XVII} \mathrm{I}^{\mathrm{e}}$ siocles, in-folio B Bithoth. He la ville de Lyon. 11s. [49].

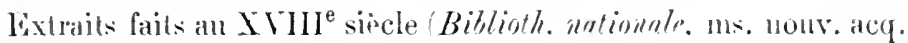
frangaises $7+25$. ff. $195-279$ ).

Pér. - Cartulaire de labbaye de Savienny, snivi du petit cartnlaire de l'abbaye d'Ainay, par Anguste Bernard. Paris. impr. inperiale, 185:3 : in-1" de cxx-1167 p. [Collection des Documents inédits.]

Savoie. - Durhé.

3634, - Re ristre des privilères des Genevois-Semunas, ducs de Savoie; ms, du SVIJ siècle [l6Lt]. sur papier. recouvert d'une reliure ganfrie anx armes de Savoie. contenant des actes de 1.j) 14 is 1609 , in-4" de :322 pages Archices dép. de lu Hautr-Sacoie, A 8 .

3635. - Recueil de privileres et docments politiques de lat maison de Savoie; ms. du X III $^{\mathrm{e}}$ siecle, sur papier, contenant destitres de 1154 à 1587 , in-to de $160 \mathrm{ff}$. (Archices dép. de la Haute-Sucoie. A 1 ). 36:36. - Cimtulaire de Sarvie: ms. dn SIV siecle [1:314], sur parchemin, relié en maroquin aux armes de Colbert, et contenant des documents des années 1262-1:309. in-4" de 17:3 fl. Biblioth. nationsle, ms. latin loI:29.

Vuir aussi Farchisy et Gexhers.

Savoie. - Etablissements religieux.

363\%. - Cartulaires des couvents de Savoie ; ns. du XVIe siècle, sur papier. contenant des textes depuis le $\mathrm{XI}^{\mathrm{e}}$. relativement an droit de patronage des ducs de Savoie sur les établissements religienx de Savoie. 2 rol. infolio Archivio de Corte, ¿ Turin. Bénefices, Mélanges. paq. 1t.

Intéressent particulierenent Abondance, Airuebelle, Aillon, Annecy, B.llevaux-en-Banges, Chambéry, Entremont, Hautecombe. L*' Bouryet, Les Échelles, Melan, Peillonex, Saint-Jean-d Aulps, Saint-Jean-d.Nlaurienne.

Sceaux-en-Gâtinais. - Village (dioc. de sons).

3638. - Petit cartulaire de Sceaux-en-Gâtinais, dépt du Chapitre de Saint-Lonis-dn-Louve; ms. du comm. du XVII siècle, sur papier. avec table finale, in $4^{0}$ de $25 \mathrm{fl}$. (Archires nationales. S 1877.

Copie du mème, par le chanoine J. Charles Carpentier, en 1779. sur papier, in-folio de $28 \mathrm{ff}$. (Archives mationales, S $188 \%$.

Dates extrêne's: 1153-1362. 
Scellières. - Abbaye de Notre-Dame (dioc. de Troyes. 3639. - Cartulaire de l'abbaye de Scellières; ms. du Xllle siècle [mutilé], avec additions jusqu'an $\mathrm{X} \mathrm{V}^{\mathrm{e}}$, sur parchemin, in-8 $8^{\circ}$ de $65 \mathrm{fr}$. Biblioth. de la ville de Troyes, ms. 2290).

Dates axtrènes: 1153-1474.

3640. - Autre du XVI ${ }^{\mathrm{e}}$ siecle, in-4", sur papier, de $23 \mathrm{ff}$. Lrchives dép. de l'Aube, $\mathrm{H}$ non coté).

Axal. : Analyse des chartes de l'abbaye de Scellières, par L. Le clert Mémoires de la Société acudémique de l'Aube, LXVI, 1902, pp. 258-308:

Scheut. - Couvent des Chartreux (dioc. de Malines). 3641. - Cartulaire des Chartreux de Schent; ms. du XVe siècle, sur parchemin. contenant des actes de 1:260 is 1442 , in $-4^{0}$ de $26 \mathrm{ff}$. (Archives du royaume de Belgique, à Bruxelles).

3642. - Aulre cartulaire du XVe siècle, sur papier. avec additions du $\mathrm{XVl}^{\mathrm{e}}$, in-4 $\mathrm{4}^{0}$ de $357 \mathrm{ff}$. (Archives du royume de Belgique. à Bruxelles).

Schœnensteinbach. - Courent (dine de Bâle.

3643. - Cartulaire du couvent de Schœnenstemback; ms. du

XV1 siecle [15.50]. sur papier. in-40 de $9 \mathrm{fr}$. (Archiv des OberElsuss, in Colmar).

l)ates extremes: 1396-1498.

Schooten. - Chartreuse (dior. de Malines).

3644 . - Cartulaire de Schooten, dépendance de l'abbaye de Villers; ms. dı X'III ${ }^{e}$ siècle. sur papier. contenant des actes de 1160 à 1761. in-folio de 210 pages Archires du royaume de Belgique, à Bruxelles.

Seclin. - Église collégiale Saint-Piar (dioc. de Tournai). 345 .5. - Cartulaire de la collégriale de Seclin [sur parchemin de $8 \mathrm{ff}$.], orig. perdu.

A été vu par Dom Queinsert en 1777 (cf. une bulle transcrite, Biblioth. nutionale, coll. Moreau, vol. 99, to 178).

Seclin. - Hôjital Notre-Dame.

3646. - Livre rouge de l'hôpital de Seclin ; ms. de l'année 1638, rédigé par Hugues Beeckman, abbé de Cysoing; orig. perdu [de 850 pages in-lolio].

Il en existe une copie de la table (Archives hospitalières de Seclin, liasse 164).

3647. - Fragment de l'ancien cartulaire; ms. du XIVe siècle, sur parchemin. de 8 ti. (Archives hospilalières de Seclin, liasse 99).

Publ. : Chartes françaises du XIII ${ }^{\ominus}$ siècle tirées des archives de 
l'hopital de Seclin, par J. L'Hermitte (Rerue des langues minanes, XLI, 18!8, pp. 381-397). - Cf. Mémoires de la Sraciété d'émulation de Roubaix, te série, IV, 1905, p. 9.

Sedan. - Principatuté.

3648. - Publ. : Privilèges de la souveraineté de Sedan. Sedan, 1669 , in $-4^{0}:-1721$, in $-4^{0}$.

Sées. - Abbaye de Saint-Martin.

3649. - Cartulaire ou livre blanc de l'abbaye de St-.llartin de Sies: ms. du XIVe siècle, sur parchemin, in-4" de $138 \mathrm{ff}^{\circ}$. (Biblisth. do l'évêché de Sées.

Copie du mème; ms. sur papier. contenant des titres do 1060 à 1216, in-folio de t5 ff. Archices dép. de l'Orne. H 938,

Copie faite en 1747. sur papier, in-folio de 105) ff. (Biblioth. de la ville ditenron, ms. 190 .

Extraits du même faits an XVII siècle (Biblin/h. malionale. ms. latin 13818, ff. 20l-208).

Aux ff. 198-201 du nême volume, un truure des extraits d'un "cartularium rubrums. Martini Sagiensis", qui ne parait plus exister.

Sées. - Chapitre cathélral saint-Gervais.

3650. - Livre rouge de l'écrlise de Sées: ms. du XIIJ siècle, sur parchemin, de plusieurs mains, in-4" (Biblioth. de l'recelté de Sées).

Acheté par Mgrr. Ruusselot, évêque, vers $186 \%$.

Extraits du précédent: ms. du XIX e siècle [1859]. sur papier, in- $4^{0}$ de $75 \mathrm{ff}$. (Biblinth. nationale, ms. latin 110.58 .

Les transcriptions ont été faites à Paris par des copistes peu "sperimentés : aussi portent-elles des corrections de la main de II. I éupold Delisle. Les date extrêmes des chartes sont 1022-1297.

365l. - « Copies de titres du chartraire de léglise cathédrale de Sées » : tome I, rédigé en 1633, sur papier, in- $4^{\prime \prime}$ de 488 Ii. (Biblioth. de la ville it Alencon, ms. 177).

Ségur. - Prieuré (dioc. d’Albi).

3652. - Chartes du prieuré de Ségur (Tarn), du XI a au XIII ${ }^{\mathrm{e}}$ siècle [1058-1243], publ. ou annotées par Edm. Cabié. Albi, Nouguies, 1889 ; in- $4^{0}$ de 37 p. [Supplément à la Recue du Turn.]

Dapres le vul. 193 du funds de Languedoc (Biblioth. nationale) et diverses autres suurees.

Seillon. - Chartreuse (dioc. (le Lyon).

3653. - Cartulaire de la chartreuse de Seillon ; vrig. perdu.

Existait au XVII siecle: Guichenon, dans son Histoire de Broso (1650), p. 9. en donne un extrail. 
Sele. - Prinuede dr Saint-Pierre (diof. de Chichestrer).

3654. - Cartulaire du prieuré anglais de Saint-l'ierre de Sele, dépendant de l'ablaye de Saint-Florent de Sammur' ms. des XIII siecles, sur parchemin, avec relinre primitive en hois reconvert de pean de daim, contenant 153 chartes des $\mathrm{XI}^{\mathrm{e}}-\mathrm{XIV}^{\mathrm{e}}$ siecles, in-40 71 fr. (Library of Madeleine Collegr, Oxforll.

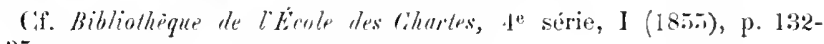
135.

Selincourt. - Abbaye de Saint-Pierre (dioc. d'Amiens).

3655. - Cartulaire de l'alhaye de Saint-P'ierre de Selincourl : ms. des

XII ${ }^{e}-\mathrm{XIII} \mathrm{e}^{\mathrm{e}}$ siècles, sur parchemin, in-t"de $72 \mathrm{ff}$. Bibliotl. de la ville d'Amiens, ms. 528.

3656. - Antre du $\mathrm{XVI}^{\mathrm{e}}$ siècle, sur parchemin, in-folio de $51 \mathrm{ff}$. (Biblinth. de ln ville d'Amiens, ms. 778).

Selles-sur-Gher. - Abbayr de Notro-I)ame (tioc. de liourgesi).

3657. - Cartulaire de l'abbaye de Selles-sur-Cher ; orig. perdu.

Une mention en existe dans le ms. latin 12742 de la Biblioth. mationule, p. 192.

Semoy. - Prieuré (dioc. d'Orléans).

3658. - Recueil de chartes relatives au prienré de Semoy, dépendant

de lialbaye de la Sarve-Ilajemre; copiées sur le cartulaire de cette ahlare en 1682 par Dom Listiennot (Biblioth. nationale, ms. latin 12739, pp. $4+1-448$.

Semur. - Église collegiale Notre-Dime (dioc. d'Autun).

3659. - Cartulaire de la chapelle Saint-Lazare en l'église Notre-Dame de Semur: ms. des $\mathrm{XVI}^{\mathrm{e}}-\mathrm{X}$ VIII ${ }^{\mathrm{e}}$ siècles. contenant 60 actes des années lol7-1724, sur papier, in-8 de $90 \mathrm{ff}$. (Archives dép. de la Cate-r'Or, ( i non coté).

Semur. - Prieurẻ de saint-Jean.

3660. - Cartulaire dı prieuré de Saint-Jean de Semur : ms. du $\mathrm{XVI}^{\mathrm{e}}$ siècle, sur papier, contenant 64 pièces des années I180-1450, $\mathrm{in}_{11} \mathbf{4}^{0}$ de $16 \mathrm{ff}$. (Archives dép. de la Côte-d'Or, $\mathrm{H}$ non coté).

Senlis. - Abbayo de Saint-Maurice.

3661. - Cartulinire de Saint-Manrice de Senlis; ms. des XIII'-XIVe siecles, sur parchemin, de $50 \mathrm{ff}$. in-folio Biblioth. Cheltenhim, $11^{\prime \prime} 7110$. 
Senlis. - Abbaye de Saint-Tincent.

366:. - Recueils de titres de l'abhaye de Saint-Vincent de Senlis ; orig. perdus.

A défaut de carlulaires, il existait plusieurs recuroils au XVIII siecle (cf. le répertoire les titres de l'abbaye, Archices matimules, I. I. 1470). (if. Biblioth. nationate, coll. Baluze, vol. XI.TII, ff. 219-225).

Senlis. - Egrise Notr-1)ame.

3663. - Cartulaire de Notre-Dame de Senlis; mis. de 120 ff., sur parchemin, relié en buis : orizir. perdu.

Copies faites par le chanoine Afforly an XVille siecle Biblioth. de la rille de Senlis.

Les pages 6-10 et suiv. du tome I de la cullertion Afforty semblent eilpruntées it un autre cartulaire moins ancien.

Exurails laits an XVIIe siècle Biblisth, nutionale, cull. Duchesne, vol. XXV, ff. 38-39, et LXXV11, ff. 38-41; ms. latin 17049, pp. 443-453).

Ax.uL. : Analyse du cartulaire, des statuls. elc. de Nolre-Iame de Senlis (1041-1395, par l'abbé ling. Muller Cómintes rendus et mémoires du Comité archíologique de Senlis, te série. VII. p. 1-230, et à part: Senlis, [1905]. in- $-8^{\circ}$ de vi- $230 \mathrm{p}$.

Senlis. - Egglise de Saint-Rieul.

3664. - Cartulaire de Saint-Rienl de Senlis ; orig. perdu.

11 id été connu et utilivé par le chanoin Afforly dans ses "Collectaneat ", II, P. 959 (Biblioth. de le cille de Senlis).

Senlis. - Évèché.

3665. - Cartulaire de lévèché de Senlis; ms. du XVIIe siècle, sur papier. contenant des actes de 1363 à 1651 , in-fulio de $182 \mathrm{ff}$. (.trchices dép. de l'Oise, G 675).

3666. - Cirtularre de l'évèché de Senlis : ms. du XVIII siècle [1733], par Me A. Marchant Du Colombier, arocat, en 2 rol. in-folio, sur papier, de 191 et 199 ff. (Archices dép. de l'Oise, G 676-6iT.

lates extremes : 1150-17\%0. - Les tomes I et 11 ont disparu.

Senlis. - Ville.

3667. - Cartulaire municipal ou «livre enchané », contenant des actes

il partir de 1173: m\%. du Xllie siècle, relié en hois, in-folio Archices inunicipules de Sentis, At!?.

3668. - Frangment d"un cartulaire de Senlis: ms. du XIII siècle, sur parchemin, inl-f" de $8 \mathrm{ff}$.

A été tronve à Amien par M. Alfred de Puisieux.

PCbl. : Fragment d’un carlulaire senlisien du X'H e siècle. par 
A. de Caix de Saint-Amour Comptes rendus et Mémoires du Comité archéologique de Senlis, IX, 1894, pp. 117-128.

36699. - Autre cartulaire nunnicipal de Senlis ; orior. perdu.

Extrait dı précédent, fait an XVIII ${ }^{\mathrm{e}}$ siècle (Biblioth. nationale, coll. Dom Grenier, vol. V. ff. 110-137.

Lne note indique que le recueil original contenait des actes de 1406 à 1610 : mais c'est à peine un cartulaire.

Senones. - Abbaye (dioc. de Saint-Diè).

3670. - Cartulaire de l'albaye de Senones: ms. du Xrie siècle, sur papier. en 2 vol. in-folio de 5332 et $547 \mathrm{ff}$. Biblioth. nationale, mss. latins (9202-920:3.

Docunıents depuis te $\mathrm{X}^{\mathrm{e}}$ siècle, dunt on retronve des extraits faits au XVIJ (Bibli,th, nutionale, ms. latin 12696, ff. 175-182).

3671. - Autre: ms. du XV11 ${ }^{\mathrm{e}}$ siècle. sur papier, in-folio de $68 \mathrm{ff}$. (Archices dép. de Mewrthe-et-Mosille. $\mathrm{H}: 226$.

Intes extrênes: $1125-1719$.

3672. - Autre du XVIII siècle [1730]. sur papier, dressé par ordre de llom cialmet [par Mazet], en 2 vol. in-folio de 15:37 ff. (Avehives dép. des Tosges, $\mathrm{H} 49$ et $49^{\text {bi.. }}$.

PrbL. : Jucuments inédils prom sereir à l'histoire des Tosges, t. Y-VI.

Sens. - Abletye de Saintr-CeIombr.

3673. - Cartulaire de Sainte-Colombe de Sens ; orig. perdu.

Il fut présenté par l'ablé dans un proces au nois de janvier 1614

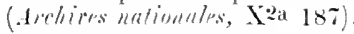

Extraits par Iom Estiennot au XVII siècle (Biblioth. de l'Arsenal, nss. 1009, p. 318-32:2 antres par Dom V. Cottron dans son histoire de lahlaye (Biblinhll. de lo rille d'Aureve, ms. 2I 7 ).

Sens. - Abbaye de Saint-Jean.

3674. - Cartuline de l'ahbaye de Saint-Jean de Sens; ms. du XIII ${ }^{\mathrm{e}}$ siècle. sur parchenin. contenant des actes de 1111 à l272, in-4" de $43 \mathrm{fl}$. Archires dép. de l' Yonne, $\mathrm{H}: 376$.

36\%. - Copies el extrails des chartres et titres de l'abbaye de Saint-Jean de Sens, écrits en $17 \cdot 29$; in-4 $4^{0}$ de 497 p. d'après un cartulaire origrinal antérieur dे 1250 Biblioth. nationale, ms. nonvelles acq. latines 400 .

Sens. - Archøvêché.

3676. - Cartulaire de l'archevêché de Sens; ms. daté de 1391 [avec additions]. contenant des pièces à purtir du $\mathrm{XII}^{\mathrm{e}}$ siècle, en 3 vol. 


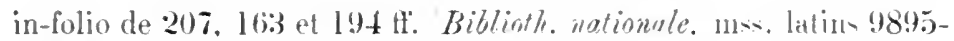
9897).

Sera publie intégralement par les soins de l'abbé E. Chartraire pour la Sociplis urrhénlonginue de Siens.

3677. - Recueil de chartes relatives anx droits de juridiction des archevèques de Sens sur leur diocèse : ms. du X Ve siécle. snr papier. contenant des actes de 1191 à 1486 . in-4" de $88 \mathrm{ff}$. Arelriess dép). de l'Yonne. G 18:3.

Sens. - Chapitre cathédral Saint-Étiønne.

3678. - Cartulaire du Chapitre de Sens: ms. daté de 1462. sur parchemin, in-t" de $74 \mathrm{ff}$. Biblioth. notionnle. ms. latin 9898 .

Provient de Munteil.

Publ. : Cartulaire du Chapitre de Sens, par l'abbé Enor. Chartraire. Sens. Duchemin, 1904: in-80 de [rv-]xxr-304 p. [Société archéologrique de Sens: Documents. t. III.]

3679. - Cartnlaires du Chapitre métropolitain de Sens: origr. perdus.

Les archive- du Chapitre métropulitain, au debut du XVIIe viècle, ne possédaitnt jas noins de 8 cartulaires, entre autres le Morellus et le

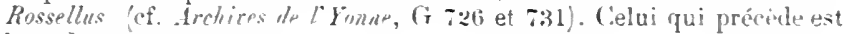
le seul qui ail survecu.

Sens. - Couront des Célrstins.

3680. - Cartulaire et censier du convent des Célestins de Sens : ms, des XVe-XTII siècles. sur papier, in-4" de $344 \mathrm{ff}$. Biblioth. de lu ville de Sens. ms. 5i3.

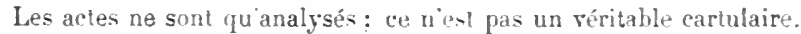

3681. - Cartulaire des Célestins de Sens: ms. dn XTe siècle, sur papier, contenant des actes des années 1348-14!33. in- $t^{0}$ de $46.5 \mathrm{ff}$. (Archires dep. de l'Yonne. $\mathrm{H} 492$.

Sens. - Léproserio du Popelin.

3682. - Cartulaire de la maladrerie du Popelin à Sens: ms. du $\mathrm{XIII}$ siècle. sur parchemin. contenant $5 \mathrm{I}$ actes de 116.5 à 1232 . in- ${ }^{\prime \prime}$ de $27 \mathrm{ff}$. Archires hospitulipies de S"ns. II A 2 .

Sens. - Ville.

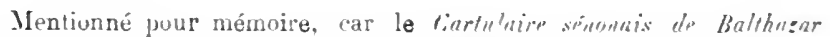
Tarean, publ. par G. Julliot (Siens, $1 \times 84$, in- $4^{\circ}$ ). n'est nullement un cartulaire, mais un inventaire de titres.

Senuc. - Prieuré de Saint-Oricole dioc. de Reims'.

3683. - Cartulaire du prieuré de Senne : ms. du XVle siècle, sur papier. in-4' de $81 \mathrm{ff}$. Bitlioth. nationale. ms. latin $54: 31$.

Cf. Cartulaires de Totre-Dame de Signy et de Saint-Oricle de 
Senue, par lisl. de Barthélemy (Tracaur de l'Académie nutionale de Reims, LIX, pp. 262-290, et à part: Reims, 1879 ; in- $8^{\circ}$ de $68 \mathrm{p}$.

Septfontaines. - Abbaye dioc. de Langres.

3684. - Curlulaire de l'abbaye des I'rémontrés de Septfontaines ; ms. dn XVIII siècle [ver's 1786]. contenant 150 chartes des années 1125 à 1683 , sur papier. in-folio de 189 đf. drchices dép. de la HauteMarne, $\mathrm{H}$ non coté

Sept-Fontaines. - Prieure (dioc. do Cambrai).

3685. - Curtulaire dı prieuré de Sept-Fonlaines; ms. dı XVe siècle, sur parchemin, contenant des actes de 1388 a 1491 , in-folio de $128 \mathrm{ff}$. (Archives du royaume de Belgique, à Bruxelles).

3686. - Autre cartulaire; ms. du XVI siècle, sur papier, contenant des actes de 1:60 à 1510, in- $4^{\circ}$ de $357 \mathrm{ff}$. (Archices du royume de Belgique, à Bruxelles).

3687. - Antre cartulaire; ms. des $\mathrm{XV}^{\mathrm{e}}-\mathrm{XVl}^{\mathrm{e}}$ siècles, sur papier, contenant des actes de 1401 à 1531 , in-4" de 127 ff. (Avclives du royaume de Belgique, à Bruxelles).

Septfonts. - Abbaye (dioc. d'Autun).

3688. - Cairtulaire de liablaye de Septfonts ; orig. perdu.

Existait encore au XVIJe siècle; la "Bibliotheca Stbusiana 》 de Fuichenon contient un acte de 1219 qui en provient (p. 10).

3689. - Recueil de titres relatifs à l'abbaye de Septfonts; ms. du XVII siècle, par Du Bonchet, sur papier (Biblioth. nationale, ms. latin 17049, fi. 459-476).

Sérignan. - Ville.

3690. - Recueil de titres relatifs à Sérignan; ms. dn XVIII siecle, sur papier, contenant des actes de 1281 à 1746 , in-folio de $202 \mathrm{ff}$. (Biblioth. de la ville de Irarseille, ms. 1435).

Serre. - Couvent des Minimes (dioc. de Toul).

3691 . - Cartnlaire cles Minimes de Serre; ms. des XVII $-X V I I I$ siècles, sur papier, in- $4^{0}$ de 206 parres Biblioth. nationale, ms. français 11851 .

Sery. - Abbaye do Notre-Dame (dioc. d'Amiens). 3692. - Cartulaire des I'rémontrés de N.-1). de Sery ; orig. [parchemin] perdu.

Copie faite en 1728. sur papier. in-10 Biblioth. Sainte-Genevière, à Paris, ms. 18.50, pp. 1-15:3).

Dates extremes: 1127-1612.

Extraits dı mème Idein, ms. 1850, pp. 346-348). 
Seurre. - Officialité. - Voy. Arxisse.

Seurre. - Ville.

3693. - Cartulaire municipal de Senrre. contenant destitres de 1:278

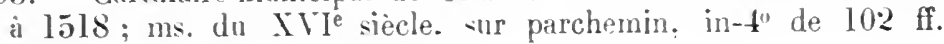

Archices municipules de Seurre.

Sexfontaine. - Prieuré (dioc. de Langres).

3694. - Cartulaire du prienré de Sexfontaine. dépendant de labbaye de Poulangy : m\%. du X $\mathrm{V}^{\mathrm{e}}$ siècle. contenant des documents depuis le Xle, sur papier. in-folio de $33 \mathrm{ff}$. Archices dép. de ln Haute-Marne, $\mathrm{H}$ non coté?

Seyne-lès-Alpes. - Ville.

3695. - Cartulaire municipal de Seyne-lès-Alpes : ms. du XV'e siècle, sur parchemin, contenant des actes de 1222 à 1419 , in-folio de 38 ff. (Archices municipales de Seyne-lès-Alpes).

Sicile. - Royaume.

3696. - PrbL. : Acta imperii inedita secnli XIII ; Urkunden und Briefe zur Geschichte des Kaiserreichs und des Köni rreichs Sicilien in den Jahren 1198 his 1273. von Ed. Winkelmann. Innsbruck, Wagner. 1880 ; in-8 $8^{0}$ de $x i-893$ p.

\section{Sicile et Naples.}

3697. - Recueil de titres relatifs anx droits des lucs de Lorraine sur la Sicile et Naples: nus. de la fin du XVIe réele. formé par Thierry Alix. sur papier. contenant des textes le 1290 à 1581 , in-folio de 222 ff. 'Archizes déj. de Meurthe-pt-IVaselle. B 411 .

\section{C.f. NAPLES.}

3698. - Prbs. : Codice diplomatico del regno di Carlo I e II d'Angiò (1265-1309). per Gin. Del (iindice. Napoli. 1863-1869.in-40.

Signes. - Ville.

3699. - Cartulaire municipal de Signnes: ms. dn XVIII siècle, sur papier, contenant des titres à partir de 1382. in-folio de $114 \mathrm{ff}$. (Archives municipules de Signes. At l.

Signy. - Abbaye do Nutre-I)amo (dion. de Reims). 3700. - Cartulaire de lahbaye de Signy: ms. du XIII' siècle. sur parchemin. contenant 54:3 documents des années 1134-1250. in- $4^{\circ}$ de $237 \mathrm{ff.}$ 'Archices dép. des Ardennes. H 203 .

Ce volume était auirufois, ainsi que lo suivan, conservé à la Biblioth. de la rille de Charlorille, mss. nos 46 et 276.

3701. - Antre cartulaire du XVIII siècle, sur papier. contenant des 
documents classés clıronologiquement des années 1134 a 1729, in-folio de 5̈3+ff. (Archives dép). des Ardennes, H 205).

Reproduit en parlie le précédent et esi suivi d'une table alphabétique des localités.

3702. - Autre cartulaire-inventaire; ms. du XVIII ${ }^{\mathrm{e}}$ siècle, sur papier, in-folio de 38 p. (Biblioth. nationale, ns. français 8:344).

Classé par domaines.

Cf. : Cartnlaires de Notre-Dame de Signy et de Saint-Oricle de Senuc, par Ld. de Barthélemy Travaux de l'Académie nationule de Reims, LIX, pp. 26i2-290 . ef à part : Reims, 1879 , in-8 ${ }^{\circ}$ de 68 p.

3703. - Autre du XIV siècle, sur parchemin, relié en maroquin traufré (Xve s.). in-to de 84-vi ff. Biblinth. de la ville de Reims. ms. 1568 .

3704. - Antre du XVIe siècle, sur papier. contenant des actes de 1141 à 1373, in-4' de $13 \mathrm{ff}$. (Archives dép). des Ardennes, H 204).

Sigournay. - Prieuré de Saint-siaturnin (dioc. de Luçon).

3705. - Publ.: Cartnlaire des prieurés de Marmoutier en Bas-Poitou, par Panl Marchegray, dans: Cartulaires du Bas-Poitou La Roche-surYon, 1877, in-8, p. 1-xxiv et $61-2 \cdot 25$.

Silly. - Mbaye (dioe. de Sées).

3706. - Cartulaire de labbaye de Silly : ms. dn XIII ${ }^{e}$ siècle [vers 12807, de plusiems mains. sur parchemin, in-40, avec quelques additions du XIVe siècle Biblioth. nutionale, ms. latin 11059, ff. 24 à 21 li).

Les premieres charles sont du Xlle siecle. Ies feuillets 27,49 et 120 sont mutiles.

3707. - Fragment d'm antre cartulaire de labbaye de Silly: ms. du $\mathrm{X} V$ e siècle, sur papier. contenant des actes de 1210 a 1444 , in-folio de $19 \mathrm{ff}$. Archives dép. de l'Orne. H 1112.

Voir linventaire détaillé dans l'Inventaire sommaire des Archives dép. de l'Orne, série $\mathrm{H}$, tome I, p. 2311-232.

3708. - Extrait d'un cartulaire de l'abbaye royale de Silly, couvert de cuir roux; ms. sur papier. contenant des documents du XII ${ }^{e}$ siècle à 1391 [avec deux additions postérieures], in-4" de $10 \mathrm{ff}$. (Archives dép. de lOrne, H 1096.

3709. - Autres copies d'actes depuis le XII siècle, in-fol. de 32 ff. sur papier Archives dép. de l'Orne, H 1637; ; antres (Idem, H 1791); et sommaire des chartes contenues dans le cartulaire de Silly relatives au patronage de l’égrlise Saint-Lambert (Idem, H 1720).

Simorre. - Abbitre (dioc. d'Auch).

3710. - Cartulaire de l'abbaye de Simorre; orig. perdu. 
Extraits faits en 1648 parJ. Contauld, notaire Biblioth. nufionule, coll. Baluze. vol. IXXII, pp. 369-383;.

(.e cartulaire a été utilisé encore par Dom Brugèles. Chroniques ecclésiastiques du diocise d Auch $(1746)$, qui en a publié inteiralement quelques chartes aux pièces justificatives : - par Dom Villevieille, qui le cite a plusieurs reprises: - tel antérieurement par Oihenart et Larcher (Glanages, III, pp. 77 ss., aux Archires dip. des Houtes Pyreilees). - Don Brugèles, op. cit., p. 27 de l'appendices publie ausis une charle de lannée 1301 extraite du cartulaire de la "ville") de -imorre; mais cest la seule mention que nous en ayons rencontrée. et il nous parait probable qu'il $y$ a la une confusion avecl" "abbaye" " dudit lieu.

Sion. - Église de Valère.

3711. - Cartulaire de l’église de Valère à Sion; mis. du XIII siècle. sur parchemin 'Archires du Chupitre de Sion en Valais.

PcBl. : Un certain nombre de pièces des XIIe-XIII siècles unt été imprimées dans les . Yémoires et documents publ. pior ln Société d'histsire de la Suisse romande, XVIII, 1864, pp. 363 et suiv.. par l’abbé J. Grémaud.

Sisteron. - Ville.

3712. - Cartulaire de la ville de Sisteron: ms. du XVe siècle. sur parchemin. contenant des actes de 1212 à 1410 , in-folio de $8: 2 \mathrm{ff}$. (Archives dép. des Bouches-du-Rhöne, B 1406,

Soignies. - Chapitre Saint-Tincent (dioc. de Cambrai).

3713. - Cartulaire de St-Yincent de Soignies, dit «Livre enchainé »: ms. du XIII siècle, contenant des titres depuis 1053 arec additions jusque en 1741 . sur parchemin, in $t^{0}$ de $126 \mathrm{fr}$.' Biblisth. de l'église puraissiale de Soignies.

Avil. : par Th. Lejeune. dans les Mémoires de la Société des sciences, des arts et des lettres du Hainut. $3^{e}$ série, IV. 1870. pp. $335-38 \%$.

3714. - Autre cartulaire ou « Livre rouge »; ms. du XTe siècle. sur parchemin. in- $4^{\circ}$ de $62 \mathrm{ff}$. (Archices de $l$ Elat à Mons).

Axal. : par Th. Lejeune, (Idem, p. 279 et 421 ).

3715. - Autre cartulaire: ms. des XIII'-XIVe siècler. sur parchemin. contenant des titres de 1093 à 1274 . in $-4^{\circ}$ de $67 \mathrm{ff}$. Biblioth. de M. Lefort, à Horrues en Hainaut .

C.e rolume présente plusieurs lacunes.

Axal. : Yotice sur un carlulaire du Clrapitre de Saint-Tincent de Soignies. par Léopold Devillers (Comptes-rendus de la Commission royale Thistoire de Belgique, LXXIII. pp. 268-288). et it part: Bruxelles. 1904; in-8" de $23 \mathrm{p}$. 
3716. - Autre cartulaire ou "Livre llanc » ms. du XVIIIe siècle, sur papier. contenant des titres de 1092 a 1779. in-folio de $171 \mathrm{fl}$. (Biblioth. de l'église pmorissinle de Srignies).

Cie registre contient les mêmes actes que le "lisré enchainé " plus 57 autres pieces.

Axal. : par Th. Lejeune, dans les Mémnires et publicutions do la Soriété des sciences, des arts et des lettres dn Hainaut, $3^{\mathrm{e}}$ serie, IV, p. :388-4:0.

Soissons. - Abbaye de Notre-Dame.

3717. - Cartulaire de lahbaye de X.-I) de Soisons, contenant 549 actes de 6.56 à 165.5 : nis. commencé au $\mathrm{XVI}^{\mathrm{e}}$ siècle et termine en 1739, sur papier. de 6993 $\mathrm{H}$. in-folio drchices dép. de l'Aisute, H 1508 .

3718. - Cartulaire de Totre-Dame de Soisons ; orig. perdu.

Extraits faits du précedent an $\mathrm{XVII}^{\mathrm{e}}$ siècle Biblioth. nationales ms. nouv. acquisizions frangaises 74.55, Il. 333:3-336: - coll. Dom Grenier, vol. LXIll bi-, fl. 2:3-27.

Publ. : Histoire de l'abbaye royale de Soisouns [par Dom Michel

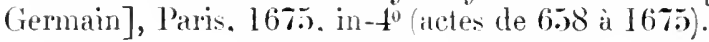

Soissons. - Abbaye de Sitint-Crepin-le-Grand.

3719. - Cartulaire de Saint-Crépin-le-Grand re Soissons. contenant 23.) pièces de 85.5 is 1710 ; ms. du XVIII siècle, sur papier, de

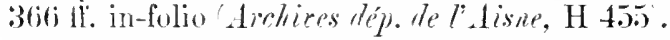

Soissons. - Abbatye de Satint-Joan-des-Tignes.

3720. - Cartulaire de lablaye de Simt-Jean-des-Vignes: ms. du XIIIe siècle, sur parchemin, incomplet des quatre premières chartes au commencement et incomplet également à la fin, contenant 98 pièces des années 1088 a 12.57 classies topographiquement, in-4 de $13 \pi \mathrm{fr}$. (Bibliolh. nutionule, ms. latin 11004.

I.e feuillet 116 est coupé : Ies feuillets 120-129 sont blancs. En réalité

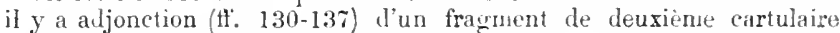
à peu près contenuporain et renfermant seulement des pieces des années 125̃o-1251 (annexé ell 1855).

3721. - Autre cartulaire de l'ablaye de Saint-Jean-des-Yinnes; ns. du XIVe siècle. aves quelques additions du $\mathrm{XVI}^{\mathrm{e}}$, sur parchemin, in-4" de 318 11. (Biblioth. de ln ville de Soissons, ms. 5).

Beaucoup d'actes sont en francais. - Cf. Notice sur le cartulaire de Saint-Jan-des-Vignes, par J. Plateau (Bulletin de le Socipts archéologique et scientifique de Soissmas, $3^{\mathrm{e}}$ sirien, IT, 1897, p. 98-114).

Soissons. - Abbayr de Saint-Lègrer.

3722. - Cartnlaire de l'ablaye de St-Lénger de Soisons; ms. du 
XII siecle, contenant des documents depuis lannée 1070. arec additions posterienres Biblioth. des Pères Linzristes de St-Léger.

On en trouve différents extraits dans le tona CXI de la coll.

1). Crenier (Biblioth, wotionale), ff. 38 et ss.

P'ubl. : Cartulaire de l'ablaye de St-Léger de Suisions (1070-1666), par l'ahlué Pècheur. Soissons. I arcosse. $1870:$ in $-4^{0}$ de 209 p. et pl. (Extr. du Bulletin de lu Saciété archéologique et scientifinue de Soissnis. 2e serie. II. pp. 183-396i).

Soissons. - Abbaye de Saint-Médard.

3723. - Cartulaire de Saint-Medard de Soissons. ou « Cartularium antiquum ", contenant $2: 37$ actes des années 633-1325; ms. des XIII'-XIVe siècles. commencé vers 1280. sur parchemin. de $14: 3 \mathrm{ff}$. in- $4^{\circ}$ (drchives dép. de l' tisue. $\mathrm{H} 4 \mathbf{7}$ ).

Lacunes anciennes aux ffr. a et 15 .

Copie du précédent, exécutée en 1649. sur parchenin, in-folio de 367 p. Archires nationals, LL 1021.

3724. - Autre cartulaire. dit « Cartularium novum »: ms. du XIII siècle, arec additions. sur parchemin, contenant des documents du XIe siecle à 13:33. in-t" de $158 \mathrm{ff}$. Bibliath. imtionale. ms. latin 9986 .

Ce registre était composé originairement de $160 \mathrm{fi}$. et présente deux lacunes (ff. 48 et 51 ).

Exiraits et copies Biblinth. nationale, ms. latin 12684. $\mathrm{fr}$. 187-285: - ms. latin 13818. ff. 312-319; - coll. Baluze, vol. XLVI. ff. 479-487: - coll. I). Grenier, vol. CCXLIII et passim). 3725. - Antre cartulaire dit Cartulaire violet : ms. in-4" de 372 pages, orič. perdu.

Extraits faits en 1785 (Archives nutionules. H 3173).-Cf. Biblioth. uationale, coll. Dom Grenier. vol. CCXXXIII. f" 6 .

3326 . - Autre cartulaire ancien. en 2 vol.; orig. perdu.

Extraits faits an XVII siècle (Biblioth. Malionule: coll. Dom Grenier. vol. CCXXXIII. ff. 66 et 80 ).

Soissons. - Chapitre cathédral.

3727. - Cartulaire du chapitre cathédral de Soisons, contenant 348 rlocuments de 1089 a 1453 : ms. du $\mathrm{X} \mathrm{V}^{\mathrm{e}}$ siècle, sur papier. de $326 \mathrm{tr}$. in-folio (Archices dép. de l'Aisne, G 253 .

Soissons. - Courent des Cèlestins.

3728. - Cartulaire du convent des Celestins de Soissons; orig. perdu.

On en trouve un txtrait dans un manuscrit relatif à Nogent-sous Coucy (Biblioth. mutimnle, coll. Dom Grenier, vol. 268, fo 1i). 
Soissons. - Couvent des Dames de la Congrégation. 3729. - Cartulaire des Lames de la Congrégation de Soissons; ms. du XVII siecle [incomplet], sur papier, contenant des titres de 1638 ì 1645, in- 8" de $240 \mathrm{tf}$. (Archives municipales de Soissons).

Axal. : Le cartulaire des Dames de la Congrégration de Soissons, par M. Platean (Bulletin de la Société urchéologique et scientifique de Soissons, 3 éérie. I, 1891. p. 197-231).

Soissons. - Eglise cathédrale.

3730. - Recueil des titres de l'égrlise cathédrale de Soissons, fait par I lom Muley d'après les archives an XVIII siècle, sur papier, in-folio de $245 \mathrm{ff}$. (Biblioth. nutionale, ms. latin 9985).

Les pieces transcrites, des années 1170-1341, sont classées chronolocriquement. - (Ce recueil faisait jadis partie de la collection Dom Grenier (3e patp. n $\left.n^{\circ} 3\right)$.

Soissons. - Église collégiale Saint-Vaast.

3731. - Cantulaire de la collégiale St-Vaast de Soissons ; orig. perdu. lixtrait fait an XVIII siècle, contenant un acte de 1197 (Biblioth. nutionule, coll. Morean, vol. 98, fo 1:33).

Soissons. - Évêché.

3732. - Cartulaires de l'évèché de Soissons ; origr. perdus.

Lxlraits faits an XVIII siècle par I). Grenier (Biblioth. nationale, coll. Dom (irenier, vol. IXIII, t1. 378 et 38I).

Soleilmont. - Abbaye (dioc. de Namur).

3733. - I'cbL. : Archives de l'ałbaye de Soleilmont, par Léopold Devillers, dans: Description de cartulaires et de clartriers dn Hainat. III 1875, pp. 1-115.

Actés des années 1237-17\%6 analysés ou intégralement publiés.

3734. - Registre des transactions passées par l'abbaye de Soleilmont avec les communes de Clhâtelineau et de Fleurus: ms. du XYTe siècle, in-t" de 14 1f. (Archives de l'Etat à Mons).

Solesmes. - Ibbaye de Saint-Pierre. - Voy. Le Maxs (Abbaye de La Coutme).

Solignac. - Abbaye de Saint-Pierre (dioc. de Limoges).

3735. - Cartulaire de l'ablaye de Solignac; ms. du début du XII siècle, snr parchemin, incomplet dn commencement et de la fin, in-8 ${ }^{\circ}$ de $42 \mathrm{ft}$. (Biblioth. nationule, ms. latin 18363).

Chartes et notices non datées.

3736. - Recueil de titres relatifs à l'abbaye de Solignac, fait au 
XVIII siècle [1769], en mande partie d'après le précédent. par Dom Col (Biblioth. nationule, ms. latin 9193. pp. 293-45.).

Documents jusqua à 1509.

Copie moderne du précédent (Archices dép. de ln Hunte-I Tenne, H 9241 ).

Abrécé du nème cartulaire [fragments]; ms. dı XIIe siècle, sur parchemin. If. 2 à 24 et 43 à 46 , in- $t^{*}$ (Archires dép. de lu HavteVienne, H 9180 bis).

3737. - Petit cartulaire de l'abbaye de Solignac: ms. de XIII ${ }^{\mathrm{s}}$ siècle. avec additions postérieures, in- $\mathbf{t}^{\circ}$ de 34 ff. (Bibliolh. nationale, ins. nouv. acq. latines 461 ).

3738. - Cartulaire de l'abbaye de Solignac, recueilli par Dom Estiennot: ms. du XVII siècle [1676], contenant 67 ducuments de 641 à 1676 , in-folio de $365 \mathrm{ff}$. (Archizes dép. de lu Haute-Tienne. H. 9240 ).

Même recueil de titres relatifs à l'abbaye de Solignac, fait par Dom René Du Cher et Dom Estiennot en 1676 d'après les oricrinatux (Biblioth. nationale, ms. latin 12748. pp. 103-2:34 et 27l-36l.

S’arrête à l'année 1620 .

Solre-le-Château. - Voy. Beacriecx.

Sommereux. - Commanderie de Templiers flioc. de Beauvais).

3739. - Cartulaire des commanderies de Sommereux et de .Milly-sousClermont en Beanvaisis; ms. du XIII ${ }^{\mathrm{e}}$ siècle, sur parchemin, de i7 fl. in-folio (Biblisth. Cheltentuin, $\mathrm{n}^{0} 2973$ ).

Sorde. - Abbaye de Saint-Jean (dioc. de Dax).

3740. - Fragment du cartulaire de St-Jean de Sorde: ms, du $\mathrm{XIII}^{\mathrm{e}}$ siècle, contenant 184 pièces des $\mathrm{XI}^{\mathrm{e}}-\mathrm{XII}^{\mathrm{e}}$ siècles. sur parchemin, in $t^{0}$ de $46 \mathrm{fr}$. (Biblioth. nationale, ms. nour. acq. latines 18:2.

Plbl.: Cartulaire de l'abluaye de Saint-Jean de Sorde. par P. Raymond. Pau. Ribant [Paris. Dnmonlin], I873: in-8 ${ }^{0}$ de xxil-18:3 p.

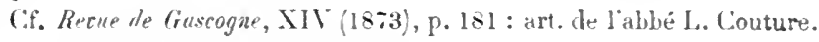

Souday. - Eglise (alioc. de Blois).

3741. - Cartulaire paroisial de Souday; ms.des XVle-XVIIIe siècles, in- $8^{0}$ (Archices de lu fubrique de Souday).

Axal. : par l'abbe Ch. Metais dans «Etules et documents», 2 série (Orlèans, I890, in-80), pp. I29-148. 
Souilly. - Châtellenir en Lemraine.

3742. - Recueil de titres relatifs à là chàtellenie de Sonilly ; ms. de la fin du XVI e siècle, formé par Thierry Alix, sur papier, contenant (les textes de 1255 à 1580 , in-folio de $2.52 \mathrm{ff}$. (Archices dép. de Weurthe-et-1Coselle, B 395 .

Copie du précédent, faite an XVII siècle. intfolio, sur papier Archires dép. de la Meuse. B $2+7$.

Soultz. - Commanderio dr l’Ordre do Malte (dione de Bàle).

3743. - Cartulaire de la commanderie de Sonlt\%; ms. des XVII XYIII siècles, sur papier, in-to de 380 lf. Archic tes Ober-Els"ss, in Colmar .

L.e plu- ancien document est de 1292.

Souvigny. - Prieuré (dicr. de C.lermont).

3744. - Cartulaire dn prieuré clunisien de Souvigny. on «thesaurus Sylviniacensis », contenant I69 documents des années 916-1647; mis. du XVII" siècle. sur parchemin, de $1157 \mathrm{fr}$. in-4 ${ }^{3}$ Archives dép. de l'sllier. H non coté,

374一. - Extraits laits an XVIIe siecle «d'un manuscrit où estoient plunieurs coppies touchant le druit de juntice de Charles duc de Bonton >. Biblinth. nutionale. ms. latin I3819, ff. 303-307.

Spalding. - Prieuré do Saint-Nirolas (dioce de Lincoln).

3746. - Cartulaire du prieuré anglais de Spalding. dépt de SaintSicolas d'Angrers: ms. dn XI" siècle. avec additions du XYe, sur parchemin. ef table analytique en tète. contenant des actes à partir du XI" siecle. in-40 de 352 ff. British .luseum, ms. Harleian 742.

Cf. auss le Harleian 7.43, ainsi que les vol. $133-44$ du fonds Cole au

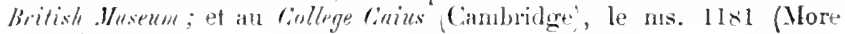
1) 11\%).

Spire. - Érohis.

3747. - Pubı.. : Urkundenbuch zur (ieschichte der Bischöfe zu Speier. von F. X. Remling. Mainz, 1852-185:3; 2 vol. in $4^{\circ}$ de 722 et $79.4 \mathrm{p}$.

Stavelot-Malmédy. - Abbaye (dinc. do Liège).

3748. - Cartulaire de l'abbaye de Starelot; ms. des $\mathrm{X}^{\mathrm{e}}-\mathrm{XI}^{\mathrm{e}}$ siècles, sur parchemin. contenant des actes à partir de l'année 644 , in-4 ${ }^{0}$ (Körigl. Biblinllek zu Bumberg, E min 1).

Cif. K. Rimer, Der Colex Stabulensis der K. Bibliothek zu Bamberer (Winil, $188 \%$, in- $\left.8^{\circ}\right)$.

Conie du précédlent: ms. du XI ${ }^{\mathrm{e}}$ siècle, sur parchemin, avec une 


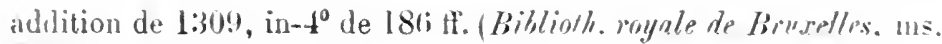
$275 \%$, 11. \$:3-89 et $104 r^{\circ}$.

Autre copie. dite «Codex Ldalrici»; ms. du XI siecle. sus parchemin $\left(K^{*} . K\right.$. Hof biblinkek zu Mien).

Autre copie. arec additions; ms. lu XVII siecle, sur papier, in-lolio (Biblirilh. royule de Briselle's, ms. 857i).

3i4!). - Autre cartulaire de l'abbaye de Stavelot; ms. du Xilie siècle. sur parchemin, contenant des actes à partir de 6.44 . in- $4^{\prime \prime}$ de $8.5 \mathrm{tf}$.

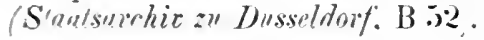

Copie du précédent avec additions. faite en $148 \pi$, perdue.

Autre copie intitulée "Cartulariun abbatiae Stabulensis »; ms. du

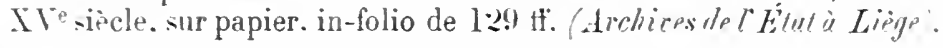

3750. - Autre cartnlaire dn XVII siècle. en partie copie sur le précedent. sur papier. infulio de 88 fi. Awhires de l'Étut is Liège).

Copie postérieure; ms. du XVIIL siècle, sur papier, contenant

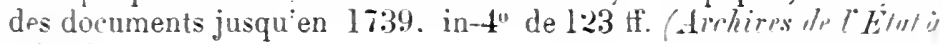
Liège).

\section{Les 34 premiers feuillets mampuent.}

3751. - Recueil de titres relatifs à Stavelot. d'après le précédent; ms. du XVIIJ siècle (Kgl. Biblinthek :" Berlin. ms. Boruss.. infolio $769 ;$.

3752. - Autre cartulaire. dit "Cartulaire Waltz »: ms. du XVI siècle [15\%2]. sur papier. contenant des documents à partir de 644 jusqu'au

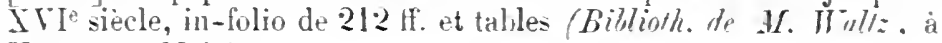
Hanau-sur-Mein;

3753. - Autre cartulaire: ms. du XYIII siècle. sur papier, par Dum Hubert Burnenville. It vol. in-folio (Stutsuschic :" Disspldorf. B 53).

3\%54. - Antre cartulaire du XIE siècle. écrit de plusienr mains. sur papier. et contenant des documents de $11: 31$ a 1576 . in- $4^{\prime \prime}$ de $2: 29 \mathrm{tt}$. Arehies de l' Etot is Liegej.

$3 \% \%$. - « Vetera documenta ad historiam Stabulensem spectintia $»$; ms. des XVII" et XVlII siècles. sur papier. in-folio lle 86it p. et talle 'Bibligh. nutionule. ms. latin $1017 \%$ ).

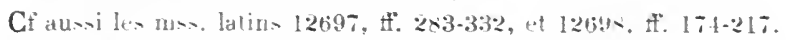

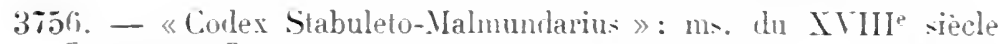
[1778-1785]. dresé par A. F. Viller. échevin de Malmédy. -ur papier. en 4 rol. in-40 de 6 ifis. 228. $2: 32$ et 489 pages arec tables. contenant des documents de 66iti a 178:3 Archices de l'litut is Liege.

l. mism. depoit posside un table chronologiqu. et alphabéfique du rartulaire jrécelent in-fulio d. 227 p.). 
375\%. - Antre cartulaire des $\mathrm{X} \mathrm{V}^{\mathrm{e}}$ et $\mathrm{XVI}$ siècles, sur papier, in-folio de 54 tr. (Arehices de l'kint à Liège).

3758. - Autre cartulaire du XVII siècle, sur papier, in-folio de $92 \mathrm{ff}$. (Archices de l'Étut à Lìge).

3759. - «Transsumptum» rédigé an XVI $\mathrm{XV}^{\mathrm{e}}$ siècle, sur parchemin, in-folio de 18 ff. (Stautsurchic zu Dïsseldorf, B 14:3).

3760. - Autre cartulaire ou "Novum transsumptum $v:$ ms. du XVIII" siecle, sur papier, in-folio de 285 pages (Archices de l'Etat is Lirge).

Tous ces divers cartulaires dérivent plus ou moins de celui du XIII siècle qui est conservé à Düsseldorf $\left(n^{\circ} 3740\right)$. C'est d̀ II. Joseph Halkin que revient l'honneur d'avoir élabli cette classification a la suite d'une époque approfondie. Cf. sa notice dans les Comples-rendus de la Commission royale ditistoire de Brlgique, 1897, pp. 239-44凶, où sont indiqués divers autres recueils peu importants. Cff. au British Whuseum, additional ms. 24149, in-folio du XVIII siecl: (HI. 25$\therefore$ a) la table d'un cartulaire du $\mathrm{XVI}^{\mathrm{e}}$ siècle.

3761. - Publ.: Recueil des chartes de l'abbaye de Stavelot-Malmédy, par Joseph Halkin et C. G. Roland. I (64t-1200). Bruxelles, Hayez, 1907 ; in $-4^{0}$. [Commission royale d'Histoire.]

1)ans l' Amplissima collectio » de Martene et Durand, II, pp. 1 et ss., on trouve imprimée une importante collection de documents relatifs ì l'abbaye de Sitavelot $(6.18-1.185)$, surtout d'après le ms. Waltz, de Hanau-sur-Mein.

Steige. - Prieure (dioc. de Strasbourg).

3762. - Fragment de cartulaire du prieuré d'Obersteige; copie du XVIII siecle. sur papier Grossher:ogl. Lundesurchio in Karlsruhe, Nachlass von Grandidier, X 12 .

Stenay. - Ville.

37603. - Recueil de privilètres de Stenay: ms, du XVrle siècle. sur papier, in-folio Biblintl. royule de Bruxelles, ms. 6900).

Strasbourg. - Chapitre Saint-Ėtienne.

3764. - Cartulaire du Clapitre St-Étienne de Strabourgr: ms. du

XVII siècle, contenant des titres de 84.5 à 1366, sur papier. in-folio de $411 \mathrm{ff}$. (trchio des Unter-Elsuss. in Strassburg).

3765. - Antre du XVle siècle, contenant des titres de 845 à 15:30, sur papier, in-4" de $9 \mathrm{fr}$. Archiv des Ober-Elsass, in Colmar.

3766. - Publ. : Die ältesten Lrkunden für S. Stephan, von W. Wiegand Zeitschrift für die Geschichte des Oberrheins, nene Folge, IX, 1894, pp. 389-442.

Strasbourg. - Chapitre Saint-Pierre le jeune. 3767. - « Statuta ecclesiae sancti Petri junioris Argentinensis 》; ms. 
du $\mathrm{Xresiecle.} \mathrm{sur} \mathrm{papier.} \mathrm{in-4"} \mathrm{do} 81$ ff. Archio des Cutri-L\%s, in Strasburir.

Contient la transcription d'une série de hulles à partir de 121i.

Strasbourg. - Commanderie des Hospitaliers de saintJuim de Jerusialem.

3768. - « Antiquorum protocollorum copiate domus Viridis insulate Arentinensis ע: ms. du X Ve siecle, sur papier. en 3 rol. in-folio de 2:32. 2:31 et $150 \mathrm{ff}$. (Archic des Unter-E'suss. in Strassburar.

Documents de 1265 iे 1430 .

3769. - Autres cartulaires cotés A à F; ms. sur papier des $\mathrm{X} \mathrm{V}^{\mathrm{E}}$

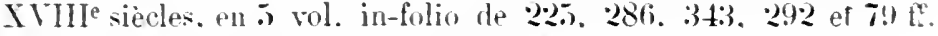
(Archir iles Unter-Elsass, in Strasiburn.

Documents de $13 \% 0$ à 1708 .

Strasbourg. - Courent de saint-Arbogast on des louminicains.

3770. - Cartulaire C des Dominicains de Strasbourg; ms. du XVe siècle, contenant des actes de 1439 i $14 i 1$. in-40 Arhices hospilnlières de Shreslonurg).

$37 i 1$. - Cartulaire D; ms. du XVe siècle, contenant des actes de 1467

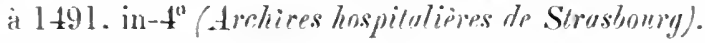

$37 \% 2$. - Cartulaire E : ms. du XVIe siècle. contenant des actes de 149:2

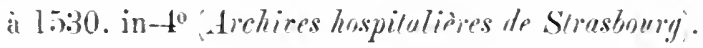

3773. - Protocole des titres du convent de Saint-Arbourast: ms. du X Te ciècle. contenant des titres depuis le XIIIe sur parchemin.

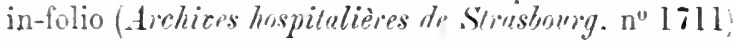

37it. - Autre protocole: ms. du $\mathrm{XVI}^{\mathrm{e}}$ siecle. contenant des titres de

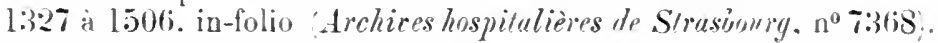

3775. - Autre protocole: ms. du XVIe siècle, contenant des titres de

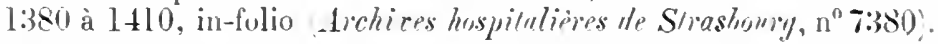

Strasbourg. - Courrnt dr sainte-Yarguerite.

376 . - « I'rotocollum monasterii sanctæ Margarellae Aronentinensis y : ms. du $\mathrm{XVI}^{\mathrm{e}}$ siècle, sur papier, in-4" de :273) II. (Awhiv des L'nter-Elsuss, in Strasshury.

Lew ducuments transerits sont tous du XVle siecle.

Strasbourg. - Egliso athislrall Xotre-l)amr.

$377 \%$ - Cartulaire de l'église cathedrale de Strabourgr oridg. perdu.

On a une table de ce cartulaire dressér en 108\%, in-\$3 (Biblinth. nationute. m... latin 10(34) 
Strasbourg. - Église collégialı de Saint-Pirrr-lo-Vienx. 3778. - Cartulaire de la collégiale Saint-Pierre-le-Vieux de Strasbonrg; ms. du XIe siecle, orig. perdu.

Copie du précédent, ms. du XVe siècle [ver's 1475]. sur papier, in-4" drehives de l'rglise Suint-Pierve le Tienx).

[tilisée par Grandidier (Histoire de l'église de strasbourgrg).

Strasbourg. - Oratoire do la Toussaint.

3759. - Recueil de tilres relatifs anx frères de la Pènitence (Saccites) de loraloire de la Toussaint à Strasbonrgr ms. du XVIIIe siècle, -ur papier, in-folio de 48 pages Grossherzogl. Landesarchic in Kumlsinlie, Nachlass (irandidier's.

Strasbourg. - Ville.

3780. - Carbulaire municipal « $A$ » de Strashomrn; ms. commencé en 1370. sur parchemin, avec additions postirieures. contenant des titres de Il:2! a I 448. in-folio de $298 \mathrm{fr}$. Archiess municipules de Strustoring, AA 6a).

3781. - Cintulaire B: ms. commencé en 1529, sur parchemin,

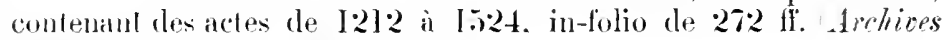
municipules de Strusbong. At 66 ,

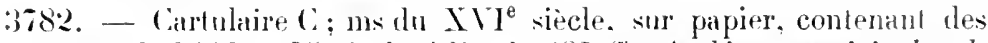
actes de I:330 a 1508, in-folio de :38I ff. Arrhives municipules de Strosbrimy, AA 68 .

378:3. - (artulaire 1) : ms. cln $\mathrm{XVI}^{\mathrm{e}}$ siecle, sur papier, avec arditions postirienres, contenant des actes de 1:360 à l638. in-folio de $169 \mathrm{ff}$. Arrlites municipules de Struslomig. At (i8).

3784. - Cartulaire li ; ms. du XVII e siècle. sur papier, contenant des actes de 1440 ì 1594 , in-folio de 264 ti. Archires muturipales dr Strusbonig. At 69 .

Rípertoire, en langure allenande et par ordre de matieres des cartulares A à E : ms. dlu XVIle siècle. sur papier, in-folio de 248 panges drehires muicipules te Strasbowrg. AA 70).

3785. - « Privilerrienluch »: ms. du $\mathrm{XVII}^{\mathrm{e}}$ siècle, sur papier in-folio te: 370 fI. Arehives muricipules de Straslourg, A. 3I.

3786. - Pusı. : Urkundenbuch der Stadı Strassburg, bearb.von Wilh. Wiecrand. Al. Schulte und (i. Wolfram. Strasisurg, I879-1890; 4 vol. ill-4" de xv-586, vi-482, xivmi-45l et vi-3699 p.

Straten. - Commanderio (dior do Bruges).

3787. - Carmbitre de la conmanderie de Stralen; ms. du X VI ${ }^{6}$ siècle, 
sur parehemin. contenint des actes de 1345 a 147.5, in-folio de 206 if. Arehies de l' État à Bronges).

Ce recristre contient auss des documents relatifs it la commanderie de" Brugeses.

Sturzelbronn. - Abbaye (dioc. de Metz).

:3788. - Cartulaire de l'abhaye de Slurzelbronn; ms. du XVIe siècle, perdir.

Il existait avant 1870 dans la Bibliothèque de lin ville de titrastourar et a disparu dans lincentlie de cet établissement.

Suisses. - Soldats au service de la France.

3789. - Pubr. : Les privilèges des Suisses, ensemble ceux accurdés aux Villes Impériales et Anséatiques. et aux Habitans de Genève résidens en France. [par M. Vogel]. Telle i $\mathrm{d}^{0 n}$. Yverdon. 1770; in- $t^{0}$ de $\mathrm{vI}-566^{\circ} \mathrm{p}$.

Dates extrềnes: $1481-1728$.

Sully-sur-Loire. - Seigneurie.

3790. - Cartulaire des seigneurs de Sully: ms. du XIII siècle, sur parchemin. in-12 de (?) ff. (Aichices dip. du Cher. E non coté).

De ce cartulaire non cité nous avons retrouvé $79 \mathrm{ff}$. qui ne forment qu une partie de loriginal et sont des fragments, dailleurs recon-tituables, échappés d̀ lincendie des archives du Cher en 1859 : le- bords de chaque cahier ont subi les atteintes du feu. On y trouve un certain nombre d'actes en français.

$3790^{\text {bis. }}$ - Lxxtraits d'un carlulaire des sires de Sully, rédigé en 1:329, faits an XVII siècle (Biblioth. nationale, coll. Dnchesne, vol. LXXVI, ff. $265-275)$.

Suresnes. - Village (dioc. le Paris).

3791. - Cartulaire de Suresnes. dépentant le l'ahbaye de SaintGermain-des-Prés ; ms. du XVIII sièele [175l-52]. rédigné par $\mathrm{Ph}$. Duroussin. religieux, sur papier. contenant des actes du IS siècle a 1747 , en 2 vol. in-folio de $333: 3-x x i r$ et 361 th. Archios ustionales, I.L. $1041-1042$.

Le tome II intéresse "n outre Bouafl", Crespièren, Longuesse, Puteaux ot Tiyerny (actes depuis 918).

Surgères. - Aumônerie ot courent des Minimes (diow. de Maillezais).

3792. - Cartulaire des Minimes on de Saint-Gilles de Surgères : orig. 「du XVe siècle] perdu.

Extraits du « Grov livre rouge » des Minimes de Surnères: m. du XVIII siecle. sur papier Biblioth. de ln cille de La Rorhelle. ms. 1:31. tf. 29-30).

D'apris un document nanuscrit, recemment enlré dans les collpetions 
de la Bibliothène de la Rochelle et que reut bien me signaler M. Mussel, ce "livre rouge ") était au XIII siècle à Paris.

379:3. - Publ. : L'ammonerie de Saint-Gilles de Surgères, par P. de Fleury Arefives historiques de la Suintonge et de liunis, VI, 1879, p. $9-2: 2$.

Recueil factice de 15 documents (dont 14 tirés du cartulaire des Minimes), empruntés au vol. XXVIIler de la collection Dom Fonteneau à la Biblioth. de la ville de Poitiers; dates extrêmes : $1105-1447$.

Swavesey. - Prieuré de Saint-.André (divc. d'Ely).

3794. - Cartnlaire du prieuré anglais de Swavesey, dépendant de l'ablaye de Saint-Serge d'Angers; ms. du XVe siècle, sur papier, contenant 25 actes des années 1140 environ) à 1395, , in-to British Museu!n, fouds cule, ms. XINIII, pp. 36-45.

Sylvanès. - Abbare (dioc. de Vabres).

3795. - Cartulaire de l'abbaye de Sylvanès; ms. du XIII siècle, sur parchemin, contenant 464 actes depuis le commencement du

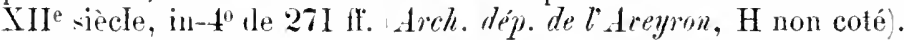

Extraits faits en 1667-1668 (Bibliotl, mationale, coll. Ioat, rol. $150-151$.

Dates extrònes: $10966-1 \pi 39$.

Talleyrand. - Famille.

3796. - Recneil des tilres de la matison de Talleyrand; ms. de I741, sur papier, conlenant des documents de 124.) a 1723 , in-folio de $337 \mathrm{ff}$. Biblioth. nationale. ms. latin 9146 .

Talloires. - Mbave (dioc. de Geneve).

3797. - Fragmenl d'un cartulaire de l'abbaye de Talloires; ns. du Xlle siècle, sur parchemin. '2 lenillels in-4" Biblioth. dn Vaticun, ms. Rerina 450 , ff. 1:2:-1:3:

Talmont. - Abbaye de Sainte-Croix (dioc. de Luçon).

3798. - Cartulaire de l'al,baye de Talmont; ms. dn XVIe siècle, sur parchenin. conlenant 536 charles des amnées 1042-1254, de 226ff. in-folio Archices dép. de la Téndée, $\mathrm{H}$ non coté).

P'ubl. : Cartnlaire de l'abbaye de Talmont, par Lonis de I a Bontetière lémoires de la Suciété des dntiquaires de lonest, IXXTI, 1872. p. 41-498.

Tarascon. - Ville.

3799. - Livre rouge on cartulaire municipal de Tarascon; ms. du $\mathrm{XVI}^{\mathrm{e}}$ siècle, sur parchemin, contenant des actes des années 1168 à 1535. in-folio de $411 \mathrm{ff}$. (Archices inmicipules de Turascon, AA 9). 
Tarbes. - Chapitre cathédral.

3800. - Cartulaire on « livre noir » d" Clapitre cathidral de Tarthes: orig. perdu.

Extrait du précédent fait en 1740 Biblioth. de lu cille de T'urbes, Glanagre de 1 archer, vol. II. p. 296. et VI, p. 395).

L.e premier extrail a élé publié par XI. G. Balencie duns la Rerue de Gascogne, 1904, p. 250, note 8 .

3801. - Autre cartulaire dn Chapitre ou « livre ronge » : orig. perdu.

Il était en 1747 dans les archives du marquis de: Rothelin, baron te Bénae. Cif. Glanage de I archer, VI, p. 420.

Tarbes. - Tillı.

3802. - Cartulaire municipal de Tarhes on « Livre de las Trobsas 》; ms. sur parchemin. in- $4^{\circ}$. orig. perdu.

Contenait, à côté des privilegres de la ville, des règrlenents de polices. Deux feullels (XIVe siècle), subsistants, ont été rus par M. G. Balencie, en 1886, entre les mains de R. P. Cassaiguère, prieur de X. D. do Piétat près de Barbazan-Debat, el décéclé depuis en Amérique.

Fxtraits du précédent [règlements de police seulement] faits en 1752 Biblisth. de la ville de Tarbrs, Glanage de I.archer, vol. XXT. pp. 24-28 et 261 .

Tarragona. - Église cathédrale.

3803. - Recueil de titres relatifs à l'église de Tarragone. fait pour Baluze an XVII siècle (Biblintl. mutimule, coll. Baluze. vol. CVII, tf. $84-108$ ).

Tavant. - Prieuri /lioc. de Trums.

3804. - Franguent de cartulaire du prieuré de Tavant. dépendant de Marmoutier: uns. dur Y'VI siècle. contentant des documents des année, 98 $-126 \pi$, sur papier, in-folio de $25 \mathrm{tf}$. Archires dép. d'Indreet-Loire, H 333.).

Termonde. - Courent du Saint-Saureur ou de sainteBrigitte (dioc. de Gand).

3805. - Recueil de titres et privilèges de l'ordre du Suint-Sauveur fonde par sainte Brigitte, et spécialement du couvent de Termonde; m. du XVII siècle. sur papier, ecrit par Art. Chr. Damerin. chanoine de Diest, in- $4^{\circ}$ 'British . Wuseum at Londres. ms. additional (15)32).

Termonde. - Ville.

3806. - Recueil de privilèges de la ville de Termonde on « Roodenhoeck »: ms. des $\mathrm{XIV}^{\mathrm{e}} \mathrm{X}^{\mathrm{X}} \mathrm{VI}^{\mathrm{e}}$ siècles. sur parchemin, contenant des

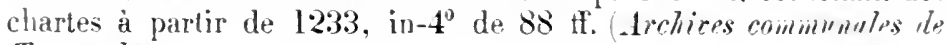
Termonde. 
3807. - Autre recueil on « Zwarte hoeck»; ms. des XVI XVIII siecles. sur parchemin. contenaut des actes de I2:33 à 1787, in-folio de $164 \mathrm{ff}$. Archices cominumales de Termonde).

Ax.1.. : Analyse sommaire des registres aux privilèges de la ville de Termonde. par Alph. de Vlaminck. Termonde, Dncaju, 1876; in $-8^{\circ}$ de $6.5 \mathrm{p}$.

3808. - Prвы. : Cartulaire de la ville de Termonde, publ. par Alph. de Vlaminck. Livr. I-1II. Gand, Annoot-Braeckman, 1876-77; in-8 de $288 \mathrm{p}$.

Publication restér inachevée.

Teutonique (Ordre).

3804. - Pebr. : Tabula ordinis Tentonici, edid. Mrm. Strehlke. Berolini. Weidmann. 1869 : in-8" de vi-49l p.

l'ublication faite d'après quatre cartulaires dont un conservé à l3erlin, el trois à Königsberg, qu'il ne paraît superflu de décrire. - Parmi les 72. documents imprimés dans cet orrrage, il en est 'puelques-uns en langue francaise ou intéressant la France. - Il existe un autre mimuscrit contenant les priviliges de l'Ordre Teutonique (Bibliath. du Vutiran, ms. Ottoboni iz2 : parch., XYe sièce, in-folio de $\pi \mathrm{ff}$.).

Thann. - Chapitre (liơ. de Bâlo).

3810. - Cartulaire du Chapitue de Thann: ms. dn XVIIe siecle. sur pilpier. in-4" de $17 \mathrm{ff}$. Archir des Ober-E/suss, in Colmar').

le plus ancien texte transerit est de 1318.

Thann. - Courent des condeliers.

:3811. - Cartulaire des Cordeliers de Thann; ms. dn Xrile siècle [1674], sur papier, contenant 18 documents des années 1341-1467, in- $\mathbf{4}^{\prime \prime}$ de $27 \mathrm{ff}$. Archio des Ober-Elsass, in Colmar).

Thenailles. - Ablare (dior. de Laon).

3812. - Cartulaire de l'abbaye de Thenailles; ms. du XIII siecle. sur parchemin, in- $4^{\circ}$ de $117 \mathrm{ff}^{\circ}$. Biblioth. nationale, ms. latin $5(649)$.

Analyse sommaire et extraits dı précédent, faits an XVII siècle (Biblioth. mutiomale, col. Baluze, vol. IXXV, ff. 186-206).

Thérouanne. - Église collégiale Notre-Dame.

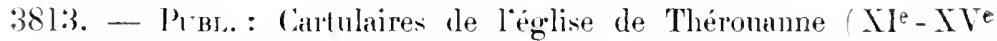
viècle' par Th. Iuchet et A. Giry. Saint-Omer, d'Homont, 1881 ; in-4" de w-4:37 p. [Société des tntiquaires de la Morinie.]

la préface de $\mathrm{A}$. Giry annoncée n'a jamais paru.

C. all Bi Bol toxwas.

Theuley. - Abaye (dior. de Langres).

3814. - Cartulaire de lablave de Thenley ; orign. perdn. 
Copie du précident : ms. du XVIIL siecle. sur papier Biblinth. muliounle, coll. Yorean, vol. 873. ff. 105-169.

Theuvy. - Prioure de Notro-Dame dlive. dre Chaldress.

3815. - Cartulaire dn prieuré de Thenry. dépendant de labluate de Saint-Jean-en-Vallée: ms. dn X $\mathrm{V}^{\mathrm{e}}$ siècle $[1488]$. sur papier. in-folio de 4 ff. Archices dep. dEure-et-Loir, H 3486 .

Dates extrèmes : 1213-1280.

Thiais. - Village (lior. dr Paris).

3816. - Cartulaire de Thiais. dependant de l'alhaye de Saint-Gerraindes-Prés; ms. du XVII sierde [1611]. smr papier. in-4" de 8!) ff. en

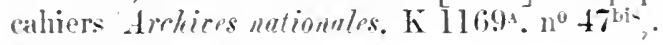

Thielt. - Villr.

3817. - Recueil des privilères de la ville de Thielt : m. rédigé en 1641 par P. Vande Watere, contenant des actes de 12\%) a l.56\%. sur papier, in-4 Arclices commuales de Thielt.

Thonon. - Chapitre de la Saintr-Maison dior. de Genére.

3818. - Publ.: Bnllarium sen litterae romanurum pontificum pertinentes ad sacram religionem et ordinem militarem d. 1. Manritii et Lazari nunc ad aedem Thononiensem... Aurnstae Taurinomm, s. d. (XVII"s.), in-folio.

Thorn. - Abbaye (dioc. de Liège).

3819. - Pubt. : De archieven van het kapittel der hooradellijke Rijksabdii Thorn 966-1794). nitir. door Jos. Habets [en A. J. Flament]. Yaastricht, 1889-1899: 2 rol. in-8" de Lxxx-5ti8 et xc-84t p. avec pl.

Thouars. - Abhay de Sint-Laun dion. de Poitiers. 38:0. - Cartnlaire de Saint-Lan de Thonars : ms. fait pour Gaignières an XVIIle siècle, smr papier, in-folio cle 143 p. Bithloth. nationule, ms. latin 5484 .

Prbl. : Cartulaire de labblaye de Saint-Laon de Thonar. par Hurnes Imbert Mémoires de lu Srriété de stutistique du dép. des Deux-Sèrres, 2e série. XII. pp. I-xL et 1-216. et a part: Xiurt. 1876 : in-8" de sxxum-216 payes.

Lee plus ancien document est de $110 \%$.

Lixtrait fait an XVII siècle Biblinth. He ln cille de Pritions, coll. Iom Fontenean. vol. I.XXX VII. fo 28.5 .

Thouars. - Hòpital un aumònerie dr Saint-Miehel.

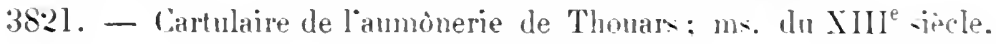


sur parchemin [incomplet de la fin]. contenant 48 actes de 1206 a 1.5:3, in-4 de 3:2 pages Chartrier de Thouars, il M. le duc de la Trémoille).

P’ubr. : Cartulaire el chartes de l'aunònerie de Siant-Mlichel de 'Thonars, publ. par B. Ledain (Aichioes historiques du Poitou, XXXI, 1901, p. .)-81).

Thuin. - Ville.

38:2. - Cartulaire de la ville de Thuin: ms. des XVIIe-XVIII siècles,

sur papier, contenant lles actes de 1164 a 1742 , in-folio, pariné 59 i :3:2l drelieses communales de Thuin.

Thuir. - Ville.

38:2:3. - Cartulaire de la ville de 'l'huir ou « Livre vert mineur»; ms.

dn XIV siècle [1:315] avec additions postérienres, sur parchenin, conterant des actes [en partie catalans] de 1191 a $144 \%$, in-10 de $.2 \mathrm{ff}$. Archices municipales de Thuir. At 1 ).

38:4. - Autre ou " livre vert majenr »: uns. des XIVe-XVIII siècles, sur papier, contenant des actes de 1270 a 1771 , in-folio de $182 \mathrm{ff}$. Archices mmicipales de Thuiv, At 2 .

Tinselve. - Prieuré (dioc. de Laon).

38:5. - Cartulaire de la cense de Tinselve. près de Leuilly, dépendant

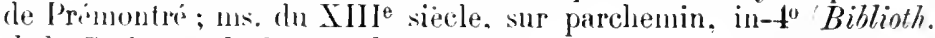
de lu Société archéolagique de Sonissons.

I’ubl.. : Carhulaire de Tinselve. par l'abbé Pècheur (Bulletin de la Société archéolongique al scientifinue de Sorssons, 2u série. V, 1875, p. $21: 2-248$.

Tirlemont. - Egrlise Saint-( ie:main (dioc. de Malines).

38:2i. - Carmlaire de l'église St-Germain de 'Tirlemont: ms, des XVe_ $\mathrm{X} \backslash \mathrm{I}^{\prime}$ siecles. sur parchemin. contenanl 184 actes de $\mathrm{I} 2 \mathrm{l} 4$ à 1459 , in-4" rle llin tf. drchices de l'église de Tirlemont).

Manquent les ff: 26-39.

Tirlemont. - Ville.

3827. - Recueil des privilèges de 'Tirlenont; ms. du XVIII' siècle, sur papier, conlenant des titres de 1290 à 1489 , in-4" de 88 pages Archires communales do Tivlemont.

Tiron. - Abbaye de la Trinite (dioc. de Chartres).

38:28. - Cartulaire de l'ahbave de Tiron: ms. du XIJe siècle, sur parchemin. in-folio de $93 \mathrm{ff}$. (Archices dép. d'Eure-et-Lair, $\mathrm{H} \mathrm{1374).}$

On y a ajouté 4 feuillels du $\mathrm{XV}$ e sicele, provenant sans aucun doute. d'un autre cartulaire (perdu) de la mème abbaye. 
Copie du précedent. faite au XVII siècle [16:30], sur papier, infolio de 282 pares (Archioes dép. de Eure-et-Loir, $\mathrm{H} 13375$ ).

On $y$ a joint 6 feuillets supplémentaires, du $\mathrm{XVI}^{\mathrm{e}}$ siacle, cotéancienn' $212-217$, et paraissant provenir d'un "Cartulaire de Blois et de Dunois ").

Copie moderne du même, par E. Lefevire [1846]. in- $4^{0}$ de $2: 32$ ff. (Bibliath. de la ville de Chartres, ms. 1311).

Autre copie par Lejeune [1840], in-folio de 418 page- Billioth. nutionale, ms. latin 10107 .

Publ. ; Cartulaire de l'abbaye de la Sainte-Trinité de Tiron. publ.. par Lucien Merlet. Chartres, Garnier, 188:3 : 2 vol. in $4^{\circ}$ de cxuII254 et Iv-377 p. [Société archéologique d'Eure-et-Loir.]

3829. - Recueil de titres relatifs à l'abbaye de Tiron; ms. du XVII ${ }^{e}$ siècle, par Dom Anselme Le Michel, sur papier, in- $8^{0}$ Biblioth. nationale, ms. latin 13820, ff. 33-62 et 73-81).

Les ff. intermédiaires sont extraits du cartulaire préeédent ou du volume suivant.

38:30. - "Vetus registrum papyraceum cartarum Tironensium »: orig. perdu.

Extraits faits par le même an $\mathrm{XVII}^{\mathrm{e}}$ siècle (Idem, ms. latin 13820 , ff. 69-72) Cf. le vol. XXII de la coll. Duchesne. ff. 347-360.

Tiverny. - Village (dioc. de Chartres). - Voy. Suresses.

Toiselay. - Prieurè de Saint-Tibutce, à Chàtillon-sur-Indre (dioc. de Bourges).

38:31. - Cartulaire du prieuré de Toivelay. dép de l'abbaye de Déols; ms. du XVII ${ }^{e}$ siècle [1608]. sur papier, contenant des actes à partir de 1459, in-folio de $97 \mathrm{ff}$. (Archives nationales, P $111 \mathrm{l}$ ).

Tongres. - Église collégiale Notre-Dame.

38:32. - Cartulaire du Chapitre collégial Notre-Dame de Tongres: ms. du $\mathrm{XVl}^{\mathrm{e}}$ siècle [1532], sur papier, rédigé par Guillaume de Merca, in-folio de 315 ff. (Archices de $l$ Élut à Hasselt).

38:33. - Autre du $\mathrm{XVI}^{e}$ siècle [1590], sur papier. transcrit par le chanoine Salomon, et contenant des actes a partir de 1164, in-folio de $180 \mathrm{ff}$. (Archives de Wotre-Dame de Tangres,

Axal. : Bulletin de l'Institut archéologique liégeois, XVI (188I), pp. 324-385, par l'abbé J. Daris.

Les plus anciennes chartes seulement sont analysées. - Cf.aussi Annales de l'Acudrimie d'archéologie de Belgique, te strie, III (1887).

Tongres. - Courent de Sainte-Agnès.

3834. - Cartulaire de Sainte-Agnès de Tongres; nts. des XVe-XYIIt. 
siicles, sur papier, contentant des actes de 1472 a 1601 , in-folio de $84 \mathrm{fr}$. Arohives do l' État à Hasselt.

Tongres. - Villr.

3835. - Camulaire de la ville de Tongres; uss. du XVIIIe siecle, sur papier. contenant des acles de 8:3l à 1299, in-folio de $296 \mathrm{ff}$. Archires conmunules de T'ongres.

Tonnerre. - Abbaye de Siant-Mirhel (dioc. de Langres).

38:36. - Cartulaire de Saint-.Michel de Tonnerre, composé vers 1500152.2 ; !nss. sur parchemin, comprenant originairement 12 vol. dont il en subsiste senlement 8 [manr [uent les vol. cotés A, B. E, K] , infolio de 218, v1-291, 168, 110, 14:3. 189. 134 et 204 ff. Bibliotl. de la ville de Tomnerre, mss. 27-34.

C. E. Petit dans l'Amanaire de l'Yonue, 1876, p. 31 ( $3^{*}$ parlie).

38:37. - Autre cartulaire de Siant-Nlichel de Tonnerre; ms. du XVI siecle, sur papier, in-folio de 215 th. Irclices dép. de l'Yonne, $\mathrm{H}$ $2 ! 6 !$.

38:38. - Recueil d'actes relatifs ì St-Michel de Tonnerre; ms. du XVIII siècle, formé par Dom (ionjet, et contenant les actes de 980 à 1.509 (Bibliollh. nutionale, coll. Champagne, vol. XLIV, 11. $103-13(6)$.

\section{Tonnerre. - Comlé.}

38:39. - Cartulaire du romté de Tonnerre (XIII ${ }^{\mathrm{e}} \mathrm{X} \mathrm{V}^{\mathrm{e}}$ siècles); orig. perrlu.

Copie du précédent; us. du XVIIle siecle, sur papier, in-fulio de $2: 34$ parres drchices dép. de l'Yonne. E 190 ).

3840. - Cartulaire des fiefs du comté de Tonnerre; ms. du XVe siècle, sur parchemin, contenant des actes de 12l:3 ì 1405, in-folio de 1:32 1f. (.1rchives dép. de le Côte-d Or, B 104:38).

Gontient d'autres actes que des areux et hommagres.

Tonnerre. - Hòtel-Dieu.

3841. - Cartulaire de l'Hòtel-Dien de Tomnerre ; ns. rédigé par Jean de Flarigny an XIVe siècle [13333], sur parchemin, avec quelques pieces copises postérieurement, in-folio de $44 \mathrm{l}$ ft. (Archires hospilalieves de Trunerve, A $\mathbf{t}$ ).

(if. Bulletin historique et philologique du Comité, 19006, 1p. 14-22.

Tonnerre. - Ville.

384.2. - Publ. : (hartres et litres anciens des habitans de Tonnerre. Anxerre, C. de Villiers. 1630 ; in-8" de 228 p.

Torcé. - Prienure de Notro-Dame (dioc. du Mans).

384:3. - Cartulinire de Notre-Dame de Toreé, dépendant de l'abbaye 
de Marmontier; ms. du Xl'Ile siecle. sur papier, contenant dos titres depuis le $\mathrm{XI}$. in-folio de $60 \mathrm{Ht}$. (Archices dép. de In Sierthe. H $375)$.

Copie du mène (Archives dép. de la Surthe, $\mathrm{H}: 376$ ).

\section{Toul. - Abbaye de Saint-Eprre.}

3844. - Recueil de titres relatifs à l'abbaye de Saint-Lipre de Tunl: ms. du XVIle siècle, sur papier. de plusieurs mains, contenant des textes à partir de l'année 948 collationnés en partie d'après les originanx (Biblioth. nationale, mis. latin 12661. If. 2-56).

Toul. - Abbaye de Saint-Mansuy.

3845. - Cartnlaire de l'abbaye de Saint-Iansuy de 'T'onl; orig. perdin.

A été utilisé en 1712 par B. Picart: Supplément à l'histoire de lid maison de lorraine.

Extraits faits an $\mathrm{XVII}^{\mathrm{e}}$ siècle (Biblinth. nationute, coll. Baluze, vol. XLVII. ff. 31-62 et 66-68.

Toul. - Église collégiale saint-Gengoul.

3846. - Cartulaire de Saint-Gengoul de Toul ou « Livre du soleil »; ms. di XIV'e siècle. sur parchemin. in $t^{\circ}$ de .ot. fir. Archices nationales, L.L 986.

Actes des annérs 105 a i 1311 arec aldition de 1544. Plusieurs ffo lacérés ont élé reconsilués.

3847. - Autre cartulaire; ms. du $\mathrm{XVe}$ siècle [14633]. sur parchemin, in-40 de $15 \mathrm{ff}$. (Biblioth. nutionuls, ms. 10020).

Toul. - Église cathédrale.

3848. - Cartulaire de l'église de Toul : orig. perdu.

Extraits par Nic. Riganlt an XVIIe siecle « ex veteri chartulario ecclesie Tullensis ». sur papier (Biblioth. nationale, coll. Dupny, rol. 593 , tf. 175-182.

3849. - Cartulaire du Chapitre cathédral de Toul ; ms. du XVe siècle, : $11 r^{\circ}$ parchemin, contenant des actes de 1263 i 1297, in- t" de $^{\prime \prime} 106 \mathrm{ff}$. (Archives dép. de Jeurlhe-e--Moselle. G 1:331).

3850. - Recueil de titres relatifs à l"église de Toul : ms. fait an XVII siècle. sur papier (Bibliath. nutionule. coll. Baluze, vol. XIrII. ff. 3-29).

Toul. - Érèchí.

:38.5l. - Recueil de titres relatils à l'éveche de Tunl: ms. du XTII siècle, sur papier. contenant des actes depuis le XI" siècle. infolio

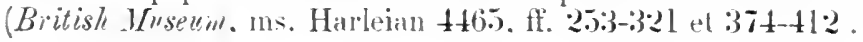


3852. - Frigment diun cartulaire des évêques de Toul, concernant en partie le prieuré de Commercy ; ms. dn X Ve siècle [148t], sur papier, contenant des actes depuis 1049, in-folio (Idem, ff. 555-566).

Toul. - Évèques et cilè.

385:3. - Recueil des titres relatifs anx évêques et à la cité de Toul; ms. de la fin du XVIe siècle, formé par Thierry Alix, sur papier, contenant des textes de 1213 à 1583 , in-folio de $247 \mathrm{ff}$. (Archives dép. de .Meurthe-et-.Mosclle, B 396).

Toul. - Ville.

3854. - Recueil des privilèges de la cité de Tonl: ms. du XVI siècle, sur papier, contenant des titres de 1253 à 1588 , in-folio de $77 \mathrm{ff}$. (Archives municipales de Toul, AA 1).

3855. - Cartulaire des anciens titres de la ville de Toul; ms. de 1780, rédigé par l'archiviste C. J. F. Le Moine, sur papier, contenant des titres de 1367 a 1681 . in-folio de $72 \mathrm{ff}$. (Archives cominunales de Toul, AA 2 ).

Toulon. - Chapitre cathédral.

3856. - Fragnent d'un cartulaire de Sainte-Marie de Toulon [ $\left.\mathrm{f}^{0} 34\right]$; ms. dn XIV siècle, sur parchemin, un feuillet in-folio (Archices de l" paroisse Saint-Cyr à Toulon).

Cf. une note de l'abbé M. Criraud (Bulletin de la Sociéte des sciences, belles-lettres et arts du Var, XXV1I, p. 341-348). - le fragment recouvré est de l'année 1364.

Toulouse. - Abbaye de Saint-Sernin.

3857. - Cartulaire de l'ahbaye de Saint-Sernin de Toulonse; ms. de la fin du XII" siècle, sur parchemin, in- $t^{\prime \prime}$ de $170 \mathrm{ff}$. (Arckices de la fulrique de Saint-Sernin, ì Toulouse).

Publ. : Cartulaire de labbaive de Saint-Sernin de 'Tonlouse (8441200), par l'ahbé C. Donais. Paris, Picard ['Tonlonse. Privat], $1887^{\circ}$; in- $4^{0}$ de $[1 \mathrm{v}-] \mathrm{calv}-6 \mathrm{Il}$ p. et pl.

3858. - Autre des $\mathrm{XVI}^{\mathrm{e}-\mathrm{XII}}{ }^{\mathrm{P}}$ siècles, contenant 80 titres des années I097-163I, sur parchemin, in-folio de $130 \mathrm{ff}$. Archives dép. de la Haute-Garonne, $\mathrm{H}$ non coté).

3859. - Autre cartulaire [du XIIJe siècle] ; orig. perdu [arait au moins $181 \mathrm{ff}$.$] .$

Extraits du précédent. faits an. XVII ${ }^{\mathrm{e}}$ siècle (Biblioth. natinnale, coll. Baluze, vol. LXXY, If. 25:3-278).

Toulouse. - Archerèrlié.

3860. - Livre blanc de l'archevêché de Toulonse: ms. des XIII _ 
IVle siecles, confenant is acles des ammers 810-1514. sur parchenin,

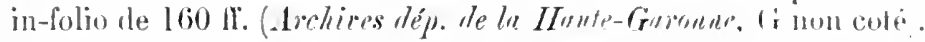

3861 - Antre carlulaire du XIVe siecle. conterant 14.) acles des

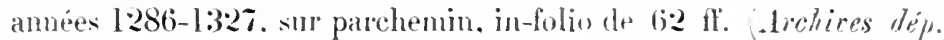
de lu Huute-Guronne, (i non colé.

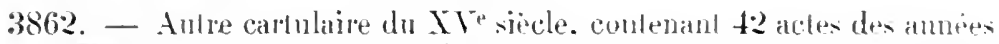

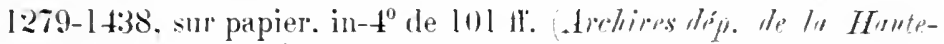
Groronne, (i non cute.

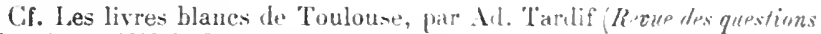

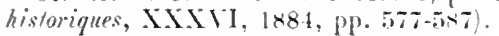

Toulouse. - Chapitre métropolitain.

3863. - Cantulaire du Chapilre de Saint-lifinute de Tonlonse: ms. dir IV siècle, contenant des actes de celfe seule époque. sur papier,

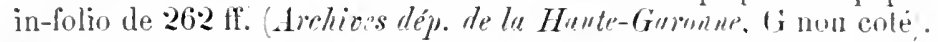

3864. - Antre du XVe siecle, contenant des fitres des annés 1460 1478. sur papier. en 2 rol. in-folio de 148 a $282 \mathrm{H}$. Archires dep. de la Huute-Gurome, (i non coté).

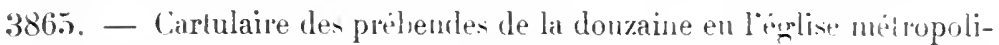
taine de Tonlonse: ms. du IT sièle. contentant lif acies is partir

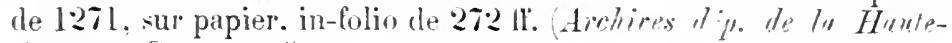
Gurouse, Gr non coté.

Toulouse. - Comle.

3866. - Cartulaire du comle de Tomlonse. comm sur le nom de « Garnlaire de Raymond VII»; ms. dn XIIJ siecle.sm parchemin. avec talile en tête. contenant des tilres de 1144 à $124 \%$, in-t" de v-189 11. (Arrhices mintionles, J.J 19).

Copie du précédent. faite en li.s8 par Baluze, in-4 (Biblinth. nutionule, ms. latin 6220$)^{\circ}$.

Antre copie faite an XVI" pour Colbert, in-t" Biblinth. antionsle, ns. Iatin 6009 .

Antre copie faite par $X$. de Sainle-Marlhe pour l'abluave de SiantGermain-les-l'rés, in-lolio (Biblioth. matinull'. ms. latin 12853'.

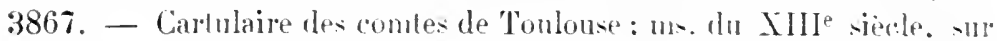

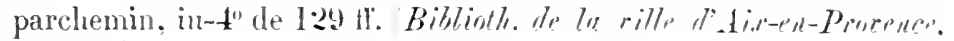
ins. 671 ).

Cé renueil est classé méthodiquement par dior-inen. E-t-ree relui que sipnale (Chantereau-Lefebre (Traite des tiefo) comme elant alors (16itie) -n la possession des Jésuites de Toulouse?

Toulouse. - Confrérir dr Sainte-Anno.

3868. - Cartulaire de la confrérie de Sainte-Anne de Tonlouse: ms. des XVIe-XVIF siecles. contenant 72 actes des anneres 1:318-1699. 
sur parchemin, in-lolio de $192 \mathrm{fl}$. (Archires dép. de la Haute-Garonne, $\mathrm{H}$ non coli).

Toulouse. - Confrerir de Saint-Jarpues. 3869. - Cartulaire de la confrérie de Saint-Jarques à Toulouse; ms. dır $\mathrm{XVII}^{\mathrm{e}}$ siècle [I617], contenant 47 actes des années 1507-1617, surp parchemin, in-folio de $74 \mathrm{ff}$. Archioes dép. de la Haute-Garonne, H non cote $)$.

Toulouse. - Conliérie du Corpus Christi.

3870. - Cartulaire de la confrérie du Corpus-Christi de Toulouse; ms. dn XVI $\mathrm{X}^{\mathrm{e}}$ siecde. contenant 204 documents des années 1:347-1550, sur papier. in-folio de 210 Ir. Archives dip. de le Haule-Garnne, $\mathrm{H}$ non cote.

3871. - Autre du $\mathrm{XVII}^{\mathrm{e}}$ siccle, sur parchenin, in-folio de $192 \mathrm{fr}$. (Archives dép. de la IIaute-Guroune, $\mathrm{H}$ non coté).

Toulouse. - Confrère du Pain-Bénit.

3872. - Cartulaire de la confrérie du Pain-Bénit à Toulouse: ms. des $\mathrm{XVl}^{\mathrm{p}}-\mathrm{XVI} \mathrm{I}^{\mathrm{e}}$ siècles. contenant $7 \mathrm{l}$ actes des années $140 \mathrm{I}-\mathrm{I} 662$, sur parclennin. in-folio de 197 II. Archices dép. de la Haute-Garonne, $\mathrm{H} n$ non cotín.

Toulouse. - Comlrérie lu saint Nom de Jésus.

3573. - Cartulaire de la confrérie du Saint-Nom de Jésus à Toulouse; ns. des $\mathrm{XVI}^{\mathrm{e}}-\mathrm{XVHI}^{\mathrm{e}}$ siècles, contenant des documents des années 134:-I78:2. sur parchenin, in-lolio de $67 \mathrm{fr}$. Archives dép. de la Haute-Garonte. H non coté.

Toulouse. - (inurent des bominicains.

3874. - Cartulaire du convent rles Frères Prècheurs de Toulouse; ms. des XVII $-\mathrm{XVIII}$ siècles, contenant 209 titres des années 15:38-1717, sur papier. en 2 vol. in-folio (Avchices dép. de la Houte-Garonne, H non coti .

3875. - Prbl. : Mocunents relatifs à l'histoire des Fì̀res Prêcheurs de la province de Toulouse. [Marseille, 1865]; in-40 de 124 et $32 \mathrm{p}$.

Toulouse. - Convent des Girands Augustins.

3876. - livre noir des Grands Augustins de Tomlouse; ms. du $\mathrm{XV1}^{\mathrm{e}}$ sièrle [1542], contenant 90 documents des années I398-I497, sur purchemin, in-folio de $278 \mathrm{ff}$. Archives dép. de la Haute-Garonne, H min coté.

3877. - Livre rouse des Grands Angustins de Toulouse; ms. du $\mathrm{XVII}^{\mathrm{e}}$ siecle [ $[6.54]$, contenant $5 \mathrm{I}$ clocmments des années 1378-1660, 
sur parchemin, in-folio de $270 \mathrm{HI}$. Archices dép. de lo Muute-Gajomne, $\mathrm{H}$ non cotes .

3878. - Autre cartulaine des cirands Aumustins de Toulouse, dil le "Livre de Notre-Dame de P’itié »; ms. du XVIIe siècle [I(j80)], contenant 116 doemments des années 1268 - l 6 (i8, sur papier, in-folio de $270 \mathrm{fl}$. (Archires dép. He la Haute-Graronne, H non coti.

Toulouse. - Compent des Trinitaires.

3879. - Cartulare des Trinitaijes de Toulouse ; ns. compone en 1692 par (irégoire Revnès, sur papier. in-folio drehiess dép. de lu HurteGuronne, H non coté).

Ciest une histoire abrégée contendnt lat transcription l'un reertain nombre d'actes anciens.

Toulouse. - Egrlise de Notre-Dame de la Dalbade.

3880. - Cintulaire de Notre-Dame de la Dalbade; ms. des $\mathrm{Xl}^{\mathrm{r}}-\mathrm{XVI}$ siecles, contenant des acles des années 1296-1569, sur parchemin in-folio de 288 If. Archives tép. de la Haute-Guronme. (i nun cote.

Toulouse. - Prieuré de Notre-Dame dr la Dauradr.

3881. - Cartulaire de Notre-Dame de la laurade; ms. du XVII ${ }^{\mathrm{e}}$ siecle, contenant des titres de 1611 à 1690 . sur papier. en 2 rol. in-folio de 461 et 2:2:3 ff. (Archives dép. de la Hante-Gumane, $\mathrm{H}$ non cuté.

Toulouse. - I'niversité.

3882. - Cartulaire du collège des Jésuites de Toulouse: nus. des XVII $-X V I 1 I^{e}$ siècles. contenant des titres des années $1616-1737$, sur papier, en 2 vol. in-folio de [.2.2 et $96 \mathrm{ff}$. Archives de la IfunteGaronne, 1) non coté).

3883. - Cartulaire dı collège Saint-Bernard de Toulouse; ms. dn Xl11 ${ }^{\mathrm{e}}$ siècle. sur parchemin, contenant des actes des années 1161 1218, in-4" de 188 ff. (Archices dép. de ln Haute-Grionne, 1) non coté).

3884. - Antre du XV111 sièle, contenant des actes de $1[6 ; 3$ i 1776 , sur papier, in-folio de $284 \mathrm{ff}$. Aichives dép. de la Haute-Gurrome, D non coté.

3885. - Cartulaire du collère Saint-Martial de Toulouse; ms. du XVIII siècle, contenant I:30 actes des années 1294-1667. sur papier.

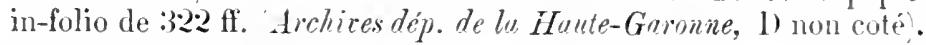

Toulouse. - Ville.

3886. - Cartulaire de la ville de Toulouse. connn sous le nom de «Consuetudines civitatis Tolose 》; ms. dn XIVe siècle [1:30.)], collationné par Jacques Vedel, notaire à Toulouse, sur parchemin, avec table moderne à la fin, contenant des actes de 1141 í 12416 , in-8 $8^{\circ}$ de $92 \mathrm{ff}$. (Archices nutionales, J.J 21). 
3887. - l'remier cartulaire dn Consulat de Toulonse on « Ildefonsus»; 11s. commence en l:205, par le notaire Guillame Bernard, sur parchemin. contenant des documents de 1141 a 1279 . in-40 de $126 \mathrm{ff}$. Arrhires innicipules de Toulouse. At 1.

Enlevé des archives en 1806, è regintre $y$ a ité réintégré en 1822. - Un double (aver puatr" documents nouvenux) est conservé sous la rote 1A 2 (parch., $118 \mathrm{ti}$.

:3888. - Antre cartulaire dı Consmat de Toulonse on « Live hlanc »; ns. commence en l:2!5 par le jotale Bernard de Sante-tiulalie el

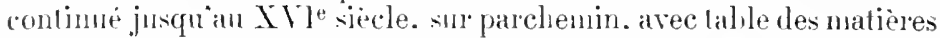

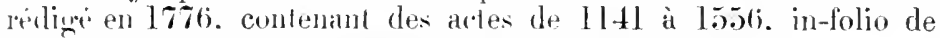

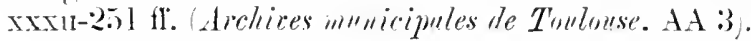

Double du précédent : ms. du XIIle siecle. sur parchemin, in-4u de $96 \mathrm{ff}$. (K.K. Hofliblinlleph an Wien, ns. 2210).

Ct. Vietor Molinies dans Rerueil de l'Aculsmir de léplislation de Tou-

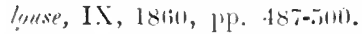

:388?. - Rerneil d'arles ofliciels concernant la ville de Tonlonse: ms. du XlVe sièle. sur papier. contenam des actes de 1192 a $1: 3: 202$,

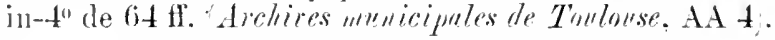

:3890. - Recueil des privilines de la ville. ms. du X TI siècle [1540], rédicra par $\mathrm{I}^{\mathrm{e}}$ ( imill. Mazamdier. sur parchemin. avec reliure ancienne en pean extampee. et contenant des actes de 11.52 a 1539 . in-80 de

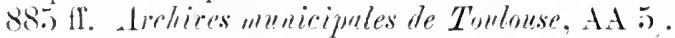

Cie registre, longtemus appele "lo vidimat del libre blane w, nest pats une reproluction du registre AA 3. - Cf. le regristre AA 6 exécuté en litito.

Ax.x.. : Inventaire des arelives communales de 'Toulouse, par li. Roscharch, l (I8!) 1). pl). 1-104.

$38: 3$. - P’rz. : Recuril des tilres concernant le privilege de la ville el hourapoisic de 'Tolone Tolose. 166:3. in-4"; nouvelle édition

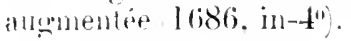

Tournai. - Mblatr dr Simb-Martin.

3892. - Cartulaire de Saint-Marlin de Tournai ; ms. du XIII siècle, sur parthemin. incomplet de la fin. in-folio de $59 \mathrm{ff}$ i 2 col. Lirlices de litut à Mons .

389:3. - Aulre du XIV siecle. sur parchemin, in-folio de 179 pages à 2 col. Arehires de litat is lons.

3894. - Antre dn XIII siecle [1265)]. sur parchemin, revêtu d'une relinre de cuir ronue in lemoirs de cuivre, avec addilions posté-

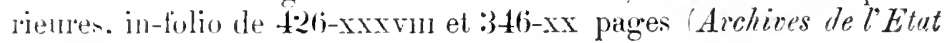
i) 1 onls.

La premier volune contient une table qui est conmune aux deux.

389.5. - Autie de la fin du XIII siecle, sur parchemin, incomplet au 
commencement el à la fin, et formé de franguents muliles. in-fulio de 112 parres ì 2 col. Archices de le litut à 1 forls.s.

3896. - Antre du XIlle siècle. sur parchemin. conplété par 3 ff. de

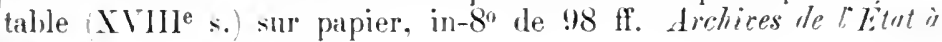
Vons.

3897. - Autre lu XlVe siècle. sur parchemin. spécial anx biens possédes par l'ahbaye à Thorellies et it Maude. in-t" de lol pares Archires de litut à Wons.

3898. - Autre du Xille siècle. formé de denx frament diflérents, sur parchemin. incomplet an commencement et à la lin. in- $4^{0}$ de $\mathrm{I} 4 \mathrm{ff}$. (Archices de l'Etut à . Mons.

Les 8 premiers feuillets sont à 2 colonnes.

3899. - Antre de la fin du XlVe siècle. avec additions du X $\mathrm{V}^{\mathrm{e}}$ sur parchemin. orné d'une reliure de cuir rouge à fermoirs de cuivre. in-folio de 666 pages à 2 col. Archices de l Étut is Mons.

3900. - Autre du XIVe siècle. sur papier. in-folio de l: ff. à 2 col. Archives de l lítat ù Mons .

390l. - Autre, rédigé en 1687-169l et collationné par le notaire Lours Delionne, sur papier, en 2 vol. in-folio de 1032 pares dichices de l'État ù Mons).

3902. - Autre. rédigé an XV1Ile siècle et collationnè par le notinire Delerue. sur papier. in-folio de 200 pages tochices de liftut is .1\%oss).

3903. - Antre du XVIII siècle, sur papier. in-folio de l.t2 panges

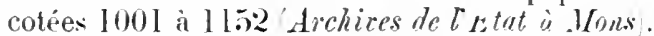

3904. - Cartulaire de la pitancerie: ms. des XIIle-XVe sipcles, sur parchemin, in-folio. pp. 344 a 3366 Lrehives de lis tut it Wows.

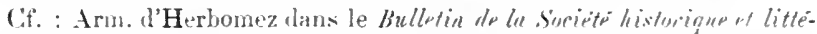
raire de Tourna, XXIT, 1893, pp. 316-339. - lors de la rélaction de ces notices, les eartulaires étaient conservés aux .1rchices d" Roymume à Bruxelles, ou ils portajent respectivement les nos 119-132: : le dernier seul provient de Cheltenham (anc. no 2155 ).

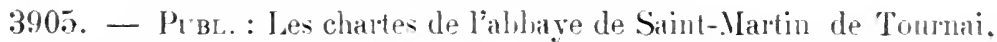
par Arm. d'Herhomez. Bruxelle. Hayez. 1898-1901 : '2 rol. in-to de $[1-]$ xurv-747 et iv-688 p. [Collection des chronic!nes betgres inéditro.

Cette publication s'arrête à liannée 1690 .

Tournai. - Abbay" de Saint-Médard ou de Saint-Nicolas-
des-Pres.

3906. - Cartulaire de l'ablare de Sinint-Mfédard de Tournai on "Livre rouge »: ms. du XIlle siecle. - wr parchemin, contenint des docn- 
ments de 1126 i 1276, in-folio de 27.) ff. (Archives du Grand. Srminuive de Tournai.

Publ. : par le chanoine J. Vos dauns les Mémoires de la Saciété

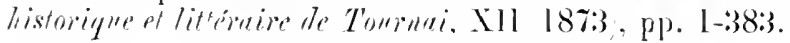

Tournai. - Chapitere athèdral Notro-l amm.

3:4)7. - Camblatire du Chapitre cathédral de Toumai on « Magnum

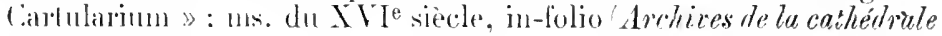
de Tournit.

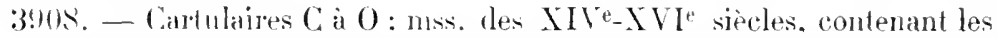
privilemes ef donations du chapitre X.-I). de Tournai, en 12 vol. intol. de !2. 35., 210. 280, :312. 401, 240, 269, 267. 198, 166

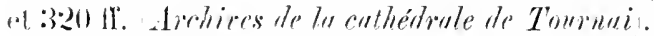

En réjurtoire des précídents cartulaires existe sous le titre de "Summa "lartulariorum" (in-folio d" $391 \mathrm{ft}$, XVII" siecle).

390!\%. - Carrulatre R du Chapitre cathédral de Tournai ; ms. du

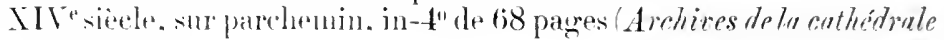
de T'surnui.

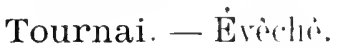

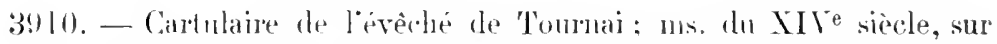
parchemin. incomplet an commencement et à lis fin, in-4" de $40 \mathrm{fr}$.

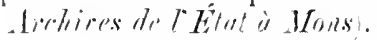

Dathe extrêmes: 1221-1251.

3911. - Autre cirtulaire du XlVe siéle. sur papier, mulilé el incomplet du début, avec addilions postricienres, de plusienrs mains, intfolio de $8: 3 \mathrm{fr}$. Airclieres te le Étut à Mons.

1)ites extrimen. 12:5-1424.

$391: 2$ - Antre carlularie du XVe siecle. sur parchemin, de plusienrs mains. en :? vol. in-lolio de 168 . 8.) et 13:3 ff. Archives de l'État à Mrols.

Dates ixtrêmes: : 12:31-141i0.

Arec des tahles alphabéliques rédigées par Denys Codefroy.

11 exinte deux zemplaires d'un inventaire de ces trofs volumes

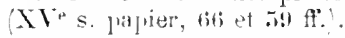

391:3. - Autre cardulatire du XVe sirele. sur papier, in-folio de 85 pages

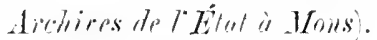

Ditis tratrites : $1142-1: 320$.

3914. - Autre du XIVe siècle. de phusieurs mains, sur parchemin,

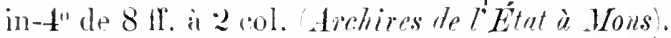

3:15.). - Antre des $\mathrm{XVI}^{\mathrm{e}} \mathrm{X}$ VIIle siècles, sur papier, avec lahles finales de lat mime éporque. in-folio de $202 \mathrm{ff}$. (1rehives de l'État à Mons). 
3916. - Autre du XVIe siecle, sur papier. avec relinre armorice du $\mathrm{XVIl}$ siecle, in-folio de 9.) ff. (Archioes de l' Etat is . Wrous.

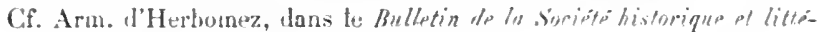
raire de Tinrinai, XXIN, 1×93, pp. 288-296.

\section{Tournai. - Ville.}

3917. - Cartulaire municipal de 'Tommai on "remi-tre de cuir noir" »; ms. du Xille siècle. avec additions postérienres. sur parchenin. contenant des actes de 1267 i 1647 . in-folio Archires communales de Townai, $\mathrm{n}^{0} 2$.

3918. - Antre cartulaire on "respistre de cuir roume " : ms. des AllleXlVe siècles, avec additions postérieures, sur parchemin. contenant des actes de 1197 a $17 \cdot 27$, in-folio de $221 \mathrm{ff}$. et $333 \mathrm{ff}$. de tables (Archices communules de Tourmi, $11^{\circ} 1$.

3919. - Antre cartulaire on « $33^{\text {e }}$ renistre de cuir rougre»; niss. du XIVe siecle. avec additions postérieures. sur parchemin, contendunt des actes de 13332 à 1.57l. in-folio de $315 \mathrm{ff}$. Archires commundes to Torimi, $\mathrm{n}^{0} 3$.

3920. - Antre cartulaire ou « reuristre de cuir blane $»: m$. du XVe siète. sur parchemin, avec une reliure de bois recouverte de cuir hanc, in-folio de $28 \mathrm{ff}$. Archices rommumales de Tominui. n"5).

3921. - Regristre des chartes de la ville de Tonmai : ms. dn XVIle siecle. sur papier. contenant des actes de 1:3:3:3 à 1688. in-folio de .008 10 (Archires comimuales de Tourmi, $\mathrm{n}^{0} 12$.

3922. - Antre recueil. inventaire-cartulaire: ms. dn $\mathrm{XVI}$ siecle. sn! papier. in-folio de 35.5 ff. (Biblioth, de la ville te Tourumi, ms. 214.

3923. - Cartulaire général de Toumai: ms. du IVIIJ siècle. sur papier. contenant des actes de 1211 à 1725 , en 4 vol. in- 4 trokres communales de Touruai, $\mathrm{n}^{0 .} \boldsymbol{z}$ et 10 .

Tourne. - Bironnir.

3924. - Prbr. : La baronnie de Tonrne et sessejurneurs, par A. Philippe (Bulletin de la Société diafriculture, industrie, scipuces at urts do lo Lozère. annexe 190:3-1904, pp. 1-220.

Recueil factice de textes des XIIe-Xi' rimeles.

Tournon. - Ville.

39.5. - Cartulaire municipal de Tournon : copje du IVIlle siècle, sir papier. contenant des actes de $1188-$ I541), in-folio de $599 \mathrm{ff}$. 'Arehires nationales. KK I2:30.

Tournoux. - Ville.

3926. - Cartulaire municipal de Tournoux ; ms. du XVe siècle [1497], rédigé par le notaire l'ierre Nitard, en forme de rouleau de parchemin. 


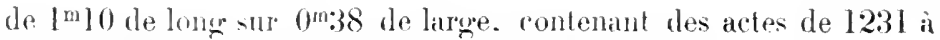
1:385 Arrlices dip. des Bassss-Alpes, E non coté.

Tours. - Iblaye de Saint-Julien. 3927. - Curtulinire de Saint-Julien de Tonrs ; orig. perdu.

Extrats du cartulaire de Saint-Julien de Tours, faits an XVIII" iecle. sur papier Biblioth. mutionmle, coll. Baluze, vol. XVIII, LIV, et LXXVII. ff. 85-88 et 98-105).

Autre extrait. fait par Giaionières, in-folio de 1:29 pages Biblioth. nutionale, ms. latin it4:3); - autre du XVIIJ siècle Idem, coll. Dom Housseilu, vol. XIII .

3928. - Recueil de titres sur l'ablatye de Sirint-Julien de Tours; ms. dn XIXe siècle. sur papier. rédigú par André Salmon d'après des ropies de Gaimnières et antres. in-40 de $340 \mathrm{ff}$. (Biblioth. de la ville de T'mrs, ms. 1:278).

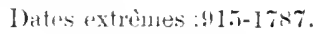

Tours. - Irehrèche.

39:29. - «Liber honirum grentimm » on Livre hanc de lareherêché de Tours; orig. perdn.

Copie laite en 178:3 par Don de Bétencourt. sur papier. in-to de

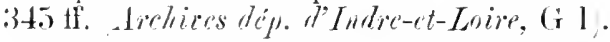

Autrer copie. finte en 1873 Biblioth. nationale, ms. nonv. acq. latines 1217-1:218; - antre copie. par Audré Salmon. sur papier Biblivith. de la ville de Tours. 111. 1267.

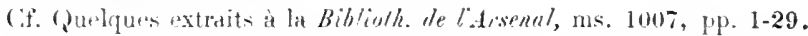

Pubr. : Cartulaire de larchevèché de Tonr's. par Louis de Grandmaicon Mrimsires de la Société urchéologique de Touraine. XXXVIIXXXYII. 1892-1894: : vol. in-8" de 304 et 504 p. .

3930. - Framenent d'un cartulinire de larchevèché de Tonrs; ms. du XVIe siecle. stl papier, contenant $2: 3$ actes des Xle-XIIIe siècles, in-t" drolliess dn latican. il Rome. Nise. Arm. XV, t. 144).

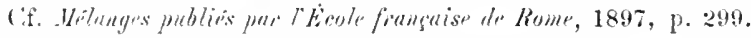

Conpie laite an XVHe siecle Biblinth. nutionnle, n1s. latin 11888 , fi. $1.5-4: 3$.

Tours. - Eglisr cathedrale Saint-Xlaurice.

3931. - « Lilher ecclesie Turonensis qui dicitur compositionmm »; ms. du XHI siecle. sur parchemin. aver additions des $\mathrm{XV}^{\mathrm{e}}-\mathrm{X} \mathrm{Vl}^{\mathrm{e}}$ siècles, in-folin de xu-245 panges Biblinth. de la ville de Tours, ms. 1281).

bates extremmes: 1118si-1 490.

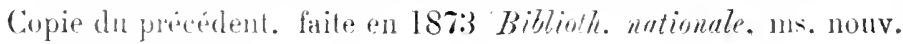
i:cop. Satines $118: 3$. 
Copie de la première partie du même [pp. l-96i]. sur papirar. par

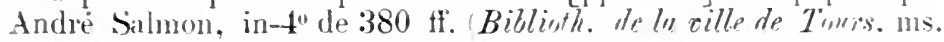
1272 .

3932. - « Regristrum ecclesie Turonensis v on « livre de l'lischenuele »; ms. du Xlle sipcle, sur parchemin, de plusienrs mains. comenant

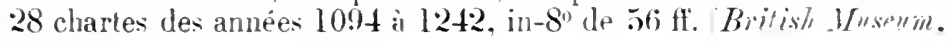
fonds Lansdowne, $n^{0} 349$.

Sur ce volume, of. Archires des Missions scientifinus of lithroires 1 (18.00), p. 488: et Bibliothèque de l'Écale des Churtes, te sirie. 1 1855), p. 108. - On y trouve quelques bulles relatives à l'ablave th Dtols.

393:3. - Cartulaire de la chapelle des Anges en l'église métrópolitaine de Tours: ms. du XVe siècle, sur papier, en mauvais état. contenant des actes de 1309 à 1466, in-folio de $25 \mathrm{ff}$. (Archieses drp. I'Irdreet-Loire, G 1082).

Tours. - Église collégiale Saint-Martin.

3934. - La « pancarte noire » de Saint-Martin de Tonrs rédigée avant 1137 par le sous-écolâtre Joubert, et comprenant 148 pièces et $15.5 \mathrm{ff}$. au moins : orig. détruit.

Nombreux extraits a la Biblinth. nutionale. coll. Baluze. vol. LXXVI, fl. 3-177 et 32:2 ; coll. Dupuy. vol. 828 ; coll. D. Hunsseau, vol. XIII; ms. latin 13898, ff. 4:3-14i, etc.

Axal. : La pancarte noire de St-Martin de Tours. hrullée en 179:3, restituée d'après les textes imprimés et manuscrits. par Enile Maliille. Tonrs, Ladevèze [Paris. Henaux], 1866 ; in-80 de 240 p.

Ce recupil factice comprend linalyse de: 148 pièces cortespondant aux années $806-1211$.

3935. - La « pancarte blanche » de Saint-Martin de Tums 'XIII s.. 303 ff. au moins); orier. détruit.

Extraits à la Biblioth. nutionale. coll. Balnze, vol. I.XIVI, fo 213 . et LXIXIV. ff. 127-128: coll. I)npuy. vol. $\$ 28$, ff. 79-105; coll. D. Housseau. vol. XIII.

Cf. ausi las rol. cclxxxir-cchxxxm de la coll. Baluze. ett: Défense des privilères de l'église de st-Martin de Tours (Yaris. 1716, in-folio).

Autre copie de la « pancarte blanche » $145 \mathrm{tr}$.). égalenent perdue. mais en partie lranscrite par Baluze Biblioth. mutiounle. coll. Baluze, vol. I.X.VII, ti. $151-158$ et $196-274$.

3936. - La « pancarte ronge » de Saint-Martin de Tonr- urig. détruit.

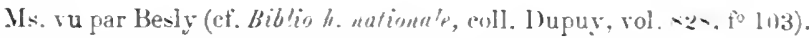
Extraits divers des mss. précédents on des archives de l'éplise Archices untionales. $\mathrm{h}$ 18.): - Bibliotl. nutionule. cull. Baluze. vol. XLVII. II. $140-146$ et 1.59-18t. al LXXIV. t1. 110-1?l tet 
127-132: Mélanges Collert, vol. 46, fr. 52-136; ms. latin 12683,

fl. 1-20; ms. Iatin 13817, ff. 289-290; ms. latin 1:3818, ff. 242-250). 3937. - Recueil de titres relatifs à Saint-Martin de Tours; ms. du XIX"e siècle, rédigé par André Silmon, sur papier, en 5) vol. in-10 (Biblioth. de la ville de Tours, inss. 1285-1289).

Dates extrêmes: 1315-1790. La collection est chronologique.

Tours. - Ville.

3938. - Publ. : Privilèges de la ville de Tours, par Jean Chenu. Paris, 1620 , in- $4^{0}$.

3939. - Publ. : 'Tiltres de l'élablissement dı corps de ville de Tours; privilènes des maires, eschevins et habitans d'icelle ville. 'Tours, [ $66 \mathrm{l}$, in- $\mathbf{1}^{0}$.

Tourves. - Ville.

3940. - Cartulaire municipal de Tonrves; ms. du XVIo siecle, strr papier. contenant des actes depuis 1350), in-40 de 73 II. (Archives municipules de Tomres, AA 1).

Trappes. - Voy. SaInT-Denis.

Treize-Vents. - Prieuré de Notre-Danne (dioc. de Luçon).

3941. - Pras. : Cintulaire des prieurés de Marmontier en Bas-Poitou, par l'aul Marchegay, dans: Cartulaires du Bas-l'oiton (La Rochesul-Yon, 1877, in-8'), pp. I-xxiv el (51-2:5.

Trésoriers de France.

394:. - Publ. : Recueil général des titres concernant les Trésoriers de France, par S. Fonrnival. Paris, 1672, in-folio.

Trèves. - Abbaye dr Saint-Maximin.

394:3. - «Liber intens Trevirensis »; orig. perdu.

Copie du XVe sipele; ms. sur parchemin, in-folio (Stadtbiblinthek Trier, n11. I (632).

Cif. Trieristhes Arhir, IX (1906).

Antre copie du XVI ${ }^{e}$ siecle, sur papier (Stunlsarchiv zu Coblenz). :3944. - « Das gronse Maximiner Diplomatar »; copies du XVII siècle, en I.t vol. in-folio (Stattbiblintlek Trier, mss. 1254-1266).

Cf. A. Dopsch, Die falschen Karolinger-Urkunden fuir Sit-Maximin (Mitheilungen des Instiluts für oesterreichisehe Geschichtsforschmi, XVII, 1896, 1p. 1-34): - et le mêne (Henes drehix, XXV, 1900, pp. 317-344).

394.). - Pcвs.: N. Zyllesius, Defensio abbatiae imperialis Sancti Maximini. Coloniae, 1638, in-folio.

Trèves. - Archevêchí.

3946. - «Liher privilegriorum et jurium ecclesiæ Treverensis », vel « Codex pictuatus Balduini »; ms. des XIII -XIVe siècles, 
contenant de documents jusqu'd 1354, sur parchening. in-folio (Stnatsarchic zu Coblenz.

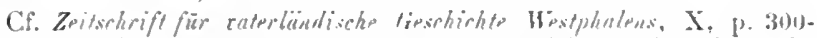
321 : - et G. Irmer, Die Romfuhrl Kaiver Hoinrirt's HII in Bildorychs

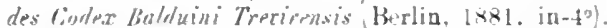

Cos numes archives possinfent encore xli reoristres do transcriptions

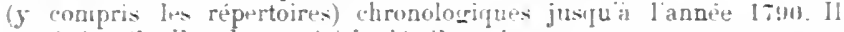
paraît inutile d'en donner ice le detail, mais on pourra se reporter सम travail de Krestinger : Extrails des "artulaires des archevèques-élenteurs de Treves (113\%-1760) qui se trouvent a Cobleno (lomplose

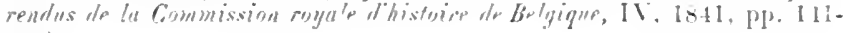
$1(11)$

3947. - «Balduinemm »: ms. du XIV"e iècle. sur parchemin. in-4" de t.27 fi. (Stadt-Bibliothek Trier. m- 18.01.

Beaucoup de pifices, il fartir le l'an $41 \%$, tirées de ces recueils, sont imprimées dans J.-N. de Honthein. "Historia Trevirmois diphnatica et pragmatica $\$$ Aususto Vindelicorum. 1751)-1757, 3 rol. in-folio).

3948. - Fragment d’un cartulatire de l'églive de Trèves: ns. du Xille siècle. á lungues lignes. sur parchemin. contenant des fragments de bulles pontificales des années 1137-115i. sur:2 tif. Biblinth. nationule. ms. nonv. acr. latines 88\%.

Trèves. - Alcherishot chapitre.

3949. - Recueil de titre- relatif- a l'archevishé et an Chapitre de Trèves: ms. de la fin du XÝ sièrle. forme pal Thierry Alix. sur papier. contenant der textes de 1280 a 158.5 . inffolio de $24 \mathrm{ff}$. (Archires dép. de Leurth-et-Moselle. B 397.

3950. - Extraits de divers cartulaires le Trìves: ms. du ATII siècle. sur papier. in-folio Biblioth. royule de Brujelles. ms. tiitti.

Triel. - Hospico.

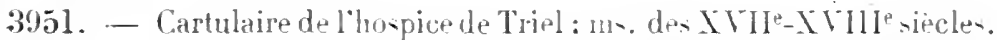
sur papier. contenant des documents de 169.5 a 17.5 ti. in-fuliu de 280 ff. Archires hrspitslisess de Tripl.

Trinquetaille. - Commandrie (dioc. d'Alesi).

3952. - Cartulaire de Trinquetaille. dépendant du Ciranul prieuré de Saint-Gilles: ms. des XII -XIJ siecles. sur parchemin. in-fulio de $85 \mathrm{ff}$. (Archices dép. des Bouches-du-Rhionte. H non cotè).

Troarn. - Abbare (dioc. de Biypus).

3953. - Cartulaire de labbave de Troarn : m.. du début du XIV" siècle, sur parchemin. in-folio de r子-242 If. Biblioth. nutionate. ms. latin 10086).

Dates "xtrêmes : 1101-1336. Provient de l'abbe de la Rue et if A. Le Prérost qui l'a donné en 1>4: ì la Bibliother fue.

3954. - Autre cartulaire on "Liber rubeus »: ms. dn XIII siecle. 
sur parchemin, avec additions posterienres. in- $4^{0}$ de $160 \mathrm{ff}$. (Archives dép. du Calpatos, $\mathrm{H}$ non colè).

("est hien certainement ce registre qui est ainsi clésigné : " Un ancien ") charlries de la trésorerie de Troarn relié ef couvert de cuir rougre, i) fermant de courriettes de cuir noir ferré de cuivies" (Archices dép. de Itrine, H 1454).

3955. - Antre cartulaire dit « parvus Liber rubeus y; ms. des XIII" XVIe siecles, sur parchemin, ill-40 de 57 If. (Archives dép. du Caloudos. H non coti.

3956. - Autre cartulatie dit « C'hartrier blane 》; ms. du XVe siècle, sul parchemin, contermut des documents à partir du XIe, et muñi

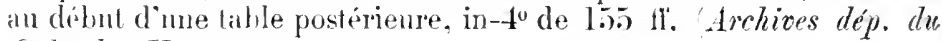
Calcades. H non coli).

(if. un recristre in-folio de la collortion Mancel (ms. 159) à la Biblioth. de lit cille de citest.

Trognon. - Chàtellenie en Lorraine.

3957. - Recneil de titres relatifs à la chatellenie de Trognon et Sampisny : ms. de lia fin du XVI siècle, formé par Thierry Alix, sul papier. coutenant des textes de 1276 i 1574 , in-folio de $316 \mathrm{ff}$. (Archiors dip. de Werthe-et-Woselle, B 398).

Copie partirlle dı pricédent, faite an XVII siècle, sur papier, conlentant des litres de 1276 i 15in8, in-folio de $260 \mathrm{ff}$. (Archives

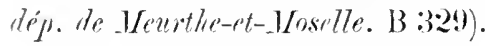

Voir aussi yo Jorkoy-t.e-tekc.

Trois-Fontaines. - Abbaye (dioc. de Châlons-sur-Marne). 3!t58. - Cirlulatre de l'abbiye de Trois-Fontines : orig. perdu.

Copie dn précédent; nns. du XVIlle siècle, sur papier, in-folio Biblinth. antivale, coll. Champanne, vol. XLV).

Tronchiennes. - Abbaye (dioc. de (iand).

3959). - Cartulaire de l'albaye de Tronchiennes; ms. dı XIVe siècle, sur parchemin, contentaut des documents de 1130 à $130: 3$, en 2 cahiers

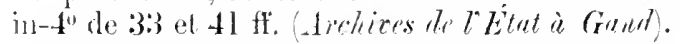

Troô. - Prieuré de X.-I). des Marchais. - Voy. Marmoutier.

Troyes. - Abbaye de Notre-Lame aux Nonnains.

39660. - Cartulaire de l'abbaye de Totre-Dame-aux-Nonnains de Troyes; orig. perdu.

Extraits faits an XVII siècle (Biblinth. nutionule. coll. Duchesne, vol. XX. tf., $391-393$ :

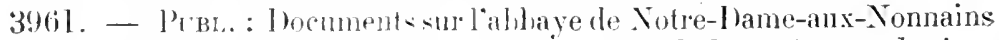
de Troyes. pars l'abibe Ch. Lalore Hémoires de la Société ucadémique 


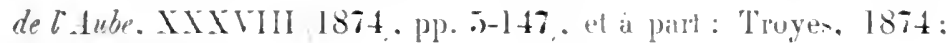
in-8" de $2: 38$ p.

Recueil fartice lew années 1147 it 1500 , publiées intérralenent ou par extrails, dapres les originaux et lapres les copies cuntenues dan.

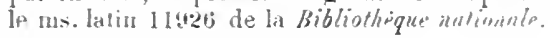

Troyes. - Abbare de saint-Loup.

3962. - Cartulaire de St-Loup de 'Trove: m. dı Xille viecle. sur

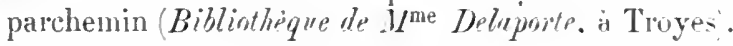

Extrait fait par Besly an XVI" siecle (Biblioth. untionule. coll. Dupuy, vol. 828, t1. 129-1:30).

Prbl. : Cartulaire de l'abbaye de Saint-Luup de Troves. par l'abbé Ch. Lalore. dans sit Collection des principunx curtuluires dne diocese de Troyes, I (187.) : in-8" de xuri-36.) p.

Compread 274 chartes des annét 1181 at 1303

\section{Troyes. - Chapitre cathélral Saint-Pierre.}

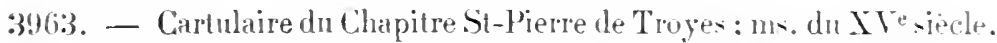

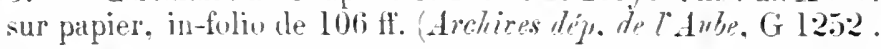

3964. - Autre cartulaire du $\mathrm{XV}^{-e}$ siecle. sur papier. contenant 48 piece. des années 12:26 à 1468 el plus particulièrement relatif anx bienpossédés par le Chapitre à Montier-la-Calle, in-folio de $60 \mathrm{ll}$. (Archices dép. de l:1ulie. G 125:3.

3965. - Premier et second curtulaires der oftices du Chapitre cathédral : ms. di XVII siècle. sur papier, contenant des titres de I278 à 16.54,

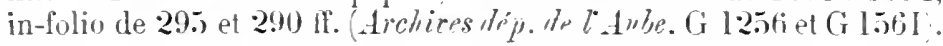

Troyes. - Commanderir de Saint-Jran-de-Jérusal’m.

3966. - Cartulaire de la commanderie de Saint-Jean-de-Jérusalem a Troyes ; ms. daté de 15\%2. contenant 23 actes des années 1194 1566, sur papier. infolio de $48 \mathrm{ff}$. Amchires aip. he linbe. $\mathrm{H}$ non coté.

Troyes. - (ompent des Trinitaines.

3967. - Cartulaire des Trinitaires de Troye : ms. di XVIIL siecle, sur papier, contenant des actes de $[260$-I 781 ). en 2 vol, in-folio de $31: 2$ et $289 \mathrm{fr}$. Amhires dép. te labe. $\mathrm{H}$ 150.3.

Troyes. - Eglise cathédrale saint-Étienne.

3968. - Cartulair de st-Étienne de Troyen: m. du XIII" siecle [rers 1260], avec addilions contenant des chartes de Philippe III. ef lettres ornees, sur parchemin. in-folio de $394 \mathrm{fl}$. à 2 col. (Bibliath. nationale, ms. latin 17098 . 
Troyes - Évêchri.

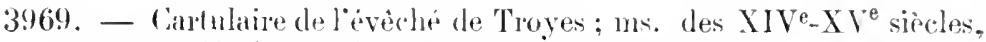
contenant 2 I chantes te $1: 362$ i 1473 , sm papier, in-folio de 58 ff. (Archives dél). de l'Aube. (ir 19).

Troyes. - Hôtel-Dien le Comk.

3970. - Premier cartuline de l'Hôtel-Dien le Conte de Troyes; ms. daté de 1:36l. et rédigé par " frère Pierre Trolier, $m^{\mathrm{e}}$ de la dite maison », sur papier. contenant des actes depnis 1 I80, avec additions jusqu'en 1373, in-4" de 114 II. (Avehives dép. de l'Aube, $40 \mathrm{H} \mathrm{127}$ ).

3971. - Antre de l'ammie 1382. rédigé par le nème; ms. sur papier, contenant des actes a partir de 1169 , in-folio de $141 \mathrm{ff}$. Archives

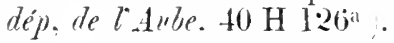

3972. - Autre des XIVe-XVe siècles; ms. sur parchemin, contenant des actes de 1169 a 1488 . in-folio de I04 ff. it 2 col. (Avchives dép. de l'Aube. $40 \mathrm{H} \mathrm{l}: 26^{\mathrm{b}}$.

Troyes. - Léproserie Saint-Lazare.

3973. - Cartulaire de la léproserie Sant-Lazare de Troyes: ns. des XII-X Yesiècles. sur parchemin, contenant des titres de II 23 à 1480 , in-folio de I:24 ff. Archices dép. de l'Aube, $41 \mathrm{H} \mathrm{I}$ ).

I’ubl. : Yotice historique sur la léproserie de la ville de Troyes, suivie de la liste des dons fait à cette maison depuis I I 23 jusqua la fin du $\mathrm{XV}^{\text {re }}$ siècle, avec tontes les pièces justificatives tirées des cartnlaires ef des archives de ladiie léproserie, par J. Harmand. Troyes, Bomprot. 1849) ; in- 80 de $252 \mathrm{p}$.

Y sont publices 170 chartes dlis années 1123 à 1531 .

Troyes. - Villi.

3974. - Cirand cartulaire de lat ville de Troyes; ms. commencé en 1377, et contime an XVesiècle. sur parchemin. contenant 82 chartes deptis de XIII siècle. in-folio de I50 ff. (Archioes municipales de Thyes.

Copie du précedent. laite en 1837 par Harmand; ms. sur papier, en 2 vol. in-4" de 330 et 320 If. (Biblioth. de la ville de Troyes, ms. 2249).

3975. - Petit cartulaire de la ville de T'royes; ms. du XVe siècle, sur parchemin, in-40 de 60 fr. (Bibliolh. de la ville de Troyes, ms. 2591).

Copie du précédent, fiite en 1838 par Harmand; ms. sur papier, in-4" de I10 ff. Biblioth. de la ville de Troyes, ms. 2250).

Tulle. - Mhaye de Saint-Martin.

3976. - Publ. : Cartnlaire des abbayes de Tulle et de Roc-Amadour, par J.-B. Champeval. Brive, imp. Roche, I90:3; in-80 de Iv-632 p. 
(Extr. du Bulletin de la Société scientifique. histurique et archéulugique de la Corrèze, à Brive, de 1887, p. 42I, i 1902, p. 299.

Doit ètre utilisé avec précaution (Le Biblioplile limousin, 1904, p. 15). A partir de la page 5.2 , la pagination du volume est errunée. Dans son préambule, l'éditeur déclare avoir utilisé deux cahier- de copies su XVIII siecle, dont l'un est un extrait "fait sur celui de M. Balu\%+". Les documents concernant Roc-Amalour sont in appendice.

3977. - Grand cartulaire de Saint-Marlin de Tulle: stu parchemin, de $260 \mathrm{ff}$., orig. perdu.

3978. - Petit cartulaire de Saint-Martin de Tulle; origr. perdu.

A été vu par Baluze, et par Mabillon en 1701.

3979. - Cartulaire de l'aumònerie : ms. du XIV siècle. origr. perdu.

Copie du XVII ${ }^{e}$ siècle, contenant quelques copies d'actes et un terrier Biblisth. de I. J.-B. Champeval).

Tulle. - Confririe de Notre-Dame de Gràr.

3980. - Cartulaire de la confrérie de Notre-Dame de Gràce à Tulle: ms. du $X V^{e}$ siècle, sur parchemin, in- $t^{0}$ de 80 p. (Bitlinth. de M. G. Clément-Simon, au chàteau de Bach en limousin.

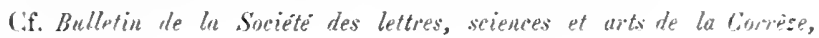
. 1901 , p. 495 .

Tulle. - Courent des Récollets.

3981. - Cartulaire du couvent des Récollets de 'Tulle ; ms. conmencé en 1608, sur papier, contenaut des textes à partir de 1491 , in- $4^{\circ}$ cle $409 \mathrm{ff}$. (Biblioth. de .M. G. Clément-Simon, au chau de Bach .

Tulle. - Église cathérliale.

3982. - Cartulaire de l'aumònerie de la cathédrale de Tulle: orig. perdu.

Copie incomplète du précédent, faite au $\mathrm{XVII}^{\mathrm{e}}$ siècle, sur papier.

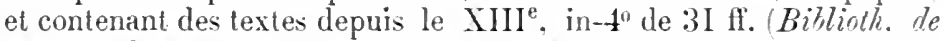
M. G. Clément-Simon, au cha de Bach.

Tulle. - Ville.

3983. - Cartulaire municipal de Tulle. contenant des titres des annes 1495 à 1681 ; ms. du XVII ${ }^{\mathrm{e}}$ siècle, sur papier, de 176 fl. in-folio (Archives municipales de Tulle).

Turenne. - Vicomtr.

3984. - Publ. : Liherlén el franchises de lil vicomlé de Turenne. Paris, Pellé, 1658, in-4". 
Turin. - Eglise Siant-.Jean.

3985. - Cartulaire ancien de l"égrlise Saint-Jean de T'urin; origg. perclu ?

Guichenon th a extrait une charte qui est publiée dans l'Histoire grénéalogritue de la nuaison de siavoie, nouv. édition, IV, P. 14.

Turnhout. - Ville.

3986i. - Recueil des privileyres de la ville de Thurnhout; nus. du

XVI sircle, sur papier. in-4" (Archives communules de T'urntrout.

Dates extrimes: 1311-1557.

3987. - Autre recueil du XVIIle siècle, sur papier, in-folio (Archives cominunales de Turnhout,

Dates extrêmes: 1311-1761.

Turpenay. - Abbaye (dioc. de Tours).

3988. - Cartulaire de l'abbiye de Turpenay ; orig. perdu.

Nombrenx extraits fails au XVIII siècle (Biblioth. nationule, coll.

1). Honsiean, passim,

3989. - Recueil de chartes relatives à l'abbaye de T'urpenay : ms. du

IIA ${ }^{e}$ siecle, sur papier. par André Salmon Biblinth. de la rille de Trums. ms. 132.5).

Tusson. - Abbayo (dioce d'Angoulême).

3950. - Casmlaire de liablaye de Tusson, dépt de l'abbaye de Fonlevandd ; orion. perdn.

lixtraits « ex cartulario monialium Tucionensium », par 1)om Col vers I769) (Biblioth. mutionule, ms. latin 9196, p. 441-44:3.

Tykford. - Prieuré (Burkinghamshire).

3991. - Cartulaire du prieuré de Tyklord en Anrleterre, dép' de l'ablaye de Marmontier: ms. du XIII siècle Biblioth. du comte de Gre. ì Wreskpark. Berlforlshire).

Cette indication date d 18\%1). Nous ignorons si le cartulaire test "mcore entre les mains du même propriétaire.

Ully-Saint-Georges. - Village (dioc. de Beauvais).

39!2. - Cartulaire d'Clly-Saint-Georges. Franconville, Montmorency, Noyvillers el Saint-IIartin-du-Tertre, dépendant de l'ablaye de Saint-1)enis; ms. du XIII siècle, sur parchemin, avec additions pustiriemes. contenant des actes des années $1170-1401$, in $-t^{0}$ de II-201 il. (Arelives nutionales, L.L. 117l.

Ce registre offír une lacune en tête, à la suite de la table.

Ulmois. - Prieuró, à Heiltz-le-Maturupt (dioc. de Chàlonssire-_larmo). 


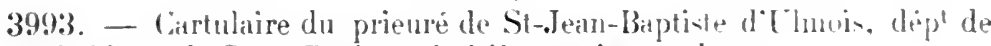
l'abbaye de Saint-Bénizme de l)ijon : urig. perdı.

Exstrait fait all IVIle siocle Biblioth. nationslo. cull. Baluze, vol. XXXIX. If. 1:34-1:39!

Urgel. - Comti.

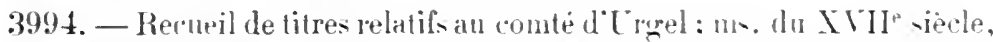
contenant des actes des année. 969 a 1428 . in-fulio snr papier. (Biblioth. nationale. coll. Doat, vol. 161, ff. 2:35-292. et rol. 162, ff. $1-161$.

Urgel. - Église "athédralı.

3995. - « lotaliorum ecclesie Urcellems, liber prinus : ms. du XIIJ siècle. sur parchemin. arec additions postérieures. in-fulio de 31:3 ff. Archico del Curbildn de Uigel .

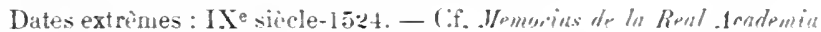
do buenas letras de Barcelonu, I, p. 3332.

Extraits informes faits en 1660 (Biblinll. nutionule. coll. Baluze, vol. CXVII, ff. 334-335.) :379-380 et :384-38.) .

Ces extraits sont suivis des cupies de pipcen failes sur les originatu.

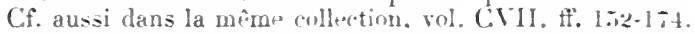

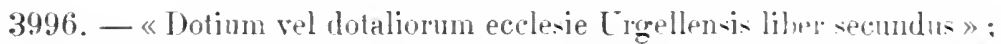

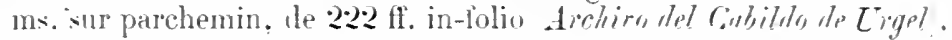

Extraits faits en I660) par Guillaume Costa. moine de Cuxa. pour Baluze. contenant des rlucuments de 819 à la fin du XII siècle

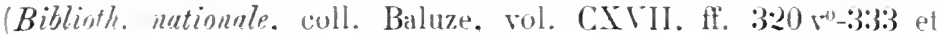
$345-357$.

Uzerche. - Abbara dioc. de Limoges'.

3997. - Cartulaire de l'abuye d'Ćzerche ; orig. perdu.

Copie faite sur le précédent au XrIIe ? siecle : ms, perdu.

Dans le Journal de Dom Jacipes linver, pull. par A. Vermière, p. 249 , on lit is la dale de 1712 : "le travaillai aux archives it Nleymac et je fis un catalogue des abbés: il y a une copie du cartulaire d'Uzerche $"$.

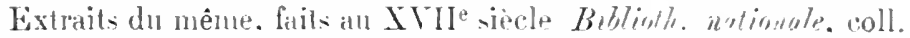
Duchesne. vol. XXII. ff, 2I.5-2:38; coll. 1)upuy. vol. 8\%8. ff. 19-22 : coll. Baluze. vol. 377. avec talle : ms latin 1:2701. ff. 89. par Dom Chantelon: ms. latin 12746. p. 701-702. et ms. latin 12\%5. pp. 207-21l et 25.), parr bom René du Cher: m1. latin Iills. pp. $2 \tau-8: 2$ extraits'.

3998, - Plbu. : Cartulaire de l'abbaye d'Czerche. ares: tahle- identifications. notes historipues du $\mathrm{X}^{\mathrm{e}}$ au $\mathrm{XIV}^{-}$siècle, par J.-I3. Champeral. Tulle. Crauffon [Paris, Picard et fils]. 1901 ; in- 8 " de 
544 p. Lixtr. du Bulletin de la Sociélé des tottres, sciences et arts de la Correze, de 1887, p. 398, i 1897 , p. 527, sauf les tables).

láateur a utilisé entre autres manuscrits une copie "tirée sur l'xirait de .1. Bandel " qui a appartenu ì Mrr. Berteaud, évếque If 'lulle (39 et $22 \mathrm{fr}$.), et dont nous ignorons la destination actuelle.

Vabres. - Ėglise el évêché.

3999. - Cartulaire de l'église et de l'évèché de Vabres; ms. daté de 1667. contenimt des acles des années 864 ì 1560 , in-folio de $2: 37 \mathrm{ff}$. (Biblioth. nationale, coll. I) aat. vol. 148.

Vaillampont. - Commanderie de Malk (dioc. de Namur). 4000 . - Cartulaire des commanderies de Vaillampont et Chantraine ; ms. du XYlle siecle, sur papier, contenant des titres de 1160 à I655, in-4" de 305 Ir. (Archices du royanme de Belgique, à Bruxelles).

4001. - Autre cartulitire des commanderies de Vinilampont, Tirlemont et Chantrine; ms. dn $\mathrm{XVHI}^{\mathrm{e}}$ siècle. sur papier, contenant des litres de II 60 it 1719, in-folio de I6:2 fr. sujvis d'un index Archives de l'Etut à Mous .

Valais. - Palys.

4002. - Publ. : Iocuments relatifs ì l'histoire du Valais, recueillis et puhliés par l'athé J. Grémaud Mómoires el documents publiés pur lu Saciele d"histoire de lu Suisse romande. I. XXIX à XXXIII, XXXVII à IXXIX, 1875-1898, 8 vol. in-8" de xxiv-604,641, 660, 648,

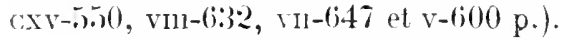

Cerecueil antient miron 3000 pieres depuis les temps les plus rerulés jusquà l'année $145 \pi$; mais brautoup d'entre elles ont été

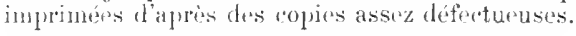

Val d'Aoste. - Toir au «supplément».

Val-Dieu. - Abbaye flioc. do Liege.

4003. - Pcor. : Chartes de Val-1 lieu, par Jung. Bacha Comples-rendus de la Comminssion rongale d’histoire de Belgique, 50 série. IV. 1894, pp. 1:2:3-l(it et :24I-29!3).

1)o vuments dis XIII -XIVe siecles.

Val-Duchesse. - Prieuré (dioc. de Malines).

4004. - Cimlulitre du prieuré de Val-Duchesse ; ms. du XVIe siècle. sur papier, conteniant des titres de 1:368 à 1484, in-folio de $35 \mathrm{ff}$. (Arehices dur royaume de Belgique, ì Bruxelles).

Valence. - Évêthé.

4005. - Cimrulaire de l'évêché de Valence ou « livve rougre »; origg. perdu. 
4006. - Antre cartnlaire on "Livre l, lanc »: ms. dn XVIJ siède. sur

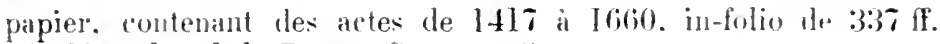
(Archices dép. de la Drône, G non coté).

Valence. - Ville.

4007. - Cartnlaire de Valence: ms. copié par Jules Ollivier en 1835 sur l'exemplaire in-folio ms. appartenant a M. de I,il Tourette,

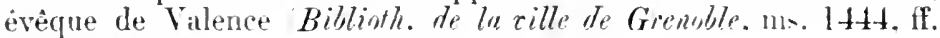
$217-32 \pi$.

Valenciennes. - Abaye de Saint-Jean (dioc. li. Cambrai). 4008. - Cartulaire de l'abbaye de Saint-Jean de Valencienues: ms. du $\mathrm{XIII}^{\mathrm{e}}$ siècle. sur parchemin. rontenant 30 pieces des années

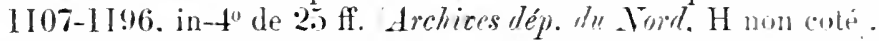

4009. - Cartulaire de la cure de la mème ahbare: ms. du XIV siecle, sur papier. contenant I9 pièces des années 1122-1384. in-4" de "2tiff. (Archices dép. d" Mork. H non cotè).

4010. - Cartulaire de l'écolàtre de Saint-Jean; ms. du XTe iècle, sur papier. contenant 24 pièces des amues 1 17\%-14:21. in-4" de $43 \mathrm{ff}$. Archices dép. du. . Wrod. H non cote).

Valenciennes. - Abbaye le saint-saulve.

4011. - Frigment du cartulaire de Saint-Saulve de Valenciennes; ms. dı XIII èèle, sur parchemin. in-4" Biblioth. de ln rille de

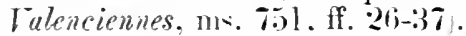

Valenciennes. - Chapitre de Saint-Géry.

4012. - Frárment du cartulaire de Saint-Géry de Talenciennes: ms. dn XII ${ }^{e}$ siècle. sur parchemin. in- $t^{0}$ Biblioth. de la rille de Tinlenciennes. ms. 751 , ff. $05-76$.

Ce cartulaire était encore complet au XVIII siecle, quanl Dom Queinsart l'eul entre les mains Cit. Biblinth. Mutionale, coll. Mureau, vol. 97, to $^{\circ} 42$ ).

Valenciennes. - Domaine royal.

4013. - Cartulaire du domaine royal de Valemeiennes: ms. du $\mathrm{XIII}^{\mathrm{e}}$ siècle. arec additions dn $\mathrm{XIV}^{-e}$ et table en tète, sur parchemin, contenant des actes depuis le IX e siècle jusquà I340. in- $4^{\prime \prime}$ de 11 If. (Archices nationales. JJ 22 ?.

Cif. une notice de Bonamy Weimoires de T.Aratomir les Lascriptions et Belles-Lettips, XXXVII, pp. 433-4t66).

Valenciennes. - Prieuré de Braumont.

4014. - Cartulaire dn prienre de Beamont; orig. perdu.

Extraits par Dom Cilfiaux Biblinth. nationale, ms. français:33076, ff. $337-348$. 
Valenciennes. - Villr.

401.. - I'remier cartulaire de Valenciennes; ms. du XIIIe siecle, sur pirchemin. contenant des actes de $1: 287$ it I29), in-folio de $8 \mathrm{ff}$. (1.rehices di'r. du Nord, B 1588).

40I6. - Second cartulaire de Valenciennes; ms. dı XIVe siècle, sur papier. contenant des actes de 1288 i I:3:38, in-folio de $6 \mathrm{ff}$. (Archices dép. Al! Nom, B 1.58!).

401\%. - Recueil de pièces sur l'histoire de Valenciennes ou « Iivre noir »; ms. du XIVe siecle. sur papier [ff. I-2.2] el parchemin, in-4 Biblinth. de lo ville de Valenciennes. ms. 679), ff. 1-115).

Voir la table complete dans le catalogue Nangeart (1860), pp. 694-704.

4018. - Recueil de transcriptions des privilèges et franchises de la ville de Valenciennes; ms. dn XYI $\mathrm{XV}^{\mathrm{e}}$ siecle. sur papier. contenant

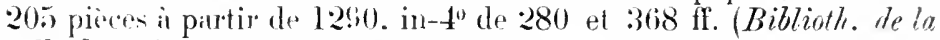
ville te Talenciennes. mis. 67.7-670.

Axal. : A. Muloir. Eswai sur l'histaire municipale de la ville de Valencimnes. Valenciennes. I84I. in-8".

Valenton. - Village (dim. dr Paris).

401!. - Cartulaire de Valenton. Châtillon-sous-Barnenx et Fontenayanx-Roses. dépendant de l'alblaye de Sirint-(jermain-des-Prés; nns.

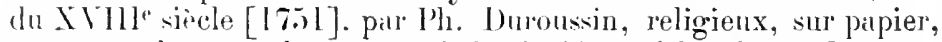
contenant des actes des annés 812 a 1745 , in-folio de 1I-189 et xrx If. Lrehives mimales. 1.L. 1043).

Valloires. - Mbaye (dim. l'Amiens).

4020. - Cartulaire de lablare de Valloires-en-Ponthien; ms. du X111" sierle. sur parchemin. contenant 572 actes des années 1135 -

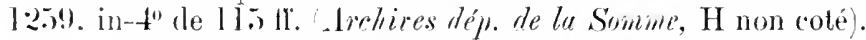

Une copie du XIX" sicle (in-folio de 628 p.) a passe en vente à Paris

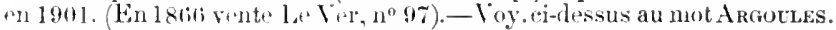

Cit. Rapport descriptif et analytique sur le Cartulaire de Valoires,

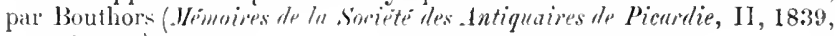
pp. 181-224).

Extraits faits par 1) Cange an XVIre siècle (Biblioth. nutionale, ms. liançais 9500. pp. 141-147).

Valmagne. - Abbaye do Notro-lame (dioc. d'Igde).

4021. - Cimblaire de l'abbaye hénédictine de Valmagne; ms. du

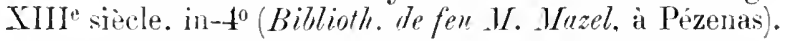

Extraits faits an XVII siècle par Dom Fstiemnot (Biblinth. naliomle, ms. latin 122760, pp. 42!)-440, et latin 12770, pp. I3:2141 . 
Valmont. - Abbaye de Notre-1)ame (dioc. de Rourn . 4022. - Cantulaire de lathange de Valmont; origo. perdis.

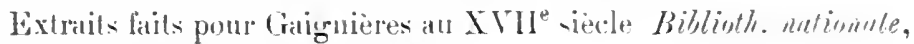
ms. litin 17049, partoses 525-527.

Val-Notre-Dame. - . hbaye (dioc. de Liège).

402:3. - Cartulaire de l'abbaye du Vial-Noire-Dame; im. da

XVII siècle, sur papier, contenant des actes de l:210 à l $166 b^{1}$. inl-lolio de $262 \mathrm{ff}$. Arclices de l'Étut ì Liège.

4024. - Aulre cirtulaire du XVII e siècle, sur papier. contruant des

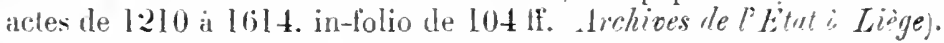
4025. - Aulre cartulaire du XVII e iècle, sur papier, contenant des actes de 1241 a 1616 . in-folio de 129 If. Archices te l' litut is Liegej. 4026. - Autre cartulaire des $\mathrm{XVe}^{\mathrm{X}} \mathrm{XVI}^{\mathrm{e}}$ siècles, sur papier. conterrant des autes de 1402 à 1579 , in-folio. Archives de l" Etut is Lirge.

4027. - Autre cartulaire des $\mathrm{XVII}_{\text {-XVIII }}$ siècles, sur papier, contenant des actes de 12503 à 1464 , in-folio. Archices te l"Etut ò Liège.

Val-Notre-Dame. - Abbaye (dioc. de Paris). - Voy. Le VAL-NOTRE-UAME.

Valognes. - Courent des Bénédictines (dion de Coutunces). 4028. - Cartulaire des Bénédictines de Valognes on de l'abbaye de

X.-I), de Protection; m. du XVII siècle. sur parchemin. contenant des actes de 16233 a 1660 , in-4 de 32 ff. Archies dép. de lu. Hanrhe, $\mathrm{H}$ norl coté.

Valpriez. - Abbaye, a Bieury dioc. de Solisons,

4029\%. - Cartulaire de labbaye de Vilpriez: M1\%. du XIII siècle. sur parchemin. contenant des acter de [135) is l2.)l, in-8" de 34 ff. (Archices dép. de lisisue, $\mathrm{H}$ i5:3).

Valprofond. - Abbaye (dioc de Paris). 4030. - Cartulaire de l'ablaye de Valprofond on dn Val-de-liràce; Inw. In XV'le -iècle. sur papier, contenant des actes de l18:3 à 1:349, in-4" de 35) ff. Archires nationales. S $4566, \mathrm{n}^{0} \mathrm{l}$ )

Van Borsselen. - Fanille. - Voy. ZÉLAvor.

Vance. - Seigneurir.

40:31. - Cartulaire de la seigneurie de Vance, appartenart à la lamille

Nothomb: m. Un XV111" siècle. sur papier, contenant des acter de 
1284 is 168.5, in-folio de 734 pages Biblioth. de l'Instimu archéologique dr.lolon.

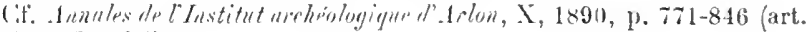
(lo Em. 'Tandell.

Vannes. - Diocèse. - Toy. Morbihax.

Vaour. - Commandrier des Templiers dioe. d'Albi'.

40:3\%. - Carlulaire tes Templier's de Vaour ; ms. de l'année l202,

linmant mu ronlealn de parchemin de $5^{\mathrm{mt}} 60$ de long, et contenant des

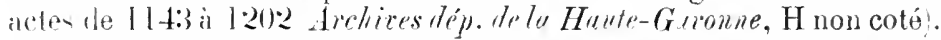

Pubr.. : Cartulaire des Templiers de Vaur Tarn, par Ch. Porlal el Eidn. Cabié. Alli. Nongries. 1894; in-80 de [1-] xxm-132 p. [Archives hisioric [ues de l'Albigeois, I.]

les textes sont en langue romane, ch tris grande partie.

Varennes-en-Argonne. - Chàtellenie.

40:3:3. - Cartulaire de la chàlellenie de Varemes-en-Argome: nus. du

XYI" vierle. contenant des titres depuis le XIVe in-folio sur papier de :390) tr. (Arehiress du chatean de Cihantilly. $\mathrm{n}^{\circ} 107^{\mathrm{e}}$ ).

Varzy. - Élise efligiale sainte-Eugenie dioc. d'Auxerre). 40:34. - Cintulaire du Chapitre Ste-Eugénie de Varzy; orig. perdu.

l élé utilisé par l'abhé Ltebeuf dan les preuves jointes au tome II It ses Memoires concernant l'histoire d'Auxerre (1743).

Vassy. - Forgess.

40:30. - Cartulaime de formes de Vassy : ms. du XVe siècle, contenant 12 chartes den anneses $11.7-1264$. sir palpier, in-40 de 5 ff. (Arehices dre. de l'atube. H non colé. fonds de Clainvanx.

Vaucelles. - Mbhaye do Notre-I)ame (dioc. dr Cambrai). 4036i. - Cartulaire de labbaye de Vancelles: ms. du XIII siècle, sur

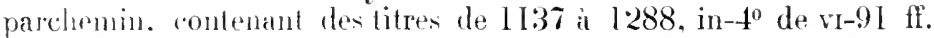

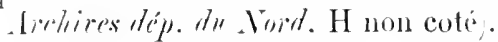

Copie moderne [187: ]. in-folio de 95 p. (Biblioth. nutionale, ms. nowr. acq. latines 12066 .

Vauclair. - Abaye dior de Laon).

40:37. - Camblaire de lablaye de Vauclair; ms. de la fin du XIle viecle, stur parchemin. in-t" de 92 ff. (Biblioth. nationule, ms. latin L107:3.

40:38. - Antre antulaire du XIII siècle, sur parchenin, in- $4^{0}$ de $77 \mathrm{ff}$. Bildiotle. untionule, nis. latin llo74.

Lues table contenporaine de ce derniter ms. (Is ff.) se trouve dans le 
volume suivant (ms. latin 11070). Ciette table prouve glue te manuscrit rentermait originairement 278 chartes (il nen contient plus ylu: 218).

Vauclair. - Preuri. - Voy. Le VAL-DEs-Chol:

Vaucouleurs. - Priente (dior. de Tonl.

4039. - Cartulaire du prieuré de Vancoulenrs: ms. In XIVe wiecle. contenant 15) actes des années $110.5-1284$, sur parchemin, in-40 de

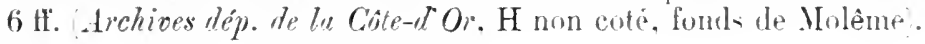

Vaudémont. - Châtollonìr.

4040. - Recueil de titres relatifs is la chàtellenie de V́andémont; ms. dn XVII siècle. formé par Thierry Alix. sur papier. contenant des

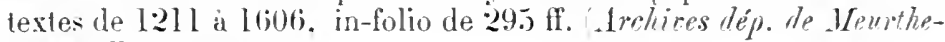
et-aroselle. B :399.

Vaugirard. - Village (dioce do Paris). - Vuy. Issy.

Vauluisant. - Abbaye (1liu. de Soms).

4041. - Cartulaire de l'abbaye de Vauluisant: mis. du Xille siècle,

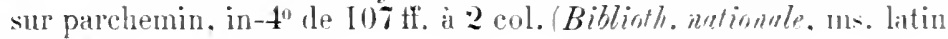
9901 .

Ce registre est compusé de plusieurs parties, axéculé par plusièrs mains, el offre des lacunes: il e-il en outre incomplet de a feuillets au lébul. Les dates extrènes sont 1128-1229. 1'apris une note du P. Laire qu'on lit en tête, c'était le seul cartulaire le l'abbaye.

4042. - Exiraits des chartes et titres de l'abbave de Vauluisant : ms. du XVIII siecle. sur papier, in-folio de 195 "ff. (Biblisth. de la ville de Sens, ms. 128.

4043. - Autre recupil. formé au XVII esiecle, in-folio, pour Gaignieres (Biblioth. nutionale. ms. latin 5458, pp. 1-209.

Vaulx, a Saint-Alban-th-Rocho (Isère). - Commanderie de Templires (dioc. do Vienno).

4044. - Cartulaire dı Temple de Vaulx : ms. des XIIP-XIII siècles, sur parchemin, contenant 92 chartes et notices, en $11 n$ rouleau [incomplet du début] de ..$^{\mathrm{m}} 26$ de lon sur $0^{\mathrm{m}} 16$ de larro Bibliotle de la ville de Lyon. fonds (coste. ms. $42: 3)$.

Publ. Cartulaire dn Temple de Vanlx, par R. Welachenal (Bulletin de l'Aculémie delphinule, $4^{\mathrm{e}}$ série. X. pp. 351-475) et à part : Paris, Picard et fils, $189 \%$; in- 8 " de $15-125$ p.

Vauville. - Prienré diore de Coulanees.

4045. - Cartulaire lu prieuré de Saint-.Vichel-du-ILont de Viturille, dépendant de l'abbaye de Cerisy : ms. daté de 1594-160\%, contenant 
62 actes des amnées 11 (6i3-1276. sur papier, in-folio de $22 \mathrm{ff}$. (Archives

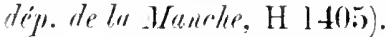

C'est un roruril de chartes extraites tu livre noir de l'abbaye de Cericy.

Vaux. - Seigneurie a Savigny-sur-() rege.

4046. - Cartulaile de la seimnenrie de Viux, dlépendant du couvent de N.-1). de Bomne-Nouvelle d'Orléans: ms. de la fin du XVIJe siècle, contenant des docmments des ameses l6iati-1696, in-4" de $57 \mathrm{ff}$. Archices dep. de Lairet, H 176 provisoire). Velay. - Hospitaliers de Saint-Jean-de-Jérusalem.- Voy.
Lx: Ply.

Vendôme. - Abbayr do la Trinitri (dioc. de Blois).

4047. - Frannent d'un cartulaire le la Trinité de Vendome ; ms. dn $\mathrm{Xl}^{\mathrm{e}}$ siecle [1070 environ], sur parchenin, avec ailditions postérienres juscrn'en 1 lol. contenant log chartes. in- $4^{\prime \prime}$ de 40 ff. à 2 col. [ sauf les 8 premiers] avec inclex en lète (Biblioth. Cheltenham, ms. 2970).

Complet, cecartulaire comptail $284 \mathrm{ft}$. ef 570 pièces : il était couvert de cuir blanc. Disparu une premirre fois entre 1528 et 1640 , il a été connu de Mabillon, de Dom Housseau, de l'abbé Simun, et a fait partie plus récemment de la collection Nonteil. - Voir une table dans le ms. latin l2700 de la Biblioth. urtionale, ti. 262-26:3.

Copies du précident avec addition de 60 chartes. faite en 1849 , par André Silmon. sur papier (Biblisth. de la ville de Tours, ms. 1195). - et en 1857 sur relle-ci. par XI. Bouchet (Biblioth. de la ville de lestome. ms. 272.

4048. - Aulre frament d'un cartulaire de la Trinite de Vendòme; ms. des Xlle-X11' siècles. sur parchenin, in- $0^{0}$ de $29 \mathrm{ff}$. Biblioth. Cheltenlum. n" 2971 .

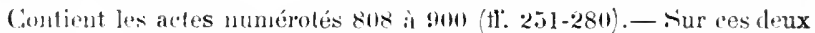

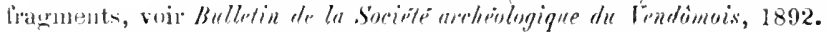

4049. - Aul res framents du mème; ms. du XIJe siècle. sur parchemin, 2 fl. in- $4^{0}$ Biblinth. Cheltenterm, no 17712 .

Contient les artos numérotés 904-905 et 910-911 (ff. 282 el 28.5).

On ne saurait dire si cest it ce manuscrit que se rapporte la mention " in Inanibus l'arisiis antipnum et insigne catularium liujus abbatiae », font il y a rles extraits du XVI" sircle par Dom Anselne Le Hichel (Biblioth. nationde, ms. latin 13820, ti. 239 et ss.).

4050. - Aulre cartulaire de la Triniti de Vendòne, « cartularium nembranem viride »: ms. sur parchemin de 5.3 ff., orig. perdı.

Extraits du précrédent, par Dom Anselme Le Michel Biblioth. nutiounle. 111. latin 1:3820, ff. 31:3 et :35:3).

Il est prolahle que c'est le mème recueil que le bullaire dont il est 'question dans le ms. latin 10402 de la kiblioth. wationale, ff. 80-8.4, ainsi que dans le ms. latin 12700 . 
4051. - Antre petil cartulaire, «exiguns codex papyracens recenter scriptus»: ms. perdu.

Extraits par le mėme Idem. ms. latin 1:38:0, ff. 3:3:3-3:34 .

4052. - Autre cartulaire, "codex papyracens recenter conscripus in quo sunt exemplaria diversarum cartarnm $>$; orig. perdı.

Extraits par le mème Idem, ms. latin 1:3820, ff. 341-34:2,

4053. - Extraits dn cartulaire, envoyés à Dom Mabillon par Dom Hugues Lanthenas: ms. des XVIJe-XVIIJ siècles. sur papier. infolio de $269 \mathrm{ff}$. (Biblioth. intionale, ms. nonv, acq. françaines: 20225). Était aupararant chez Sir Thomas Phillipp= (Billiroth. Cithelterellum, $\left.n^{0} 4263\right)$.

Extraits divers Biblioth. nutionale. ms. latins .74I9. 12700. et 17049, pp. 665-729 : ms. français 24l333. pp. 173-187 : coll. Duchesne, vol. XXII ; coll. Baluze, vol. XLYII, pp. 226-29:3, IXXVII et CXXXIX ; nour. acq. françaises 7430 , et 7433, ff. 91-105.

4054. - Publ. : Cartulaire saintongeais de la Trinité de Vendòme, publ. par l'abbé Ch. Métais Archices listoriques de lo Sinintorige et de l'Aunis, XXII. 1893, pp. 1-431 .

4055. - Publ.: Cartulaire de l'abbaye cardinale de la 'Trinité de Vendòme. par l'abbé Ch. Métais. Vannes, Lafolye, 1893-1904: 5 vol.

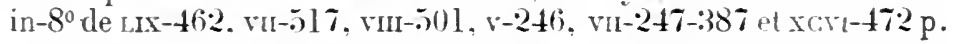

Le $5^{\mathrm{e}}$ volume confient des tables dressees par l'auteur. le $4^{\circ}$ renferme aussi des tables onomastique par l'abbé llétais et géographique par II. Colas. Cette double publication provient d une mésintellipencententre l'auteur et la société archéologique du Vendòmois sous les unvich de qui s'est faite limpresion. Les actes vont de l'année 987 it I 790.

Vendôme. - Église rollégiale Saint-Grorges.

4056. - Cartulaire de l'église St-Georges de Vendòme ; orig. perdu.

L'abbe Simon, historien de Vendòme, l'a connu et utilis ' au XVIIIle siècle.

Vendôme. - Hòtrl-Lièt.

Les historiens locaux, de Pétigny putre autres, ont cité parfois un cartulaire do l'Hòtel-Dieu de Vendòme, qui n'est en réalité qulun inventaire des titrés de la Maison de l'Oratoire dlo Vundome. réunie à l'Hitw-Dirul (Archices dép. de Lnir-ot-Chene).

Vendôme. - Prietré de Saint-Lare. - Toy. Marnottier.

Verdun. - Abbaye de Saint-Airy.

405\%. - Cartulaire de Saint-Airy de Verdun; ms. hu AVIII siècle, in-folio Bibliuth. dr. Ille Burignier-Clouël, à Verdum.

Verdun. - Abbaye do Saint-Maur.

4058. - Cartulaire de liabaye de Saint-YIan de Verdun.

Ce volune existe dans une collection partirulière à Verolun : nous navons pu nou- procurer aucun renstignement is son sujet. 
Verdun. - Abbaye de Saint-Nicolas des Prés.

4059. - Recueil de chartes relatives à l'abbaye de Saint-Nicolas des

Prés de Verdun : ms. du XVII s siècle. sur papier, contenant des actes de 1:226 i 1292 (Bithlioll. nutionale, coll. Lorraine, vol. 725, fi. $2.5 .5-279$.

\section{Verdun. - Abbaye do Saint-Paul.}

4060. - Cartulaire de l'abbaye de Saint-Paul de Verdun; ms. du XlII siècle. in- $4^{0}$ sur parchemin Biblioth. de MIle Burignier-Clonët, à Verdun .

Cif. : Clouet, Histoire de Verdun, II, p. $27 \%$.

Verdun. - Abbaye de Saint-Tanne.

4061. - Cartulaire de Saint-Vanne de Verdun; ms. du XI" siècle, oricr. perdu.

Sie trouvail a Dijon en 17\&4.

406:. - Autre cartulaire: ms. du XII siècle, orig. perdı.

Existait encore en 1784: cétait un petit in- $4^{\circ}$ de $76 \mathrm{fr}$. sur parcheInin, relié en cuir. Voir la table dans le ms. francais 20841 de la Biblinth. nutionales, tit. 2222-2:28.

Copie dı précédent, exécutée au commencement du XVI ${ }^{e}$ siècle, sur papier, in-4" de 50 tr. (Biblinth. nalionule, coll. Dupuy, vol. $24+4$.

Dates extrêrnes : $702-1146$.

Autre copie du mème, écrite de la mème mais que la précédente au XVI" siècle, sur papier. in-40 de 72 fr. (Biblioth. nutionale, ms. latin $54: 3.3$.

Autre copie faite pour Baluze au XVII siècle, sur papier, in $-4^{0}$ de $2: 30$ pares (Bibliolli. malimale, ms. latin 5214.

Autre copie du XVII siècle, assez médiocre, faite pour Bouhier, sur papier (Bibliolh. nulionale, ms. latin 17639, (1. :30-77).

Autre copie morlerne. faite par Ch. Buvignier, sur papier, in-folio (Bibliolli. the lie ville de Verdun, ms. 184).

Autre copie incomplete. du XVIII ${ }^{\mathrm{e}}$ siècle, in-folio (Biblioth. de $3^{\text {lle }}$ Buvignier-(lonël, à Verdun).

Extraits faits an XVII" siècle (Biblioth. nutionule, coll. Duchesne, vol. XCIII, il. 30-39, coll. Baluze, vol. XLVII, fl, 64, 73-74 et 78-8. et vol. LXXV. If. $441-442$; an XVII" siècle (Idem, coll. Moreau, vol. 10 et -6 ).

Publ. : Die älteren Urkunden des Klosters S. Vanne zu Verdun, von Hermann Bloch (Juhrbuch der Gesellschuft für lothringische (iteschichte und dlroinmshunde, X, I898, pp. 341-449). 
Verdun. - Chapitre cathéchal.

4063. - Cartulaire du Clapitre cathédral de Virdun : mis. du $\mathrm{XIII}$ siècle, sur parcheninin. contenant des chates depuis los XIe, in-4" Biblinth. de lu rille de V'erdun. ms. s.

Copie moderne du précédent. par l'h. Burigniner: in-f" sur papier (Biblioth. Ae le cillo de lerdun. mis. 18:.

Verdun. - Evèthí.

4064. - Cartulaire de lévèché de Verdun : orirr. perdu.

Copie d'un mannscrit du Xll ${ }^{p}$ sitcle. int-folio (Biblioth. de Melle Bucignier-Cilonett. à Verdun .

4065. - Antre du Xinle siècle [incomplet du début et de la fin]. contenant des acter de $10.5 \%$ it I.27.5. in-folio de $70 \mathrm{ff}$. Biblonth. nationale, coll. Lorraine. vol. 716 .

Cif. Table alphabétique des noms de lienx d'un cartularire de l’évèché de Verdun (Biblisth. nutimule. coll. Lorraine. vol. T24, ff. $41+-425)$.

Verdun. - Érètuse ot Chapitre.

4066. - Recueil de titres relatifs anx érèques et au Chapitre de Verdun: ms. le la fin du XVIe siècle. form: par Thierry Alix. sur papier, conterrant des titres de 11333 is 1.589 . in-folio de 324 ff. Archioes dép. He Meurthe-et-1 Wrselle, B 401 .

Verdun. - Hôpital Saint-Hipponlyte.

4067. - Cartulaire de l'höpital Saint-Hippolyte de Verdun; n1s. dn TrIIle siecle. sur papier. contenant des actes de 1716 is 1752. in-

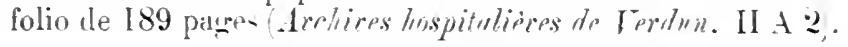

Vergy. - Église colléghials Saint-I) nits, a Nuits (flioe. (1.Autun).

4068. - Cartulaire de l'érlise St-Deni- de Vergy : mis. du XIV'e siècle, sur parchemin. in-4" de 28 If. (Biblisth, ustionale, ms. latin 5.529.4). 4069. - Autre du XIIIe siecle. sur parchemin. in-4 de $56 \mathrm{ff}$. (Biblioth. de la ville de Dijoun. Mn. 1057.

Extraits faits an XVII siècle (Biblisth, mutionuls. coll. Baluze. vol. XLVII. HI. 294-299!.

Vermand. - Abbayn (dioce de Noyon'.

4070. - Framment d'un cartulaire de l'ablaye de Termand; mis. du XIII siècle. sur parchemin. in-8" de \& ff. (Biblioth. antionale, ms. latin 11069 . 
Vernaison. - Abbayr dioc. de Valence!.

I. l'abbé [1]. Cht'valier a cité dans un de sés travaux le cartulaire de Vernaison, recueil faclice 'qu'il ke dispositit a publier mais qui n'a janais vu le jour.

Vernon. - Primbridion. dre Romen).

4071. - Fragment diun cartulaire du prjeuré de Vernon, dépendant de l'abbaye de Montebonr': ms. du XV siecle. sur parchemin, contenant 1:3 chartes dn Xlie, in-4" de 4 ff. (Apchives dép. de la Menche, $\mathrm{H} 8: 381$ ).

Vernon. - Ville.

4072. - Cartulaire de la ville de Vernon: ms. des X Ve-XVIJe siecles, sur parchemin, in-4 de 50 ti. Biblinth. he la cille de Rouen, ms. sippl. 20 ,

Provient It lancienne collection Coquebert do Montbret.

Verrières-le-Buisson. - Voy. AxTray.

Vertus. - Abbaye de saint-Laurent (dioc. do Chàlons-surNarnio.

4073. - Cintulaire de labhaye de Saint-lanuent de Vertus; ms. du XVII siècle, sur pipier, in-folio de $350 \mathrm{tr}$. Archives dép. de la Jurue. H non cole;.

Dates extrines : $1179-1656$.

Vézelay. - Abbily" dioc. d'Autun.

4074. - Cardulaire de l'ablatye de la Madoleme le Vézelay; uns. du Xlle siecle. sur pawehenin, in-4" de $33: 3 \mathrm{fl}$. Biblivtech Laurenziana, à Florence. n1s. XXXII.

Se trouve intercalé dans un rerueil des cenves de sitint Ambroise.

Publ. : Privilegria of chartae Vizeliacensis cuenolii ; ed. D. L. لAchery dans son « Spicilegrinm». III (1659). pp. 446-505.

Pевт.. A. M. Bandini. Catidono della Bibliotecar Lamrenziana, 1. 1774. in-folio. col. 128-1+1 19 chirtes; - abbé A. Pissier, dars le Bulletin do li Srorété des scirnces historiques de l"Yonne,

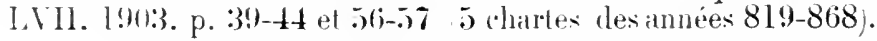

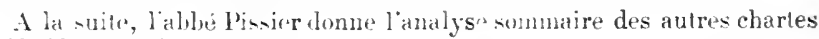
$(I)^{2}-X^{\prime \prime} \sin \left(\sin ^{2}\right)$.

4075. - Bullaire de l'abbaye de Vézelay: ms. du Xlle siècle, sno

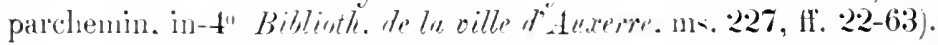
407ti. - Recueil de litres relatifs is la mène abbare. fait an XVllle

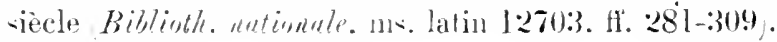




\section{Viane. - Vills.}

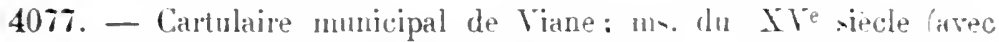
une addition dı $\mathrm{XVI}^{\mathrm{e}}$, rédigé par Bernard Clot, notaire. snr parchemin, arec me reliure de lowis et cuir noir. cuntenant it chartes

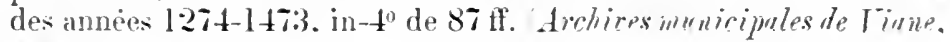
A.t 1:

Cf. 1. cartulaire do Viane (Rerwe historique. scivatifique pl litteraire dis

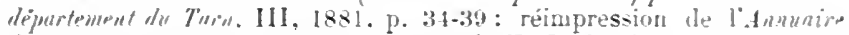
du Tarn putr 1863. 1'. 2201-227 (notices de E. Jolibuis).

Vich. - Comti.

4078. - Recueil de titres relatifs an conte de Vich : ms. du XVII siècle. contenant des acter des années 1:224-1398, in-folio sur papier (Biblioth. nationale, coll. Duat, rol. 162, ff. 162-31)9.

Vich. - $\dot{\text { Eglist: }}$

4079. - "Liber dotationum ecelesie Vicensi-»: ms. du XIIJ siecle. sur parchemin. in-folio Archico del Conbild, te Tirle.

Vich. - Ville.

4080. -- Privilegion de la ciudad de Vich: recuenl de ducuments des années 120.5 a 1711. en 22 rol. in-folio Archiro muricipal de Tich.

Vicogne. - Abbaye (dior. d'Aras).

4081. - Cartulaire de l'abbaye de Vicogne: m1. dn XIII e siecle. sur parchemin, contenant 10:3 pièces de années 11333-1215. in-40 de $99 \mathrm{Hi}$. Archices dép. dr. Word. H nun cotè.

4082. - Autre cartulaire: ms. du Xille siecle. avec additions pustérienres jusqu'au $\mathrm{XVI}$. sur parchenin. contenant 292 pièces à partir

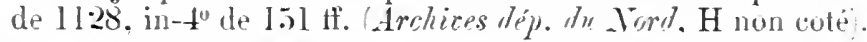

408:3. - Autre cartulaire: ms. du Xille siecle. avec additions postérieures jusqu'au $\mathrm{XVI}^{\mathrm{e}}$, sil parchemin. contenant des documents à partir de $11: 32$. in-4" de 170 tf. Archires dep. dn Vord. H non cute, 4084. - Pelit cartulaire de Vicorne [lu Xive siècle. contenant $117 \mathrm{ft}$.$] ; ms. perdu.$

On en troure des extraits a la Biblistlo untivente, coll. Moreau, rol. 98 , fo 164 , et passim.

Vidauban. - Vill..

408.). - Cartulaire municipal de Vilauban: m. des $\mathrm{IVII}^{\mathrm{e}}-\mathrm{SVIII}^{\mathrm{e}}$ siècles, sur papier. contenant des titres a partir de 1311. in-4" de 20) At. Archices mmicipules de Tidnubus. At 1.

Vienne. - Abbaye do saint-Andló lo Bas.

4086. - Cartulaire de Saint-André le Bas: ms. détruit en 1854.

Une (\%) pro m arait été faite, qui a servi à la publication suivant. (Biblioth \%o kille de rionne, mis. 123). 
l'ubr.: Cartulaire de lahlaye de St-Andrí le Bas de Vienne, ordre de Si-Benoil. snivi d'un appendice $\mathrm{LX}^{\mathrm{e}}-\mathrm{XlI} \mathrm{I}^{\mathrm{e}}$ siècles par l'abbé Ul. Chevalier. Vieme. Savirne, 1869 ; in-8 de xur-:36i8-4:3 p. [Collection de cartulaires dimplinois, l. ]

Extraits faits an $\mathrm{XV}^{\circ}$ siecle par I)om Esiennot (Biblioth, natio-

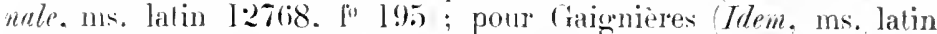
17049. pp. 5.59-5(i.); ponr Balluze Intem. coll. Baluze. vol. LXXV. pp. $40 \cdot 2-42: 3$.

Lorsque Guichenon cut connaissance du cartulaire original, it lui fut rommuniqué far (Chorier (voir : Histoire grénéalogique de la maison de Savoie, I1, 1780, p. 7 et 25). - (if. 1). I. d'Achery, spicilecrum, X111 (1677), pp. $2165-280$ et 293.

Vienne. - Clapitr"athédral de Saint-Maurice.

4087. - Cintulaire du Clapilre de Saint-Manrice à Vienne: ms. du XII siècle, sur parchemin, in-folio, contenant 259 pièces; orig. perclu?

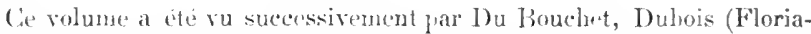
comsis vetus bibliotheci), I) (ange, Baluze, (iaigniors, Rivaz,

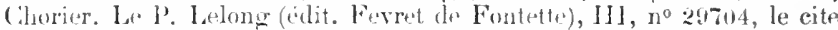
ronnme alphartenant à 11 . de Caumartin, et il semble qu'il ait été retmis aux archives do la Chambre des Comples de Dauphiné.

Axıl.: l)escription analytirue du cartulaire du Chapitre de SaintManuce de Vienne. par l'abbé Ul. Chevalier Bulletin d'histoire

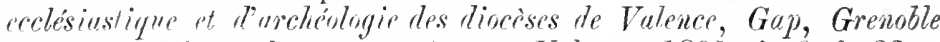
ef Tivirs. XI supplément ; et à part: Valence, 1891 ; in-80 de 88 p. [Collection des cartulatire- dauplinois, II, 2.]

Citte analyse est la pullication d'un manuscrit fait d'après l'original

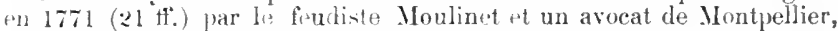
ot acleté en 18.15 par l'. E. Giraud, qui le communiqua it M. Chevalier.

Exarsilslaits an XVII" siecle pour Gaignières (Biblioth. nationule, ws. lalin 17049, pp. 567-580: par Rivaz clans son " Diplomalarimu »: pom Baluze Idem. coll. Baluze, vol. XIV. ff. $47-54$ el 1.XXV. pp. $307-400$; et autres Idom, mss. latins 5214, lf. 1-185 el 217-219, el 1174:3, 11. I11-154).

Vienne-le-Ghâteau. - Seigneurie en Argonne.

4088. - Cirtulaire de Vienne-le-Chàtean; ms. du XIVe siècle, comtenant des docmuents des annces $1260-1: 312$, in- $4^{0}$ sur parchemin de $20 \mathrm{fi}$. Archices de chatere de Chantilly, $\left.n^{0} 107^{\mathrm{b}}\right)$.

Viennois (Dauphins de).

4089. - Cartulaire des Danphins de Viennois; ms. du XVe siècle, sur papier, in-t" de 30 ff. Bibliath. ationale, ms. latin 9908.

Cf. Votice sur un eartulare des Danphins de Viennois en partie 


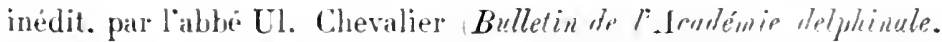
3 série, III, pp. 127-1:35, et à part : Cirenoble. 1867. in-8" de 11 p.

(utelques chartes impériales pour les Dauphins de Viennunis (13031310) sont imprimées dans le leues drchir, XXIX (19014), pp. bink-1in6.

Extrait du mine cartulaire. fait au XVIIe siècle Bihlioth. metionule.

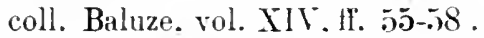

Des extraits dun cartulare des hauphins, appartenant jallis at

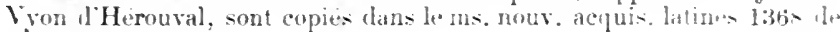
la Biblioth. antionale.

Vierzon. - Abbaye de Saint-Pirre (dion. dr Bunges).

4090. - Cartuliare de l'abbaye de Vierzon; ms. du Xlle-iectr. - parchemin. urné de rlessins en lète de la plupart des charte- lram-rites (quelques-mes sont carolingiennes, in-folio de $29 \mathrm{ff}$. Biblinth. mationale. ms. latin 986.5 .

Extraits du même Biblinth. mationale. coll. Huchesne. wol. XXII. ff. $313-3: 30$.

Cif. Note sur le cartulaire de l'abbave Saint-Pierre de Timzon, jar M. Daiguson (Congrès archealogique de Frrne, toe session à Chàteauroux, 1873 , p. $576+620 \%$.

Vieupou. - Prieure (dion do Sens).

4091. - Cartulaire dn prieuré de Vieupon; ms. rédigé en 17t0. contenant 165 documents a partir de 1173, sur papier. in-fulio de 113 ti. Archives dép. de t Yonne. $\mathrm{H} \mathrm{814.}$

Vieux-Bellême. - Prieuré (llioc. de Sées).

4092. - Cartulaire du prieuré de St-Martin du Vienx-Bellème. dep ${ }^{1}$ de labbaye de Marmoutier; ms. en ronleau de parchemin, du XlII siècle. contenant 62 documents des années 1169 à $1 \cdot 26.5$. et mesurant $8 \mathrm{~m} .10$ de long Archives dép. de li Or.⿲丿. H 2170 .

4093. - Autre cartulaire en forme de rouleau de parchemin. du XIII siècle, contenant 44 documents des années 1281 a l:304. et mesurant $4 \mathrm{~m}$. 84 de long (Archives dép. de l Orae, $\mathrm{H} \cdot 2 \cdot 215$.

4094. - Recueil de titres sur le prieuré de Vieux-Bellẻme, fait pour Gaignières au $\mathrm{XVII}^{\mathrm{e}}$ siècle (Bibliofh. nulionule. ms. latin 5 $44 \mathrm{I}^{\mathrm{B}}$. pp. 289-340,

4095. - Publ. : Cartulaire de Marmutier pour le I'erche. publ. par lablé Barret. Mortagne, impr. Meaux. 1894; in-8" de vi-323 p. [1 tocuments sur la province du Perche, $3^{n}$ série, $n^{0}$ 2.]

Dates exlrèmes: 940-1472. Interesse à la fois la colltrialto le sintleonard de Bellêne et le prieuré de siant-Martin du Vinux-

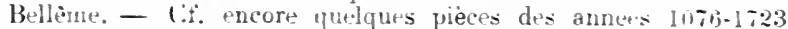
(Biblinth. Mationele, mis. 100it5, ff. 6u-74). 
Vigeois. - Mbbay dr Saint-Pierre (dioc. de Limoges.

4096. - Cintulaire de St-Pierre de Vireois; ms. du XIIe siècle, sur parchemin, in $4^{0}$ de 81 17. Bibliolli. He M. le duc de Mouchy, au chetritu de Monchy, Oise.

Les 15 premières pages mánjuaient déji au XVIIe siècle.

Copie du précédent, lirite par bom Col en 1769 (Biblioth. nationule, nus. latin 9193, paines .529-568.

Antre copie du XVIII siecle, in-4 de 231 pagres (Biblioth. matimule, ms. latin 17119 .

Extraits informes faits par I)om Maliklon (Biblioth. nutionule, ms. latin 12703 , (f. :203-204: 128.

Autre copif Biblinth. untionule, coll. Baluze, vol. LXXXV, ff. 1-

Publ. : Cartulaire du monastère de St-Pierre de Vigeois, par H. de Montégut Mémoires do la Socisté archéologique et hissorique In Limousin, XXXIX, 1890, pp. 1-303).

la préface n'a pas été pulliee.- Ct'. : Not's topographiques sur le cartulaire de Vigeois, par J.-B. (ihamperal (Aumules du Dirti, VII, 1895$, pp. $432-135)$.

Vignacourt. - Eglisi rollegiale Saint-Firmin (dioc. l'Amiens.

4097. - Cartulaire de l'Égrise St-Firmin de Vignacourt; ms. du IIV siecle, avec additions postérieures. sur parchemin, muni d'une reliure ancieme, contenanl des pieces de $12 \mathrm{l} 6$ i 1444 , in-4 $4^{\circ}$ de 49 fr. (Arehioes dép. de la Somme, G non coté).

Extraits firits an XVIJ siècle (Biblioth. de l'Arsenal, ms. 465̆2, 1"28.); ct ms. 5259. If. 1:30-131 ; Biblinth. nationale, ms. français 9497, pp. $266-268$.

Vigneux. - Villagr.

4098. - Cantulaire de Vinneux, dép' de l'ablane de Saint-lictor de l'aris; ms. du XIV"esiecle, sur papier, contenant des actes de 1170 enviroul it 1282 , in- $4^{0}$ le $1^{2} 2 \mathrm{If}^{\circ}$. (Archives nutionales, S $2168,1^{0} 5$.

las dates mises en narge par une main moderne sont généralentent filusises.

Vignory. - Prieuré (dioc. de Langres).

4099. - Cartulaire dn prieuré de Vignory; ms. daté de I380, sur parchemin. iu-4" de 69 ff. (Archiors dép). de la Côte d'Or, H non coté.

Copie du précédent, faite en 1760, sur papier, in-folio de $103 \mathrm{ff}$. (Avclizes dép. de lit Ilaute-Murne, H non coté).

P'rı.. : Cartulatre dı prienré de St-Étienne de V̈innory an diocèse 


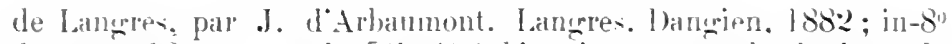
de cct.-318 p. et pl. [Société historique et archéologrirgue de laturines.]

Villars. - Seigneurie.

4100. - Cartulaire des fiels des sires de Villar: en Bresse et en Bugrey; ms. du $\mathrm{XV}^{-e}$ siècle. sur papier. contenant des actes de l:299 à 1369 ,

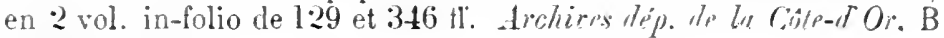
$10455-10456$.

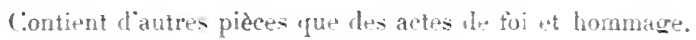

Villechasson. - Voir Rozor.

Villedieu-en-Dreugesin. - Commanderie (dinc. de (Chartres).

4101. - Cartnlaire de la commanderie de Villedien en Drengesin: m. du XVIe siècle [1580]. wur parchemin. incomplet du commencement et mutile. in-folio de $31 \mathrm{nt}$. Archires nutioninles. II 15. no 30 . Datrs extrèmes : 1219-1:248.

\section{Villedommange. - Vill .}

4102. - Cartulaire municipal on «livre vert» de Villedommange: m. du XVIIIe siècle. contenant des transcriptions dactes depuis le XIII dirchires mulcipules de Villedominenge. Marne.

(:i. H. Jatart, dans Tracunx de l'teudemis its Reims, LXX, p. 3:21.

Villefranche-de-Conflent. - Ville.

410:3. - Cartulaire de Villefranche-de-Conflent. on « Livre des quatre clous: :ms. du XIVe sipcle [1324]. avec additions postérieures, sur parchemin. contenant des actes des années 1095 à 1640 . in-folio

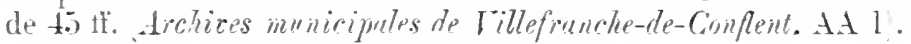

Villefranche-de-Rouergue. - Ville.

4104. - Récneil de titres relatifs à Villefranche-de-Ronerunte: ms. de

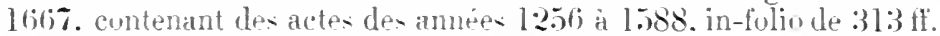
(Biblioth. dutionale. coll. Doat. rol. 147.

Voir linventaire de ce volume (Conbinot historique, XIV, 1868, p. $5.5-63$.

Pcrt. : B. Alart. Quelques chartes et privilèges de Villefranchede-Conflent. Lectoure, 18.52, in-8".

Villefranche-sur-Mer. - Ville.

410.5. - Recueil de titres relatif à Villefrunche-sur-ILer: ms. du TVIlIe siecle. sir papier. contenant des atctes des années 1295-1686.

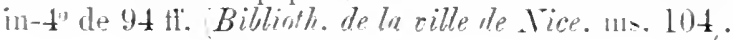

Voir aussi le ms. 105. 
Villejuif. - Voy. Boltafle et La Saussaye.

Villeloin. - Abbaye (dioc. de Tours).

4106. - Cartulaire de l'ablatye de Villeloin; nss. du XIVe siècle, sur parchemin (Archives du châtean de Beaurepaire-en-Valois, Oise).

Copies par extraits (Biblioth. nationale, mis. latin 12702. 17. 315333 ; - ms. latin 17l29, pp. 1-98; - coll. Duchesne, vol. XXII, fi. 4:35-465; - et coll. Iom Honssean, I, XII et passim).

Villelongue. - Abbaye (dioc. de Carcassonne).

4107. - Recueil de titres relatifs à l'ahlaye de Villelongue; ms. de

1668-1669. contenant des titres des années 1145 à 1428 . in-folio de $273 \mathrm{ff}$. (Biblioth. untionale, coll. Doat, vol. 70).

Villemartin. - Commanderie des Hospitaliers (dioc. de Bordeaux).

4108. - Cartulaire [frament] de la commanderie des Hospitaliers de Villemartin. nuembre de la commanderie d'Areins; ms. dn $\mathrm{XIll}{ }^{\mathrm{e}}$ siècle. sur parchemin, in-4 ${ }^{0}$ de $27 \mathrm{ff}$. Arclives dép). de la Irente-Guromine, H non coté).

Villemur. - Vicomté. - Voy. Lavtric.

Villenauxe. - Voy. Nesle-IaA-Reposte.

Villeneuve. - Abbayc, au Bignon (dioc. de Nantes).

4109. - Recueil de titres (notices et extraits) relatifs à l'abbaye de Villeneure: ms. du XVII" siècle, sur papier, contenant des actes de 1201 a 1450, in-folio de 52 fi. (Archives dép. de la Loire-Inférieure, H 86 .

Villeneuve-d'Aveyron. - Ville.

4110. - Cartulaire municipal de Villeneuve-la-Crémane ou Villeneuve d'Aveyron: 1ns. dı XIV siècle, sur parchemin, in-40 de $64 \mathrm{ff}$. (Biblisth. de .1\%. le Curé de Villeneuve).

Les premiers feuillets sont occupés par des fragnents d'évangiles, les derniers par des ordonnances consulaires ajoutées après coup (des XVe-XVIe siecles).

Villeneuve-lès-Avignon. - Abbaye (dioc. d'Avignon). 4111. - Cartulaire de l'abbaye de Saint-André de Villeneuve-lèsAvignon [de $49 \mathrm{ff}$. au moins, années 982-1125]; orig. perdu.

Extuaits dans les «Annales » de Polycarpe de La Rivière (Biblioth. de la ville de Carpentras, ms. áf)3).

Villeneuve-Saint-Georges. - Village. -- Voy. BrieCONTE-R(IBERT. 
Villers. - Abbaye (dioc. le Namur).

4112. - Cartulaire de l'iblaye de Villers: ms. dn XIVe siècle, sur parchemin, contenant des titres des annees $1197-1297$, in- $8^{\circ}$ de $73 \mathrm{tr}$. Archices du royumine de Belyique. à Bruxelles).

4113. - Antre cartnlaire de la fin du XIVe siècle. sur parchemin, contenant des titres des annees $1176-1347$, in-8" de $79 \mathrm{ft}$. Archires du royaume de Belgique, à Bruxelles).

4114. - Antre du XVe siècle, sur papier. contenant des titres des années 1184-1312, in-folio de 6ff.' Archices de l' Étut à Liège).

4I15. - Publ. Chartes du XII siècle de labbaye de Villers en Brabant. par Ell. de Moreau. Iourain, P'. Smeesters. 1905; in-8 de 117 p. (Analectes pour serrir à l'histoire ecclésiastique de la Belgique, 2 e série. VII).

Villers-Bettnach. - Abbaye (dioc. de Metz).

4116. - Cartulaire de lahbaye de Villers-Betnach; ms. des XirIeXVII siècles, sur papier. in-folio de xxxm-594 ff. (Archires de Lorraine, it Netz. H 1714.

Villiers-la-Joye. - Abbaye (dioc. de Sens).

4117. - Cimptulaire de labbaye de Villiers-la-Joye: ms. de 158:3. fait par (iilles de Mornay, cure de Guigneville et receveur de l'abbaye, avec quelques additions postérienres, sur papier, in-folio de v-3iz ff. (Archices dép. As Seine-et-Oisp. H pon coté.

Vilvorde. - Chàtellenie.

4118. - Cartulaire de la chàtellenie de Vilvorde: ms. du XVIIe siècle, sur parchemin. contenant des locuments de 1357 à 1670 . in-folio de $55 \mathrm{fil}$. (Archires din royaume do Belgique. à Bruxelles).

Vinça. - Ville.

4119. - Cartularie municipal de Vinça: ms. du Xl Yre siècle, sur parchemin, contenant des actes de 1207 a $134+2$, in- $8^{\circ}$ de $12 \mathrm{ff}$. (Archives im unicipales de Vinrn. At 1).

4120. - Autre. contenant la traduction catalane des mèmes actes, faite en 1350. sur parchemin. in-folio de $25 \mathrm{ff}$. Archices municipales de Vinca, AA 2).

4121. - Recueil de pièces. par B. Alart: ms. du XIXe siècle. sur papier.in-4" de $486 \mathrm{p}$. Biblioth. de la cille de Perpignan. ms. 110 .

Vincelottes. - Couvent des Lazaristes (dioc. d'Auxerre,

4122. - Cartulaire des Lazaristes de Vinceloltes: ms du XVIIJ siècle, contenant 600 actes des années 1477 à 1779 . $\$$ ir papier, in-folio de $615 \mathrm{ff}$. (Archices dép. de l' Ionne. H supplément). 
Vincennes. - Cournt des Ninimes (dioc. de Paris).

4123. - Cartulaire tles Vlinines du Bois de Vincennes; ms. du

XVII siècle. sur papier, in-4" de 4.) ft. Archives nutionales, L. 1.57 .5 .

Vinetz. - Priende de Notre-l)ame dioc. do Châlons-surMarne).

4124. - Axar. : Chartes du prieuré de Vinetz $1167-1240$, dans ; Le dincèse ancien de Châlons, par lial. de Barthélemy, II 1861 , p. 44044.

Virandeville. - Prieuré dioc. de Coutanres.

41:5. - Cartulaire du prieure de Virandeville, dépendant de Suint-Sanvenr-le-Viconte; ms. daté de 1.509, contenant 11 acfes des

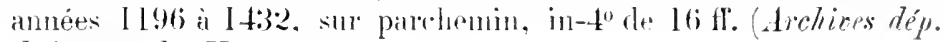
de la luncle, $\mathrm{H}$ non colé.

Visé. - Ville.

4126. - Cintulaire municipal de Visé : ns. du XY11" siècle sur papier,

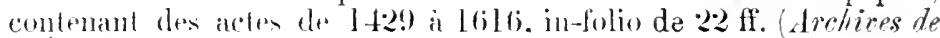
l" Fitut ì Liriqr.

Vitré. - Baromnir.

41:27. - Cartulaire de la barounie de Vilré; ms. du XIVe sièele, sur parchemin, in-4" de $61 \mathrm{ll}$. (Achicess de .1\%. le duc de la Trémoille ou Chertrier de Thomers.

Copie morlerne [1874] du précédent ; in-folio de 159 p. Biblioth. untionale, mi. nouv. arcq. latines 122!),

Vitré-Laval. - Famille.

41:28. - Cartulaire de Vilri-Laval ; nss. du XVIIe sièele, snr papier, in-4" Archices dép. d" Jlle-rt-Viluine, série F, fonds Hévin),

Vitry-en-Perthois ou Vitry-le-François. - Chapitre Notre-l)ame (dioce de Châloms-sur-Marne).

4129). - Cintulaire du ('hapitre de Notre-l)ante de Vitry-en-Perthois, contenint 3:2.) actes de 1210 i $1: 370$; ms. écrit en 149.2, sur parchenin, in-folio Archices municipales de Vitry-le-Fransois.

A été rachelé par la ville pour une somme minime en 1842 , a la vente appres lécès de M. de Torcy, ¿i Cithâlon--sur-Marne.

Vitry-le-François. - Ville.

4130. - Cimtulaire municipal de Vitry-en-Francois; ms. du X Yl1" siecte [ 1641$)]$, sur papier, contenant des documents de 1545

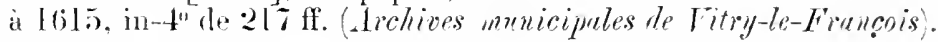

Vitry-sur-Seine. - Toy. Bousfle. 
Viviers. - Eviche.

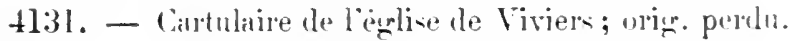

A été utilisé par 1)u Cinnge.

4132. - Recueil de titres relatifs at lévishes de Vivines: ms. du

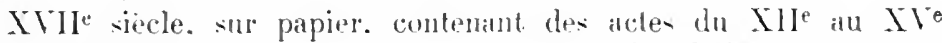
(Biblintl. antindule. coll. Baluze. vol. XIX. If. 2-141.

Viviers. - Prieure de Notre-Lame-dé-(iloile dior. dr Metz. 4133. - Insentaire et cirtulaire des titres dn prienre de Cotre-Damede-(iloire de Viviers: nıs. du XVIII siècle. sur papier. int-folio de 113 4f. Archices dép. de Meurthe-et-1ruselle. H 1602.

Vivoin. - Prieuré dioc. llu Mans.

41:34. - « Chartae de Vironio »; ms. dn XIII sjecle arec additions postérienres. sur parchemin. avec reliure en bois recouverte de veau

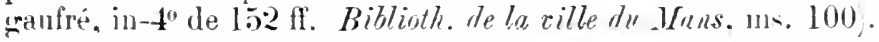

Pebl. : Cartulaire du prieuré de Saint-Hippolyte de Vivoin et de ses anneves 1060-12.08. par l'abbe L. J. IDenis. Paris. Picard et fils, 1894 ; in-4" de $[\mathrm{rr}]-\mathrm{xI}^{-}-360 \mathrm{p}$. et pl.

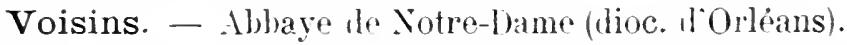

4135. - - Cartulaire-inventaire de l'ahbaye de Voisins: ms. datio de 1697. snr papier. in-folin Archives dép. du Loiret. H non cote".

Pebl.: Cartulaire de Notre-1)ame de Voisins 1207-134:3). par Jules Doinel 'Méunoires de In Surcété urchéslogique et historique de

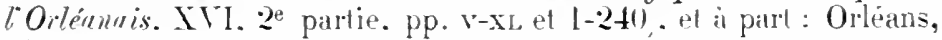
Herluison. 1887: in-8" de xL-240 p.

Avec de nomlureuses additions d'apris les chartes origrinales.

Voormezeele. - Ablare (dioc. d'Y pres).

4136. - Cartulare de l'alhlave de Voormezeele: ms. dn Xille siècle, sur parchemin. contenaut der documents de 1100 it 1285.5 . in- $t^{\prime \prime}$ de $46 \mathrm{ff}$. Arclives de l'Etul is Bruges.

Vosge. - Lailliage nn Lorraine.

4137. - Recueil de titres relatifs an hailliakne de Voupe: mus. du XVII siecle. forme par Thierry Alix. sur papier. contenant des

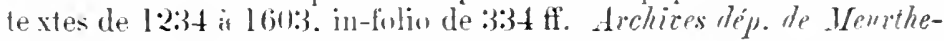

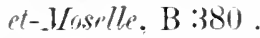

41:38. - Mème recueil un pen moins complet 128t-1605. sur papier, in-folio de 279 tf. Archices dép. de Meurthe-pt-IIsselle. B 381 .

Copir partielle dn précestemt. faite an XVII siecle. sur papier, contenant der textes de 12.54 it 1580. in-folio de 1112 ff. Archires dejp. de Ifeurthe-pl-1hoselle. B 33:5. 


\section{Voulton. - Prieuré de Notre-I)ame (dioc. de Sens).}

4139. - Cartulaire de Notre-1)ane de Voulton [XVIe siècle]; orig. perdı.

Copie du précédent, faite an XVIII siècle, in-folio de 60 parges.

Mention en est faite dans le Bulletin de la Confirence du diocesso de Veatux, II (18:19), p. 22:3.

Walincourt. - Courent des Guillemins dioc. de Cambrai). 4140. - Cartulaire des Cinillemins de Walincourt ; ms. des $\mathrm{XV}^{\mathrm{e}} \mathrm{XVII}^{\mathrm{O}}$ siècles. sur papier. contenant 2.00 pièces des années 11933 ì 1688 , in-folio de 25.) ff. (1rehiers dép. de Nord, H non cota).

Wanze. - Prieurí pres de Huy (dioc. de Liige).

4l4l. - Publ. : Documents concernant le prieuré de Wanze, extraits du cartulaire de l'ahlaye de Floreffe Analectes pour servir is lihistoire eccésiustique de la Belgique. XII, 1875, p. :3:3-76).

Daten extrènes: : 1128-133ix.

Watten. - Mbbayr (dioc. do Théroname).

4142. - Cirtulaire de l'ablaye de Watlen: ns. du XVIe siecle, sur papier, in-f" de 217 ff (Biblinth. de la rille de Saint-Omer, m. 852).

Axal. : Docunents relatils a la Flandre maritime, extrails du cartulaire de l'ahlate de Watlen. Xle-Xll ${ }^{\mathrm{e}}$ s., par Galm. de Coussemaker (Annules dn Comité fumand de Fronce, V, p. 297-383), el a part : Lille. 1860); in-8" de $91 \mathrm{l}$ p.

Waulsort. - Abbaye (dioce de Nammer).

414:3. - Cartulaire de lahbaye de Watulsort: ms. des X $\mathrm{T}^{\mathrm{e}} \mathrm{XV} \mathrm{XV}^{\mathrm{e}}$ siècles, strr papier, contenant des actes de 1190 à 1580 , in-4 $4^{0}$ de $181 \mathrm{lf}$. (Archives de l" Ettat à Namun).

4144. - Autre cartuline du XVII" siècle [1735.5], sur papier, contenanl des actes de 646 a 1735 , en 5) vol. in-folio de 35.5, 31:3,

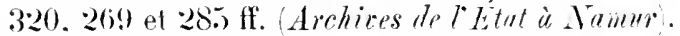

4145. - I'cro. : Documents concernant les monastères de Vianlsort et d'Hastière, par Jos. Bathier Analectes pour servir is l'histoire ecclésiastique de la Belgique. XVI, 1879, p. .)-80 el 129-190.

Aetes des années 1050 a 165 publiés tant d'apres les cartulairts que l'après les origrinaux.

Westwode. - Prieuré anglais de Fonterrauld (dioc. de Wor'('rster).

4146. - « Registrun cartarum monasterii de Westwode in comitatu Wigornensi »: nls. du XIII siècle, sur parchemin, in-4t de $8 \mathrm{ff}$. (British Museum, fonds Cotton, Vespas. Is IX, ff. I v $\mathrm{v}^{0}-8$ ). 
Publ. : en partie dans le «. Ionasticum Anglicanum ». new edit., VI. p. 1004.

Wevelghem. - Cartulaire de l'abbaye de X.-1). lu Montd'Or (dioc. de Tournai).

4147. - Cartulaire de l'abbaye de Wevelghem: ms. de 1520. sur parchemin. in $4^{0}$ de 84 ff. (Biblioth. royale de Bruselles. ms. 3914 ).

Wisches. - Village.

4148. - Cartulaire municipal de Wisches près de Schirmeck: ms. du XVI siecle. sur papier. in-folio de $131 \mathrm{ff}$. Archires muncipules de Wisches. 1) I!.

Wissembourg. - Ibbaye (dioc. de Spire).

4149. - « Cartularium Wizenburgense »: ms. du IX siecle [rers 870]. contenant 279 pieces des Vlle-IXe siècles. de $86 \mathrm{ft}$. S S/ua/sArchir Speier).

Plbl. : Traditiones pussessionesque Wizenburgenses: Codices duo cum supplementis, edid. C. Zenss. Spirae. 1842; in- $4^{\prime \prime}$ de xx-390 p. et pl. [Sociefas historica patatina.]

4150. - «Edelini Liber possessionum »; ms. du ẌLle siècle [1284], sur parchemin, in-folio de $65 \mathrm{ff}$. (S/unls-Archir zu Iriph).

41ว̆l. - Copialbuch Wizenburgense; ms. du XV'e siècle [1492]. sur parchemin. in $4^{\circ}$ de $62 \mathrm{ff}$. Biblioth. des historischen Verpins, Speier).

4152. - "Liber privilegiorum »: ms. du XVI siècle, sur papier, in-folio 'S/ants-Archic z" Wieil).

Extraits faits an XVIle siècle du précédent (Biblioth. nationale, ms. latin 12703 . ff. $277-279$.

Yères. - Abbaye (dinc. de Paris).

4153. - Cartulaire de l'albaye d'Yères: m. du XIIle siècle, sur patchemin. avec une ancienne reliure en hois. in -40 de vul-1:20 ff. (Archices mationules. L.L 1599.

Dates extrêmes: : 1134-1264.

Extraits faits par Dom Malsillon (Biblinth. nationule, ns. latin 12669. If. 2-10) : par Baluze (Idem, coll. Baluze. vol. IXXIII. ff. 98-II7, et pour Gaignières (INem. ms. latin 17049, pp. 609-635).

Yères. - Seigneurir.

4lă4. - Cartulaire de la seigneurie d'Tères en Brie; ms. du XVIo siècle [1560]. sur papier, contenant des titres de $1: 389$ à 1560 , in-4" de 73:3 17. Archices dép. de Seine-et-Dise. A 1010).

Les 99 premiers feuillets sont de parehemin.

Copie du mẻme. faite an IVI siècle (Irlem. A 1012). 


\section{Yolande de Flandre, dame de Cassel.}

4155. - Cartulaire de la dame de Cassel [2e] : ms. du XIV siecle. sur papier, contenint des actes de I370) à 1:38:3, in-folio de 166 pages (Archives dép. du Vord, B 1574).

4156. - Antre cartulaire [3e]; ms. du XIVe siècle, sur papier, formant la suite dn précédent et contenant des actes de l:38I à 1400. in-folio de $65 \mathrm{fr}$. (Archives déjp. du Nort. B 1575).

Yonne. - Iripartrment.

4157. - Publ. : Curtulaile grénéral de l'Yonne, recneil de ductuments anthentiques ponr servir a l'histoire des pays qui forment ce departement, par Vlaximilien Quantin. Auxerre, 1854-1860, 2 rol. in-40 de xum-630 et cur-589 p. avec pl. [Sociótí des sciences listoriques et naturelles de l'Yonue.]

- Recueil de pièces pour laire suile an cartulaire ménéral de l'Yonne, XIlI siècle, par le mème. Anxerre, Perriquet. I873; in- $8^{0}$ de xul-494 p. [Société des sciences historiques et naturelles de l'Yonne.]

\section{Ypres. - Abbaye tlo Saint-Jean.}

4158. - Cartnlatre de liathaye de Saint-Jean d'Ypres; ms, du XVIIe siècle, sur papier. contenant des actes de 12333 a 1626 . in-4" trchives de l'Étut ì Bruges).

Ypres. - Béguinages de Sainte-Christine et Saint-T'homas.

4159. - Cartulaire des héguniages de Sainte-Christine et SaintThomas d'Ypres: ms. des $\mathrm{A} / \mathrm{V}^{\mathrm{e}} \mathrm{-} \mathrm{X}^{\mathrm{e}}$ siècles, sur parchemin, contenant des actes de 1254 it 1444 , in-folio de $28 \mathrm{ft}$. Archives communales d'Tpres).

Ypres. - Chapitre dr Saint-Martin.

4160. - Cartulaire [incomplet] du chapitre de Saint-Martin d'Ypres on « Gelewen hoek»; ms. dn X VI ${ }^{e}$ siècle, sur parchemin, contenant des actes à partir de 1217, in-folio de $160 \mathrm{fr}$. Archives cominnales de Ipres.

Ypres. - Chatcllenie.

4161. - Ciurulaire des privilèges de la châtellenie d'Ypres: ms. des XVe-X VIle siecles. sur papier, contenant des actes de I:268 à I622, in-folio de 31.5 ff. (Archices de l'Etat à Bruges).

Ypres. - Confrérie de Notre-I)ame.

4162. - Cartulaires de la confrérie N.-D. à Ypres [fragments] ; mss. 
des $\mathrm{XIVe}-\mathrm{XV}^{\mathrm{e}}$ siedes, sur parchemin. in-40 de $52 \mathrm{ff}$. (Biblioll, roymle de Birrelles. ms. Hoil.

Cf. le ms. 4tuif lu mème fonds.

Ypres. - Hispin Belle.

4163. - Cartulaire de lhospice Belle à lpres: mi. de 1397. snr parchemin. contenant des actes des amnes 1:219 il 1408 , in-folio de $108 \mathrm{ff}$. Archioes des hospices cicils d" Fipres.

Ypres. - Hospier de Notre-I)ame dr Nazareth.

4l64. - Cartulaire de l'hospice de X.-I). de Nazareth d'Y pres: ms. dn XVe siècle, sur parchemin, contenant des actes des années 12971475, in-folio de $161 \mathrm{ff}$. (. Lichices des hospices cirils d Fires.

Ypres. - Préròté de saint-Martin.

4165. - Cartulaire de la prévòté de Saint-. Yartin d'Y Pres ou « Regristrum rubrum »; ms. des XIIJ- XIV e viècles. sur parchemin. contenant des titres de 1102 à 1304 . in- $4^{0}$ de $150 \mathrm{ff}$. 'Biblioth. de la cille tripres.

4166. - Autre cartulaire on "Rearistrum normm 》: ms. du XVesiècle, sur parchemin. contenant destitres de 1176 is 1422 . in-folio de $222 \mathrm{ff}$. (Avchices de lécéché de Bruges .

4167. - Autre cartulaire on « Recristrum niyrum »; ms. des XVe $\mathrm{XVIe}$ siècles. sur parchemin. contenant des titres de 1110 à 1543 , in-folio de 27!) ff. Archires de léxéché de Bruges).

Cf. : E. Feys ef A. Nelis, Les carlulaires de la prérôlé de saint-

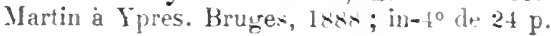

Ypres. - Table des panros dr. Saint-Yiculas.

4168. - Cartulitire de la tahle des paurer de Saint-Nicolas d'Yópres; ms. des XIV'e-XVe siècles. sur parchemin. contenant des titres de 1:265 à 1498. in-folio de $89 \mathrm{ff}$. Archices du Bureut de bienfaisunce त' Fpres.

Ypres. - Tible des paures de Saint-Pierre.

4169. - Cartulaire de la table des panves de Saint-l'ierre d'Y pres; ms. du X Te siecle. sur parchenin. contenant des docnments de l263 a 1488. infolio de I1!) ff. Archices de Buren! de bienfuisance "T Ipres.

Ypres. - Vill.

4170. - Cartulaire municipal d'Ypres on « Wittenbonck»; m. des XIVe_XVI siecles. sur parchenin. arec relinre de bois et une table, contenanl des docmment s de 1116 à 1.536 . in-folio de $3223 \mathrm{ff}$. Archires conimunules dP Fires. 
417I. - Autre cartulaire dit «Swartenbonck»; ms. dı XV siècle, sur parchemin, avec reliure anciennne et table, contenant des documents de 1116 à 155.5, in-folio de 426 et $16 \mathrm{fr}$. Archives communales rYpres).

4172. - Autre cartulaire dit «Roodenbouck $v$; ms. du XVIe siècle, sur parchemin, avec reliure anciene et : tahle, contenant des documents de I209 à 1580 , in-folio de 400 et $17 \mathrm{ff}$. (Archives commusales c. Ypres:

Le même dépồ contient des inventaires détaillés de ces registres. Voir aussi au "sipplément".

Zeelhem. - Courent des Chartreux (dioc. de Liège).

4173. - Cirtulaire des Chartrenx de Zeelhem; ms. du XVe siecle, sur papier, in-40 (Archicess du royaume de Belgique, à Bruxelles).

Dates extrêmes: : 1373-1:000.

4174. - Autre curtulaire du XVe siècle, sur papier, in-4 $4^{0}$ (Archives $d u$ royaume de Belgique, a Bruxelles.

Dates extrême's : $1325-14 \% 9$.

4175. - Autre cartulinire des XVIIe-XVIII siècles, sur papier, in-4 ${ }^{0}$ (Archives du royaune de Belgique, à Bruxelles .

Dittes extrines : 1328-1660.

\section{Zélande.}

4176. - Cartulaire des titres et privilèges relatifs aux propriétés de la famille Van Borsselen en Zélande; ms. dn XVIe siècle, sur parchemin et papier, incomplet du début, el contenant des actes des années 13338-1555, in-folio de 19.2 ff. Biblioth. de l'Université de Gand, ms. 164 .

Zonnebeke. - Abbatye de clamoines rimuliers de SaintAugustin dioc. d'Ypres;.

4177. - "Jura, privilegia et slatuta abbatiæ ef conventus monasterii ecclesiæ B. Mariæ Sinnebekensis »; ms, daté de 1295, orig. perdu.

Copie du précédent, sur papier, exécutée en 1632, et contenant des actes de 1072 à 1295, in-folio de $60 \mathrm{ff}$. Archives du Grand Séminaire de Brugess.

Publ. : prochainement, par la Société d'émulation de la Flandre. Zwyveke. - Abbaye (dioc. de Gand .

4178. - Publ. : Cartulaire de l'abbaye de Zwyveke-lez-Termonde, par Alph. de Vlaminck. Ire partie. Gand, impr. Annoot-Braeckman, 1869 ; in-8 $8^{\circ}$ de 176 p. 


\section{SUPPLÉMENT}

Agaune. - Abbaye.

4179. - Recueil de titres relatiis à l'albaye d'Agraune, fait au XVIII siècle par D. J. de l'Isle, sur papier, in-folio Biblinth. roynle de Bruxplles. ms. 3728, ff. I4:-169.

A la suite diune histoipe de ce nonastère.

Aire-sur-la-Lys. - Ville.

4180. - Recueil de chartes relatives ả Aire-sur-la-Lys ; ms. composé au IVIII siècle par d'Assenoy, contenant des actes de 1188 à 1660 . sur papier, en 2 vol. in $4^{0}$ de 357 et $35.5 \mathrm{ff}$. (Bibliolh. de la ville Whire-sur-la-Lys. mss. 48-49,

Aix-en-Provence. - I'niversité.

4181. - Pubr. : Les Statuts et privilègres des Universités françaises, par Marcel Fournier. III (Paris. 1892, in-4 ${ }^{\circ}$, pp. 1-32.

Ambournay. - Abbaye (dioc. de Lyon).

4182. - Cartulaire de l'abbaye d'Ambournay; oriy. perdu.

Lihistorien dauphinois de Valbonnais a connu et signalé ce registre.

Andenne. - Ville.

4183. - Prbi. : Cartulaire de la commune d'Andenne 1101-1792. par Léon Lahaye. Yamur. Wesmael-Charlier, 1893-1896; 2 vol. in- $\delta^{0}$ de $c x_{c}-317$ et $15-460 \mathrm{p}$.

Angers. - Abbaye de N. D. du Ronceray.

4184. - Cartulaire de l'abbaye de X.-D. du Ronceray d'Angers: ms. écrit en' 1179 "par II. 'Tallebot, sacriste de l'abbaye »; orig. perdu.

Extraits faits en 1739 (Biblioth. nationale, coll. Dom. Housseau, vol. II², ff. 192-213).

Angers. - Chapitre cathédral Saint-Yaurice.

A ajouter aux extraits du Grand cartulaire : Biblioth. nationale, coll Dom Housseau, vol. XIII, ff. 17:-193. 
Angers. - Iniversitè.

4185. - Pubi. : Les Statuts et privilèges des Universités françaises, par Marcel Fouruier. I (Paris, 1890, in- $4^{\prime \prime}$ ), pp. 261-436; et III (I892), pp. 495-520.

Anvers. - Abbaye de Saint-Michel.

4186. - Publ. : Cartularium der abdij van St. Michiels te Antwerpen, ed. P. J. Goetschalckx (Bijdragen tot de geschiedenis bijzonderlijk van het aloude hertogytom Brabant, IV, 1905, pp. 549-600; V, 1906, pp. 297-361 [à suivre]).

Arménie. - Voy. Cilicie.

Arras. - Église collégiale Sainte-Croix.

4187. - Cartulaire de l'érlise Sainte-Croix d'Arras; ms. du débunt du $\mathrm{XVII}$ siècle, sur papier, relié en maroquin ronge, avec additions postérieures, contenant des actes de 1453 à 1688 , in-folio de $473 \mathrm{ff}$. (Archives dép. du Pas-tle-Cirlais, G non coté).

Volume réintégré en 1900 des archives de l'éréché d'Arras.

\section{Artillerie.}

4188. - Publ. : Recueil des ordonnances du Roy concernant le service de l'artillerie. Mletz, Vve Brice Antoine, 1730, in-8 .

Aspe (Tallée d').

4189. - Publ. : Sequense lous priviledges, franquesses et libertats domnats et autreiats aux vesins, manans et habitans de la montaigne et val d'Aspe parlous seignours de Bearn. Pau, J. Dupoux, I694; in- $4^{0}$ de $1 \mathrm{v}-\mathrm{I} 43 \mathrm{p}$.

Documents ì partir de 1398. - Cif. Recue de Béurn, 1883, pp. 469$4 \leqslant 0$.

Asti. - Seigneurie.

Un eartulaire de mème nature que celui des Arehives nationales de Paris (ci-dessus n $n^{\circ}$ 212) se trouve à l'Arehicio di stato de Turin. It paraìt mêne un peu plus complet.

Averbode. - Abbaye.

4190. - Fragments de plusieurs anciens cartulaires de l'abbaye d'Averbode; mss. de $\mathrm{XV}^{\mathrm{e}} \mathrm{e}-\mathrm{XVIII} \mathrm{I}^{\mathrm{e}}$ siècles, reliés ensemble, sur papier, contenant des actes de 1135 à 1654 , in 40 "le 523 pages (Archives générales du royaume, a Bruxelles).

Avesnes. - Comte.

419I. - Cartulaire de la seigneurie d'Avesnes, contenant « les chartres et lettres de tonte la terre de Avesnes, des appertenances et 
dou ressort, qui esloient au cartulaire de Guise »; ms. dressé en 1327 , sur parchemin, contenant 1:22 textes de 12602 à 1394 , in-folio de I4t ff. (Biblioth. de le Sociélé archéologinue d'Aresues.

Cif. Jote de L. Devillers dans les Complesorendus de ln Commission ruyale dhistoire, 1902, pp. 151-155.

Publ. : prochainement dans le tome VIII des Anuules de la Société archéologique d' Aresines.

Avignon. - Université.

4192. - Pcbl. : Les Statuts et privilèges des Universités françaises, par Marcel Fournier. II (Paris, 1891, in-4"), pp. 301-535; et III (1892), pp. 647.666.

\section{Avocats.}

4193. - PubL. : Recueil des statuts, ordonnances, règlements, antiquitez, prérogatives et prééminences du royaume de la Basoche. Nouvelle édition. Paris, Besongne. 1654. in $-8^{\circ}$.

Bâle. - Couvent de Saint-Alban.

4194. - Cartulaire A du couvent de Saint-Alban de Bâle, dépendant de Cluni : ins. du $X V^{\text {e }}$ siècle, sur papier, in-4 de 3222 pares (Stautsarchic zu Busel).

Quelques documents en ont été extraits par Trouillat, Monuments d. l'histoire de l'ancien évêché de Bàle.

4195. - Cartulaire C de Saint-Alban de Bàle; ms. du XVe siècle, sur papier, avec reliure de bois, in $\mathbf{4}^{0}$ de $15 \%$ pagres (Stuntsarchic $2 u$ Basel).

$4195^{\text {bi: }}$. - Cartulaire $\mathrm{R}$ ou «Codex Pfisteri »; ms. du XITe siècle avec additions, sur papier, contenant des titres de 1088 à 1409 , in-folio de $84 \mathrm{ff}$. (Stautsurchir z". Busel).

Bâle. - Église cathédrale.

4196. - Cartulaire de "Domstift » de Bâle ou « Codex diplomaticus ecclesie Basiliensis »; ms. des XII contenant des titres de 99:3 à 1:302, in-4" 'Staalsarchic zu Bern'.

Copie du précédent, faite en I8:39 (Slaatsarchio zu Busel).

Bâle. - Église Saint-Léonard.

4197. - Cartulaire de l'église Saint-Léonard de Bâle; ms. du XIIle siècle [1295], sur parchemin, in $-4^{0}$ de $36 \mathrm{fr}$. (Staatsarchio z! Busel).

Même observation que pour le registre Ade sit-Alban. - On a aussi un court fragment diu autre cartulaire du XVIe siècle (6 ti. 1,archemin). 
Bâle. - Ėglise Saint-Pierre.

4198. - Cartulaire de l'éğlise Saint-Pierre de Bâle: ms. du XIVe siècle, sur parchemin, in- $4^{\circ}$ (Stautsarchiv zu Basel).

Bâle. - Églisı Saint-Théodore.

4199. - Cartulaire de l'éolise Saint-Théodore de Bâle ; ms. du XVe siècle, sur papier. in-folio de 146 pages (Stuutsarchio zu Busel).

Barbiers-chirurgiens.

4200. - Publ. : Les statuts, privileges et ordonnances royalles accordez et confirmez par les Roys à leur premier harbier, ses lieutenans on commis et autres barliers-chirurgiens du royaume de France. Lyon. 1633 , in- $4^{0}$.

Basse-Wawre. - Prieuré (dioc. de .Malines).

420I. - Cartulaire du prieuré de Basse-Wawre: ms. du XVIe siècle, sur papier, contenant des titres de II40 a 1452 , in-40 de $53 \mathrm{fr}$. (Archices die roymume de Belgique, à Bruxelles).

Bar-le-Duc. - Prieuré. - Voy. SaIst-Miniel.

Béarn. - Province.

4202. - Publ. : Compilacion d'aurguns priviledoris et reglamens den pays de Bearn, feyts et octroyats à l'intercession deus Estats ab los serments de fidelitat deus seignours à soos subjects. A Lascar, G. de La Place, 16:33. in $4^{\circ}$. - Nouv, édit. Orthez, 1676, in-40 ; et Pau. 1716 , in-4".

Beaucaire. - Sénéchaussée.

420:3. - Cartulaire de la sénéchaussée de Beaucaire; ms. du XIVe siecle. sur papier, contenant les actes dadministration depuis le règne de Louis IXj jusqu'à Philippe VI, in-4" de 221 ff. (Biblioth. nulionale. ms. latin I 1016 .

Beauvais. - Chapitre cathédral.

4201. - Cartulaire de la trésorerie du Chapitre de Beauvais, ou «Livre ronge $\gg$; orig. ( $\mathrm{XV}^{\mathrm{r}} \mathrm{s}$. ?) perdu.

Extraits faits au XVIIIe siècle (Biblioth. de la ville de Beauvais, coll. Buequet-Auxcousteaux, vol. XXX1, p. 2227 et ss.).

Beauvais. - Église collégiale Saint-Vaast.

4205. - Cartulaire de la collégiale St-Vaast de Beauvais : orig. perdu. Extraits faits au XVIII siècle (Biblioth. de la ville de Beauvais, coll. Bucquet-Auxcousteaux, vol. XXXVIII, pp. 2:5-239). 
Beauvais. - Ville.

4206. - Publ. : Arrèts el titres pour la ville de Beauvais. S. 1. n. d., in-12 de $19 \mathrm{p}$.

Dates extrèmes : $12660-1368$.

$4206^{\text {bis. }}$ - Publ. : Privilè res de la ville et commune de Beauvais. S. I. n. d.. in- $8^{\circ}$ de 84 p.

Dates extrèmes : $147 \%-1634$.

4207. - Cartulaire de Beauvais ou « Livre velu»; ms. des XIVe-XVe siècles, sur papier, in-folio de 126 ff. (Biblioth. du chateau de Troussares, Oise.

Sur ce volume récemment retrouvé (cf. ei-dessus no 426), voir

H. Quignon dans le Bulletin historique ef philologique du Comite, 1906, pp. 203-215.

Extraits du précédent, faits au XVIII siècle (Biblioth. de la ville de Beaurais, coll. Bucquet-Auxcousteanx, vol. LXX).

Un exemplaire des deux recueils imprimés est conservé dans la même collection (rol. LIII).

Bellelay. - Abbaye (dioc. de Bàle).

4208. - Cartulaire de l'abbaye de Bellelay; ms. écrit en l114 par Nicolas Huninger, notaire de l'officialitè de Bâle, sur papier, contenant des actes à partir de 1141 , in- $4^{\circ}$ Staatsarchio zu Bern).

En partie publié dans Troullat, Monuments de l'histoire de l’ancien évèché de Bâlte.

Belley. - Cathédrale Saint-Jean.

4209. - Cartulaire de l'église de Belley ou «Liber donationuin»; ms. écrit en 114 , auj. perdu.

Il existait encore en $16 \% 1$ quand on en fit un extrait d'un acte de l'année 1100 relatif à la forèt de Rothonod (Archires depp. de l'Ain).

Besançon. - Chapitre métropolitain.

4210. - Publ. : Titres et actes concernant les droits et privilèges des haut cloyen et chanoines de l'illustre Chapitre de l'église métropolitaine de Besançon. Besançon, s. d., in-4"

Besançon. - I'niversité. - Voy. DoLE.

Besançon. - Ville.

4211. - Publ. : Édits. lettres patentes et arrêts concernant l'administration municipale de Besançon. Besançon. 1731. in- $8^{\circ}$.

Bétharram. - Ermitage de Notre-Dame (dioc. de Lescar). 4212. - P'ubl.: Documents sur Bètharram (1308-XIX'e siècle), par 
l'abbé V. Dubarat (Bulletin de la Syciété des sciences, lellres el ar/s de Pun, '2" série, XXIII, 1894, pp. 107-231 et 269-324).

Bonafoux. - Famille bordelaiso.

4213. - Fragment d'un cartulaire des lamilles Bonafonx et Carpentey; ms. du XIII e siècle [commençant au f" 57], sur parchemin, contenant 33 actes de 12.8 à 1278 , in-folio de $7 \mathrm{tr}$. (Avchices municipules de Burdear r).

Bonne-Espérance. - Abbaye (dioc. de Cambrai).

4214. - Cartulaire général de Prémontrés de Bonne-Espérance; ms. du XVIIle siecle, sur papier, contenant des titres de 1126 à 1736 , en 18 vol. in-folio (Biblioth du Pelit-Séminuire de Bonne-Espérance).

Bonneval. - Abbaye (dioc. de Chartres).

4215. - Extraits du cartulaire [perdu] de Bonneval, faits par l'olluche au XVII ${ }^{\mathrm{e}}$ siècle (Biblioll. de lu rille d'Oilérns, ms. 556, pp. 4988 .

Complète lindication domée cirlessus sous le ñ 528.

Bordeaux. - Juges-consuls.

4216. - I'ubl. : Recueil des édits, déclarations, lettres patentes du Roy et arrests des parlemens donnez en faveur de Messieurs les jugre et consuls de la lourse commune des marchands de la ville de Bordeaux. Bordeaux, Mongiron-Millanges. 1691, in- 4 ".

Bordeaux. - Eniversiti.

421\%. - YubL.: Statuts et règlements de l'ancienne Université de Bordeanx (1441-I793), publ. par H. Barckliausen. Bordeaux, Gounonithou. I886; in-4" de trov-172 p.

Cif.: Marcel Fournier. Les statuts at privileges des Universités françaises, III (1892), pp. 3337-360.

Bourbon-lès-Gaillon. - Chartreuse.

4218. - Cartulaire de la Chartreuse de Bourbon-lès-Gaillon: ms. du XVIIe siècle. rédigé à la requête du prieur D. Pierre Huvier, avec tahles. in-folio de Xvi-94l pages (Bibliolh. de la ville de Rouen).

Précédenment dans la collection de Charles Lormier (Catalogue, $\left.n^{0} 5606.1\right)$ vendue at Paris en mars $190 \pi$.

Bourgogne. - Etats.

4219. - Yubl. : Recueil des édits, déclaritions. lettres patentes. arrêts du Conseil, ordonnances et autres règlemens émanés du Roi et de son Conseil, concernant l'administration des Etats de Bourgogne, des arrêts des parlements. chambres des comptes. cours des aides, 
qui peuvent avoir quelque rapport aux olyets de ladite alministration. Dijon, Defay, 1784-1787, ? vol. in-4'.

Bretagne. - Chambre des Comptes.

4220. - PcBL. : Recueil des édits. ordonnances et règlements concernant les fonctions ordinaires de la lihambre rles Comptes de Bretagne. tiré des titres originaux, par. J. Artur de La (irbonays. Nantes. ve A. Guerro, 172I-1722: 4 rol. in-folio.

Bretteville-l'Orgueilleuse. - Seignemrie en Normandie.

4221. - Cartulaire de la sei zneurie de Bretteville-l'Orgneilleuse ; ms. du $\mathrm{Xl}^{\mathrm{e}}$ siecle [1461]. avee quelques additions postérienres. sur parchemin, in-t' de 518 pares lichices dép. du Culcudos. E non coté).

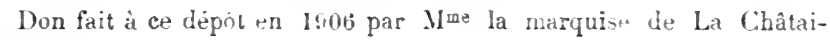
irneraye.

Brienne (de). - Famille.

4222. - Recueil de documents relatils à la maison de Brienne, de 1160 à l:2:30; ms. du XVII siecle. sur papier, in-folio (Biblinth. nationule, coll. Duchesne. vol. IXIXI, pp. 35-60 .

Bruges. - Bẻguinage.

4223. - « Copyen chaerters van de jaren 1200 en l:300 »; ms. du XIVe siècle, sur parchemin, in-4" Archices du Béguinuge de Bruges, res. l'.

42:24. - Autre recueil, lait d'après les originaux et collationné en 15:0, sur parchemin, contenant des actes des XIIJ $-\mathrm{XVI}^{\mathrm{e}}$ siecles. in $-4^{0}$ (Archices du! Béguinuge te Biruges, reg. ?.

Bruges. - Chapelle du Saint-siang.

42:25. - Cartulaire de la chapelle du Saint-Sang is Bruges: ms. du $\mathrm{Cl}^{\mathrm{e}}$ siecle, sur papier. contenant des actes de 12:36 a 1476 . in $-4^{\circ} \mathrm{de}$ $43 \mathrm{tif}$. Archices commules de Bruges;.

Les $\mathrm{ff} .16$ it 25 manquent.

Bruges. - Collège des Jésuites.

42:26. - Cartulaire du collèye des Jésuites coté E. contenant des actes

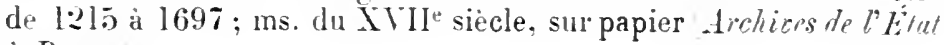
à Brugres,

Doit sajuuter anx quatre autres clu mêne fonds inventoriés ci-lessus (page 94). 
Bruges. - Courent des Cisterciennes de Spermalie. 42:27. - Cartulaires des Cisterciennes de Spermalie.

On a signalé lexistence de deux registres qui apparliennent sans doute au dit couvent : les renstignements font completenent défaut.

Bruges. - Église collégiale Notre-Dame.

4228. - Cartulaires de l'église Notre-l lame de Brugres.

L'église Notre-l)ane possedre quatre cartulaires qui nont jamais èté étudic et dont la mention seule figure en 1906 dans les Anirales de la Sucirté d'émulation de la Flundre.

Bruges. - Église collégiale Saint-Donatien.

42:29. - Cartulaire de l'église Saint-l)onatien; ms. du XIV siècle, sur parchemill, avec reliure ancienne, in-folio de $129 \mathrm{ff}$. Archives de l'évêché de Bruges.

Dates exlrêmus: :161-1337. Cf. L. Gilliodts Van Severn, Cioutumes de la prévité de Brugtes, 11 (Bruxell s, 188\%, in-4\%).

Bruges. - Églises.

4230. - Cartulaire de l'éólise collégiale Saint-Sauveur de Brugres.

4231. - Cartulaire de l'église Sainte-Anne.

4232. - Cartulaire de l'église Saint-Gilles.

4233. - Cartulaire de l'érolise Saint-Jacques.

Cés quatre recutils sont conservés respectivement dans les quatre églises ainsi dinommés de Bruges ; ils sont mentionnes pour la prenière fois un loni dians les Amales de la Sociéte d'imulation de la Flawde et ne cont pas autrement connus.

Bruges. - Hospice de lit Potterie ou du Saint-Esprit.

4234. - Cartulaire-censier de l'lospice de la Potterie de Bruges; ms. du $X V^{\text {ee }}$ siècle [142.5]. rédigé par fr. I'ierre Clavant et complété an $\mathrm{XVI}$ siècle. sur parchemin. contenant des actes de 1250 à 1478 , in-folio de $294 \mathrm{tr}$. Archices de llospier de la Pollevie te Bruges, $\left.n^{\prime \prime} 1\right)$.

4235. - Autre cartulaire du $\mathrm{XVI}^{\mathrm{e}}$ siècle, sur parchemin, contenant des actes de 1432 à 1515 , in-folio de $192 \mathrm{ff}$. (Arclives de lhospice de la Potterie de Bruges. n ${ }^{0} 2$.

Bruges. - Hospice Elisabeth Zorghe.

4236. - Recueil des titres relatifs à l'hospice Zorghe (fondé en 1632); ms. du XIXe siècle, sur papier Archives des hospices de Bruges, fonds de l'Hospice Zorghe). 
Bruges. - Hospice de N. D. de Nazareth.

4237. - Cartulaire de l'hospice de $\mathrm{N}$. D. de Nazareth à l'ruges : ms. daté de 137:2 et rédigé par Simon van der lloere et Jean Hosten, in-folio Ltrchices de bhospice de ln . Wadeleine de Bruges,

Bruges. - Hospice Saint-Julien.

4238. - Cartulaire de l'hospice Saint-Julien de Bruges: ms. daté de 1392, et dressé par le frère Gilles Berthilden. avec reliure ancienne de bois recouverte de cuir rouge. contenant des actes depuis 1:280 et continue jusquen 1522, sur parchemin. in-folio de $147 \mathrm{ff}$. Archires de lhospire Suint-.Julien ì Bruges).

4239. - Autre cartulaire, dressé en 1399 par Jean Camphin et Jean Buersen, aver additions jusqu'en 1760. sur parchemin. contenant des actes à partir de 1236, in-folio (Archives te Thospice SuintJulien à Brruges .

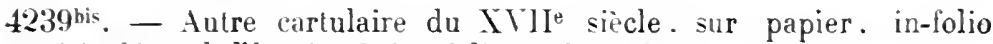
(Archiops de l'hospice Sulul-.Julien à Binges.

Bruges. - Hospice Saint-Nicolas.

4240. - Cartulaire de l'hospice Saint-Nicolas de Bruges; ms. dressé en 1400. sur parchemin, in-t" Archices de thospice Saint-Nicolas is Briges).

Bruges. - Lépreux agrestes.

4241. - Cartulaire des léprenx agrestes de Brưres: ms. daté de 1407, sur parchemin. contenant des actes de 1:258 à 1407 . in- $4^{0}$. Archices de l'hospice de ln . Wudeleine à Bruges.

$4241^{\text {bis. }}$ - Autre cartulaire de la fin du XVe siècle, avec additions du XVIe, sur parchemin, contenant des actes de 1:258 a $15+0$, in-folio (Archives de l'hospice de lin. Indeleine ì Bruges).

Bruges. - Léproserie de la Madeleine.

4242. - Cartulaire de la Mfadeleine de Bruges ou « Antiquus liber»; rédigé en 1337 par frères Jean Rengote et G. van Zerkenghem, contenant des actes à partir de l2230 et continué jusçu'en 1486. sur parchemin avec reliure de hois. in-folio Archices de lhospice te la Madeleine de Bruges, n" 1 .

4243. - Autre cartulaire daté de 1461, dressé par (hr. Juervers, contenant des actes à partir de 1.274 et continué jusqu'en 1503. sur parchemin. avec reliure de bois, in-t" (Archives de l'hospice de lo Irudeleine de Bruges, $\mathrm{n}^{\circ}$ t. 
4244. - Autre cartulaire daté de 1476, contenanl des actes depuis l:2:34 et continué jusqu'en 1.988, sur parchemin avec reliure de bois,

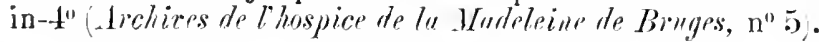

4245. - Autre carlulaire du X l'e siècle, dressé par ('hr. Juerveys, et contenant des actes de 1:230 à 1486, sur parchemin avec reliure de

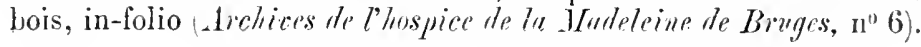

Bruges. - Table des paluvres de la paroisse Saint-Gilles. 4:46. - Cartulaires de la tahle des pauvres de Saint-Gilles de Bruges.

On a signale deux registres de ce nom, sur lestuelo les renseiynements manciurnt complitem 'nit.

Bruxelles. - Couvent de Jíricho.

4247. - Cartulaire lu couvent de Jéricho à Bruxelles : ms. du XVo

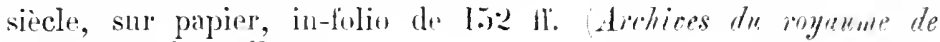
Brlyique, à Bruxelles'.

lindication relative à un cartulaire du mêne établisorment fei-

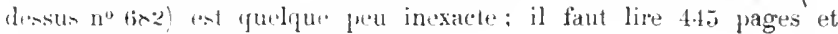
combnte diatrs "xtrêmes: $11: 31-1643$.

Bruxelles. - Convent de Sainte-Élisabeth.

4248. - Cartulaire tu couvent de Sainte-lílisabeth, à Bruxelles; ms. du XVe siecle $/ 4777$, avec additions du $\mathrm{XVI}^{\mathrm{e}}$, sur papier. contenant des actes de 1368 à 15.5l, in-folio de 13: fl. (Aiclires duroyname de Bolgiqur, à Bruxelles.

Bruxelles. - Courent des Chartreux. - Voy. Scinsut.

Bruxelles. - Courent des Jésuites.

4249. - « Cartularinm templi Bruxellensis Sucietalis Jesu »; ms. du XVIIle siècle, sur papjer, in-4" de $172 \mathrm{fr}$. (Bibliwh. royyle de Birselles, ins. 40.58.

Bruxelles. - Eglise (•ollégiale de SS. Michel et Gudule.

4:50. - Cartulaire de l'église collériale S.S. Michel et Gudule de Bruxelles; ms. du XYe siecle [1468]. par I'ierre à Thymo, in-folio

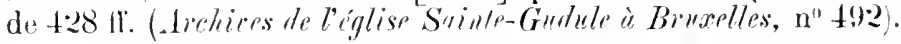

4:551. - Autre dil "Registrum album »; ms. du XVI siècle, contenant des actes de $104 \%$ à $I 46 \%$. in-4" de 13.) $1 \mathrm{r}$. (Archives de l'église

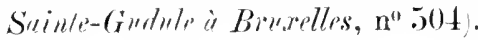

425\%. - Autre dil « Regristrum ceruleum »; ms. des $\mathrm{XVI}^{\mathrm{e}}-\mathrm{XVII}^{6}$ siècles, avec table, et contenant des actes vle 1047 is 1616 . in $4^{0}$ de

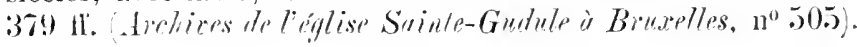


4253. - Autre cartulaire: us. du XIN"e siecle. contenant les chartes

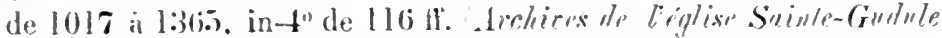
à Brurelles. n" $4 ! 9$.

425̃ut. - Autre inlitulé « P'rivileuria el concordata pro capitulo »: ms. des $\mathrm{X} H \mathrm{I}^{\mathrm{e}-\mathrm{K}} \mathrm{I}^{\circ}$ siecles. sur parchemin. contenint des chartes de $104 \mathrm{~T}$ $\dot{a}$ 1tril, in-fulio Archice? dr liglise Sainlp-Gudule à Bruxplles, $11^{\prime \prime} 48 \%$.

4.5.5. - Aulre dit « Regristrum diversarum capellaniarum»: ms. du XYe siecle. sur papier. in-folio de $188 \mathrm{fl}$. dichires lo l'iglisp SuinteGurlule a Bruxplles, n" s0)

4256. - Autre dil « Capellaniarum liversarum bona »: ms. du $\mathrm{XV}^{\theta}$ siècle, sur papier. in-folio de bo tf. Arehices de Ciglisp SuinteGiedule is Brimelles. n" 2 !).

4257. - Autre cartulaire: ms. des $\mathrm{XV}^{\mathrm{e}} \mathrm{XVI}$ e siècles, sur papier, contenant des actes de 1047 a 1501 . in-folio de $5 !$ ) 17. (1) clires de

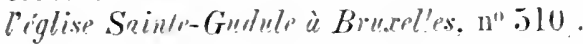

4.258. - Autre cartulaire; ms. des $\mathrm{XV}^{\mathrm{e}}-\mathrm{XVI}^{\mathrm{e}}$ siècles, sur papier, contenant des actes de l047 a 159l. in-folio de l:38 lif. arec table Archices de léglise Suintr-Gudule ì Brucelles, n" $4 ! n$.

4259. - Autre du $\mathrm{XVI}^{\mathrm{e}}$ siècle. sur papier, mulilé. contenant iles

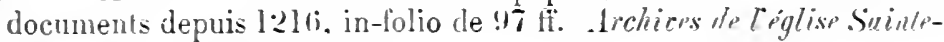
Gudule is Billsellos. n".jli).

4260. - tutre du XI ${ }^{\circ}$ siecle. sur parchemin. contenant les titres de propriélés du Chapitre aux environs de Bruxelles, le l:29ti a l:39:3,

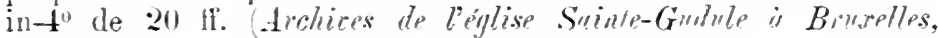
$\mathrm{n}^{0}: 396 j$.

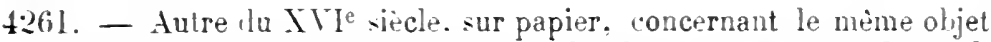
pour une période plus nodern in-folio le $2: 34$ pares derkices de Téglise Suinlr-Gudule is Bruxplles. n" +200 .

4262. - Frarment d'un autre cartulaire du $\mathrm{X}^{\top} \mathrm{l}^{\mathrm{e}}$ siecle. sur papier,

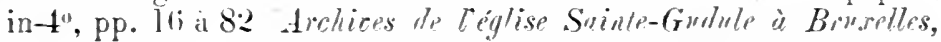
$\left.n^{\prime \prime} 5 \geq 0\right)$.

4263. - Autre cartulaire llu XVII siecle, avec chronique, sur papier, contenant des actes du $\mathrm{XI}^{\mathrm{e}}$ au $\mathrm{XVI}$. in-folio de $4.5 \mathrm{ff}$. Aichires de Féglise Suintr-Gwdule ù Brwsplles. $\left.11^{0}+2: 3\right)$.

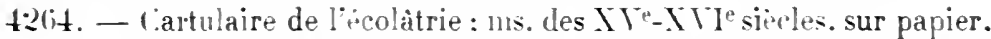

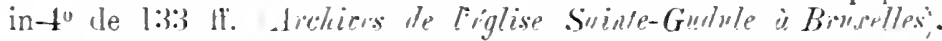

4:65. - Cartulaire des pelis Clhanoines: 1ns. des XIVe-XVe siecles.

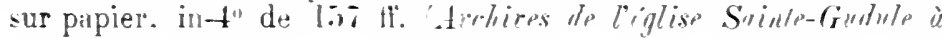
Bruxelles, n" I 69 . 
4266. - Autre recueil du XVe siècle, sur parchemin, mutilé, contenant des actes depuis le XIIle, in- $4^{\circ}$ de 12:2 pares (Archioes de leglise Suinte-Gudule à Bruxelles, n" (io).

4267. - Autre cartulaire de Sainte-Gudule; ms. du XVe siècle, sur parchemin, in-folio de $17 \mathrm{ft}$. (Biblirth. roygle de Brurelles, ms. $4: 30: 3$.

Caen. - Courent des chanoines réguliers de Saint-Augustin ıu Prieuré de l’Hôtel-Dieu (dioc. de Bayeux).

4268. - Cartulaire des chanoines réguliers de Sl-Aurustin on frères de Sainte-Croix de Caen : orig. perdu.

Copie du précédent. faite en l66i3, sur papiere, contenant des actes

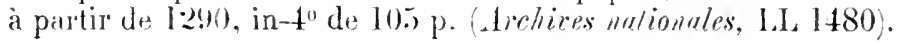

Gaen. - Englise collégiale du Simint-Sépulere.

4269. - Cartulaire de la collérgiale du Saint-Sépulcre de Caen; ms. "xéculé en l'an 1:300 par Allin de Sainte-Anne, orig. perdu.

lixtraits laits in XVIII siècle (Bibliolh. melionule, ms. latin $10067,11.1-10$.

11 semble qu'il $y$ ait wu dans te mên fonds un rout:au en parchemin, contenant dets charites (Ittem, it. 11-2x).

Caen. - Lniversitó el colleges.

4270. - Plbı. : Les Statuts et privilères des Universités françaises, par Marcel Fonrnier. 111 Paris, 1892 , in- $\left.4^{\prime \prime}\right)$. pp. 14.5-28.2.

Cahors. - Lniversite el collegges.

4271. - PubL. : Les Statuts et privileges des Universités françaises, par Marcel Fournier. 11 (Paris, I8!) I, in $4^{\circ}$, pp. 5:37-650.

Galci. - Lihartruse (dioc. d'Aleria).

427:2. - Recneil de pieces relatives à la Chartreuse de Calci (Bulloin

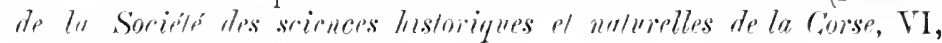
1887 , pp. $286(-3 ; 3: 37$.

A la suite dun inventaire de titres (4t; doruments des années l095$1: 312)$

\section{Cambrésis.}

4273. - Cartulaire du Cambrésis; ms. du XVe siècle, sur parchemin, contenant des titres de 1189 à 1468 , in-folio de $23 \mathrm{ff}$. (Archives dép. du Lirt. B 1.590).

Capitaineries des chasses.

4274. - Prbu. : Recueil des édits et déclarations des roys, depuis 
François Ier jusques à présent, pour la jurisdiction et fonction des capitaines des chasses. Paris. 16.54. in-1:.

4275. - Publ.: Recueil des titres du bailliage el capitainerie des chasses de la Varenne et du chàteau du Louvre. Paris. 1676 , in $-4^{0}$.

Garmes. - Ordre religieux.

4276. - Recueil des privilèges de lordre des lames; ms, du XVII siecle [1652-57]. rédigé par Jean de Meerbeck, procureur des provinces des Pars-Bas. sur papier, in-folio de $31: 3 \mathrm{ff}$. (Biblioth. royule de Brixelles. ms. 3812,.

Garpentey. - Famille. - Voy. Bosafoux.

Célestins. - Ordre religieux.

4277. - Cartulaire des Cẻlestins; ms. du XTe siècle [1457]. dressé par Me Jean Savin d'après les originaux, sur parchemin. contenant des titres de 1.294 à 14.07 . in- $t^{\circ}$ de $21 \mathrm{ff}$. Archires nationales. LL 1504 .

Chartres. - Comté.

4278. - Cartulaire du comté de Chartres: ms. dressé en 1:302 par Renard de Bennes, bailli de Chartres : oriłr. détruit.

Cete volume, rui faisait partie des archives de la Chambre de Comptes de Paris, était surtout relatif aux cens, fiefs et coutumes dn conté : touturois il sy tonvait auss quelques chartes qui Iui donnent Iroit de cité iei fef. extraits dans Biblioth. nafinale, ms. francais $20 j 91$, [p. $.53-5192$ )

\section{Chasses.}

4279. - PrbL. : Les ordonnances, royalles sur le faict des chasses, eaues et forestz du rovaume de France, avec celles du roy Henry deuxiesme de ce nom. vérifiées et collationnées aux originaux. Paris, L'Angelier. 15.5. in- $8^{\circ}$.

4280. - Code des chasses. [par C. M. Saugrain]. Paris, 1765, 2 rol. in-l:.

Ghezal-Benoit. - Abbaye et Congrégation.

4281. - Prbi.. : Pièces et titres concernant les abbaves de ChezalBenoit. Paris, M. Lambert, 1764: in- $4^{0}$ de $111 \mathrm{p}$.

Dates extrêmes : 14 ş-1650.

Gilicie. - Groisades.

4282. - Prbz. : Le Trésor des Chartes d'Arménie ou Cartulaire de la chancellerie rovale des Roupéniens. comprenant tous les documents 
relatifs anx étahlissements fondés en Cilicie par les ordres de Chevalerie institués pendant les croisades et par les répuhliques marchandes de l'Italie, etc.. par Victor Langlois. Venise, typ. arménienue de Saint-Lazare, 1863 ; in- 4 " de $\mathrm{x}-242 \mathrm{p}$.

Confient 52 documents (1201-1392) dont quelques-uns intérinscrnt lat France.

Clermont-en-Beauvaisis. - Église Saint-Samson (dioc. Beauvais).

4283. - Livre vert de Saint-Samson de Clermont; ms. contenant copie, vidimée en 153.), de tons les titres de propriété de l'église,

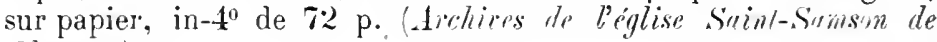
Clerimonl.

\section{Compagnie des Indes.}

4284. - Publ. : Recueil ou collection des titres, édits. déclarations, arrêts, rè̀rlements, et autres pièces concernant la Compagnie des Indes orientales étallie au mois d'aoùt l664, par Demis. Paris, 175.5-17.56; 4 vol. in $4^{\circ}$ de 689. 688. 7.56 et $697 \mathrm{p}$.

\section{Compagnies de la Guinée et du Sénégal.}

4285. - I'vbL. : Recueil des édits, déclarations, arrêts et lettres patentes concernant les Compannies de Guinée et du Sénégal. Paris, Boudet, 1754. in $-4^{\prime \prime}$.

\section{Concordat.}

4286. - Pubc. : Documents sur la négociation dn Concordat et sur les autres rapports de la France avec le Saint-Siège en 1800 et 1801, par le Cte Boula; de la Meurthe. Paris, Leroux, 1891-190.); (6 vol.

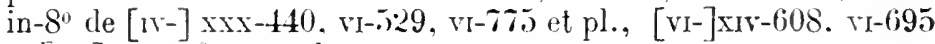
et [IV-] $\mathrm{xvI}^{-2}: 2: 3$ p. et pl.

Condé-en-Barrois. - Voy. SAINT-MIHHFL.

Conserans [Saint-Liziel]. - Évèché.

428\%. - Recueil de pièces relatives à l'église de Conserans; ms. du XVIIe siècle, sur papier (Biblioth. nationale, coll. Baluze, vol. XX, ff. I8t-193).

Datris extrêmes: $119 \%-1530$.

Coucy-le-Château. - Seigneurie. 4288. - Cartulaire de la seigneurie de Concy ; orig. perdu.

A eti ru et cité par Dom Villevieills. 


\section{Cours des Aides.}

4289. - Punc. : Élits et ordonnances concernant l'autorité des Conrs des Aides de France. par Jean Philippi. Montpellier, Gilel, 1.997, in-folio.

Courtrai. - Abbaye de Groeninghe.

4290: - Cartulaire de labbaye de Groeninghe; ms. des XVII XVIII siècles, sur papier. in-folio Bibliolli. mynte te Bruselles, ms. 3907 . $11.50-5 \% 5$.

(.f. la publication ci-dessus mentionner no $10 \mathrm{n}$.

Courtrai. - Église collégiale Notre-l)ime (dioc. de Tournai). 4291. - Cartulaire de l'église collegriale de Courtrai. ou « Liber fundationis »; ms. du XI 'e siècle. in $4^{\circ}$ de 113 fr. (Arckices de l'église .Y. D. de Compruit.

Les auteurs de la publication mentionnée ci-lessus ( $n^{0} 1082$ ) ont encore uilisé une compilation du XVIlle siècle, du chanoine P. F. de Meulenaere, ${ }^{2} \mathrm{i}$ rol. in-folio, sur papior, de $416,459,433,429$ et 420 pages (Biblioth. de lu cille de Courtrai, fonds (roethals-Vereruysse).

Courtrai. - Église collegiale saint-ylartin.

429:2. - Cartulaire de Saint-Martin de Courtrai : ms. des XVIJe XVIII siècles, sur papier. contenant des titres à partir du XIT"e siècle, in-4" de m-180 dr. (-Lochiress te lu fubrique de SnintWurlin de courmi).

4293. - Autre cartulaire dressé vers 1772; ms. sur papier. contenant

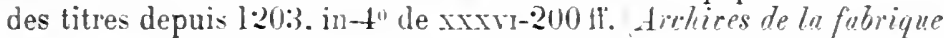
de Srint-Werlin de Courliui).

4294. - Autre dressé en I76 et continné jusqu'en 1790 ; ms. sur papier. contenant des actes de fundations à partir de la fin du

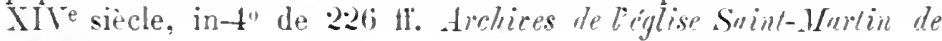
Conclicil).

Il paraîl certain qư îl a existé d'autars cartulaires de cette église, aujourd hui prerdus.

Courtrai. - ville.

4295. - " lepraminen I'rivilegiehoeck van der stede van Curtryche »; ms. "du $\mathrm{XVI}^{\mathrm{e}}$ siècle. sur" parchemin, contenant des titres de 1324 a 1570. in-folio de $458 \mathrm{ff}$. plus une table (Archices comimuntes de (oomlini).

4296. - «Erkten pampieren Privilegriebouck »: ms. des XVIe_ XVIJ siecles. sur papier. contenant des titres le lot3 à 1664 ,

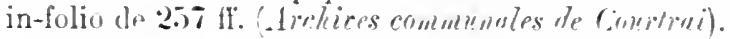


4297. - « Tweeden cleene I'rivilegielouck; ns. des XVII' XVIIr siècles, sur papier, contenant des titres de 1366 ì 1724 , in-folio de 46.5 $\mathrm{ff}$. (Archives comminales te Comprai).

4298. - «Derden pampieren Privilegiebouck»; ms. des XVIII XIXe siècles, sur papier, contenant des titres de 17:5 a 1808, infolio de $356 \mathrm{ff}$. (Archives communales de comitiai).

Couvin. - Ville.

4299. - Cartulare de la ville de Couvin; ms. du XVI" siècle, sur papier, in-folio de 30 pages Biblioth. de l'Unirersité de Liège, ms. 1116 .

Croisiers. - Ordre religieux.

4300. - Bullaire de l'ordre des Croisiers: ms. du XVI siècle, sur papier, in-4" de $27 \mathrm{fl}$. (Biblinth. royale de Bruxelles, ms. 3922).

Dates extrêmes : $1240-14 \times i$.

\section{Dauphiné.}

4:301. - Pubr. : Recueil des édits, déclarations, arrèts du Conseil et du Parlement de Grenolule concernant les provinces du Dauphiné. Grenoble, (iroul, l(i90-1720); 19 vol. in- $4^{0}$.

\section{Dieppe. - Seignemie.}

4302. - Cartulaire de la seigneurie de Dieppe: ms. du XI ${ }^{\mathrm{e}}$ siècle [1:396], sur parchemin. in-4" de 97 tf. (Archices dép. de lis SeineInferieure, G 8.51:

Dijon. - Abbaye de Saint-Étienne.

Aux publications deja signalées di-dessus ( $\mathrm{r}^{\circ} 11(\mathrm{iz})$, il $\mathrm{y}$ a lieu d'ajouter deux morraux trarax parus récemment:

- Escai sur le louaire dans lancienne Bourgogne et chartes de labbaye de siant-Etienne de Dijon de 1230 it 12\%0, par Abel Ridard (1)ijon, inpr. Jobard, 1906 ; in-xo de vil-15s p.).

- Essai sur l'amodiation dans l'ancienne bourgogne et clartes de l'abbaye de Saint-Étienne de Dijon de $137 \%$ à 1381 , par Freorges Jantiaux (1)ijon, inper, Johard, 1!nt: in-80 de xil-135, p.).

Dijon. - Ville.

4303. - Punl. : Titres relatifs à la ville de Dijon. Dijon, Causse, 1774 , in-t".

Dole. - U'niversití.

4304. - Publ. : Les Statuts et privilèges des Universités françaises, par Marcel Fournier. III (Paris, 1892, in-4 ${ }^{\circ}$ ), pp. 97-144 el 667-674.

Intéresen lry trois universités franc-comtoises de Dole, Besancon et Poligny. 


\section{Domaines.}

4305. - P'́bl. : Recueil des édits, déclarations. arrèts et règlemens concernant la ferme générale des domaines de France. Paris. 1672, in-folio.

4306. - Publ. : Recueil des édit. ordonnances. déclarations.... concernant les domaines du Roy. Paris, 17.53. in-4.

4307. - Pcbl. : Recueil les anciens édits et ordonnances łu Poy concernant les domaines et droits de la Couronne. Paris. 1719, in $4^{\circ}$.

Dombes. - Parlement.

4308. - Prbu. : Recueil des droits et privilèges du Parlement de Dombes. Lyon. 1itl, in 4 ".

Donchery. - Ville.

4309. - Cartulaire de la ville de Donchery; ms. de 1320, orig. perdu.

Cie registre a été siurnalé en 178: et existail encore à celte date (Archices nutionales, $\mathrm{H}$ :3173).

Dreux. - Ville.

4310. - Publ. : Documents historiques et pièces justificatives de l'histoire de Dreux, par Ime Philippe-Lemaitre. Rouen, 18.50 ; in-8 de $175 \mathrm{p}$. et $\mathrm{pl}$.

Contient, pp. 10J-146, le texte des chartes accordées à la ville de Dreux par les rois de France et ses comtes, de 1132 à 1350 .

\section{Eaux et forêts.}

4311. - Publ. : Fidits et ordonnances des eaux et forèts. par Cl. Rousseau. Paris, 1649. in $4^{\prime \prime}$.

Un prenier recueil arait paru déja en 1610 par les soins de C. It saint-Yon. - Voy ausi ro Chasses.

Eeckhoutte. - Abbare de chanoines réguliers de SaintAugustin.

4312. - Cartulaire de l'abbaye d'Eechhoutte.

Ce deuriène rolume nous est inconnu, mais son existence est afirmée par les Anuales de la Société d'émulation de la fllandre en $190 b^{\circ}$.

Enghien (Belgique). - Confraternité de Notre-Dame.

4313. - Cartulaire de la confraternité de Notre-Dame; ms. frit en 1591 par Th. Panen, sur papier, in $t^{\circ}$ (Arehices commumles dEnghien). 
Évaux. - Prévòté.

4314. - Cartulaire de la prévôté d'ívaux en limousin : ms. du XVe siècle, sur papier, légèrement endommagé an déhut et à lil fin, avec quelques licunes, in-lolio de $228 \mathrm{ll}$. Archices dip. de l'Allier, $\mathrm{H}$ 994 provisoire,

Eversham. - Abbaye.

4315. - Cartulinire de l'abbaye d'Tiversham.

Ce cleuxième cartulaire st signalé pour la première fois par les

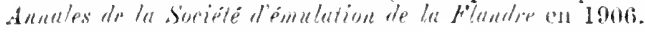

Faremoutiers. - Abbaye.

4316. - Cartulaire de l'ablaye de Faremouliers; ms. du Xille siècle, sur parchemin, in-4" (Biblioth. du Grand-Séminutre de Meanx .

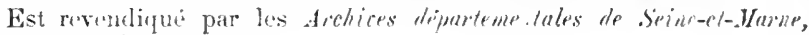
qui le posiederont bientrit.

\section{Finances du royaume.}

4317. - l'tra. : Recueil des édits, déclarations, règlemens, arrests et ordomances concernant les tailles, aicles et gabelles, recueillis par le sieur de Ia Marinière. Paris. Jangelier, 1660. in-8".

4318. - Pubs. : Recueil de reigrlemens, édicts, orlonnances of ohservations sur le faict des finances. Prris, Richer, 1599, in-8".

Flandre. - Comti.

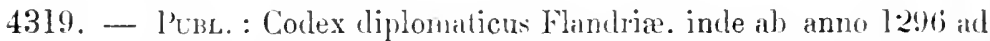
usque 1:325. ou Recueil de documents relatils aux guerres et dissensions suscitées par l'hilippe le Bel. roi de France. contre Gui de lampierre. conte de Klandre. puls. el annoté pirr Th. de IlimburgStirm. Bruges. 187!-188!! : 2 vol. in 4 " de xix-110 et $15-4: 32 \mathrm{p}$.

4320. - Additions au (odex diplomaticus Flunlriæe (1296-1325), par Fr. Funck-Brentano 'Bibliohèune del Ecole des Char es. I.VII, 1896, pp. 33:3-417 et 52!)-572 : et a part : l'aris. 18996 ; in-8".

Florennes. - Abbaye.

4321. - Cartulirire de lahlare de Florennes; ms. du Xrille siècle [1708]. sur papier. contenant des actes de 1012 à 1651 , in-lolio de $25: 3 \mathrm{fl}$. (Biblioll. de l'ubluye de Mriedsons, Belgique).

Fontevrauld. - Abaye.

4322. - PUbL. : Clypeus nascentis Fontebraldensis ordinis: edil. J. de Ia Vainferme. Nova editio. Silmurii-Parisiis. 1684-1692; 3 vol. in $-8 "$.

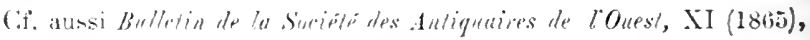




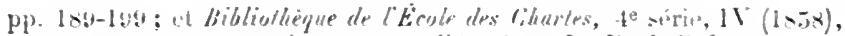
pp. 132-170 et 321-34t [coneernant l'Aunis et La Rochelle].

Fosses. - Chapitre de Saint-Feuillen.

4323. - Cartulaire de Saint-Feuillen de Fosses : ms. du XYIII" siècle [17:36]. sur papier. contenant cles actes de 13339 a 167.5. in-folio de 301 el 263 ff. Archices de lu fubrique de léglise de Fosses.

A chacun des volumes est jointe une table non fuliotée.

\section{Frères Mineurs.}

4324. - Recueil des privilèges accordés à l'ordre des Frères Mineurs par les papes : ms. du XV siècle, sur parchemin. in-t" de xII-117tf. (Biblioth. nationale. ms. nour. acquisitions latines 8!)7.

Furnes. - Église collégiale sainte-Walburge.

4325. - Cartulaire de l'église Sainte-IValburge de Furnes Archires de l'église Suinle-IFalburge de F'urnes.

Cous ne savons rien de ce cartulaire, mentionnée pour la première fois en 1906 dans les dulnalas de la Soriets" d'emulation de In Flundro.

Gand. - Abbaye de Saint-Pierre.

4326. - Recueil des privilèges de l'ablave de Saint-Pierre de Gand; ms. du XVII siècle. sur papier. in-folio de $68 \mathrm{tt}$. (Bibliollh. ronyule de Bru.xelles, ms. 3740 .

A consulter encore. surtout pour corriger la publication delectueuse de Van Lokeren (ci-lessus n 1513 ) : Notice sur un diplom d'Arnulf le Vieux, par G. des Marez (tomptes owndus de la lommission royale lhistoire, l8!n, pp. 208-252):- La bulle fausse de Nieolas Ier pour 15 monastere de saint-Pierre a Gand, par Henri Pirenne Itlem, 1902, pp. 156-1;2): - Note sur qualipues chartes de lahbar saint-Pierre de Gand. par C. Tanden Haute (INom, 1903, pp. 401-41\%); - ainsi yue tpuelques autres publications secondairs mentionness dans ce dernier travail.

Gap. - Ẻvèché.

4327. - Cartulaire de l’évèché de Gap; orig. perdu.

I.historien dauphinois de Valbonnais a connu et sipnale ce repistre.

Gascogne. - Province.

4328. - P'cbl. : Ròles gàscons. transcrits et publiés par Francisque Yichel el Ch. Bémont. Paris, Imp. nationale. 188.5-1906: 3 rol.

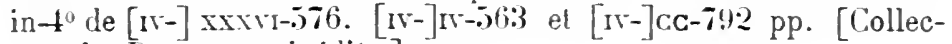
tion des Documents inédits.]

Dates extrêms: 1242-13n\%. L.es documents contenus dans cette publication intéresent ladministration de la Gascogne, de la frugenne, 


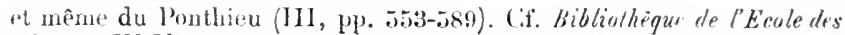
Chaptes, XlVI, 1885, pp. 678-683: art. critique de Ch. I. Janglois sur le premier volume.

4329. - Publ. : Documents pontificaux sur la Gascogne d'après les archives du Vatican; Pontificat de Jean XXII (13I(i-13:34), publ. par l'abbé Lonis Guérard. Auch, Cocharaux [Paris, Champion], 1896-1903: 2 vol. in $-8^{\circ}$ de $\left[\mathrm{vI}-\mathrm{Lxxx}_{\mathrm{L}}-25^{\circ}\right.$ et 164 p. [Archives historiques de la Gascogne, 2 é série, II et VI.]

l'ublication actuellement arrêtée à l'année 1325.

\section{Gendarmerie.}

4330. - P'br. : Recueil des édits. ordonnances, déclarations, arrests et reglemens. privileges. franchises et exemptions de la grendarmerie et créalion des trésoriers généraux et provinciaux, commissaires et controlleurs de lordinaire et extraordinaire les guerres. Paris. Charpentier. 16:32. in- $8^{n}$.

Grimberghem. - Seigneurie en Brabant.

4331. - Ciatulaire de la seigneurie de Grimberghem; ms. du $\mathrm{XVI}^{\mathrm{e}}$ siecle, sur papier, in-40 de $13 \mathrm{fr}$. (Archives du royanme de Belgique. à Bruxelles).

Groenendael. - Abbaye.

4332. - Cartulaire de Groenendael ; ms. du XVIIle siècle, sur papier. in-40 (Bibliolh. royale de Bruxelles. ms. 3666, if. 1-50).

433:3. - Autre cartulaire; ms, des X Te-XVIIe siècles, sur parchemin, in-4" de 44 tr. (Biblioth. royale de Biruxelles, ms. 4505).

Contient surtout des actes du duc de Bourgogne Philippe-le-Bon.

4334. - Autre cartulaire; ms. du XVIIe siècle, sur parchemin, contenant les litres de 1450 à l(694, in-4" de 93 pages (Archives du royaume de Belgique, à Bruxelles!.

Guerre (Gens de).

4335. - P'ubl. : Ríglemens et ordonnances da roi pour les gens de guerre. Paris, $16 \% 3,2$ vol, in-1:2.

4336. - Pebl.: Code militaire, par Briquet. 1'aris, 1761, 8 vol. in-12.

Guise. - Chapitre collégial (dioc. de Laon).

4337. - Cartulatres de la collégiale de Guise ; orig. perdus.

N. I.e I.ong, dans son Histoire ecclessiastique et civile du diocèse de Laon (1733), p. 615i, signale un mandement de François Ier du 
1\% decemlin 1515, oì il est specitic que bes anciens cartulaires du

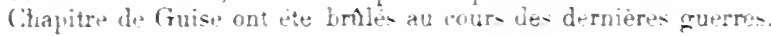

Guyenne. - Province.

4338. - Cartulaire de Guvenne. improprement dit "de Henri VI

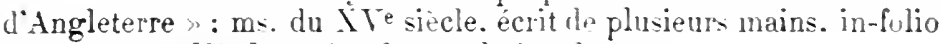

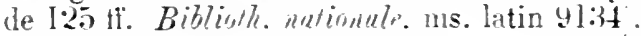

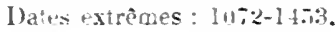

Perbl. : par H. Barckhausen Aircliers listoriques de la Gironde, XV. 18\%8. in-t". pp. I-xxin et 3-335.

Voir aussi riachiga.

Harcourt de. - Famille.

433\%. - PtbL. : Prenves généalogiques et historiques de la maison de

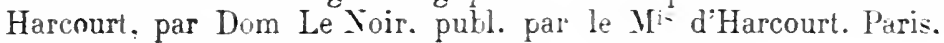
Champion. 1907 : in-8" de 500 p. et pl.

Hemmerode. - Abbaye (dioc. de Trères).

4340. - Cartulaire de l'ahbave d'Hemmerode: ms. du XIVe siècle, -ur papier. in-to S/mtl-Bibliollep Trier. ms. 1717-1i19.

Hérinnes. - Chartreuse (dioc. de Cambrai).

4341. - Cartulaire de la Chartreuse d'Hérinnes; ms. du XVe siecle. sur parchemin. in-folio de $60 \mathrm{ff}$. Bitlioth. royule de Bruxelles, ms. $386 \%$ ?

Héverlé. - Prieuri le Terbanck.

434:. - Cartulaire llu prieuré d'Héverlé; ms. du X'Te siècle, sur papier, contenant des actes de $1: 203$ à $14: 21$, in-8" de $59 \mathrm{ff}$. Archices dur roynume de Belgique. à Bruxelles .

4343. - Autre lu XVI sierle. sur papier. contenant des actes de l:203 à 1421 . in $-8^{\circ}$ de $1: 21$ fï. Archires du romyntme de Belgique. à Bruxelles).

4344. - Autre du $\mathrm{XVI}^{\mathrm{e}}$ siècle, sur papier, in-\$" de 19 ti. Archices du rorymume de Belginne. à Bruxelles.

4345. - Autre du $\mathrm{XTI}^{\mathrm{e}}$ siècle. sur papier. in-80 de 4: ti. Archires du roymume te Belgique. à Bruxelles.

4346. - Autre du NVIIe siecle, sur papier. in-folio de 394 ti. contenant des actes de l:2lit a ltitt tichices thr royame de Belginue, à Bruxelles.

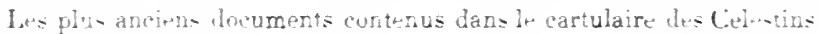

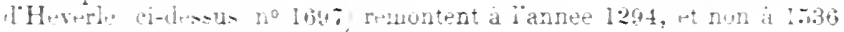
comine il at ete ingrime par erreur. 
Honau. - Abbaye de Saint-Michel (dinc. de Strasbourg). 4347. - Cartulaires de Labbilye de Honau Archiv des Unler-Elsass, in Strussbury.

Nous niavons pas de renseignements sur ces deux recurils; ef.

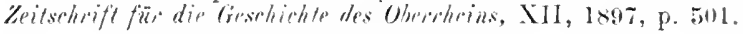

Houdain. - Prieuré (dioc. d'Arras'.

4348. - Cartulaire du prieuré d'Houdain, dépendant de Saint-Remi de Rrims, puis de l'abbaye de Lobhes : ms. sur vélin, orig. perilu.

Humières. - Toy. Moxchy-Le-Perredx.

Imprimerie.

4349. - P'ubl. Code de la Lihrairie et Imprimerie de I'aris ou conférence du règlement arrèté au Conseil d'Éfat du Roy le 28 février $172: 3$, avec les anciennes ordunnances. édits. déclarations, arrêts, règiemens et jugentens rendus au sujet de la Librairie et de l'Imprimerie depuis l’un 13332 juspu’à présent, [par J. Saugrain]. Paris, 1744, in-12. - Répertuire de librairie. contenant tuutes les lois sur la librairie et l'imprimerie depuis 1723, par Ravier. Paris, 1807 , in- 8 ".

Ingrandes. - Seigneurit.

43.50. - Cartulaire d'Ingrandes ou de Maurice $V$ de Craon; ms. du XVe siècle. sur papier. ("ontenant 31 chartes des années 1275-1368,

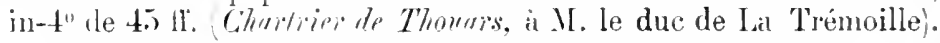
Le recueil de chartes ne commence en réaliti qu au fo 17 .

\section{Instruction publique.}

435. L. - PubL. : Recueil des lois et rèrtemens concernant l'instruction publique, depuis l’édit de Henri IV en 1.598 jusqu’à ce jour [1824]. Paris, 1814-18.5, 7 vol. in- $8 "$.

Jésuites. - Ordre religieux.

4352. - Bullaire et cirtulaire de la Société de Jésus: ms. du XVII siècle, sur papier, in-t" de 310 it. (Biblioth. royale de Bruxelles, ms. 3974 .

Kloosterrade ou Rolduc. - Abbaye (dioc. de Liège).

4353. - I'ubl. : Oorkonden en bescheiden der voormalige abdij Kloosterrade, loor.J. Paquay (Publicntions de la Sociélé hislorique et archéologique d" Limboury, XL, 1905, pp. 220-302).

La Gambre. - Abbaye.

4354. - Cartulaire de l'abluaye de Ia Cambre; ms. du XY' $I^{\mathrm{e}}$ siècle, 
sur papier. en 3 vol. ir-lolio de 532,414 et 371 ti. (Biblioth. royale de Briselles, ms. 3900 .

La Capelle. - Abbaye (dioc. de Boulogne).

$4354^{\text {bis. }}$ - Cartulaire de l'abbaye de La Capelle ; orig. perdu.

A été ru par Dom Grenier Biblioth. nationale, coll. Moreau, vol. 174,

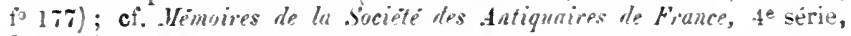
$1(1.59)$, p. 252 .

La Fontaine-Saint-Martin. -- Prieuré (dioc. du .Mans).

435̃.). - Prb. : Le prieuré conventuel de La Fontaine-Saint-Martin

au Maine: étude historique suivie lu cartulaire, par Raoul de Linière. Mamers. impr. Fleury. l!nti: in- $8^{\prime \prime}$ le rr-302 p. et pl.

Lagnieu (Ain). - Ville.

435. ${ }^{\text {bis. }}$ - Recneil de titres relatio a Lagnien: ms. dressé en $16+1$, sur papier. in-t" de $41 \mathrm{fl}$. (Achires drip. de lin. E 446 ).

La Haye. - Baronnie en Touraine.

4356. - Recueil de titres relatils a li baronnie de La Hare. fait au XVII" siecle Bibliofh. nutiontsle. coll. Hom Huusseau. vol. II'. If. $18: 2-214$.

La Neuville-en-Hez. - Village.

435\%. - Recueil de titres relatifs à La Neuville-en-Hez: ms. redigé au XYIII siècle p!r Bosquillon de Fontenay [Appartenait. rer's 1870 , a II. Prosper Wimy ancien notaire à Là teuville-en-Hez].

Lantosque. - Voy. Tistmille.

Laon. - Arquebusiers.

4358. - P'rbt. Recueil des lettres patentes et arrests concernant l'établisement de la compagnie des arquebusiers de la ville de Laon ef les privileges... qui leur sont accordés. Paris. I'rault. 1734. in-4".

La Trémoille. - Famille.

4359. - Pcbl. : Les La Trémuille pendant cinq siècles. Yantes. F. Grimand. 1890-1896: :5 rol. in-4" de xxw-318, xri-25:2. x-26ti. $x-278$ et vin-276 p.

Dates extrêmes: : 1343-1 1331 .

Le Chêne, près d’Arcis-sur-Aube. - Pripuré (dioc. de Truresis.

4360. - Cartulaire du prieuré du Chène. dép. de l'abbaye de Molème, puic, le Silint-Remi de Reims: orig. perdu. 
Wxtraits faits au XVII ${ }^{e}$ siècle (Biblioth. nationale, coll. Baluze, vol. 1.1, pp. 210-222).

Leeuw-Saint-Pierre. - Église (dioc. de Malines).

4361. - Cartulaire de l'église de Leenw-Saint-Pierre; ms. du XVII ${ }^{e}$ siècle, sur papier, contenant des titres de 1399 à 1600 , in- $4^{0}$ de $176 \mathrm{ff}$. (Archives du royaume de Belgique, à Bruxelles).

Le Mont-Sainte-Marie. - Abbaye (dioc. de Besançon). 4362. - Cartulaire du Mont-Sainte-Marie; orig. perdu.

Outre la copie précédemment cité $\left(n^{\circ} 2008\right)$, on a encore:

Extraits faits au XVIII ${ }^{\mathrm{e}}$ siècle (Bibliolh. de la ville de Besancon, coll. Droz, vol. 74, pp. 334-390).

Lens-en-Artois. - Chapitre collégial de Saint-Léger

4363. - Cartulaire du Chapitre collégial de Lens ; orig. perdu? .

Ln document en est publié dans une brochure relative à cette église et intitulée: Pièces justificatives. . .. I. n. 1., in-10 de xxrun p. (Dates "xtrênes: $1070-1678)$.

Le Puy-en-Velay. - Église Saint-Pierre.

4364. - Recueil de titres relatifs à l'église St-Pierre du Puy. fait au

XVII siècle (Biblioth. nutionale, ms. latin 12749, $\mathrm{ff} .161-186$ ). Cif. le vol. 11 r de la coll. Doat.

Les Saintes-Maries. - Ville.

4365. - « livre rouge » des Saintes-Maries ou cartulaire municipal; ms. du XIVe siècle [de 79 fl. au moins]; orig. perdu.

Nombreux extraits du précédent. faits an XVIII siècle (Biblioth. nationule. ms. nouv. acc. latines 1368, pp. 109-206).

Le nuène volume (pp. 1-108) contient des extraits considérables de l'autre cartulaire dit "livee noir », mentionné ci-dessus sous le n²054.

Lessay. - Abbaye (dioc. de Coutances).

43666. - Livre blanc de l'abbaye de Lessay ou « Liber de beneficiis »; ms. du $\mathrm{X}^{\mathrm{T}} \mathrm{e}$ siècle $[1461]$, sur papier, contenant des actes de 1106 à $145 \%$, in-4" de $141 \mathrm{kr}$. (Avchives dép. de la Manche, $\mathrm{H} 4667$.

Extraits du précédent. faits au XIX ${ }^{\mathrm{e}}$ siècle (Biblioth. nationale, ms. latin 10071 , 11.47 et $67-90$.

Librairie. - Voy. ImPrIMERIE.

Liège. - Éçrlise cathédrale Saint-Lambert.

Le m. 833 de la Biblioth. de l'Unicersité de Liège est une copie du

"Liber clartarum prinus") décrit ci-dessus sous le no 2112. 
Liège. - Église collégiale Saint-Martin.

4367. - Cartulaire de l'église Saint-Martin de Liège: ms, du “ vilue siècle, sur papier. in-t" de +19-xuntt. (Archices de lu, fabrique de: Sainl-.Marlin à Liege).

lates extrênes: :163-1736.

Liessies. - Abbaye dioc. de Cambrail.

4368. - Axal.: Analyse des actes intére sant l'abbaye de Liessies (1095-1147. par le $\mathrm{P}$. Jacquin [d'après le cartulaire ci-dessus11"2148 et les originaux] Complessiphdus de la Cominission royule d'histoire de Belyique. 1!10:3. pp. 35.53-384.

Lille. - Courent des Dominicaines de l'Abbiette.

4369. - Cartulaire de l'Abbiette de Lille: ins. du XIV siècle. sur parchemin. in 4 " de $58 \mathrm{ti}$. (Biblinth. voygle te Bruselles. ms. 45:3i).

Lisieux. - Église cathidrale Saint-Pierre.

4370. - Second cartulaire du Chapitre de Lisieux; orič. perdu.

Est connu par un extrat qui le designe comme un a grand livre en vélin reljé, couvert de lois et de cuirre, enchainé à la table et contoir de l"église cathérlrale de saint-1'iere de Lisirux, intitule secundus liber chartarun capituli n (Biblioth. Mrignalo, ms. Iatin 10071, fo 97).

Longueau. - Prieurẻ (dioc. de Reims).

43i1. - Cartulaire du prieuré de Longueau : ms. du $\mathrm{XVl}^{\mathrm{e}}$ siècle. sur papier, contenant 30 chartes des années 1189 à 1355 . in-t" de $36 \mathrm{ff}$. (Archices dép. de lu Murne. H non coté.

4372. - Autre cartulajre; ms. de la fin du XVIe siècle.sur papier, contenant 34 chartes les années 11.5 a 1243 , in $4^{\circ}$ de 29 ff. (Archives dep. Ar lu Murue. H non coté).

Loo. -- Abbaye le chanoines de Saint-Augustin.

4373. - Cartulaire de l'abbaye de St-Pierre de Loo; ms. du XVé siècle,

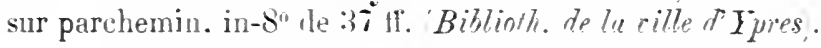

Cest le volume qui a rerri à la publication mentionnée ci-dessus $\left(\mathrm{n}^{\circ} 2228\right)$.

Lorraine. - Felme du Tabac.

4374. - Prbu. Recueil des édits. déclarations. arrêts et règlements concernant la ferme grénérale du tabac de Lorraine et Barrois. Nancy, Lescure. 1752 . in $4^{\circ}$.

Lorraine. - Gabelles.

43\%5. - Publ. : Recueil des édits. ordonnances. déclarations et arrêts 
concermant les gabelles ot les droits de máque des fers de Lorraine et Barrois. Nincer. (.harlot, 1745, in $4^{0}$.

Louvain. - Villr.

4376. - Pubr..: Codex (hronologiro-diplomalicus rerum Lovaniensium, in : Joannis Molnni Historiar I.ovaniensium libri XIT; edit. A. de ham. Bruxelles. 1861. 2 vol. in-4" (pp. 1 185-1:298 du tome I1). [collection des cihroniques belges:]

Lyon. - Eglise allégiale Saint-litienns.

437\%. - « Fragmenta charlularii S. Stephini Lugolunensis »; ms. perdil.

Cités sous cette forme par Chorier.

Lyon. - Foires.

4378. - Publ. : Privilères des foires de Lyon et leur antiquilé... et les confirmations l'icelle despuis Philippe de Valois. Lyon, 1560, in- $8^{\prime \prime}$.

Maastricht. - Eglise collégiłle Saint-Servais.

4379. - Cartulaire de la confrérie des chapelains en l'église Saint-

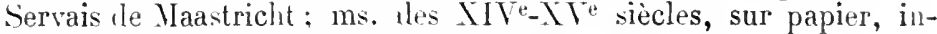
folio de 181 pares (Archires de l: Elul ì Munstivichl).

Dattin wxtrènes: : 1310-146:t.

4380. - Autre cartulaire du même objet; ms. du XVI $\mathrm{XV}^{\mathrm{e}}$ siècle, sur papier, in-folio de $207 \mathrm{ff}$. (Aichires de la fabrique de Saint-Srrevais à Wurstricht.

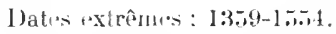

4381. - Cartulaire de la clapelle Saint-Vincent en l'église SaintServais ; ms. "ln XIV" siècle, sur papier, in-10 de $12 \mathrm{fr}$. (Archives de le fubrique de Suint-Serruis is Mtrastricht).

Maastricht. - Eglise Notre-Dame.

438:2. - Carlulaire de l'église Notre-Dame de Maastricht; ms. du

X $\mathrm{THL}^{\mathrm{e}}$ siècle, sir papier, contenant des titres de 1096 a 1785 , en 2 vol. in-lolio de 610 et $63 \pi$ pages (Archives de la fulvique de Notre-Denime is Manastricht).

Maison du Roi.

4383. - Publ. : Les privilèges anciens et nouveaux des officiers domestiques et commensaux de la maison du lioy, de la Royne, enfans de France et autres. Paris, C. Morel, 1620. in-8". 


\section{Manufactures.}

4384. - R'br.: Recueil des règlemens zrénerax et particuliers concermant les manufachures at labriques du royaume. et Supplément de 1669 i 1741 . l'aris. 1730-1742. T rol. in-4".

Marais (Dessèchement lles).

4385. - P'bBL. : Recueil des édils. déclarations. arrèts et régolemens concernant le dessechement des marais. Nour. edition. Paris, Prault. 1735. in-4'. - Adelition an Recueil des édits... Paris, Prault. 1735. in $-4 "$ ".

\section{Marchands de vin suivant la Cour.}

4386. - PrbL. : Reeueil dëdits. léclarulion:.... du roy. portant création et confirmation les privilège- accordés aux douze el vingrtcinq marchands de vin privilérie\% suivant la Cour. Paris. llifio. in $t^{\prime \prime}$.

Marchiennes. - Abbaye (llio d'Arras).

4387. - Recueil de tilres relatif a labbaye de Narchiennes: ms. du Irile siècle. sur papier. in-folio de 130 li. Bibliolh. rongle de Bivelles, ms. 4516 .

Marcigny. - Abbaye le Notre-Iam. (dioc. l'Autun).

4:388. - Recueil de pièces les XIe-X1I siecles relatives à l'abbare

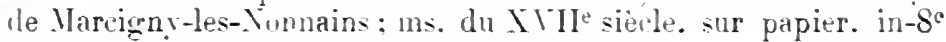
de 9.7 11. Airchices untionules, L 965. n"10).

Maréchaux (Prérôlédes).

4:389. - l'crb. : Ordunnances et arrèts concernant les prévòts des maréchaux (1598-1614). S. 1. n. 1.. in-8".

Maréchaux (Tribunal (tés).

4:390. - I’cbr.: Recneil concernant le trihnual des maréchaus de France. par de Beaufort. Paris, 1784. 2 rol. in-8".

Marine. - Voy. Prises.

Marlagne. - Courent des Carme dé.hausés.

4:391. - Cartulaire du Couvent des Carme- de Marlagne Biblioth. du Cround Séminuise de Vinume.

Lets ristignement- are ce volum. man fuent.

Marloux. - Terre du Chapitre de Remiremont, il Mellecey Sàne-rthuire.

439.2. - Cartulaire des titres de Marloux; ms. du XIV siècle, sur 
parchemin. contenant it pièces des années 1:205-1:330, in-folio de $33 \mathrm{ff}$. (Avchires dép. des Trosges, G 2212).

On conserve sous la même cote une copie du XVe siècle [1425] in-folio, at une autre copie du mêne sièrle, in-10, du présenl registre.

\section{Marmoutier. - Abbaye.}

Il ne sera pas inutile de anner le content exict des quatre volumes consacrés par Dom Noël Mars (roir ci-dessus $11^{\circ} 2355$ ) aux transeriptions plus ou moins nombreunes dlactes relatifs aux diffirents prieurés dépendant de Marmoutier. Ms. Latin .5 $4+11$ : Treize-Vents (pp. 29-32); saint-(puentin de. Chalonmes $32-37$ : Boré $38-12)$; lak Celle en Brie

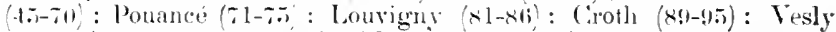
$(17-102)$ : Sarton (105-109); Vierzin (11:3-1:0); 1)anjou (121-124); coulaires (12\%-127 : Maintenay (129-137) : Saint-Maurice de Rejus

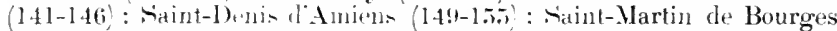

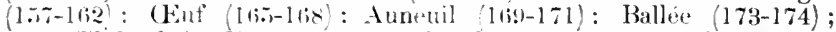

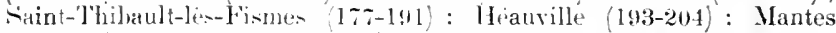

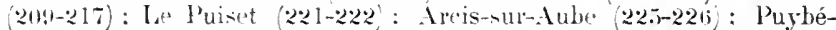
liarl (22:1): (ontevoult (2:33-237); Montignv-en-1Beauce (241-248);

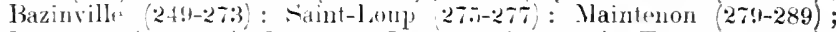

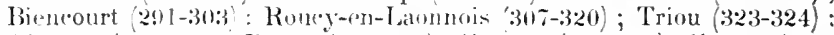
Aizenay (347-31! : Renty 351-360) : Crosson (363-3150) : Cernay (367-

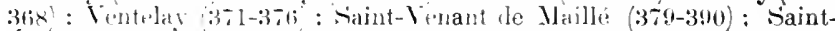

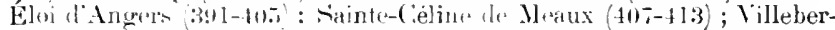
fol $(11.5-125)$ : (hatillon-sur-siver $(127-4291)$ : Villepreux $(431-447)$;

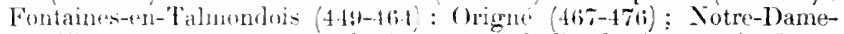

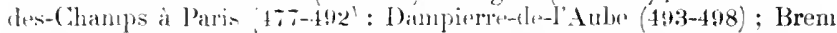

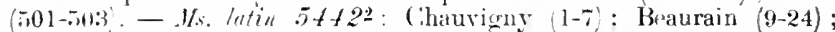
Bohon (25-52): (huines (73-72) : Pierrofonls (73-83) ; Perrières (8597): Orchatise (101-f11\% : Sinint-l)enis-de-file (109-110); Bertineourt

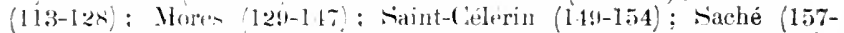

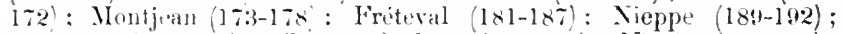
Epernon (193-21!); (hateau-du-Loir (221-2.1) : Vivoin (2-19-272); Tavent (273-287' : Bellème 2x!1-3t0) : Saint-Marc-lis-Vendòne (341-

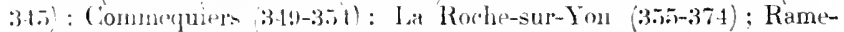

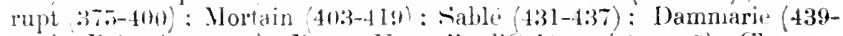
4.2): Boire 143-152): Bonne-Xouvelle lorleans (45i-457); Chamars

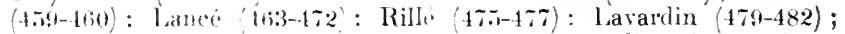

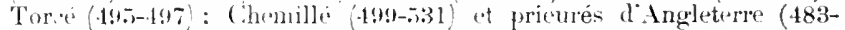
493 . - Ms. hitin $5 f+1^{3}:$ Laval $(1-13)$ : Chantoceaux (17-21 ef $372-$ $\left.32^{\circ}\right)$ : Saint-Palai-n-B.rri (25-26) : Higournay (27-32) : Mesland (3342): Varades (4! : Vitré (31-.5) : Foungères $59-61,301-30$ 7 et 403$40(i)$ : L'He Tristan $(63$ et 415$)$ : Sallertaine ( $65-66 i)$ : Gahard $(67,81-$ $86,309-315$ et $10 \%-108)$ : Sant-Pèlerin $(69$ et $416-418)$ : NartignéBerchaud (71.316 et 409 : Machecoul (73-7.1); Combourg (75-80, 175189 a $230-245)$ : Saint-raveur-des-tandes (87-91, 318-322 et 411 414): Donges (93 ot 119-141): Saint-Malo de Dinan (97-102 et 143$168)$ : Josselin (103-105 at 171-175); (hàteaubriand (107); Lamballe (109-111, 207-210, 27 -2×0 ef 343-349) ; Jffendic $113-114$ et 207-210); lohon (1911-206 ef 246-275): Malestroit (211-220) : Rochefort-en-Terre (22:-22!1): Jugron (281-281): Mareillé (285-300 et 351-358); Nort (3233-325); Pouance (325-328): Biré (328-337 et 419-429): Becherel (339-342) : Sainte-Croix de Nantes (363-371 et 383-386) : Pontchâteau (387-392): Sace (393-39-4) : et extrats du "Cartularium britannicum ") 


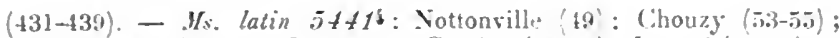
Sapaillé (j7-fil) : Saint-Laurent-en-Gastine (b-7-7) : Lavaré (79-98), et Fontcher (101-111).

4393. - Cartulaire de la greneterie de Blois pour l'abluave de Marmoutier; orig. perdu.

On en trouve liverses mentions au $\mathrm{XTH}^{\circ}$ siecle.

Maroc.

4394. - Publ. : Les sources inédites de l'histoire du Maroc de 15:30 a 1845. par le (te Henry de Castries. Ire série (Dynastie saadienne: 1530-1660). I. Paris, Leroux. 1905; in $4^{0}$ de [ $\mathrm{r}-\mathrm{KrI}_{-} 68+\mathrm{p}$. et pl.

Ce folume est exclusivement consacré aux sources dorigine française.

Marseille. - Abbaye de Saint-Victor.

4395. - Bullaire de Saint-Victor de Marseille; ms. des XIVeXVII siècles, sur parchemin, contenant $18: 3$ bulles des années 1050 à 1622. in-folio de $107 \mathrm{ff}$. (Archices dép. des Bouches-du-Rhoine. $\mathrm{H}$ non coté).

4396. - « Recueil de copies de chartes et łitres déposés dans les archives du monastère de Saint-Victor de Varseille "; ms. du $\mathrm{XVII}^{e}$ siècle, rédigé par Dom Lefournier. sur papier. et contenant des documents des années $780-1446$, en 3 vol. in-folio de 529, 59:3 et $347 \mathrm{ff}$. Archic. dép. des Bouches-du-Rhóne, $\mathrm{H}$ non coté,

Marseille. - Ville.

4397. - Publ. : Recueil de pièces concernant les privilèges de Marseille du 17 mai 1200 au 12 juin 16ăl. S. l. n. U., in $4^{0}$.

Martigues. - Pècheries.

$4397^{\text {bis. }}$ - PtBL. : Chartes, titres et documents principaux relatifs aux pêcheries de Martigues, appelées bordigues [publ. par II. Agard]. Aix, Nicot, 1864 ; in-8".

Marville. - Village.

4398. - Chartes des archives communales de Marville Wense). des XIII -XVI ${ }^{e}$ siècles. par Léon Germain Publicutions de la Société historique de linstitul grund-tucal luxembourgeois. XXXY. 1881. pp. $4: 31-439$ ).

Dates extrêmes: 1252-1400.

Meerssen. - Prévôté (dioc. de Liège).

4399. - Cartulaire de la prévôté de Meerssen. dépendant de l'abbaye 
d'Eaucourt: ms. du XYIII siècle. sur papier, contenant der actes de gric à lo48, in-s" (Rijksurchiof, Mustricht).

l'ubl. : par J. Habets (Publications de la Société histritique et archéoliginue du Limbonig, XXT. 1888. pp. :3-160).

(if. A. Schaepkens, Cartulair de lancien prixnté de Meerssen. Maastricht, 1s6tit; in-8 de 19 p. (Extr. dess Publications do lit Sociéte du Limboury, I.)

Menou (de). - Famille.

400. - Recueil de titres relatifs à la maison de Menou, originaire du lerche. extraits des archives du château de Boussay an X V'II" siècle (Biblin/li. nutionule coll. Dom Houssean, vol. XII, t1: 80-1:2:2).

Meulan. - Prieuré de Saint-Nicaise (dioc. de Rouen). 401. - Cartulaire du prieuré de saint-Nicaise de Meulan: orig perdu.

Fxlrait fait au XVII siècle (Biblioth. nationale, coll. Duchesne, vol. XXII. f"25(i); — all XYIII (Inem, coll. Vexin, vol. VIII, $\left.f^{\circ}: 35: 3\right)$.

(ce volume arait au moins 31 s feuillets ; il était plus considérable et sans dout plus récent que celui qui est indiqué ci-dessus no 2443.

\section{Mines.}

4402. - Pubr. : Les ordonnances et lettres palentes du Roy sur le faict des mines le France. faictes et données tant par le roy Charles sixiesme que autres ses successeur. Lỵon, Patrasson, 15\%5. in $-8^{\circ}$.

$4402^{\text {bis. }}$ - Édits. ordonnances. arrèts et règlemens sur le fait des mines et minières de France. P'aris. 1619, in-8". - Nuuvelles éditions. Pari. 1748. in-12; et 1764, in-12.

Voir en outret aux moti I orraint: (ci-lessus no 223s) et Raxcié $\left(n^{\circ} 3133\right)$.

\section{Moerkerke. - Canaux.}

403. - Cartulaire de la wateringue de Moerkerke; ms. du XV" siècle [14t8], collationné par Rombaut de Doppere, clerc dı diocèse de Tournai, sur parchemin, avec reliure de bois entre deux ais, in-folio de $45 \mathrm{ft}$. (Appartenait en 1867 à M. Van de Pitte, à Brugres).

Axal. : Jar M. L. Gilliodts-Tan Severen, dans La Flundre, I (1867), pp. 379-454, et 11 (1868), pp. 76-99 et 2:21-2:34.

Moncé. - Abbaye cistercienne, à limeray dioc. de Tours). $4403^{\text {bis }}$. - Cartulaire de l'abbaye de Iloncé ; ms. du XIII ${ }^{\mathrm{e}}$ siècle, sur parchemin, incomplet de la fin [avait originairement $143 \mathrm{fl}$.], infolio de 59 ff. it $\stackrel{2}{2}$ col., plus une tahle contemporaine complète (Biblioh. parliculière d'un chanoine, à Tours).

Publ. : Prochainement, par les soins de .N. l'abbé Audard. 
Monchy-le-Perreux. - Ahbaye (dive. de Beauvais). 4404. - Cartulaire de l'abbaye de Monchy-le-l'errenx; orig. perdu.

Extraits du précédent laits au XVII" siècle Bibliolh. Je lu ville de Benucuis, coll. Buequet-Auxconteaux. vol. XiL. pp. 310--3320).

Monfort Gers). - Ville.

4405. - Cartulaire municipal de Monfort: ms. du XIVe siècle. détruit par le fen en 18633. Etait alors conservé anx Aichives muniripules de Bordenury.

Montauban. - Cour des lides.

406. - Publ. : Édit. déclarations concernant la juridiction et la jurisprudence de la Cour des aides et finances de Montanban. Nontauban, J. F. Teulières. 1752. in-4".

Montbazon. - Seigneurie en Touraine.

407. - Recueil de titres relatifs à la seignenrie de Monthazon. extraits du Trésor du châtean an XV'llIe siècle (Biblinth. nationale. coll. Housseau, vol. $1 I^{2}$. II. (5.5-9)2).

Mont-Garmel (Notre-Dame du). - Ordre religieux.

4408. - P'ubl. : Recueil des édits. déclarations et arrests depuis l6j:2 jusques en 1694 concernant l'ordre de Totre-Dame du Mont-l armel et dle Saint-Lazare de Jérusalem. Paris. Nichallet, 1694, in- $4^{\circ}$.

Montfrin. -- Commanderie de Templiers, puis d'Hospitaliers (dioc. de Nimes .

4409. - Cartulaire dit «Authentique 》 de Montfrin; ms. dressé et collationné en 1619 par Jean de Mesnyer. notaire au parlement de Toulouse, sur papier, contenant 219 actes des années $1146-1417$, in 4 " de 306 ff. (-1rrhives dép. des Bourches-du-Rlüine, série $H$, fonds du Granıl-Prieuré de Saint-Gilles).

Dans le même depòt existe une copie pustérieure (XVII siècle).

Montjoie (Valle de). - Voy. SaIst-Gervals.

Montpellier. - Inniversité.

4410. - Publ.: Les Statuts et privilèges des Cniversités françaises, par Marcel Fournier. II (Paris. 1891. in $4^{\circ}$. pp. 1-300 : et III (1892), pp. 641-645.

Mont-Saint-Jean. - Prieuré (dinc. l'tutun).

4411. - Cartulaire de Munt-Saint-Jean en Bourgogne; orig. perdu.

E-t mentionne par le P. lelong (erl. Werret de Fontette, III, no 29075) comme ayant fait partie do la Bibliothe lue de II. de Caumartin, vèque de Bluis $(+1733)$. 
Mortain. - Abbaye de Notre-Lame la Blanche (dioc. d'Avranches).

4412. - Recueil de titres relatits à l'abbaye de Notre-Dame la Blanche, fait au $\mathrm{X} \mathrm{III}^{\mathrm{e}}$ siècle et contenant des actes à partir de l'année I105 (Bibliolh. wutionale, ms. latin 10065, pp. 113-129, et ms. latin 10078. pp. 141-162).

Münster. - Abbaye (lioc. de Bàle).

4413. - Recueil des privilègres de l'abbaye de Münster; ins. du XVII siècle [1665]. sur papier, contenant des titres de 672 à 1635 , in-4" de 27 II. (Aichic des Ober-Elsuss. in Colmar).

$Y$ est joint un autre petit cahier de papier, du XVIe siècle [1503], contenant transcription moins complète des mêmes documents.

Musiciens.

4414. - Publ.: Recueil d'édits, arrêts du Conseil du roi, lettres patentes, mémoires et arrêts clu Parlement.... en faveur des musiciens du rovaume. Paris. 1774. in-8".

Nantes. - Université.

4415. - Recueil de titres relatifs à l'Lniversité de Nantes; ms. du XYII siècle. sur papier, contenant des acles à partir de 1460 , in-4 $4^{0}$ de 5:3 tf. (Archires lip. d' Ille-et-Vilaine. C: 1:316).

44l6i. - l'ubl.. : Les Statıts et privilèges des Universités françaises, par Marcel Fournier, III (Paris, 189., in-4*), pp. 33-96.

Neufchâtel-en-Bray. - Ville.

441\%. - Puni. : Histoire civile et militaire de Nenfchàtel-en-Bray, suivie de remarques, addlitions et cartulaire, par Dom Bodin (édité par $F$. Bonquet. Ronen. Métérie, 188.5; in-8 $8^{\circ}$ de xxvin-217 p. [Société de l'hist oire de Tormanclie.]

C. soi-disant cartulaire (actes de 1188-1220) est tout à fait insignifiant $(\mathrm{pp} .142-163)$.

Nevers. - Église cathédrale Saint-Cyr.

4418. - Copie d'un cartulaire original, exécutée au XVIII ${ }^{e}$ siècle sur les ordres de Fontanieu, contenant 115 chartes, in-4 ${ }^{\circ}$, sur papier (Bibliolh. mulionale, ms. nouv. acquis. françaises 7819).

Il paraît $y$ avoir eu jalis quatre recueils différents.

Nevers. - Ville.

4419. - I'ubl. : Privileges, droictz, libertez, immunitez et franchises des eschevins, hourgeois, manans et hilbitans de la ville de Nevers. Nevers, I60:2, in-4". 
Nice. - Érlise cathédrale.

4420. - Cartulaire le l’église cathédrale de Nice; ms. de la fin du $\mathrm{XVI}^{\mathrm{e}}$ siècle. sur papier (1rchices du Chapitre cuthédral de Vice).

Contient unc partie des mêmes documents que le $n^{\circ} 2723$ ri-rlessun. - On peut y voir une continuation du "Liber niger ", contenant de. chartes depuis le $\mathrm{XV}^{\mathrm{T}}$ siècle, acyuis par les Archices dép. des Alpes. Jaritimes.

Nizelles. - Abbaye (dioc. de Namur).

4421. - Registre aux titres de l'abhaye de Nizelles: ms. des XVI XTII siècles. sur papier, contenant des titres de 1439 à l6ljo. infolio de $238 \mathrm{tf}$. (Archices du roymme de Belgique, à Bruxelles).

Normandie. - Cour des Aides.

4422. - Publ. : Recueil d'édits. réglemens. etc., concernant l'autorite, la compétence. etc., de la Cour des Aydes de Normandie. Rouen, Viret. 1672. in -12 .

\section{Notaires-secrétaires du roi.}

4423. - Recueil des privilèges du collège des notaires et secrétaires du roi : ms. du XVIe siècle. sur parchemin, avec reliure ancienne et miniatures, in-4" de l:38 ti. Biblioth. He P'Arsenml. à Paris, ms. 5l69\%.

Nouaillé. - Abbaye (dioc. de Poitiers).

4424. - Cartulaire de l’abbaye de Saint-Junien de Nouaille: orig. perdu.

Exlraits faits au XVII siècle Biblioh. nulionale. ms, latin 17148 . pp. 149 et $15 \pi$.

\section{Officiers municipaux.}

4425. - Prbl. : Code municipal. ou Recueil des principaux édits qui intéressent les officiers municipaux et de police. Grenoble, 1760. 2 vol. in-12.

\section{Officiers royaux.}

4426. - Publ. : Recueil des édits. ordonnances et arrèts du Conseil d'État concernant les gages. taxations, droits et privileye- des receveurs des aides et tailles. par $\therefore$. Hardy. Paris. 1613. in- $8^{0}$. Recueil d'édits. arrêts et règlemens concernant les juges et autres officiers rovaux. par $\mathbf{S}$. d'Escorbiac. Paris. 16i38. in-folio.

412i. - Purl. : Recueil des édits. déclarations. lettres patentes du hoi. arrêts de rècrlement et autres pièces concernant les offices des conseillers du roi et substituts de $\mathbf{M}$. le procureur général et adjuints 
anx enquêtes. instructions des proces crininels, et aut res commissions. de la Cour. Paris. Ibio, in-t".

44:8. - PUbl. : Recueil des édits. declalations, arrests. reralements et ordonnances du Roy concernant les charoes de controlleurs des exploits, leurs droits et fonctions dans l'étendue du royamne depuis 16 (i)9 à l697. Dunkerque. A. F. vin Lrsel. s. d. ; in- I'2.

4129. - Publ.: Pécueil les édits. déclarations, arrèts et règlemens concernant les créations. étallissemens. droits. privilieges et fonctions des recevenrs des consignations du royame. Paris. 1701 , in $-8^{\circ}$.

44:30. - Pubr. : Recueil des édits, déclarations ılu Roy et arrests du Conseil concernant les offices des conseillers du Roy receveurs des épices dans toutes les cours et juridictions, laris. 1704, in-4".

4431. - Publ. : Recueil des élits. léclarations. arrests et räglemens concernant les qualitez nécessaires pour être pourvus des olfices de judicature (1605-170!). S. 1. n. d., 2 vol. in-40.

41:2. - Publ. : Recueil d'édits et areèts concernant les ecclésiastiques, les juges et autres officiers royux. par J. Filleau. Jaris. 1731, 2 vol. in-folio.

4433. - P'UBL. : Recueil des édits, déclarations, arrests, tarifs, réglemens et instructions concernant les grelles des Cours d. Parlement, Grand Conseil. Chambre les Comptes, Cour des Ardes, des Monnoyes. Requestes le l"Hostel et du Palais. Chambre du Trésor, des Eaues et forests. Talile de marbre et sièges présidianx, bailliages, sénéchaussées. prérostés et vicomtés. prévôts des marchands. jugreśconsuls. Paris, 1730 , in-4".

41:34. - P'vbl. : Privilioes des officier's du Grand C.onseil. Paris. s. d., in $t^{\circ}$.

Orléans. - Aumòne gènérali.

4435. - Cartulaire-inventaire de l'Aumòne générale d'Orléans; ms. llu XVI siècle, sur papier, in-folio de $506{ }^{\circ} \mathrm{Ht}$. Archires hospilalières d'Oiléuns. I A l).

(it. encore sur l'Hòtel-1)ieu: Biblioth. de la ville dorlean, nss. 596, ff. 273-320 (copies du XV11

Orléans. - Hôpital Saint-Antoine.

4436. - Cartulaire-inventaire de l'hòpital Saint-Antoine au pont d'Orléans; ms. du XVIle siècle, sur parchemin, in-folio de 478 ff. (Archives hospitalieres "Orléans, III A I).

Dates extrenn: : 1:331-1030. 
Orval. - Abbaye ilioc. de Trères.

A ajouter: Particularités relatives a un acte du cartulaire d'Orval (1308), par A. lesort (Comptes rendus de In fiummission roynle d'histoire, 19012, pp. $196-194)$.

Palz. - Église collégiale (dioc. de Trèves).

44:37. - « Chartularium ecclesiae colleviatae in Palatiolo»; ms. du XTlle siècle, sur papier, in-4" (S'udl-Bibliotliek Trier, ms. $\left.1616^{\mathrm{a}}\right)$.

Paris. - Archer's.

4438. - l'ubr.. : Recueil des chartes, créations, confirmations des colonel, capitaines. major. ofticiers el trois cents archers de la ville de Paris, par Drouart, colonel. l'aris, Baudry, 166\%, in $4^{n}$.

Dates extrêmes: 1410-16ibs.

Paris. - Assainissement.

44:34. - Publ. : Service Municipal de Paris : Assainissement. Recueil des ordonnances et arrètés depuis 1:376 jusqu à 1864. Paris, Juteau, [18tit], in-8.

Paris. - Bourse et agents de change.

4440. - l'ubl. : Recueil des ordonnances, édits, déclaralions, lettres patentes. arrêts du Conseil..... concernant la Bourse et les agents de change. banque. commerce et finances à Paris. Paris, 1774. in-4".

Paris. - Chambre des Comptes.

4441. - Publ. : Recueil des édits. déclarations et arrests du Roy concernant la Chambre des Comptes. Rouen, Besongne. 1702. in $4^{\circ}$.

444:. - P'vbl.. : Recueil des édits. ordonnances, déclarations. lettres patentes. arrests et autres pièces justiticatives de la juridiction contentieuse de la Chambre des Comptes tant au civil qu'au criminel. S. 1. n. d.. in $4^{*}$.

4443. - Prbl. : Recueil d'édits concernant les privilèrres. exemptions et droits des officiers de la Chambre des Comptes. Paris, Mariette, 1756 . in $t^{\circ}$.

Paris. - Chapitre cathédral Notre-Dame.

4444. - Recueil dactes relatifs aux biens compris dans le domaine de la marıruillerie laïque du (hapitre cathédral de Paris; ms. du XYle siècle. sur papier. in-4" (Biblioth. nutionale, ms. français 5.55:3, ff. $37-55)$.

Paris. - Châtelet.

4445. - Pcrl. : Recueil des ordonnances. édits. déclarations. arrèts et autres titres qui étahlissent en faveur dı Châtelet de Paris la police 
grénérale et le droit de prévention... dans l'étendue des ville, fanbourgs et banliene de Paris. Paris, Chardon, 1740, in-4".

446. - Prib. : Recueil des privilèges attribués aux offices d'huissiers servants à cheval au Châtelet de Paris [par $N$. Chocquart]. S. I. n. d., in-16.

4477. - l'ubl. : Recueil des lettres patentes, édits, déclarations, arrets, sentences et règlements concernant l'exercice et fonction des sergens à verure du roi an Châtelet, recherchés par H. Nardeau de la Grange, Cl. Regnard, Jean Bertinet et Th. Becasse. Paris, Baudouin, 1669 , in $4^{\circ}$.

Paris. - Echevinage.

4448. - P'uri. : Ordonnances royaulx de la jurisdiction de la prevosté des marchans et eschevinaigre de la ville de l'aris; constituez et ordomnez tant par les feus roys que par le roy nostre Sire Françoys premier de ce nom; et plusieurs arrestz et ordonnances de la court de Parlement avec plusiems beaulx privileges donez aux bourgeois de Paris. Paris, Nyverd. I5:28; in-folio de Iv-116 ff.

Paris. - Hôpital ğénéral.

4449. - P'bi.. Recueil des édits, déclarations, lettres patentes du roy, arrests de reglement et autres pièces concernant l'établissement de l'Hospital grénéral pour le renfermement des pauvres mendiants de Paris. Paris, 1661 , in $t^{\circ}$.

Paris. - Hòtel des Invalides.

4450. - Publ. : Recueil des édits. déclarations, ordonnances, arrêts et règlements concernant l'Hôtel royal des Invalides. Paris. Imp., royale, I781; '2 vol. in-4".

Paris. - Juridiction consulaire.

$4451 .-$ l'ubl. : Recueil contenant les édits et déclarations du roi sur la juridiction des consuls. Paris, 16660, in-4 $4^{0}$ - Nouv. édit. Paris, Thierry, 1705, in $4^{0}$.

Paris. - Ville.

4452. - Punl. : Recueil des chartes, créations et confirmations des colonel.. capitaines, majors, officiers. arbalestriers, archers, arqueliusiers et fusiliers de la ville de Paris, par M. Hay, colonel. Paris, G. Despre\%, 1770 ; in- $4^{0}$ de $[\mathrm{IV}-] 276-\mathrm{xxm} \mathrm{p}$.

Dates extrême's : 135\%-17zo.

4453. - Pubi. : Mémoires concernans le contrôle des rentes ou Recueil abrégé de tous les titres qui étallissent les offices, privilèges, droits, 
fonctions et devoirs des contròleurs des rentes de l'hôtel-de-Ville de Paris. [par Pierre Le Roy]. Paris, Le . Mercier. 1717. in-1:.

Perpignan. - Université.

454. - « Liber statutorum Iniversitatis Perpinianensis »: ms. des $\mathrm{XV}-\mathrm{Xlll}^{\mathrm{e}}$ siècles, sur parchemin et papier, de différentes mains,

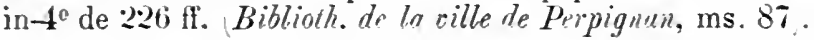

Cf. Harcel Fournier, Les statuts et privileges des ['niversitis françaises, II (1891), pp. 6.51-i16.

Poitiers. - Université.

4455. - Publ. : Les Statuts et privilèzes des Lniversités Irançaises, par Marcel Fournier. III (I'aris. 189.2, in $4^{0}$ ), pp. 28:3-335.

Poligny. - Lniversité. - Toy. Doue.

Pontchâteau. - Prieuré dépt de Marmoutier (dioc. de Nantes).

4456. - Prbl. : Chartes relatives au prieuré de Pontchâteau, par M. de Bréhier (Bulletin de la Société urchéalogique de Vantrs. III, 1863. pp. 17-40), et à part: [1864]. in-8" de 24 p.

Ponthieu. - Voy. Gascogre.

Postes (Maitres des).

445\%. - PrbL. : Recueil des édits, déclarations, arrèts, et ordonnances concernans les privilèges et exemptions accordez aux maistres des postes du royaume (1669-1710). Paris, Fournier, 1720. in-4".

Pouzauges. - Voy. Tiffauges.

Prévôté de l'hôtel.

4458. - Publ. : Le prérost de l'hostel et le ı̣rand prévost de France; arec les édicts. arrests, reylements et ordonnances concernant sa juridiction, par Pierre de Yiraumont. Paris, Chevalier. lil5, in- $S^{0}$.

\section{Prises.}

459. - Pebl. : Code des prises ou Recueil des édits.... sur la course et l'administration des prises, [par Chardon]. Paris. 1784, 22 vol. in $-4^{\circ}$.

\section{Procureurs.}

4460. - Publ. : Recueil d'arrèts et règlemens concernant les procureurs, [par P. Gillet]. Paris. 1694, in-4\%. - Nouv. édit. Paris. $171 \%$ int 4 . 


\section{Protestants.}

4461. - Pubr.. : Recueil des édils. déclarations et arrêts du Conseil rendus au sujel des grens de la Religion Prétendue Réformée. Nouv. édit. Paris, Sangrain, lilt, in-12. - Youvean recueil des édits... Grenoble, A. Faure, 17.2. in-40. -- Édits, déclarations el arrests concernans la Religion I'. Réformée $1662-1751$, précédés de l'Édit de Nantes, réimprimés pour le deuxième centenaire de lit Révocation de l'ídit de Nantes. Paris. Fischbacher, 188.5; n-16 de Lxxxy$661 \mathrm{p}$.

Prüm. - Abbaye flioc. de Trères.

1) extraits du " Liber aurtus ) (ci-1 tessus no 3112$)$ ont eté faits au XVI siecle par I) (Cangé (bib'ioth. he lissenal, a l'aris, ms. Jz62, ff. $88-89)$.

Puiseaux. - Prieuré (dioc. de Sens).

4462 . - Recueil de titres relatils au prieuré de I'uiseaux; ms. du XVIe siècle. sur papier, in-4" de "2:3 il. (Bibliolh. nutionale, ms. latin 10093).

Actes récents, font peu intéressants.

Reims. - Lniversité.

4463. - Cartulaire de l'Lniversité de Reims : orig. perdu.

Est m+ntionné dans linventaire Raussin (175\%). - Cn recueil de pièces fut imprimé en 178, lat Fillion, dordre de l'Lniversité.

Relay. - Prieuré, à Pont-lte-Ruau (dioc. de Tours).

4464. - Frayments d'un cartulaire du prieuré de Relay, dépt de Fontevrauld: ms. du XIVe siècle, avec additions jusqu'au XVIIle, sur papier. in-4" de $\tau$ \% ff. (Archices dép. d'Indre-el-Loire, $\mathrm{H} 8 \mathrm{l} \%$ ). Cif. Biblintly. untionale, coll. Don Housseau, rol. XTIII.

Rolduc. - Abbaye. - Toy. Kloosterrane.

Rosières. - Abbaye dioc. de Besançon;

4465. - Cartulaire de labliaye de Rosières; ms. en forme de rouleau de parchemin. du $\mathrm{X}^{\mathrm{re}}$ siècle (1rehir. dép. de Juru, $\mathrm{H}$ non coté.

Ce paraît être l'original des transcriptions indiquées ci-dessus $\left(n^{\circ} 3234\right)$; mais il ent aujourdhui incomplet.

Rouen. - Vicomté de l'eau.

4466. - Publ. : Recueil des arrests et rémlements donnez lant en instances civiles que criminelles sur le faict de la jurisdiction et compétence de la Vicomté de l'eaue à Rouen. Ronen, 16:4 : in-8 de 209 et $18 \mathrm{p}$. 


\section{Rouen. - Ville.}

446i. - PlbL.: Recueil des arrests et rècrlements donnez pour la conservation des privilèges des bourreois de la ville de Rouen concernant le faict de la marchandise. Rouen, Viret, 1656 . in $4^{\circ}$.

4468. - Y'É : Recueil d'édits et déclarations du roi, règlements et arrèts du Conseil et de la Cour concernant la jurisdiction consulaire de Rouen. Nouv, édit. Rouen, Oursel. [755; in-4" de xx-819 p.

Royon. - Léproserie, à Vienne-le-Château (dioc. de Châlonssur-Marne).

446\%. - Axal. : dans l'thmuire de lu Wurne. 1865. p. 478 (chartes da XIIIe siècle extraites du cartulaire de Noiremont;.

Rumilly. - Ville.

44i0. - Registre des privilèges de la ville de Rumilly : ms. rédigé en 1.515. contenant des titres des années 1:291 à 1514. in-folio (1rchizes mminicipales dr Rumilly. Haute-Savoie).

Saint-Denis-en-Broqueroie. - Abbaye.

4171. - Recueil de titres relatifs à l'abbaye de Saint-Denis-enBroqueroie : ms. du X III $^{\mathrm{e}}$ siècle. sur papier, in-40 de $15 \mathrm{fr}$. (Biblinth. royule de Bruxplles, ms. 3759?.

Sainte-Livrade. - Prieuré (diw. l'Agen).

44i2. - Recueil de titres relatifs au prieuré de Sainte-Livracle. envoyé à Balnze en I682, sur papier (Biblioth. nutionule, coll. Baluze. vol. CCV1. pp. 25(6-265).

Sainte-Maure. - Comtéen Touraine.

4473. - Recueil de titres relatil's au comlé de Sainte-Maure, extrait des archives du comté au X'III' siècle 'Biblinth. nutionale, coll. Dom Honseau, vol. Xill1' ti. 1:2-399.

Saint-Florent-lès-Saumur. - Ahlaye.

44it. - Cartulaire de l'albave de Saint-Florent-lès-Situmur: ms. des $\mathrm{X}^{\mathrm{e}}-\mathrm{XI}^{\mathrm{e}}$ siècles. en forme dè rouleau de parchemin, mesurant $3^{\mathrm{m}}, 6 \mathrm{j}$ de long sur (1) 4.5 de larire. et contenant des actes de 8.24 it 1004 (Archices dip. de Irnine-et-Loive. $\mathrm{H}$ non coté,

4475. - Autre cartulaire en forme de rouleau : ms. de la fin du XiJe

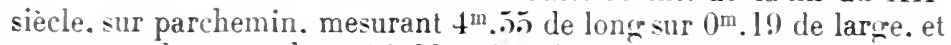
contenant des actes de 966 à 1150 (Archires dép. de Buine-et-Loire. $\mathrm{H}$ non coté,

I) nombreux actes sont en outre transerits dans l'histoire du monas- 
tère écrite par 1). Huynes, in-40 de 150 ff. sur papier (Archices dép. de Maine-et-Luire), dont il $y$ a une autre copie dans le ms. francais 19862 de la Biblioth. antionale.

\section{Saint-Gervais. - Ville.}

4476. - Cartulaire de la vallée de Montjoie, contenant les titres des communes de Saint-Gervais, Saint-Nicolas-de-Veroce et Les Contamines-Saint-Gervais depuis 1289 ; ms. rédizé en 1837 par M. Octenier, ancien notaire, in-folio de 409) p. Archives communales de Saint-Gervais, Haute-Savoie).

Saint-Mihiel. - Abbaye (dioc. de Verdun).

4477. - Recueil de titres relatifs aux droits de labbaye de SaintMihiel à Condé-en-Barrois, et an prieuré de Bar-le-Duc; ms. du X Ve siècle, sur parchemin, contenant un seul acte de 1241 et les autres très postérieurs. in-80 de $19 \mathrm{fl}$. (Archives nalionales, L I010, $\mathrm{n}^{0} 78$ ).

Saint-Quentin. - Église collégiale (dioc. de Noyon).

4478. - Pubr.. : C. Hémeré, Augrusta Yiromanduorum vindicata et illustrata. Parisiis. I64:3, in $4^{0}$.

Saint-Trond. - Église collegiale Notre-Dame.

4479. - Cartulaire de l'éclise N.-1). de Saint-Trond; ms. des XVIe et XVIII siècles, sur papier, contenant des titres de [263 à 1789, infolio de 65.9 If. (Archives de la fabrique de Notre-Dume à SaintTrond).

4480. - Cartulaire du lureau des panvies de la même égrlise ; ms. du $\mathrm{XVII}^{\mathrm{e}}$ siècle, sur papier, contenant des titres à partir du XIII ${ }^{\mathrm{e}}$, infolio de $38: 3$ et 575 II. (Archives du bureau de bienfaisance de SaintTrondt).

Lin volune complémentaire (xrine s., 284 fi.) se trouve aux archives de la fithrique de l'église.

4481. - Cartulaire des confréries de l'égrlise N.-I). de Saint-Trond; ms. du XVIlle siècle, sur papier, contenant des titres à partir de I445, in-folio de $541 \mathrm{ll}$. (Archives de lu fabrique de Nolre-Dame à Saint-Trond).

4482. - Cartulaire de la confrérie de la Sainte-Croix en la mėme érlise ; ms. lu $\mathrm{XVII}^{\mathrm{e}}$ siècle, sur papier, contenant des titres à partir de $\mathrm{I} 444$, in-40 de 50 II. (Archives de lu fabrique de Notre-Dame à Suinl-Trond).

Saint-Trond. - Église Saint-Gengoult.

483. - Cartulaire de l'érrlise St-Gengonlt de Saint-Trond; ms. du 
XVII siècle. avec additions, sur papier. contenant rles titres de 1:308 à 1791, in-folio (Archices de la fabrique de Folre-Dntine à Saint-Trond).

4483 $3^{\text {bis. }}$ - Cartulaire de la mense des pauves de la même écrlise; ms. des $\mathrm{XVIJ}^{\mathrm{e}-\mathrm{XVIII}} \mathrm{I}^{\mathrm{e}}$ siècles, sur papier, contenant des titres de l:297 à 1788, in-folio de $5 \% \mathrm{fr}$. (Archires dn bureun de bienfuisunce de Saint-Troin).

Sallanches. - Ville.

4484. - Cartulaire de la ville de Sallanches; ms. du XVIIle siècle, en 2 vol. in $4^{\circ}$. contenant des titres de 12933 à 1780 (Archices communales de Sallanches).

Sarrance. - Prieuré de Notre-Dame (dioc. d'Oloron.

4485. - Publ. : Docmients sur X.-1. de Sarrance 1:34:3-X1. $\mathrm{X}^{\mathrm{e}}$ siècle, par l'ablé V. Dubarat. dans: Hélanges de biblingruplie et dhisloire locale. 1 Paris. 1894, in-8 .

Sault-de-Vaucluse. - Comté.

4486. - Plbl. : Titres de l'ancien comté de Sault. Apt. J. S. Jean, $1865-1867 ; 2$ vol. in- $8^{\circ}$.

Scheut. - Courent des Chartreux.

4487. - Cartulaire des Chartreux de Scheut; ms. du XVe siècle, sur papier, in $4^{\circ}$ de 357 tf. (Archices du royaume de Belgique, à Bruxelles).

\section{Secrétaires d'État.}

4487 bis. - Publ. : Recueil des édits. ordonnances, déclarations et arrèts concernant les secrétaires du roi et des finances, [par Justel]. S. l., 1634 , in $t^{\circ}$.

Solières. - Abbaye 'dioc. de Namur'.

4488. - Recueil des titres [traduits en français] de l'abbaye de Solières: ms. du XVIIle siècle [1736]. par Dom Ign. Bourguignon, in-folio de 66 pages. sur papier Biblioth. de $1 \%$. F'r. Sacré, à Huy. Publ.: Documents pour servir à l'histoire de Solières. Huy, I888; in-8 de 56 p.

Stenay. - Chàtellenie.

4489. - Recueil de titres relatifs à la châtellenie de Stenay : ms. de la fin du XVIe siècle, sur papier. contenant destitres de 1252 à 1598 , in $4^{\circ}$ de 244 et $28: 2 \mathrm{H}$. Archices dép. de la . Mense, B :2:37-2:38.

Concerne surtout les fiefs, avec quelques autres documents. 
Strasbourg. - Université.

4490. - PUbl. : I.es statuts el privilènes des Lniversités françaises ; IV Strashourg. 15:5-16:1), par Marcel lournier. I'aris, Delalain, 1894 : in $4^{\prime \prime}$.

Thérouanne. - Église.

4491. - Ciartulaire de l'étrlise de Théronanne Archives de l'écêclé de Bruges.

Ce volune, dont lexistence a été constatée il y a un demi-siècle (ef. Compless realus de la Commission royale d'histoive de Belgique, 1851,

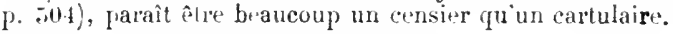

Tiffauges. - Seigneurie en Poilou.

44!2. - Cartulaire des sires de Pouzanges et Tiffaures; ms. du XVII siècle, sur papier. contenant 39 chartes des années $1256-1601$, in-4 de $8: 3 \mathrm{HI}$. (Charlvier de Thouars, a M. le duc de La Trémoille.

Touchet (de). - Fimille.

4493. - l'ubl. : P'reuves peur servir à l'histoire de la maison de Touchet Normandie et Angleterre, 1082-1802), par Th. Courtaux. Paris, Calinet de l'Historiographe, 1906; in-10 de [1v-]xvr-200 p. el pl.

Toulouse. - Eniversité.

4494. - l'vbı.. : Les Statuts et privilègres des Lniversités françaises, par Marcel Fournier. I Paris, 18910 , in- $4^{0}$, pp. 437-880, et III (1892, pp. .ㄹ--640.

Tournai. - Ablaye de Notre-Dame-des-Prés.

4495. - Petit cartulaire de Notre-Dume des l'rés près Tonrnai; ms. tu XVIe siècle, sur parchemin. contenant des actes de 12:30 à l:2:34, in-4" de 1:3 fl. (Billiolh. mulionule, ms. latin 1016!).

Tours. - Abbaye de Saint-Julien.

4496. - Jubl.: Fragments de chartes du X" siècle provenant de Saint-Julien de Tours, recueillis sur les rewistres d'état-civil d'Indreet-Loire, par ('h. de Grandmaison Bibliolh. de l'Ecole des Cikarles, XIVI, 1885, pp. 373-429, et XLVII. 1886, pp. 226-273, et à part : l'aris, 1887 ; in- $8^{\circ}$ le 122 p. et pl.

38 locuments dis annees 847 à 997 .

Trèves. - Abbaye de Notre-Dame des Marlyr's.

4497. - « Chartularium beatue Mariae Yirginis ad Martyres»; ms. du XVe siècle. sur parchemin, in-folio (Stad-Biblinthek Trier, ms. $1335)$. 
Trèves. - Abaye de Saint-Matthias.

4498. - Cartulaire de l'abbaye de Saint-Malthias de T'rèves; ms. du XVII" siecle, sur papier, in-folio (S/adt-Bibliothek Trier, ms. 269).

Trèves. - Abbaye le Saint-Maximin.

4499. - Cartulaire de Saint-Maximin de Trèves : ms. du XVllle siècle, sur papier. contenant 100 actes des années ti4:3 à 1381;, in-folio de II fi. (Biblioth. roynle de Bruxelles, ms. 451!).

4500. - Publ. X. Zvilesius, Defensio abbatiae imperialis S. Maximini. Treviris. 16i38. in $-t^{\prime \prime}$.

(it. H. Bres-lau, Leber dit älteren hönigs-und lapsturkunden hir

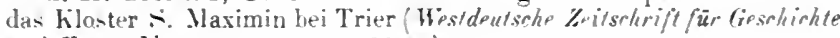

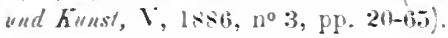

Trèves. - Abhare d'Horreen.

4501. - Cartulaire de l'abbave l'Horreen : ms. du XIVe siècle. sur papier. in t $^{*}$ (S/udt-Bibliolhek Trier, ms. 2099).

Trèves. - Église collégiale Saint-Siméon.

4502. - Cartulaire de l'église Saint-Siméon de Trèves: ms. des XIV̌e IVIIle siècles, sur parchemin. in-folio (Stadt-Bibliothek Trier, ms. 1611).

\section{Trinitaires.}

4503. - PubL. : Bullarium ordinis Sanctae Trinitatis. cum ejusdem institntione; ed. Christophorus de Jesu. S. 1., 1591, in-folio.

4504. - Prubl. : I'rivilèges et indugrences donnés et octrorés par les Papes aux religieux. confrères et saurs de la Sainte Trinité pour la Rédemption des Captifs. Troves." 1672 . in-32.

Val d'Aoste.

4505. - P'UBL. : Recueil de chartes valdotaines antérienres au $\mathrm{IV}^{\circ}$ siècle. par F. G. Frutaz (Bulletin de lu Sarciété acudémique it.toste, XV, 18!1. pp. 1399-194!

Valence. - Universite.

4506. - PcbL. : Institutio, privileyria, et statuta Lniversitatis Valentinae, edid. Andr. Basset. Turnone. 1601. in $4^{0}$.

(if. : Marenl Fournier, Les statuto et privileges des: Lniversité- fran-

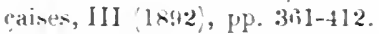

Valenciennes. - Hospice de la Charité Saint-Jacques.

4507. - Cartulaire de la Charité Saint-Jacques de Valenciennes ; origr. perdu? .

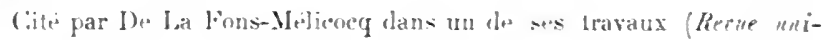


versplle des Arts, XXII, p. 2(69), il n'a pu être retrouvé. Mais s'agit-il d'un véritable cartulaire?

Van Artevelde. - Famille gantoise.

4508. - Publ. : Cartulaire des Van Artevelde, par N. de Pauw ! sous presse; Collection des ('hroniques belges].

Vertus. - Abbaye de Notre-Dame dioc. de Châlons-surMarne).

4509. - Cartnlaire de l'ablaye de N.-D. de Vertus ; orig. perdu.

Extrait fait au XYIJ siècle (Bibliolh. nntionale, coll. Baluze, vol. LI, p. 2:35-2:36;.

Vienne. - Archevèchè

4510 - Cartulaire de l'archevèché de Vienne ; orig. perdu.

Chorier I"a connu ot utilisè au XVII siècle, ainsi que celui de SaintPierre de Vienne

\section{Vintimille, - Comlé}

4511. - Pubr. : Statuts et privilèges accordés au conté de Vintinille et Tal de Lantosque par les comtes de P'rovence, par le Cie Eug. Cais de I'ierlas. Genova, 1890, in-folio.

Virton. - Église dioc. de Liege).

45l:2. - Cartulaire du curé Masset; ms. du XVIIIe siècle, sur papier, in-4" Archiess de l'église de Virlon).

Cf. Comptes Rendus de la Cummission royale d'histoire de Be'gique, $1^{e}$ série, $\mathrm{XV}$, p. 152. - Ce registre est à peine un cartulaire.

Ypres. - Confrerie de Saint-Nicolas.

45l3. - Cartulaire de la confrérie de Saint-Nicolas d'Ypres; ms. de 1:317. avec additions du XV1e siecle, sur parchemin, in-folio de $84 \mathrm{ff}$. Biblisth. de .K. A. Merghelyuck, is Ypres).

Ypres. - Eglise Saint-Pierm.

4514. - Cartulaire de la confrérie «Zeven ghetyden» en l'église Saint-l'ierre; ms. du XVle siècle [1578], sur parchemin, in-4 ${ }^{\circ}$ de $94 \mathrm{ft}$. Lrchives comimuales a' Ypres:

Ypres. - Hòpital Notre-Lame.

4515. - Cartulaire de l'hòpital N.-D. d'Ypres; ms. des XVe [1409] et $\mathrm{XVI}^{\mathrm{e}}$ siècles, en deux parties, sur parchemin, contenant des actes a partir de 1:2:31. in-folio de 134 If. (Archives des hospices civils d'Ypres. 
Ypres. - Table des paurres de la paroisse Saint-Jacques.

4516. - Cartulaire de la table des paurres de la paroisse Saint-Jacques d'Ypres; ms. du XVe siècle, sur parchemin, contenant des actes de 1298 à 1554 . in-folio de 6i3-vun ff.' 'Biblinth. de .1. A. Merghelynck, à Ypres'.

Ypres. - Ville.

4517. - Cartulaire de la ville d'Ypres; ms. du Xille siècle, en un rouleau de parchemin mesurant $2^{\mathrm{m}}, 86^{\circ}$ de long sur $0^{\mathrm{m}} .1 \%$ de large (Archives comimunales th 'Pres'.

Dates extrêmes : 1203-126!.

4518. - Autre cartulaire des XIVe-XVIe siècles, sur papier, contenant des actes des années 18335-1570, in-folio de $297 \mathrm{ff}$. (Archives communales d'Y Yreses.

4519. - Recueil de titres relatifs à la ville d'Ypres; ms. In XIX'e siècle. formé par J. J. Lambin, sur papier, en 4 volumes in-40 (Biblioth. de lin ville a' Ypres.

4520. - Cartulaire on «Gelewenhoek ». spécial aux relations de la ville d'Y pres avec le Chapitre de Saint-Martin ; ms. du $\mathrm{XV}^{\mathrm{V}} \mathrm{I}^{\mathrm{e}}$ siècle. inçomplet [jadis 484 it.]. sur parchemin. in-folio de $160 \mathrm{tI}$. [Archires coinimunales d' I'pres,

1)ates extrêmes: $1217-1595$.

Zonnebeke. - Abbaye.

4521. - Cartulaire de l'abbaye de Zonnebeke.

Car deuxième cartulaire, qui ne nous est pas connu, est mentionné jour la première fois en 1,106 dans les Amales de la Soriété d'emulation de la Flentie.

Zweibruicken 'Deux-Ponts), - Ville.

4522. - Publ. : Trkundenbuch zur Geschichte der ehemals pfalzbayerischen Residenzstadt Zweibrücken, herausg. von Ludw. Molitor. Zweibrücken. Ruppert, 1888; in-8" de xxiv-252 p.

Dates extrêmes: $1170-1816$. 



\title{
TABLE DES CARTULAIRES CIVILS
}

\author{
(liassement par provinces anciennes et par pays (1).
}

Afrique. - Maroc.

Allexagie, - Aix-la-chaprelle, DeuxPonts, Empire, Hanse, Nassau, Rhénans (pays), "Zweibrüchen.

Arsack. - Bergheim, Haguenau, Mulhouse, Ribeaupierre, Saverne, **'trasbourg.

Axpurre. - Urgel.

Axgovmors. - Angoulème, Cognac.

Axsov. - "Angers, Anjou, Ciraon, "Ingrandes.

Axwers, - Anvers, Broecken, Lierre, Oeleghem.

Aragox. - Barcelone, Banalu, Puigcerda, Vich.

Anturs. - Aire-sur-la-Lys, Arras, Artois, Béthune, Boulogne-sur-Mer, Hénin-Liétarı, Hesdin, saint-Oner, naint-Pol-sur-Ternoise.

Asit. - Armenie, (hypre.

Auriagse. - Aurorgne, brivadois, Carladez, Castalnau, ('habannes (de), Mercour, Monthrun, Murat, Polignac.

Bżar. - "Aspe, Bayonne, "Béarn, Mauléon-le-soule, X̃avarre, Oloron, ()rthez, Ossau, Pau.
BkRri. - Bourçes, Chàteauruux, Graçay, Indre, l.es Aix d'Angrillon.

Botrbussals. - Bourbonnais, Chabannes (de).

Butrgoge. - Auxerre, Beane, Bèze, Bourg-en-Bresse, "Bourgorne, ('eyzeriat, Chalon-sur-saone, Chastellux, Chatillon-sur-Seine, Davayé, "Dijon, "Dombes, "Lagnieu. lamarche-sur-saome, Marloux, Miribel, Montbarl, Montluel, Nesle, Saint-Aubin-Chàteauneuf, Sturre, * Tonnerre, Villars, Yonne.

Brabast. - Aerschot, Alost, Brabant, Bruxelles, Diepenbeke, Diest, Gaesbeek, Grammont, "Grimberghen, Hal, léan, Louvain, Malines, Nivelles, Tirlemont, Vilvorde.

Bretacise. - "Bretagne, l'ougeres, Morbihan, "Nantes, Saint-Aubindu-Cormier, Saint-Meloir, Vitré.

Chaypagse. - Aceorre, Bagneanx, -Brienne, Champagne, Coulummiers, Crécy-en-Brie, Domreny, "Donchery, Fépin, Féricy-en-Brie,Funay, Greux, Joinville, I.ouremont, Maraye-en-Othe, Meaux, Mézières, Montsaugeon, Mouzon, Nogentl'Artanel, Pont-sur-Yonne. P'rovins, "Rerins, Rethel, Revin. Rianconrt,

(1) L.es roms jrécédes du signe pont ceux qni figurent seulement dan-le suppliment "; les noms pricedes du double signe * mont ceux qui flgurent à la fois dans le corps du volume et dons le supplement. 
Rocroi, Saint-Ciermain-lès-Couilly, Sedun, Troyes, Vassy, Vienne-leC'hâteau, Villedonmange, Vitry-l lFrancois, Yonne.

Chypre, - Lasignan.

Comtat-Vexalssis. - Voy, Pruvence.

Corsk. - Bastia, Bonifacio, Calvi.

Darphiš. - Briancon, Brianconnais, Châteaudouble, Château-(Queyras, Corps, "*Dauphiné, Die, Embrun, Gap, Goncelin, Grenolle, I a Rochesur-Buis, Mévouillon, Iontélinar, **alence, Viennois.

Espagxi: - Andorre, Aragron, Barcelone, Besalu, Majorque, Navarre, Puigcerda, Ligel, Vich.

Flaxbre: - Aulenarde, Bailleul, Bergnes, Bourbourg, Bruges, Cassel, Comines, *'Courtrai, Douai, Enghien, Excaul, E-pierrt", "Flandre, Franc de Brugest, liurnes, Gand, Hertsberg, Lille, "Moerkerke, Nieuport, Oudenbourg, Roubaix, 'Fermonde, Thielt, 'Turnhout, Van Arterelde, "Vpres.

Forx. - Ax, Fuix, Mazires, Miglos, Mirepoux, Paniers, Rancié.

Frixtsk. - *Artillerie, "Avocats, "Barbiers-chirurgiens, "Capitaineries des chasses, "Chasses, "Compagnie des Indes, "Compagnies de la Guinée et du Nénécral, "Concordat, "Cours des aides, "Donaines, *Eaux et forêts, *Finances, "Gendarmerie, "Guerre (gens de), "Inprimerie, "Instruction publique, Israélites, "Librairie, * Llaison du rui, "Manufactures, * Marais (dessèchement des), "Marchands de vin suivant la Cour, Maréchausséé, "Maréchaux (I'révòté des), * Maréchaux (Tribunal des), "Mines, * Iusiciens, " Notaires-secrétaires du roi, "Officiers municipaux, "Officiers royaux, "*aris, Postes, "Prévôté de l'hòtel, "Prises, "I'rocureurs, "Protestants, "Secrétaires d'Etat, Trésoriers de France.

Franche-Comité. - Arbois, Belroir, "Besançon, Bourgogne, Chalon Arlay, Delle, "Dole, Faverney,
Franclee-Conté, Montbéliard, Montfaucon, Morteau, Neufchâtel, " $\mathrm{P}_{0}$ ligny, Salins.

Gascogine. - Argeles, Auch, Beanmont-de-Jomagne, Bénac, Bigorre, Condom, Dax, * Gaseogne, Hastingues, Lavedan, Luz, Mirande, "Monfort, Tarbes.

Grimaxk. - Agen, "Bonafoux, " ${ }^{\star}$ Borleaux, "*ahors, *Carpentey, Castela, Casteljaloux, Figeac, Gourdon, * Guyenne, La Capelle-Livion, Laguepie, La Penche, Le Mas-d'Agenais, Libourne, Marmande, Monségur, Mosfuéjouls, Najac, Rodez, Saint-Affrique, Saint-Antonin, SaintCéré, Saint - Geniez - d'Olt, Villefranche de Rouergue, Villeneuved'Aveyron.

Hanalt. - Ath, "*Avesnes, Beaurieux, Cambrai, "Cambrésis, Charleroi, Esne, Flobeeq, Grand-Fayt, Hainaut, La Howarderie, Landrecies, Marbaix, .Mons, Mortagne, Prisehes. Qu'snor-lè-Comte, Nolre - le - Châtean, Thuin, Tournai, Valenciennes,

ILF-DE-Fraxck. - Antony, Avrainville, Baron, Betaurain, Beaurose, Bessancourt, Betz-en-Valois, Boissy, BrieComte-Robert, Cachan, Carrièressolix- Poissy, Cersy, Chantilly, Châtillon-sous-Bagneux, Chevreuse, Combs - la - Ville, Compiègne, Corneeilles, Corny, Coye, Cirespières, Dampierre, Deuil, Fontenay-auxRoses, Franconville, Gif, Gonesse, Grégy, Grosbois, Hallate, 1ssy, lrry-sur-Seine, Limours, Marly, Montfort-l'Amaury, Montmorency, Montrenil - sous - Bois, Morangris, Moyvillers, Nemours, Noyers-enVexin, "*Paris, Poigny", Poissy, Puchay-en-Vexin, Puteaux, Rueil, Saint - Martin - du-Tertre, Senlis, Suresnes, Thiais, Tiverny, Trappes, Clly-saint-Georges, Valenton, Vaugirard, Vaux, Ferrières-Ie-Buisson, Vigneux, Villejuif, Villeneuve-SaintGeorges, Vitry-sur-Seine, Yères.

Italik, - **Asti, Naples, Rome, Saluces, Sicile.

Laskitenuc. - Agde, Aigues-Mortes, Alais, Albi, Balarue, "* Beaueaire, 
Bézirers, Bonssaynes, (iapestaner, Carcasonne, Carnuingr, Ciastelnaudary, Castres, Cordes, Cuxae-d Aude, Fontjoncouse, Crevandan, lad'aune, Lángubloc, lautrec, Lavaur, I,imoux, [,'Is]'-en-Jourdain, Lodève, Majorune, Meyrueis, Millau, Moissac, * Montauban, " Mlontprllicr, Montréal, Xarbonne, ['ézenas, Ponssan, Rabasturs, Renunlins, Saint-Jeandp-lius, traint-Puns-lle-Thomieres, *'Toulcuse, Tourne. Tounon, Viane, Villemur.

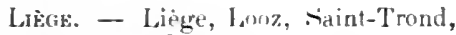
Tongres, Vise.

Lispurre, - Limbonre, Rechlecin.

Linelsix. - Bunsac, Brive, •Éraus, Joussinem, Lastours, Limogres, Lubersal", Marche, Ruchechouart, Tulle, Turentet.

Lorkmas. - Ancerville, AnglureBourleiusut, Apremont, Bacearal, Bar, Barrois, Bauffremont, Blamont, Boucunville, Bonlay ot sarrerguemines, Buurmont. Bries, Chambley; C'hnitel-sur-WLonellè, "Châtillonsur-sanne, Clhovetul. Clermunt-enArsonne, Clermontois, Colonbeysur-Fañn, Commerey. "Condé-enBarrois, Cunflans-en-Bassimny, (ionflans-ten-Jarnisy, Cons-la-Grandrille, Corrirux, Empire. Epinal, Éain, Foug, Frenoy-la-Monlagne, Gondrecourt, Grand, Hattonchâtel, I a a Chansetes, lamarche, Lat Mothe-enBassigny, Laxou, Ligny-m-Burrois, Longwy, "I Iorraine, Loupjy-le'Chàteau, Mandres, Marville. Metz, Mirecunrt, Morlex-en-Barrois, Nancy, Dorroy-le-ste , Pierrefitter Pont-àMour-on, Rarécuurt. Remlereourtatux-Pots, Naint-YIihiel, Saint-Nicolasdu-l'ort, Sancy, Soutlly, "stenar, Toul, Trognon, Varennes-ern - Argoune, Vaudémont, Vosge, Wisches.

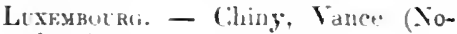
thomb).

Lyoxiss. - Cornillon, Forez, "Iyon, Lyounais.

Marx. - Château-du-l oir, I daral, Le Mans, Marillé, "Jl:nou (de).

Nimrk. - *Andenne, Bourignes,
Ciney, "Couvin, I Dinant, Fosses, Namur.

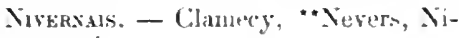
vernais.

Nurmavink - Alencen, Ardevon, Avarville, Baycux, "Bretteville-!'()rgueilleust", Bricquebec, Brix, " "Caen, Ciroismare, "Dieppe. Ecuguenéauville, Eu, Fontenay-]e-\armiou, Graindor, Granville, "Harcourt (de), Le Fournet, Le l'igny, Lonviers, "Neufchàtel-en-Bray", Nonancourt, "*ornandie, Perche, "Rouen, *Touchet (le), Vernun.

Orléasas. - Blois, "Chartres, "Dreux, Dunois, Janville, Marchenoir, Montartris, Orléans, Perche, Romorantin, sully-sur-Loire.

Par-Bss. - Gueldre, Limbourg, I.uxenbourg, Kélande.

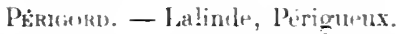

Pacarbur - Abbeville, Albert, Aniens, Ancre, Arguules, "Beaurais. Braysur-fomme, Bremil-k-Vert, Chauny, Clermont-n-Beauraisis, "Cuucy-leChàteau. Dumart, Doullens, Guise, "La Veuville-en-Hez, "Laon, Montdidier, Montreuil-sur-Mer, Novon, Péronne, Picquigny; " Punthieu, Rue, saint-p putentin.

Pultut: - Chàtellerault, La Forêtsur-sive, "I,a Trimnille, MontaiguVendée, "Puitiers, Puitun, Pufferrier, Rays. "Tiffauges.

l'rovexak. - Aighun, "Aix-mn-l'novence. Arless Aubagne, Aups, Auriol. "Arignon, Barjuls, Belrédère, Brignoles, Castellane, Cotignac, Cuers, Digne, Draguignan, Grasse, Guillaume. "Lantosque, Le Cannet, Le Luc, " Les Yaintes - Maries, Mallemort, Manosfur", "Marseille, *Martigues. Mérindol, Nice, Ollioules, Orange, Pertuis, Peyrolles, Provence, Riez, Naint-('ésaire, Naint-Maximin, Saint-Tropez, "rault, riérignan,

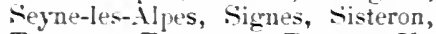
Tarascun, Tournoux, Tuurres, Vidauban, Villefranche-sur- Iler, Tintimille.

Rhéxass (Pays). - Aix-la-Chapelle, 
Chiny, Deux-Punts, Empire, Nassau, Rhénans (pays), "\%weibricken.

Rotssiliox. - Cerdagne, Collioure, Elne, ** Perpignan, Prades, Pratsde-Nollo, Puigcerda, Rivesaltes, Roussillon, Thuir, Vill franche-deConflent, Vinça.

Ssrout. - Aoste, Asti, Biella, Chambéry, Evian, laucigny, Geneve, Genevois-Yemours, "Mlontjoie, "Ru- nilly, "Saint-Gervais, "Sallanches, Savoie.

Sarsoxia. - la Rochelle, Oleron, lons, Saintonge.

Siciste. - Buurgogne, Bulle, Gendve, Gruyire, Neuchàtel, Nyon, "Nuisse, cuisses, Valais.

Torkarke. - Amboise, Aroine, Cihinon, "I áa Haye [Descartes], "Montbazon, Richelieu, "sainte-Maure, Tours.' 


\title{
TABLE DES CAR'TULAIRES ECCILÉSIASTIQLES
}

\author{
Classement par diocèse- anciens.
}

\author{
Agkx. - Agen, "rainte-Livrade. \\ Agrs. - Agde, saint-Tuibéry, Val- \\ magne.
}

Alre. - Aire, ( reaune, Saint-Ferer.

Arx-ba-Prurkack. - Aix, saint-Gerrais-lès-Fus, Saint-.laximin.

Aı.вг. - Albi. Candeil, Craillac, Rabastens, regur, Vaour.

AlERR: - "Calci.

Als.t. - Caucliès.

Ampis. - Albeville, Amieus, Bertaucourt, Cercanp, Corbie, Éterpigny, Fieffes, Flixecourt, l'oullloy, Gamanhes, Le Gard, Le Munt-saint(kuentin, L: Paraclet, Le Val-dekugny, Lihons, Longrpré-les-Corpssuint, Maintenay, Jlontreuil-sur-

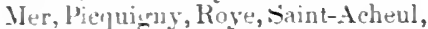
Saint-André-au-Bois, - raint-Fuscienau-Bois, Saint-Josse-alt-Bois, saintJosst-sur-Mer, saint-lodprent - auBois, saint-Riequer, Saint-Valerysur-ionm, Selincourt, sery, lalloire"s, Vignacourt.

Asgrers - - Angers, Anuiere--Bellay, Boce, Bourstueil, Brion. Brissarthe, Carbay, Chalunnes-sur-loin', Château-Ciontier, (Cle'mille, Craon, Créant, Gouls, Juinné-la-Prée, Ia Hayeaux-Bonshommes, la Primaudière, La Roe, Le Géneteil, Le Louroux, L. Perray-aux-Nonnains, " Le Ron- $^{-}$ cerdy, LiEviere, lire, Melinais, Monnais, Nioiseau, Pontron, "saintFlorent-lès-samur, saint-.Maur-surloire ou Glanfeuil, Fiant-Xicolas-
des-Locherpaux, saint-Quentin-enMauge, saint-kemy-la-Varenne.

Axgorlèse. - Angoulême, Beaulieu, Cellefrouin, Champilon: Cognac, Gourville, La Couronne, La Rochefourauld, Sint-Anand-de-Boixe, Tusson.

Arrees. - "Anvers, Lierre.

Aoste. - Aoste, "Val-d'Aoste.

ApT. - Apt.

Arlks. - Arles, Montmajour, SainGilles, Trinquetaille.

Arras. - "Arras, Arrouaise, Aubigny, Béthune, Bomy, Crémarest, Douai, Gosnay, Hasnon, Haut-Avesnes, *Houdain, La Bravelle d'Annai, "Lens-en-Artois, "Marchiennes, Marcuil-lès-Arras, Notre-Dame-desPrés (roy. Duuai), Virogne.

Arian - Auch, Berdoues, Boulaur, Flaran, Fimont, la Case-Dieu, Moncasin, l'e-san, Saint-Mont, Simorre.

Artrs, - Autun, Avallon, Bar-le-Régulier, Beaune, Bourbon-Lancy, Corbigny, Flavigny, Fontenay, Issyl'Érèque, La Bussière, La Rochepot, " Mareigny, Marmagne, "Mont-saintJean, Nuits, Oigny, Paray-le-Monial, Perrecy-les-Forges, Saint-Thibauten-Auxois, Saint-livant-sous-lergy, Saulieu, "Sernur, septfonts, Vergy, Vézelay:

Arszraf. - Auxerre, Basseville, Bouras, ('hablis, Crisenon, La C'harité, Le Saulce, Iontigny, Regny, Roches, Varzy, Vincelottes, Yonne. 
Avigiox. - Avignon, Montaut, Villeneuve-lès-Arignon.

Arraxches. - Avranches, lad HayePesnel, La Luzerne, Le Mont-SaintMichel, Montmorel, *Mortain, Pontorson, Saint-Gernain-sur-Ay, Saintlair, Savigny.

Balz. - **Bâle, "Bellelay, Colmar, Lautenbach, Lucelle, Münster, Murbach, Oelenbers, Pairis, Saint-Anarin, Saint-Jlare, Sclınensteinbach, Soultz, 'Thann.

Bargelone. - Barcelone, Camprodon, San Cugat del Vallés.

Bayeux. - Artenne, Bayeux, Bretteville-le-Rabet, " Caen, Cierisy, Cordillon, Fontenay, Fornigny, Longues, Mondaye, Saint-Nicolas-de-la-Chenaie, Troarn.

Bayoxie. - Bayonme.

Bazas. - la Réole.

Bralvals. - Bealumont-sur-Oise, Beaupré, ** Beauvais, Boran, Breteuil, *Clemont-en-Beauvaisis, Froinont, Gerberoi, J Jry-le-Tenr]l't, Lannoy, Le Fay, Messelan, *Monchy-le-Perreux ou Humieres, Pantlemont, Royaumont, Saint-(iermer-de-Flay, Saint-Just, Saint-Leu-d'Esserent, sommereux.

Belaky. - Arvière, ** Belley, SaintSiulpice-en-Bugey.

Besaxgon - Acey, Auxonne, Balerne, Baume-les-Moines, ** Besancon, Bithaine, Buillon, Calmoutier, Cherlieu, Clairefontaint, Corne ux, Darney, Dole, Faverney, Goailles, Gray, Jouhe, La Maison-Dieu, Le Marteroy, ${ }^{\star \star}$ Le Mont-Sainte-Marie, Lieu-Croissant, Lure, Luxeuil, Montbenoit, Morteau, l'oligny, "*Rosières, salins.

Bézerss. - Béziers, Jaucel.

Blors. - Blois, La l'erté-Avrain, L'Aumòne ou le Petit-Citeaux, Les Fouteaux, Mesland, Périgny, Souday, Troô, Vendòme.

Borpkarx. - Blaye, Bordeaux, Fronsac, La Sauve-Majeure, Saint-tmilion, Villemartin.
Boulogx: - Auchy-les-Moines, Beaulieu, Boulogne, Boulonnais, Guines, "La Capelle, Lieques, Notre-Damedes-Prés, (Euf, Renty, Samer.

Bolrges. - Aubignae, Bourges, Chalivoy, " Chezal-Benoit, Deols, Fontgombaud, Fontmorigny, Indre, La Chapelle-Aude, Levroux, Massay, Orsan, Saint-Benoit-rlu-sault, saintSatur-sous-Sancerre, Selle-sur-Cher, Toiselay, Vierzon.

Brtgks. - ${ }^{\star \star}$ Bruges, Iunes, " Eeckhoutte, Oudenbourg.

Cahors.- Berulieu, Cahors, Carennac, Figeac, Fons, Leyme, Lissac, Marcillac, Moissac, Roeamadour.

Cambral. - Binche, Bois-tigigneurIsaae, "Bonne-Espéranee, Cannbrai, Cambron, Chàteau-l'Abbay", Chièvres, Condé-sur-Escaut. Cirespin, Cysoing, ${ }^{\star}$ Enghien, Épinliru, Fesmy, Flines, Ghislenghien, Hautmont. Hautrage, "* Hérinnes, La Marche, Le Catea-Cambrésis, Le MontSaint-Martin, Le Quesnoy, Lerinnes, Letessines, lee Verger, * liessies, Lobbe's, ** Loo, Maroilles, Mlaubeuge, Ninove, Pommerœul, Rculx, " "SaintDenis-en-Broqueroie, Saint-Ghislain, Soignies, *^Vilenciennes, Vaueelles, Walincourt.

Ciarcassonxr. - Carcassonne. Caunes, La Grasse, Montoljeu, Montréal, Villelongue.

Ciaplextras. - Carpentras.

Ciastress. - Castres.

Cihaloxis-mer-Marie. - Andecy, Châlons-sur-Alarne, Cheminon, Donjeux, Huiron, Joinville, La Charnoye, L'Anour-Iieu, la Neurille, Le Vald'Osne, Moiremont, Montier-enArgonne, Montiérender, Perthes, *Royon, Saint-Amand, Sainte-Menehould, Trois-Fontaines, Ulmois, ${ }^{\star *}$ Vertus, Vinetz, Vitry-en-Perthois.

Chalon-str-sades. - Châlon-surSaône, Citealix, Époisses, La Fertésur-Grosne, Le Mont-Saint-Martin, Maizières, Saint-Julien, Saint-Marcel.

Chambéry. - Aillon, Saint-Hugon, Savoie. 
Chartras. - Belhomer, *Bomneval, Chartres, Châteaudun, Coulombs, Davron, Dreux, Epernon, Eure-etl.oir, Fossard, Gohory, Grandchamp, Josaphat, Joyenval, La Bourdinière, Ia Brosse, I.'Eau, L for Grand-B'aulieu, Maintenon, Cogent-le-Rotrou, Notre-Danie-des-Moulineaux, sitintCheron, Sainte-Gauburge, Saint-Hilaire-sur-Yerre, Naint-Jean-en-Vallée, Saint-Julien-de-I ouy, Saint-.Martinล - Val, Saint-Vincent-au-Bois , Theury, Tiron, Villedimu-en-Dreugesin.

Chichester. - śle.

Cueruort-Ferraxu). - Clermont-Ferrand, Ebreuil, Mauriac, Mozac, Saint-Étienne-sur- ['sson, Sauxi]langes, Souvigny.

Comprages. - Bonnefont, Comminges. Ia Bénisson-Dieu ou Nizor, Montsaunès, faint-Bertrand-de-Comminges.

Conpon. - Condom, Iarrounieu.

Cosszraxs [sint-Lizier]. - *'Conserans.

Cosstarce. - Constance.

Cuctaxces. - Blanchelande, Bolleville, Cherbourg, Coutances, Hambya, La Bloutière, La Luthumière, la Perrine, Le Mesnil-Amey, "*Lessay, Lodres, Montebourg, Néville, Saint-Frmond, Saint-Lò, SaintSauveur-le-Vicomte, Valognes, Vauville', Virandeville.

Dar. - Cagnotte, Dax, Ordios, sorde.

Die. - Die, Léoncel.

Digxe. - Digne.

Dol. - Conbourg, Dol, La Vieuville, Saint-Jacut.

Elase [Perpiguan]. - Arles, Cusa, Elne, Espira-de-1'Agly, Mas-Deu, Orle, Perpignan, - Fint-Martin-duCanisrou.
Ely. - Siravesey.

Exartx. - Boscoton, Embrun.

Évrexx. - Beaumont-le-Roger, Bonport, "Bourbon-lès-Gaillon, Conches, Evreux, La Chaise-Dien, La CroixSaint-Leufroy, I a Garde-Châtel, LH Yok, Io Breuil-Brnoit, la IHantellès-Bréval, L.Estrée, Notre-I bumedu-Disert, Pont-Audemer, saintAubindes-Fresnes.

Frf́J's. - Barjols, Correns.

Gaxn.- Deynze," Gand, Oost-Eecloo, Peteghen-lès-Audenarde, Termonde, Tronchiennes, Zwreke.

GAP, - Bertaud, Durbon, "Gap, Saint-Andre.

Gexère.-Chamonix, Chézery, Grève, Hautecombe. Saint-Paul-en-Chablais, savoie, Talloires, Thonon.

Geruxa. - Besalu, Gerona, Rosas. (1)

Grasse, - Gramse, Lérins.

Grexuble. - Chalais, Domène, Grenoble, La Grande-Chartreuse, Les Ecouges, Miséré, Montfleury, saintRobert-de-Cornillon, Nalettes.

Hertford. - Monmouth.

JËrr Saley. - Jérusalea, Josaphat.

Laxgres. - Auberive, Bar-sur-Aube, Bar-sur-Seine, Benoitevaux, Bèze, Bonvaux, Bourbonne-les-Bains, Bracancourt, Châtillon-sur-seine, Cilairvaux, "Dijon, Ecurey, Fauverney, Is-en-Bassigny, Jully-les-`onnains, Langres. Larrey, Le Val-des-Choux, Le Val-des-Ecoliers, Le Val-desVignes, Longuay, Lugny, . Marcenay, Marzannay-la-Cöte, Mirebeau, Molème, Montbard, Montier-en-Illle, Mores, Morinont, Mormant, Moutier-Saint-Jean, Notre-Dant-de-laPresle, Ougres, Pothières, Quincy, Remonvaux, Ricey, saint-Apullinaire, Saint-Geosiue, Saint-Léger,

1 A ce diucene apparlendient encore les deux abbayes de san E-teban de Batols et de San Felice de Guixul-; heur cartulaires ont èté utilicés rar Marca et par lEspaña sigrarla (t. 43: 
Sitint-seine, Septfontaines, Sexfontain 'Theuley, 'Tonnerre, Virnory.

Laox. - Bucilly, Foingly, *ruise, Laon, la l'aix-Notre-1)ante, Le Valsaint-lierre, Nogent-suus-Coucy, Origny-sānte-Benoite, P'rénontré, Ribesiont, Rozoy-en-'lhiérache, Saint-Mlichel-en-Thieracle, siantNieolas-aux-Buis, Thenailles, l'inselve, Vauclair.

La Rocanthe. - Voy. Maillezais.

Larsasse. - Hauterêt, Hauterive, Ia Lance, Lausanne, Montheron, Oujon, Romainmotier.

Larack. - I avaur.

Is: Alaxs - Assón-le-Riboul, Auversle-Hamon, Beaulien, Chàteau-l'Helmitage, Cherre, Évron, FontaineDaniel, L'Abbayeite, "la FontaineSaint-Martin, la I'tice, Le Mans, Let Parcen-Chamie, Maners, Perseigne, Saint-Calais, Rulesmes, 'Turcé, Vivoin.

I.F Pry. - Chamalieres, La ChaiseDieu, lá Voute, +*lee Puy, SiaintChaffre-du-Monastier.

Lascar. - *Betharran, lescar, lance, Saurelade.

Lik̇k - Alne, Bernarlfagne, Bouillun, Couvin, Dinant, l'lòne, "*Florennes, Hasselt, Herckenrode, Heylissem, Houffalize, Huy, "Kloosteriade ou Rulduc, I,es Vieux-Jones, Le ValBenoit, lee Val-Notre-Dane, Le Val-siaint-lambert, "*iege, Looz, * Maastıicht, Maeseych, Malonne, *.Meerssen, Muno, Orienten, Raansdonck, Robermont, Saint-Hubert, - iaint-fiverin-en-Controz, ** SaintTrond, stavelut-Malmédy, Thorn, Tongres, Yal-I)ieu, *Yirton, Wanze.

Limocits. - Aubepierre, Aureil, Beaulieu, Benévent, Blessac, Bonlieu, Bonnaigue, Bonnesaigne, Dalon, Giandiers, Grandinont, Guéret, la Règle, L Artige, le lieuil, Le Palais, Les Alloix, Lesterps, Limoges, Meymac, Notre-Dame-des-Ternes, Obazine, Prébenoist, saint-Yrieix, sulignac, Lzerche, Vipreois.

Liscosx. - spalding.
Lastivx, - Abenon, Asnieres, friardel, Le Plessis-Grimoult, ** Lisieux, Maupas, Nassandres, Préaux, SainteBarbe-en-Aurre, saint-Évroul, SaintHynter.

Losìs. - Gellone, Gignac, Lodeve.

Licox.- Bois-Grolland, Commequiers, Coutrie, la Chaiste-le-Vicomte, la Rocler-sur-Yor, Ice Puybeliard, les Fontenelles, Libaud, Lucon, NotreDane-rle-la-Blanche, Orbestier, Salertaine, Sigrournay, Talmont, TreizeVents.

Lyox. - Ainay, **Ambuurnay, Innimont, La Chassagne, Le Mliroir, 1.'IleBarbe, , "Lyon, Meyriat, Muntbrison, Montmerle, Nantua, Portes, SaintCliamond, Saint-sauveur-en-Rue, savigny, seillon.

Macox. - Beaujeu, Charlieu, Cluni, Mâron.

Mathakzan [La Rochelle]. - Challans, Li1 Grâcé-I)iéu, La Grâce-NotreDant", La Ruchelle, Maillezais, Maulíon ou Cilàtillon-sur-Sèver, Surgères.

Malristis. - Aerschot, Afflighem, Alost, Anderlecht, "*Averhode, "* BasseWavre, Beaupré, Bierbeek, ** Bruxelles, Cortenberg, Eenaeme, Forest, Grammont, Grand-Bigard, Grimberghen. "Groenendael, "Haerlebecke, Hanswijek, "*Héverlé, Ixelles, "*Ia Cambre, Léau, Le Parc-les-Danes, le Parc-les-Louvain, Le Tal-desEcoliers, Ite Val-Saint-Bernard, Lierle-Saint - Martin, Loon-beek, I.ouvain, Malines, Rouge-Ciloître, Sirint-Gille's-les-Bruxelles, ** Scheut, schouten, Sept-l'untaines, Tirlemont, Val-1)uchesse.

Marsianc. - ${ }^{\star \star}$ Marseille, Montrieux, Saint-lamien.

Meatx. - Chambrefontaine, Clivisyle-'Temple, Coulommiers, Crécy-enBrie, Ohuisy, **Faremoutiers, Fontaines-les-Nonnes, Juuarre, Le J'ontaux-Darnes, Maison-Dicu-en-Brie, Meaux, Nantruil-le-Haurlouin, Noéfort, Relais, Reuil, Saint-Faron, saint-Fiacre. 
Mrxpe. - Ia Canourgue, I,e Monastier-lès-Chirac, Marvejols, Mlende, Notre-Dame-de-Bonheur.

Metz. - Bouzonville, Étival, Freistrof, Glandières, Gorze, Hornbach, Metz, Notre-Dame-du-Val sous Apremont, Saint-Martin-de-la-Glandière ou Longeville-lès-Saint-Arold, SaintMartin-devant-Metz, Saint-Pierremont, Salival, Sturzelbronn, VillersBettnach, Viviers.

Mirepoix. - Boulbonne, Mirepoix.

Mostacbas. - Belleperche, Montauban.

Mostpeluer [Maguelone]. - Aniane, Maguelone, Montpellier.

Nastr. - Andenne, Aywières, Brogne, Ciney, Chantraine, Floreffe, "*Fosses, Frasnes,Gembloux,Géronsart.Grandpré, *Marlagne, Mellemont, Moulins, Moustier, Namur, Nivelles, "Nizelles, Oignies, Salzinnes ou Le Yal-saintGeorges, Soleilmont, "Solières, Vaillampont, Villers, Waulsort.

Naycx. - Voy. Toul.

Nastes. - Champtuceaus, Guérande, Melleray, Nantes, Pontchâteau, Villeneure.

Narboxic. - Narbonne.

Nevers. - Decize, "Nevers, SaintPierre-le-Moutier.

Nice. - Nice, Saint-Pons.

Nicosie. - Nicosie.

Nimes. - Montfrin, Nìnes, PontSaint-Esprit, Psalmodi, Saint-Gilles.

Noros. - Caumont, Ferraques, Héronval, Homblières, Noyon, Ourscamp, Péronne, Saint-Amand, SaintEloi-Fontaine, "Jaint-Quentin, Saint-Quentin-en-l'Ile, Vermand.

Ortsae. - Orange.

Oloros, - Morlaas, Olorun, "ìarrance.

Ordres religiers. - Billettes, Capucins, "Carmes, "Célestins, Chartreux, Cisterciens, "Croisiers, Dominicains, Frères de la Charité,
"Fries Mineurs, Grandinont, Hospitaliers de. Saint-Jean de Jérusalem, "Jésuites, Minimes, "Mont-Carmel, Prímontrés, Naint-Antoine-de-Viennois, saint-Lazare, Teutonique (ordre), "Trinitaires.

OrLkiss. - Beaugency, La CourDieu, Là Macrdeleint-lès-Orléans, Le Lieu-Notre-Dame, Le Puiset, Meung-sur-l vire, Micy-saint-Mesmin, "Orléans, Saint-Benoît-surLoire, Siaint-Gondon-sur - Loire, Semoy, Voisins.

Pamers. - Paniers.

Paspeltse. - Roncevaux.

Parls. - Champeaux, Charenton, Chelles, Cherreuse, Corbeil,Gonesse, Gournay - sul - Marne, Hérivaux, l'Abbaye-au-Bois, Lagny, La Roche, La Saussaye, Les Vanx-de-Cernay, Le Val-Notr-Dame, Linas, Livry, Longchamp, Longpont, .Marcoussis, Marulle-men-Brie, Iontmartre, Nanterre, "Paris, Port-Royal, SaintAntoine, Saint-Cloud, Saint-Cyr, Saint-Denis, raint-Germain-enLaye, Saint-Maur-des-Fossés, Valprofond, Tincennes, Yeres.

PÉrigczex. - Chancelade, Cubas, La Rochebeaucourt, Le Bugue, Ligueux, Montcaret, Paunat, SaintAstier.

Perpigxax. - Voy. Elne.

Porterers. - Bandouille, Bran, Chambon, Charroux, Fontblanche, "*Fonterrauld, L'Absie, La Chatille, La Grenetière, La Mlerci-Dieu, Les Châtelliers, L'Étoile, Montazé, Montierneuf, Montmorillon, Montreuil-Bellay, Nanteuil-en-Vallée, Niort, "Youaillé, Poitiers, Quinçay, Saint-Denis-en-Vaux, Saint-Jouinde-Jlarnes, Saint-Maixent, SaintNicolas-de-la-Chaise, Thouars.

Qumper. - Landévennec, Quimper, Quinıperlé.

Rerms. - Arnicuurt, Arenay, Belral, Bonnefontaine, Chandefontaine, Donchery, Elan, Épernay, Evergnicourt, Grandpré, Hautvillers, Igny, La Piscine, la Presle, Laval-Dieu, 
La Val-Roi, Le Munt-I)ieu, "*Longucau, Mézières, Montfaucon-enArgonne, Mouzon, Novy, Reims, saint-Basle, Sienue, signy.

Rexses. - Fougreres, liennos, sitintSilpice-la-Forêt.

Rurax. - lee. Mas ditzil, Lrzat, Salanipues.

Ronez. - Aubrac, Bonnecombe, Bonneval, Conques, Espagnae, loeDieu, Millan, Nant, Rodez, SiantAntonin.

Rocks. - Arpues, Aumale, Bomber, Beaulieu, Brines, Bonafle, BourgAchard, Chaumont-en-Vexin, Corneville-sur-Rille, Euvermen, Fécamp, Fonearmont, Gomerfontaine, Gournay-en-Bray, Graville, Immiéges, Lá Cornouillère, la Bec, I te Tréport, Le 'Trésor, la Valassé, I imay, Longueville, Mantes, Naubuisson, ** Meulan, Montivillier's, Mortemer, Noyon-sur-Andelle, Ouville, Pontoise, Rouen, Rourray - en - Bray, Saint-Greorges-de-Boscherville, SaintMartin - au-Bose, , taint- Victor-enCaux, saint-Wanclrille, Saupuerille, Triel, Valmont, Vernon.

Saint-Britace - Beauport, Boguen, Jugon, Lamballe, Lantenae, SiaintAubin-des-Bois, Saint-Rion.

SANT-Cizalde: - Saint-liaude.

Sinvt-Diḱ. - Voy. Toul.

Sanxrs. - Baigne, Barbezieux, Bassac, Fontdouce, La Garde-enArvert, Pons, Royan, sainteGrmme, Saintes, Saint-Étienne-deVaux, raint-Iean-d'Angély.

SAart-litotr. - Briude, Notre-1)amedu-Pont, Pébrac, Saint-Flour.

SAINT-JHAN-DL-MATRIFXNe - Maurienne, Siavoie.

SAlNy-Lazifar. - Voy. Cionseran.

Sarr-Alalo [Aleth]. - Dinan, léhon. Sastr-Oner, - Voy. Thérouane.

Sant-Paporz. - Orsons, Prouille.

Saxt-Path-Tron-(hatratx. - Richerenches, Saint-Paul-Trois-l 'hàteaux.
SAsrr-l'uxs. - Fontcaude, Saint-Pons [de-'Thomières].

fialiks. - Oulx.

Sirrat. - Cadouin, Calabre.

Síks. - Rellène, Ia Cochère, La Trappe, le Val-Dieu, Lonlay, Monceaux, Notre-Dame-des-Clairets, Perrières, Saint-André-en-Gouffern, S'ées, filly, I ieux-Bellême.

Sisuls, - Acy, Bray, Chaalis, Creil, Cripy-en-Valois, La Vietoire, Morienval, Saint-( 'hristophe-en-Halatte, saint-Remi-lès-Senlis, Senlis.

Sixss. - Barberau, Chaumes, 1)ilo, Esmans, Etampes, Ferrières, Fleuryen-IBière, Fontainejean, Joigny, Jony, I a ('our-Notre-Dame ou Miehery, La (iroix-en-Brie, La Joye, Le Jard, Le Lys, le Mont-Notre-Dame, Le Mont-sainte-Catherine, Les Éeharlis, Melun, Morigny, Néronville, Pontfraud, Preuilly, Pringy, Provins, * I'uiseaux, Rozoy ou Villechasson, Saint-Barthélemy-du-Buisson, SaintFlurentin, Śceaux-en-Gâtinais,sens, Vauluisant, Vieupou, Villiers-laJoye, Voulton, Vonne.

Sirox. - **Agaune, Sion, Valais.

Surssoxs. - Braisue, Cilézy, Choisyau-Bac, Clairefontaine, Coiney, Compiègne, La Bonne-Maison, La JoyeSiainte-liaire, Le Charme, LieuRestauré, Longpont, Nogent-l'Artaud, Pierrefonds, Royallieu, SaintCrepin-en-Chaye, Nainte-Croix-sousOffimont, Saint-Jean-au-Bois, SaintPierre-en-Chastres, Soissons, Valprie'z.

SPrRk. - Spire, Wissembourg.

Sitrashorrg. - Altorff, Andlau, Berghein, Guebwiller,Haguenau, ${ }^{\star} \mathrm{Honau}_{\text {, }}$ Issenheim, Les Trois-Epis, Neubourg, Neuviller, Saverne, Steige, itrasbourg.

Tarbis. - I arreube, Madiran, Saintl'é-de-Ginerez, Saint-Savin-de-Lavedan, Tarbes.

Tarkariosk. - Tarragone.

'Thúrocanxe: [raint-Omer]. - Airesur-la-Lys, Beaurain, Boulonnais, 
Bourbourg, Clairmarais, Hant, Hesdin, Le Yal-de-siainte- Allegonde, Ravensberghe, saint-André-les-Aire, Saint - Augustin - lès - Theirouanne , Saint-Bertin, saint-Oner, "'Therouanne, IVatten.

Tock: - "*Bar-le-Due Beaupré, Belchamp, Belval, Bonfays, Bosserville, Bouxières-aux-Dames, Châtenois, Chaumouzey, Clairlieu, Dieu-enSouvianne, Dumèvre, Droiteral, Epinal,Evaux, Flavigny-sur-Mloselle, Gerbéviller, Haute-ieille, Hérival, Jand'heures, Laitre-sous - Amance, Lamarche, Lay - Saint - Cliristophe, L'Ftanche, Ligny-en-Barrois, L'Isleen-Barrois, Lunéville, Moyenmoutier, Mureau, Nancy, Pont-à-Muusson, Rangúval, Remiremont, Saint-Dié, Sainte-Hoilde, hainte-Marie-au-Bois, Saint-Hilaire, Senones, Ferre, Toul, Vaucouleurs.

Torzox. - Toulon.

Torwut:e. - Ciastanet, Douzens, - Eames, Grandselve, La Selve, I,Espinasse, l'eyrolières, Toulouse.

Tocrstl. - Antoing, Aymeries, Cheregles-Tournai, Ciomines, "Courtrai, Lens, l.e Piéton, " I.ille, Loos, Marquette, Mons, saint-Amand-d'Elnone, Sieclin, *'Tournai, Wevelghem.

Totrs. - Baugerais, Beaumont-lèsTours, Cormery, Fontaines-lesBlanches, La Clarté-Dieu, Le Grais, Le I igget, Le Plessis-lès-Tours, Loches, ** Marmoutier (1), Noncé, Novers, "Relay, Tavant, *'Tours, Túrpenay, Villeloin.

TrËres. - Bunnevoie, Clairefontaine, Echternach, Fraulautern, "Hemurerode, Luxembourg, Marienthal, Mettlach, Orval, "lalz, "Prüm, $\star \approx$ Trèves.
Trores. - Bassefontaine, Beanlieu, Beauvoir, Boulancourt, Fuicy, La Chapelle-aux-Planches, La GràceSutre-Dame, Larivour, "Le Chêne, Le lardin-lès-Pleurs, Le l'araclet, Le Reclus, Montiéramey, Montierla-Cielle, Vesle-la-Reposte, NotreDame-des-Prés, Oyes, Ramerupt, Saint-Martin-ès-Aires, ścellières, Troyes.

Tulle. - La Valette, Tulle.

Trrss. - Fructuare, Pignerol, saintMichel-de-la-C.luse, Turin.

Urgel. - Urgel.

Vabres. - Nonenque, Sylvanes, Vabres.

Varsus. - Roaix.

Valrace. - Beaunont-lès-Valence, Bourg-lès-Talence, Le-Val-siainteMarie, saint-Félix-lès-Valence, saint-Ruf, riaint-Vallier, Valence, Vernaison.

Vasxes. - Prières, Redon, Vanues.

Verpix. - Beauchamp-en-Argonne, Beaulieu-en-Argonne, Châtillun-enViërre, La Chalade. * Saint-Mihiel, Verdun.

Viexxe.- Bonnevaux, Romlans, DaintPaul-lès-Ronans, Taulx, *Tienne.

Vich. - Ripoll, Vich.

Viviers. - Aubenas, Mazan, saintJulien, Viviers.

Worcester. - Westwude.

Ipres. - Bergues-Saint-Winoe, Éringhem, "Eversham, "Furnes, Hemelsdaele, Nieppe, Nonnenboosche, Poperinghe, Voormezeele, *Ypres, * Zonnebeke.

(1) A l'article - Marmontier du supplëment, on trouvera une série de prieurés dépendant de cette abbaye, qui ne figurent pas nominativement dans la presente table. 






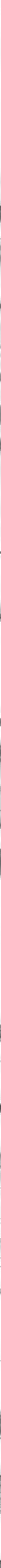




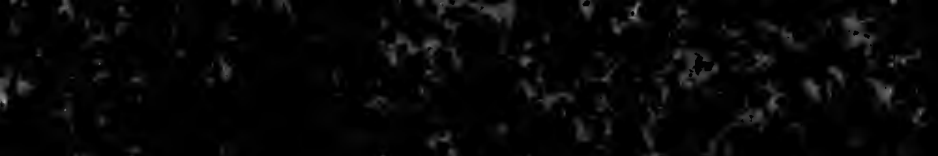

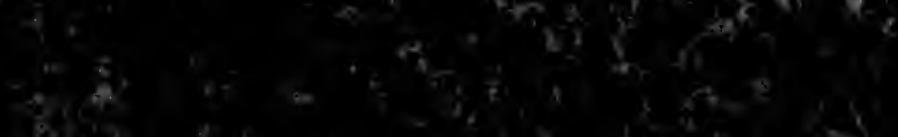

4.

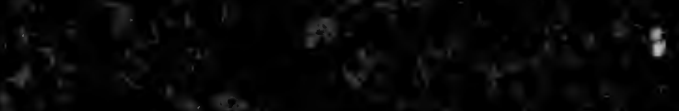

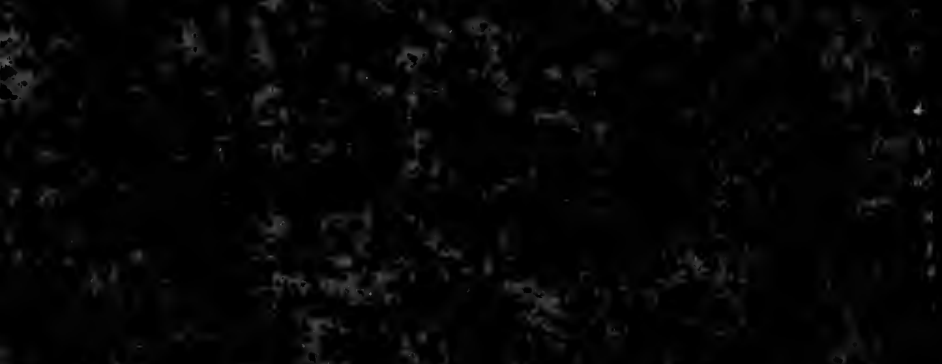

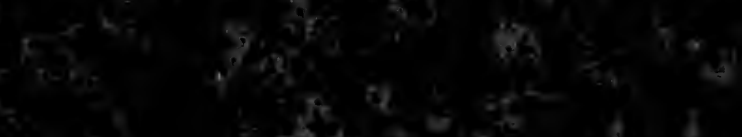

m

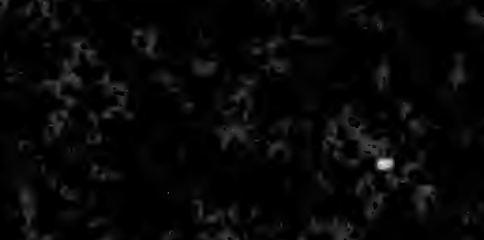

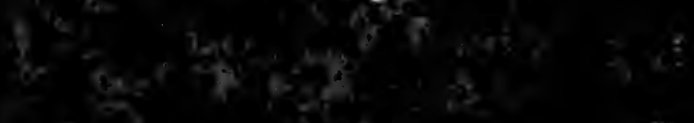

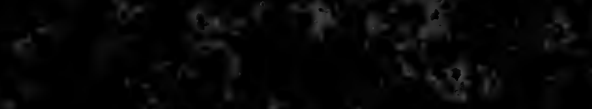

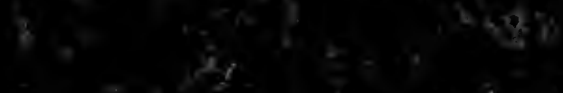

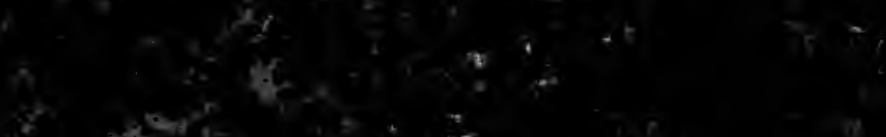

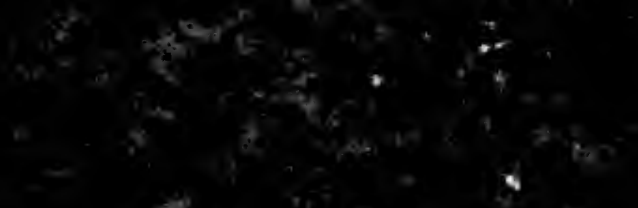

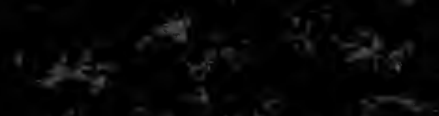
$x^{5} x^{4}+x^{2}-2 x^{2}$

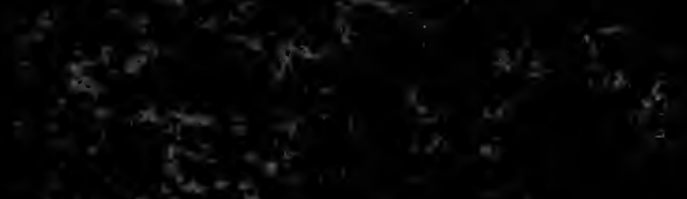

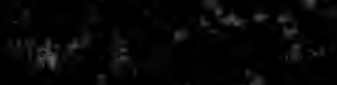

